\title{
Report Title: Steam Turbine Materials for Ultrasupercritical Coal Power Plants
}

Type of Report: Final Technical Report Reporting Period - Start Date: October 1, 2005 End Date: June 30, 2009

Principal Authors:

R. Viswanathan - EPRI, J. Hawk, R. Schwant, D. Saha - General Electric Co. T. Totemeier, S. Goodstine - ALSTOM Power, Inc. M. McNally, D.B. Allen - Siemens Power Generation, Inc.

Project Director:

Robert M. Purgert - Energy Industries of Ohio

Report Issue Date: November 5, 2009

DOE Award Number DE-FC26-05NT42442 OAQDA-OCDO Grant Number 05-02(B)

Submitting Organizations:

Energy Industries of Ohio

6100 Oak Tree Boulevard, Suite 200

Independence, Ohio 44131

Electric Power Research Institute

3420 Hillview Avenue

Palo Alto, California 94304

ALSTOM Power, Inc. 2000 Day Hill Road

Windsor, Connecticut

General Electric Company

1 River Road

Schenectady, New York 12345

Siemens Power Generation, Inc.

4400 Alafaya Trail

Orlando, Florida 32826 


\section{ACKNOWLEDGEMENT}

This material is based upon work supported by the Department of Energy under Award Number DE-FC26-05NT42442 and the Ohio Coal Development Office of the Ohio Air Quality Authority under Grant Number 05-02(B).

\section{DISCLAIMER}

This report was prepared as an account of work sponsored by an agency of the United States Government and an agency of the State of Ohio. Neither the United States Government nor any agency thereof, the State of Ohio nor any agency thereof, nor any of their employees, makes any warranty, expressed or implied, or assumes any legal liability or responsibility for the accuracy, completeness, or usefulness of any information, apparatus, product, or process disclosed, or represents that its use would not infringe on privately owned rights. Reference herein to any specific commercial product, process, or service by trade name, trademark, or manufacturer, or otherwise does not necessarily constitute or imply its endorsement, recommendation or favoring by the United States Government or any agency thereof or the State of Ohio or any agency thereof. The views and opinions of authors expressed herein do not necessarily state or reflect those of the United States Government or any agency thereof or the State of Ohio or any agency thereof. 


\section{ABSTRACT}

The Ultrasupercritical (USC) Steam Turbine Materials Development Program is sponsored and funded by the U.S. Department of Energy and the Ohio Coal Development Office, through grants to Energy Industries of Ohio (EIO), a non-profit organization contracted to manage and direct the project. The program is co-funded by the General Electric Company, Alstom Power, Siemens Power Generation (formerly Siemens Westinghouse), and the Electric Power Research Institute, each organization having subcontracted with EIO and contributing teams of personnel to perform the requisite research. The program is focused on identifying, evaluating, and qualifying advanced alloys for utilization in coal-fired power plants that need to withstand steam turbine operating conditions up to $760^{\circ} \mathrm{C}\left(1400^{\circ} \mathrm{F}\right)$ and $35 \mathrm{MPa}(5000 \mathrm{psi})$. For these conditions, components exposed to the highest temperatures and stresses will need to be constructed from nickel-based alloys with higher elevated temperature strength than the highchromium ferritic steels currently used in today's high-temperature steam turbines. In addition to the strength requirements, these alloys must also be weldable and resistant to environmental effects such as steam oxidation and solid particle erosion. In the present project, candidate materials with the required creep strength at desired temperatures have been identified. Coatings that can resist oxidation and solid particle erosion have also been identified. The ability to perform dissimilar welds between nickel base alloys and ferritic steels have been demonstrated, and the properties of the welds have been evaluated. Results of this three-year study that was completed in 2009 are described in this final report. Additional work is being planned and will commence in 2009. The specific objectives of the future studies will include conducting more detailed evaluations of the weld-ability, mechanical properties and repair-ability of the selected candidate alloys for rotors, casings and valves, and to perform scale-up studies to establish a design basis for commercial scale components. A supplemental program funded by the Ohio Coal Development Office will undertake supporting tasks such as testing and trials using existing atmospheric, vacuum and developmental pressure furnaces to define specific metal casting techniques needed for producing commercial scale components. 



\section{List of Acronyms}

\begin{tabular}{|c|c|}
\hline AP & As-processed \\
\hline A-USC & Advanced Ultra-Supercritical \\
\hline CTQ & Critical to Quality \\
\hline DOE & Department of Energy \\
\hline ESR & Electro-slag Remelting \\
\hline FCC & Face Centered Cubic \\
\hline $\mathrm{HCF}$ & High Cycle Fatigue \\
\hline HP & High Pressure \\
\hline HT & Heat Treat \\
\hline HTC & Heat Transfer Coefficient \\
\hline IP & Intermediate Pressure \\
\hline LCF & Low Cycle Fatigue \\
\hline LMP & Larson-Miller Parameter \\
\hline NETL & National Energy Technology Laboratory \\
\hline $\mathrm{OA}$ & Over Aged \\
\hline OEM & Original Equipment Manufacturer \\
\hline ORNL & Oak Ridge National Laboratory \\
\hline PA & Peak Aged \\
\hline RA & Reduction in Area \\
\hline $\mathrm{RT}$ & Room Temperature \\
\hline SA & Solution Annealed \\
\hline SEM & Scanning Electron Micrographs \\
\hline SM & Special Metals \\
\hline SPE & Solid Particle Erosion \\
\hline SW & Siemens-Westinghouse \\
\hline ТCP & Topologically Close Packed \\
\hline TEM & Transmission Electron Micrographs \\
\hline USC & Ultrasupercritical \\
\hline UTS & Ultimate Tensile Strength \\
\hline VAR & Vacuum Arc Remelting \\
\hline VIM & Vacuum Induction Melting \\
\hline WQ & Water Quench \\
\hline YS & Yield Strength \\
\hline
\end{tabular}




\section{TABLE OF CONTENTS}

\begin{tabular}{|l|l|l|l|}
\hline Task & Task & Lead & Page \\
\hline \multirow{2}{*}{12.1} & $\begin{array}{l}\text { Coating for Steam Oxidation and Solid Particle } \\
\text { Erosion Resistance }\end{array}$ & Alstom & 25- 116 \\
\cline { 2 - 3 } & $\begin{array}{l}\text { Energy Erosion Resistant Coatings Study for } \\
\text { USC Steam Turbine } 760{ }^{\circ} \text { C Department of } \\
\text { Energy Initiative }\end{array}$ & Siemens & $117-218$ \\
\hline 12.2 & Process Development for Welded Rotors & Alstom & 219-344 \\
\cline { 2 - 4 } 12.3 & $\begin{array}{l}\text { Materials for non-Welded Rotors, Buckets and } \\
\text { Bolting }\end{array}$ & $\begin{array}{l}\text { General } \\
\text { Electric }\end{array}$ & $345-514$ \\
\hline 12.4 & $\begin{array}{l}\text { Cast Ni-based Superalloys for Turbine Casing } \\
\text { Application }\end{array}$ & Siemens & $515-535$ \\
\hline 12.5 & Design And Economic Studies & Alstom & $536-577$ \\
\hline
\end{tabular}

* PLEASE NOTE THAT THIS REPORT IS DIVIDED INTO SIX PARTS AND THAT EACH PART CONTAINS ITS OWN SEPARATE AND DETAILED TABLE OF CONTENTS. 


\section{EXECUTIVE SUMMARY}

\subsection{Executive Summary}

\subsection{Project Objective}

The principal objective of this project is to develop the materials technology for Advanced-Ultrasupercritical (A-USC) steam turbines capable of operating with steam conditions of $760^{\circ} \mathrm{C}\left(1400^{\circ} \mathrm{F}\right)$ and $35 \mathrm{MPa}(5000 \mathrm{psi})$.

\subsection{Background and Relevance}

In the 21st century, the world faces the critical challenge of providing abundant, cheap electricity to meet the needs of a growing global population while at the same time preserving environmental values. Most studies of this issue conclude that a robust portfolio of generation technologies and fuels should be developed to assure that the United States will have adequate electricity supplies in a variety of possible future scenarios.

The use of coal for electricity generation poses a unique set of challenges. On the one hand, coal is plentiful and available at low cost in much of the world, notably in the U.S., China, and India. Countries with large coal reserves will want to develop them to foster economic growth and energy security. On the other hand, traditional methods of coal combustion emit pollutants and $\mathrm{CO}_{2}$ at high levels relative to other generation options. Maintaining coal as a generation option in the 21st century will require methods for addressing these environmental issues.

This project has established a government/industry consortium to undertake a multiyear effort to evaluate and develop advanced materials that will allow the use of advanced steam cycles in coal-based power plants. These advanced cycles, with steam temperatures up to $760^{\circ} \mathrm{C}$, will increase the efficiency of coal-fired power plants from an average of $35 \%$ (current domestic fleet) to $47 \%$ (HHV). This efficiency increase will enable coal-fired power plants to generate electricity at competitive rates (irrespective of fuel costs) while reducing $\mathrm{CO}_{2}$ and other fuel-related emissions by as much as $29 \%$.

Success in achieving these objectives will support a number of broader goals. First, from a national prospective, the program will identify advanced materials that will make it possible to maintain a cost-competitive, environmentally acceptable coal-based electric generation option. High sulfur coals will specifically benefit in this respect by having these advanced materials evaluated in high-sulfur coal firing conditions and from the significant reductions in waste generation inherent in the increased operational efficiency. Second, the results of this program will enable domestic manufacturers to successfully compete in world markets for building high-efficiency coal-fired power plants

This project is based on an R\&D plan developed by the Electric Power Research Institute and an industry consortium that supplements the recommendations. A Phase I 
(three year national effort) sponsored by the U.S. DOE and OCDO was completed in March, 2009. The Phase I effort was performed under a prime contract with Energy Industries of Ohio (EIO) through a consortium made up of the Electric Power Research Institute (EPRI), Oak Ridge National Laboratory (ORNL) and all of the U.S. domestic turbine manufactures: General Electric, Alstom Power and Siemens Westinghouse. The initial Phase I scope addressed the need to identify and evaluate candidate A-USC turbine materials and coatings from the perspective of creep strength, weldability, erosion performance, and oxidation resistance. The Phase I effort has accomplished these goals and a more robust five year Phase II effort has been initiated.

The Phase II effort will focus on select candidate alloys identified as meeting the basic requirements set forth in the Phase I effort. These requirements included addressing fabrication processes, particularly metal casting, required to make USC steam turbine components such as casings, housings, valves and rotors. In particular, efforts associated with high nickel alloys will be targeted for developing the specific means of casting these alloys using electric arc/AOD, vacuum, and/or pressure casting. Longer duration creep tests will be conducted using specimens from larger forgings. Weldability of thicker section samples will also be evaluated.

Funding is being provided by OCDO and DOE with cost sharing and technical participation from, Alstom Power, EPRI, General Electric and Siemens. Oak Ridge National Laboratory is funded directly by NETL/DOE to provide support and participation for the project. Due to a corporate decision including to relocated the Siemens steam turbine R\&D organization to Europe, Siemens withdrew participation during the course of the project.

\subsection{Project Tasks}

The project structure as it was in Phase I and the responsibilities of the consortium members is shown in Figure 1. 


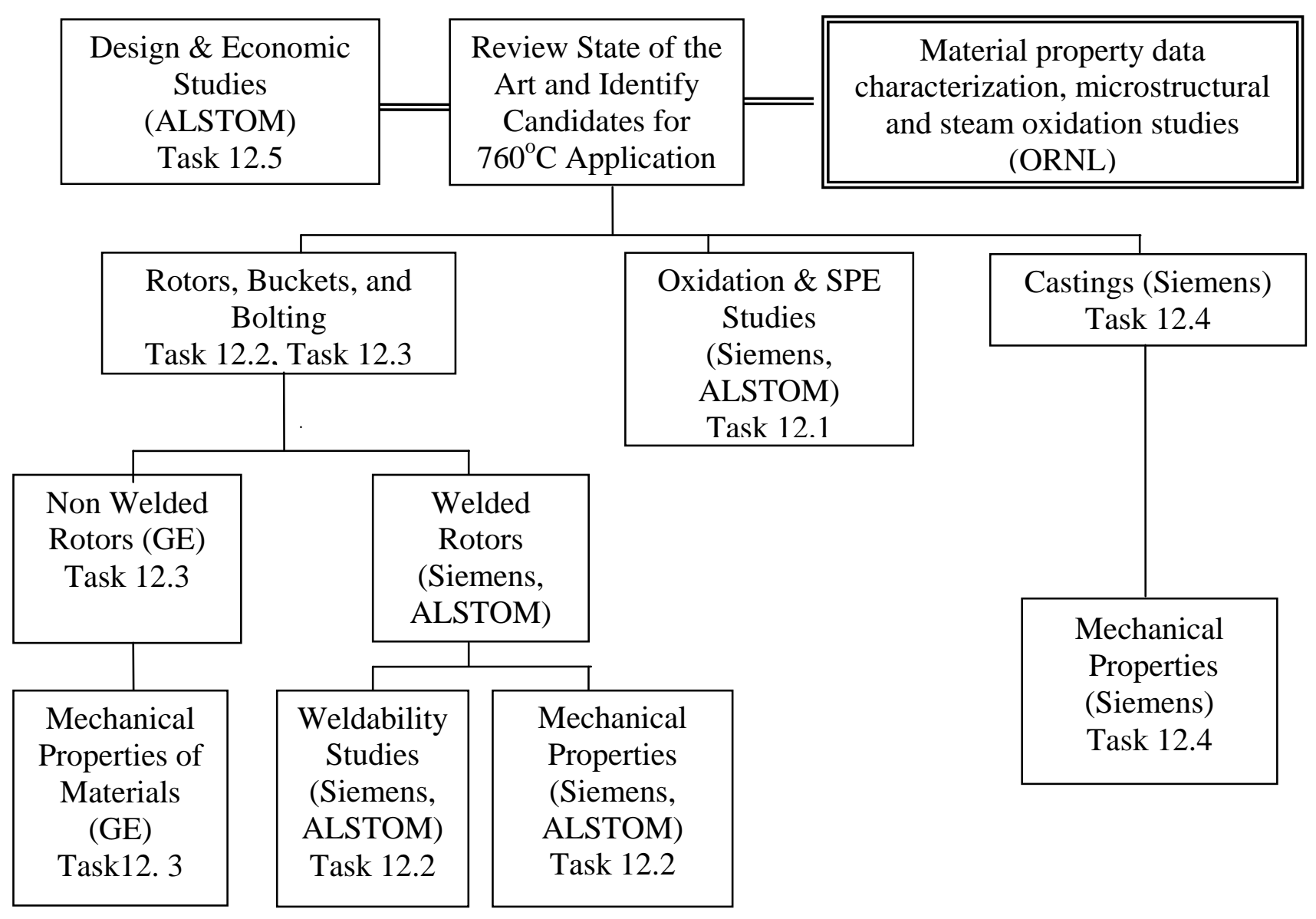

Figure 1 Program Logic and Task Assignments

\subsection{Task Overview}

Task 12.1 consisted of selecting and evaluating coatings for application to hot section parts of the rotors, nozzles and buckets (blades). Siemens screened candidate coatings based on a literature review and experience at lower temperatures. Twelve coatings were identified, and high-temperature erosion tests were conducted at $760^{\circ} \mathrm{C}\left(1400^{\circ} \mathrm{F}\right)$ to identify their suitability to withstand erosion by exfoliated solid particles from the boilers. The same coatings were also evaluated for resistance to steam oxidation through longer-term steam oxidation testing.

Task 12.2 consisted of exploring the concept of a composite welded rotor design by Alstom and Siemens to reduce the size of required forgings, and to allow for more economical use of expensive (nickel-based) rotor materials. The feasibility of welding has been demonstrated and the mechanical properties of weldments including longterm aging simulating rotor heat-treatment and operation have been determined.

Task 12.3's goal was to identify suitable nickel-based alloys for a single piece rotor (monolithic rotor), buckets (blades), and bolting. Initial screening of a large matrix of alloys was conducted on the basis of published literature (including European research activities on A-USC), thermodynamic modeling, and past research by the U.S. 
DOE/OCDO USC Steam Boiler Consortium. Key alloys were then subjected to shorterterm screening tests to identify the best candidates for future studies.

Task 12.4 was not performed by Siemens due to the withdrawal from the project. However, casting trials and mechanical testing was conducted by the National Energy Technology Laboratory (NETL), Albany, OR and ORNL. Seven candidate alloys were identified in conjunction with the other consortium members and were successfully cast.

Task 12.5 was a design and economic study to evaluate A-USC steam cycles including both the boiler and the turbine and the sensitivity of plant costs to the price of nickelbased alloys. The task was primarily the responsibility Alstom Power.

\subsection{Report Structure}

The Final Technical Report being submitted contains the above results obtained during the 3 year initial effort. Since the different tasks were carried out by different consortium members addressing different issues, it was decided to compile the report in six parts corresponding to the five tasks (with Task 12.1 divided into two parts for the respective organizations) rather than arbitrarily group together disparate technical material dealing with different issues from different organizations. Each part is therefore meant to be a standalone document, with its own table of contents, list of tables and list of illustrations addressing a particular aspect of the project. The six parts of the Final Technical Report are as follows:

- Coating for Steam Oxidation and Solid Particle Erosion Resistance (Alstom)

- Coatings to Resist Solid Particle Erosion (Siemens)

- Process Development for Welded Rotors (Alstom and Siemens)

- Materials for non-Welded Rotors, Buckets and Bolting (GE)

- Cast Ni-based Superalloys for Turbine Casing Application (Siemen's task conducted by ORNL and NETL)

- Steam Turbine Materials For Ultrasupercritcal Coal Power Plants - Design And Economic Studies (Alstom)

For the welded rotor task, the contribution from Siemens was limited to a scoping study so the results are included in the appendix of that report section. Additionally, the casting task was conducted by ORNL and NETL working closely and guided by the active consortium participants. ORNL and NETL continue to work on casting activities as part of a second phase funded separately by DOE. There work is being guided by the consortium members at the direction of DOE. 


\subsection{Results Summary}

During the initial stages of the project development and planning, the history of steam turbine material improvements and the current world-wide status was reviewed in light of the goals for developing the materials technology to successfully build and operate a $760^{\circ} \mathrm{C}\left(1400^{\circ} \mathrm{F}\right) \mathrm{A}-\mathrm{USC}$ turbine. This review and discussions within the consortium resulted in the key attributes of the workscope and tasks conducted on the program.

The most advanced steam turbines in operation today have a maximum steam temperature capability between 590 and $610^{\circ} \mathrm{C}$. The rotors in these turbines are constructed from advanced high chromium martensitic steels containing alloying additions of Mo, W, V, and $\mathrm{Nb}$. Rotors may be welded or non-welded (monolithic) construction. For the welded rotors, these highly alloyed steels are welded to more traditional $\mathrm{CrMoV}$ forgings. There are no current welded steam turbine rotors utilizing a dissimilar metal weld between a nickel-based alloy (austenitic structure) and a martensitic (ferritic structure) steel. Thus, the program decided to explore both concepts for rotor materials: welded and non-welded construction.

There has been a large effort ongoing in Europe, as part of AD700, COST, and other European and national programs, to develop the materials technology to build and operate a $700^{\circ} \mathrm{C}\left(1300^{\circ} \mathrm{F}\right) \mathrm{A}-\mathrm{USC}$ plant. The turbine materials research has largely focused on the use of alloy 617 in a welded rotor construction and the use of alloy 625 for cast components. Testing of 617 and 625 valve components was included in the European Comtest (component test facility). Large scale forgings and casting have been made of these alloys. When considering a $760^{\circ} \mathrm{C}\left(1400^{\circ} \mathrm{F}\right)$ turbine, the 617 and 625 materials have limited or no use for turbine components due to lack of strength and other requisite properties at the higher temperatures. Using this knowledge, the consortium decided to focus on alternative higher-strength alloys. The program, in the welded rotor task, took advantage of the fact that from a materials research standpoint the 617 to ferritic steel welded rotor joint has already been proven so it was not retested. Instead, the key welds were made between higher strength alloys such as 263 , 282 , and $720 \mathrm{Li}$ as well as lower strength nickel-based alloys such as 617 .

A review of past and current research showed deficiencies in understanding the oxidation kinetics of some of the alloys and coatings being considered. Furthermore, the traditional coatings and hardfacing alloys used in steam turbine components and valves are not proven at $760^{\circ} \mathrm{C}\left(1400^{\circ} \mathrm{F}\right)$, thus studies were planned to address this deficiency and to the consortium's knowledge this program was the first to evaluate the erosion resistance of blading for A-USC conditions.

The manufacturers involved also produce industrial gas turbines. Gas turbines have a long history of using nickel-based alloys at higher temperatures than $760^{\circ} \mathrm{C}\left(1400^{\circ} \mathrm{F}\right)$. However, there are key differences which need to be considered and why technology from a gas turbine is not directly applicable to a steam turbine. This includes that: in a steam turbine the pressure is higher which results in higher stresses on blades, blade cooling is not utilized so metal temperatures can be very challenging, sizes can be larger requiring larger melting and forging capability, welding is not a standard manufacturing route for some manufacturers, and the casing is much thicker (due to the higher pressure) thus castings become more difficult. Therefore, an A-USC steam 
turbine cannot necessarily take advantage of all the materials and materials developments used in current gas turbines, and a major project such as this consortium is required.

Finally, this project built off the successes and data generated by the U.S. DOE A-USC steam boiler consortium. Steam turbines are not subject to the American Society of Mechanical Engineers (ASME) Boiler and Pressure Vessel Code, so a much larger range of alloys were considered for the turbine. However, when materials did overlap testing was judiciously chosen to avoid duplication and overlap. For example, hightemperature creep-rupture data for Inconel 740 was provided by the steam boiler consortium to the turbine consortium to eliminate the need for that costly testing as part of the material's selection task. In some cases duplication of data were necessary when non-standard tests were involved. For the steam oxidation testing, alloys Inconel 740 and 617 were subjected to similar (but longer term) test conditions used in the boiler program. This was beneficial to both consortia because (a) comparisons between test techniques could be obtained and (b) since the turbine was assessing alloys not fully vetted the boiler consortium, the boiler consortium had a reference point to compare steam oxidation kinetics data.

\subsection{USC Turbine Candidate Materials}

In order to screen the many possible candidate nickel-based superalloys for a rotor forging, minimum mechanical property criteria were established for yield strength ( 400 $\mathrm{MPa})$ and 100,000 hour creep life $\left(100 \mathrm{MPa}\right.$ minimum) at the $760^{\circ} \mathrm{C}\left(1400^{\circ} \mathrm{F}\right)$ steam inlet temperature of the turbine. Chemistry, microstructure, mechanical and physical properties, processing and heat treatment information was collected, where available, for each alloy. ThermoCalc simulations were then performed using the nominal chemistry of each candidate alloy to establish temperature ranges for precipitate formation and the approximate volume fraction for each phase. From this information it was possible to identify the more thermally stable alloys (or microstructures) in the alloy heat treatment and operating temperature ranges. This information was collated and the most promising nickel-based superalloys were selected for in-depth screening studies. From the initial list of over 25 alloys, the following five alloys were identified as candidate materials for a rotor forging.

1. Nimonic $® 105$ (hereafter N105)

2. Haynes $282(\mathrm{H} 282)$

3. Udimet 720Li (U720Li)

4. Inconel 740 (IN740)

5. Waspaloy

Of these five alloys the first three were selected for further property evaluation. Testing of Udimet $720 \mathrm{Li}$ was halted due to a lack of material availability and less than acceptable creep performance at $760^{\circ} \mathrm{C}\left(1400^{\circ} \mathrm{F}\right)$. From a practical point of view, Nimonic 105 is the best alloy from a tensile strength and creep perspective, based in large part on the strength derived from $\gamma^{\prime}$ (gamma prime) and matrix $y$. However, Nimonic 105 would be difficult to process as a large ingot for a rotor segment. Also, 
Nimonic 105 is not easily weldable. These practical issues in no way detract from using this alloy at $1400^{\circ} \mathrm{F}$. Nimonic 105 has, in the past, been forged into gas turbine blades, and its use in a $760^{\circ} \mathrm{C}\left(1400^{\circ} \mathrm{F}\right)$ steam turbine can be envisioned for blades, bolts, valve stems, and other parts of this nature. Waspaloy and Haynes 282 have similar creep capability but of the two, Haynes 282 is unique in that its creep capability is relatively insensitive to the starting micro structural condition. Another factor in considering Haynes 282 for a rotor alloy is that it has the lowest yield strength of the three alloys, especially in the solution annealed condition. If yield strength is a primary design limiting concern, then the starting condition of Haynes 282 must be considered carefully in order to obtain the necessary level of yield stress.

Electron microscopy studies were completed on interrupted creep-rupture specimens to evaluate creep-strengthening mechanisms. The results show the importance of utilizing lower-stress creep-data to properly infer long-term strength. The results also showed clear differences in observed creep mechanisms for materials, which lead to the observed differences in rupture strength and ductility.

In conclusion, Haynes 282 is the leading candidate alloy for rotors, while Nimonic 105 and Waspaloy for blading and bolting.

\subsection{Weldability}

A welded rotor concept involving nickel-based alloys 263 and 617 and ferritic steel was evaluated through welding trials joining 263 to 617. The Edison Welding Institute (EWI) developed a narrow-groove gas-tungsten arc welding process (GTAW) for joining thicksection Nimonic 263 to Inconel 617 using Inconel 617 filler wire. Following the successful demonstration, the microstructure and mechanical properties of a twelveinch long weld in two-inch thick plate were characterized in the as-post-weld heat treated (as-PWHT) condition. The cross-weld tensile properties were equivalent to those of Inconel 617, with rupture occurring in the weld metal. Charpy V-notch impact tests at room temperature showed that all micro structural zones of the weld had reasonable toughness with ductile fracture features. Cross-weld stress-rupture tests at $750^{\circ} \mathrm{C}$ and $800^{\circ} \mathrm{C}$ had lives similar to those of Inconel 617 at stresses less than 125 $\mathrm{MPa}$ but had lives shorter than the base metal at higher stresses. All ruptures occurred in the weld metal. A second welded rotor configuration was evaluated this by Siemens. Heat-treatment studies were conducted on a successfully produced Haynes 282 to Udimet 720 Li welded joint to determine if strain age cracking of Udimet 720Li would be an issue. No evidence of strain age cracking was observed for three heat-treatments after welding. This included different aging conditions and subsolvus heat-treatments, which confirmed the robustness of the developed weld procedure.

The effect of long-term $(10,000 \mathrm{hr})$ simulated service exposure at $725^{\circ} \mathrm{C}$ on the microstructure, hardness, tensile properties, and impact strength of the 263-617 weld joint were also assessed. There was little change in microstructure, hardness, or tensile properties as a result of thermal exposure, but the impact strength was reduced in all 
micro structural zones of the weld. However, all zones had impact strengths greater than $30 \mathrm{~J}$, even after exposure.

\subsection{Oxidation Resistance}

All candidate alloys showed a low rate of oxidation in long-term testing at $700^{\circ} \mathrm{C}, 760^{\circ} \mathrm{C}$ and $800^{\circ} \mathrm{C}$. Predicted total metal loss (scale formation plus internal oxidation) after 100,000 hours were estimated to be less than $150 \mu \mathrm{m}$ at $760^{\circ} \mathrm{C}$ and less than $250 \mu \mathrm{m}$ at $800^{\circ} \mathrm{C}$ for all alloys. Substrate alloys which showed the best oxidation resistance were Udimet 720Li, Waspaloy and Inconel 740.Thin Cr-rich external oxide scales were found on all substrate alloys. The predicted external scale thickness after 100,000 hours were less than $25 \mu \mathrm{m}$ at $760^{\circ} \mathrm{C}$ and less than $35 \mu \mathrm{m}$ at $800^{\circ} \mathrm{C}$. Weight loss and porosity associated with internal oxidation were observed in some alloys at $760^{\circ} \mathrm{C}$ and in most alloys at $800^{\circ} \mathrm{C}$.

A literature review of coatings for erosion resistance was completed and 14 coatings have been identified for the target turbine blade conditions. Samples coated with these coatings were subjected to steam oxidation testing. Candidate SPE-resistant coatings which showed the best steam oxidation resistance were Stellite 6B, Tribaloy T-400C, Metco 45, and $\mathrm{CrC}-\mathrm{NiCr}$. The extent of oxidation for these coatings after 1000 hour exposure was comparable to that of the substrate alloys. The SHS 7170, SHS 9172, and $\mathrm{MoB}-\mathrm{CoCr}$ coatings suffered from extensive internal oxidation or oxidation along coating crack, and are not considered suitable for application in an USC steam turbine environment.

In summary, the steam oxidation resistance of nickel-based alloys is acceptable for AUSC steam turbine conditions up to $760^{\circ} \mathrm{C}$. The data generated in this task indicates that the candidate substrate alloys considered would perform as well or better, relative to steam oxidation, than current state-of-the-art applications. For applications which may require coatings for erosion resistance (such as blades), steam oxidation resistance of the coating must be considered as this research shows there exist some coatings which will afford a reasonable level of oxidation protection but other coatings will be seriously impacted by steam oxidation. Of the current coatings tested, Tribaloy T-400C appears to give both good steam oxidation and SPE resistance.

\subsection{Coatings to Resist Solid Particle Erosion}

Erosion tests have been carried out at $760^{\circ} \mathrm{C}\left(1400^{\circ} \mathrm{F}\right)$ using magnetite particles at a velocity of $900 \mathrm{Ft} / \mathrm{Sec}$ using coated coupon samples. A molybdenum boride-cobalt chromium coating supplied by Kermetico, Inc (MB-42) had the lowest overall erosion rates and volume loss of the 12 coatings tested. The top 4 coatings ranked according to their erosion rates and volume losses are shown in Table 1. 
Table 1. Best performing coatings for solid particle erosion resistance at $760^{\circ} \mathrm{C}$ (1400 $\mathrm{F})$

\begin{tabular}{|l|l|}
\hline \#1 MolyBoride-Cobalt Chromium & $\begin{array}{l}\text { Co-30 CrMo alloy -45 MoB- } \\
\text { Balance (B total -8.2) }\end{array}$ \\
\hline \#2 Zircoat & Dense Segmented 8YSZ \\
\hline \#3 T400C (Tribaloy) & $\begin{array}{l}\text { Cr-8.5, Mo -26, Si-2.6, Co } \\
\text { Balance }\end{array}$ \\
\hline \#4 Conformaclad & WC Based \\
\hline
\end{tabular}

Examination of the eroded coupons in the scanning electron microscope showed the surfaces of the Molyboride and the Zircoat were virtually untouched by the Silica sand with a particle load of $5 \mathrm{~g} / \mathrm{cm}^{2}$. In both instances the Molyboride and the Zircoat surfaces appeared smeared rather than eroded and the surfaces still retained some of their original morphology. When the particle load was increased to $10 \mathrm{~g} / \mathrm{cm}^{2}$ the Molyboride surface appeared more affected but some of the original surface could still be seen.

The bare metal alloys all had comparable erosion rates. However, because of its higher density Haynes 282 had the smallest volume loss. The above results are from very limited test data and should be viewed as the basis for narrowing down the number of coating candidates from 12 to 4 . When compared to the steam oxidation resistance, only Tribaloy T400C performed well in both tests suggesting further research on this and other similar coatings would be beneficial.

\subsection{Castings}

Large-scale A-USC castings have been explored through discussion with vendors, casting companies, and casting experts. Significant challenges were identified to casting age hardenable alloys due primarily to concerns of internal oxidation of $\mathrm{Al}$ and other hardening elements during typical air or protected air melting and pouring. Under direction of the consortium, a project at NETL (Albany) and ORNL was initiated to address these fundamental issues and a total of 7 alloys were identified for the initial trials. All seven alloys were successfully cast and homogenization heat-treatments were developed for each alloy. At the time of writing this report, evaluation of these alloys was in progress.

\subsection{Phase 2 work}

This Phase 1 study has been of limited scope and exploratory in nature. The creep tests conducted have been of short duration and cannot be used to confidently predict the long time behavior of the alloys. Base metal as well as weld tests have been performed on limited geometries and trial specimens which do not fully replicate the envisaged full circumferential welds. Only a limited number of mechanical tests such as fatigue, fracture toughness, creep, relaxation, and creep-fatigue have been conducted. 
Properties of bolting and blading alloys have only been evaluated on a limited basis for the purposes of screening the alloys and identifying the ones with the highest potential for meeting the program requirements and casing alloys need further characterization. A critical step for the program is to scale-up the forgings and casting to sizes and shapes representative of a steam turbine. The current Phase 1 effort has utilized bar and plate stock available off-the-shelf which will not likely give the exactly same properties as a large scale forging or casting. Phase 2 of the project was therefore initiated to remedy these shortcomings. The entire scope of the phase 2 study is included in appendix of the executive summary.

\subsection{Future Work}

The USC steam turbine project currently in progress has made substantial progress in laying the groundwork for selection and use of materials that can operate under steam conditions up to $760^{\circ} \mathrm{C}\left(1400^{\circ} \mathrm{F}\right)$. During the current phase of work, a wide spectrum of alloys and coatings were considered from which promising candidate alloys were chosen. Preliminary evaluations of the mechanical properties, oxidation resistance, weldability and suitability of coatings were conducted. Much work remains to be done. The mechanical properties evaluated in Phase 1 were merely for screening purposes, so that potential candidates could be chosen. These properties have to be characterized in much more depth on the selected alloys using scaled- up prototype castings and forgings, in order to provide a practical design data base.

Since the Phase 1 tests were mostly short-term screening tests, the long-term properties, which are generally subject to embrittlement, over-aging and other forms of deterioration, need to be evaluated. Large forgings and castings have many types of defects such as inclusions, segregation, and lack of consolidation which may not captured in small specimens. Gradients in microstructure and properties may be present in large components, while smaller specimens have more uniform structure and properties. Inspectability also varies with component size.

Weldability studies using laboratory size specimens suffer from similar limitations. Particularly, welding of precipitation strengthened alloys poses many difficulties and the problems are exacerbated in larger sizes. The reparability of castings and dissimilar weldments in piping -to- casing welds needs to be addressed.

Available facilities for producing large forgings, casings, valves and pipes of high strength $\mathrm{Ni}$-base alloys worldwide have to be identified, since this issue is critical to building A-USC Plants. It is necessary to demonstrate successful, long-term operation of prototypically sized turbine and boiler components in an operating coal-fired plant modified to develop A-USC operating conditions of temperature and operating stress. Demonstration of the practical reality of Advanced-Ultrasupercritical coal-based electric power plants, with carbon capture, that can be operated with different coal types is required. The technical and economic data needed for these types of plants to gain acceptance by the coal, electricity, and banking industries, and the public at large, as a cost-effective means for producing electric power in a carbon constrained world needs assessment. 


\section{EXECUTIVE SUMMARY APPENDIX}

\section{PHASE 2 STATEMENT OF PROJECT OBJECTIVES \\ (SOPO)}


DOE Award DE-FE0000234

\title{
ATTACHMENT 2
}

\section{STATEMENT OF PROJECT OBJECTIVES}

\author{
STEAM TURBINE MATERIALS FOR ADVANCED ULTRA SUPER CRITICAL (USC)
} COAL POWER PLANTS

\section{A. Objectives}

The overall objective of the current project is to contribute to the development of materials technology for use in advanced ultra supercritical (AUSC) pulverized coal power plant steam turbines (STs) capable of operating with steam conditions up to $760^{\circ} \mathrm{C}$ $\left(1400^{\circ} \mathrm{F}\right)$ and $35 \mathrm{MPa}(5000 \mathrm{psi})$. The specific objective is to conduct detailed evaluation of the weldability, mechanical properties and repair ability of the selected candidate alloys for rotors, casings and valves and to perform scale-up studies to establish a design basis for these components on a commercial scale.

\section{B. Scope of Project}

It has been estimated that an AUSC pulverized coal power plant operating under steam conditions of $1400^{\circ} \mathrm{F} / 5000 \mathrm{psi}$ can result in increased plant efficiency and corresponding reductions in emissions by as much as $30 \%$ compared to the current fleet of sub critical plants. In a recent four year study sponsored by the DOE , the mechanical properties, oxidation resistance, weldability and suitability of coatings were evaluated on a wide spectrum of alloys and coatings, based on which promising candidate alloys for operation under USC conditions were chosen. Much work remains to be done, however, while the short term screening tests have enabled potential candidates to be chosen, the properties of the chosen candidate alloys need to be characterized in much more depth using scaledup prototype castings and forgings, in order to provide a practical design data base.

Long term properties are generally subject to embrittlement, over-aging and other forms of deterioration, that cannot be detected in short term test. Unlike small specimens, large forgings and castings have many types of defects such as inclusions, segregation, lack of consolidation and property gradients. The ability to inspect properly also varies with component size. Welding of precipitation strengthened alloys poses many difficulties and the problems are exacerbated in larger sizes. Available facilities for producing large forgings, casings, valves and pipes of high strength Ni-base alloys worldwide have to be identified, since this issue is critical to building AUSC Plants. If such capability is not available, alternate material or design solutions have to be developed. The reparability of castings and dissimilar weldments in piping-to-casing welds remains to be addressed. This project is being proposed to address these issues. 
C. Tasks and Subtasks to Be Performed

Task 1: Project Management and Planning (EIO/EPRI)

Task 1.1 Develop and maintain a comprehensive Project Management Plan that clearly identifies the organizational structure, roles and responsibilities of the project team members, technical scope, budget, schedule baselines, key milestones and decision points, cost and schedule control, and project risk management. (EIO)

Task 1.2 Monitor progress on the Project Management Plan with respect to technical progress on each task, achievement of milestones and deliverables, Gantt chart schedule progress and financial comparisons to the budget.

(TECHNICAL: EPRI) (FINANCIAL: EIO)

Task 1.3 Provide reports according to the "Federal Assistance Reporting Checklist". (TECHNICAL: EPRI) (FINANCIAL: EIO)

Task 2: Process development and the full-scale rotor weld (ALSTOM)

The purpose of this task is to identify processes for producing large scale welds that can be directly used in production. The concerns to be addressed include:

- Development and demonstration of welding dissimilar nickel alloys for rotor applications, particularly to evaluate the effects of increased weld depth (to 8 inches) and weld constraint (due to welding large cylinders together). The mechanical properties of such full-scale welds need to be determined for design. The ability to non-destructively evaluate these welds will be critical, and difficult in nickel-base alloys, particularly if the grain size is large.

- Long-term metallurgical stability of nickel-base alloys at the service temperature. These alloys can form embrittling phases during long-term, high-temperature exposure with commensurate loss in ductility and toughness. This may be a particular concern when combined with less-ductile microstructural regions in the vicinity of welds.

Task 3: Materials for Non-welded Rotor Buckets and Bolting (GENERAL ELECTRIC)

Under this task the long-term mechanical properties and microstructure characteristics will be investigated for materials used for non-welded rotors.

Task 3.1: Mechanical Property and Microstructural Characterization of Rotor/Disk Alloys (GENERAL ELECTRIC)

Prior studies demonstrated that Haynes 282 and Nimonic 105 possessed the elevated temperature tensile, fatigue and creep capability to serve as a non-welded rotor/disk alloy in a $1400^{\circ} \mathrm{F}$ steam turbine. Activities under this task will investigate the tensile, fatigue and creep behavior of these two alloys plus selected others for use as aerofoil blades, bolting and valve internals in much greater 
detail. This task will consist of accumulating short-term mechanical and physical property data that can be used for conceptual steam turbine design activities. Long-term ( $>30,000$ hours) creep, creep rupture and load-control creep-fatigue tests will be run to develop robust life prediction methods for creep and creep with an imposed fatigue cycle. The load-based creep-fatigue information (as a function of dwell time at maximum load) will assess the environmental cracking susceptibility of the nickel base alloys in steam.

Continuation of fatigue testing program will be used to determine the variability in LCF behavior as a function of strain level. Selected strain-control hold-time tests will be conducted on the two candidate alloys to establish the approximate effect of a tensile hold at maximum strain on the low-cycle fatigue life. Fatigue crack growth rate tests will be used to develop $(\mathrm{da} / \mathrm{dN})$ behavior and the threshold $\mathrm{K}$ value for crack growth.

Microstructural characterization activities related to understanding the interaction of environment $\left(1400^{\circ} \mathrm{F}\right.$ air and steam) on crack growth and microstructure stability. Examination of creep and creep-fatigue samples will be done in the TEM expressly to determine coarsening behavior and the development of any TCP phases or carbides as a result of long-term exposure. The fracture surfaces of creep, creep-fatigue, and fatigue crack growth rate samples will be examined in the SEM to determine mode of failure and possible change in failure mechanism.

Task 3.2: Mechanical Property and Microstructural Characterization of Candidate Blade/Bolting Alloys (GENERAL ELECTRIC)

The objective of this task is to develop sufficient mechanical property information on nickel-base blade/bolting candidate alloys so preliminary steam turbine design calculations can be initiated. Establish the long-term microstructural and environmental stability of the candidate alloys to predict 100,000 and 250,000 hour creep rupture life at $1400^{\circ} \mathrm{F}$ and $15 \mathrm{ksi}$.

High cycle fatigue (HCF) tests will be run at $1400^{\circ} \mathrm{F}$ and three R-ratios (e.g., $\mathrm{R}=$ $1, R=0.05$ and $R=0.5$ ) for the candidate blade alloys. The HCF data will allow calculation of Goodman-type diagram for a preliminary estimate of fatigue life at $1400^{\circ} \mathrm{F}$.

Stress relaxation tests will be performed for up to 10,000 hours at 1350,1400 \& $1450^{\circ} \mathrm{F}$ and three strain levels (e.g., $0.25 \%, 0.20 \%$ and $0.15 \%$ strain) for two candidate blade/bolting alloys. The relaxation response of the blade/bolting alloys will be explored and the results compared to the creep results.

Microstructural characterization activities related to understanding the interaction of environment $\left(1400^{\circ} \mathrm{F}\right.$ air and steam) on microstructure stability Examination of creep samples will be done in the TEM expressly to determine coarsening behavior and the development of any TCP phases or carbides as a result of long- 
term exposure. The fracture surfaces of creep and high cycle fatigue samples will be examined in the SEM to determine mode of failure and possible change in failure mechanism as a function of exposure time.

Task 3.3: Mechanical Property and Microstructural Characterization of Candidate Valve Internal Alloy (GENERAL ELECTRIC)

The objective of this task is to develop sufficient mechanical property information on nickel-base valve candidate alloy so preliminary steam turbine design calculations can be initiated and to establish the long-term microstructural and environmental stability of the candidate alloy to predict 100,000 and 250,000 hour creep rupture life at $1400^{\circ} \mathrm{F}$ and $15 \mathrm{ksi}$.

This task will consist of accumulating short-term mechanical and physical property data that can be used for conceptual steam turbine design activities. Long-term ( $>30,000$ hours) creep, creep rupture and load-control creep-fatigue tests will be run to develop robust life prediction methods for creep and creep with an imposed fatigue cycle. The load-based creep-fatigue information (as a function of dwell time at maximum load) will assess the environmental cracking susceptibility of the nickel base alloys in steam.

Fatigue testing will consist of LCF and HCF. The LCF portion will characterize one alloy at $1400 \mathrm{~F}$ and four strain levels. The HCF portion will look at one alloy at $1400^{\circ} \mathrm{F}$ and three $\mathrm{R}$-ratios (e.g., $\mathrm{R}=-1, \mathrm{R}=0.05$ and $\mathrm{R}=0.5$ ), sufficient to allow calculation of a preliminary Goodman-type diagram.

Microstructural characterization activities related to understanding the interaction of environment $\left(1400^{\circ} \mathrm{F}\right.$ air and steam) on microstructure stability. Examination of creep samples will be done in the TEM expressly to determine coarsening behavior and the development of any TCP phases or carbides as a result of longterm exposure. The fracture surfaces of creep and fatigue samples will be examined in the SEM to determine mode of failure and possible change in failure mechanism.

\section{Task 4: Castings (ALSTOM/GENERAL ELECTRIC)}

Task 4.1: Casting Alloy Selection and Chemistry Optimization for Superalloys Used As Cast Articles in the $1400^{\circ} \mathrm{F}$ Steam Turbine (ALSTOM/GENERAL ELECTRIC)

The objective of this task is to evaluate superalloys chemistries with sufficient high temperature strength and long-term environmental stability to be used as cast articles for turbine shell casings and valve bodies. Develop cast articles of sufficient size for material characterization, property evaluation and welding potential. Establish a standard of practice for producing large superalloy castings 
suitable for use in steam turbines. This work will be conducted in conjunction with ORNL and NETL who already have ongoing activities in this area.

Task 4.2: Develop Full-Size Casting Model (GENERAL ELECTRIC)

The objective of this task is to develop a feature article casting drawing that has various section thicknesses and features that will allow welding pipe sections and repair activities.

Casting manufacturers will be contacted to assess potential for making a large, multi-feature superalloy casting with section sizes large enough to simulate cooling in a full-size shell or valve box. Initiate discussions with potential cast houses for making a very large cast article suitable for evaluation of scale-up potential. Determine costs of making such article and delivery schedule.

NOTE: A concurrent effort for developing metal casting production processes for large scale high nickel alloy castings for use on USC systems will be undertaken and funded as a separate activity under Ohio's Advanced Energy Initiative. This activity will support the USC effort to stimulate supplier base development and will be provided and coordinated through Energy Industries of Ohio (EIO).

\section{Task 4.3 Casting Alloy Screening Tests (ALSTOM)}

The casing alloy castings made at NETL will be evaluated to determine if the properties in the cast form are suitable for use in a casing application. The degree of chemical and microstructural segregation will be evaluated, as will the basic mechanical properties of tensile strength, creep-rupture strength, low-cycle fatigue strength, toughness, and physical properties. The effect of long-term thermal exposure at service temperatures on the microstructure and properties of the casting are also of interest, due to the potential for embrittlement.

Task 5.0: Process Development and Characterization of Casing Repair Welds (ALSTOM)

The objective of this task is to produce and characterize repair welds in a casting alloy suitable for the casing using a weld filler material similar to the casing alloy.

Initial development of casing repair weld procedures will be performed on small $(\sim 20-50$ lb) castings of the casing alloy, which likely will be one of the nickel-base alloys 617 , 625,263 , or 282 . Casing weld repairs will be made using a filler metal similar to the casing alloy. If the casing alloy is precipitation-hardened, development tests will be performed to determine the maximum width and depth of defect that can be weldrepaired without cracking of the weld metal or in the HAZ. 
After development of weld repair procedures, larger casing castings $(\sim 200 \mathrm{lb})$ will be made with simulated repair welds. The completed welds will be extensively characterized to develop materials property data needed for design. Testing will include non-destructive evaluation, metallography, and a variety of mechanical tests (tensile, creep-rupture, impact, and low-cycle fatigue). Sections of the completed welds will be subject to long-term isothermal aging at anticipated service temperatures. Additional characterization of the aged welds will be performed, particularly with respect to potential loss of ductility and toughness.

\section{Task 6.0: Process Development and Characterization of Casing-Pipe Welds (ALSTOM)}

The objective of this task is to produce and characterize welds of main steam line pipe to cast casing material.

Butt welds of prototypical main steam line pipe to cast casing alloy will be made. Short lengths of pipe, approximately 10-12 inches in diameter, with a wall thickness 2-3 inches, will be procured commercially. If necessary, round bar of appropriate diameter will be procured and machined to pipe dimensions. A cylindrical casting of the casing alloy will be produced with dimensions similar to the pipe, and the two will be joined using appropriate weld filler metal. The completed welds will be extensively characterized to develop materials property data needed for design. Testing will include non-destructive evaluation, metallography, and a variety of mechanical tests (tensile, creep-rupture, and impact). Sections of the completed welds will be subject to long-term isothermal aging at anticipated service temperatures. Additional characterization of the aged welds will be performed, particularly with respect to potential loss of ductility and toughness.

\section{Task 7: Design and Economic Studies (EPRI)}

The purpose of this task is to assess the cost and performance tradeoffs associated with the use of $1400^{\circ} \mathrm{F}$ steam turbine materials, and their weld joint properties, and to integrate the understanding developed during the project to ensure a coherent vision is developed for AUSC ST's.

Based on limited design studies performed within this task and other tasks, some of the cost/performance tradeoffs (e.g. reduce pressure to enable operation at higher temperatures, cooling, etc.) will be examined and USC plant models will be used to establish costs. The impact of a USC ST on such plants will be quantified based on limited up-front work and more focused work toward the end of the project when the initial studies can be revisited based on what has been learned. This will ultimately lead to an assessment of the benefit provided by USC ST's and a vision/roadmap for their future development and deployment. An evaluation of the potential megawatt rating and thermal efficiency of a $1400^{\circ} \mathrm{F}$ ST produced from the program alloys will be included. 
D. Deliverables

The Recipient shall provide reports in accordance with the enclosed Federal Assistance Reporting Checklist and the instructions accompanying the Checklist. In addition to the reports identified on the Reporting Checklist, the Recipient shall provide the following:

- Topical report summarizing all mechanical and physical properties of the rotor/disk alloys from task 3.1 (GENERAL ELECTRIC)

- Topical report summarizing all mechanical and physical properties of the blade/bolting alloys from task 3.2 (GENERAL ELECTRIC)

- Topical report summarizing all mechanical and physical properties nickel-base valve alloys from task 3.3 (GENERAL ELECTRIC)

- Topical report for task 4.2 including prototype feature casting drawing, estimate of cost to produce feature casting, and estimate of production schedule to produce feature casting. (GENERAL ELECTRIC)

- Topical report for task 7 - Economic assessment of AUSC plant and the impact of AUSC STs (EPRI) 


\section{TASK 12.1 COATINGS FOR STEAM OXIDATION AND SOLID PARTICLE EROSION RESISTANCE (ALSTOM POWER)}





\section{REPORT SUMMARY}

This report presents the results of efforts by Alstom Power on Task 12.1 of the ultrasupercritical (USC) steam turbine materials development program, which has consisted of short- and longterm steam oxidation testing of candidate nickel-base alloys for USC steam turbine components and candidate coatings for solid-particle erosion (SPE) resistance. Following the completion of short-term screening tests in a thermo-gravimetric analyzer (TGA), the candidate turbine component alloys (also referred to as "substrate alloys") were exposed for 10,000 hours in steam at atmospheric pressure and temperatures of 700,760 , and $800^{\circ} \mathrm{C}$. The candidate SPE coatings were selected and subjected to SPE wear testing by Siemens Power Generation Inc. Because the coatings were not available until later in the project, steam exposures of only 1,000 hours have been completed on the candidate SPE coatings.

All candidate nickel-base USC alloys showed a low rate of oxidation in long-term testing at 700, 760 , and $800^{\circ} \mathrm{C}$. Substrate alloys which showed the best steam oxidation resistance were Udiment 720 LI, Waspaloy, and Inconel 740.

Thin, Cr-rich external oxide scales were found on all substrate alloys. No spallation of external scales was observed. Weight loss and porosity associated with internal oxidation were observed in some alloys at $760^{\circ} \mathrm{C}$ and in most alloys at $800^{\circ} \mathrm{C}$. It is unclear whether the weigh loss resulted from chromia evaporation, $\mathrm{MoO}_{3}$ evaporation, or both. The data generated in this task indicates that the candidate substrate alloys considered would perform as well or better, relative to steam oxidation, than current state-of-the-art applications.

Candidate SPE-resistant coatings which showed the best steam oxidation resistance were Stellite 6B, Tribaloy T-400C, Metco 45, and CrC-NiCr. The extent of oxidation for these coatings after 1000 hour exposure was comparable to that of the substrate alloys. The SHS 7170, SHS 9172, and $\mathrm{MoB}-\mathrm{CoCr}$ coatings suffered from extensive internal oxidation or oxidation along coating cracks, and are not considered suitable for application in an USC steam turbine environment. 



\section{LIST OF NOMENCLATURE}

$\begin{array}{ll}\text { A } & \text { area, } \mathrm{cm}^{2} \\ \Delta \mathrm{m} & \text { mass change } \\ \mathrm{k} & \text { parabolic mass gain rate constant, } \mathrm{g}^{2} / \mathrm{cm}^{4} . \mathrm{s} \\ \mathrm{k}^{\prime} & \text { parabolic thickness gain rate constant, } \mathrm{cm}^{2} / \mathrm{s} \\ \mathrm{T} & \text { Temperature, }{ }^{\circ} \mathrm{C} \\ \mathrm{t} & \text { time, } \mathrm{s} \\ \mathrm{TGA} & \text { thermogravimetric analyzer } \\ \text { thk } & \text { thickness, mm } \\ \text { thk } & \text { depth of internal attack, } \mathrm{mm} \\ \text { thk }_{\text {scale }} & \text { thickness of oxide scale, } \mathrm{mm} \\ \text { TML } & \text { total metal loss, mm } \\ \mu \mathrm{m} & \text { Length, microns }\end{array}$





\section{TABLE OF CONTENTS}

\section{TASK 12.1 COATINGS FOR STEAM OXIDATION AND SOLID PARTICLE

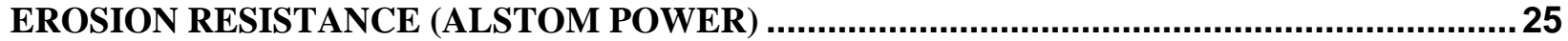

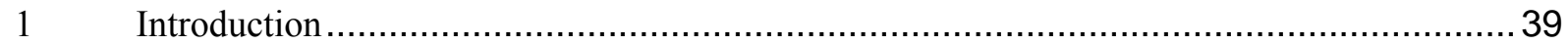

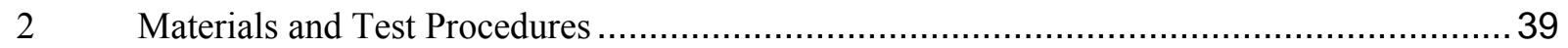

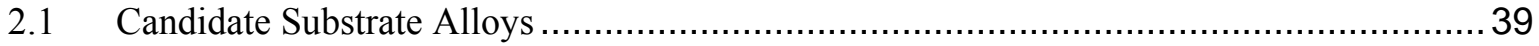

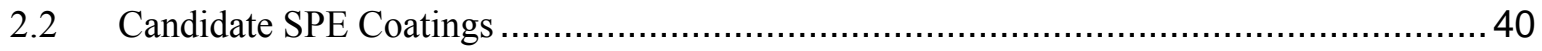

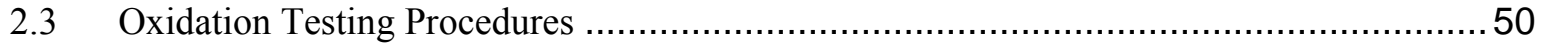

3 Results and Discussion - Substrate Alloys ......................................................... 54

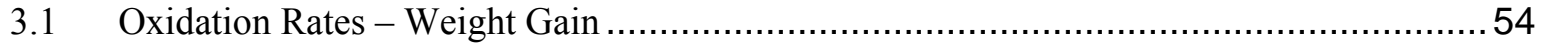

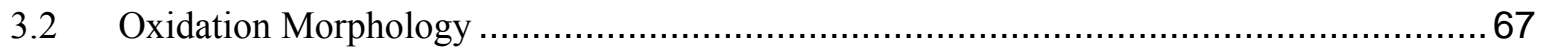

3.3 Oxidation Rates - Scale Thickness and Internal Attack...................................... 80

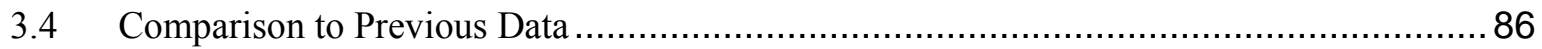

3.5 General Discussion - Significance of Results for Substrates.................................. 92

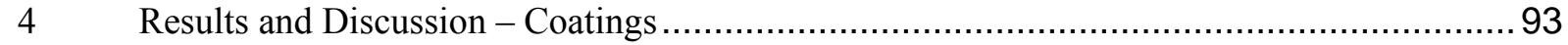

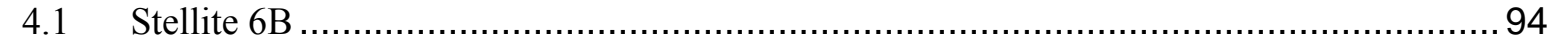

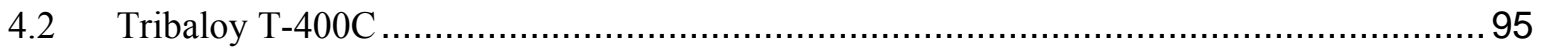

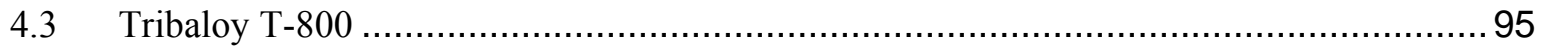

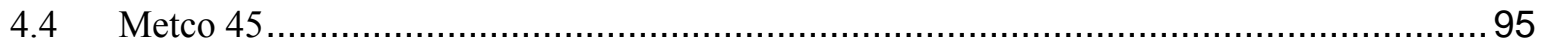

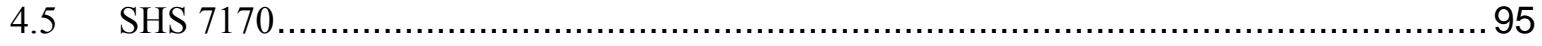

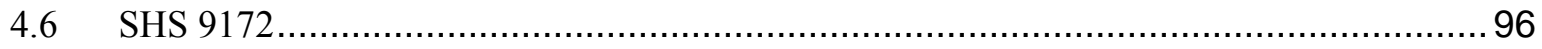

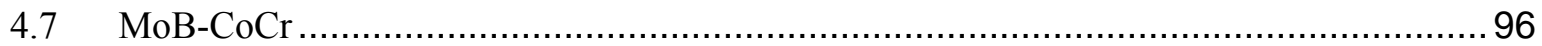

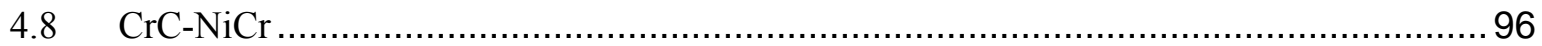

$4.9 \quad$ General Discussion - Significance of Results ................................................. 96

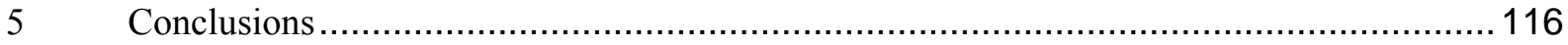

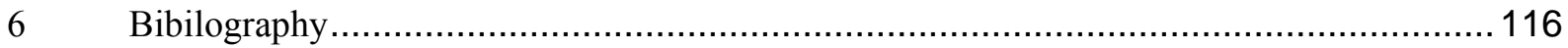





\section{LIST OF FIGURES}

Figure 2-1 Stellite 6B As-Received Microstructure. Unetched, Backscattered Electron Images.

Figure 2-2 Optical and Backscattered Electron Overviews of As-Received Tribaloy T-800

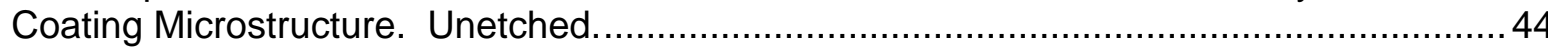

Figure 2-3 Higher-Magnification View of As-Received T-800 Coating Microstructure. Unetched. 45

Figure 2-4 Overview of As-Received Metco 45 Coating Microstructure. Unetched.................. 45

Figure 2-5 Close Views of As-Received Metco 45 Coating Surface. Unetched. ...................... 46

Figure 2-6 Overviews of As-Received SHS 7170 Coating Microstructure. Unetched................46

Figure 2-7 Close Views of As-Received SHS 7170 Coating Surface. Unetched..................... 46

Figure 2-8 Overviews of As-Received SHS 9172 Coating Microstructure. Unetched............... 47

Figure 2-9 Close Views of As-Received SHS 9172 Coating Surface. Unetched..................... 47

Figure 2-10 Optical and Backscattered Electron Overviews of As-Received MoB-CoCr

(MB-42) Coating Microstructure. Unetched.......................................................... 48

Figure 2-11 Higher-Magnification View of As-Received MoB-CoCr Coating Microstructure. Unetched. ......................................................................... 48

Figure 2-12 Optical and Backscattered Electron Overviews of As-Received CrC-NiCr (CRC-25) Coating Microstructure. Unetched.

Figure 2-13 Higher-Magnification View of As-Received CrC-NiCr Coating Microstructure. Unetched.

Figure 2-14 Close Views of As-Received CrC-NiCr Coating Surface. Unetched.....................50

Figure 2-15 Long-Term Steam Oxidation Test Rig, Consisting of Three Horizontal Tube Furnaces (Wrapped in Insulation) with a Recirculating Water/Steam Supply (Below Furnaces).

Figure 2-16 Coupon Boats Loaded with Substrate Alloy Coupons Prior to Exposure.

Figure 2-17 Coupon Boats After 4000 hour Exposure. The Alumina Hanger Rods of Some Alloys Have Been Stained Green and Yellow.

Figure 3-1 Weight Gain Data for Haynes 230 Long-Term Exposure Coupons. Lines represent Parabolic Rate Kinetics Fitted to Data up to 4,000 hours.

Figure 3-2 Weight Gain Data for Haynes 282 Long-Term Exposure Coupons. Lines represent Parabolic Rate Kinetics Fitted to Data up to 4,000 hours.

Figure 3-3 Weight Gain Data for Inconel 617 Long-Term Exposure Coupons. Lines represent Parabolic Rate Kinetics Fitted to Data up to 4,000 hours.

Figure 3-4 Weight Gain Data for Inconel 740 Long-Term Exposure Coupons. Lines represent Parabolic Rate Kinetics Fitted to Data up to 4,000 hours.

Figure 3-5 Weight Gain Data for Nimonic 105 Long-Term Exposure Coupons. Lines represent Parabolic Rate Kinetics Fitted to Data up to 4,000 hours.

Figure 3-6 Weight Gain Data for Nimonic 263 Long-Term Exposure Coupons. Lines represent Parabolic Rate Kinetics Fitted to Data up to 4,000 hours. 
Figure 3-7 Weight Gain Data for Udimet 720Li Long-Term Exposure Coupons. Lines represent Parabolic Rate Kinetics Fitted to Data up to 4,000 hours.

Figure 3-8 Weight Gain Data for Waspalloy Long-Term Exposure Coupons. Lines represent Parabolic Rate Kinetics Fitted to Data up to 4,000 hours.

Figure 3-9 Weight Gain Parabolic Rate Constants for Substrate Alloys Measured in Long-Term Testing Using Data to 4,000 hours.

Figure 3-10 Weight Gain Parabolic Rate Constants as a Function of 1/T and Estimated Scale Thickness after 100,000 hours

Figure 3-11 Comparison of Weight Gain Parabolic Rate Constants Obtained in LongTerm and TGA Tests.

Figure 3-12 Typical oxidized surface of Haynes 282 as a function of time

Figure 3-13 Typical oxidized surface of Nimonic 105 as a function of time.....

Figure 3-14 Typical oxidized surface of Haynes 230 after 8,000 hours of exposure at 700,760 , and $800^{\circ} \mathrm{C}$

Figure 3-15 Typical oxidized surface of Haynes 282 after 8,000 hours of exposure at 700,760 , and $800^{\circ} \mathrm{C}$

Figure 3-16 Typical oxidized surface of 617 after 8,000 hours of exposure at 700,760 , and $800^{\circ} \mathrm{C}$

Figure 3-17 Typical oxidized surface of Inconel 740 after 8,000 hours of exposure at 700,760 , and $800^{\circ} \mathrm{C}$

Figure 3-18 Typical oxidized surface of Nimonic 105 after 8,000 hours of exposure at 700,760 , and $800^{\circ} \mathrm{C}$

Figure 3-19 Typical oxidized surface of Nimonic 263 after 8,000 hours of exposure at 700,760 , and $800^{\circ} \mathrm{C}$

Figure 3-20 Typical oxidized surface of Udimet $720 \mathrm{Li}$ after 8,000 hours of exposure at 700,760 , and $800^{\circ} \mathrm{C}$

Figure 3-21 Typical oxidized surface of Waspalloy after 8,000 hours of exposure at 700, 760 , and $800^{\circ} \mathrm{C}$

Figure 3-22 BSE Image of Haynes 282 after exposure at $800^{\circ} \mathrm{C}$ for 8000 hours. Results of EDS analysis at various locations are provided.

Figure 3-23 BSE Image of Waspalloy after exposure at $760^{\circ} \mathrm{C}$ for 8000 hours. Results of EDS analysis at various locations are provided. 80

Figure 3-24 Example plots of total metal loss versus the square root of time .83

Figure 3-25 TML rate constants for substrate alloys.

Figure 3-26 TML after 100,000 hours exposure based on extrapolation of TML parabolic kinetics

Figure 3-27 External scale thickness after 100,000 hours based on extrapolation of scale thickness oxidation kinetics

Figure 3-28 Plot of TML Parabolic Rate Constants for Substrate Alloys versus Inverse of Temperature.

Figure 3-29 Comparison of parabolic rate constants (mass gain kinetics) for this study (Alstom) and previous work from the A-USC Steam Boiler Consortium (ORNLand B\&W) for Haynes 230 
Figure 3-30 Comparison of parabolic rate constants (TML) for this study (Alstom) and previous work from the A-USC Steam Boiler Consortium (ORNL) for Haynes 230

Figure 3-31 Comparison of parabolic rate constants (mass gain kinetics) for this study (Alstom) and previous work from the A-USC Steam Boiler Consortium (ORNLand B\&W) for 617

Figure 3-32 Comparison of parabolic rate constants (TML) for this study (Alstom) and previous work from the A-USC Steam Boiler Consortium (ORNL) for 617

Figure 3-33 Comparison of parabolic rate constants (mass gain kinetics) for this study (Alstom) and previous work from the A-USC Steam Boiler Consortium (ORNLand B\&W) for Inconel 740

Figure 3-34 Comparison of parabolic rate constants (TML) for this study (Alstom) and previous work from the A-USC Steam Boiler Consortium (ORNL) for Inconel 740

Figure 3-35 Comparison of parabolic rate constants (mass gain kinetics) for this study (Alstom) and previous work from the A-USC Steam Boiler Consortium (B\&W) for Nimonic 263

Figure 4-1: Typical Oxidized Surface of Stellite 6B after 1000 hours Exposure at 700, 760 , and $800^{\circ} \mathrm{C}$.

Figure 4-2: Backscattered Electron Image of Stellite 6B Exposed at $760^{\circ} \mathrm{C}$ for 1000 hours. Results of EDS Analysis at Locations Indicated are Listed Below the Image.........98

Figure 4-3: Optical and Backscattered Electron Overviews of T-400C Coating Microstructure After 1000 hour Exposure at $760^{\circ} \mathrm{C}$. Unetched.

Figure 4-4: Higher-Magnification View of T-400C Coating Microstructure After 1000 hour Exposure at $760^{\circ} \mathrm{C}$. Unetched.

Figure 4-5: Overviews of Exposed T-400C Coupon Showing Extensive Oxidation of the Type 304 SS Substrate and Substrate Oxide Spallation. .......................................... 100

Figure 4-6: Thick Oxide on Type 304 SS Substrate After 1000 hour Exposure at $760^{\circ} \mathrm{C} . \ldots . . .100$

Figure 4-7: Typical Oxidized T-400C Coating Surface After 1000 hour Exposure at $760^{\circ} \mathrm{C}$. Unetched.

Figure 4-8: Backscattered Electron Image of T-400C Coating Exposed at $760^{\circ} \mathrm{C}$ for 1000 hours. Results of EDS Analysis at Locations Indicated are Listed Below the Image....... 102

Figure 4-9: Typical Oxidized T-800 Coating Surface After 1000 hour Exposure at $760^{\circ} \mathrm{C}$. Unetched.

Figure 4-10: Backscattered Electron Image of T-800 Coating Exposed at $760^{\circ} \mathrm{C}$ for 1000 hours. Results of EDS Analysis at Locations Indicated are Listed Below the Image. 104

Figure 4-11: Typical Oxidized Surface of Metco 45 Coating after 1000 hours Exposure at 700,760 , and $800^{\circ} \mathrm{C}$. Unetched. Note that top image is at higher magnification than lower images.

Figure 4-12: Coating Debonding Observed at Corners of Coupons Exposed at 700, 760, and $800^{\circ} \mathrm{C}$. Unetched.

Figure 4-13: Backscattered Electron Image of Metco 45 Coating Exposed at $760^{\circ} \mathrm{C}$ for 1000 hours. Results of EDS Analysis at Locations Indicated are Listed Below the Image.

Figure 4-14: SHS 7170 Coating After 1000 hour Exposure at $760^{\circ} \mathrm{C}$, Showing an Oxidized Through-Coating Crack. Unetched. 108 
Figure 4-15: Typical Oxidized Surface of SHS 7170 Coating after 1000 hours Exposure at $760^{\circ} \mathrm{C}$. Unetched.

Figure 4-16: Backscattered Electron Image of SHS 7170 Coating Exposed at $760^{\circ} \mathrm{C}$ for 1000 hours. Results of EDS Analysis at Locations Indicated are Listed Below the Image.

Figure 4-17: SHS 9172 Coating After 1000 hour Exposure at $760^{\circ} \mathrm{C}$, Showing an Oxidized Through-Coating Crack. Unetched.

Figure 4-18: Typical Oxidized Surface of SHS 9172 Coating after 1000 hours Exposure at $760^{\circ} \mathrm{C}$. Unetched.

Figure 4-19: Backscattered Electron Image of SHS 9172 Coating Exposed at $760^{\circ} \mathrm{C}$ for 1000 hours. Results of EDS Analysis at Locations Indicated are Listed Below the Image.

Figure 4-20: Typical Oxidized Surface of MoB-CoCr Coating after 1000 hours Exposure at $760^{\circ} \mathrm{C}$. Unetched.

Figure 4-21: MoB-CoCr Coating After 1000 hour Exposure at $760^{\circ} \mathrm{C}$, Showing Deep Internal Oxidation. Unetched.

Figure 4-22: Backscattered Electron Image of MoB-CoCr Coating Exposed at $760^{\circ} \mathrm{C}$ for 1000 hours. Results of EDS Analysis at Locations Indicated are Listed Below the Image.

Figure 4-23: Typical Oxidized Surface of CrC-NiCr Coating after 1000 hours Exposure at $760^{\circ} \mathrm{C}$. Unetched.

Figure 4-24: Cracking Observed in Corner of $\mathrm{CrC}-\mathrm{NiCr}$ Coating After Exposure at $760^{\circ} \mathrm{C}$ for $1000 \mathrm{hr}$. Cracking was Associated with Abnormal Coating Build-Up. Unetched.

Figure 4-25: Backscattered Electron Image of $\mathrm{CrC}-\mathrm{NiCr}$ Coating Exposed at $760^{\circ} \mathrm{C}$ for 1000 hours. Results of EDS Analysis at Locations Indicated are Listed Below the Image. 


\section{LIST OF TABLES}

Table 2-1 Nominal Compositions (wt. \%) of Candidate USC ST Alloys Tested........................40

Table 2-2 Candidate SPE Coating Details ................................................................... 41

Table 2-3 Results of Alstom Evaluation of SPE Coating Hardness and Chemical Composition (Carbon content could not be quantitatively measured by EDS and is not listed).

Table 3-1 Summary of Weight Gain Parabolic Rate Constants Obtained by TGA and Long-Term Testing. Also listed are 100,000 hour Oxide Scales Predicted Using these Constants and a Summary of the Metallographic Data

Table 3-2 Scale thickness and internal oxidation measurements from metallurgical cross-sections

Table 4-1 Summary of steam oxidation test results on coatings after 1,000 hour exposure 



\section{Introduction}

An ultrasupercritical (USC) steam turbine materials development program, sponsored by the U.S. Department of Energy and the Ohio Coal Development Office, is focused on identifying, evaluating, and qualifying advanced alloys needed to withstand the operating conditions of a steam turbine operating at a steam temperature and pressure of $760^{\circ} \mathrm{C}\left(1400^{\circ} \mathrm{F}\right)$ and $35 \mathrm{MPa}$ (5000 psi). For these conditions, components exposed to steam at the highest temperatures will need to be constructed from nickel-base alloys with higher elevated temperature strength than the high-Cr ferritic steels currently used in high-temperature steam turbines. In addition to the strength requirements, these alloys must also be resistant to environmental effects such as steam oxidation and solid particle erosion. The objective of Task 12.1, Coatings for Steam Oxidation and Solid Particle Erosion Resistance, was to evaluate the oxidation and solid particle erosion (SPE) resistance of candidate nickel-base alloys for USC applications, and to identify and evaluate candidate coatings to resist oxidation and SPE.

This report presents the results of efforts by Alstom Power on Task 12.1, which has consisted of short- and long-term steam oxidation testing of candidate nickel-base alloys for USC steam turbine components and candidate coatings for SPE resistance. Following the completion of short-term screening tests in a thermo-gravimetric analyzer (TGA), the candidate turbine component alloys (also referred to as "substrate alloys") were exposed for up to 8,000 hours in steam at atmospheric pressure and temperatures of 700,760 , and $800^{\circ} \mathrm{C}$.

The candidate SPE coatings were selected and subjected to SPE testing by Siemens; the results of their efforts, including test results, are presented in the next section of this report. Because the coatings and some of the substrate alloys used in the coatings tests were sourced by Siemens, they were not made available for steam oxidation testing until late in the project. Prior to testing, Siemens reviewed a large number of coatings and identified 12 coatings for trials. Work was then conducted to produce coatings from multiple manufacturers. This activity took a considerable amount of time and resources, thus a limited number of coupons were made available during the late stages of testing. Once the coated samples were received, Alstom utilized the remaining time and limited space in the steam oxidation test rigs to conduct testing on SPE coupons. Steam exposures of 1,000 hours have been completed on the candidate SPE coatings.

\section{$2 \quad$ Materials and Test Procedures}

\subsection{Candidate Substrate Alloys}

Eight candidate USC steam turbine alloys were selected for long-term steam oxidation testing: HAYNES ${ }^{*}$ alloys 230 and 282, INCONEL* alloys 617 and 740, NIMONIC* alloys 105 and 263, UDIMET* alloy 720 LI, and Waspaloy. Nominal compositions are listed in Table 2-1. All are commercially available nickel-base alloys and are candidates for application in wrought forms as rotors, blading, valve internals, and piping due to their high-temperature mechanical properties. Cast alloys of similar compositions are being considered for use as casings and valve bodies.

\footnotetext{
* HAYNES is a trademark of Haynes International Inc.; INCONEL, NIMONIC, and UDIMET are trademarks of Special Metals Corporation.
} 
The alloys, intended for service at temperatures up to $760^{\circ} \mathrm{C}$, rely primarily on solid-solution strengthening, but some contain significant additions of the gamma-prime formers aluminum and titanium for additional precipitation strengthening.

Substrate alloys for steam oxidation testing were obtained in various wrought forms (sheet, tube, bar) from several sources. Rectangular test specimens were electro-discharge machined from the starting stock; all faces were subsequently ground in steps to a 1200 grit surface finish. The TGA specimen dimensions were approximately $33 \times 6 \times 3 \mathrm{~mm}\left(\sim 6 \mathrm{~cm}^{2}\right.$ surface area); the longterm oxidation test specimens dimensions were approximately $20 \times 10 \times 3 \mathrm{~mm}$ (also $\sim 6 \mathrm{~cm}^{2}$ surface area). Both specimen types had a small hole drilled into one end from which the specimen was suspended. The presence of the hole was accounted for in specimen surface area calculations. All coupons were cleaned and weighed prior to exposure.

Table 2-1 ${ }^{1}$ Nominal Compositions (wt. \%) of Candidate USC ST Alloys Tested

\begin{tabular}{llcccccc}
\hline Alloy & $\mathrm{Ni}$ & $\mathrm{Cr}$ & $\mathrm{Co}$ & $\mathrm{Mo}$ & $\mathrm{Al}$ & $\mathrm{Ti}$ & Others \\
\hline Haynes 230 & Balance & 22 & 5 & 2 & 0.3 & & $14 \mathrm{~W}, 3 \mathrm{Fe}$ \\
Haynes 282 & Balance & 19.5 & 10 & 8.5 & 1.5 & 2.1 & \\
Inconel 617 & Balance & 21.5 & 11 & 8.5 & 1.2 & 0.4 & \\
Inconel 740 & Balance & 25 & 20 & 0.5 & 0.9 & 1.8 & $2 \mathrm{Nb}$ \\
Nimonic 105 & Balance & 15 & 20 & 5 & 4.7 & 1.2 & \\
Nimonic 263 & Balance & 20 & 20 & 6 & 0.6 & 2.3 & \\
Udimet 720 LI & Balance & 16 & 14.8 & 3 & 2.5 & 5 & $1.3 \mathrm{~W}$ \\
Waspaloy & Balance & 19.5 & 13.5 & 4 & 1.4 & 3 & \\
\hline
\end{tabular}

\subsection{Candidate SPE Coatings}

Eight candidate coatings were selected and procured by Siemens Power Generation Inc. (Siemens) for SPE testing and supplied to Alstom Power for oxidation testing. Table B-2 lists the coatings, their nominal compositions, thickness, method of application, and vendor from which they were obtained. A wide range of coating types were represented: hardfacing Co-based alloys, carbide and boride composites, and nano-structured Fe-based alloys. With the exception of Stellite 6B, which was obtained in wrought sheet form, and the Triabaloy coatings, which were applied using a proprietary process developed by Deloro Stellite, all coatings were applied by high-velocity oxy-fuel (HVOF) thermal spraying. According to the material vendor, Stellite $6 \mathrm{~B}$ has been successfully used in sheet form as protective blade guards against SPE in existing steam turbines.

Pre-machined Stellite 6B long-term test coupons were supplied by Siemens. The T-400C and T800 coatings were applied to one face of Type 304 stainless steel substrates; the coated substrates were then EDM machined into test coupons. The other thermal spray coatings were applied to one face of pre-machined HASTELLOY X substrate test coupons. The coupons were roughly the same dimensions ( $20 \mathrm{~mm} \times 10 \mathrm{~mm} \times 3 \mathrm{~mm}$ ) as the other substrate test coupons described above

\footnotetext{
${ }^{*}$ HAYNES is a trademark of Haynes International Inc.; INCONEL, NIMONIC, and UDIMET are trademarks of Special Metals Corporation.
} 
with the coating thickness identified in Table 2-2. All coupons were cleaned and weighed prior to exposure.

Table 2-2

Candidate SPE Coating Details

\begin{tabular}{|c|c|c|c|c|c|}
\hline Coating & $\begin{array}{c}\text { Nominal } \\
\text { Composition (wt } \%)\end{array}$ & Thickness $(\mu \mathrm{m})$ & $\begin{array}{l}\text { Application } \\
\text { Method }\end{array}$ & Substrate & Vendor \\
\hline Stellite 6B & Co-30Cr-4.5W-2Si-1.5Mo-1.1C & N/A & Wrought Form & None & Deloro Stellite \\
\hline Tribaloy T-400C & Co-27Mo-14Cr-2.6Si & 920 & Alloy Fusion* & Type 304 SS & Deloro Stellite \\
\hline Tribaloy T-800 & Co-28Mo-18Cr-2.4Si & 960 & Alloy Fusion* & Type 304 SS & Deloro Stellite \\
\hline Metco 45 & Co-25.5Cr-10.5Ni-7.5W-0.5C & 250 & HVOF & Hastelloy X & BASF \\
\hline SHS 7170 & Fe-Cr-W-B-Mn-Mo-C-Si & 250 & HVOF & Hastelloy $X$ & Kermetico \\
\hline SHS 9172 & Fe-Cr-W-Nb-Mo-B-C-Mn-Si & 250 & HVOF & Hastelloy X & Kermetico \\
\hline MB-42 (MoB-CoCr) & MoB - 40\%(Co-33Cr) composite & 250 & HVOF & $\begin{array}{c}\text { Hastelloy X; } \\
25 \mu \mathrm{m} \text { CoNiCrAlY } \\
\text { bond layer }\end{array}$ & Kermetico \\
\hline CRC-25 (CrC-NiCr) & $\mathrm{Cr}_{3} \mathrm{C}_{2}-25 \%(\mathrm{Ni}-20 \mathrm{Cr})$ composite & 210 & HVOF & Hastelloy X & Kermetico \\
\hline
\end{tabular}

* Alloy Fusion is a proprietary coating application method developed by Deloro Stellite; details are not available.

The chemical composition, microstructure, and hardness of the as-received coatings were evaluated by Alstom. The results of microhardness testing and compositional analysis by energy dispersive spectroscopy (EDS) are listed in Table 2-3 and the results generally agreed with the vendor-stated nominal compositions given in Table 2-2. The chemical composition of the superhard steel (SHS) coupons was not given by the manufacturer, but the elements present are in agreement with those stated. A measurable oxygen content was present for all coatings prepared by HVOF, reflecting a small degree of oxidation of spray powder particles in air during flight. A wide range of coating hardness was found, from $340 \mathrm{HV}$ for the Metco 45 coating, to over 1000 $\mathrm{HV}$ for the CRC-25 coating. Specific microstructural details for each coating are given as follows.

Table 2-3

Results of Alstom Evaluation of SPE Coating Hardness and Chemical Composition (Carbon content could not be quantitatively measured by EDS and is not listed).

\begin{tabular}{|c|c|c|c|c|c|c|c|c|c|c|c|c|c|}
\hline \multirow{3}{*}{$\begin{array}{l}\text { Coating or } \\
\text { Substrate }\end{array}$} & \multicolumn{2}{|c|}{ Microhardness $\left(\mathrm{HV}_{500}\right)$} & \multicolumn{11}{|c|}{ Composition by EDS (wt.\%) } \\
\hline & & After $1000 \mathrm{hr}$ & & & & & & & & & & & \\
\hline & As-Received & @ $760^{\circ} \mathrm{C}$ & $\mathrm{O}$ & $\mathrm{Al}$ & Si & $\mathrm{Cr}$ & $\mathrm{Mn}$ & $\mathrm{Fe}$ & Co & $\mathrm{Ni}$ & $\mathrm{Nb}$ & Mo & W \\
\hline Stellite 6B & 395 & 471 & -- & -- & $\overline{--}$ & 34.8 & 1.4 & 1.0 & 55.3 & 2.1 & -- & 1.1 & 4.3 \\
\hline Tribaloy T-400C & $\mathrm{N} / \mathrm{A}$ & 774 & 1.0 & -- & 3.0 & 14.5 & -- & 2.2 & 54.5 & -- & -- & 24.9 & -- \\
\hline Tribaloy T-800 & 778 & 777 & 0.4 & -- & 3.8 & 18.7 & -- & 1.6 & 47.2 & -- & -- & 28.3 & -- \\
\hline Metco 45 & 344 & 372 & 3.4 & -- & -- & 23.4 & -- & 0.8 & 53.8 & 9.7 & -- & -- & 8.9 \\
\hline SHS 7170 & 908 & 707 & 1.2 & -- & -- & 20.9 & 2.8 & 62.8 & -- & -- & -- & 5.3 & 7.1 \\
\hline SHS 9172 & 854 & 883 & 1.7 & -- & 3.4 & 18.5 & 1.0 & 60.9 & -- & -- & 6.3 & & 8.3 \\
\hline MB-42 (MoB-CoCr) & 947 & 1339 & 1.8 & -- & 0.6 & 23.7 & -- & -- & 28.8 & -- & -- & 42.6 & 2.5 \\
\hline CRC-25 (CrC-NiCr) & 1040 & 920 & 1.2 & 1.7 & 0.9 & 69.3 & -- & 0.3 & -- & 26.6 & -- & & -- \\
\hline Type 304 SS & & & -- & -- & 0.4 & 18.9 & 2.0 & 70.3 & -- & 7.9 & -- & 0.5 & -- \\
\hline Hastelloy X & & & -- & 0.2 & 0.6 & 22.8 & 0.8 & 19.7 & -- & 47.2 & -- & 8.7 & -- \\
\hline
\end{tabular}




\section{Stellite 6B}

Low and high-magnification electron backscattered images of Stellite 6B material in the asreceived condition are shown in Figure 2-1. The microstructure consisted of spherical to oblongshaped Cr-rich carbides in a Co-rich matrix. Mo and $\mathrm{W}$ were present in both the matrix and carbide phases. The nominal composition of the matrix phase was Co-26Cr-5W-2.3Ni-1Mo$1 \mathrm{Fe}$; the metal content of the carbide reinforcing phase was $\mathrm{Cr}-12 \mathrm{Co}-2.4 \mathrm{~W}-1.1 \mathrm{Mo}$. A very small fraction of spherical pores was observed.

\section{Tribaloy T-400C}

A sample of the Tribaloy T-400C coating in the as-received condition was not available for examination - all specimens were used in oxidation testing. See section 4 of this chapter for a description of the microstructure observed after 1000 hours exposure at $760^{\circ} \mathrm{C}$.

\section{Tribaloy T-800}

Optical and backscattered electron images (BEI) of the as-received Tribaloy T-800 coating microstructure are shown in Figure 2-2. The coating had a uniform thickness of approximately $960 \mu \mathrm{m}$ and very smooth surface. A small fraction of porosity was present near the coatingsubstrate interface. A higher-magnification BEI view (Figure 2-3) showed the coating to be comprised of a three-phase structure. The dark matrix phase in Figure 2-3 was Co-rich with approximately $24 \% \mathrm{Cr}, 8 \% \mathrm{Mo}$, and $2 \% \mathrm{Si}$. The lightest spherical reinforcing phase was a Laves phase with nearly equal proportions of $\mathrm{Co}$ and $\mathrm{Mo}(40 \%$ each), $13 \% \mathrm{Cr}$, and $5 \% \mathrm{Si}$. The intermediate-gray spherical reinforcing phase was also Laves, but with lower Mo and Si content ( $20 \%$ and $3 \%$, respectively), and commensurately higher $\mathrm{Cr}$ content (25\%).

\section{Metco 45}

An overview of the as-received Metco 45 coating is shown in Figure 2-4. The coating was approximately $250 \mu \mathrm{m}$ thick and showed a lamellar microstructure characteristic of thermallysprayed coatings. A number of alumina particles residual from grit-blasting of the substrate surface were present at the coating-substrate interface. The coating surface was relatively rough (Figure 2-5), typical for an as-sprayed coating. The coating appeared to have a relatively high fraction of oxides interspersed along inter-splat boundaries, at least in comparison with the other HVOF coatings examined.

\section{SHS 7170}

Typical optical micrographs of the as-received SHS 7170 coating are shown in Figure 2-6. The coating was approximately $250 \mu \mathrm{m}$ thick and showed a lamellar microstructure characteristic of thermally-sprayed coatings. The coating showed numerous through-coating cracks and other, smaller cracks, as well as significant porosity. A small fraction of unmelted prior powder particles were also observed in the structure. The coating surface was relatively rough (Figure 2-7), typical for an as-sprayed coating. The amount of oxide, however, appeared to be relatively 
low, especially compared with the Metco 45 coating. A number of alumina particles residual from grit-blasting of the substrate surface were present at the coating-substrate interface.

\section{SHS 9172}

Typical optical micrographs of the as-received SHS 9172 coating are shown in Figure 2-8. The coating was approximately $250 \mu \mathrm{m}$ thick and showed a lamellar microstructure characteristic of thermally-sprayed coatings. As with the SHS 7170 coating, the SHS 9172 coating had numerous cracks and significant porosity, although the cracks were qualitatively less severe in the SHS 9172 coating. A small fraction of unmelted prior powder particles were also observed in the structure. The coating surface was relatively rough (Figure 2-9), typical for an as-sprayed coating. The amount of oxide was relatively low, similar to the SHS 7170 coating. A number of alumina particles residual from grit-blasting of the substrate surface were present at the coatingsubstrate interface.

\section{MB-42 (MoB-CoCr)}

Typical optical and BEI microstructures of the as-received MoB-CoCr coating are shown in Figure 2-10. The coating itself was approximately $250 \mu \mathrm{m}$ thick; there was also a bond layer approximately $25 \mu \mathrm{m}$ thick. EDS analysis showed the bond layer to be a NiCoCrAlY type. Also visible in Figure 2-10 is a relatively high density of residual alumina grit-blast particles present between the substrate and the bond layer. The coating contained a small fraction of porosity, but did not show a clear lamellar splat structure. The coating surface was relatively rough. A higher-magnification view of the coating structure is shown in Figure 2-11; the structure is fine and comprised primarily of a middle-gray phase with composition of approximately $50-60 \% \mathrm{Mo}$, $25-40 \% \mathrm{Co}$, and $10 \% \mathrm{Cr}$. The darker gray phases are richer in $\mathrm{Cr}$; the lighter gray phases are nearly entirely Mo (presumably as MoB). Note that B could not be quantitatively analyzed using the current EDS system; its presence was only detected in the Mo-rich light gray areas of the coating.

\section{CRC-25 (CrC-NiCr)}

Typical optical and BEI microstructures of the as-received $\mathrm{CrC}-\mathrm{NiCr}$ coating are shown in Figure 2-12. The coating was approximately $210 \mu \mathrm{m}$ thick and showed the typical features described above for the other HVOF coatings - porosity and residual alumina grit particles. As with the MoB-CoCr coating, a pronounced lamellar structure and unmelted particles were not observed. As shown in Figure 2-13, the coating is comprised of blocky, Cr-rich carbide particles in a matrix containing both $\mathrm{Ni}$ and $\mathrm{Cr}$. Perhaps due to the size of the electron beam interaction volume, no Ni-rich areas with composition matching the vendor-stated matrix composition were found. The Cr-rich carbide particles also showed a small $(\sim 3.5 \%)$ concentration of W. Both the thickness and surface (Figure 2-14) of the $\mathrm{CrC}-\mathrm{NiCr}$ coating were notably more uniform than the other HVOF coatings in the as-coated condition. 


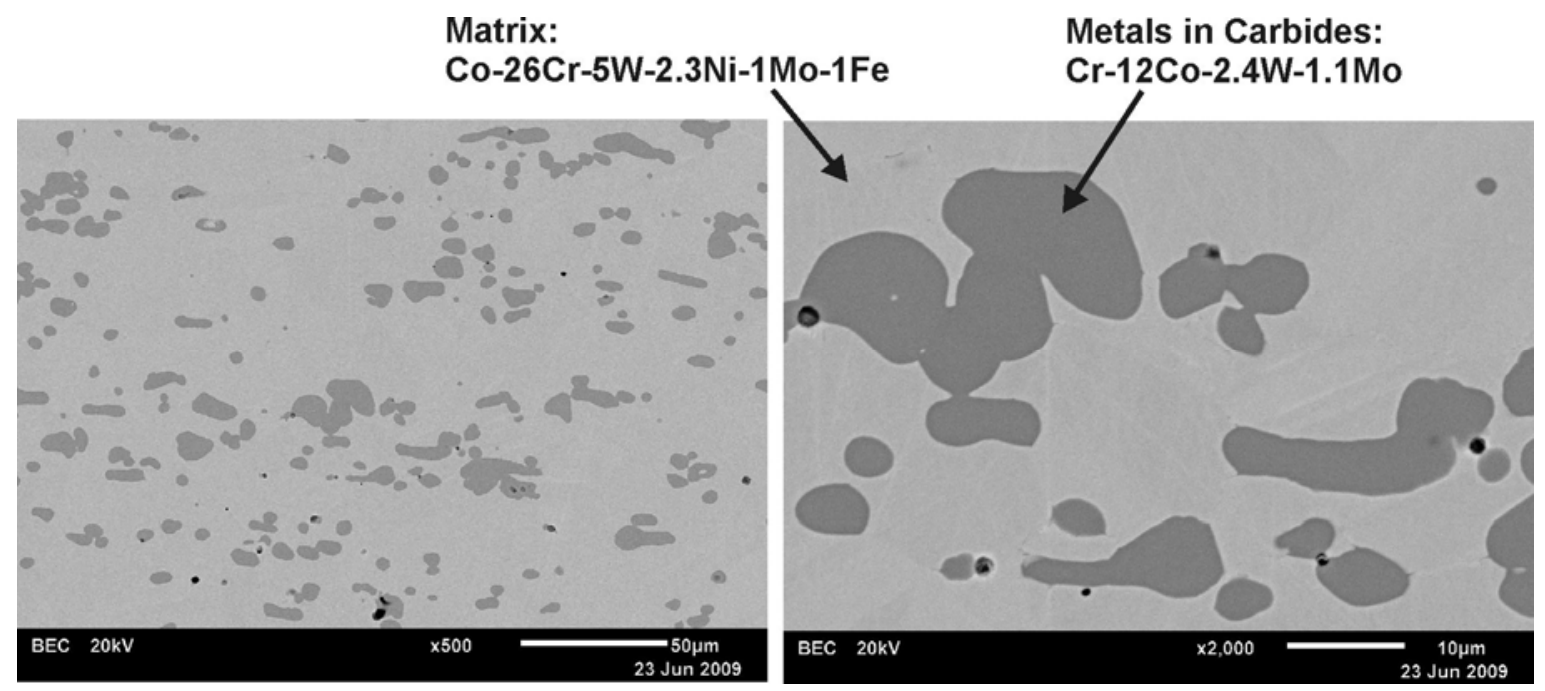

Figure 2-1

Stellite 6B As-Received Microstructure. Unetched, Backscattered Electron Images.

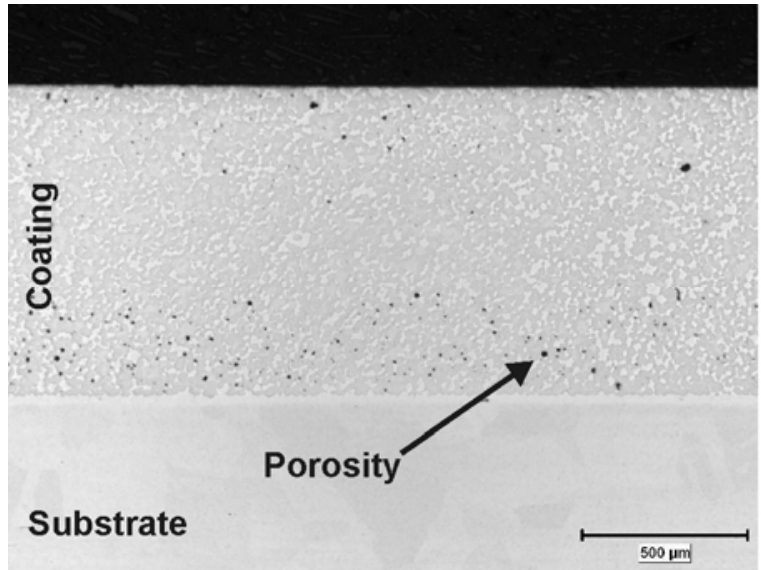

Optical (50X)

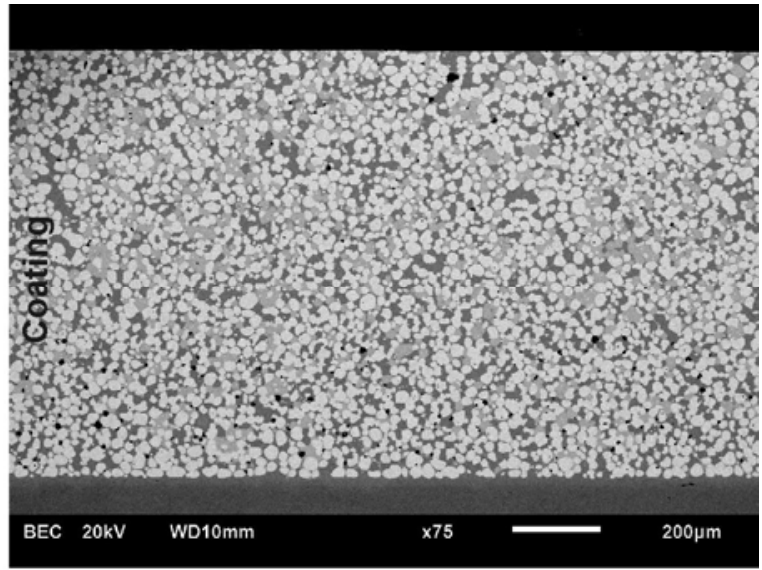

SEM-Backscattered Electron (75X)

Figure 2-2

Optical and Backscattered Electron Overviews of As-Received Tribaloy T-800 Coating Microstructure. Unetched. 


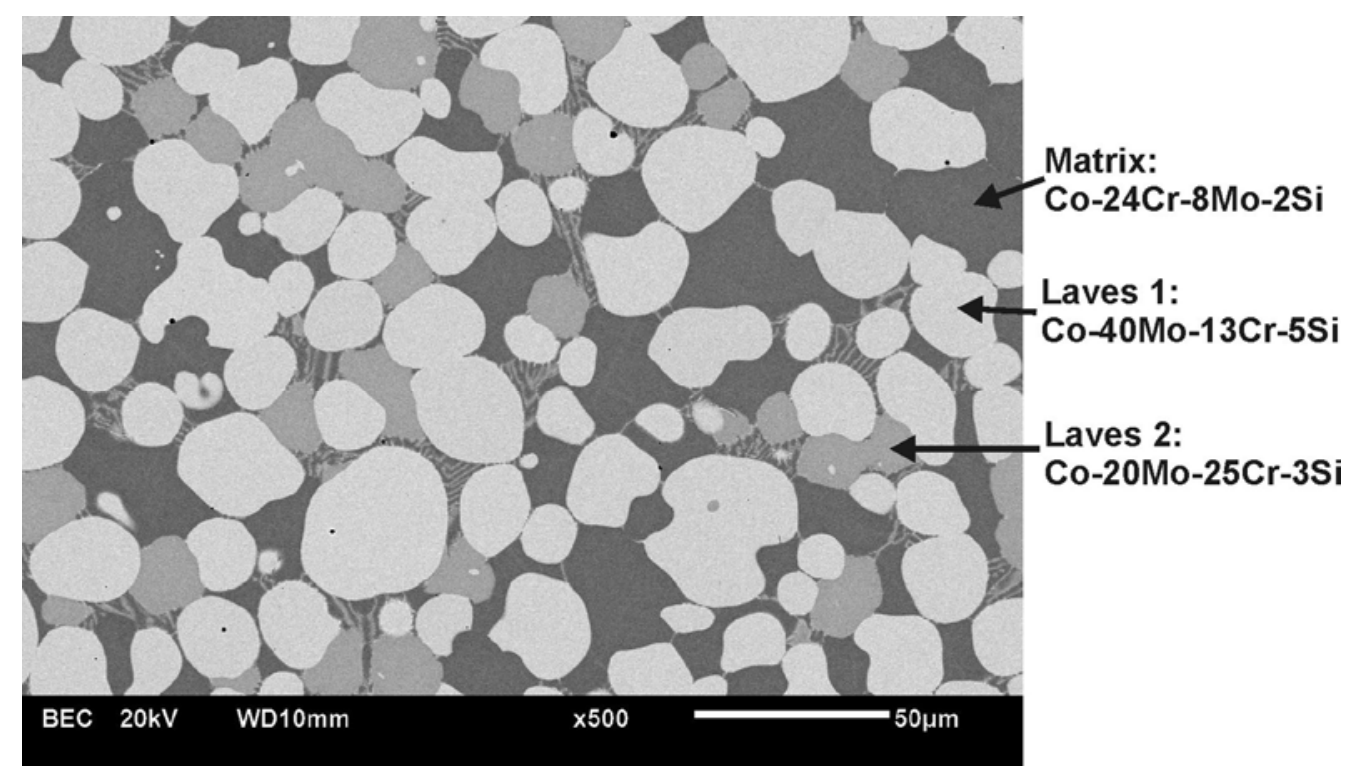

Figure 2-3

Higher-Magnification View of As-Received T-800 Coating Microstructure. Unetched.

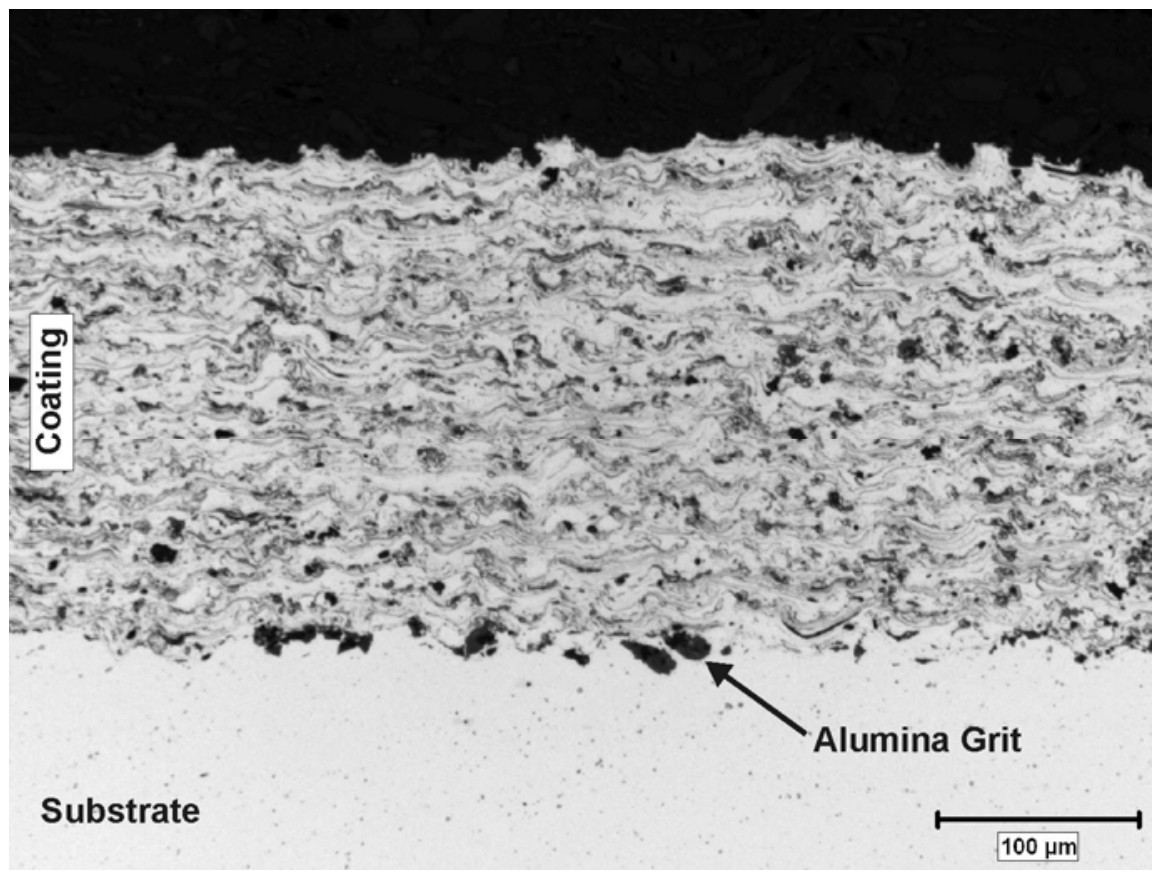

Figure 2-4

Overview of As-Received Metco 45 Coating Microstructure. Unetched. 

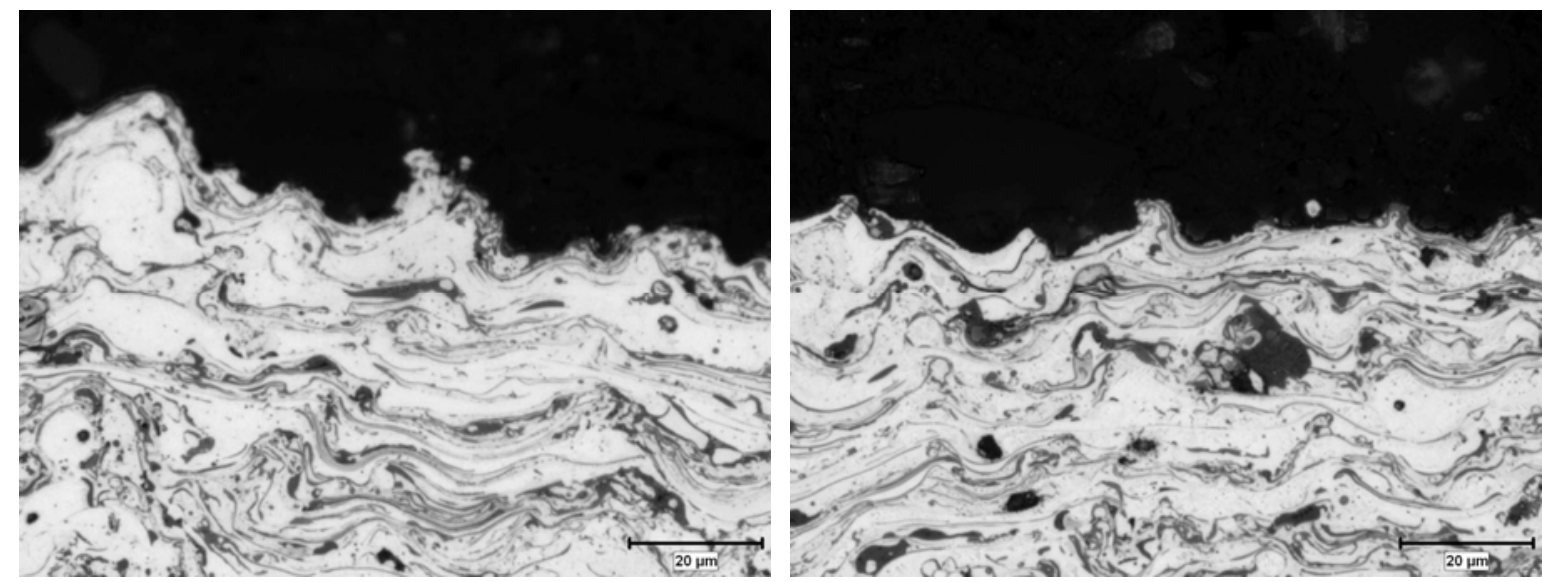

Figure 2-5

Close Views of As-Received Metco 45 Coating Surface. Unetched.
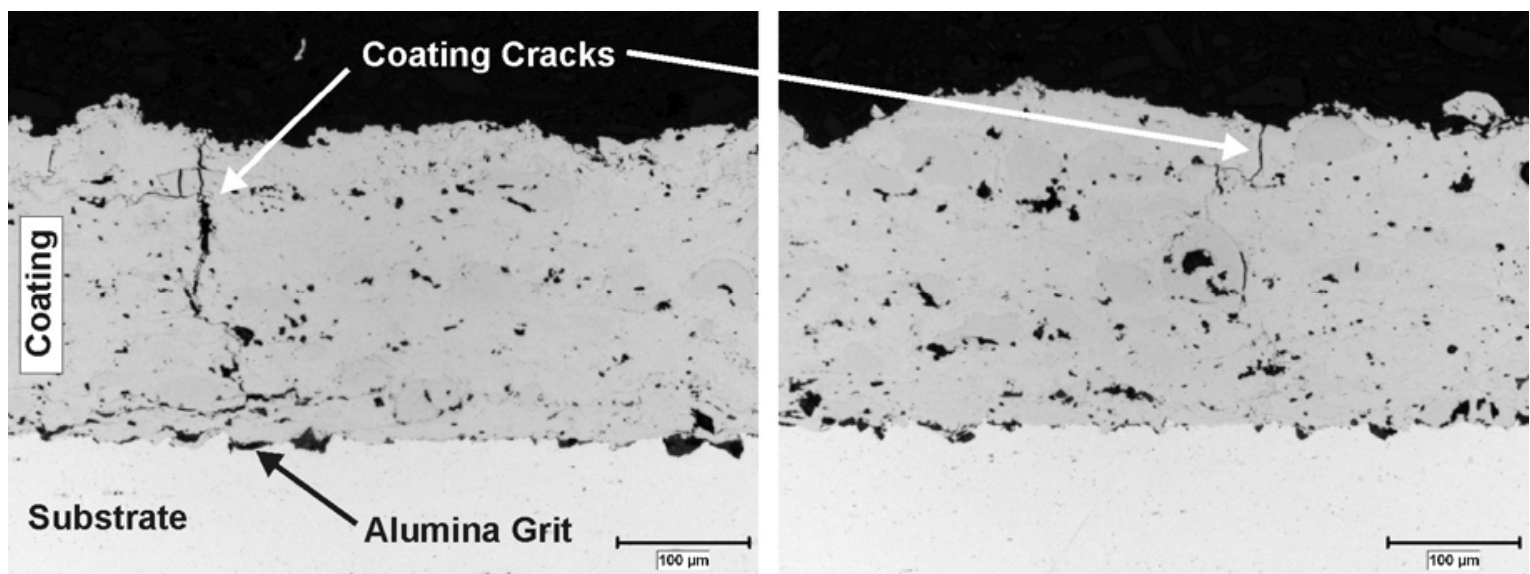

Figure 2-6

Overviews of As-Received SHS 7170 Coating Microstructure. Unetched.

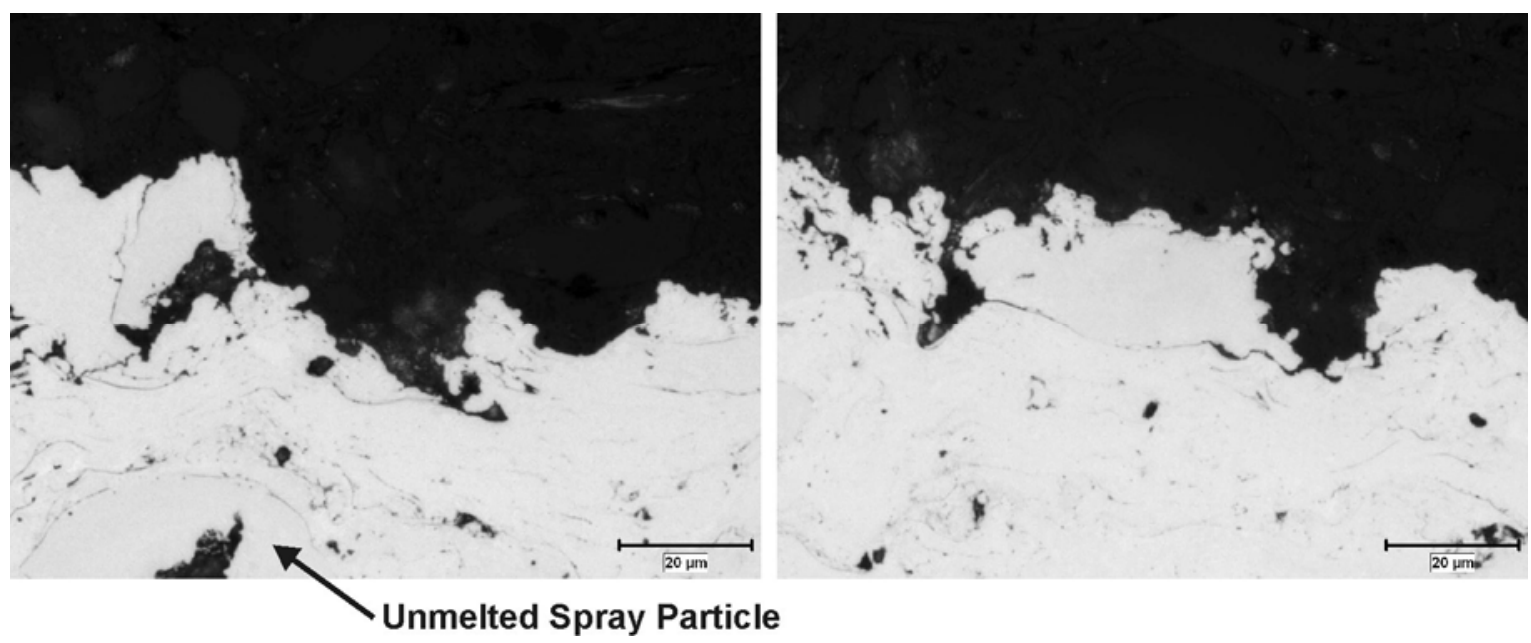

Figure 2-7

Close Views of As-Received SHS 7170 Coating Surface. Unetched. 


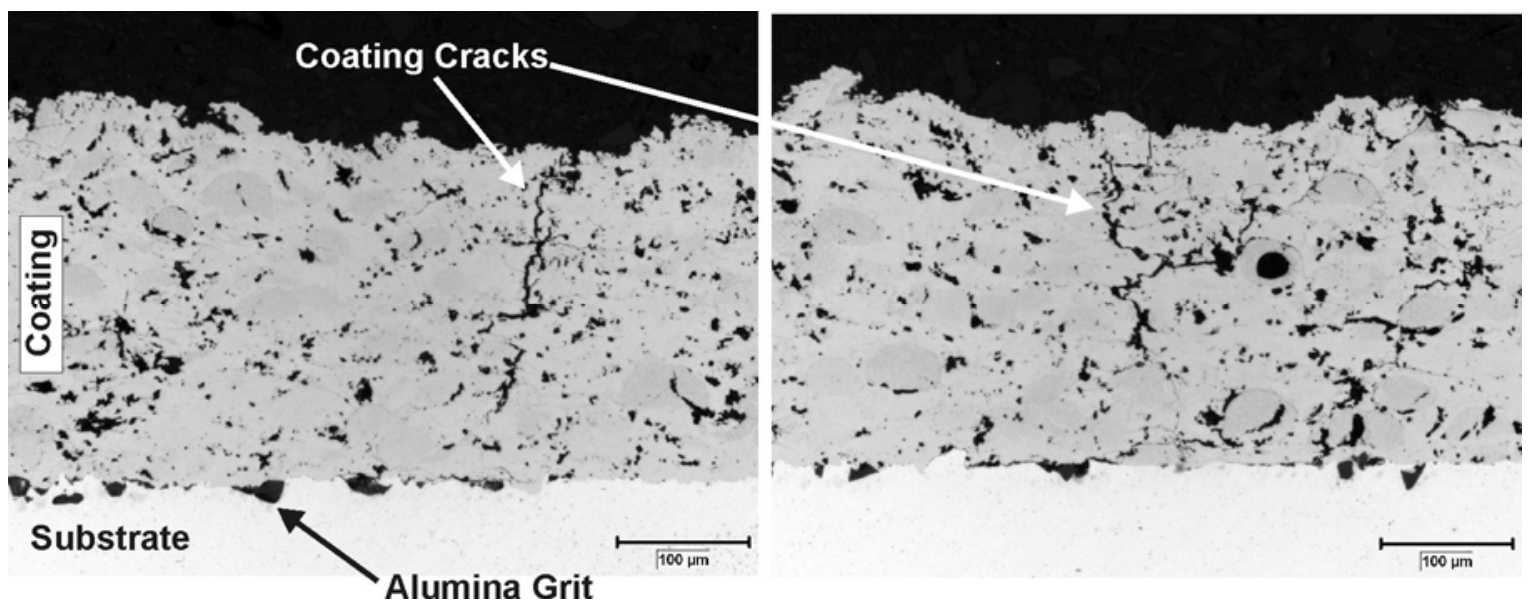

Figure 2-8

Overviews of As-Received SHS 9172 Coating Microstructure. Unetched.

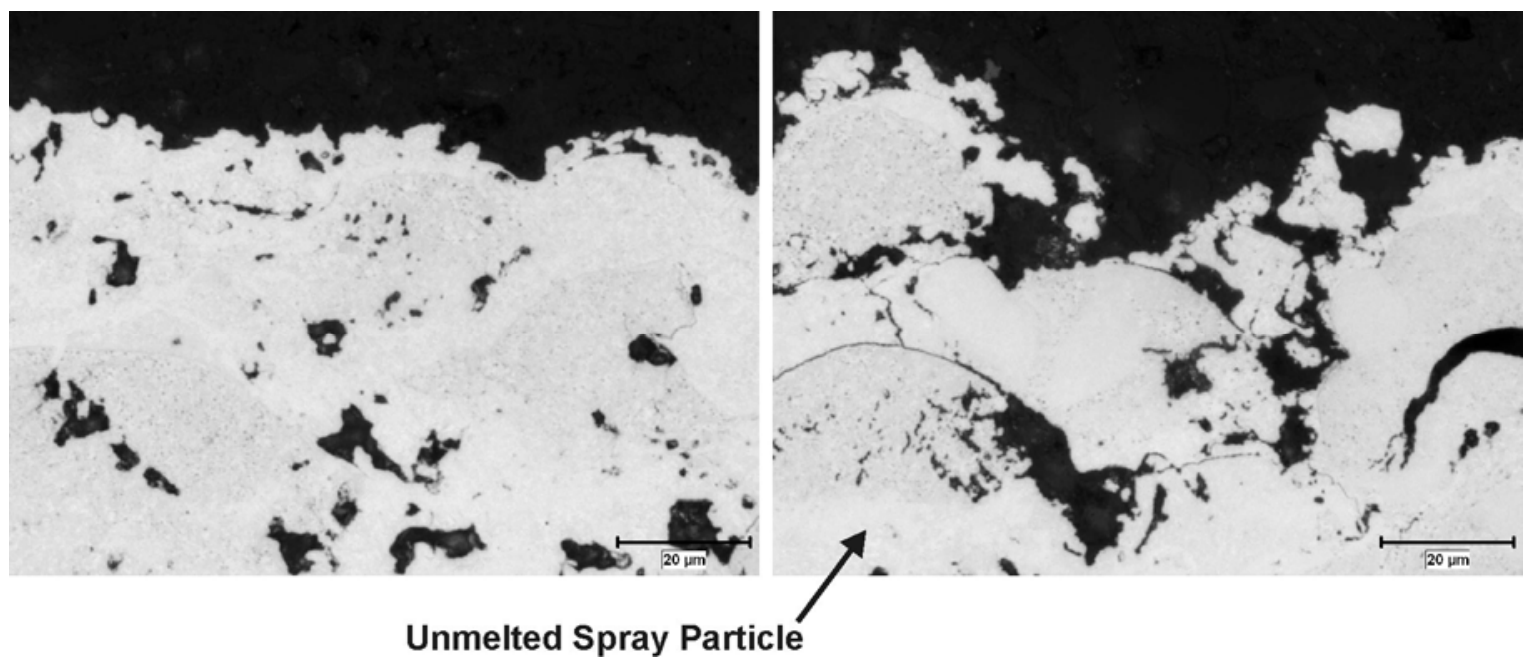

Figure 2-9

Close Views of As-Received SHS 9172 Coating Surface. Unetched. 


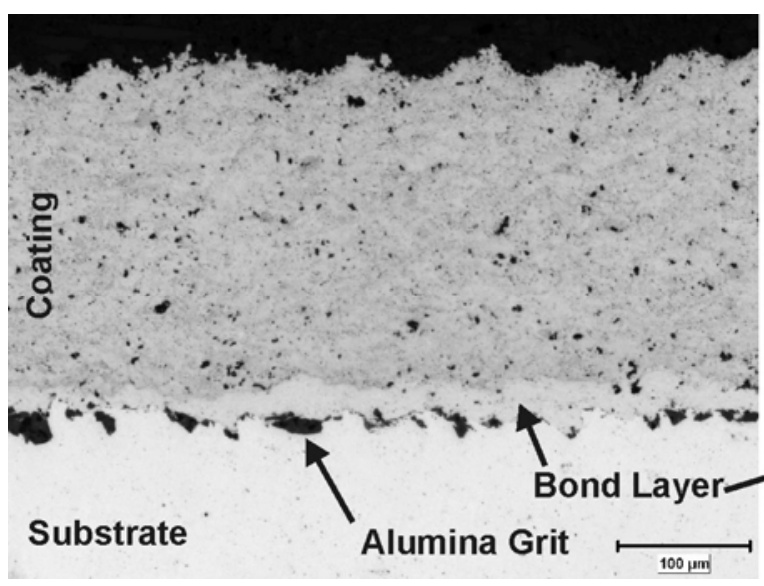

Optical (200X)

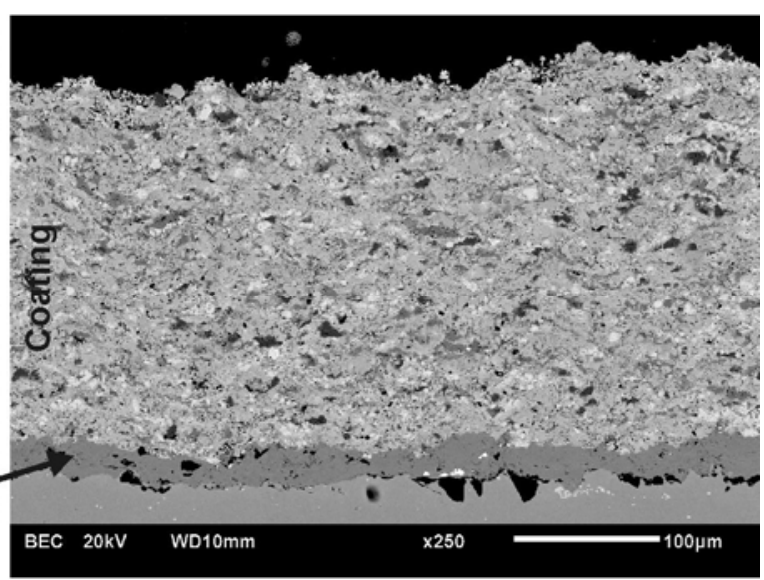

SEM-Backscattered Electron (250X)

Figure 2-10

Optical and Backscattered Electron Overviews of As-Received MoB-CoCr (MB-42) Coating Microstructure. Unetched.

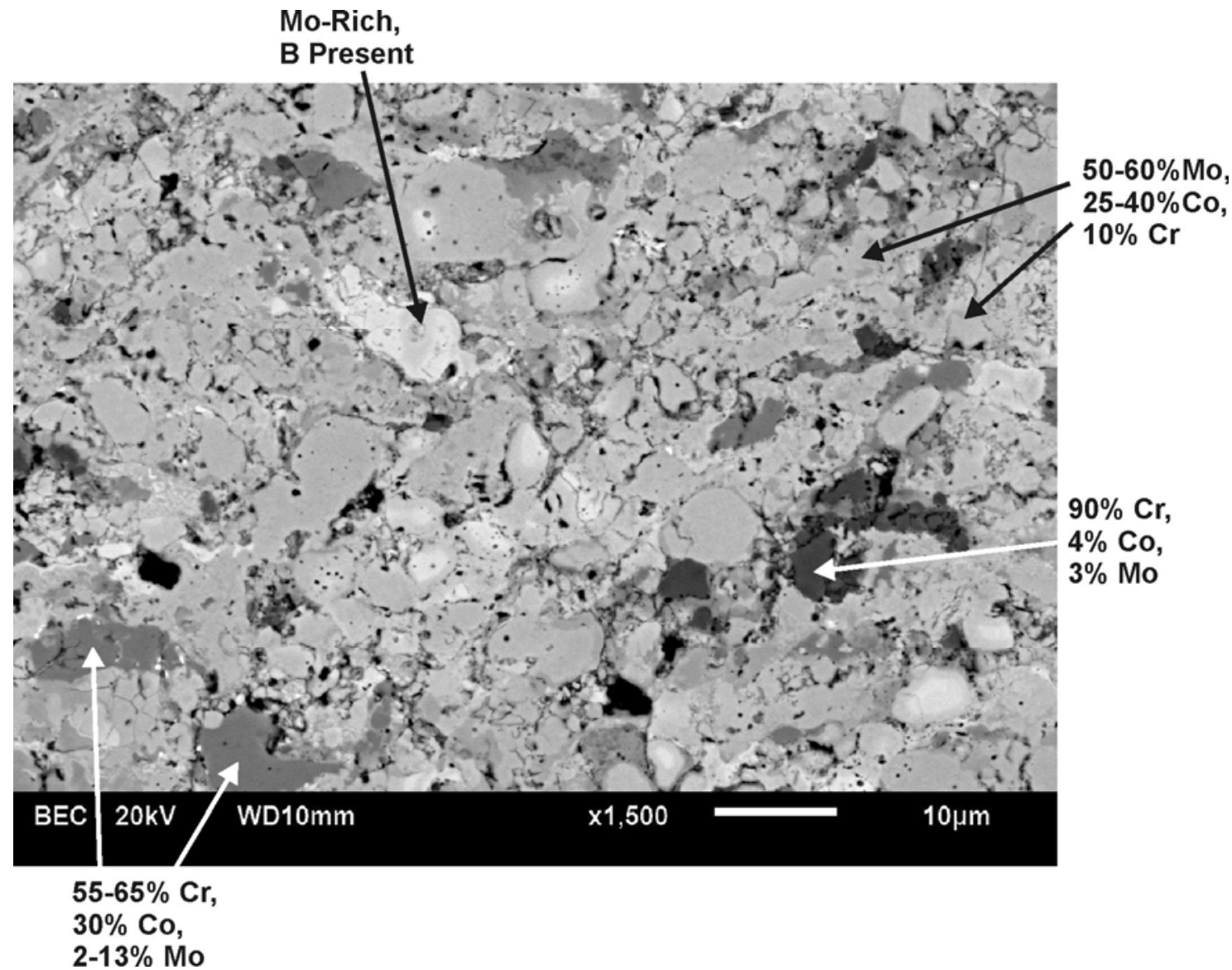

Figure 2-11

Higher-Magnification View of As-Received MoB-CoCr Coating Microstructure. Unetched. 


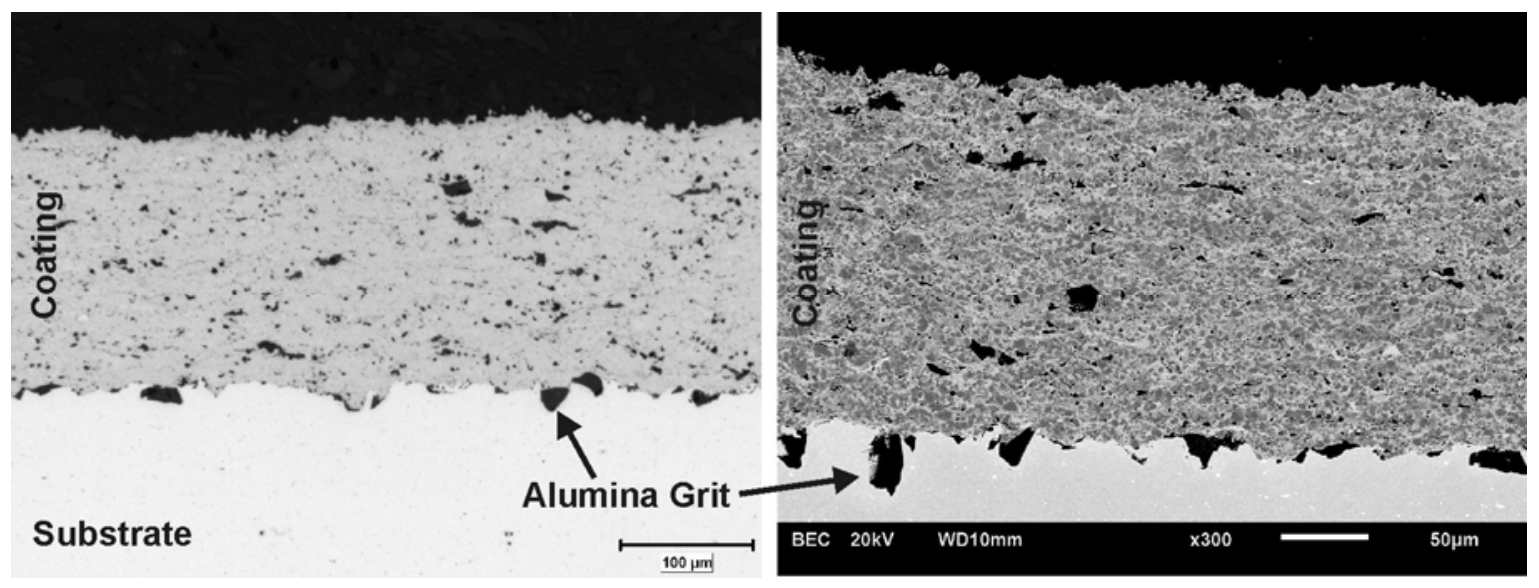

Optical (200X)

SEM-Backscattered Electron (300X)

Figure 2-12

Optical and Backscattered Electron Overviews of As-Received CrC-NiCr (CRC-25) Coating Microstructure. Unetched.

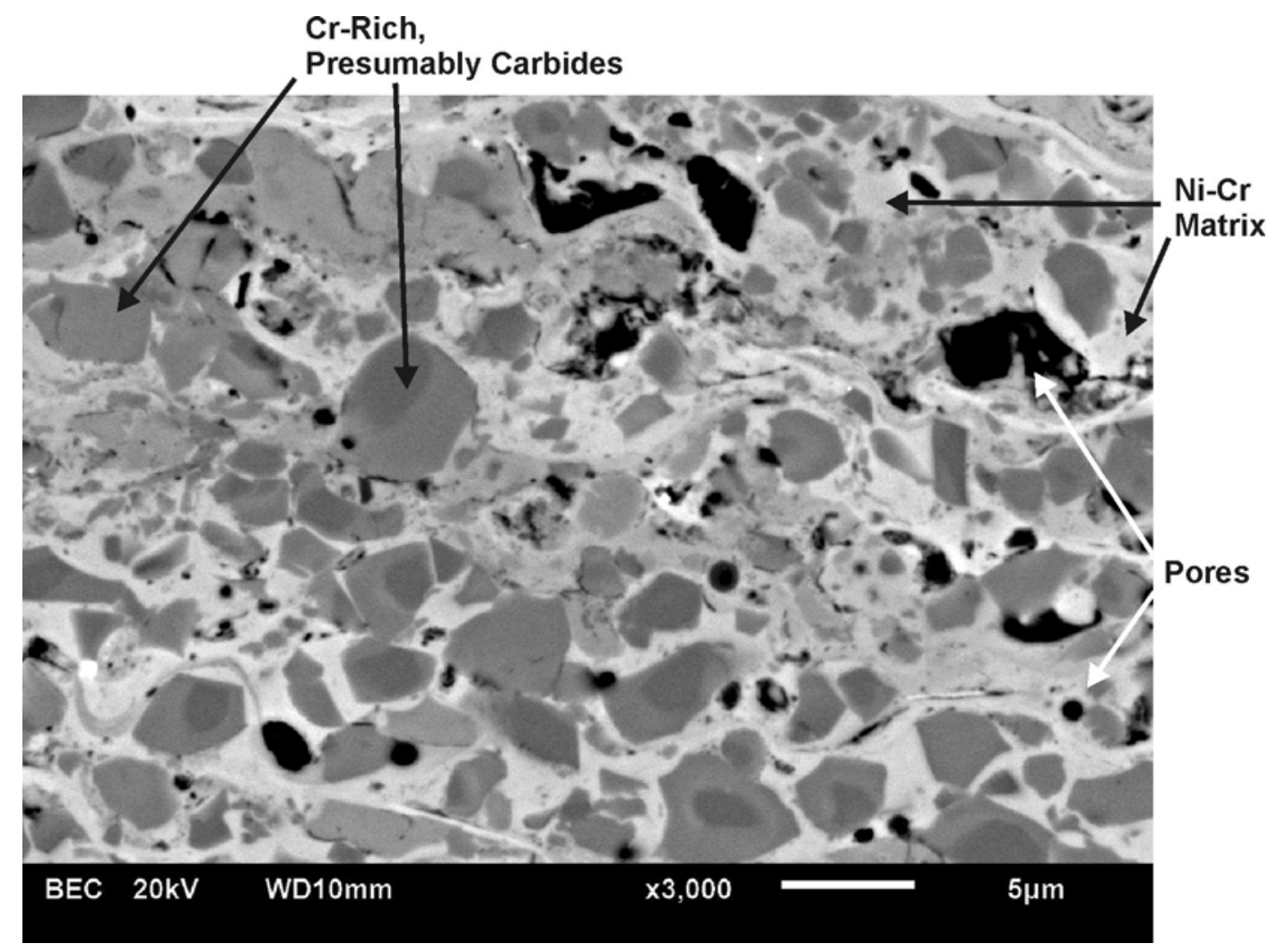

Figure 2-13

Higher-Magnification View of As-Received CrC-NiCr Coating Microstructure. Unetched. 

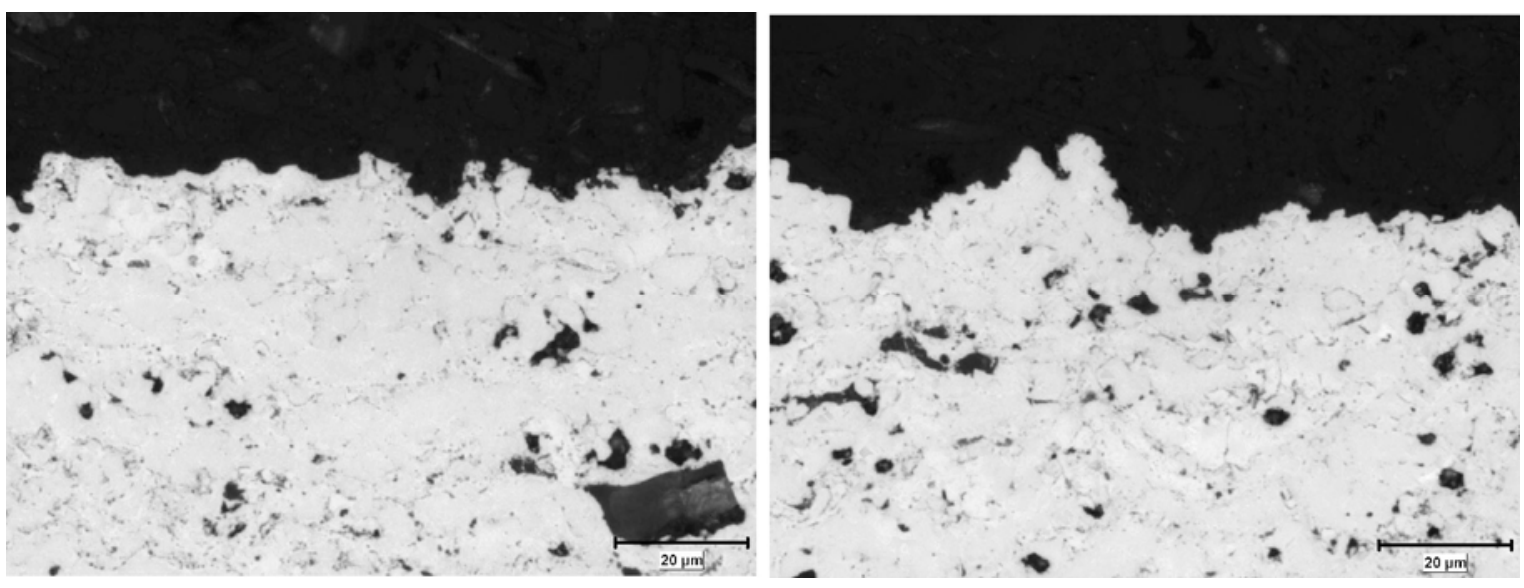

Figure 2-14

Close Views of As-Received CrC-NiCr Coating Surface. Unetched.

\subsection{Oxidation Testing Procedures}

\section{TGA Testing}

Short-term steam oxidation tests for screening purposes were performed in a thermo-gravimetric analyzer (TGA). In the TGA, a test specimen was suspended into a furnace from a microbalance head (Cahn Instruments model 1000) and exposed to a slowly flowing pure steam environment at atmospheric pressure. The velocity of steam passing the test specimen was approximately 0.015 $\mathrm{m} / \mathrm{s}$. Steam was continuously generated and condensed in a closed, recirculating system. Distilled water was used which was continuously de-aerated during testing by bubbling with $\mathrm{N}_{2}$ gas. Specimens were exposed for approximately 140 hours; the weight of the specimen was recorded at 5 minute intervals during the exposure. Weight gain data was analyzed to derive a parabolic rate constant for each test. In general, the oxidation rate kinetics for the tests performed were very close to parabolic. TGA tests were performed at temperatures of 760, 800, and $850^{\circ} \mathrm{C}$; the higher temperatures were required to obtain measureable weight gains in the short test durations for the oxidation-resistant nickel-base alloys. Only substrate alloys Inconel 617, Inconel 740, Nimonic 105, Haynes 230, Haynes 282, and Nimonic 263 were tested. Since these alloys represented a range of chemistries and test results (presented in the later sections) did not indicate excessive oxidation rates (for short-term screening), it was determined to move quickly to long-term testing to generate data more representative of long-term operation.

\section{Long-Term Oxidation Testing}

Long-term steam oxidation tests were performed on all substrate alloys and coatings. Testing consisted of long-term exposure of test specimens to slowly flowing pure steam at atmospheric pressure. Figure 2-15 shows the long-term testing apparatus, which consisted of three cylindrical tube furnaces sharing a common water reservoir and recirculation system. The steam supply (water pump and steam generator) for each furnace was independent. The rectangular test specimens were suspended by alumina rods in alumina fiberboard boats, as shown in Figure 2-16. As with the TGA test system, water was recirculated and continuously de-aerated by nitrogen bubbling of the water reservoir. Although the oxygen content of the steam was not 
directly measured, it is believed that in a reasonably leak-tight system the oxygen concentration at the test temperatures was controlled by the equilibrium dissociation of steam.

Thermodynamic calculations show the equilibrium concentration of oxygen to be $7 \mathrm{ppm}$ at $700^{\circ} \mathrm{C}, 19 \mathrm{ppm}$ at $750^{\circ} \mathrm{C}$, and $48 \mathrm{ppm}$ at $800^{\circ} \mathrm{C}$. It should be noted that there is not standard test method for high-temperature steam oxidation such as a standard in the American Society of Testing Materials (ASTM). Testing by the U.S. DOE/OCDO A-USC steam boiler consortium on similar alloys evaluated testing techniques at three different laboratories on the same alloys and did not find any clear trends with test pressure and/or water treatment. The test set-up used in this research closely matches the set-up utilized in the atmospheric testing by the boiler program but most of the alloys were of different composition.

Long-term steam oxidation exposures were performed at temperatures of 700,760 , and $800^{\circ} \mathrm{C}$. Coupons were exposed continuously (barring the need to shut down the system for leaks or power outages) for 1000 hour durations. After each 1000-hour period, the system was shut down and all coupons were weighed. Four coupons for each substrate alloy were placed into testing for each temperature; one of the four coupons was removed for metallographic analysis on a parabolic time basis: after 1000, 4000, and 8000 hour exposures. The appearance of the coupons after 4000 hours exposure duration is shown in Figure 2-17. Green and yellow staining was observed on the alumina hanger rods of some alloys, particularly alloys Inconel 617, Inconel 740, Haynes 230, and Haynes 282.

Long-term exposures were started for alloys 617, 230, 282, 105, 740, and 263 in July 2007. Udimet $720 \mathrm{LI}$ and Waspaloy coupons were not available at the time of test initiation but were added after 900 hours (Udimet 720 LI) and 3000 hours (Waspaloy) as sourcing stock product with required sizes took longer than anticipated for these materials. Therefore, most substrate samples achieved 10,000 hours of long-term oxidation data with the exception of Waspalloy which achieved 7,000 hours by the end of the test program.

As indicated earlier, SPE coating coupons for steam oxidation tested were only obtained after selection, procurement, and sourcing from Siemens. Coated coupons were received in January of 2009 which gave limited time for pre-test analysis, steam oxidation testing, post-test metallography, and evaluation of the data. A decision was made by the consortium to focus the testing on the application temperature of $760^{\circ} \mathrm{C}$ which was the same temperature the coatings were subjected to erosion testing. For these coatings, coupons were placed into exposure with a removal at duration of 1000 hours.

\section{Post-Exposure Metallographic Analysis}

The extent and morphology of oxidation were assessed after exposure by metallographic analysis using light and scanning electron microscopy. Exposed coupons were sectioned with a lowspeed abrasive cut-off saw, mounted in bakelite, and prepared for examination using standard metallographic procedures. All coupons were examined in the unetched condition.

Microstructural changes, other than those directly associated with oxidation, were not assessed. Due to the thin and adherent nature of the oxide scales formed, it was not necessary to plate the coupons with nickel prior to mounting. 
The average thickness of the external oxide scale was determined from measurements at several locations (generally five) along one face of the coupon. The external oxide scales were uniform, with little variation from location to location. Little difference in oxidation extent was observed on different faces of the substrate alloys; there appeared to be little effect of any anisotropy in the microstructure due to forming processes. The maximum depth of internal attack was also assessed at the locations at which external scales were measured. The depth of internal attack was also uniform over all faces of the coupon. Selected specimens were examined using SEM and EDS to determine the composition of scales and internal attack, and also to assess any oxidation-related alloy depletion effects.

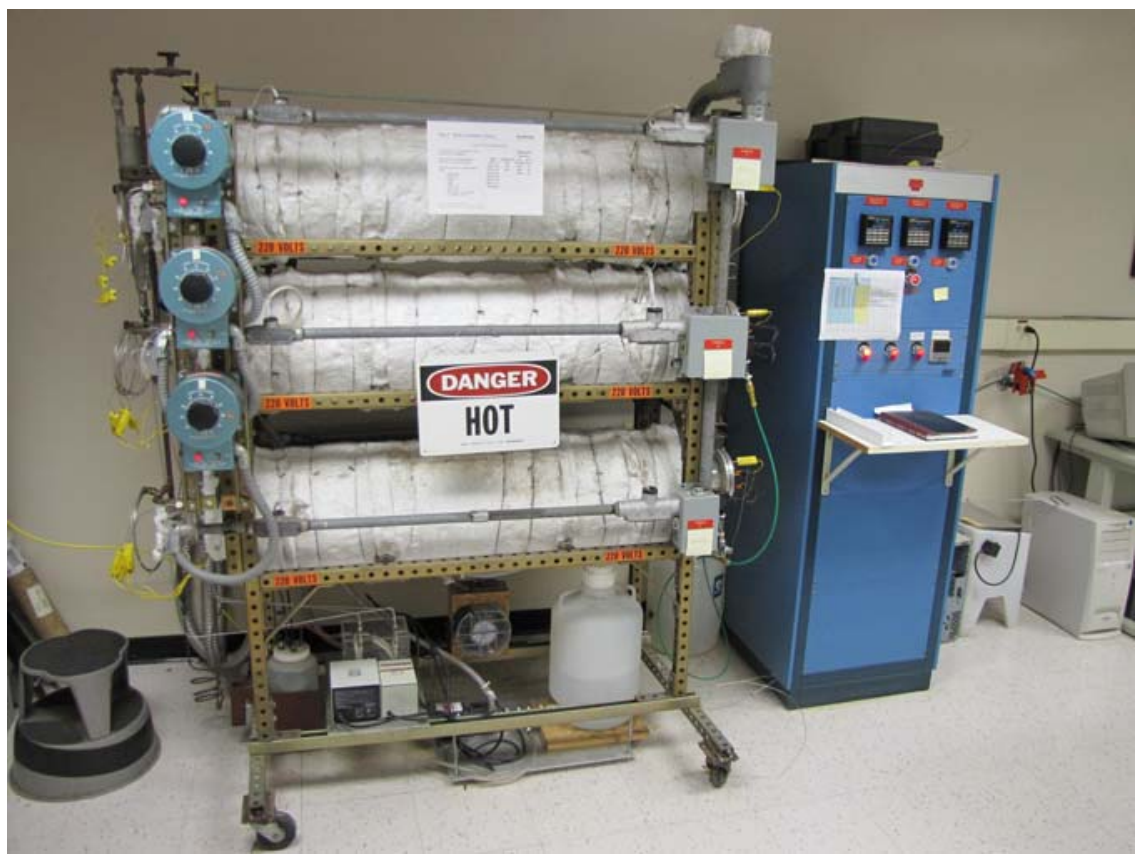

Figure 2-15

Long-Term Steam Oxidation Test Rig, Consisting of Three Horizontal Tube Furnaces (Wrapped in Insulation) with a Recirculating Water/Steam Supply (Below Furnaces). 


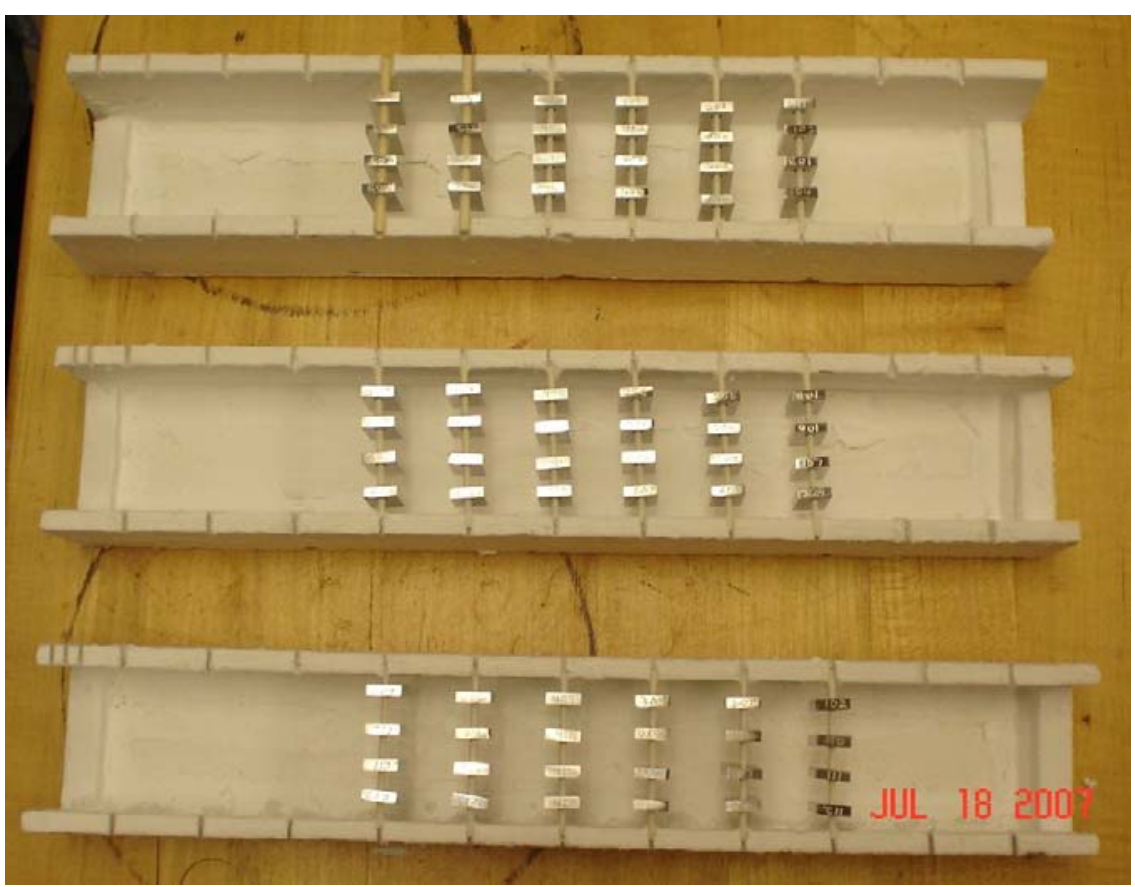

Figure 2-16

Coupon Boats Loaded with Substrate Alloy Coupons Prior to Exposure. 


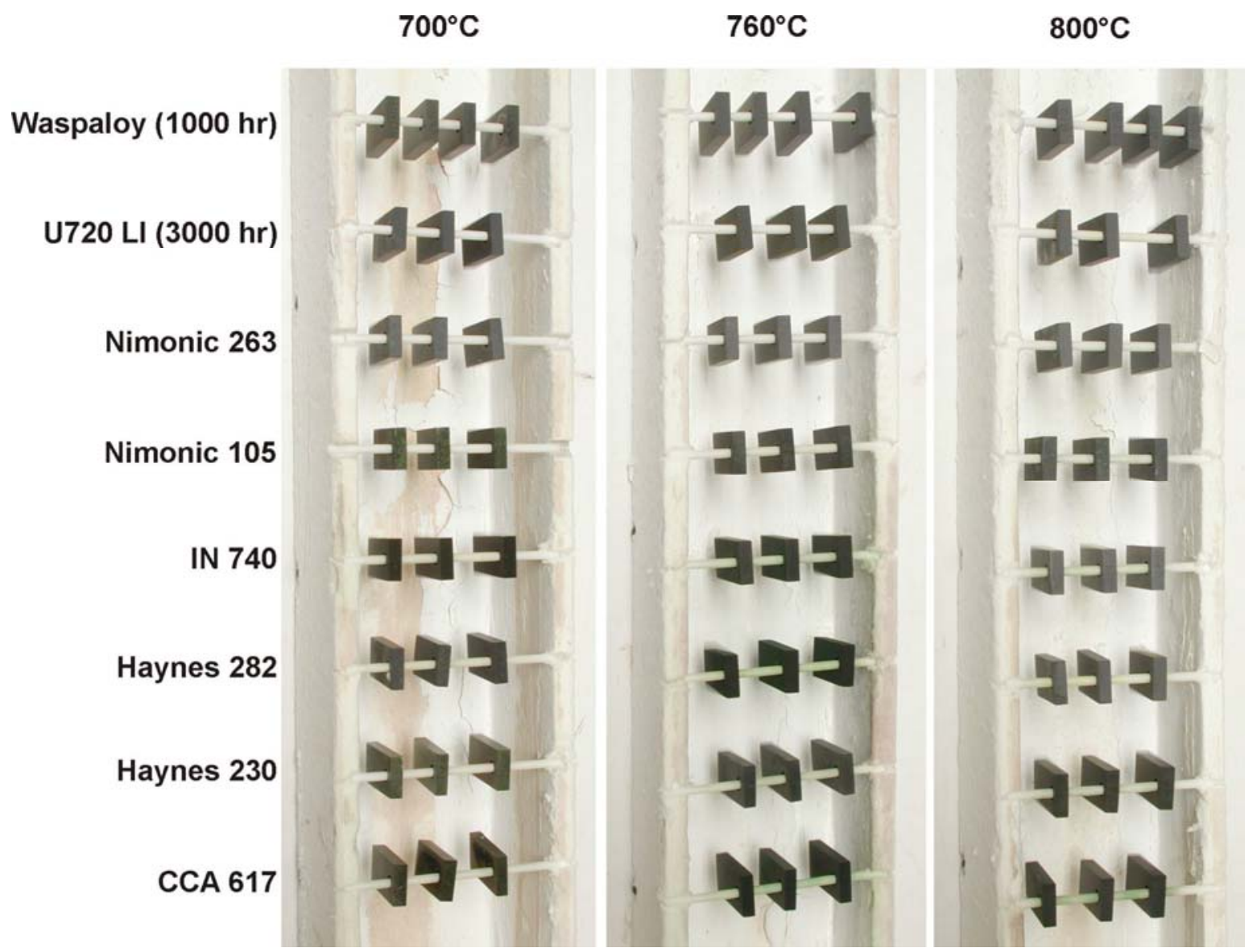

Figure 2-17

Coupon Boats After $\mathbf{4 0 0 0}$ hour Exposure. The Alumina Hanger Rods of Some Alloys Have Been Stained Green and Yellow.

\section{$3 \quad$ Results and Discussion - Substrate Alloys}

\subsection{Oxidation Rates - Weight Gain}

Weight gains $(\Delta \mathrm{m})$ for all long-term substrate coupons as a function of the square root of exposure duration are shown in Figures 3-1 to 3-8. Weight gain of different coupons tested at the same condition were generally very consistent. Some scatter was observed for alloys 617 and 230 at $700^{\circ} \mathrm{C}$; for this condition the absolute weight changes approached the resolution of the microbalance used to weigh the specimens $(\sim 0.00002 \mathrm{~g})$.

While the initial weight gains for all alloys and temperatures varied linearly with the square root of time (implying parabolic kinetics), a marked deviation (reduction) from this initial linear relationship was observed for some alloys at longer exposure durations, particularly at 760 and $800^{\circ} \mathrm{C}$. Alloy 230 and 617 specimens tested at $800^{\circ} \mathrm{C}$ ultimately lost weight. As described below in the section on oxidation morphology, this deviation was associated with porosity observed in and below the oxide scale rather than oxide spallation, indicating that the deviation from parabolic kinetics was likely due to evaporation of volatile species from the specimen surface. 
Parabolic weight gain rate constants $(\mathrm{k})$ were calculated as follows where $\mathrm{t}=$ time in hours, $\Delta \mathrm{m}$ =weight gain, and A was the sample area.

$$
\left.\Delta \mathrm{m} / \mathrm{A}=\mathrm{kt}^{1 / 2} \quad \text { (equation } 1\right)
$$

Table 3-1 is a summary of parabolic weight gain rate constants for all substrate alloys. Data from both TGA and long-term tests are listed; weight gain data in all TGA tests closely followed parabolic rate kinetics. The scale thickness after 100,000 hours exposure, predicted from the long-term rate constants assuming all weight gain is manifest as a compact external chromia scale, is also listed.

Figure 3-8 compares the weight gain rate constants for the different alloys and temperatures. As expected, oxidation rates increased with temperature. Alloys 230 and 617 showed the lowest rates of weight gain, while alloys 282, 263, and Udimet 720LI showed the highest, the difference being over an order of magnitude at $700^{\circ} \mathrm{C}$. The differences between the alloys reduced with increasing temperature, but the general ranking of alloys was the same. The 100,000 hour oxide scale thickness predicted from these rate constants varied from $3 \mu \mathrm{m}$ for alloy 617 at $700^{\circ} \mathrm{C}$ to 63 $\mu \mathrm{m}$ for Udimet $720 \mathrm{LI}$ at $800^{\circ} \mathrm{C}$. As will be shown below, these predictions differ from those made using actual scale thickness data from metallographic examination.

Figure 3-9 is an Arrhenius plot of weight gain parabolic rate constant versus inverse temperature for all substrate alloys; all alloys show an activation energy of approximately $290 \mathrm{~kJ} / \mathrm{mol}$ (shown as a solid black line), indicating a similar oxidation mechanism for all alloys. Figure 3-10 compares parabolic weight gain rate constants obtained in TGA and long-term tests. Good agreement between the two test techniques was observed at $800^{\circ} \mathrm{C}$, while at $760^{\circ} \mathrm{C}$ rates measured by TGA were considerably higher than those measured in long-term tests. This difference is believed to be due to the very low extent of oxidation in the TGA tests at $760^{\circ} \mathrm{C}$; a fully protective oxide scale and parabolic rate kinetics may not have been established in the 140 hour test duration. These results show the importance of using the long-term oxidation tests compared to the short-term TGA results. 
Table 3-1

Summary of Weight Gain Parabolic Rate Constants Obtained by TGA and Long-Term

Testing. Also listed are 100,000 hour Oxide Scales Predicted Using these Constants and a Summary of the Metallographic Data

\begin{tabular}{|c|c|c|c|c|c|c|c|c|}
\hline \multirow{4}{*}{ Alloy } & \multirow{4}{*}{$\begin{array}{c}\text { Temperature } \\
\left({ }^{\circ} \mathrm{C}\right)\end{array}$} & \multicolumn{3}{|c|}{ Weight Gain Data } & \multicolumn{4}{|c|}{ Metallography Data } \\
\hline & & TGA & Long-Term & LT-Predicted & External Scale & Predicted & Total Metal Loss & Predicted \\
\hline & & $\begin{array}{l}\text { Rate } \\
\end{array}$ & Rate & 100 kHr Scale & Rate & 100 kHr Scale & Rate & 100 kHr TML \\
\hline & & & & $(\mu \mathrm{m})$ & & $(\mu \mathrm{m})$ & & $(\mu \mathrm{m})$ \\
\hline \multirow{4}{*}{ Haynes 230} & 700 & -- & $1.06 \mathrm{E}-15$ & 4 & $1.72 \mathrm{E}-04$ & 4 & $6.81 \mathrm{E}-02$ & 82 \\
\hline & 760 & 2.87E-13 & $7.65 \mathrm{E}-15$ & 10 & 1.10E-03 & 10 & $1.20 \mathrm{E}-01$ & 110 \\
\hline & 800 & 1.12E-13 & $5.28 \mathrm{E}-14$ & 28 & $5.10 \mathrm{E}-03$ & 23 & $1.84 \mathrm{E}-01$ & 136 \\
\hline & 850 & $3.59 \mathrm{E}-13$ & -- & -- & -- & -- & - & -- \\
\hline \multirow{4}{*}{ Haynes 282} & 700 & -- & $3.06 \mathrm{E}-14$ & 21 & $2.21 \mathrm{E}-03$ & 15 & $3.81 \mathrm{E}-02$ & 62 \\
\hline & 760 & $6.56 \mathrm{E}-13$ & 4.71E-14 & 26 & $3.36 \mathrm{E}-03$ & 18 & 1.16E-01 & 108 \\
\hline & 800 & 4.20E-13 & $2.54 \mathrm{E}-13$ & 60 & $1.21 \mathrm{E}-02$ & 35 & 3.59E-01 & 189 \\
\hline & 850 & $9.93 \mathrm{E}-13$ & -- & -- & -- & -- & -- & -- \\
\hline \multirow{4}{*}{ Inconel 617} & 700 & -- & $6.50 \mathrm{E}-16$ & 3 & $3.49 \mathrm{E}-04$ & 6 & $3.89 \mathrm{E}-02$ & 62 \\
\hline & 760 & $2.73 E-13$ & $1.60 \mathrm{E}-14$ & 15 & $1.60 \mathrm{E}-03$ & 13 & 1.12E-01 & 106 \\
\hline & 800 & $1.75 \mathrm{E}-13$ & 8.87E-14 & 36 & $5.64 \mathrm{E}-03$ & 24 & 2.03E-01 & 142 \\
\hline & 850 & 8.57E-13 & -- & -- & -- & -- & - & -- \\
\hline \multirow{4}{*}{ Inconel 740} & 700 & -- & $2.13 \mathrm{E}-15$ & 6 & $5.52 \mathrm{E}-04$ & 7 & $1.37 \mathrm{E}-02$ & 37 \\
\hline & 760 & $7.10 \mathrm{E}-14$ & $3.40 \mathrm{E}-14$ & 22 & $3.20 \mathrm{E}-03$ & 18 & $5.63 \mathrm{E}-02$ & 75 \\
\hline & 800 & $2.20 \mathrm{E}-13$ & $1.47 \mathrm{E}-13$ & 46 & 7.98E-03 & 28 & $1.83 \mathrm{E}-01$ & 135 \\
\hline & 850 & $1.08 \mathrm{E}-12$ & -- & -- & -- & -- & -- & -- \\
\hline \multirow{4}{*}{ Nimonic 105} & 700 & -- & $2.86 \mathrm{E}-15$ & 6 & $9.84 \mathrm{E}-04$ & 10 & $3.90 \mathrm{E}-02$ & 62 \\
\hline & 760 & $6.35 \mathrm{E}-14$ & $3.62 E-14$ & 23 & $3.01 \mathrm{E}-03$ & 17 & $1.15 \mathrm{E}-01$ & 107 \\
\hline & 800 & $9.65 \mathrm{E}-14$ & $1.45 \mathrm{E}-13$ & 46 & 5.61E-03 & 24 & 2.20E-01 & 148 \\
\hline & 850 & $7.00 \mathrm{E}-13$ & -- & -- & -- & -- & -- & -- \\
\hline \multirow{4}{*}{ Nimonic 263} & 700 & -- & $1.67 \mathrm{E}-14$ & 15 & $1.86 \mathrm{E}-03$ & 14 & $3.79 \mathrm{E}-02$ & 62 \\
\hline & 760 & $2.39 \mathrm{E}-13$ & 4.61E-14 & 26 & $3.96 \mathrm{E}-03$ & 20 & 2.13E-01 & 146 \\
\hline & 800 & $2.95 \mathrm{E}-13$ & $1.69 \mathrm{E}-13$ & 49 & 1.13E-02 & 34 & 4.71E-01 & 217 \\
\hline & 850 & $7.85 \mathrm{E}-13$ & -- & -- & -- & -- & -- & -- \\
\hline \multirow{3}{*}{ Udimet $720 \mathrm{LI}$} & 700 & -- & $1.85 \mathrm{E}-14$ & 16 & $1.00 \mathrm{E}-03$ & 10 & $1.70 \mathrm{E}-02$ & 41 \\
\hline & 760 & - & $1.01 \mathrm{E}-13$ & 38 & $3.32 \mathrm{E}-03$ & 18 & 8.75E-02 & 94 \\
\hline & 800 & -- & $2.80 \mathrm{E}-13$ & 63 & 1.15E-02 & 34 & $1.65 \mathrm{E}-01$ & 128 \\
\hline \multirow{3}{*}{ Waspaloy } & 700 & -- & $8.04 \mathrm{E}-15$ & 11 & $4.86 \mathrm{E}-04$ & 7 & $1.57 \mathrm{E}-02$ & 40 \\
\hline & 760 & - & $7.26 \mathrm{E}-14$ & 32 & 4.47E-03 & 21 & $1.94 \mathrm{E}-01$ & 139 \\
\hline & 800 & - & $1.21 \mathrm{E}-13$ & 42 & $7.85 \mathrm{E}-03$ & 28 & $1.26 \mathrm{E}-01$ & 112 \\
\hline
\end{tabular}



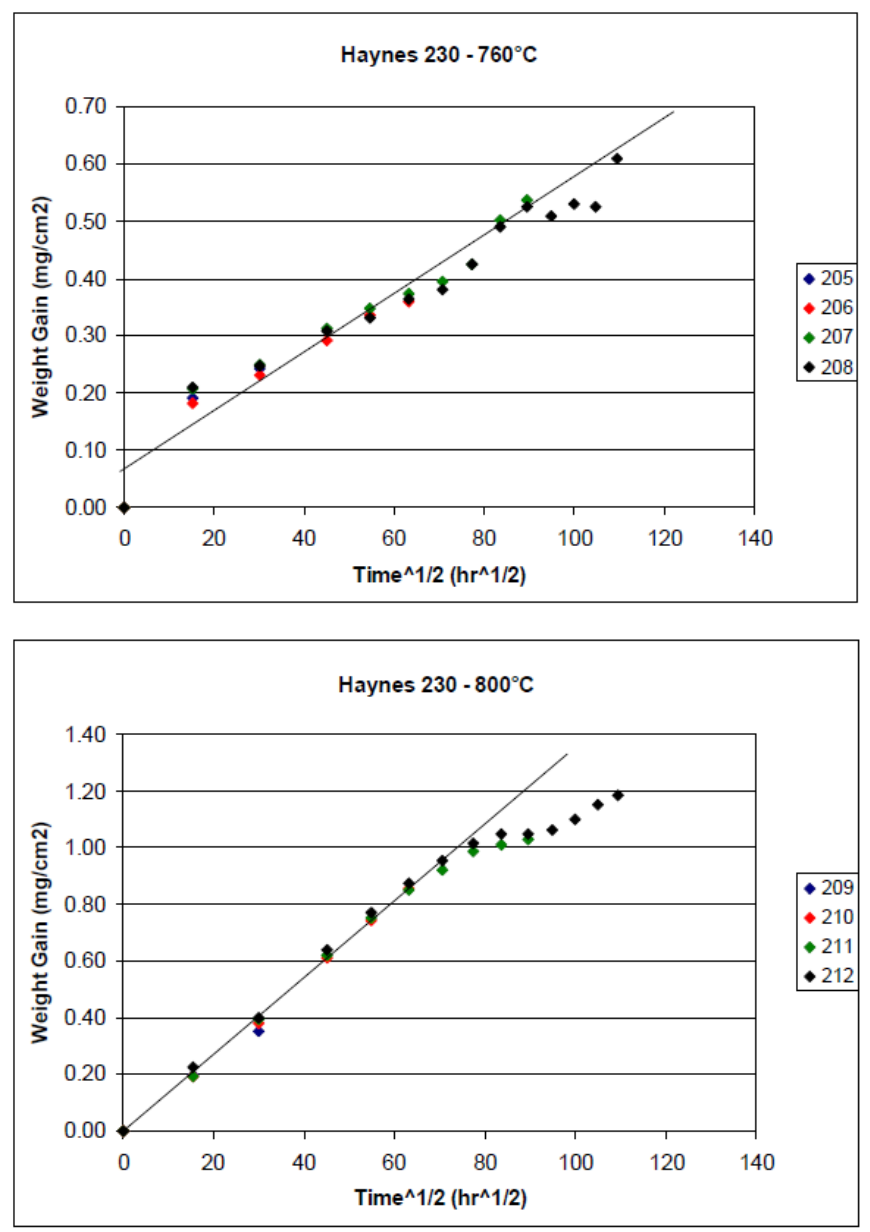

Figure 3-1

Weight Gain Data for Haynes 230 Long-Term Exposure Coupons. Lines represent Parabolic Rate Kinetics Fitted to Data up to 4,000 hours. 

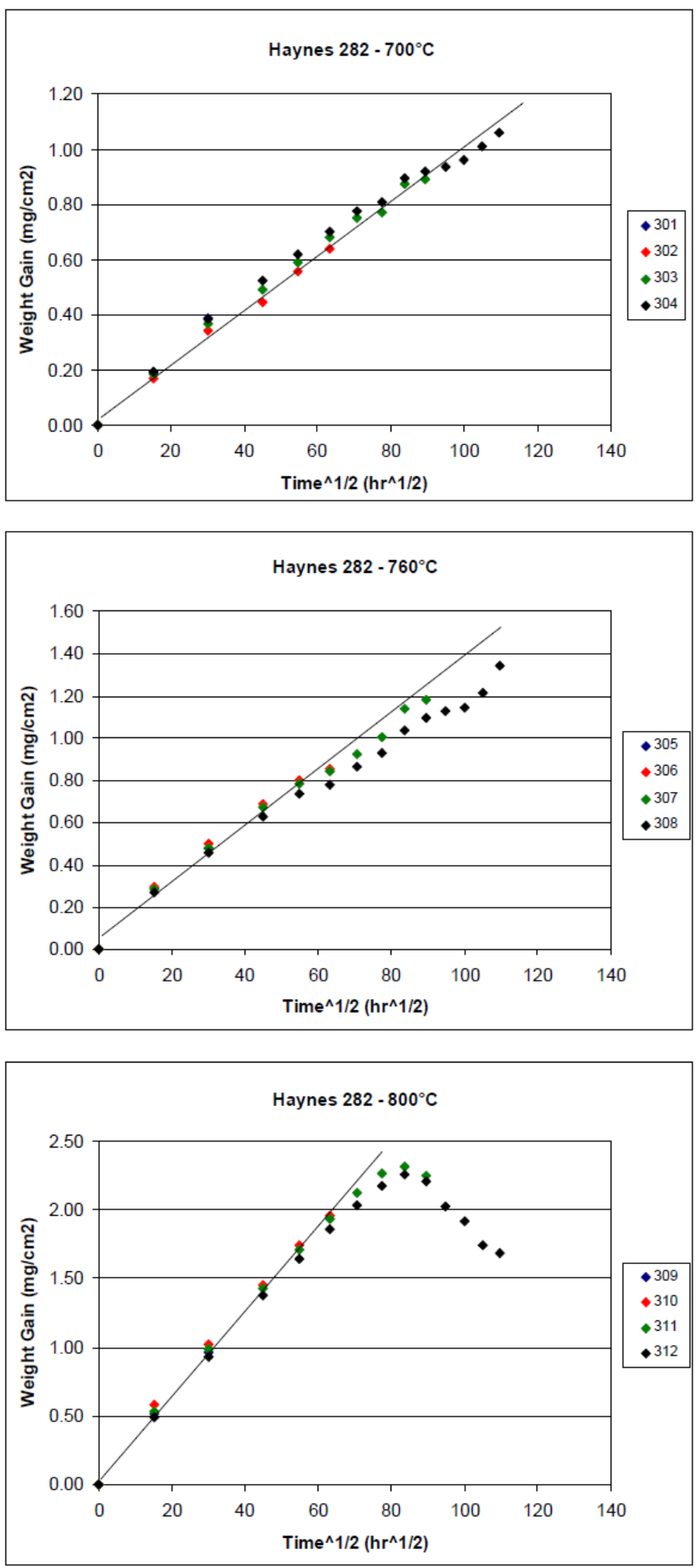

Figure 3-2

Weight Gain Data for Haynes 282 Long-Term Exposure Coupons. Lines represent Parabolic Rate Kinetics Fitted to Data up to 4,000 hours. 

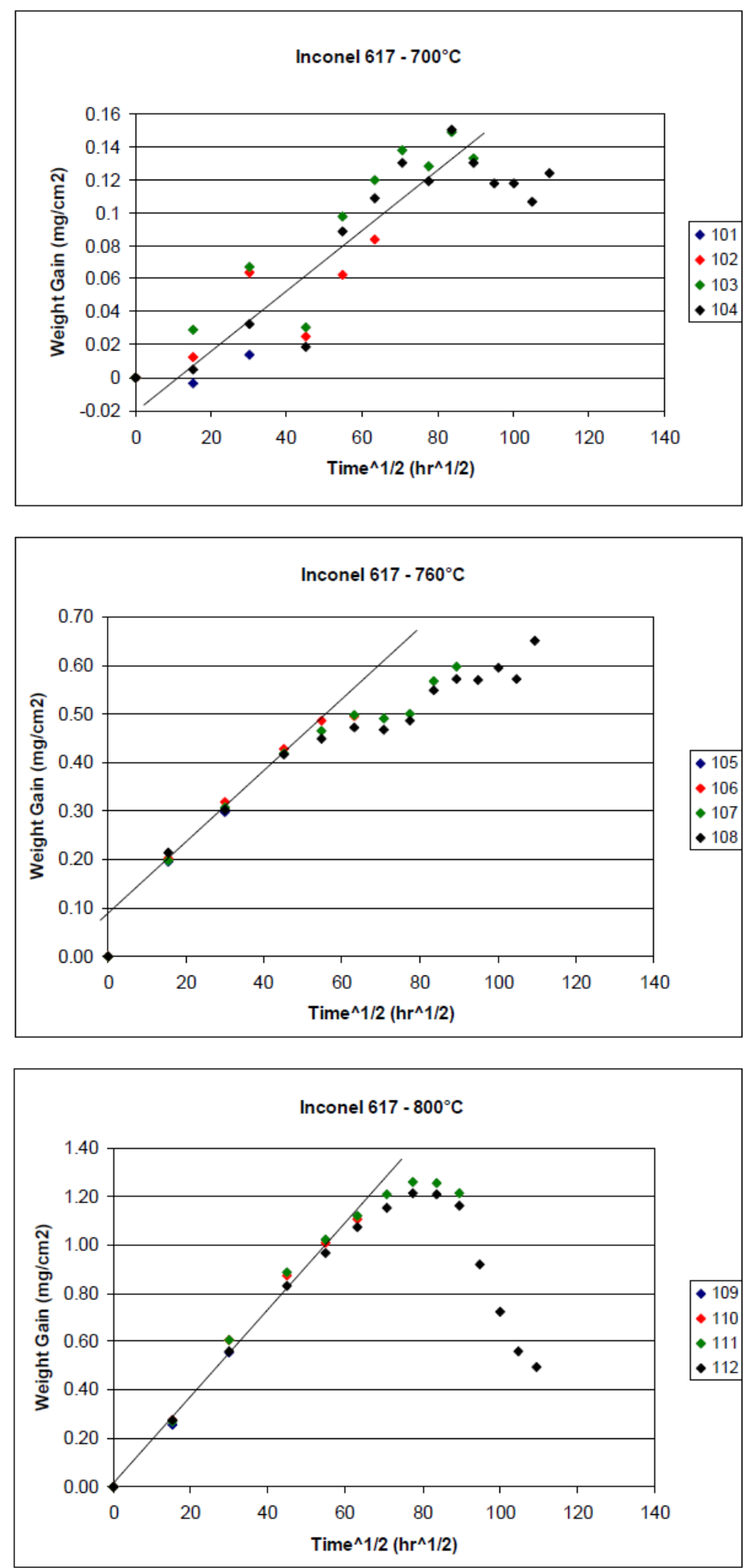

Figure 3-3

Weight Gain Data for Inconel 617 Long-Term Exposure Coupons. Lines represent Parabolic Rate Kinetics Fitted to Data up to 4,000 hours. 

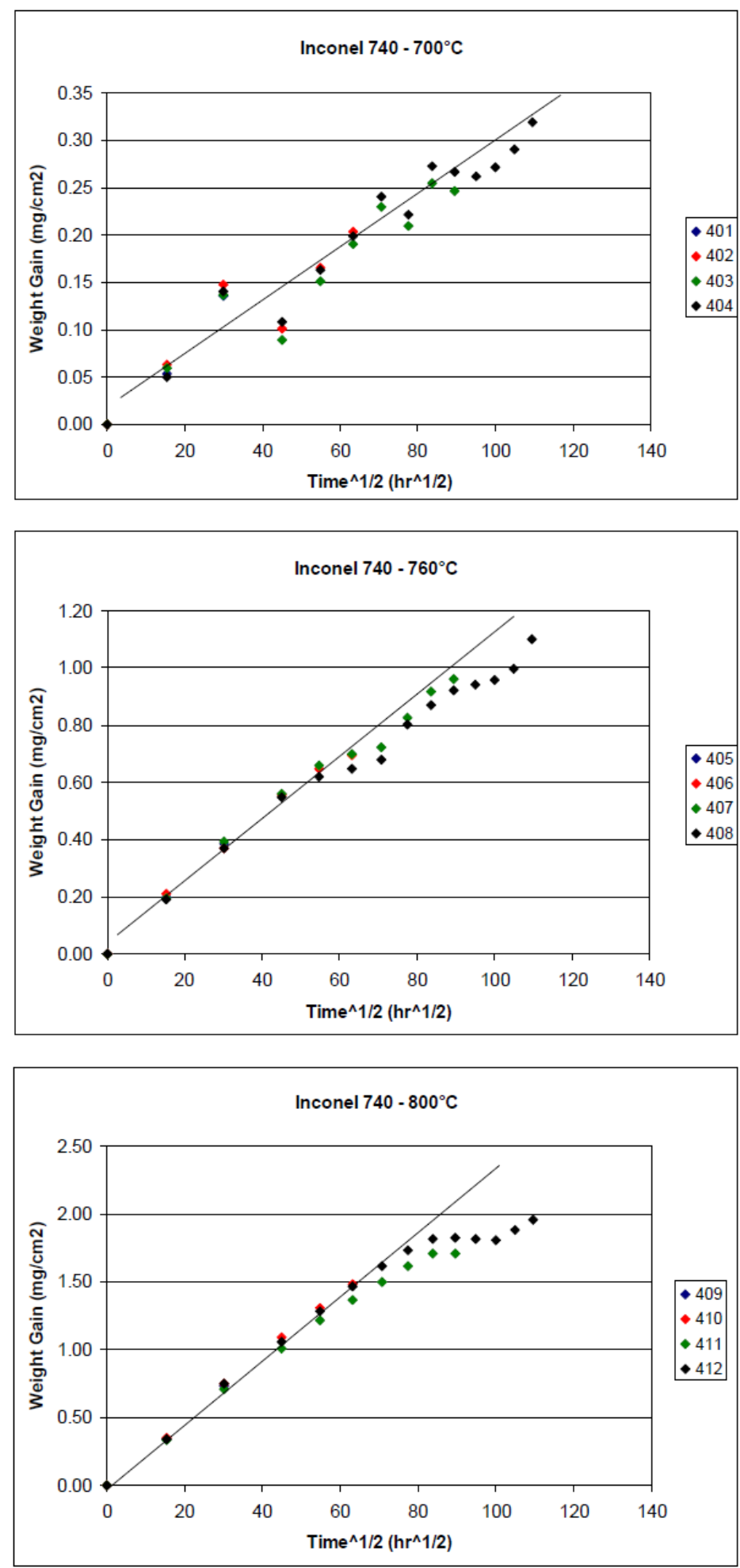

Figure 3-4

Weight Gain Data for Inconel 740 Long-Term Exposure Coupons. Lines represent Parabolic Rate Kinetics Fitted to Data up to 4,000 hours. 

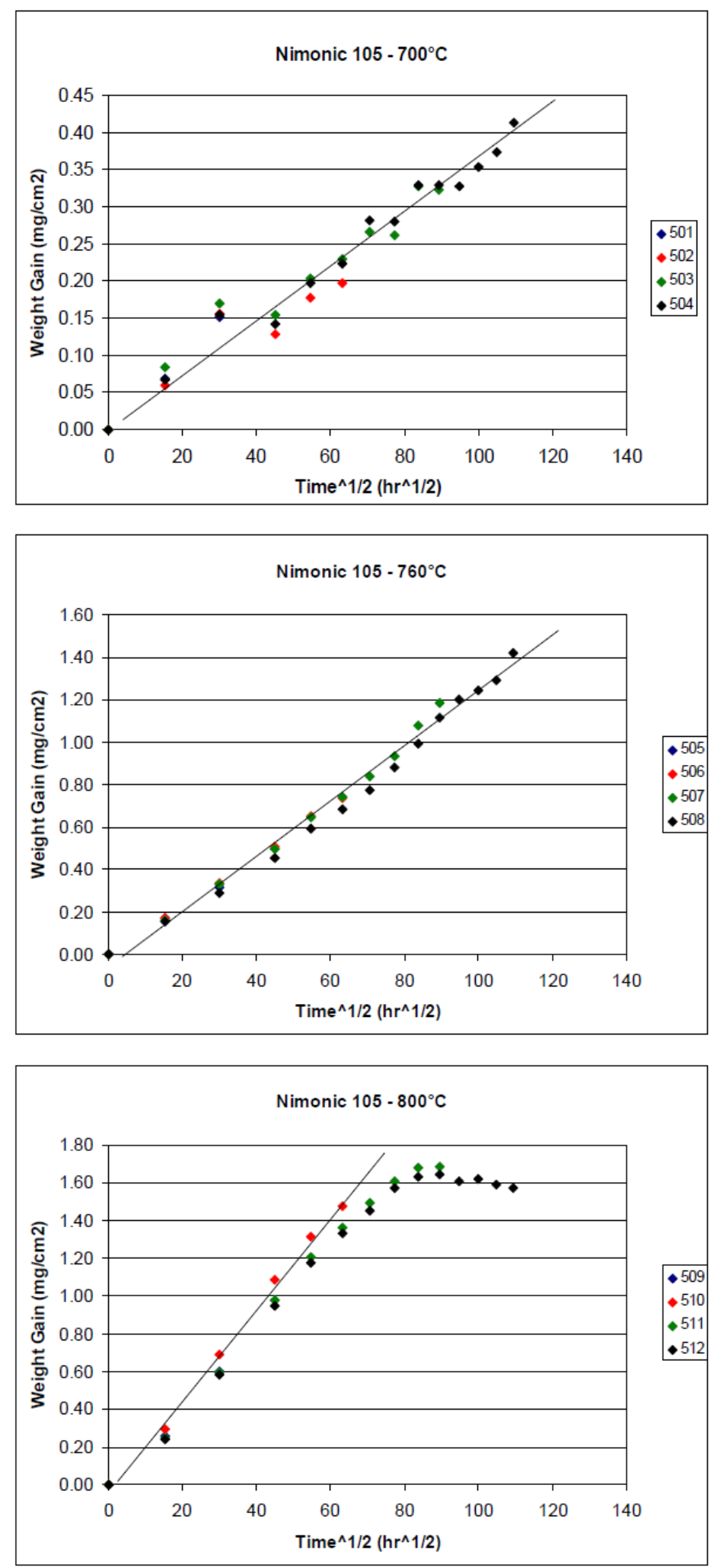

Figure 3-5

Weight Gain Data for Nimonic 105 Long-Term Exposure Coupons. Lines represent Parabolic Rate Kinetics Fitted to Data up to 4,000 hours. 

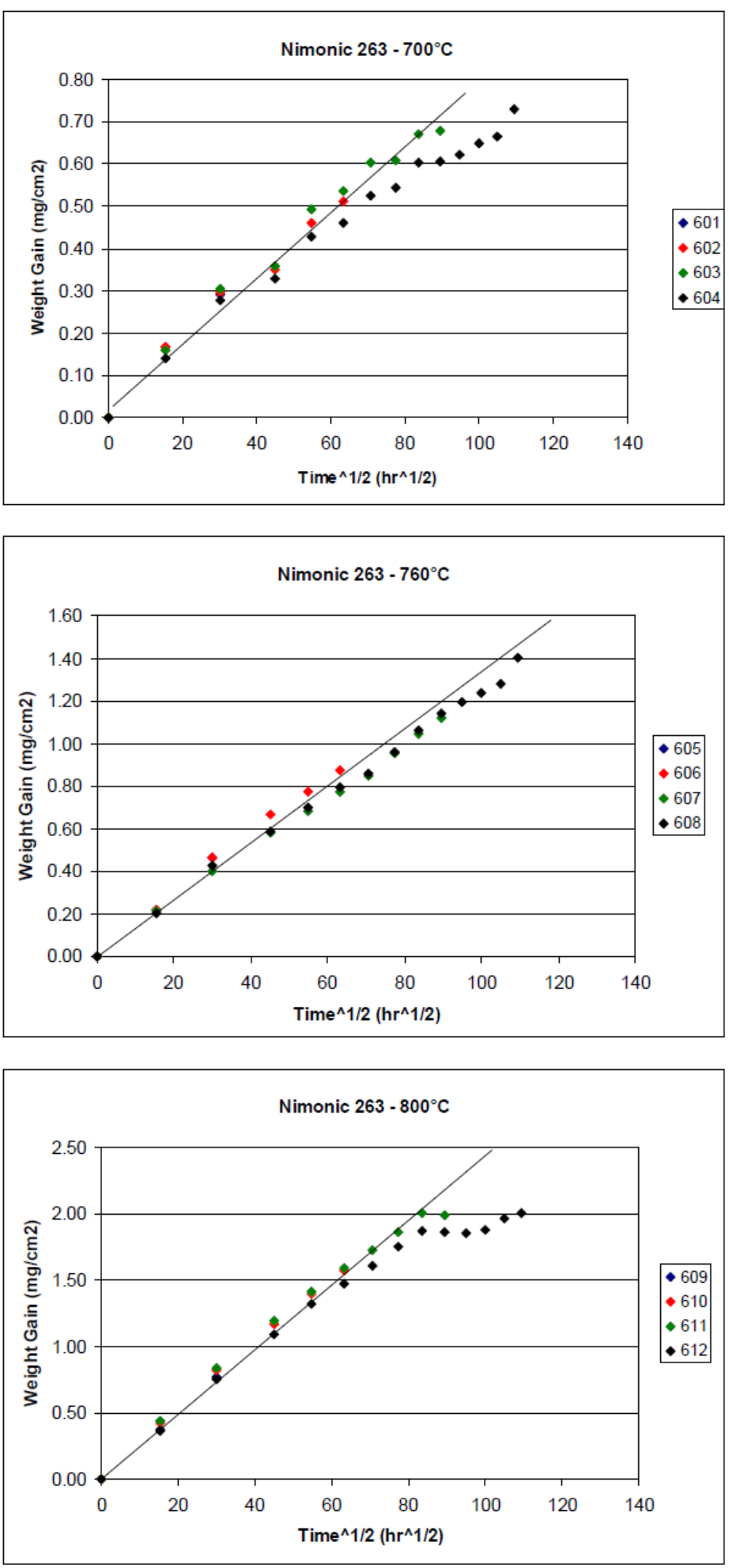

Figure 3-6

Weight Gain Data for Nimonic 263 Long-Term Exposure Coupons. Lines represent Parabolic Rate Kinetics Fitted to Data up to 4,000 hours. 

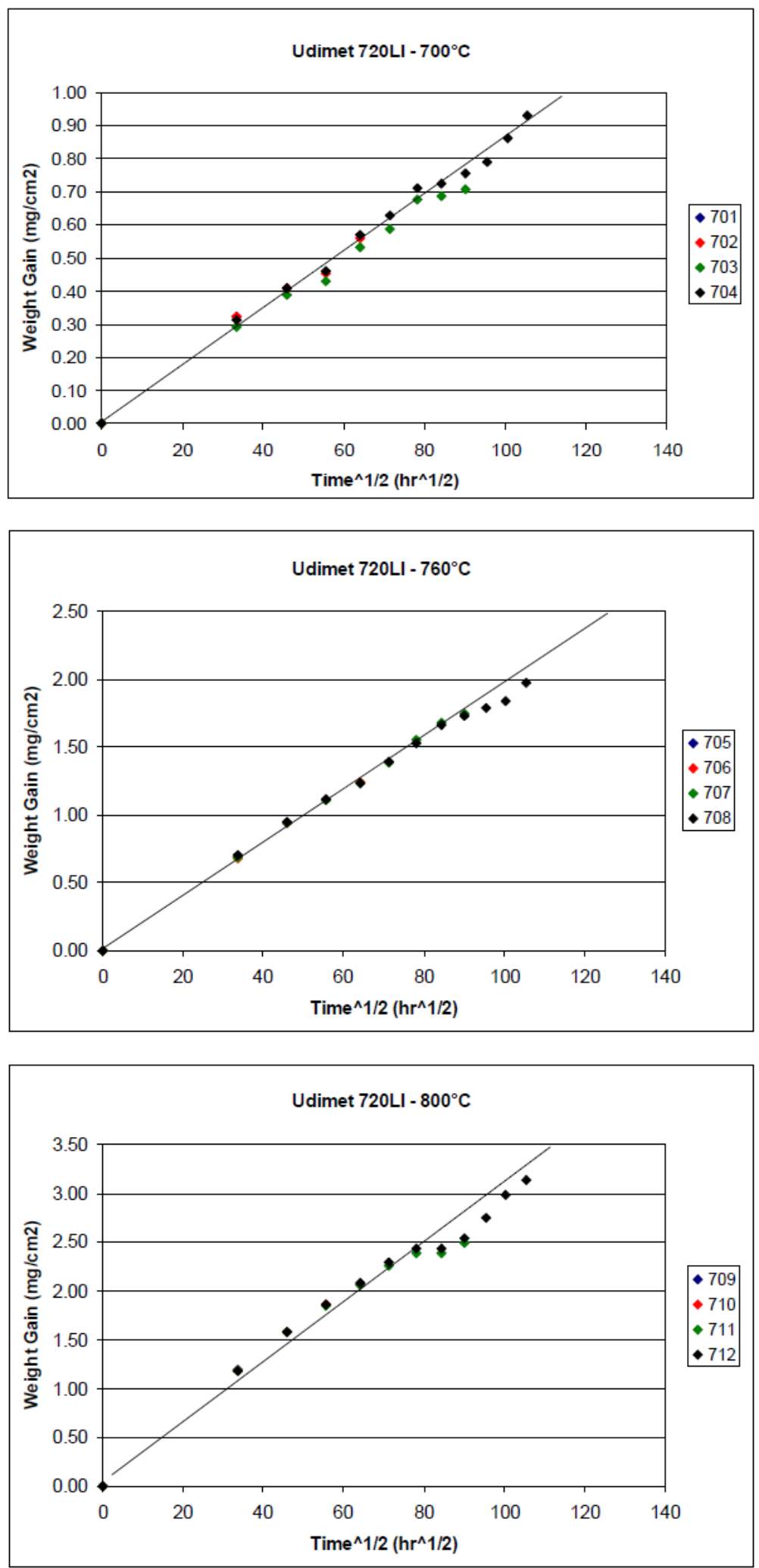

Figure 3-7

Weight Gain Data for Udimet 720Li Long-Term Exposure Coupons. Lines represent Parabolic Rate Kinetics Fitted to Data up to 4,000 hours. 

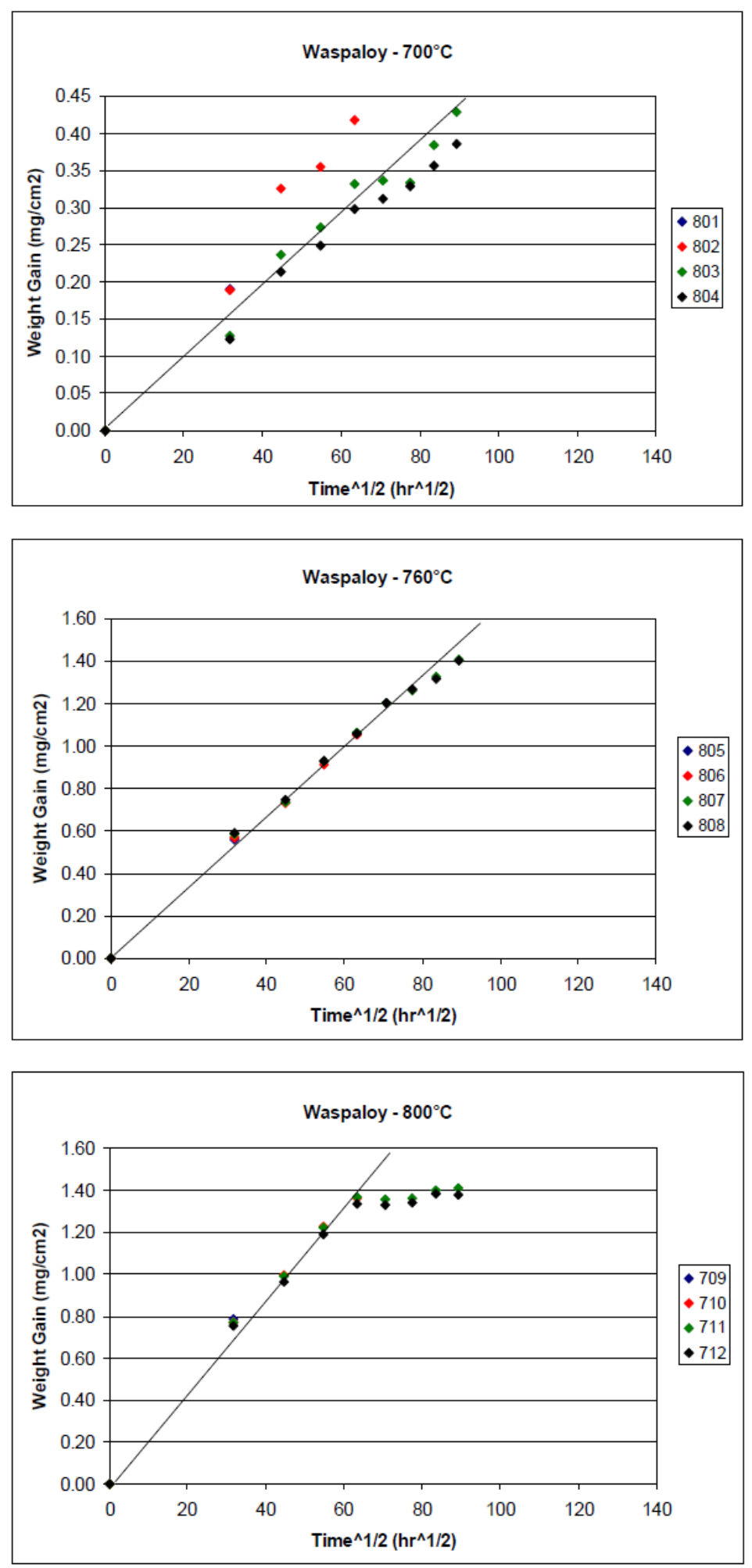

Figure 3-8

Weight Gain Data for Waspalloy Long-Term Exposure Coupons. Lines represent Parabolic Rate Kinetics Fitted to Data up to 4,000 hours. 
Long-Term Steam Oxidation -

Rates Calculated Using Data Up to $4,000 \mathrm{hr}$ Duration

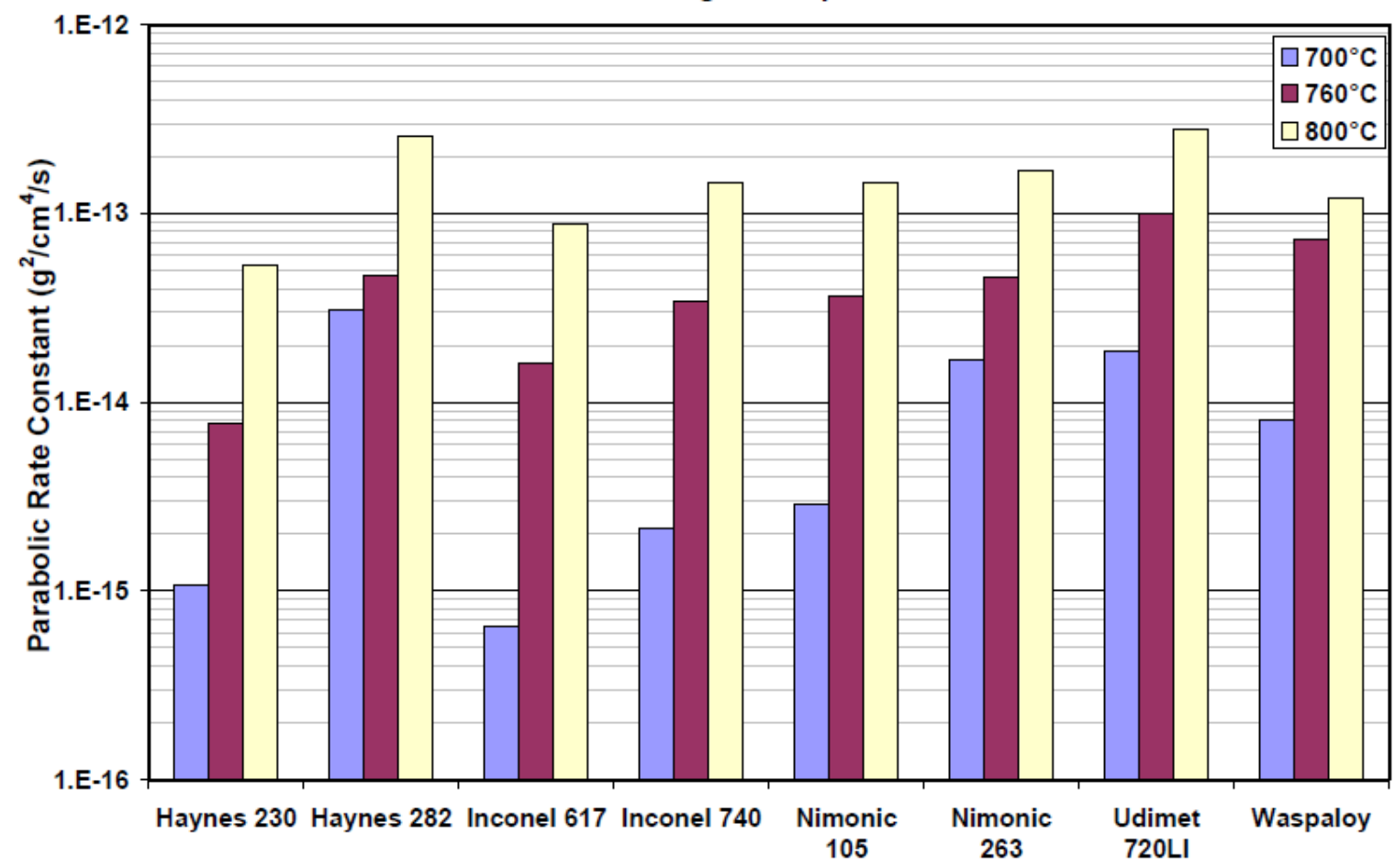

Figure 3-9

Weight Gain Parabolic Rate Constants for Substrate Alloys Measured in Long-Term Testing Using Data to 4,000 hours. 


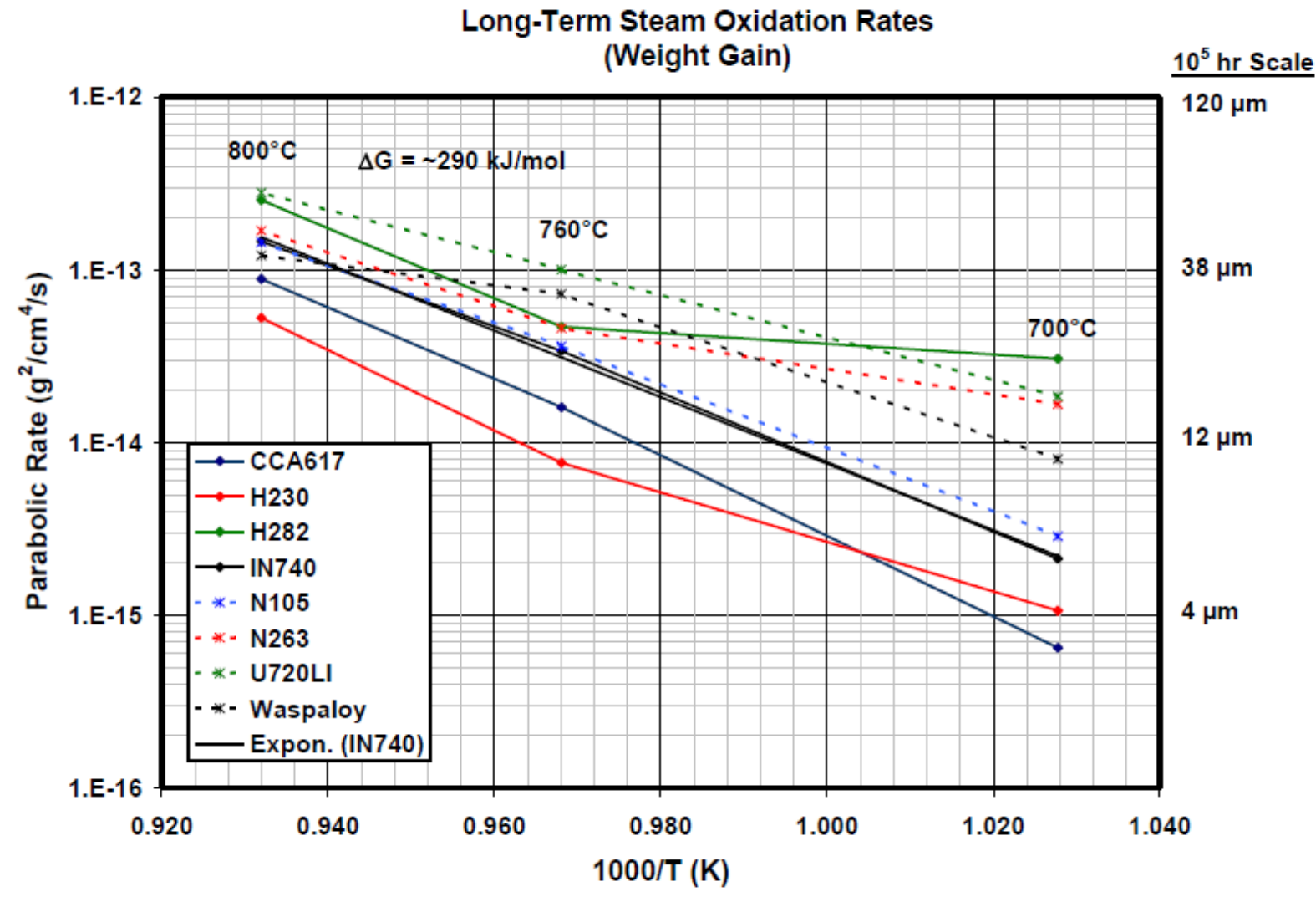

Figure 3-10

Weight Gain Parabolic Rate Constants as a Function of 1/T and Estimated Scale Thickness after 100,000 hours 


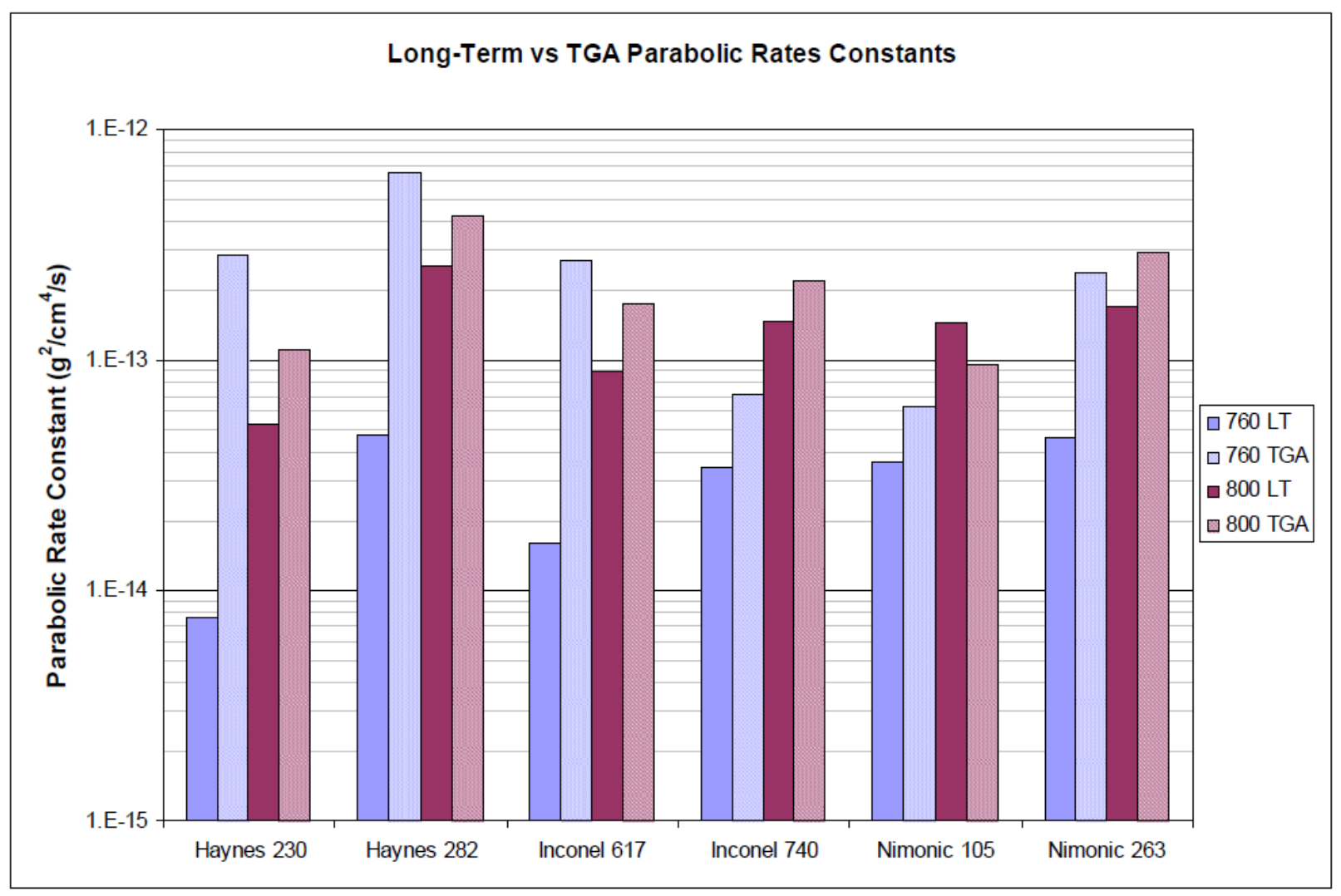

Figure 3-11

Comparison of Weight Gain Parabolic Rate Constants Obtained in Long-Term and TGA Tests.

\subsection{Oxidation Morphology}

Typical oxidation morphologies as observed by light microscopy are shown in Figure 3-12 through Figure 3-21. Figure 3-12 and Figure 3-13 show the progression of oxidation with time at $760^{\circ} \mathrm{C}$ for Haynes 282 and Nimonic 105; Figure 3-14 through Figure 3-21 show the oxidation morphology after 8000 hour exposure for all substrate alloys at each of the three testing temperatures. The general morphology of oxidation was similar for all alloys. A thin compact external scale was present on the surface and there was also extensive internal oxidation, apparently along grain boundaries. For some alloys significant porosity was observed at the higher exposure temperatures, mostly associated with areas of internal oxidation rather than in the external oxide scale. For all alloys except for Nimonic 105 the thickness of the external oxide layer and the depth of the internal oxidation was very uniform; for Nimonic 105 areas of the surface covered only by a very thin external oxide with no internal oxidation were observed at all test temperatures.

SEM-EDS analysis was performed on oxide scales and internal oxides of all alloys at $760^{\circ} \mathrm{C}$ and on Haynes 282 and Inconel 740 at all three temperatures. The external scale was invariably a chromium-rich oxide. In alloys which had significant Ti content (e.g., Haynes 282) the oxide scale near the oxide-substrate interface was enriched in Ti. Internal oxides in all alloys were rich in Al; Ti was also found for alloys with significant Ti content. Examples of backscattered electron images and EDS analysis results are shown in Figures 3-22 and 3-23 for Haynes 282 
exposed at $800^{\circ} \mathrm{C}$ and Waspalloy at $760^{\circ} \mathrm{C}$. In the Waspaloy coupon a continuous layer of oxide enriched in Ti formed below the $\mathrm{Cr}$-rich outer oxide scale. This continuous, distinguishable layer was not observed in the scale at $800^{\circ} \mathrm{C}$. 

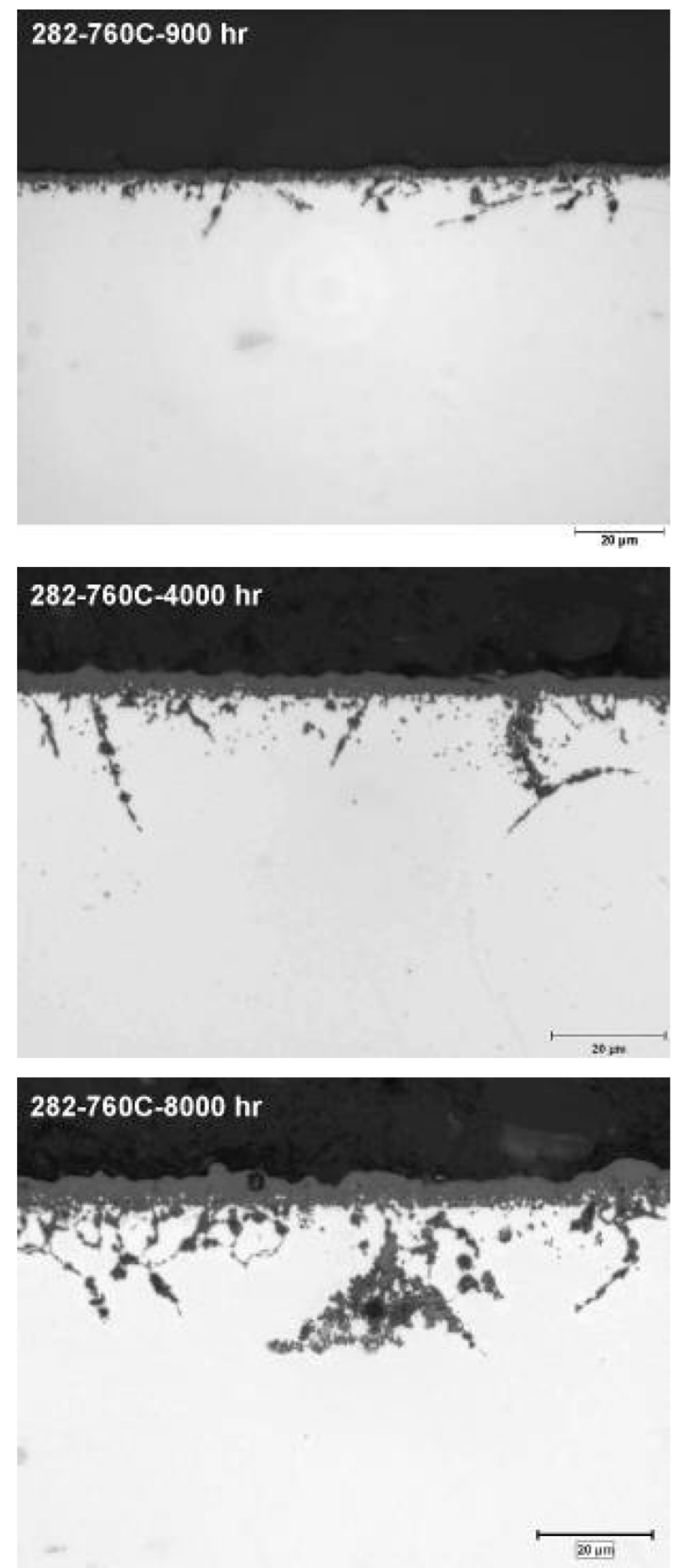

Figure 3-12

Typical oxidized surface of Haynes 282 as a function of time 

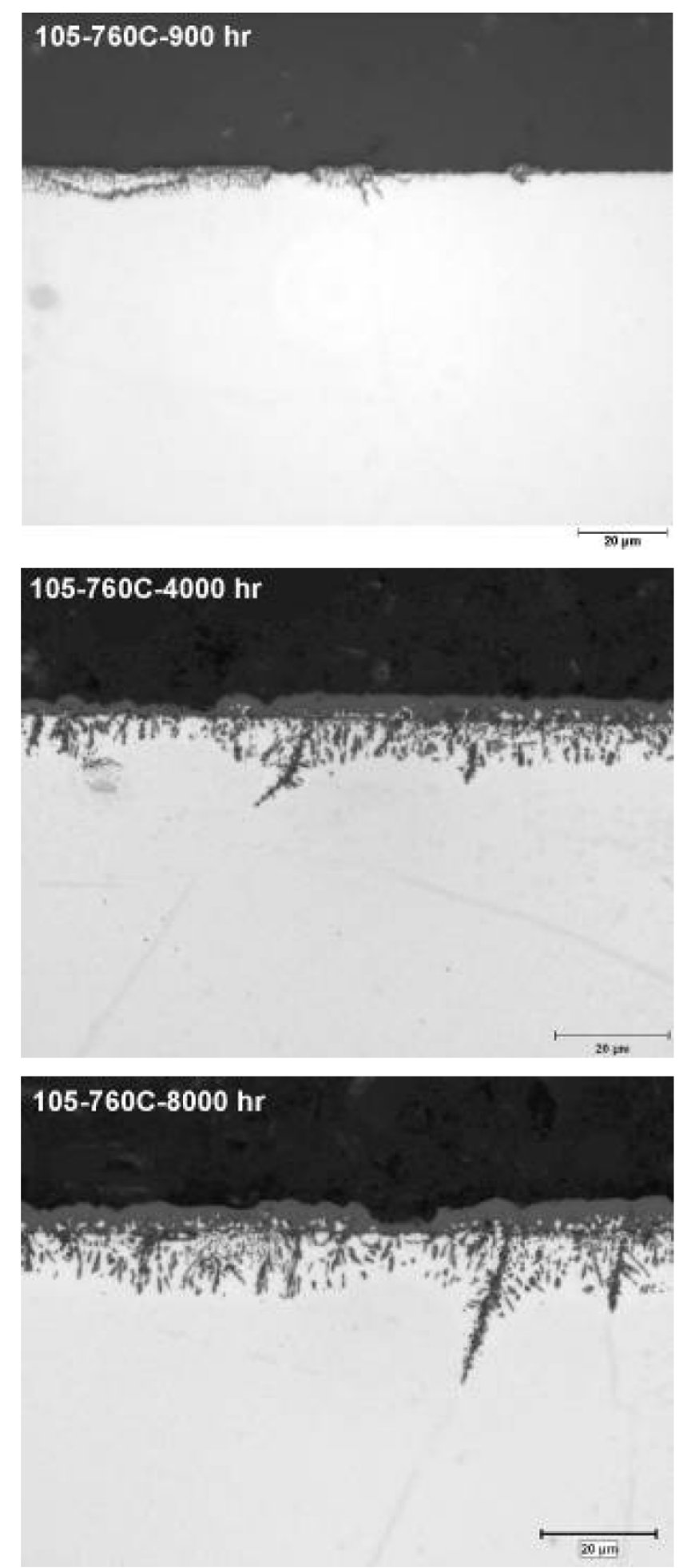

Figure 3-13

Typical oxidized surface of Nimonic 105 as a function of time 

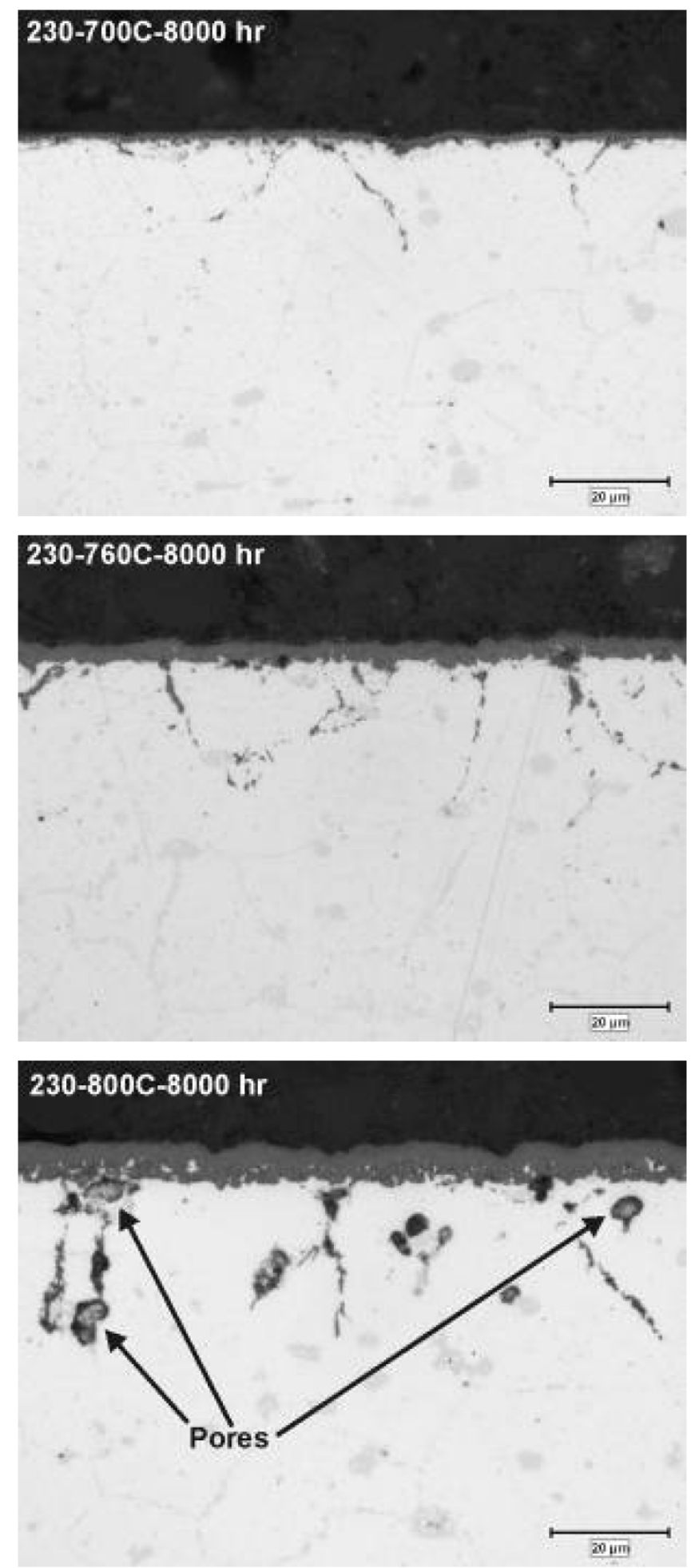

Figure 3-14

Typical oxidized surface of Haynes 230 after 8,000 hours of exposure at 700, 760, and $800^{\circ} \mathrm{C}$ 

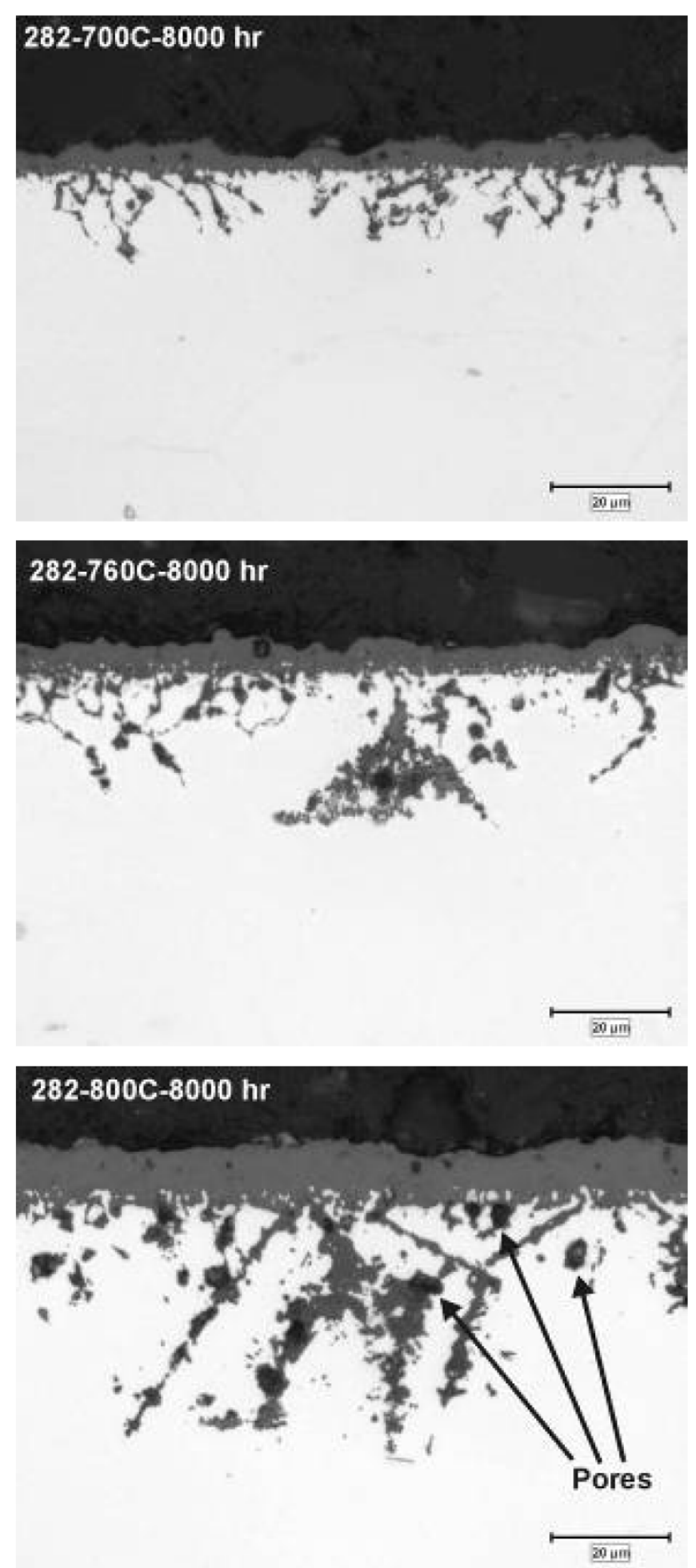

Figure 3-15

Typical oxidized surface of Haynes 282 after 8,000 hours of exposure at 700, 760, and $800^{\circ} \mathrm{C}$ 

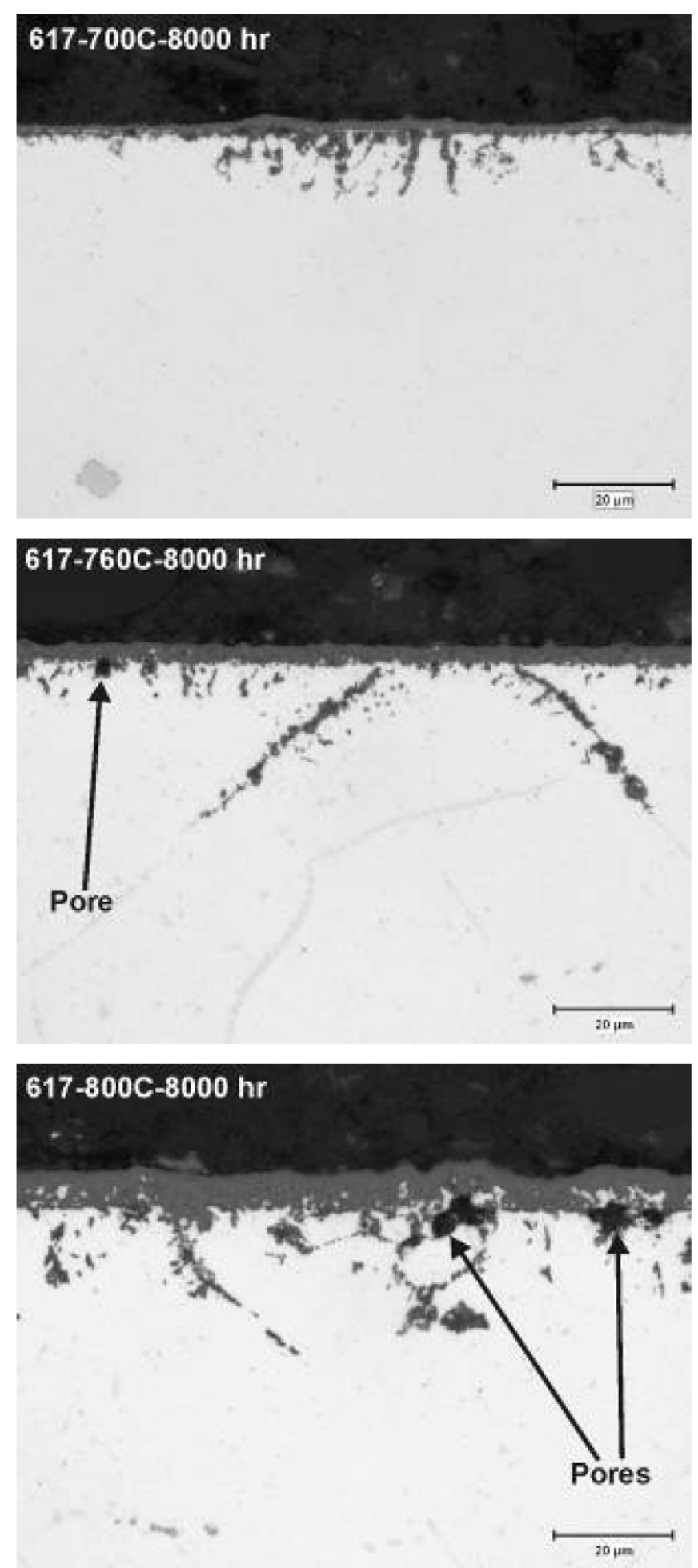

Figure 3-16

Typical oxidized surface of 617 after 8,000 hours of exposure at 700,760 , and $800^{\circ} \mathrm{C}$ 

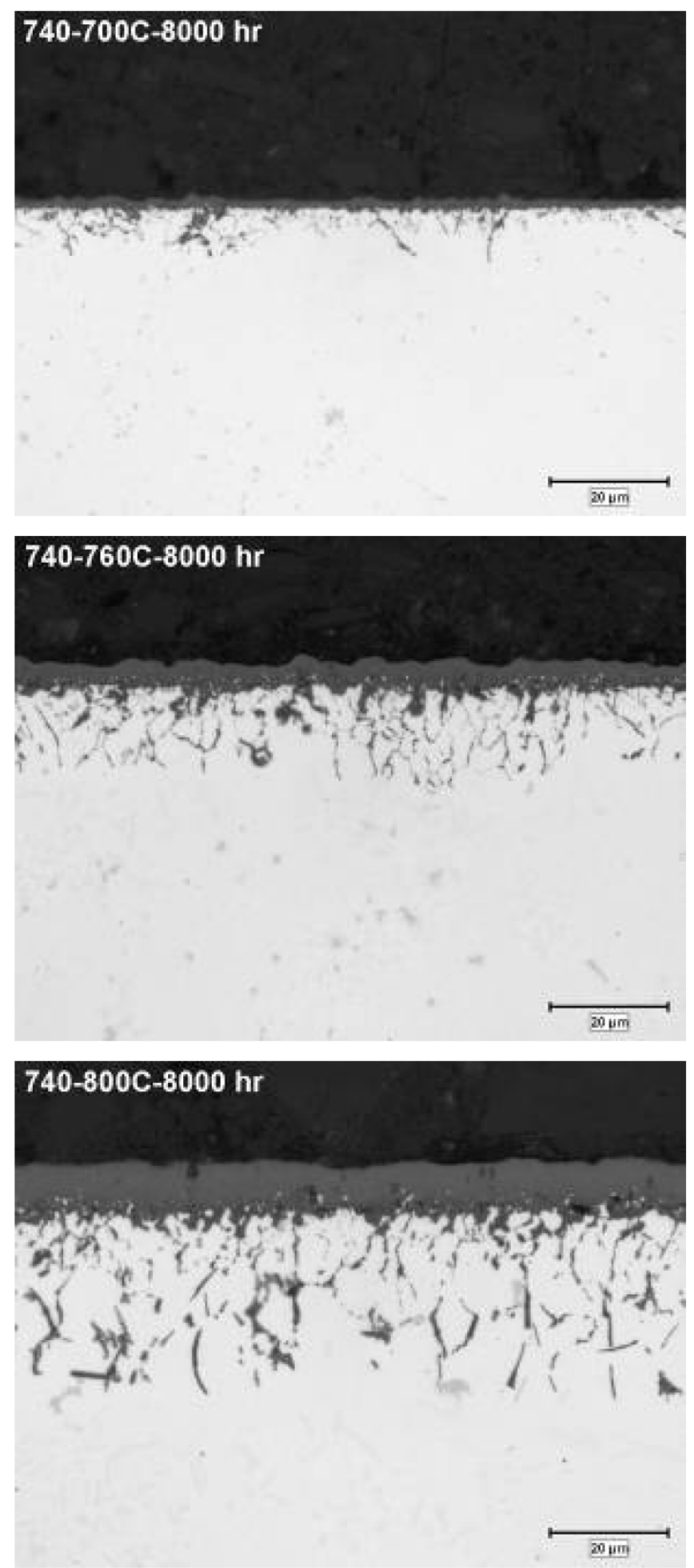

Figure 3-17

Typical oxidized surface of Inconel 740 after $\mathbf{8 , 0 0 0}$ hours of exposure at 700,760 , and $800^{\circ} \mathrm{C}$ 

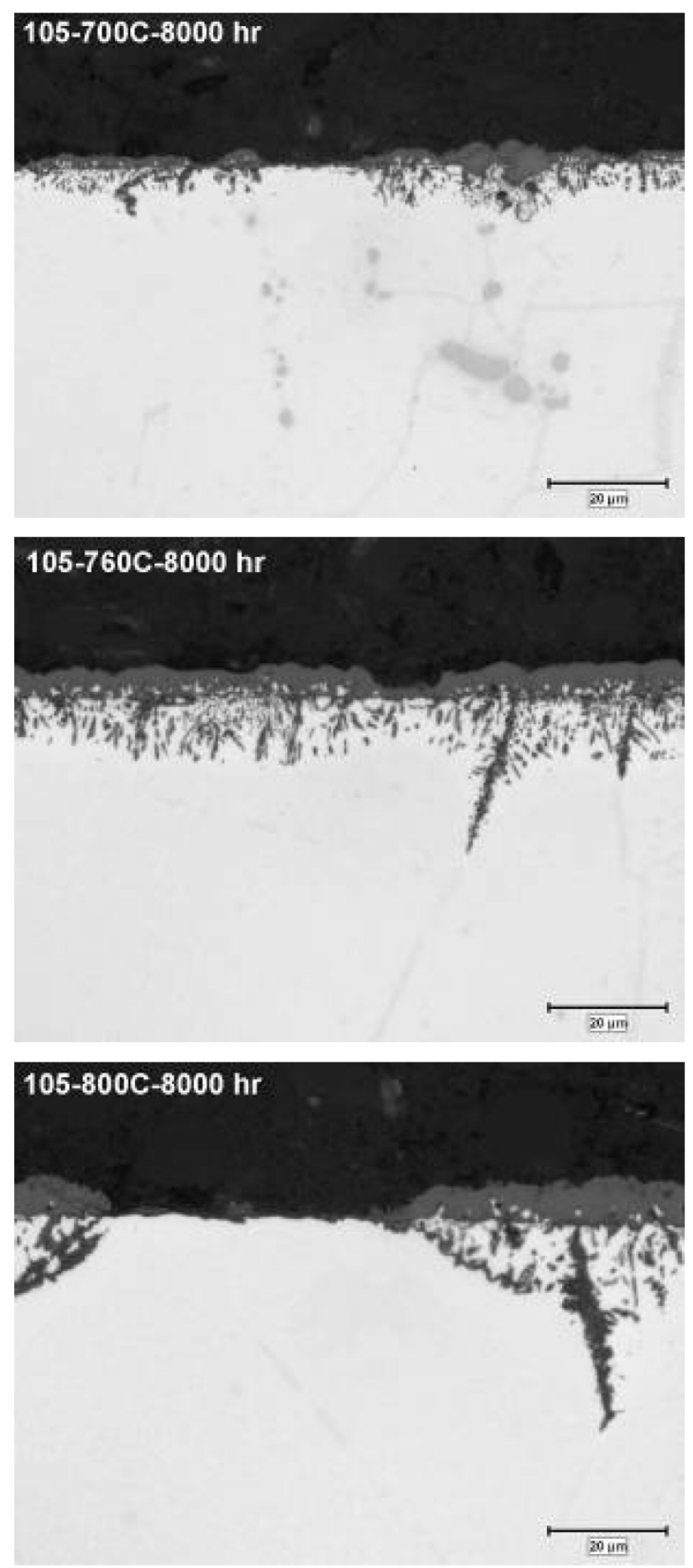

Figure 3-18

Typical oxidized surface of Nimonic 105 after 8,000 hours of exposure at 700, 760, and $800^{\circ} \mathrm{C}$ 

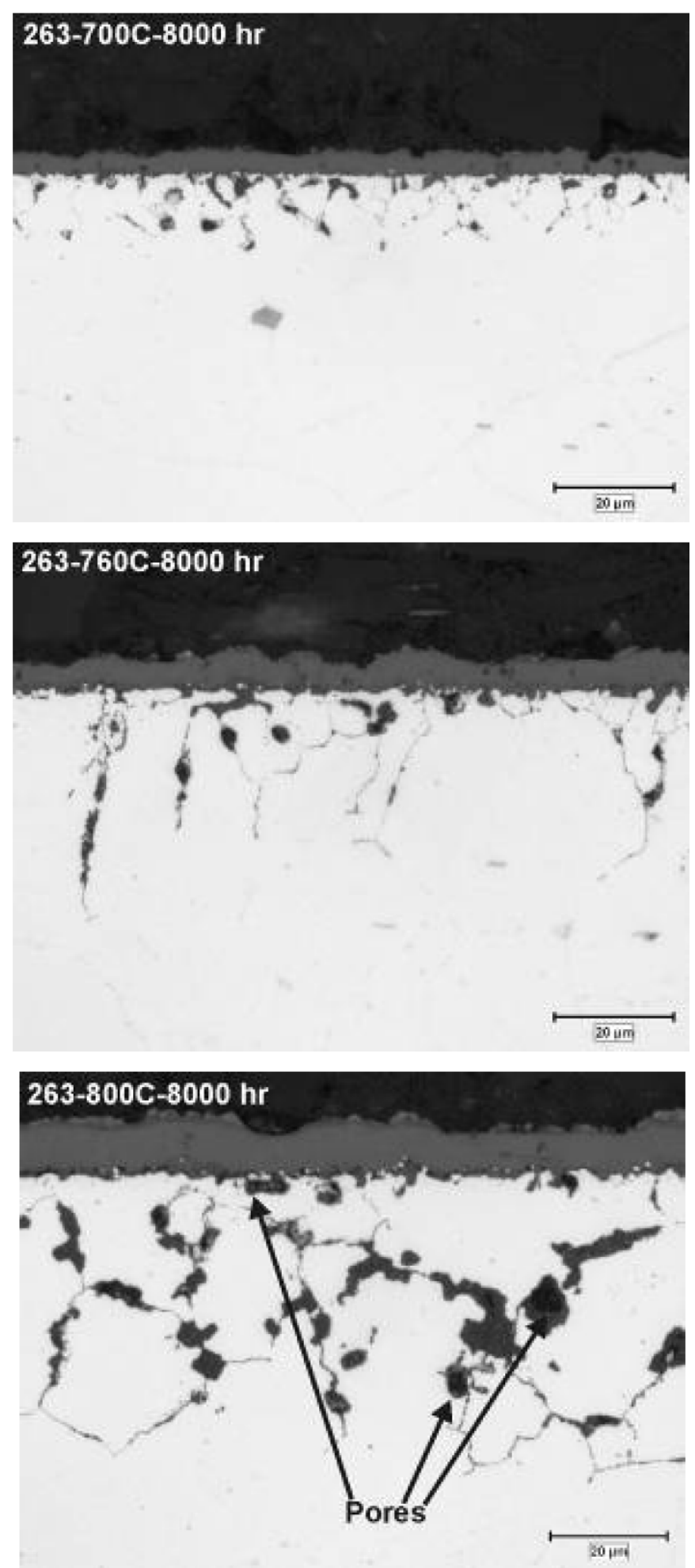

Figure 3-19

Typical oxidized surface of Nimonic 263 after 8,000 hours of exposure at 700, 760, and $800^{\circ} \mathrm{C}$ 

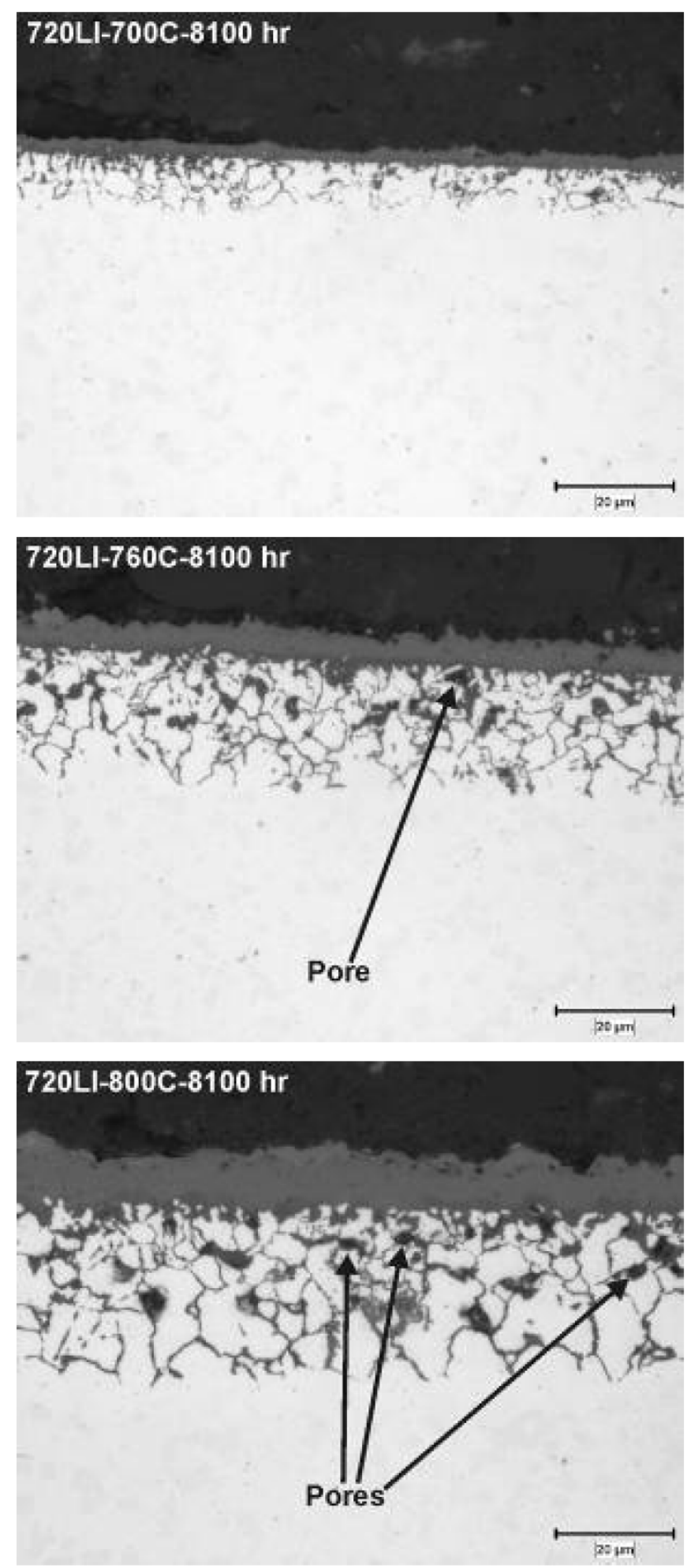

Figure 3-20

Typical oxidized surface of Udimet $720 \mathrm{Li}$ after 8,000 hours of exposure at 700,760 , and $800^{\circ} \mathrm{C}$ 

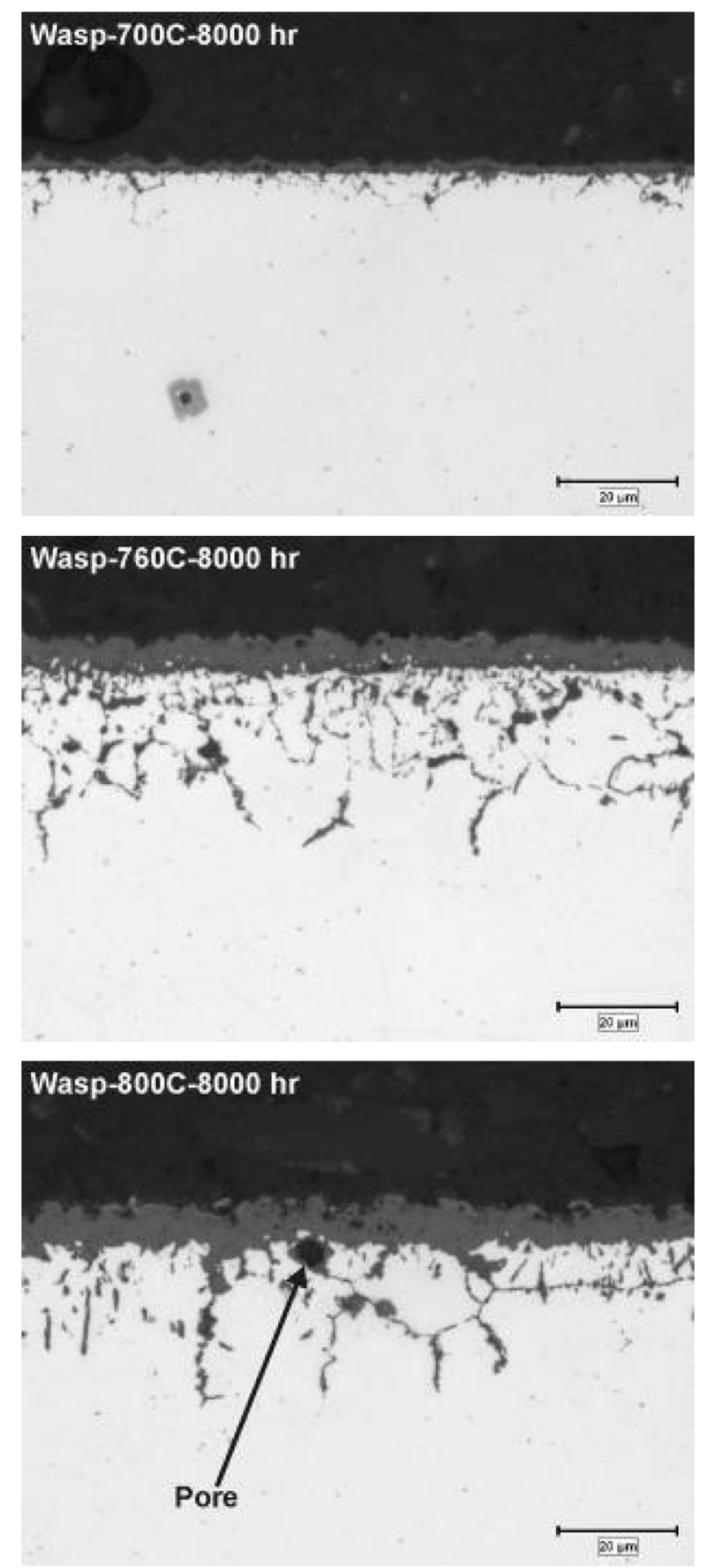

Figure 3-21

Typical oxidized surface of Waspalloy after 8,000 hours of exposure at 700,760 , and $800^{\circ} \mathrm{C}$ 


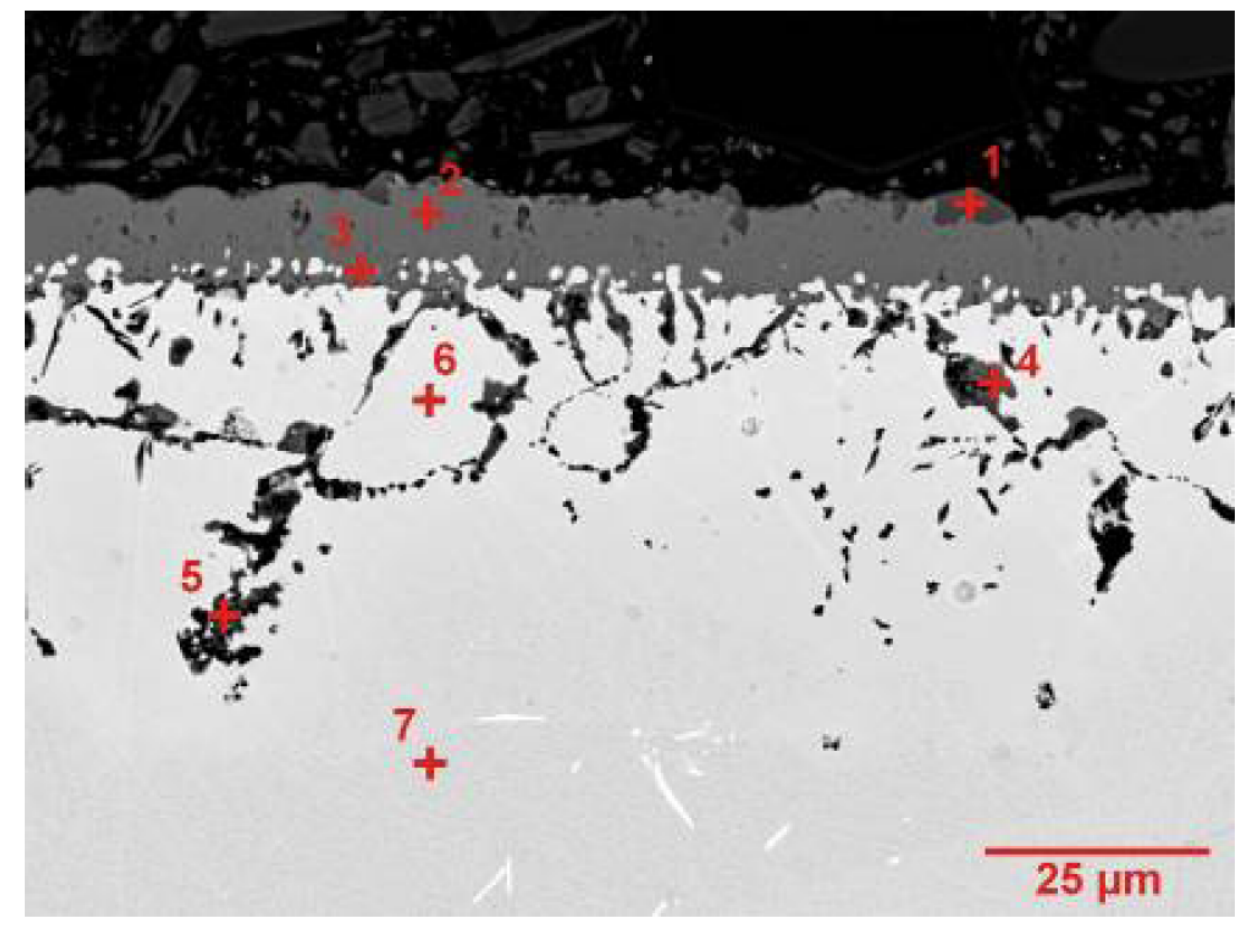

Composition (wt.\%)

\begin{tabular}{cccccccccccc} 
Location & O-K & Al-K & Si-K & Ca-K & Ti-K & Cr-K & Mn-K & Fe-K & Co-K & Ni-K & Mo-L \\
\hline 1 & 26.4 & 0.1 & 0.1 & 0.2 & 69.9 & 2.7 & 0.3 & & & 0.4 & \\
2 & 25.8 & 0.1 & & 0.3 & 1.7 & 71.5 & & & & 0.6 & \\
3 & 27.6 & 0.6 & 0.3 & 0.1 & 4.8 & 65.6 & & & & 1.0 & \\
4 & 22.3 & 0.3 & 0.1 & & 42.5 & 9.4 & & & 3.6 & 17.6 & 4.2 \\
5 & 32.0 & 18.9 & 2.3 & 2.0 & 32.9 & 4.0 & & & 0.9 & 5.9 & 1.0 \\
6 & & 0.1 & 0.2 & & & 9.8 & & 0.6 & 12.3 & 65.2 & 11.9 \\
7 & & 1.3 & 0.0 & & 2.3 & 18.1 & & 0.4 & 10.1 & 59.8 & 8.1 \\
\hline
\end{tabular}

Figure 3-22

BSE Image of Haynes 282 after exposure at $800^{\circ} \mathrm{C}$ for 8000 hours. Results of EDS analysis at various locations are provided. 


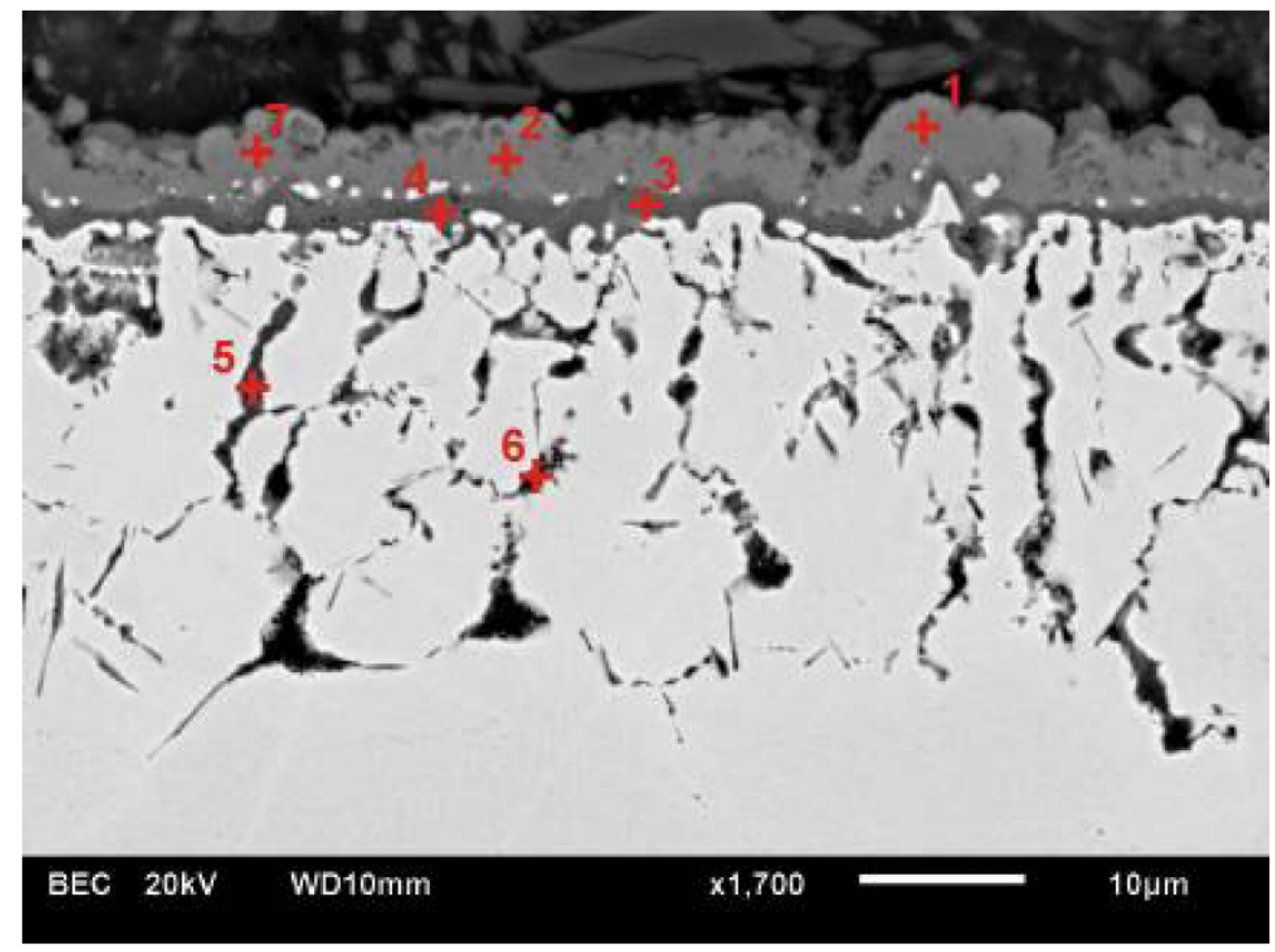

\begin{tabular}{ccccccccc}
\hline & \multicolumn{8}{c}{ Composition (wt.\%) } \\
\cline { 2 - 9 } Location & O-K & Al-K & Si-K & Ti-K & Cr-K & Co-K & Ni-K & Mo-L \\
\hline 1 & 29.3 & 0.2 & 0.1 & 3.9 & 64.0 & 0.4 & 1.9 & 0.2 \\
2 & 30.8 & 0.6 & 0.5 & 3.3 & 64.0 & & 0.8 & \\
3 & 32.8 & 0.5 & 0.1 & 38.6 & 26.5 & 0.3 & 1.3 & \\
4 & 21.9 & 0.5 & 0.2 & 44.2 & 21.2 & 2.2 & 9.0 & 0.8 \\
5 & 0.2 & 0.2 & 0.2 & 0.6 & 16.9 & 15.1 & 62.0 & 5.0 \\
6 & 2.6 & 3.2 & 0.1 & 1.3 & 15.9 & 14.3 & 58.0 & 4.6 \\
7 & 29.7 & 0.1 & 0.2 & 3.0 & 66.3 & & 0.7 & \\
\hline
\end{tabular}

Figure 3-23

BSE Image of Waspalloy after exposure at $760^{\circ} \mathrm{C}$ for 8000 hours. Results of EDS analysis at various locations are provided.

\subsection{Oxidation Rates - Scale Thickness and Internal Attack}

A total metal loss (TML) was calculated from values of external oxide scale thicknesses and depths of internal oxidation attack measured on metallographic sections as half of the external scale thickness plus the depth of internal attack, per the following equation:

$$
T M L=t h k_{\text {scale }} / 2+t h k_{i a}
$$


These values are tabulated in Table 3-2. The calculation assumed that the volume of the external scale was approximately double that of the metal from which it was formed. For the substrate alloy coupons the depth of internal oxidation dominates the total metal loss. Both the external scale thickness and the depth of internal attack appeared to follow parabolic rate kinetics; example plots are shown in Figure 3.24. Parabolic rate constants for external scale thickness and TML were calculated from the following equation:

$$
(\Delta t h k / A)=k^{\prime} t^{1 / 2}
$$

Figure 3-25 is a chart comparing the TML rate constants for the substrate alloys. Figure 3-26 compares TML after 100,000 hour exposure predicted from the rate constants and Figure 3-27 compares predicted external scale thickness after 100,000 hour exposure calculated from measured scale thickness. The data are also compared in Figure 3-28 against the inverse of temperature to show the activation energies. All data are tabulated in Table 3-1. The activation energy for TML for most alloys was similar to that observed for weight gain. An exception was Waspaloy, for which the TML rate constant at $800^{\circ} \mathrm{C}$ was less than that at $760^{\circ} \mathrm{C}$. Examination and EDS analysis of the oxide scales formed at these two temperatures did not reveal any obvious differences in morphology or composition that would explain the apparently reduced rates at $800^{\circ} \mathrm{C}$. 
Table 3-2

Scale thickness and internal oxidation measurements from metallurgical cross-sections

\begin{tabular}{|c|c|c|c|c|c|c|c|}
\hline \multirow{2}{*}{ Alloy } & \multirow{2}{*}{ Temp. $\left({ }^{\circ} \mathrm{C}\right)$} & \multicolumn{3}{|c|}{ External Scale $(\mu \mathrm{m})$} & \multicolumn{3}{|c|}{ Internal Attack $(\mu \mathrm{m})$} \\
\hline & & $900 / 1000 \mathrm{hr}$ & $4000 \mathrm{hr}$ & $8000 \mathrm{hr}$ & $900 / 1000 \mathrm{hr}$ & $4000 \mathrm{hr}$ & $8000 \mathrm{hr}$ \\
\hline \multirow{3}{*}{ Haynes 230} & 700 & 1.5 & 1 & 1.5 & 6 & 14 & 23 \\
\hline & 760 & 1 & 2 & 3 & 13 & 25 & 29 \\
\hline & 800 & 3 & 5 & 6.5 & 17 & 30 & 35 \\
\hline \multirow{3}{*}{ Haynes 282} & 700 & 2 & 4 & 4 & 6 & 10 & 16 \\
\hline & 760 & 3 & 4 & 5.5 & 13 & 25 & 27 \\
\hline & 800 & 6 & 9 & 10 & 32 & 40 & 52 \\
\hline \multirow{3}{*}{ Inconel 617} & 700 & 1 & 2 & 1.5 & 3 & 14 & 15 \\
\hline & 760 & 1.5 & 3 & 3.5 & 12 & 20 & 29 \\
\hline & 800 & 5 & 6.5 & 7 & 17 & 30 & 37 \\
\hline \multirow{3}{*}{ Inconel 740} & 700 & $\overline{1}$ & 2 & 2 & 4 & 6 & 10 \\
\hline & 760 & 2 & 4 & 5 & 8 & 14 & 19 \\
\hline & 800 & 4.5 & 6 & 8.5 & 15 & 28 & 34 \\
\hline \multirow{3}{*}{ Nimonic 105} & 700 & 1.5 & 2 & 3 & 3 & 5 & 18 \\
\hline & 760 & 2.5 & 4 & 5 & 10 & 20 & 28 \\
\hline & 800 & 4.5 & 6 & 7 & 20 & 35 & 38 \\
\hline \multirow{3}{*}{ Nimonic 263} & 700 & 2 & 3 & 4 & 5 & 12 & 15 \\
\hline & 760 & 3.5 & 4.5 & 6 & 17 & 27 & 40 \\
\hline & 800 & 5.5 & 7.5 & 10 & 34 & 45 & 60 \\
\hline \multirow{3}{*}{ Udimet 720 LI } & 700 & 1.5 & 2 & 3 & 5 & 9 & 10 \\
\hline & 760 & 4 & 4.5 & 5.5 & 10 & 18 & 24 \\
\hline & 800 & 5.5 & 7.5 & 10 & 14 & 26 & 31 \\
\hline \multirow{3}{*}{ Waspaloy } & 700 & 1.5 & 2 & 2 & 5 & 9 & 10 \\
\hline & 760 & 2.5 & 4.5 & 6 & 13 & 27 & 36 \\
\hline & 800 & 3.5 & 6 & 8 & 19 & 23 & 28 \\
\hline
\end{tabular}



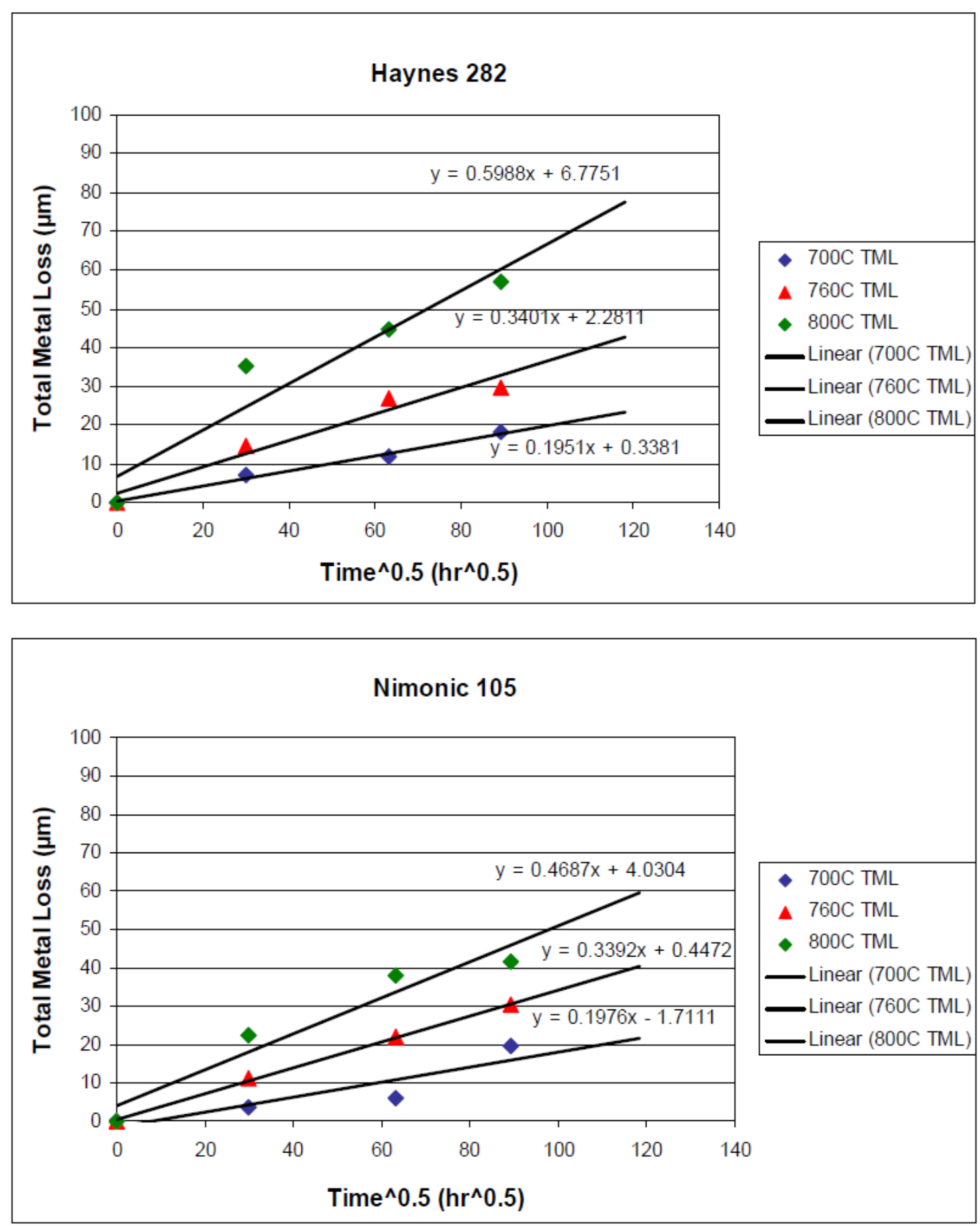

Figure 3-24

Example plots of total metal loss versus the square root of time 


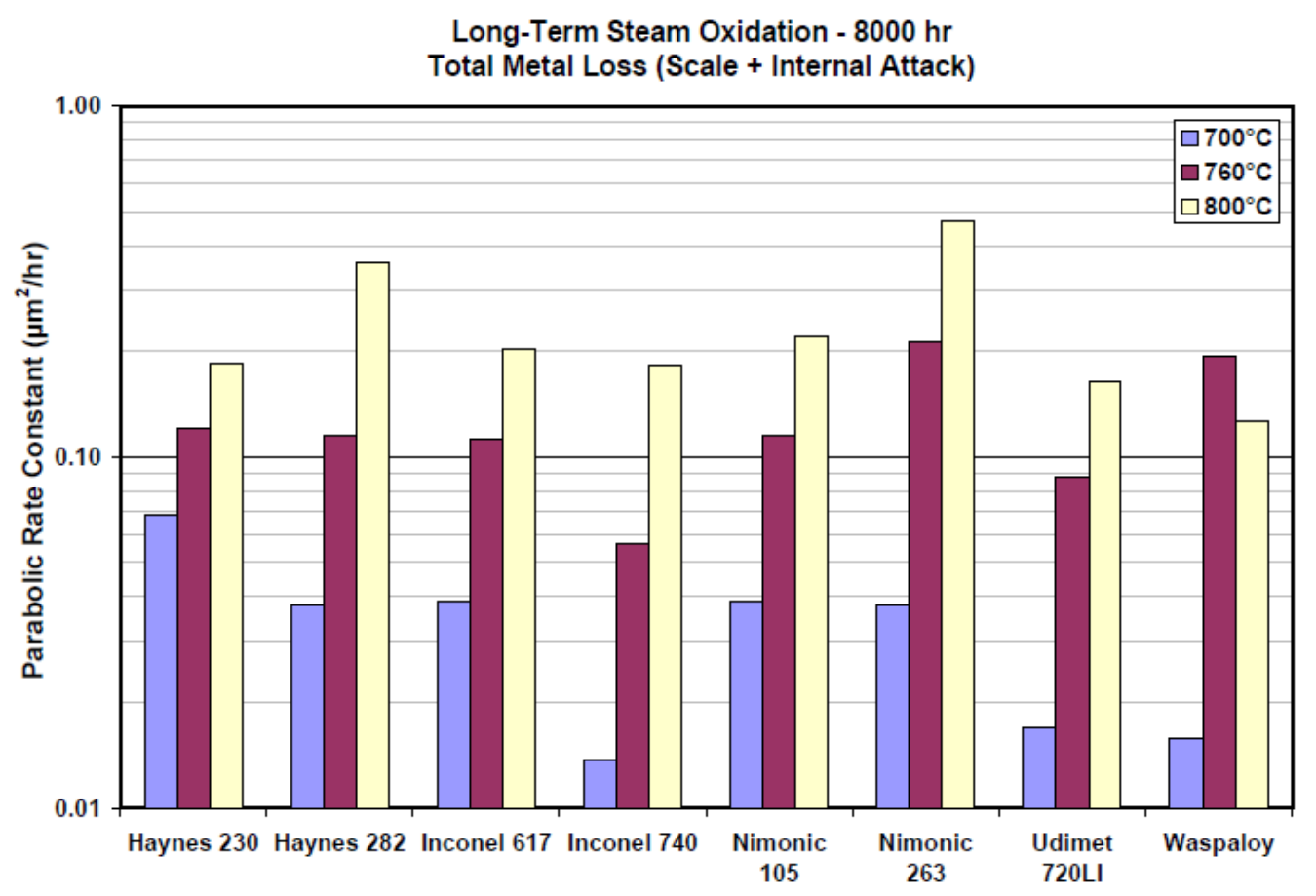

Figure 3-25

TML rate constants for substrate alloys

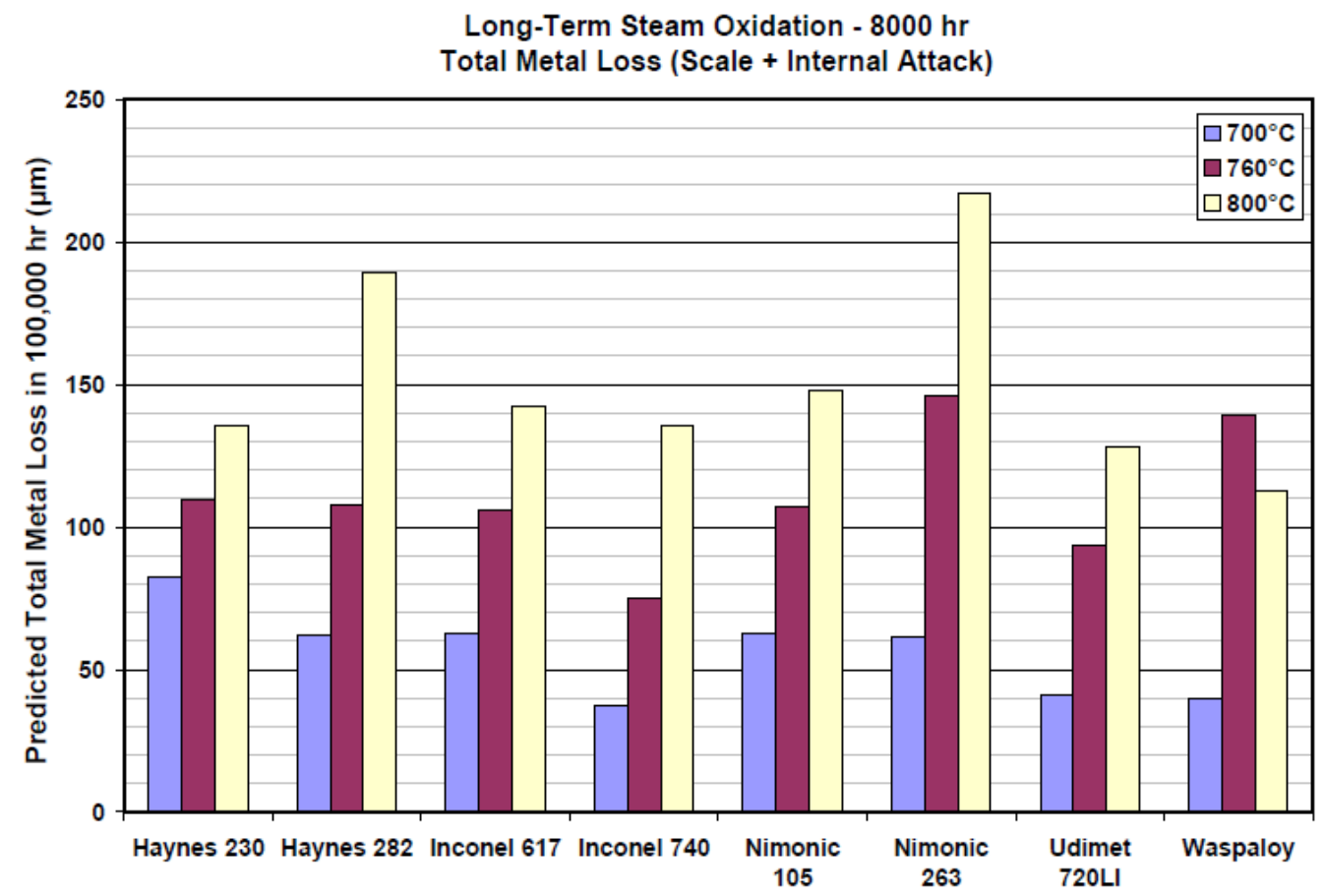

Figure 3-26

TML after 100,000 hours exposure based on extrapolation of TML parabolic kinetics 


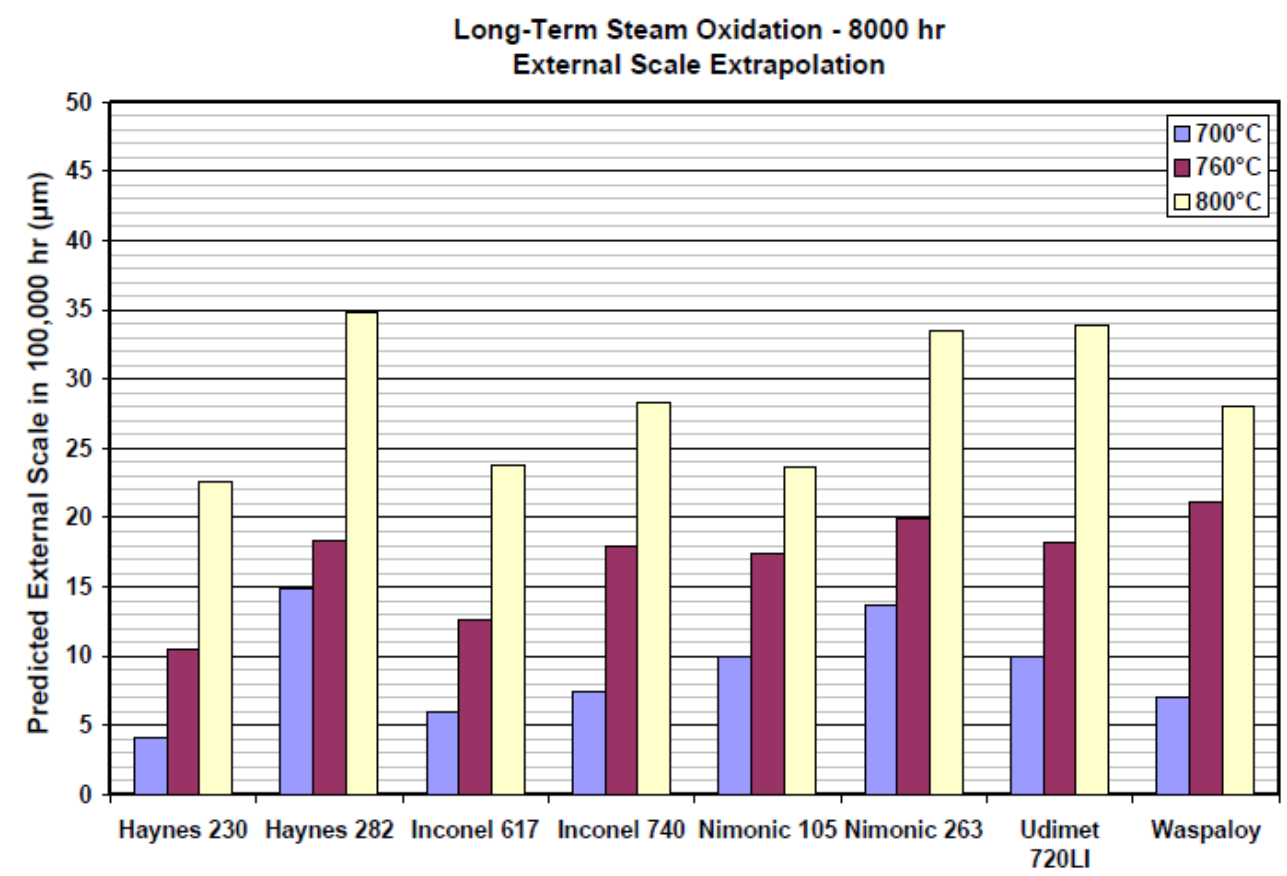

Figure 3-27

External scale thickness after 100,000 hours based on extrapolation of scale thickness oxidation kinetics

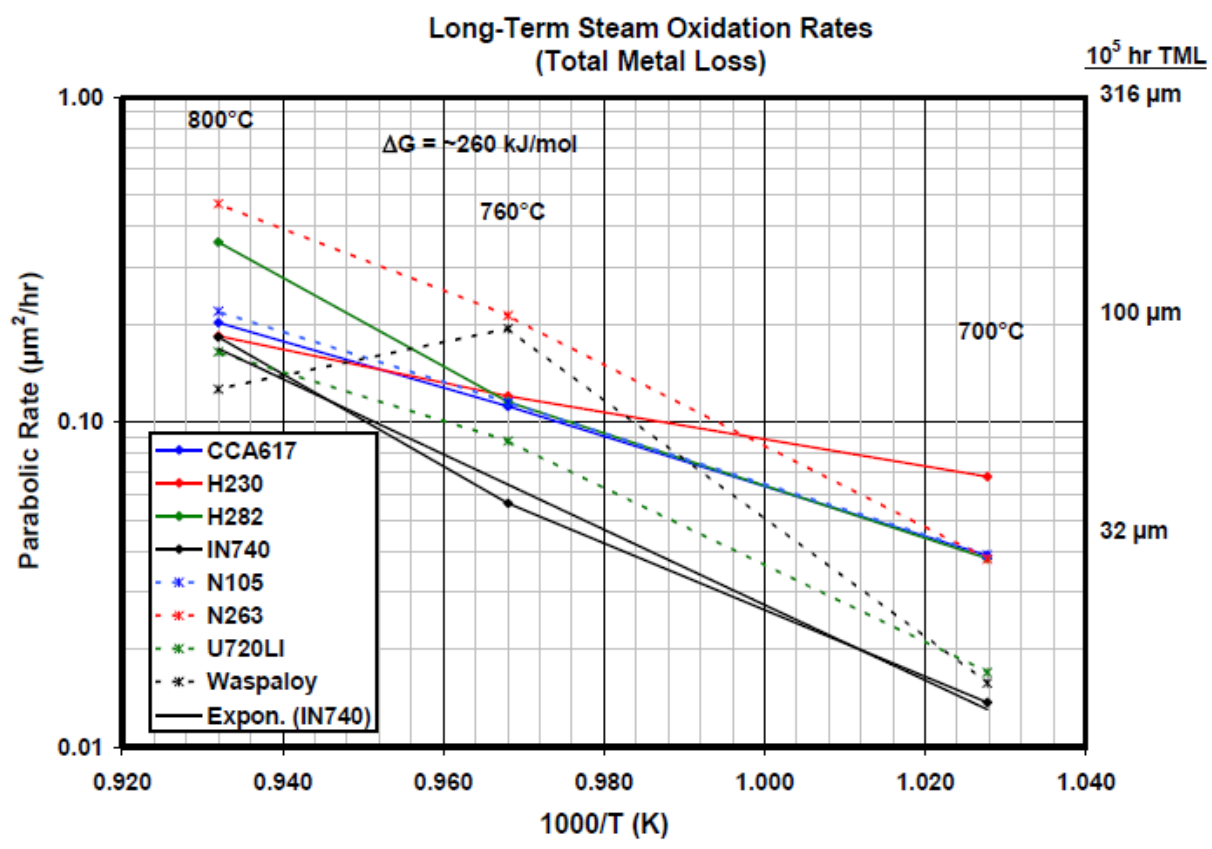

Figure 3-28

Plot of TML Parabolic Rate Constants for Substrate Alloys versus Inverse of Temperature 


\subsection{Comparison to Previous Data}

Figure 3-29 through Figure 3-35 compare weight-gain and total metal loss oxidation rates measured in this study with those previously reported by Babcock and Wilcox (B\&W) and ORNL under the auspices of the DOE USC Boiler Materials Program. Data were obtained from program quarterly reports and the interim (unpulished) ORNL Task 3 final report. In general, reasonable agreement was observed between the different studies, i.e., oxidation rate constants agreed within a factor of ten. In some cases, for example Inconel 740, very good agreement was observed, while in others (Haynes 230) the agreement was relatively poor. Considering all the variables and lack of standardization of test technique, this is not unexpected. Furthermore, it allows for relative comparison between the two programs despite minimal overlap of materials.

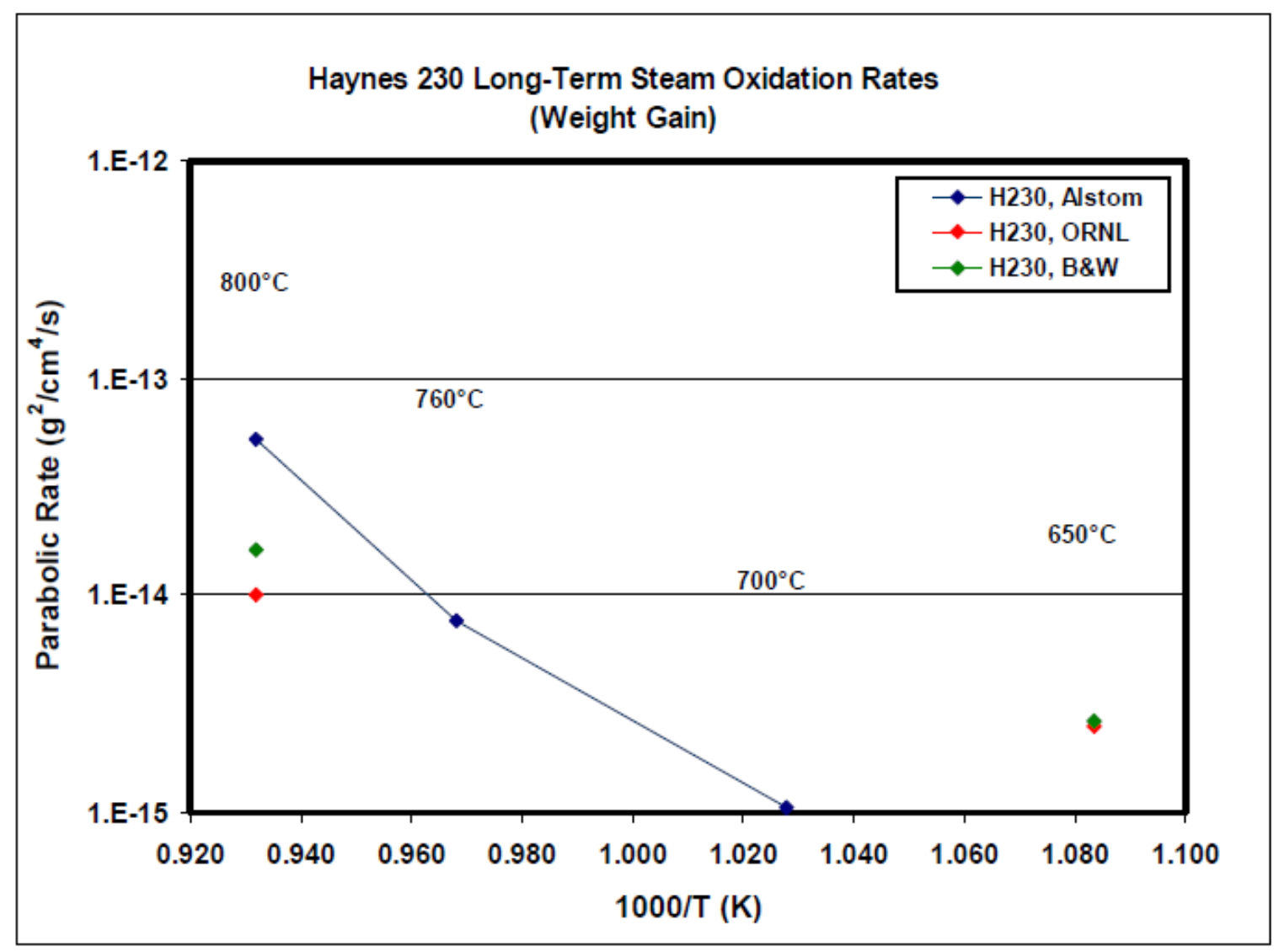

Figure 3-29

Comparison of parabolic rate constants (mass gain kinetics) for this study (Alstom) and previous work from the A-USC Steam Boiler Consortium (ORNLand B\&W) for Haynes 230 


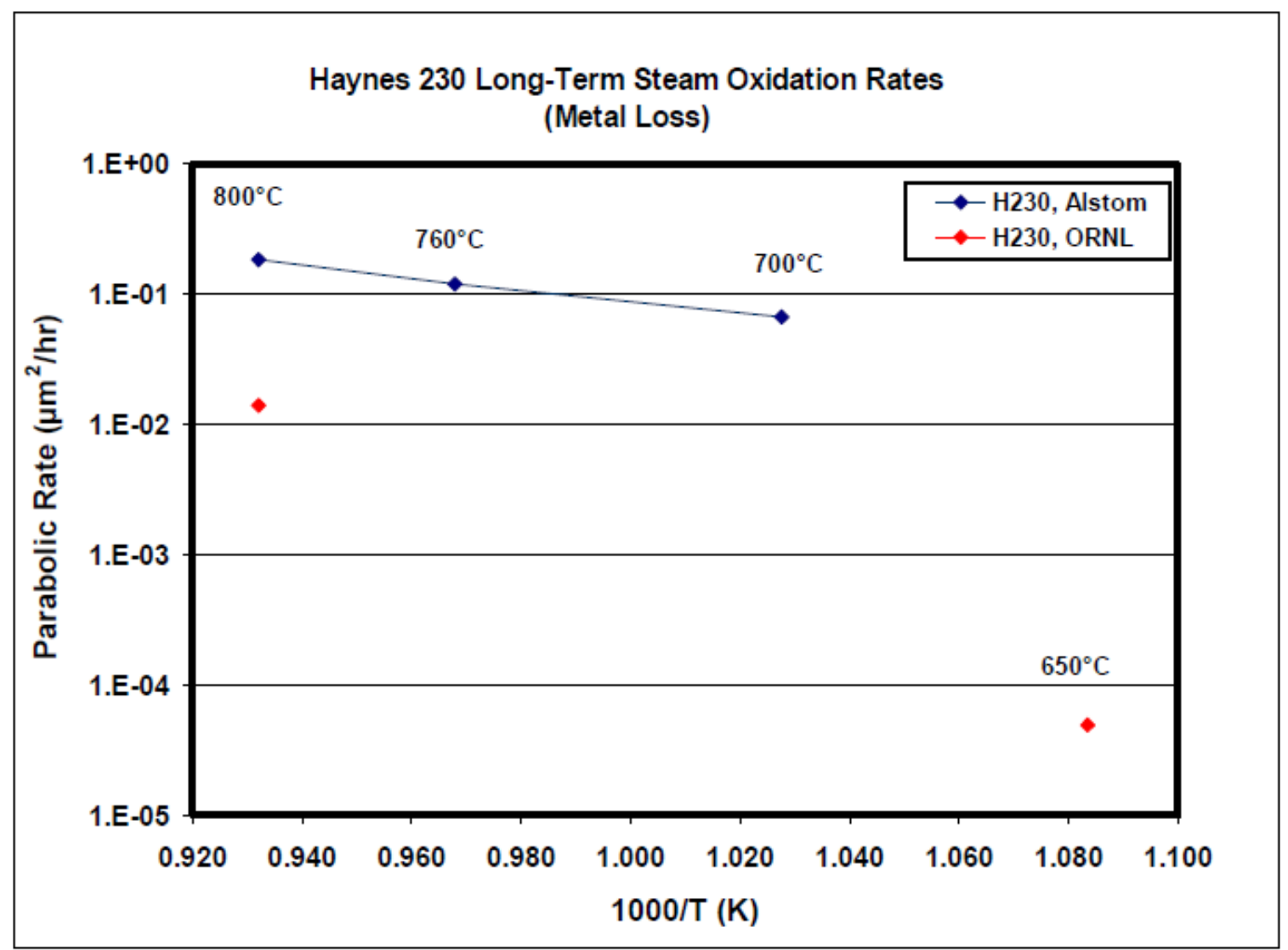

Figure 3-30

Comparison of parabolic rate constants (TML) for this study (Alstom) and previous work from the A-USC Steam Boiler Consortium (ORNL) for Haynes 230 


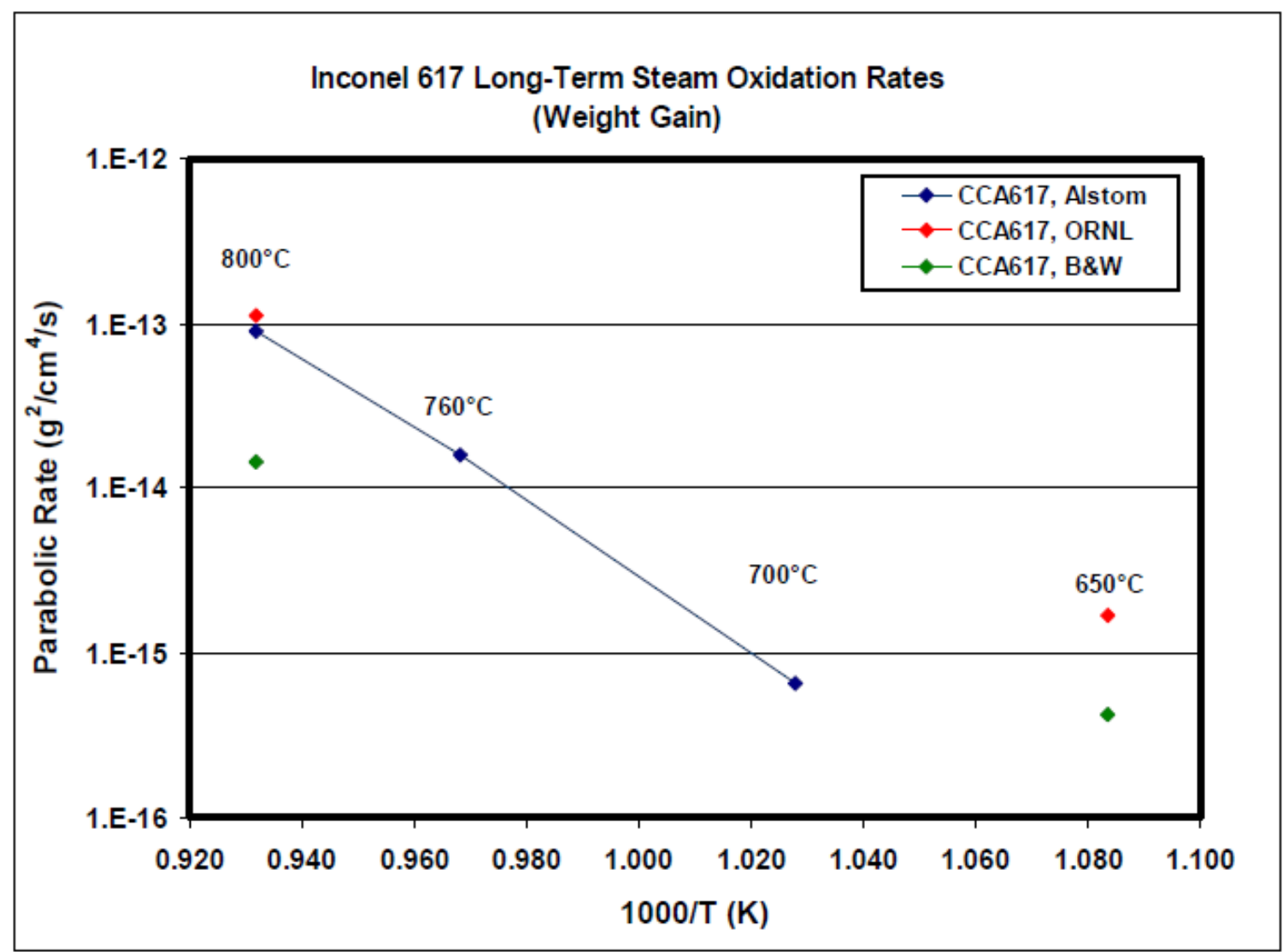

Figure 3-31

Comparison of parabolic rate constants (mass gain kinetics) for this study (Alstom) and previous work from the A-USC Steam Boiler Consortium (ORNLand B\&W) for 617 


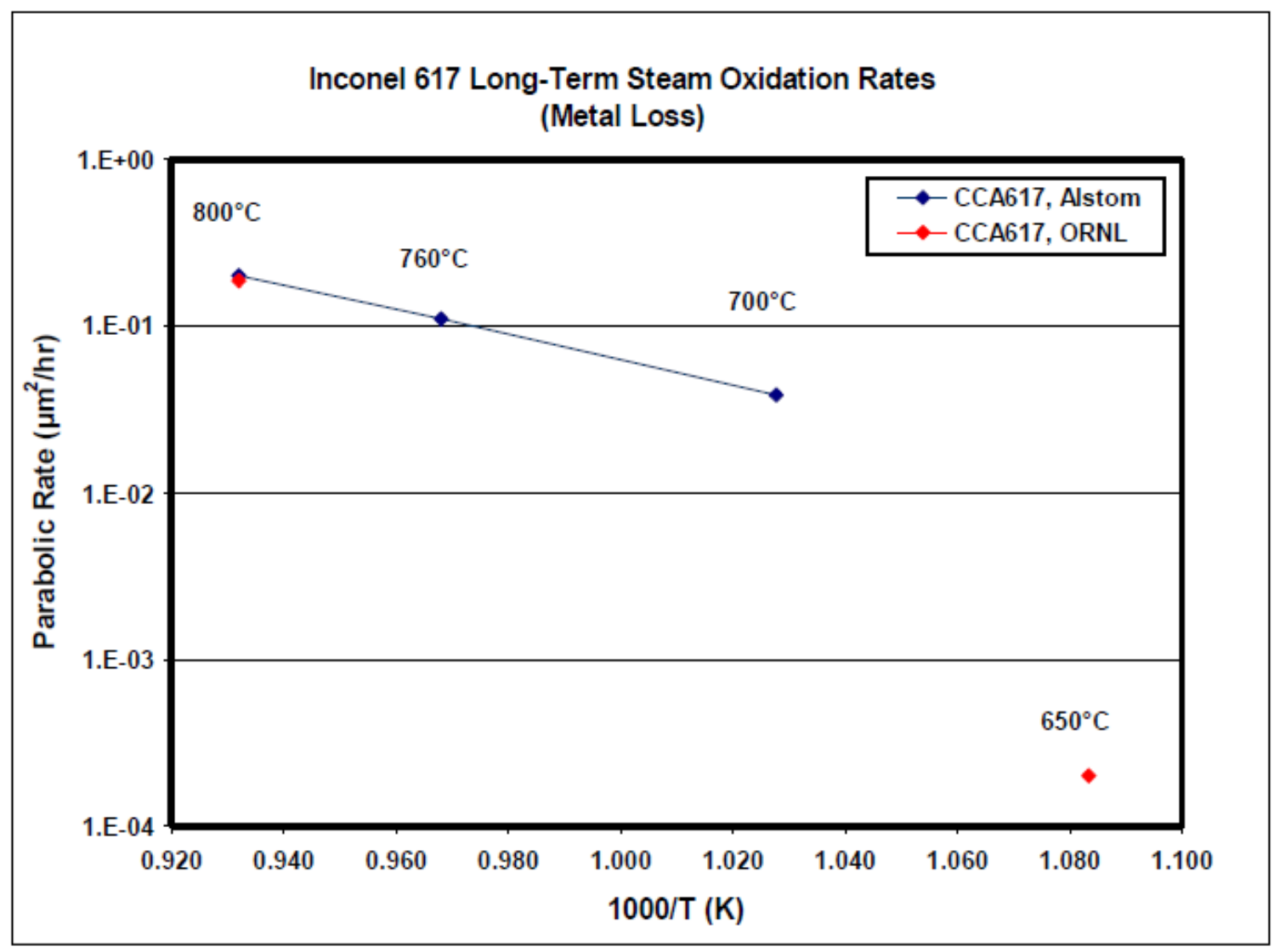

Figure 3-32

Comparison of parabolic rate constants (TML) for this study (Alstom) and previous work from the A-USC Steam Boiler Consortium (ORNL) for 617 


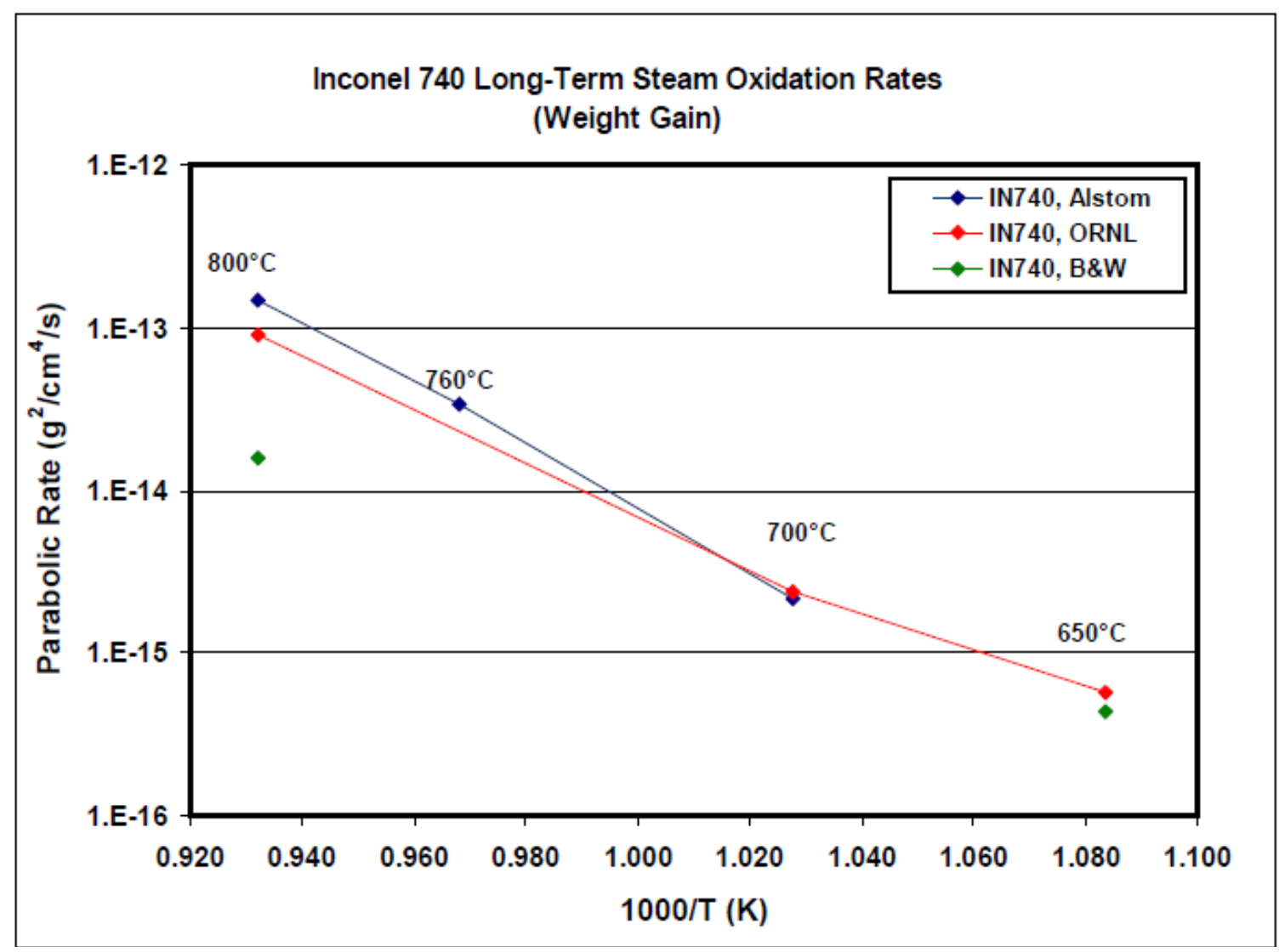

Figure 3-33

Comparison of parabolic rate constants (mass gain kinetics) for this study (Alstom) and previous work from the A-USC Steam Boiler Consortium (ORNLand B\&W) for Inconel 740 


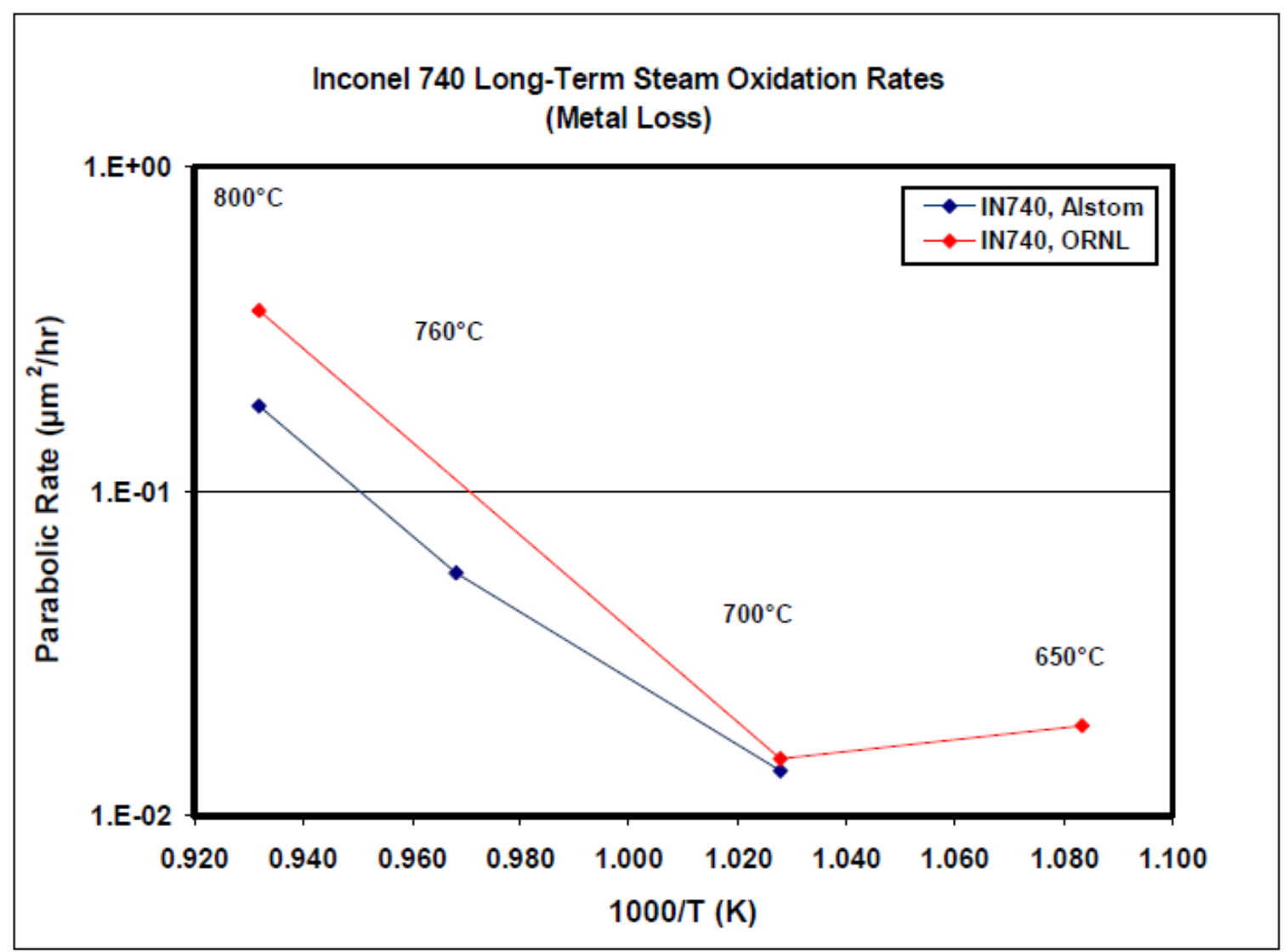

Figure 3-34

Comparison of parabolic rate constants (TML) for this study (Alstom) and previous work from the A-USC Steam Boiler Consortium (ORNL) for Inconel 740 


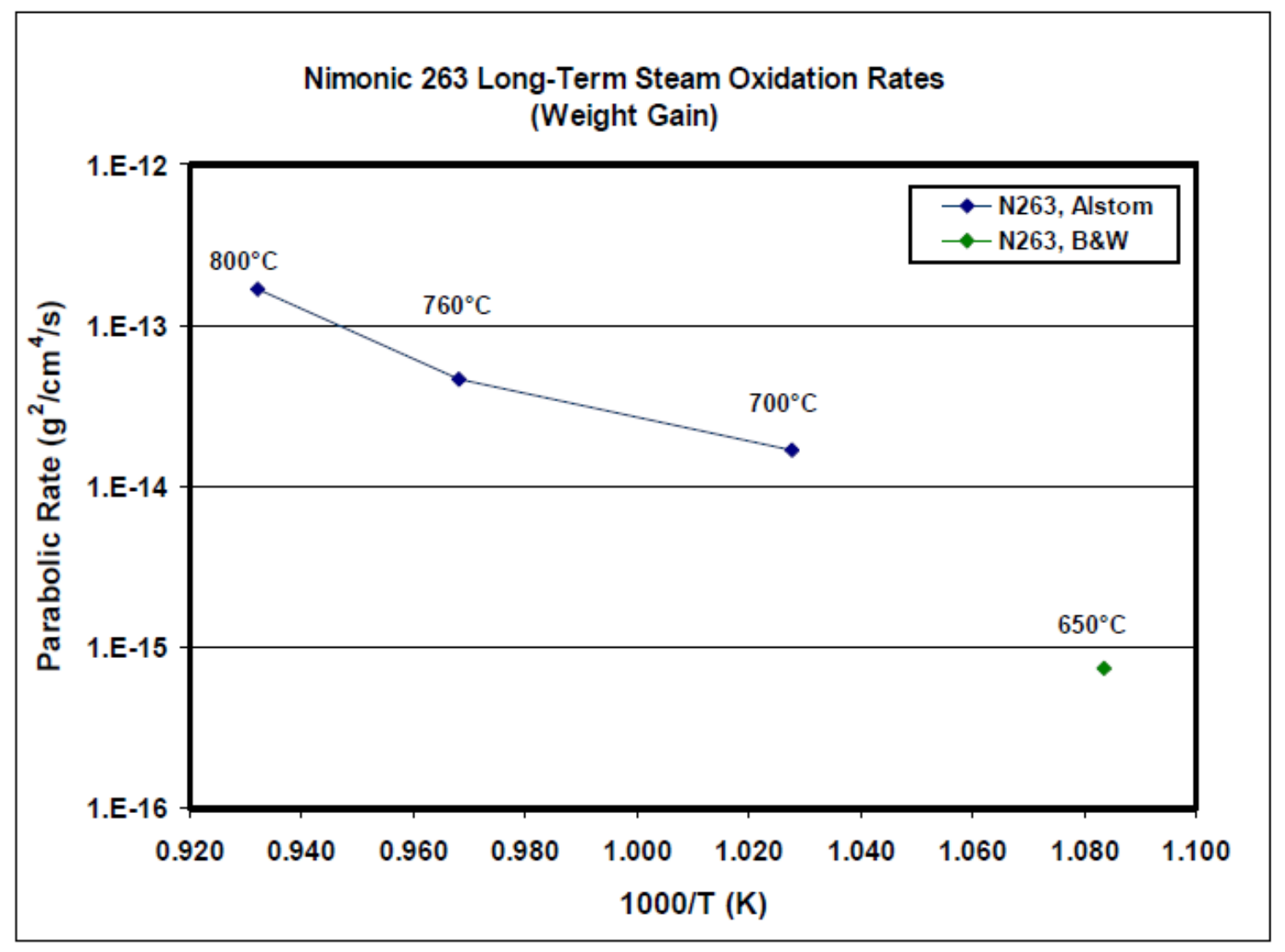

Figure 3-35

Comparison of parabolic rate constants (mass gain kinetics) for this study (Alstom) and previous work from the A-USC Steam Boiler Consortium (B\&W) for Nimonic 263

\subsection{General Discussion - Significance of Results for Substrates}

There are three major concerns (criteria to judge) for steam oxidation resistance of substrate alloys: exfoliation, oxidation rates, and internal oxidation. Exfoliation was not observed in any testing suggesting these alloys are much more resistant to this type of oxidation damage which is routinely seen in stainless steels operating at lower temperatures. From an oxidation rate standpoint, the substrate alloys tested, at temperatures from 760 to $800^{\circ} \mathrm{C}$, showed rates comparable and lower to ferritic and some austenitic alloys operating at current steam conditions $\left(550-650^{\circ} \mathrm{C}\right)$. As such, it is not anticipated that any of the substrate alloys tested would need additional oxidation protection by coatings based on scale thickness kinetics.

Internal oxidation rates were higher than external scale growth. Turbine designers can utilize the internal oxidation rate and/or TML data to design blading to account for this minor attack. It has been suggested that evaporation of chromia scales at the high pressures and flow rates encountered in an actual A-USC steam turbine could be a concern (Holcomb and Hsu, Proc. $22^{\text {nd }}$ Annual Conference on Fossil Energy Materials, DOE-NETL, 2008). In this testing, weight loss, possibly but not definitively due to oxide evaporation, was observed for several alloys at atmospheric pressure and very low flow rates. It is also notable that alloys which showed greater 
weight losses (Inconel 617, Haynes 282, and Nimonic 105) have higher Mo contents. Therefore some of the weight loss observed may have resulted from evaporation of $\mathrm{MoO}_{3}$, although again no definitive data to confirm this was developed. The amount in this testing was considered minimal and was reflected in the slowing of the oxidation rate with increasing test time.

In summary, the data generated in this task indicates that the candidate alloys considered would perform as well or better in A-USC conditions, relative to steam oxidation, than current state-ofthe-art applications. However further study is recommended to fully explore chromia and/or molybdenum evaporation. This could be done by modeling of the vaporization phenomena, laboratory oxidation testing at high pressures and flow rates, or exposure of test coupons in steam test loops.

\section{$4 \quad$ Results and Discussion - Coatings}

Table 4-1 summarized the results of the 1000 hour oxidation exposure of the candidate SPE coatings. There were insufficient coupons and time available to expose all coatings at all three temperatures. All coatings were exposed at $760^{\circ} \mathrm{C}$ since this was the SPE test temperature; Stellite $6 \mathrm{~B}$ and Metco 45 were exposed at 700,760 , and $800^{\circ} \mathrm{C}$. The oxidation exposure results were determined both in terms of weight gain and oxidation extent as measured on metallographic sections. Weight gain is a more ambiguous measure of oxidation extent for the coatings - because the coatings were only applied to one of the substrate surfaces, the total weight gain of the coupon is the sum of weight gain from the coating and the substrate combined. Stellite $6 \mathrm{~B}$ is an exception because the entire coupon was the candidate material. In order to provide a rough comparison with substrate values, a net weight gain for the coating was calculated by subtracting an estimated weight gain contribution from the substrate from the total weight gain. The substrate weight gain was estimated from the thickness of oxide measured on the exposed substrate surface, assuming that for the chromia scale formed, $1 \mu \mathrm{m}$ of scale was equivalent to $6.3 \mathrm{mg} / \mathrm{cm}^{2}$ of weight gain. This correlation was observed to be reasonably accurate for the other substrate alloys. The overall calculation of coating weight gain is summarized as follows:

$$
\Delta m_{\text {coating }} / A_{\text {coating }}=\left(\Delta m_{\text {overall }}-6.3 \times \text { thk } k_{\text {substate_scale }} \times A_{\text {substrate }}\right) / A_{\text {coating }}
$$

Similar to the other nickel-base alloys, Hastelloy X showed only a very thin oxide scale after 1000 hour exposure, even at $800^{\circ} \mathrm{C}$.

For the T-400C and T-800 coatings applied to Type 304 stainless steel substrates, the coupons lost weight due to substrate oxide spallation. Thick oxides were observed on the substrate surfaces after 1000 hour exposure at $760^{\circ} \mathrm{C}$. Therefore, for these coatings, quantitative determination of the net coating weight gain was not possible. 
The estimated net coating weight gains (where available) were used to calculate an equivalent thickness of chromia scale using the $6.3 \mathrm{mg} / \mathrm{cm}^{2}$ per $\mu \mathrm{m}$ of scale conversion factor, to qualitatively compare the weight gain against the measured oxide scale thickness. For the Stellite 6B material there was good agreement between these values; however, for most of the coatings the weight gain indicates a much thicker oxide scale than actually observed on the coupons. For some coatings (e.g, SHS 7170 and 9172), this is clearly due to extensive internal oxidation along coating cracks. For others, the extra weight gain is postulated to be due to the difficulty in accurately measuring the external oxide scale thickness and the extra area presented by the convoluted thermal spray coating surface. For the MoB-CoCr coating much less oxidation was indicated by weight gain than was actually observed. In this case, it is postulated that $\mathrm{MoO}_{3}$ may have formed and evaporated during exposure, thereby reducing the weight gain measured. For all coatings, the metallographic measurements are believed to represent a more realistic assessment of the oxidation extent than weight gain measurements.

Details for each coupon are provided in the sections below and in Figures 4-1 to 4-25. In general, most coatings showed significantly thicker external oxide scales than the substrate alloys (Table 3-1), Stellite 6B being an exception with comparable weight gain, external scales, and internal attack. Some coatings showed extensive internal attack in the form of oxidized coating cracks; the MoB-CoCr coating also showed deep areas of internal oxidation. Therefore, the only coatings which show the potential to be sufficiently oxidation resistant for service in a A-USC steam turbine are Stellite 6B, Tribaloy T-400C, Metco 45, and CrC-NiCr.

Table 4-1

Summary of steam oxidation test results on coatings after 1,000 hour exposure

\begin{tabular}{|c|c|c|c|c|c|c|}
\hline \multirow[b]{2}{*}{ Coating } & \multirow[b]{2}{*}{ Temp. $\left({ }^{\circ} \mathrm{C}\right)$} & \multicolumn{2}{|c|}{ Weight Measurements } & \multicolumn{3}{|c|}{ Metallography Measurements } \\
\hline & & $\begin{array}{c}\text { Net Weight } \\
\text { Gain }(\mathrm{mg} / \mathrm{cm} 2)\end{array}$ & $\begin{array}{c}\text { Equiv. External } \\
\text { Scale }(\mu \mathrm{m})\end{array}$ & $\begin{array}{c}\text { External } \\
\text { Scale }(\mu \mathrm{m})\end{array}$ & $\begin{array}{c}\text { Internal } \\
\text { Attack }(\mu \mathrm{m})\end{array}$ & Notes \\
\hline \multirow{3}{*}{ Stellite 6B } & 700 & 0.16 & 1.0 & 1 & 12 & \\
\hline & 760 & 0.33 & 2.1 & 1.5 & 7 & \\
\hline & 800 & 0.14 & 0.9 & 2 & 18 & \\
\hline Tribaloy T-400C & 760 & $\mathrm{~N} / \mathrm{A}$ & $\mathrm{N} / \mathrm{A}$ & 3 & 17 & \\
\hline \multirow{2}{*}{ Tribaloy T-800 } & 760 & $\mathrm{~N} / \mathrm{A}$ & $\mathrm{N} / \mathrm{A}$ & 5 & 130 & Long oxidized crack \\
\hline & 700 & 2.15 & 13.6 & 7.5 & 0 & Significant coating debonding \\
\hline \multirow[t]{2}{*}{ Metco 45} & 760 & 2.45 & 15.5 & 7 & 0 & Minor coating debonding \\
\hline & 800 & 1.68 & 10.6 & 8 & 0 & Minor coating debonding \\
\hline SHS 7170 & 760 & 4.30 & 27.1 & 10 & 270 & Oxidized through-coating cracks \\
\hline SHS 9172 & 760 & 3.84 & 24.2 & 2 & 270 & Oxidized through-coating cracks \\
\hline $\mathrm{MoB}-\mathrm{CoCr}$ & 760 & 1.56 & 9.8 & 20 & 145 & Local areas of deep internal oxidation \\
\hline $\mathrm{CrC}-\mathrm{NiCr}$ & 760 & 2.60 & 16.4 & 3.5 & 0 & Cracks in coating corner \\
\hline
\end{tabular}

\subsection{Stellite 6B}

Thin external oxide scales were observed on Stellite 6B after 1000 hour exposure at all three temperatures as shown in Figure $4-1$. At $700^{\circ} \mathrm{C}$ crack-like penetrations around reinforcing carbide particles were observed; similar penetrations were observed after $800^{\circ} \mathrm{C}$ exposure but not at $760^{\circ} \mathrm{C}$; it is unclear if these could possibly be related to coupon preparation. The external 
oxide was found to be rich in $\mathrm{Cr}$ and $\mathrm{Co}$, with measurable concentrations of $\mathrm{Al}, \mathrm{Si}$, and $\mathrm{Mn}$ as shown in Figure 4-2.

\subsection{Tribaloy $\mathrm{T}-400 \mathrm{C}$}

Overviews of the T-400C coating are shown in Figure 4-3. The T-400C coating structure was similar to T-800, with a smooth surface, no indications of typical thermal spray features, and a significant fraction of porosity present, particularly near the substrate (Figure 4-4). The Type 304 stainless steel substrate was found to be severely oxidized (Figure 4-5); a thick oxide scale was observed in the metallographic cross-section. Weight loss observed for this coupon and the T-800 coupon (which showed similar substrate oxidation) was clearly due to substrate oxide spallation. In contrast, the coating appeared to be little affected by the exposure.

Typical vies of the coating surface after 1000 hours are shown in Figure 4-7. A relatively thin external scale was found on the coating surface, with areas of deeper penetration which appeared to be associated with Laves phase. The external oxide contained $\mathrm{Cr}$ and $\mathrm{Co}$, along with higher levels of Si and Al than present in the coating overall. Oxide associated with the deeper attack contained significant Mo.

\subsection{Tribaloy $\mathrm{T}-800$}

Oxidation attack of T-800 after 1000 hours exposure at $760^{\circ} \mathrm{C}$ was similar to that observed for T$400 \mathrm{C}$, except that relatively deep, oxidized cracks were observed along with the external scale and deeper oxidation in the Laves phase areas. The 1000 hour exposure appears to have transformed the coating microstructure from one of two Laves phases with slightly different compositions into one Laves phase, as seen in T-400C. The compositions of the external scale and internal attack were similar to those observed on T-400C. Figures 4-9 and 4-10 shows these features.

\subsection{Metco 45}

Metco 45 coupons were exposed at all three temperatures. The morphology and extent of apparent oxidation were similar at all temperatures as shown in Figure 4-11. Visual examination showed there was an apparent slight increase in mean external scale thickness with increasing temperature, but detailed measurements were not taken to quantify this finding. The weight gains at the three temperatures were also similar. Significant coating de-bonding occurred at the edges of the coupon exposed at $700^{\circ} \mathrm{C}$ (Figure 4-12); de-bonding occurred to a lesser extent in the coupons exposed at 760 and $800^{\circ} \mathrm{C}$. The external oxide scale was complex with $\mathrm{Cr}$-rich and Co-rich areas; W was also found in some areas (Figure 4-13).

\subsection{SHS 7170}

The SHS 7170 coating was significantly oxidized after 1000 hours exposure at $760^{\circ} \mathrm{C}$. A relatively thick oxide scale had formed on the surface and there was extensive oxidation along pre-existing cracks in the coating. Some of these cracks extended to the substrate. EDS analysis showed the oxides to be rich in $\mathrm{Mn}$ and $\mathrm{Si}$, and low in $\mathrm{Cr}$ content. This coating is clearly unsuitable for service in high-temperature steam conditions as shown in Figures 4-14 to 4-16. 


\subsection{SHS 9172}

Similar to SHS 7170, the SHS 9172 coating had coating cracks extending to the substrate which were oxidized during exposure at $760^{\circ} \mathrm{C}$. The overall extent of oxidation was less than SHS 7170 , but still higher than most of the other coatings. Oxide scales in this alloy contained high levels of $\mathrm{Fe}$ rather than $\mathrm{Mn}$, along with a small concentration of $\mathrm{Cr}$. Because of the throughcoating cracking, the coating is also unsuitable for service in high-temperature steam conditions as shown in Figures 4-17 to 4-19.

\subsection{MoB-CoCr}

The MoB-CoCr coating showed significant oxidation after 1000 hours exposure at $760^{\circ} \mathrm{C}$. Thick external scales were observed, as were areas of relatively deep oxide penetration along what might have been pre-existing cracks. The oxides formed were rich in Co and Mo, with relatively low $\mathrm{Cr}$ content. The high oxidation extent and presence of significant Mo in the oxide scale indicate that this coating is unsuitable for high-temperature steam service as shown in Figures 420 to $4-22$.

\section{8 $\mathrm{CrC}-\mathrm{NiCr}$}

Only a thin external oxide layer was found on the $\mathrm{CrC}-\mathrm{NiCr}$ coating after 1000 hours exposure at $760^{\circ} \mathrm{C}$ (Figure 4-23), although the weight gain of the coupon indicated that significantly more oxide should have formed. It is suspected that the initial coating surface roughness may have contributed to the higher weight gain, or that internal oxidation may have occurred which was not easily resolved in optical examination. A number of cracks were found at one corner of the coating (Figure 4-24); these were associated with an abnormal build-up of coating at the corner. SEM-EDS analysis of the exposed coating (Figure 4-25) showed the external and internal oxides to be Cr-rich, with small concentrations of $\mathrm{Ni}$ and $\mathrm{Si}$.

\subsection{General Discussion - Significance of Results}

The 1000 hour steam exposure has served as a very useful screening tool to evaluate potential SPE coatings. Several coatings were shown to have insufficient steam oxidation resistance for application in an A-USC steam turbine, these were the SHS 7170, SHS 9172, and MoB-CoCr coatings. The deep cracking in the T-800 coating may have been the result of specimen preparation; examination of coupons after longer-term exposures may clarify its potential suitability. The best-performing coating in terms of oxidation resistance was Stellite $6 \mathrm{~B}$, which

is not a coating at all, but rather a sheet product. Thermal spray powder with a composition similar to Stellite 6B can be obtained; whether a coating prepared with this powder would show similar oxidation resistance is open to question due to the defects introduced during thermal spraying.

Comparison of the oxidation test results with the SPE test results reported by Siemens shows that the only coating with good results in both was T-400C. The coatings which were reported to have had the best SPE test results were MoB-CoCr, a yttria-stabilized zirconia, T-400C, and Conformaclad WC. Unfortunately time constraints and supply of specimens meant that only the $\mathrm{MoB}-\mathrm{CoCr}$ and T-400C were subjected to oxidation testing. 

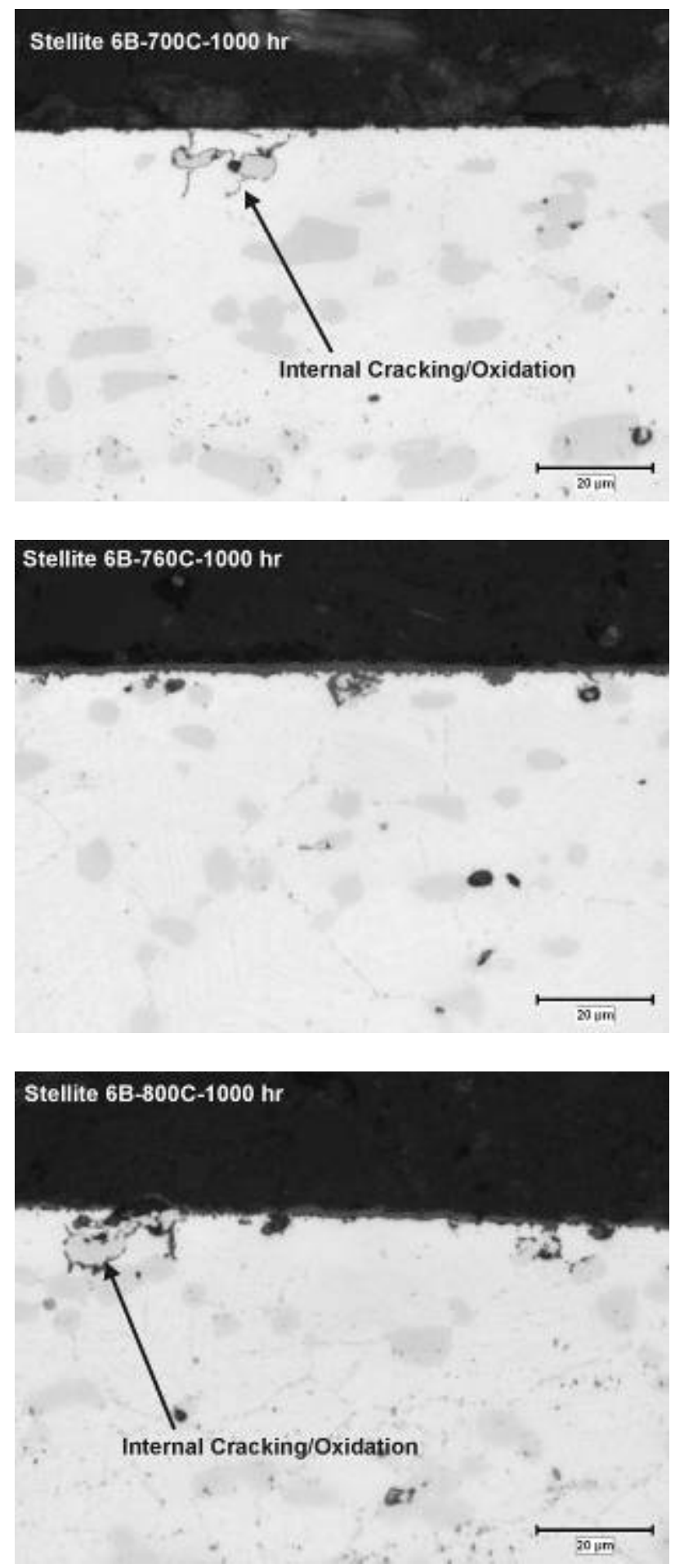

Figure 4-1: Typical Oxidized Surface of Stellite 6B after 1000 hours Exposure at 700, 760, and $800^{\circ} \mathrm{C}$. 


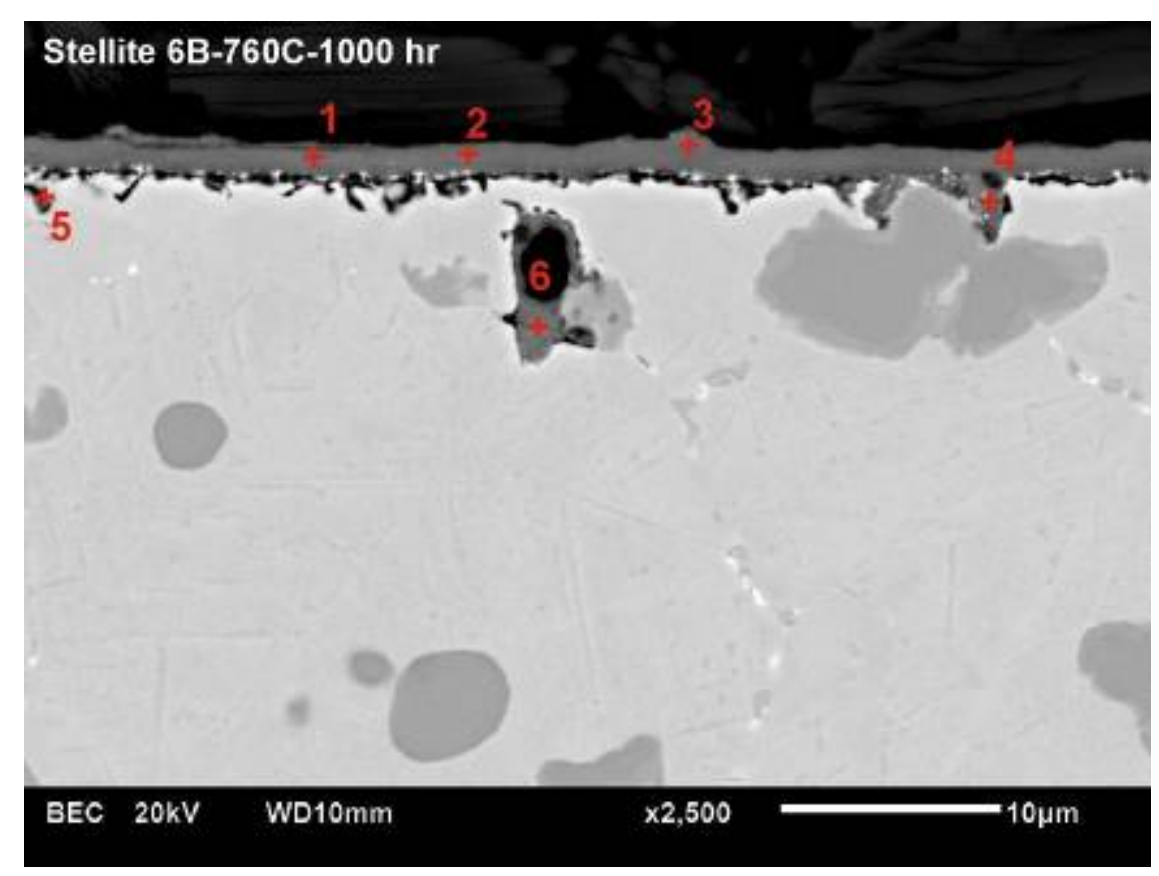

\begin{tabular}{ccccccccccc}
\hline & \multicolumn{10}{c}{ Composition (wt.\%) } \\
\cline { 2 - 10 } & O-K & Al-K & Si-K & Cr-K & Mn-K & Fe-K & Co-K & Ni-K & Mo-L & W-L \\
\hline 1 & 15.9 & & 4.4 & 43.8 & 3.2 & & 29.5 & & & 3.2 \\
2 & 20.0 & 0.3 & 6.0 & 34.0 & 3.9 & & 33.1 & & & 2.8 \\
3 & 17.6 & 0.3 & 7.5 & 37.1 & 2.6 & & 32.1 & & 0.4 & 2.5 \\
4 & & & & 84.8 & & 0.3 & 11.9 & & & 3.0 \\
5 & 0.6 & & & 20.0 & & 1.4 & 69.2 & 2.8 & 1.2 & 5.0 \\
6 & 2.2 & & & 24.7 & 1.0 & 1.1 & 62.9 & 2.5 & 1.0 & 4.7 \\
\hline
\end{tabular}

Figure 4-2: Backscattered Electron Image of Stellite 6B Exposed at $760^{\circ} \mathrm{C}$ for 1000 hours. Results of EDS Analysis at Locations Indicated are Listed Below the Image. 


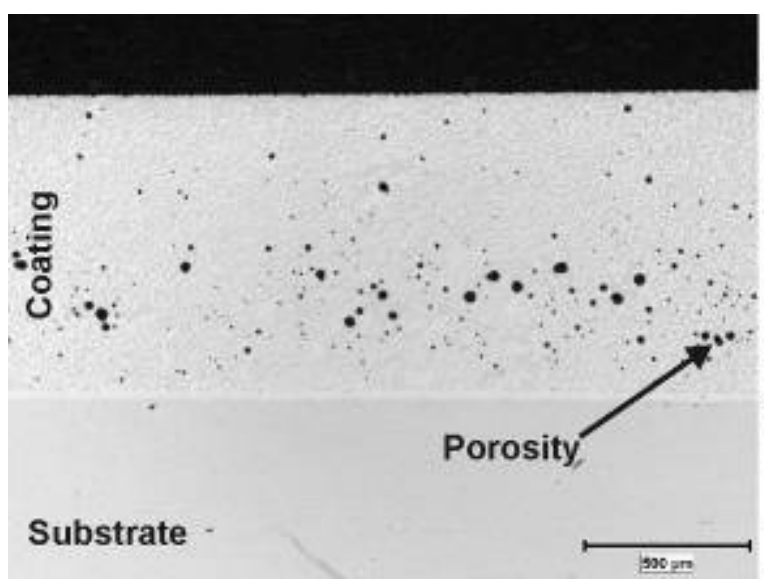

Optical (50X)

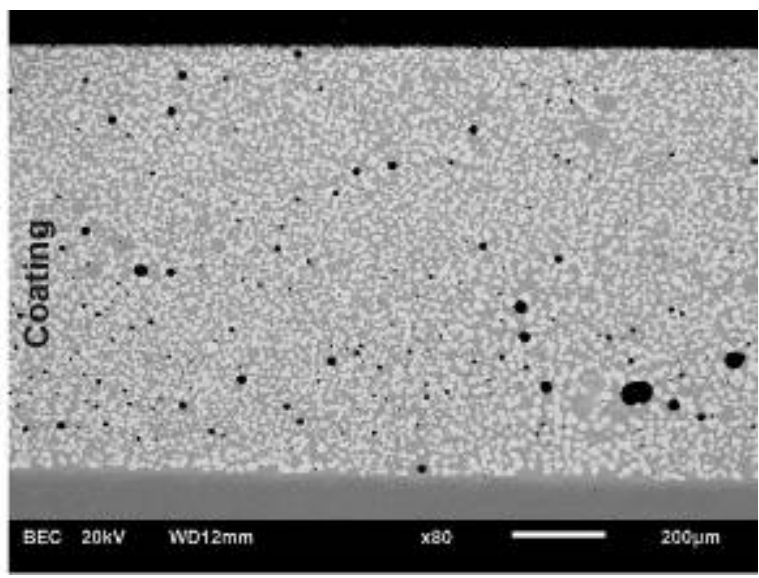

SEM-Backscattered Electron (75X)

Figure 4-3: Optical and Backscattered Electron Overviews of T-400C Coating Microstructure After 1000 hour Exposure at $760^{\circ} \mathrm{C}$. Unetched.

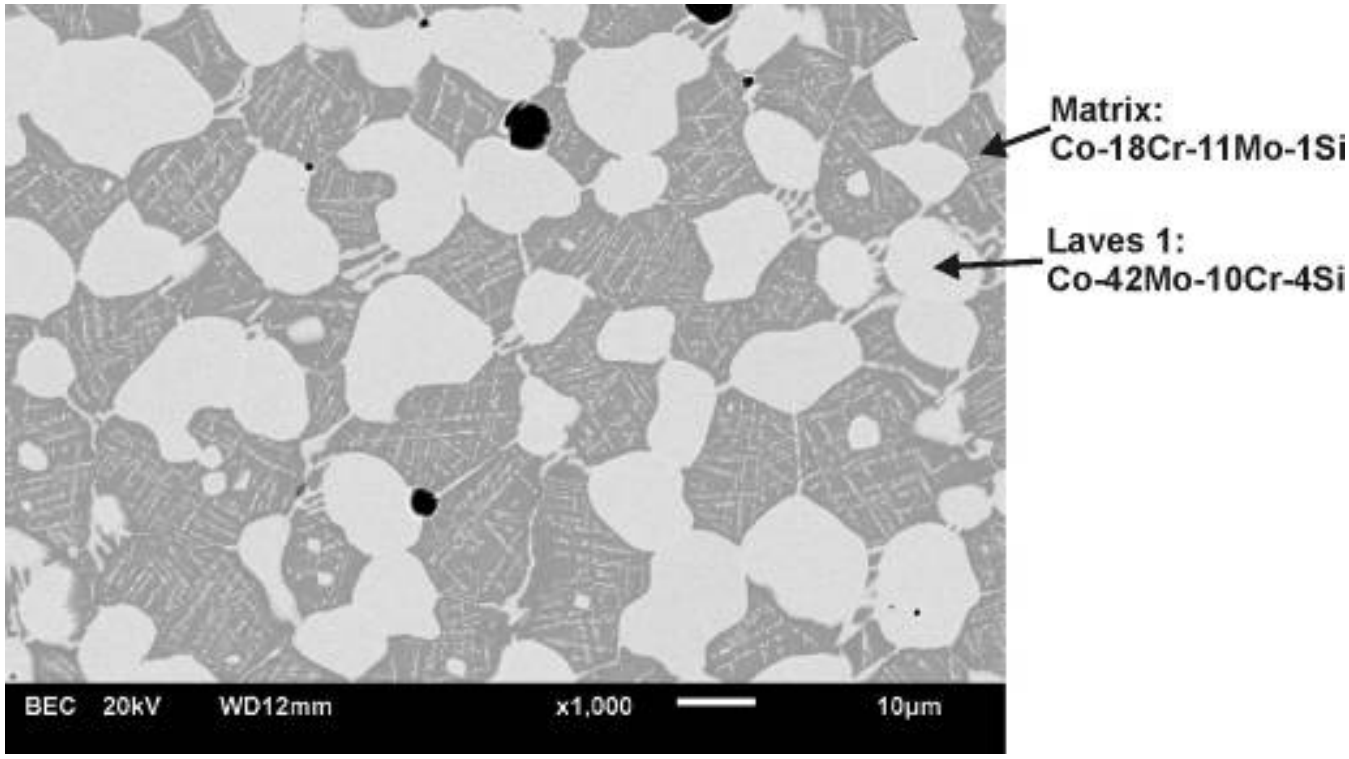

Figure 4-4: Higher-Magnification View of T-400C Coating Microstructure After 1000 hour Exposure at $760^{\circ} \mathrm{C}$. Unetched. 


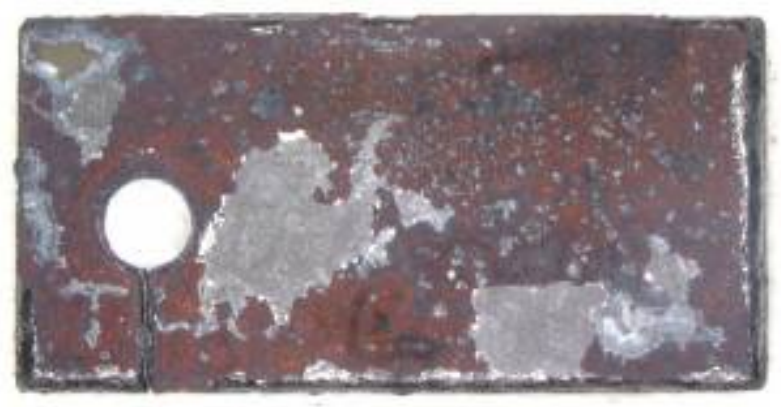

Overview of Exposed Substrate Surface

\section{T-400C Coating}

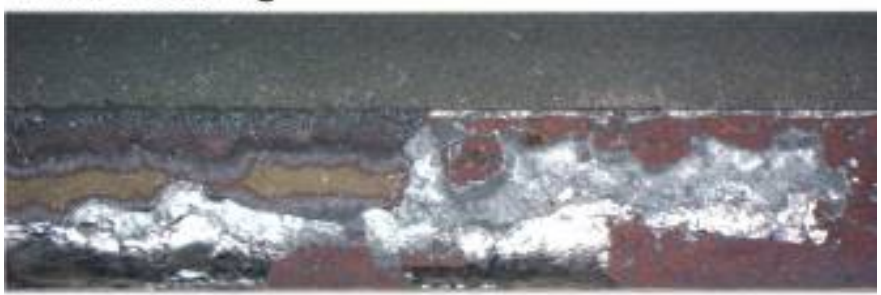

Type 304 SS Substrate

Close Side View of Exposed Coupon

Figure 4-5: Overviews of Exposed T-400C Coupon Showing Extensive Oxidation of the Type 304 SS Substrate and Substrate Oxide Spallation.

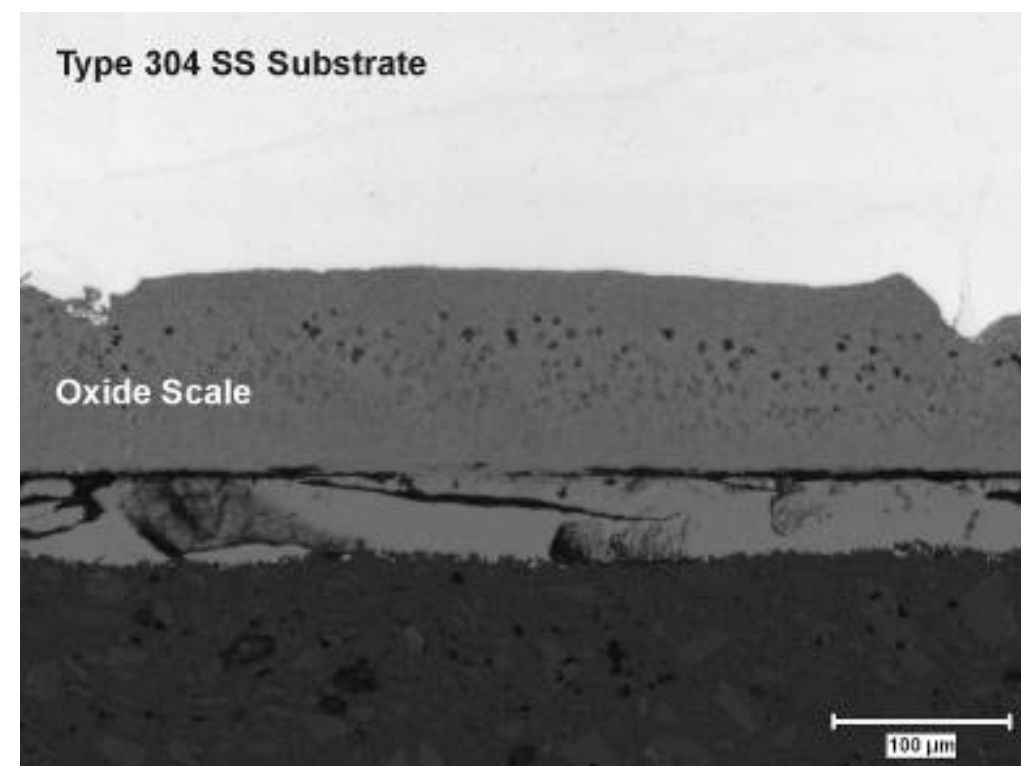

Figure 4-6: Thick Oxide on Type 304 SS Substrate After 1000 hour Exposure at $760^{\circ} \mathrm{C}$. 

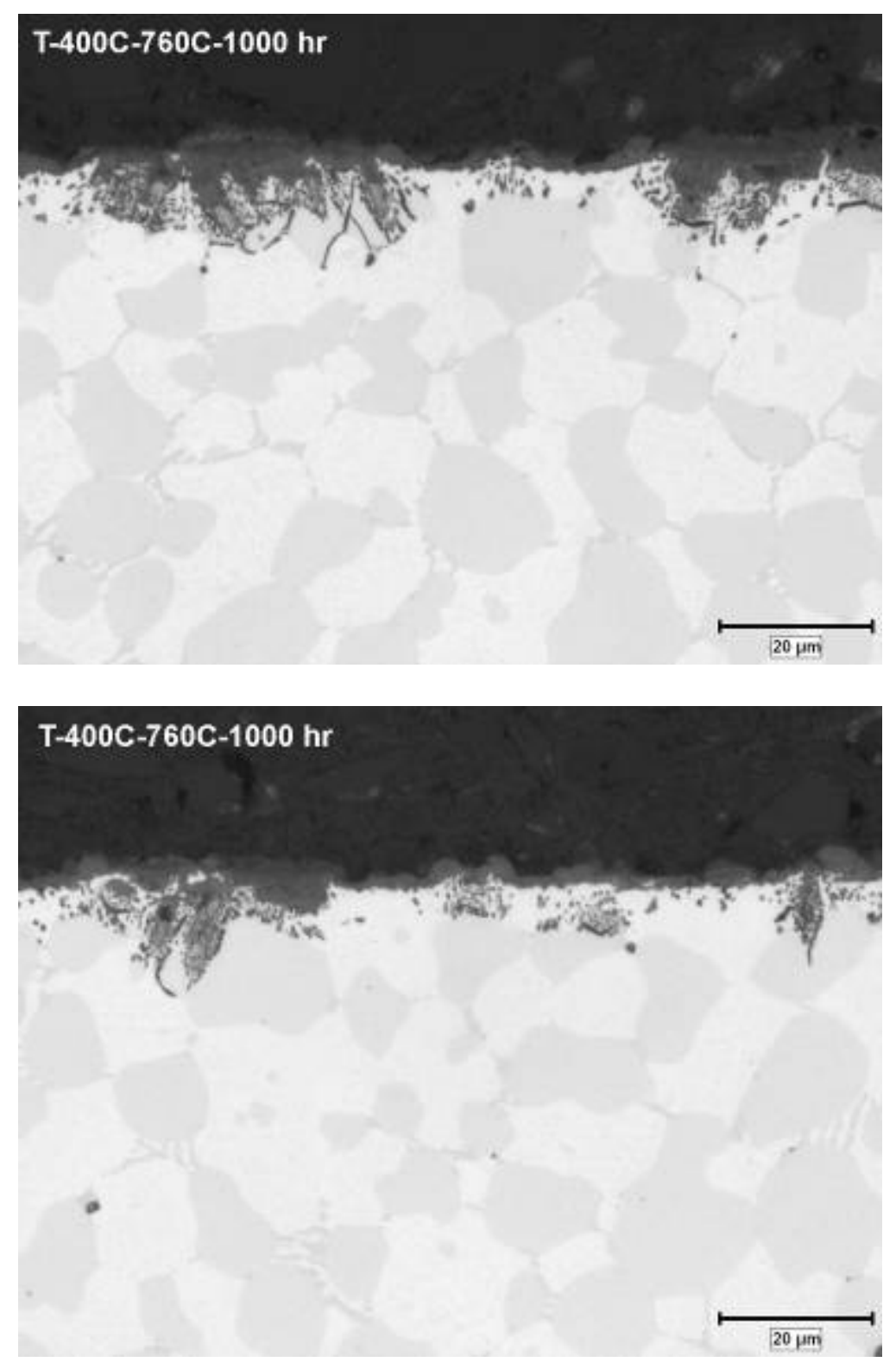

Figure 4-7: Typical Oxidized T-400C Coating Surface After 1000 hour Exposure at $760^{\circ} \mathrm{C}$. Unetched. 


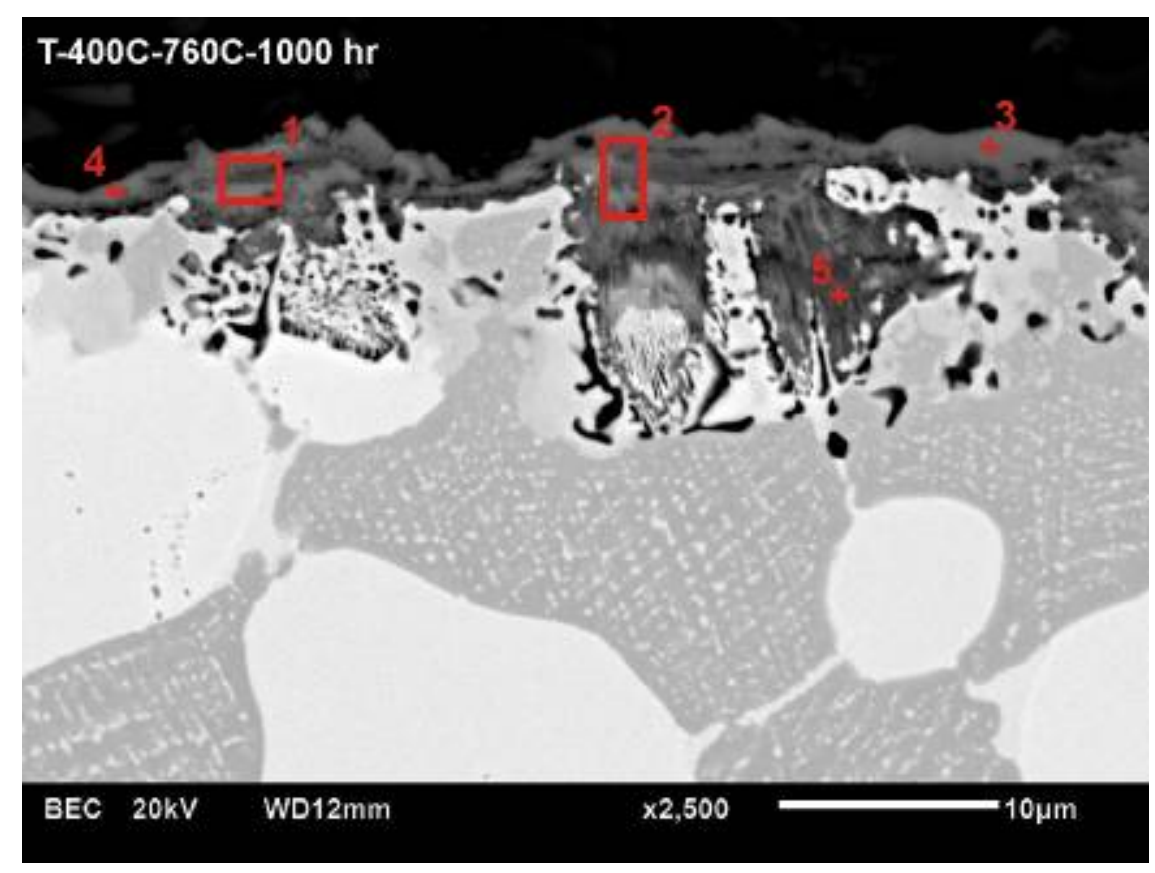

\begin{tabular}{ccccccccc}
\hline & \multicolumn{7}{c}{ Composition (wt.\%) } \\
\cline { 2 - 9 } Location & O-K & Al-K & Si-K & Ca-K & Cr-K & Fe-K & Co-K & Mo-L \\
\hline 1 & 27.3 & 1.9 & 10.5 & 0.8 & 22.6 & 0.7 & 33.6 & 2.8 \\
2 & 25.9 & 0.4 & 7.8 & & 29.3 & 0.3 & 29.6 & 6.9 \\
3 & 26.6 & 6.2 & 4.8 & 3.1 & 40.6 & 0.3 & 18.5 & \\
4 & 15.4 & 13.5 & 6.5 & 4.7 & 35.2 & 4.9 & 18.8 & 0.8 \\
5 & 27.4 & 0.1 & 9.9 & & 45.8 & & 10.8 & 6.0 \\
\hline
\end{tabular}

Figure 4-8: Backscattered Electron Image of T-400C Coating Exposed at $760^{\circ} \mathrm{C}$ for 1000 hours. Results of EDS Analysis at Locations Indicated are Listed Below the Image. 

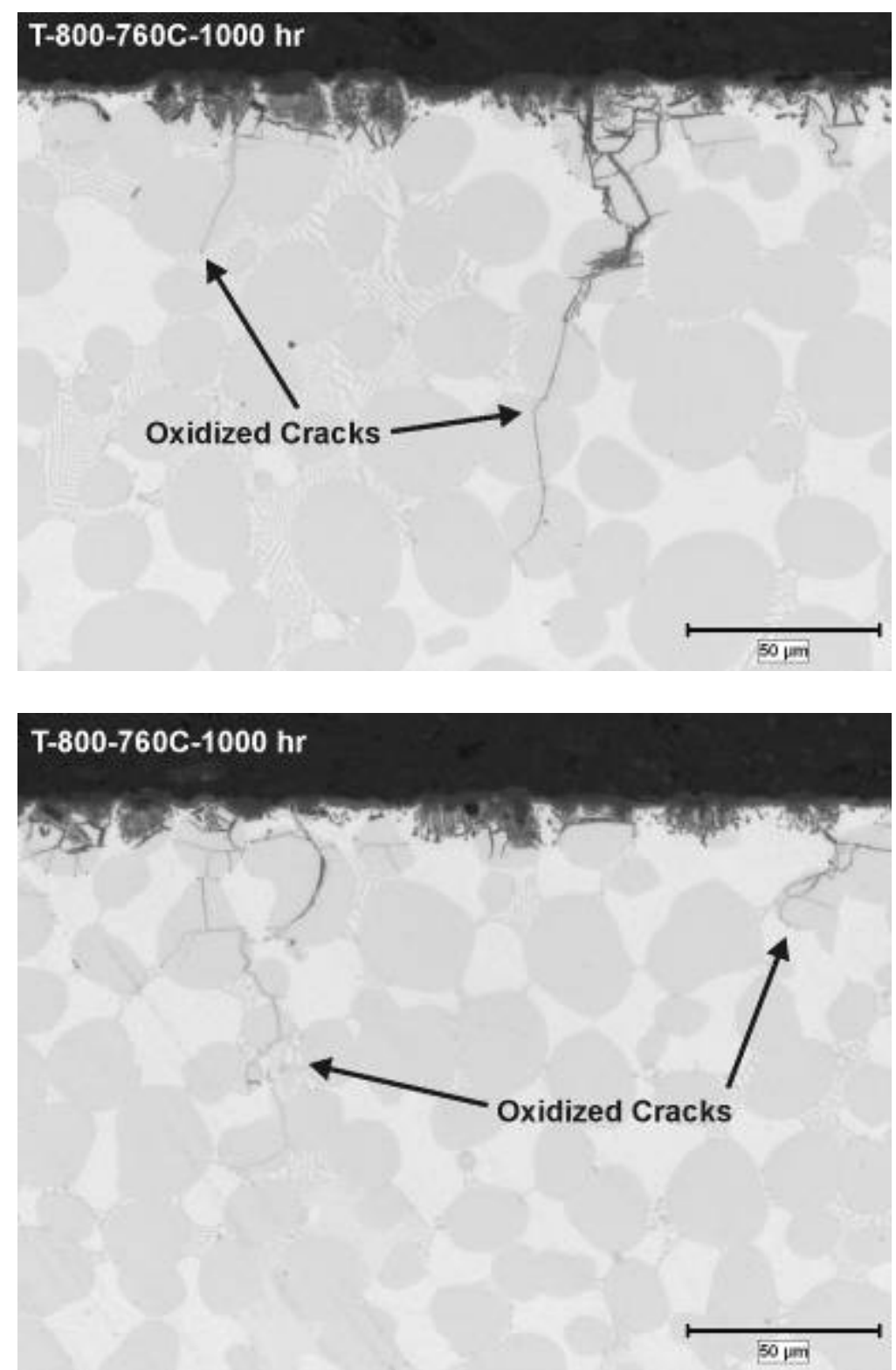

Figure 4-9: Typical Oxidized T-800 Coating Surface After 1000 hour Exposure at $760^{\circ} \mathrm{C}$. Unetched. 


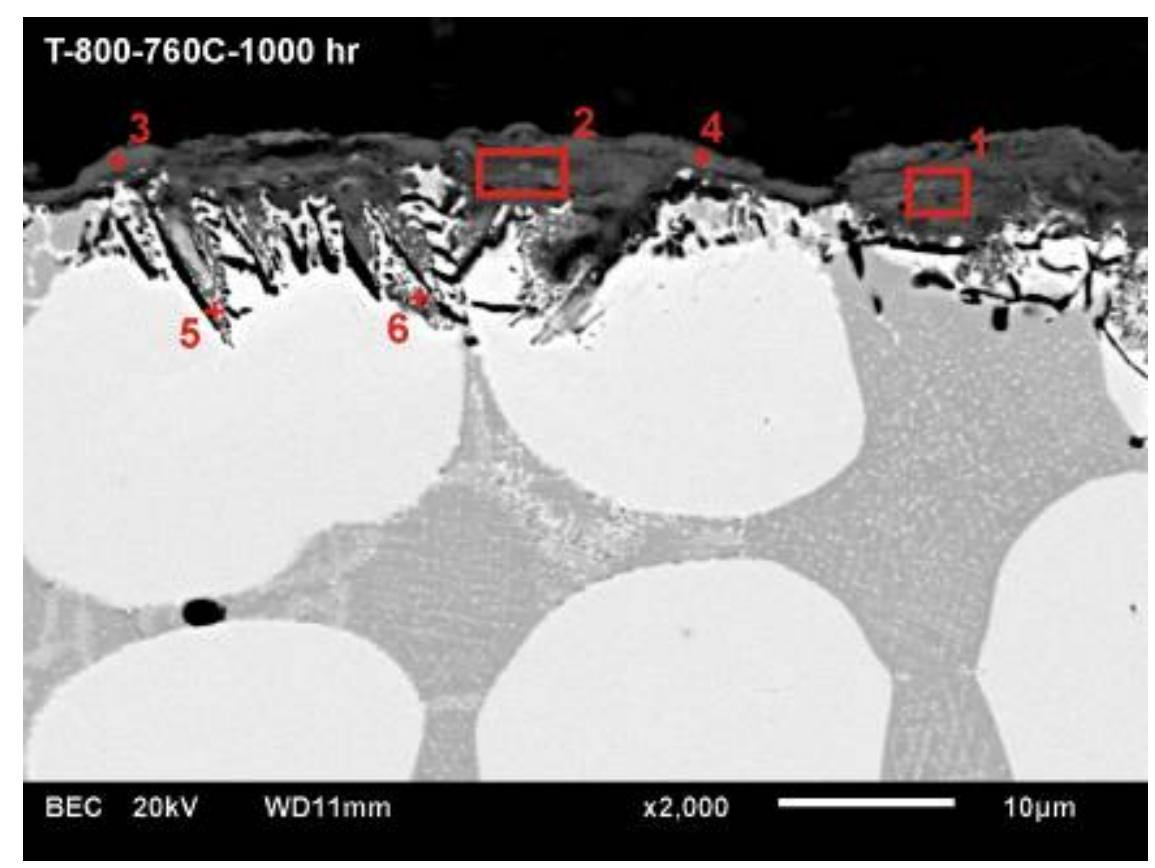

\begin{tabular}{ccccccccc}
\hline & \multicolumn{7}{c}{ Composition (wt.\%) } \\
\cline { 2 - 9 } Location & O-K & Al-K & Si-K & Ca-K & Cr-K & Fe-K & Co-K & Mo-L \\
\hline 1 & 27.7 & 0.3 & 7.7 & 0.5 & 36.1 & 0.5 & 20.0 & 7.1 \\
2 & 28.2 & 0.4 & 9.8 & 0.3 & 29.4 & 0.8 & 26.9 & 4.4 \\
3 & 21.1 & 13.0 & 4.2 & 1.9 & 39.8 & 0.7 & 19.3 & \\
4 & 26.1 & 2.6 & 10.0 & 0.8 & 14.6 & 1.7 & 43.1 & 1.1 \\
5 & 19.9 & & 12.7 & & 6.3 & 0.8 & 29.3 & 31.1 \\
6 & 15.5 & & 11.4 & & 4.8 & 0.7 & 30.2 & 37.4 \\
\hline
\end{tabular}

Figure 4-10: Backscattered Electron Image of T-800 Coating Exposed at $760^{\circ} \mathrm{C}$ for 1000 hours. Results of EDS Analysis at Locations Indicated are Listed Below the Image. 

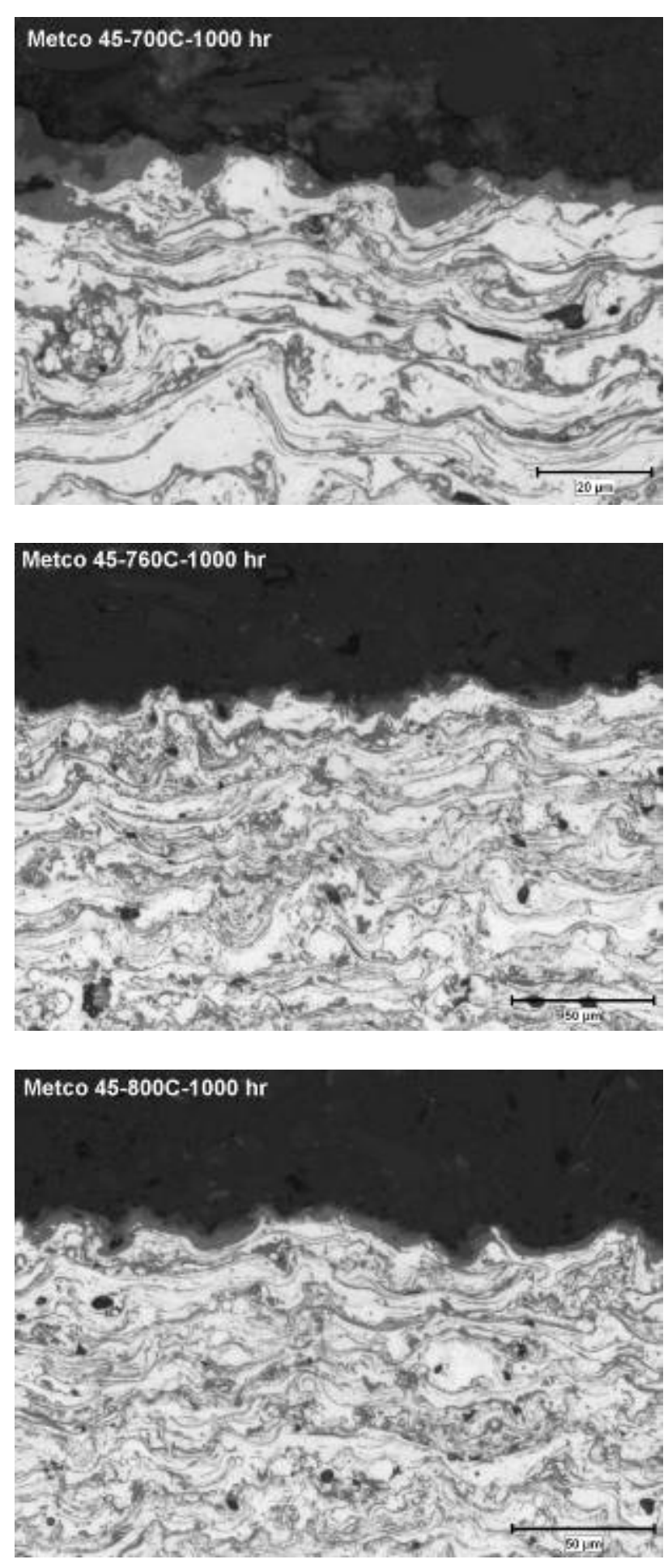

Figure 4-11: Typical Oxidized Surface of Metco 45 Coating after 1000 hours Exposure at 700,760 , and $800^{\circ} \mathrm{C}$. Unetched. Note that top image is at higher magnification than lower images. 

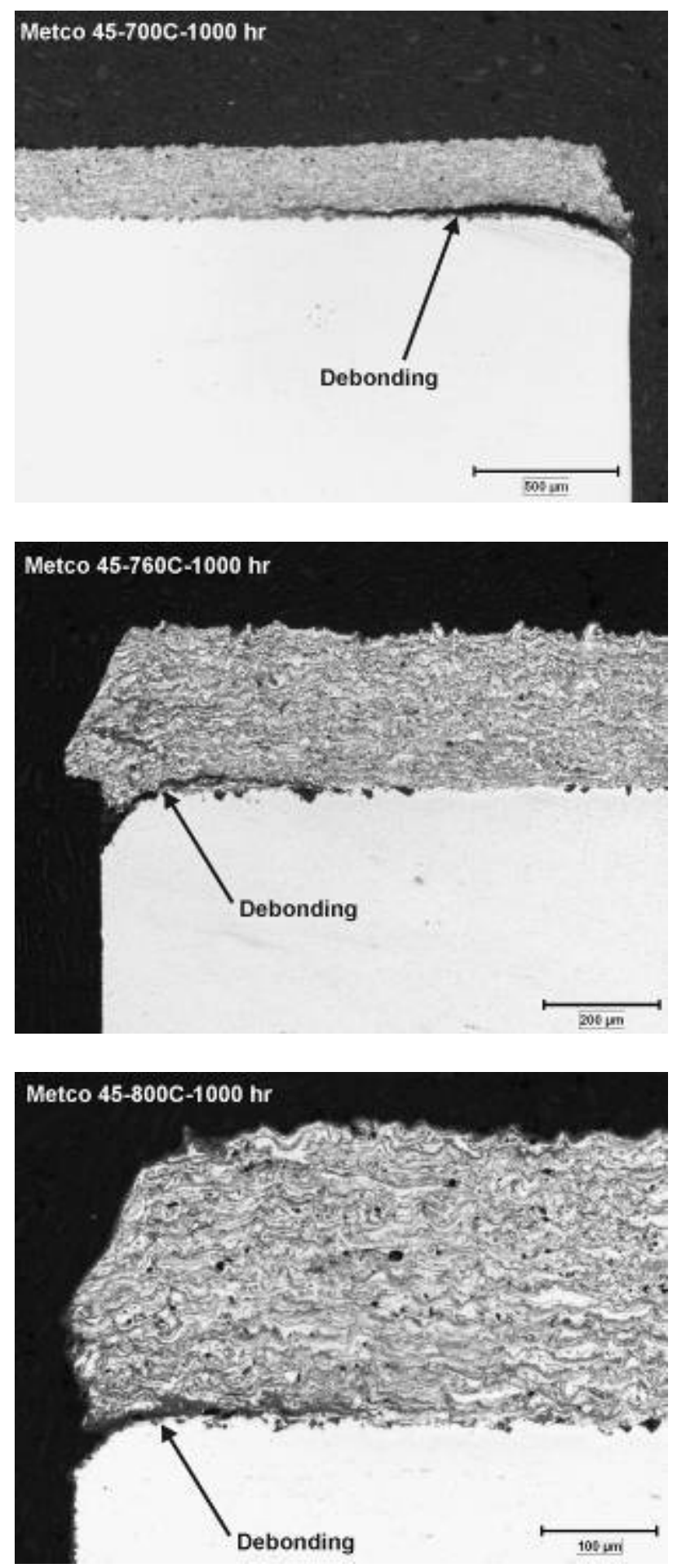

Figure 4-12: Coating Debonding Observed at Corners of Coupons Exposed at 700, 760, and $800^{\circ} \mathrm{C}$. Unetched. 


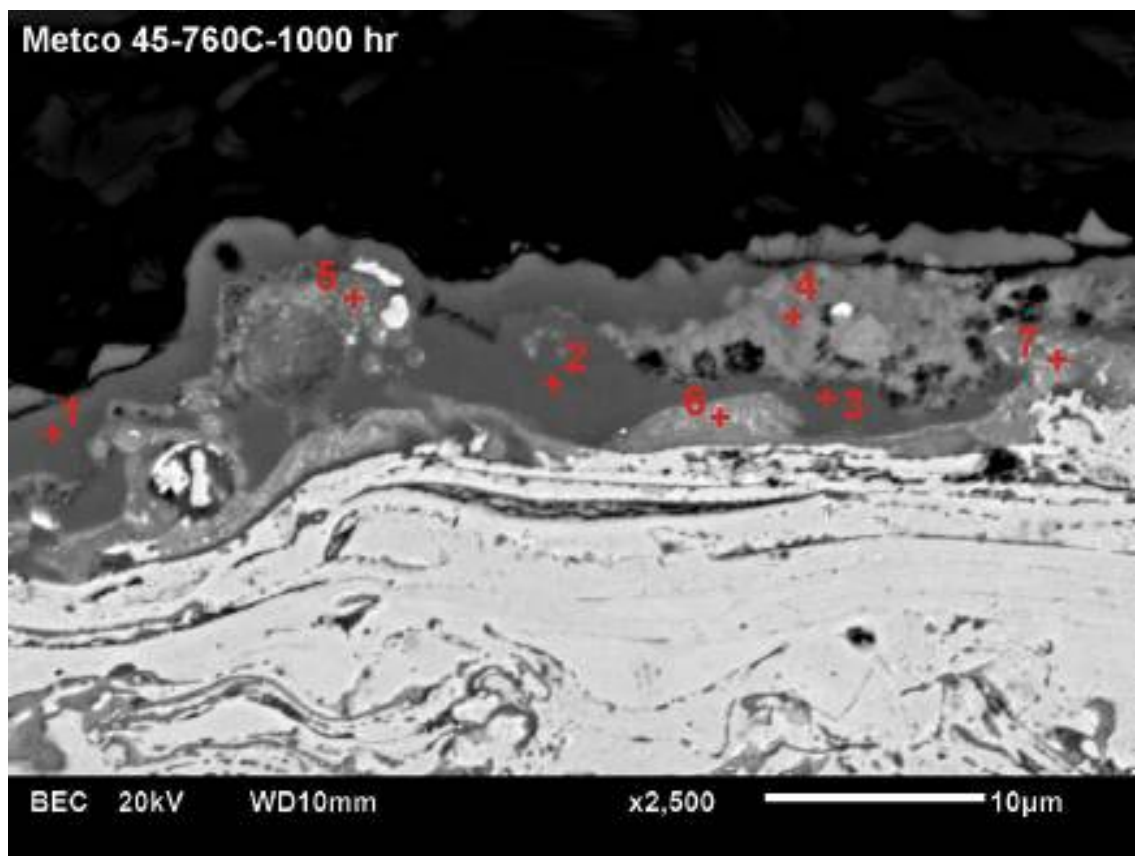

\begin{tabular}{ccccccccccc}
\hline & \multicolumn{10}{c}{ Composition (wt.\%) } \\
\cline { 2 - 10 } Location & O-K & Al-K & Si-K & Ca-K & Cr-K & Fe-K & Co-K & Ni-K & Mo-L & W-L \\
\hline 1 & 27.4 & 1.3 & 15.5 & 1.0 & 1.3 & & 48.4 & 4.8 & 0.3 & \\
2 & 29.6 & & & & 66.7 & & 1.1 & & & 2.6 \\
3 & 19.7 & & 0.7 & & 16.5 & 1.4 & 49.3 & 12.4 & & \\
4 & 23.7 & 0.1 & 2.4 & 0.2 & 6.0 & 1.2 & 59.4 & 7.1 & \\
5 & 26.2 & 0.2 & 2.1 & & 55.4 & 0.2 & 9.8 & 1.5 & 2.7 \\
6 & 30.7 & & & & 61.3 & & 4.6 & 0.7 & \\
7 & 24.4 & & 1.0 & & 26.8 & 1.8 & 42.8 & 3.3 & & \\
\hline
\end{tabular}

Figure 4-13: Backscattered Electron Image of Metco 45 Coating Exposed at $760^{\circ} \mathrm{C}$ for 1000 hours. Results of EDS Analysis at Locations Indicated are Listed Below the Image. 


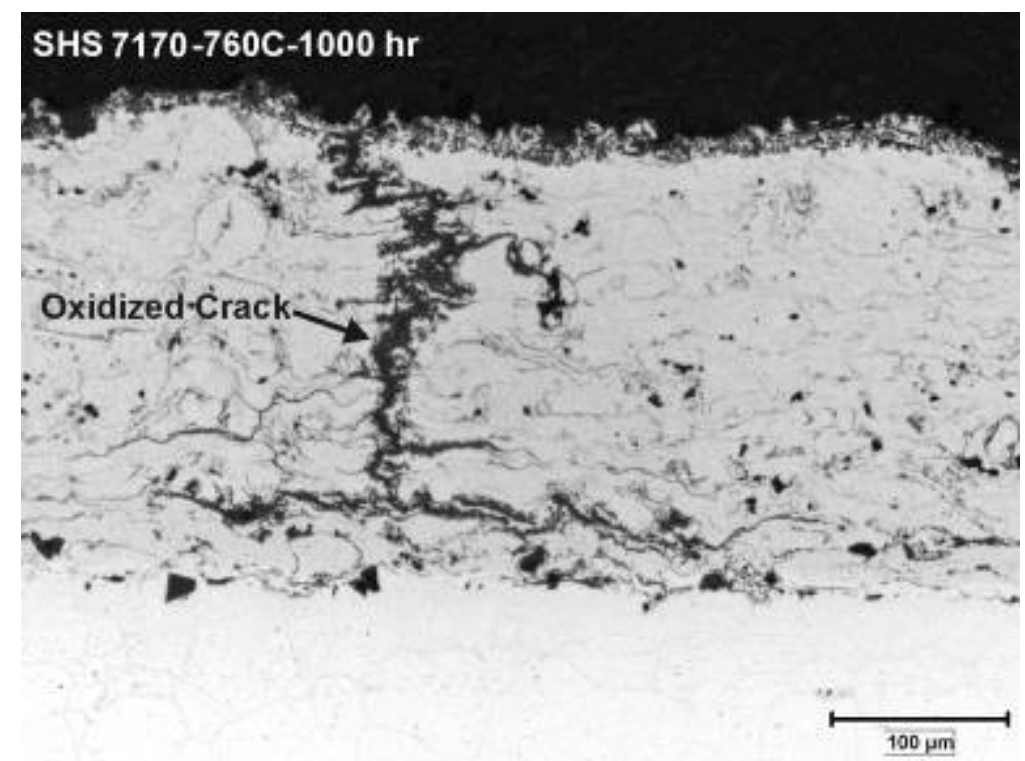

Figure 4-14: SHS 7170 Coating After 1000 hour Exposure at $760^{\circ} \mathrm{C}$, Showing an Oxidized Through-Coating Crack. Unetched.

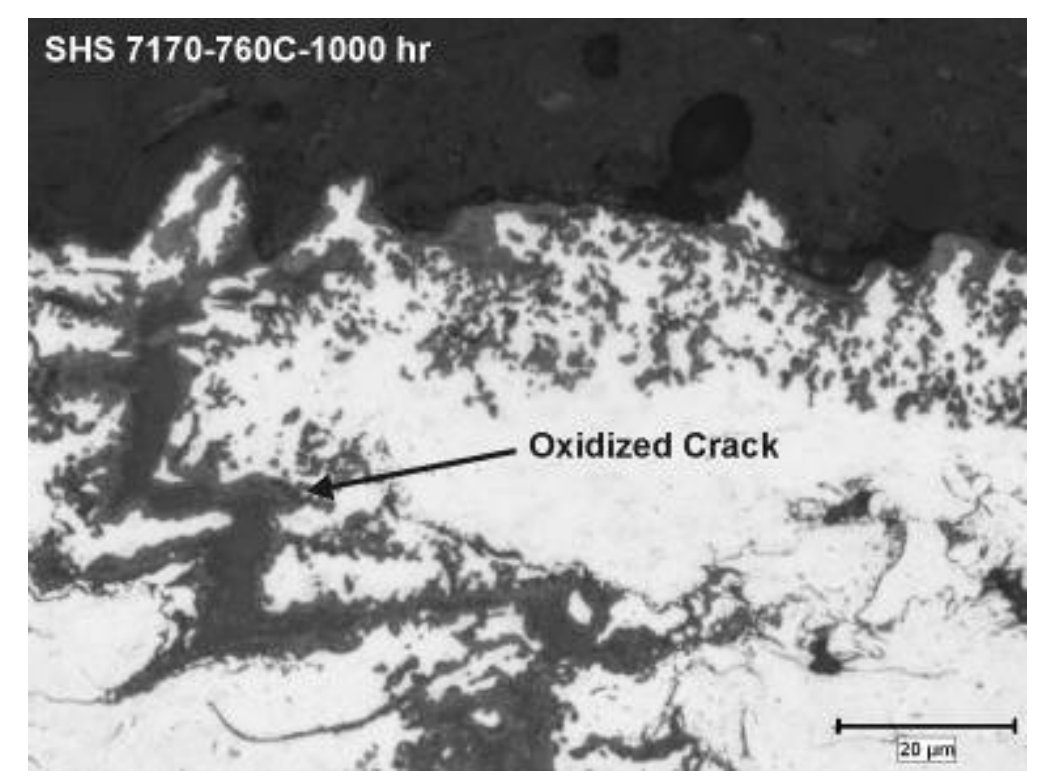

Figure 4-15: Typical Oxidized Surface of SHS 7170 Coating after 1000 hours Exposure at $760^{\circ} \mathrm{C}$. Unetched. 


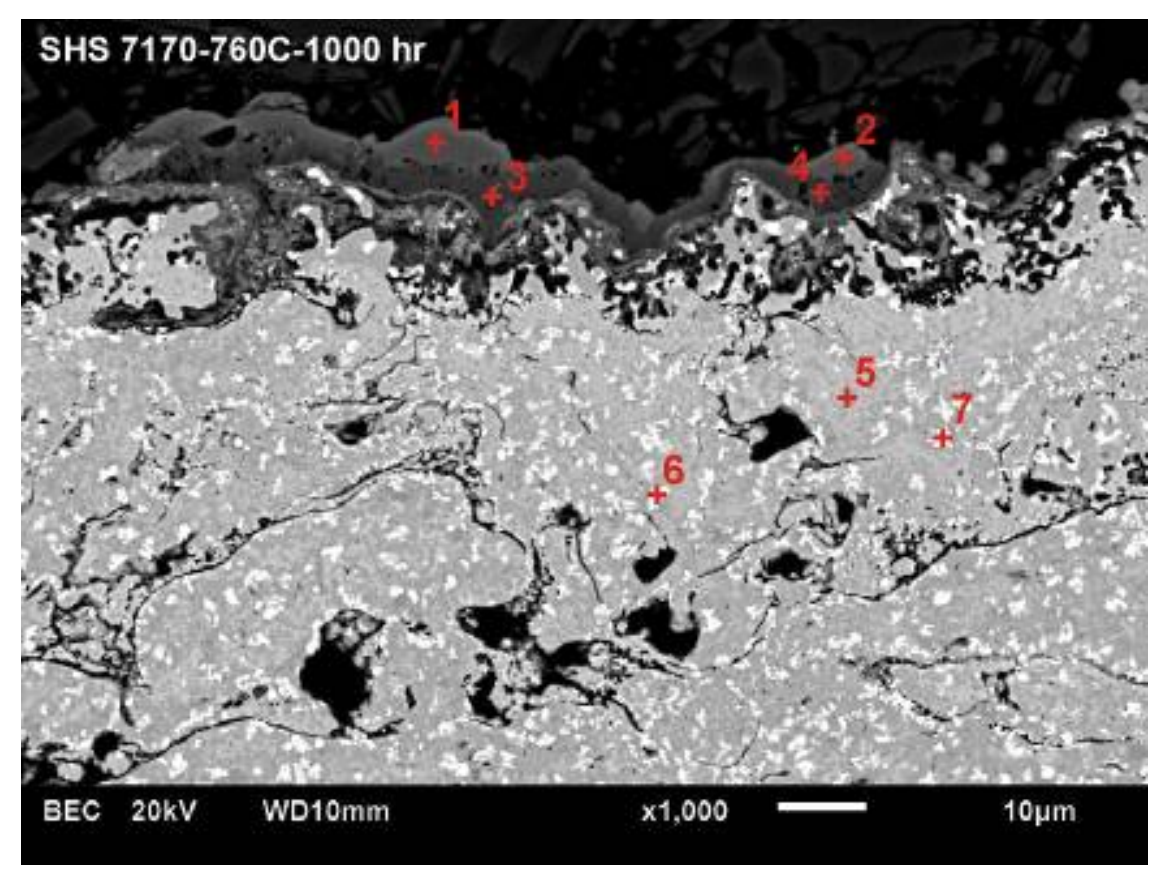

\begin{tabular}{cccccccccc}
\hline & \multicolumn{7}{c}{ Composition (wt.\%) } \\
\cline { 2 - 9 } Location & O-K & Al-K & Si-K & Ca-K & Cr-K & Mn-K & Fe-K & Mo-L & W-L \\
\hline 1 & 26.9 & 0.1 & 14.6 & 0.3 & 0.2 & 57.9 & & & \\
2 & 28.0 & 0.1 & 15.2 & 0.3 & 0.5 & 56.0 & & & \\
3 & 31.6 & & 20.8 & 0.2 & 4.5 & 43.0 & & & \\
4 & 28.3 & & 14.4 & & 21.7 & 28.5 & 6.3 & 0.8 & \\
5 & & & & & 22.6 & & 68.7 & 3.2 & 5.5 \\
6 & & & & & 24.7 & & 69.5 & 2.9 & 2.9 \\
7 & & & & & 22.4 & 1.2 & 68.4 & 4.1 & 4.0 \\
\hline
\end{tabular}

Figure 4-16: Backscattered Electron Image of SHS 7170 Coating Exposed at $760^{\circ} \mathrm{C}$ for 1000 hours. Results of EDS Analysis at Locations Indicated are Listed Below the Image. 


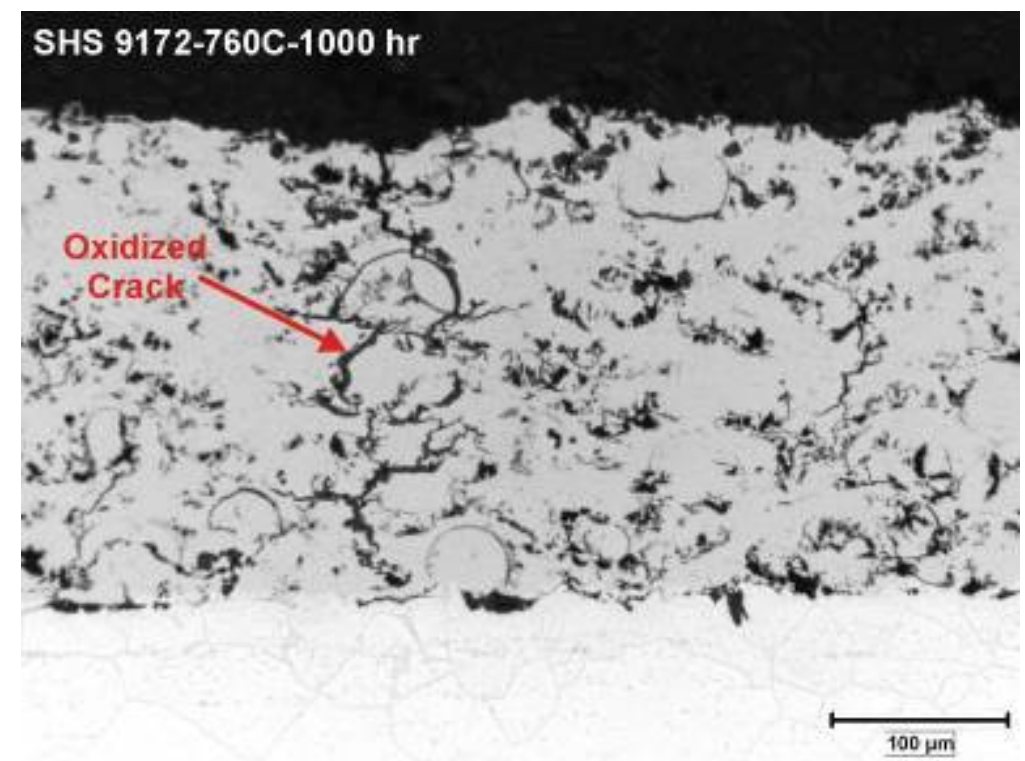

Figure 4-17: SHS 9172 Coating After 1000 hour Exposure at $760^{\circ} \mathrm{C}$, Showing an Oxidized Through-Coating Crack. Unetched.

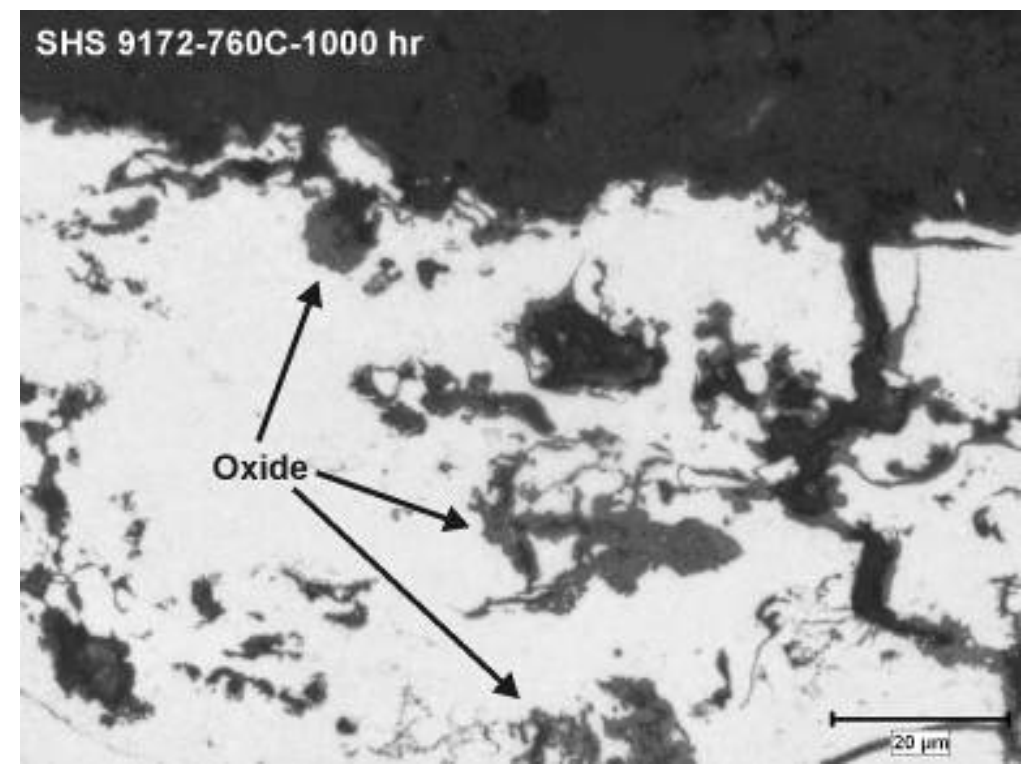

Figure 4-18: Typical Oxidized Surface of SHS 9172 Coating after 1000 hours Exposure at $760^{\circ} \mathrm{C}$. Unetched. 


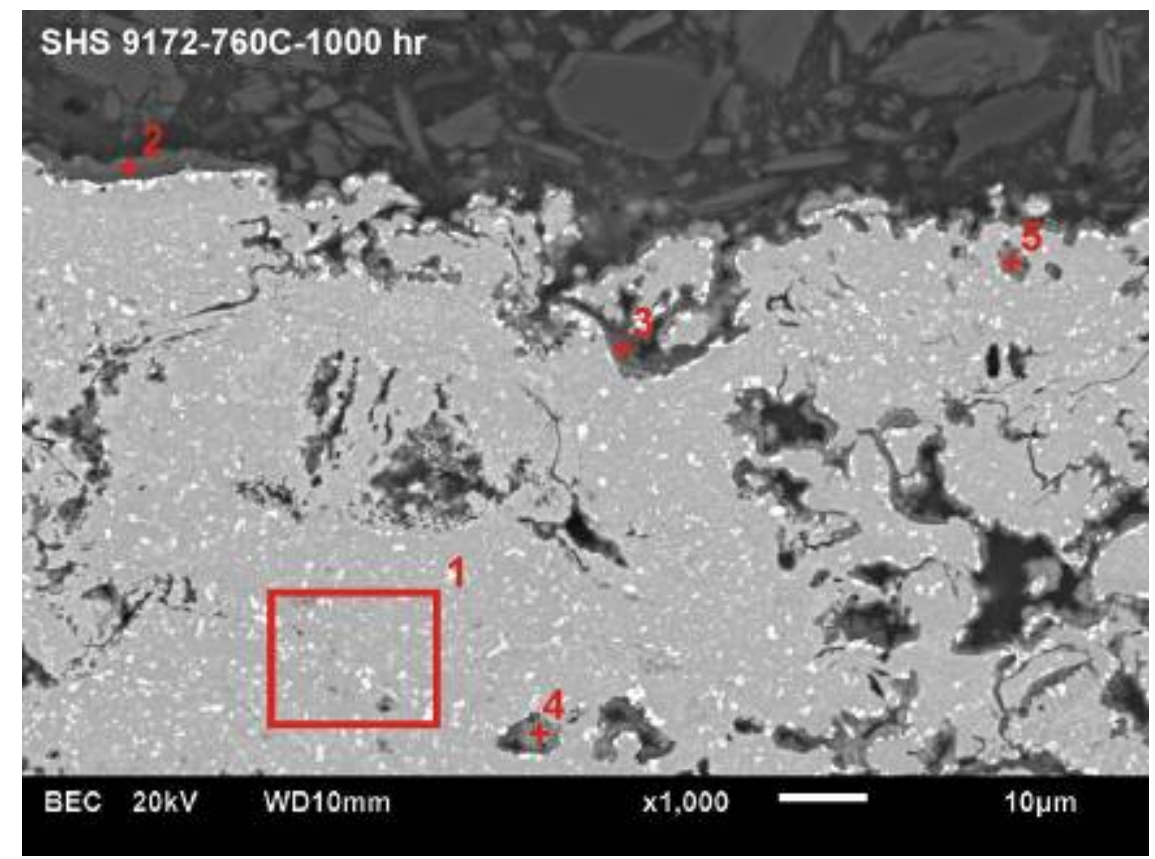

\begin{tabular}{ccccccccc}
\hline & \multicolumn{7}{c}{ Composition (wt.\%) } \\
\cline { 2 - 9 } Location & O-K & Al-K & Si-K & Cr-K & Mn-K & Fe-K & Nb-L & W-L \\
\hline 1 & & 0.4 & 0.7 & 19.0 & & 65.6 & 6.4 & 7.9 \\
2 & 37.4 & 0.7 & 3.6 & 39.9 & 1.1 & 13.5 & & 3.9 \\
3 & 35.3 & 0.1 & 3.3 & 24.2 & 0.5 & 24.1 & 3.5 & 9.0 \\
4 & 33.5 & 1.1 & 7.3 & 28.8 & 5.8 & 11.4 & 4.4 & 7.6 \\
5 & 12.5 & 0.9 & & 21.1 & 1.1 & 47.0 & & 17.4 \\
\hline
\end{tabular}

Figure 4-19: Backscattered Electron Image of SHS 9172 Coating Exposed at $760^{\circ} \mathrm{C}$ for 1000 hours. Results of EDS Analysis at Locations Indicated are Listed Below the Image. 


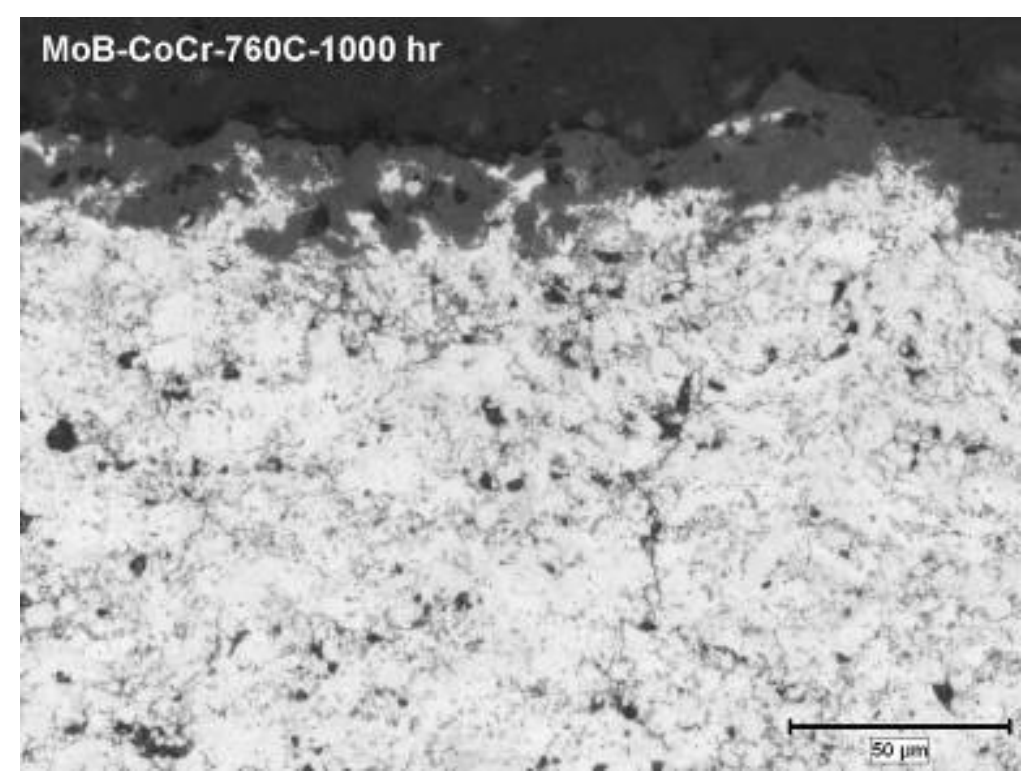

Figure 4-20: Typical Oxidized Surface of MoB-CoCr Coating after 1000 hours Exposure at $760^{\circ} \mathrm{C}$. Unetched.

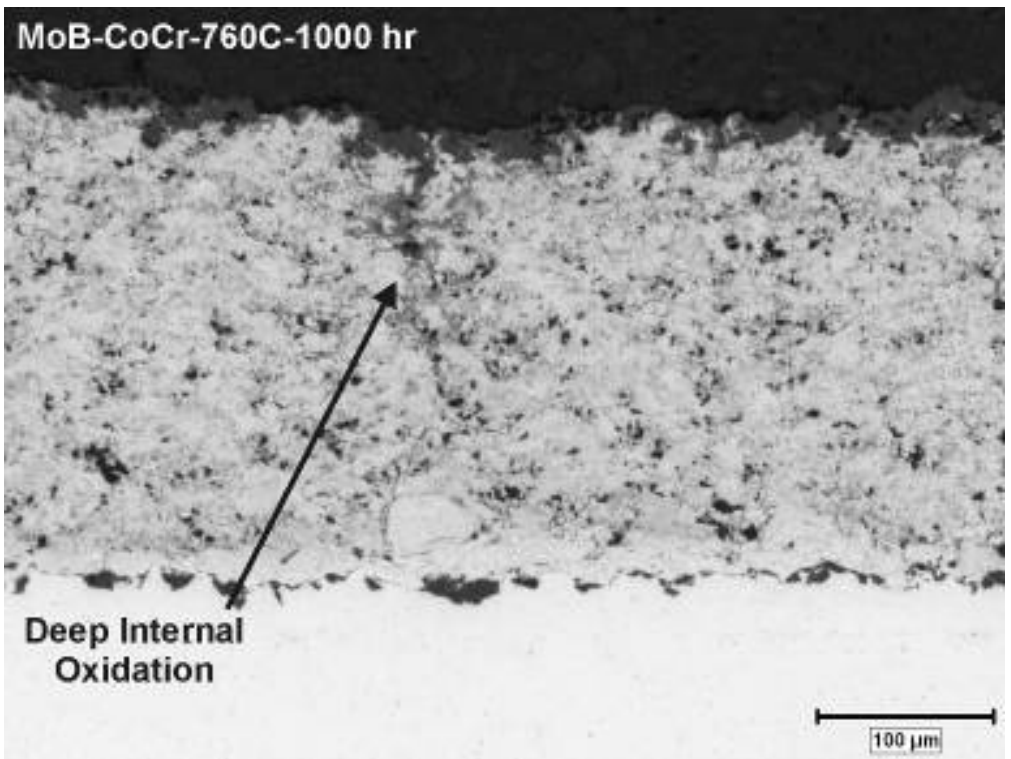

Figure 4-21: MoB-CoCr Coating After 1000 hour Exposure at $760^{\circ} \mathrm{C}$, Showing Deep Internal Oxidation. Unetched. 


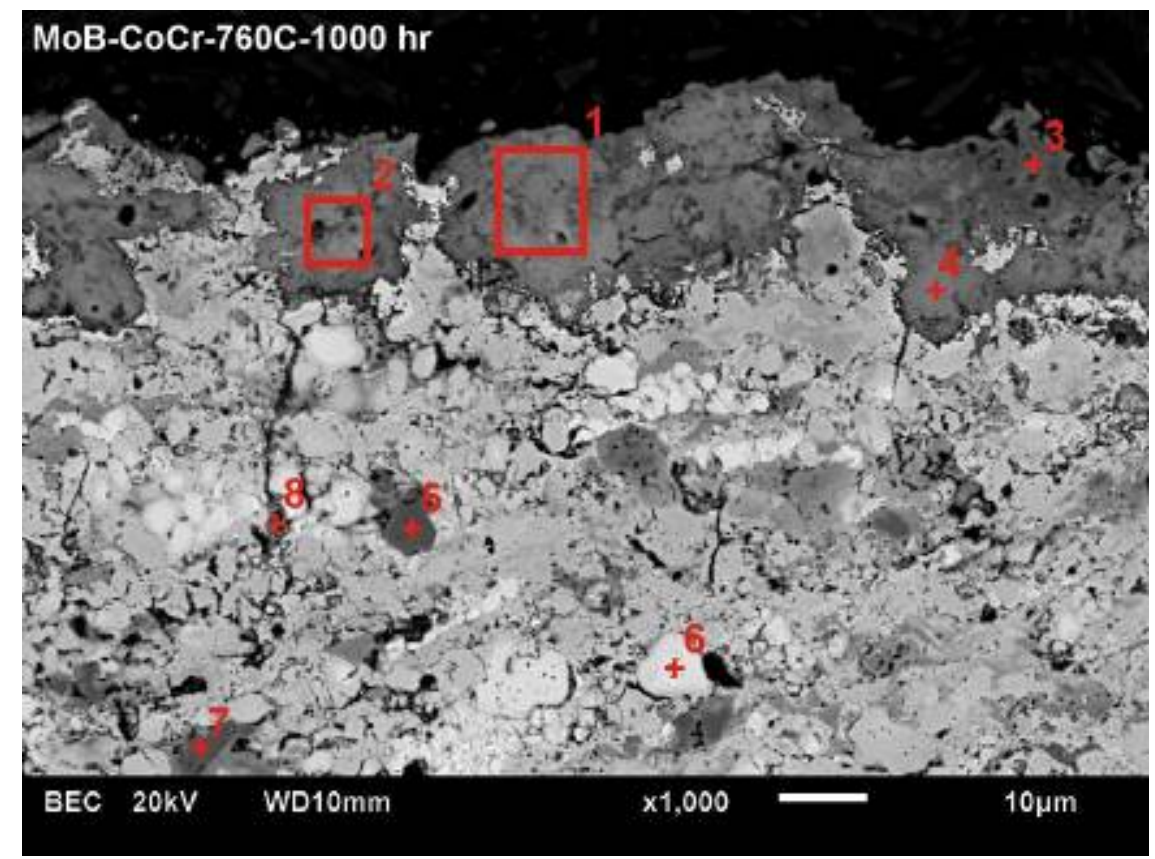

\begin{tabular}{ccccccccc}
\hline & \multicolumn{7}{c}{ Composition (wt.\%) } \\
\cline { 2 - 9 } Location & O-K & Al-K & Si-K & Cr-K & Fe-K & Co-K & Mo-L & W-L \\
\hline 1 & 25.8 & 0.1 & 1.1 & 17.9 & 0.3 & 29.1 & 25.6 & \\
2 & 23.8 & & 0.4 & 22.1 & 0.3 & 28.5 & 23.1 & 1.8 \\
3 & 24.7 & 0.1 & 6.5 & 21.7 & 0.3 & 43.0 & 3.6 & \\
4 & 24.2 & & 1.1 & 24.2 & & 29.2 & 21.3 & \\
5 & & & 0.1 & 92.8 & & 4.7 & 2.4 & \\
6 & & & & 0.4 & & 0.8 & 98.8 & \\
7 & & & 0.4 & 94.2 & & 3.5 & 1.9 & \\
8 & 12.2 & 0.1 & & 19.1 & 0.5 & 49.5 & 15.0 & 3.7 \\
\hline
\end{tabular}

Figure 4-22: Backscattered Electron Image of MoB-CoCr Coating Exposed at $760^{\circ} \mathrm{C}$ for 1000 hours. Results of EDS Analysis at Locations Indicated are Listed Below the Image. 

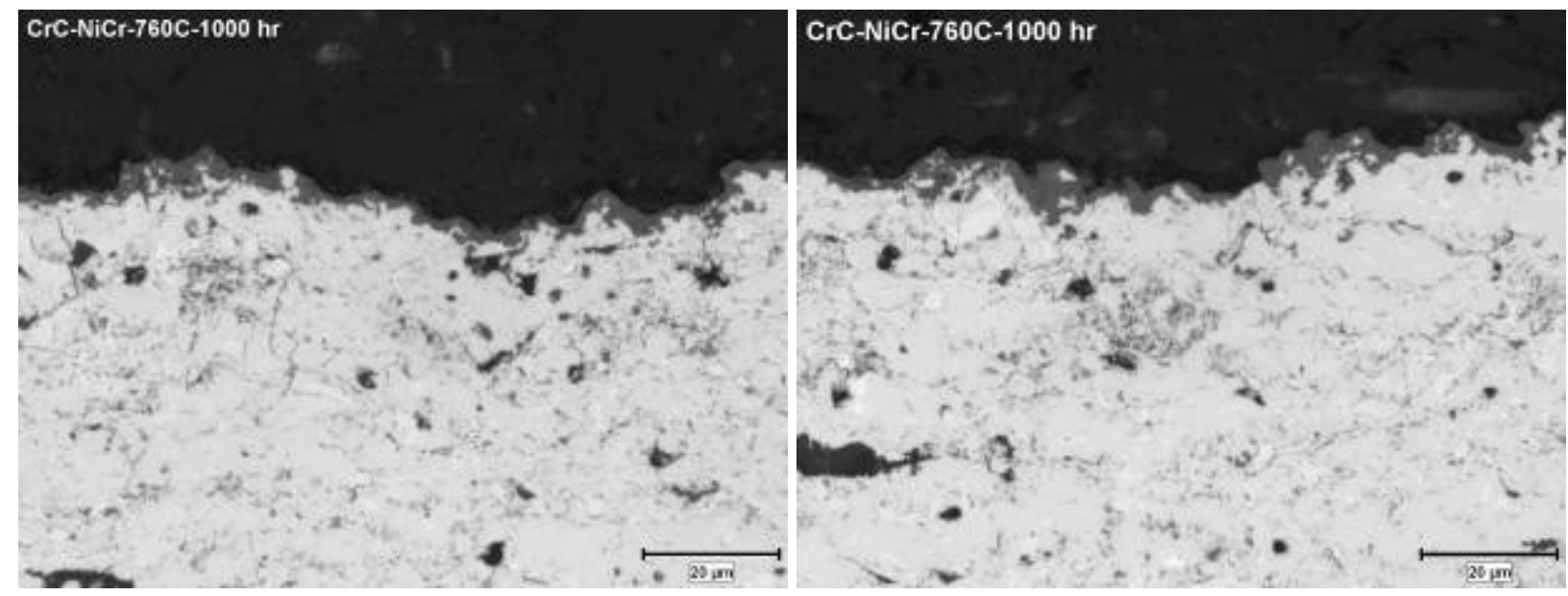

Figure 4-23: Typical Oxidized Surface of $\mathrm{CrC}-\mathrm{NiCr}$ Coating after 1000 hours Exposure at $760^{\circ} \mathrm{C}$. Unetched.
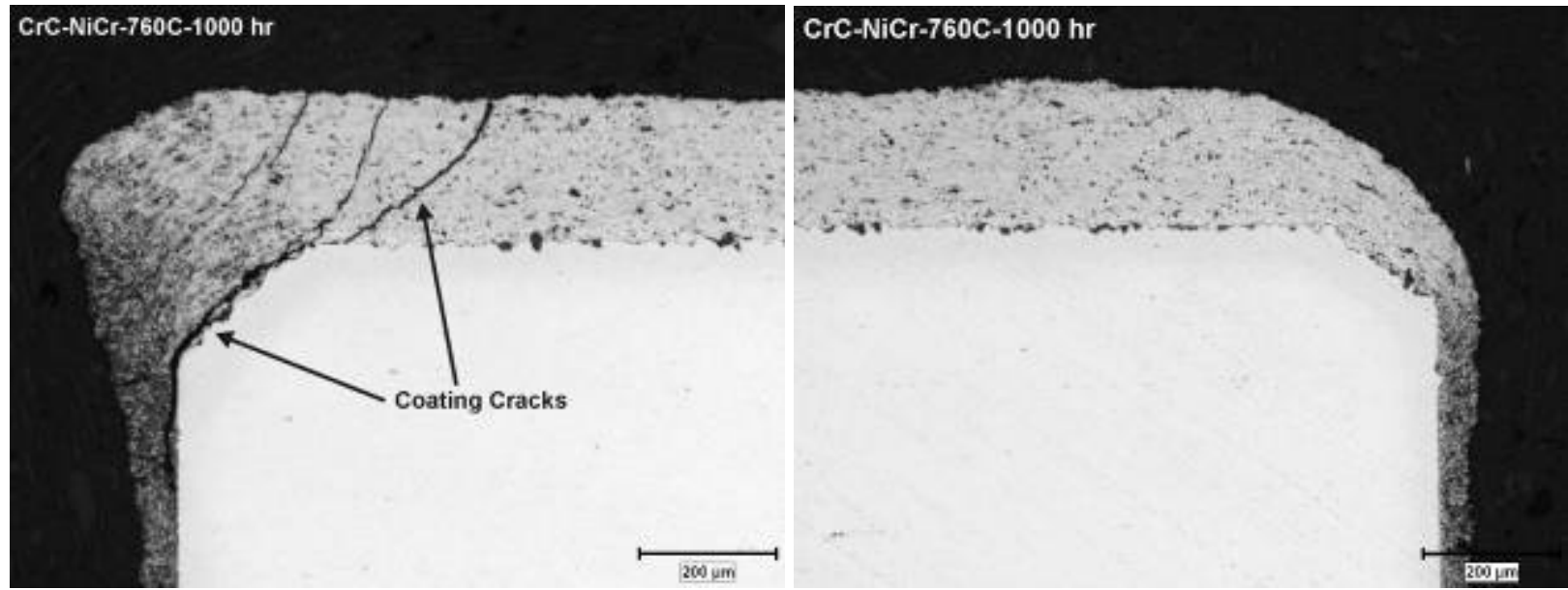

Figure 4-24: Cracking Observed in Corner of $\mathrm{CrC}-\mathrm{NiCr}$ Coating After Exposure at $760^{\circ} \mathrm{C}$ for 1000 hr. Cracking was Associated with Abnormal Coating Build-Up. Unetched. 


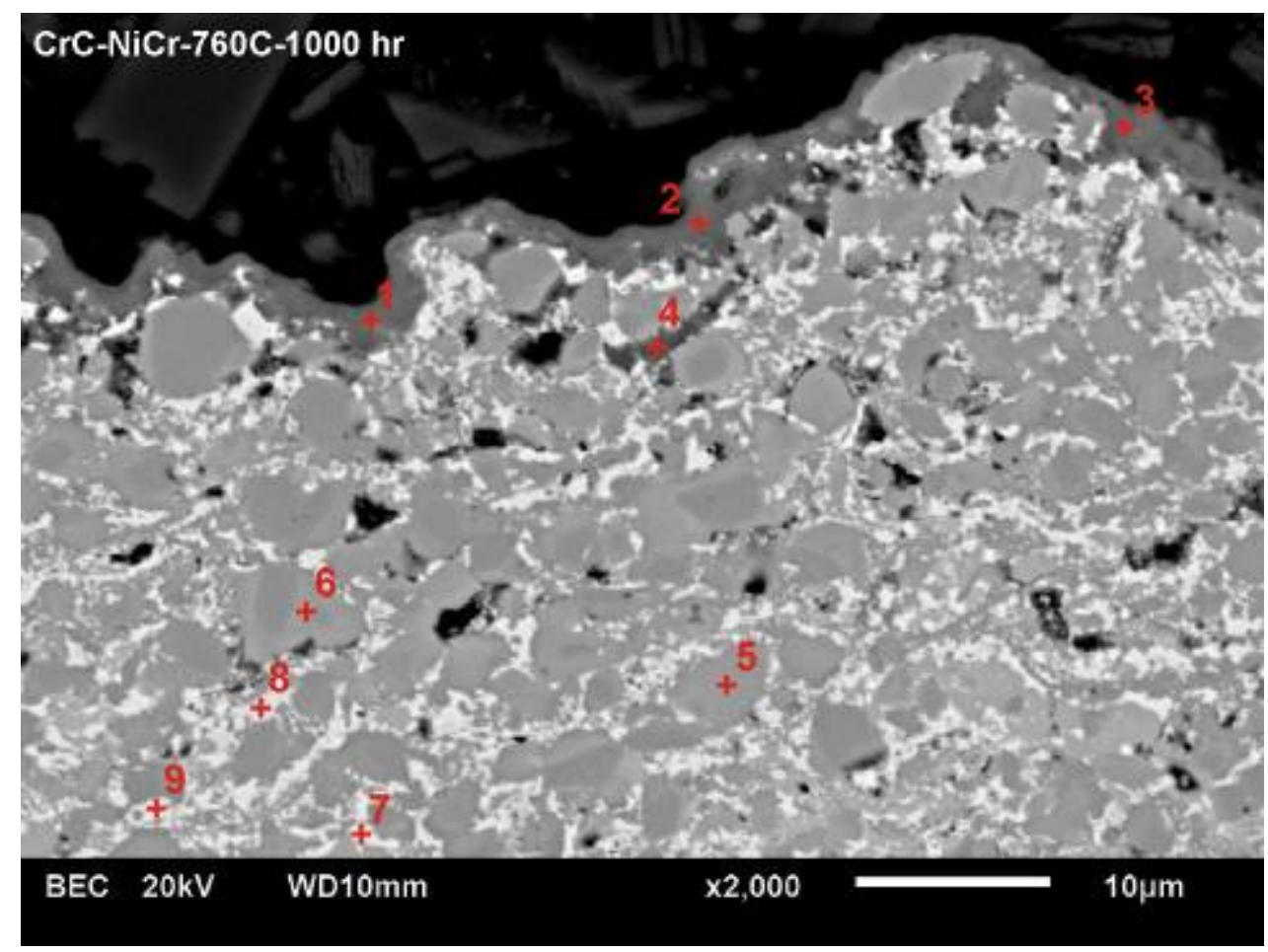

\begin{tabular}{cccccccccc}
\hline & \multicolumn{7}{c}{ Composition (wt.\%) } \\
\cline { 2 - 9 } Location & O-K & Al-K & Si-K & Ca-K & Cr-K & Fe-K & Ni-K & Mo-L & W-L \\
\hline 1 & 25.5 & & 3.7 & & 63.2 & & 7.7 & & \\
2 & 22.5 & 0.1 & 3.4 & & 70.2 & 3.6 & 0.3 & \\
3 & 17.9 & 4.7 & 5.4 & 1.7 & 66.0 & 4.2 & & \\
4 & 18.2 & & 3.1 & & 71.2 & 7.1 & 0.5 & \\
5 & & & & & 92.8 & & 4.2 & & 3.0 \\
6 & & & & 95.5 & & 1.5 & & 3.0 \\
7 & 0.9 & & 0.9 & 56.3 & 0.3 & 41.6 & & \\
8 & & & 0.8 & 49.9 & 0.5 & 48.8 & & \\
9 & & & 0.7 & 76.0 & & 23.4 & & \\
\hline
\end{tabular}

Figure 4-25: Backscattered Electron Image of CrC-NiCr Coating Exposed at $760^{\circ} \mathrm{C}$ for 1000 hours. Results of EDS Analysis at Locations Indicated are Listed Below the Image. 


\section{$5 \quad$ Conclusions}

The significant findings in this research were:

1. All candidate nickel-base USC alloys showed low rates of oxidation in long-term testing at 700,760 , and $800^{\circ} \mathrm{C}$ and no evidence of spallation. Predicted total metal loss (scale formation plus internal oxidation) after 100,000 hour exposures were less than $150 \mu \mathrm{m}$ at $760^{\circ} \mathrm{C}$ for all alloys.

2. Substrate alloys which showed the best steam oxidation resistance were Udiment $720 \mathrm{LI}$, Waspaloy, and Inconel 740.

3. Thin, Cr-rich external oxide scales were found on all substrate alloys. The predicted external scale thicknesses after 100,000 hours exposure were less than $25 \mu \mathrm{m}$ at $760^{\circ} \mathrm{C}$. No spallation of external scales was observed.

4. Weight loss and porosity associated with internal oxidation were observed in some alloys at $760^{\circ} \mathrm{C}$ and in most alloys at $800^{\circ} \mathrm{C}$. It is unclear whether the weight loss resulted from chromia evaporation, $\mathrm{MoO} 3$ evaporation, or both. More research is needed to clarify this observation.

5. Short-term, 1000 hour, steam oxidation screening tests were useful in eliminating erosion resistant coatings which did not provide oxidation protection.

6. Candidate SPE-resistant coatings which showed the best steam oxidation resistance were Stellite 6B, Tribaloy T-400C, Metco 45, and CrC-NiCr. For these coatings the extent of oxidation after 1000 hour exposure was comparable to that of the substrate alloys.

7. The SHS 7170, SHS 9172, and MoB-CoCr coatings suffered from extensive internal oxidation or oxidation along coating cracks, and are not considered suitable for application in an USC steam turbine environment.

In summary, the steam oxidation resistance of nickel-based alloys is acceptable for A-USC steam turbine conditions up to $760^{\circ} \mathrm{C}$. For applications which may require coatings for erosion resistance (such as blades), steam oxidation resistance of the coating must be considered as this research shows there exist some coatings which will afford a reasonable level of oxidation protection but other coatings will be seriously impacted by steam oxidation. Of the current coatings tested, Tribaloy T-400C appears to give both good steam oxidation and SPE resistance.

Bibilography

Holcomb and Hsu, Proc. $22^{\text {nd }}$ Annual Conference on Fossil Energy Materials, DOE-NETL, 2008 


\section{Task 12.1 Energy Erosion Resistant Coatings Study for USC Steam Turbine $760^{\circ} \mathrm{C}$ Department of Energy Initiative (SIEMENS)}





\section{ABSTRACT}

Siemens Energy participated in Phase 1 of the Ultra Super Critical Steam Turbine program run by the Department of Energy (DOE). The purpose of the consortium was to pool information and resources to investigate alloy materials and coatings that could withstand long term steam turbine environments at an operating temperature of $760^{\circ} \mathrm{C}$.

Typically steam turbines operate at no higher than $600^{\circ} \mathrm{C}$ so the materials and coatings used for the current generation of steam turbines may not be applicable to the $760^{\circ} \mathrm{C}$ turbine. The average life of a steam turbine unit is 30 years and solid particle erosion has long been an issue in these units due to exfoliation of iron oxides from the boiler and piping. One element of the Ultra Super Critical Steam Turbine $760^{\circ} \mathrm{C}$ program was tasked with investigating the resistance of high temperature coatings to solid particle erosion.

Siemens portion of this program was to research and investigate erosion resistant materials. This report discusses the coatings selected for test, the erosion data and the recommendations for further work. 



\section{TABLE OF CONTENTS}

TASK 12.1 ENERGY EROSION RESISTANT COATINGS STUDY FOR USC STEAM TURBINE $760^{\circ} \mathrm{C}$ DEPARTMENT OF ENERGY INITIATIVE (SIEMENS) ................117

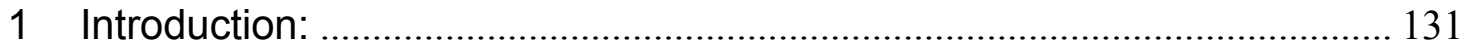

2 Task 1: Coatings for High-Temperature Steam Oxidation and Solid Particle Erosion (SPE).

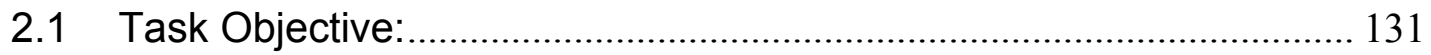

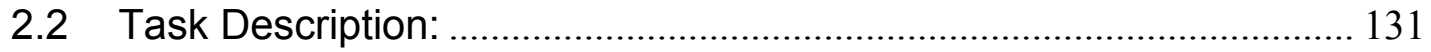

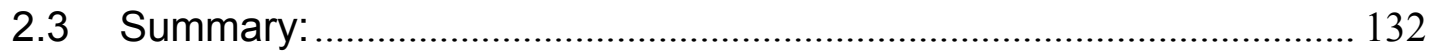

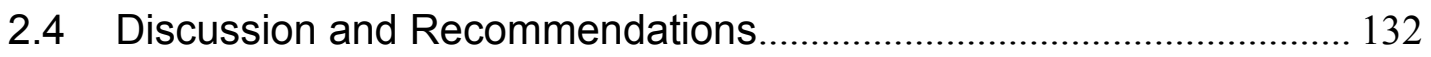

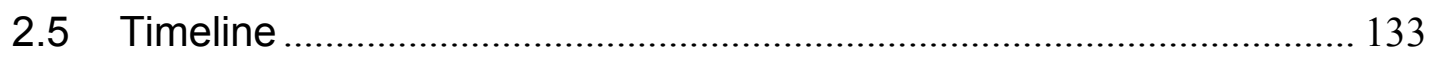

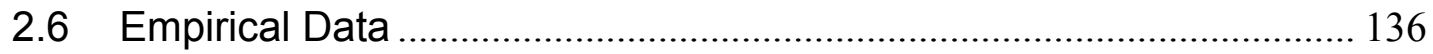

3 Steam Turbine Airfoil Erosion and Comparison with Laboratory Results 155

4 SEM Analysis of Coated Specimens ......................................................... 161

5 Metallographic Analysis of Coated Samples ............................................ 174

6 SEM and Metallographic Analysis of Bare Metal Alloys ............................. 185

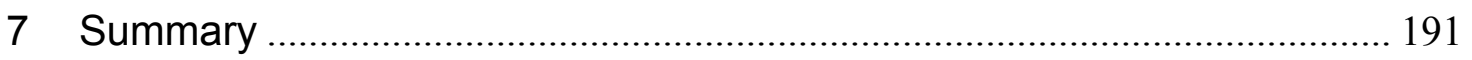

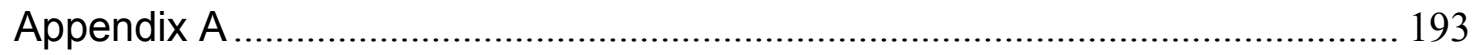

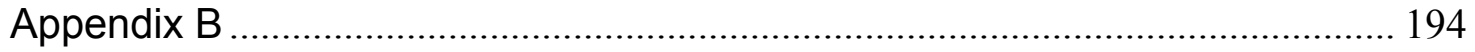

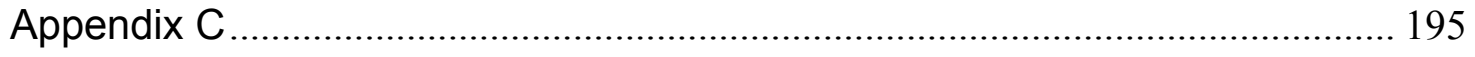

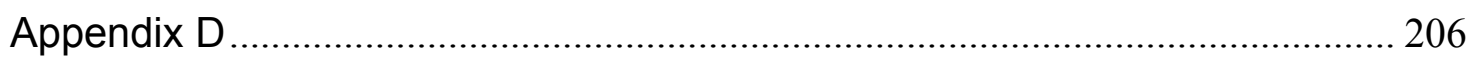

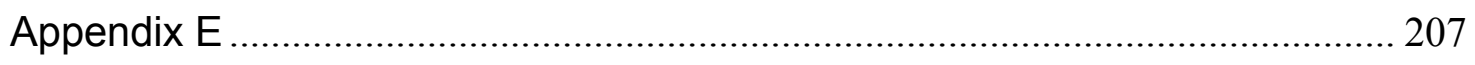

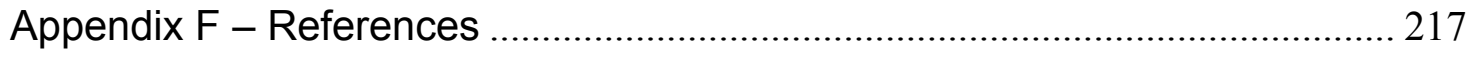





\section{TABLE OF FIGURES}

Figure 1 Erosion-oxidation wastage of various coatings obtained by HVOF process as a function of temperature.

Figure 2: Schematic diagram of the Erosion Test Facility at the University of Cincinnati.

Figure 3: Typical coated erosion coupon.

Figure 4: Erosion coupon configuration in the holder prior to testing. The shim is wedged behind the coupon (blue arrow) to ensure the coupon fits snugly into the holder.

Figure 5: Erosion Rates of Coated Samples using Silica Sand, Qp 5, 20 degrees.

Figure 6: Volume loss for the 12 Coated samples using Silica sand, Qp 5, 20 degrees.

Figure 7: EDS spectra and analyses from the as-coated surfaces of the Molybdenum-boride coated test coupons

Figure 8: EDS spectra and analyses from the eroded surfaces of the Molybdenum-boride coated test coupons.

Figure 9: The back (substrate side) of coupon \#29, CrC-9 showing the areas of contamination from the aluminum shim (blue arrows).

Figure 10: Elemental analysis in weight percent of the clean area on the substrate side of coupon \#29, CrC-9 via EDS

Figure 11: EDS analysis of coupon \#29, CrC-9 shim contaminated area which shows a higher concentration of Aluminum than the analysis from the uncontaminated area.

Figure 12: Erosion rate of the Molybdenum boride coating using Silica Sand, Qp 10, 20 degrees.

Figure 13: Volume loss of Molybdenum-boride coating eroded with Silica Sand, Qp 10, 20 degrees.

Figure 14: Erosion Rate of selected coated specimens using Silica Sand, Qp 5, 30 degrees.

Figure 15: Volume loss of selected coated specimens using Silica Sand, Qp 5, 30 degrees.

Figure 16: Erosion rate for the Bare Metal alloys tested using Silica Sand, Qp 5, 20 deg.

Figure 17: Volume loss from the Bare Metal Alloy eroded with Silica Sand, Qp 5, 20 degrees. 
Figure 18 SEM images at 250X of the bare alloy coupons in their as-received condition and after erosion testing with silica sand. The smooth machined surfaces of the coupons have clearly been impacted and eroded by the silica sand. X-ray energy dispersive spectrographic analysis of the coupons surfaces show an increase in silicon content (yellow column) of the eroded test coupons as compared with the as-received coupons.

Figure 19: Erosion rates of coated specimens using Magnetite, Qp 5, 20 degrees.

Figure 20: Volume loss of coated samples using Magnetite, Qp 5, 20 degrees.

Figure 21: Erosion rate of Nimonic 105 using Magnetite 0-50 micron.

Figure 22: Volume loss of Nimonic 105 eroded with Magnetite 0-50 micron.... 155

Figure 23: The concave side of a steam turbine airfoil. The red arrow indicates where, over time, the steam has cut into the airfoil just below the shroud. The area circled in yellow was examined at higher magnification.

Figure 24: Scalloped pattern due to solid particle erosion, found on the concave side of a steam turbine airfoil.

Figure 25: Shows a section of control stage blades from a steam turbine. Here the erosion of the trailing edge can be seen clearly.

Figure 26: A control stage blade, or tri-pin, after removal from engine service has pronounced erosion on the trailing edge and the shroud. 158

Figure 27: Closer examination of the trailing edge, concave surface of the control stage blade shows signs or pitting and scalloping typical of solid particle erosion.

Figure 28: The scalloped pattern on the surface of the control stage blade is shown at higher magnification in this image taken with a stereoscopic camera.

Figure 29: This steam turbine airfoil does not show the same degree of erosion seen in other airfoils however a pattern of erosion is still evident on the concave side of the airfoil's surface.

Figure 30: Higher magnification reveals the beginnings of the scallop pattern caused by solid particle erosion along the concave side of the trailing edge..... 160

Figure 31: Typical appearance of a coupon's erosion surface, after testing..... 160

Figure 32 Appearance of SPE damage from laboratory test coupons exposed under different erosion test conditions.

Figure 33 Stellite 6B Surface SEM Results As-coated and after laboratory erosion testing.

Figure 34 Conformaclad Surface SEM Results As-coated and after laboratory erosion testing. 
Figure 35 Metco 45 Surface SEM Results As-coated and after laboratory erosion testing

Figure 36 Tribaloy T400C Surface SEM Results As-coated and after laboratory erosion testing.

Figure 37 T800C Surface SEM Results As-coated and after laboratory erosion testing

Figure 38 Zircoat Surface SEM Results As-coated and after laboratory erosion testing.

Figure 39 Bodycote Tech 12 Surface SEM Results As-coated and after laboratory erosion testing (Note: The Bodycote Tech 12 sample had undergone humidity testing prior to erosion testing). 168

Figure 40 Bodycote Tech 23 Surface SEM Results As-coated and after laboratory erosion testing (Note: The Bodycote Tech 23 sample had undergone humidity testing prior to erosion testing).

Figure 41 Chrome-carbide Surface SEM Results As-coated and after laboratory erosion testing.

Figure 42 SHS 7170 Surface SEM Results As-coated and after laboratory erosion testing.

Figure 43 SHS 9172 Surface SEM Results As-coated and after laboratory erosion testing.

Figure 44 Molyboride Surface SEM Results As-coated and after laboratory erosion testing.

Figure 45 Stellite 6B Test coupon cross-sections at 200X.

Figure 46 Conformaclad Test coupon cross-sections at 100X

Figure 47 T400C Test coupon cross-section at 200X ........................................... 176

Figure 48 T800C Test coupon cross-section at 200X .......................................... 177

Figure 49 Zircoat Test coupon cross-section at 200X........................................ 178

Figure 50 Bodycote Tech 12 Test coupon cross-section at 200X........................ 179

Figure 51 Bodycoat Tech 23 Test coupon cross-section at 200X....................... 180

Figure 52 Chrome Carbide Test coupon cross-section at 200X ......................... 181

Figure 53 SHS 7170 Test coupon cross-section at 200X.................................... 182

Figure 54 SHS 9172Test coupon cross-section at 200X .................................... 183

Figure 55 Molyboride Test coupon cross-section at 200X ................................... 184

Figure 56 Haynes 282 SEM surface image ......................................................... 185

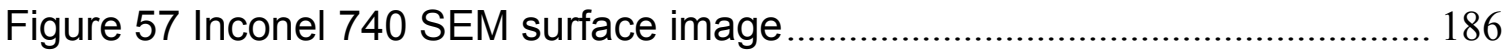

Figure 58 Nimonic 105 SEM surface image ........................................................ 187 
Figure 59 Nimonic 105 SEM surface image ........................................................ 188

Figure 60 Haynes 282 Cross-section SEM image after testing.......................... 188

Figure 61 Inconel 740 Cross-section SEM image after testing ............................ 189

Figure 62 Nimonic 105 Cross-section SEM image after testing ........................... 190

Figure 63 Udimet 720Li Cross-section SEM image after testing.......................... 191 


\section{TABLE OF TABLES}

Table 1 Top performing coatings in this study.

Table 2 Recommended test plan for additional studies for erosion resistant coatings for a $760^{\circ} \mathrm{C}$ steam turbine

Table 3: Erosion tested coating samples with their basic chemical compositions and coating sources.

Table 4: Erosion tested Metal alloys

Table 5: The amount of Erodent medium necessary to deliver a specific Particle mass (Qp) at various angles of impingement ( $\alpha$ ) to a 1 inch square erosion test coupon.

Table 6: Coated coupons Eroded with Silica Sand (149-840 micron), Temperature $760 \mathrm{C}$, Velocity $900 \mathrm{ft} / \mathrm{sec}$, Particle load (Qp) 5, and angle of impingement ( $\alpha$ ) 20 degrees. (note volume loss measurement accuracy should be 3 significant figures) .....

Table 7: Erosion rate and volume loss of a Molybdenum boride coated sample eroded with Silica Sand, Qp 10, 20 degrees.

Table 8: Coated coupons eroded with Silica Sand, Qp 5, 30 degrees

Table 9: Bare metal alloys Eroded with Silica Sand (149-840 micron), Temperature $760 \mathrm{C}$, Velocity $900 \mathrm{ft} / \mathrm{sec}$, Particle load (Qp) 5, and angle of impingement ( $\alpha) 20$ degrees. Note; Two Haynes 282 coupons were tested 150

Table 10: Selected coated coupons eroded with "Coarse Silica Test Dust (100200 micron) Qp 5, 20 degrees.

Table 11: Erosion rates and volume loss from coated samples eroded with Magnetite (0-50 micron) Qp 5, 20 degrees.

Table 12: Erosion Rate and volume loss of Nimonic 105 eroded with Magnetite (0-50 micron) Qp 5, 20 degrees. 



\section{EXECUTIVE SUMMARY}

Siemens Energy participated in Phase 1 of the Ultra Super Critical Steam Turbine program run by the Department of Energy (DOE) during the period April 1, 2007 through March 31, 2009. The purpose of the consortium was to pool information and resources to investigate alloy materials and coatings that will withstand long term steam turbine environments at an operating temperature of $760^{\circ} \mathrm{C}$.

Alloys and coatings were procured from various vendors and erosion tested using the University of Cincinnati's test rig. Silica sand and magnetite were the erodent materials used for this testing. A limited amount of testing was done with alumina as well.

The molybdenum boride-cobalt chromium coating supplied by Kermetico, Inc (MB-42) had the lowest overall erosion rates and volume loss of the 12 coatings tested. The top 4 coatings ranked according to their erosion rates and volume losses were:

1. Moly-Boride - Cobalt Chromium

2. Zircoat

3. T400C (Tribaloy)

4. Conformaclad WC 



\section{Introduction:}

The current fleet of steam turbines for nuclear, coal and combined cycle gas turbine applications operates at a maximum temperature of approximately $600^{\circ} \mathrm{C}$ (subcritical steam regime) and has a usable service life of approximately 30 years. The next generation of steam turbines will operate in the ultrasupercritical (USC) temperature range of $760^{\circ} \mathrm{C}$ which has great benefit in terms of efficiency and power output but which simultaneously imposes greater stresses on the operating components. The overall objective of the project is to contribute to the development of materials technology for use in ultra supercritical (USC) pulverized coal power plant steam turbines capable of operating with steam up to $760^{\circ} \mathrm{C}\left(1400^{\circ} \mathrm{F}\right), 35 \mathrm{MPa}(5000 \mathrm{psi})$. It is estimated that a plant operating under these steam conditions will result in increase in plant efficiency and corresponding reduction in emissions by as much as 30\% compared to the current fleet of sub critical plants. R\&D is needed on advanced materials to lead to a full-scale demonstration and eventual commercialization of USC power plants.

Solid particle erosion has long been an issue in steam turbine engines and has been addressed by thermally sprayed coatings such as $\mathrm{Ni} / \mathrm{Cr} \mathrm{Cr}_{3} \mathrm{C}_{2}$ on blades and by pack diffusion boride coatings on vanes. Part of the Ultra Super Critical Steam Turbine, $760^{\circ} \mathrm{C}$ program is to investigate the resistance of high temperature coatings to solid particle erosion. Since the chromium carbide coatings are not expected to survive $760^{\circ} \mathrm{C}$ steam environments [ref 1], new erosion resistant coatings will be explored and tested by Siemens.

\section{Task 1: Coatings for High-Temperature Steam Oxidation and Solid Particle Erosion (SPE)}

\subsection{Task Objective:}

Identify coatings that will protect HP steam turbine (ST) components from excessive steam oxidation and from solid particle erosion (SPE) at inlet temperatures of up to $760^{\circ} \mathrm{C}\left(1400^{\circ} \mathrm{F}\right)$.

\subsection{Task Description:}

Review coatings for oxidation prevention suitable for candidate alloys chosen by the consortium eam. Selected coatings will be applied to test coupons. The coated test coupons, along with uncoated baseline specimens, will be exposed to atmospheric

pressure steam at high temperature and the kinetics of oxidation will be evaluated by Alstom. Conditions and components where SPE is expected in the USC ST will be identified and compared with operating experience from commercially available coatings. At least 3 high-potential coatings for SPE resistance will be identified. Tests will be conducted on these coatings under worst-case scenarios in the USC ST. 


\subsection{Summary:}

The molybdenum boride-cobalt chromium coating supplied by Kermetico, Inc (MB-42) had the lowest overall erosion rates and volume loss of the 12 coatings tested. The top 4 coatings ranked according to their erosion rates, taking the best performers under the Silica Sand, Qp 5, 20 degree conditions. For these erodent conditions the volume losses are shown in the table below.

Table 1

Top performing coatings in this study

\begin{tabular}{|c|c|c|}
\hline Coating & Composition & $\begin{array}{l}\text { Erosion Rate } \\
\text { (info) }\end{array}$ \\
\hline $\begin{array}{l}\text { \#1 Moly-Boride-Cobalt } \\
\text { Chromium }\end{array}$ & $\begin{array}{l}\text { Co- } 30 \text { CrMo alloy- } 45 \text { MoB- } \\
\text { Balance (B total }-8.2)\end{array}$ & $\begin{array}{l}0 \mathrm{cc} / \mathrm{gram} \text { erodent } \\
(0.008 \mathrm{~g} \text { deposition noted })\end{array}$ \\
\hline \#2 Zircoat & Dense segmented 8YSZ & $1.70 \mathrm{E}-04 \mathrm{cc} / \mathrm{gram}$ erodent \\
\hline \#3 T400C (Tribaloy) & $\begin{array}{l}\text { Cr-8.5, Mo-26, Si-2.6, Co } \\
\text { Balance }\end{array}$ & $2.35 \mathrm{E}-04 \mathrm{cc} / \mathrm{gram}$ erodent \\
\hline \#4 Conformaclad & WC based & 2.65E-04 cc/gram erodent \\
\hline
\end{tabular}

Examination of the eroded coupons in the scanning electron microscope showed the surfaces of the Molyboride and the Zircoat were virtually untouched by the Silica sand with a particle load of $5 \mathrm{~g} / \mathrm{cm}^{2}$. In both instances the Molyboride and the Zircoat surfaces appeared smeared rather than eroded and the surfaces still retained some of their original morphology. When the particle load was increased to $10 \mathrm{~g} / \mathrm{cm}^{2}$ the Molyboride surface appeared more affected but some of the original surface could still be seen.

The bare metal alloys all had comparable erosion rates. However, because of its higher density Haynes 282 had the smallest volume loss. The above results are from very limited test data and should be viewed as the basis for narrowing down the number of coating candidates from 12 to 4 . Once the top 4 coatings have been established a more rigorous test program should be implemented. Additionally, the steam oxidation test results must also be reviewed prior to launching a more detailed test program.

\subsection{Discussion and Recommendations}

The unforseen high cost of the erosion testing prevented this portion of the program from testing a statistically valid amount of coupons. However it is believed that enough data has been presented to recommend that more study may $\mathrm{b}$ done on the following 4 coatings: Molybdenum boride-cobalt chromium (MB-42), Zircoat, Tribaloy T400, and Conformaclad (WC).

It is recommended that the following test matrix, or similar, be used for additional studies of these four coatings. 
Table 2

Recommended test plan for additional studies for erosion resistant coatings for a $760^{\circ} \mathrm{C}$ steam turbine

\begin{tabular}{|c|c|c|c|c|c|c|c|}
\hline Coating & Erodent & $\begin{array}{l}\text { Number of } \\
\text { Tests at } \\
T=760 \mathrm{C}, \\
V=900 \mathrm{ft} / \mathrm{sec} \\
\alpha=20 \mathrm{degs} .\end{array}$ & $\begin{array}{l}\text { Number of } \\
\text { Tests at } \\
T=760 \mathrm{C}, \\
V=900 \mathrm{ft} / \mathrm{sec} \\
\alpha=20 \mathrm{degs} .\end{array}$ & $\begin{array}{l}\text { Number of } \\
\text { Tests at } \\
T=760 \mathrm{C}, \\
V=900 \mathrm{ft} / \mathrm{sec} \\
\alpha=20 \mathrm{degs} .\end{array}$ & $\begin{array}{l}\text { Number of } \\
\text { Tests at } \\
T=760 \mathrm{C}, \\
V=900 \mathrm{ft} / \mathrm{sec} \\
\alpha=30 \mathrm{degs} .\end{array}$ & $\begin{array}{l}\text { Number of } \\
\text { Tests at } \\
T=760 \mathrm{C}, \\
V=900 \mathrm{ft} / \mathrm{sec} \\
\alpha=30 \mathrm{degs} .\end{array}$ & $\begin{array}{l}\text { Number of } \\
\text { Tests at } \\
T=760 C, \\
V=900 \mathrm{ft} / \mathrm{sec} \\
\alpha=30 \mathrm{degs} .\end{array}$ \\
\hline & & \multicolumn{3}{|c|}{ Particle load Qp } & \multicolumn{3}{|c|}{ Particle load Qp } \\
\hline \multirow{4}{*}{ Molyboride (MB-42) } & Erodent & Qp 5 & Qp 10 & Qp 20 & Qp 5 & Qp 10 & Qp 20 \\
\hline & Silica Test Dust 100-200 micron & 5 & 5 & 5 & 5 & 5 & 5 \\
\hline & Magnetite 0-50 micron & 5 & 5 & 5 & 5 & 5 & 5 \\
\hline & Alumina $100-200$ micron & 5 & 5 & 5 & 5 & 5 & 5 \\
\hline \multirow[t]{4}{*}{ Zircoat } & Erodent & & & & & & \\
\hline & Silica Test Dust 100-200 micron & 5 & 5 & 5 & 5 & 5 & 5 \\
\hline & Magnetite 0-50 micron & 5 & 5 & 5 & 5 & 5 & 5 \\
\hline & Alumina $100-200$ micron & 5 & 5 & 5 & 5 & 5 & 5 \\
\hline \multirow[t]{4}{*}{ Tribaloy T400C } & Erodent & & & & & & \\
\hline & Silica Test Dust 100-200 micron & 5 & 5 & 5 & 5 & 5 & 5 \\
\hline & Magnetite 0-50 micron & 5 & 5 & 5 & 5 & 5 & 5 \\
\hline & Alumina $100-200$ micron & 5 & 5 & 5 & 5 & 5 & 5 \\
\hline \multirow[t]{4}{*}{ Conformaclad } & Erodent & & & & & & \\
\hline & Silica Test Dust 100-200 micron & 5 & 5 & 5 & 5 & 5 & 5 \\
\hline & Magnetite 0-50 micron & 5 & 5 & 5 & 5 & 5 & 5 \\
\hline & Alumina $100-200$ micron & 5 & 5 & 5 & 5 & 5 & 5 \\
\hline & \multicolumn{5}{|c|}{ Total number of tests 360 -Approximate cost of testing $\$ 360,000$} & & \\
\hline
\end{tabular}

Note that the cost above is for the erosion test portion only; it does not include costs for sample preparation, coating of samples, or post-test analysis. It is also recommended that when changing erodent mediums one should run several loads of the new medium through the rig to adequately flush the system of the previous particles and thus avoid contamination.

\subsection{Timeline}

The task began with a literature search to find candidate coatings that could withstand the $760^{\circ} \mathrm{C}$ temperatures. The candidate coatings were chosen for their high temperature resistance, their wear characteristics and method of application. The blade airfoils can be coated using a line-of-sight method but the control stage blades or tri-pins require a coating that is not line of sight.

In November of 2008 a list of 14 coatings was presented to the USC steering committee as possible candidates for solid particle erosion testing. Vendor sources and procurement of coated test coupons commenced over the next three months. $\mathrm{NiCr}-\mathrm{Cr}_{3} \mathrm{C}_{2}$, which is a commonly used erosion-resistance coating at current steam turbine temperatures, was includedl as a baseline. As Figure 1 shows, this coating begins deteriorating at temperatures above about $600^{\circ} \mathrm{C}$. Substrate materials, Hastelloy X and stainless steel, were chosen based on Siemen's experience and readily available coupon materials. Since a breach of the coating in the erosion test would be considered a coating failure, it was decided that a nickel-based alloy with similar properties to the candidate A-USC alloys 
would be sufficient for the purposed of erosion testing. In two cases stainless steel samples were provided by the vendor supplying the coating. Testing of bare substrate materials was done on alloys under consideration by the consortium.

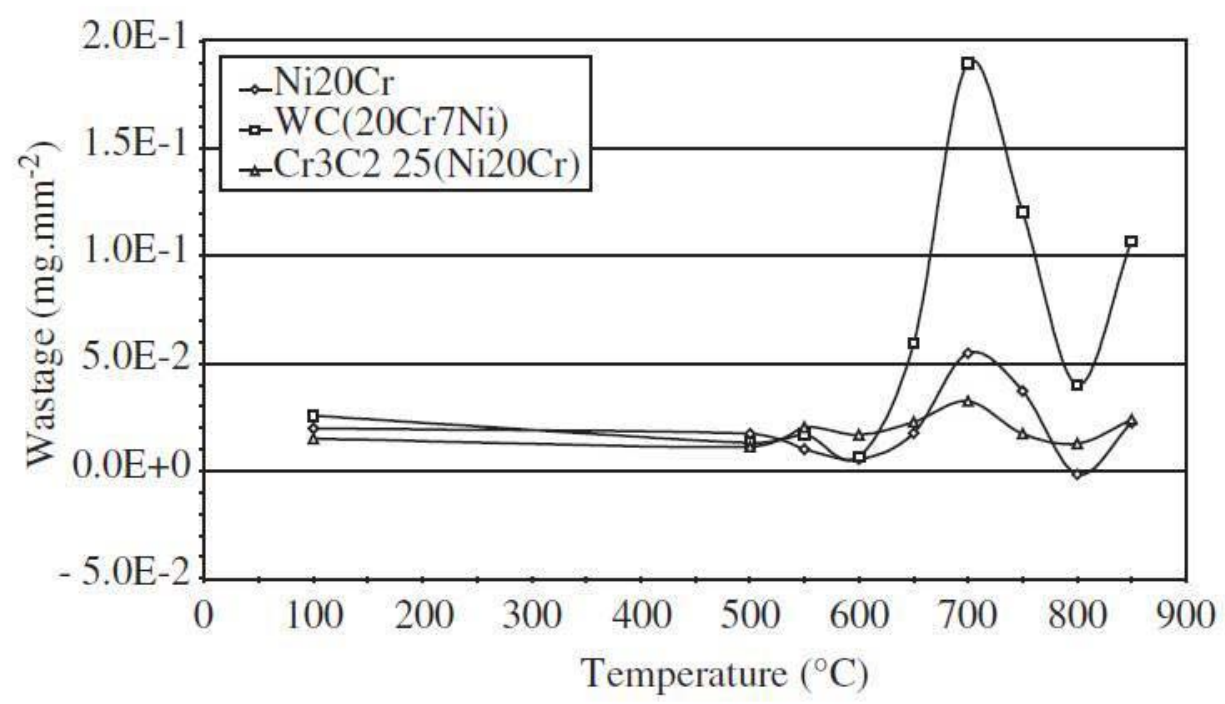

Source: Erosion-Oxidation Behavior of Thermal Sprayed Ni20Cr Alloy and WC and Cr3C2 Cermet Coatings, Kunioshi et al, Mat. Res. Vol 8 no. 2, 125-129, 2005 (Ref 1).

\section{Figure 1}

Erosion-oxidation wastage of various coatings obtained by HVOF process as a function of temperature.

In February of 2009, 12 of the original candidate coatings were erosion tested.

We were unable to procure the Boride diffusion coating and the Hardide T coated coupons did not arrive in time for testing. A list of the 12 coatings tested along with their basic chemistry and the vendor who provided them is shown in Table 3. Additional vendor contact information can be found in Appendix A.

All coatings were applied under conditions and using techniques that would be typical of those used in coating actual steam turbine parts and all coating thicknesses were representative of those that would be used in a steam turbine. 
Table 3: Erosion tested coating samples with their basic chemical compositions and coating sources.

\begin{tabular}{|c|c|c|}
\hline \multicolumn{2}{|c|}{ Coating Vendor Contact Information } & \\
\hline Coating & Basic chemistry & Vendor/Source \\
\hline Zircoat & $\begin{array}{l}\text { Dense Segmented } \\
\text { 8YSZ }\end{array}$ & Praxair \\
\hline Stellite 6B & $\begin{array}{l}\text { Cr-27,W-4,C-1,Co } \\
\text { Balance (solid metal } \\
\text { no substrate) }\end{array}$ & Doloro Stellite \\
\hline T400C (Tribaloy) & $\begin{array}{l}\text { Cr-8.5, Mo -26, Si-2.6, } \\
\text { Co Balance }\end{array}$ & Doloro Stellite \\
\hline T800C (Tribaloy) & $\begin{array}{l}1.5, \mathrm{C}-0.08, \mathrm{Co}- \\
\text { Balance }\end{array}$ & Doloro Stellite \\
\hline Metco 45 & $\begin{array}{l}\text { Co } 25.5, \mathrm{Cr} 10.5, \mathrm{Ni}-7.5 \\
\text { W } 0.5\end{array}$ & BASF \\
\hline Conformaclad & WC Based & Kennametal \\
\hline Bodycote Tech 12 & $\begin{array}{l}\text { Ceramic Composite } \\
\text { thermochemically } \\
\text { bonded (chemistry } \\
\text { unavailable) }\end{array}$ & Bodycote Arkansas \\
\hline Bodycote Tech 23 & $\begin{array}{l}\text { Ceramic Composite } \\
\text { thermochemically } \\
\text { bonded (chemistry } \\
\text { unavailable) }\end{array}$ & Bodycote Arkansas \\
\hline $\begin{array}{l}\text { Chrome Carbide-25 Nickel } \\
\text { Chrome }\end{array}$ & $\mathrm{CrC3}-25 \mathrm{NiCr}$ & Kermetico \\
\hline Nanosteel SHS 7170 & $\begin{array}{l}\text { Cr25 Mo-8 W-10,C-2,Si } \\
\text { 2,Mn-5, B-5, Fe- } \\
\text { Balance }\end{array}$ & Kermetico \\
\hline Nanosteel SHS 9172 & $\begin{array}{l}\text { Nanosteel } \\
\text { (Fe0.8Cr0.2)79B17W2 } \\
\text { C2 }\end{array}$ & Kermetico \\
\hline MolyBoride-Cobalt Chromium & $\begin{array}{l}\text { Co-30 CrMo alloy }-45 \\
\text { MoB-Balance (B total } \\
8.2 \text { ) }\end{array}$ & Kermetico \\
\hline
\end{tabular}


The following eight coatings were provided to Alstom Power Systems for steam oxidation testing:

- Stellite 6B

- Tribaloy T400C

- Tribaloy T800C

- Metco 45

- Chrome Carbide 25-Nickel Chrome

- Nanosteel SHS 7170

- Nanosteel SHS 9172

- Molyboride

Schedule constraints and the number of sample procured for erosion testing meant that 4 coatings were not subjected to steam oxidation testing.

Erosion coupons were also machined from four metal alloys chosen by the USC consortium as the primary candidates for steam turbine rotors. The alloys chosen are shown in Table 4.

Table 4: Erosion tested Metal alloys

\begin{tabular}{|l|}
\hline Bare Metal Alloys \\
\hline Haynes 282 \\
\hline Inconel 740 \\
\hline Nimonic 105 \\
\hline Udimet 720 \\
\hline
\end{tabular}

\subsection{Empirical Data}

The erosion testing was conducted at the University of Cincinnati. The University's erosion rig is the only domestic erosion test rig where one can change the following parameters: temperature $(\mathrm{T})$, particle dose $(\mathrm{Qp})$, velocity $(\mathrm{V})$ and angle of particle impingement $(\alpha)$. The erosion team was lead by Dr. Widen Tabakoff, Professor Emeritus Department of Aerospace Engineering, assisting with the testing were three graduate students, Sesha Gobor Manavasi, Dong Yin Shin, and Albert Todd Morel. The erosion tests were observed by Dr. David Allen and Melanie McNally of Siemens. A sketch of the erosion rig used at the University of Cincinnati is shown in Figure 2. 


\section{Schematic of Erosion Test Facility}

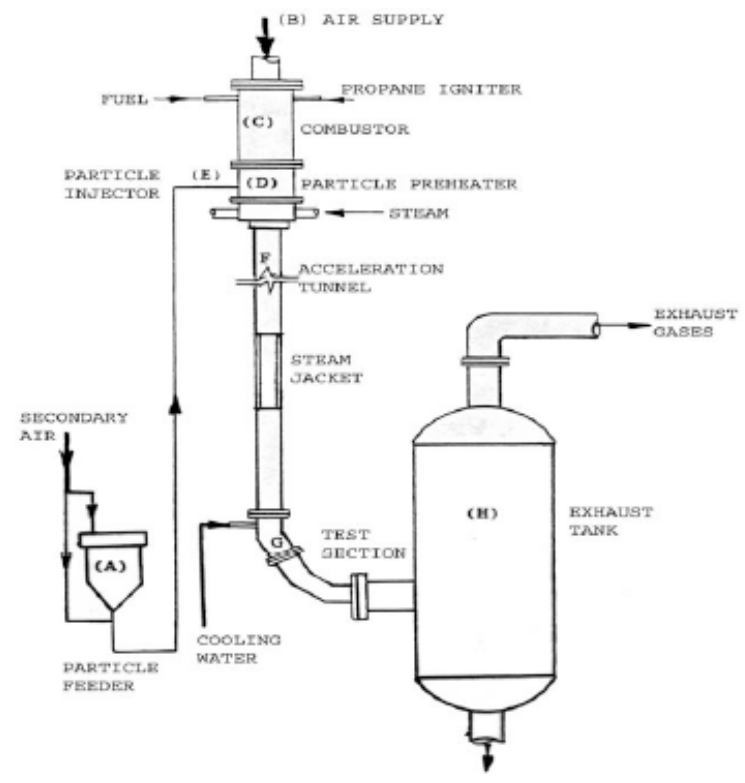

\section{Hot Erosion Wind Tunnel}

UC's high temperature erosion tunnel rig simulates particle surface interactions at operating conditions in compressors and turbines

- Temperatures (ambient $\left.-2000^{\circ} \mathrm{F}\right)$

- Impact velocities (60-1800 ft/sec)

- Impingement angles $\left(0^{\circ}-90^{\circ}\right)$

- Particles and target materials (various)

- Particle loading (various)

Figure 2: Schematic diagram of the Erosion Test Facility at the University of Cincinnati.

The erosion tests were conducted at $760^{\circ} \mathrm{C}\left(1400^{\circ} \mathrm{F}\right)$. Research and discussions with members of the Steam Turbine group at Siemens defined the optimum particle velocity to be between 800 and 1000 feet per second. The particle velocity selected for testing was 900 feet per second. Consultation with internal Siemens steam turbine experts suggested that the angle of incidence (the angle at which the particles impact the specimen) resulting in the highest rate of erosion would be between 20 and 30 degrees. This data was taken from chapter 12 of Evaluating and Improving Steam Turbine Performance, by 
K.C Cotton, a copy of which is attached in Appendix E. The particle velocity of 900 $\mathrm{ft} / \mathrm{sec}$ was based upon this paper as well.

The erodent mediums selected for the testing were Silica sand and Magnetite. Magnetite was selected because it is found inside the steam turbine environment. The magnetite is exfoliated from low carbon steel components such as the kettle boilers and tubing. As magnetite is very soft we also needed a more aggressive test media to accelerate the rate of erosion. We chose silica sand which is more aggressive than magnetite but not as aggressive as alumina.

Cost was a primary limiting factor in the amount of testing conducted in Phase 1. Ten years ago the cost of an erosion test at the University of Cincinnati was $\$ 150$. The current cost per test is $\$ 1000$. We tested a total of 41 coupons. For reference, the quote for 40 erosion tests ( 1 coupon $=1$ test) conducted at the University of Cincinnati's erosion rig is attached in Appendix B.

To fit the erosion rig the coupons were machined to dimensions of 1 inch by 1 inch by 0.1 inches thick with a tolerance of 0.03 inches on each dimension. The coatings were then applied to the erosion coupon blanks at varying thickness. A typical erosion coupon is shown in Figure 3.

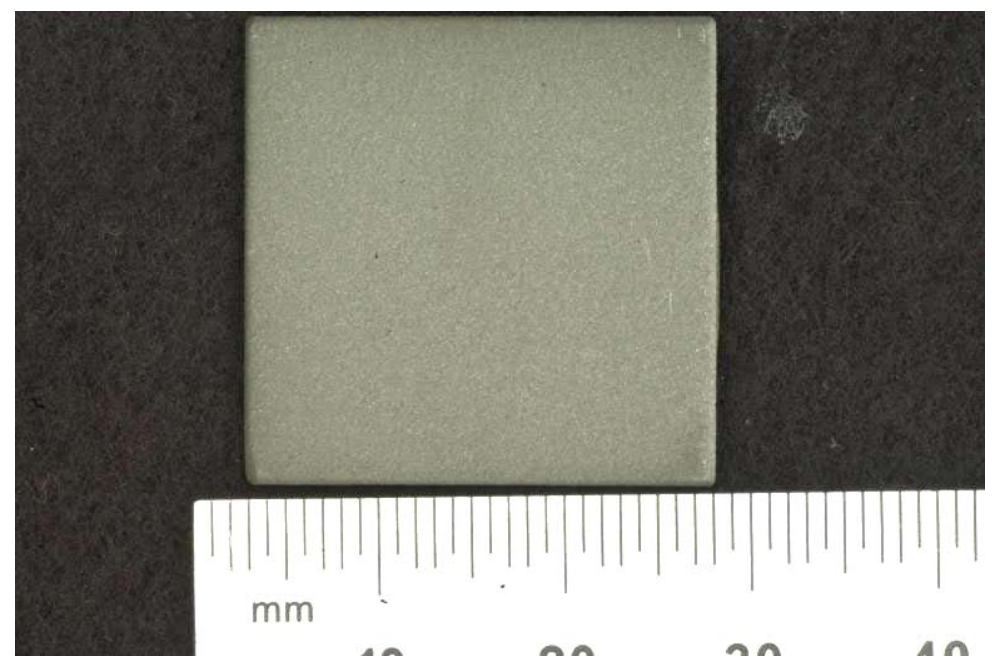

Figure 3: Typical coated erosion coupon.

The erodent media were purchased from Powder Technology Inc. and shipped directly to the University. We ordered Silica Test Dust, (MIL-STD-810E4 Dust) in 100-200 micron and Magnetite 0-50 micron. The magnetite was a custom powder cut made for Siemens.

Unfortunately we received Silica Sand 149-850 micron instead of the Silica Test Dust that was ordered. As time was at a premium we decided to use the Silica Sand for the first series of coated test coupons. The data sheets for the erodent mediums, including particle size and distributions are attached in Appendix C.

The procedure for all of the erosion tests was the same. Each coupon was engraved on the back side with a label and serial number. The initial weight was recorded and the amount of erodent medium was weighed according to the criteria listed in the Table 5, 
below for the specified particle mass and angle of impingement. These calculated values were developed by Dr. Tabakoff for the erosion rig at the University of Cincinnati.

Table 5: The amount of Erodent medium necessary to deliver a specific Particle mass (Qp) at various angles of impingement $(\alpha)$ to a 1 inch square erosion test coupon.

\begin{tabular}{|c|c|c|c|c|c|}
\hline \multirow[b]{3}{*}{$\alpha$ (degrees) } & $\begin{array}{r}\text { PAR } \\
\text { PAC } \\
\text { SA }\end{array}$ & $\begin{array}{l}\text { CLE M- } \\
\text { NGLE } \\
\text { PLE W }\end{array}$ & $\begin{array}{l}\text { AS A } \\
\text { IMPA } \\
H=1.0^{\prime}\end{array}$ & $\begin{array}{l}\text { JNCTIO } \\
\text { T MASS }\end{array}$ & \\
\hline & \multicolumn{5}{|c|}{ Qp (grams) } \\
\hline & 1 & 2 & 3 & 4 & 5 \\
\hline 5.0 & 46.5 & 92.9 & 139.4 & 185.8 & 232.3 \\
\hline 10.0 & 23.3 & 46.6 & 69.9 & 93.2 & 116.5 \\
\hline 15.0 & 15.7 & 31.3 & 47.0 & 62.6 & 78.3 \\
\hline 20.0 & 11.9 & 23.7 & 35.6 & 47.4 & 59.3 \\
\hline 25.0 & 9.6 & 19.2 & 28.8 & 38.4 & 48.0 \\
\hline 30.0 & 8.1 & 16.2 & 24.3 & 32.4 & 40.5 \\
\hline $35: 0$ & 7.1 & 14.1 & 21.2 & 28.2 & 35.3 \\
\hline 40.0 & 6.3 & 12.6 & 18.9 & 25.2 & 31.5 \\
\hline 45.0 & 5.8 & 11.5 & 17.3 & 23.0 & 28.8 \\
\hline 50.0 & 5.3 & 10.6 & 15.9 & 21.2 & 26.5 \\
\hline 55.0 & 5.0 & : $\quad 9.9$ & 14.9 & 19.8 & 24.8 \\
\hline 60.0 & 4.7 & 9.4 & 14.1 & 18.8 & 23.5 \\
\hline 65.0 & 4.5 & 8.9 & 13.4 & 17.8 & 22.3 \\
\hline 70.0 & 4.3 & 8.6 & 12.9 & 17.2 & 21.5 \\
\hline 75.0 & 4.2 & 8.4 & 12.6 & a 16.8 & 21.0 \\
\hline 80.0 & 4.1 & 8.2 & 12.3 & 16.4 & 20.5 \\
\hline 85.0 & 4.1 & . 8.1 & 12.2 & 16.2 & $20: 3$ \\
\hline 90.0 & 4.1. & 8.1 & 12.2 & $\quad 16.2$ & 20.3 \\
\hline
\end{tabular}

The coupons are placed in a metal holder and depending on the coupon thickness a metal shim is wedged against the back side of the coupon to hold it tight in the specimen holder. This configuration is shown in Figure 4. 


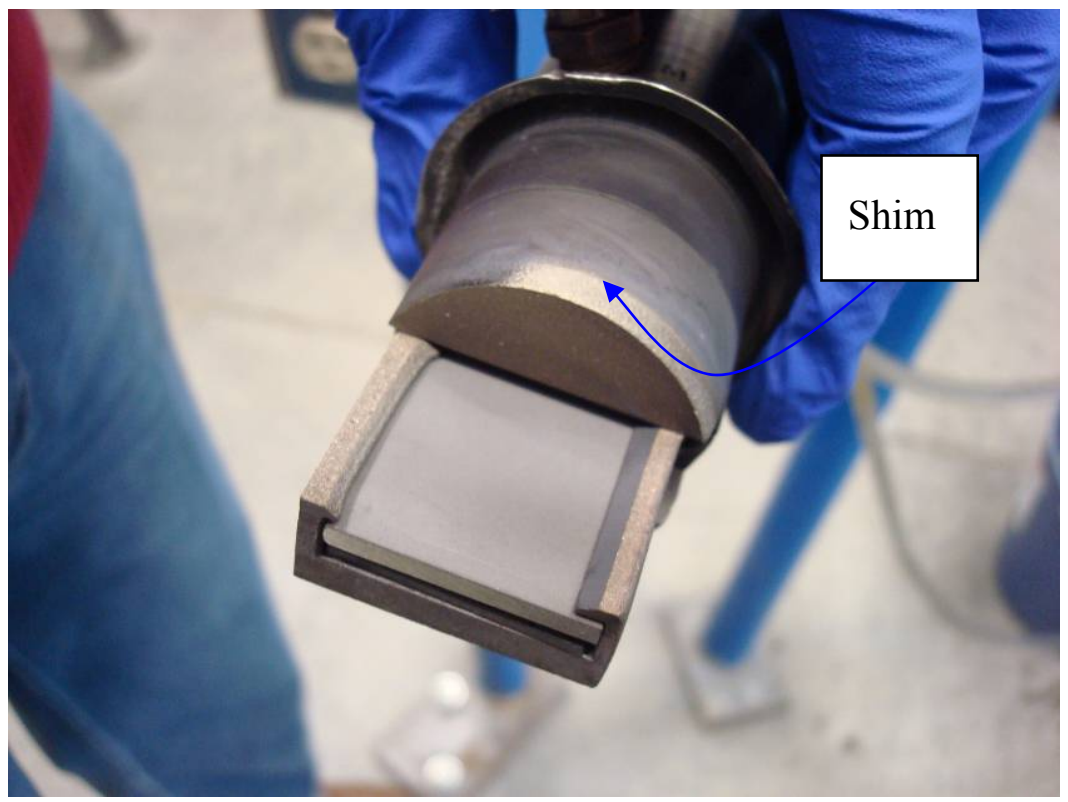

Figure 4: Erosion coupon configuration in the holder prior to testing. The shim is wedged behind the coupon (blue arrow) to ensure the coupon fits snugly into the holder.

The temperature and the particle velocity for all of the tests were the same, $760^{\circ} \mathrm{C}$ and $900 \mathrm{ft} / \mathrm{sec}$. For the first series of tests the Qp was 5 and the angle of impingement was 20 degrees. After the erosion test was concluded final weight of the coupon was recorded and subtracted from the initial weight to determine the weight loss. The erosion rate was calculated by dividing the weight loss in milligrams by the particle load (Qp). To convert the weight loss to volume loss one divides the delta $\mathrm{W}$ by the density of the specific coating to achieve a volume loss of $\mathrm{cc} / \mathrm{g}$.

The results of the coated coupons tested using Silica Sand (149-850 micron) are shown in Table 6.

Table 6: Coated coupons Eroded with Silica Sand (149-840 micron), Temperature 760C, Velocity $900 \mathrm{ft} / \mathrm{sec}$, Particle load (Qp) 5, and angle of impingement (a) 20 degrees.

*Note for Volume Loss, the data are only accurate to 3 significant figures

\begin{tabular}{|c|c|c|c|c|c|c|c|}
\hline SAMPLE IDENTIFICATION & Erodent & Temperature & Velocity & Angle & Erosion Rate & Density & \begin{tabular}{|l|} 
Volume Loss \\
\end{tabular} \\
\hline & Silica sand $140-850$ micron & $760 \mathrm{C}(1400 \mathrm{~F})$ & $900 \mathrm{ft} / \mathrm{sec}$ & 20 & delta WIQp & & Erosion rate/density \\
\hline Sample \# & Weight (initial) $\mathrm{g}$ & Weight (final) $\mathrm{g}$ & delta $W(g)$ & $Q p(g)$ & $\mathrm{mg} / \mathrm{g}$ & $\mathrm{g} / \mathrm{cc}$ & cc loss $/ g$ \\
\hline \#1 STELLITE 6B/ S6B-3 & 17.4192 & 17.3975 & 0.0217 & 5 & 4.340 & 8.3870 & 0.000517468 \\
\hline \#2 CONFORMACLAD/ CC4 & 17.5743 & 17.5589 & 0.0154 & 5 & 3.080 & 11.6200 & 0.00026506 \\
\hline \#3 METCO 45/ MET45-3 & 14.3193 & 14.3070 & 0.0123 & 5 & 2.460 & 14.5000 & 0.000169655 \\
\hline \#4 T800C /T8-2 & 13.0933 & 13.0744 & 0.0189 & 5 & 3.780 & 9.0000 & 0.00042 \\
\hline \#5 ZIRCOATI ZR-10 & 14.7564 & 14.7493 & 0.0071 & 5 & 1.420 & 6.0300 & 0.000235489 \\
\hline$\# 7$ T400C/T4-2 & 12.7083 & 12.6933 & 0.0150 & 5 & 3.000 & 9.0000 & 0.000333333 \\
\hline \#12 BODYCOTE TECH 23/11-5 & 12.7083 & 12.6333 & 0.0750 & 5 & 15.000 & not available & NA \\
\hline \#13 BODYCOTE TECH $12 / 10-9$ & 12.6545 & 12.6116 & 0.0429 & 5 & 8.580 & not available & NA \\
\hline \#21 ZIRCOAT/ZR-15 & 14.7487 & 14.7094 & 0.0393 & 5 & 7.86 & 6.03 & 0.001303483 \\
\hline $\begin{array}{l}\text { \#29 CHROME CARBIDEINICKEL } \\
\text { CHROMEICrC-9 }\end{array}$ & 13.5398 & 13.5491 & \begin{tabular}{|l} 
IIET DEPOSIT DUE TO \\
SHIM COITAMIIIATIOH
\end{tabular} & 5 & 0 & 6.665 & Net deposit \\
\hline \#35 NANOSTEEL SHS 7170/ 7170-2 & 13.9456 & 13.9058 & 0.0398 & 5 & 7.96 & 7.8 & 0.001020513 \\
\hline \#36 NANOSTEEL SHS 9172 / 9172-2 & 13.7151 & 13.6928 & 0.0223 & 5 & 4.46 & 7.59 & 0.000587615 \\
\hline \#39 MOLYBORIDE/MoB-5 & 13.8906 & 13.8914 & NET DEPOSIT (0.008) & 5 & 0 & 8.4 & Net deposit \\
\hline
\end{tabular}


The omission of coupon \#6 was due to the fact that the Bodycote Tech 12 sample was tested on the substrate side of the coupon rather than the coating side. The test was re-run and is reported as test \#13. The non- sequential numbering was because all of the different coating samples were not available at the start of testing and were subsequently tested on separate days. Test coupon \#21, another Zircoat coated specimen showed a substantially higher erosion rate than the first Zircoat coupon tested (\#5). We believe this was due to the contamination of Alumina particles into the erosion medium when the test mediums were changed from Silica Sand to the Coarse Silica Test dust. This phenomenon will be discussed later in the report.

The equations used for calculating erosion rate and volume loss were:

(1) Erosion Rate $=\frac{\text { change in mass of sample }}{\text { mass of impacting particles }}$

(2) Volume Loss Rate $=\frac{\text { changein mass of sample / density of sample }}{\text { mass of impacting particles }}$

Graphs comparing the erosion rates and volume loss rate of the 12 varieties of coated samples are shown in Figures 5 and 6.

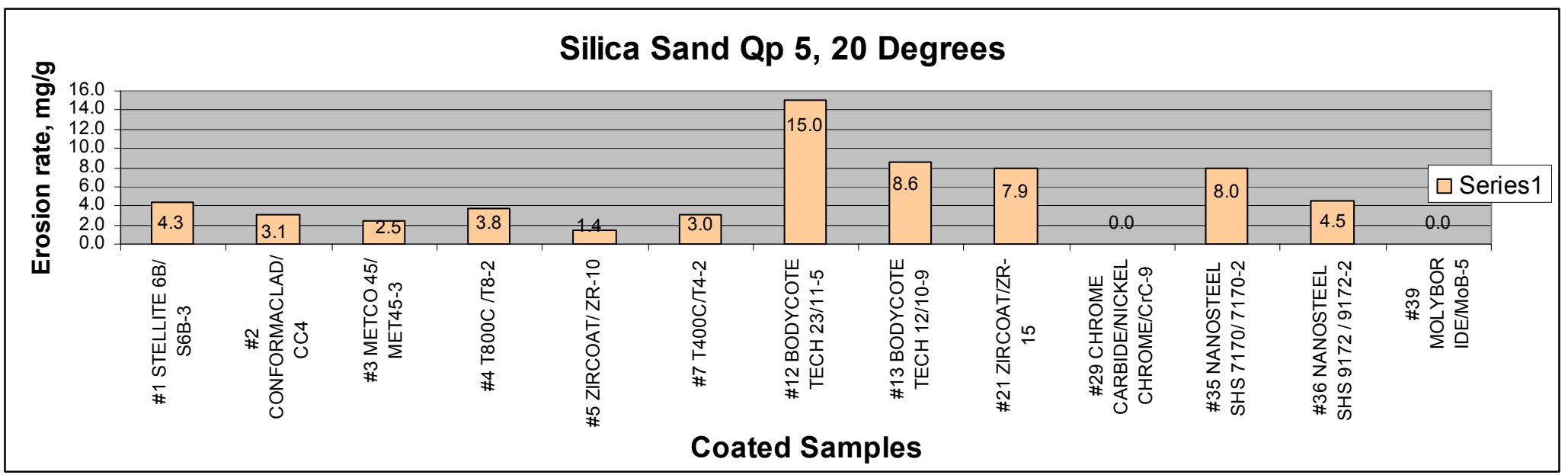

Figure 5: Erosion Rates of Coated Samples using Silica Sand, Qp 5, 20 degrees. 


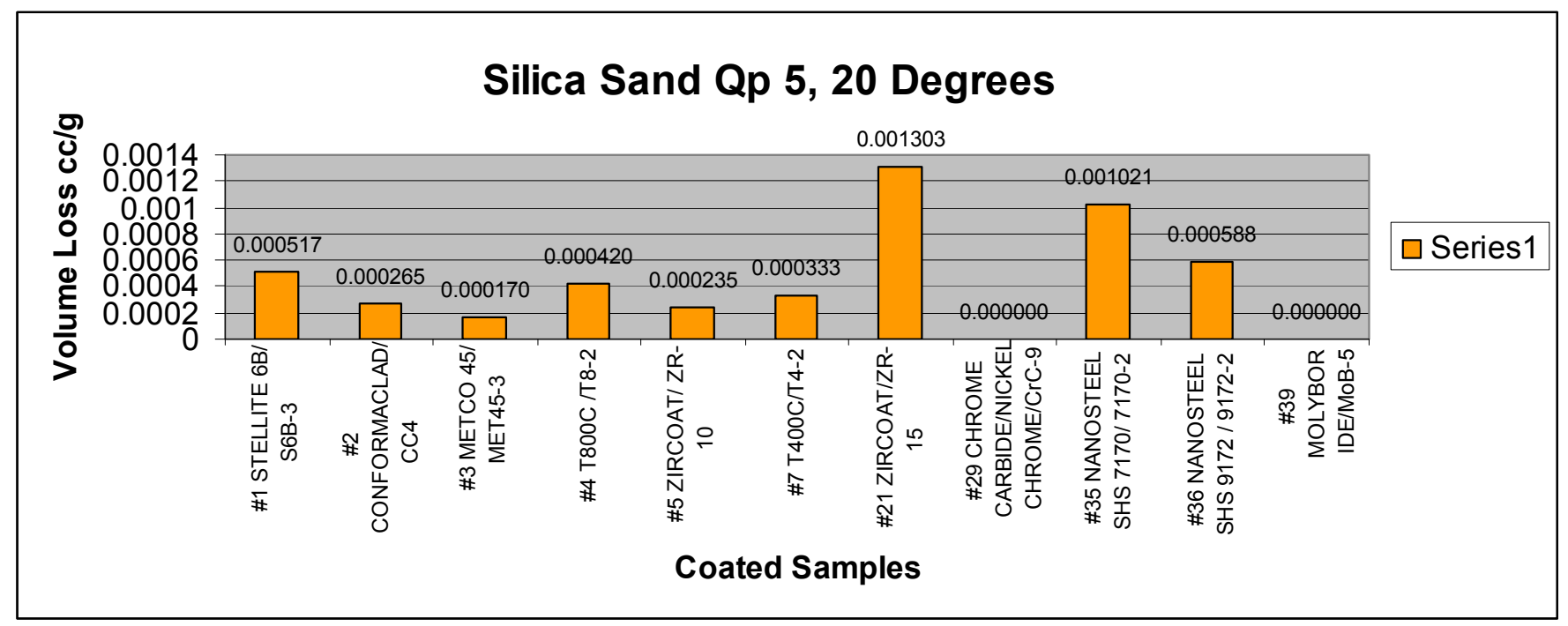

Figure 6: Volume loss for the 12 Coated samples using Silica sand, Qp 5, 20 degrees.

High erosion rates and volume loss are undesirable but we (Siemens) do not have a quantitative requirement for material loss rates due to erosion because the erodent size and quantity as well as impingement angle are unknown and would be at best an estimate. For this reason we have approached the current task with a goal of establishing relative rankings amongst the coatings tested.

Densities for the Bodycote Tech 12 and Tech 23 samples were not available at the time of reporting therefore the volume loss for these coatings could not be calculated.

The Molyboride, sample \#39, MoB-5 showed a net weight gain under the silica sand, Qp 5, 20 degree conditions. It is believed that this was due to particles of the Silica sand embedding into the coarse structure of the Molyboride surface as well as the excellent erosion resistance of this coating. X-ray, energy dispersive spectroscopy was performed on the eroded surface of MoB-5 and silica was found in quantities of slightly over 7 weight percent. This was compared with the as-coated surface of a Molyboride coupon which showed only 1.3 weight percent silica. The EDS spectra and analyses are shown in Figures 7 and 8 for comparison purposes. 


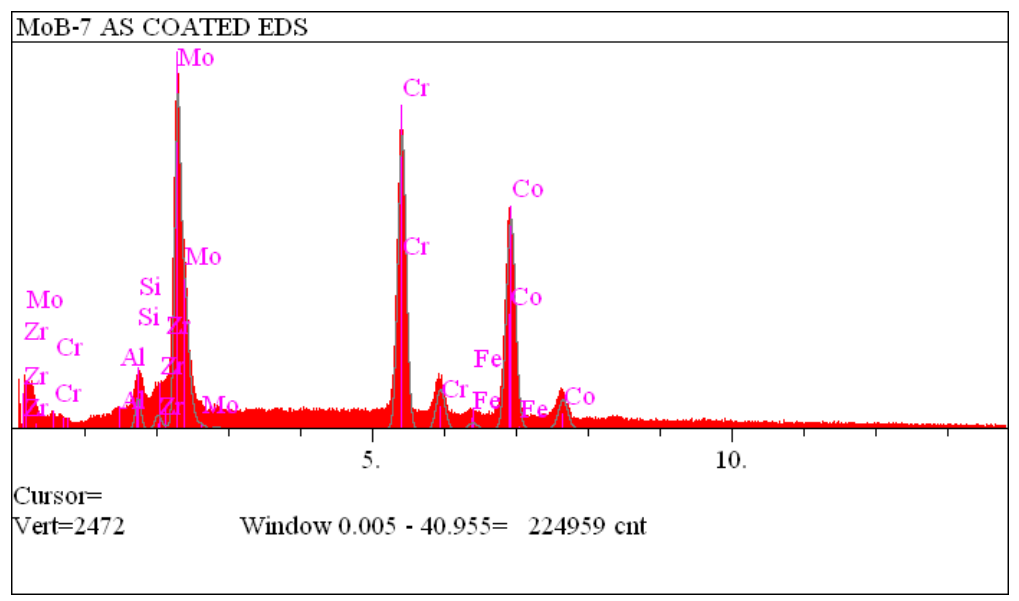

MoB-5 Eroded Silica Sand

\begin{tabular}{|l|l|l|l|l|l|l|}
\hline EIt. & Line & Conc & Units & $\begin{array}{c}\text { Error } \\
\text { 2-sig }\end{array}$ & $\begin{array}{l}\text { MDL } \\
\text { 3-sig }\end{array}$ & \\
\hline $\mathrm{Al}$ & $\mathrm{Ka}$ & 0.210 & wt.\% & 0.024 & 0.121 & \\
\hline $\mathrm{Si}$ & $\mathrm{Ka}$ & 7.655 & wt.\% & 0.134 & 0.121 & \\
\hline $\mathrm{Cr}$ & $\mathrm{Ka}$ & 21.098 & wt.\% & 0.270 & 0.156 & \\
\hline $\mathrm{Fe}$ & $\mathrm{Kb}$ & 1.068 & wt.\% & 0.187 & 1.338 & \\
\hline $\mathrm{Co}$ & $\mathrm{Ka}$ & 26.951 & wt.\% & 0.384 & 0.228 & \\
\hline $\mathrm{Zr}$ & $\mathrm{La}$ & 0.000 & wt.\% & 0.000 & 0.000 & \\
\hline $\mathrm{Mo}$ & $\mathrm{La}$ & 43.018 & wt.\% & 0.540 & 0.396 & \\
\hline & & 100.000 & wt.\% & & & Total \\
\hline
\end{tabular}

Figure 7: EDS spectra and analyses from the as-coated surfaces of the Molybdenumboride coated test coupons 


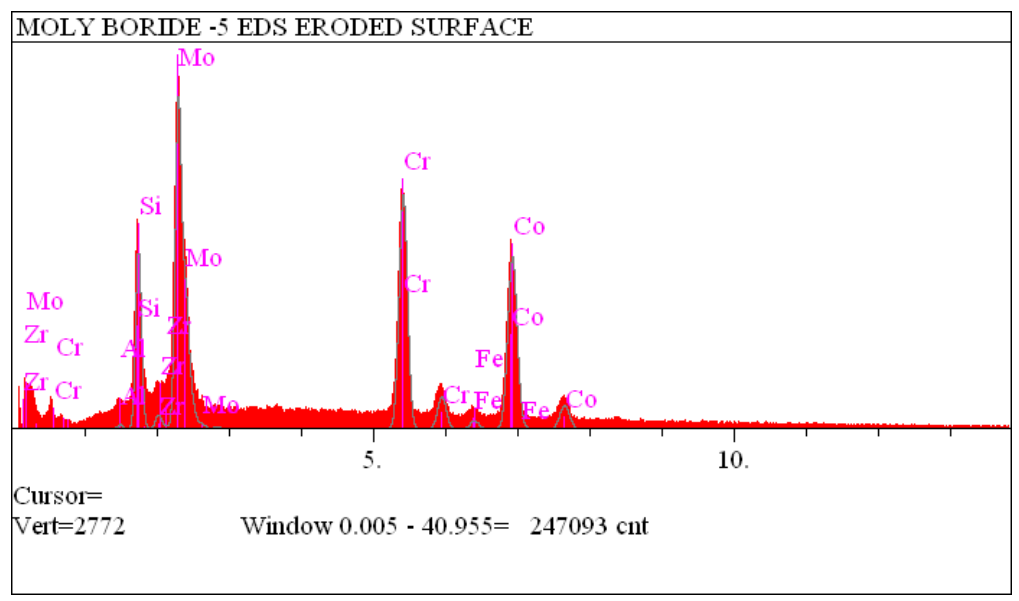

MoB-7 As-coated

\begin{tabular}{|l|l|l|l|l|l|l|}
\hline EIt. & Line & Conc & Units & $\begin{array}{c}\text { Error } \\
\text { 2-sig }\end{array}$ & $\begin{array}{l}\text { MDL } \\
\text { 3-sig }\end{array}$ & \\
\hline $\mathrm{Al}$ & $\mathrm{Ka}$ & 0.022 & wt.\% & 0.008 & 0.119 & \\
\hline $\mathrm{Si}$ & $\mathrm{Ka}$ & 1.307 & wt.\% & 0.059 & 0.121 & \\
\hline $\mathrm{Cr}$ & $\mathrm{Ka}$ & 25.220 & wt.\% & 0.306 & 0.166 & \\
\hline $\mathrm{Fe}$ & $\mathrm{Kb}$ & 0.755 & wt.\% & 0.164 & 1.401 & \\
\hline $\mathrm{Co}$ & $\mathrm{Ka}$ & 32.006 & wt.\% & 0.436 & 0.236 & \\
\hline $\mathrm{Zr}$ & $\mathrm{La}$ & 0.000 & wt.\% & 0.000 & 0.000 & \\
\hline $\mathrm{Mo}$ & $\mathrm{La}$ & 40.690 & wt.\% & 0.539 & 0.399 & \\
\hline & & 100.000 & wt.\% & & & Total \\
\hline
\end{tabular}

Figure 8: EDS spectra and analyses from the eroded surfaces of the Molybdenum-boride coated test coupons. 
The Chrome carbide-nickel chrome coating, sample \#29 CrC-9, also showed a net weight gain. However this was due to contamination with the shim material used to wedge the coupon into the specimen holder. Analysis of the CrC-9 coupon using x-ray Energy dispersive spectroscopy showed several areas of Aluminum deposited on the back of the Chrome carbide coupon. We believe an aluminum shim was inserted inadvertently into the specimen holder and the high temperatures during the test caused a portion of the shim to fuse onto the back of the test coupon. This resulted in a net weight gain. Several more tests were contaminated by similar shim deposits. Tests were suspended for a brief time while the shims were sorted according to material type and new shims were used for the remainder of the tests.

X-ray energy dispersive spectroscopy was used to confirm the deposit of foreign material onto the back of the Chrome carbide-nickel chrome coupon \#29. A photograph of the back side of coupon \#29, CrC-9 is shown in Figure 9.

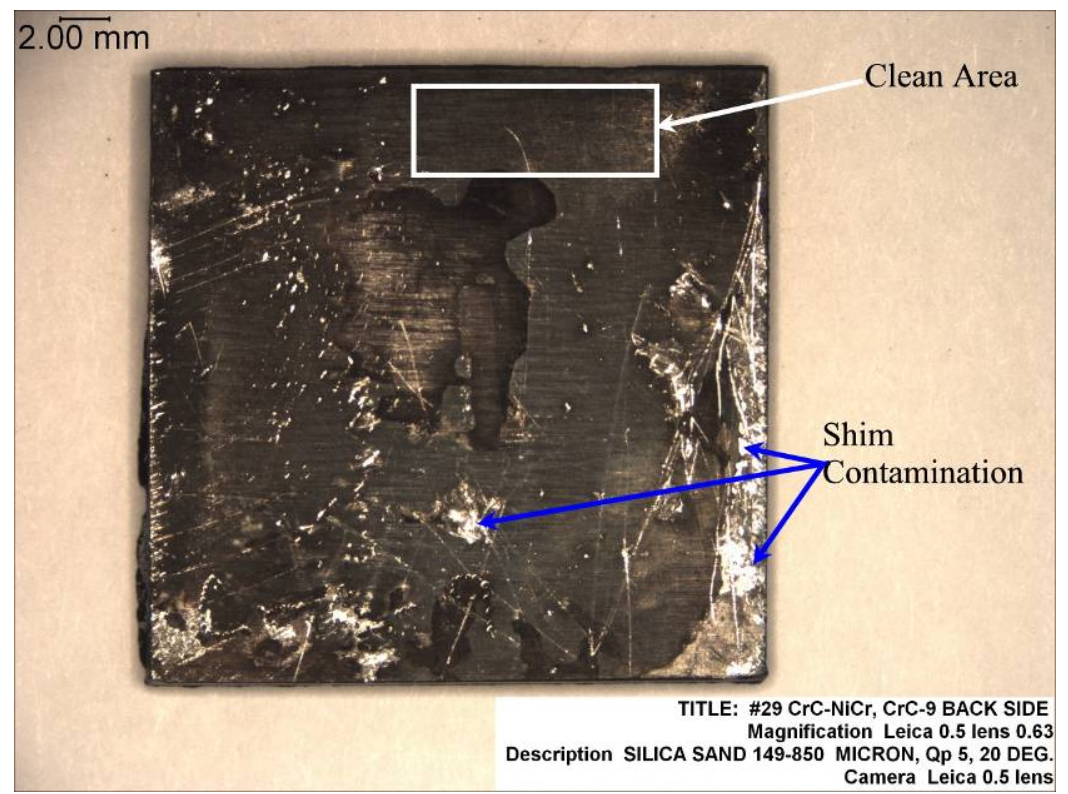

Figure 9: The back (substrate side) of coupon \#29, CrC-9 showing the areas of contamination from the aluminum shim (blue arrows).

A comparison of the contaminated area to the coupon substrate material (1018 stainless steel) is shown in Figures 10 and 11. 


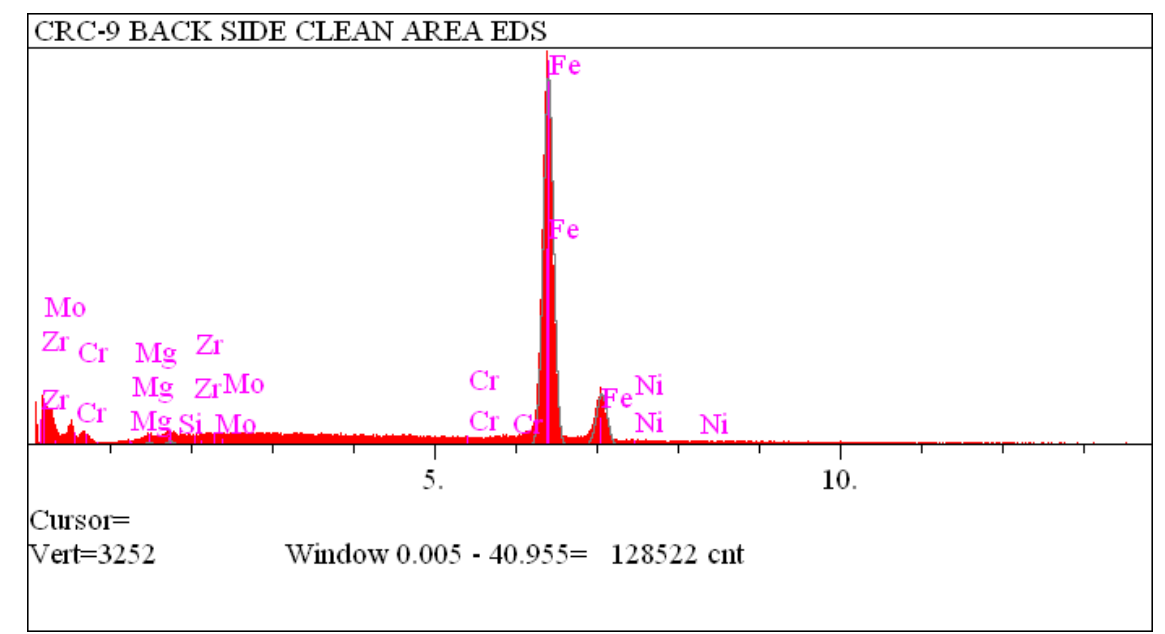

\begin{tabular}{|l|l|l|l|l|l|l|}
\hline Elt. & Line & Conc & Units & $\begin{array}{l}\text { Error } \\
\text { 2-sig }\end{array}$ & $\begin{array}{l}\text { MDL } \\
\text { 3-sig }\end{array}$ & \\
\hline $\mathrm{Mg}$ & $\mathrm{Ka}$ & 0.027 & wt.\% & 0.016 & 0.170 & \\
\hline $\mathrm{Al}$ & $\mathrm{Ka}$ & 0.386 & wt. $\%$ & 0.051 & 0.179 & \\
\hline $\mathrm{Si}$ & $\mathrm{Ka}$ & 0.475 & wt. $\%$ & 0.051 & 0.159 & \\
\hline $\mathrm{Cr}$ & $\mathrm{Ka}$ & 0.081 & wt. $\%$ & 0.015 & 0.090 & \\
\hline $\mathrm{Fe}$ & $\mathrm{Kb}$ & 98.236 & wt. $\%$ & 2.394 & 1.728 & \\
\hline $\mathrm{Ni}$ & $\mathrm{Ka}$ & 0.412 & wt. $\%$ & 0.072 & 0.307 & \\
\hline $\mathrm{Zr}$ & $\mathrm{La}$ & 0.112 & wt. $\%$ & 0.039 & 0.415 & \\
\hline $\mathrm{Mo}$ & $\mathrm{La}$ & 0.271 & wt. $\%$ & 0.056 & 0.377 & \\
\hline & & 100.000 & wt. $\%$ & & & Total \\
\hline
\end{tabular}

Figure 10: Elemental analysis in weight percent of the clean area on the substrate side of coupon \#29, CrC-9 via EDS 


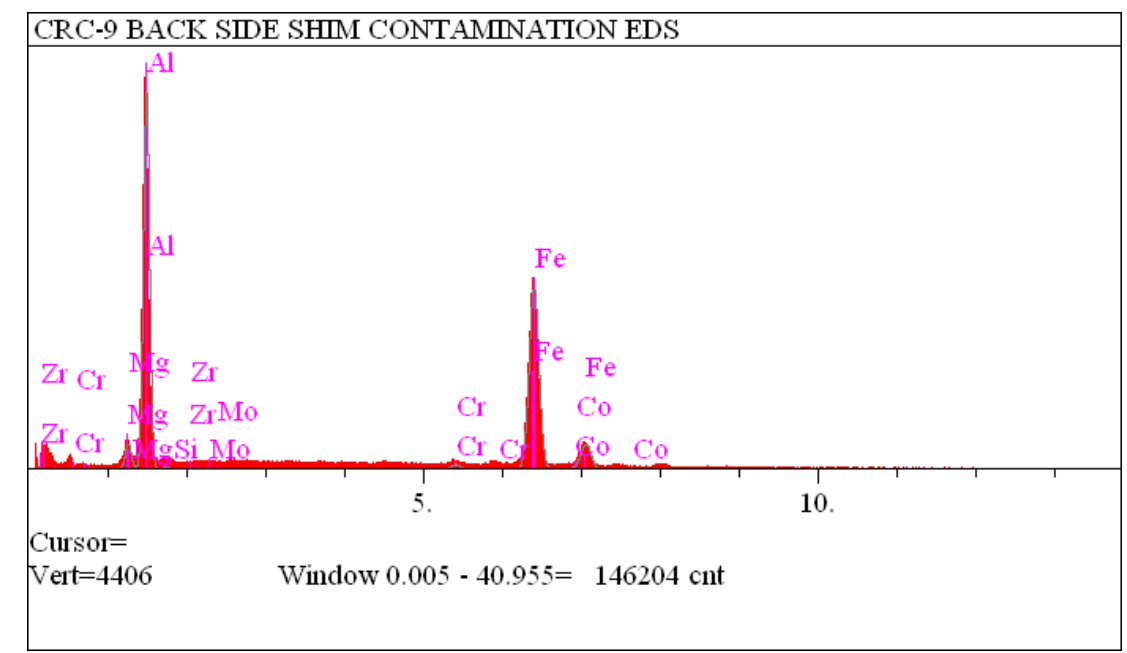

\begin{tabular}{|l|l|l|l|l|l|l|}
\hline Elt. & Line & Conc & Units & $\begin{array}{l}\text { Error } \\
\text { 2-sig }\end{array}$ & $\begin{array}{l}\text { MDL } \\
\text { 3-sig }\end{array}$ & \\
\hline $\mathrm{Mg}$ & $\mathrm{Ka}$ & 3.207 & wt.\% & 0.129 & 0.140 & \\
\hline $\mathrm{Al}$ & $\mathrm{Ka}$ & 40.961 & wt.\% & 0.420 & 0.143 & \\
\hline $\mathrm{Si}$ & $\mathrm{Ka}$ & 0.330 & wt.\% & 0.042 & 0.174 & \\
\hline $\mathrm{Cr}$ & $\mathrm{Ka}$ & 0.841 & wt.\% & 0.062 & 0.135 & \\
\hline $\mathrm{Fe}$ & $\mathrm{Kb}$ & 53.726 & wt. $\%$ & 1.659 & 1.441 & \\
\hline $\mathrm{Co}$ & $\mathrm{Ka}$ & 0.431 & wt.\% & 0.060 & 0.247 & \\
\hline $\mathrm{Zr}$ & $\mathrm{La}$ & 0.224 & wt.\% & 0.056 & 0.433 & \\
\hline $\mathrm{Mo}$ & $\mathrm{La}$ & 0.282 & wt. $\%$ & 0.060 & 0.398 & \\
\hline & & 100.000 & wt. $\%$ & & & Total \\
\hline
\end{tabular}

Figure 11: EDS analysis of coupon \#29, CrC-9 shim contaminated area which shows a higher concentration of Aluminum than the analysis from the un-contaminated area.

Since the Molyboride coating showed a negative erosion rate with a particle load of 5 (Qp 5) a second test was conducted using a particle mass of 10 (Qp 10). The rest of the test parameters remained the same. The increase particle load resulted in an erosion rate of $0.71 \mathrm{mg} / \mathrm{g}$. The erosion rate and volume loss are reported in Table 7 . 
Table 7: Erosion rate and volume loss of a Molybdenum boride coated sample eroded with Silica Sand, Qp 10, 20 degrees.

\begin{tabular}{|c|c|c|c|c|c|c|c|}
\hline SAMPLE IDENTIFICATION & \begin{tabular}{|c|} 
Erodent \\
\end{tabular} & Temperature & Velocity & Angle & Erosion Rate & Density & Volume Loss \\
\hline & Silica sand $140-850$ micron & $760 \mathrm{C}(1400 \mathrm{~F})$ & $900 \mathrm{ft} / \mathrm{sec}$ & 20 & delta WIQp & & Erosion rate/density \\
\hline Sample\# & Weight (initial) $\mathrm{g}$ & Weight (final) $\mathrm{g}$ & delta $W(g)$ & $Q p(g)$ & $\mathrm{mg} / \mathrm{g}$ & $g / c c$ & cc loss/g \\
\hline \#30 MOLYBORIDE/MoB-4 & 13.9805 & 13.9734 & 0.0071 & 10 & 0.71 & 8.4 & 0.00008452 \\
\hline
\end{tabular}

* Note for Volume Loss, the data are only accurate to 3 significant figures

Graphical representations of the erosion rate and volume loss are shown in Figures 12 and 13.

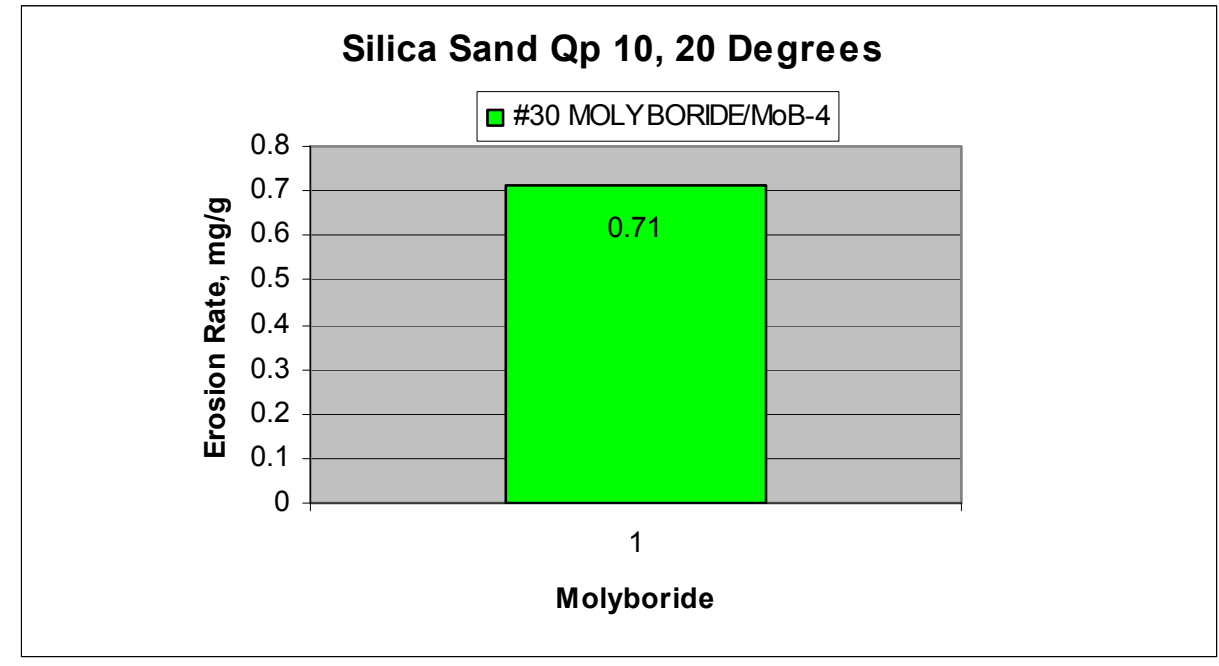

Figure 12: Erosion rate of the Molybdenum boride coating using Silica Sand, Qp 10, 20 degrees.

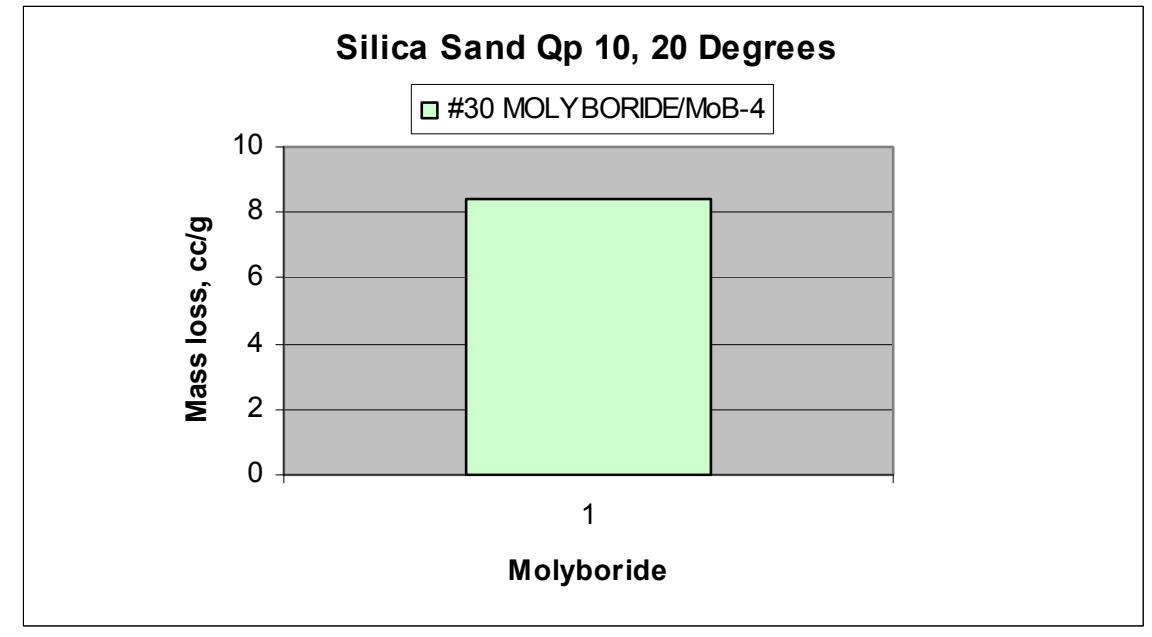

Figure 13: Volume loss of Molybdenum-boride coating eroded with Silica Sand, Qp 10, 20 degrees. 
All of the previous tests had been conducted at an angle of impingement of 20 degrees. Research has shown that erosion rates are also high at an angle of impingement of 30 degrees. It was decided to run additional tests on the Molybdenum-boride coating, the T400C coating, and the Conformaclad coating using Silica Sand at an angle of impingement of 30 degrees. The particle load was Qp 5 and the temperature was $760^{\circ} \mathrm{C}$ with a particle velocity of 900 feet per second. The results of these tests are reported in Table 6.

Table 8: Coated coupons eroded with Silica Sand, Qp 5, 30 degrees.

\begin{tabular}{|c|c|c|c|c|c|c|c|}
\hline SAMPLE IDENTIFICATION & Erodent & Temperature & Velocity & Angle & Erosion Rate & Density & Volume loss \\
\hline & $\begin{array}{l}\text { SILICA SAND 149-850 } \\
\text { MICRON }\end{array}$ & $760 \mathrm{C}(1400 \mathrm{~F})$ & $900 \mathrm{ft} / \mathrm{sec}$ & 30 & delta WIQp & & Erosion rate/density \\
\hline \#33 CONFORMACLAD/CC-6 & 17.3012 & 17.218 & 0.0832 & 5 & 16.64 & 11.62 & 0.001432014 \\
\hline \#34T400C/T4-3 & 12.6673 & 12.6276 & 0.0397 & 5 & 7.94 & 9.00 & 0.000882222 \\
\hline$\# 40$ CONFORMACLAD/CC-7 & 17.4774 & 17.4329 & 0.0445 & 5 & 8.9 & 11.62 & 0.000765921 \\
\hline \#41 MOLYBORIDE/MoB-6 & 13.8922 & 13.8829 & 0.0093 & 5 & 1.86 & 8.40 & 0.000221429 \\
\hline
\end{tabular}

*Note for Volume Loss, the data are only accurate to 3 significant figure

Once again the Molybdenum-boride coated had the least amount of mass loss and the lowest erosion rate.

Graphs comparing the Erosion rate and volume loss of Molyboride, T400C and the Conformaclad coatings are shown in Figures 14 and 15.

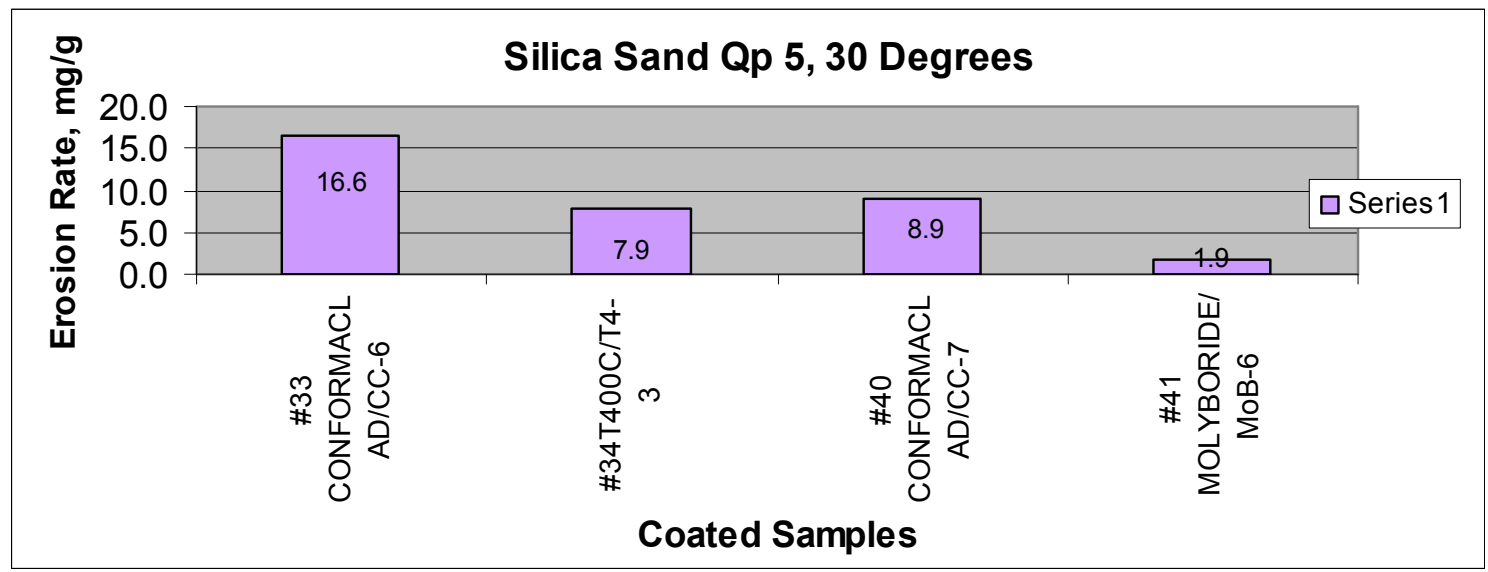

Figure 14: Erosion Rate of selected coated specimens using Silica Sand, Qp 5, 30 degrees. 


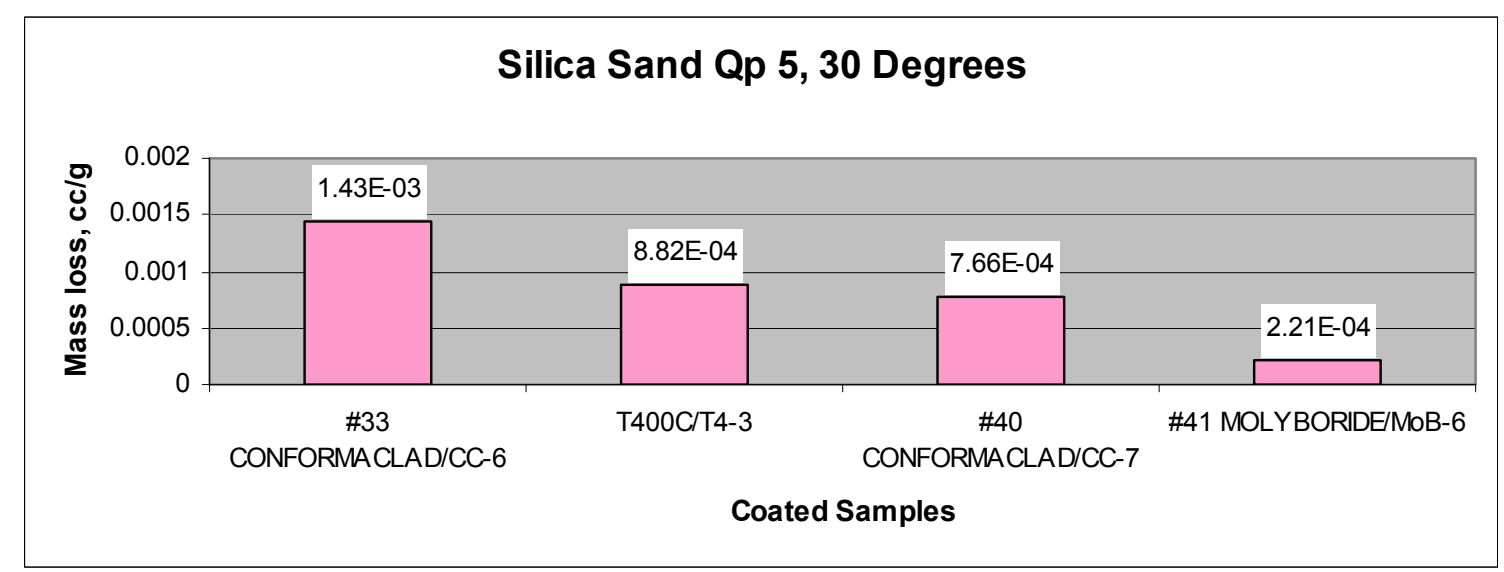

Figure 15: Volume loss of selected coated specimens using Silica Sand, Qp 5, 30 degrees.

The results of the erosion testing conducted using Silica Sand (149-850 micron) show the Molyboride coating had the lowest erosion rate and volume loss. The Conformaclad and T400C coatings also performed well under the various silica sand conditions.

The bare metal alloys were also tested using Silica Sand (149-850 micron), $\mathrm{T}=760^{\circ} \mathrm{C}$,

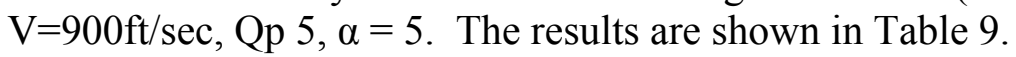

Table 9: Bare metal alloys Eroded with Silica Sand (149-840 micron), Temperature 760C, Velocity $900 \mathrm{ft} / \mathrm{sec}$, Particle load (Qp) 5, and angle of impingement (a) 20 degrees. Note; Two Haynes 282 coupons were tested

\begin{tabular}{|c|c|c|c|c|c|c|c|}
\hline SAMPLE IDENTIFICATION & Erodent & Temperature & Velocity & Angle & Erosion Rate & Density & Volume Loss \\
\hline & Silica sand $140-850$ micron & $760 \mathrm{C}(1400 \mathrm{~F})$ & $900 \mathrm{ft} / \mathrm{sec}$ & 20 & delta W/Qp & & Erosion rate/density \\
\hline & & & & & & & \\
\hline Sample \# & Weight (initial) $\mathrm{g}$ & Weight (final) $\mathrm{g}$ & delta W (g) & Qp (g) & $\mathrm{mg} / \mathrm{g}$ & g/cc & cc loss $/ g$ \\
\hline \#8 NIMONIC 105/NIM105-2 & 13.1543 & 13.1379 & 0.0164 & 5 & 3.200 & 7.99 & $4.01 \mathrm{E}-04$ \\
\hline \#9 UDIMET 720/U720-2 & 13.5172 & 13.5031 & 0.0141 & 5 & 2.800 & 8.08 & $3.47 \mathrm{E}-04$ \\
\hline \#10 HAYNES 282/282-2 & 13.6570 & 13.6449 & 0.0121 & 5 & 2.420 & 8.29 & $2.92 \mathrm{E}-04$ \\
\hline \#11 INCONEL 740/740-12 & 13.2354 & 13.2222 & 0.0132 & 5 & 2.640 & 8.05 & $3.28 \mathrm{E}-04$ \\
\hline \#27 HAYNES 282/282-2 & 13.5063 & 13.4876 & 0.0187 & 5 & 3.74 & 8.29 & $4.51 \mathrm{E}-04$ \\
\hline
\end{tabular}

Graphs comparing the erosion rates and volume loss of the 4 bare metal alloys are shown in Figures 16 and 17. 


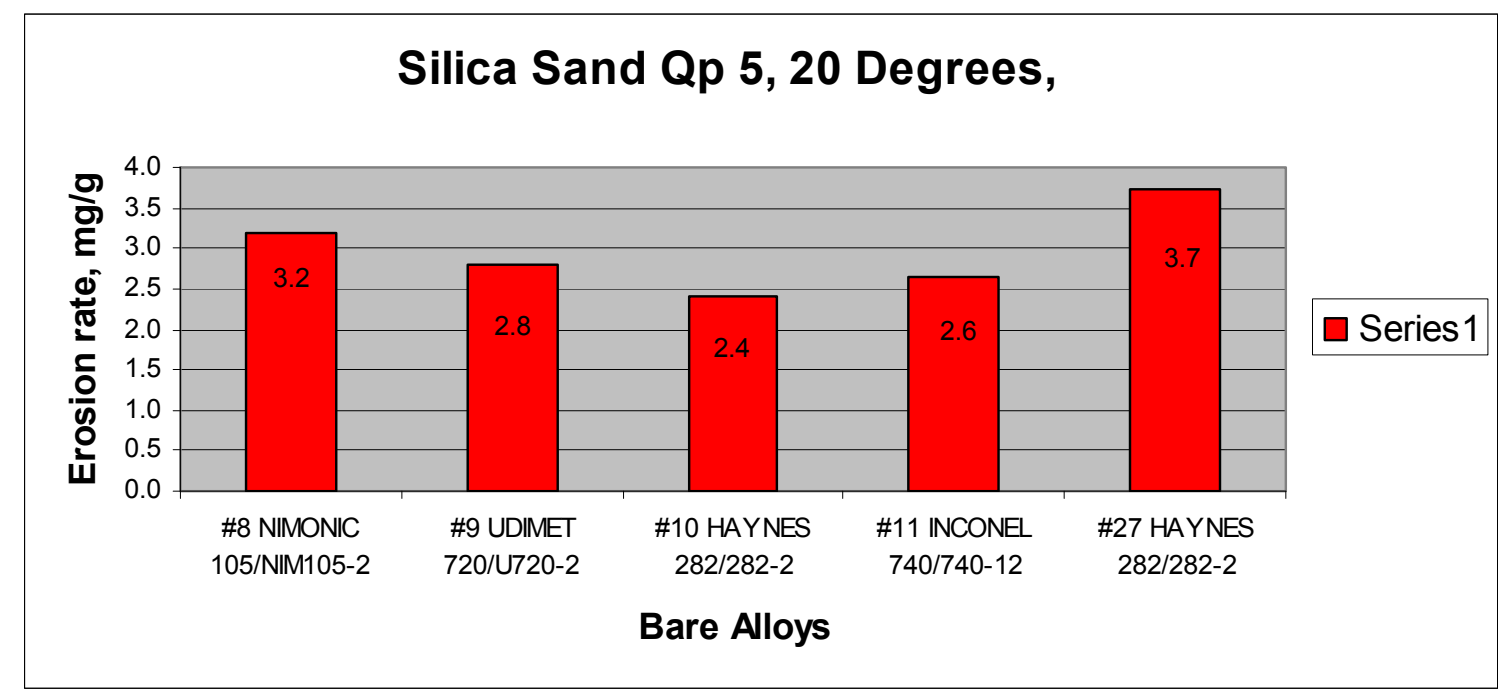

Figure 16: Erosion rate for the Bare Metal alloys tested using Silica Sand, Qp 5, 20 deg.

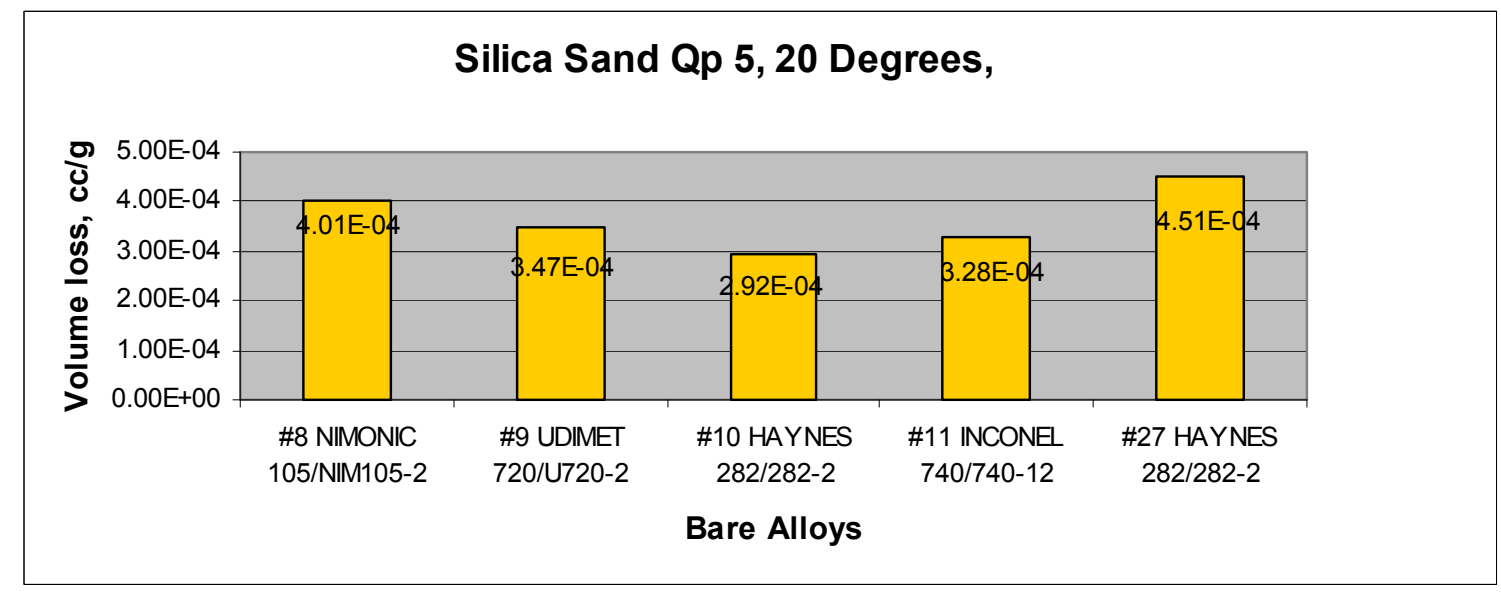

Figure 17: Volume loss from the Bare Metal Alloy eroded with Silica Sand, Qp 5, 20 degrees.

It was curious that the mass loss, or erosion rate, for the bare metal alloys was lower in some instances than the coated coupons. One possibility for this phenomenon is that the lower surface hardness of the alloys resulted in some portion of the silica erodent embedding onto the metal surface. To determine whether this was true the bare metal eroded coupons were placed in the SEM and their surfaces were analyzed via X-ray energy dispersive spectroscopy, EDS. These results were compared wth EDS analyses of the metal alloy surfaces in their as-received condition. What we found was a definite increase in the silicon content on the coupon surfaces. The results of these analyses are shown in Figure 18. The SEM images of the alloy coupons in their as-received and eroded states clearly show that the surface has been gouged by the silica sand erodent. However the silicon content on the surface eroded coupons is significantly higher than on the as-received coupons. This means that although the surface has eroded, particles of silica have indeed embedded themselves onto the surface of the metal. This would result in an increase in weight of the coupon and skew the erosion rate results to seem smaller than they actually were. One way to counter act this would be to attempt to ultrasonically 
clean the coupons after testing to ensure that any embedded particles were removed prior to reading the final coupon weight.
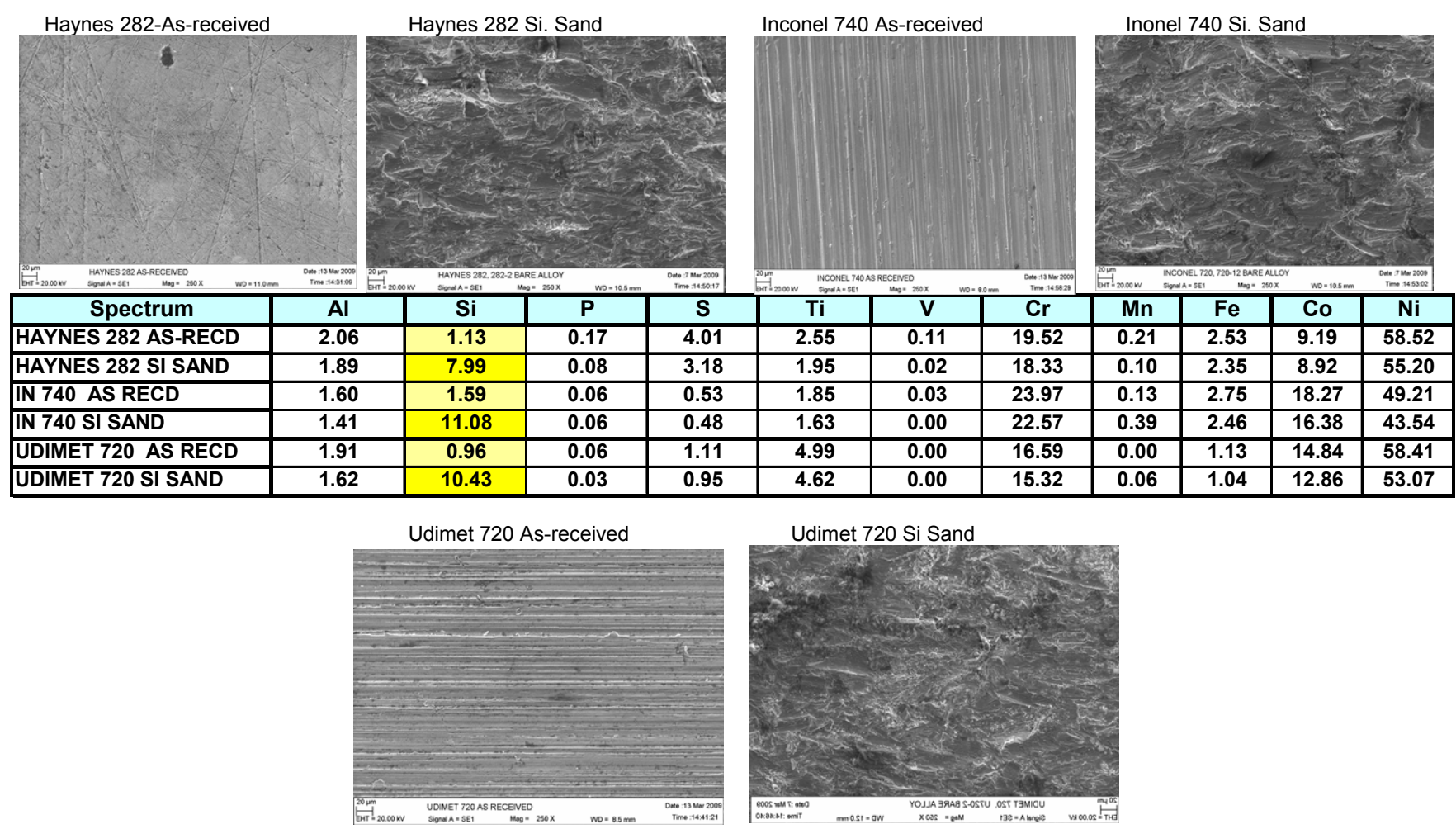

Figure 18

SEM images at 250X of the bare alloy coupons in their as-received condition and after erosion testing with silica sand. The smooth machined surfaces of the coupons have clearly been impacted and eroded by the silica sand. X-ray energy dispersive spectrographic analysis of the coupons surfaces show an increase in silicon content (yellow column) of the eroded test coupons as compared with the as-received coupons.

Since the Silica Sand was coarser than what we had planned for our testing we searched the store room at the erosion rig and located some Coarse Silica Test Dust, 100-200 micron size. Several coupons were tested using this medium and the results are reported in Table 10.

Table 10: Selected coated coupons eroded with "Coarse Silica Test Dust (100-200 micron) Qp 5, 20 degrees.

\begin{tabular}{|c|c|c|c|c|c|c|c|}
\hline SAMPLE IDENTIFICATION & Erodent & Temperature & Velocity & Angle & Erosion Rate & Density & Volume Loss \\
\hline & $\begin{array}{l}\text { COARSE SILICA TEST DUST* } \\
\text { (ALUMINA 100-200 MICRON) }\end{array}$ & $760 \mathrm{C}(1400 \mathrm{~F})$ & $900 \mathrm{ft} / \mathrm{sec}$ & 20 & delta WIQp & & Erosion rate/density \\
\hline Sample \# & Weight (initial) $\mathrm{g}$ & Weight (final) $\mathrm{g}$ & delta $W(g)$ & Qp (g) & $\mathrm{mg} / \mathrm{g}$ & $\mathrm{g} / \mathrm{cc}$ & cc loss/g \\
\hline \#18 ZIRCOAT/ZR-12 & 14.5158 & 14.4916 & 0.0242 & 5 & 4.84 & 6.03 & 0.000802653 \\
\hline \#19 ZIRCOAT/ZR-13 & 14.8441 & 14.8133 & 0.0308 & 5 & 6.16 & 6.03 & 0.001021559 \\
\hline \#20 STELLITE 6B/S6B-6 & 17.4133 & 17.3354 & 0.0779 & 5 & 15.58 & 8.387 & 1.857636819 \\
\hline
\end{tabular}

*Note for Volume Loss, the data are only accurate to 3 significant figures

The erosion rates using the Coarse Silica Test Dust were higher than for the larger particle Silica Sand. A sample of the Coarse Silica Test Dust was collected and X-ray 
energy dispersive spectroscopy, EDS, was performed in the scanning electron microscope to determine the chemical composition of the erodent. The composition of the sample was almost pure Alumina which would account for the more aggressive erosion rates and volume loss. Apparently sometime in the past, Alumina had been placed in the bottle labeled Coarse Silica Test Dust but the bottle had not been re-labeled to reflect this change. In order to verify the compositions of all three erodent mediums samples were placed in the scanning electron microscope and analyzed via x-ray energy dispersive spectroscopy. The results of these analyses are included in Appendix D.

Ten of the 12 coatings were erosion tested with Magnetite, 0-50 microns. The Bodycote Tech 12 and Tech 23 were omitted from this round of testing because of their poor performance with silica sand. The test parameters using magnetite were: temperature$760^{\circ} \mathrm{C}$, particle velocity- 900 feet per second, particle load- 5 (Qp 5) and angle of impingement, $(\alpha) 20$ degrees. The results of the testing are reported in Table 11.

Table 11: Erosion rates and volume loss from coated samples eroded with Magnetite (0-50 micron) Qp 5, 20 degrees.

\begin{tabular}{|c|c|c|c|c|c|c|c|}
\hline SAMPLE IDENTIFICATION & Erodent & Temperature & Velocity & Angle & Erosion Rate & Density & Volume Loss \\
\hline & MAGNETITE 0-50 MICRON & $760 \mathrm{C}(1400 \mathrm{~F})$ & $900 \mathrm{ft} / \mathrm{sec}$ & 20 & delta WIQp & & Erosion rate/density \\
\hline Sample \# & Weight (initial) g & Weight (final) $\mathrm{g}$ & delta W $(g)$ & Qp (g) & $\mathrm{mg} / \mathrm{g}$ & g/cc & cc loss/g \\
\hline \#14 ZIRCOATIZR-11 & 14.8325 & 14.8275 & NET DEPOSIT $(0.005)$ & 5 & 0 & 6.03 & NA \\
\hline$\# 16$ T800C/T8-5 & 12.7304 & 12.7294 & 0.0100 & 5 & 2.000 & 9.00 & 0.000222222 \\
\hline \#17 CONFORMACLAD/CC-5 & 17.3500 & 17.3470 & 0.0030 & 5 & 0.600 & 11.62 & 0.000517241 \\
\hline \#22 METCO 45/MET45-4 & 14.285 & 14.2677 & 0.0173 & 5 & 3.46 & 14.50 & 0.002386207 \\
\hline \#23 T400C/T4-4 & 12.0197 & 12.0202 & NET DEPOSIT $(0.0005)$ & 5 & 0 & 9.00 & $\mathrm{NA}$ \\
\hline \#24 Stellite 6B/S6B-7 & 17.4186 & 17.4108 & 0.0078 & 5 & 1.56 & 8.39 & 0.000185936 \\
\hline \#31 MOLYBORIDE/MoB-3 & 13.8246 & 13.8224 & 0.0022 & 5 & 0.44 & 8.40 & 0.000052381 \\
\hline $\begin{array}{l}\text { \#32 CHROME } \\
\text { CARBIDE/NICKEL } \\
\text { CHROME/CrC-3 }\end{array}$ & 13.4239 & 13.4308 & NET DEPOSIT $(0.0069)$ & 5 & 0 & 6.67 & (1) \\
\hline $\begin{array}{l}\# 37 \text { NANOSTEEL SHS } 7170 / \\
7170-3\end{array}$ & 13.6357 & 13.6375 & NET DEPOSIT $(0.0018)$ & 5 & 0 & 7.80 & NA \\
\hline $\begin{array}{l}\text { \#38 NANOSTEEL SHS 9172I } \\
9171-3\end{array}$ & 14.0777 & 14.0867 & NET DEPOSIT $(0.090)$ & 5 & 0 & 7.59 & NA \\
\hline
\end{tabular}

*Note for Volume Loss, the data are only accurate to 3 significant figures

Graphs comparing the erosion rates and volume loss of the coated specimens eroded with Magnetite are shown in Figures 19 and 20.

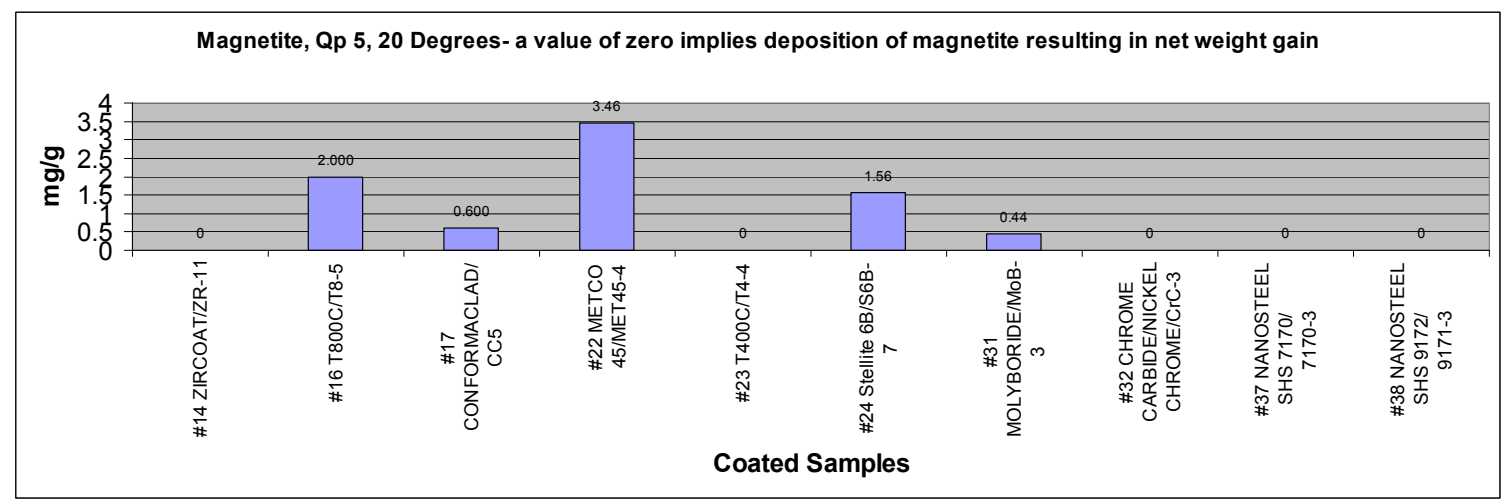

Figure 19: Erosion rates of coated specimens using Magnetite, Qp 5, 20 degrees. 


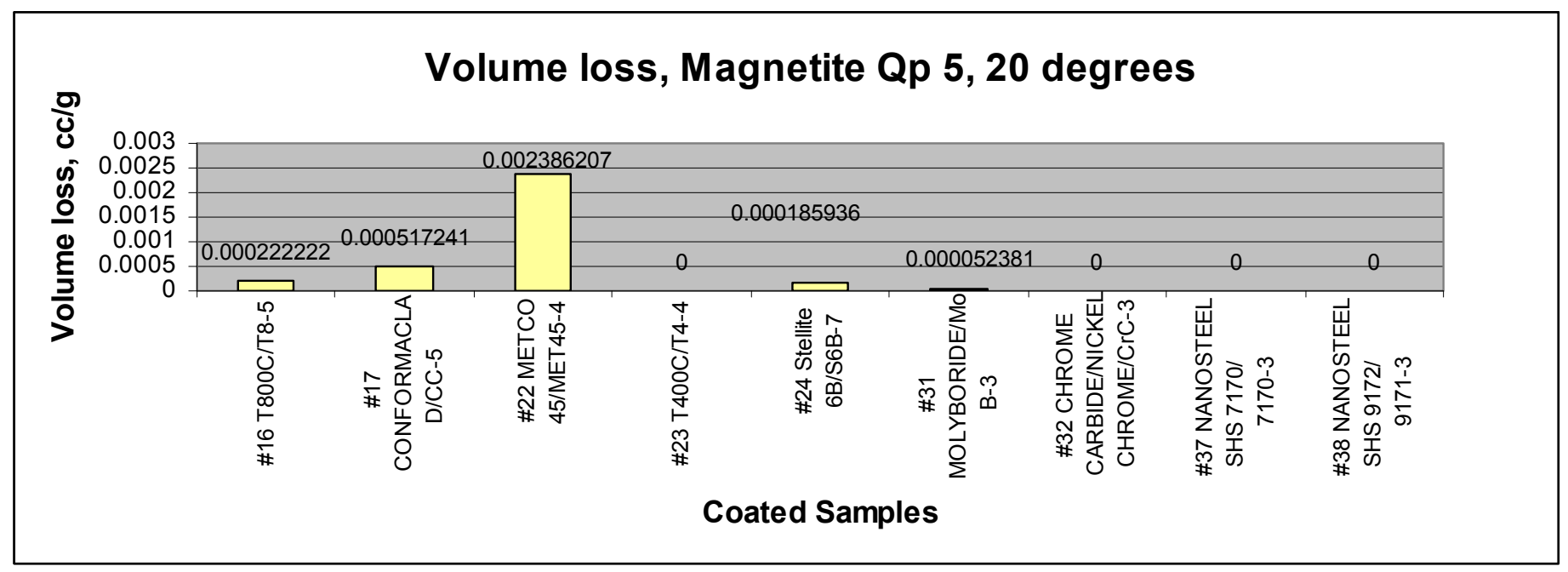

Figure 20: Volume loss of coated samples using Magnetite, Qp 5, 20 degrees.

Several coatings showed a net weight gain after being eroded with magnetite. This was caused by the magnetite particles compacting during testing and embedding onto the surface of the coatings. EDS analysis of the magnetite eroded faces confirmed the presence of iron on the surface of the coupons. It was interesting to note that although the erosion rate on the Molybdenum-boride coating was very small it did indeed show a weight and volume loss.

Of the bare metal alloys only Nimonic 105 was erosion tested using magnetite. The results are reported in Table 12.

Table 12: Erosion Rate and volume loss of Nimonic 105 eroded with Magnetite (0-50 micron) Qp 5, 20 degrees.

\begin{tabular}{|c|c|c|c|c|c|c|c|}
\hline SAMPLE IDENTIFICATION & Erodent & Temperature & Velocity & Angle & Erosion Rate & Density & Volume Loss \\
\hline Bare Alloy & MAGNETITE 0-50 MICRON & $760 \mathrm{C}(1400 \mathrm{~F})$ & $900 \mathrm{ft} / \mathrm{sec}$ & 20 & delta WIQp & & Erosion rate/density \\
\hline Sample \# & Weight (initial) $\mathrm{g}$ & Weight (final) $\mathrm{g}$ & delta W (g) & Qp (g) & $\mathrm{mg} / \mathrm{g}$ & g/cc & cc loss/g \\
\hline \#15 NIMONIC 105/NIM105-3 & 13.2738 & 13.2668 & 0.0070 & 5 & 1.400 & 7.99 & 0.000175219 \\
\hline
\end{tabular}

*Note for Volume Loss, the data are only accurate to 3 significant figure

Bar graphs representing the Erosion rate and volume loss experienced by Nimonic 105

are shown in Figures 21 and 22. 


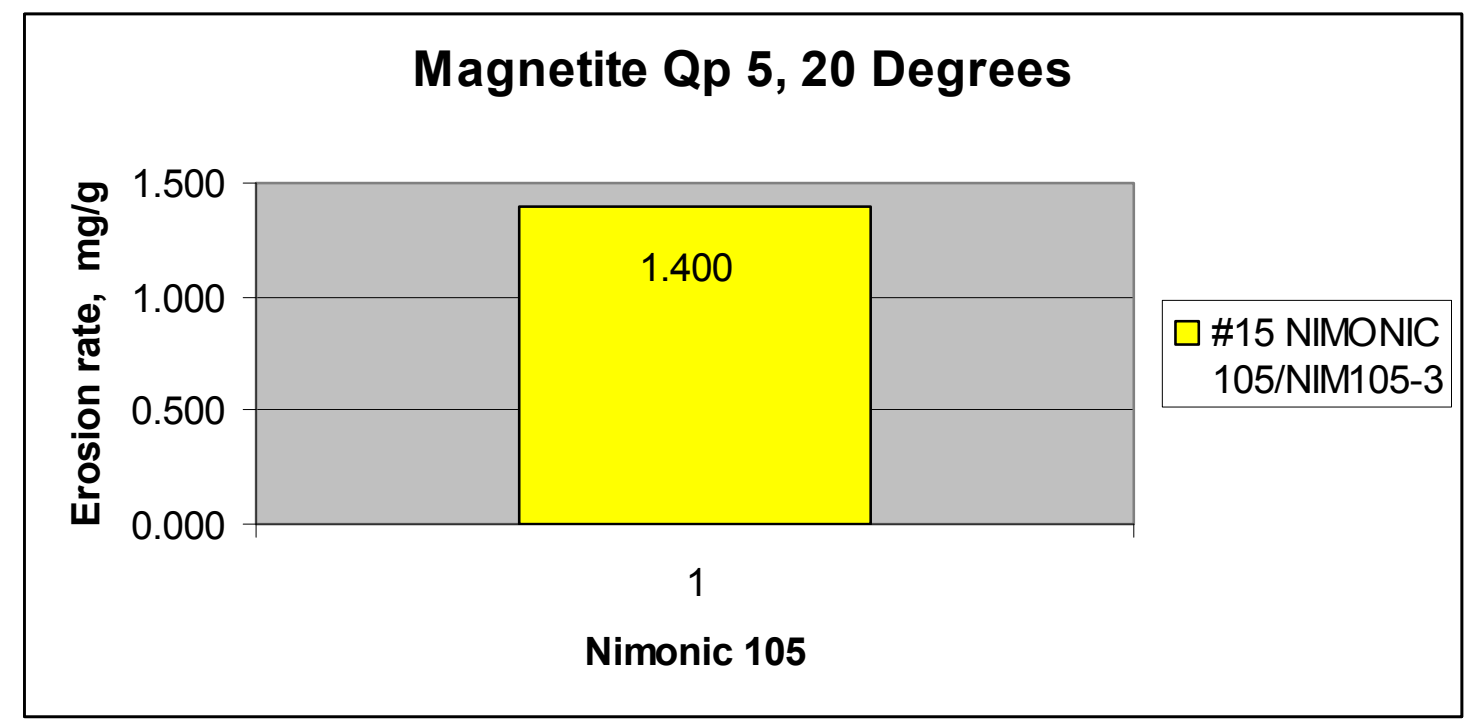

Figure 21: Erosion rate of Nimonic 105 using Magnetite 0-50 micron.

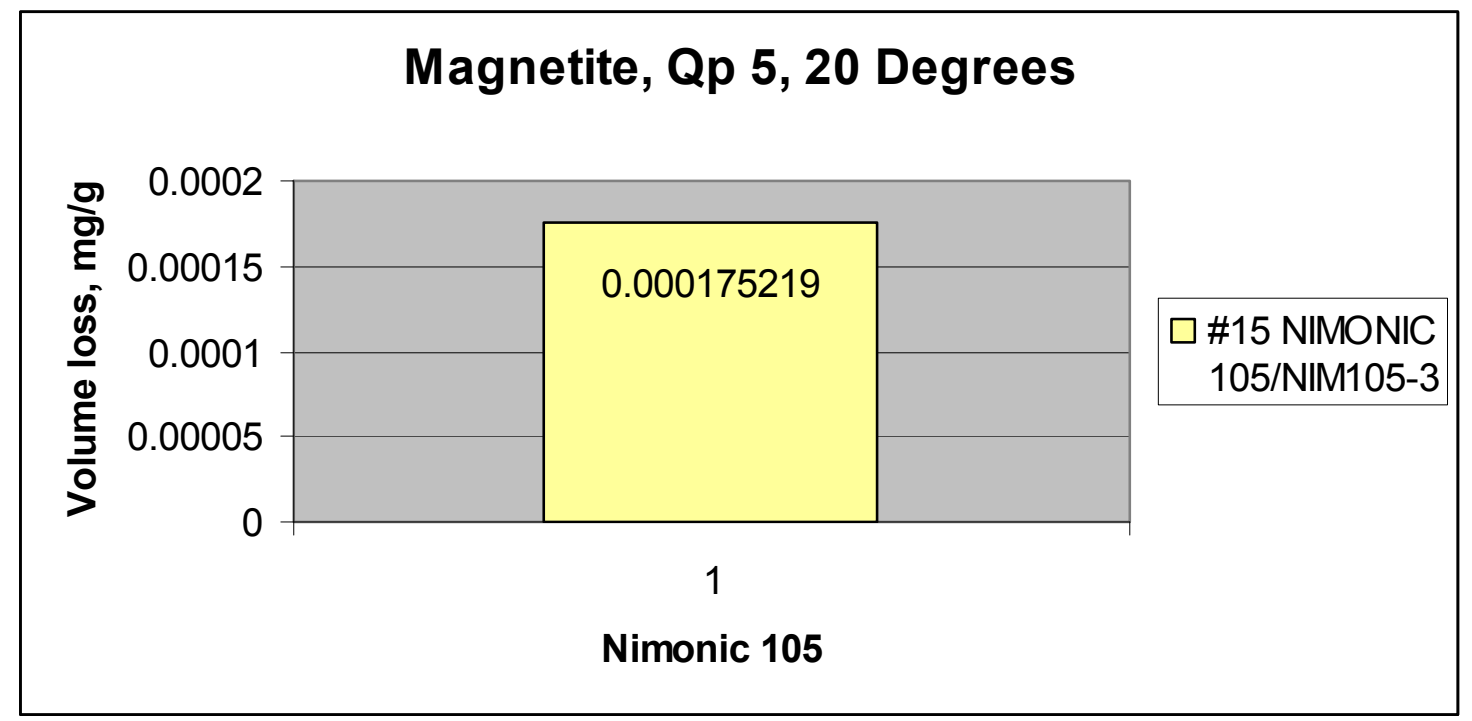

Figure 22: Volume loss of Nimonic 105 eroded with Magnetite 0-50 micron.

\section{Steam Turbine Airfoil Erosion and Comparison with Laboratory Results}

In order to understand solid particle erosion in steam turbines, several airfoils were examined and photographed. The airfoils in the following photographs have all seen at least 10 years of engine service prior to their removal. The most severe erosion is found on the concave side of the airfoil near the trailing edge. Some airfoils experience a prominent steam cut just below the shroud. This phenomenon is illustrated by the red arrow in Figure 23. The area shown in the yellow circle was photographed at higher magnification to reveal the morphology of the solid particle erosion. 


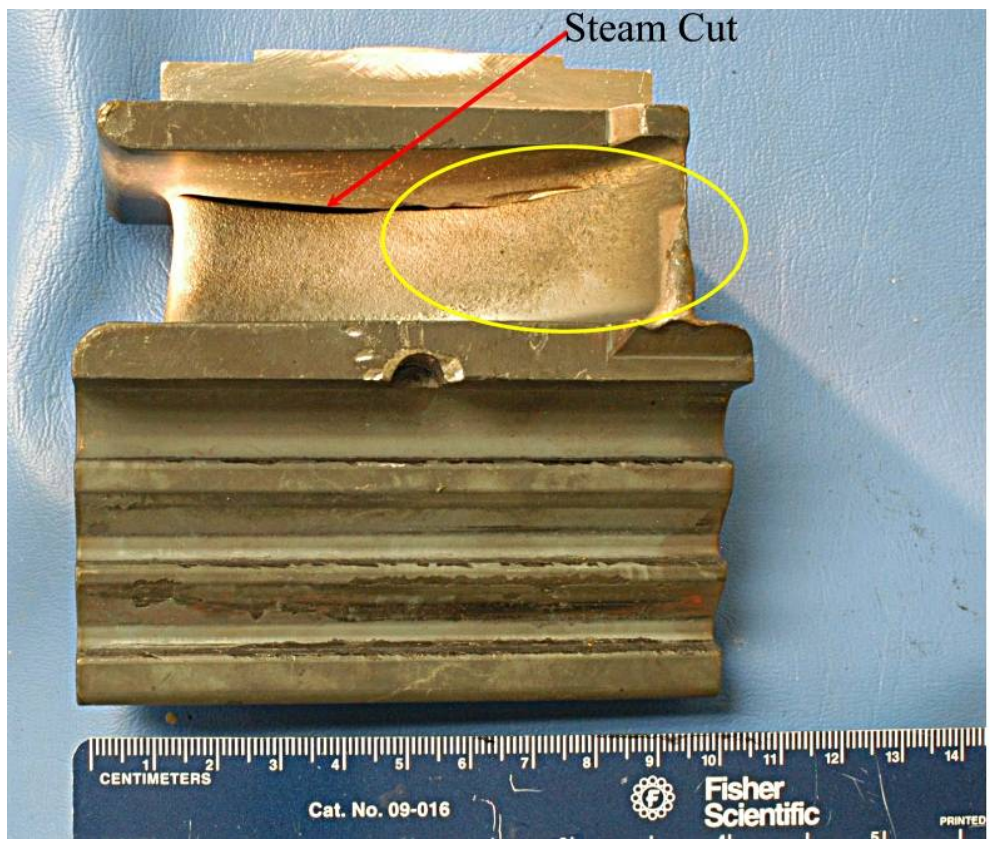

Figure 23: The concave side of a steam turbine airfoil. The red arrow indicates where, over time, the steam has cut into the airfoil just below the shroud. The area circled in yellow was examined at higher magnification.

The general erosion pattern, shown in Figure 24, reveals the distinct scalloped pattern typically found in solid particle erosion. Figures 25 to 27 show more examples of typical SPE damage from a macroscopic perspective. At higher magnification in Figure 28, this damage exhibits the same scalloped pattern. Figure 29 shows less erosion damage than the earlier figures, but closer examination in Figure 30 again shows similar microscopic features of SPE damage. A review of these field experiences is important because to judge the accuracy of the SPE test method utilized in this research project for the selection of coatings for USC steam turbines, it is first important to replicate the same damage mechanism in the laboratory. These examples of field SPE damage serve as a baseline for assessing the test method choice including test conditions such as particle loading, velocity, angle of impingement, and erodent. 


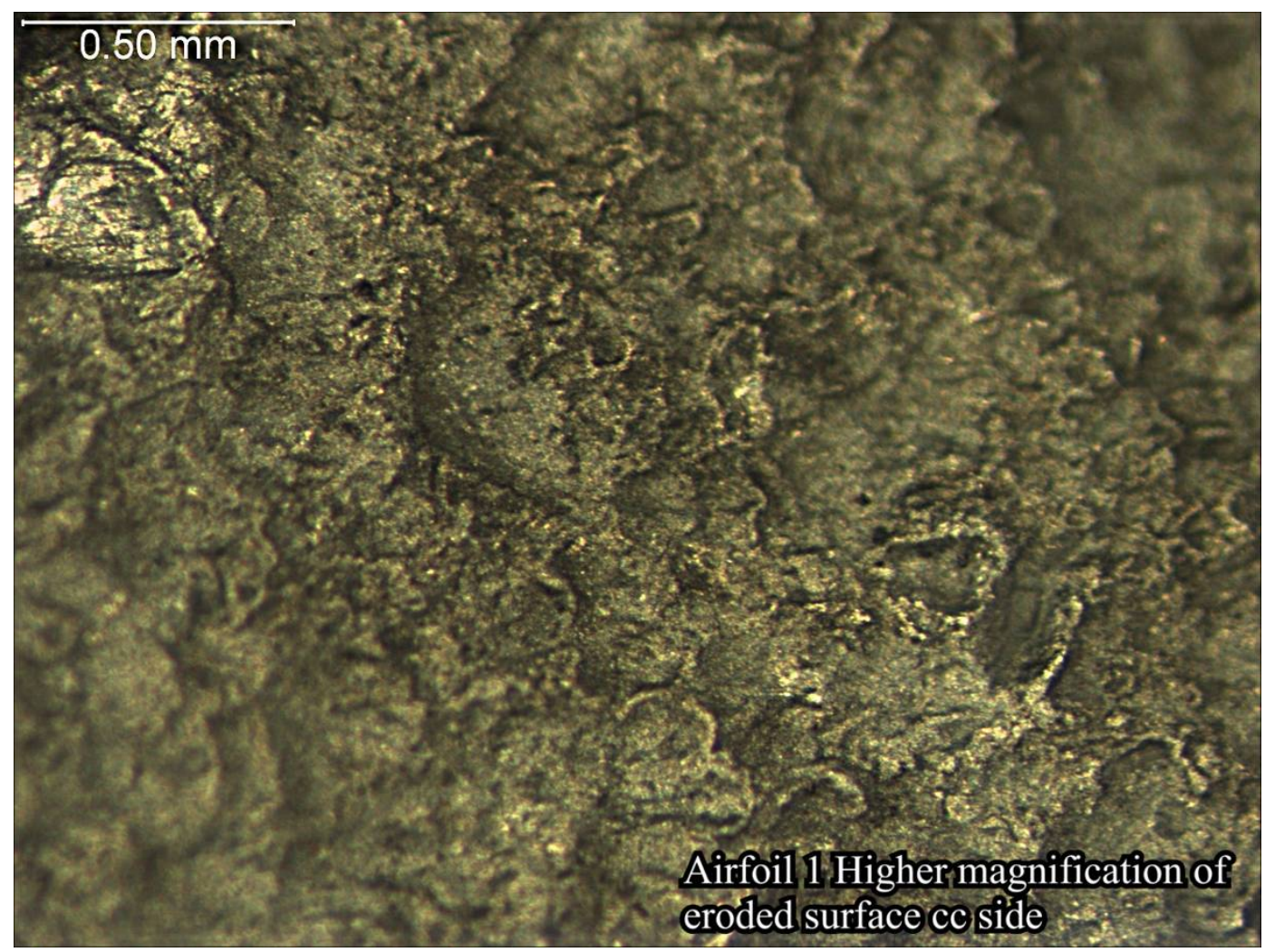

Figure 24: Scalloped pattern due to solid particle erosion, found on the concave side of a steam turbine airfoil.

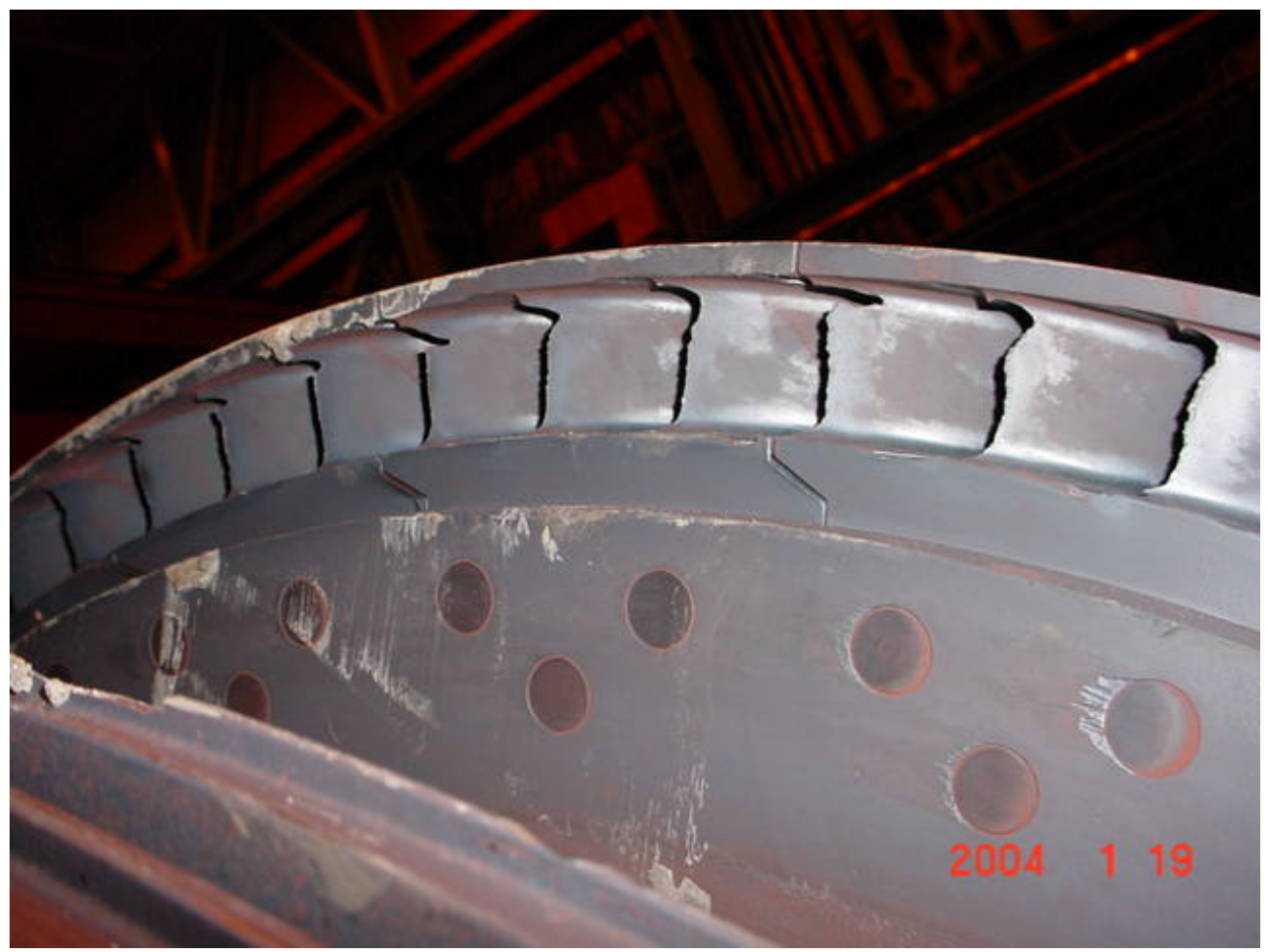

Figure 25: Shows a section of control stage blades from a steam turbine. Here the erosion of the trailing edge can be seen clearly. 


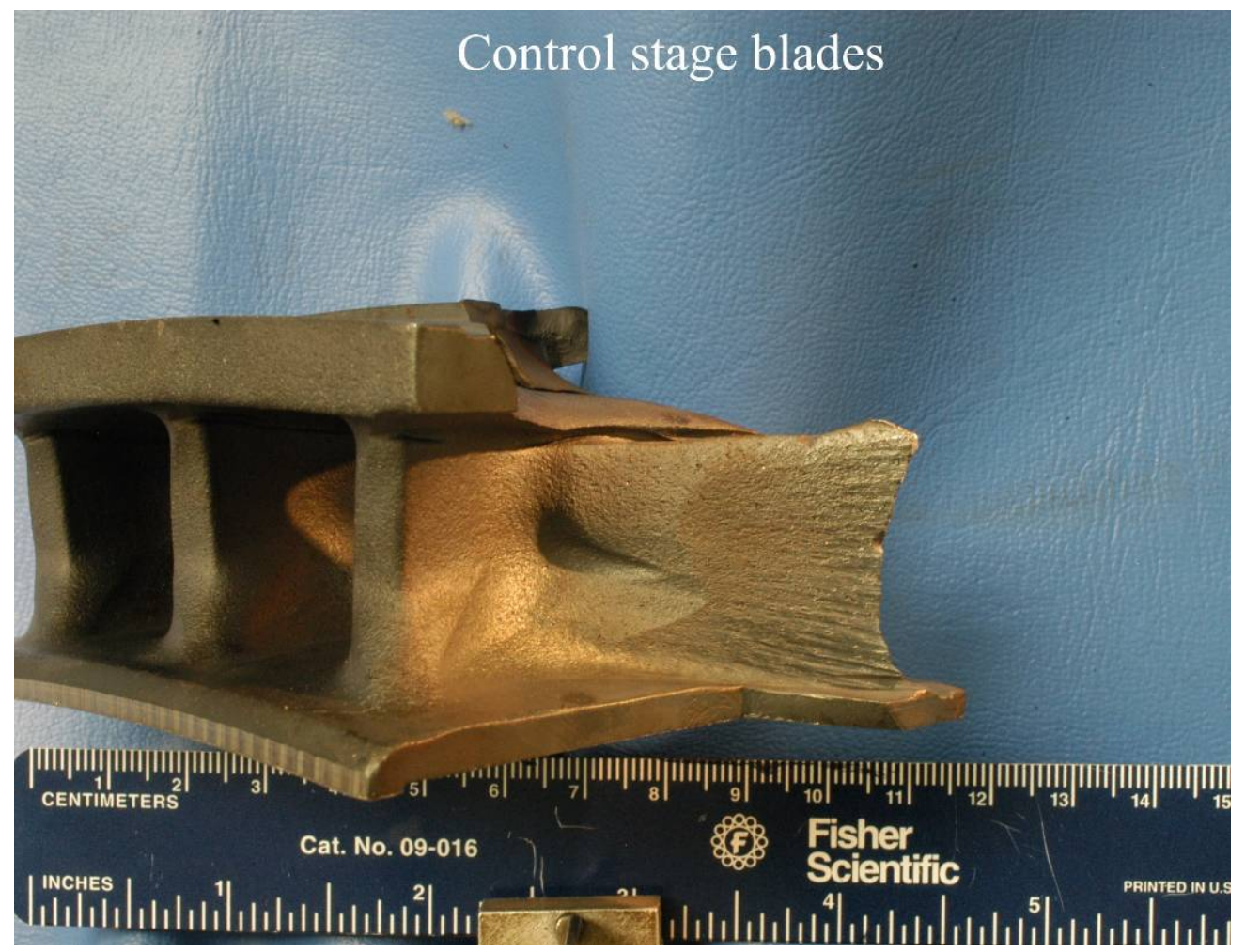

Figure 26: A control stage blade, or tri-pin, after removal from engine service has pronounced erosion on the trailing edge and the shroud.

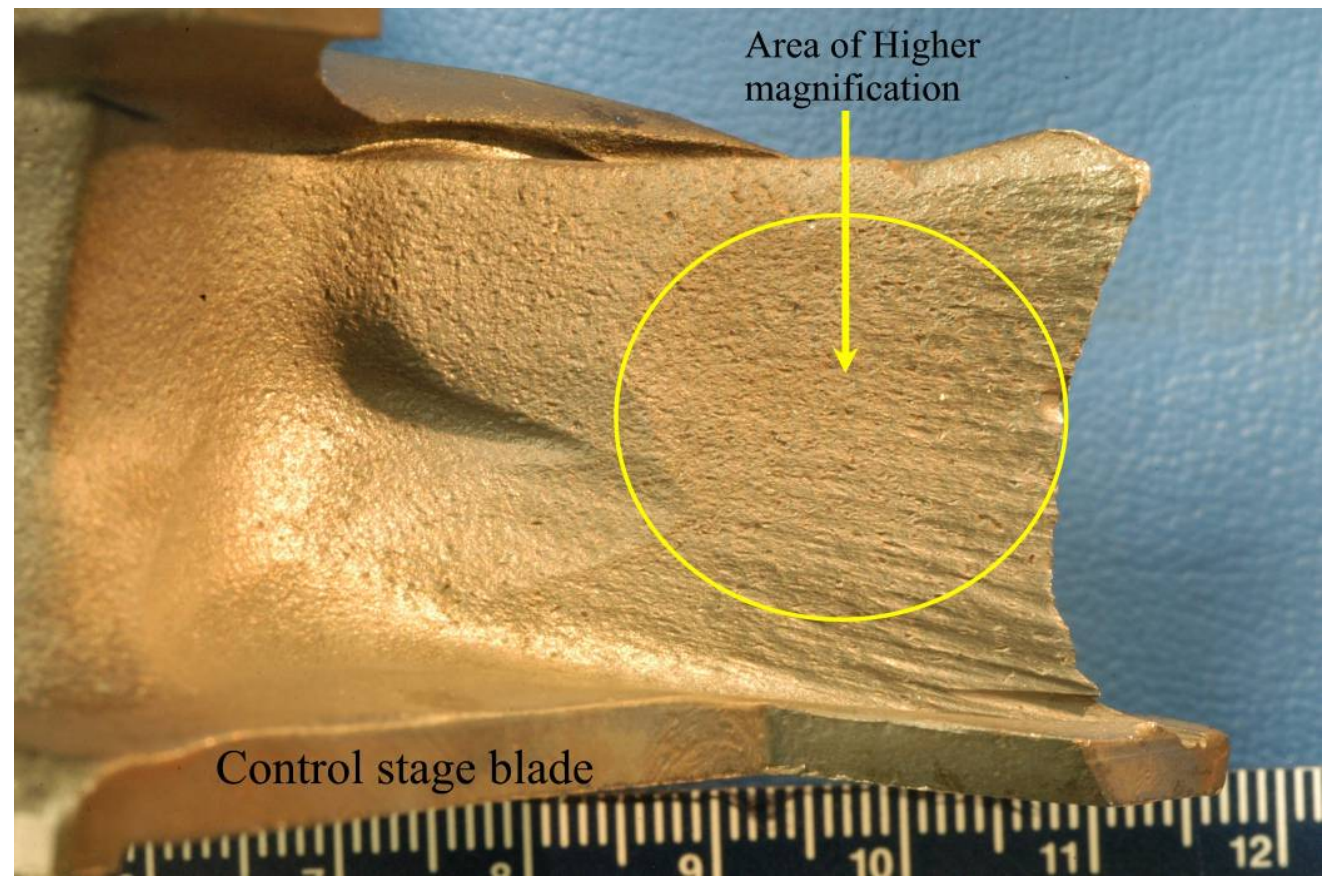

Figure 27: Closer examination of the trailing edge, concave surface of the control stage blade shows signs or pitting and scalloping typical of solid particle erosion. 


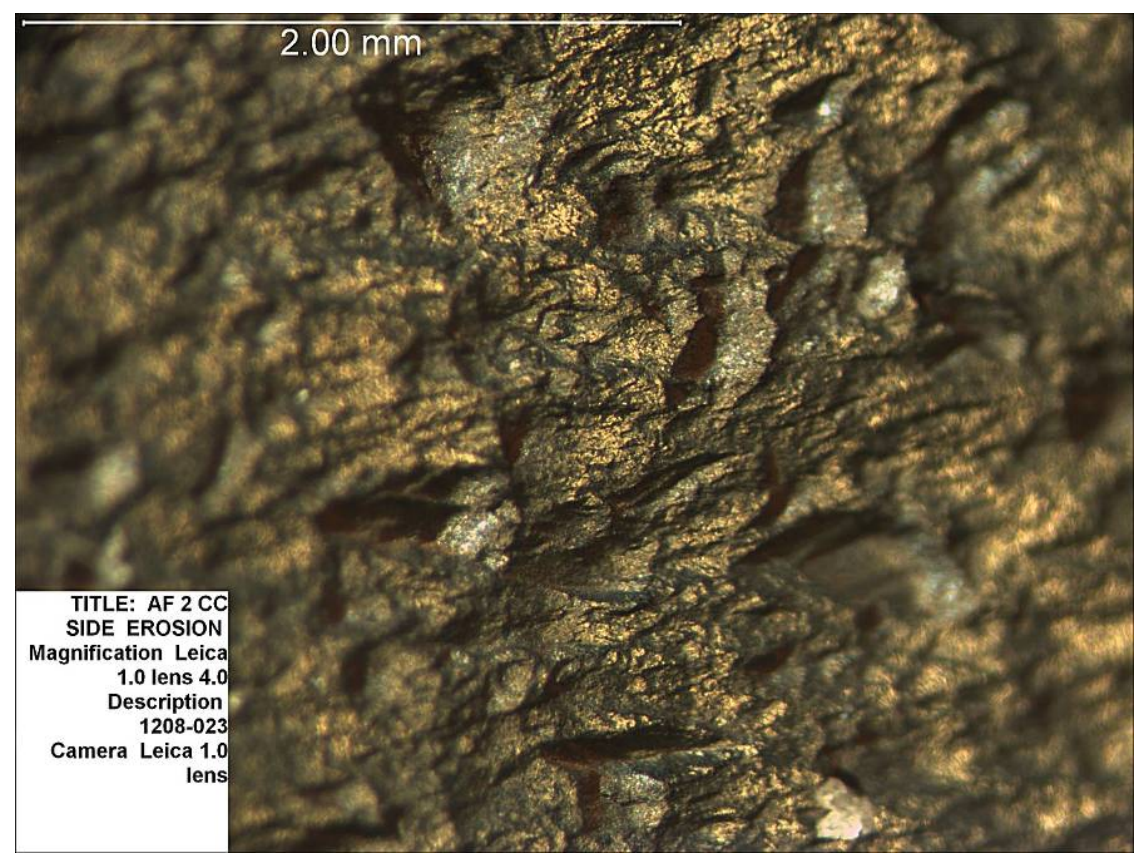

Figure 28: The scalloped pattern on the surface of the control stage blade is shown at higher magnification in this image taken with a stereoscopic camera.

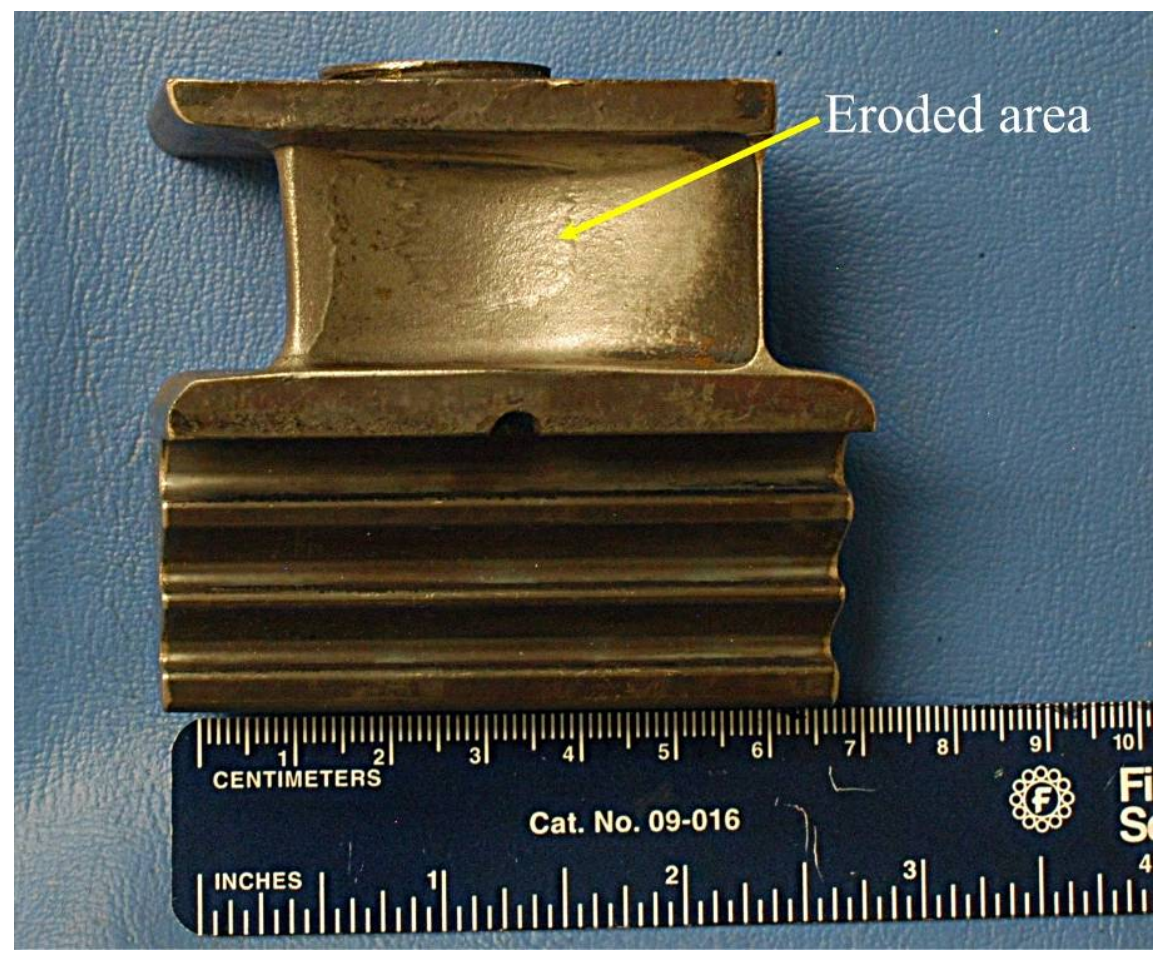

Figure 29: This steam turbine airfoil does not show the same degree of erosion seen in other airfoils however a pattern of erosion is still evident on the concave side of the airfoil's surface. 


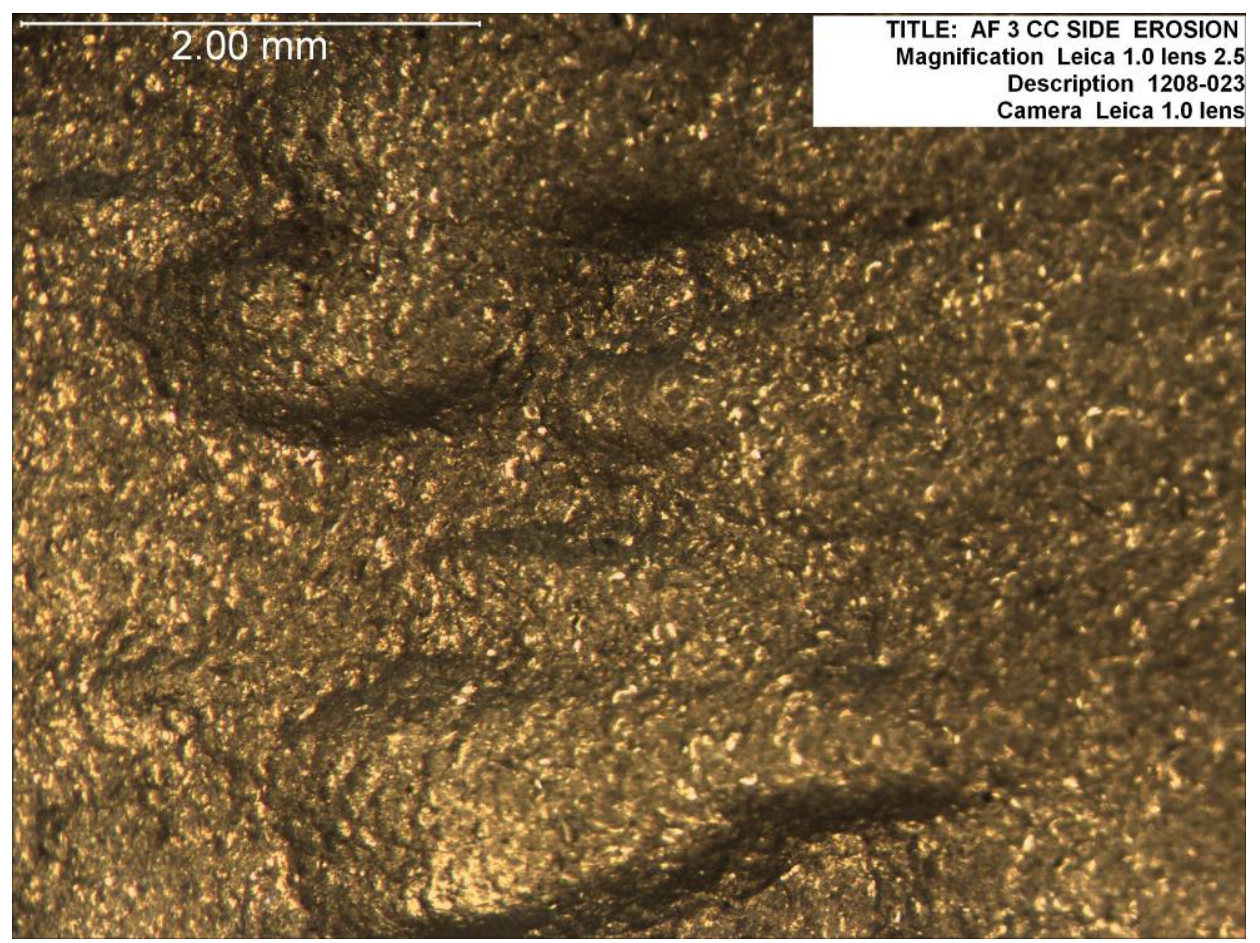

Figure 30: Higher magnification reveals the beginnings of the scallop pattern caused by solid particle erosion along the concave side of the trailing edge.

Figure 31 and 32 show typical surface images of moly-boride samples after laboratory SPE erosion testing exposed to both silica sand and the magnetite erodents. Overall, the damage appears consistent with field observations with scalloped surfaces indicative of SPE.

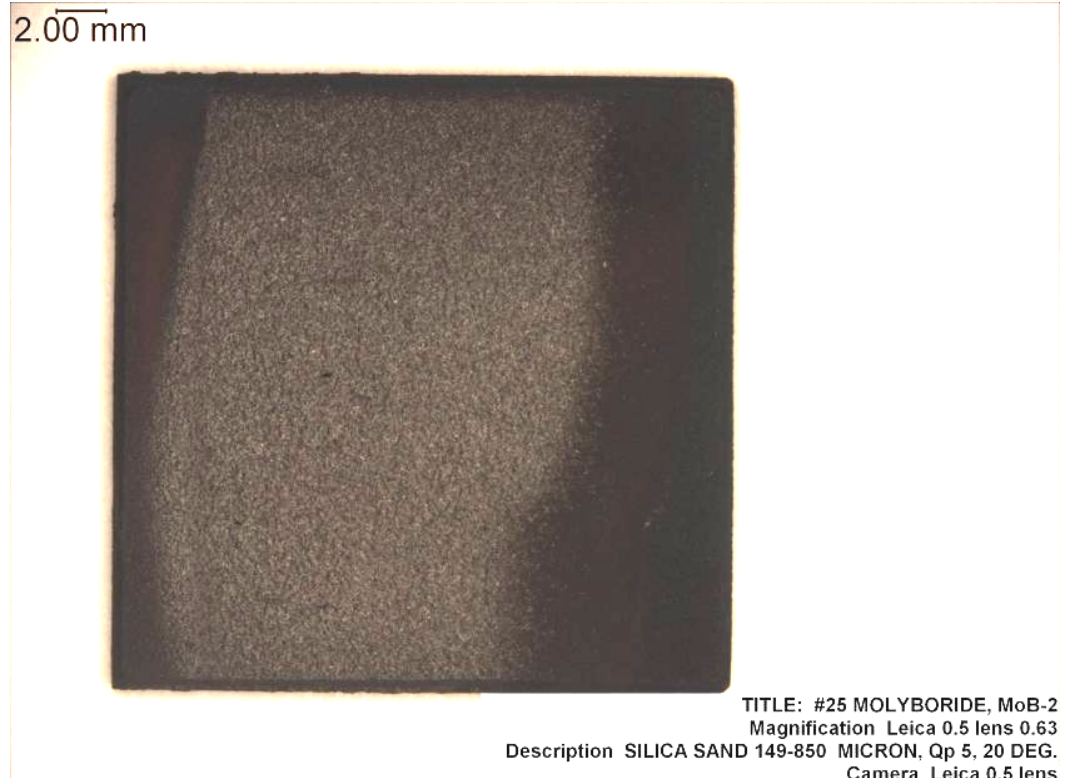

Figure 31: Typical appearance of a coupon's erosion surface, after testing. 


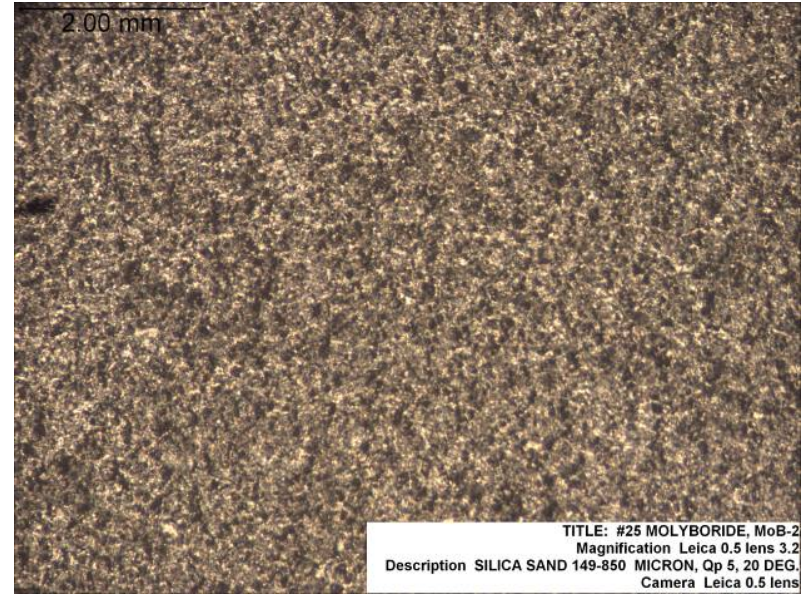

Molyboride Silica Sand Qp 5, 20 Deg.

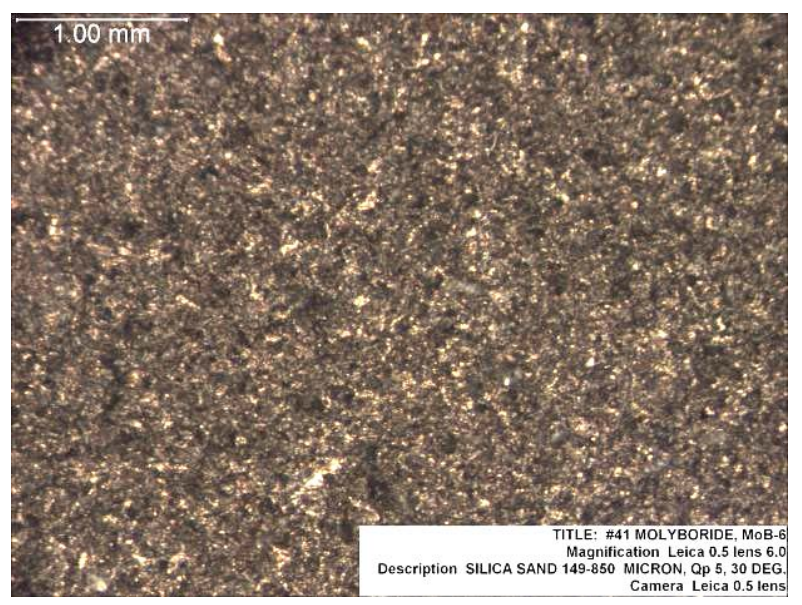

Molyboride Silica Sand Qp 5, 30 Deg.

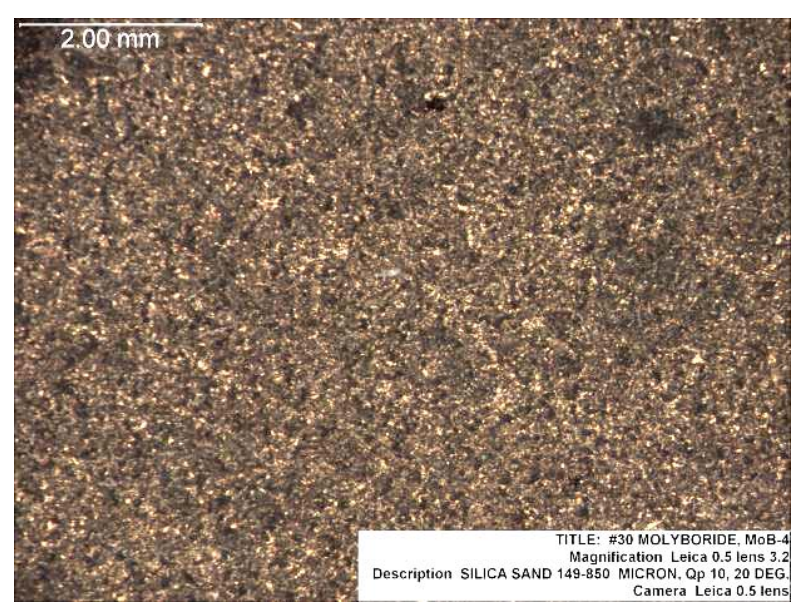

Molyboride Silica Sand Qp 10, 20 Deg.

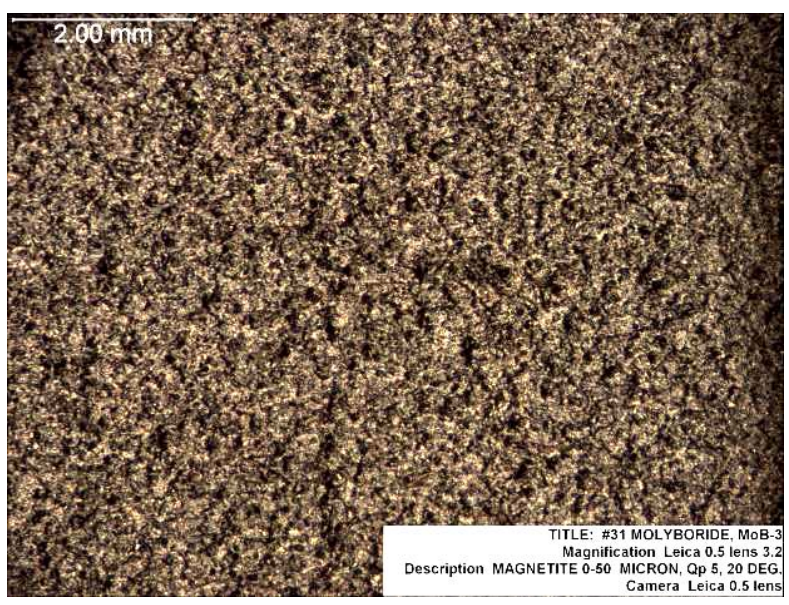

Molyboride Magnetite Qp 5, 20 Deg.

Figure 32

Appearance of SPE damage from laboratory test coupons exposed under different erosion test conditions.

\section{SEM Analysis of Coated Specimens}

The surface morphology of each type of coating was examined in the scanning electron microscope in its as-coated and eroded conditions. The following figures represent the surface characteristics of the coatings. In all cases, significant changes in surface roughness and appearance were observed which supports the volume loss and erosion rate data in the previous sections. An overall review of the images show the magnetite erodent was less severe than the Silca Sand and that the Molyboride coating showed the least visual change from the as-coated to post-test condition. 


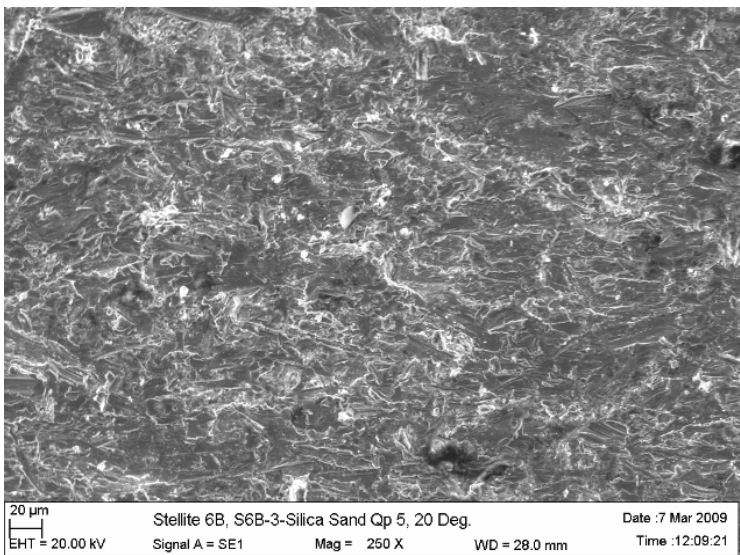

Stellite 6B-As Coated

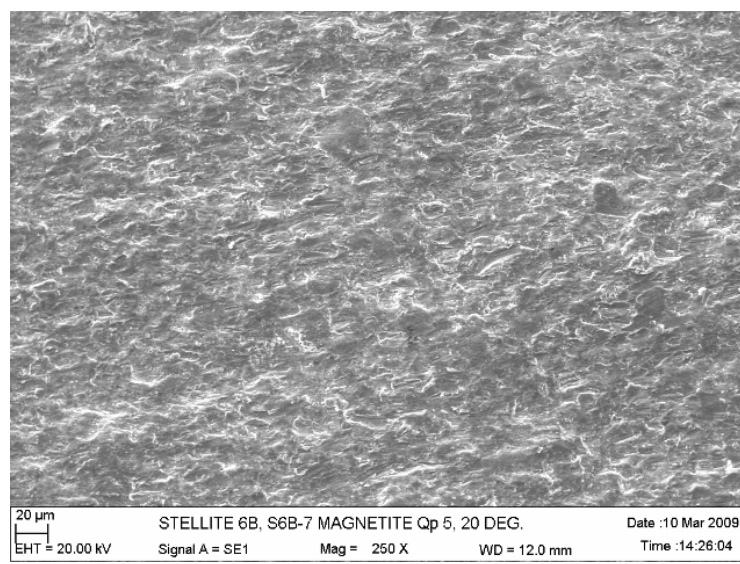

Stellite 6B- Alumina

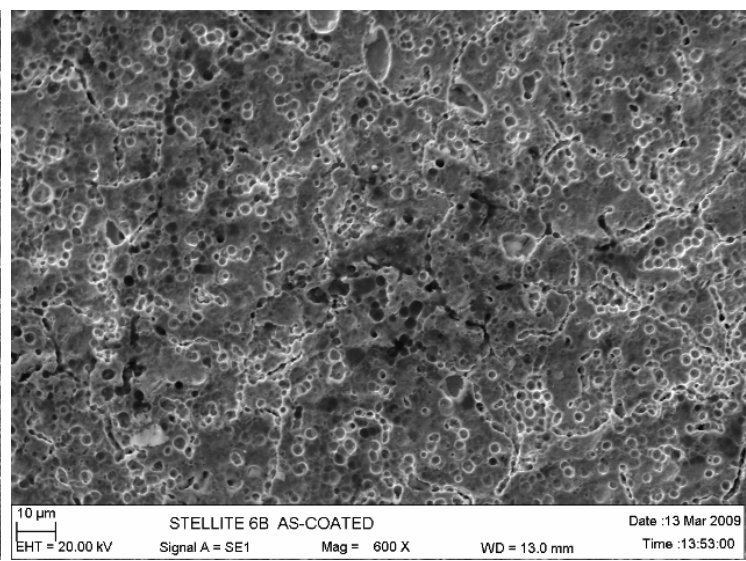

Stellite 6B- Silica Sand

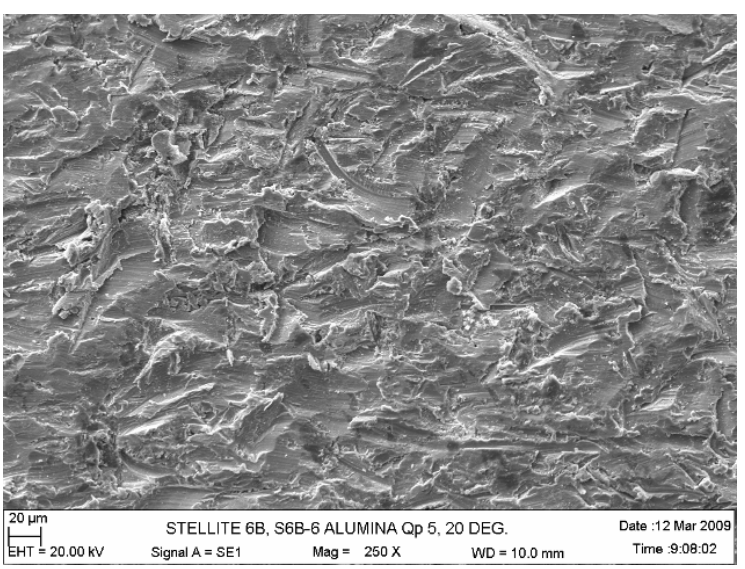

Stellite 6B-Magnetite

Figure 33

Stellite 6B Surface SEM Results As-coated and after laboratory erosion testing 


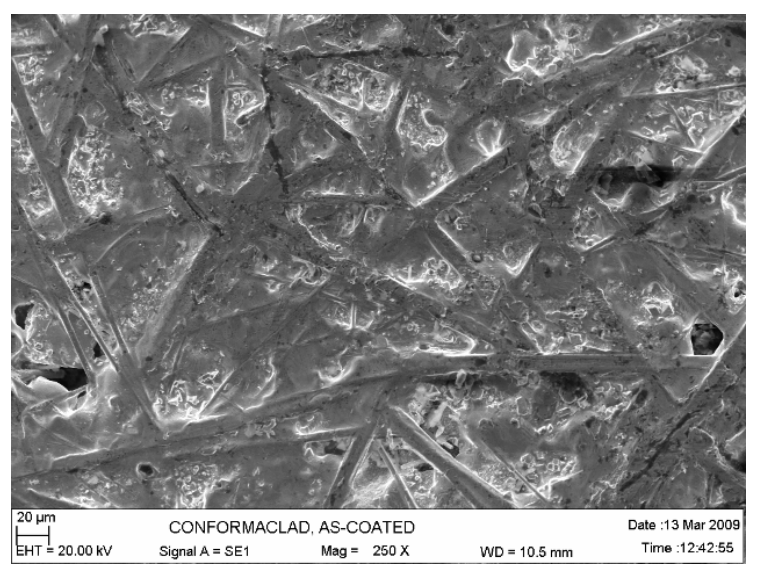

Conformaclad As-coated
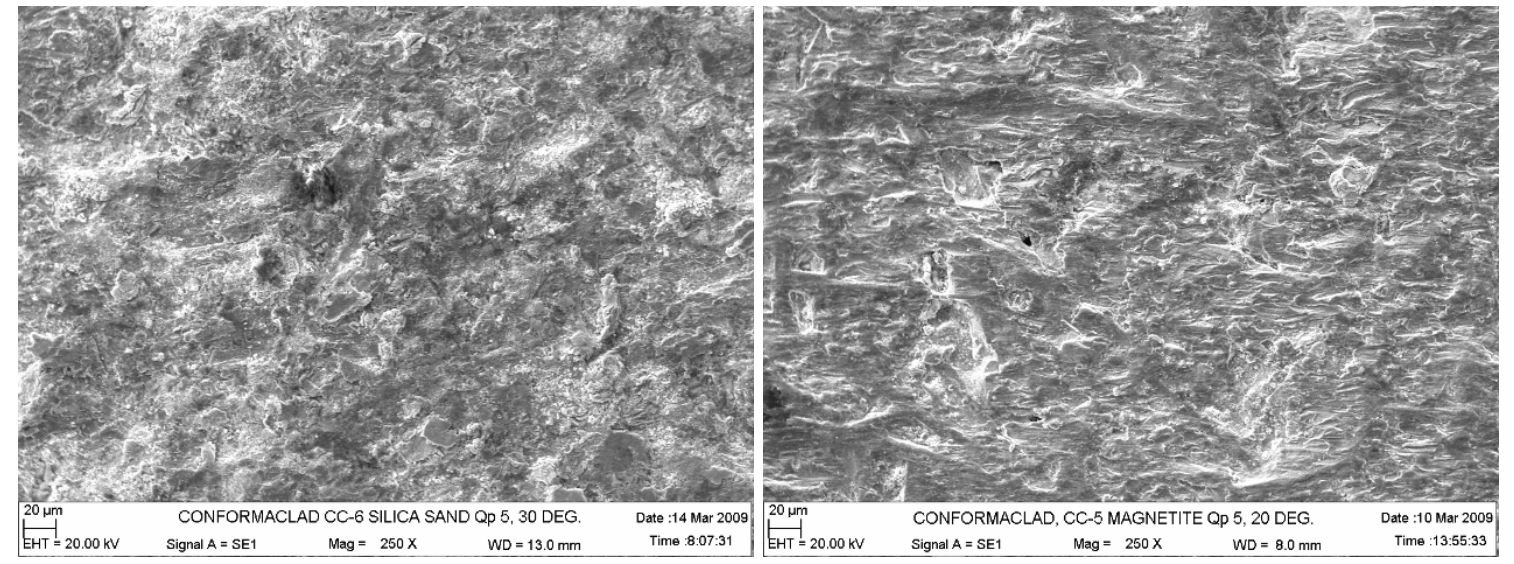

Conformaclad Silica Sand Qp 5, 30 Deg. Conformaclad Magnetite Qp 520 Deg.

Figure 34

Conformaclad Surface SEM Results As-coated and after laboratory erosion testing 


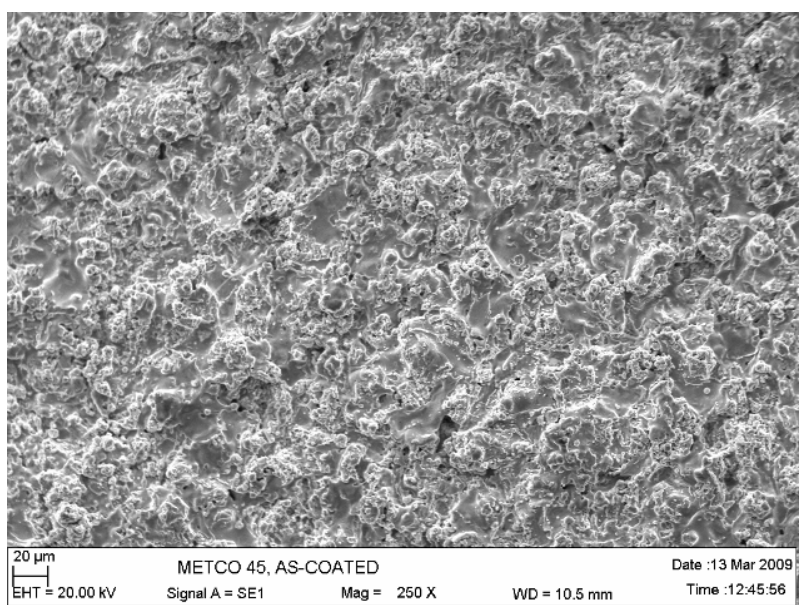

Metco 45 As-coated

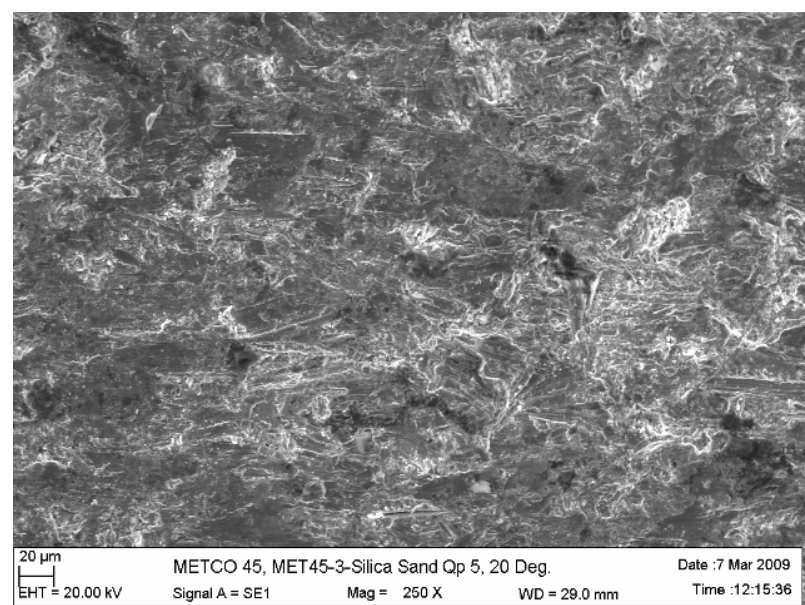

Metco 45 Silica Sand Qp 5, 20 Deg.

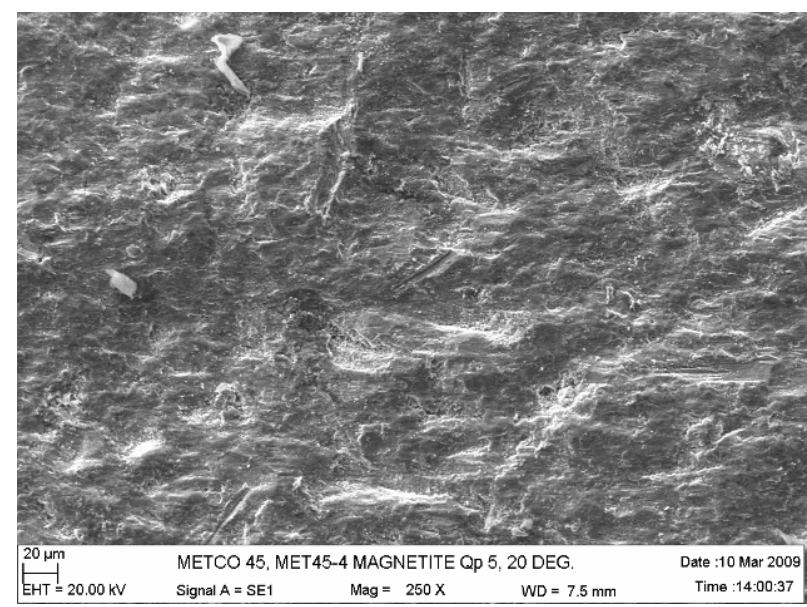

Metco 45 Magnetite Qp 520 Deg.

Figure 35

Metco 45 Surface SEM Results As-coated and after laboratory erosion testing 


\section{T400C}
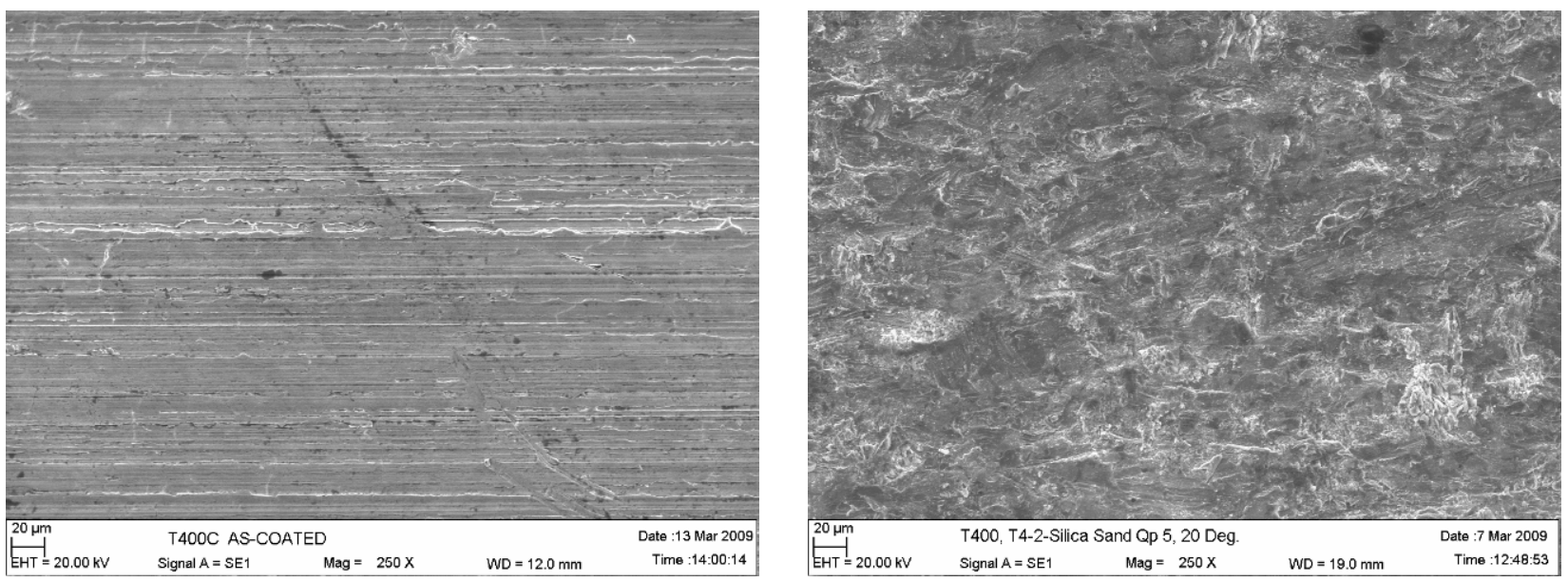

T400C As-coated

T400C Silica Sand Qp 5, 20 Deg

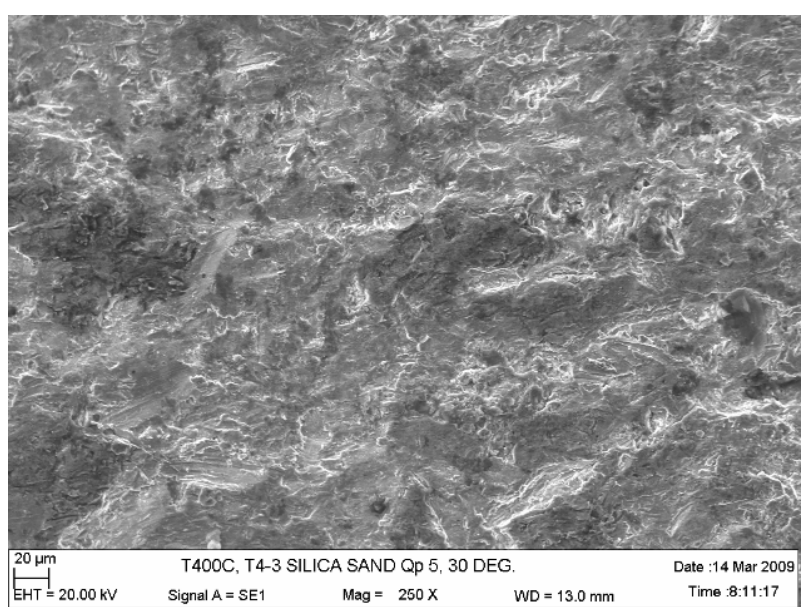

T400C Silica Sand Qp 5, 30 Deg.

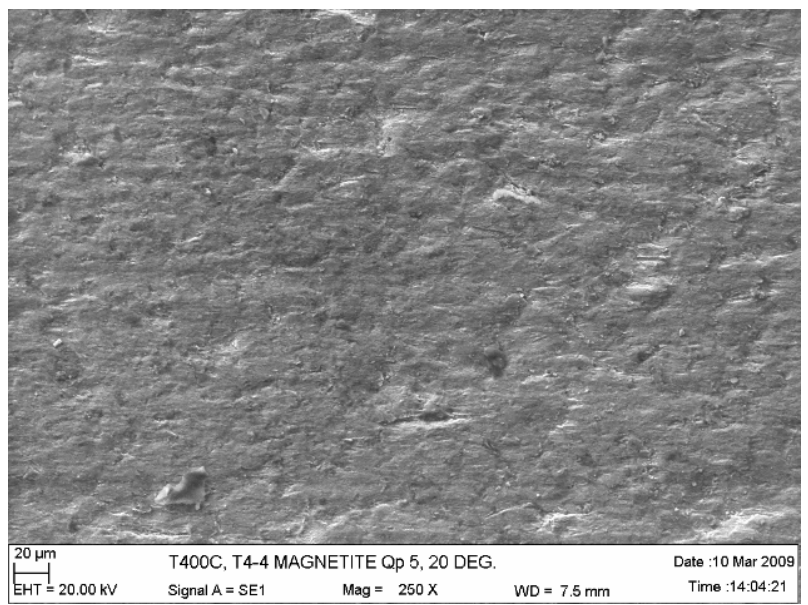

T400C Magnetite Qp 5, 20 Deg.

Figure 36

Tribaloy T400C Surface SEM Results As-coated and after laboratory erosion testing 


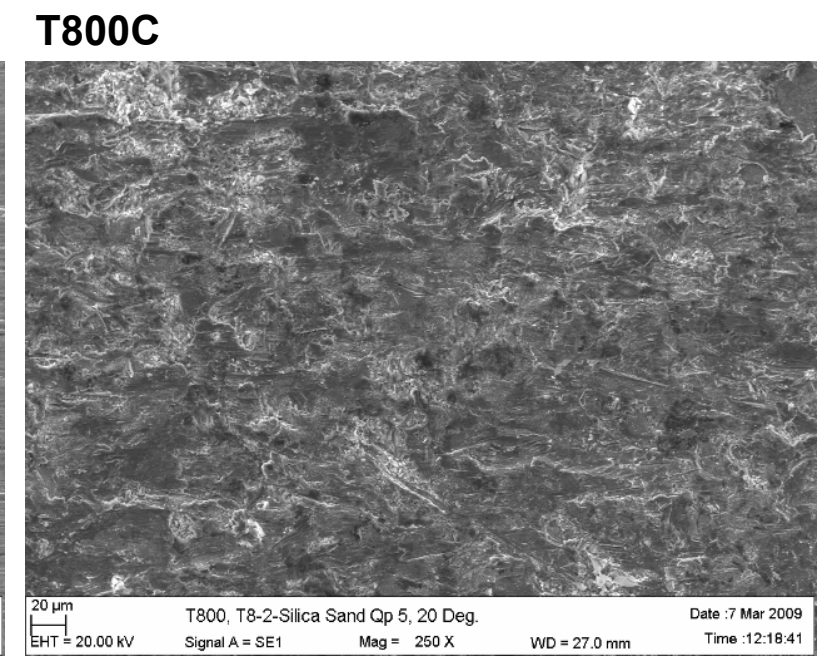

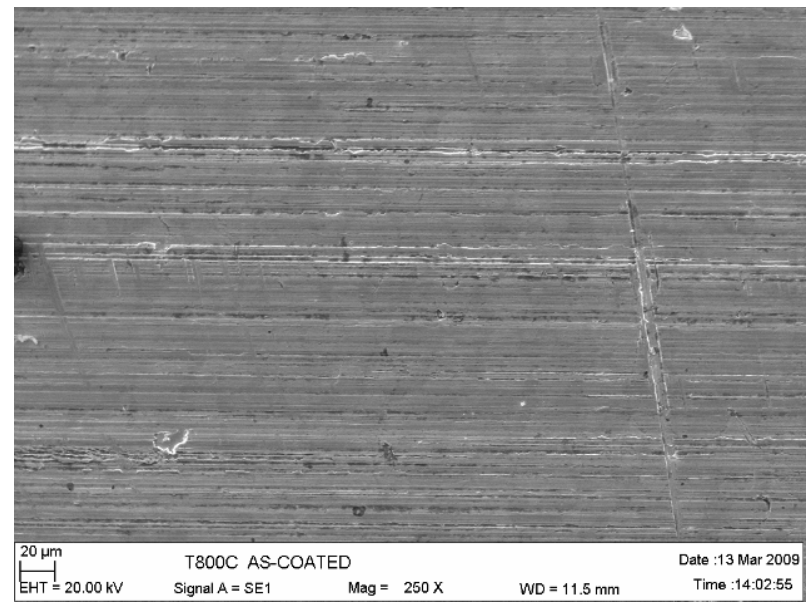

T800C As-coated
T800C Silica Sand Qp 5, 20 Deg.

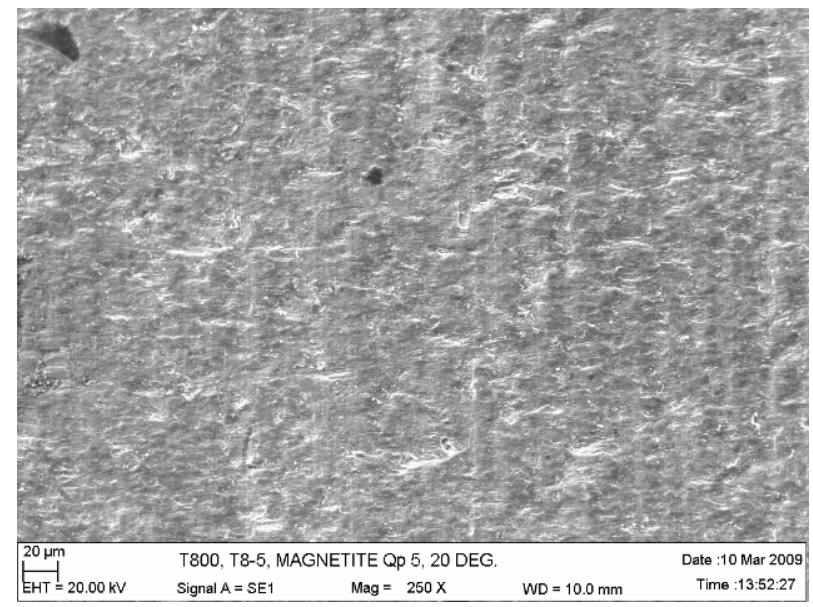

T800C Magnetite Qp 5, 20 Deg.

Figure 37

T800C Surface SEM Results As-coated and after laboratory erosion testing 


\section{Zircoat}

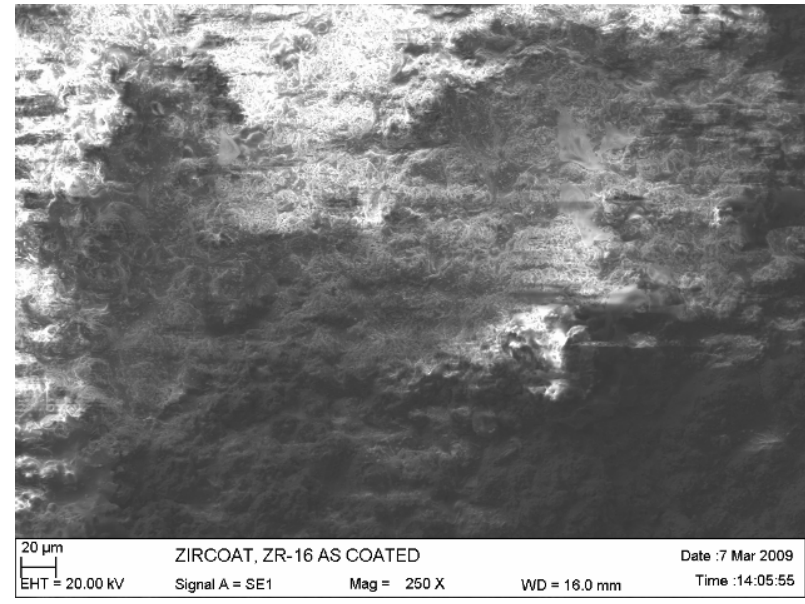

Zircoat As-coated

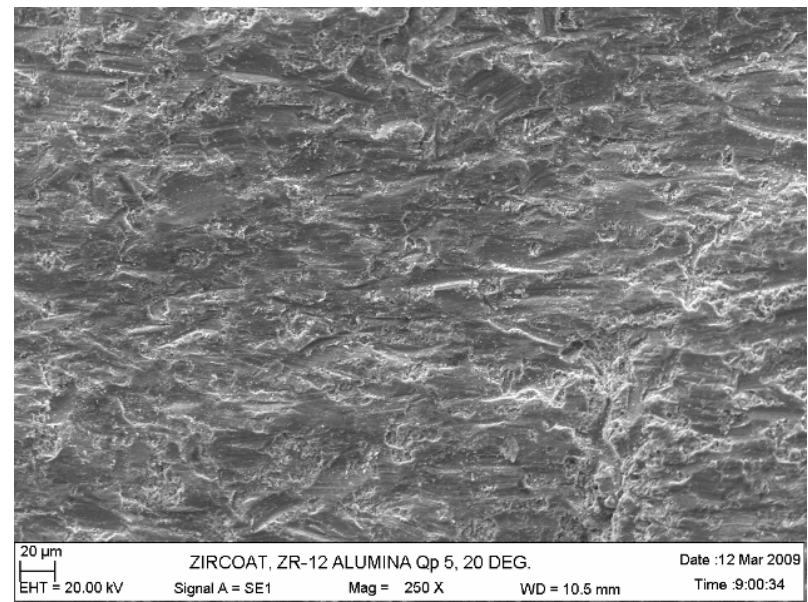

Zircoat Alumina Qp 5, 20 Deg.

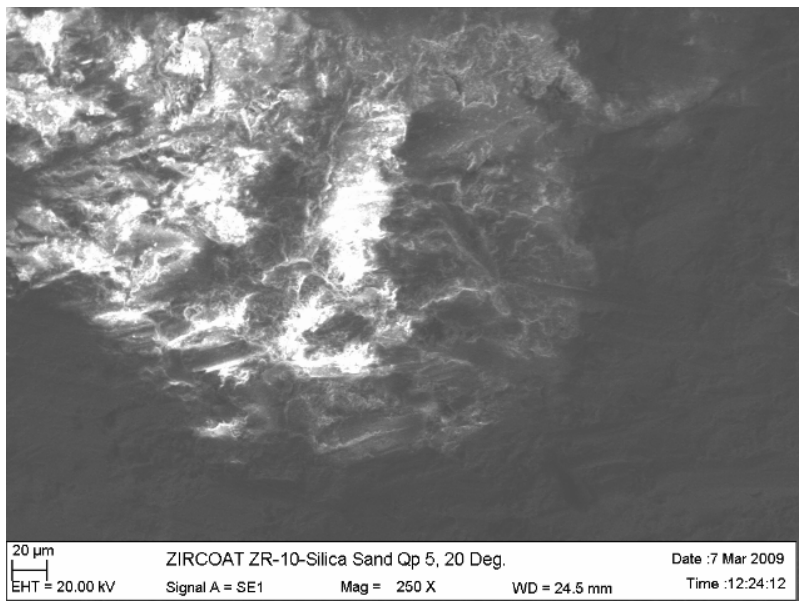

Zircoat Silica Sand Qp 5, 20 Deg.

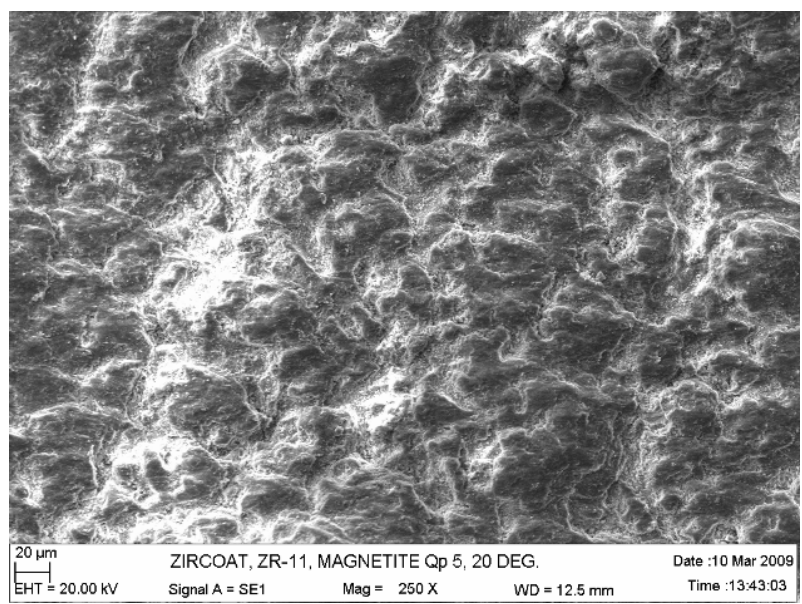

Zircoat Magnetite Qp 5, 20 Deg.

Figure 38

Zircoat Surface SEM Results As-coated and after laboratory erosion testing 


\section{Bodycote Tech 12}

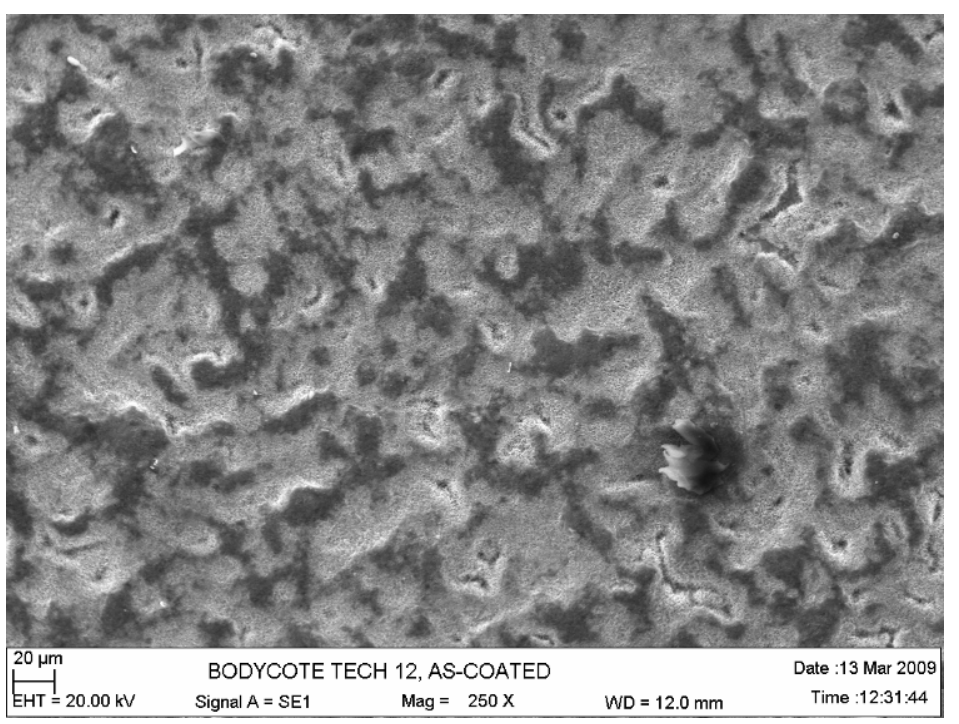

\section{Bodycote Tech 12 As-coated}

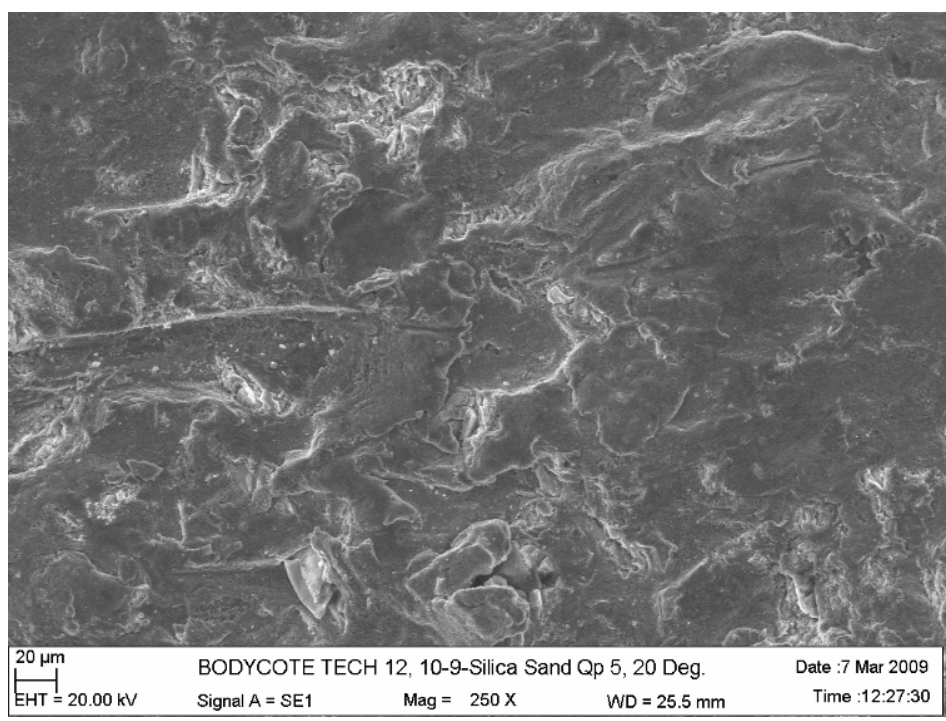

Bodycote Tech 12 Silica Sand Qp 5, 20 Deg.

Figure 39

Bodycote Tech 12 Surface SEM Results As-coated and after laboratory erosion testing (Note: The Bodycote Tech 12 sample had undergone humidity testing prior to erosion testing). 


\section{Bodycote Tech 23}

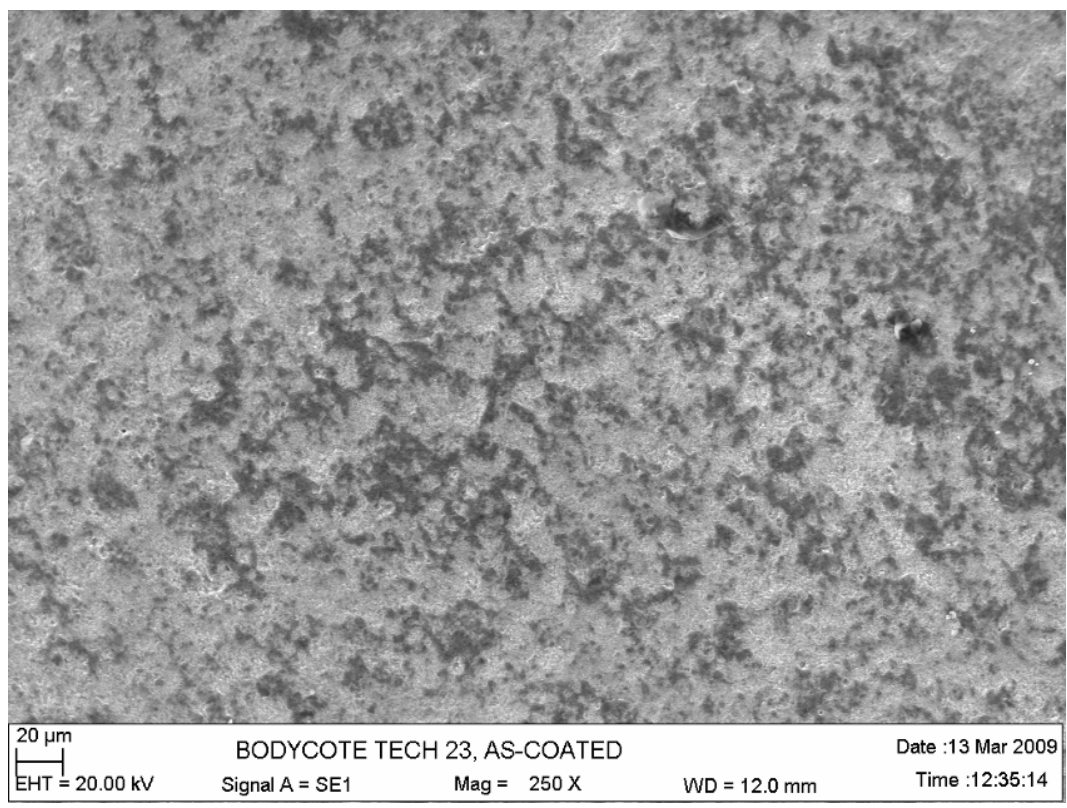

\section{Bodycote Tech 23 As-coated}

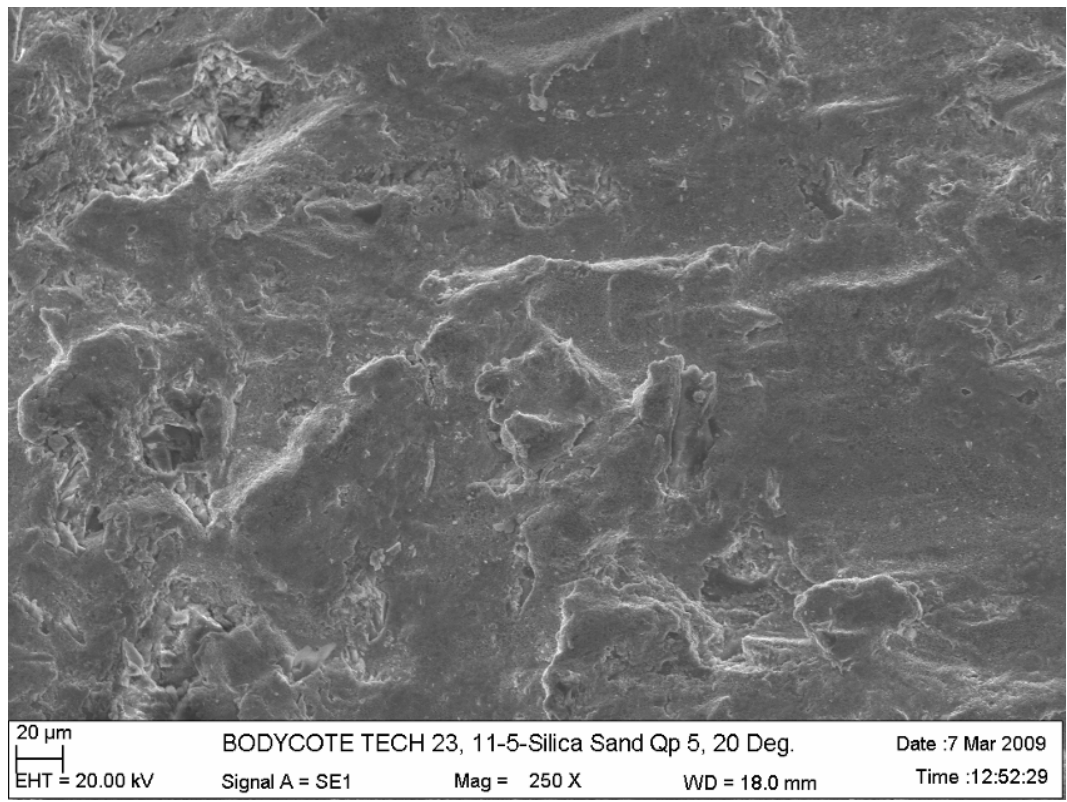

\section{Bodycote Tech 23 Silica Sand Qp 5, 20 Deg.}

Figure 40

Bodycote Tech 23 Surface SEM Results As-coated and after laboratory erosion testing (Note: The Bodycote Tech 23 sample had undergone humidity testing prior to erosion testing) 


\section{Chrome carbide-Nickel chrome}

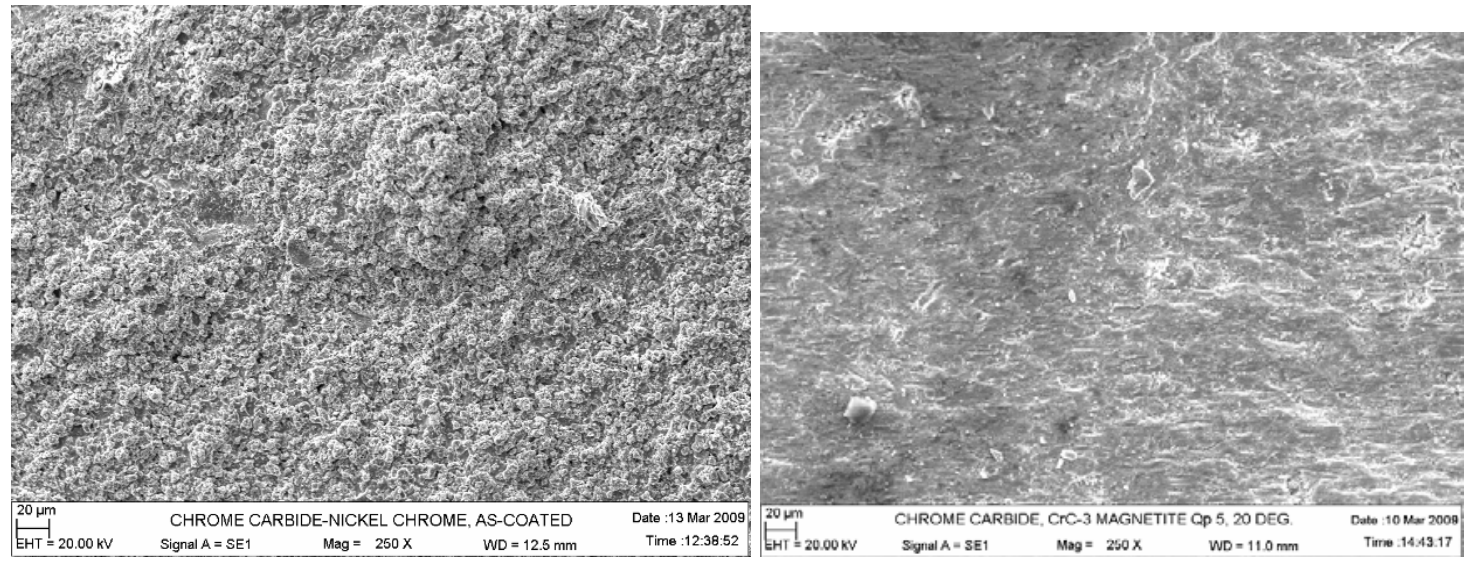

Chrome carbide As-coated Chrome carbide Silica Sand Qp 5, 20 Deg.

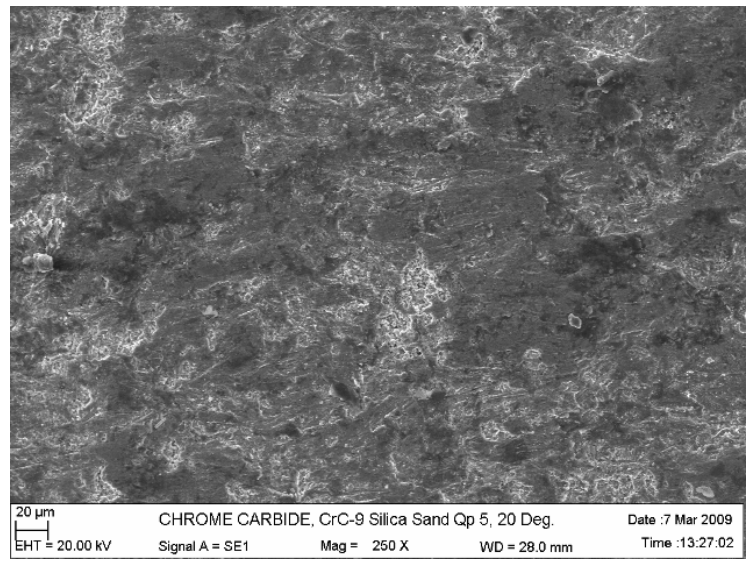

Chrome carbide Magnetite Qp 5, 20 Deg.

Figure 41

Chrome-carbide Surface SEM Results As-coated and after laboratory erosion testing 


\section{Nanosteel SHS 7170}

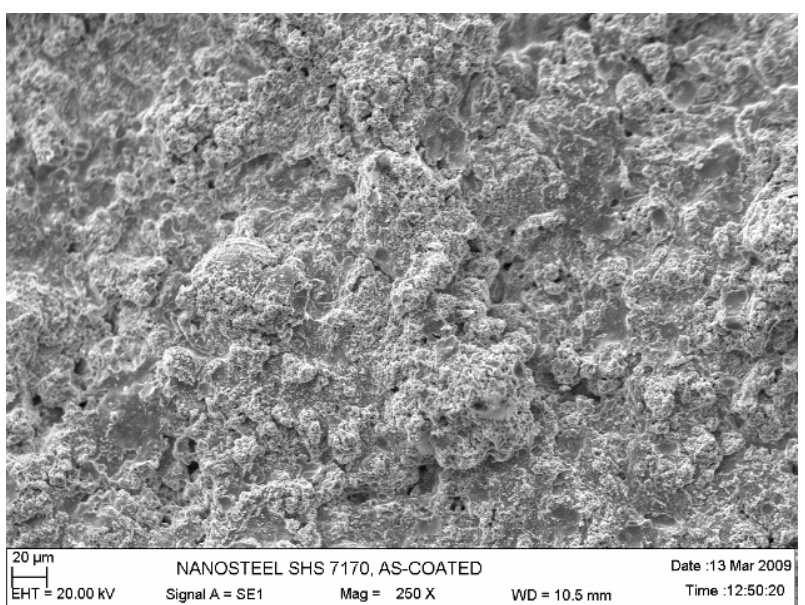

SHS 7170 As-coated

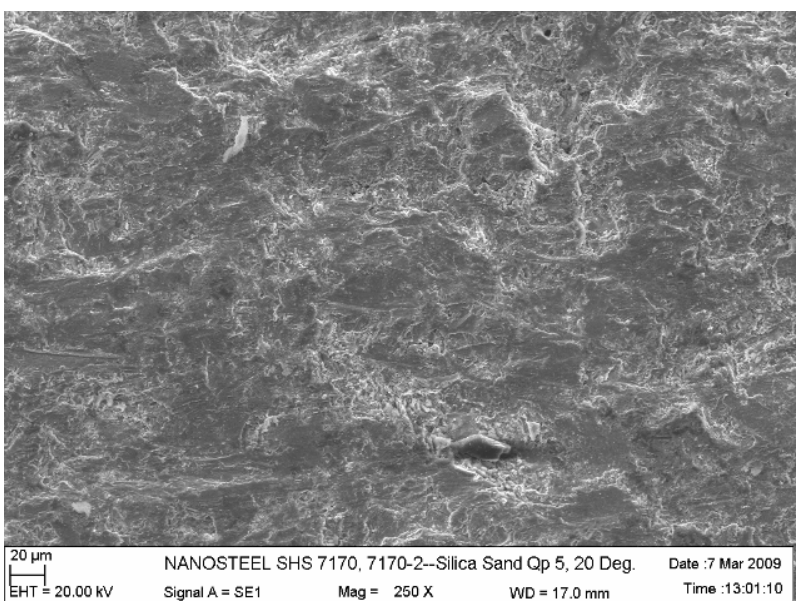

SHS 7170 Silica Sand Qp 5,

20 Deg.

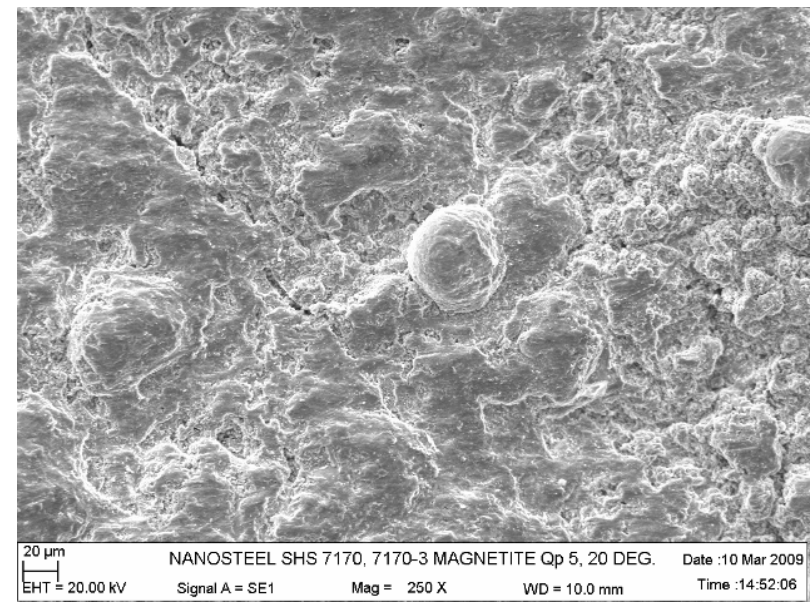

SHS 7170 Magnetite Qp 5, 20 Deg.

Figure 42

SHS 7170 Surface SEM Results As-coated and after laboratory erosion testing 


\section{Nanosteel SHS 9172}

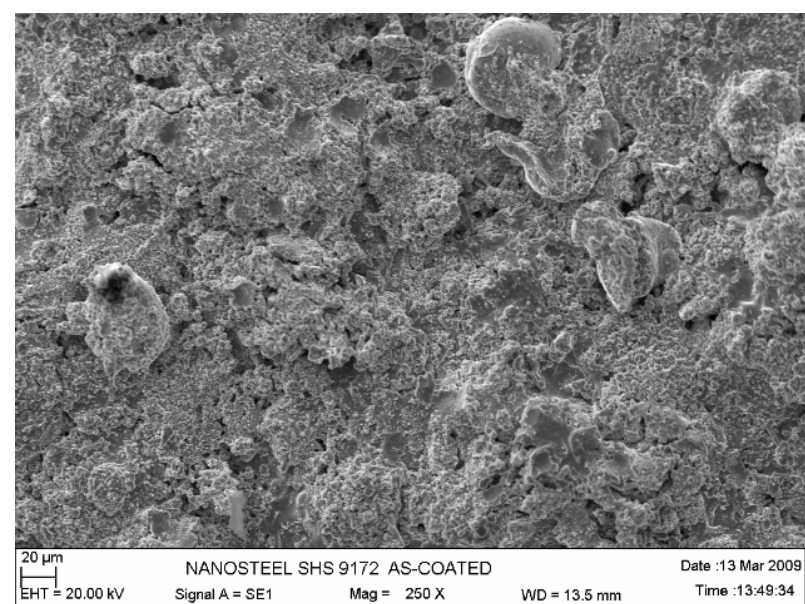

SHS 9172 As-coated

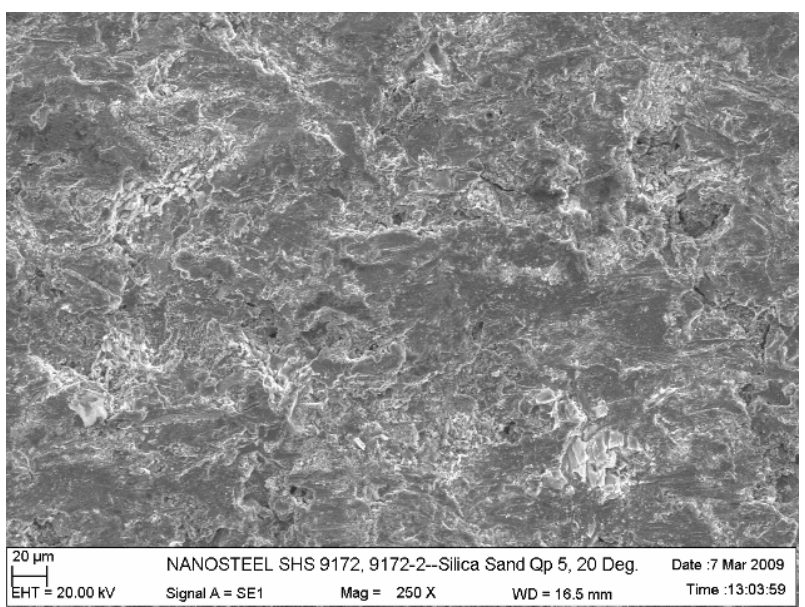

SHS 9172 Silica Sand Qp 5,

20 Deg.

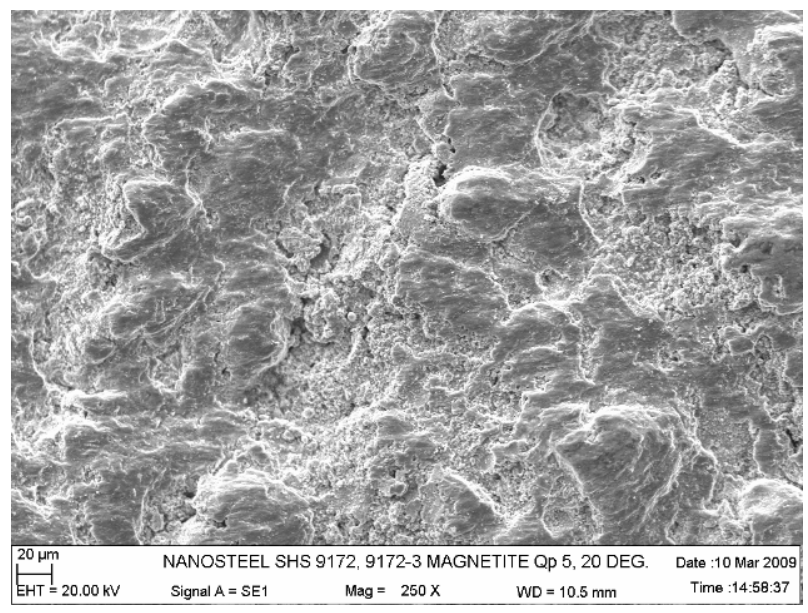

\section{SHS 9172 Magnetite Qp 5, 20 Deg.}

Figure 43

SHS 9172 Surface SEM Results As-coated and after laboratory erosion testing 

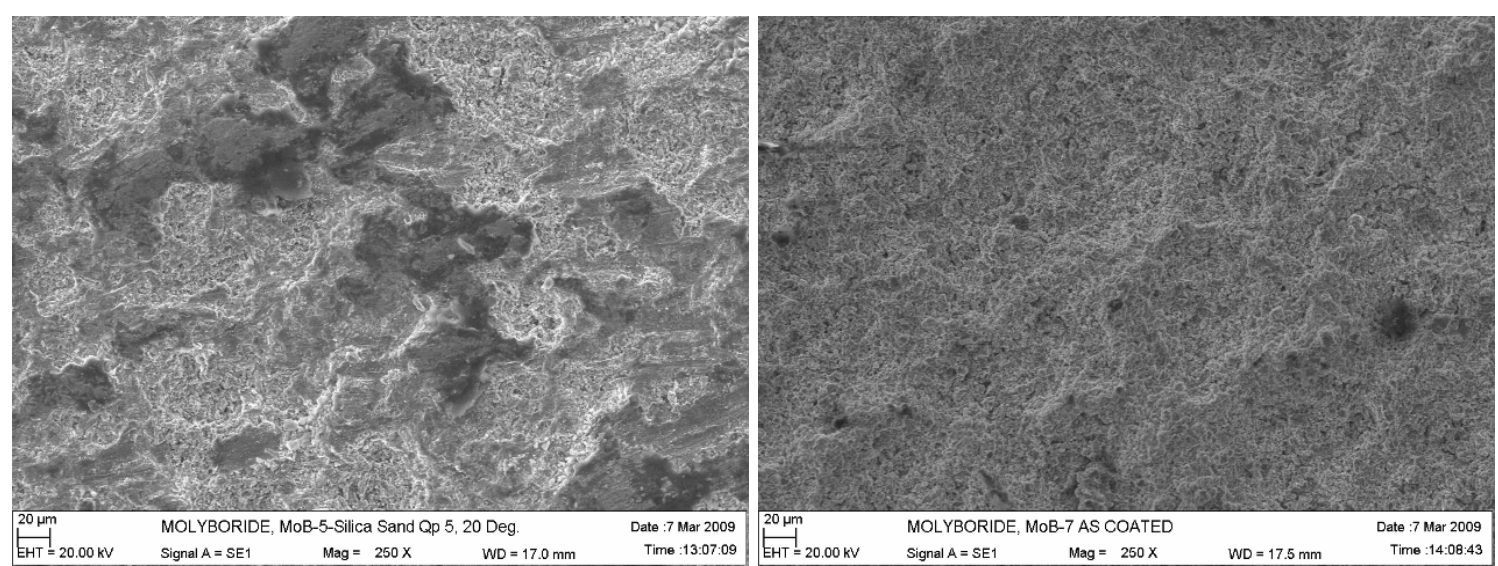

Molyboride As-coated

Molyboride Silica Sand Qp 5, 20 Deg.
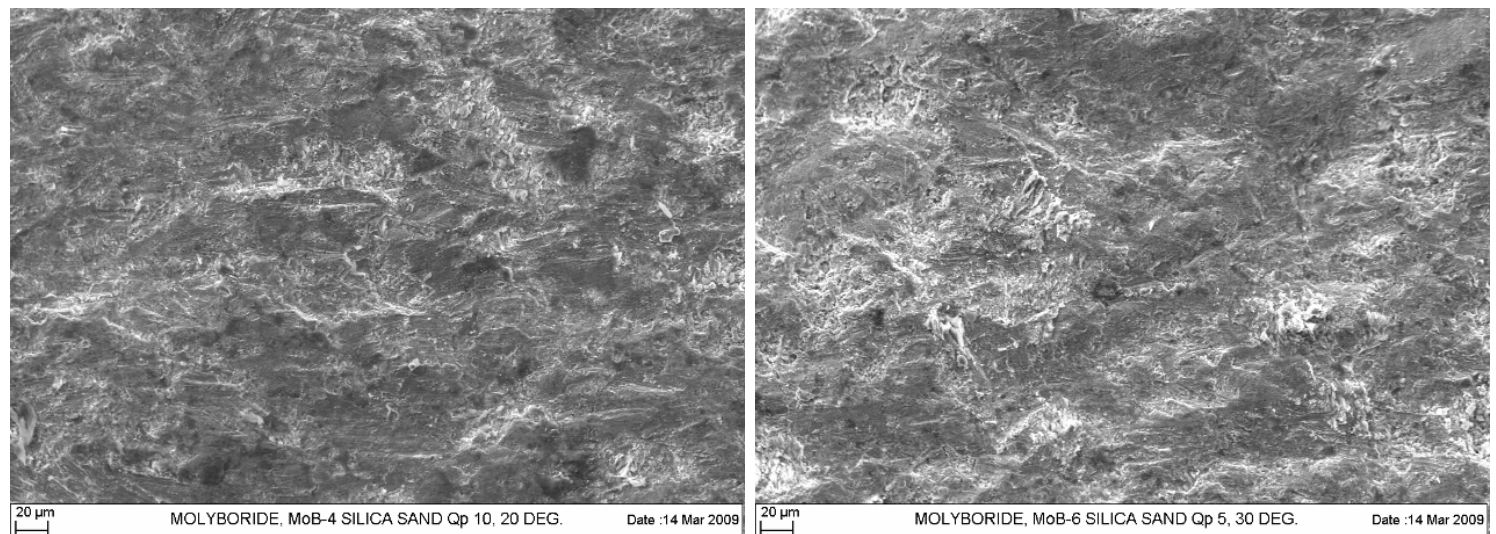

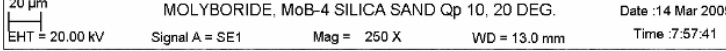

EHT $=20.00 \mathrm{kV} \quad \begin{gathered}\text { MOLYBORIDE, MOB-6 SILICA SAND Qp 5, 30 DEG. } \\ \text { Signal A }=\text { SE } 1\end{gathered} \quad$ Mag $=250 \mathrm{x} \quad$ WD $=11.0 \mathrm{~mm}$

Date : 14 Mar 2000

Molyboride Silica Sand Qp 5, 30 Deg. Molyboride Silica Sand Qp 10, 20 Deg.

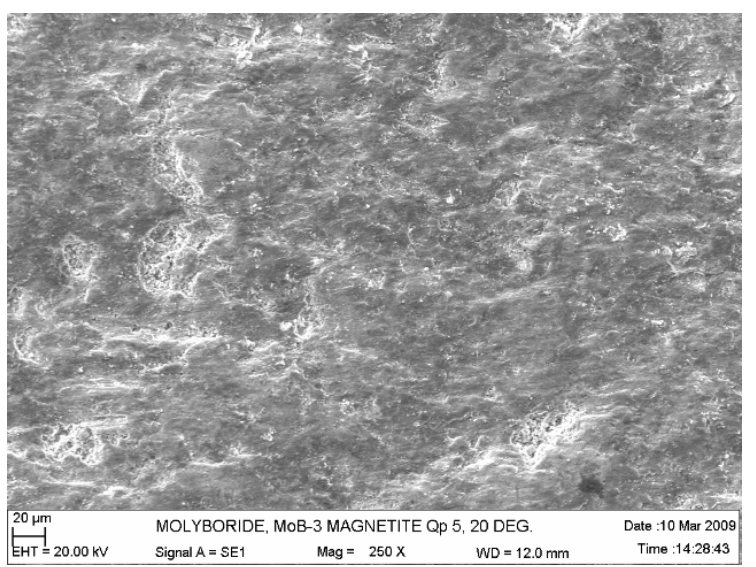

Molyboride Magnetite Qp 5, 20 Deg.

Figure 44

Molyboride Surface SEM Results As-coated and after laboratory erosion testing 


\section{$5 \quad$ Metallographic Analysis of Coated Samples}

Cross-sections were prepared from each test coupon and a representative coupon from each coating in its as-received condition for examination under the light microscope. In most instances the amount of surface scalloping when the coupons were tested with magnetite was negligible. Some evidence of scalloping was seen on most of the coupons tested with Silica sand. Those coupons tested at a 30 degree angle of impingement showed a more pronounced scalloping than was evidenced at 20 degrees confirming the choice of test conditions.

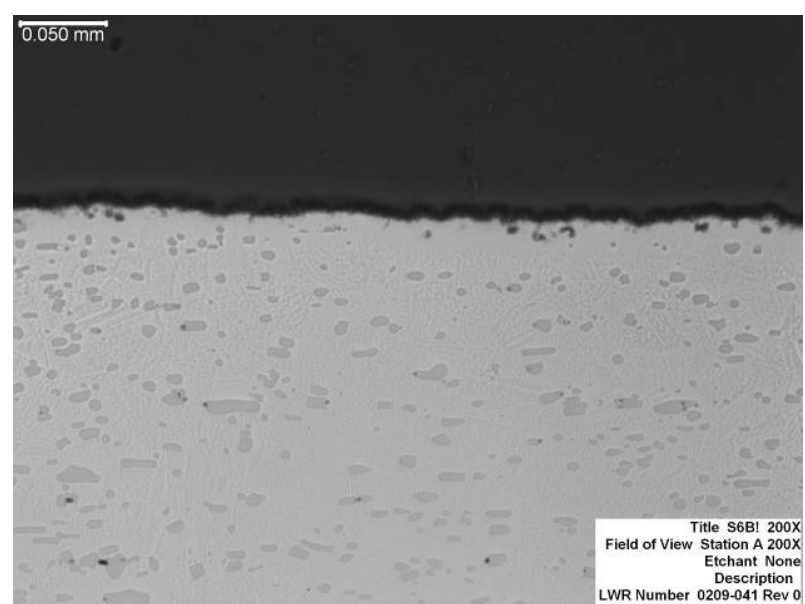

Stellite 6B As-received

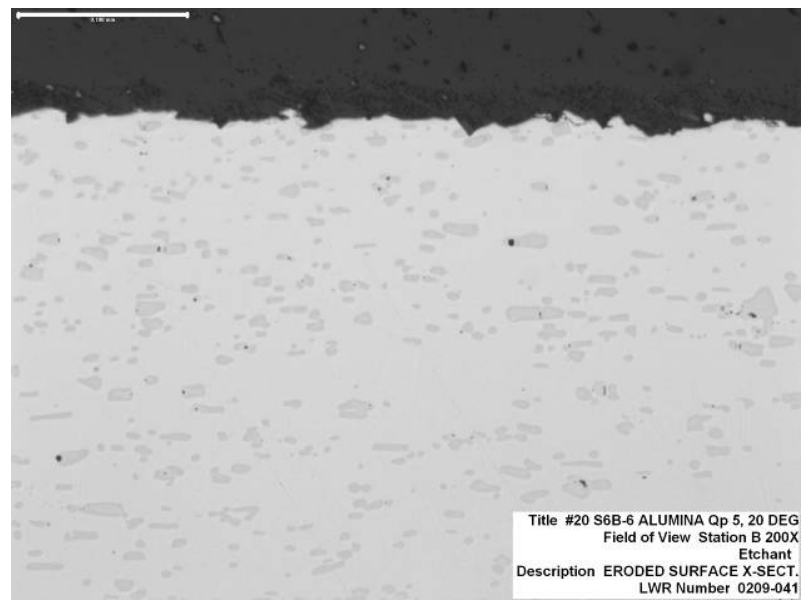

Stellite 6B Alumina Qp 5, 20 Deg.

Figure 45

Stellite 6B Test coupon cross-sections at 200X.

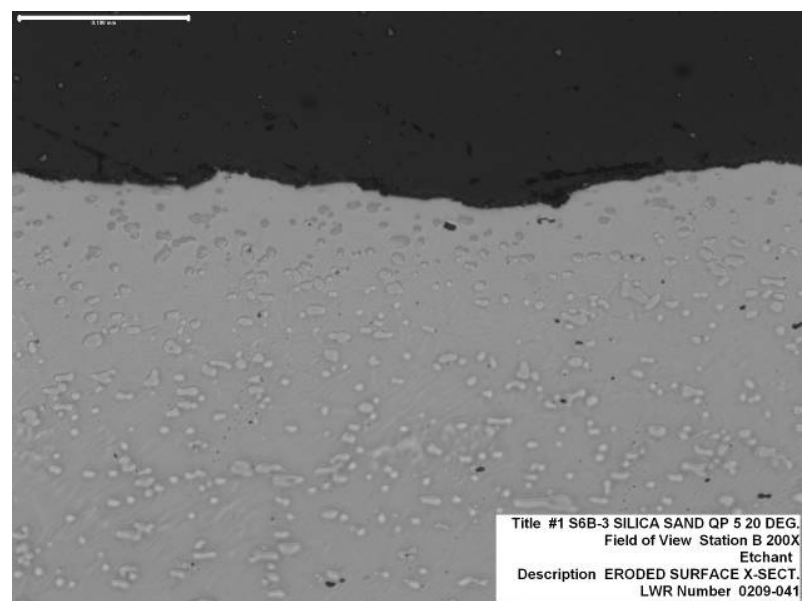

Stellite 6B Silica Sand, Qp 5, 20 Deg.

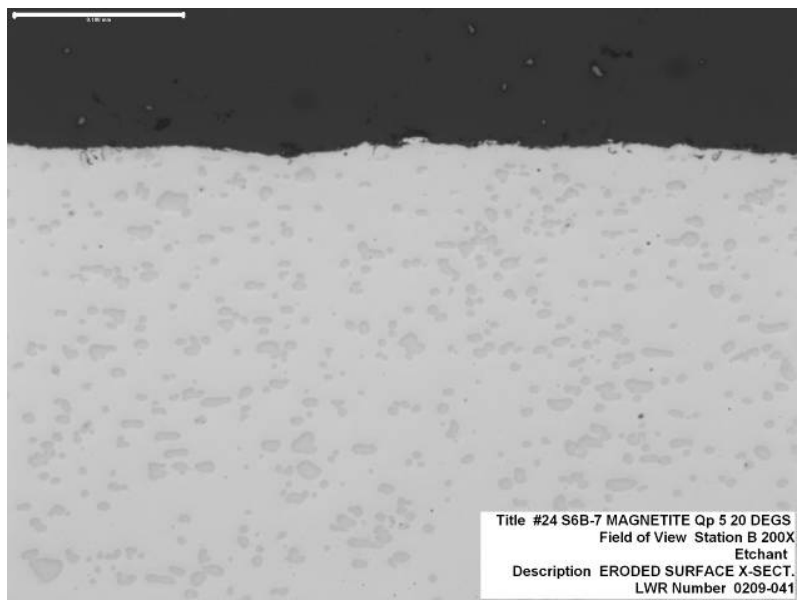

Stellite 6B Magnetite Qp 5, 20 Deg. 

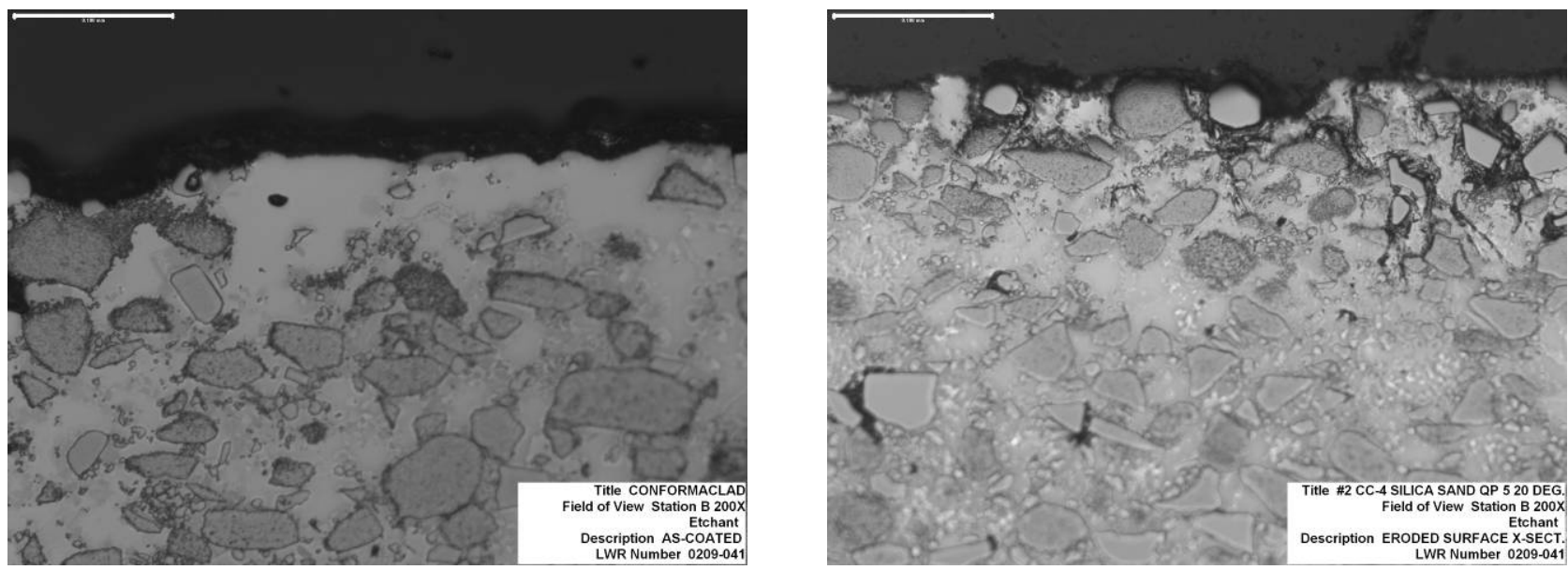

Conformaclad As-coated

Conformaclad Silica Sand Qp 5, 20 Deg.
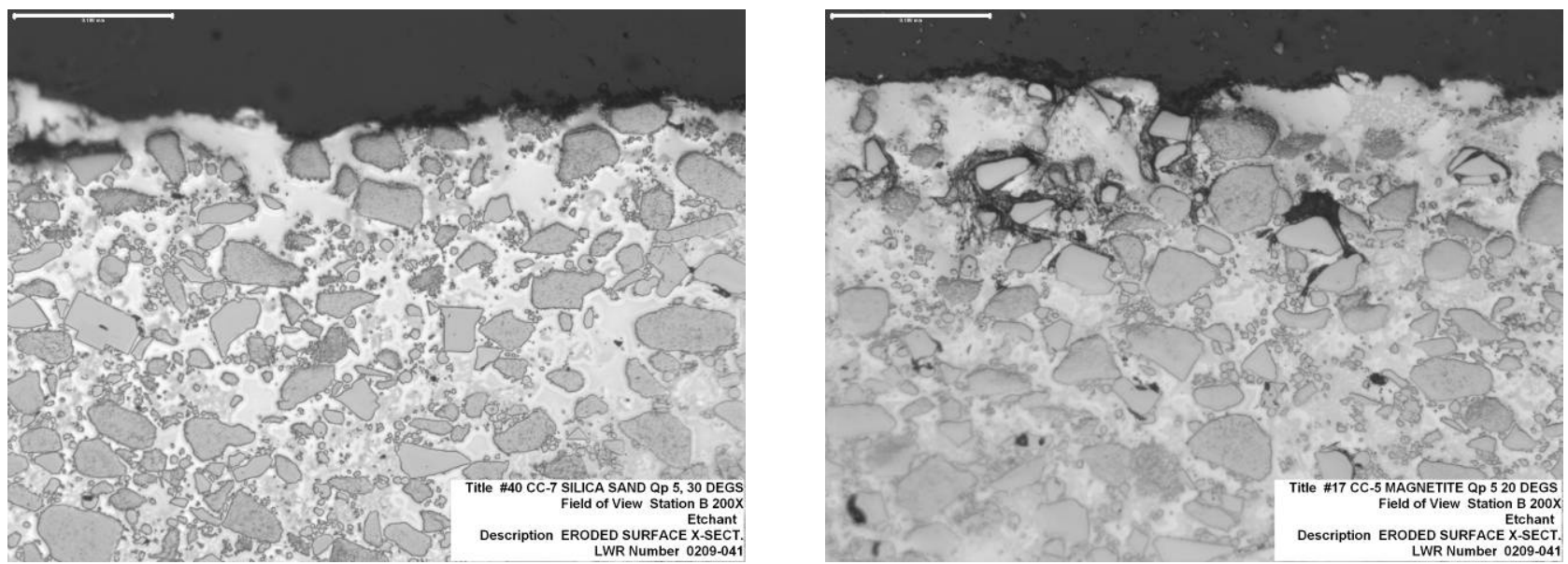

Conformaclad Silica Sand Qp 5, 30 Deg. Conformaclad Magnetite Qp $520^{\circ}$

Figure 46

Conformaclad Test coupon cross-sections at $100 \mathrm{X}$ 


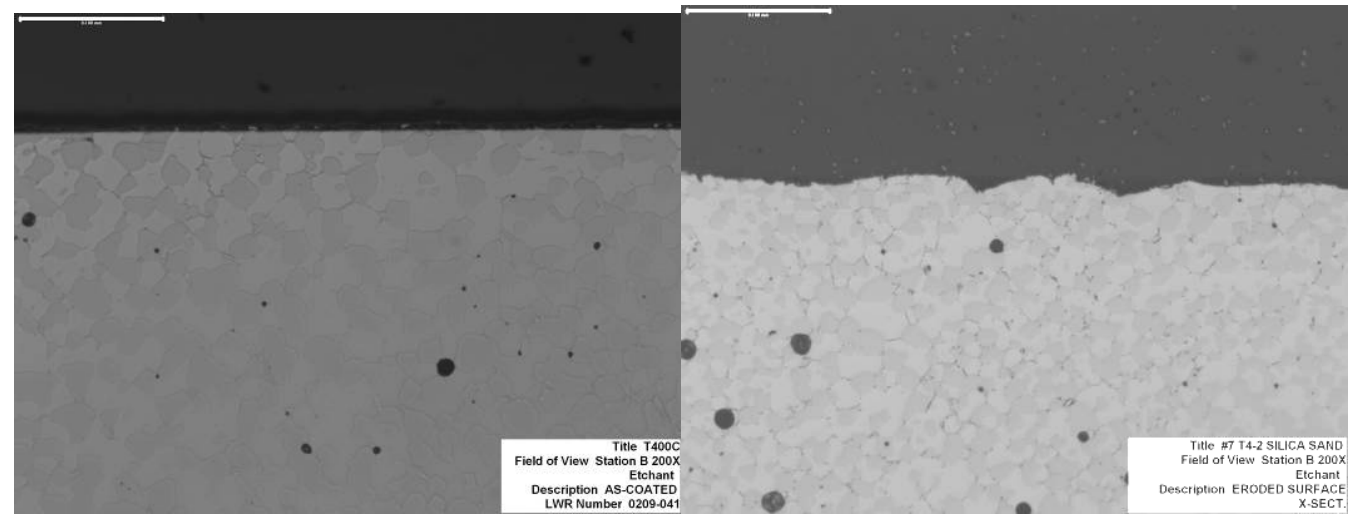

T400C As-coated

T400C Silica Sand Qp 5, 20 Deg.

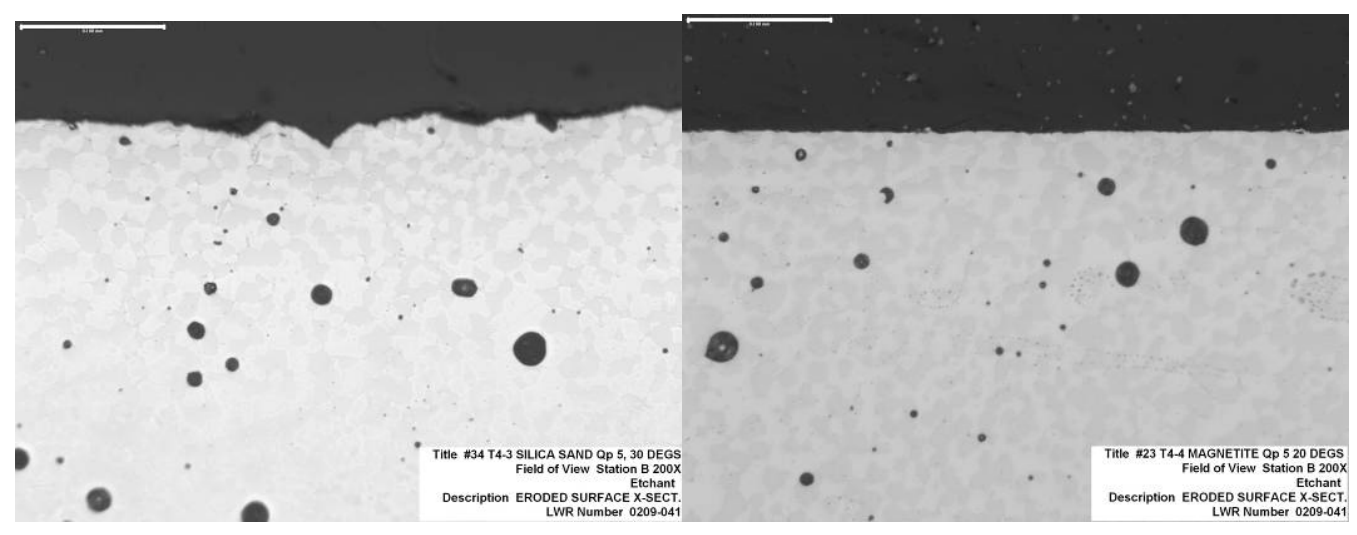

T400C Silica Sand Qp 5, 30 Deg. T400 Magnetite Qp 5, 20 Deg.

Figure 47

T400C Test coupon cross-section at $200 \mathrm{X}$ 
T800C Test coupon cross-section at 200X
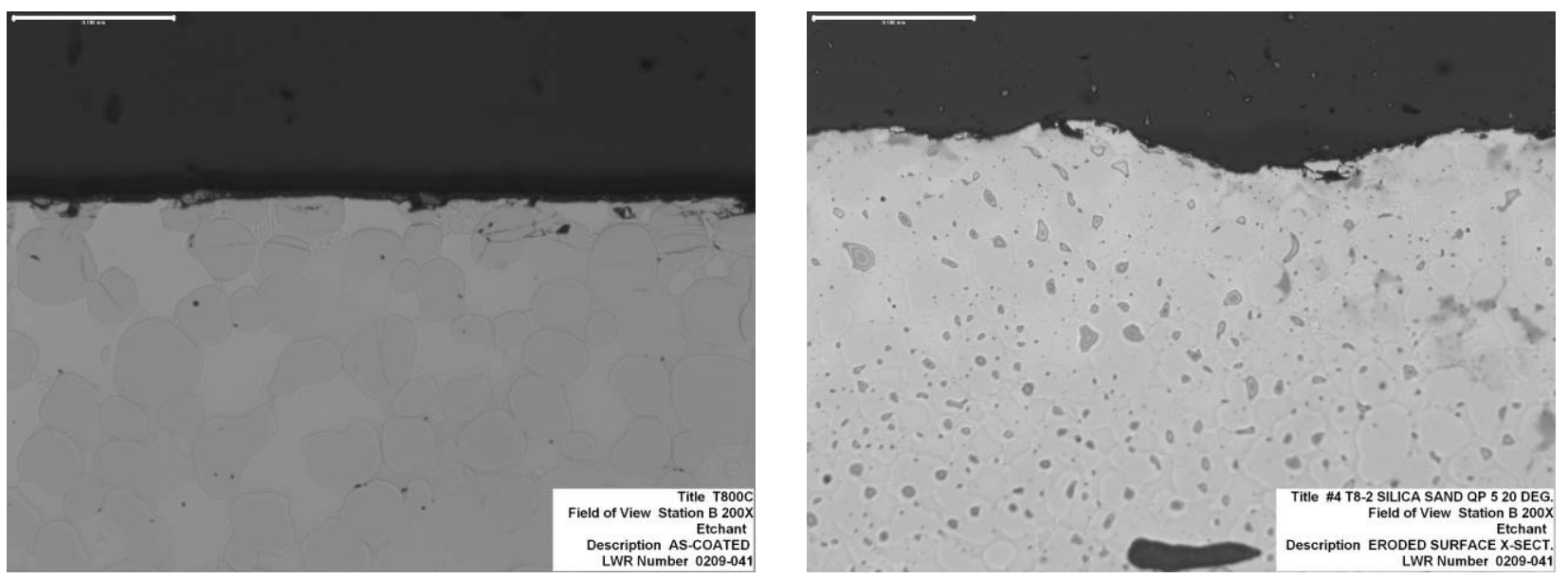

T800C As-coated

T800C Silica Sand Qp 5, 20 Deg.

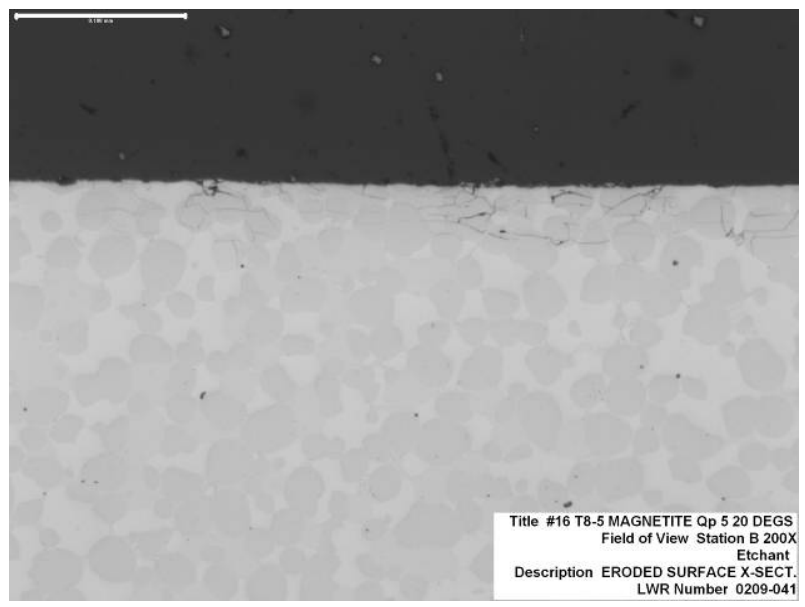

T800C Magnetite Qp 5, 20 Deg.

Figure 48

T800C Test coupon cross-section at 200X 
Zircoat Test coupon cross-section at 200X

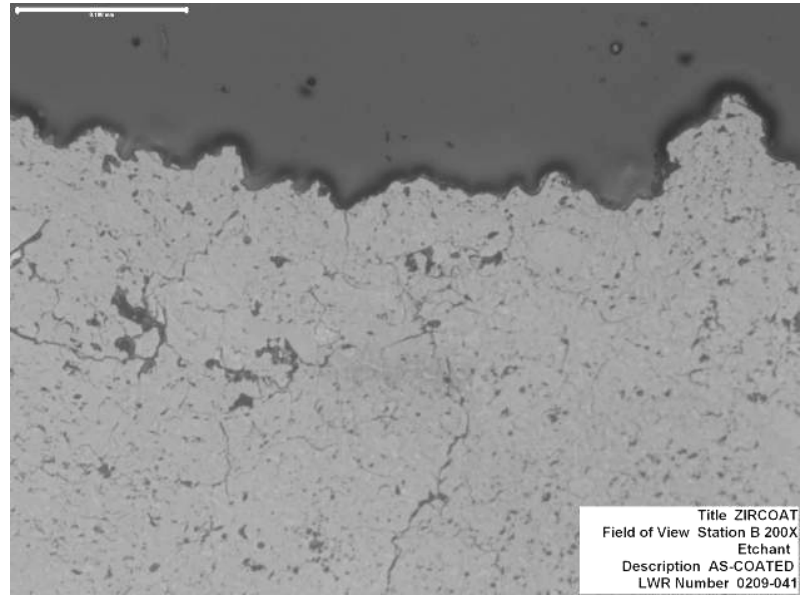

Zircoat As-coated

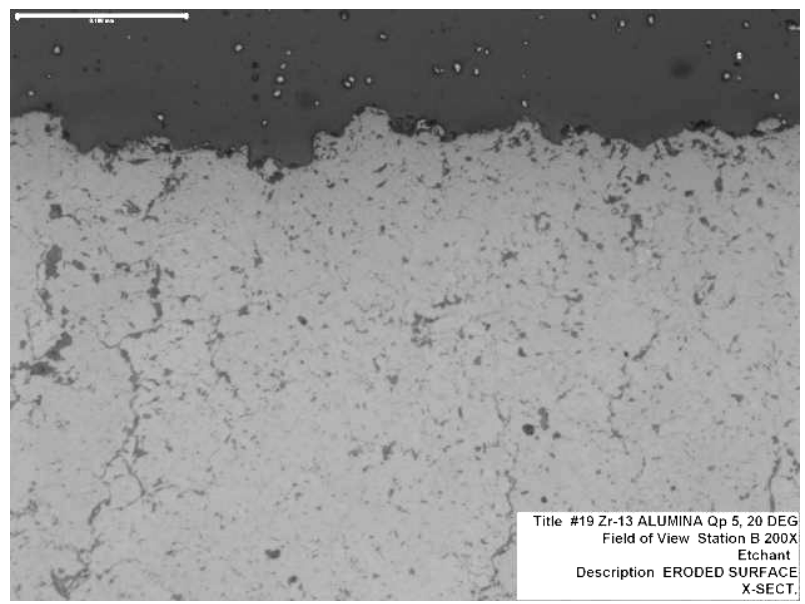

Zircoat Alumina Qp 5, 20 Deg

Figure 49

Zircoat Test coupon cross-section at 200X

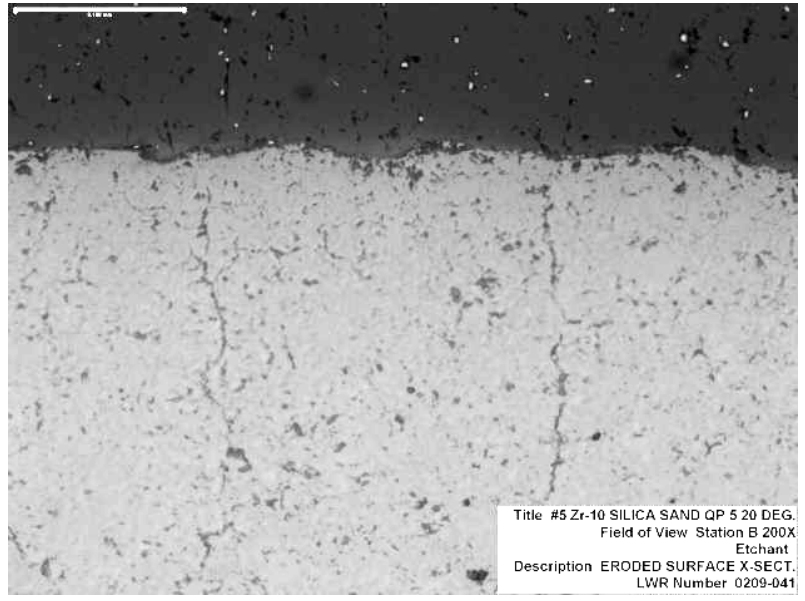

Zircoat Silica Sand Qp 5, 20 Deg.

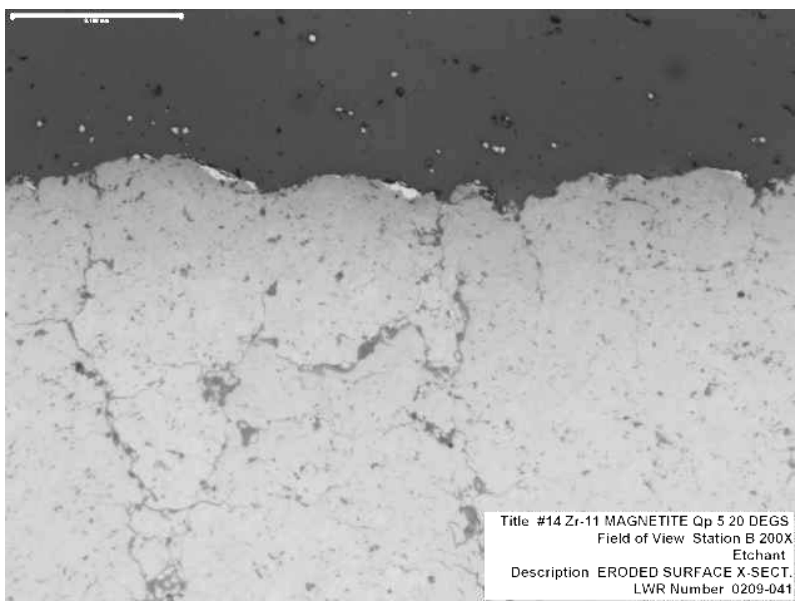

Zircoat Magnetite Qp 5, 20 Deg. 
Bodycote Tech 12 Test coupon cross-section at 200X

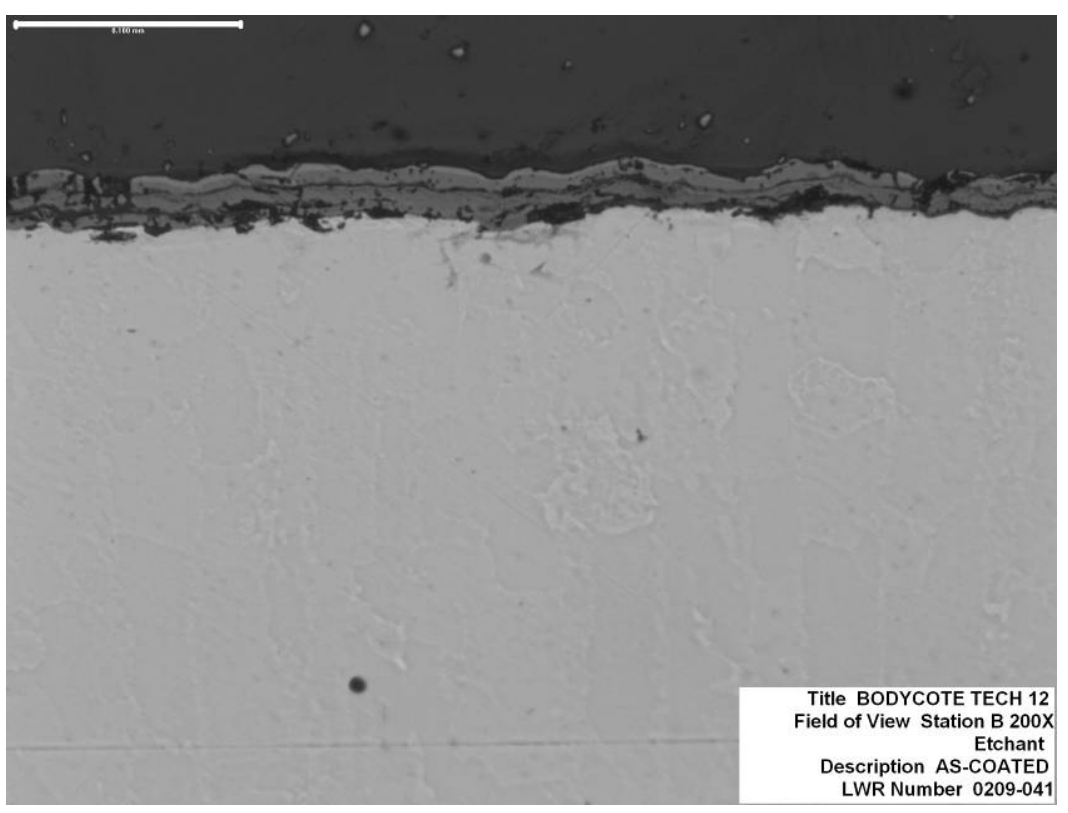

Bodycote Tech 12 As-coated (Humidity Tested)

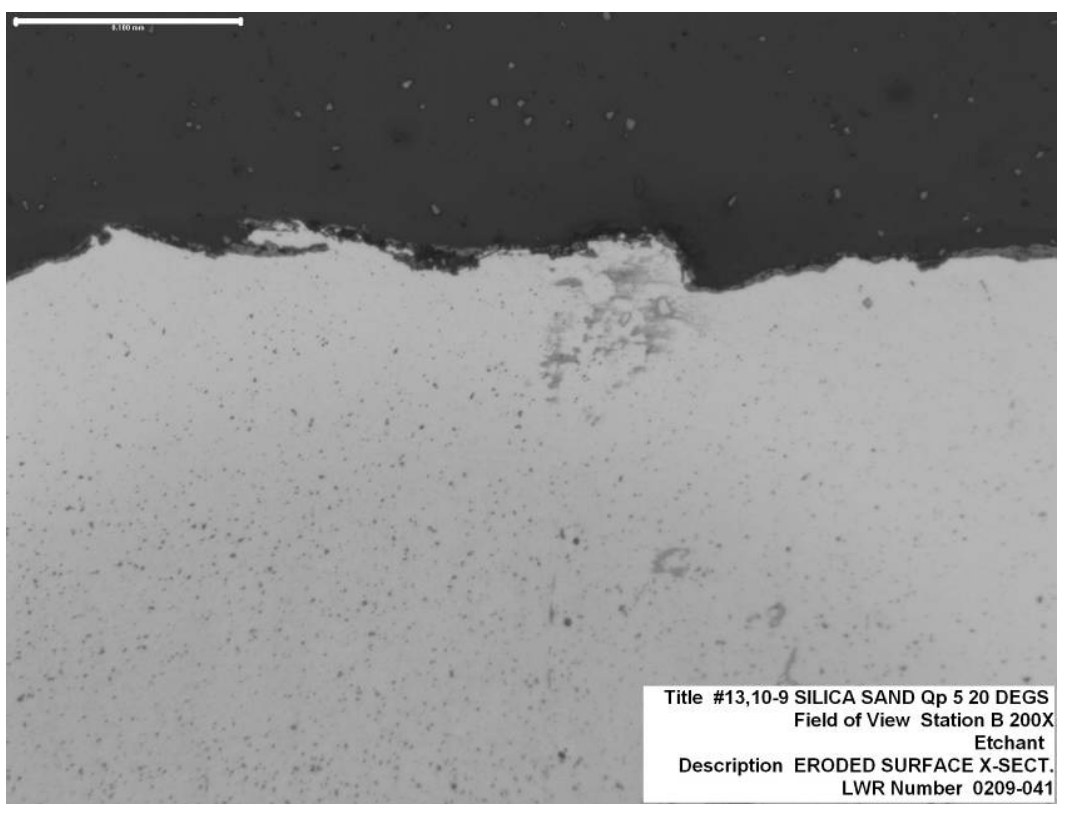

Bodycote Tech 12 Silica Sand Qp 5, 20 Deg.

Figure 50

Bodycote Tech 12 Test coupon cross-section at 200X 
Bodycote Tech 23 Test coupon cross-section at 200X

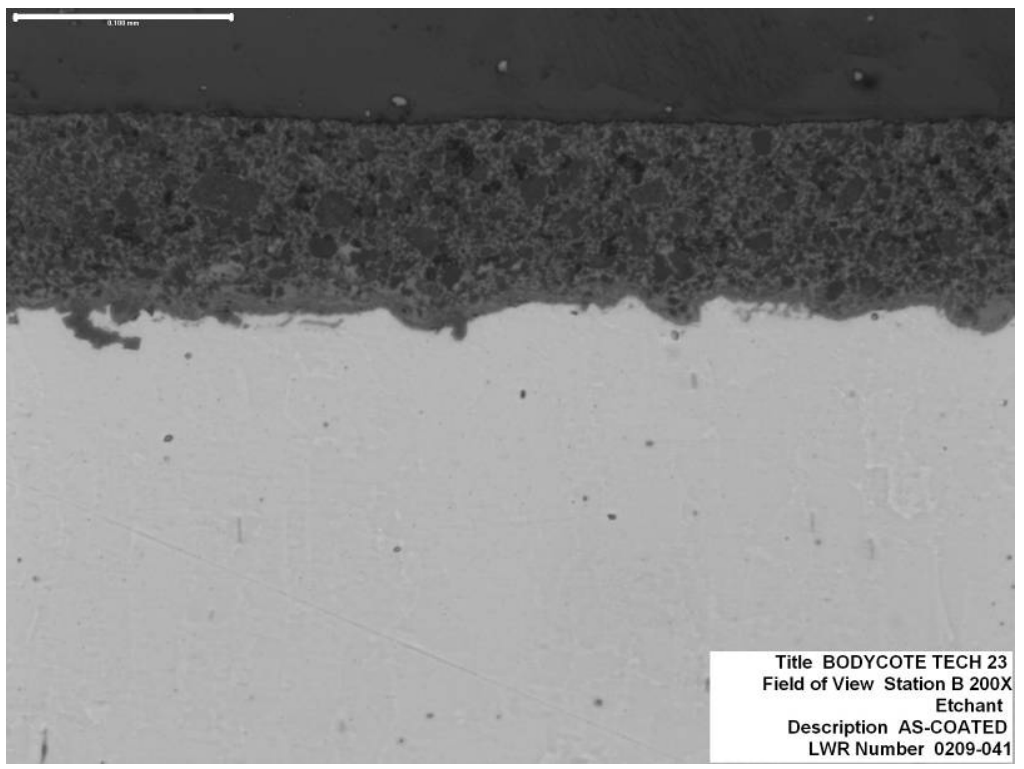

\section{Bodycote Tech 23 As-coated (Humidity Tested)}

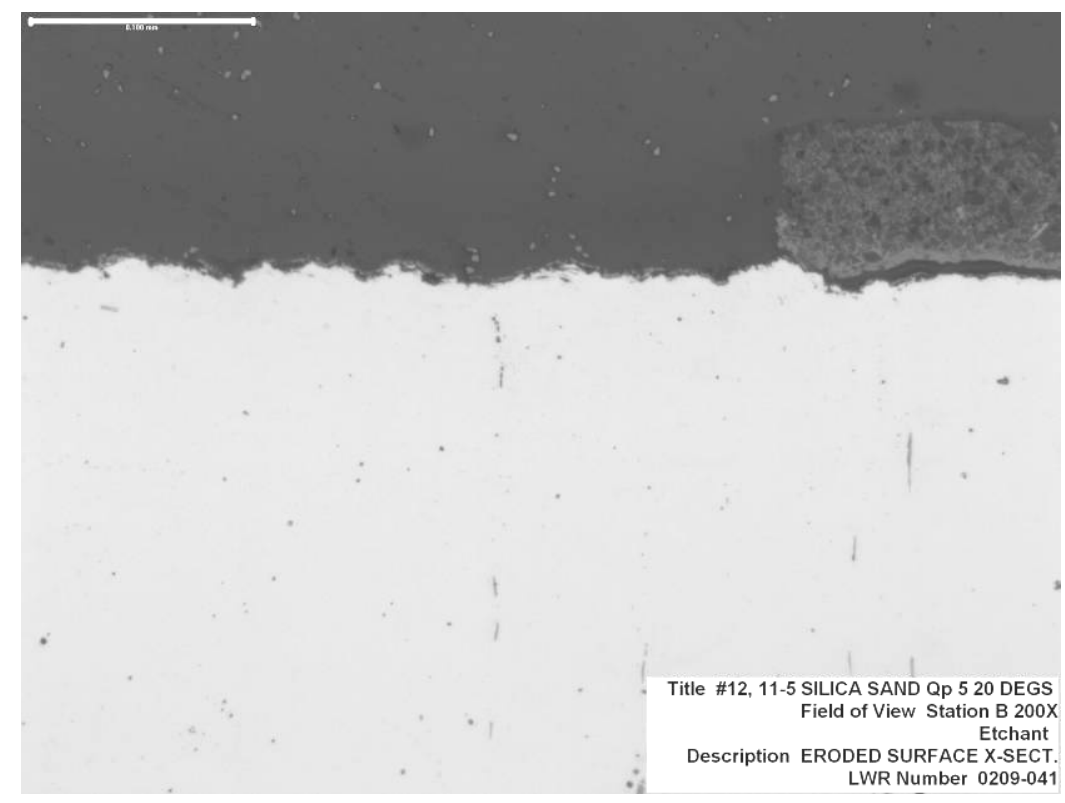

\section{Bodycote Tech 23 Silica Sand Qp 5, 20 Deg.}

Figure 51

Bodycoat Tech 23 Test coupon cross-section at 200X 
Chrome Carbide-Nickel Chrome Test coupon cross-section at 200X
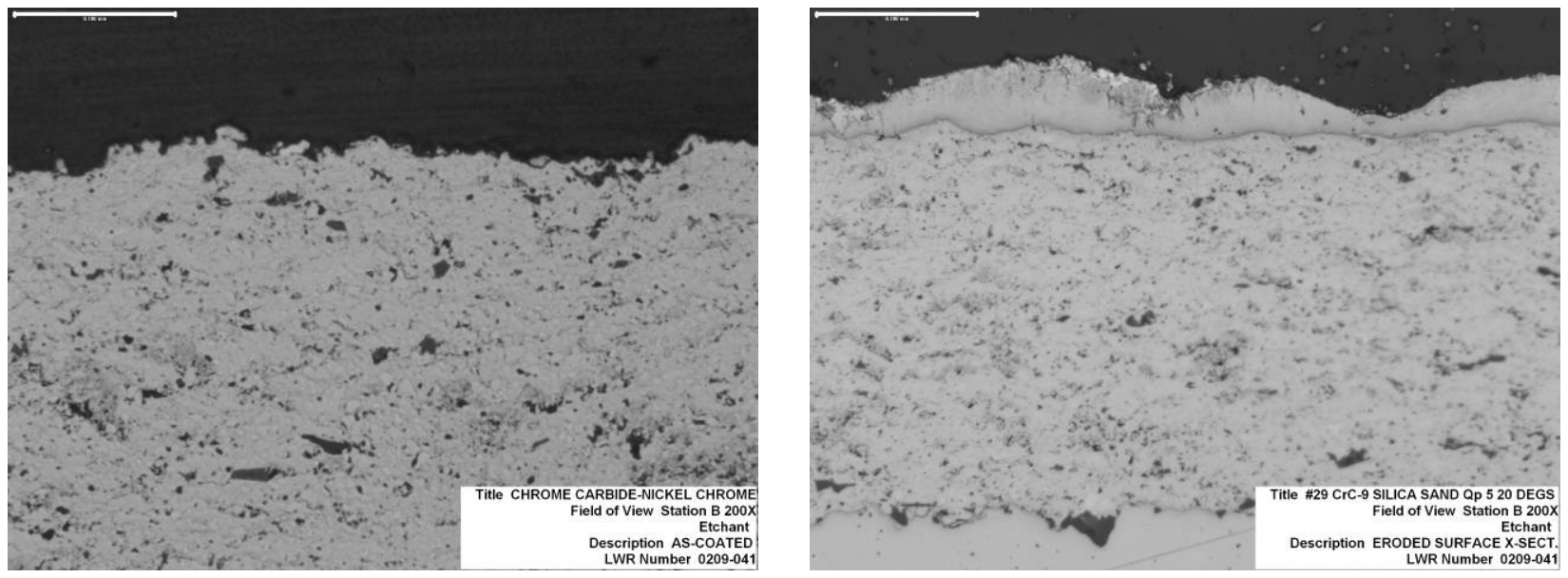

Chrome Carbide As-coated

Chrome carbide Silica Sand Qp 5, 20 Deg

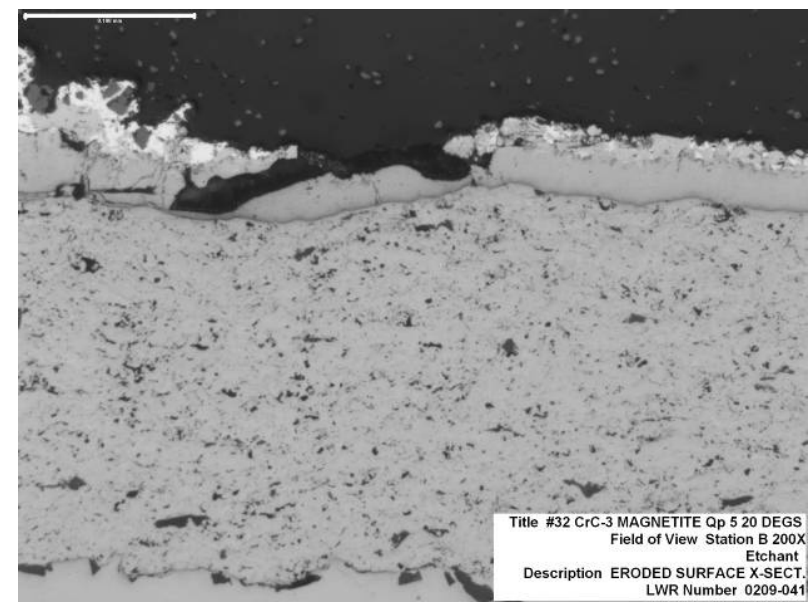

Chrome carbide Magnetite Qp 5, 20 Deg.

Figure 52

Chrome Carbide Test coupon cross-section at 200X 
Nanosteel SHS 7170 Test coupon cross-section at 200X
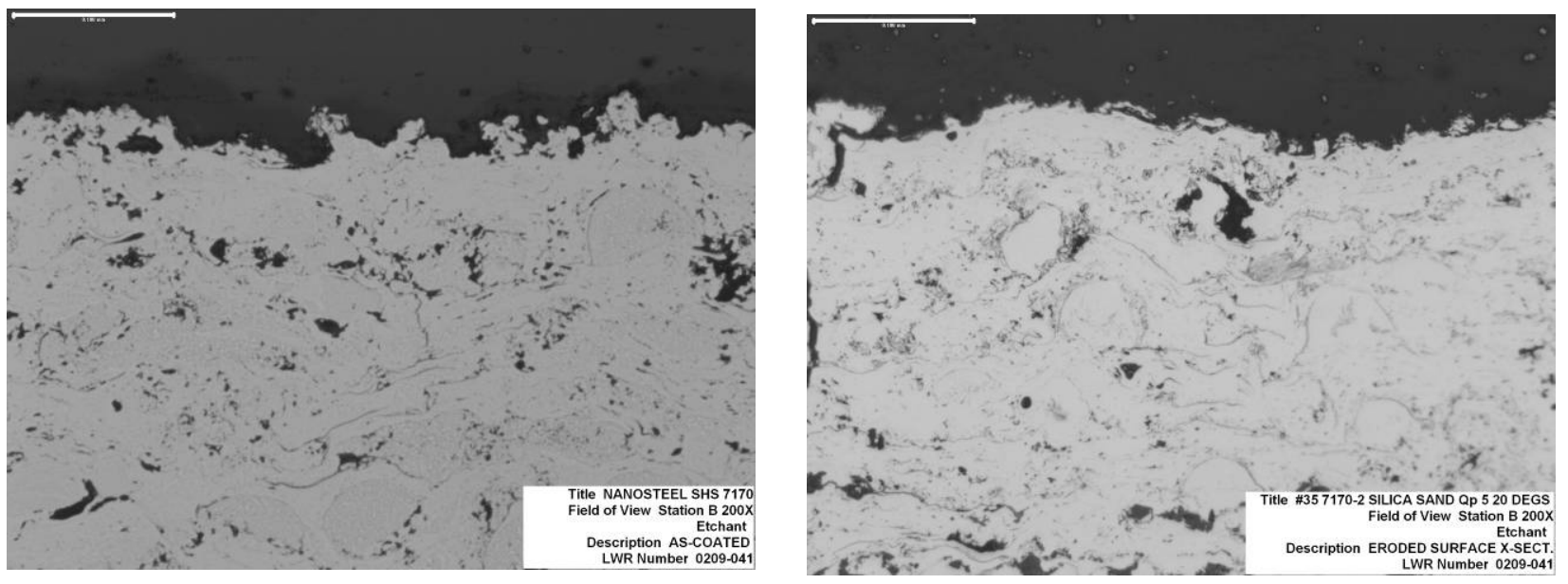

SHS 7170 As-coated

SHS 7170 Silica Sand Qp 5, 20 Deg.

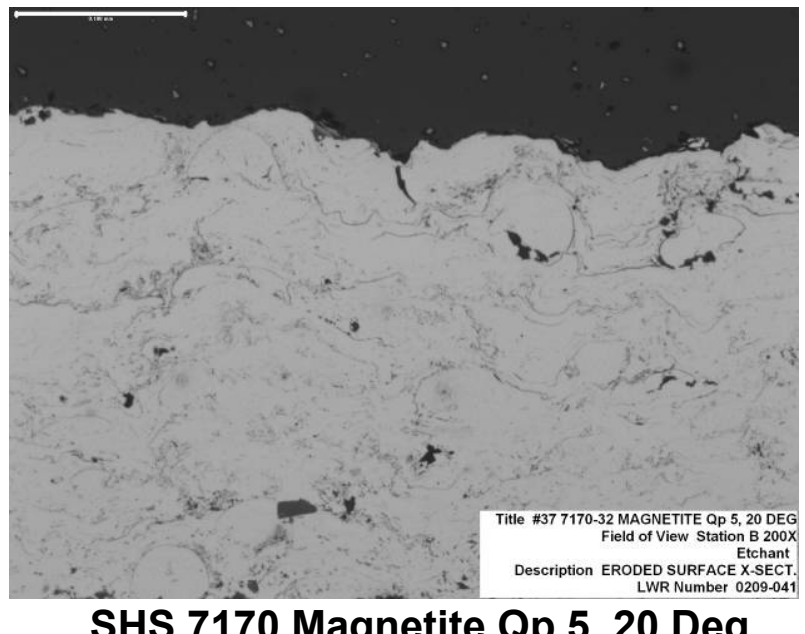

SHS 7170 Magnetite Qp 5, 20 Deg.

Figure 53

SHS 7170 Test coupon cross-section at 200X 
Nanosteel SHS 9172 Test coupon cross-section at 200X
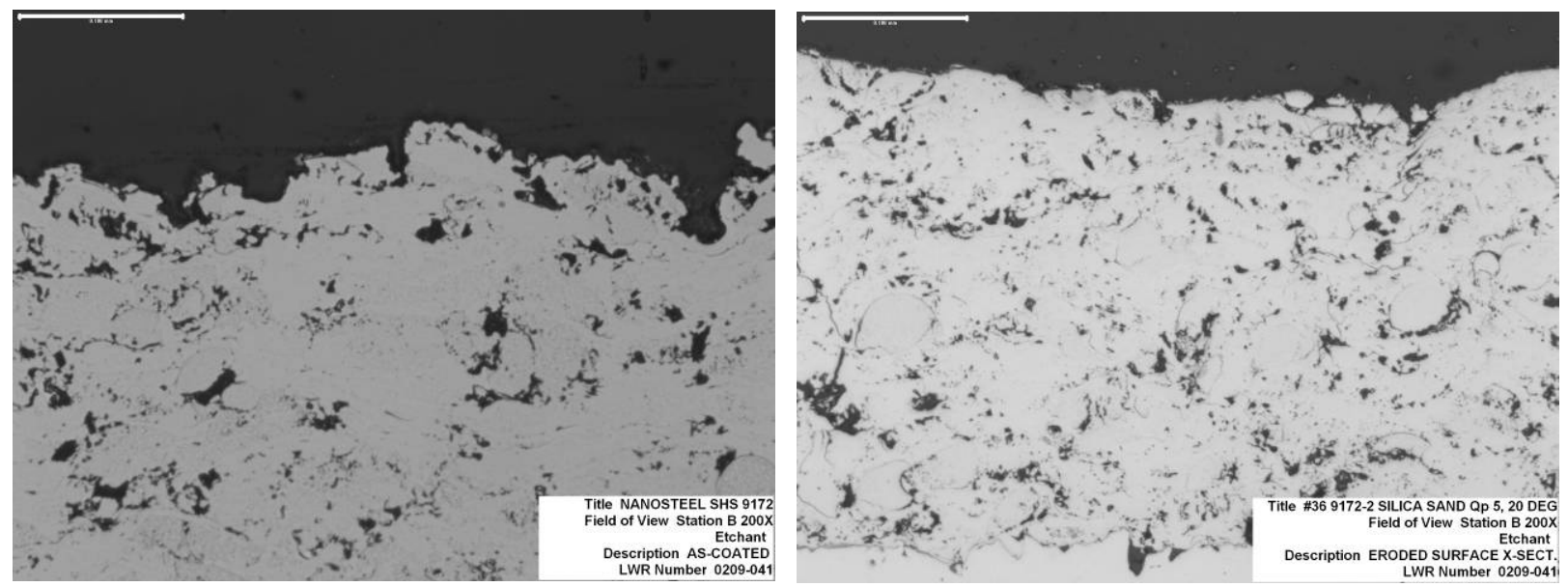

SHS 9172 As-coated

SHS 9172 Silica Sand Qp 5, 20 Deg.

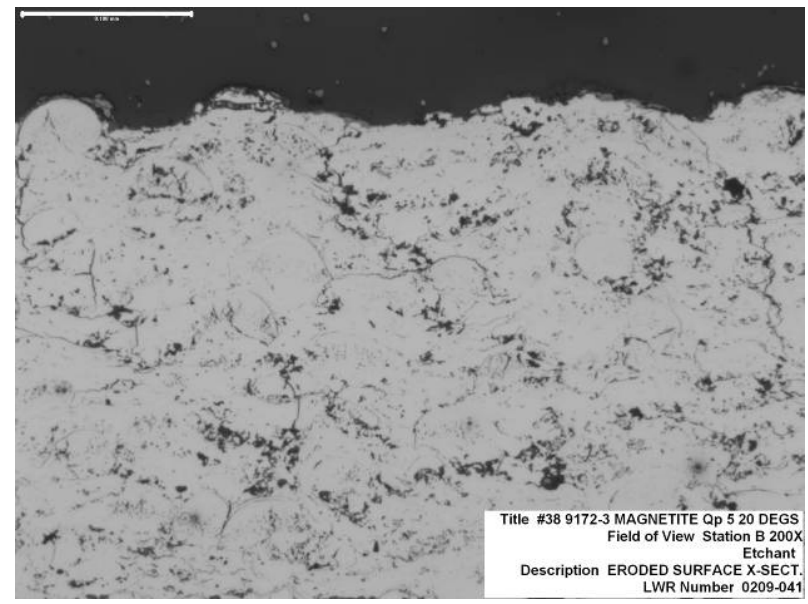

SHS 9172 Magnetite Qp 5, 20 Deg.

Figure 54

SHS 9172 Test coupon cross-section at 200X 
Molybdenum Boride Test coupon cross-section at 200X

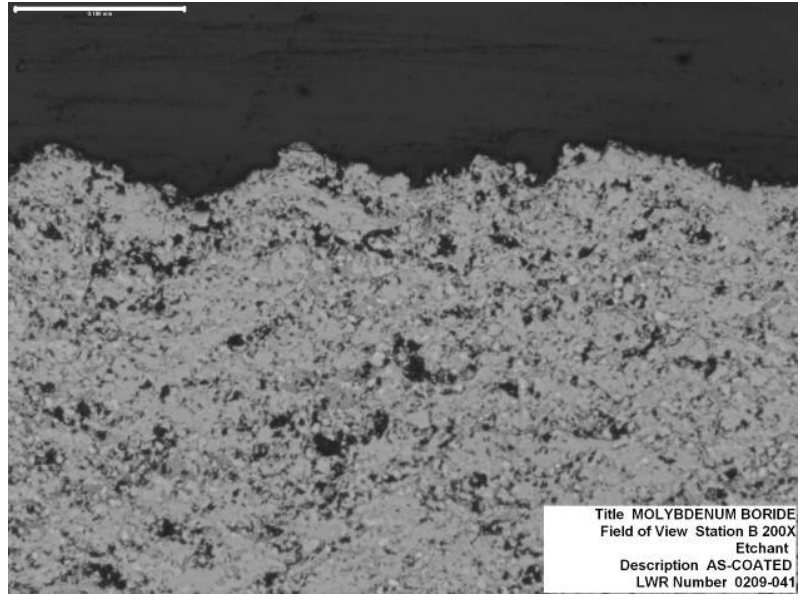

Molyboride As-coated

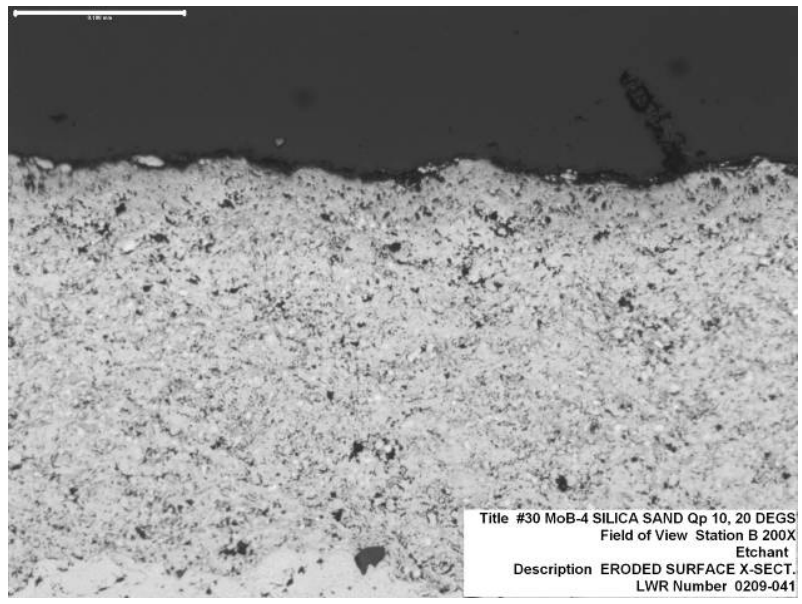

Molyboride Silica Sand Qp 1030 Deg.

Figure 55

Molyboride Test coupon cross-section at 200X

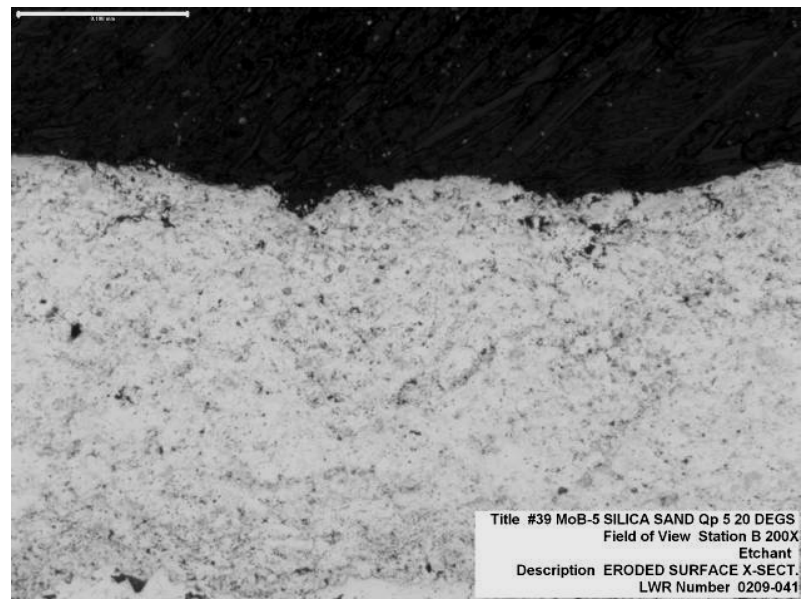

Molyboride Silica Sand Qp 5, 20

Deg.

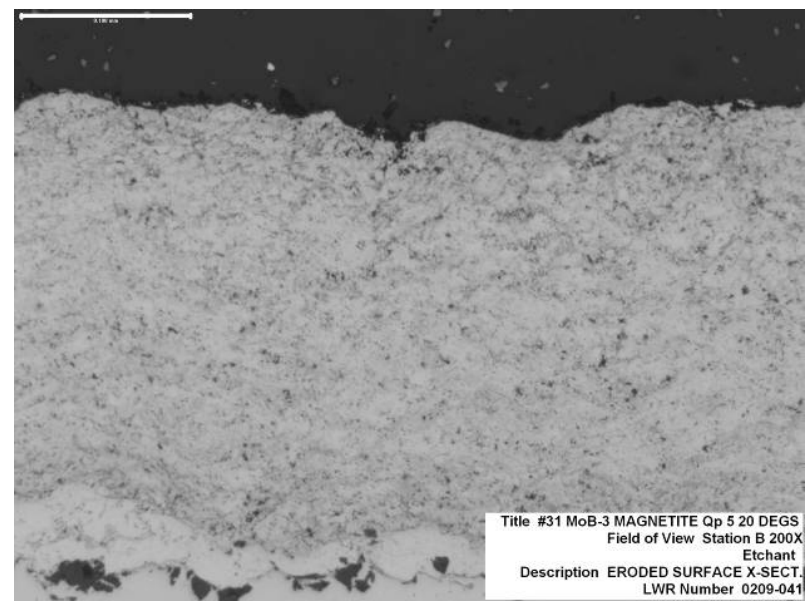

Molyboride Magnetite, Qp 5, 20 Deg. 


\section{SEM and Metallographic Analysis of Bare Metal Alloys}

The bare metal alloys showed minimal scalloping with the Silca erodent and no evidence of SPE damage with magnetite. As explained earlier in the report, this is most likely due to the erodent imbedding on the surface leading to low mass loss. The SEM images show some change in surface morphology from a smooth surface to a roughned surface, but the cross-sectional micrographs show little to no evidence of characterisitic SPE damage.

\section{Haynes 282}

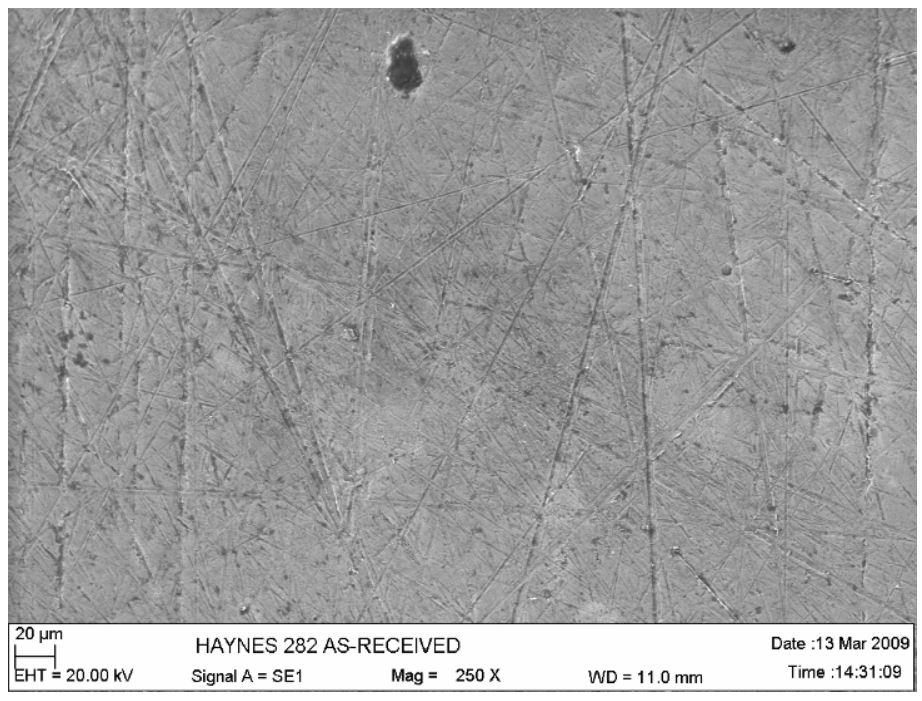

Haynes 282-As received

Figure 56

Haynes 282 SEM surface image

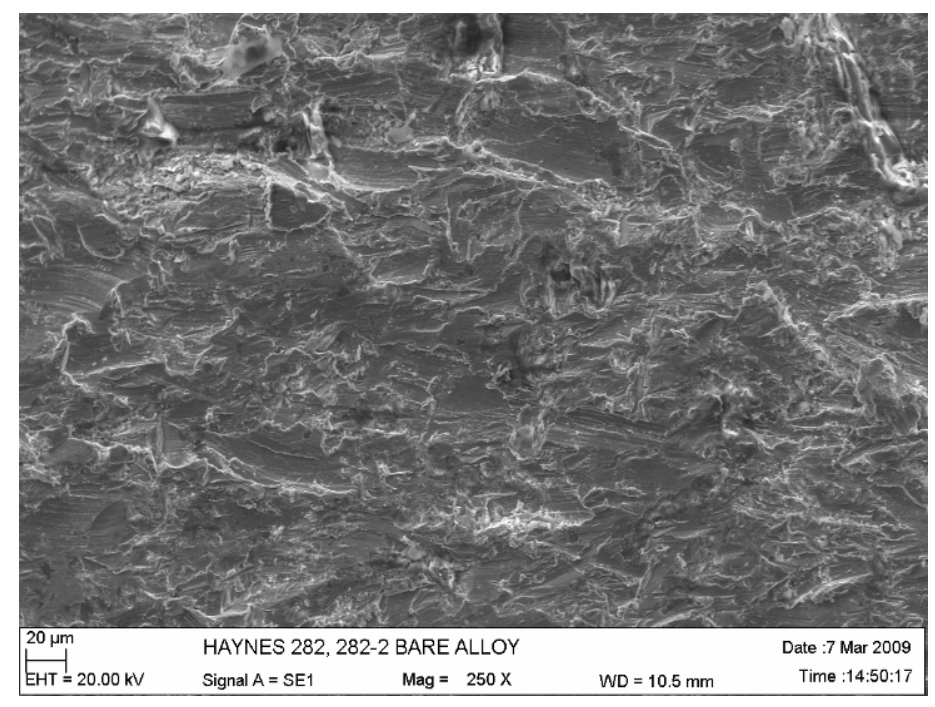

Haynes 282 Silica Sand Qp5, 20 Deg. 


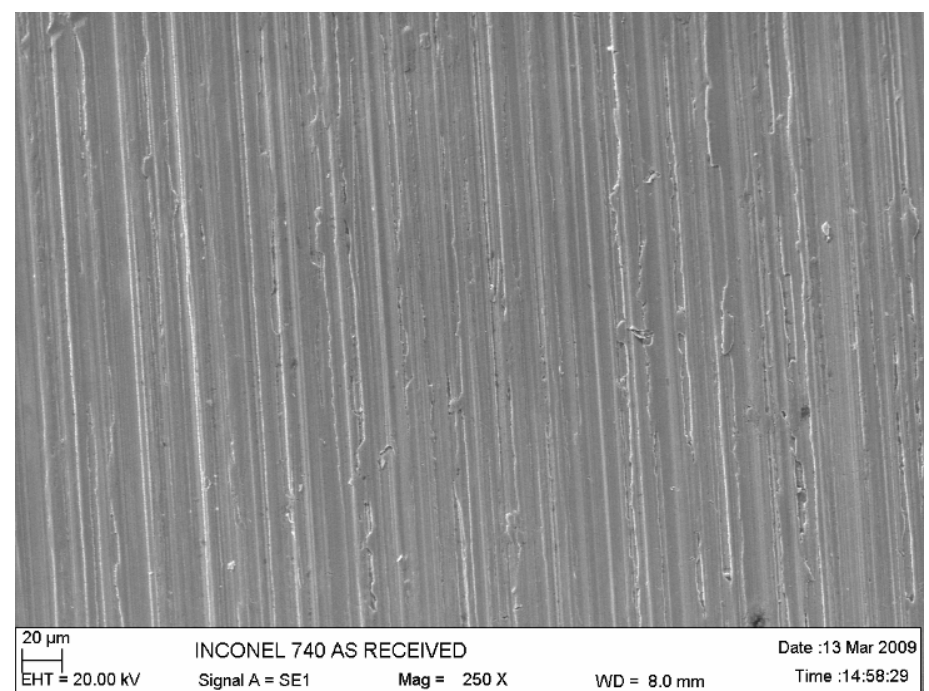

Inconel 740 As-received

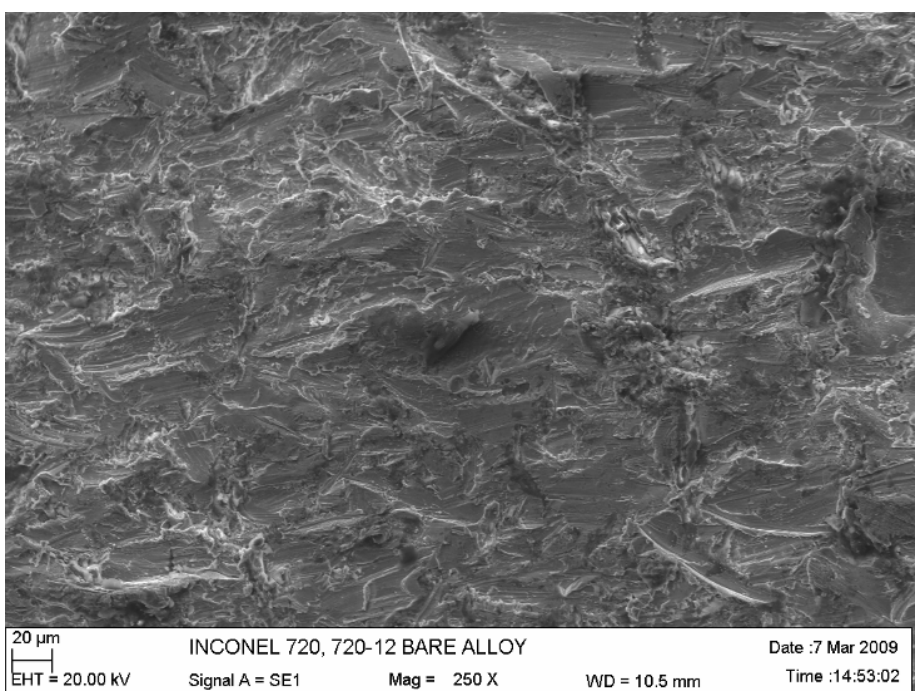

Inconel 740 Silica Sand Qp5, 20 Deg.

Figure 57

Inconel 740 SEM surface image 
Nimonic 105

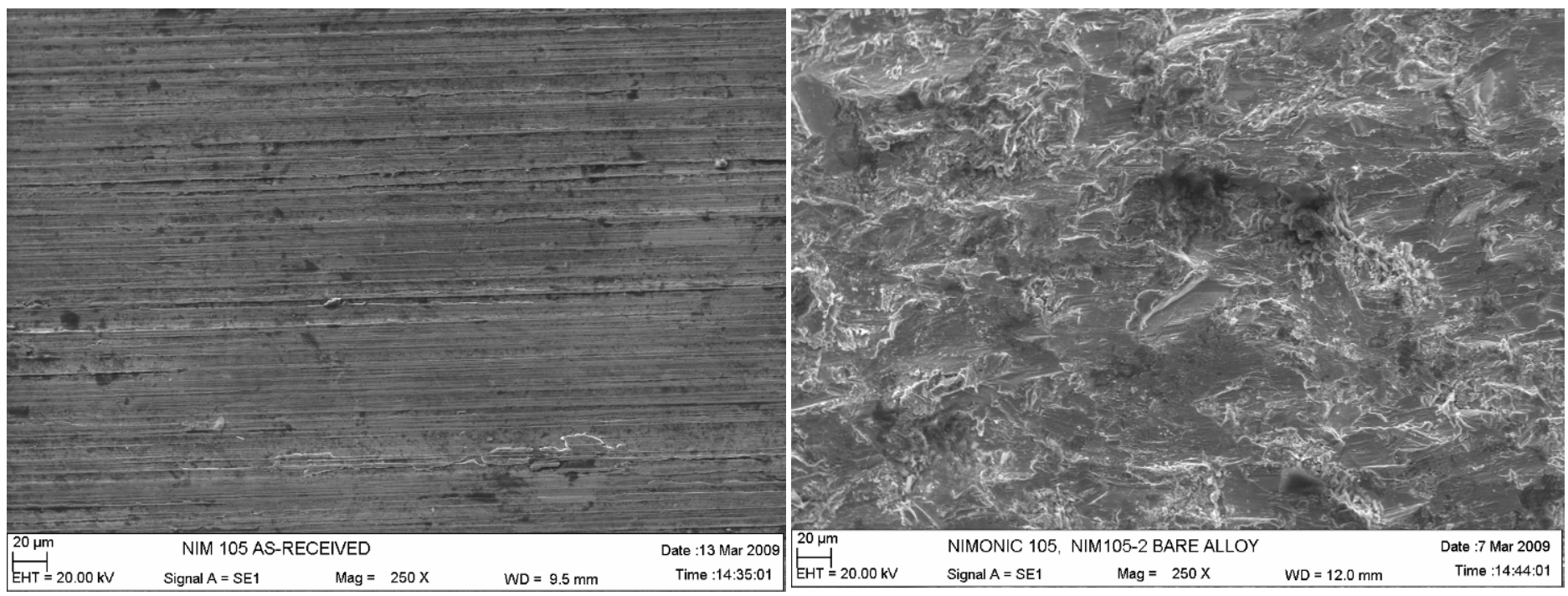

Nimonic 105 As-received Nimonic 105 Silica Sand Qp 5, 20 Deg

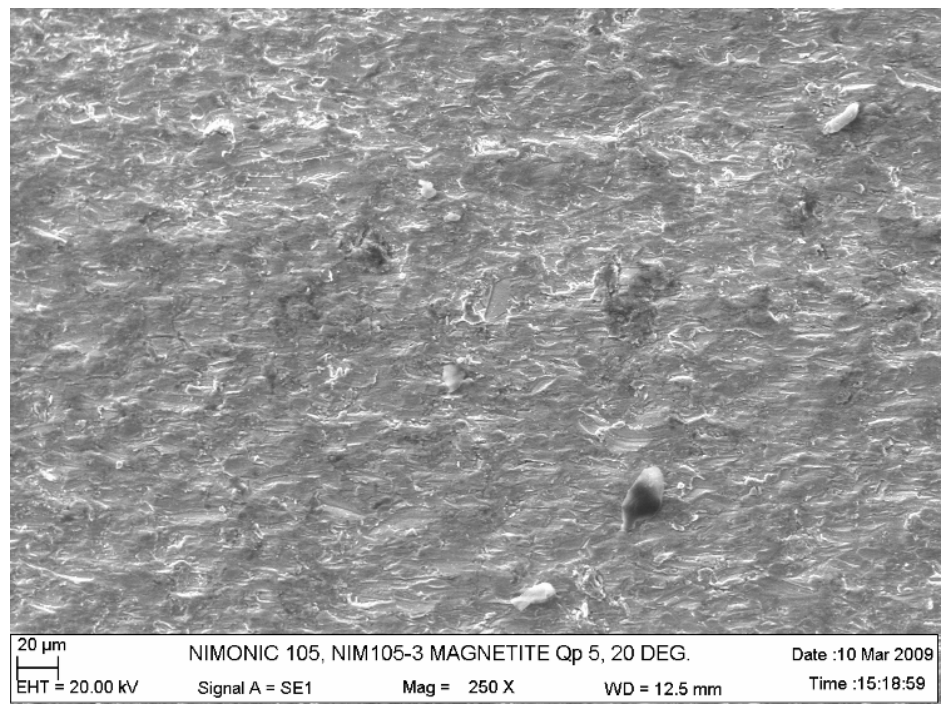

Nimonic 105 Magnetite Qp 5, 20 Deg.

Figure 58

Nimonic 105 SEM surface image 
Udimet 720
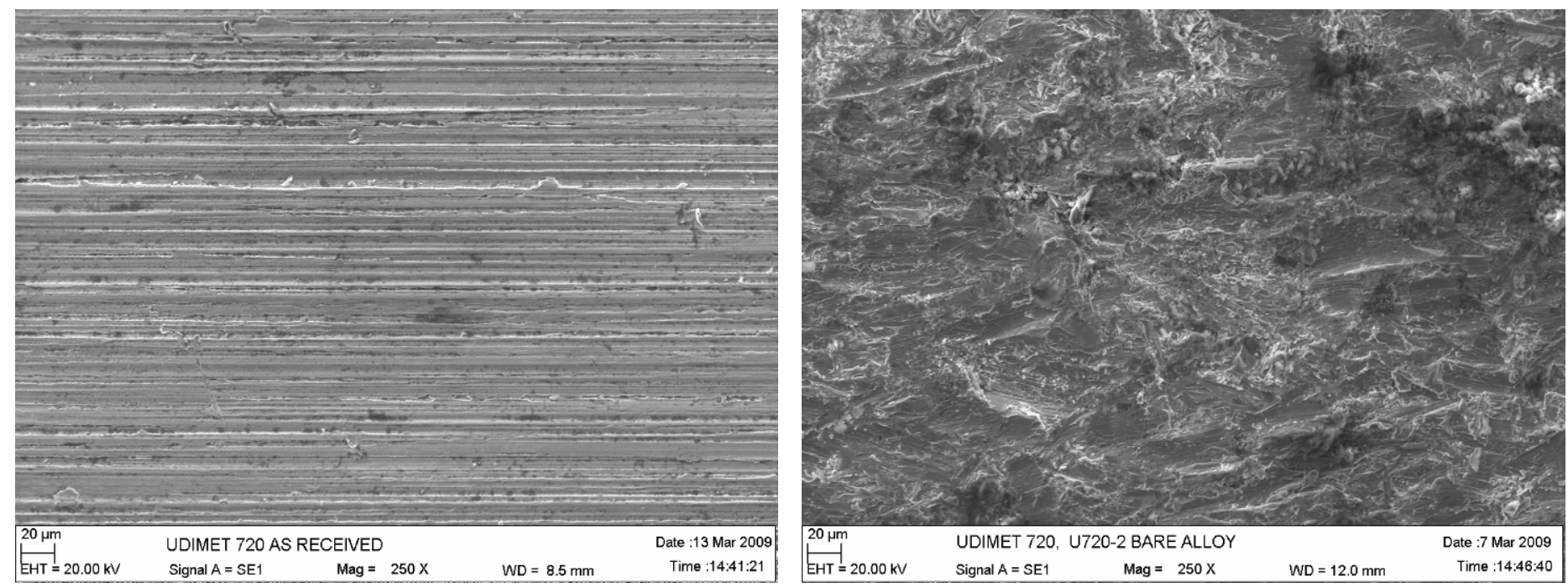

Udimet 720 As-received

Udimet 720 Silica Sand Qp 5, 20 Deg.

Figure 59

Nimonic 105 SEM surface image
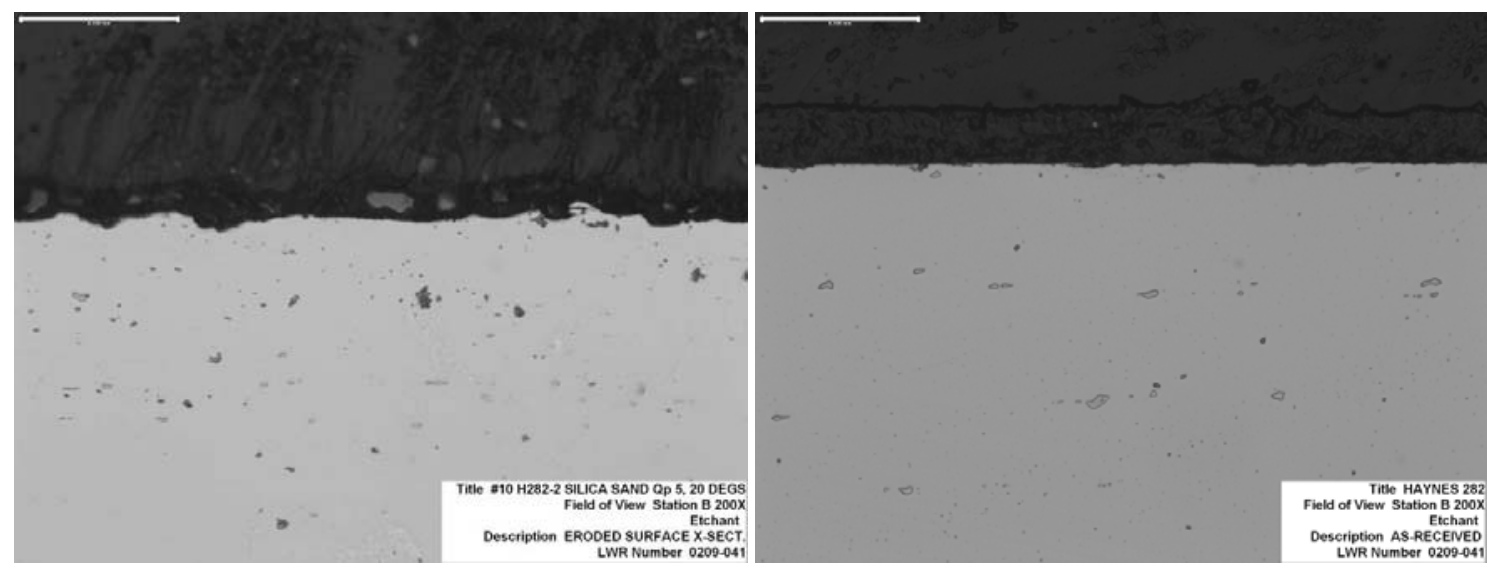

Haynes 282 As-received

Haynes 282 Silica Sand Qp 5, 20 Degs

Figure 60

Haynes 282 Cross-section SEM image after testing 
Inconel 740 Test coupon cross-section at $200 \mathrm{X}$
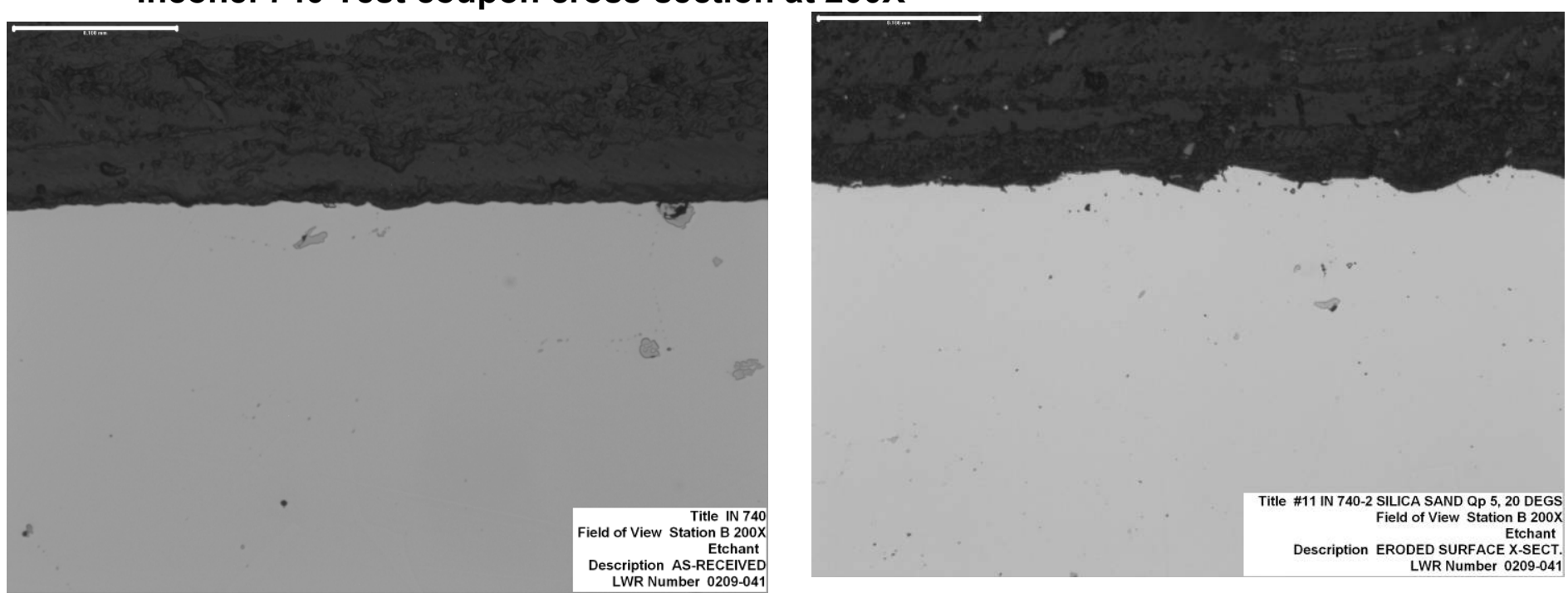

IN 740 As-received

IN 740 Silica Sand Qp 5, 20 Deg.

Figure 61

Inconel 740 Cross-section SEM image after testing 


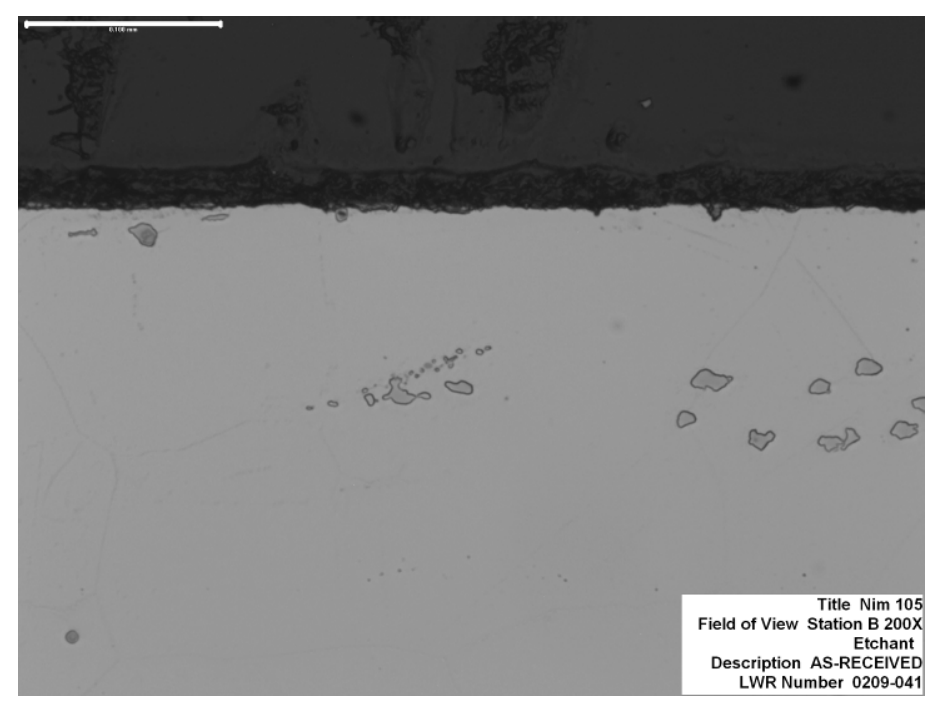

Nim 105 As-received

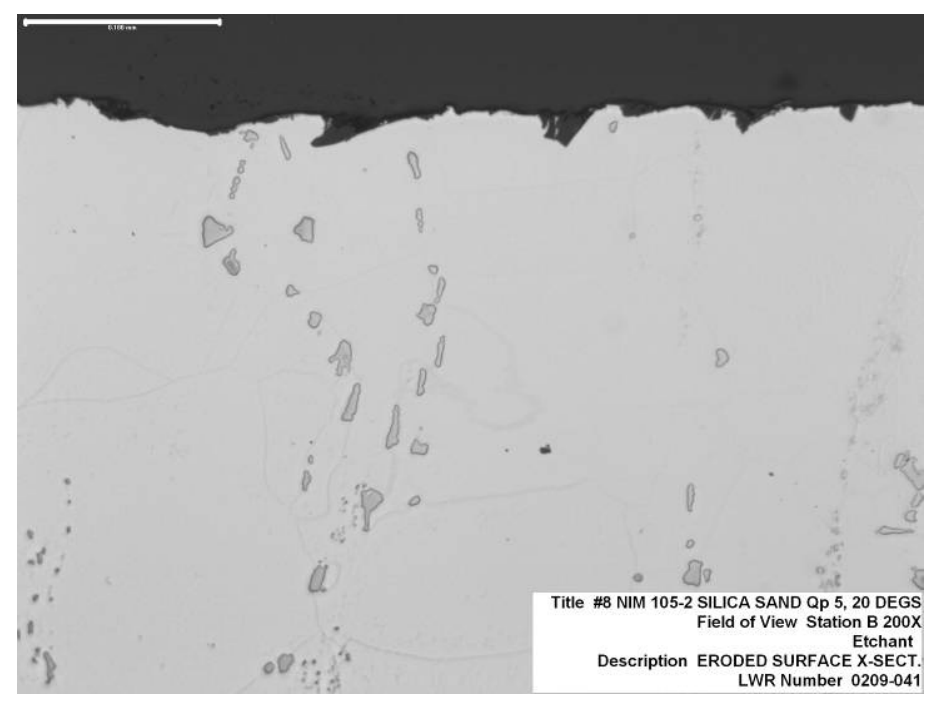

Nim 105 Silica Sand Qp 5, 20 Deg.

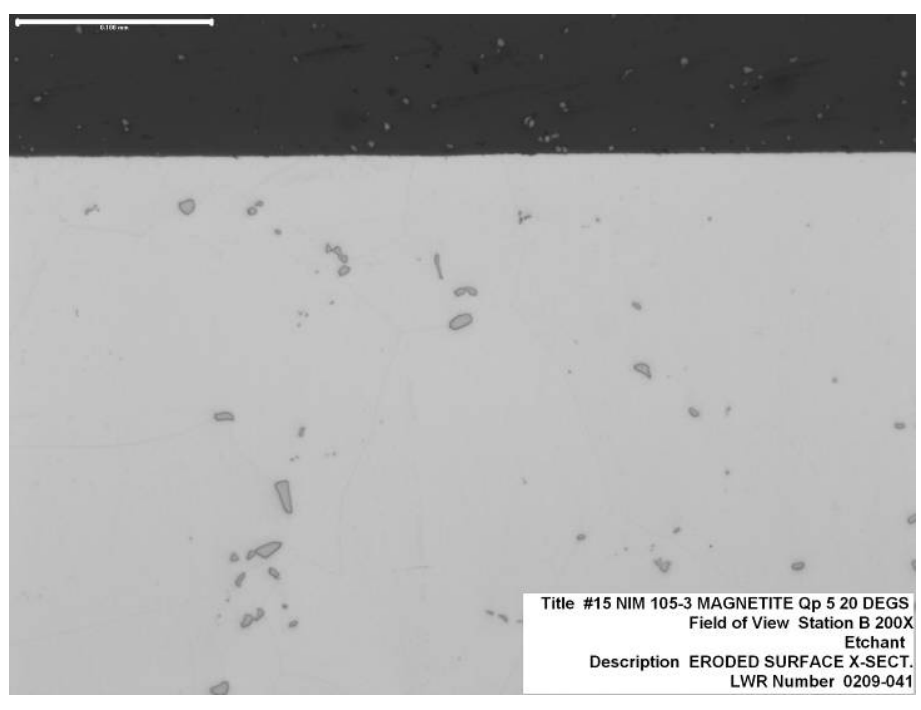

Nim 105 Magnetite Qp 5, 20 Deg

Figure 62

Nimonic 105 Cross-section SEM image after testing 


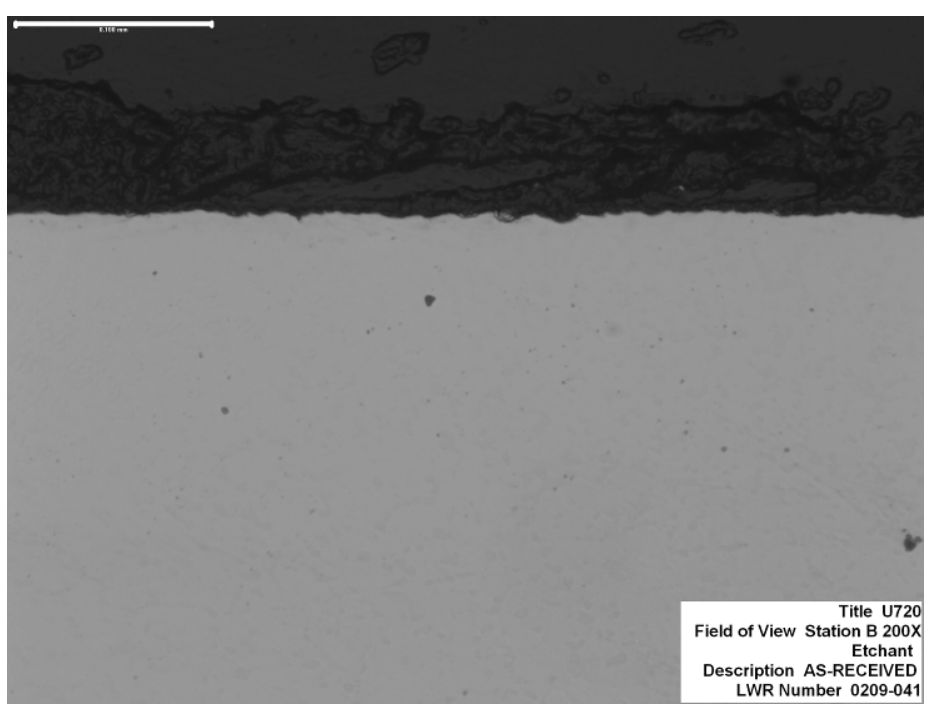

U 720 As-received

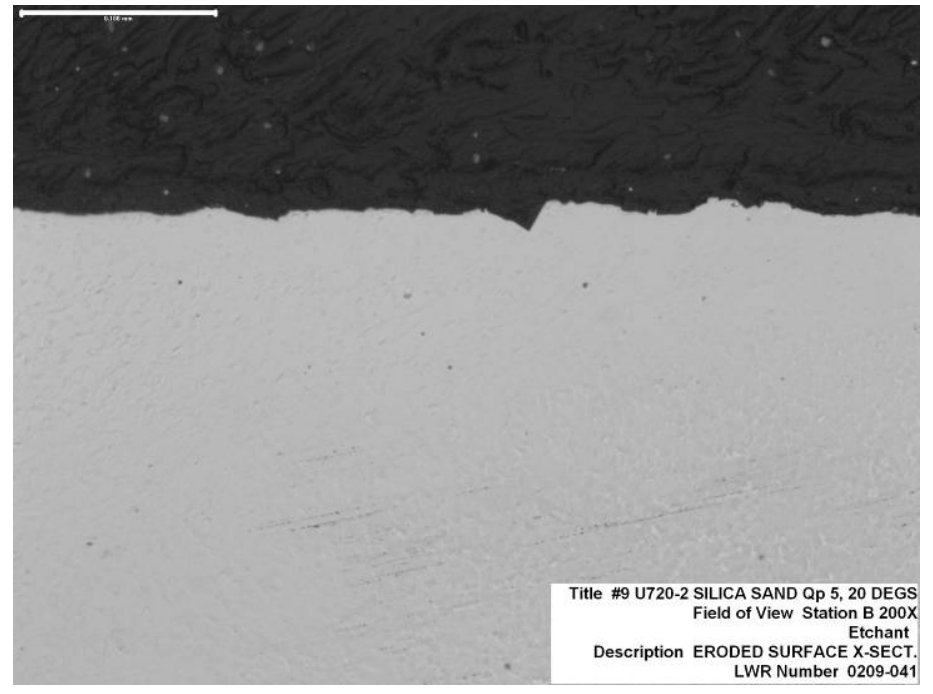

U 720 Silica Sand Qp 5, 20 Deg.

Figure 63

Udimet 720Li Cross-section SEM image after testing

\section{Summary}

Alloys and coatings were procured from various vendors and erosion tested using the University of Cincinnati's test rig. Silica sand and magnetite were the erodent materials used for this testing. A limited amount of testing was done with alumina as well. Erosion rate data were generated and analyzed. SEM surface images and cross-sectional metallography was used to evaluate if the laboratory testing reproduced damage found in the field. Analysis of the samples confirmed that in most cases characteristic solid particle erosion was the active erosion mechanism in the test.

The molybdenum boride-cobalt chromium coating supplied by Kermetico, Inc (MB-42) had the lowest overall erosion rates and volume loss of the 12 coatings tested. The top 4 coatings ranked according to their erosion rates and volume losses were:

1.Moly-Boride - Cobalt Chromium

\section{Zircoat}

\section{T400C (Tribaloy)}

\section{Conformaclad WC}

Further research is required to validate the use of these coatings for SPE resistance in a USC turbine. Steam oxidation testing is being conducted on a separate activity and a larger matrix of testing, proposed in the introduction, is suggested. 


\section{Appendix A}

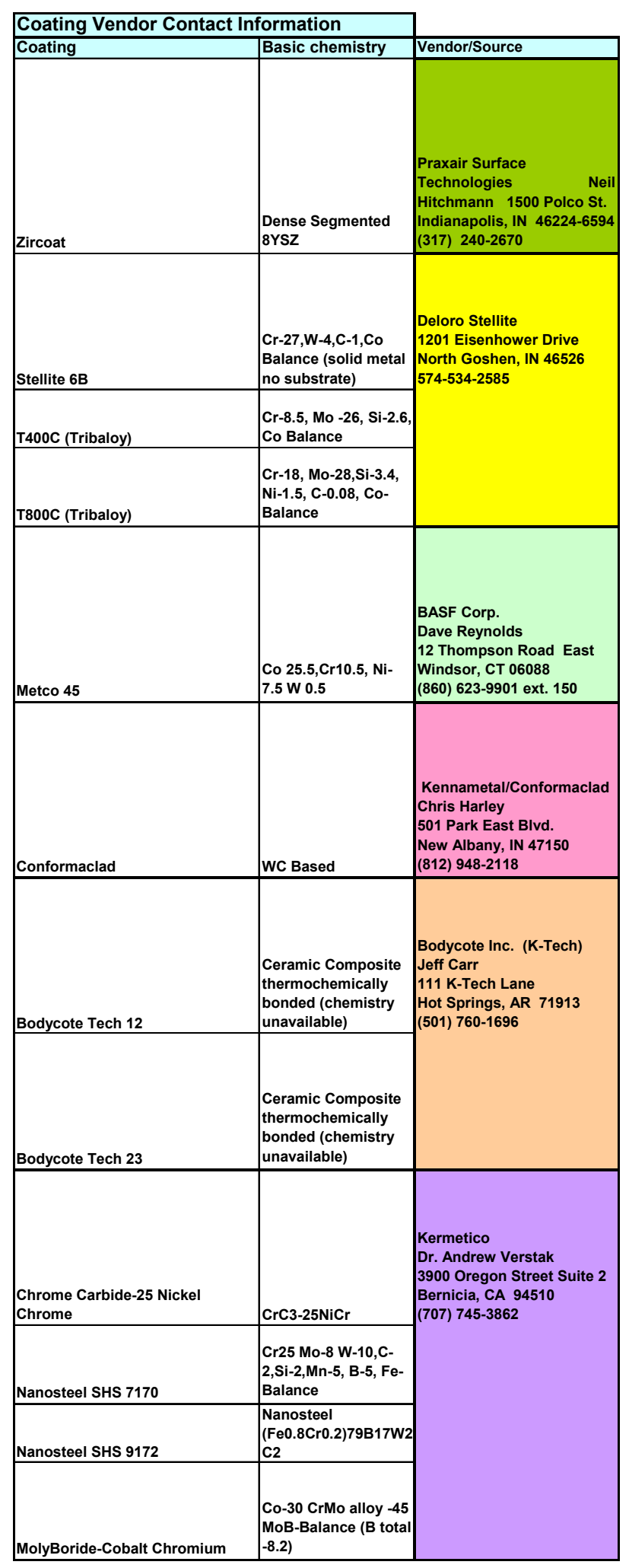




\section{Appendix B}

\section{unverstr of Cincinnati}

\author{
College of Engineering \\ Department of Aerospace Engineering \\ and Engineering Mechanics \\ University of Cincinnati \\ PO Box 210070 \\ Gincinnati, $\mathrm{OH} 45221-0070$ \\ 745 Baldwin Hall \\ Phone (513) 556-3548 \\ Fax (513) 556-5038
}

February 12, 2009

Melanie McNally

Siemens Energy Sector

Materials System Development, PE423

261 Lyman Road

Casselberry, FL 32708

\section{Estimated Budget for Erosion Tests}

(reference McNally email dated 2/10/09)

Test Conditions

Temperature: $\quad 1400^{\circ} \mathrm{F}$

Velocity $\quad 900 \mathrm{ft} / \mathrm{sec}$

Impact angles $\alpha=20^{\circ}$ and $30^{\circ}$

Solid particles Silica, 75 and 125 microns, supplied by Siemens

Sample testings

a) 40 samples $@ \$ 700$ each $\$ 28,000$

b) Wind tunnel calibration $\quad 1,000$

c) Fabrication of holders, $40 \times \$ 10 \quad 400$

d) Solid particles (Siemens)

$\frac{0}{\$ 29,400}$

e) Overhead $56 \%$

16,464

TOTAL $\underline{\underline{\mathbf{4 5 , 8 6 4}}}$

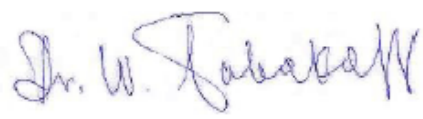

Widen Tabakoff, Professor and Director Turbomachinery Erosion Laboratory 


\section{Appendix C}

\section{MIL-STD-810E SILICA SAND}

Material: Good Commercial Quality Crushed Quartz

Analysis Number: 10053A

Date Processed: July 31, 2008

\section{MATERIAL PARTICLE SIZE DISTRIBUTION}

\begin{tabular}{|c|c|c|c|}
\hline $\begin{array}{c}\text { US Standard } \\
\text { Test Sieve No. }\end{array}$ & Micron Size & $\begin{array}{c}\text { Specified Range } \\
\text { (\% Retained By Weight) }\end{array}$ & $\begin{array}{c}\text { 10053A Analysis } \\
\text { (\% Retained By } \\
\text { Weight) }\end{array}$ \\
\hline 20 & 850 & $1.0+/-0.5$ & 0.6 \\
\hline 30 & 590 & $1.7+/-0.5$ & 1.8 \\
\hline 40 & 420 & $14.3+/-1.5$ & 14.8 \\
\hline 50 & 300 & $37.0+/-2.0$ & 35.2 \\
\hline 70 & 212 & $28.6+/-2.0$ & 29.1 \\
\hline 100 & 149 & $12.7+/-1.5$ & 13.1 \\
\hline Pan & -149 & $5.2+/-1.0$ & 5.4 \\
\hline
\end{tabular}

NOTE: Mix material prior to using. Stratification may occur during transit.

ISO 9001:2000 Certified

14331 Ewing Ave $S \bullet$ Burnsville, Minnesota 55306 • Phone: 952-894-8737 • Fax: 952-894-0734

Web: www.powdertechnologyinc.com 


\section{MATERIAL SAFETY DATA SHEET}

Section 1: Product/Company Information

Identity: Quartz, Silicon Dioxide

Mfg. Name: Powder Technology Inc. 14331 Ewing Avenue S.

Emergency Number: (952) 894-8737

Burnsville, MN 55306

Number for Info:

(952) 894-8737

Date Updated:

16 Nov 2007

\section{Section 2: Emergency and First Aid}

Eyes: Immediately flush eye thoroughly with water. Get medical attention if irritation persists.

Skin: $\quad$ N/A

Inhalation: Remove person to fresh air. If breathing is difficult, administer oxygen. If not breathing, give artificial respiration. Seek medical help if coughing and other symptoms do not subside.

Ingestion: Do not induce vomiting. If conscious, have the victim drink plenty of water and call a physician if discomfort is experienced.

Section 3: Composition Information

Typical chemical composition:

\begin{tabular}{|l|c|c|c|}
\cline { 2 - 4 } \multicolumn{1}{c|}{} & Chemical Formula & Typical \%, by Weight & CAS \# \\
\hline Crystalline Silica (Quartz) & $\mathrm{SiO} 2$ & $99.0-99.9$ & $14808-60-7$ \\
\hline Aluminum Oxide & $\mathrm{Al} 2 \mathrm{O} 3$ & $<0.8$ & $1344-28-1$ \\
\hline Iron Oxide & $\mathrm{Fe} 2 \mathrm{O} 3$ & $<0.1$ & $1309-37-1$ \\
\hline Titanium Oxide & $\mathrm{TiO} 2$ & $<0.1$ & $13463-67-7$ \\
\hline
\end{tabular}

All components are included on the TSCA Inventory. 


\section{Section 4: Hazardous Ingredients/Identity Information}

This product contains free silica. Inhalation of dust may be harmful to your health. NIOSH has recommended a PEL of $0.05 \mathrm{mg} / \mathrm{m}^{3}$ as determined by a full shift sample up to 10 hours working day, 40 hours per week.

H.M.I.S. ratings: Health $-{ }^{*} \quad$ Flammability $-0 \quad$ Reactivity -0

* see Section 5 of this MSDS for further information on health effects

\section{Section 5: Hazard Identification}

Potential Health Effects:

Eye Contact:

Inhalation:

Carcinogenic Potential:
Potential health effects may vary depending upon the duration and degree of exposure. To reduce or eliminate health hazards associated with this product, use exposure controls or personal protection methods as described in Section 12.

(Acute/Chronic) Exposure to airborne dust may cause immediate or delayed irritation or inflammation of the cornea.

(Chronic) Inhalation exposure to free silica may cause delayed lung injury, including silicosis, a disabling and potentially fatal lung disease, and/or cause or aggravate other lung diseases or conditions.

This product contains free silica, which IARC classifies as a known human carcinogen. The NTP, in its ninth Annual Report on Carcinogens, classified "silica, crystalline (respirable)" as a known carcinogen.

\section{Section 6: Accidental Release Measures}

Use clean-up methods that do not disperse dust into the air. Avoid inhalation of dust and contact with eyes. Use exposure control and personal protection methods as described in Section 12.

\section{Section 7: Physical/Chemical Data}

Boiling Point:
Melting Point:
Specific Gravity $\left(\mathrm{H}_{\mathbf{2}} \mathbf{0}=\mathbf{1 . 0}\right)$ :
Vapor Pressure:
Solubility in Water:
Appearance:
Odor:
Physical State:
Vapor Density:

Page 2 of 4 $2230^{\circ} \mathrm{F}$

$1710^{\circ} \mathrm{F}$

2.65

Not applicable

Insoluble

Light Brown, White

No Odor

Solid

Not applicable 
Flash Point: None

Auto ignition Temperature: Not combustible

Flammable Limits: N/A

Extinguishing Media: Not Combustible

Hazardous Combustion Products: None
Lower Explosive Limit: None

Upper Explosive Limit: None

Special Fire Fighting Procedures: None

Unusual Fire and Explosion Hazards: None

Section 9: Stability and Reactivity Data

Stability:

Incompatibility (Materials to Avoid):

Hazardous Decomposition:

Hazardous Polymerization:
Product is stable

Strong oxidizing agents

Will not occur

Will not occur

\section{Section 10: Handling and Storage}

Handle and store in a manner so that airborne dust does not exceed applicable exposure limits. Use adequate ventilation and dust collection. Use exposure control and personal protection methods as described in Section 12

\section{Section 11: Toxicological Information}

Conditions aggravated by exposure: Eye disease, Skin disorders and Chronic Respiratory conditions.

\section{Section 12: Exposure Control/Personal Protection}

$\begin{array}{ll}\text { Respiratory Protection: } & \text { Use local exhaust or general dilution ventilation to control dust } \\ \text { levels below applicable exposure limits. Use appropriate NIOSH } \\ \text { approved respiratory protection for respirable crystalline silica. }\end{array}$

Eye Protection:

Wear safety glasses with side shields or goggles to avoid contact with the eyes. In extremely dusty environments and unpredictable environments, wear tight-fitting unvented or indirectly vented goggles to avoid eye irritation or injury 
All disposal methods must be in accordance with all Federal, State/Provincial and local laws and regulations. Regulations may vary in different locations. Waste characterization and compliance with applicable laws are the responsibility solely of the waste generator.

\section{Section 14: Transportation Data}

Quartz is not hazardous under U.S. DOT or TDG regulations.

\section{Section 15: Other Regulatory Information}

Status under US OSHA Hazard
Communications Rule 29 CFR 1910.1200:

Status under CERCLA/Superfund, 40 CFR 117 and 302 :

Hazard Category under SARA (Title III), Sections 311 and 312 :

Status under SARA (Title III), Section 313:

Status under Canadian Environmental Protection Act:

Canadian WHMIS Classification:

European Inventory of Commercial Chemical Substances:
Silica sand is considered a hazardous chemical under this regulation and should be included in the employer's hazard communication program.

Not listed

Silica sand qualifies as a hazardous substance with delayed health effects.

Not subject to reporting requirements under Section 313

Not listed.

Class D, Division 2, Subdivision A (A very toxic material causing other toxic effects).

Listed on the EINECS Inventory or exempt from notification requirements. EINECS number for Quartz is 231-545-4.

\section{Section 16: Other Information}

The information and recommendations contained herein are based upon data believed to be correct. However, no guarantee or warranty of any kind, express or implied, is made with respect to the information contained herein. It is the user's obligation to determine the conditions of safe use of this product. 


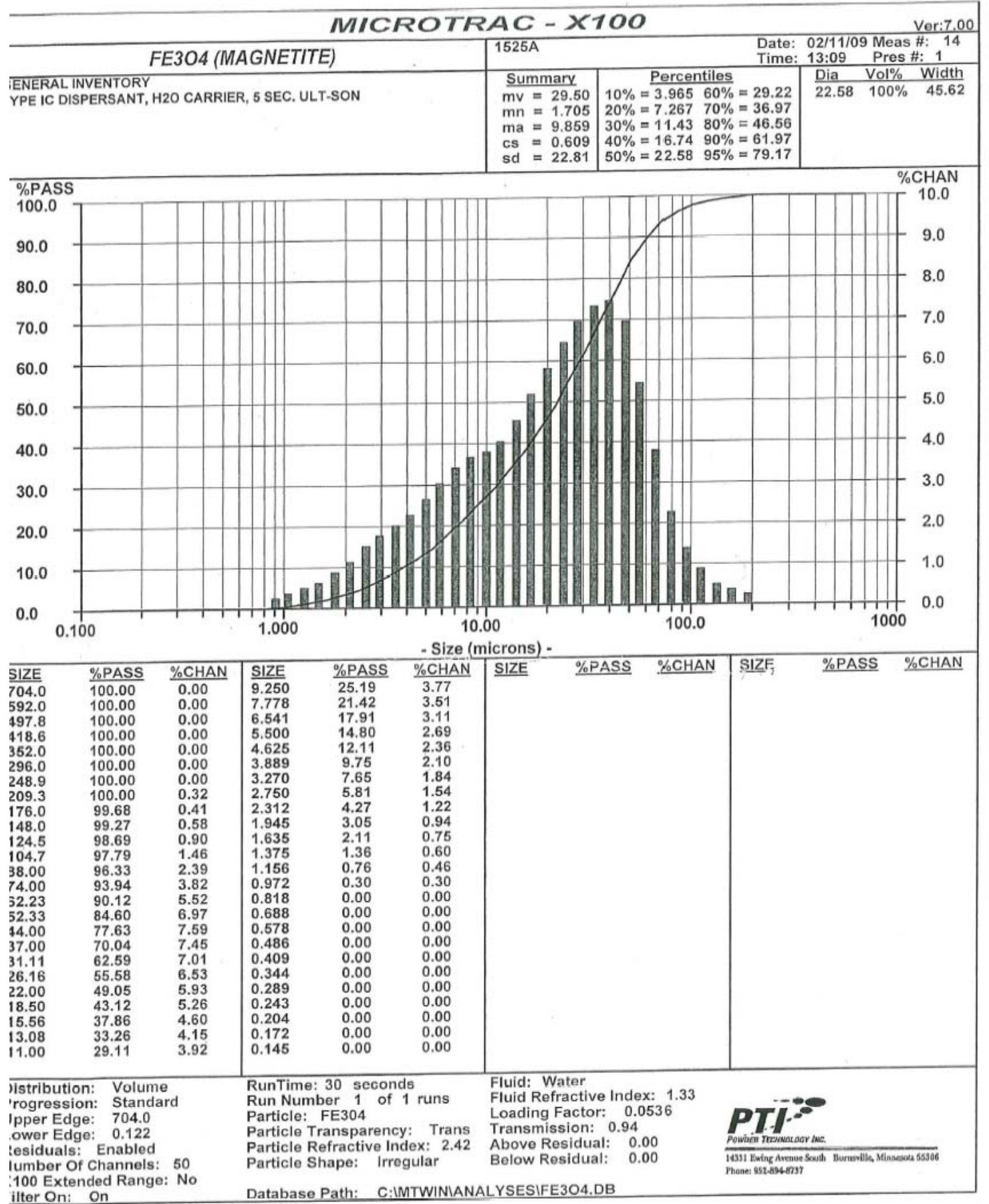




\section{MATERIAL SAFETY DATA SHEET}

Section 1: Product/Company Information

Identity: Ferrous Oxide, Hematite, Magnetite, $\mathrm{Fe}_{2} \mathrm{O}_{3}, \mathrm{Fe}_{3} \mathrm{O}_{4}$
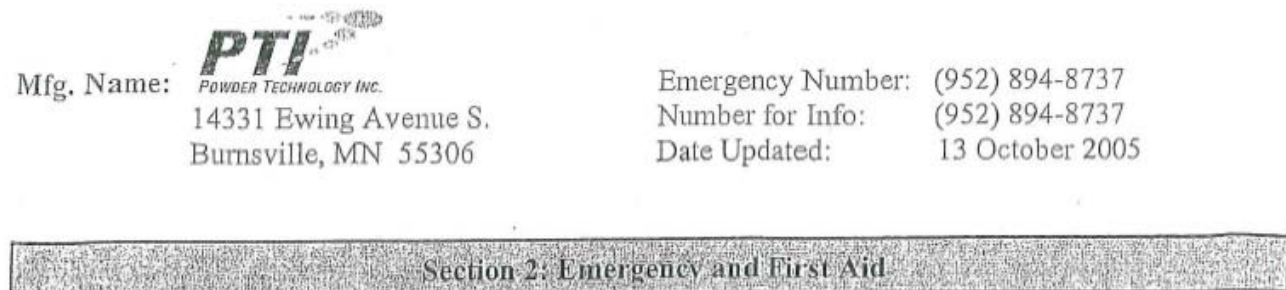

Section 2 Eimer

Eyes: $\quad$ Immediately flush eye with water for at least 15 minutes. Get medical aid.

Skin: Immediately flush skin with water for at least 15 minutes. Remove contaminated clothing. Get medical aid if irritation develops or persists. Wash clothes before reuse.

Inhalation: Remove person to fresh air. If not breathing, give artificial respiration. Seek medical help if coughing and other symptoms do not subside.

Ingestion: Do not induce vomiting. If conscious, have the victim drink 2-4 cups of milk or water. Get medical aid,

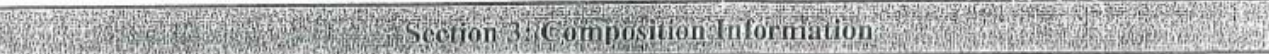

Typical chemical composition:

\begin{tabular}{|c|l|c|}
\hline \multicolumn{1}{|c|}{ CAS\# } & \multicolumn{1}{|c|}{ Chemical Name } & Percent \\
\hline $1309-37-1$ & Hematite, $\mathrm{Fe}_{2} \mathrm{O}_{3}$ & 99.4 \\
\hline $1317-61-9$ & Magnetite, $\mathrm{Fe}_{3} \mathrm{O}_{4}$ & 99.4 \\
\hline
\end{tabular}

Wection 4: Hazardous Ingredients/Identitydnformation

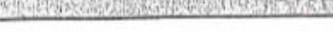

\begin{tabular}{|c|c|c|c|}
\hline Chemical Name & \multicolumn{1}{|c|}{ ACGIH } & NIOSH & OSHA - Final PELs \\
\hline Iron (III) Oxide & $\begin{array}{l}5 \mathrm{mg} / \mathrm{m} 3 \text { TWA (dust and } \\
\text { fume, as Fe) }\end{array}$ & $5 \mathrm{mg} / \mathrm{m} 3$ TWA (dust and fume, as Fe) & $10 \mathrm{mg} / \mathrm{m} 3$ TWA \\
\hline
\end{tabular}

H.M.I.S. ratings: Health $-0 \quad$ Flammability $-1 \quad$ Reactivity -1 


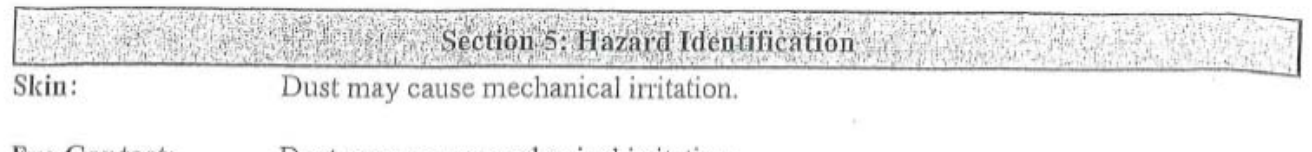

Eye Contact: Dust may cause mechanical irritation.

Inhalation: Dust is irritating to the respiratory tract. Inhalation of fumes may cause metal fume fever, which is characterized by flu-like symptoms with metallic taste, fever, chills, cough, weakness, chest pain, muscle pain and increased white blood cell count.

Ingestion: May cause severe and permanent damage to the digestive tract. May cause liver damage. Causes severe pain, nausea, vomiting, diarthea and shock. May cause hemorrhaging of the digestive tract.

Note: The toxicological properties of this substance have not been fully investigated.

P. Section 6: Accidental Release Measures

Use clean-up methods that do not disperse dust into the air. Use exposure control and personal protection methods as described in Section 12.

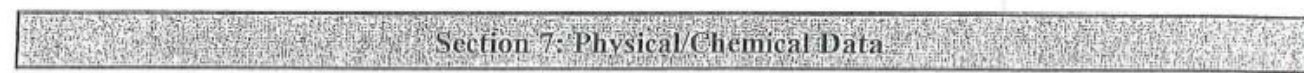

$\begin{array}{ll}\text { Melting Point: } & 2849^{\circ} \mathrm{F} \\ \text { Specific Gravity }\left(\mathrm{H}_{2} \mathrm{O}=1.0\right): & 5.24 \\ \text { Vapor Pressure: } & 1 \mathrm{~mm} \mathrm{Hg} @ 20^{\circ} \mathrm{C} \\ \text { Vapor Density: } & \text { Not applicable } \\ \text { Solubility in Water: } & \text { Insoluble } \\ \text { Appearance: } & \text { Hematite: red-brown, Magnetite: Bluish-black } \\ \text { Odor: } & \text { No Odor } \\ \text { Physical State: } & \text { Solid }\end{array}$

Section 8: Fireand Explosion Hazard Data

General Information: Wear a self-contained breathing apparatus in pressure-demand, MSHA/NIOSH approved and full protective gear. Irritating and highly toxic gases may be generated by thermal decomposition or combustion. Non-combustible, substance does not burn but may decompose upon heating to produce irritating, corrosive and/or toxic fumes.

Extinguishing Media: Substance is non-combustible; use appropriate agent for surrounding fire. 


\begin{tabular}{|c|c|}
\hline $\begin{array}{l}\text { Stability: } \\
\text { Incompatibility (Materials to Avoid): }\end{array}$ & $\begin{array}{l}\text { Product is stable, } \\
\text { Aluminum, bromine pentafluoride, calcium hypochlonite, } \\
\text { carbon dioxide, cesium carbide, ethylene oxide, } \\
\text { hydrazine, performic acid. }\end{array}$ \\
\hline $\begin{array}{l}\text { Hazardous Decomposition: } \\
\text { Hazardous Polymerization: }\end{array}$ & $\begin{array}{l}\text { Irritating and toxic fumes. } \\
\text { Will not occur. }\end{array}$ \\
\hline
\end{tabular}

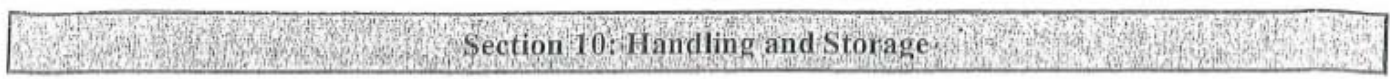

Store in a cool, dry area. Do not store at temperatures above $140^{\circ} \mathrm{F}$. Use adequate ventilation and dust collection. Use exposure control and personal protection methods as described in Section 12.

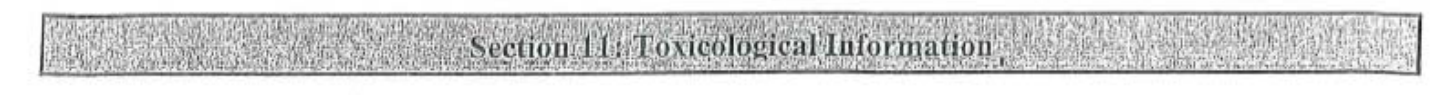

Carcinogenicity: Not listed by ACGIH, IARC, NTP or CA Prop 65.

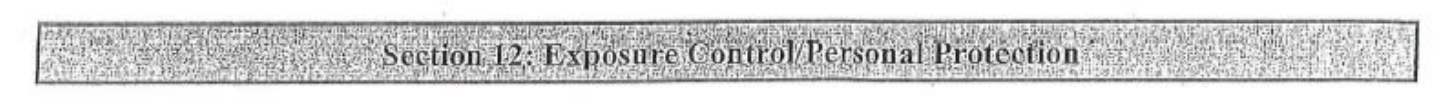

Respiratory Protection: Use local exhaust or general dilution ventilation to control dust levels below applicable exposure limits. Minimize dispersal of dust into the air.

Eye Protection: Wear safety glasses with side shields or goggles to avoid contact with the eyes. In extremely dusty environments and unpredictable environments, wear tight-fitting unvented or indirectly vented goggles to avoid eye irritation or injury

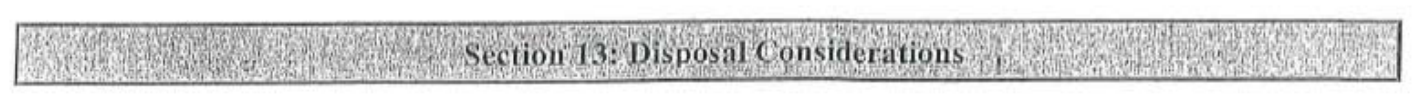

All disposal methods must be in accordance with all Federal, State/Provincial and local laws and regulations. Regulations may vary in different locations. Waste characterization and compliance with applicable laws are the responsibility solely of the waste generator.

\begin{tabular}{|c|c|c|}
\hline & Section 14: Transportation Data \\
\hline
\end{tabular}

Hematite and Magnetite are not regulated under U.S. DOT regulations. 


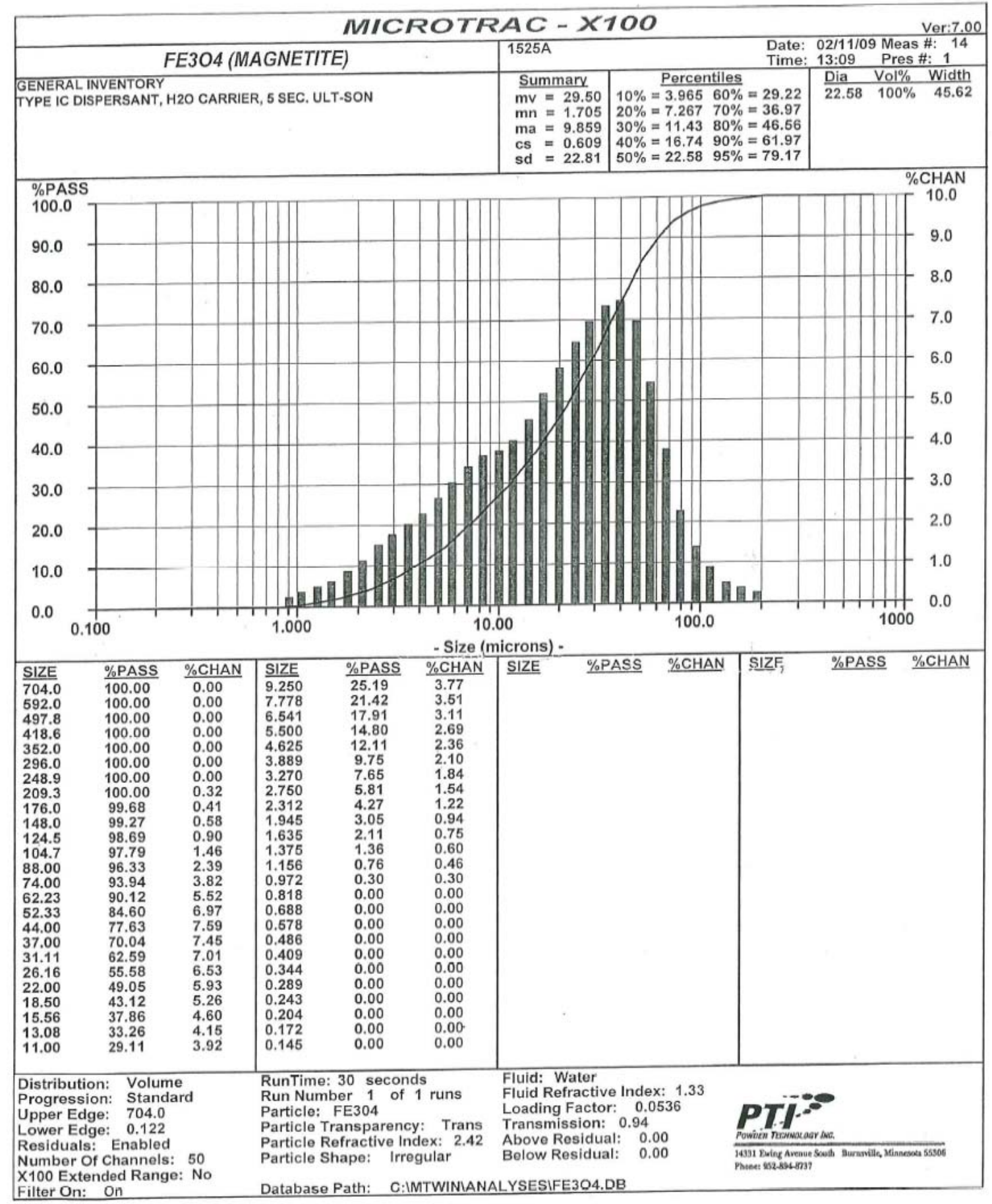




\section{Appendix D}

$\mathrm{X}$-ray energy dispersive spectrographic analysis of the various erodent mediums used during testing.

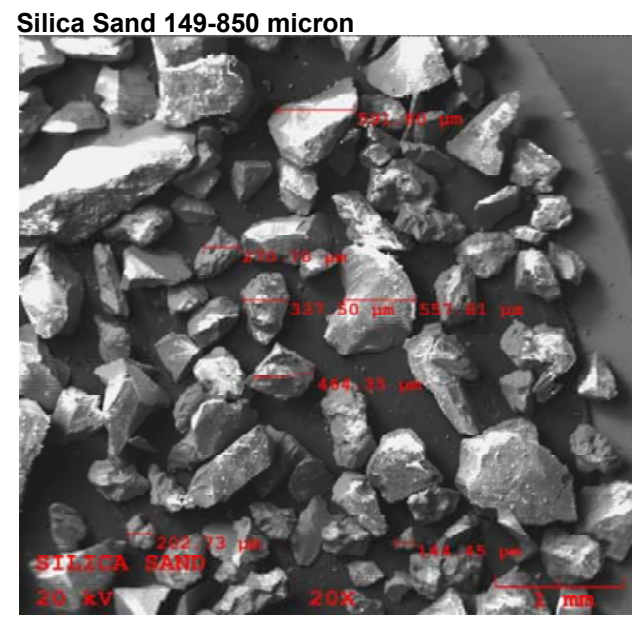

Coarse Silica Test Dust 100-200 micron

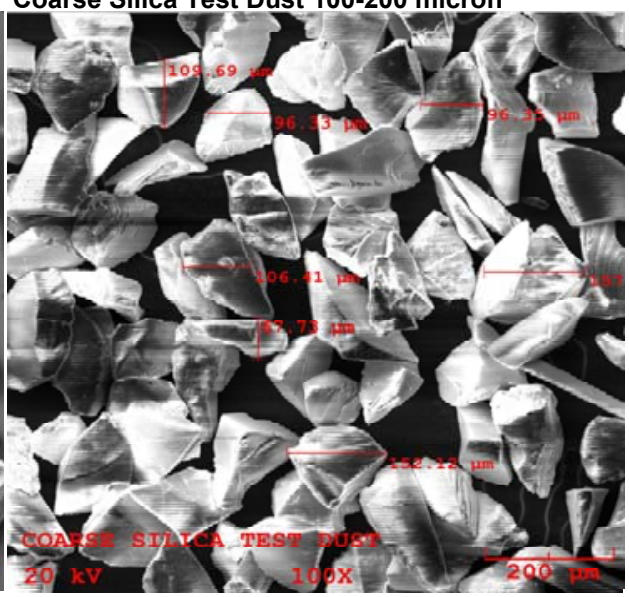

Magnetite 0-50 micron

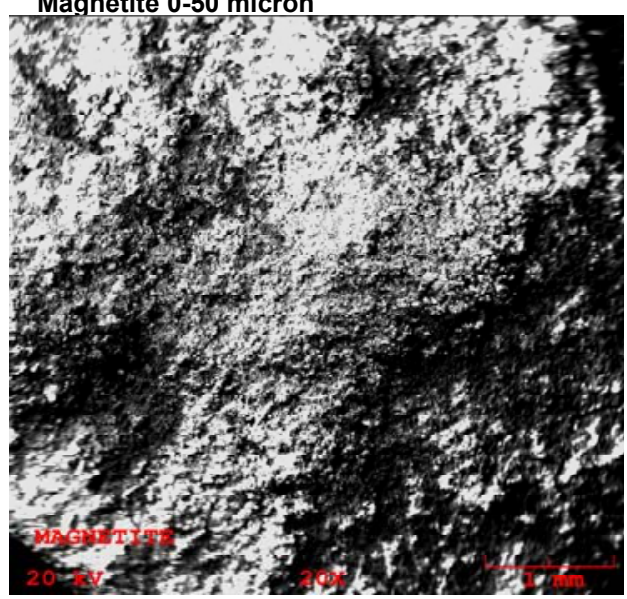

\begin{tabular}{|c|c|c|c|c|c|c|c|}
\hline Erodent & & & & & & & \\
\hline Spectrum & $\mathbf{0}$ & Mg & Al & Si & $\mathrm{Ca}$ & $\mathrm{Fe}$ & $\mathbf{Y}$ \\
\hline SILICA SAND EDS 1 & 33.65 & 0.00 & 1.33 & 65.03 & 0.00 & 0.00 & 0.00 \\
\hline SILICA SAND EDS 2 & 41.85 & 0.00 & 0.75 & 57.40 & 0.00 & 0.00 & 0.00 \\
\hline SILICA SAND EDS 3 & 38.02 & 0.00 & 0.77 & 61.21 & 0.00 & 0.00 & 0.00 \\
\hline COARSE SILICA TEST DUST EDS 1 & 28.23 & 0.00 & 58.19 & 0.00 & 0.00 & 0.00 & 13.58 \\
\hline COARSE SILICA TEST DUST EDS 2 & 0.00 & 0.00 & 0.00 & 0.00 & 0.00 & 0.00 & 0.00 \\
\hline COARSE SILICA TEST DUST EDS 3 & 32.77 & 1.87 & 62.89 & 0.00 & 0.00 & 1.97 & 0.52 \\
\hline MAGNETITE EDS 1 & 8.06 & 0.00 & 0.00 & 2.01 & 0.00 & 89.93 & 0.00 \\
\hline MAGNETITE EDS 2 & 7.58 & 0.00 & 0.00 & 1.60 & 0.00 & 90.83 & 0.00 \\
\hline MAGNETITE EDS 3 & 8.34 & 0.00 & 0.00 & 2.48 & 1.05 & 88.13 & 0.00 \\
\hline
\end{tabular}

The composition of the coarse silica test dust was found to be almost pure Alumina with trace amounts of Yttria and Iron. 


\section{Appendix E}

The Effect of Power Plan Operation on the Deterioration of Turbine Efficiency by K.C.

Cotton-Chapter 12 


\section{B. 3. Turbine Design}

Redesign of turbine stages has decreased solid particle erosion damage considerably. The solid erosion phenomenon in the control stage is completely different from the phenomenon in the first IP turbine stage. The control stage stationary blade profiles have been modified in the HP turbine and the axial distance between the stationary blade discharge and the rotating blade inlet has been increased in the first stage of the IP turbine.

A four control valve turbine with sequential valve operation experiences sonic velocity under certain conditions. At the first valve point ( $25 \%$ load), the pressure ratio across the first stage is about 4 to 1 . At the second valve point ( $50 \%$ load) the pressure ratio is about 2 to 1 . Both conditions produce sonic velocity in the first stage stationary blades. In addition, the high throttle pressure

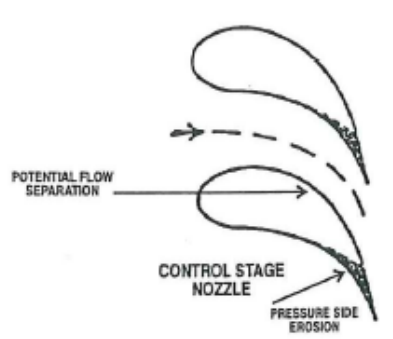

Figure 12-19. Stationary blades with solid particle erosion damage. accelerates the solid particles above the erosion threshold velocity (about $700 \mathrm{ft} / \mathrm{sec}$ ). These high velocity particles wear the concave (pressure) surface of the first stage stationary blades as shown in Figure 12-19. Figure $12-20$ is a photograph of the eroded blades.

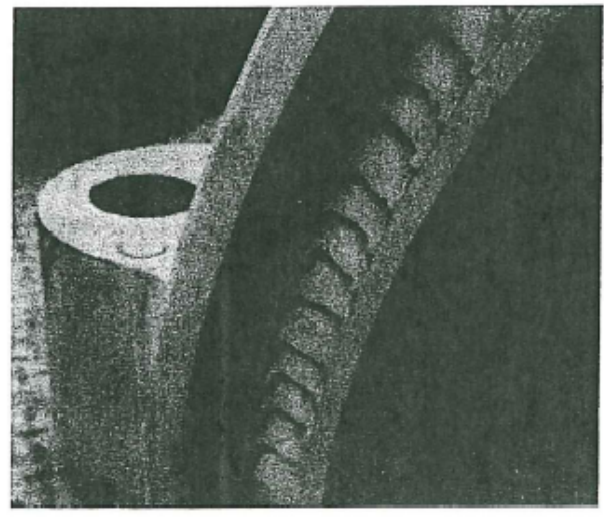

Figure 12-20. Photograph of first HP turbine stage stationary blades that experienced solid particle erosion.

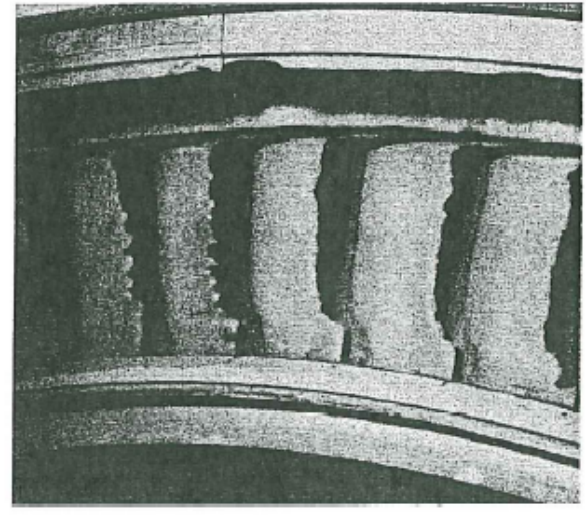

Figure 12-21. Photograph of first IP turbine stage stationary blades that experienced solid particle erosion.

In the first IP turbine stage the steam velocity and pressure level are lower than in the control stage. The solid particles are not accelerated above the threshold velocity and no erosion occurs on the concave side. Instead, the solid particles moving at considerably less than steam speed strike the inlet convex side 
of the rotating blades. They bounce back and cause erosion on the convex (suction) side of the stationary blades as indicated by the shaded area in Figure 12-19. Figure $12-21$ is a photograph of the eroded blades.

In Reference 16, W.J. Sumner calculated the trajectories of different size particles in the stationary blades of the control stage. At full load, the smaller particles (10 microns) are accelerated close to the threshold velocity (about 700 $\mathrm{ft} / \mathrm{sec}$ ). However, at $30 \%$ load the smaller particles are accelerated to velocities higher than threshold velocity because of the higher steam velocity. Therefore, solid particle erosion is generally confined to the first two arcs of a four valve unit. However, if this turbine is operated with throttling or sliding pressure control the particle velocities at $10 \%$ load are smaller than at full load and solid particle erosion damage does not occur. The results of the particle velocity calculations are shown in Figure 12-22.

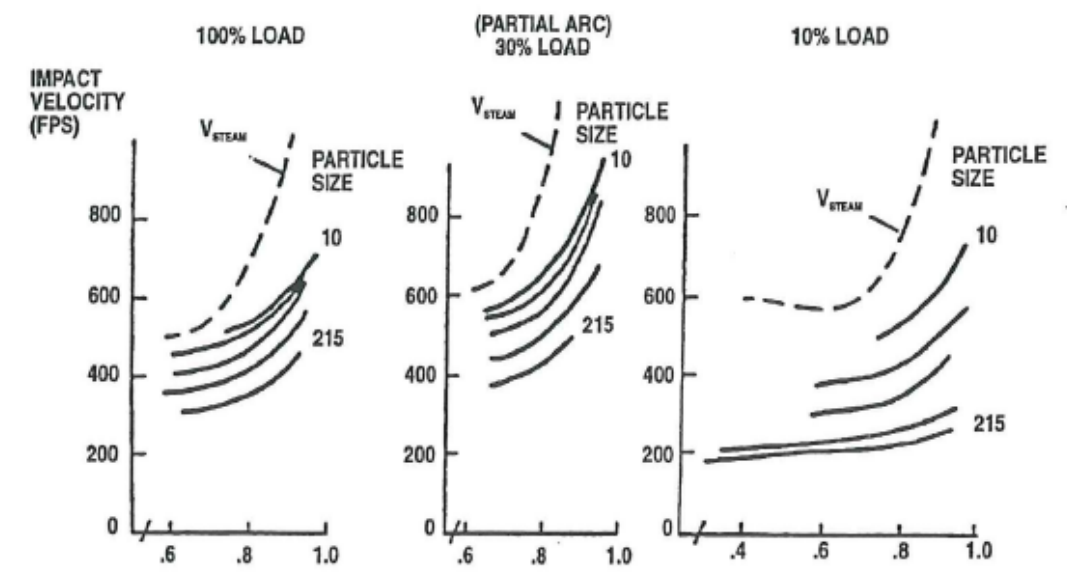

Figure 12-22. Control stage (First HP turbine stage) particle velocitiès àlong stationary blades that experienced solid particle erosion.

The solid particle erosion on the control stage rotating blades is on the inlet convex (suction) side and the discharge concave (pressure) side, as shown in Figure 12-23. The particles entering the rotating blades wear away metal leaving a sharp leading edge. There is a tendency to over-round this sharpness during repairs. If the rounding is

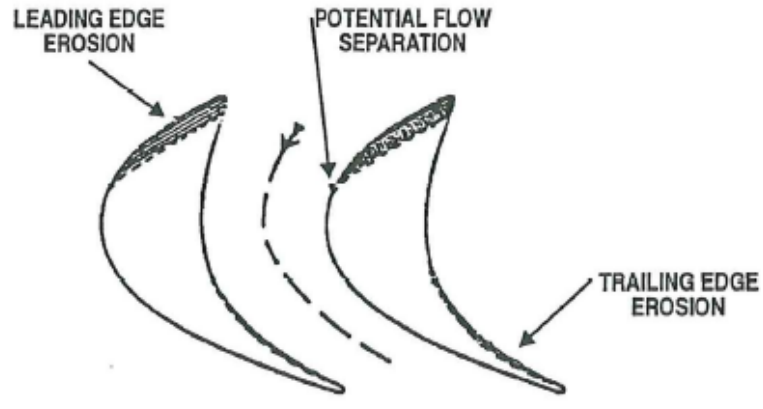

Figure 12-23. Control stage (First HP turbine stage) rotating blade damage due to solid particle erosion. 
tegrity, it has to be done. However, from an efficiency point of view, it introduces an off-angle loss. Figure 12-24 shows the off-angle loss for both a sharp and a rounded rotating blade leading edge. These losses were determined by conducting tests in the General Electric Company's Aerodynamic Development Laboratory. The loss for a sharp leading edge is greater than for a rounded leading edge, but over-rounding results in an off-angle loss even when the stationary blades have been replaced or repaired.

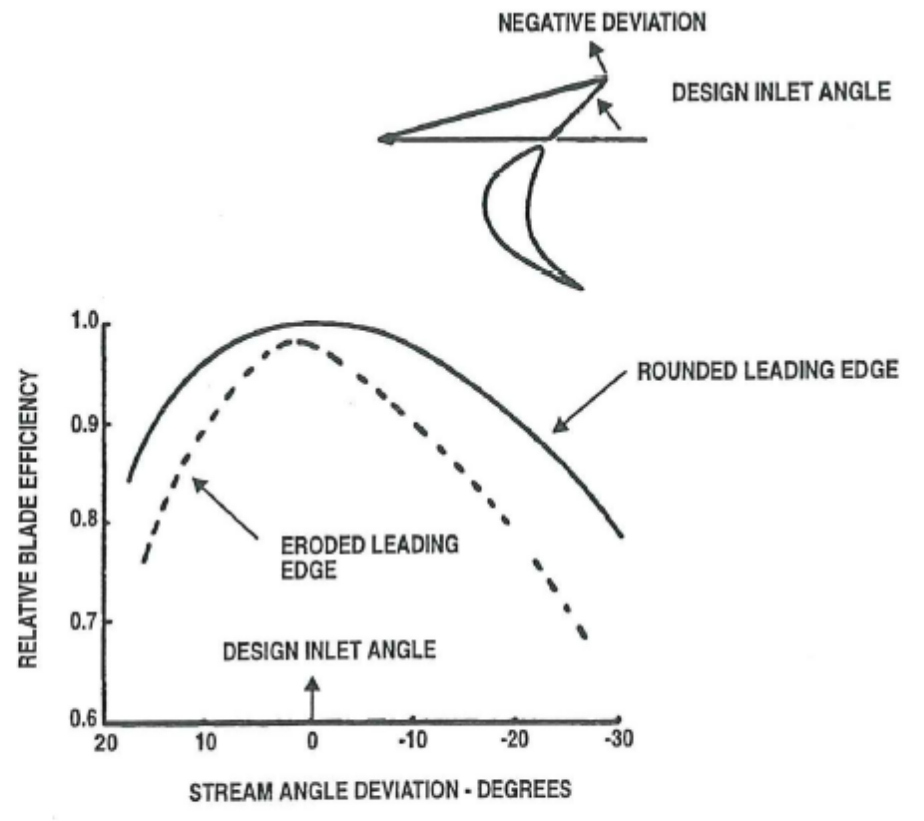

Figure 12-24. Change in rotating blade efficiency resulting from changes in inlet steam angle.

The erosion on the discharge concave side (i.e., trailing edge) of the rotating blades has a small effect on stage efficiency. However, severe erosion can cause mechanical failure.

IV. B. 3.a. Calculation of the Kilowatt Loss Due to Solid Particle Erosion

The loss in first stage efficiency due to solid particle erosion is calculated by determining the increase in stationary blade throat area. Measuring the area gives an accurate determination of the increase in area but it is time-consuming. The following estimating method is less expensive and has less chance of interfering with the outage schedule. Determine how many blades fit each of the four groupings shown in Figure 12-25. Measure the distance from the original trailing edge to the deepest erosion, d. There is usually enough of the original trailing edge at the root and tip as shown in Figure 12-20 to make this measurement. Also measure the steam path length, $1_{\mathrm{SP}}$, as shown in Figure 12-26. The decrease 

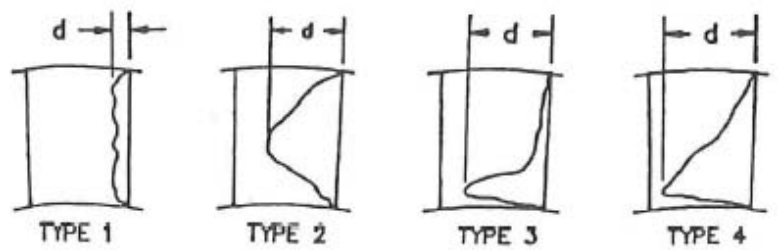

Figure 12-25. Four typical solid particle erosion patterns. Courtesy of Encotech, Inc.

in profile is $d / 1_{\text {Sp. }}$ Enter the area ratio versus profile reduction, $d / l_{S P}$, curve (Figure 12-27) at $13^{\circ}$ for an impulse type turbine and at $20^{\circ}$ for a $50 \%$ reaction turbine. If there is a question about these angles, they can be calculated from measured values or pitch, $\mathrm{P}$, and throat width, t. The sine of the angle is equal to $\mathrm{t} / \mathrm{P}$. If the area ratio is 1.1 , the increase in area is $10 \%$. In addition to the missing profile, the trailing edge thickness has also been eroded away on all four types of erosion patterns. This increases the area an additional amount, ments required to evaluate solid particle erosion damage.

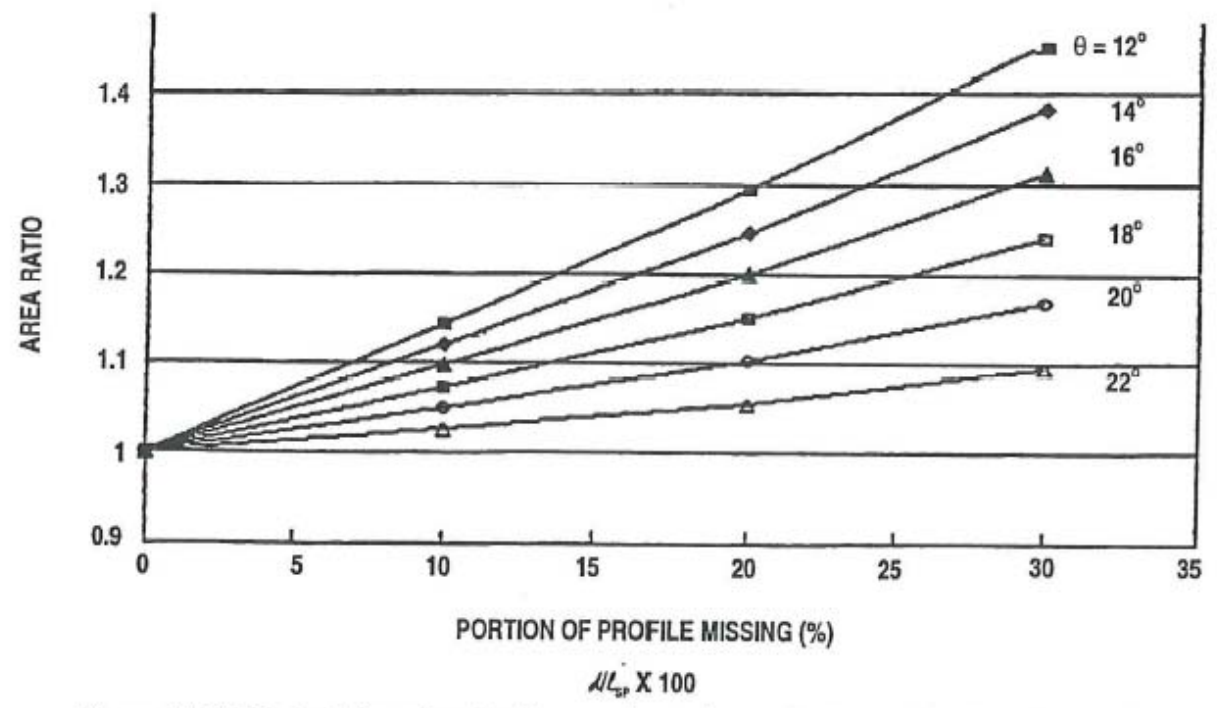

Figure 12-27. Method for estimating increase in stationary blade area based on the portion of the profile missing. Courtesy Encotech, Inc. 
THE EFFECT OF POWER PLANT OPERATION ON THE DETERIORATION OF TURBINE EFFICIENCY

which is calculated by dividing the edge thickness by the throat width. The total area increase is the sum of the area ratio increase and the trailing edge change.

A stationary throat blade area increase of $10 \%$ causes about $61 / 2 \%$ efficiency loss in the control stage and about $3 \%$ efficiency loss in the other stages. These percentages do not include the deterioration due to increased surface roughness nor rubbed seals in the downstream stages caused by solid particle erosion. Solid particle erosion in the control stage usually increases throttle flow.

The following is a sample calculation of the kilowatt loss due to solid particle erosion in the control stage. Assume the information tabulated below is from a steam path audit of an impulse type turbine.

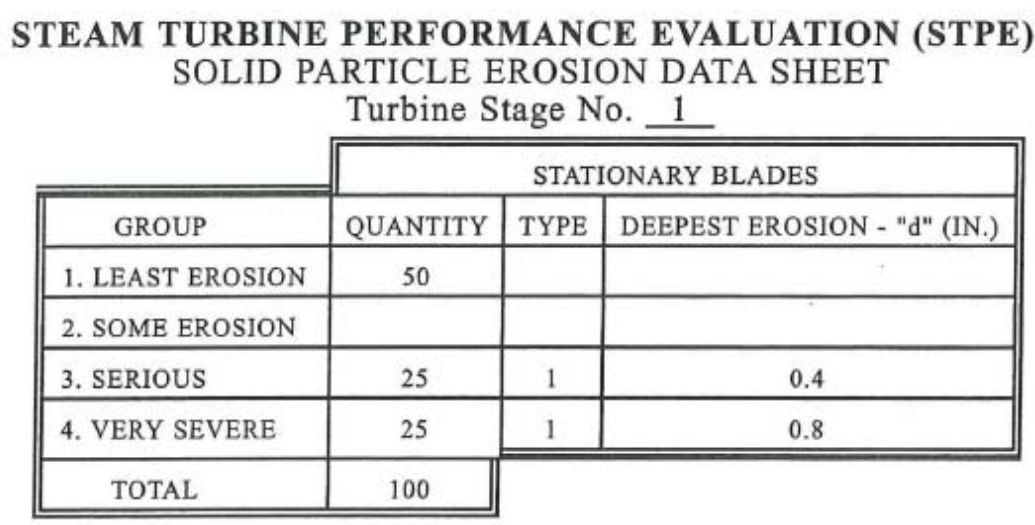

\begin{tabular}{lc} 
BLADE STEAM PATH LENGTH AT PITCH LINE & $3^{\prime \prime}$ \\
STATIONARY BLADE ANGLE $(\sin \theta=\mathrm{t} / \mathrm{P})$ & $13^{\circ}$ \\
THROAT THICKNESS (IN.) & $0.300^{\prime \prime}$ \\
TRAILING EDGE THICKNESS (IN.) & $0.040^{\prime \prime}$ \\
\hline
\end{tabular}

* NOTE: (C) Copyright Encotech, Inc. All rights reserved.

The $d / 1_{\mathrm{SP}}$ for 25 blades $=0.4 / 3=0.1333$ or $13.33 \%$, which gives an area ratio of 1.18 from Figure 12-27. This is an area increase of $18 \%$. For another 25 blades $\mathrm{d} / \mathrm{l}_{\mathrm{SP}}=0.8 / .3 .0=0.2666$ or $26.66 \%$ which gives an area ratio of 1.37 or $37 \%$. Therefore the average area increase is $(18+37) / 4$ or $13.75 \%$.

In addition, the 40 mil trailing edge thickness on the 50 eroded blades has eroded away which increases the area $40 / 300$ or $13.33 \%$. This effect on the total area increase is $13.33 / 2=6.67 \%$. Therefore the total increase in first stage stationary blade throat area is $6.67+13.75=20.42 \%$. Assuming the relationship between the area increase and the stage efficiency loss is linear, the stage loss is $(6.5 / 10) 20.42=13.27 \%$. However, a portion of this loss is recovered since the available energy to the following HP turbine stages is increased and there is less heat added in the reheater. The kilowatt loss in the control stage due to solid particle erosion is: 


$$
\begin{gathered}
\mathrm{KW}_{\text {LOSS }}=\frac{6.5}{10} \times \frac{\% \text { AREA INC }}{100} \times \text { LF } \times 1 \text { st STG KWs } \\
\mathrm{KW}_{\text {LOSS }}=\frac{6.5}{10} \times \frac{20.42}{100} \times .8^{*} \times 23,690^{* *}=2,515.5 \mathrm{KWs}
\end{gathered}
$$

* From Figure 12-12 at $\mathrm{P}_{\mathrm{EXH}} / \mathrm{P}_{\text {LOSS }}$ of $605.1 / 1829.9=0.33$

( $\mathrm{P}_{\mathrm{LOSS}}$ is the discharge pressure of the stage where the loss occurs and $\mathrm{P}_{\mathrm{EXH}}$ is the exhaust pressure of the HP turbine. Values are from the heat balance in Figure 2-9.)

$$
\text { ** } \frac{\mathrm{w}_{\mathrm{T}} \mathrm{UE}_{\mathrm{HP}}}{3412.1 \times 7}=\frac{(3,948,017-977-389.4)(1460.4-1316.9)}{3412.1 \times 7}=23,712
$$

The heat rate deterioration is:

$$
\begin{aligned}
& \mathrm{HR}_{\mathrm{DET}}=\% \mathrm{KW}_{\text {LOSs }} \times \frac{.17^{*}}{.28^{*}} \\
& =\frac{2515.5}{591906} \times 100 \times \frac{.17}{.28}=.26 \%
\end{aligned}
$$

*From Chapter 11, Section IV. A.

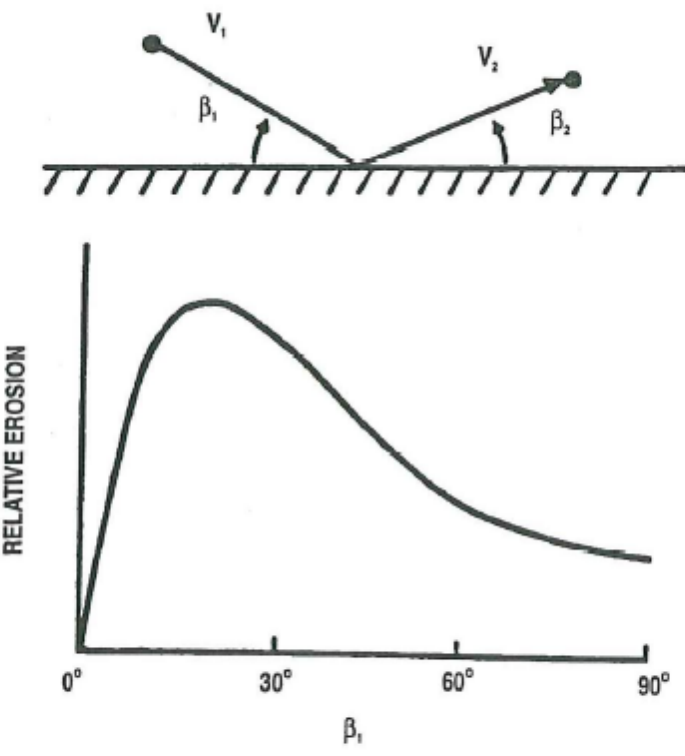

Figure 12-28. Influence of particle incidence angle on solid particle erosion.
IV. B. 3. b. Redesign of Control Stage Stationary Blades

The maximum erosion rate occurs when the particle incidence angle is about $20^{\circ}$ as shown in Figure 12-28. These results were obtained by Tabakoff, Hamed, and Ramachandran, using flyash impacting stainless steel. The trajectory calculation results also include the angle that the particles impact the stationary blades. The 10 to 45 micron particles have an incidence angle between 
THE EFFECT OF POWER PLANT OPERATION ON THE DETERIORATION OF TURBINE EFFICIENCY

$15^{\circ}$ and $30^{\circ}$, as shown in Figure 12-29. These particle trajectories are shown in Figure 12-30. To avoid the erosion at the trailing edge the General Electric Company design was modified so the particles first impact the blade at the admission concave side. In this area the blades are thicker than at the trailing edge. The new design is shown in Figure 12-31.
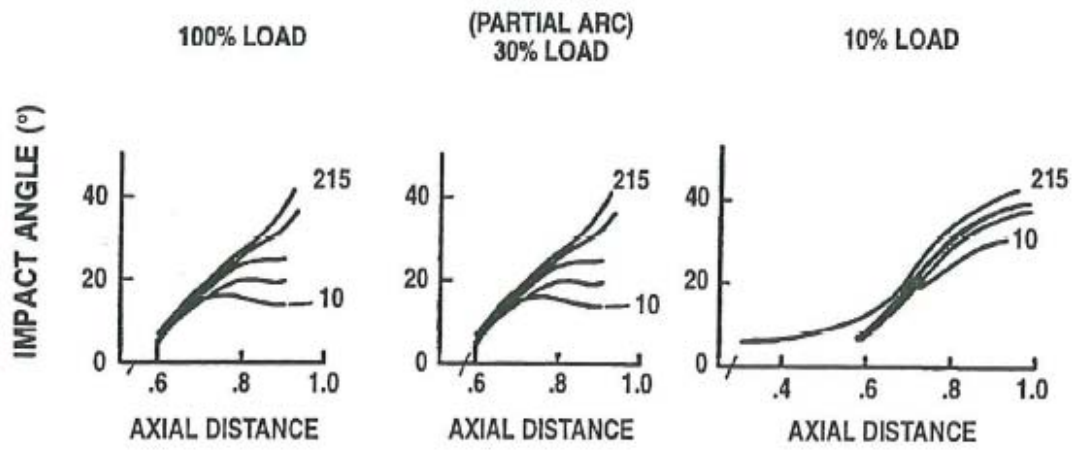

Figure 12-29. Control stage particle impact angle along stationary blade concave surface.

LOW LOAD, LARGE PARTICLES

HIGH LOAD, SMALL PARTICLES
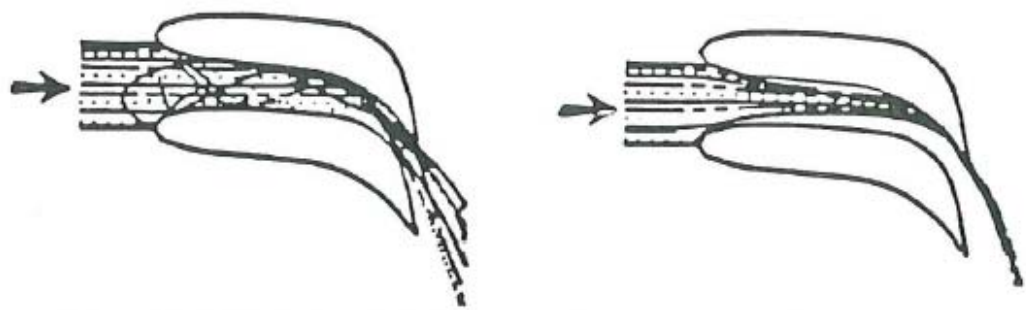

Figure 12-30. Particle trajectories in control stage stationary blade passage

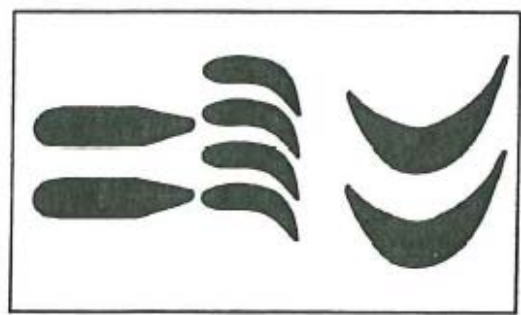

Bridges Nozzles Buckets

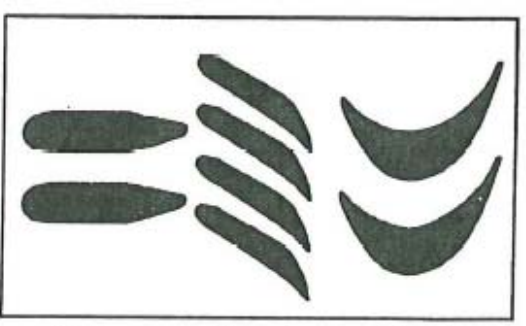

Bridges Nozzles Buckets

Modified

Figure 12-31. Modified control stage stationary blade to reduce solid particle erosion damage. 


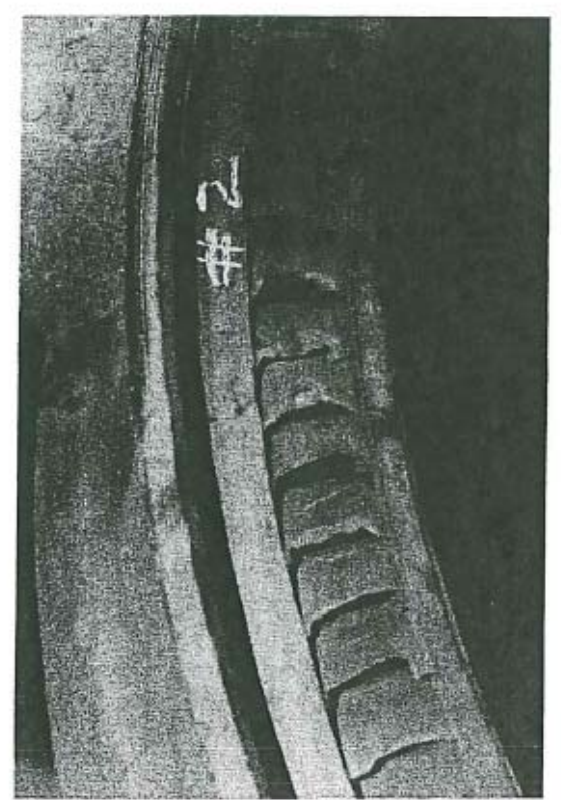

Figure 12-32. Photograph of solid particle erosion damage of original design after 18 months of operation. Courtesy of the General Electric Company.

Westinghouse has also redesigned the control stage stationary blades. The new designs allow the steam to turn during an early stage of the flow passage where the

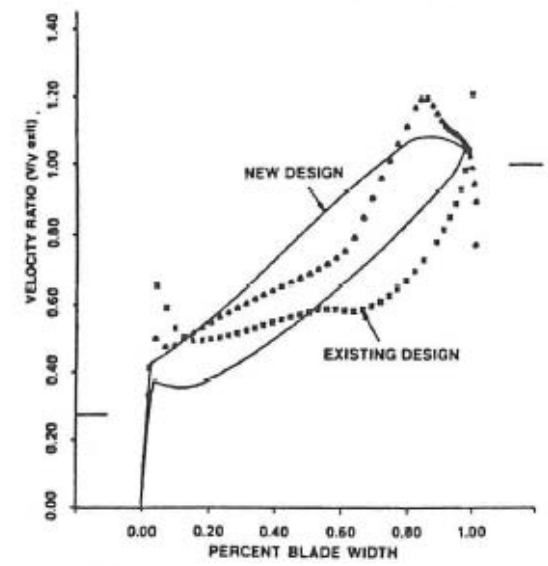

Figure 12-34. Velocity distributions along the concave and convex surfaces of stationary blades. Courtesy Westinghouse Corp.
These newly designed blades were installed in a unit having severe solid particle erosion problems after every eighteen months of operation. Figure 1232 is a photograph of the eroded blades. After installation of the new design, test measurements indicated no erosion problems. However, the turbine was opened anyway after three years of operation. So little erosion was found, as shown in Figure 12-33, that the turbine was put back into service without any repair.

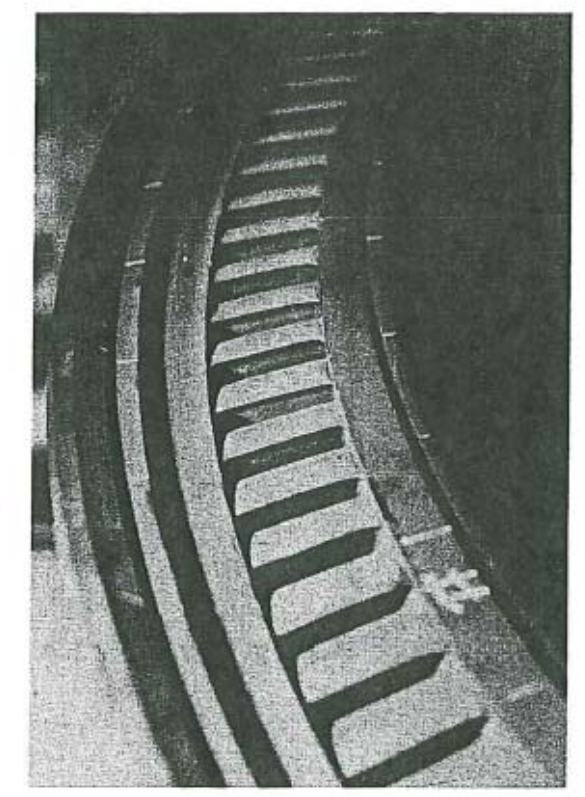

Figure 12-33. Photograph of modified design after 3 years of operation, resulting in minimal solid particle erosion damage.

Courtesy General Electric Company.

radius of curvature is large and the velocity is small. The velocity distribution in the new Westinghouse section is shown in Figure 12-34. The velocity is further reduced by using a contoured 
THE EFFECT OF POWER PLANT OPERATION ON THE DETERIORATION OF TURBINE EFFICIENCY

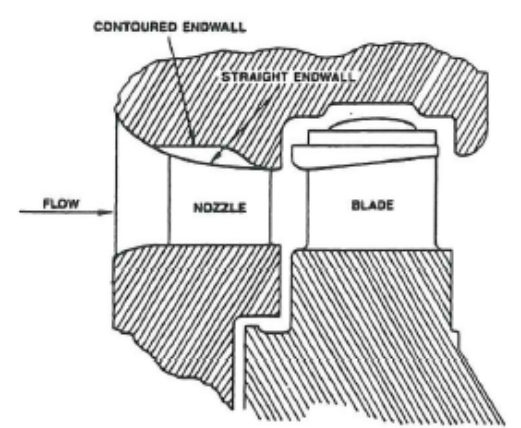

Figure 12-35. Control stage with contoured endwall. Courtesy Westinghouse Corporation. sidewall, Figure 12-35. Field inspection of the new design in service longer than three years was reported by the manufacturer in Reference 32 as reducing solid particle erosion.

IV. B. 3. c. Redesign of the IP Turbine First Stage

Particle trajectories (Figure 12-36) were also calculated for the IP turbine first stage. Figure 12-37 shows the particles are not accelerated over $400 \mathrm{ft} . / \mathrm{sec}$., which is well below the threshold velocity. Therefore, the concave (pressure side) surface is not eroded as it was in the control stage. The reason for the lower particle velocities is the pressure level is about $25 \%$ of the throttle pressure and steam velocities are well below sonic velocity.

The solid particle velocities are smaller than the steam velocities. Therefore, the particles strike the admission convex side (suction side) of the rotating blade

LOW LOAD, LARGE PARTICLES HIGH LOAD, SMALL PARTICLES
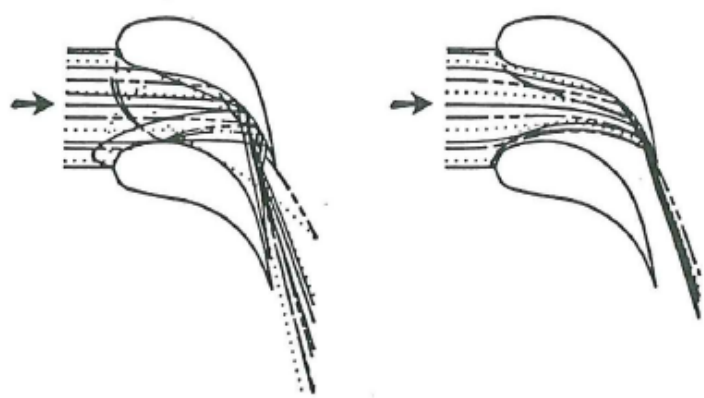

Figure 12-36. Particle trajectories resulting in solid particle erosion in the first IP turbine stage.

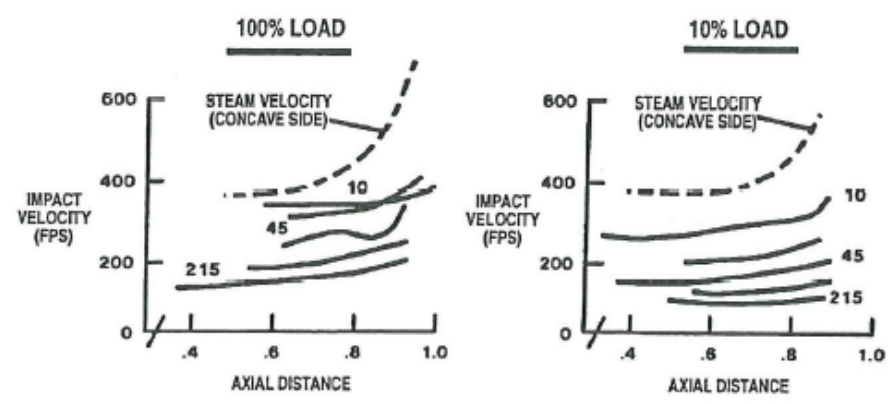

Figure 12-37. Particle velocities along first IP turbine stage concave surface. 


\section{Appendix F-References}

1. Erosion-Oxidation Behavior of Thermal Sprayed Ni20Cr Alloy and WC and Cr3C2 Cermet Coatings, Kunioshi et al, Mat. Res. Vol 8 no. 2, 125-129, 2005.

2. Advanced Gas Turbine Repairs, TurboTalk Vol 11, Spring 2006.

3. The Effects of Surface Treatments on Solid Particle Erosion of $12 \mathrm{Cr}$ Steels for USC Power Plants, Urm et al, Solid State Phenomena, 118 (2006) pp. 201-206.

4. High Temperature Erosion Resistance of Coatings for use in Turbomachinery, W. Tabakoff, Wear Vol 186-187, (1995) pp 224-229.

5. JTEG Meeting at Lima Army Tank Plant 24-26 July, 2001, Gray Simpson, Naval Air Systems Command NAS Team presentation.

6. The Oxidation Behaviour of Metals and Alloys at High Temperatures in Atmospheres Containing Water Vapour: A Review, Saunders et al, Progress in Matl's Science Vol 53 (2008) pp 775-837.

7. GE Steam Turbine Design Philosophy and Technology Programs, Couchman et al, GE Power Generation Report \# GER-3705.

8. Steam Turbine Uprates, J.F. Lesiuk, GE Power Generation Report \# GER-4199.

9. Turbine Blade Surface Deterioration by erosion, Hamed et al, University of Cincinnati, unpublished draft paper.

10. Steam Oxidation Protective Coatings for Advanced Steam Turbines, INTA, Technology Offer Ref: 30, lit source unknown (web finding).

11. Materials Issues in Renewable Energy Power Generation, D.J. Gooch, Int'I Mat. Rev. Vol 45 No. 1, (2000). 
TASK 12.2 PROCESS DEVELOPMENT FOR WELDED ROTORS (ALSTOM POWER) 


\section{REPORT SUMMARY}

This report primarily presents the results of Alstom efforts in Task 12.2, Process Development for Welded Rotors, of the DOE Ultrasupercritical (USC) Steam Turbine Materials Program. The objective of the task was to assess the weldability of Nimonic 263, a typical precipitationstrengthened, wrought nickel-base alloy which is a candidate for higher-temperature rotor applications, and to develop welding procedures for joining this alloy to Inconel 617 in thick sections.

The Edison Welding Institute (EWI) developed a narrow-groove gas-tungsten arc welding process (GTAW) for joining thick-section Nimonic 263 to Inconel 617 using an Inconel 617 filler wire. Following the successful demonstration, the microstructure and mechanical properties of a twelve-inch long weld in two-inch thick plate were characterized in the as-postweld heat treated (as-PWHT) condition. The cross-weld tensile properties were equivalent to those of Inconel 617, with rupture occurring in the weld metal. Charpy V-notch impact tests at room temperature showed that all microstructural zones of the weld had reasonable toughness with ductile fracture features. Cross-weld stress-rupture tests at 750 and $800^{\circ} \mathrm{C}$ had lives similar to those of Inconel 617 at stresses less than $125 \mathrm{MPa}$ but had lives shorter than the base metal at higher stresses. All ruptures occurred in the weld metal.

The effect of long-term $(10,000 \mathrm{hr})$ simulated service exposure at $725^{\circ} \mathrm{C}$ on the microstructure, hardness, tensile properties, and impact strength of the weld was also assessed. There was little change in microstructure, hardness, or tensile properties as a result of thermal exposure, but the impact strength was reduced in all microstructural zones of the weld. However, all zones had impact strengths sufficient to demonstrate adequate toughness, even after elevated-temperature exposure.

Siemens portion of this task was more limited and as such, an appendix is included at the end of this report which provides the details on an electron beam welding feasibility study of Udimet 720Li to Haynes 282, Haynes 282 to itself, and Inconel 617. All studies were completed on small, flat samples. The final results of all three alloy combinations were favorable. The results showed the Udimet 720Li alloy had the potential for strain age cracking, and thus special care was required for pre-weld heat-treatment to eliminate cracking. 


\section{TABLE OF CONTENTS}

TASK 12.2 PROCESS DEVELOPMENT FOR WELDED ROTORS (ALSTOM

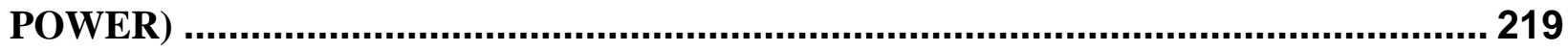

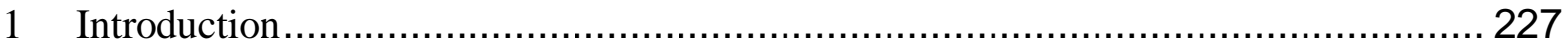

2 Weldability Evaluation and Welding Procedure Development …......................... 228

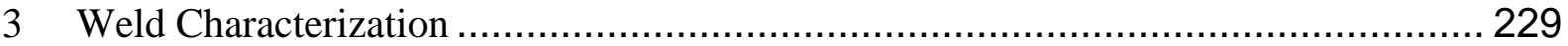

3.1 NDE - First Full-Size Weldment ................................................................ 229

3.2 Microstructure and Hardness - Effect of Thermal Exposure ............................... 229

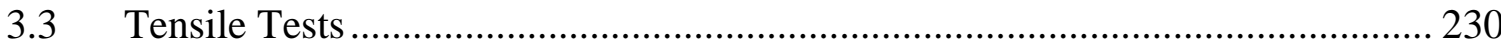

3.4 Impact Tests............................................................................................... 230

3.5 Stress-Rupture Tests ...................................................................................... 231

3.6 Discussion - Significance of Findings .................................................................. 231

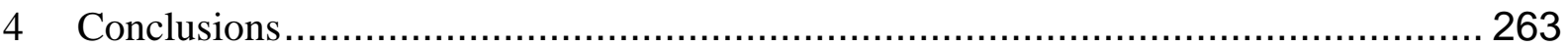

Appendix A EWI Report on the Manufacture and Evaluation of a Inconel 617 to

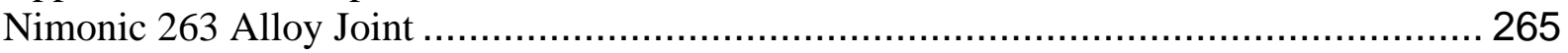

Appendix B Siemens’ Report on Process Development for Welded Rotors ....................... 331 


\section{LIST OF FIGURES}

Figure 1: Results of Ultrasonic Non-Destructive Examination of Initial Weld Produced by EWI. 235

Figure 2: Typical Microstructure of Nimonic 263 Base Metal After 10,000 hr Exposure at $725^{\circ} \mathrm{C}(200 \mathrm{X})$. Bromine-Methanol Etch.

Figure 3: Typical Microstructure of Nimonic 263 Base Metal After 10,000 hr Exposure at $725^{\circ} \mathrm{C}(500 \mathrm{X})$. Bromine-Methanol Etch......

Figure 4: Typical Microstructure of Nimonic 263 Base Metal After 10,000 hr Exposure at $725^{\circ} \mathrm{C}(1000 \mathrm{X})$. Bromine-Methanol Etch.

Figure 5: Typical Microstructure of Nimonic 263 - Weld Metal Fusion Line After 10,000 hr Exposure at $725^{\circ} \mathrm{C}(200 \mathrm{X})$. Weld Metal is on the Left. Bromine-Methanol Etch.

Figure 6: Typical Microstructure of Nimonic 263 - Weld Metal Fusion Line After 10,000 hr Exposure at $725^{\circ} \mathrm{C}(1000 \mathrm{X})$. Weld Metal is on the Very Left. Bromine-Methanol Etch. ......

Figure 7: Typical Microstructure of HAZ in Nimonic 263 After 10,000 hr Exposure at $725^{\circ} \mathrm{C}(1000 \mathrm{X})$. Bromine-Methanol Etch.....

Figure 8: Typical Microstructure of Inconel 617 Base Metal After 10,000 hr Exposure at $725^{\circ} \mathrm{C}(200 \mathrm{X})$. Bromine-Methanol Etch.

Figure 9: Typical Microstructure of Inconel 617 Base Metal After 10,000 hr Exposure at $725^{\circ} \mathrm{C}(500 \mathrm{X})$. Bromine-Methanol Etch.

Figure 10: Typical Microstructure of Inconel 617 Base Metal After 10,000 hr Exposure at $725^{\circ} \mathrm{C}(500 \mathrm{X})$. Bromine-Methanol Etch.

Figure 11: Typical Microstructure of Inconel 617 Base Metal After 10,000 hr Exposure at $725^{\circ} \mathrm{C}(1000 \mathrm{X})$. Bromine-Methanol Etch.

Figure 12: Typical Microstructure of Inconel 617 - Weld Metal Fusion Line After 10,000 hr Exposure at $725^{\circ} \mathrm{C}(200 \mathrm{X})$. Weld Metal is on the Right. Bromine-Methanol Etch.......242

Figure 13: Typical Microstructure of Inconel 617 - Weld Metal Fusion Line After 10,000 hr Exposure at $725^{\circ} \mathrm{C}(500 \mathrm{X})$. Weld Metal is on the Right. Bromine-Methanol Etch....... 242

Figure 14: Typical Microstructure of HAZ in Inconel 617 in the Area of a Fine-Grained Band After $10,000 \mathrm{hr}$ Exposure at $725^{\circ} \mathrm{C}(1000 \mathrm{X})$. Bromine-Methanol Etch.

Figure 15: Typical Microstructure of HAZ in Inconel 617 After 10,000 hr Exposure at $725^{\circ} \mathrm{C}(1000 \mathrm{X})$. Bromine-Methanol Etch.

Figure 16: Typical Microstructure of Inconel 617 Weld Metal After 10,000 hr Exposure at $725^{\circ} \mathrm{C}(100 \mathrm{X})$. Bromine-Methanol Etch...... 
Figure 17 Typical Microstructure of Inconel 617 Weld Metal After 10,000 hr Exposure at $725^{\circ} \mathrm{C}(200 \mathrm{X})$. Bromine-Methanol Etch.

Figure 18: Typical Microstructure of Inconel 617 Weld Metal After 10,000 hr Exposure at $725^{\circ} \mathrm{C}(1000 \mathrm{X})$. Bromine-Methanol Etch.

Figure 19: Vickers Microhardness (500 g Load) Traverse Across Weld in the Cap Region.

Figure 20: Vickers Microhardness (500 g Load) Traverse Across Weld in the Mid-

Thickness Region. The Results of Vickers Hardness Measurements with a $20 \mathrm{~kg}$ Load are also Shown.

Figure 21: Vickers Microhardness (500 g Load) Traverse Across Weld in the Root Region.

Figure 22: Schematic Diagram Showing Location of Tensile Specimens with Respect to Weldment (Gray Shaded Area). "C" Designates Cap, "M" Mid-Thickness, "R" Root. ......247

Figure 23: Macro Views of Tested Tensile Specimens and Longitudinal Sections. Rupture Occurred in the Weld Metal for All Specimens.

Figure 24: Macro Views of Tested Tensile Specimens from Thermally-Exposed Weldment. Rupture Occurred in the Weld Metal for All Specimens.

Figure 25: Schematic Diagram Showing Location and Orientation of Charpy V-Notch Impact Specimens Located in Different Microstructural Zones.

Figure 26: Impact Test Results for Different Microstructural Zones in the 263-617 Weldment in the As-PWHT Condition and After 10,000 hr Exposure at $725^{\circ} \mathrm{C}$. Values are Means of Two Tests.

Figure 27: Macro Views of Nimonic 263 and Inconel 617 Base Metal Impact Test Specimen Fracture Surfaces; As-PWHT Condition and After Thermal Exposure. 252

Figure 28: Macro Views of Nimonic 263 HAZ Impact Test Specimen Fracture Surfaces and Corresponding Longitudinal Sections; As-PWHT Condition and After Thermal Exposure.

Figure 29: Macro Views of Inconel 617 HAZ Impact Test Specimen Fracture Surfaces and Corresponding Longitudinal Sections; As-PWHT Condition and After Thermal Exposure.

Figure 30: Macro Views of Cap Area Weld Metal Impact Test Specimen Fracture Surfaces and Corresponding Longitudinal Sections; As-PWHT Condition and After Thermal Exposure. 255

Figure 31: Macro Views of Root Area Weld Metal Impact Test Specimen Fracture Surfaces and Corresponding Longitudinal Sections; As-PWHT Condition and After Thermal Exposure.

Figure 32: Lives of Cross-Weld Stress-Rupture Specimens, Compared with Data for CCA 617 Produced by ORNL in the DOE USC Boiler Materials Program. 
Figure 33: Macro Views of Fracture Surface (Left) and Broken Half of Specimen (Right) of Specimen TEN-4-C, Stress-Rupture Tested at $750^{\circ} \mathrm{C}$ and $155 \mathrm{MPa}$. Rupture Occurred in the Weld Metal.

Figure 34: Macro View of Fracture Surface of Specimen TEN-5-C, Stress-Rupture Tested at $750^{\circ} \mathrm{C}$ and $170 \mathrm{MPa}$. Rupture Occurred in the Weld Metal.

Figure 35: Macro Views of Fracture Surface (Left) and Broken Half of Specimen (Right) of Specimen TEN-6-C, Stress-Rupture Tested at $800^{\circ} \mathrm{C}$ and $95 \mathrm{MPa}$. Rupture Occurred in the Weld Metal.

Figure 36: Macro Views of Fracture Surface (Left) and Broken Half of Specimen (Right) of Specimen TEN-7-R, Stress-Rupture Tested at $800^{\circ} \mathrm{C}$ and $130 \mathrm{MPa}$. Rupture Occurred in the Weld Metal.

Figure 37: Overview of Longitudinal Section of Specimen TEN-4-C, Stress-Rupture Tested at $750^{\circ} \mathrm{C}$ and $155 \mathrm{MPa}$. Bromine-Methanol Etch.

Figure 38: Closer Views of Weld Metal in TEN-4-C Longitudinal Section, Showing Secondary Cracks Along Dendrite Boundaries. Stress Axis is Horizontal. BromineMethanol Etch.

Figure 39: Overview of Longitudinal Section of Specimen TEN-6-M, Stress-Rupture Tested at $800^{\circ} \mathrm{C}$ and $95 \mathrm{MPa}$. Bromine-Methanol Etch.

Figure 40: Closer Views of Weld Metal in TEN-6-M Longitudinal Section, Showing Secondary Cracks Along Dendrite Boundaries. Stress Axis is Horizontal. BromineMethanol Etch. 


\section{LIST OF TABLES}

Table 1: Room and Elevated Temperature Tensile Test Results for As-PWHT 263-617 Cross-Weld Specimens.

Table 2: Room-Temperature Charpy V-Notch Impact Test Results. ..................................233

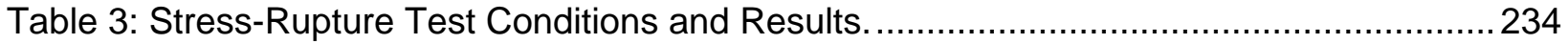





\section{Introduction}

An advanced ultrasupercritical (A-USC) steam turbine materials development program, sponsored by the U.S. Department of Energy and the Ohio Coal Development Office, is focused on identifying, evaluating, and qualifying advanced alloys needed to withstand the operating conditions of a steam turbine operating at ultrasupercritical steam temperatures and pressures of $760^{\circ} \mathrm{C}\left(1400^{\circ} \mathrm{F}\right)$ and $35 \mathrm{MPa}(5000 \mathrm{psi})$. A key component of a steam turbine is the rotor. Alstom steam turbine designs use a welded rotor construction, which has several advantages over a solid (monoblock) or bolted rotor design. One of these advantages is the ability to use different alloys at different axial locations, thereby allowing the alloy used to match the steam conditions present at that location and minimize the use of more expensive alloys that have the strength needed to withstand the highest steam temperatures and pressures. In order to fully utilize this advantage, however, dissimilar metal welds must be created between the higher-strength and lower-strength rotor sections.

In the case of an A-USC steam turbine, as many as three different material types may be required in the high-pressure (HP) and intermediate-pressure (IP) rotors sections: a precipitationhardened nickel-base alloy, such as NIMONIC ${ }^{*}$ alloy 263 or HAYNES alloy 282, in the highest temperature stages; a solid-solution strengthened nickel base alloy, such as INCONEL alloy 617 or HAYNES alloy 230, for intermediate-temperature stages; and a low-alloy steel with 2 to $10 \%$ $\mathrm{Cr}$ for the lower-temperature stages. Welding of Inconel 617 to a low-alloy steel has been demonstrated by Alstom as part of development of a steam turbine with $700^{\circ} \mathrm{C}$ capability (Pirscher, et al., Proc. $5^{\text {th }}$ Int Conf. on Advances in Materials Technology for Fossil Power Plants, Macro Island, FL, October 3-5, 2007). Welding of precipitation-strengthened nickel-base alloys in the thick, highly-restrained configurations required for rotor joining has not been attempted, however. The higher levels of aluminum and titanium in these alloys render them much more susceptible to weld cracking than typical solid-solution alloys such as Inconel 617, and these cracking tendencies will be exacerbated by high levels of weld constraint.

The objective of Alstom efforts in this task was to assess the weldability of Nimonic 263, a typical precipitation-strengthened, wrought nickel-base alloy which is a candidate for the highertemperature rotor applications, and to develop welding procedures for joining this alloy to CCA 617 using CCA 617 filler wire (CCA 617 is “Controlled Chemistry Alloy” variant of Inconel 617 and was the actual material of reference whenever "Inconel 617" is used in this report). Following successful production of a defect-free weldment, the mechanical properties of the weld were to be characterized in both the post-weld heat treated (PWHT) condition, and following a 10,000 -hour simulated service exposure at $725^{\circ} \mathrm{C}$. This report presents the results of these efforts.

Additionally, Siemens had interest in exploring a welded rotor concept to join different nickelbased alloys. Siemens research, which was not as extensive, is included in Appendix B at the end of this report for completeness. It provides the details on an electron beam welding feasibility study of Udimet 720Li to Haynes 282, Haynes 282 to itself, and Inconel 617. All

\footnotetext{
${ }^{*}$ NIMONIC and INCONEL are trademarks of the Special Metals Corporation; HAYNES is a trademark of Haynes International.
} 
studies were completed on small, flat samples. The final results of all three alloy combinations were favorable. The results showed the Udimet $720 \mathrm{Li}$ alloy had as potential for strain age cracking, and thus special care was required for pre-weld heat-treatment to eliminate cracking.

\section{$2 \quad$ Weldability Evaluation and Welding Procedure Development}

Initial work in Task 12.2 was performed by the Edison Welding Institute (EWI); the results of their efforts were summarized in a final report (Ramirez, J. E., EWI Project No. 50399GTH, "Weldability Evaluation of IN617 to NI263 Alloy Joints", July, 2007) which is provided in Appendix A. EWI was tasked with performing a weldability assessment on Nimonic 263 and Inconel 617, then preparing trial welds of Nimonic 263 to Inconel 617 to determine appropriate welding parameters, and finally prepare larger welds of Nimonic 263 to Inconel 617 in 2-inch thick plate which could be used for mechanical property characterization. The plate materials were supplied to EWI by Alstom. The Inconel 617 plate was a remnant from the DOE USC Boiler Materials welding development program; the heat of Inconel 617 used conformed to the controlled-chemistry alloy (CCA 617) variant, and two pieces of the 617 plate contained through-thickness similar welds. The Nimonic 263 plate was procured from Haynes International.

The initial weldability assessment included performing hot ductility testing using a Gleeble weld simulation tester to measure the nil ductility, nil-strength, and ductility recovery temperatures. These tests determined the susceptibility to liquation cracking. Nimonic 263 was found to be much more susceptible to liquation cracking than Inconel 617, an expected result given the higher concentrations of aluminum and titanium in Nimonic 263. The susceptibility to reheat (stress-relaxation) cracking was assessed by slow strain rate tensile tests; the results indicated that Inconel 617 is not susceptible to reheat cracking, but that Nimonic 263 was susceptible to reheat cracking at $800^{\circ} \mathrm{C}$.

After the weldability trials, the feasibility of using a narrow-groove gas tungsten arc welding (GTAW) process to join Nimonic 263 to Inconel 617 was assessed in small mockup pieces. The mockup trials were successful, and the welding parameters determined in the mockup trials were used to prepare an initial, "full-size” joint (approximately 12-inch weld length) in 2-inch thick Nimonic 263 and Inconel 617 plate. While the initial full-size joint was sound, a number of minor welding imperfections were found (lack of fusion and incomplete penetration).

Based on the results of the initial full-size joint, the welding parameters were slightly adjusted to increase penetration and eliminate the lack of fusion areas, and a second full-size joint was prepared. This weld was also sound, and no significant weld imperfections were found. A section of the weld was evaluated in the as-welded condition; hardness, tensile, and side-bend tests were performed. The tensile and side-bend results were adequate to qualify the weld by ASME Section IX rules in the as-welded condition. The remainder of the weld was subjected to a two-step post-weld heat treatment (PWHT): 8 hours at $800^{\circ} \mathrm{C}$ (PWHT for the Nimonic 263) followed by 10 hours at $670^{\circ} \mathrm{C}$ (simulated PWHT for a Inconel 617 to low-alloy steel weld). 
The basic weld properties were again evaluated. The weld did not pass the side-bend test in the PWHT condition due to reduced weld metal ductility.

\section{$3 \quad$ Weld Characterization}

The EWI report gave results of microstructural evaluation, hardness tests, tensile tests, and sidebend tests of the second Nimonic 263 - Inconel 617 weld joint in both the as-welded condition and after PWHT. Tensile specimens failed in the Inconel 617 base metal; tensile strengths increased and tensile ductility decreased as a result of PWHT and some of the side bends used to evaluate weldment ductility failed prematurely. Hardness testing showed that all areas of the weld increased in hardness after PWHT, but that the increase in the age-hardenable Nimonic 263 was greater than in Inconel 617. No microcracks were found in microstructural examination either before or after PWHT.

Additional mechanical tests on the weldments after PWHT and a long-term thermal exposure at service temperature $\left(10,000 \mathrm{hr}\right.$ at $\left.725^{\circ} \mathrm{C}\right)$ are described below. The tests were performed by Metcut Research under Alstom direction. Post-test examination was performed by Alstom.

\subsection{NDE - First Full-Size Weldment}

The initial, full-size Nimonic 263 - Inconel 617 weld joint was examined non-destructively using dye penetrant and ultrasonic techniques to characterize the extent of the lack of fusion weld defects noted by EWI. The results of the ultrasonic examination, Figure 1, were confirmed by metallographic examination of several sections through the weld. Two ultrasonic scans were made of the welded block, one of the top surface of the material and a second of the side of the block to show the weld depth. The test result from top side of weld showed one indication over the whole length at a $24 \mathrm{~mm}$ depth with a reflection trace from 1.5 to $2 \mathrm{~mm}$. Another indication was found over a $60 \mathrm{~mm}$ length at a $12 \mathrm{~mm}$ depth with a reflection trace from 1.5 to $2 \mathrm{~mm}$. Both were flat bottom hole defects (disk shape reflector). The dye penetrant and metallographic examinations confirmed that the indications found by ultrasonic examination were in fact areas of incomplete weld fusion.

Note that all subsequent results presented in this report were obtained on the second full-size weldment.

\subsection{Microstructure and Hardness - Effect of Thermal Exposure}

Characterization of the weldment microstructure after PWHT was performed by EWI and documented in their report. A light microscopy examination of the structure after $10,000 \mathrm{hr}$ exposure at $725^{\circ} \mathrm{C}$ was performed, Figures 2 to 18, to characterize any changes resulting from the exposure. There was little change observable with light microscopy - only a qualitative increase in the extent of fine inter- and intra-granular precipitation, especially in the base metals.

There were no discernable differences in the weld metal microstructure before and after thermal exposure (Figures 19-21) . Microhardness traverses were made across the weld near the weld cap, at the mid-thickness level, and near the weld root. The results showed that the thermal exposure had little effect on hardness, the only notable change being a decrease in weld hardness 
and an increase in Inconel 617 base metal hardness in the weld root area. Slight increases in Inconel 617 base metal hardnesses were also observed in the cap and mid-thickness traverses. There was no change in the Nimonic 263 base metal hardness.

\subsection{Tensile Tests}

Cross-weld tensile tests (ASTM E 8) were performed at 25,700 , and $750^{\circ} \mathrm{C}$ at a nominal strain rate of $10^{-3} \mathrm{sec}^{-1}$. Specimens were cylindrical with a $6.4 \mathrm{~mm}$ gage diameter and $40 \mathrm{~mm}$ reduced section length. The specimens were machined so that the weld metal was located approximately in the center of the reduced section; the long axis of the specimen was transverse to the welding direction. Specimens were removed at three different locations through the thickness of the plate, as shown in Figure 22. These locations were designated cap, mid-thickness, and root.

Tensile properties, Table 1, obtained from specimens at different locations through the weld thickness were nominally identical, although elevated temperature ductility was slightly lower in the root location. All test specimens failed in the weld metal. Room temperature tensile strength in the Metcut tests in the as-PWHT condition were greater than those reported by EWI, and the failure location for the EWI tests was the Inconel 617 base metal. These differences may have resulted from differences in specimen geometry because the EWI specimens were longer (90 mm reduced section) so that the base metal on either side of the weld was less constrained by the weld and the specimen shoulders and freer to deform, neck down, and rupture. The tensile strength of the weldments in the as-PWHT was greater than that reported as typical for Inconel 617 in the Special Metals alloy datasheet, but less than the reported typical values for Nimonic 263 in its datasheet.

There was little effect of long-term thermal exposure on the room or elevated temperature tensile properties, only a slight reduction in yield strength at room temperature, and in yield and tensile strengths at $700^{\circ} \mathrm{C}$. Rupture occurred in the weld metal zone for all specimens. Microstructural examination of longitudinal sections of selected tested specimens in both the as-PWHT condition and after thermal exposure did not reveal any cracking in microstructural zones other than the weld metal.

\subsection{Impact Tests}

Charpy V-notch impact tests (Table 2 and Figures 26 to 31), were performed at room temperature on specimens machined with the starter notch located in a variety of different microstructural zones within the weldments, as shown in Figure 25. These included the base metals, heat-affected zones in each base metal adjacent to the weld metal, and weld metal near the cap of the weld and the root of the weld. Specimens were oriented with long axes transverse to the welding direction and such that cracks propagated from the cap towards the root of the weld. A full complement of tests was performed on material in the as-PWHT condition and after 10,000 hour exposure at $725^{\circ} \mathrm{C}$.

In the as-PWHT condition, all zones showed impact energies greater than $60 \mathrm{~J}$, with strengths highest in the weld metal and HAZ. A reduction in impact strength was observed after long-term exposure at $725^{\circ} \mathrm{C}$. The reduction was greater in the weld metal, with the effect that a similar impact strength of 40-60 J was present in all microstructural zones. Impact strengths in the weld 
zones were similar to those reported by Special Metals in the Inconel 617 and Nimonic 263 datasheets for these alloys after short- to long-term exposure to elevated temperatures in the range of 700 to $800^{\circ} \mathrm{C}$.

No brittle fractures were observed; fracture in the weld metal occurred along dendrite boundaries; failure in base metals and HAZs was transgranular for Nimonic 263. Significant intergranular fracture was observed in the Inconel 617 base metal and HAZ after thermal exposure, which correlated with extensive intergranular precipitation observed in this heat treatment condition. Crack paths in HAZ specimens resembled those in the base metal specimens -cracks did not propagate along any obvious weak microstructural paths.

\subsection{Stress-Rupture Tests}

Stress-rupture tests (ASTM E 139) on cross-weld specimens were performed at 750 and $800^{\circ} \mathrm{C}$ (Table 3). The specimen locations and geometry were the same as described above for tensile tests. Specimens were only tested in the as-PWHT condition. Two tests were performed at each combination of stress and temperature; the results of the replicate tests did not indicate any effect of specimen location on stress-rupture strength. Stress-rupture ductility was relatively low, with nearly all values of elongation less than $10 \%$. Longer-term tests at $750^{\circ} \mathrm{C}$ showed particularly low ductility. Figures 32 to 40 provide the test results for these tests.

The stress-rupture lives of the cross-weld specimens were compared with those for CCA 617 obtained in the DOE USC boiler materials program by ORNL. The lives of cross-weld specimens are shorter than CCA 617 base metal at higher stresses and at the lower temperature $\left(750^{\circ} \mathrm{C}\right)$; the lives of cross-weld and base metal specimens become similar at stresses less than approximately $125 \mathrm{MPa}$.

Rupture in all cross-weld specimens occurred in the weld metal region, with multiple cracks observed in the weld metal for most specimens. Failure clearly occurred along dendrite boundaries in the weld metal. There were no remarkable microstructural changes which occurred during creep testing observable by light microscopy, other than an increased extent of fine precipitation along grain and twin boundaries.

\subsection{Discussion - Significance of Findings}

The data presented in this report provide an initial confirmation of the feasibility of joining precipitation-hardened nickel-base alloys to solution-strengthened nickel-base alloys in relatively thick sections. No liquation cracks were found in the HAZ zone of the precipitation-hardened alloy Nimonic 263, unlike initial efforts to weld a similar alloy, Inconel 740, in thick sections. The extensive mechanical property characterization confirms the soundness of the weld and provides basic data for preliminary rotor design. Also, the effects of long-term service exposure were shown to be minimal; although impact strengths were reduced, no brittle fractures occurred.

Further scale-up work is required before a final rotor design can be prepared. Successful welds must be made in the more-constrained geometry of a circumferential weld joining two thick cylinders along their axes. In a full-scale rotor, the cylinder outer diameter will be approximately 1 meter and the weld depth approximately $20 \mathrm{~cm}$. Once a sound weld has been 
created, a more comprehensive set of mechanical properties will need to be measured, including fracture toughness and fatigue properties. This work is planned for Phase 2 of the DOE USC Steam Turbine Materials Program, as is evaluating the feasibility of welding a second precipitation-hardened nickel-base alloy, Haynes 282, to a solution-strengthened nickel-base alloy such as Inconel 617 or Haynes 230.

Table 1: Room and Elevated Temperature Tensile Test Results for As-PWHT 263-617 Cross-Weld Specimens.

\begin{tabular}{|c|c|c|c|c|c|c|c|c|}
\hline Specimen & Location & Condition & $\begin{array}{l}\text { Temp. } \\
\left({ }^{\circ} \mathrm{C}\right)\end{array}$ & $\begin{array}{c}0.2 \% \text { YS } \\
(\mathrm{MPa})\end{array}$ & $\begin{array}{l}\text { UTS } \\
(\mathrm{MPa})\end{array}$ & $\begin{array}{c}\text { Elongation } \\
(\%)\end{array}$ & $\begin{array}{l}\text { RA } \\
(\%)\end{array}$ & $\begin{array}{c}\text { Failure } \\
\text { Location }\end{array}$ \\
\hline TEN-1-C & Cap & As-PWHT & 25 & 630 & 935 & 20 & 36 & Weld Metal \\
\hline TEN-1-M & Mid-Thick & As-PWHT & 25 & 645 & 935 & 22 & 29 & Weld Metal \\
\hline TEN-1-R & Root & As-PWHT & 25 & 640 & 935 & 22 & 25 & Weld Metal \\
\hline TEN-E-M & Mid-Thick & $10,000 \mathrm{~h} / 725^{\circ} \mathrm{C}$ & 25 & 600 & 935 & 19 & 34 & Weld Metal \\
\hline TEN-2-C & Сар & As-PWHT & 700 & 465 & 660 & 16 & 46 & Weld Metal \\
\hline TEN-2-M & Mid-Thick & As-PWHT & 700 & 456 & 680 & 15 & 34 & Weld Metal \\
\hline TEN-2-R & Root & As-PWHT & 700 & 447 & 660 & 14 & 28 & Weld Metal \\
\hline TEN-E-C & Cap & $10,000 \mathrm{~h} / 725^{\circ} \mathrm{C}$ & 700 & 426 & 620 & 15 & 30 & Weld Metal \\
\hline TEN-3-C & Cap & As-PWHT & 750 & 421 & 590 & 13 & 36 & Weld Metal \\
\hline TEN-3-M & Mid-Thick & As-PWHT & 750 & 426 & 615 & 12 & 26 & Weld Metal \\
\hline TEN-3-R & Root & As-PWHT & 750 & 431 & 580 & 8.5 & 12 & Weld Metal \\
\hline TEN-E-R & Root & $10,000 \mathrm{~h} / 725^{\circ} \mathrm{C}$ & 750 & 433 & 630 & 11 & 21 & Weld Metal \\
\hline EWI Test & Cap & As-PWHT & 25 & 510 & 891 & 23 & 31 & IN617 BM \\
\hline EWI Test & Root & As-PWHT & 25 & 497 & 837 & 16 & 27 & IN617 BM \\
\hline
\end{tabular}


Table 2: Room-Temperature Charpy V-Notch Impact Test Results.

\begin{tabular}{lccc}
\hline Specimen ID & Notch Location & Condition & Impact Energy (J) \\
\hline IMP-WM-C-1 & Weld Metal - Cap & As-PWHT & 119 \\
IMP-WM-C-2 & Weld Metal - Cap & As-PWHT & 104 \\
IMP-WM-CE-1 & Weld Metal - Cap & $10,000 h / 725^{\circ} \mathrm{C}$ & 62 \\
IMP-WM-CE-2 & Weld Metal - Cap & $10,000 \mathrm{~h} / 725^{\circ} \mathrm{C}$ & 56 \\
IMP-WM-R-1 & Weld Metal - Root & As-PWHT & 103 \\
IMP-WM-R-2 & Weld Metal - Root & As-PWHT & 100 \\
IMP-WM-RE-1 & Weld Metal - Root & $10,000 \mathrm{~h} / 725^{\circ} \mathrm{C}$ & 42 \\
IMP-WM-RE-2 & Weld Metal - Root & $10,000 \mathrm{~h} / 725^{\circ} \mathrm{C}$ & 43 \\
IMP-BM-263-1 & 263 Base Metal & As-PWHT & 61 \\
IMP-BM-263-2 & 263 Base Metal & As-PWHT & 60 \\
IMP-BM-263E-1 & 263 Base Metal & $10,000 h / 725^{\circ} \mathrm{C}$ & 42 \\
IMP-BM-263E-2 & 263 Base Metal & $10,000 h / 725^{\circ} \mathrm{C}$ & 34 \\
IMP-HAZ-263-1 & $263 \mathrm{HAZ}$ & $\mathrm{As}-\mathrm{PWHT}$ & 95 \\
IMP-HAZ-263-2 & $263 \mathrm{HAZ}$ & $\mathrm{As}-\mathrm{PWHT}$ & 87 \\
IMP-HAZ-263E-1 & $263 \mathrm{HAZ}$ & $10,000 \mathrm{~h} / 725^{\circ} \mathrm{C}$ & 51 \\
IMP-HAZ-263E-2 & $263 \mathrm{HAZ}$ & $10,000 \mathrm{~h} / 725^{\circ} \mathrm{C}$ & 47 \\
IMP-BM-617-1 & 617 Base Metal & As-PWHT & 70 \\
IMP-BM-617-2 & 617 Base Metal & As-PWHT & 69 \\
IMP-BM-617E-1 & 617 Base Metal & $10,000 \mathrm{~h} / 725^{\circ} \mathrm{C}$ & 56 \\
IMP-BM-617E-2 & $617 \mathrm{Base} \mathrm{Metal}$ & $10,000 \mathrm{~h} / 725^{\circ} \mathrm{C}$ & 49 \\
IMP-HAZ-617-1 & $617 \mathrm{HAZ}$ & As-PWHT & 96 \\
IMP-HAZ-617-2 & $617 \mathrm{HAZ}$ & As-PWHT & 95 \\
IMP-HAZ-617E-1 & $617 \mathrm{HAZ}$ & $10,000 \mathrm{~h} / 725^{\circ} \mathrm{C}$ & 30 \\
IMP-HAZ-617E-2 & $617 \mathrm{HAZ}$ & $10,000 \mathrm{~h} / 725^{\circ} \mathrm{C}$ & 33 \\
\hline
\end{tabular}


Table 3: Stress-Rupture Test Conditions and Results.

\begin{tabular}{lcccccc}
\hline Specimen ID & Location & $\begin{array}{c}\text { Test Temp } \\
\left({ }^{\circ} \mathrm{C}\right)\end{array}$ & $\begin{array}{c}\text { Stress } \\
(\mathrm{MPa})\end{array}$ & $\begin{array}{c}\text { Rupture Life } \\
(\mathrm{hr})\end{array}$ & $\begin{array}{c}\text { Elongation } \\
(\%)\end{array}$ & $\begin{array}{c}\text { RA } \\
(\%)\end{array}$ \\
\hline TEN-4-C & Cap & 750 & 155 & 1952.3 & 3.7 & 4.4 \\
TEN-4-M & Mid-Thick & 750 & 155 & 2104.1 & 3.4 & 7.2 \\
TEN-4-R & Root & 750 & 170 & 840.6 & 1.6 & 3.3 \\
TEN-5-C & Cap & 750 & 170 & 931 & 2.6 & 3.6 \\
TEN-5-M & Mid-Thick & 750 & 210 & 228.6 & 2.2 & 15.3 \\
TEN-5-R & Root & 750 & 210 & 185.5 & 2.0 & 10.9 \\
TEN-6-C & Cap & 800 & 95 & 1895.3 & 11.2 & 11.7 \\
TEN-6-M & Mid-Thick & 800 & 95 & 2427.7 & 5.4 & 13.1 \\
TEN-6-R & Root & 800 & 110 & 612.7 & 4.2 & 21.4 \\
TEN-7-C & Cap & 800 & 110 & 856.7 & 5.3 & 13.5 \\
TEN-7-M & Mid-Thick & 800 & 130 & 255.2 & 3.7 & 15.6 \\
TEN-7-R & Root & 800 & 130 & 212.8 & 6.3 & 16.0 \\
\hline
\end{tabular}


Top View of Weld

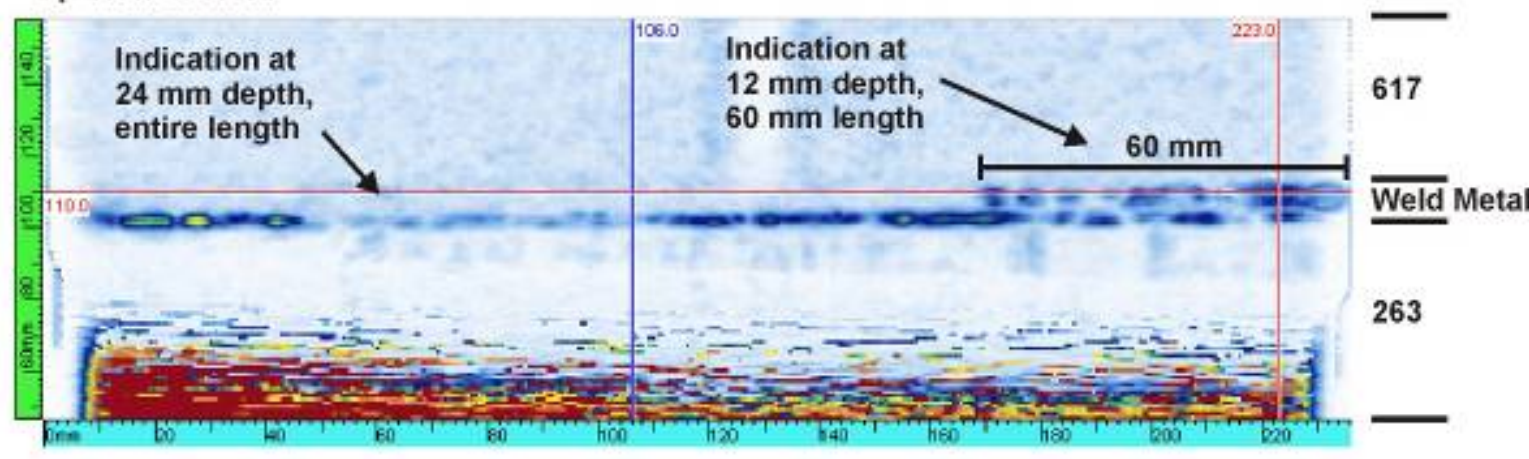

View of Weld from 617 Side

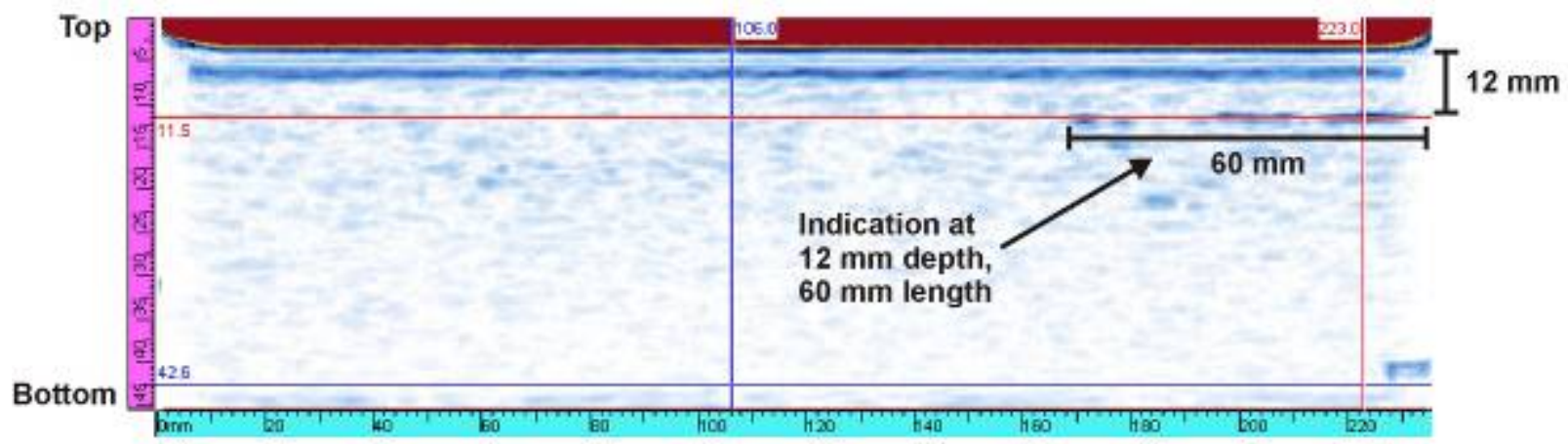

View of Weld from 263 Side

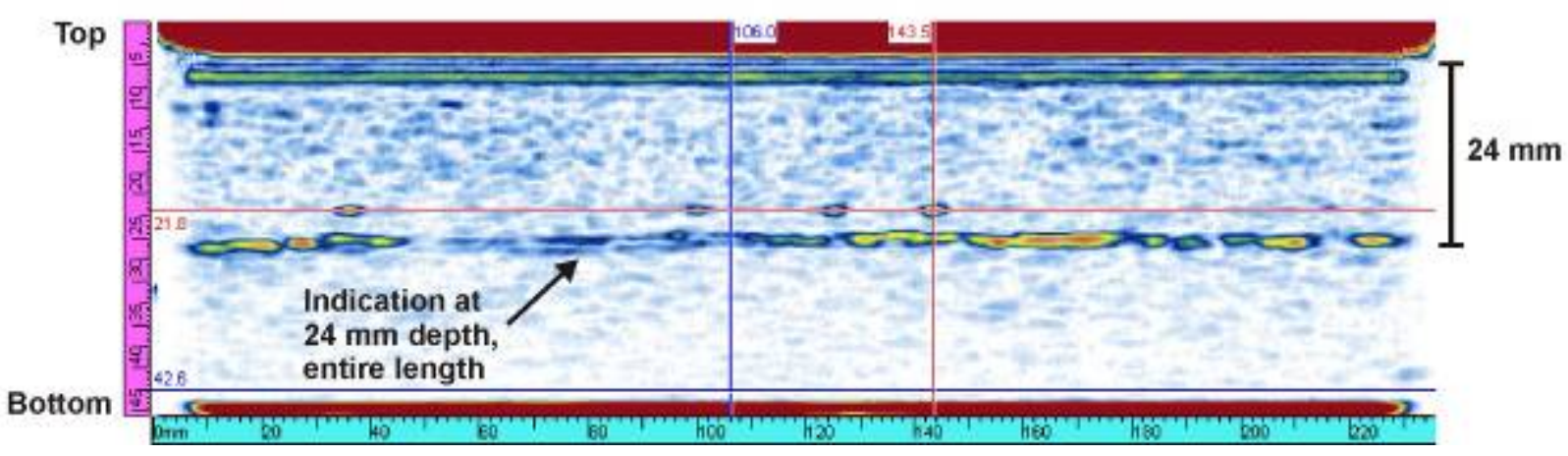

Figure 1: Results of Ultrasonic Non-Destructive Examination of Initial Weld Produced by EWI. 


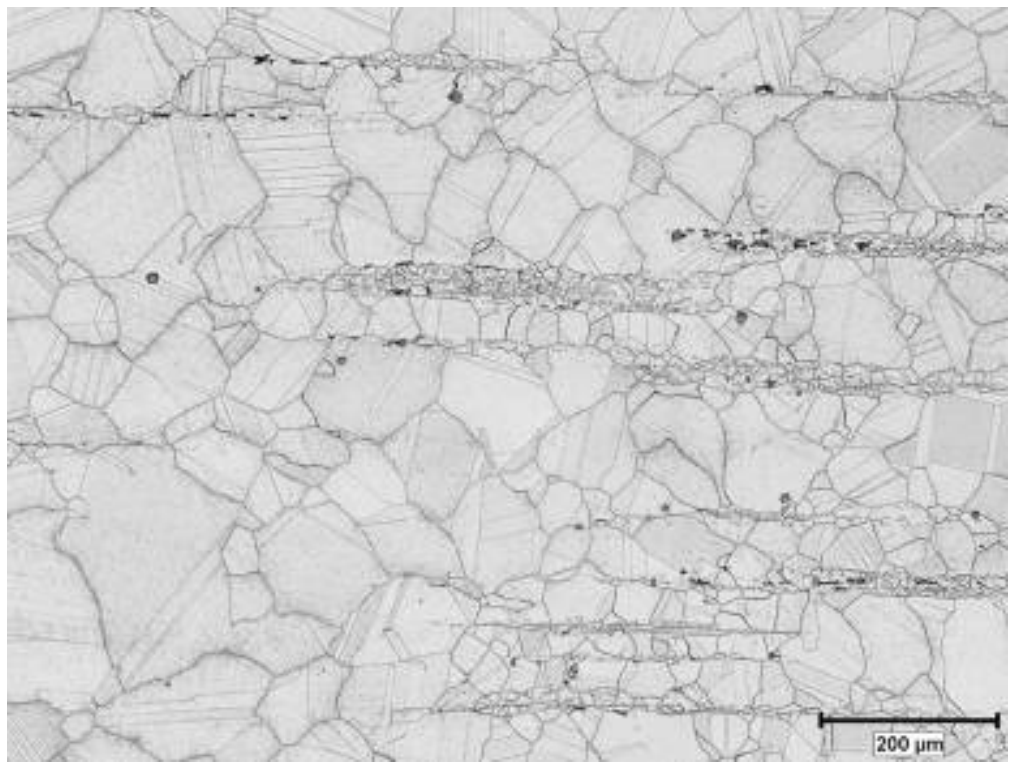

Figure 2: Typical Microstructure of Nimonic 263 Base Metal After 10,000 hr Exposure at $725^{\circ} \mathrm{C}(200 \mathrm{X})$. Bromine-Methanol Etch.

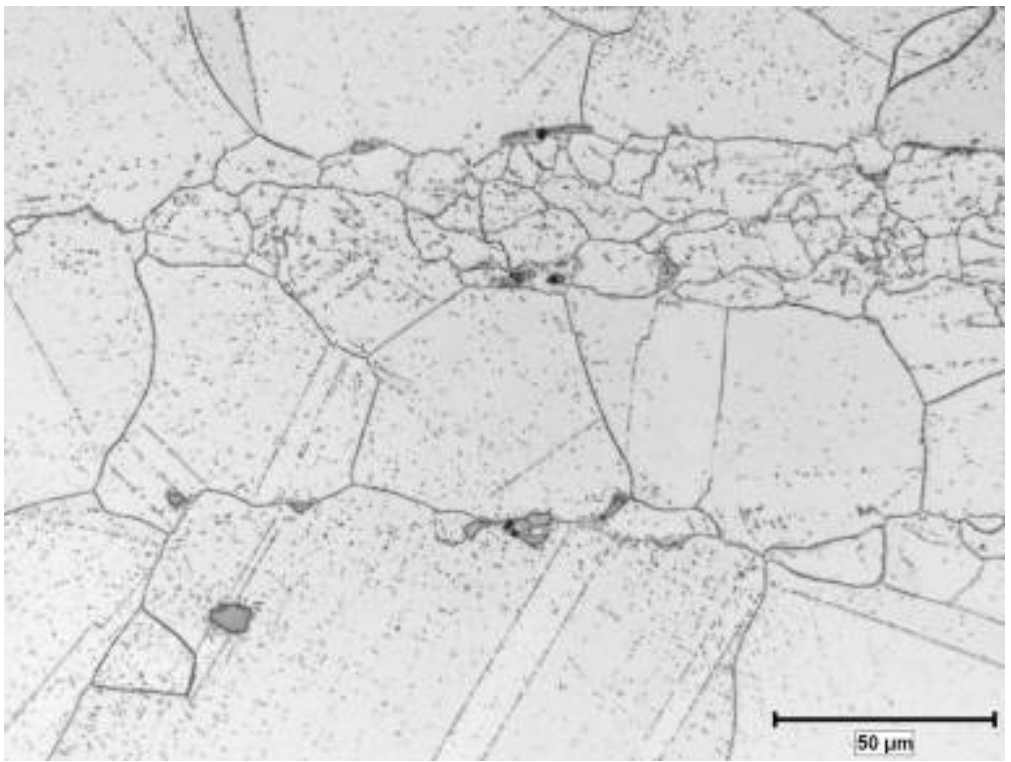

Figure 3: Typical Microstructure of Nimonic 263 Base Metal After 10,000 hr Exposure at $725^{\circ} \mathrm{C}(500 \mathrm{X})$. Bromine-Methanol Etch. 

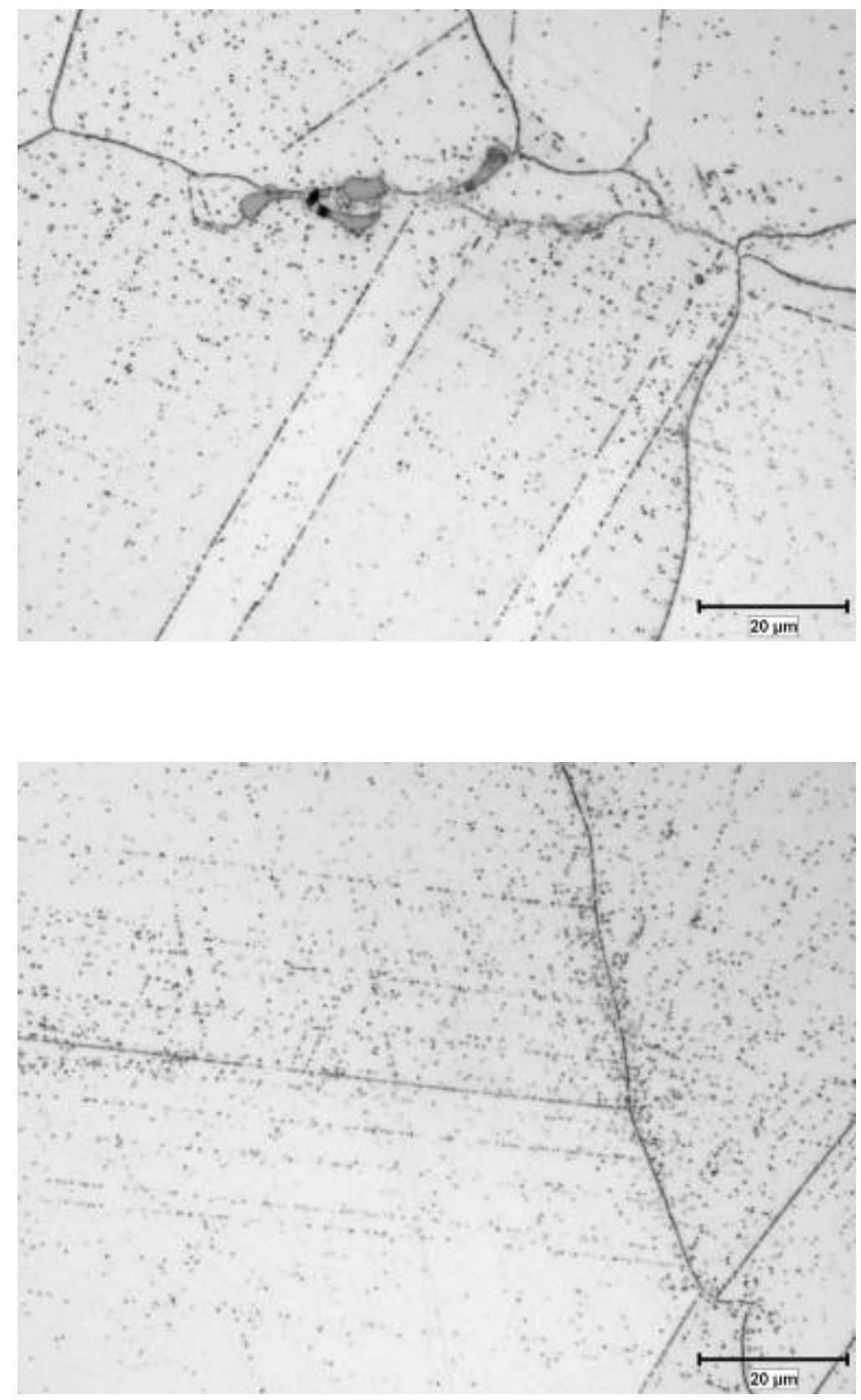

Figure 4: Typical Microstructure of Nimonic 263 Base Metal After 10,000 hr Exposure at $725^{\circ} \mathrm{C}(1000 \mathrm{X})$. Bromine-Methanol Etch. 


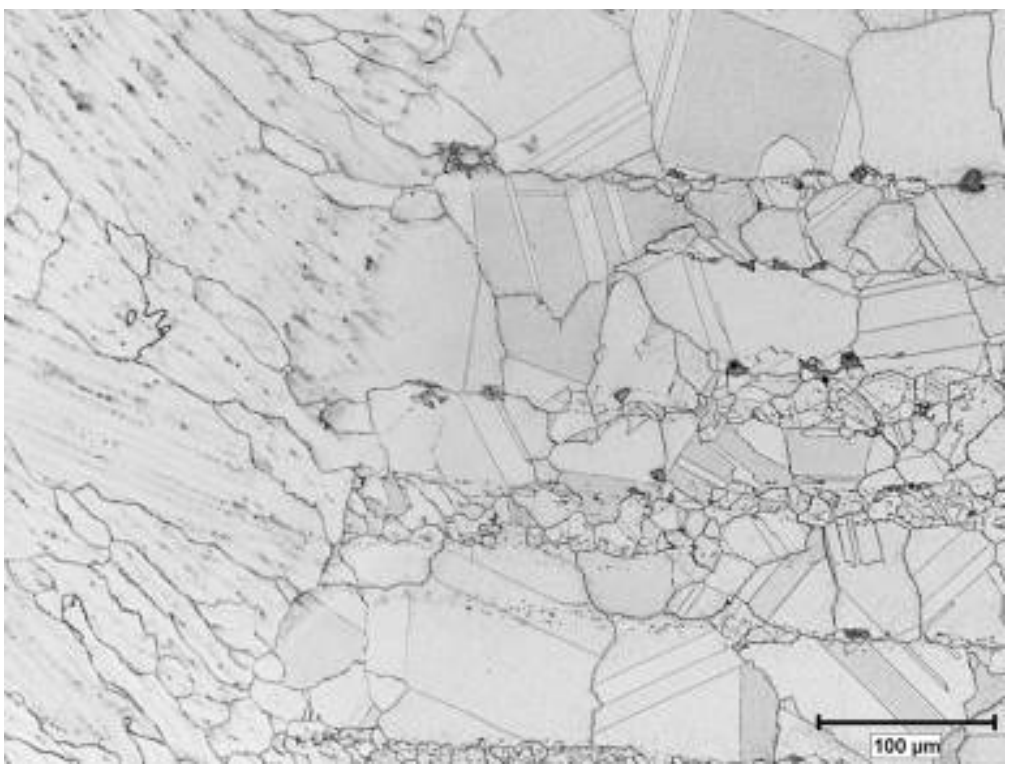

Figure 5: Typical Microstructure of Nimonic 263 - Weld Metal Fusion Line After 10,000 hr Exposure at $725^{\circ} \mathrm{C}(200 \mathrm{X})$. Weld Metal is on the Left. Bromine-Methanol Etch.

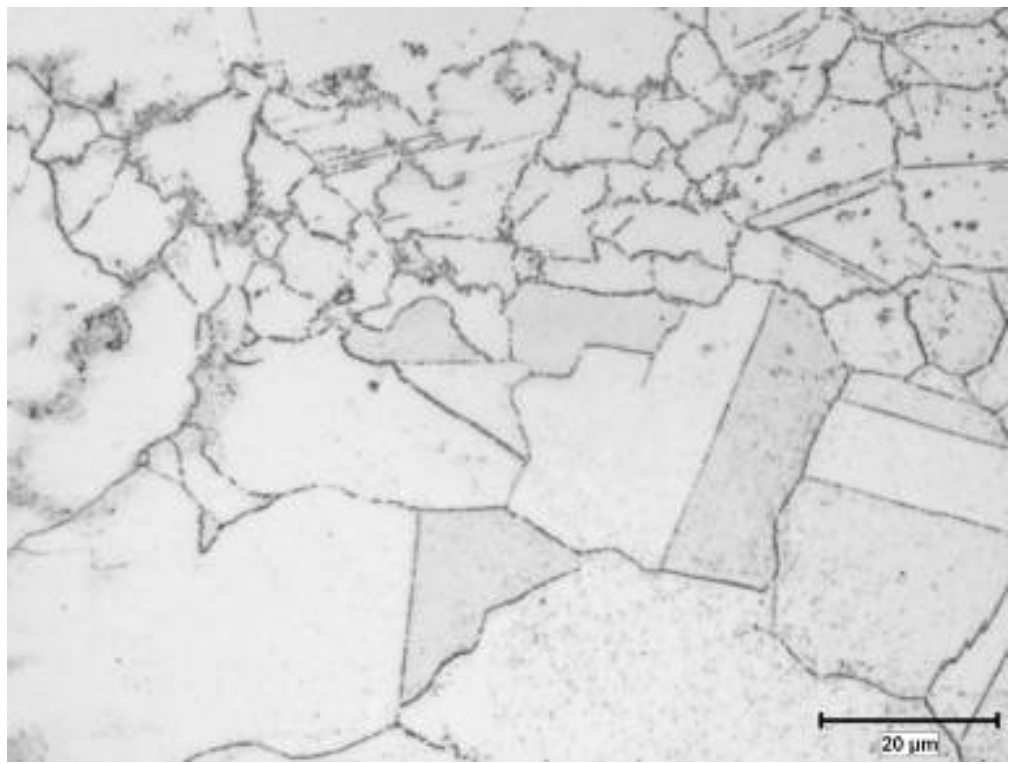

Figure 6: Typical Microstructure of Nimonic 263 - Weld Metal Fusion Line After 10,000 hr Exposure at $725^{\circ} \mathrm{C}(1000 \mathrm{X})$. Weld Metal is on the Very Left. Bromine-Methanol Etch. 

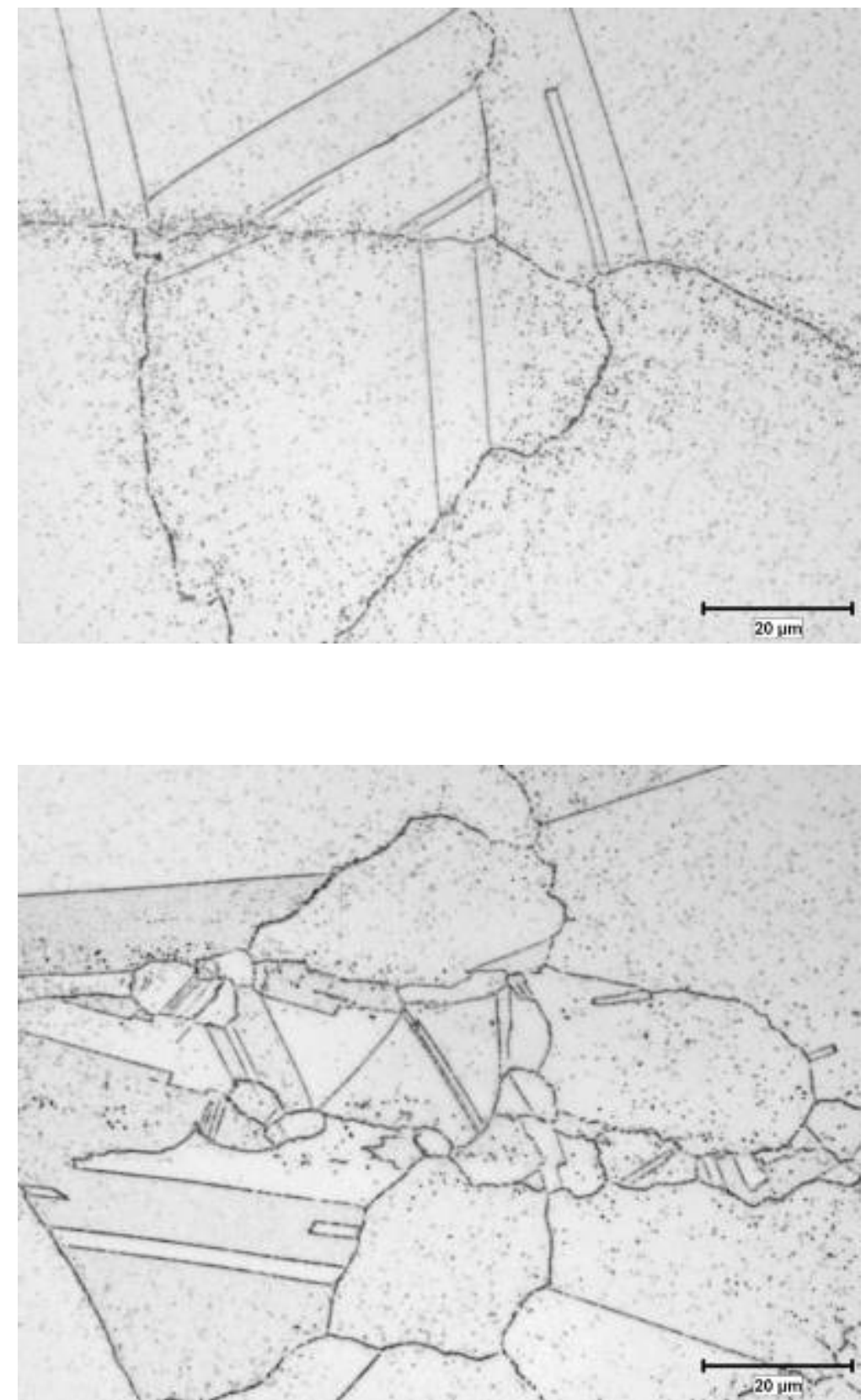

Figure 7: Typical Microstructure of HAZ in Nimonic 263 After $10,000 \mathrm{hr}$ Exposure at $725^{\circ} \mathrm{C}$ (1000X). Bromine-Methanol Etch. 


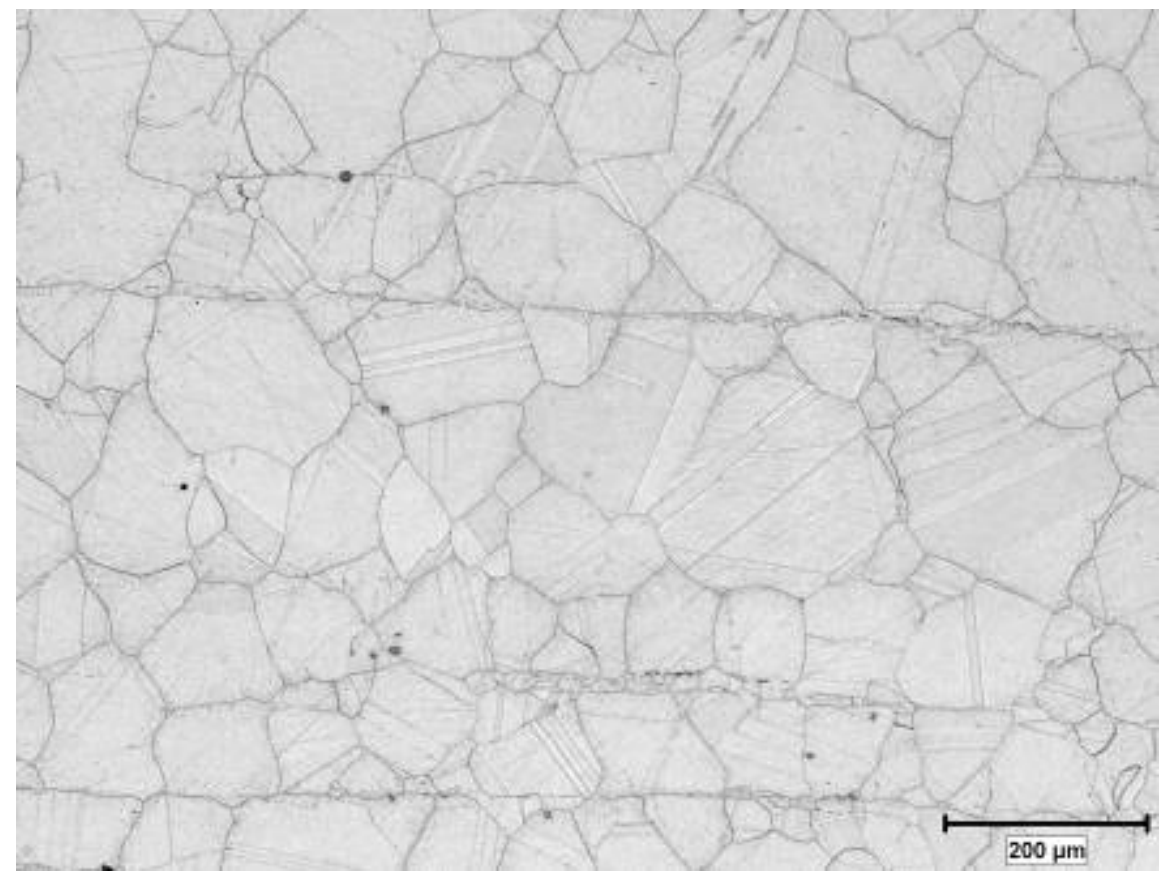

Figure 8: Typical Microstructure of Inconel 617 Base Metal After 10,000 hr Exposure at $725^{\circ} \mathrm{C}$ (200X). Bromine-Methanol Etch.

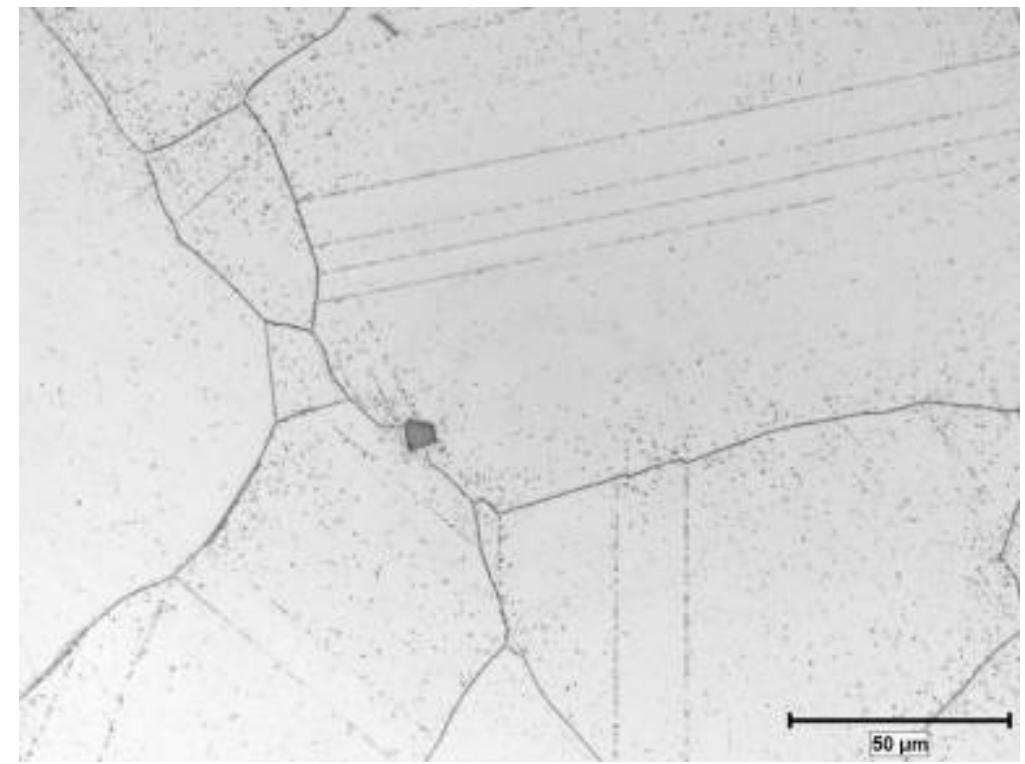

Figure 9: Typical Microstructure of Inconel 617 Base Metal After 10,000 hr Exposure at $725^{\circ} \mathrm{C}(500 \mathrm{X})$. Bromine-Methanol Etch. 


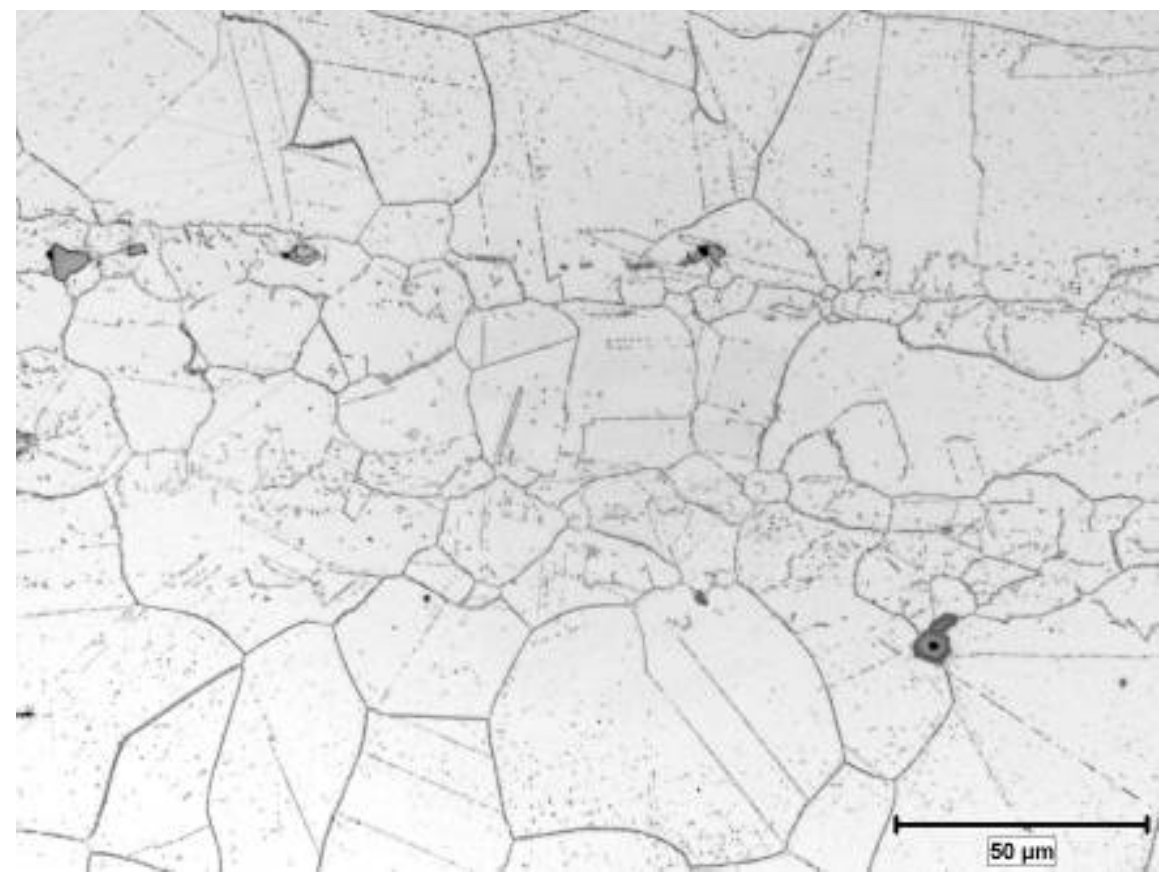

Figure 10: Typical Microstructure of Inconel 617 Base Metal After 10,000 hr Exposure at $725^{\circ} \mathrm{C}(500 \mathrm{X})$. Bromine-Methanol Etch.

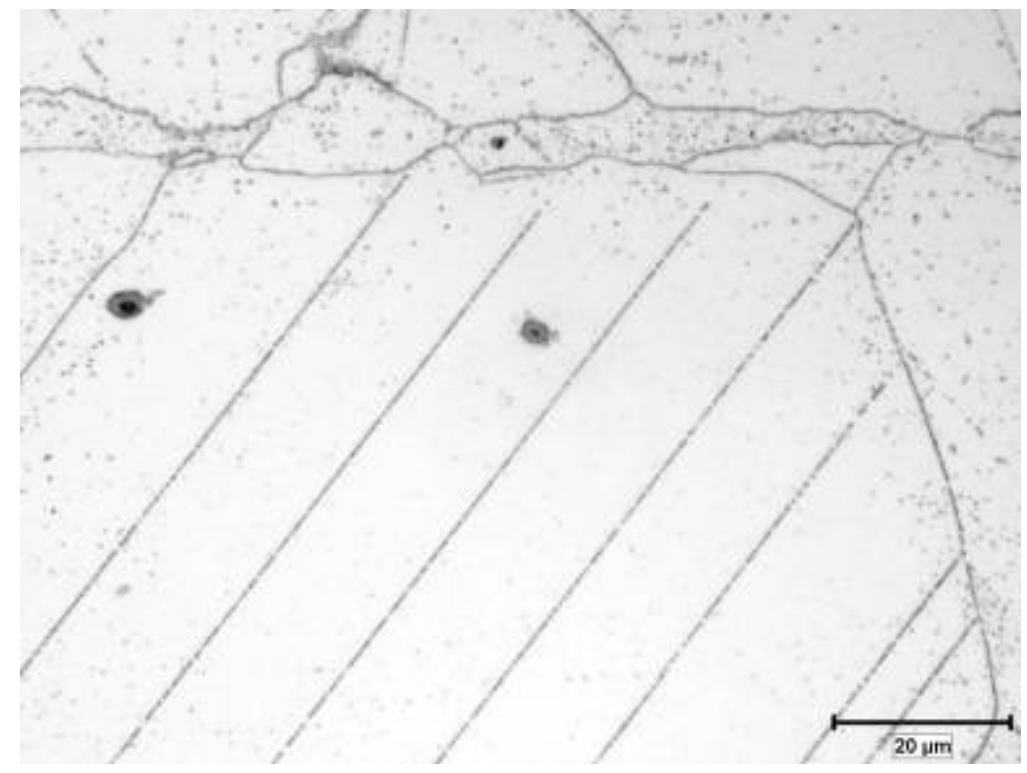

Figure 11: Typical Microstructure of Inconel 617 Base Metal After 10,000 hr Exposure at $725^{\circ} \mathrm{C}$ (1000X). Bromine-Methanol Etch. 


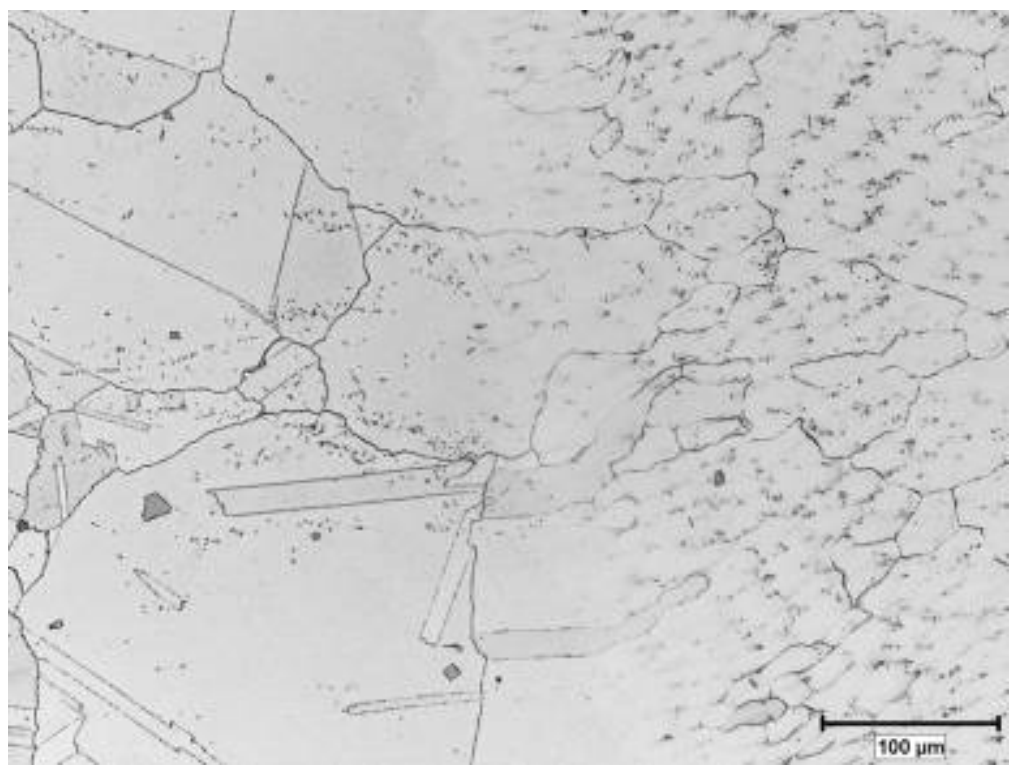

Figure 12: Typical Microstructure of Inconel 617 - Weld Metal Fusion Line After 10,000 hr Exposure at $725^{\circ} \mathrm{C}(200 \mathrm{X})$. Weld Metal is on the Right. Bromine-Methanol Etch.

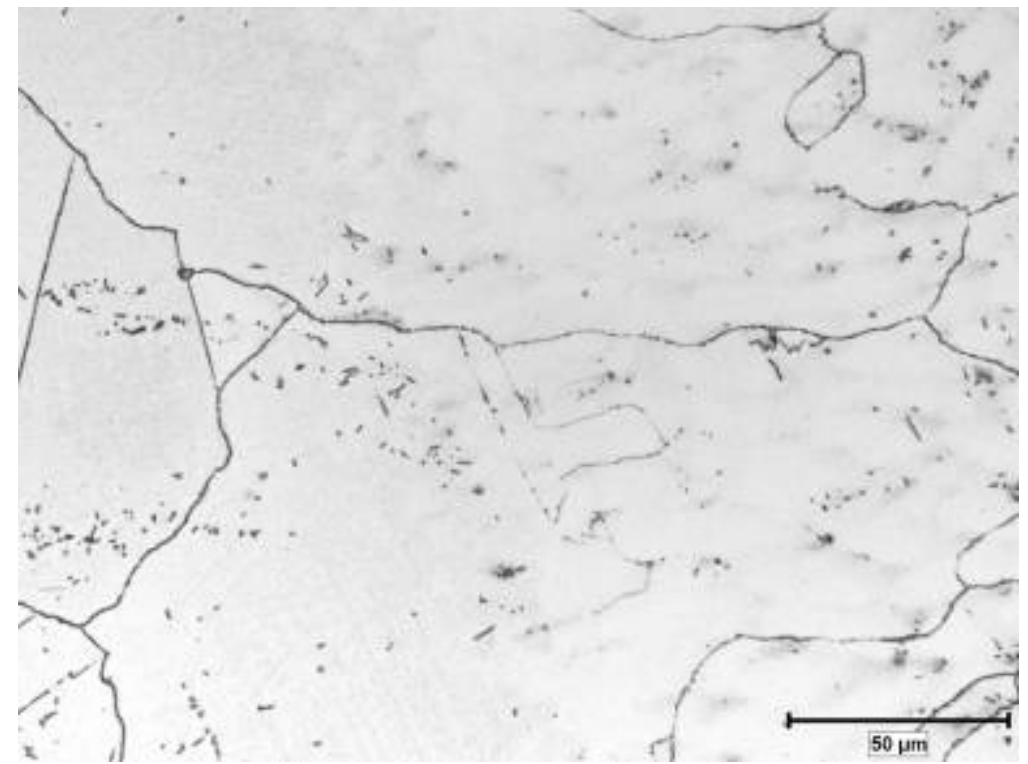

Figure 13: Typical Microstructure of Inconel 617 - Weld Metal Fusion Line After 10,000 hr Exposure at $725^{\circ} \mathrm{C}(500 \mathrm{X})$. Weld Metal is on the Right. Bromine-Methanol Etch. 


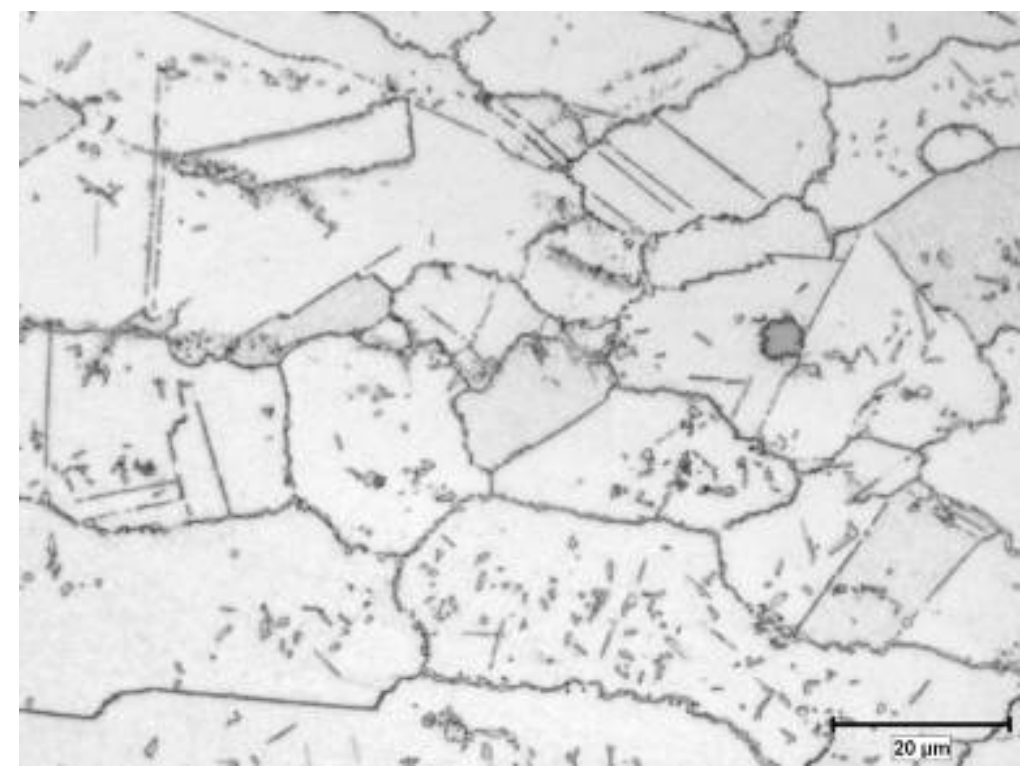

Figure 14: Typical Microstructure of HAZ in Inconel 617 in the Area of a Fine-Grained Band After $10,000 \mathrm{hr}$ Exposure at $725^{\circ} \mathrm{C}(1000 \mathrm{X})$. Bromine-Methanol Etch.

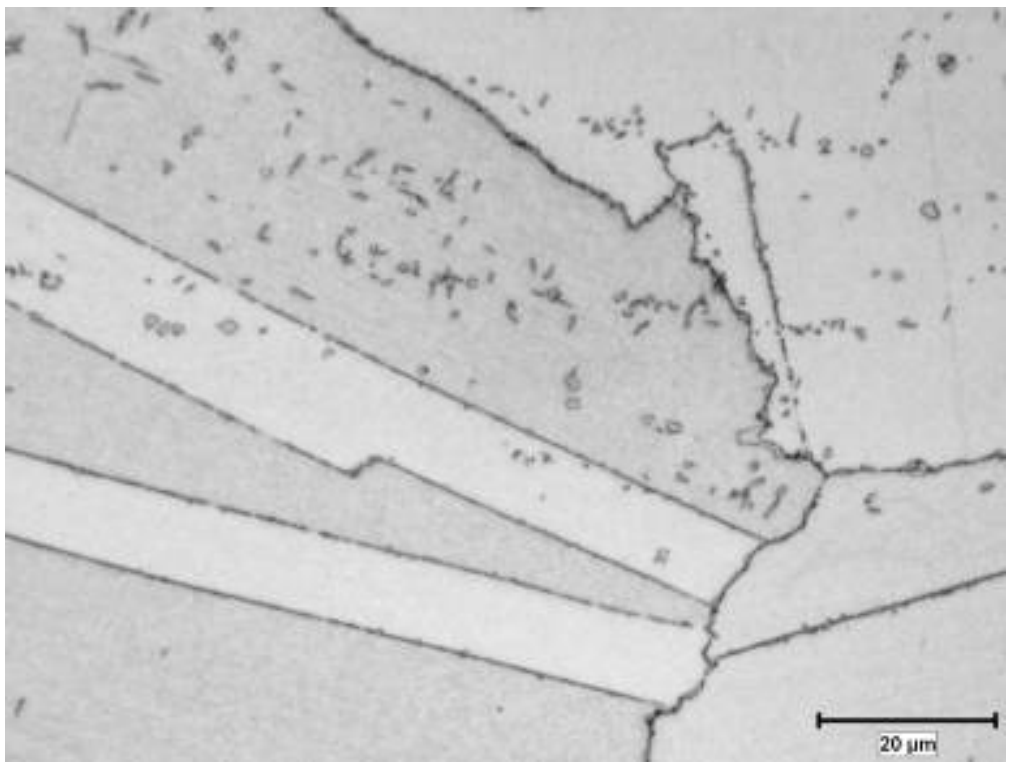

Figure 15: Typical Microstructure of HAZ in Inconel 617 After $10,000 \mathrm{hr}$ Exposure at $725^{\circ} \mathrm{C}$ (1000X). Bromine-Methanol Etch. 


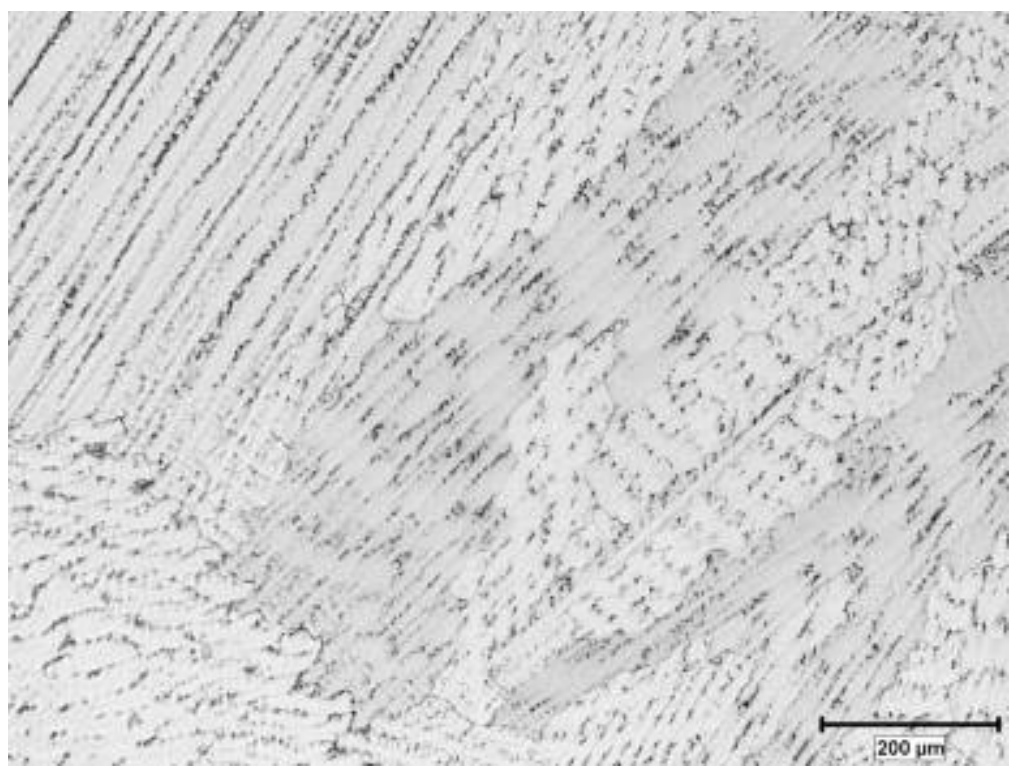

Figure 16: Typical Microstructure of Inconel 617 Weld Metal After 10,000 hr Exposure at $725^{\circ} \mathrm{C}(100 \mathrm{X})$. Bromine-Methanol Etch.

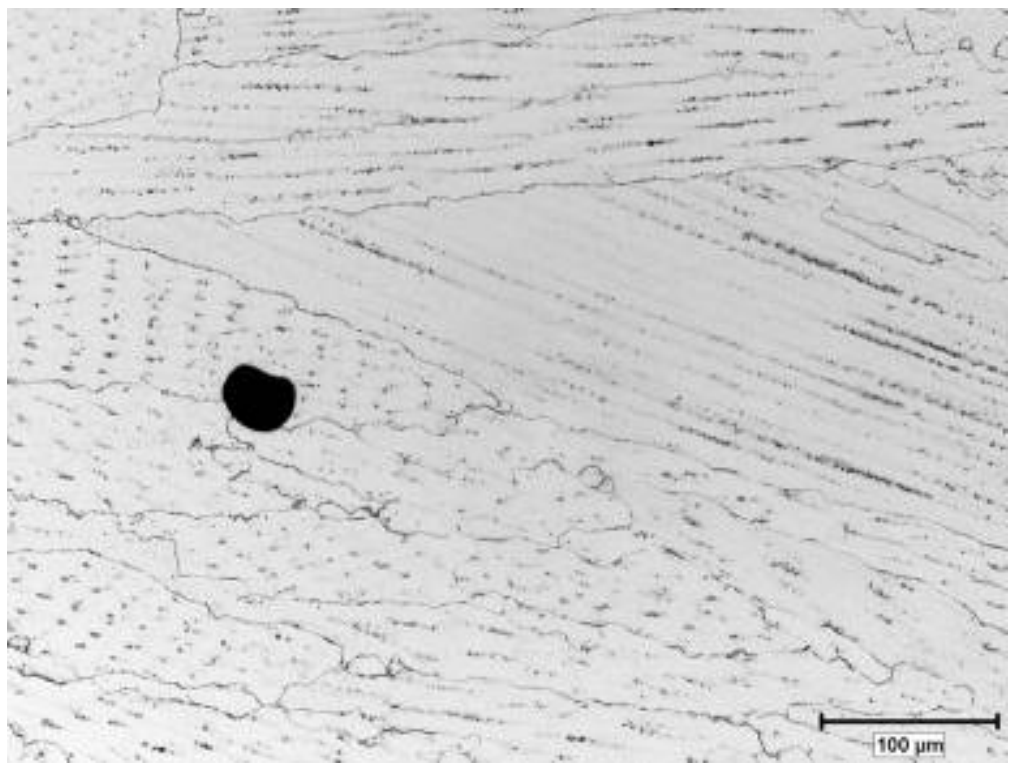

Figure 17 Typical Microstructure of Inconel 617 Weld Metal After 10,000 hr Exposure at $725^{\circ} \mathrm{C}(200 \mathrm{X})$. Bromine-Methanol Etch. 

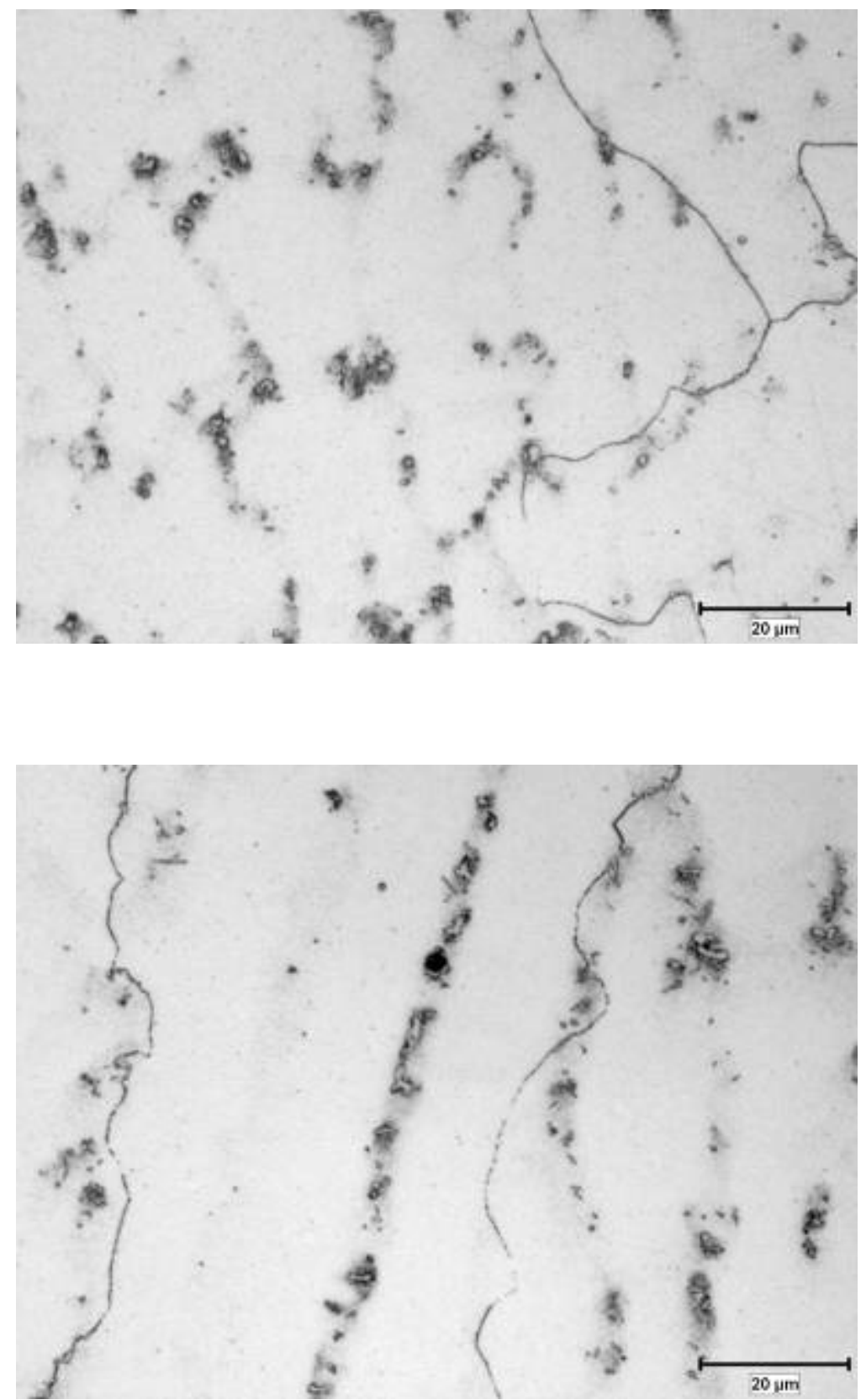

Figure 18: Typical Microstructure of Inconel 617 Weld Metal After 10,000 hr Exposure at $725^{\circ} \mathrm{C}(1000 \mathrm{X})$. Bromine-Methanol Etch. 


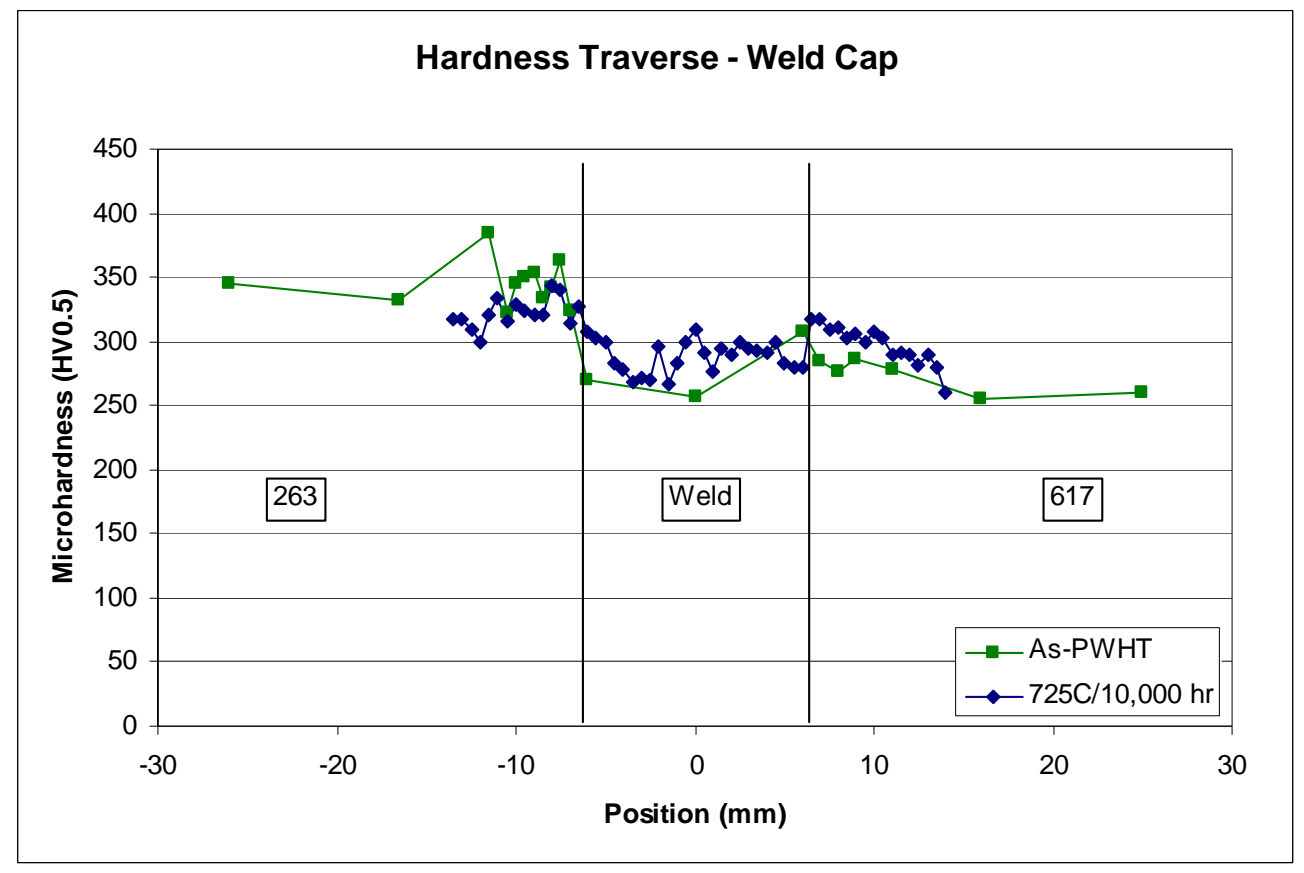

Figure 19: Vickers Microhardness (500 g Load) Traverse Across Weld in the Cap Region.

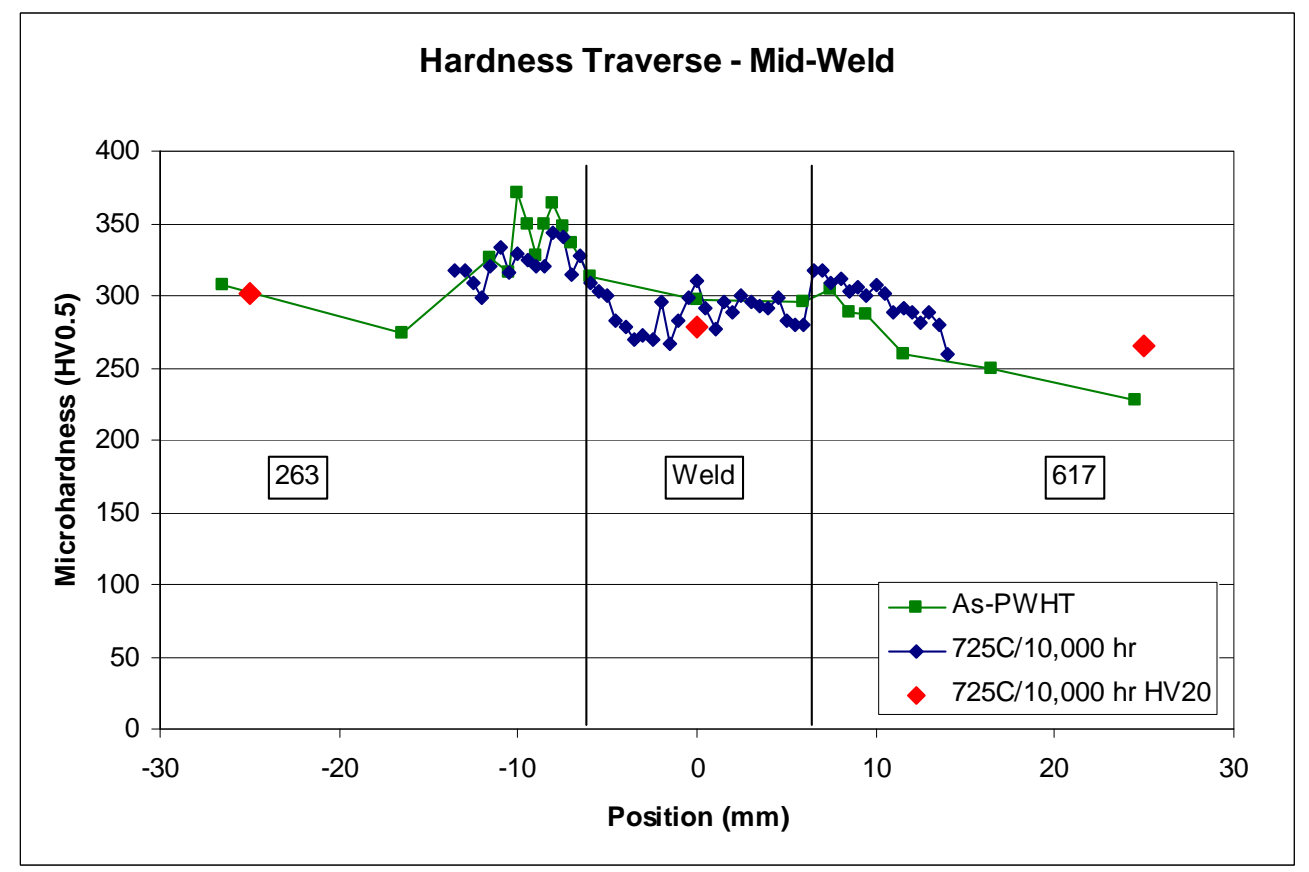

Figure 20: Vickers Microhardness (500 g Load) Traverse Across Weld in the Mid-Thickness Region. The Results of Vickers Hardness Measurements with a $20 \mathrm{~kg} \mathrm{Load}$ are also Shown. 


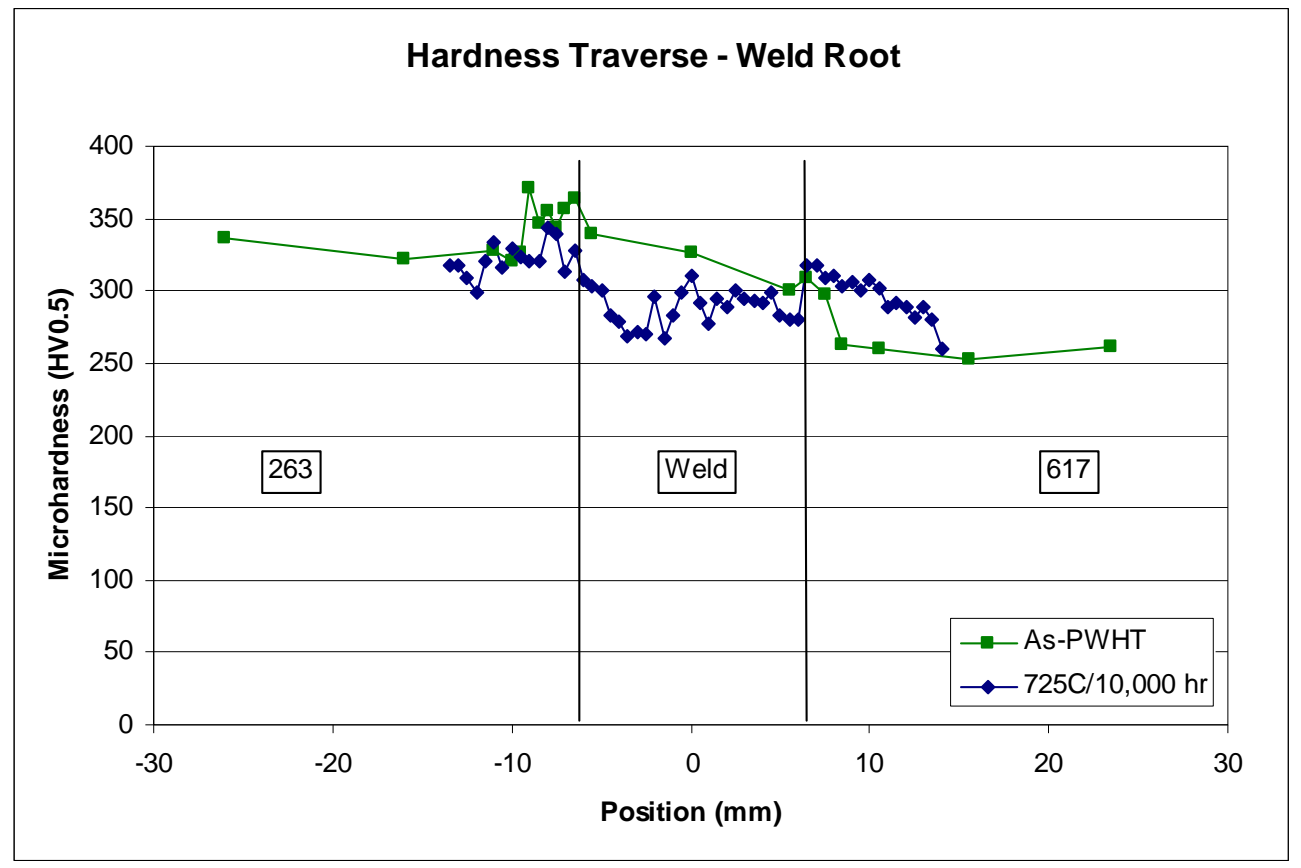

Figure 21: Vickers Microhardness (500 g Load) Traverse Across Weld in the Root Region.

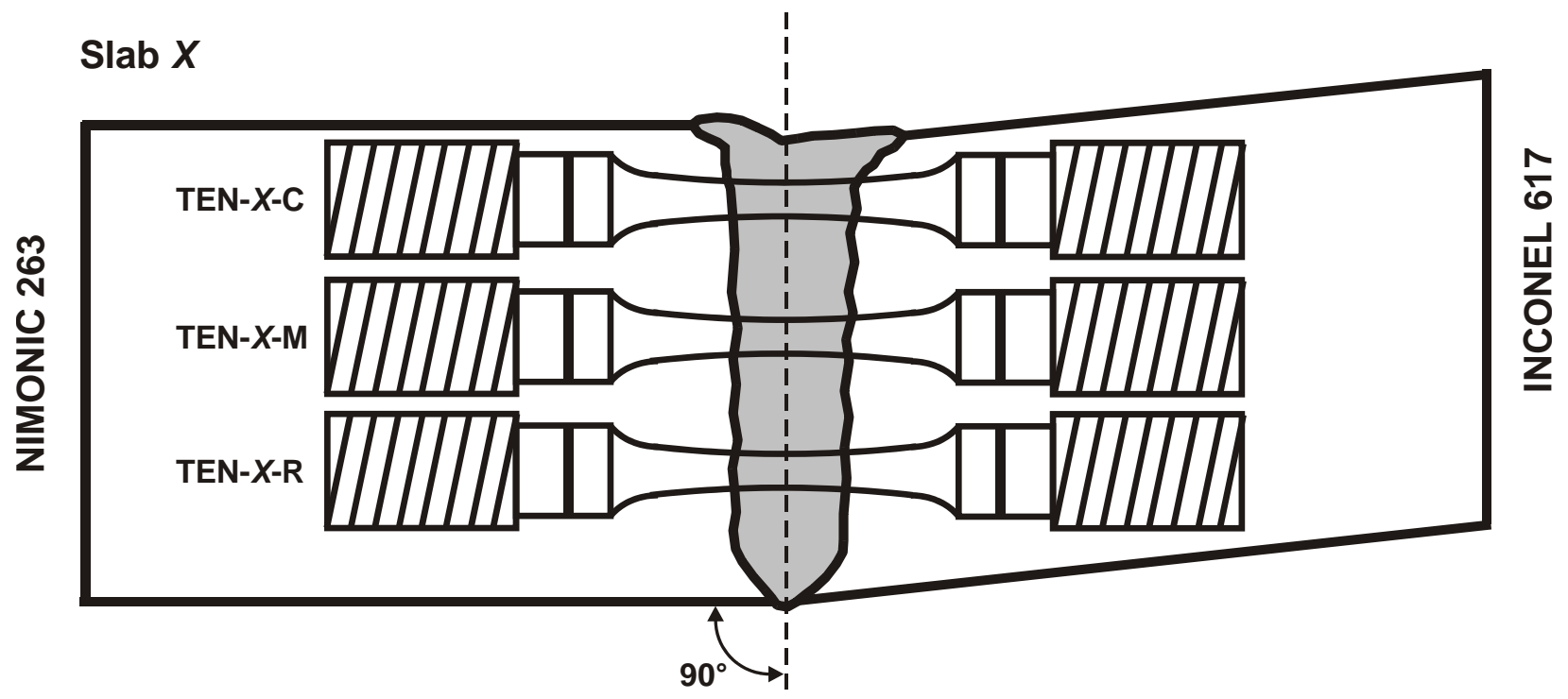

Figure 22: Schematic Diagram Showing Location of Tensile Specimens with Respect to Weldment (Gray Shaded Area). "C" Designates Cap, "M" Mid-Thickness, "R" Root. 

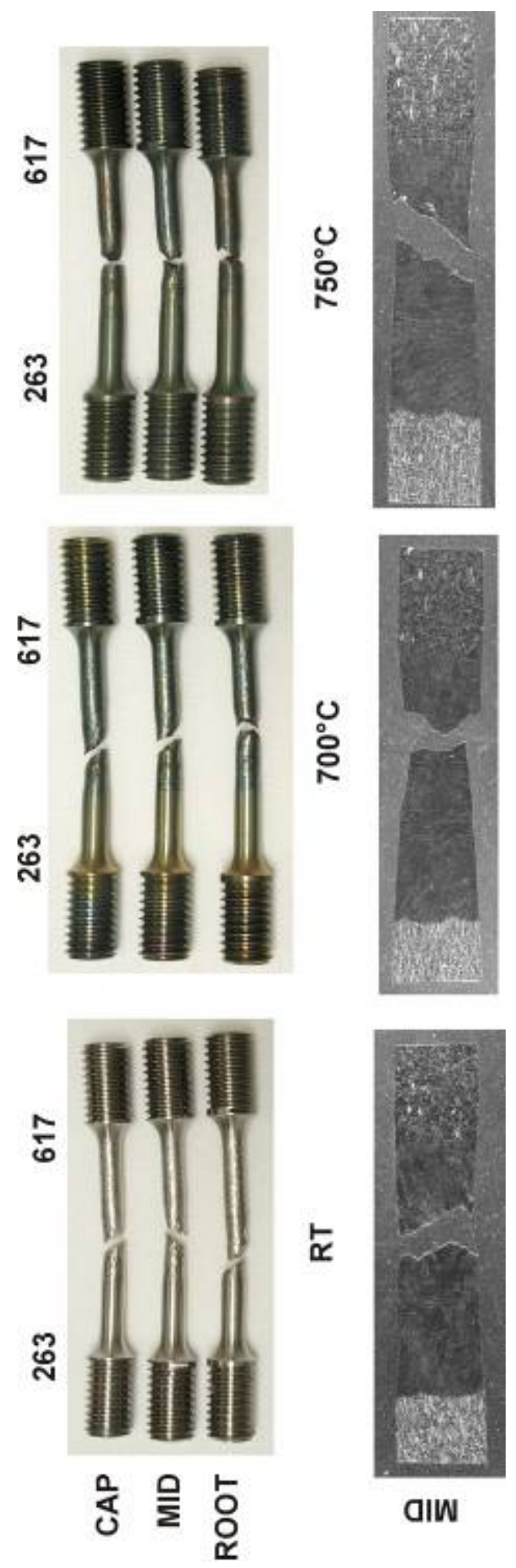

Figure 23: Macro Views of Tested Tensile Specimens and Longitudinal Sections. Rupture Occurred in the Weld Metal for All Specimens. 

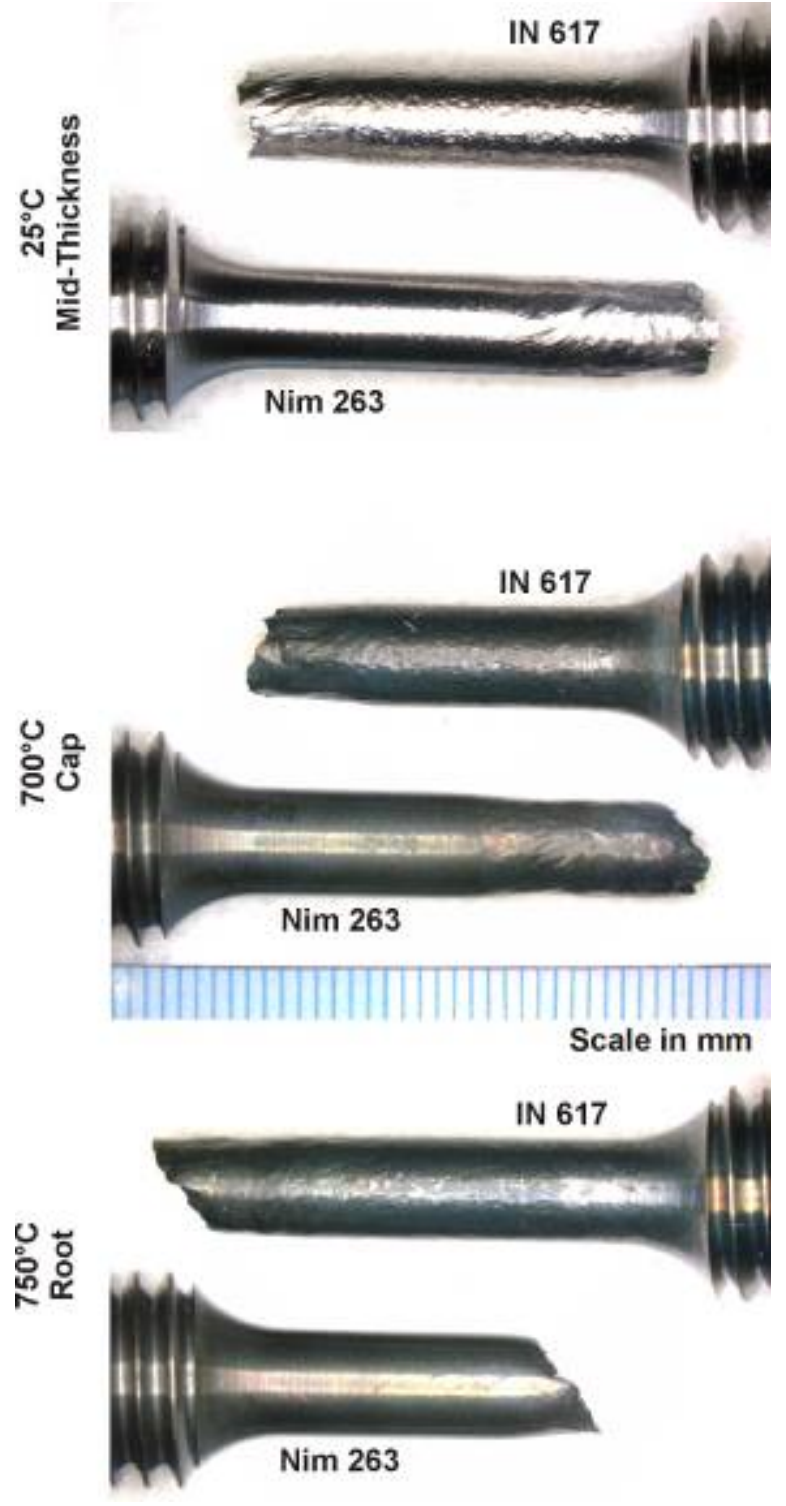

Figure 24: Macro Views of Tested Tensile Specimens from Thermally-Exposed Weldment. Rupture Occurred in the Weld Metal for All Specimens. 

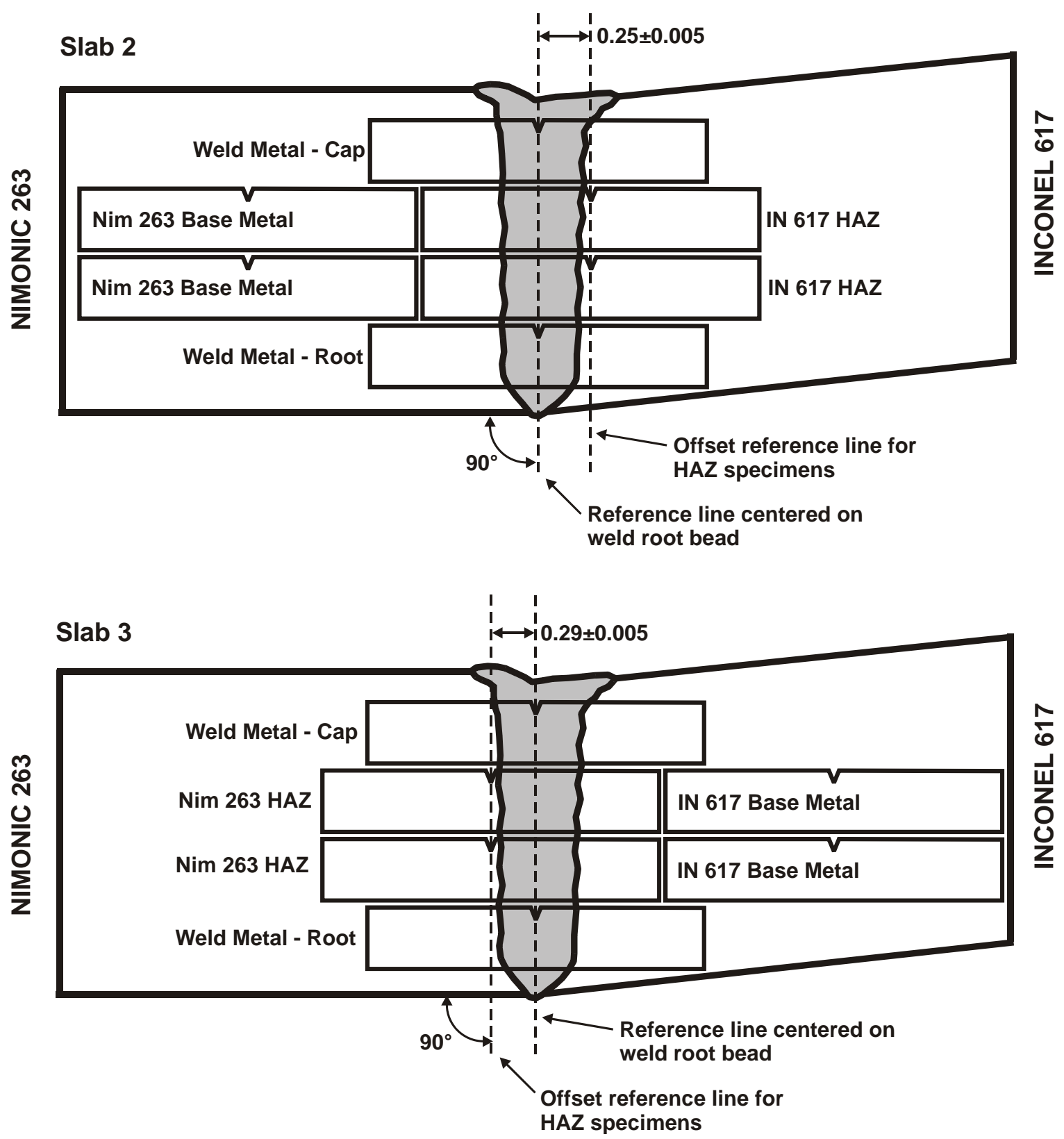

Figure 25: Schematic Diagram Showing Location and Orientation of Charpy V-Notch Impact Specimens Located in Different Microstructural Zones. 


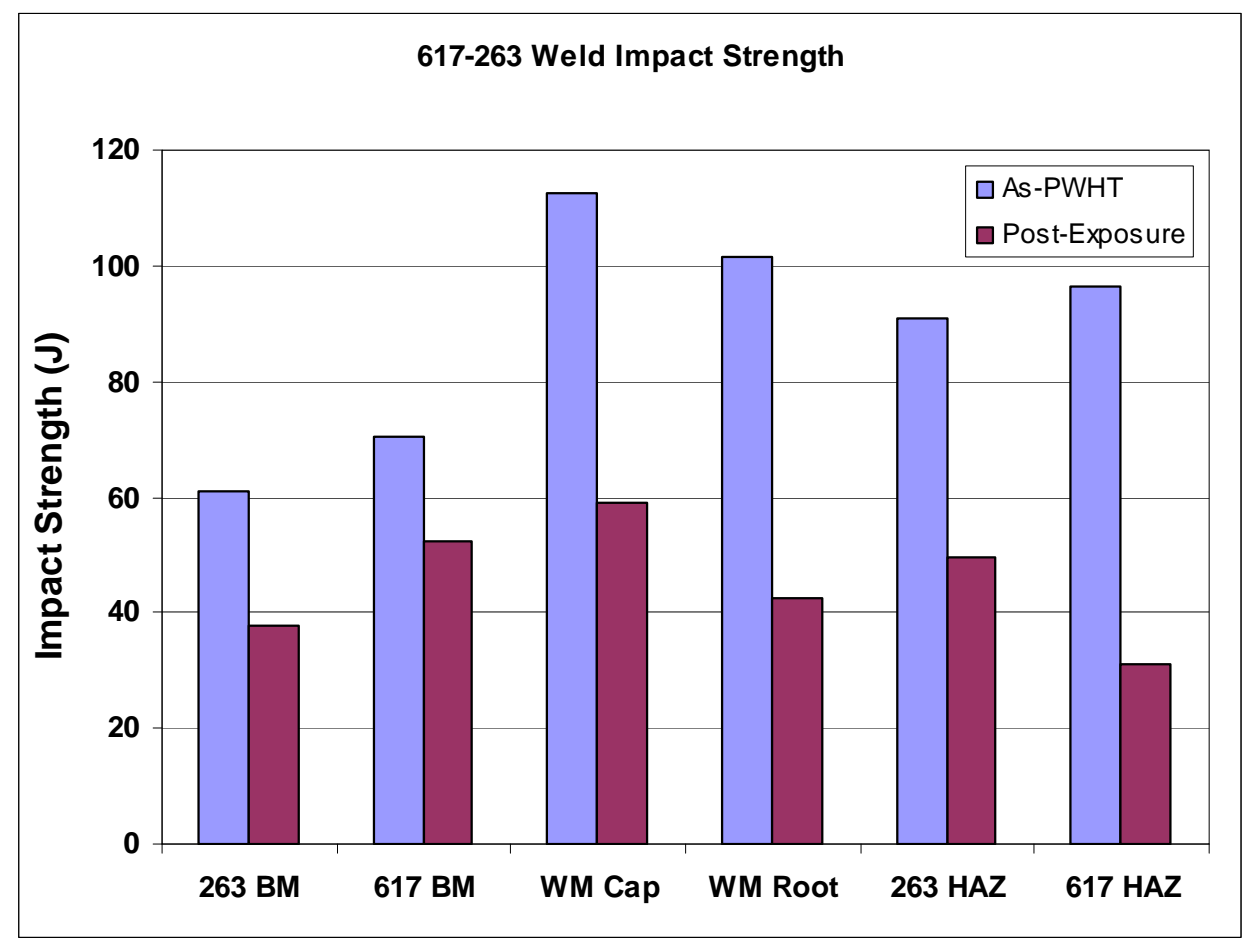

Figure 26: Impact Test Results for Different Microstructural Zones in the 263-617 Weldment in the As-PWHT Condition and After $10,000 \mathrm{hr}$ Exposure at $725^{\circ} \mathrm{C}$. Values are Means of Two Tests. 


\section{As-PWHT}

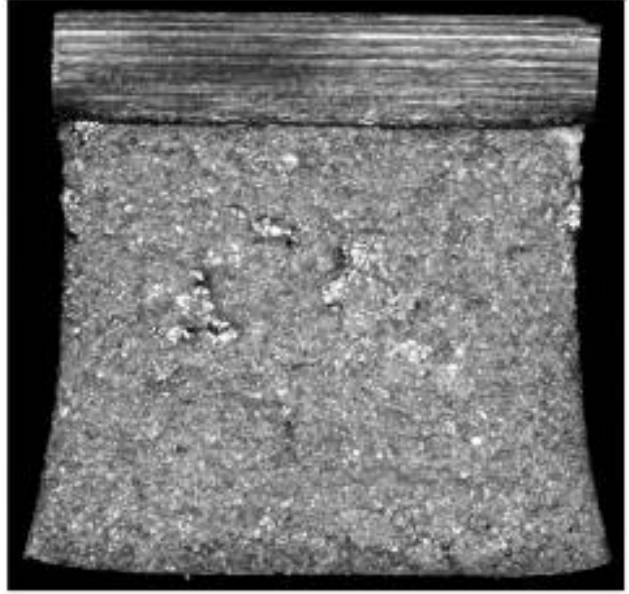

Nimonic 263 Base Metal
Inconel 617 Base Metal

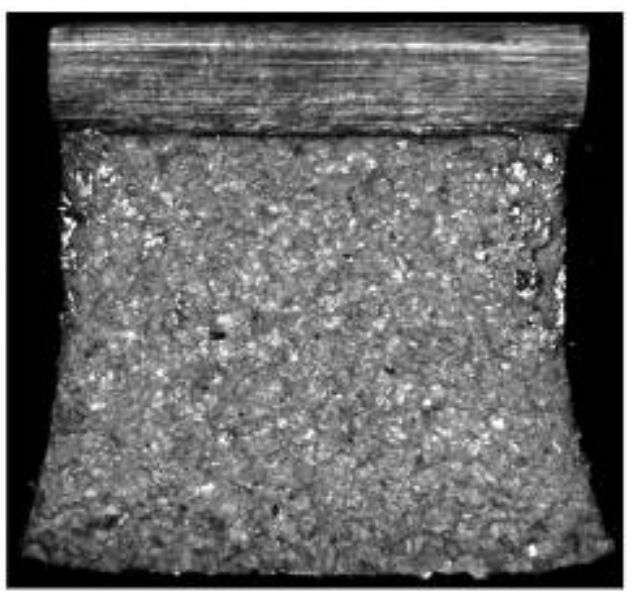

$10,000 \mathrm{hr} @ 725^{\circ} \mathrm{C}$
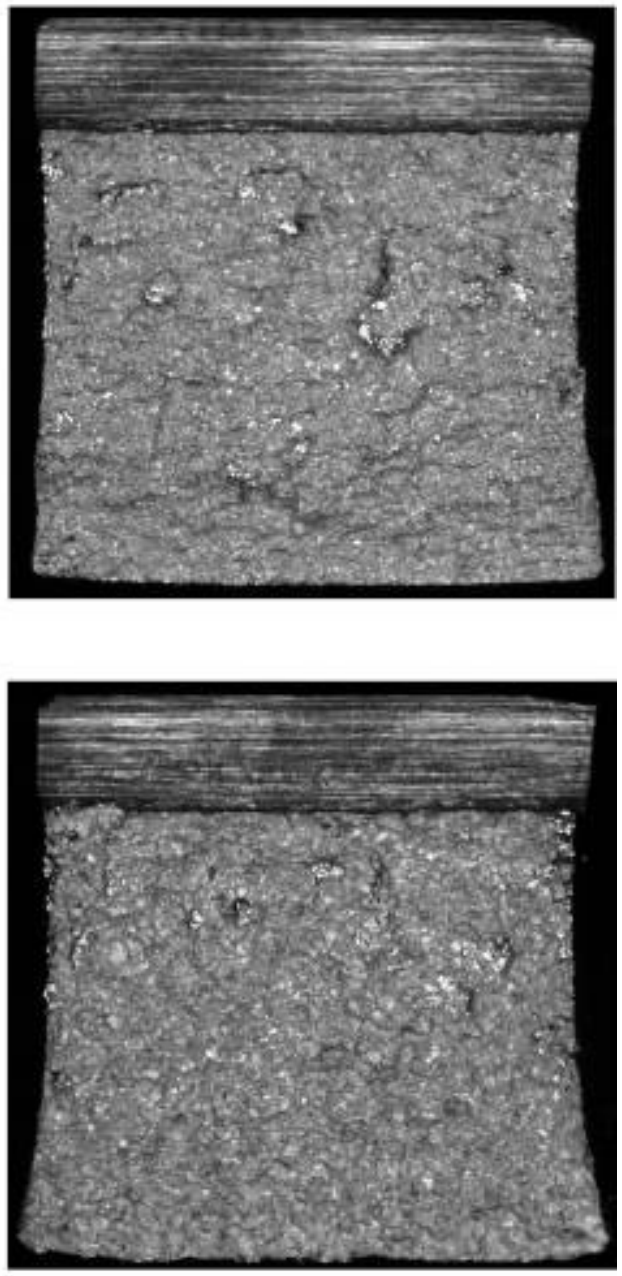

$2 \mathrm{~mm}$

Figure 27: Macro Views of Nimonic 263 and Inconel 617 Base Metal Impact Test Specimen Fracture Surfaces; As-PWHT Condition and After Thermal Exposure. 
Nimonic 263 HAZ
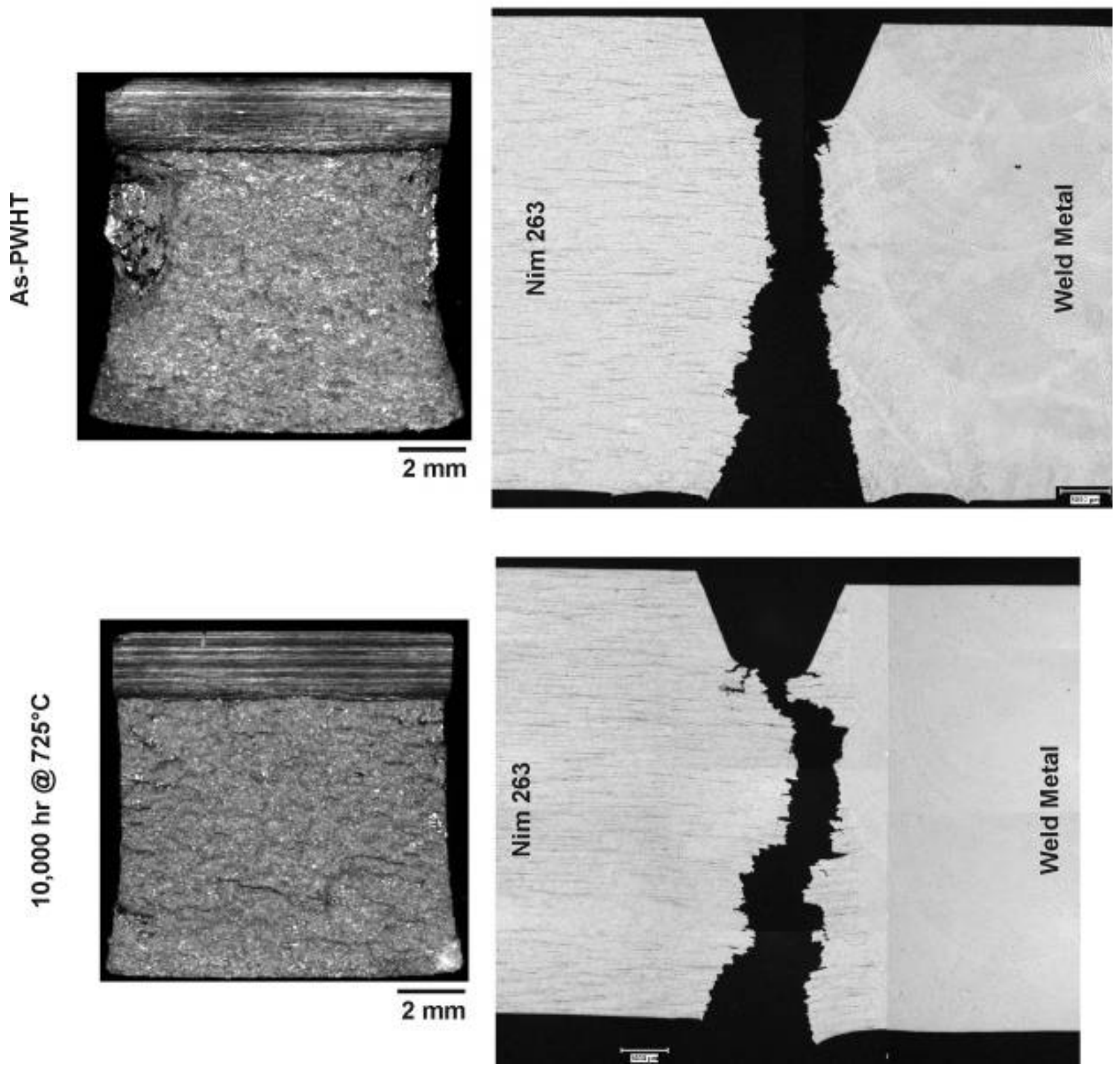

Figure 28: Macro Views of Nimonic 263 HAZ Impact Test Specimen Fracture Surfaces and Corresponding Longitudinal Sections; As-PWHT Condition and After Thermal Exposure. 


\section{Inconel $617 \mathrm{HAZ}$}
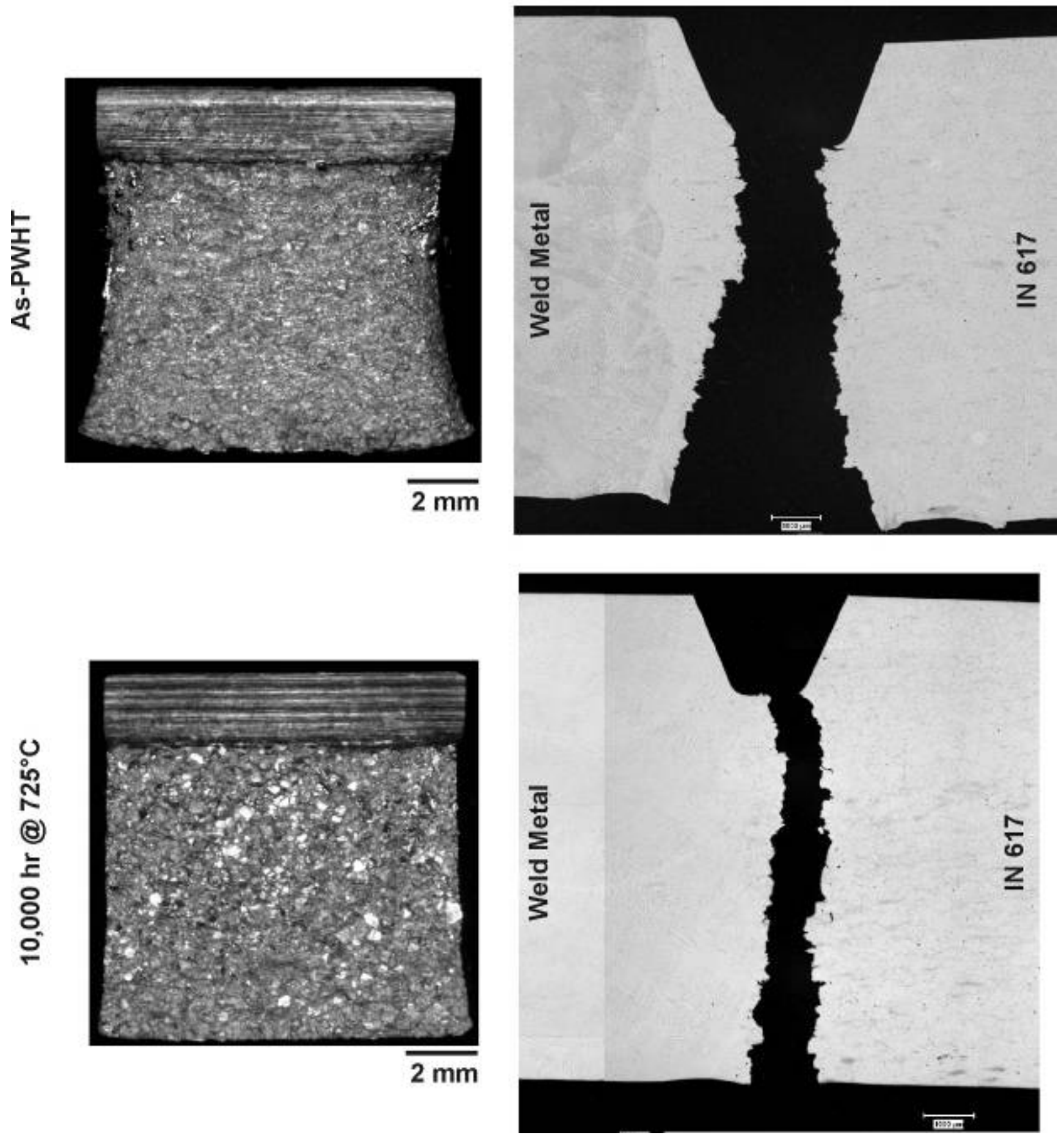

Figure 29: Macro Views of Inconel 617 HAZ Impact Test Specimen Fracture Surfaces and Corresponding Longitudinal Sections; As-PWHT Condition and After Thermal Exposure. 


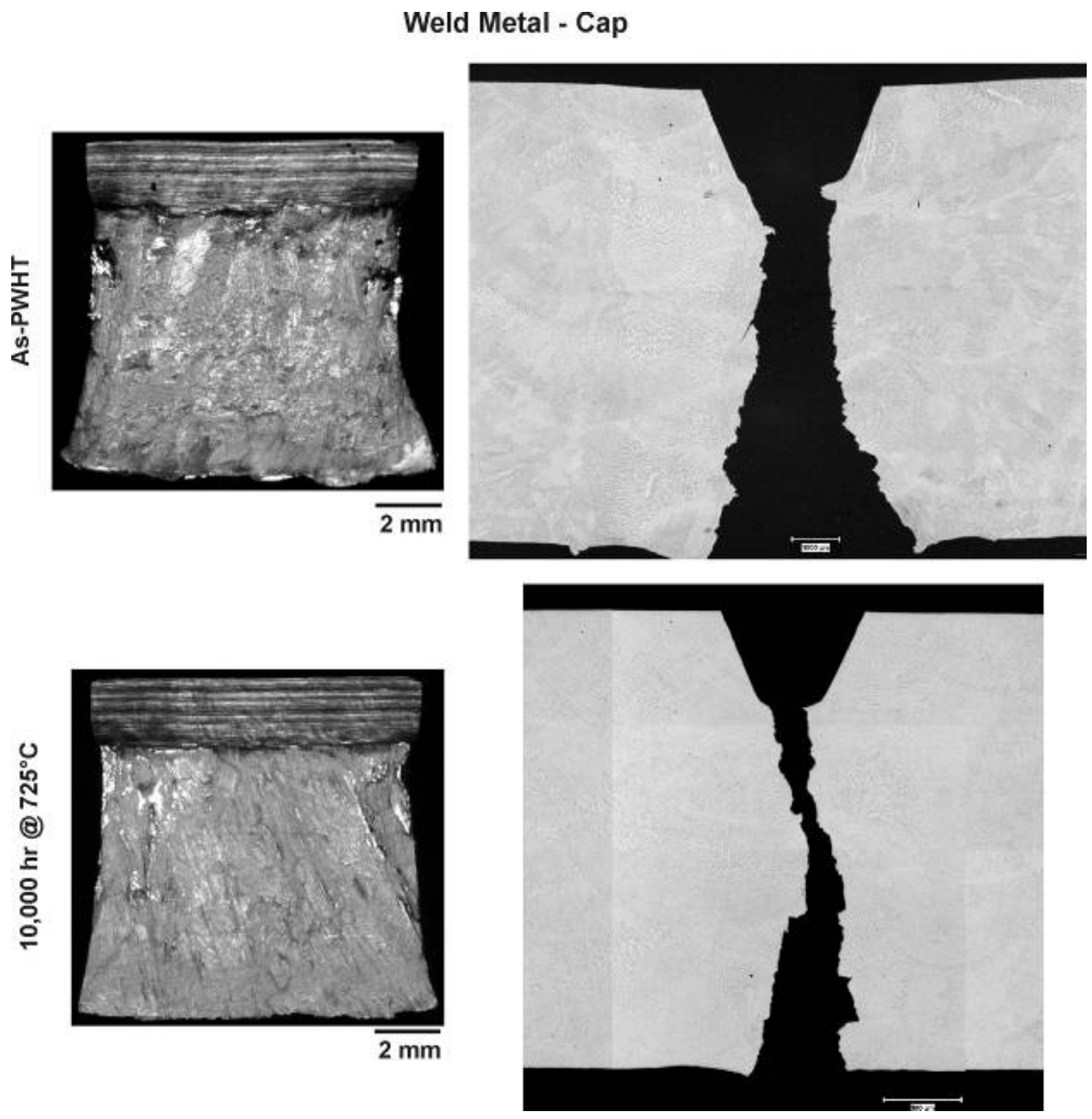

Figure 30: Macro Views of Cap Area Weld Metal Impact Test Specimen Fracture Surfaces and Corresponding Longitudinal Sections; As-PWHT Condition and After Thermal Exposure. 

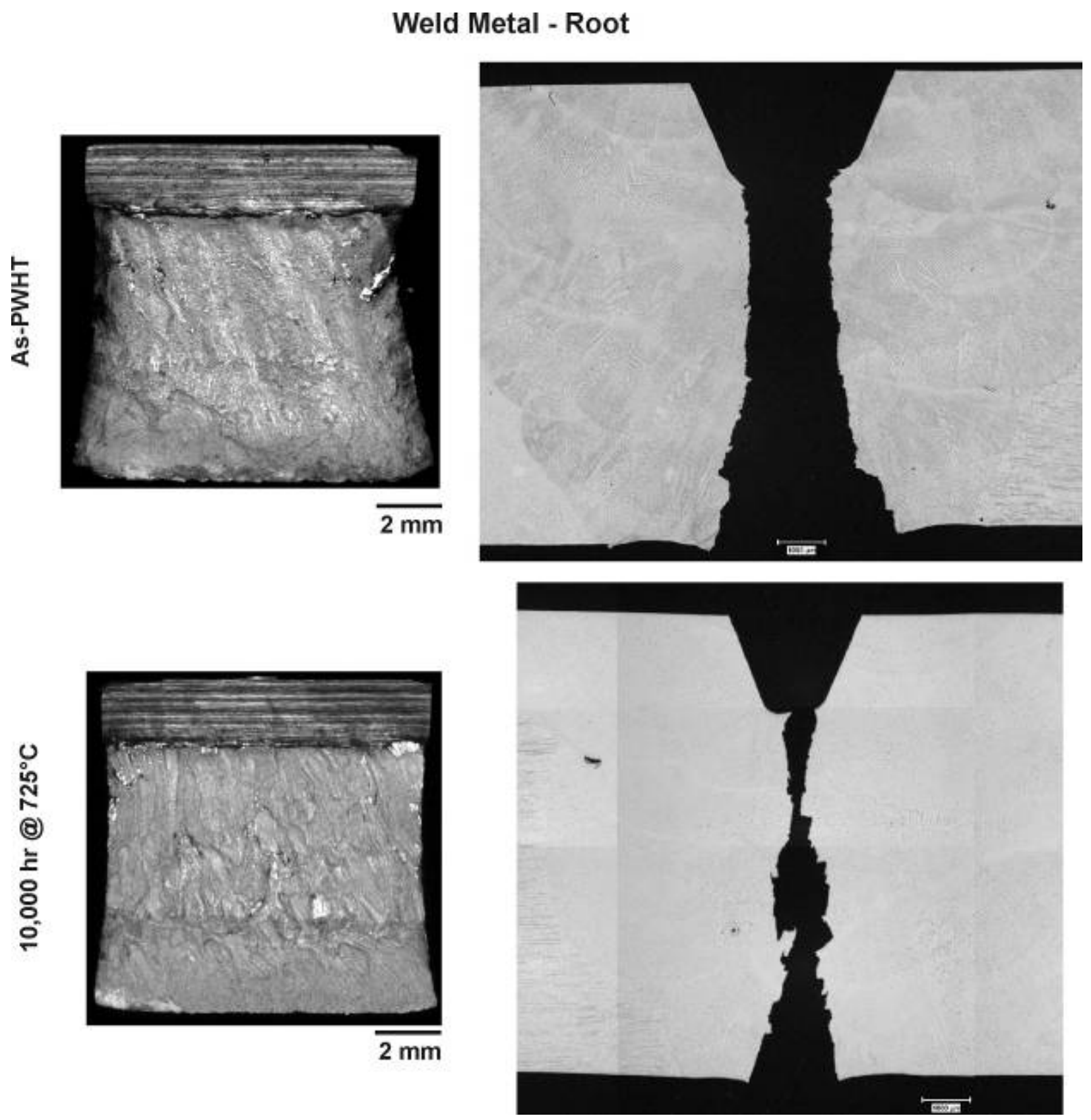

Figure 31: Macro Views of Root Area Weld Metal Impact Test Specimen Fracture Surfaces and Corresponding Longitudinal Sections; As-PWHT Condition and After Thermal Exposure. 

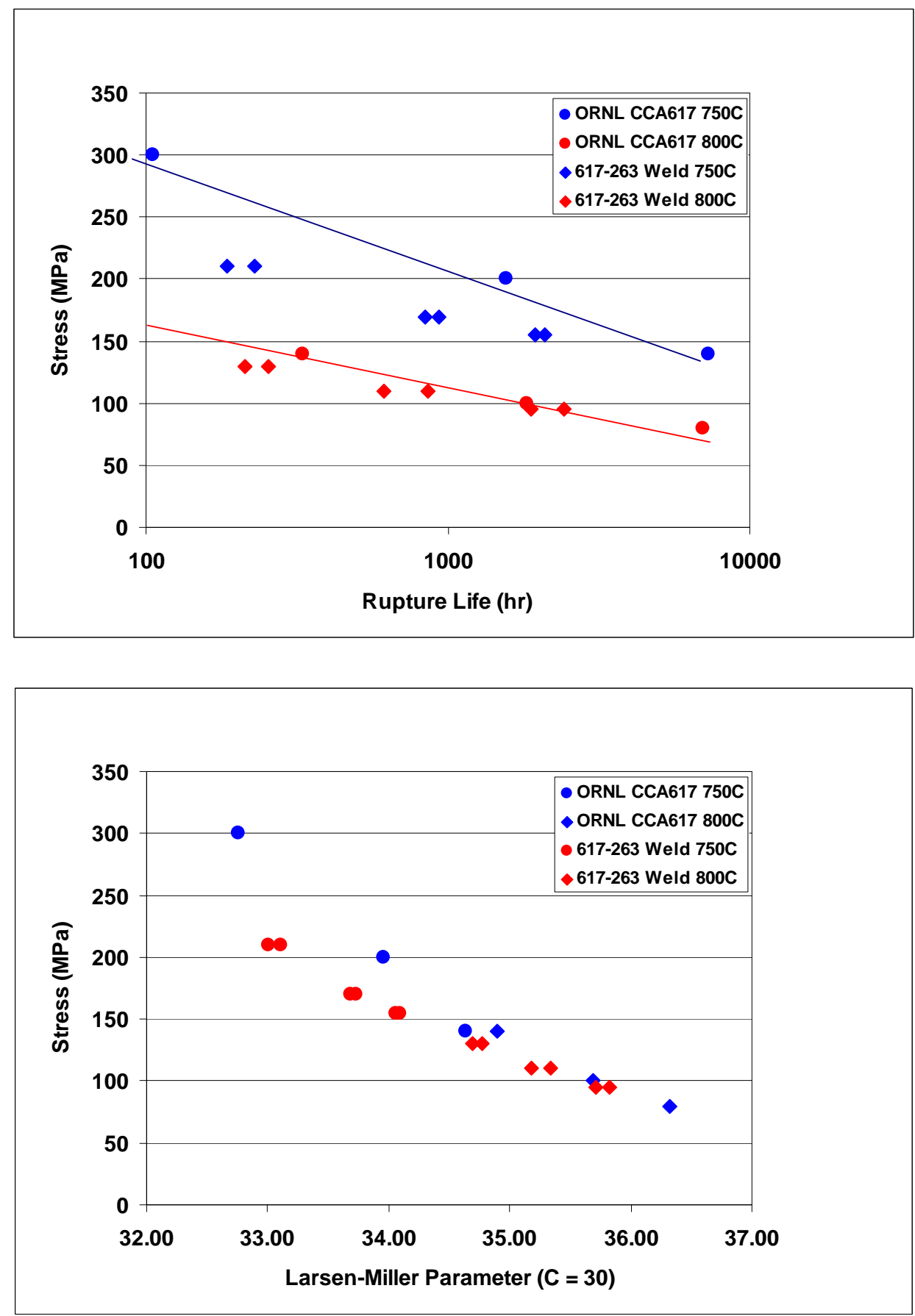

Figure 32: Lives of Cross-Weld Stress-Rupture Specimens, Compared with Data for CCA 617 Produced by ORNL in the DOE USC Boiler Materials Program. 

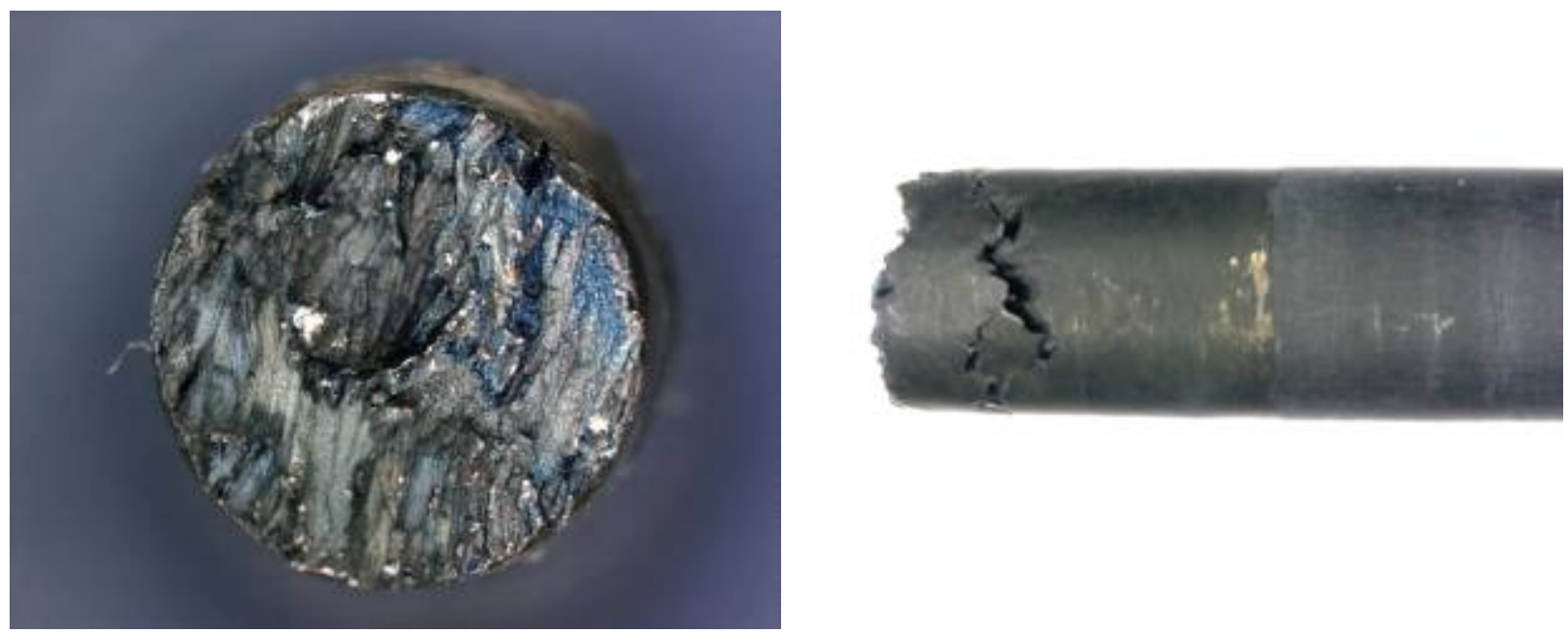

Figure 33: Macro Views of Fracture Surface (Left) and Broken Half of Specimen (Right) of Specimen TEN-4-C, Stress-Rupture Tested at $750^{\circ} \mathrm{C}$ and $155 \mathrm{MPa}$. Rupture Occurred in the Weld Metal.

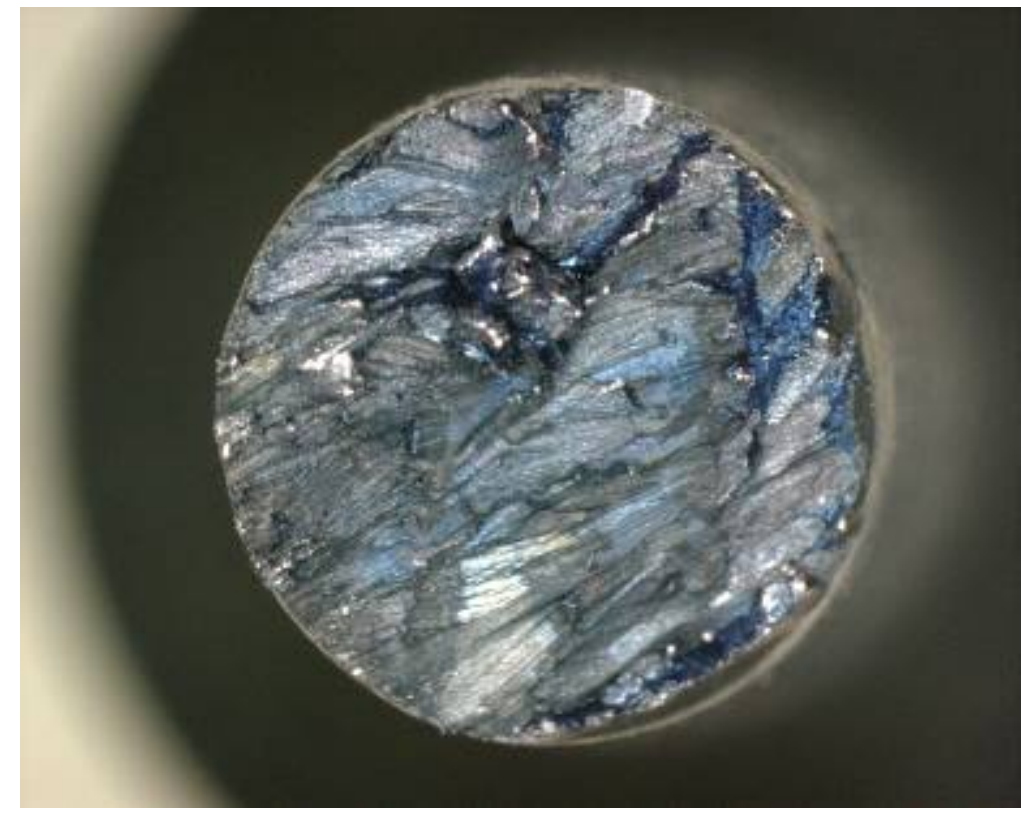

Figure 34: Macro View of Fracture Surface of Specimen TEN-5-C, Stress-Rupture Tested at $750^{\circ} \mathrm{C}$ and $170 \mathrm{MPa}$. Rupture Occurred in the Weld Metal. 

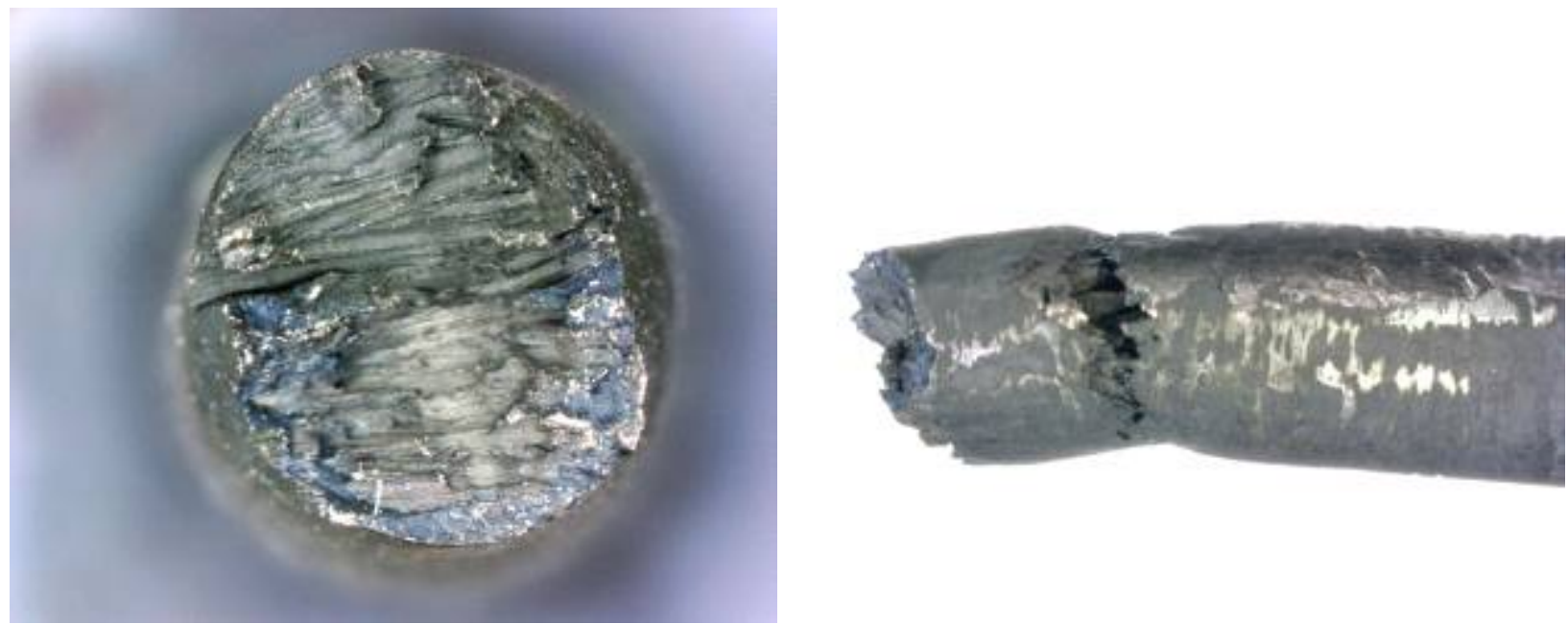

Figure 35: Macro Views of Fracture Surface (Left) and Broken Half of Specimen (Right) of Specimen TEN-6-C, Stress-Rupture Tested at $800^{\circ} \mathrm{C}$ and $95 \mathrm{MPa}$. Rupture Occurred in the Weld Metal.
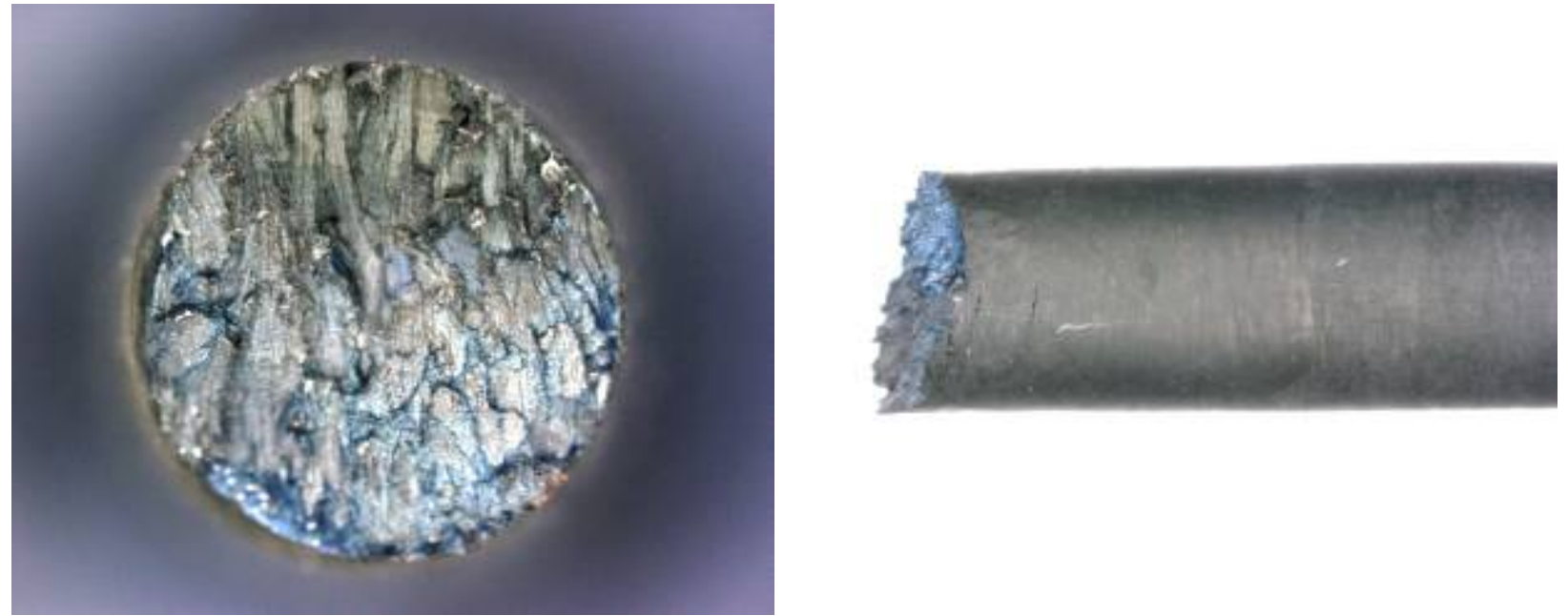

Figure 36: Macro Views of Fracture Surface (Left) and Broken Half of Specimen (Right) of Specimen TEN-7-R, Stress-Rupture Tested at $800^{\circ} \mathrm{C}$ and $130 \mathrm{MPa}$. Rupture Occurred in the Weld Metal. 


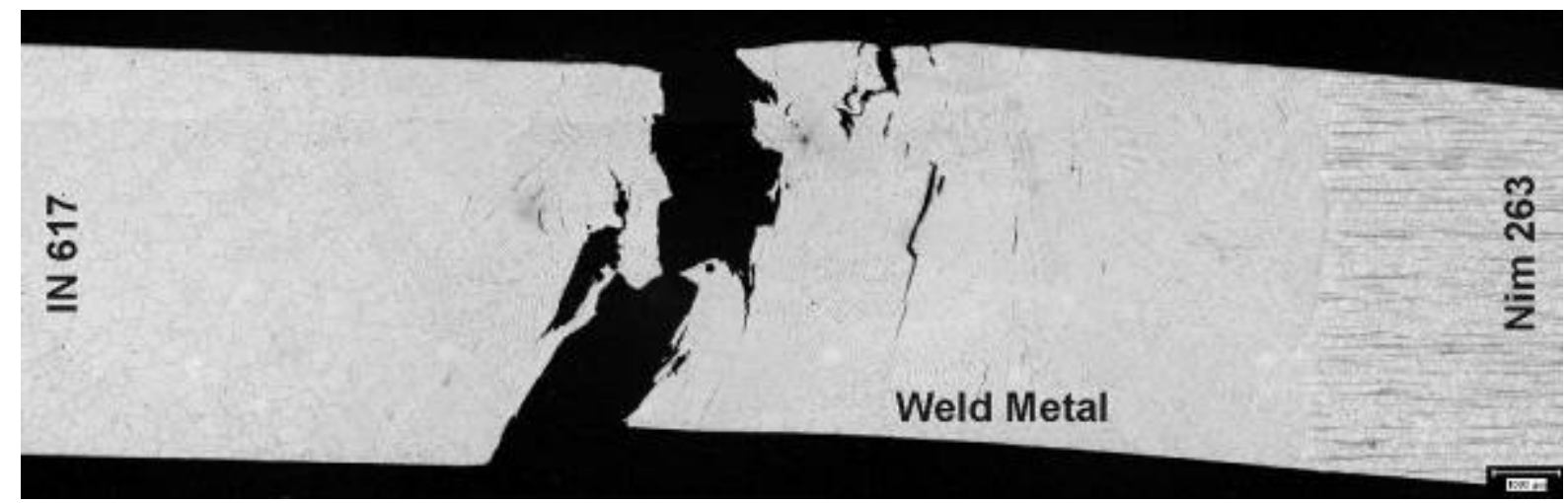

Figure 37: Overview of Longitudinal Section of Specimen TEN-4-C, Stress-Rupture Tested at $750^{\circ} \mathrm{C}$ and $155 \mathrm{MPa}$. Bromine-Methanol Etch.
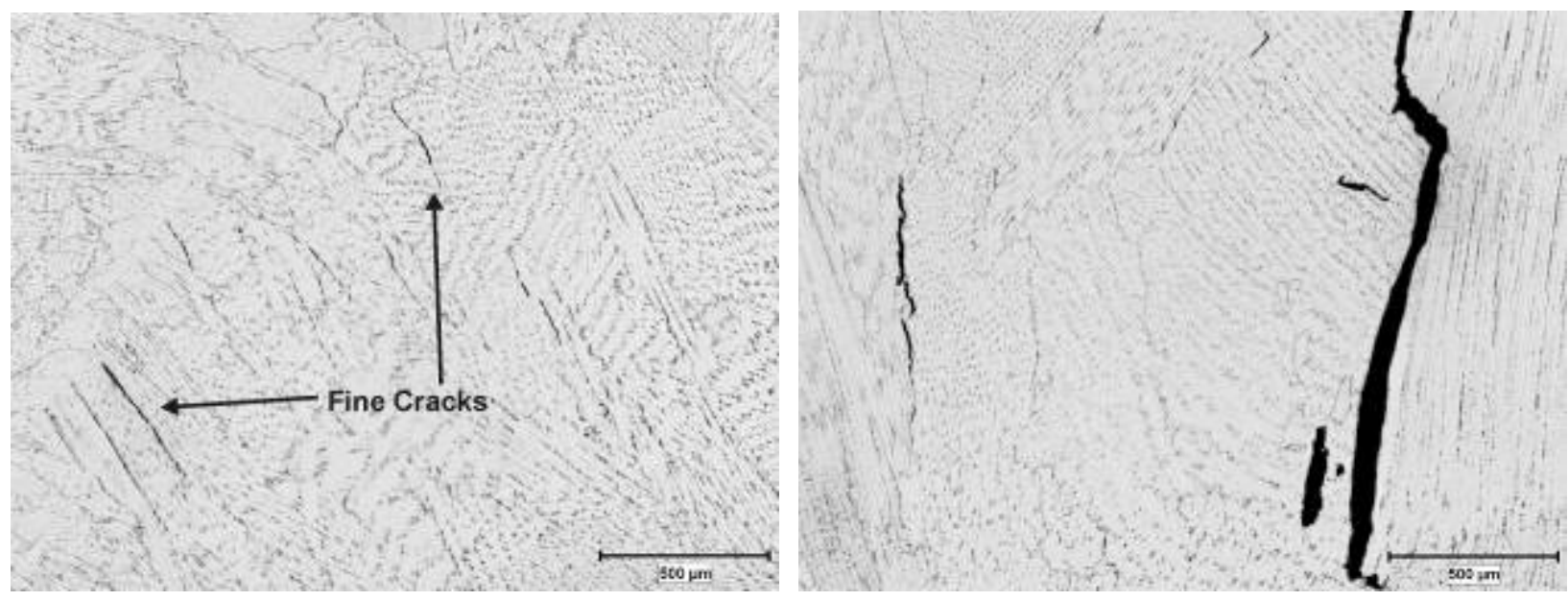

Figure 38: Closer Views of Weld Metal in TEN-4-C Longitudinal Section, Showing Secondary Cracks Along Dendrite Boundaries. Stress Axis is Horizontal. BromineMethanol Etch. 


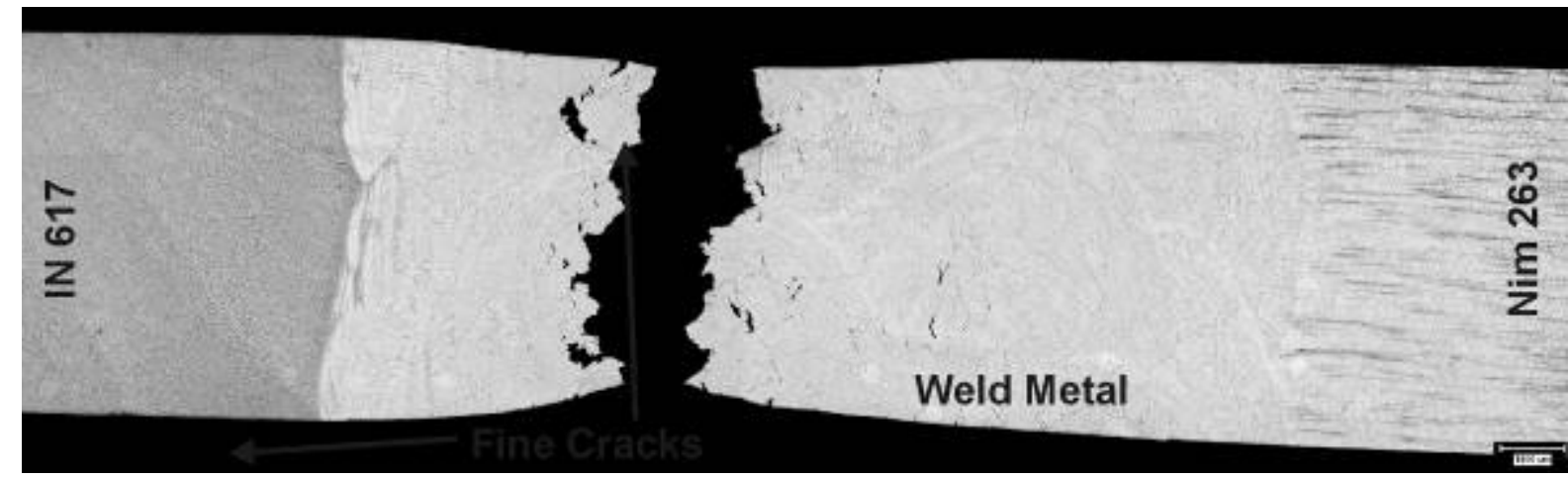

Figure 39: Overview of Longitudinal Section of Specimen TEN-6-M, Stress-Rupture Tested at $800^{\circ} \mathrm{C}$ and $95 \mathrm{MPa}$. Bromine-Methanol Etch.
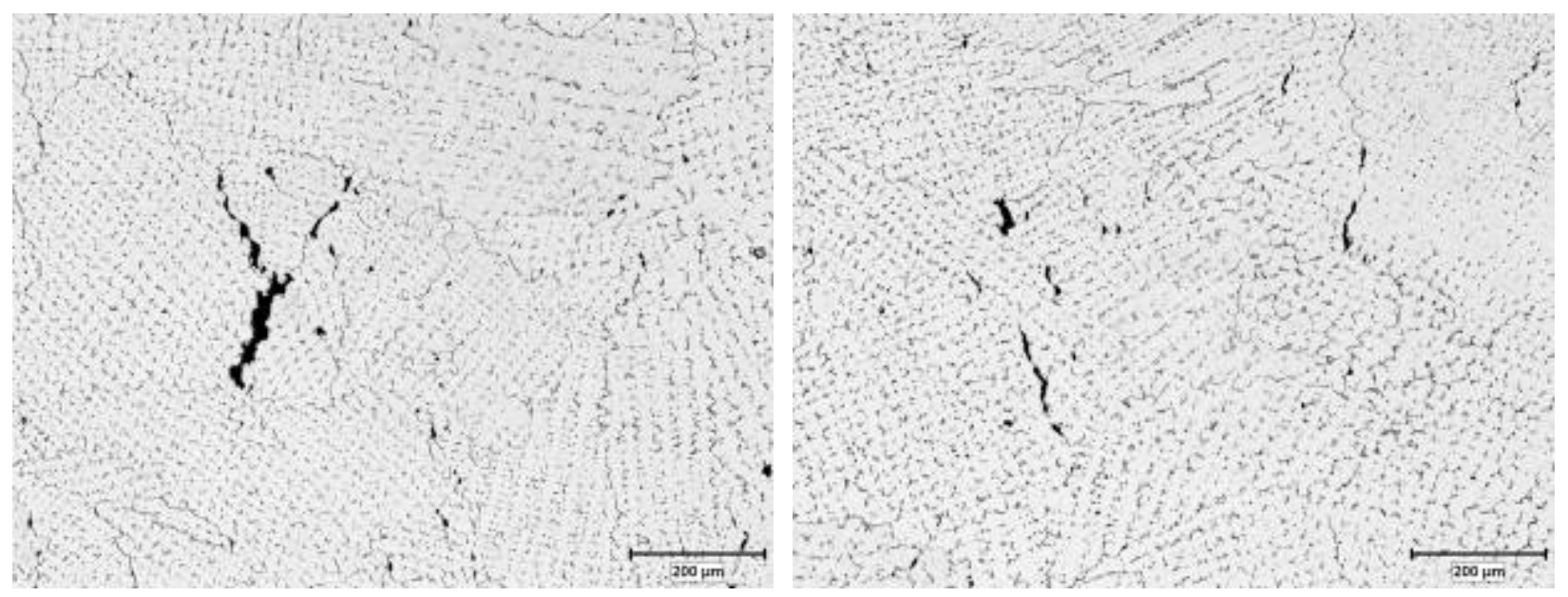

Figure 40: Closer Views of Weld Metal in TEN-6-M Longitudinal Section, Showing Secondary Cracks Along Dendrite Boundaries. Stress Axis is Horizontal. BromineMethanol Etch. 



\section{$4 \quad$ Conclusions}

1. A narrow-groove GTAW process for joining thick-section Nimonic 263 to Inconel 617 using an Inconel 617 filler wire was developed and demonstrated by the Edison Welding Institute.

2. The microstructure and mechanical properties of a twelve-inch long weld in two-inch thick plate made using this process were characterized in the as-PWHT condition:

- The cross-weld tensile properties were equivalent to Inconel 617, with rupture occurring in the weld metal.

- Charpy V-notch impact tests at room temperature showed that all microstructural zones of the weld had reasonable toughness with ductile fracture features.

- Cross-weld stress-rupture tests at 750 and $800^{\circ} \mathrm{C}$ had lives similar to CCA alloy 617 at stresses less than $125 \mathrm{MPa}$. Cross-weld lives were shorter than Inconel 617 base metal lives at higher stresses. All ruptures occurred in the weld metal.

3. The effect of long-term $(10,000 \mathrm{hr})$ simulated service exposure at $725^{\circ} \mathrm{C}$ on the microstructure, hardness, tensile properties, and impact strength of the weld was assessed. There was little change in microstructure, hardness, or tensile properties of the thick-section weldment, but the impact strength was reduced in all microstructural zones of the weld. However, all zones had impact strengths sufficient to demonstrate adequate toughness, even after elevated-temperature exposure. 



\section{Appendix A \\ EWI Report on the Manufacture and Evaluation of a Inconel 617 to Nimonic 263 Alloy Joint}

$$
\text { REPORT }
$$

July 27,2007

Weldability Evaluation of IN617 to NI263

Alloy Joints

Submitted to:

ALSTOM Power, Inc. EES USA

Windsor, CT 


\title{
Report
}

Project No. 50399GTH

on

\section{Weldability Evaluation of IN617 to N1263 Alloy Joints}

to

\section{ALSTOM Power, Inc. EES USA}

Windsor, CT

\author{
July 27,2007 \\ Jose E. Ramirez \\ EWI \\ 1250 Arthur E. Adams Drive \\ Columbus, $\mathrm{OH} 43221$
}




\section{Contents}

Page

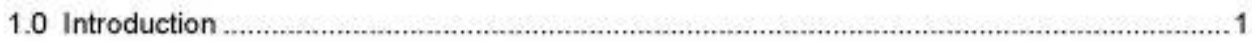

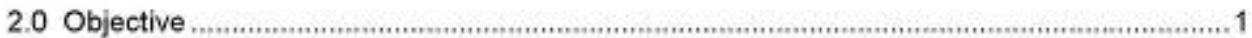

3.0 Experimental Approach and Results................................................................................... 1

3.1 Task 1 - Evaluation of HAZ Liquation, HAZ DDC, and PWHT Cracking Susceptibility .....2

3.1.1 HAZ Liquation Cracking and HAZ DDC of IN617 and NI263 Alloys ...........................2

3.1.2 Stress-Relaxation Cracking of IN617 and NI263 Alloys ......................................... 3

3.2 Task 2 - Feasibility of Narrow-Groove GTAW Process to Weld IN617-Ni263 ThickSection Joints ........................ 3 - General Characterization of Narrow-Groove GTAW IN617-NI263 Full-Size

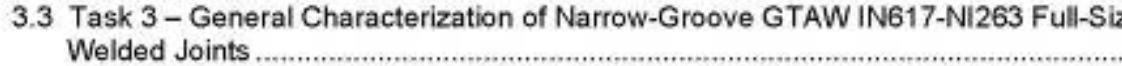

4.0 Conclusions and Recommendations

Appendix A - Tensile and Side-Bend Test Results

Appendix B - Microhardness Testing Results and Graphs

\section{Tables}

Table 1. Conditions of Gleeble Hot-Ductility Testing.

Table 2. NST of the NI617 and IN263 Alloys

Table 3. Results of Hot-Ductility Testing during On-Heating and On-Cooling of IN617 Alloy......

Table 4. Results of Hot-Ductility Testing during On-Heating and On-Cooling of NI263 Alloy.

Table 5. NDT, NST, and DRT Temperatures of IN617 and NI263 Alloys

Table 6. Condition for HAZ Simulation.

Table 7. Condition for High-Temperature Tensile Tests .

Table 8. Results of Hot-Tensile Testing of IN617 and NI263 Alloys

Table 9. Basic Welding Parameters

Table 10. Welding Parameter used for Welding Full-Size Joint 1

Table 11. Welding Parameters used for Welding of Full-Size Joint 2 


\section{Contents (Continued)}

Table 12. Tensile and Side-Bend Test Results from IN617-NI263 Full-Size Welded Joint..... 18

Table 13. Microhardness $\left(\mathrm{HV}_{0.5}\right)$ Across the IN617-NI263 Welded Joint in the AsWelded Condition.

Table 14. Microhardness ( $\left.\mathrm{HV}_{0.5}\right)$ Across the IN617-NI263 Welded Joint in the HeatTreated Condition.

Figures

Figure 1. General View of Plate Sections of Alloys Provided by ALSTOM..

Figure 2. General View of Gleeble Samples

Figure 3. Results of Gleeble Hot-Ductility Testing of Alloy IN617 .23

Figure 4. Results of Gleeble Hot-Ductility Testing of Alloy NI263

Figure 5. Results of Gleeble Hot-Ductility Testing Near Solidus Temperature of Alloys ........25

Figure 6. High-Temperature Tensile Properties of Alloy IN6717 ........................................26

Figure 7. High-Temperature Tensile Properties of Alloy NI263 ........................................2 27

Figure 8. General View of Welding Station, Welding System, Welding Head, NarrowGroove Joint, and Display of Weld Pool during Welding ........................................28

Figure 9. Example of Appearance of Root Pass Achieved during Different Welding Trials ... 29

Figure 10. Cross Section of Root Pass + Fill Passes of Partially Filled Joint Obtained from Different Welding Trials

Figure 11. Micrograph of the IN617 Side of Joint [(a) and (b)] and NI263 Side of Joint [(c) and (d)] of Partially Filled Joints

Figure 12. General View of Restraining of the Joint, Presetting of Joint, Partially and Completely Filled Joint, and Resulting Angular Distortion of the Joint.

Figure 13. View of Cross Section and Root Pass of the Welded Joint, and Defects Observed at the Start Region of the Full-Size Joint .

Figure 14. Cross Section and Defects Observed at the Stop Region of the Full-Size Joint.....34 


\section{Contents (Continued)}

Page

Figure 15. Micrograph of the IN617 and NI263 Sides of Full-Size Joint.....................................

Figure 16. General View of Restraining and Presetting of the Joint, Complete Full-Size Joint Before and After Removing Run-On/Run-Off Tabs, and Resulting Angular Distortion of the Joint.

Figure 17. Preparation of Tensile and Side-Bend Samples .................................................37

Figure 18. General View of As-Welded Tensile and Side-Bend Specimens after Testing ........38

Figure 19. General View of PWHT Tensile and Side-Bend Specimens After Testing..............39

Figure 20. Microhardness Profiles of the IN617-NI263 Welded Joint in the As-Welded and PWHT Conditions.

Figure 21. General Microstructure of the NI263 and IN617 Sides of the Welded Joint in the As-Welded Condition.

Figure 22. Laminar Segregation Observed in the N1263 Base Material and Preferential Etching of the Grain Boundaries of the HAZ of the NI263 Material in the AsWelded Condition.

Figure 23. General Microstructure of the IN617 Side of the Welded Joint in the PWHT Condition

Figure 24. General Microstructure of the NI263 Side of the Welded Joint in the PWHT Condition. 


\subsection{Introduction}

ALSTOM is coordinating an effort to develop turbines associated with ultra-supercritical (USC) boilers. The goal of the USC boilers is to increase boiler efficiencies and achieve lower emission levels. This translates into higher hot steam path temperatures and the need for materials possessing the required strength, heat, and corrosion resistance for long-term, reliable service at higher temperatures. However, as important as the base material properties are, a material's weldability or ability to produce crack-free welded joints with acceptable mechanical properties after post-weld heat treatment (PWHT) during original fabrication and repair, are equally important.

Different working conditions in the low-, intermediate-, and high-pressure turbine sections of USC systems will require the use of different alloys. ALSTOM has considered the use of Inconel 617 (IN617) and Nimonic 263 (NI263) alloys to meet the requirements in different sections of the turbine. IN617 and NI263 are solid solution and carbide-strengthened and solid solution and precipitation-strengthened alloys, respectively.

ALSTOM requested EWI to conduct a preliminary evaluation of the weldability of IN617 to NI263 alloy joints welded with an IN617 filler metal. ALSTOM provided EWI with all the base materials and consumables required during this project. Plate sections of IN617 and NI263 alloy that were 2.0- and 2.125-in. thick, respectively, and a 0.045-in. IN617 (ERNiCrCoMo-1) welding wire were used for this work. A general view of some of the alloy plate sections that were used are shown in Figure 1.

\subsection{Objective}

The primary objective of this project was to conduct a preliminary evaluation of the weldability of IN617 to NI263 alloy joints for USC steam turbines applications.

\subsection{Experimental Approach and Results}

EWI achieved the described goal by using a multi-task approach as follows:

- Task 1. Preliminary evaluation of the susceptibility of IN617 and NI263 alloy thicksection to heat-affected zone (HAZ) liquation cracking, HAZ ductility dip cracking (DDC), and PWHT cracking. 
- Task 2. Evaluation of feasibility of using narrow-groove gas tungsten arc welding (GTAW) process to weld these two materials to each other.

- Task 3. General metallurgical characterization of narrow-groove GTAW IN617-NI263 welded joints.

\subsection{Task 1 - Evaluation of HAZ Liquation, HAZ DDC, and PWHT Cracking Susceptibility}

The weldability of nickel-based alloys depends on different factors including their chemical composition, grain size, and degree of homogeneity which result from alloy processing and material thickness. Additionally, increasing the section thickness will increase the level of restraint and associated stresses in the joint. These two alloys, especially NI263, are normally used in thin-section in the aerospace industry. Therefore, the susceptibility of thick-sections of these two nickel alloys to liquation cracking and DDC in the HAZ during welding, and strain-age cracking or PWHT cracking in the HAZ during PWHT was evaluated.

The susceptibility to HAZ liquation cracking and HAZ DDC of the IN617 and NI263 alloys was evaluated using Gleeble hot-ductility testing. The susceptibility to PWHT cracking was evaluated using slow strain-rate high-temperature tensile testing.

\subsubsection{HAZ Liquation Cracking and HAZ DDC of IN617 and NI263 Alloys}

The Gleeble hot-ductility test characterizes the ductility of the material at elevated temperatures and relates this ductility to cracking sensitivity. Basically, small tensile samples are pulled to fracture rapidly at specific temperatures and the transverse reduction in the area of the fracture samples is determined, thereby, providing a measure of the ductility of the material at high temperatures.

Testing temperatures for HAZ liquation cracking susceptibility is in the vicinity of the solidus temperature during the on-heating and on-cooling portion of a simulated weld thermal cycle in a Gleeble machine. For DDC evaluation, the small tensile samples are fractured rapidly during the on-heating and on-cooling portions of a simulated weld thermal cycle at some specific temperatures in the $500-1100^{\circ} \mathrm{C}$ temperature range.

The conditions used for the Gleeble hot-ductility testing are listed in Table 1. Standard specimens $6.35 \mathrm{~mm}$ in diameter and 100 - $\mathrm{mm}$ long $(0.25 \times 4 \mathrm{in}$.), as shown in Figure 2, were used. Only a limited number of samples were tested to determine the general trend and 
susceptibility to liquation and DDC of the two base materials. The determined nil-strength temperature (NST) for Alloys IN617 and NI263 is included in Table 2. The results of hot-ductility testing during on-heating and on-cooling of Alloys IN617 and NI263 are listed in Tables 3 and 4 and showed in Figures 3 and 4, respectively.

The susceptibility to liquation cracking was evaluated by determining the nil-ductility temperature (NDT), the nil-strength temperature (NST), and the ductility recovery temperature (DRT) as listed in Table 5 and shown in Figure 5. The susceptibility to HAZ liquation cracking was determined by using the zero-ductility temperature range (NDR) criterion. This is defined as the temperature difference between the NST found during the on-heating portion of the simulated weld thermal cycle and the on-cooling DRT, the temperature at which the ductility starts to recover after exposure to the NST.

The NDR for Alloys IN617 and NI263 is about 100 and $314^{\circ} \mathrm{C}$, respectively. These results indicated that Alloy NI263 is highly susceptible to liquation cracking.

Figure 3b shows that Alloy IN617 presented a ductility dip in the temperature range between 1000 and $1100^{\circ} \mathrm{C}$. This indicates that Alloy IN617 is susceptible to DDC during welding. On the other hand, Alloy NI263 did not present any ductility dip. However, as shown in Figure $4 b$, the ductility of the material below $800^{\circ} \mathrm{C}$ is slightly low which made this alloy potentially susceptible to DDC.

\subsubsection{Stress-Relaxation Cracking of IN617 and NI263 Alloys}

The reduction of area at fracture under slow strain-rate high-temperature testing provides an indication of the susceptibility of materials to stress-relaxation cracking. Based on this criterion. an alloy is considered to be susceptible to stress-relaxation cracking if the reduction in area is below $10 \%$, partially susceptible if the reduction of area is between 10 and $20 \%$, and resistant to stress-relaxation cracking if the reduction in area is above $20 \%$ at a particular test temperature.

Since stress-relaxation cracking is most prevalent in the coarse-grained HAZ (CGHAZ), the microstructure of this region was reproduced using a complete simulated welding thermal cycle. The conditions used for the simulation of the HAZ are listed in Table 6. After HAZ simulation the samples were heated to the test temperature and were pulled to fracture under slow strainrate condition as listed in Table 7. For each alloy, slow strain-rate high-temperature tests were run at five different testing temperatures. Standard specimens $6.35 \mathrm{~mm}$ in diameter and 100 $\mathrm{mm}$ long $(0.25 \times 4 \mathrm{in}$.) were used. After that, the transverse reduction in the area of the fracture 
samples was determined, thereby, providing a measure of the susceptibility of the material to stress-relaxation cracking.

The results of slow strain-rate hot-tensile testing of IN617 and NI263 alloy are included in Table 8 and shown in Figures 6 and 7 . There were two test results that showed a very low reduction in area of Alloy NI263 at 670 and $800^{\circ} \mathrm{C}$. However, these two results do not follow the general trend observed in the material in the testing temperature range. Therefore, it was considered that these two data points represented scattering in the alloy behavior that sometimes is observed in thick alloys. The results of slow strain-rate hot-tensile testing of IN617 and NI263 alloy indicate that Alloy IN617 is not susceptible to stress-relaxation cracking. Alloy NI263 seems to be partially susceptible to stress-relaxation above $800^{\circ} \mathrm{C}$ and especially susceptible at $850^{\circ} \mathrm{C}$.

\subsection{Task 2 - Feasibility of Narrow-Groove GTAW Process to Weld IN617-Ni263 Thick- Section Joints}

GTAW produces high-quality welds, but it is considered to be a relatively low productivity process, especially when joining thick-section materials. Narrow-groove welding is an important technique in the manufacture of thick-walled components because it reduces weld joint volume, improves welding times, and reduces weld distortion. However, the nature of the process demands an automated approach and precise control to ensure consistently high weld quality.

One of the most important requirements of narrow-groove welding is to maintain uniform and sufficient fusion at both groove faces. However, the increased weld pool viscosity characteristic of high-nickel alloy can result in poor wetting, and may increase the difficulties of achieving adequate and consistent quality of the welded joints. Additionally, root concavity, surface tension, and root face thickness are important to achieve a high-quality root pass. A high degree of weld metal dilution by the base metals occurs in the root pass and may affect the general weldability characteristics and good quality of the deposited root weld metal.

Additionally, weld bead profile affects the sidewall fusion and characteristics of the root pass. Therefore, the feasibility of applying narrow-groove GTAW to join IN617 to NI263 alloy was evaluated.

Welding was performed using an AMI 415 power supply with a track-mounted M15 NGT weld head. This welding head has a Narrow Groove Rotating Tungsten torch on it. Figures 8 a to -c show a general view of the welding station, the welding system, and the welding head. Both materials (approximately 2 -in, thick) were machined with a modified extended land $V$-groove. The land thickness was held at $0.090 \pm 0.010 \mathrm{in}$. A land extension of $0.090 \pm 0.010 \mathrm{in}$. and a radius of 0.1875 in. were used. The parameter development mockups were small and had a 
joint angle of 2.5 degrees per side. A general view of the narrow-groove joint is shown in Figure 8d.

Different welding trials were conducted to determine welding parameters such as current, voltage, delay time, travel speed, sync pulsing, rotation angle, and groove gap needed to obtain complete penetration of the root pass, as well as a proper weld bead shape in the root and filling passes. Due to the small bevel angle of the narrow groove and to the high degree of angular distortion experience by the small mockups during welding, only partially filled joints were welded during the initial trials. The welding trial samples were evaluated by visual examination using a video display during welding as shown in Figure $8 \mathrm{e}$, penetration and final visual appearance of the root pass after welding as shown in Figure 9, and examination of weld cross sections to determine the presence of lack of fusion (LOF), lack of penetration, or cracking as indicated in Figure 10. As shown in Figure 11, cracking was not observed in either the IN617-side or the NI263-side of the partially-filled joint.

After full-penetration root and fill pass parameters were developed in the small mockups, a complete full-size joint was welded. The welding parameters used to weld this first full-size mockup are listed in Tables 9 and 10. However, in order to fill the complete joint in a bigger mockup; a stronger clamping system, angular presetting of the butt joint, and a joint angle of 4.5 degrees per side instead of 2.5 were used as shown in Figures 12a to -c. Figures $12 \mathrm{~d}$ and -e show a general view of the first full-size joint and the resulting angular distortion.

In general, the welding looked good. Most of the welded joint showed proper root-pass penetration and sufficient fusion at both groove faces. However, after examination of weld macros from the start and stop regions of the joint it was noted that the root did not penetrate completely in some areas of the joint, and that there were several LOF indications as shown in Figures 13 and 14. These LOF were located at about the weld area between vield passes 14 to 18. They were located at both the side wall as well as between beads. The lack of penetration in the root pass was probably due to slight changes in the fixturing and back purging technique made from the small to the big mockup welds. Cracking was not observed in either side of this full-size joint, as shown in Figure 15.

Therefore, in spite of the presence of few weld metal defects, the experimental observations indicate that narrow-groove GTAW is a feasible technique to weld dissimilar metal joints between IN617 and NI263 alloys. However, in order to obtain sound and crack-free joints, optimization of fit-up, joint geometry, welding parameters, and welding sequence is required. However, this goal was not within the scope of this project. 


\subsection{Task 3 - General Characterization of NarroW-Groove GTAW IN617-NI263 Full-Size Welded Joints}

Dissimilar material joints are particularly characterized by compositional gradients and microstructural changes that produce large variations in the chemical, physical, and mechanical properties across the joint. Joining dissimilar materials is, therefore, far more complex than joining similar materials. Specific issues related to the IN617-NI263 joints includes cracking susceptibility of both alloys during welding and aging, effect of base metal dilution on cracking susceptibility and aging response of the resulting weld metal, and the effect of the PWHT aging on the properties of base material and their HAZ.

In order to conduct a general characterization of some mechanical properties of the IN617N1263 joint, a second full-size joint was welded. The welding parameters, especially those applied in areas where defects were observed in the previous full-size joint, root pass, and between passes 14 to 18 , were modified to increase penetration and eliminate the LOF. The welding parameter used for the second full-size joint are listed in Table 11.

Figure 16 shows a general view of the clamping, presetting of the joint, completed joint, and resulting angular distortion. Most of the defects observed in the previous full-size joint were avoided. In one of the evaluated cross section, a LOF was observed in the last cap pass. However, the presence of some defects did not affect the area of interest included in the samples for mechanical testing.

A section of the welded joint was exposed to a two-step PWHT to simulate the aging of the NI263 material and the potential PWHT required if the IN617 alloy were joined to a12Cr steel. A general description of the PWHT applied to this welded joint section is as follows.

- Step 1 - Heat treatment to age the NI263

- Thermocouple was attached to the weldment.

- Weldment was placed in a cold furnace.

- Joint was heated to $800^{\circ} \mathrm{C}\left(1472^{\circ} \mathrm{F}\right)$.

a Joint was held for 8 hours at $800^{\circ} \mathrm{C}\left(1472^{\circ} \mathrm{F}\right)$.

- Joint was removed from the furnace and left to cool to room temperature in still air. 
- Step 2 - Heat treatment of the joint to simulate the PWHT of an IN617 to $12 \mathrm{Cr}$ steel weld joint

- Joint was placed in a cold furnace with the same thermocouple attached.

- Joint was heated to $670^{\circ} \mathrm{C}\left(1238^{\circ} \mathrm{F}\right)$.

- Joint was held at $670^{\circ} \mathrm{C}\left(1238^{\circ} \mathrm{F}\right)$ for 10 hours.

a Joint was removed from the furnace a left to cool to room temperature in still air.

The joint was evaluated in the as-welded condition and after the two-step PWHT. Transwerse tensile test from the root and cap regions, transverse side-bend test, microhardness profiles, and general metallographic examination, were used to evaluate the general metallurgical characteristics and mechanical properties of the joint in each condition. Microhardness profiles across the welded joint were obtained from locations corresponding to the root, mid-thickness, and cap regions of the welded joint. Figure 17 shows the different joint sections in the aswelded and PWHT conditions, and a general view of the tensile and side-bend specimens.

The results of tensile and side-bend tests are listed in Table 12 and included in Appendix A. The tensile specimens in both as-welded and PWHT conditions failed in the IN617 side of the welded joint as shown in Figures 18a and 19a. As a result of the two-step PWHT, the strength of the welded joint increased and its ductility decreased. The average yield and ultimate strength increased from 53.3 and $107.8 \mathrm{ksi}$ to 73.0 and $125.3 \mathrm{ksi}$ ( 368 and $744 \mathrm{MPa}$ to 503 and $864 \mathrm{MPa}$ ), respectively. The average ductility decreases from $47 \%$ elongation to $19.6 \%$.

The overall decrease in ductility of the welded joint with the two-step PWHT is also evident in the result of the side-bend tests. The welded joint in the as-welded condition passed the bend test as shown in Figure 18b. However, the welded joint in the PWHT condition failed the sidebend test as shown in Figure 19b. In the PWHT condition, the side-bend sample showed the presence of cracks in the weld metal in the root region of the joint and the final failure took place in the NI263 base metal as shown in Figure 19b.

The results of the microhardness profile across the joint in the root, mid-thickness, and cap regions in both the as-welded and PWHT conditions are listed in Tables 13 and 14. respectively, shown in Figure 20, and included in Appendix B. In general, a lot of scattering was observed in the microhardness of the welded joint in the as-welded and PWHT conditions. This is expected in aged materials that are strengthened by precipitation and that are PWHT without a previous full solution annealing heat treatment. The thermal cycles imposed by the different welding passes result in different material conditions in the HAZ in the through-thickness direction and therefore produce different aging responses to the PWHT. 
The joint in the as-welded condition presented an over-matching condition of the weld metal and more even microhardness profiles as compared to the PWHT condition. This situation allows a better distribution of the plastic deformation along the entire gage length during tensile testing and can be one of the reasons to explain the higher percent elongation observed in the joint in the as-welded condition. On the other hand, in the PWHT condition, the IN617 side of the joint is well under-matched which resulted in the failure of the joint in this side during tensile testing.

Both the IN617 and NI263 sides of the joint as well as the weld metal responded to the two-step PWHT. In general, the average hardness increase of the IN617 alloy base material and HAZ was about $60 \mathrm{HV}_{05}$. The average increase in hardness of the NI263 alloy base material and $\mathrm{HAZ}$ was about $130 \mathrm{HV}_{05}$. The average increase in hardness of the weld metal in the root, midthickness, and cap regions of the weld metal was 81,67 , and $48 \mathrm{HV}_{0.5}$. The higher increase in hardness in the root region of the weld metal during PWHT may be due to the higher level of weld metal dilution from the base metals during welding. The higher aging response of the root region of the weld metal $\left(81 \mathrm{HV}_{0.5}\right)$ and of the NI263 alloy $\left(130 \mathrm{HV}_{0.5}\right)$ to the applied two-step PWHT helps to explain the presence of cracking and final location of failure in those regions of the side-bend test of the joint in the PWHT condition.

Figure 21 shows a cross section of the welded joint in the as-welded condition and the microstructure characteristic of the HAZ in both the IN617 and NI263 sides of the joint. Cracking was not observed in either side of the joint as shown in Figures $21 \mathrm{~b}$ to $-e$. Laminar segregation in the N1263 alloy base metal and preferential etching of the grain boundaries in the $\mathrm{HAZ}$ of the IN263 alloy was observed as shown in Figure 22. The preferential etching of the grain boundaries in the HAZ of the NI263 alloy may be caused by the precipitation of carbides or second phases at the grain boundaries or adjacent areas.

Figures 23 and 24 show the microstructure characteristic of the HAZ in both the IN617 and NI263 sides of the welded joint in the PWHT condition. There were not major microstructural changes, as observed with light microscopy, induced by the two-step PWHT in the HAZ or base material of either IN617 or NI263 alloys. As shown in Figure 24e, the areas of laminar segregation observed in the NI263 alloy correspond to band regions with smaller grain size.

Cracking was not observed in either of the two sides of the welded joint in the PWHT condition. Therefore, in spite of the susceptibility of NI263 alloy to HAZ liquation cracking and of IN617 to DDC cracking as determined by the Gleeble testing, the narrow-groove GTAW NI263-IN617 welded joint did not experienced cracking during welding or PWHT. 
The overall weldability of a welded joint depends not only on the material behavior but on the joint design and welding procedure as well. Depending on the material susceptibility to a given cracking mechanism, the size of the operational window of joint design and welding procedure to produce crack-free joints will change accordingly. A higher material susceptibility to cracking will result in a smaller operational window of joint design and welding procedure to produce sounds joints. The normal welding approach to address this problem is control of the heat input, deposition techniques, and residual stresses.

Therefore, the experimental observations indicate that the use of the narrow-groove GTAW technique help to produce crack-free NI263-IN617 joints due to the fewer amount of thermal cycles imposed in the welded joint, lower volume of deposited weld metal, and lower resulting residual stresses.

\subsection{Conclusions and Recommendations}

- The NDR for Alloys IN617 and NI263 is about 100 and $314^{\circ} \mathrm{C}$, respectively. These results indicate that Alloy NI263 is highly susceptible to liquation cracking. Alloy IN617 presents a ductility dip in the temperature range between 1000 and $1100^{\circ} \mathrm{C}$ which indicates that Alloy IN617 is susceptible to DDC during welding. Alloys IN617 and NI263 are not susceptible to stress-relaxation cracking in the test temperature range between 600 and $850^{\circ} \mathrm{C}$.

- In spite of the presence of few weld metal defects, the experimental observations indicate that narrow-groove GTAW is a feasible technique to weld thick dissimilar metal joints between IN617 and NI263 alloys. However, in order to consistently obtain sound and crackfree joints, optimization of fit-up, joint geometry, welding parameters, and welding sequence is recommended.

- The tensile specimens in both as-welded and PWHT conditions failed in the IN617 side of the welded joint. As a result of the two-step PWHT, the strength of the welded joint increased and its ductility decreased. The average yield and ultimate strength increased from 53.3 and $107 \mathrm{ksi}$ to 73.0 and $125.3 \mathrm{ksi}$ ( 368 and $744 \mathrm{MPa}$ to 503 and $864 \mathrm{MPa}$ ). respectively. The average ductility decreases from $47 \%$ elongation to $19.6 \%$.

- The welded joint in the as-welded condition passed the side-bend test. However, due to the overall decrease in ductility of the welded joint induced by the two-step PWHT, the welded joint in the PWHT condition failed the side-bend test. In the PWHT condition, the side-bend sample showed cracks in the root region of the weld metal and the final failure took place in the NI263 base metal. 
- Evaluation of the effect of each one of the two steps ( 8 hours at $800^{\circ} \mathrm{C}$ and 10 hours at $670^{\circ} \mathrm{C}$ ) of the applied PWHT on the strength and ductility of the joint is recommended.

- In general, a lot of scattering was observed in the microhardness of the welded joint in the as-welded and PWHT conditions. The joint in the as-welded condition presented an overmatching condition of the weld metal. In the PWHT condition, the IN617 side of the joint presented a higher degree of under-matching.

- The IN617 and NI263 sides of the joint as well as the weld metal responded to the two-step PWHT. In general, the average hardness increase of the IN617 alloy base material and $\mathrm{HAZ}$ was about $60 \mathrm{HV}_{05}$. The average increase in hardness of the NI263 alloy base material and $\mathrm{HAZ}$ was about $130 \mathrm{HV}_{0.5}$. The average increase in hardness of the weld metal in the root, mid-thickness, and cap regions of the weld metal was 81,67 , and $48 \mathrm{HV}_{0.5}$.

- The narrow-groove GTAW NI263-IN617 welded joint did not experienced cracking during welding or the two-step PWHT. These experimental observations indicate that the use of the narrow-groove GTAW technique helped to produce crack-free thick NI263-IN617 joints. This behavior may be due to the fewer amount of thermal cycles imposed in the welded joint, lower volume of deposited weld metal, and lower resulting residual stresses. 
Table 1. Conditions of Gleeble Hot-Ductility Testing

\begin{tabular}{|l|l|}
\hline \multicolumn{1}{|c|}{ Parameter } & \multicolumn{1}{c|}{ On-Heating Description } \\
\hline Test temperature & $\begin{array}{l}600^{\circ} \mathrm{C} \text { and higher }\left(1112^{\circ} \mathrm{F} \text { and }\right. \\
\text { higher) }\end{array}$ \\
\hline Heating rate to test temperature & $111^{\circ} \mathrm{C} / \mathrm{s}\left(200^{\circ} \mathrm{F} / \mathrm{s}\right)$ \\
\hline Holding time at test temperature & $0.03 \mathrm{~s}$ \\
\hline Stroke rate & $5 \mathrm{~cm} / \mathrm{s}(2 \mathrm{in} / \mathrm{s})$ \\
\hline Sample-free span (jaw spacing) & $19 \mathrm{~mm}(0.75 \mathrm{in})$. \\
\hline Atmosphere & Argon \\
\hline \multicolumn{2}{|c|}{ NST Determination } \\
\hline Load & $\begin{array}{l}\text { Just enough to overcome frictional } \\
\text { force }[\approx 20 \mathrm{~kg}(45 \mathrm{lb})]\end{array}$ \\
\hline Number of samples & 3 \\
\hline \multicolumn{2}{|c|}{ On-Cooling } \\
\hline Peak temperature & $1300\left[\mathrm{NST}-\left(10-15^{\circ} \mathrm{C}\right)\right]$ \\
\hline Heating rate to peak temperature & $111^{\circ} \mathrm{C} / \mathrm{s}\left(200^{\circ} \mathrm{F} / \mathrm{s}\right)$ \\
\hline Holding time at peak temperature & $0.03 \mathrm{~s}$ \\
\hline Cooling rate to test temperature & $40^{\circ} \mathrm{C} / \mathrm{s}\left(72^{\circ} \mathrm{F} / \mathrm{s}\right)$ \\
\hline Holding time at test temperature & $0.03 \mathrm{~s}$ \\
\hline Stroke rate & $5 \mathrm{~cm} / \mathrm{s}(2 \mathrm{in} / \mathrm{s})$ \\
\hline Sample-free span (jaw spacing) & $19 \mathrm{~mm}(0.75 \mathrm{in})$ \\
\hline Atmosphere & Argon \\
\hline
\end{tabular}

Table 2. NST of the NI617 and IN263 Alloys

\begin{tabular}{|l|c|c|c|}
\hline Alloy & Specimen & NST $\left({ }^{\circ} \mathrm{C}\right)$ & Average NST $\left({ }^{\circ} \mathrm{C}\right)$ \\
\hline \multirow{3}{*}{ IN617 } & 1 & 1290.2 & \\
\cline { 2 - 3 } & 2 & 1322 & \multirow{2}{*}{1311} \\
\cline { 2 - 3 } & 3 & 1321 & \\
\hline \multirow{3}{*}{ I263 } & 1 & 1314 & \multirow{2}{*}{1314} \\
\cline { 2 - 3 } & 2 & 1313 & \\
\cline { 2 - 3 } & 3 & 1316 & \\
\hline
\end{tabular}


Table 3. Results of Hot-Ductility Testing during On-Heating and On-Cooling of IN617 Alloy

\begin{tabular}{|c|c|c|c|c|c|c|}
\hline \multicolumn{2}{|c|}{ Specimen } & \multicolumn{2}{|c|}{$\begin{array}{c}\text { Temperature } \\
\left({ }^{\circ} \mathrm{C}\right)\end{array}$} & \multirow{2}{*}{$\begin{array}{l}\text { RA } \\
(\%)\end{array}$} & \multirow{2}{*}{$\begin{array}{c}\text { Fracture } \\
\text { Load } \\
\text { (lb) }\end{array}$} & \multirow{2}{*}{$\begin{array}{l}\text { Fracture } \\
\text { Strength } \\
\text { (ksi) }\end{array}$} \\
\hline Number & ID & Peak & Test & & & \\
\hline $\mathrm{HT}-1^{(\mathrm{D})}$ & IN-H1250 &.- & 1253 & 0.0 & 692 & 14.1 \\
\hline HT-2 & $\mathrm{IN}-\mathrm{H} 1200$ & -. & 1202 & 67.2 & 1370 & 27.9 \\
\hline HT-3 & $1 \mathrm{~N}-\mathrm{H} 1100$ & $\ldots$ & 1102 & 78.4 & 2049 & 41.7 \\
\hline HT-4 & IN-H9OO & 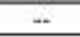 & 902 & 60.7 & 3065 & 62.4 \\
\hline HT-5 & IN-H600 & -- & 604 & 57.1 & 3915 & 79.8 \\
\hline $\mathrm{HT}-6$ & IN-H1225 & - & 1228 & 45.7 & 1475 & 30.0 \\
\hline HT-7 & IN-H1240 & $m$ & 1242 & 5.2 & 1276 & 26.0 \\
\hline HT-8 & IN-H800 & $*$ & 802 & 63.9 & 3399 & 69.2 \\
\hline NST-1 & NST-1 & - & 1290 & $\ldots$ & - & - \\
\hline NST-2 & NST-2 & -- & 1322 & - & - & - \\
\hline NST-3 & NST-3 & -- & 1321 & - & - & - \\
\hline$C T-1^{(b)}$ & IN-C1200 & 1301 & 1199 & 10.2 & 1501 & 30.6 \\
\hline CT-2 & IN-C1100 & 1300 & 1099 & 6.4 & 1523 & 31.0 \\
\hline CT-3 & IN-C1000 & 1300 & 999 & 11.5 & 1636 & 33.3 \\
\hline CT-4 & IN-C900 & 1301 & 898 & 49.7 & 3286 & 66.9 \\
\hline CT-5 & IN-C800 & 1300 & 798 & 35.9 & 2961 & 60.3 \\
\hline CT-6 & IN-C950 & 1300 & 948 & 36.9 & 2992 & 61.0 \\
\hline CT-7 & IN-C700 & 1299 & 707 & 15.3 & 1710 & 34.8 \\
\hline CT-8 & IN-C1225 & 1300 & 1224 & 1,0 & 967 & 19.7 \\
\hline CT-9 & IN-C1150 & 1300 & 1149 & 595 & 1907 & 38.8 \\
\hline CT-10 & IN-C975 & 1300 & 972 & 24.3 & 2684 & 54.7 \\
\hline CT-11 & IN-CS00 & 1300 & 628 & 26.8 & 3055 & 62.2 \\
\hline CT-12 & IN-C1175 & 1300 & 1173 & 35.1 & 1582 & 32.2 \\
\hline CT -13 & IN-C1125 & 1300 & 1122 & 37.5 & 1944 & 39.6 \\
\hline
\end{tabular}

(a) $\mathrm{H}$ : On-heating test specimens; $\mathrm{T}$ : test temperature

(b) C: On-cooling test temperature; $\mathrm{T}$ : test temperature 
Table 4. Results of Hot-Ductility Testing during On-Heating and On-Cooling of NI263 Alloy

\begin{tabular}{|c|c|c|c|c|c|c|}
\hline \multicolumn{2}{|c|}{ Specimen } & \multicolumn{2}{|c|}{$\begin{array}{c}\text { Temperature } \\
\text { ( }\end{array}$} & \multirow{2}{*}{$\begin{array}{l}\text { RA } \\
(\%)\end{array}$} & \multirow{2}{*}{$\begin{array}{l}\text { Fracture } \\
\text { Load } \\
\text { (lb) }\end{array}$} & \multirow{2}{*}{$\begin{array}{l}\text { Fracture } \\
\text { Strength } \\
\text { (ksi) }\end{array}$} \\
\hline Number & ID & Peak & Test & & & \\
\hline$H T-1^{(0)}$ & $\mathrm{NI}-\mathrm{H} 1250$ & -- & 1252 & 22.6 & 989 & 20.1 \\
\hline HT-2 & $\mathrm{NI}-\mathrm{H} 1200$ & -. & 1202 & 91.4 & 1327 & 27,0 \\
\hline HT-3 & NI-H1100 & . & 1102 & 89.3 & 1971 & 40.1 \\
\hline HT-4 & NI-H900 & - & 902 & 65.6 & 3438 & 70.0 \\
\hline HT-5 & NI-H60O & -- & 601 & 54.7 & 4427 & 90.2 \\
\hline $\mathrm{HT}-6$ & $\mathrm{NI}-\mathrm{H} 1275$ & - & 1277 & 0.0 & 623 & 127 \\
\hline HT-7 & NI-H1265 & .. & 1267 & 0.2 & 569 & 11.6 \\
\hline HT-8 & NI-H800 & . & 802 & 59.8 & 3891 & 79.3 \\
\hline NST-1 & NST-1 & -- & 1314 & - & - & - \\
\hline NST-2 & NST-2 & -- & 1313 & - & - & - \\
\hline NST-3 & NST-3 & -- & 1316 & - & - & - \\
\hline$C T-1^{(b)}$ & $\mathrm{Nl}-\mathrm{C} 1200$ & 1299 & 1198 & 0.0 & 757 & 15.4 \\
\hline CT-2 & NI-C1100 & 1300 & 1097 & 3.4 & 1541 & 31.4 \\
\hline CT -3 & NI-C1000 & 1300 & 999 & 2.0 & 1154 & 23.5 \\
\hline CT-4 & NI-C900 & 1300 & 898 & 25.0 & 3111 & 63.4 \\
\hline CT-5 & NI-C800 & 1300 & 798 & 3.2 & 984 & 20.0 \\
\hline CT-6 & NI-C950 & 1301 & 947 & 24.7 & 2563 & 52.2 \\
\hline CT-7 & NI-C800-2 & 1299 & 798 & 18.2 & 1738 & 35.4 \\
\hline$\overline{C T-B}$ & NI-C700-2 & 1300 & 705 & 9.2 & 1865 & 38.0 \\
\hline CT-9 & NI-C975 & 1299 & 973 & 119 & 2027 & 413 \\
\hline CT-10 & NI-C850 & 1299 & 843 & 11.7 & 2115 & 43.1 \\
\hline CT-11 & NI-C850-2 & 1300 & 848 & 22.0 & 3124 & 63.6 \\
\hline CT-12 & NI-C700-3 & 1301 & 703 & 577 & 3892 & 79.3 \\
\hline $\mathrm{CT}-13$ & NI.C600 & 1299 & 627 & 9.4 & 2080 & 42.4 \\
\hline
\end{tabular}

(a) $\mathrm{H}$ : On-heating test specimens; $\mathrm{T}$ : Test temperature

(b) C: On-cooling test temperature; $\mathrm{T}$ : Test temperature 
Table 5. NDT, NST, and DRT Temperatures of IN617 and NI263 Alloys

\begin{tabular}{|r|l|l|l|l|}
\hline Alloy & NDT $\left({ }^{\circ} \mathrm{C}\right)$ & NST $\left({ }^{\circ} \mathrm{C}\right)$ & DRT $\left({ }^{\circ} \mathrm{C}\right)$ & NDR $\left({ }^{\circ} \mathrm{C}\right)$ \\
\hline IN617 & 1250 & 311 & $1200-1225$ & $86-111$ \\
\hline N1263 & 1265 & 1314 & 1000 & 314 \\
\hline
\end{tabular}

Table 6. Condition for HAZ Simulation

\begin{tabular}{|l|l|}
\hline \multicolumn{1}{|c|}{ Parameter } & \multicolumn{1}{c|}{ Description } \\
\hline Peak temperature & $1290\left[\mathrm{NST}-\left(25\right.\right.$ to $\left.\left.50^{\circ} \mathrm{C}\right)\right]$ \\
\hline Heating rate to peak temperature & $111^{\circ} \mathrm{C} / \mathrm{s}\left(200^{\circ} \mathrm{F} / \mathrm{s}\right)$ \\
\hline Holding time at peak temperature & $0.03 \mathrm{~s}$ \\
\hline Cooling rate to room temperature & $40^{\circ} \mathrm{C} / \mathrm{s}\left(72^{\circ} \mathrm{F} / \mathrm{s}\right)$ \\
\hline Atmosphere & Argon \\
\hline
\end{tabular}

Table 7. Condition for High-Temperature Tensile Tests

\begin{tabular}{|l|l|}
\hline \multicolumn{1}{|c|}{ Parameter } & \multicolumn{1}{c|}{ Description } \\
\hline Test temperature $\left({ }^{\circ} \mathrm{C}\right)$ & $600,670,740,800,850$ \\
\hline Heating rate to test temperature & $50^{\circ} \mathrm{C} / \mathrm{s}\left(90^{\circ} \mathrm{F} / \mathrm{s}\right)$ \\
\hline Time allowed for thermal stabilization & $30 \mathrm{~s}$ \\
\hline Holding time at testing temperature & $0 \mathrm{~s}$ \\
\hline Applied load & To fracture \\
\hline Stroke rate & $0.00127 \mathrm{~cm} / \mathrm{s}(0.0005 \mathrm{in} / \mathrm{s})$ \\
\hline Sample free span (jaw spacing) & $19 \mathrm{~mm}(0.75 \mathrm{in})$. \\
\hline Atmosphere & Argon \\
\hline
\end{tabular}


Table 8. Results of Hot-Tensile Testing of IN617 and N1263 Alloys

\begin{tabular}{|c|c|c|c|c|c|}
\hline \multirow[b]{2}{*}{ Specimen ID } & \multicolumn{2}{|c|}{ Temperature $\left({ }^{\circ} \mathrm{C}\right)$} & \multirow{2}{*}{$\begin{array}{c}\text { Reduction of } \\
\text { Area (\%) }\end{array}$} & \multirow{2}{*}{$\begin{array}{l}\text { UT Load } \\
\text { (lb) }\end{array}$} & \multirow{2}{*}{$\begin{array}{l}\text { UTS } \\
\text { (ksi) }\end{array}$} \\
\hline & Peak & Test & & & \\
\hline \multicolumn{6}{|c|}{ IN617 Alloy } \\
\hline IN-HTT 600 & 1291 & 600 & 40.2 & 2790 & 56.8 \\
\hline IN-HTT $670-1$ & 1291 & 670 & 28.0 & 2348 & 47.8 \\
\hline IN-HTT $670-2$ & 1291 & 670 & 43.1 & 3336 & 68.0 \\
\hline IN-HTT740 & 1290 & 740 & 515 & 3470 & 70.7 \\
\hline IN-HTT 800 & 1290 & 800 & 648 & 2604 & 530 \\
\hline IN-HTT 850 & 1291 & 850 & 758 & 2084 & 424 \\
\hline \multicolumn{6}{|c|}{ N1263 Alloy } \\
\hline IN-HTT600-2 & 1290 & 600 & 30.3 & 4758 & 97.0 \\
\hline IN-HTT670-2 & 1290 & 670 & 30 & 1031 & 21.0 \\
\hline IN-HTT $670-3$ & 1290 & 670 & 33.3 & 4137 & 843 \\
\hline IN-HTT740 & 1290 & 740 & 29.7 & 4059 & 827 \\
\hline IN-HTT800-1 & 1290 & 800 & 0.2 & 919 & 18.7 \\
\hline IN-HTTBOD-2 & 1291 & 800 & 166 & 2650 & 540 \\
\hline IN-HTT $850-1$ & 1289 & 850 & 4.0 & 1608 & 328 \\
\hline IN-HTT $850-2$ & 1291 & 850 & 4.4 & 1142 & 23.3 \\
\hline
\end{tabular}

Table 9. Basic Welding Parameters

\begin{tabular}{|l|l|}
\hline \multicolumn{1}{|c|}{ Parameter } & \multicolumn{1}{|c|}{ Description } \\
\hline Shielding gas/backing gas & $75 \mathrm{Ar}-25 \mathrm{He} ; 50 \mathrm{CFH} / \mathrm{Ar}, 2 \mathrm{CFH}$ \\
\hline Pre-purge (s) & 5.0 \\
\hline Upslope time (s) & 2.5 \\
\hline AVC start delay (s) & 2.7 \\
\hline Wirefeed start delay (s) & 2.7 \\
\hline Travel start delay (s) & 5.2 \\
\hline & \\
\hline Postpurge (s) & 10 \\
\hline Downslope (s) & 5.0 \\
\hline AVC stop delay (s) & 1.0 \\
\hline Wirefeed stop delay (s) & 0.0 \\
\hline Travel stop delay (s) & 0.1 \\
\hline & \\
\hline Start level (A) & 50 \\
\hline Num starts & n/a \\
\hline Level advance & Manual \\
\hline Start mode & Touch \\
\hline AVC response (\%) & 15 \\
\hline AVC deadband (V) & n/a \\
\hline Wirefeed retract (in.) & 0.500 \\
\hline
\end{tabular}


Table 10. Welding Parameter used for Welding Full-Size Joint 1

\begin{tabular}{|c|c|c|c|c|c|c|}
\hline \multirow[b]{2}{*}{ Parameter } & \multicolumn{6}{|c|}{ Weld Pass } \\
\hline & $\operatorname{Root}^{(3)}$ & $2^{[b]}$ & $\begin{array}{c}3 \text { and } 4 \\
R / F^{(\tau)}\end{array}$ & $\begin{array}{c}5-20 \\
R / F / C^{\text {(d)(Ne) }}\end{array}$ & $\begin{array}{l}21-22 \\
F / R^{(1)}\end{array}$ & $\begin{array}{c}23-30 \\
F / R / C^{(910)}\end{array}$ \\
\hline Primary (A) & 160 & 180 & 180 & 210 & 240 & 240 \\
\hline Background (A) & 100 & 120 & 180 & 210 & 240 & 240 \\
\hline Primary AVC (V) & 9.2 & 95 & 9,3 & 9,3 & 93 & 93 \\
\hline Primary wirefeed (ipm) & 15 & 50 & 60 & 65 & 65 & 65 \\
\hline $\begin{array}{l}\text { Background wirefeed } \\
\text { (ipm) }\end{array}$ & 15 & 40 & 60 & 65 & 65 & 65 \\
\hline Travel (ipm) & 4.0 & 4.0 & 4.0 & 4.0 & 4.0 & 4.0 \\
\hline Primary pulse (s) & 0.10 & 0.15 & $\mathrm{n} / \mathrm{a}$ & naa & $n / a$ & na \\
\hline Background pulse (5) & 010 & 0.12 & na & nia & $n / a$ & ria \\
\hline $\begin{array}{l}\text { Osc. amplitude } \\
\text { (degrees) }\end{array}$ & 0 & 30 & 0 & 0 & 0 & 20 \\
\hline Osc in dwell time (s) & 0 & 015 & 0 & D & 0 & 15 \\
\hline Osc. excursion time (s) & 0 & 0.12 & 0 & 0 & 0 & 0.12 \\
\hline Osc. out dwell time (s) & 0 & 0.15 & 0 & 0 & 0 & 0.15 \\
\hline Pulse mode & On & Sync & $\mathrm{OA}$ & $\mathrm{Off}$ & Off & Off \\
\hline AVC mode & Pri & Pri & Pri & Pri & Pri & Pri \\
\hline
\end{tabular}
(a) Root pass welded well but did not produce a complete penetration.
(b) Ran OK, slightly convex, pass was at center.
(c) Passes run OK, slightly sluggish, left a substantial " $V$ " at center of groove
(d) Passes 15 and 20 was at center to slightly outside.
(e) Defects found between passes 15 and 18
(f) There was a pronounce ' $V$ ' at center of groove.
(g) Pass 23 welded at center with oscillation.
(h) Location of passes: F: front; $R$ : rear; $C$ : center 
Table 11. Welding Parameters used for Welding of Full-Size Joint 2

\begin{tabular}{|c|c|c|c|c|c|}
\hline \multirow[b]{2}{*}{ Parameter } & \multicolumn{5}{|c|}{ Weld Pass } \\
\hline & $\operatorname{Root}^{(3)}$ & $2^{[b]}$ & $\begin{array}{c}3 \text { and } 4 \\
R / F^{[\epsilon]}\end{array}$ & $\begin{array}{c}5 \\
c^{(6)}\end{array}$ & $\begin{array}{c}\text { 6-32 } \\
R / F / C^{(0) 11 !}\end{array}$ \\
\hline Primary (A) & 180 & 180 & 180 & 210 & 240 \\
\hline Background (A) & 115 & 120 & 180 & 210 & 240 \\
\hline Primary AVC (V) & 9.3 & 95 & 93 & 9.3 & 94 \\
\hline $\begin{array}{l}\text { Primary wirefeed } \\
\text { (ipm) }\end{array}$ & 15 & 50 & 60 & 65 & 70 \\
\hline $\begin{array}{l}\text { Background } \\
\text { wirefeed (ipm) }\end{array}$ & 15 & 40 & 60 & 65 & 70 \\
\hline Travel (ipm) & 4.0 & 40 & 4.0 & 4.0 & 40 \\
\hline Primary pulse (s) & 0.10 & 0.15 & nda & na & nfa \\
\hline $\begin{array}{l}\text { Background } \\
\text { pulse (s) }\end{array}$ & 0.10 & 0.12 & $\mathrm{n} / \mathrm{a}$ & $n / a$ & $n / a$ \\
\hline $\begin{array}{l}\text { Osc. amplitude } \\
\text { (degrees) }\end{array}$ & 0 & 30 & 0 & 0 & 0 \\
\hline $\begin{array}{l}\text { Osc. in dwell time } \\
\text { (s) }\end{array}$ & 0 & 0.15 & 0 & 0 & 0 \\
\hline $\begin{array}{l}\text { Osc. excursion } \\
\text { time (s) }\end{array}$ & 0 & 0.12 & 0 & 0 & 0 \\
\hline $\begin{array}{l}\text { Osc. out dwell } \\
\text { time (s) }\end{array}$ & 0 & 0.15 & $\overline{0}$ & D & 0 \\
\hline Pulse mode & On & Sync & Off & Off & Off \\
\hline AVC mode & $\mathrm{Pri}$ & Pri & $\mathrm{Pri}$ & Pri & $\mathrm{Pti}$ \\
\hline
\end{tabular}

(a) Run ok, full penetration, oxidized due to poor shielding

(b) Run ok, slightly convex surface, pass was at center

(c) Passes run ok, left a " $V^{\prime}$ at center of groove

(d) Weilded ok

(e) Welded ok, alternated between front and rear, Pass 31 at center

(f) Location of passes: F: front; R: rear; C: center 

Table 12. Tensile and Side-Bend Test Results from IN617-NI263 Full-Size Welded
Joint

\begin{tabular}{|c|c|c|c|c|c|}
\hline \multirow[b]{2}{*}{ Condition } & \multirow[b]{2}{*}{ Test } & \multicolumn{4}{|c|}{ Transverse Tensile Properties } \\
\hline & & $\begin{array}{l}\text { Yield Strength } \\
\text { ksi (MPa) }\end{array}$ & $\begin{array}{l}\text { Uitimate Strength } \\
\text { ksi (MPa) }\end{array}$ & $\begin{array}{c}\text { Percent } \\
\text { Elongation }\end{array}$ & $\begin{array}{l}\text { Location of } \\
\text { Failure }\end{array}$ \\
\hline \multirow[t]{2}{*}{ As-welded } & Root & $53.2(367)$ & $108.0(745)$ & 46.7 & IN617 \\
\hline & Cap & $53.5(369)$ & $107.7(743)$ & 473 & IN617 \\
\hline \multirow[t]{2}{*}{ Heat-treated } & Root & $72.0(497)$ & $121.4(837)$ & 162 & IN617 \\
\hline & Cap & $74.0(510)$ & $129.2(891)$ & 23.0 & IN617 \\
\hline \multicolumn{6}{|c|}{ Transverse Side Bend Test } \\
\hline As-welded & 1 & \multicolumn{3}{|c|}{ Pass } & \\
\hline Heat-treated & 1 & \multicolumn{3}{|c|}{ Fail } & Weld/N/263 \\
\hline
\end{tabular}


Table 13. Microhardness $\left(\mathrm{HV}_{0.5}\right)$ Across the IN617-NI263 Welded Joint in the AsWelded Condition

\begin{tabular}{|c|c|c|c|c|c|}
\hline \multirow{2}{*}{ Reading } & \multicolumn{2}{|c|}{ Distance from the WCL (mm) } & \multicolumn{3}{|c|}{ Hardness (HV $\mathbf{H}_{\mathbf{5}}$ ) } \\
\cline { 2 - 6 } & Root & MT/Cap & Root & Mid-Thickness & $\begin{array}{c}\text { Ca } \\
\mathbf{p}\end{array}$ \\
\hline 1 & -24.5 & -26.5 & 215 & 179 & 207 \\
\hline 2 & -14.5 & -16.5 & 243 & 201 & 201 \\
\hline 3 & -9.5 & -11.5 & 224 & 227 & 234 \\
\hline 4 & -8.5 & -10.5 & 236 & 252 & 236 \\
\hline 5 & -8.0 & -10.0 & 251 & 245 & 223 \\
\hline 6 & -7.5 & -9.5 & 255 & 248 & 230 \\
\hline 7 & -7.0 & -9.0 & 244 & 256 & 236 \\
\hline 8 & -6.5 & -8.5 & 231 & 240 & 245 \\
\hline 9 & -6.0 & -8.0 & 232 & 259 & 253 \\
\hline 10 & -5.5 & -7.5 & 234 & 251 & 230 \\
\hline 11 & -5.0 & -7.0 & 264 & 244 & 223 \\
\hline 12 & $-4.0($ WM) & $-6.0(\mathrm{WM})$ & 234 & 224 & 222 \\
\hline 13 & $0.0(\mathrm{WM})$ & $0.0(\mathrm{WM})$ & 245 & 252 & 234 \\
\hline 14 & $4.0(\mathrm{WM})$ & $6.0(\mathrm{WM})$ & 244 & 228 & 236 \\
\hline 15 & 5.0 & 7.0 & 253 & 234 & 227 \\
\hline 16 & 6.0 & 8.0 & 226 & 222 & 222 \\
\hline 17 & 7.0 & 9.0 & 228 & 230 & 233 \\
\hline 18 & 9.0 & 11.0 & 219 & 211 & 203 \\
\hline 19 & 14.0 & 16.0 & 191 & 191 & 191 \\
\hline 20 & 24.0 & 26.0 & 201 & 173 & 192 \\
\hline
\end{tabular}


Table 14. Microhardness $\left(\mathrm{HV}_{0.5}\right)$ Across the IN617-NI263 Welded Joint in the HeatTreated Condition

\begin{tabular}{|c|c|c|c|c|c|}
\hline \multirow[b]{2}{*}{ Reading } & \multicolumn{2}{|c|}{ Distance from the WCL (mm) } & \multicolumn{3}{|c|}{ Hardness $\left(\mathrm{HV}_{0.5}\right)$} \\
\hline & Root & MT/Cap & Root & Mid-Thickness & $\begin{array}{c}\mathrm{Ca} \\
\mathrm{p}\end{array}$ \\
\hline 1 & -26.0 & $-26.5 ;-26.0$ & 336 & 307 & 346 \\
\hline 2 & -16.0 & -16.5 & 322 & 274 & 332 \\
\hline 3 & -11.0 & -11.5 & 328 & 326 & 385 \\
\hline 4 & -10.0 & -10.5 & 320 & 316 & 322 \\
\hline 5 & -9.5 & -10.0 & 326 & 371 & 345 \\
\hline 6 & -90 & -9.5 & 371 & 350 & 350 \\
\hline 7 & 8.5 & -9.0 & 346 & 328 & 353 \\
\hline 8 & -8.0 & -8.5 & 355 & 350 & 334 \\
\hline 9 & -7.5 & -8.0 & 344 & 364 & 342 \\
\hline 10 & -7.0 & -7.5 & 357 & 348 & 364 \\
\hline 11 & -6.5 & -7.0 & 364 & 336 & 324 \\
\hline 12 & -5.5 (WM) & .6 .0 (WM) & 340 & 313 & 270 \\
\hline 13 & $0.0(\mathrm{WM})$ & 0.0 (WM) & 326 & 297 & 257 \\
\hline 14 & $5.5(\mathrm{WM})$ & 6.0 (WM) & 300 & 295 & 307 \\
\hline 15 & 6.5 & $75,7.0$ & 309 & 304 & 284 \\
\hline 16 & 7.5 & $85: 80$ & 298 & 288 & 276 \\
\hline 17 & 8.5 & $95: 9.0$ & 263 & 287 & 287 \\
\hline 18 & 10.5 & $11.5,11.0$ & 260 & 260 & 279 \\
\hline 19 & 15.5 & $165,16.0$ & 253 & 249 & 256 \\
\hline 20 & 23.5 & $24.5,25.0$ & 261 & 227 & 261 \\
\hline
\end{tabular}




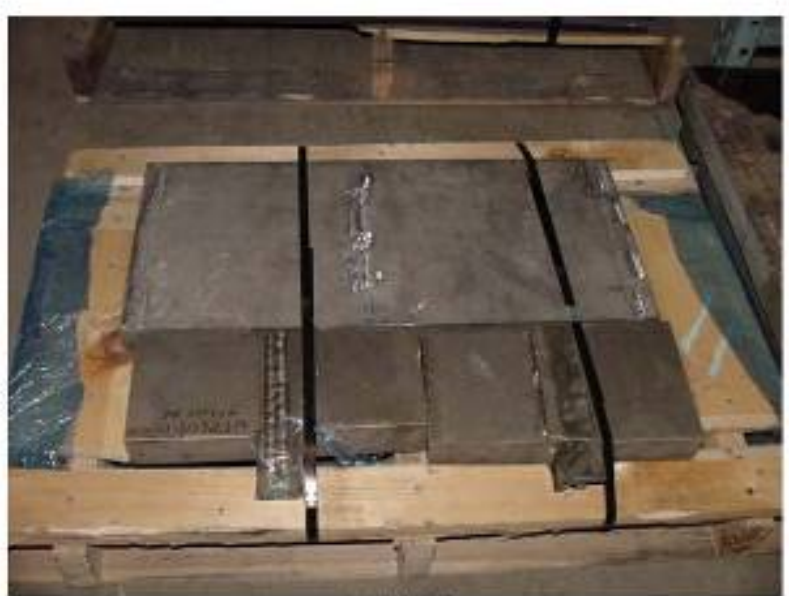

(a) IN617

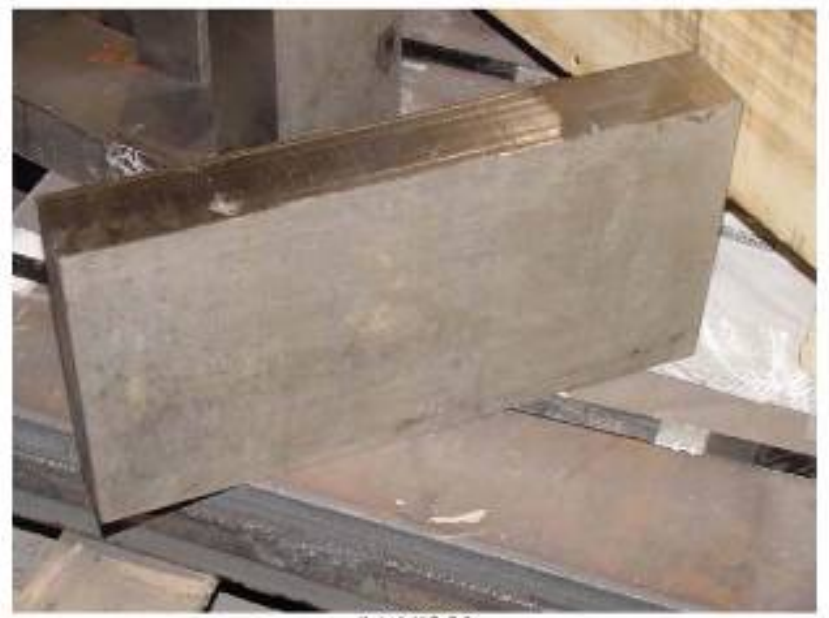

(b) N1263

Figure 1. General View of Plate Sections of Alloys Provided by ALSTOM 


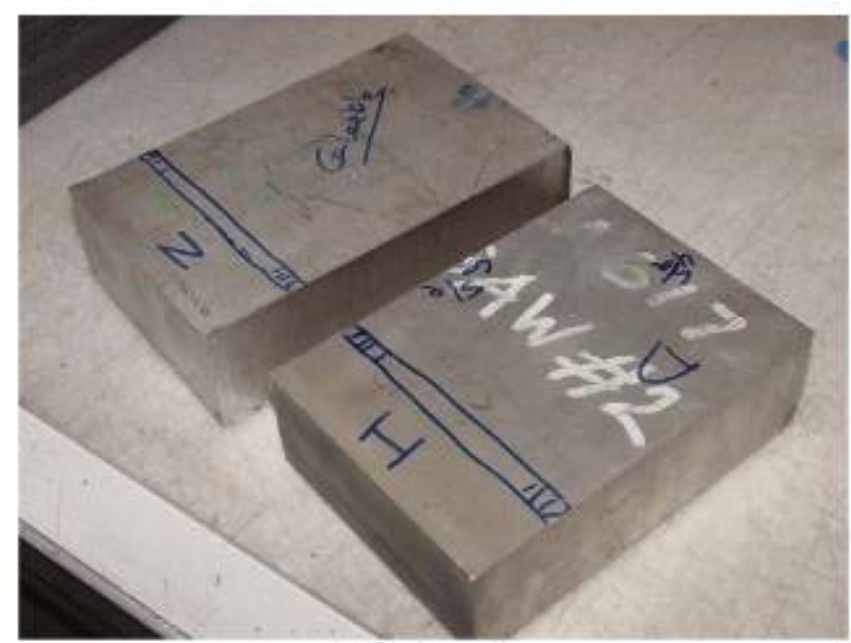

(a) Plate section

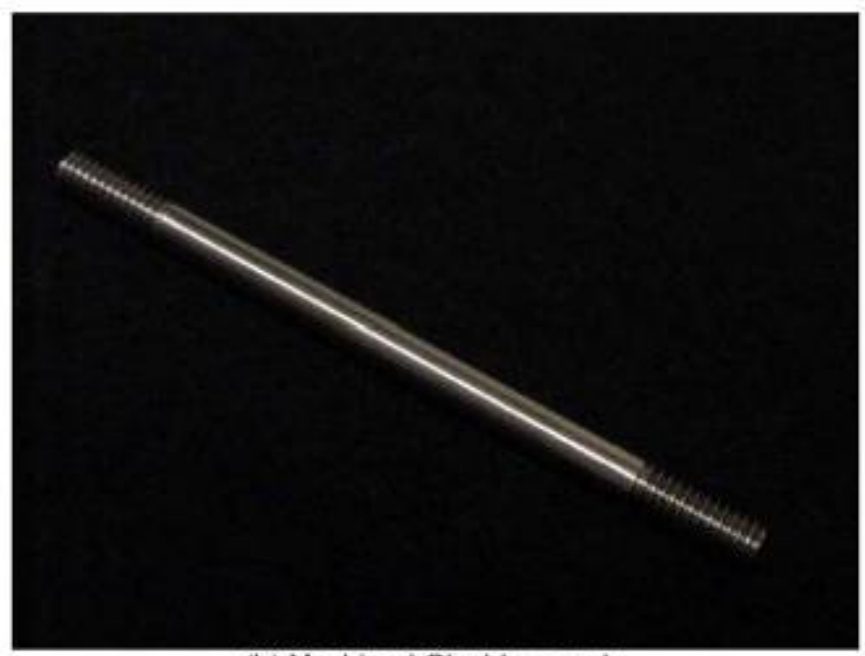

(b) Machined Gleeble sample

Figure 2. General View of Gleeble Samples 


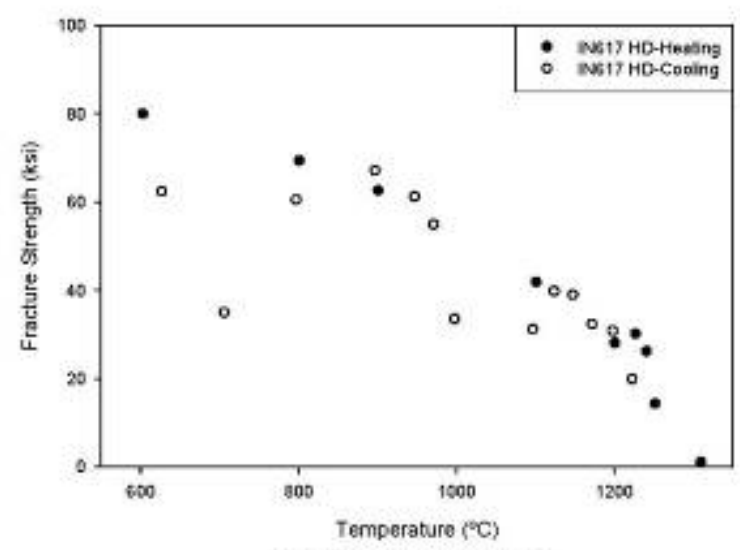

(a) Fracture strength

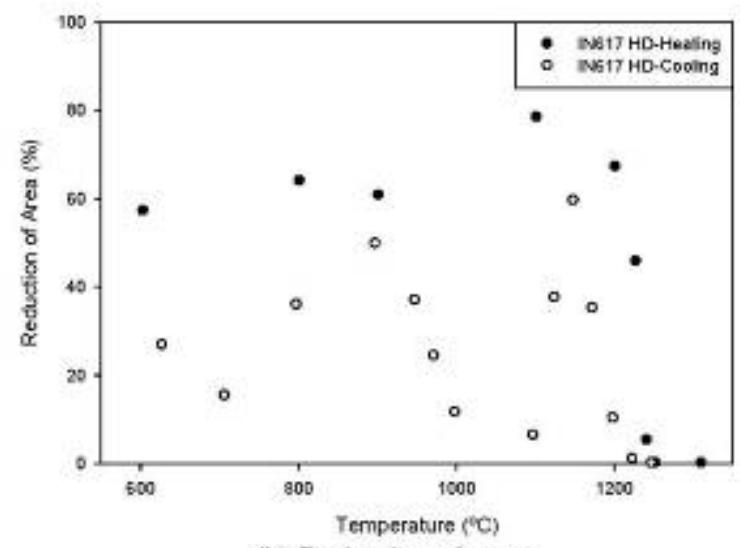

(b) Reduction of area

Figure 3. Results of Gleeble Hot-Ductility Testing of Alloy IN617 


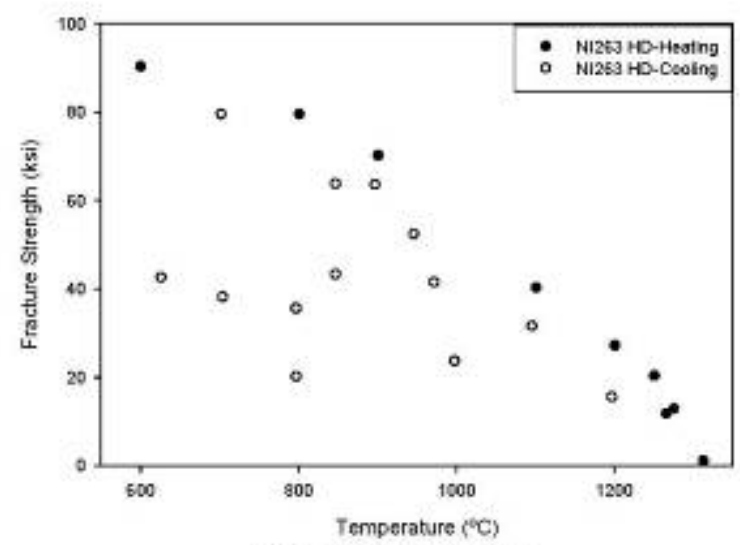

(a) Fracture strength

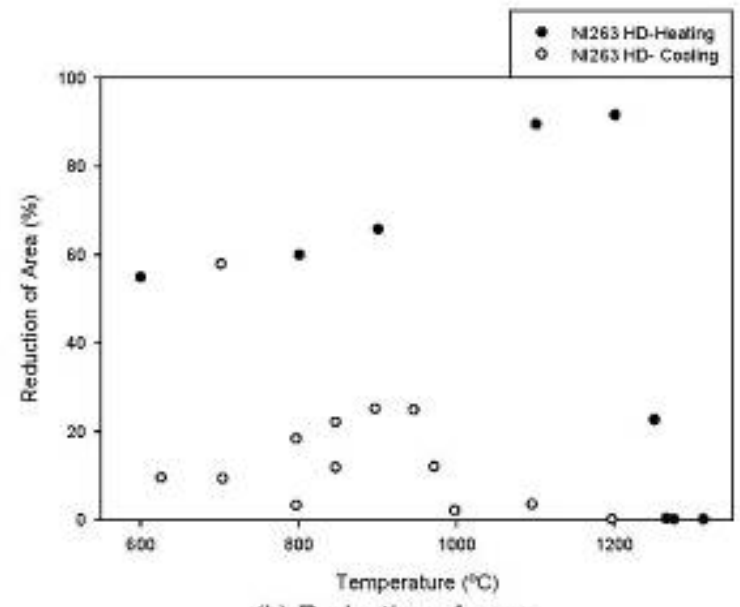

(b) Reduction of area

Figure 4. Results of Gleeble Hot-Ductility Testing of Alloy NI263 


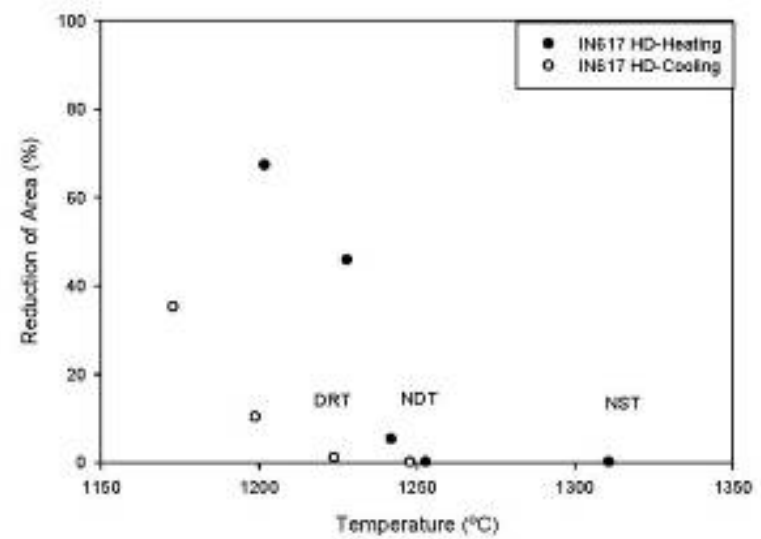

(a) IN617

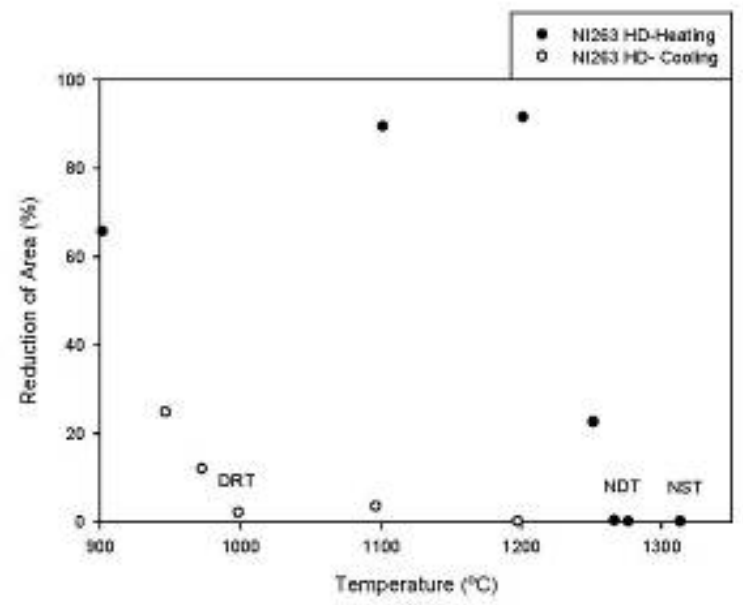

(b) NI263

Figure 5. Results of Gleeble Hot-Ductility Testing Near Solidus Temperature of Alloys 


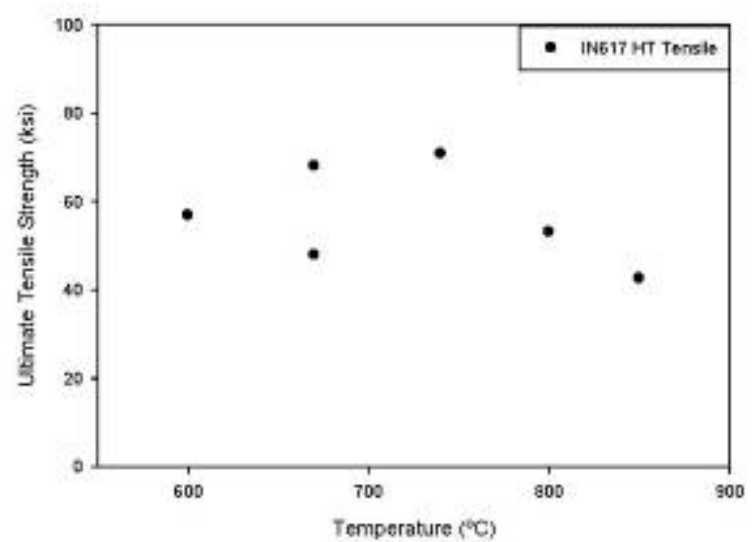

(a) UTS

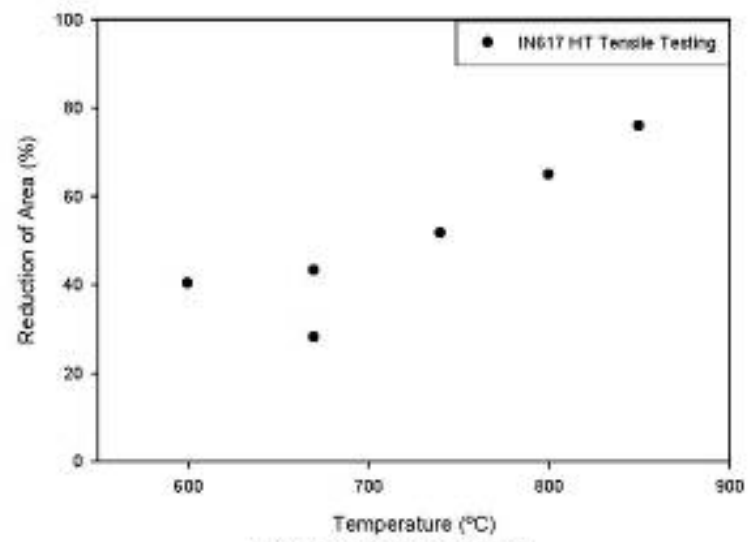

(b) Reduction of area

Figure 6. High-Temperature Tensile Properties of Alloy IN6717 


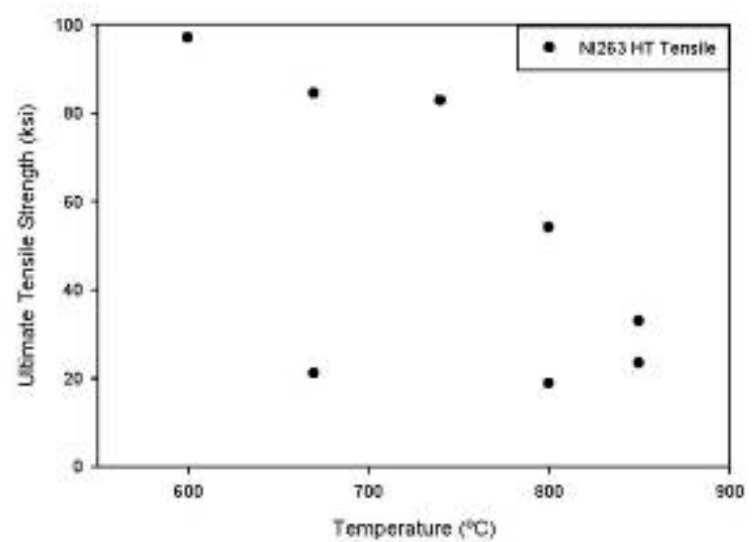

(a) UTS

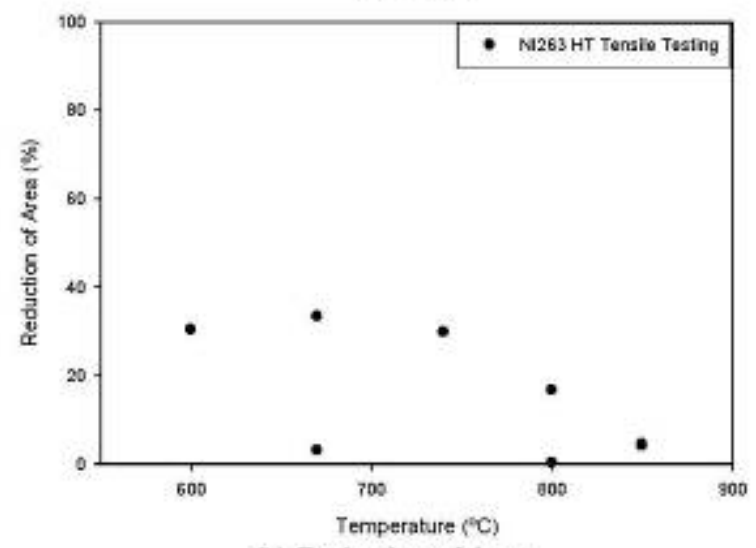

(b) Reduction of Area

Figure 7. High-Temperature Tensile Properties of Alloy NI263 


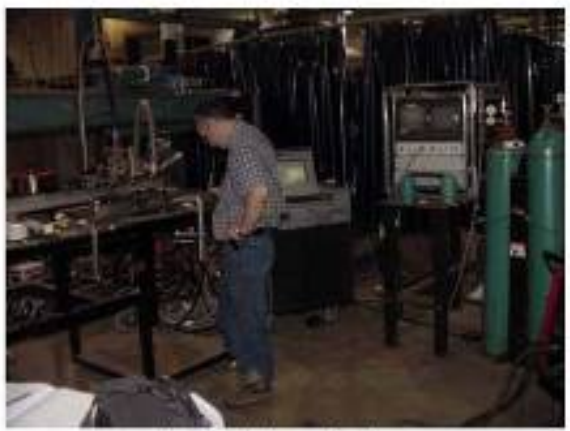

(a) Welding station

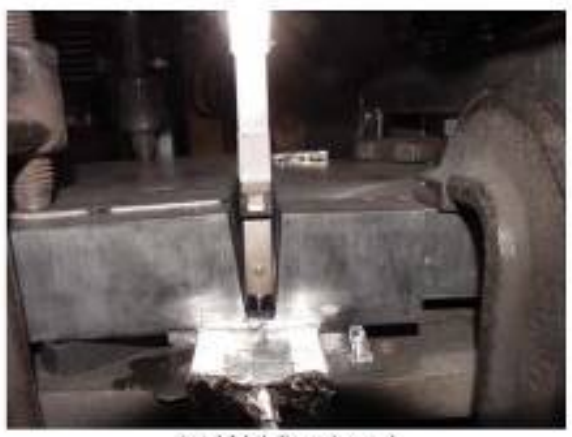

(c) Welding head

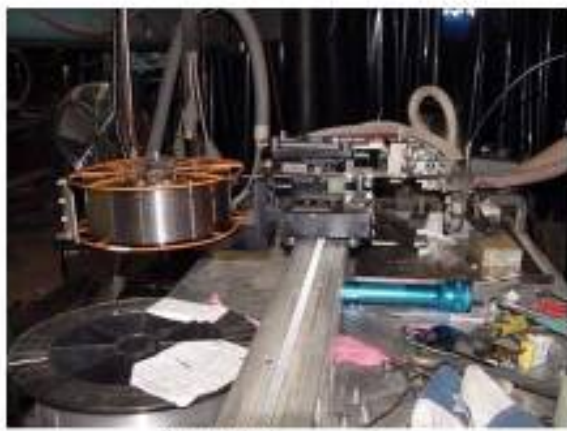

(b) Welding system

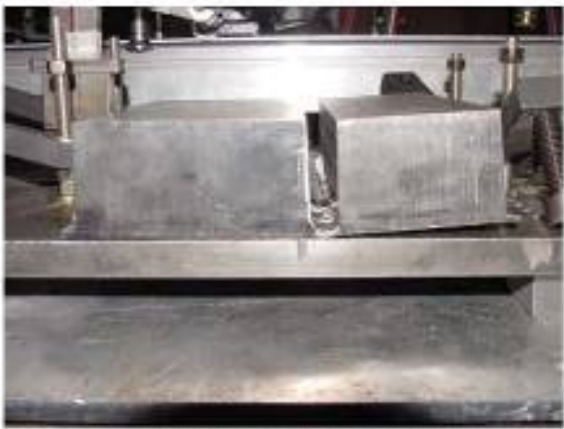

(d) Narrow-groove joint

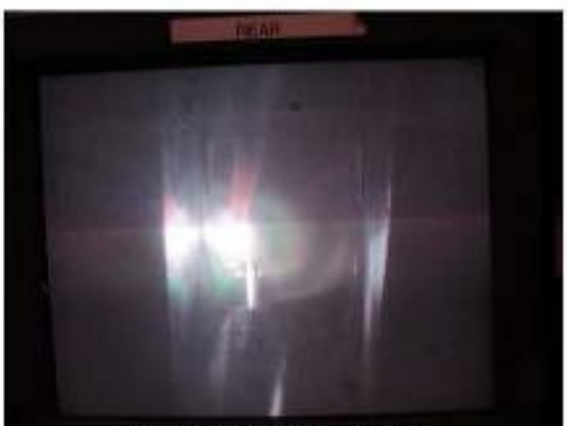

(e) Display of weld pool

Figure 8. General View of Welding Station, Welding System, Welding Head, NarrowGroove Joint, and Display of Weld Pool during Welding 


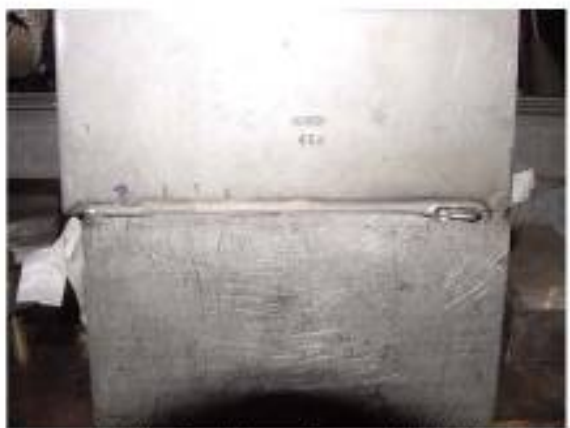

(a) Back side root pass Trial 1

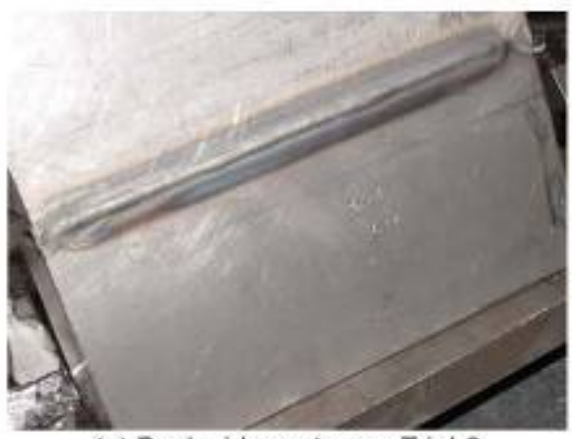

(c) Back side root pass Trial 3

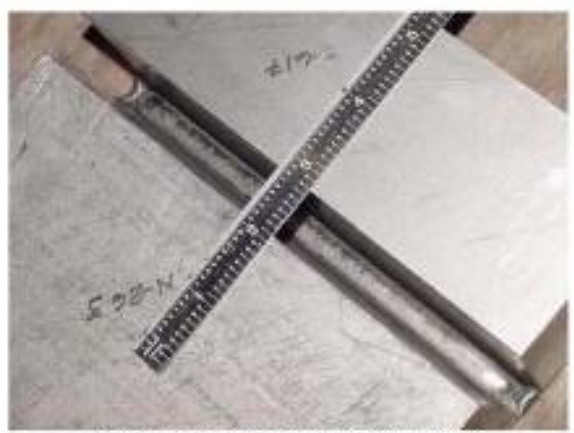

(e) Front side root pass Trial 3

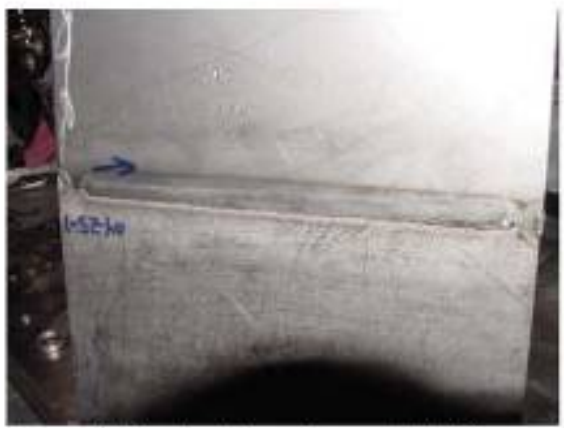

(b) Back side root pass Trial 2

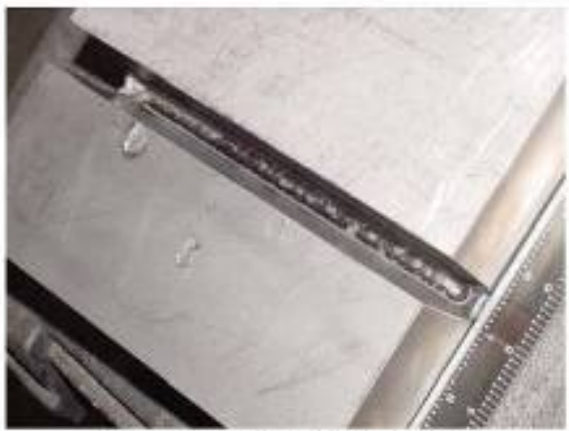

(d) Front side root pass Trial 2

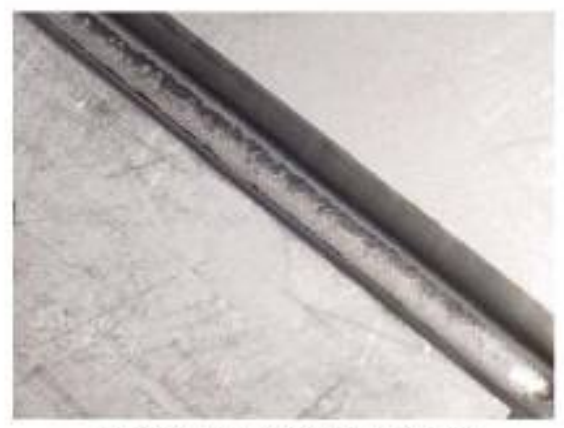

(f) Front side root pass Trial 3

Figure 9. Example of Appearance of Root Pass Achieved during Different Welding Trials 


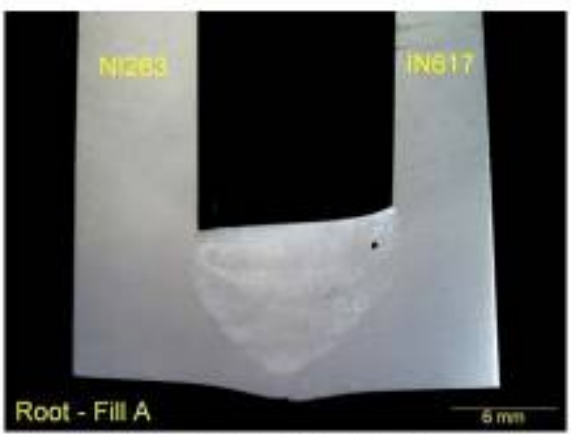

(a) Lack of complete penetration

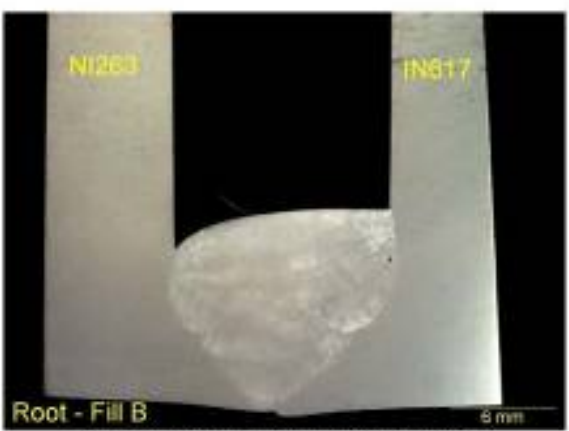

(b) Lack of complete penetration

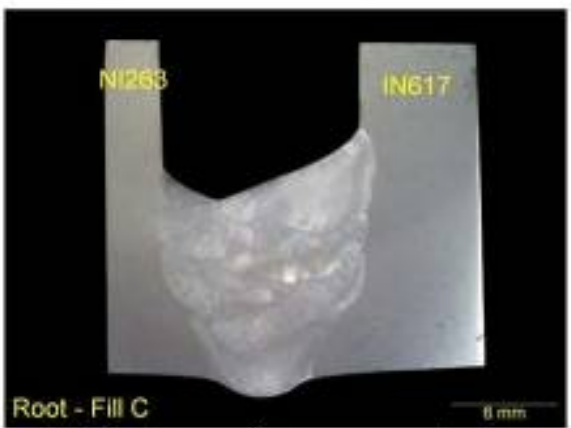

(c) Root pass with proper penetration

Figure 10. Cross Section of Root Pass + Fill Passes of Partially Filled Joint Obtained from Different Welding Trials 


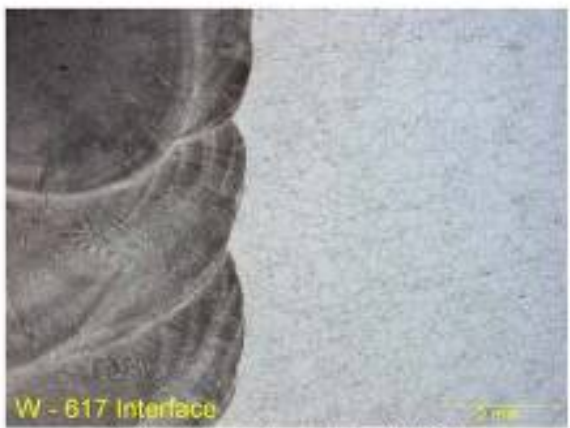

(a) IN617 side of joint (12)

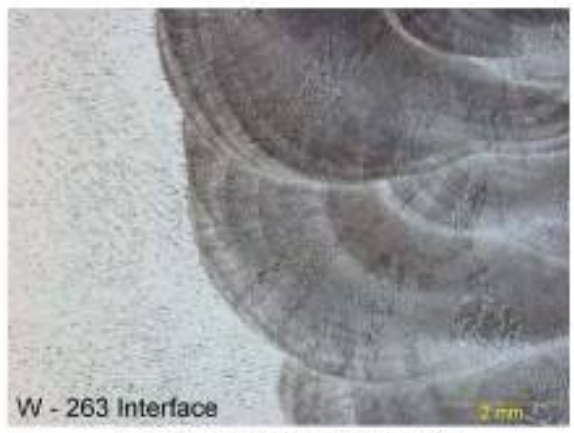

(c) NI263 side of joint (12x)

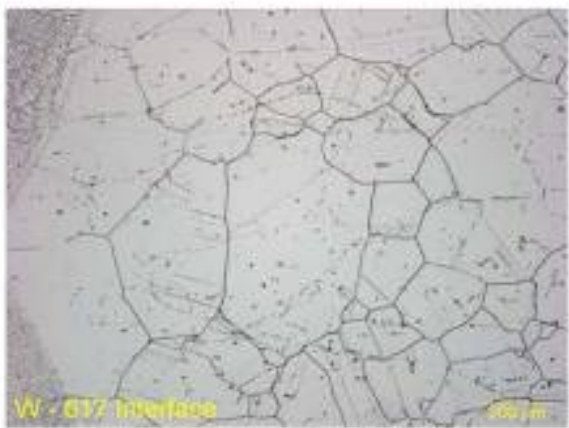

(b) IN617 side of joint (100x)

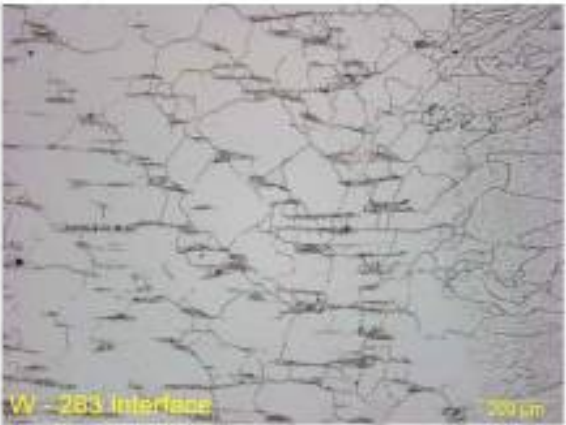

(d) NI263 side of joint ( $100 \times$ )

Figure 11. Micrograph of the IN617 Side of Joint [(a) and (b)] and NI263 Side of Joint [(c) and (d)] of Partially Filled Joints 


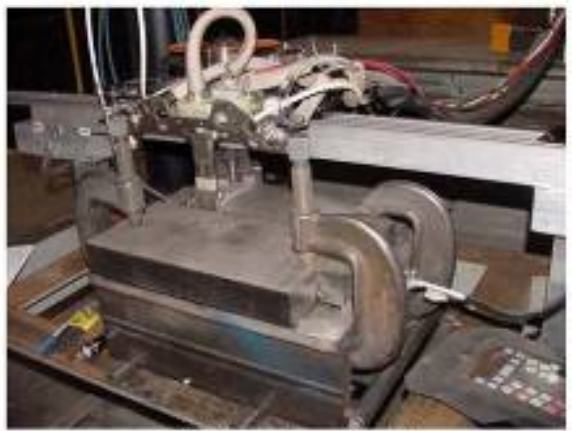

(a) Clamping of joint

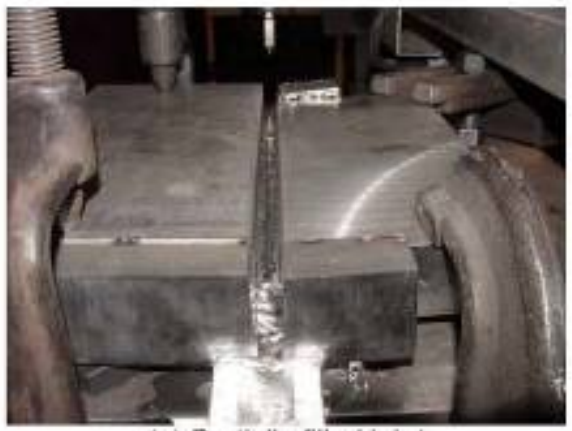

(c) Partially filied joint

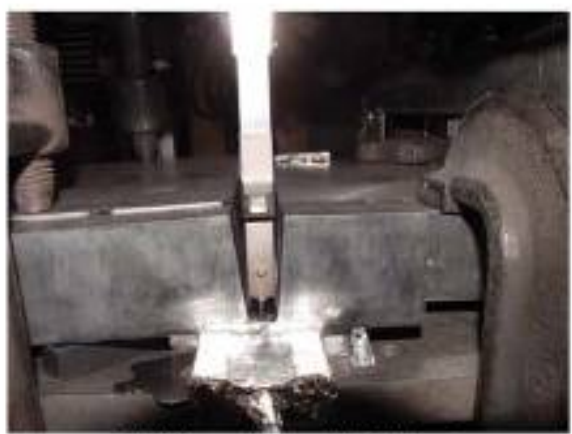

(b) Presetting of butt joint

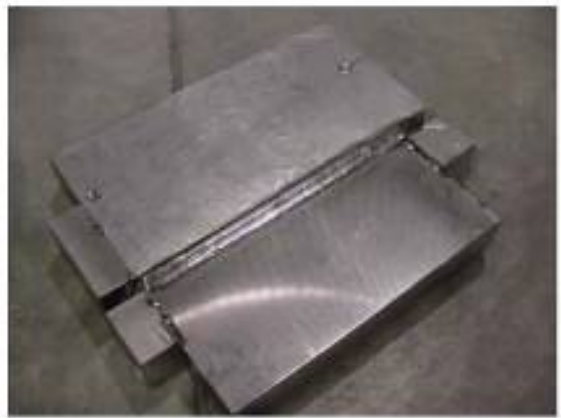

(d) Complete joint

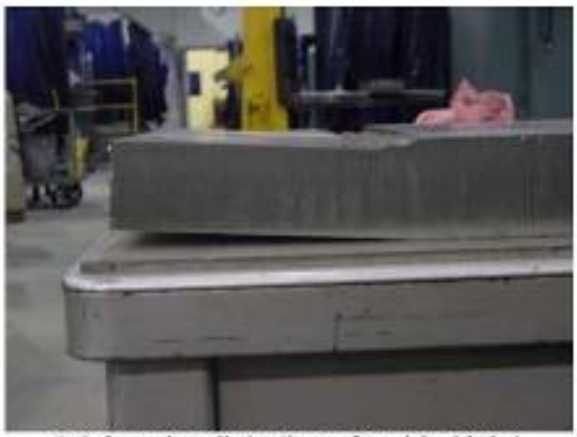

(e) Angular distortion of welded joint

Figure 12. General View of Restraining of the Joint, Presetting of Joint, Partially and Completely Filled Joint, and Resulting Angular Distortion of the Joint 


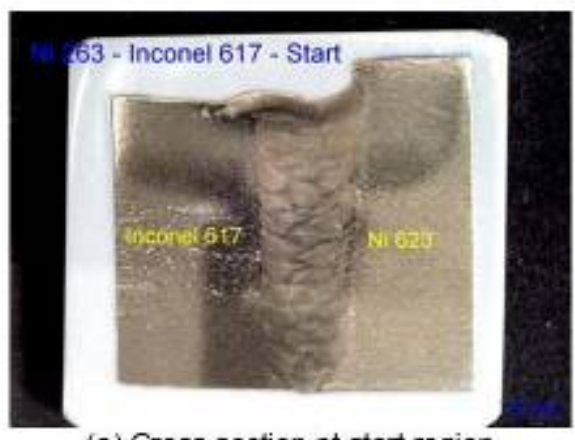

(a) Cross section at start region

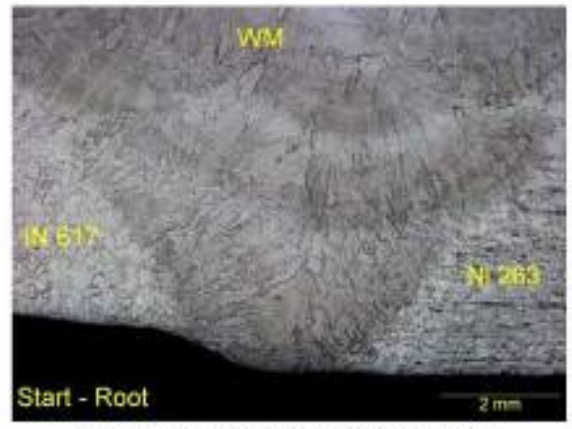

(b) Root pass at start point (12×)

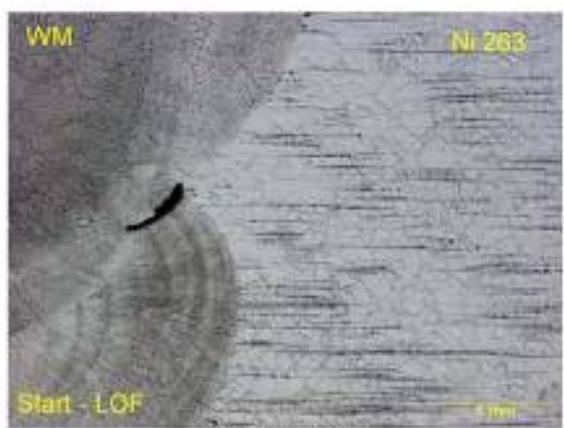

(d) $\operatorname{LOF}(25 x)$

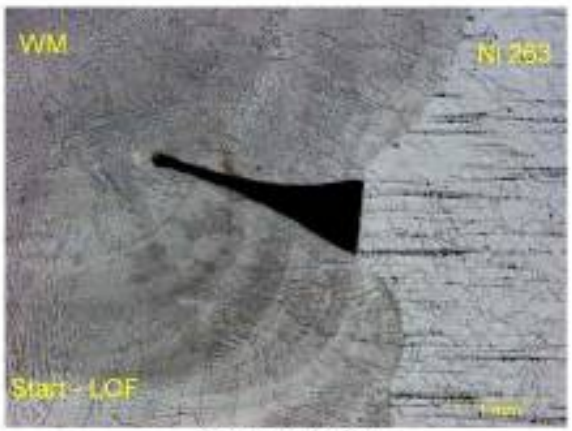

(c) LOF (25x)

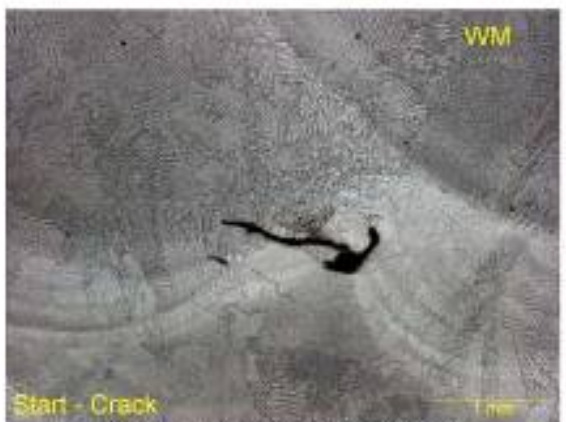

(e) Crack or inclusion (25x)

Figure 13. View of Cross Section and Root Pass of the Welded Joint, and Defects Observed at the Start Region of the Full-Size Joint 


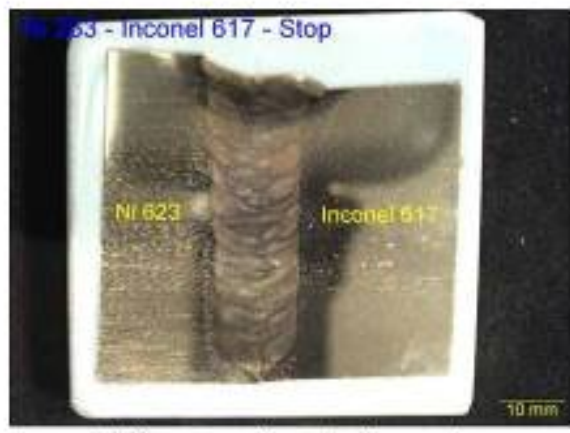

(a) Cross section at stop region

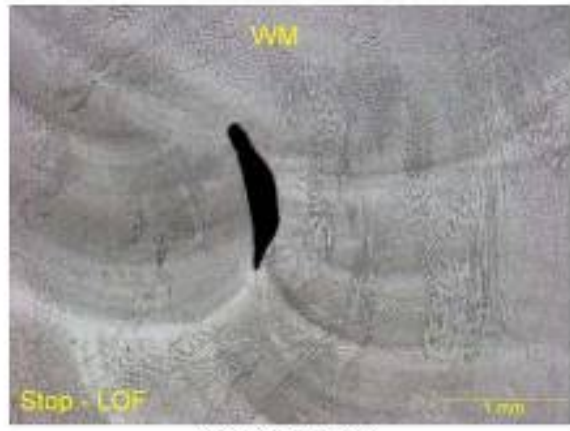

(c) LOF $(25 \times)$

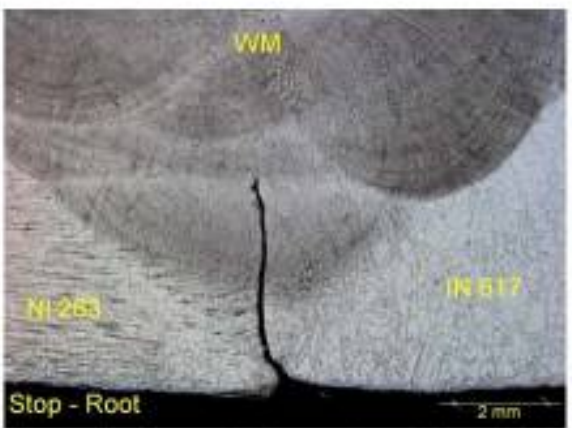

(b) Lack of penetration and cracking (12x)

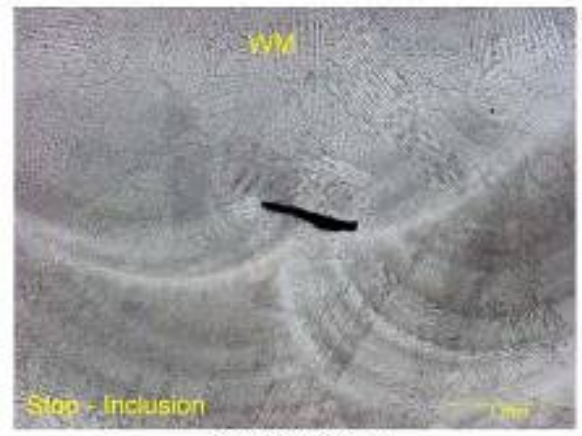

(d) LOF (25x)

Figure 14. Cross Section and Defects Observed at the Stop Region of the Full-Size Joint 


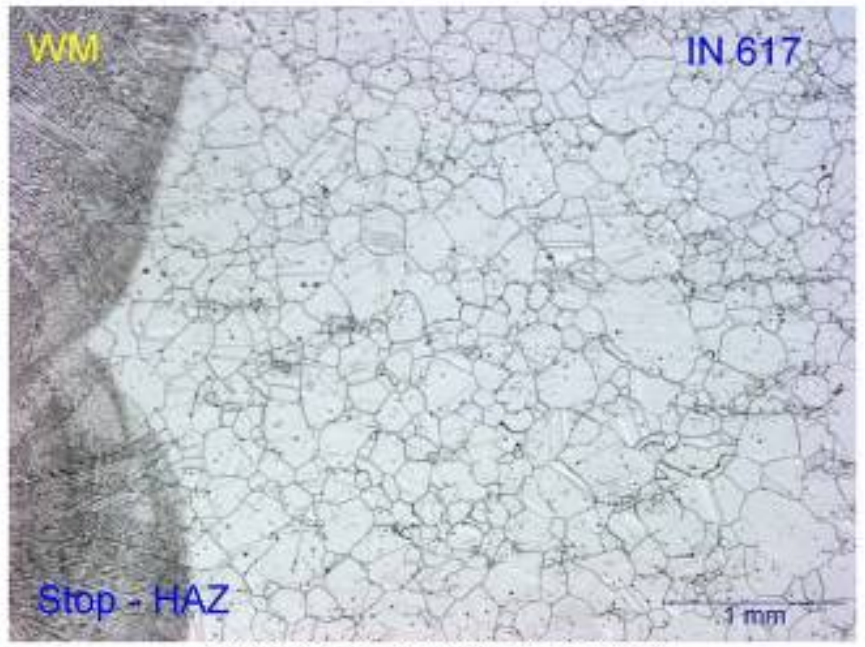

(a) IN617 side of full-size joint ( $25 x$ )

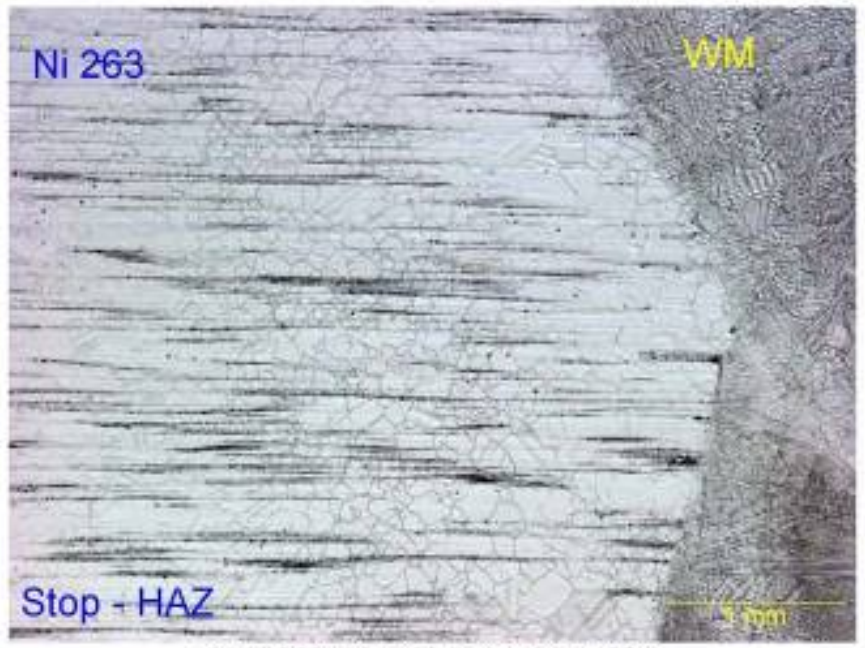

(b) NI263 side of full-size joint (25x)

Figure 15. Micrograph of the IN617 and NI263 Sides of Full-Size Joint 


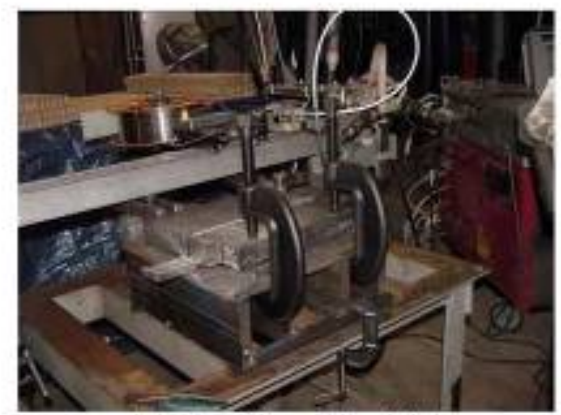

(a) Clamping of the joint

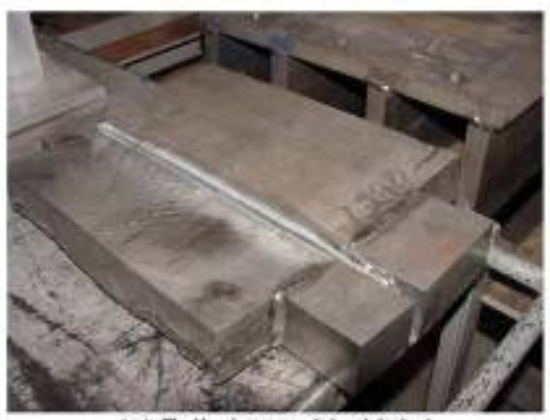

(c) Full-size welded joint

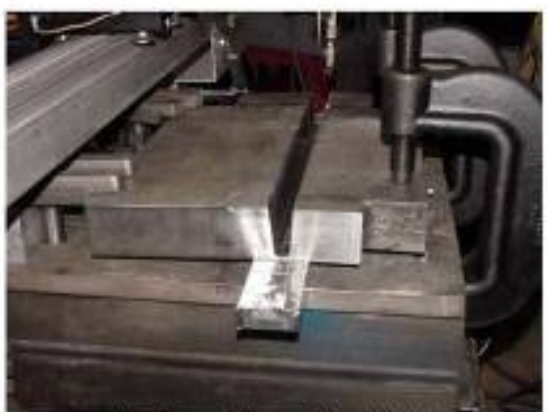

(b) Presetting of butt joint

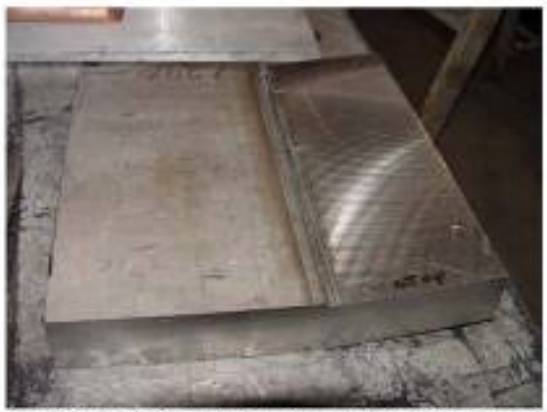

(d) Joint after cutting of run-on and run-off

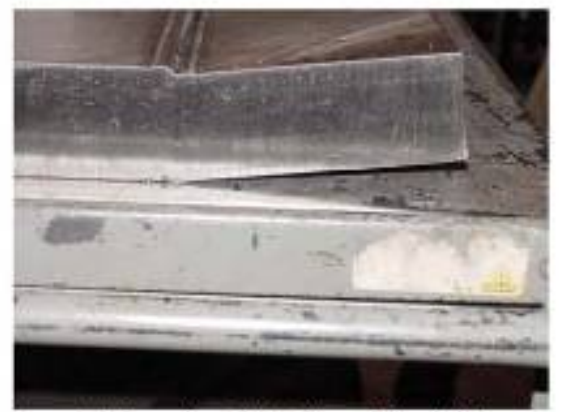

(e) Angular distortion of the joint

Figure 16. General View of Restraining and Presetting of the Joint, Complete Full-Size Joint Before and After Removing Run-On/Run-Off Tabs, and Resulting Angular Distortion of the Joint 


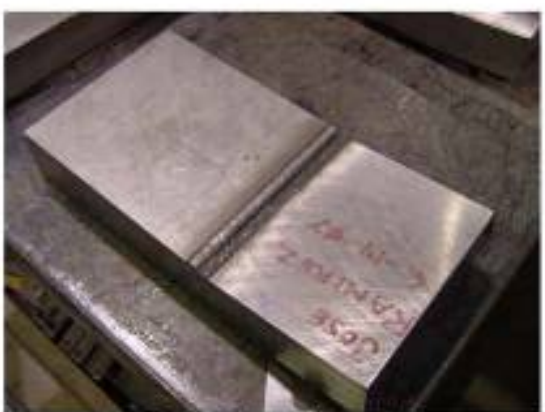

(a) Remaining joint section

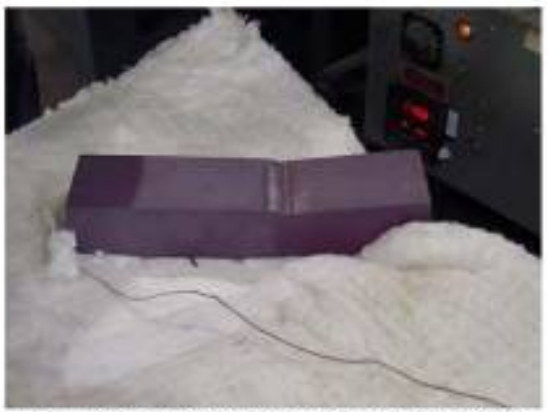

(c) Joint section in the PWHT condition

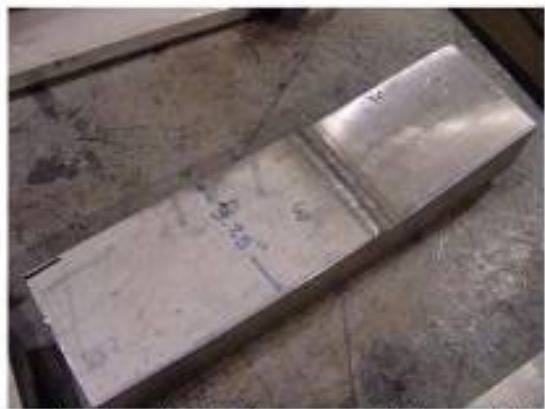

(b) Joint section in the as-welded condition

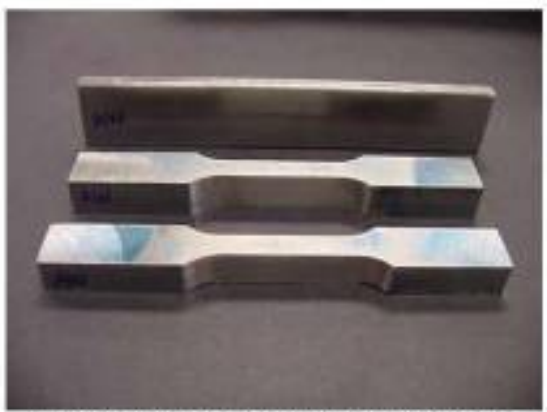

(d) Tensile and side-bend specimens

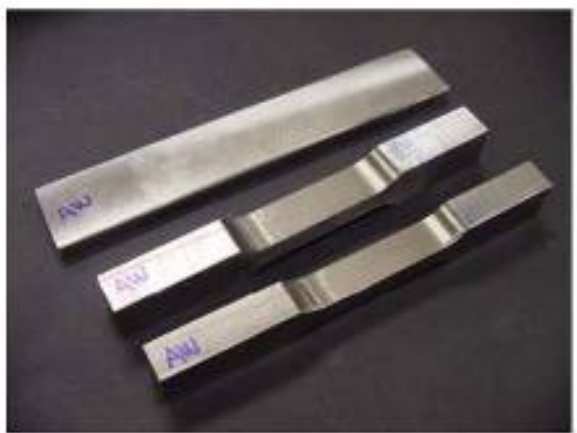

(e) As-welded tensile and side-bend samples

Figure 17. Preparation of Tensile and Side-Bend Samples 


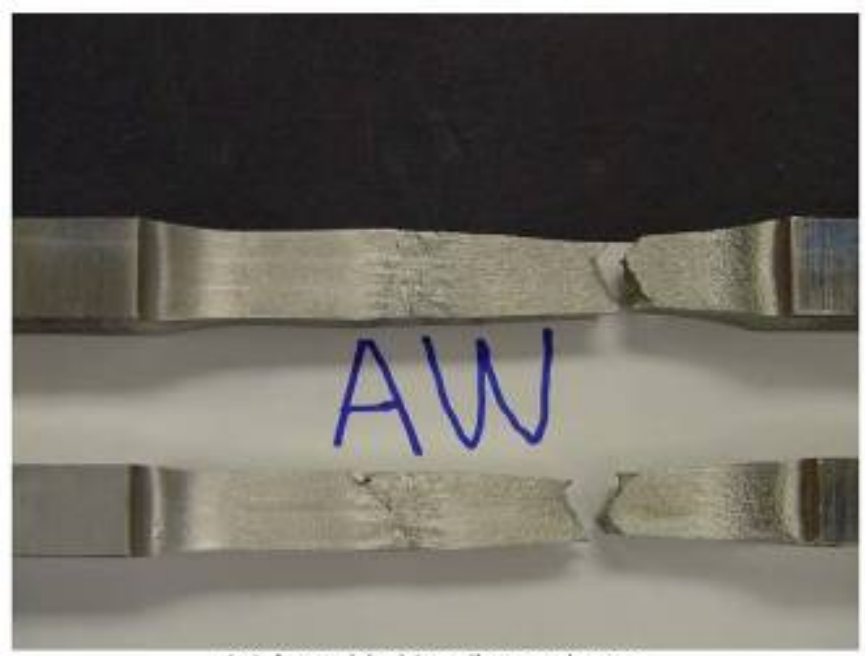

(a) As-welded tensile specimens

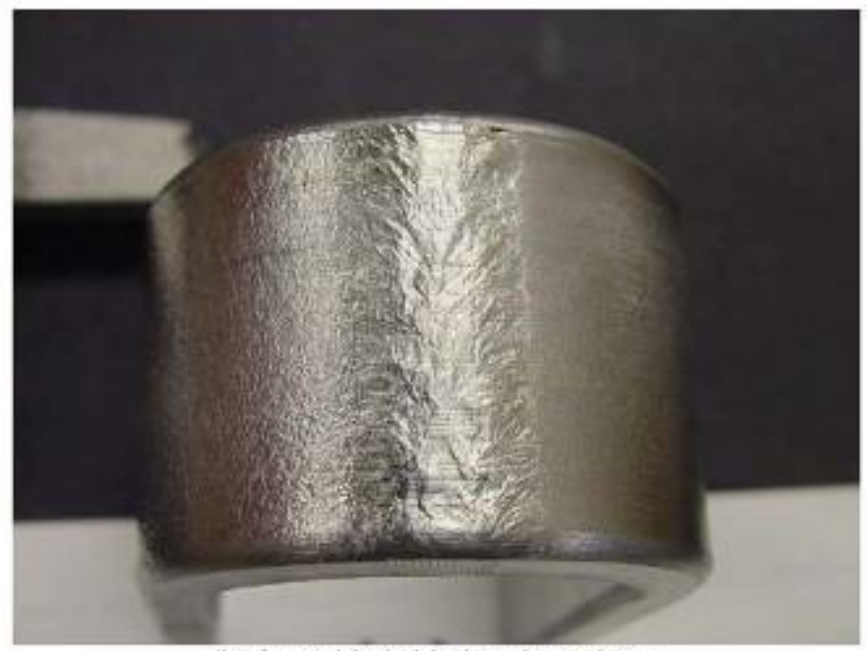

(b) As-welded side-bend specimen

Figure 18. General View of As-Welded Tensile and Side-Bend Specimens after Testing 


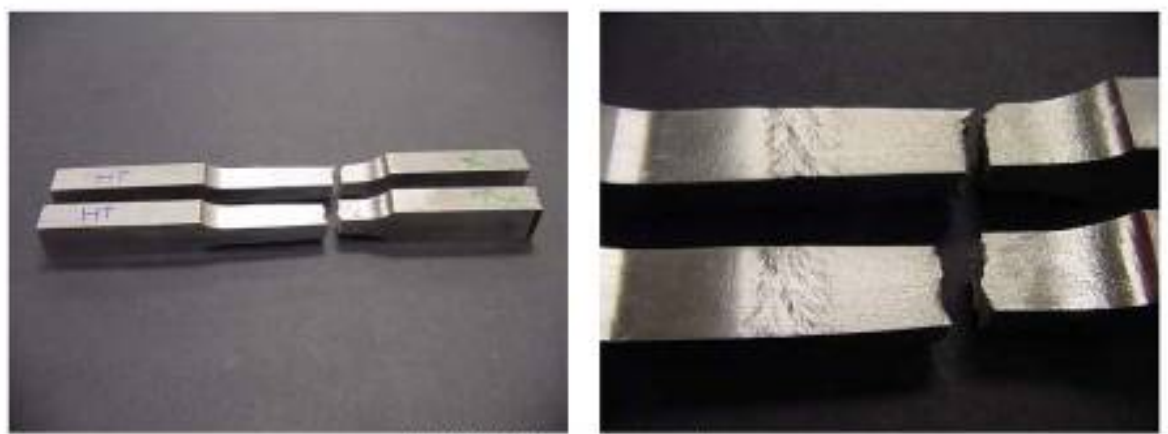

(a) PWHT tensile specimens
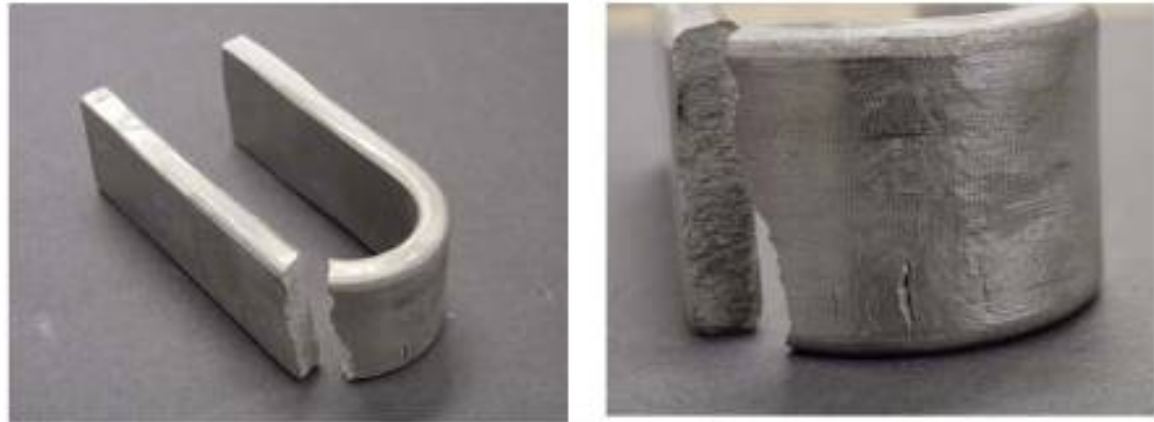

(b) PWHT side-bend specimens

Figure 19. General View of PWHT Tensile and Side-Bend Specimens After Testing 


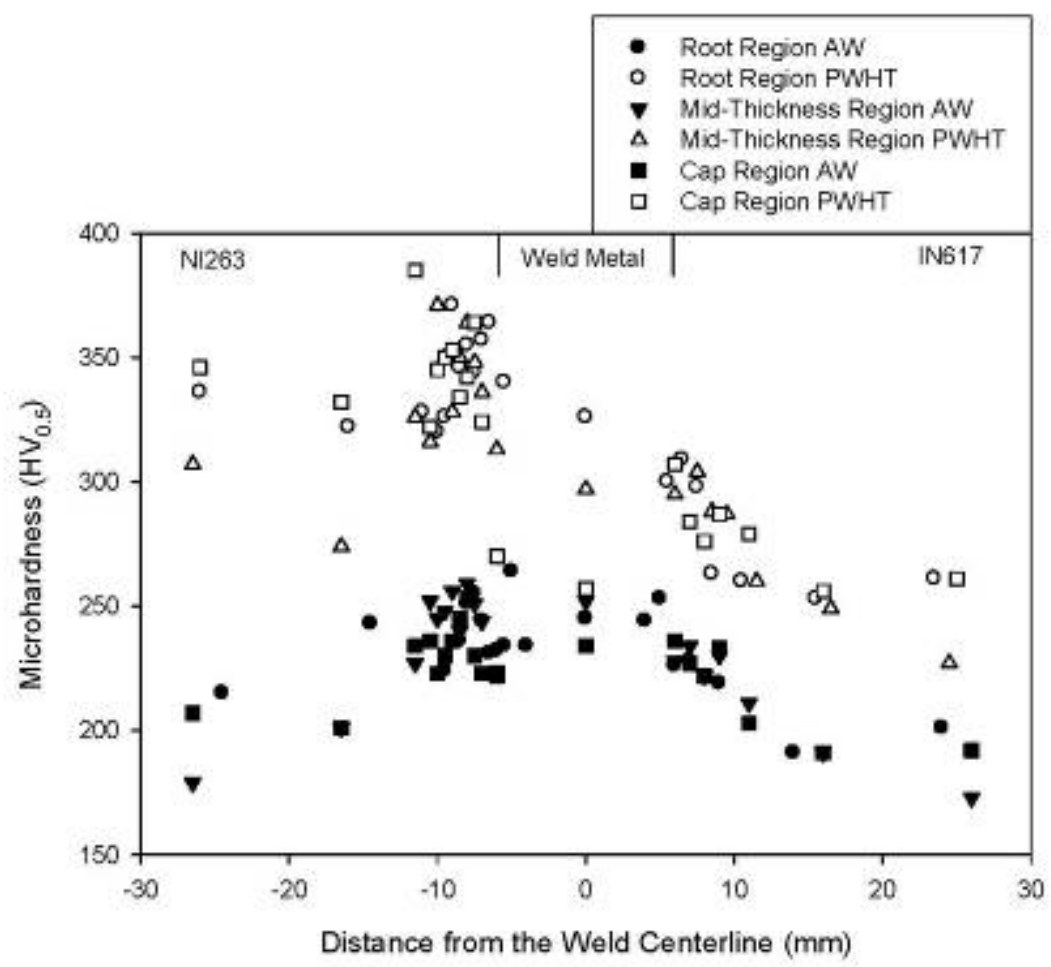

Figure 20. Microhardness Profiles of the IN617-NI263 Welded Joint in the As-Welded and PWHT Conditions 


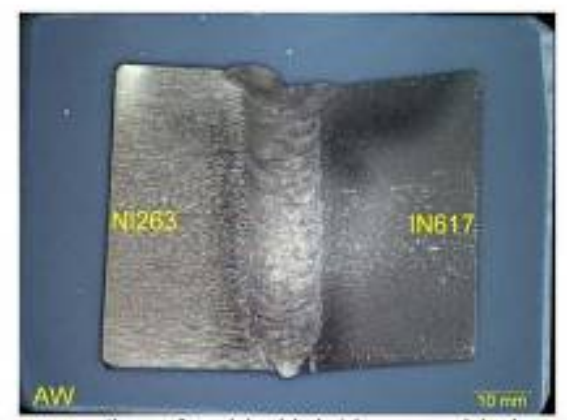

(a) Cross section of welded joint in as-welded condition

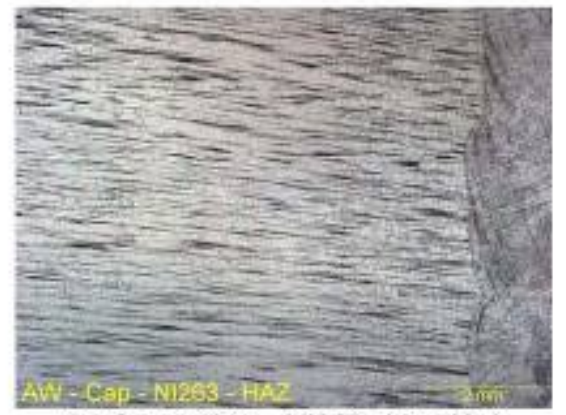

(b) Cap region - NI263 side (12x)

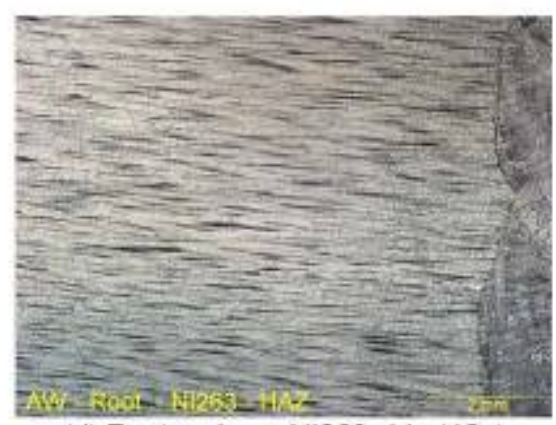

(d) Root region - NI263 side (12x)

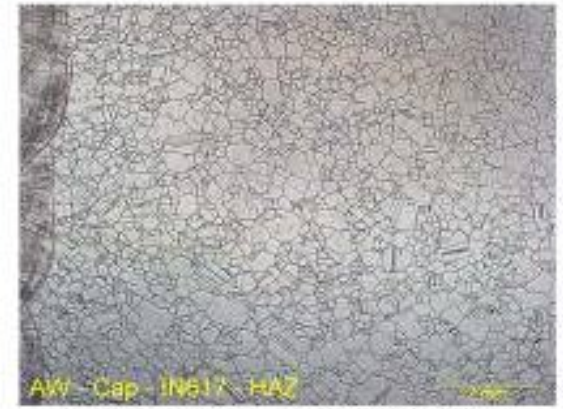

(c) Cap region - IN617 side (12×)

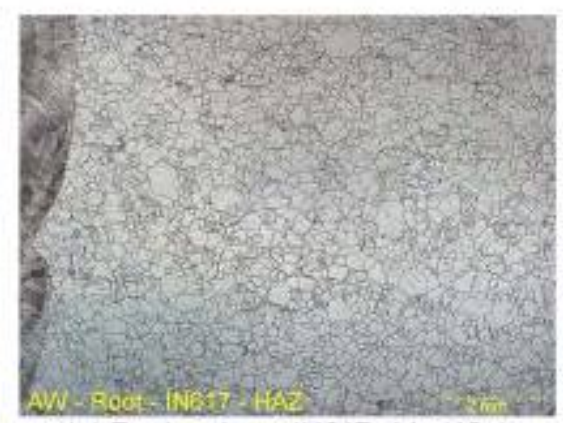

(e) Root region - IN617 side (12)

Figure 21. General Microstructure of the NI263 and IN617 Sides of the Welded Joint in the As-Welded Condition 


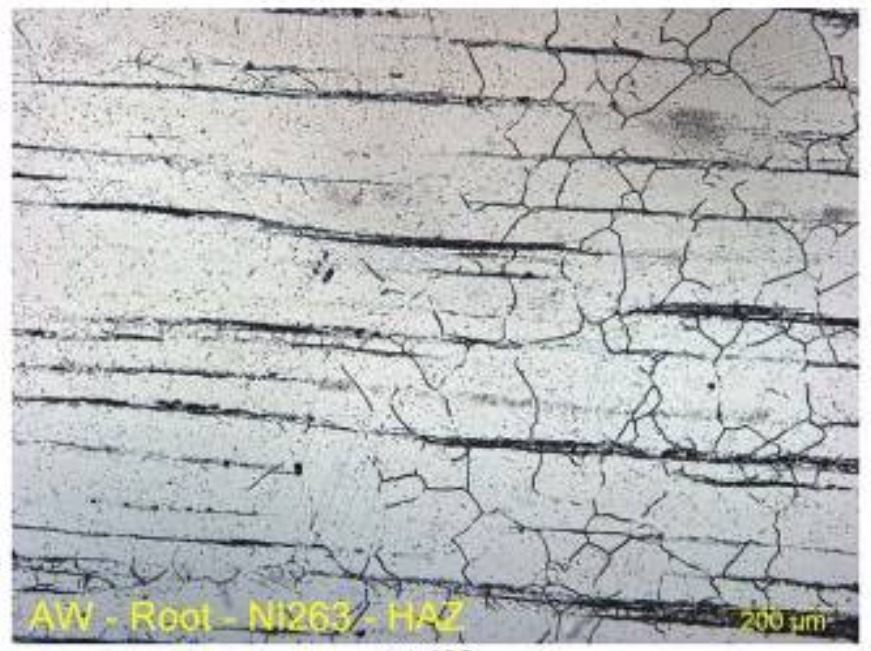

(a) $100 \times$

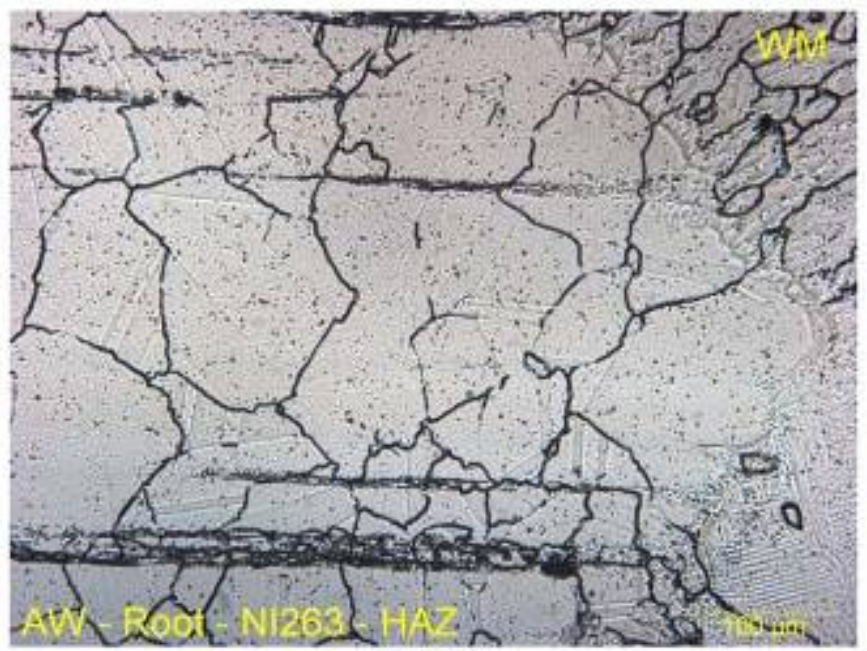

(b) $200 x$

Figure 22. Laminar Segregation Observed in the Nl263 Base Material and Preferential Etching of the Grain Boundaries of the HAZ of the Nl263 Material in the AsWelded Condition 


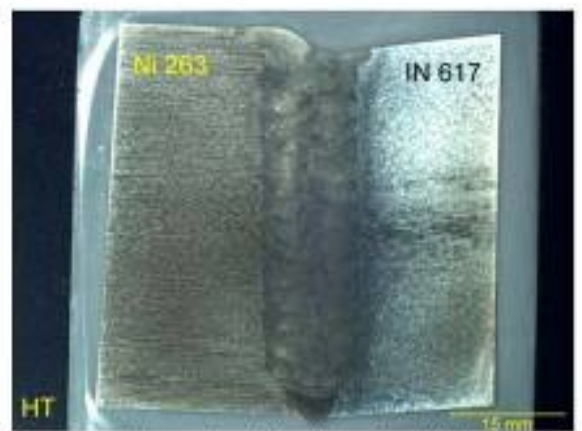

(a) Cross section of welded joint in PWHT condition

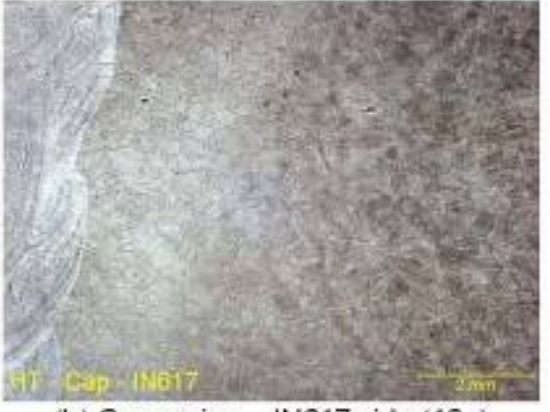

(b) Cap region - IN617 side (12×)

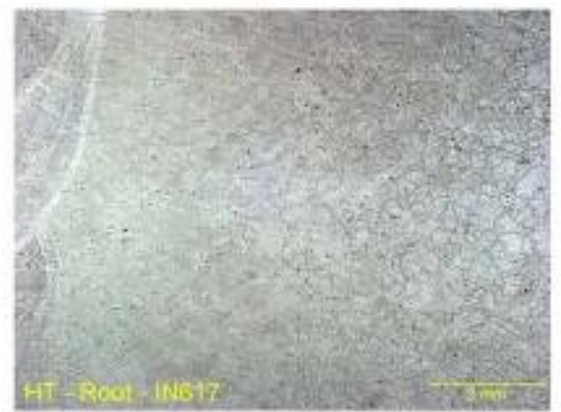

(d) Root region - IN617 side (12x)

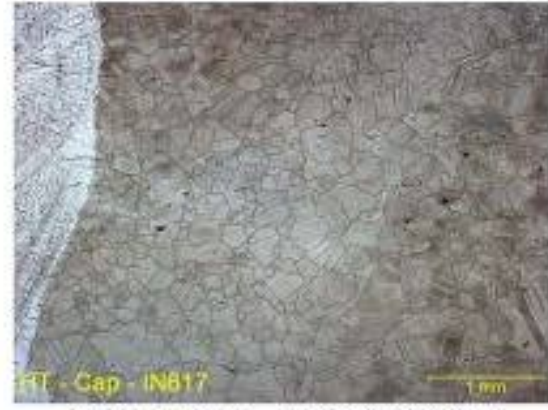

(c) Cap region - IN617 side (25x)

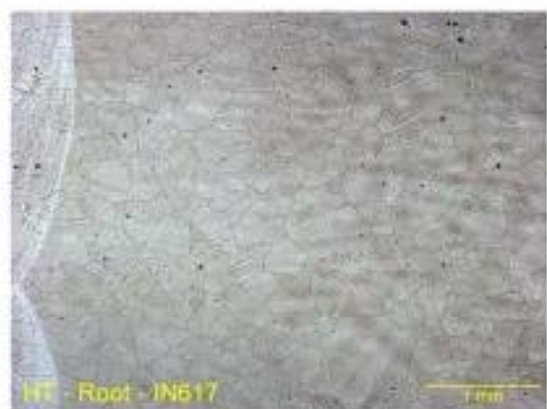

(e) Root region - IN617 side (25x)

Figure 23. General Microstructure of the IN617 Side of the Welded Joint in the PWHT Condition 


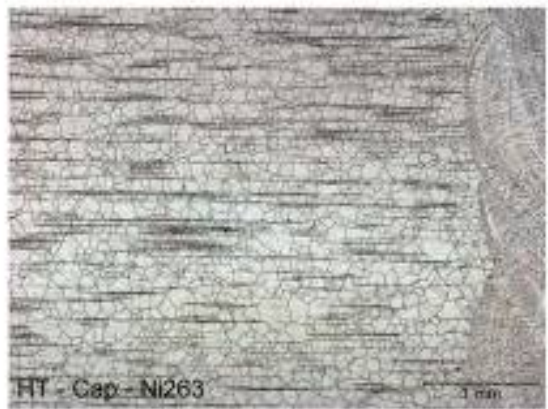

(a) Cap region - NI263 side (25x)

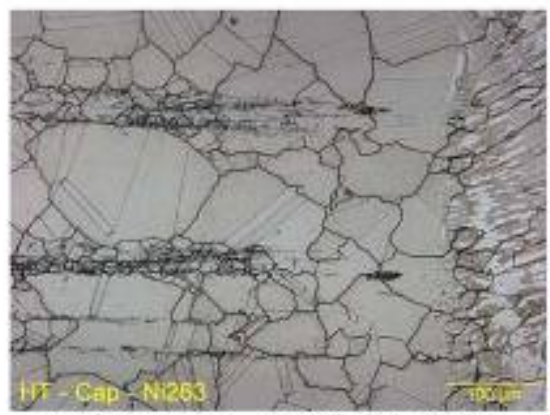

(c) Cap region - NI263 side (200x)

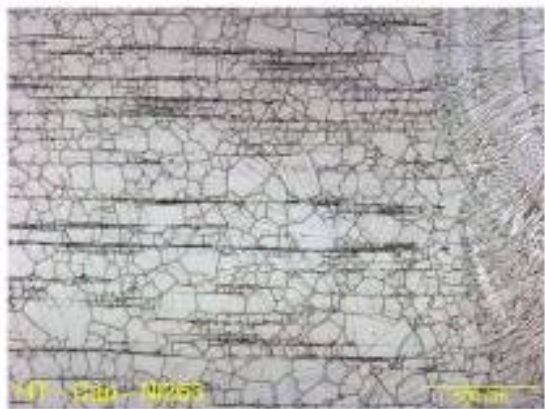

(b) Cap region - N1263 side (50x)

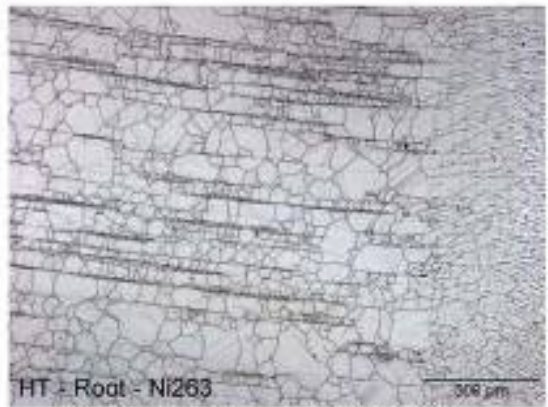

(d) Root region - NI263 side (50x)

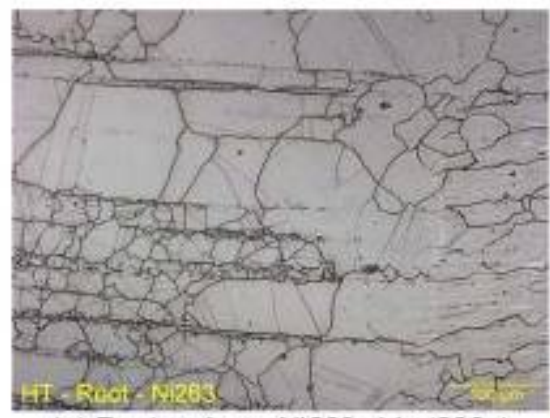

(e) Root region - NI263 side (200x)

Figure 24. General Microstructure of the N1263 Side of the Welded Joint in the PWHT Condition 


\section{Appendix A}

Tensile and Side-Bend Test Results 
WELD QUALIFICATION TEST RECORD

Project No:: $50389 \mathrm{GTH}-0.3$

Weld No: AW

Job No.: 2007-114924

Customer: bose Ramirez

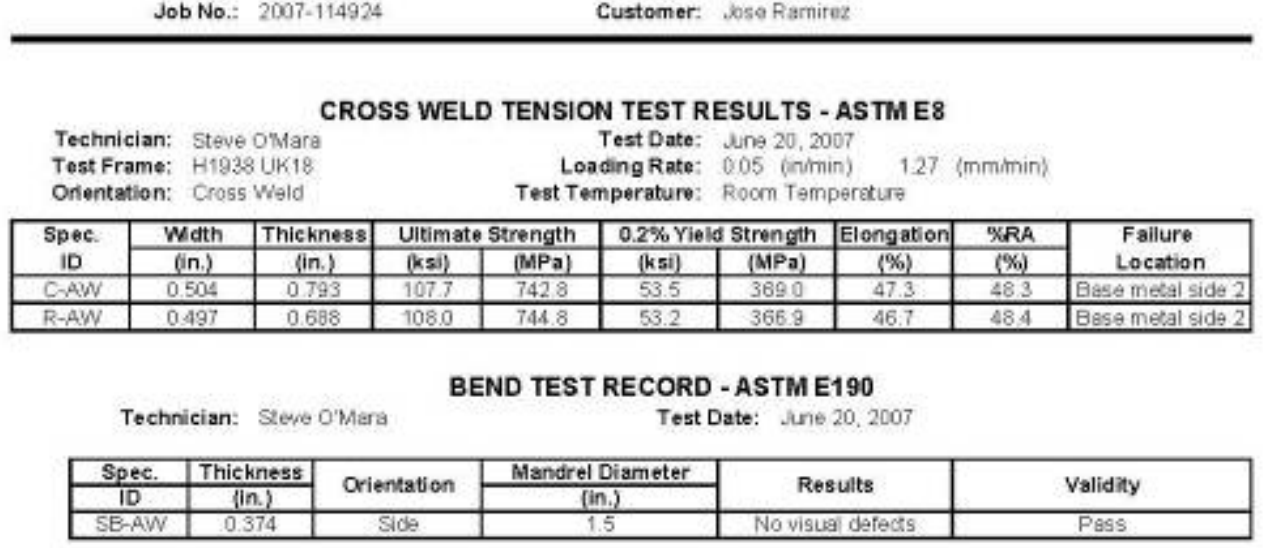

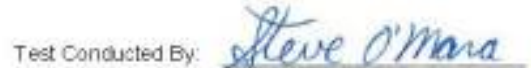

Titla; Techricien
Reviewedby Sloper $\angle$ tuepp

Title: Senior Engnear 
WELD QUALIFICATION TEST RECORD

Project No: 503996 Th-03

Weld No:- Cap, Root Heat Treated

Job No.: 2036-11525

Customer: L9se Parrire

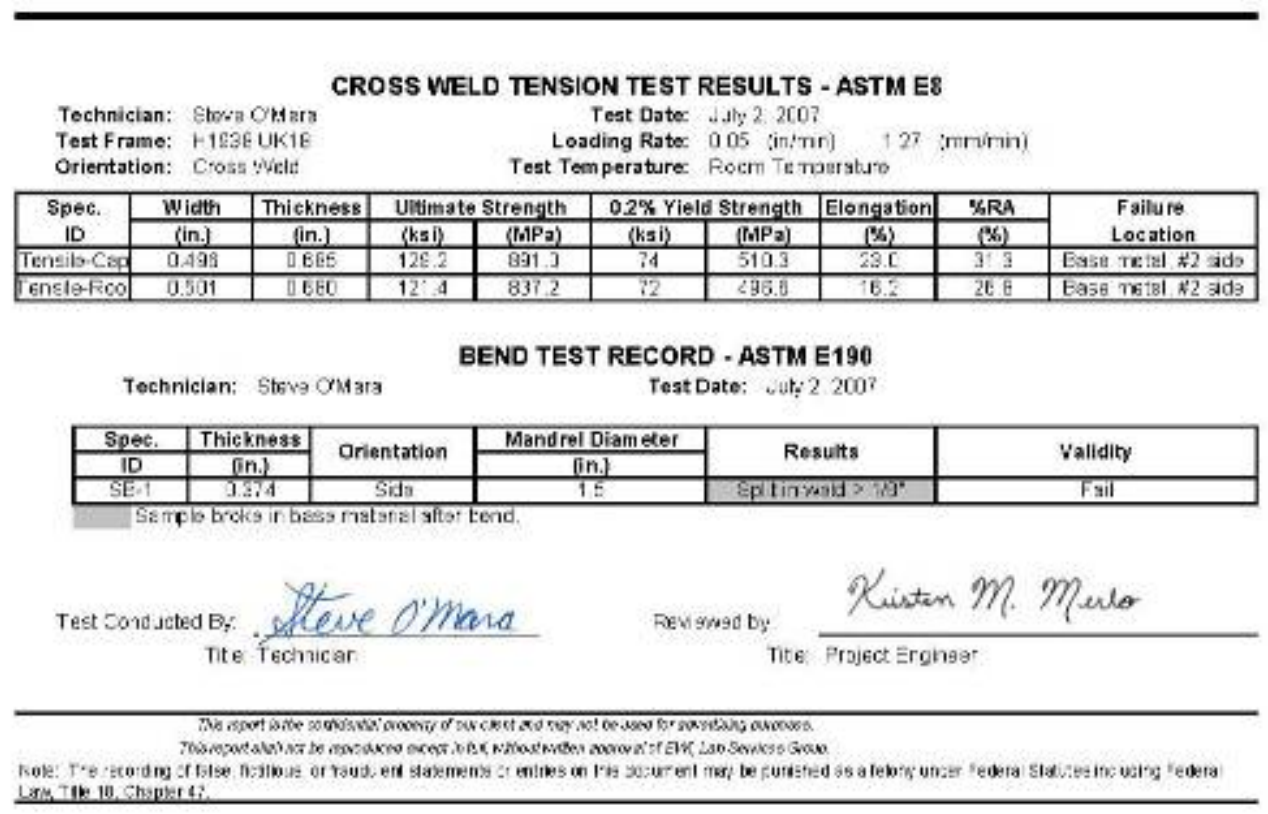




\section{Appendix B}

Microhardness Testing Results and Graphs 
EUIH.

1260 Asthu E Adams Drive Coimous, OH 43221 Lab Services

Vickers Hardness Test Results - ASTM E92

\begin{tabular}{|c|c|c|c|c|}
\hline \multicolumn{2}{|c|}{ Project No.: 50399CSP-03 } & \multicolumn{2}{|c|}{ Job No: : $2007-114725$} & Date: July 2, 2007 \\
\hline \multicolumn{2}{|c|}{ Customer: Jose Ramirez } & \multirow[b]{3}{*}{ Load: } & \multicolumn{2}{|c|}{ Technician: D Reaf } \\
\hline Address: & & & & fication: \\
\hline Specimen No.: AWr-cap & & & $0.5 \mathrm{logf}$ & Tester LECO - 293295 \\
\hline Indent Na. & $\begin{array}{c}\text { Distance } \\
\text { (mm) }\end{array}$ & $\mathrm{HV}$ & $\begin{array}{l}\text { Indent } \\
\text { Location }\end{array}$ & \\
\hline 1 & -265 & 201 & \multirow{11}{*}{ Ni 263} & \\
\hline $\bar{z}$ & -165 & 201 & & \\
\hline 3 & -115 & 234 & & \\
\hline 4 & -10.5 & 236 & & \\
\hline 5 & -10 & 223 & & \\
\hline 6 & -9.5 & 230 & & \\
\hline 7 & -9 & 236 & & \\
\hline 8 & -85 & 245 & & \\
\hline 9 & -8 & 253 & & \\
\hline 10 & -7.5 & 230 & & \\
\hline 11 & -7 & 223 & & \\
\hline 12 & -6 & 222 & \multirow{3}{*}{ woild } & \\
\hline 13 & 0 & 234 & & \\
\hline 14 & $\overline{6}$ & 236 & & \\
\hline 15 & 7 & 227 & \multirow{6}{*}{$\ln 617$} & \\
\hline 16 & 8 & 222 & & \\
\hline 17 & 9 & 233 & & \\
\hline 18 & $\pi$ & 2003 & & \\
\hline 19 & 16 & 191 & & \\
\hline 20 & 25 & 192 & & \\
\hline
\end{tabular}

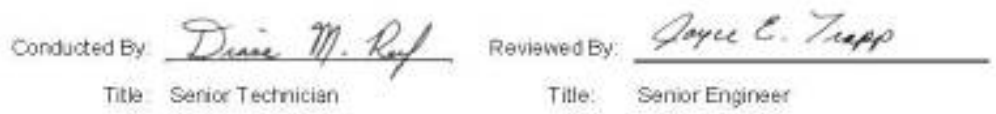

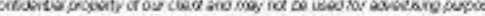

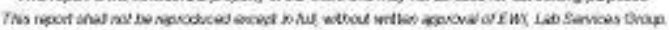

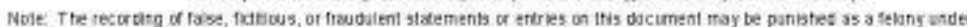

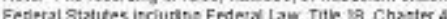
Feteral Statutes itciuting Federal Law, Title 18 , Chapter 47 


\section{Vickers Hardness Test Results - GRAPH}

Project Number: 50399CSP-03

Customer: Jose Ramirez

Job No.: 2007-114725

Address:

Specimen No.: AW-cap

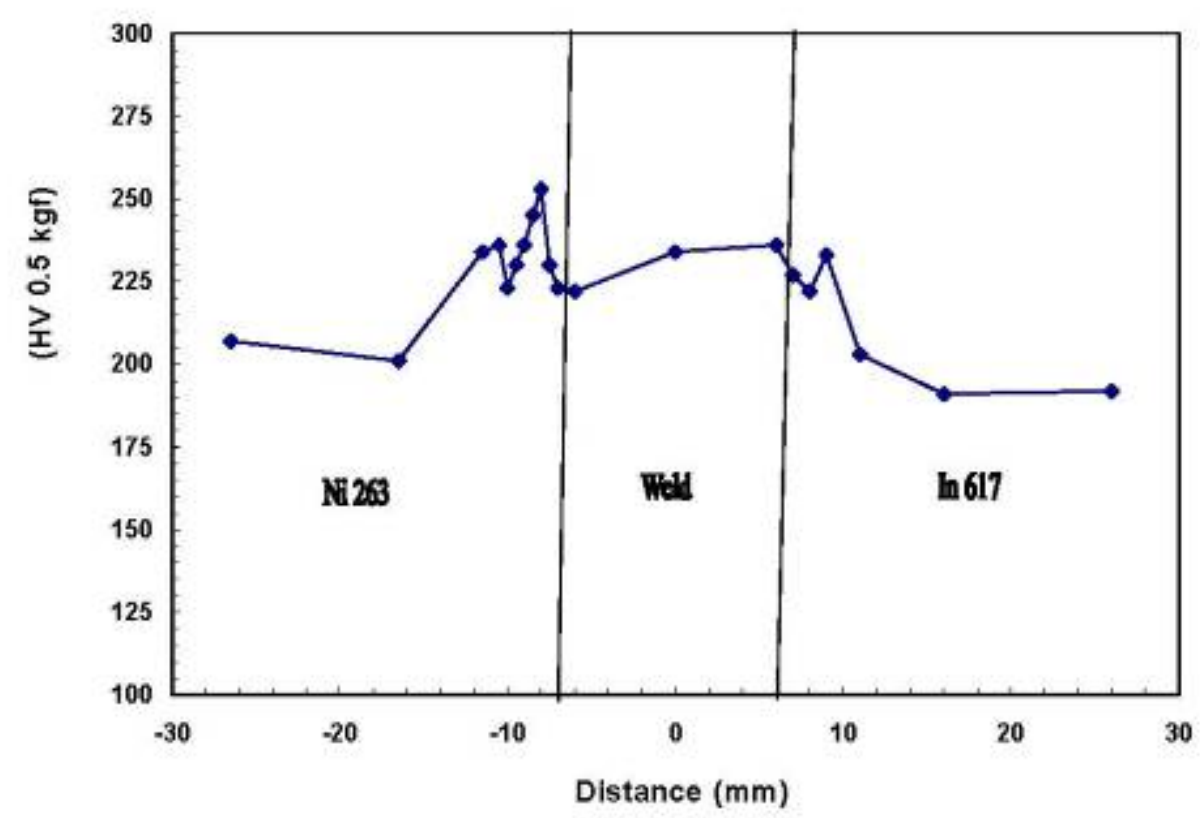

Notec The recording of false, fictnous, or frajdulant stetements or entries on this document may be punished as a felony under Federel Statutes includng Federal Lav, Title 18 Chapter 47
Date: July 2, 2007

Technician: D. Reef

Specification:

Tester: LECO - 293295 
EUII.

1250 ATthu E Adoms Dorve Coimaus, OH 43221

Lab Services

\section{Vickers Hardness Test Results - ASTM E92}

\begin{tabular}{|c|c|c|c|c|}
\hline \multicolumn{2}{|c|}{ Project No: $50399 \mathrm{CSP}-03$} & \multicolumn{2}{|c|}{ Job No.: $2007-114725$} & Date: Uy 2, 2007 \\
\hline \multicolumn{2}{|c|}{ Customer. Joso Ramirez } & \multicolumn{3}{|c|}{ Technician: D. Resf } \\
\hline \multicolumn{2}{|l|}{ Address: } & \multicolumn{3}{|c|}{ Specification: } \\
\hline Specimen No.: AW/en id & & Load: & $0.5 \mathrm{ligf}$ & Tester: LECO - 293295 \\
\hline Indent No. & $\begin{array}{c}\text { Oistance } \\
\text { (mm) }\end{array}$ & $\mathrm{HV}$ & $\begin{array}{l}\text { Indent } \\
\text { Location }\end{array}$ & \\
\hline 1 & \begin{tabular}{|l|}
-26.5 \\
\end{tabular} & 179 & \multirow{11}{*}{ Ni 263} & \\
\hline 2 & -16.5 & 201 & & \\
\hline 3 & -11.5 & 227 & & \\
\hline 4 & -10.5 & 232 & & \\
\hline 5 & -10 & 245 & & \\
\hline 6 & -9.5 & 248 & & \\
\hline 7 & -9 & 256 & & \\
\hline 8 & -85 & 240 & & \\
\hline 9 & -8 & 259 & & \\
\hline 10 & .75 & 251 & & \\
\hline 11 & -7 & 244 & & \\
\hline 12 & -6 & 224 & \multirow{3}{*}{ weld } & \\
\hline 13 & 0 & 252 & & \\
\hline 74 & 6 & 228 & & \\
\hline 75 & 7 & 233 & \multirow{6}{*}{$\ln 617$} & \\
\hline 18 & 8 & 222 & & \\
\hline 17 & 9 & 230 & & \\
\hline 18 & 11 & 211 & & \\
\hline 19 & 76 & 791 & & \\
\hline 20 & 26 & 173 & & \\
\hline
\end{tabular}

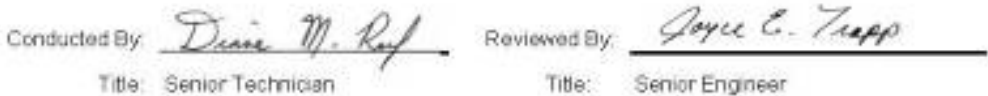

The peot that ont be

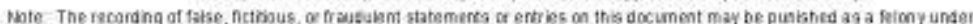

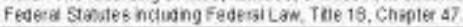




\section{Vickers Hardness Test Results - GRAPH}

Project Number: 50399CSP-03

Job No.: 2007-114725

Date: July 2, 2007

Customer: Jose Ramirez

Technician: D. Reef

Address:

Specimen No:: AW-mid

Load: $0.5 \mathrm{kgf}$

Specification:

Tester: LECO - 293295

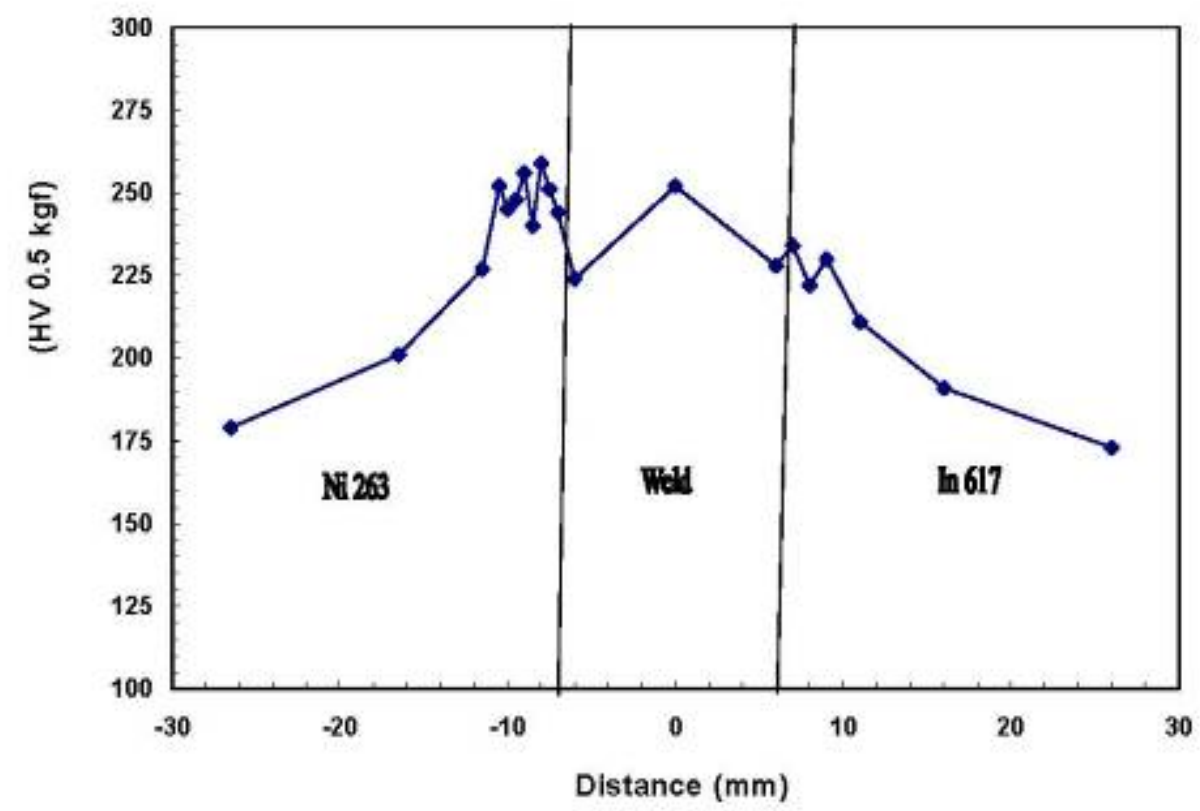

Notec. The racording of false, fictnous, or fraudulant stetements or entries on this document may be punished as a felony under Federal Statutes includng Federal Lav, Title 18 Chapter 47 
EU⿱日一)

1250 . Arther E. Adame Dove Columbus OH $4322 \%$ Lob Services

\section{Vickers Hardness Test Results - ASTM E92}

Project No.: 50399CSP-03

Customer: Jose Ramirez

Job No.: 2007-114725

Address:

Specimen No.: Aviroot:

\begin{tabular}{|c|c|c|c|}
\hline Indent No. & $\begin{array}{c}\text { Distance } \\
(\mathrm{mm})\end{array}$ & $\mathrm{HV}$ & $\begin{array}{c}\text { Indent } \\
\text { Location }\end{array}$ \\
\hline 1 & 245 & 215 & \multirow{11}{*}{$\operatorname{No} 263$} \\
\hline 2 & -14.5 & 243 & \\
\hline 3 & .95 & 224 & \\
\hline 4 & -85 & 235 & \\
\hline 5 & .8 & 251 & \\
\hline 6 & -7.5 & 255 & \\
\hline 7 & -7 & 244 & \\
\hline 8 & -6.5 & 231 & \\
\hline$\frac{9}{8}$ & -6 & 232 & \\
\hline 10 & .55 & 234 & \\
\hline 11 & -5 & 264 & \\
\hline 12 & -4 & 234 & \multirow{3}{*}{ weld } \\
\hline 13 & D & 245 & \\
\hline 14 & 4 & 244 & \\
\hline 15 & 5 & 253 & \multirow{6}{*}{ h 617} \\
\hline 18 & 8 & 228 & \\
\hline 17 & 7 & 228 & \\
\hline$\overline{T B}$ & 8 & 219 & \\
\hline 19 & 14 & 191 & \\
\hline 20 & 24 & 201 & \\
\hline
\end{tabular}

Date: July 2, 2007

Technician: 0 . Reet

Specification:

Tester: LECO - 293295

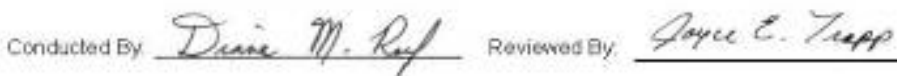

Title: Serior Technician Titbe: Serior Engineer

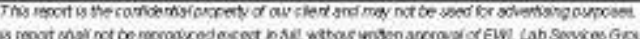

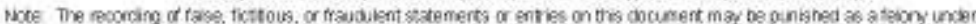
Fostera Strates including Federa Law, The 98 , Chapter 47. 


\section{Vickers Hardness Test Results - GRAPH}

Project Number: 50399CSP-03

Customer: Jose Ramirez

Job No.: 2007-114725

Address:

Specimen No.: AW-root

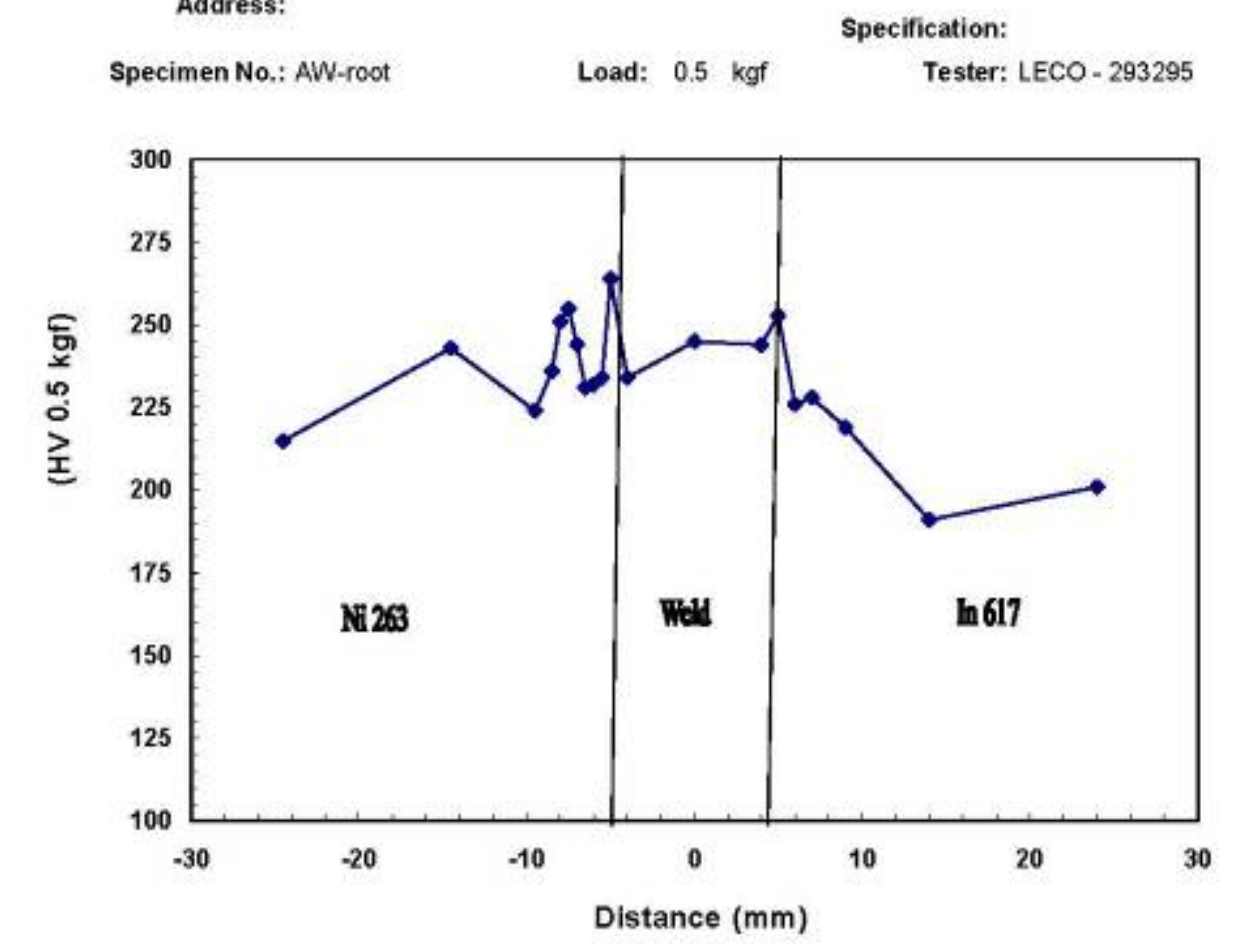

Notec The recording of false, fictnous, or frajdulant stetements or entries on this document may be punished as a felony under Federel Statutes includng Federal Lav, Title 18 Chapter 47

$\begin{array}{lr} & \text { Specification: } \\ \text { Load: } 0.5 \mathrm{kgf} & \text { Tester: LECO }-293295\end{array}$

Technician: D. Reef

Date: July 2, 2007 
EUIF.

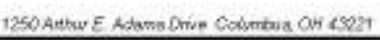
Lab Services

Vickers Hardness Test Results - ASTM E92

Project No: 50999GTH-03

Customer: Joce Riamirez

Job No.: 2003-115171

Date: July 11, 2007

Address:

Technician: D. Rect

Specimen Na: HT-cap

Load: $05 \mathrm{kgg}$

Specinication:

\begin{tabular}{|c|c|c|c|}
\hline Indent No. & $\begin{array}{c}\text { Distance } \\
\text { (mm) }\end{array}$ & HN & $\begin{array}{l}\text { Indant } \\
\text { Location }\end{array}$ \\
\hline 1 & \begin{tabular}{|l|}
.26 \\
\end{tabular} & 345 & \multirow{11}{*}{ Ni 263} \\
\hline 2 & 165 & 332 & \\
\hline 3 & -115 & 385 & \\
\hline 4 & .105 & 322 & \\
\hline 5 & -10 & 340 & \\
\hline 6 & .85 & 350 & \\
\hline 7 & -9 & 353 & \\
\hline 8 & -8.5 & 334 & \\
\hline 8 & -8 & 942 & \\
\hline 10 & -75 & 364 & \\
\hline 11 & -7 & 324 & \\
\hline 12 & -8 & 270 & \multirow{3}{*}{ vesid } \\
\hline 13 & 0 & 257 & \\
\hline 14 & 8 & 307 & \\
\hline 15 & 7 & $2 \%$ & \multirow{6}{*}{$\ln 617$} \\
\hline 16 & 8 & 276 & \\
\hline 17 & 9 & 287 & \\
\hline 18 & $\pi 1$ & 279 & \\
\hline 19 & 18 & 256 & \\
\hline 20 & 25 & 281 & \\
\hline
\end{tabular}

Tester: LEOO - 293295

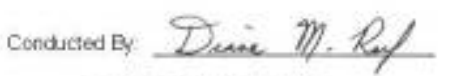

Reviemeday Slopec C. Teepo

Trle Senior Technician

Title Senior Engneer

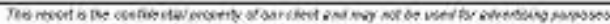

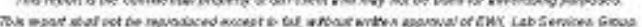

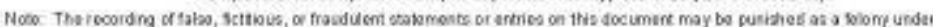
Foserd Sialues ind wing Fadeal Les, THe 1B, Chaper 4 t. 


\section{Vickers Hardness Test Results - GRAPH}

Project Number: 50399GTH-03

Job No.: 2008-115171

Date: July 11, 2007

Customer: Jose Ramirez

Technician: D. Reef

Address:

Specimen No.: HT-cap

Load: $0.5 \mathrm{kgf}$

Specification:

Tester: LECO - 293295

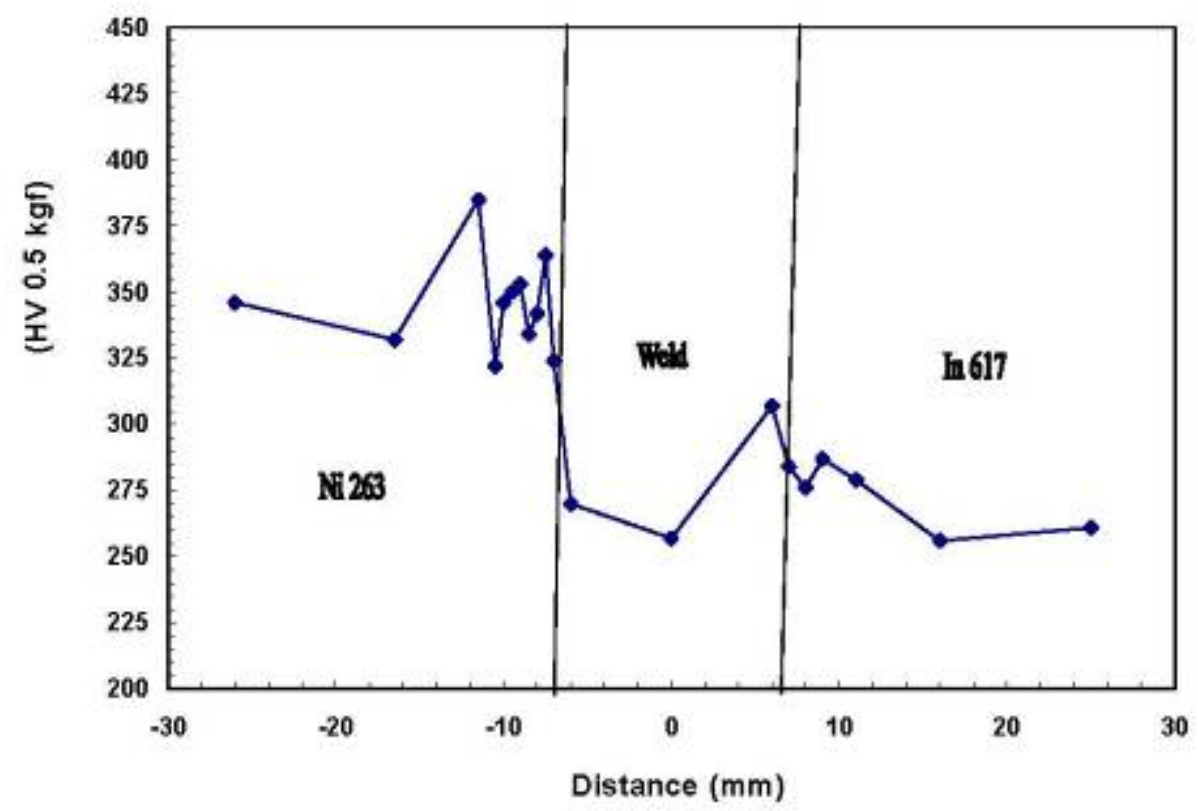

Note. The recording of fal 59 , fictnous, or fraudulant stetements or entries on uns document may be punished as a felony under Federal Statutes includng Federal Lar, Title 18 , Chapter 47 . 
탠.

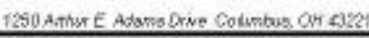

Lab Services.

Vickers Hardness Test Results - ASTM E92

Project Na: $50390 \mathrm{GTH}-03$

Job No:- 2009-115177

Date: aly 11, 200?

Customer: Joge Ramiror

Technician: D Rect

Address:

Specimen Na: HT-mid

Load: $0.5 \mathrm{kgt}$

Specification:

\begin{tabular}{|c|c|c|c|}
\hline Indert No. & $\begin{array}{c}\text { Dstance } \\
(\mathrm{mm})\end{array}$ & HiV & $\begin{array}{c}\text { Indent } \\
\text { Location }\end{array}$ \\
\hline 1 & -265 & 307 & \multirow{11}{*}{ N N. 263} \\
\hline 2 & .165 & 274 & \\
\hline 3 & -115 & 326 & \\
\hline 4 & -905 & 396 & \\
\hline 5 & 10 & 371 & \\
\hline 5 & -95 & 350 & \\
\hline 7 & -9 & 328 & \\
\hline 8 & .85 & 350 & \\
\hline 9 & .8 & 364 & \\
\hline 10 & 7.5 & 348 & \\
\hline 11 & 7 & 336 & \\
\hline 72 & .5 & 313 & \multirow{3}{*}{ weld } \\
\hline 13 & 0 & 297 & \\
\hline 14 & 6 & 255 & \\
\hline 15 & 75 & 304 & \multirow{6}{*}{ In 617} \\
\hline 16 & 85 & 288 & \\
\hline 17 & 85 & 287 & \\
\hline 18 & 115 & 200 & \\
\hline 19 & 165 & 249 & \\
\hline $20^{\circ}$ & 245 & 227 & \\
\hline
\end{tabular}

Tester LECO - 299295

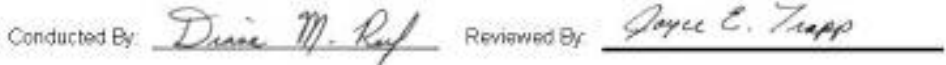

Ttles Senor Technician Ttie Senior Engines
}

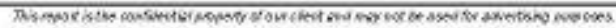

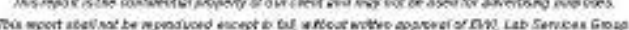

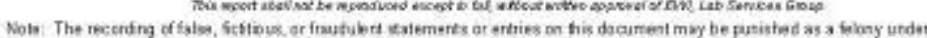
Fedaral Statues inclueng Federai Low. Trib 18, Chapter A? 


\section{Vickers Hardness Test Results - GRAPH}

Project Number: 50399GTH-03

Job No.: 2008-115171

Date: July 11, 2007

Customer: Jose Ramirez

Technician: D. Reef

Address:

Specimen No.: HT-mid

Load: $0.5 \mathrm{kgf}$

Specification:

Tester: LECO - 293295

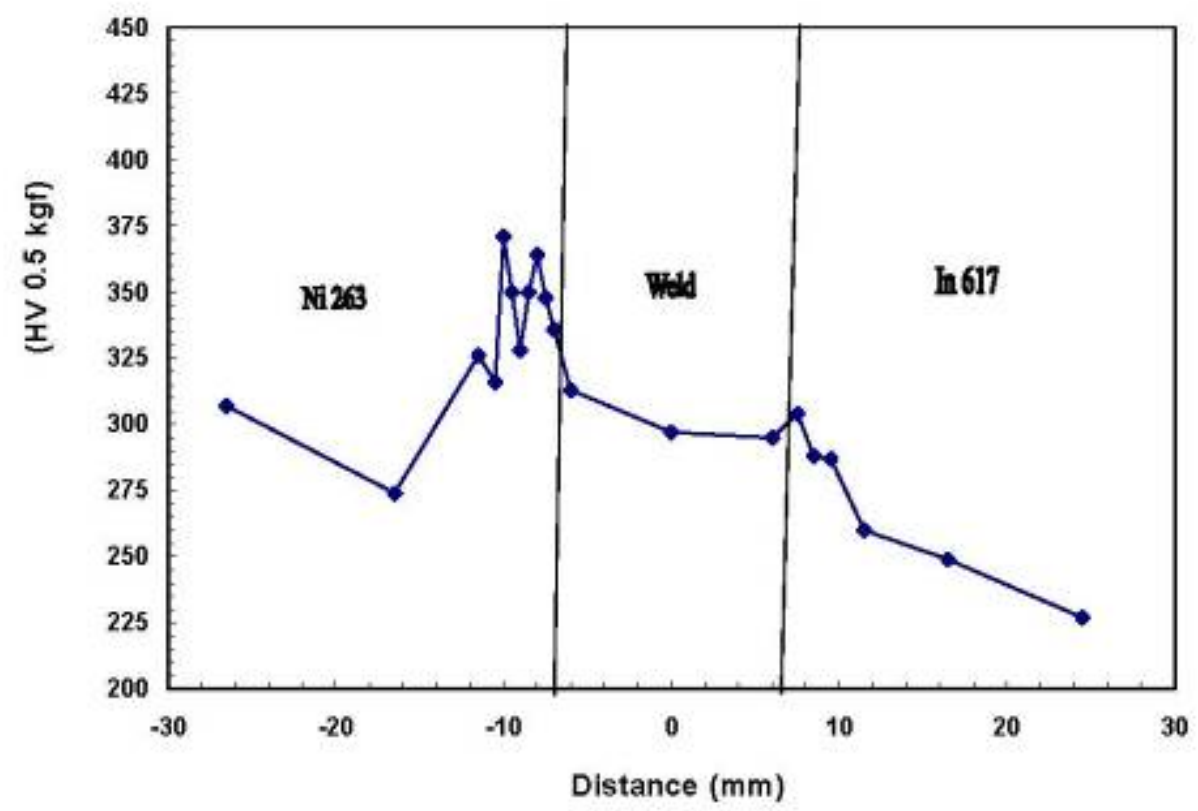

Note. The recording of fal 59 , fictnous, or fraudulant stetements or entries on uns document may be punished as a felony under Federal Statutes includng Federal Lar, Titte 18 , Chapter 47 . 
EU⿱一𫝀口.

1250 A Althur E Acluwa Drive Columbus OH 43227

Lab Services

Vickers Hardness Test Results - ASTM E92

Project No: 503990TH-03

Job No: 2008-115171

Date: Jisy 11, 2007

Customer: Jose Ramirez

Technician: D Reet

Address:

Specimen No: HT-root

Load $0.5 \mathrm{kgt}$

Specifieation:

\begin{tabular}{|c|c|c|c|}
\hline Indert: No. & $\begin{array}{l}\text { Destance } \\
\text { (mm) }\end{array}$ & HV & $\begin{array}{l}\text { Indent } \\
\text { Location }\end{array}$ \\
\hline 1 & -26 & 336 & \multirow{11}{*}{ Ni 263} \\
\hline 2 & -16 & 322 & \\
\hline 3 & -11 & 328 & \\
\hline 4 & .10 & 320 & \\
\hline 5 & -95 & 326 & \\
\hline$\frac{5}{6}$ & 9 & 37 & \\
\hline 7 & 85 & 346 & \\
\hline 8 & -8 & 355 & \\
\hline 9 & -75 & उद & \\
\hline 10 & -7 & 357 & \\
\hline 11 & .65 & 364 & \\
\hline 12 & .55 & 340 & \multirow{3}{*}{ well } \\
\hline 13 & 0 & 326 & \\
\hline 14 & 55 & 300 & \\
\hline 15 & 85 & 309 & \multirow{6}{*}{ In 617} \\
\hline 18 & 75 & 208 & \\
\hline 73 & 85 & 263 & \\
\hline 18 & 305 & 200 & \\
\hline 19 & 155 & 253 & \\
\hline 20 & 235 & 2651 & \\
\hline
\end{tabular}

Tester: LECO - 293295

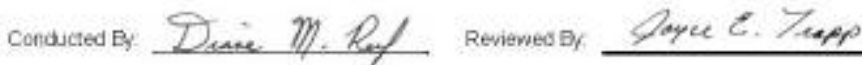

Title: Senior Techniciar

Ttle Senior Engneer

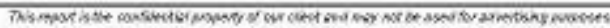

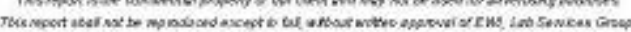

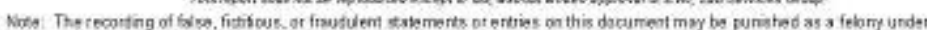

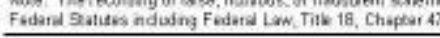




\section{Vickers Hardness Test Results - GRAPH}

Project Number: 50399GTH-03

Job No.: 2008-115171

Date: July 11, 2007

Customer: Jose Ramirez

Technician: D. Reef

Address:

Specimen No.: HT-root

Load: $0.5 \mathrm{kgf}$

Specification:

Tester: LECO - 293295

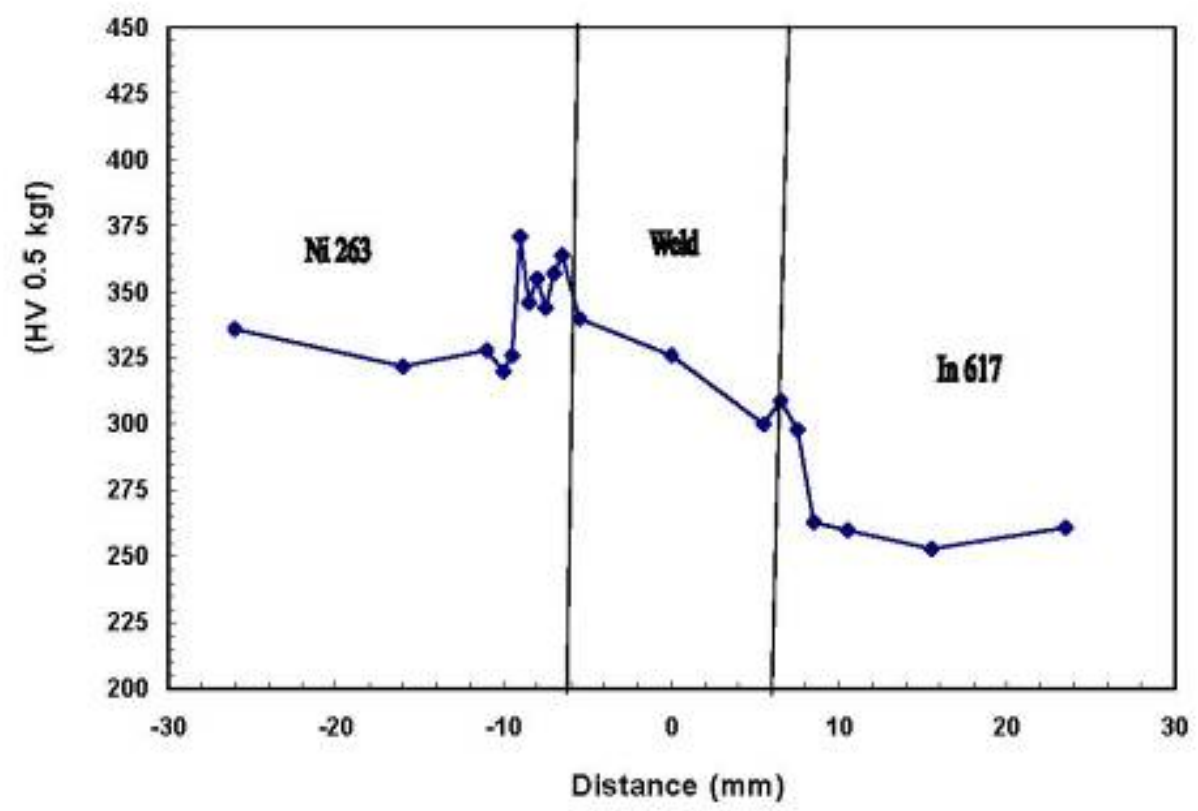

Note. The recording of fal 59 , fictnous, or fraudulant stetements or entries on uns document may be punished as a felony under Federal Statutes includng Federal Lar, Title 18 , Chapter 47 . 



\section{Appendix B \\ Siemens' Report on Process Development for Welded Rotors}

Task 12.2 Welded rotor:

\section{Abstract:}

In support of the Ultra Super Critical Steam Turbine, Udimet 720Li, Haynes 282 and Inconel 617 materials were selected for the rotor disks. As these materials have not been implemented by Siemens for any rotor disk, evaluations of alloy performance was necessary. The goal of this task was an electron beam welding feasibility study of Udimet 720Li to Haynes 282, Haynes 282 to itself and Inconel 617. All studies were completed on small, flat samples. The final results of all three alloy combinations were favorable. The results also showed the Udimet $720 \mathrm{Li}$ alloy had the potential for strain age cracking, and thus special care was required for pre-weld heat-treatment to eliminate cracking.

Boundary conditions:

- Material combinations are Udimet 720Li to Haynes 282, Haynes 282 to itself and Haynes 282 to Inconel 617.

- $\quad$ All welding trials are to be completed on simplified weld samples, not entire rotors, as a feasibility study.

- $\quad$ Use Siemens - Finspong for welding development as weld joint configurations, weld techniques and inspection techniques are currently employed for rotor welding.

- Weld process selection was electron beam welding due to weld penetration requirement, rigidity of postweld component, base alloy selections, weld quality requirements and current available technologies which could accommodate the production size of the component.

Deliverables:

- $\quad$ Acquire named materials for studies.

- $\quad$ Machine small scale samples of proposed weld joints.

- $\quad$ Weld using production techniques at Siemens - Finspong.

- $\quad$ Evaluate per non-destructive and metallographic inspections.

- $\quad$ Evaluate weldability of named alloy combinations using current production techniques.

- $\quad$ Implement any necessary modifications to current techniques to attempt satisfactory welding results.

- $\quad$ Provide small weldability assessment.

\section{Executive Summary:}

In support of the Department of Energy's Ultra Super Critical (USC) steam coal power plants, electron beam welding trials were completed at Siemens - Finspong in support of welded rotors. Alloys had already been downselected based on required mechanical properties and service temperatures. Weld alloy combinations were as follows:

- $\quad$ Inconel 617 to Haynes 282 
- $\quad$ Haynes 282 to itself

- $\quad$ Haynes 282 to Udimet 720Li (low interstitials)

As weld joint configurations, weld techniques and inspection techniques are currently employed for rotor welding at Siemens - Finspong, a strong baseline aided in the efficiency with which favorable results were attained. A summary of those efforts are provided herein.

Simplified weld joints were employed in order to establish welding parameters at approximately 21mm penetration. The Haynes 282 to itself and Haynes 282 to Inconel 617 showed ease of weldability with the main concentration on attaining weld penetrations and slope-out parameters of the electron beam equipment. The slope-out parameters are essential as they occur at the termination of the weld, which will be important once these parameters are transferred from the simplified flat design to the circumferential weld on actual disks. Visual, ultrasonic immersion testing and metallurgical analysis all attained favorable results with these two material combinations. The welds were replicated by completing 3 welds of each at the same welding parameters for a total of six favorable welds.

The same simplified joints were pursued for the Haynes 282 to Udimet 720Li. The preliminary results yielded strain age cracking in the weld heat affected zone of the Udimet 720Li. A reduction in the heat input allowed for crack length reduction. It also directly affected the penetration by a reduction to $18 \mathrm{~mm}$. However, the overall crack distribution was consistent with the previous $21 \mathrm{~mm}$ penetration trial. A series of overage heat treatment studies attained a 120 Vickers hardness reduction of the optimized overage cycle in comparison to the industry standard heat treatment of subsolvus solution plus dual age of Udimet 720Li. The hardness reduction was sufficient to mitigate the cracking upon welding. Additional post-weld heat treatment evaluations were necessary to fully analyze the strain age cracking susceptibility of the Haynes 282-Udimet 720Li system. Multiple variants of the standard Udimet 720Li heat treatment and the Haynes 282 heat treatment were all tried on samples of the Haynes 282-pre-weld overaged Udimet 720Li weld joint. These heat treatments also yielded satisfactory results in areas of visual, nondestructive and metallurgical evaluations. Thus, the welds were crack free.

It can be concluded that all three weld combinations attained favorable weld results via visual, ultrasonic immersion testing and metallographic evaluations on small, flat samples. Additional work is required for a full assessment of manufacturability and fitness for service. Such work would entail the following, although the list may not be allinclusive.

- $\quad$ Post-weld heat treatment optimization for all three alloy combinations for microstructure and mechanical properties.

- $\quad$ Scanning electron microscopy evaluations of the weld Haynes 282-pre-weld overaged Udimet 720Li for understanding of the effects of the various post-weld heat treatments.

- Evaluation of the mechanical performance of the weld joint and base material

- $\quad$ Welding trials on representative parts.

- $\quad$ Heat treatment control of representative parts.

- $\quad$ Non-destructive techniques on representative parts as ultrasonic immersion testing would not be a viable option.

\section{Development:}

Inconel 617 plate, Haynes 282 plate and Udimet 720 Li (low interstitials) powder forged billet were attained for the welding trials. The Udimet $720 \mathrm{Li}$ was ordered to the following conditions:

\section{- Billet:}

Initial billet powder size: -140 mesh

Billet pedigree: sub-solidus HIP (hot isostatic press) + cogged into billet, nominally 9” diameter

Billet Grain size: ASTM 11-12 average, 5-6 ALA 


\section{- Forging:}

Post forge heat treatment: Sub-solvus solution $2020^{\circ} \mathrm{F}\left(1104^{\circ} \mathrm{C}\right) / 2 \mathrm{hrs} /$ oil quench + Age $1202^{\circ} \mathrm{F}\left(650^{\circ} \mathrm{C}\right)$ / 24hrs / Air $+1400^{\circ} \mathrm{F}\left(760^{\circ} \mathrm{C}\right) / 16 \mathrm{hrs} /$ Air

Grain size: ASTM 11 average, ALA 9

All three alloys were either received in the solution heat treatment condition or heat treated in a vacuum of 10-4 torr or better to attain the following solution heat treatment conditions.

- $\quad$ IN 617 Plate

$$
\text { Bright Anneal } 2150{ }^{\circ} \mathrm{F}\left(1176{ }^{\circ} \mathrm{C}\right)
$$

- Haynes 282 Plate

$$
\text { Bright Anneal } 2100^{\circ} \mathrm{F}\left(1150^{\circ} \mathrm{C}\right)
$$

\section{- $\quad$ U720LI Forged Disk}

Sub Solvus solution anneal $2020^{\circ} \mathrm{F}\left(1104^{\circ} \mathrm{C}\right)$

The materials were then machined into samples as shown in Figure 1. All dimensions are in millimeters (mm). Shown are the joint configurations with the alloys identified. In each case of dissimilar weld combination, the easier to weld alloy acted as the weld backing. Ease of welding is rated based on theoretical resistance to strain age cracking as shown in Figure 2. All three named alloys are shown on plot along with other common turbine alloys.
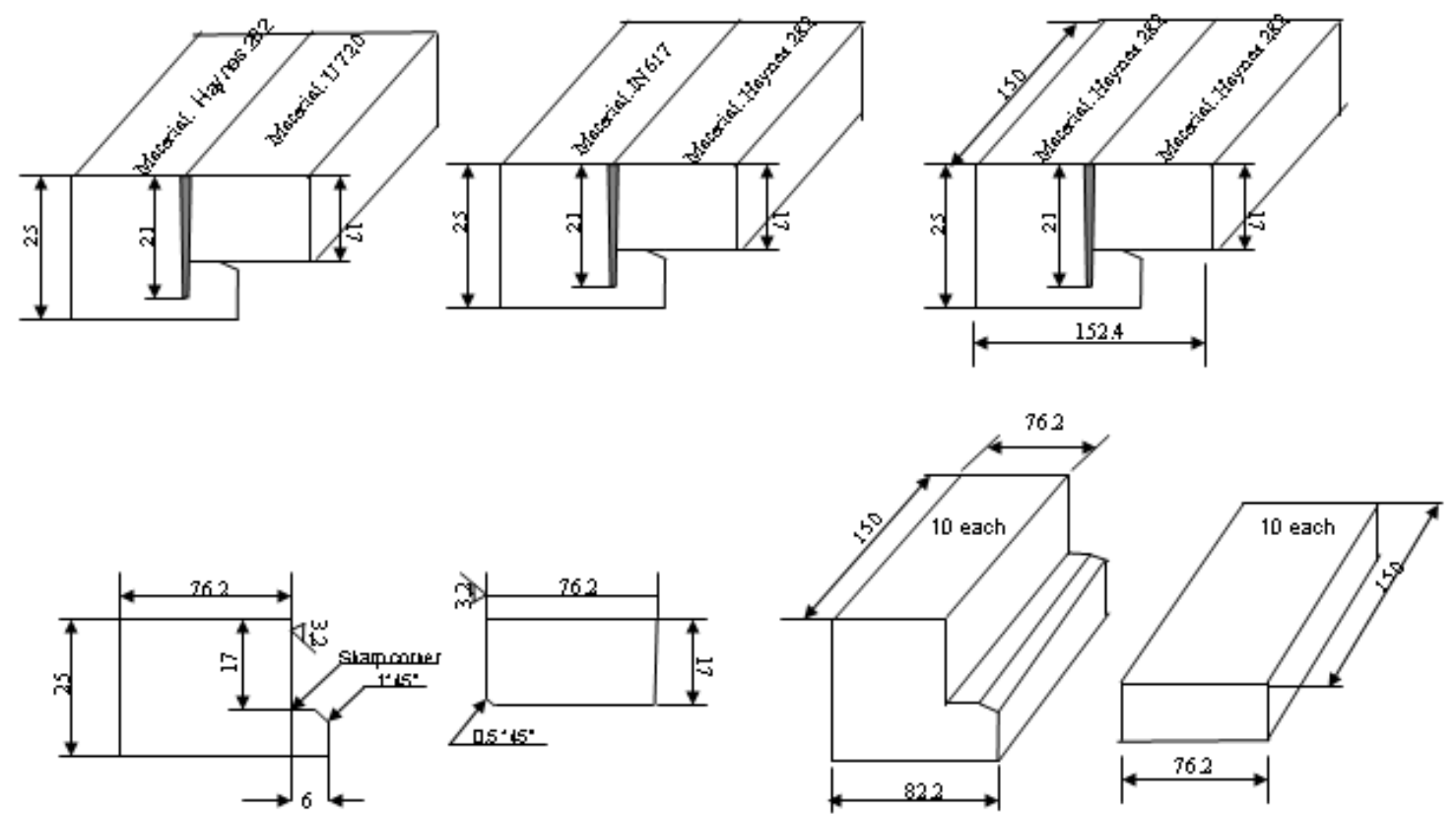

Figure 1. Weld sample dimensions and material combinations. 


\section{Weldability per Resistance to Strain Age Cracking}

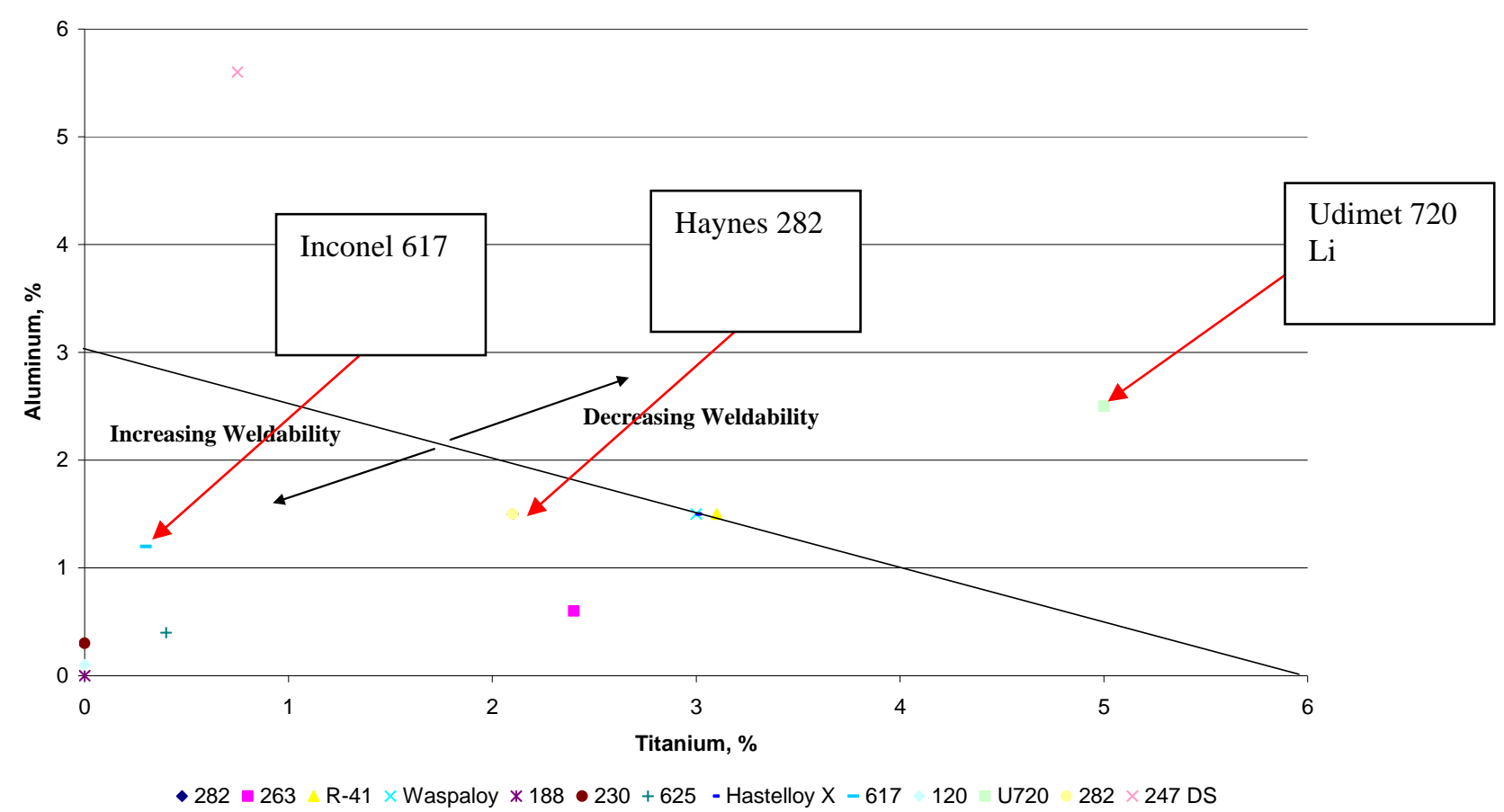

Figure 2. Plot shows theoretical resistance to Strain Age Cracking.

Weld Trial 1

Welds were made for all three welding configurations targeting $21 \mathrm{~mm}$ weld penetration. The welds were made using electron beam welding equipment.

The welds were subsequently visually inspection, immersion tested and metallographically examined. Each weld in all trials had multiple cross sections for metallographic examination; however, representative cross sections are shown herein. Set-up and probe for immersion testing is shown in Figure 3 with key constituents of the weld labeled for future discussion.

Probe:

Krautkramer IAP10.6.3 (10MHz, D=20mm, 75mm PTF)

Water path:

$8 \mathrm{~mm}$

Scanning increment:

$0.5 \mathrm{~mm}$ for both scan (length) and index (depth)

Calibration:

$2 \mathrm{~mm}$ flat bottom hole in steel set at $100 \%$ amplitude

The water path was chosen to have the water-material interface echo away from the weld zone. This locates the sound field focus just in front of the weld zone. 


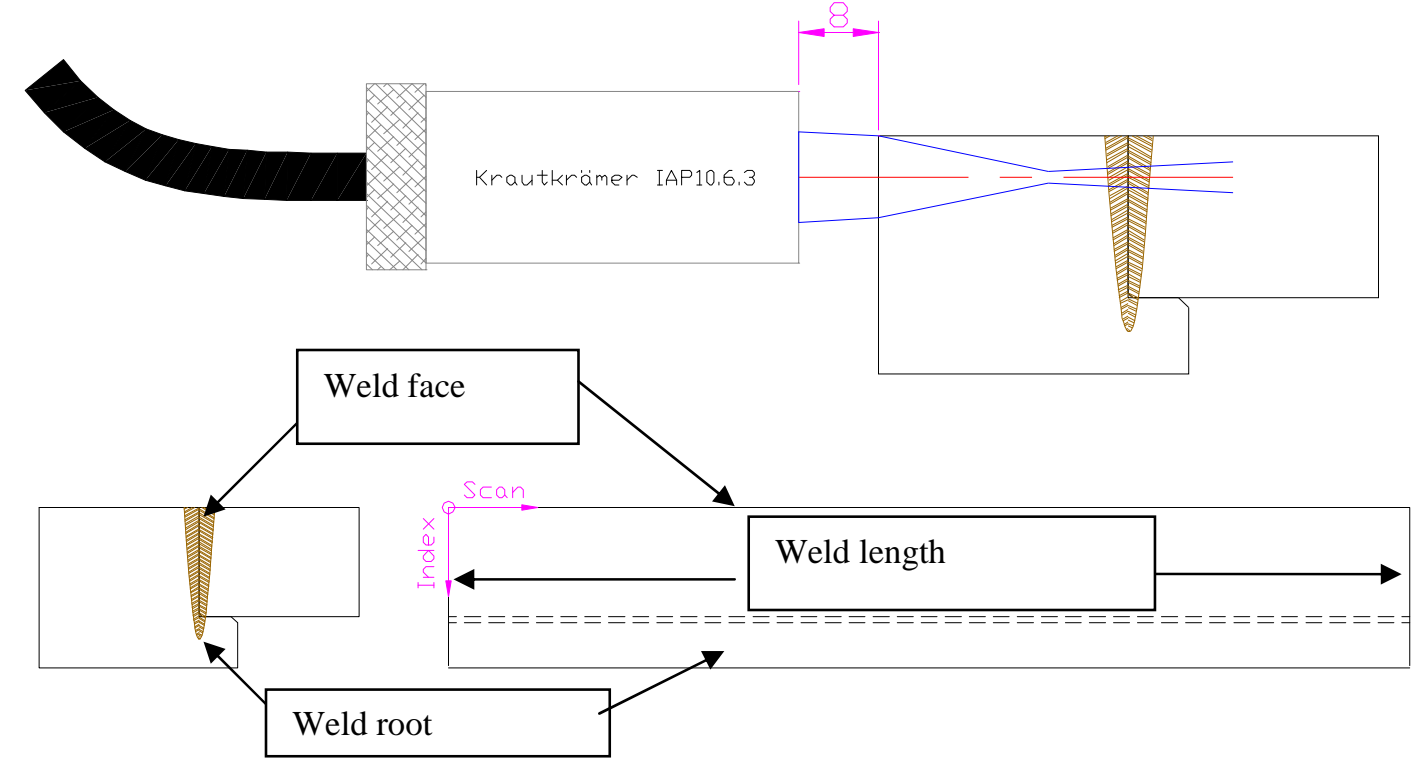

Figure 3. Immersion testing set-up and probe available at Siemens - Finspong is shown.

After welding was completed, all three welds were visually inspected with favorable results. All three welds passed visual inspection. Figures 4 shows a typical completed weld.

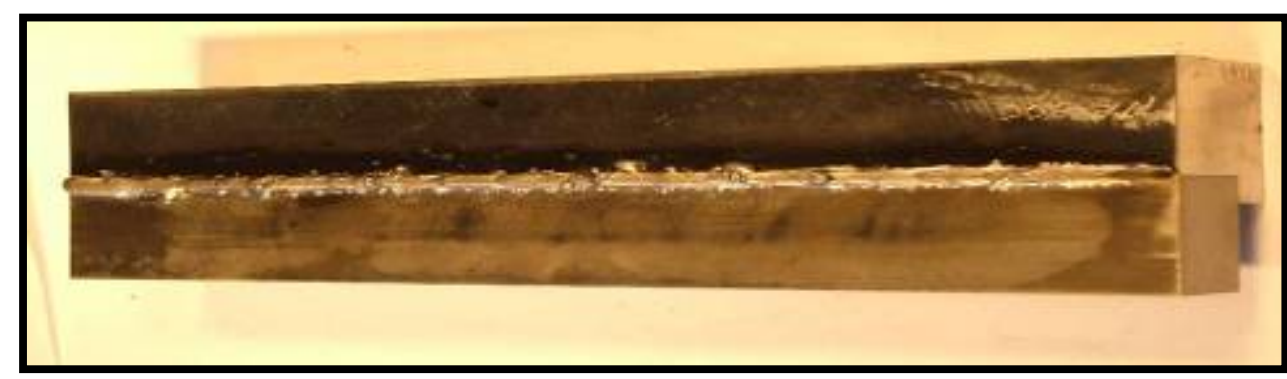

\section{Figure 4. Typical completed E-beam weld.}

Figure 5 shows the results of the immersion testing for Trial 1. Ultrasonic immersion testing was completed in order to detect the length and depth with respect to axis of the weld. The length of the indications was correlated directly from the resultant image. The depth of the defects was to be established by employing test blocks with known reflection depths. The results of the ultrasonic testing determined locations of metallographic cross sections. The defect depths were to be validated as part of the actual measurements from the metallography.

Regarding weld combinations of Haynes 282 to itself and Inconel 617 to Haynes 282 from Trial 1, immersion testing only identified defects corresponding to less than full penetration at the starts and stops. These indications were a result of the slope in and slope out of the welding parameters. In production, the circumferential welded rotor would consume the weld start via weld overlap but the weld stop must have good weld quality. For this reason, trial two attempted to optimize the slope-out effect to prevent these defects.

For weld combinations of Haynes 282 to Udimet $720 \mathrm{Li}$, indications were detected throughout the weld joint. As the ultrasonic immersion test provides a scale along the length of the weld, cutting (for metallurgical examination) was completed in areas of significant indication findings. Also shown is a depth scale with " 0 " being the weld face. 

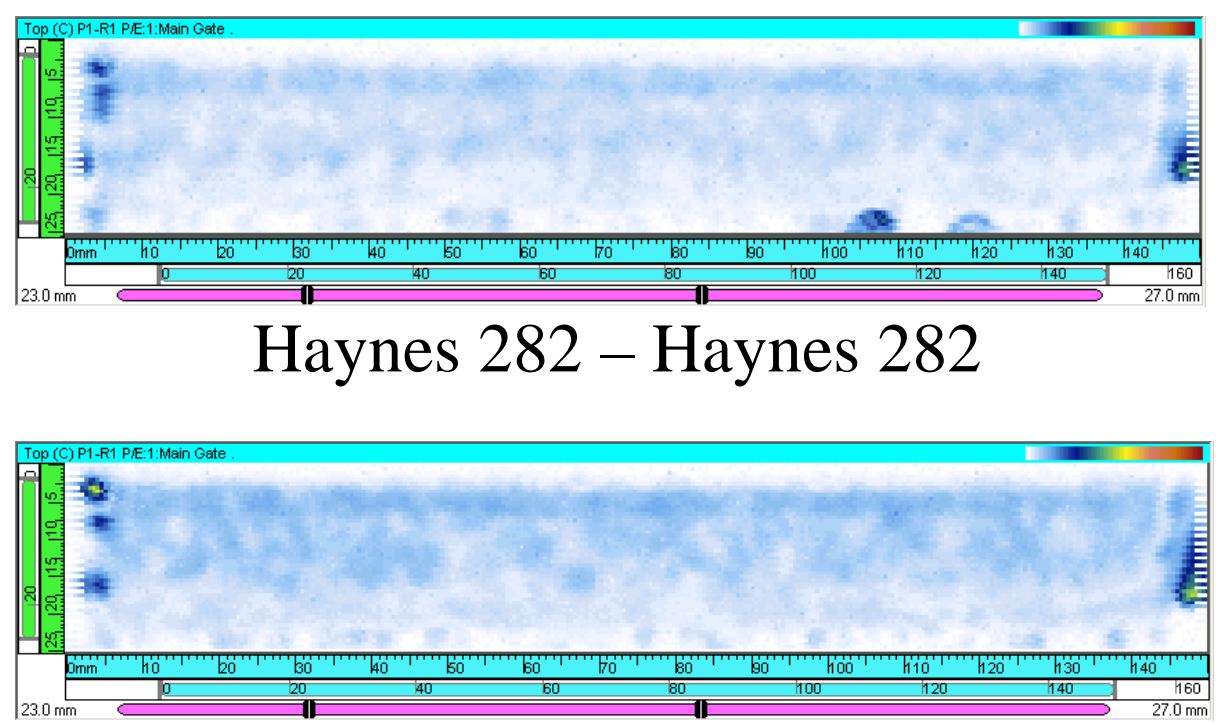

\section{Haynes 282 - IN617}

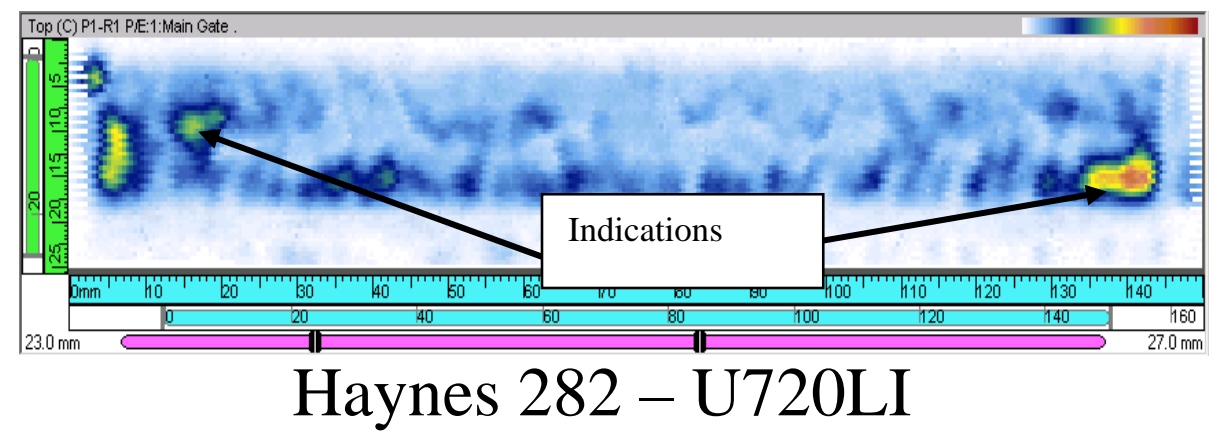

Figure 5. Results of immersion testing from Trial 1. Haynes 282 to 282 and Haynes 282-617 show minor indications at the start and stops. Haynes 282 to Udimet $720 \mathrm{Li}$ show numerous defects.

Metallographic results from Trial 1 are provided in Figure 6. The cross-section for Inconel 617 to Haynes 282 and Haynes 282 to itself were taken in regions away from the starts and stops of the welds and showed favorable weld quality and penetration. The metallography confirmed the Haynes 282 to U720Li had significant indications. Further investigation showed the Haynes 282 to Udimet 720 Li yielded cracking in the heat affected zone (HAZ) of the weld in the U720Li base material. The cracking was intergranular as shown in Figure 7. 

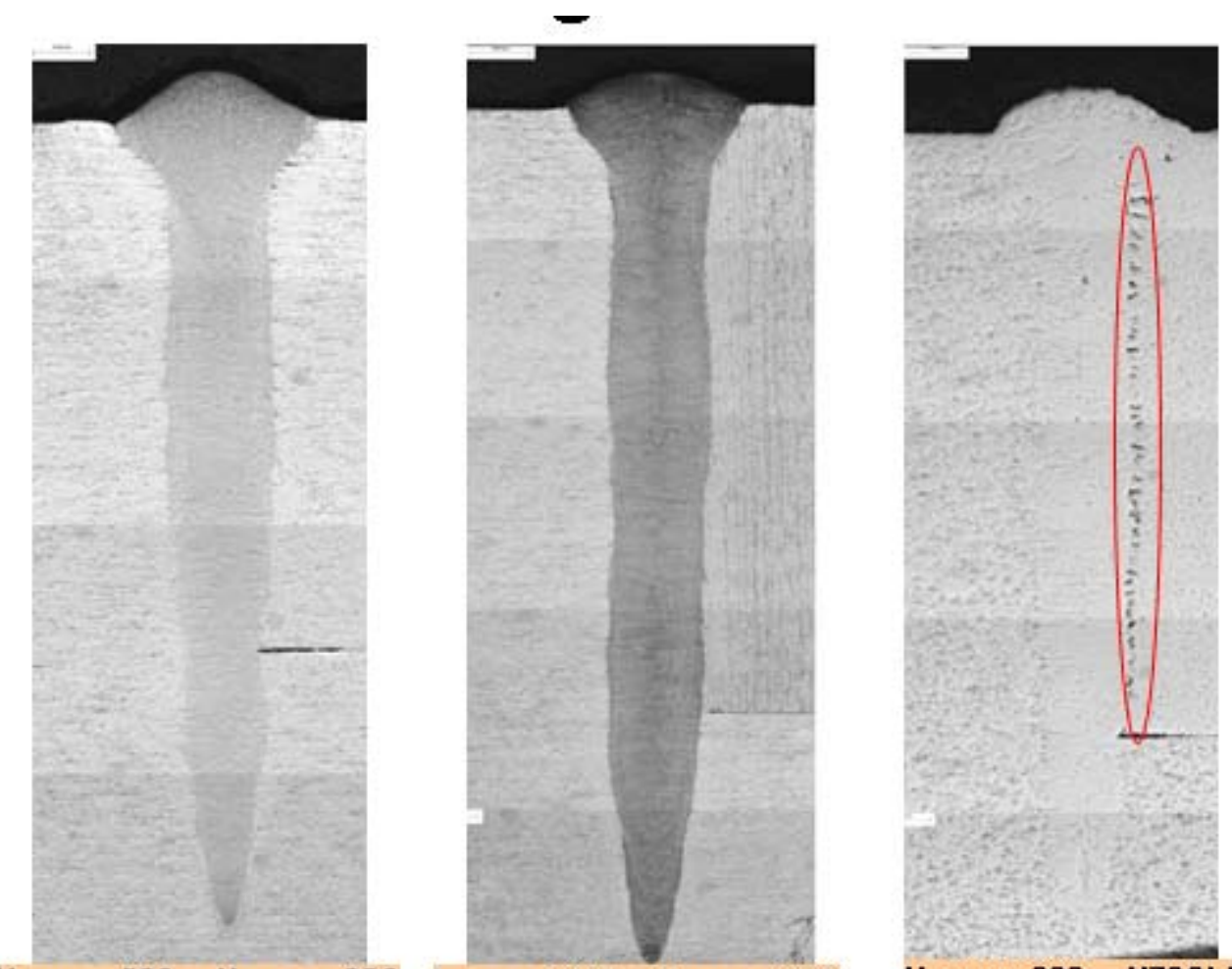

Haynes 282 - Haynes 282 Inconel 617 - Haynes 282

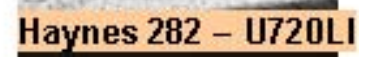

Figure 6. Metallographic examination in Trial 1 confirming ultrasonic examination findings including defects in the Haynes 282 to Udiment 720Li joint.

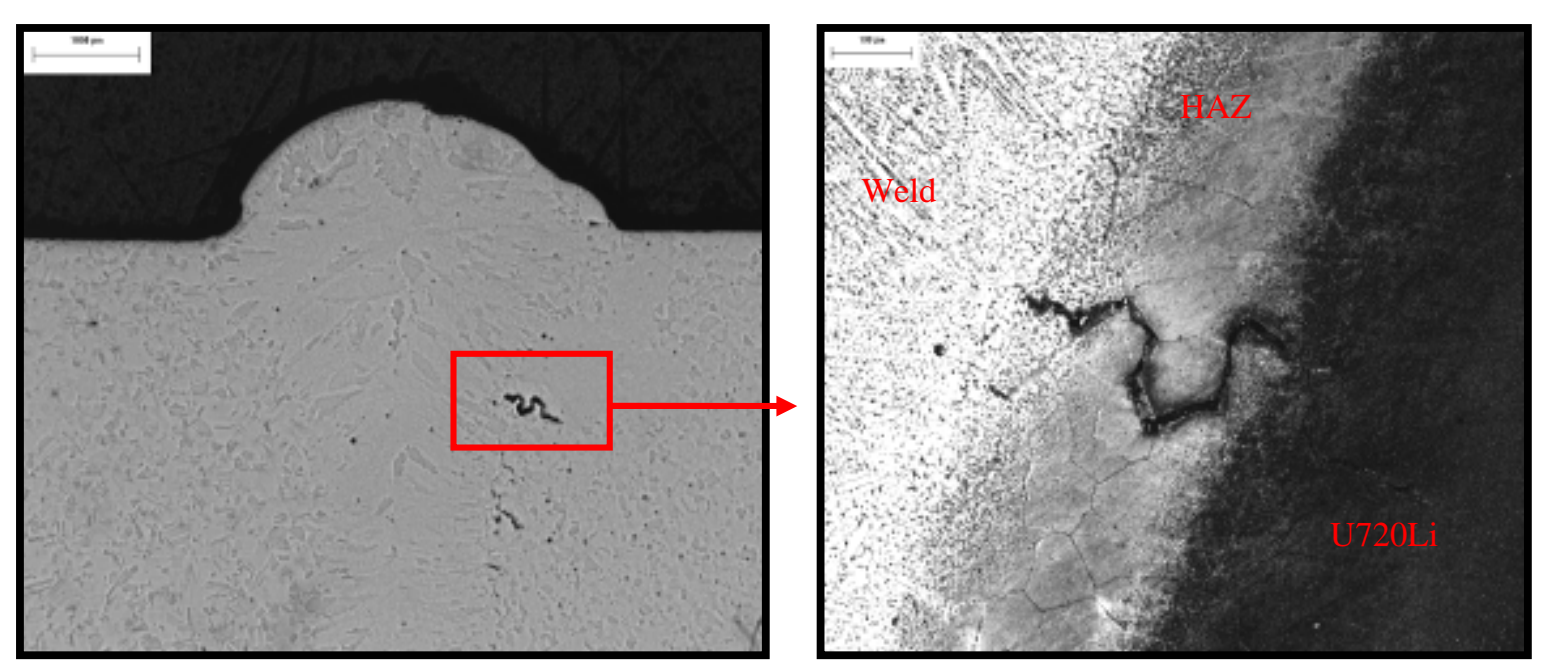

Figure 7. Intergranular cracking in heat affected zone adjacent is portrayed.

For the Haynes 282 to itself and Haynes 282 to Inconel 617 material combinations, the weld slope at the termination of the welding required improvement. This was the goal for trial 2 for these two alloy combinations. For the Udimet 720Li to Haynes 282, the cracking was determined to be the result of strain age cracking in the as-welded condition. Essentially, the aluminum and titanium content of the alloy directly correlate to the gamma prime amount in the microstructure. Optimized gamma prime size and amount provides a significant amount of creep resistance for U720Li. As a set-back to alloys with significant creep resistance, the heat affected zones and/or welds do not have enough ductility to compensate for the stresses induced by welding. Thus, cracking occurs and typically 
intergranularly. As a goal of trial 2, the heat input for the weld was reduced to evaluate the effects on the cracking. Figure 8 shows the ultrasonic test results for weld trial 2.
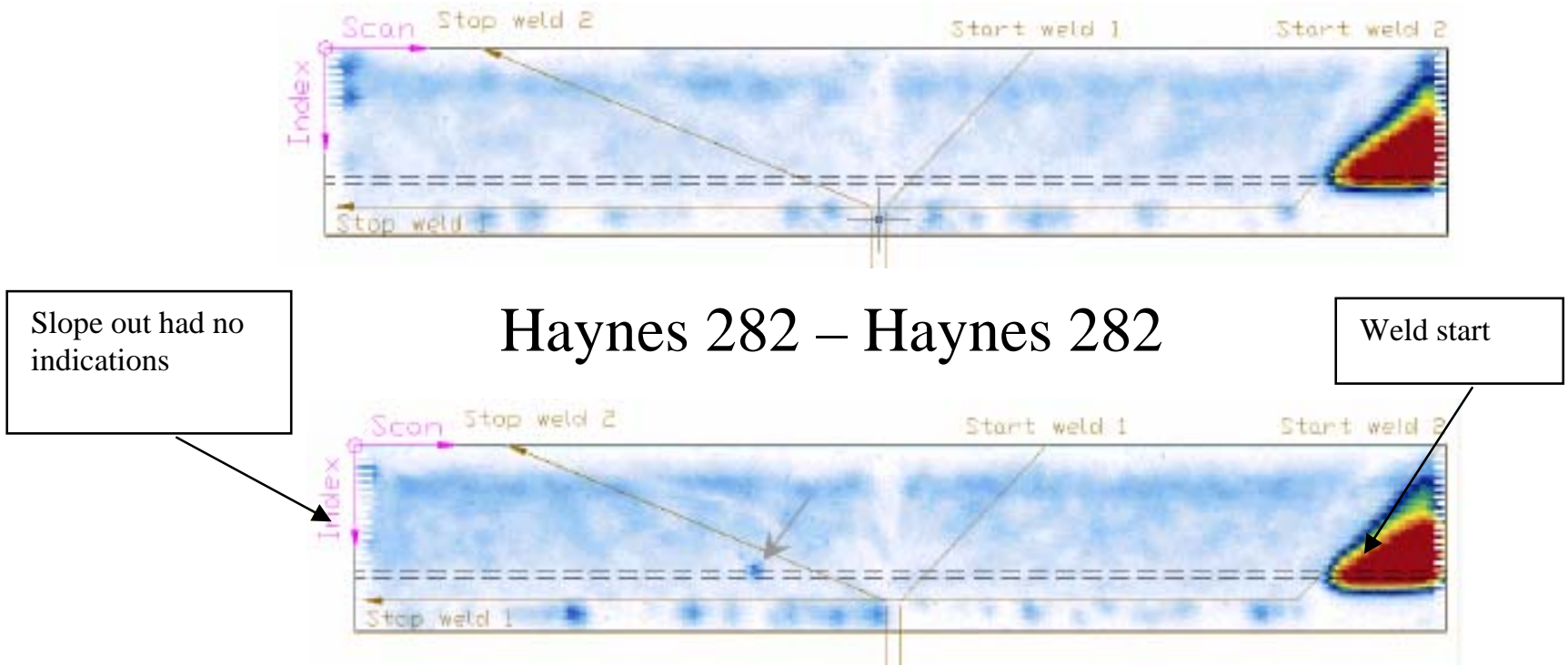

\section{Haynes 282 - IN 617}

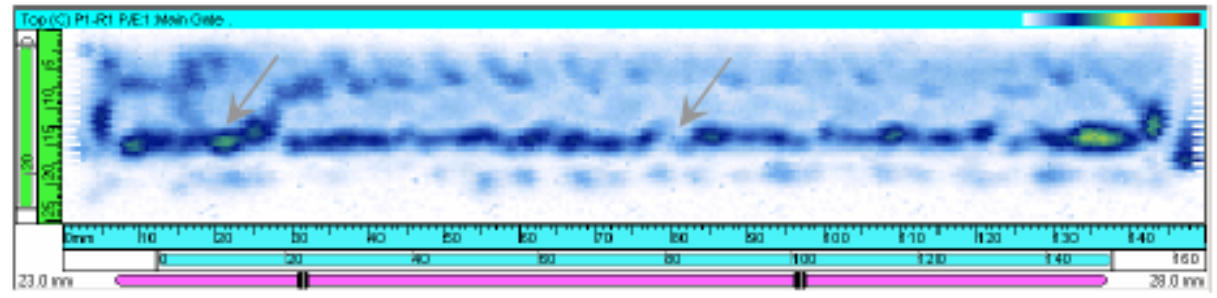

\section{Haynes 282 - U720LI}

Figure 8. Ultrasonic immersions results for trial 2.

The slope-out weld parameters for Trial 2 had favorable results as shown by the non-destructive evaluations in Figure 8. As expected, the weld starting point still shows the slope-in effect. However, the Haynes 282 to Udimet 720Li weld still shows indications throughout the weld joint per the ultrasonic scan in the as-welded condition.Metallurgical results for the three welds are shown in Figure 9. Except at the start of the weld, the metallographic sections of Inconel 617 to Haynes 282 and Haynes 282 to itself have favorable results in both weld quality and penetration. The welds were crack free. For the Haynes 282 to Udimet $720 \mathrm{Li}$, strain age cracking is still apparent in the weld heat affected zone of the Udimet $720 \mathrm{Li}$ base material in the as-welded condition. The weld penetration was also decreased to $18 \mathrm{~mm}$ as a result of reduced heat input. 

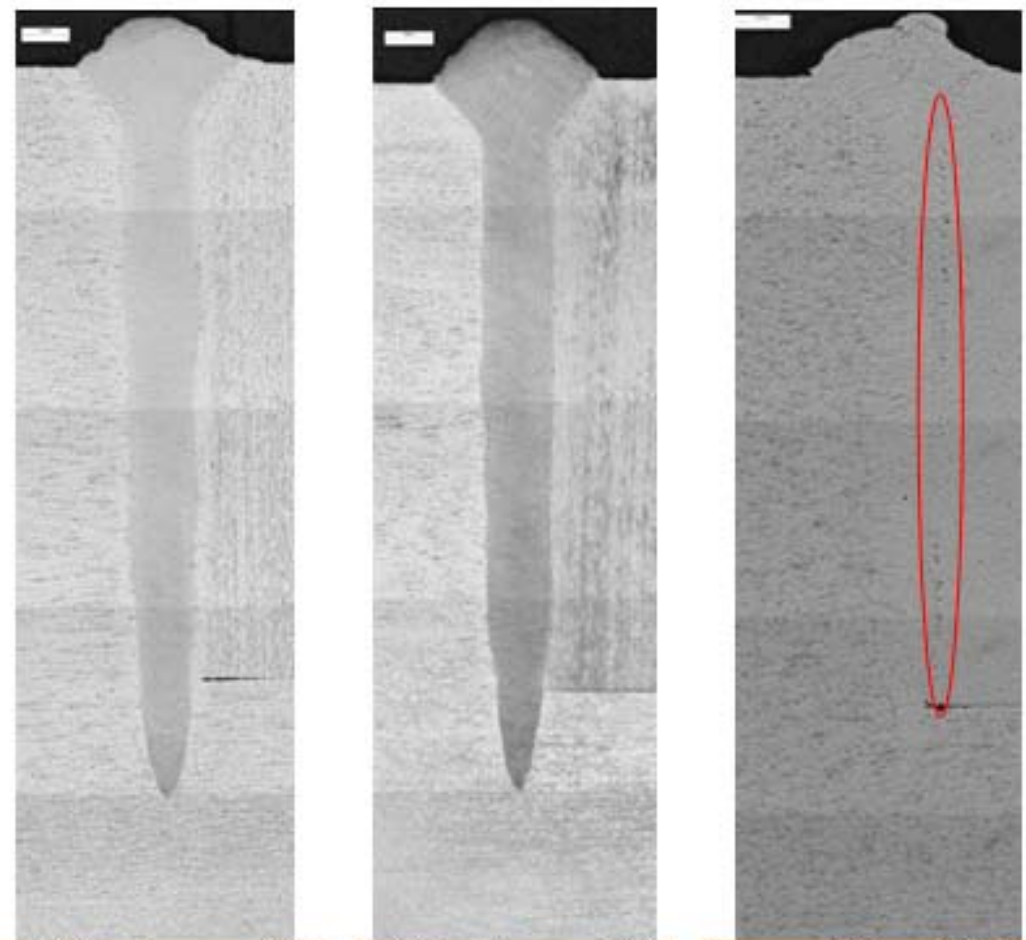

Haynes 282 - Haynes 282 IN617 - Haynes 282 Haynes 282 - U720LI

Figure 9. Metallographic cross-sections from Trial 2.

To mitigate the strain age cracking for use in weld trial 3 for the Haynes 282 to Udimet 720Li material combination, the following options were considered:

- Overage the Udimet $720 \mathrm{Li}$ to change the size and distribution of gamma prime and thus reduce the hardness. This should result in increased ductility.

- Pre-heat the material to reduce the quench effect of the heat affected zone.

\section{Weld Trials $3 \& 4$}

While considering both probable options to mitigate the strain age cracking, Udimet 720 Li overage heat treatments were explored to evaluate the potential hardness reductions and gamma prime microstructure changes.

Three different heat treatments in a vacuum of 10-4 torr or better were compared to the baseline, which is an industry recommended heat treatment of U720Li. The heat treatments were labeled as Samples W-4, W-6 and W-9, and the industry recommended is referred to 'As Received'. The 'As Received' heat treatment is intended to optimize the gamma prime size and amount as well as age hardening precipitation; said heat treatment is intended to optimize creep properties but not weldability.

After heat treatment, the samples were cut, mounted, polished, etched and evaluated on the Scanning Electron Microscope (SEM). SEM images are shown in Figure 10. Vickers hardness values were attained by using a 50g load cell. Hardness decreased significantly with the over-aging treatments as compared to the 'as' received standard solution anneal and double age heat treated Udimet 720Li. This was attributed to the difference in primary, secondary and tertiary gamma prime sizes and their distributions within the microstructures. 

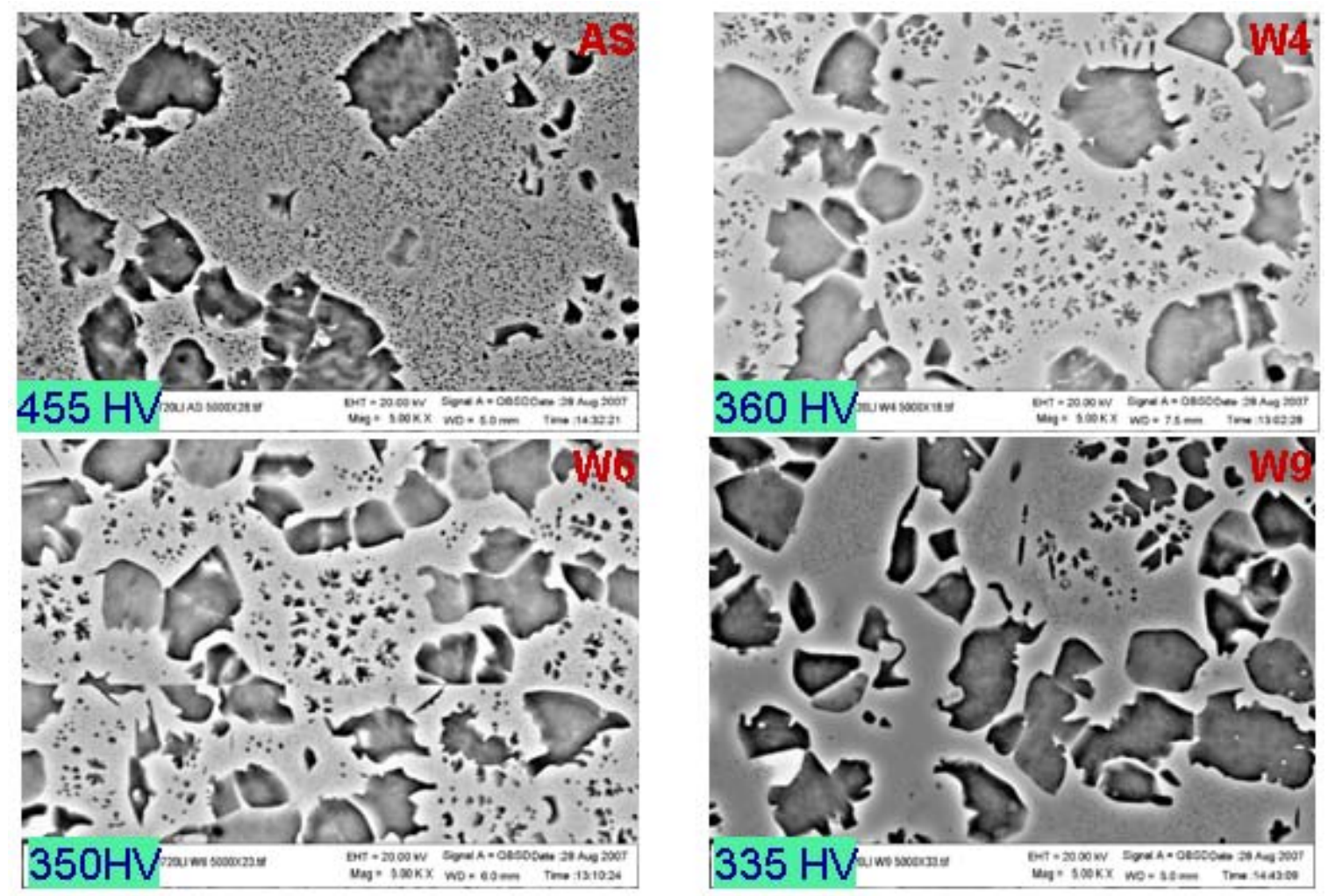

Figure 10 Microstructures of the as-received, W-4, W-6 and W-9 heat treatments as well their corresponding average Vickers hardness values.

For the Haynes 282 to itself and Inconel 617 to Haynes 282, trial 2 was reproduced on two additional welds of each material combination totaling three welds each at Trial 2 welding parameters. This represented Trials 3 and 4 for these material combinations. The purpose was to review the repeatability of results. Visual, ultrasonic immersion testing and metallographic evaluations were consistent with Trial 2 and deemed acceptable.

As for the Haynes 282 to Udimet 720Li material combination, Udimet 720Li was given the W9 pre-weld overage heat treatment prior to welding. Then, the alloy combination was welded with the same welding parameters as used in Trial 2 which had the reduced heat input. The results were favorable per the ultrasonic testing shown in Figure 11. Figure 12 shows multiple cross sections are shown of the microstructure which were free of heat-affected zone cracks. This include one metallographic section that contained weld spiking, which is a typical upset condition in electron beam welded microstructures.

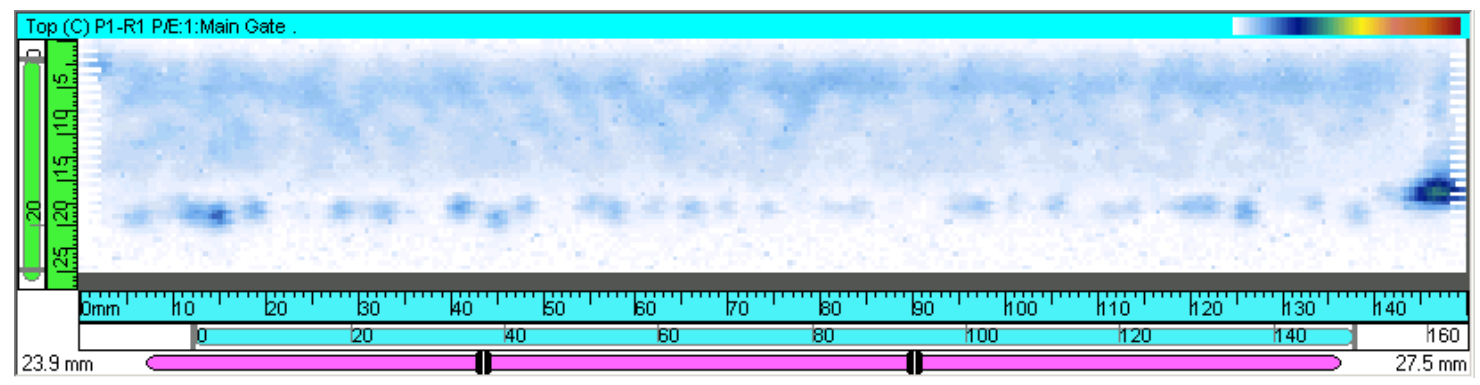

Figure 11. Immersion test of Trial 3 for Haynes 282 to Udimet 720Li has favorable results. 


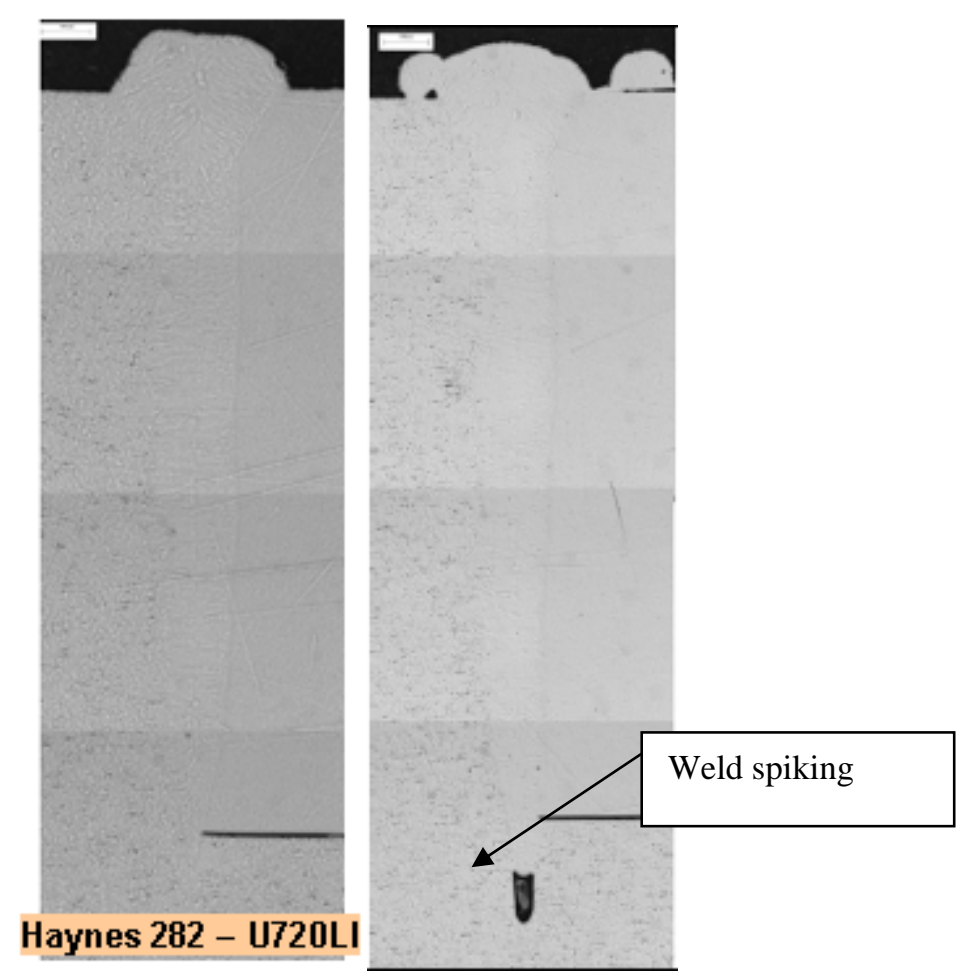

Figure 12. Metallographic sections of Trial 3 for Haynes 282 to Udimet $720 \mathrm{Li}$ have favorable results. Weld spiking of electron beam processing is shown in the image on the right. Favorable results (no optically observable cracking) were obtained even with the process upset.

Given that the welds yielded good results with no cracking in the as-welded condition, it was essential to evaluate the welds after post-weld heat treatment conditions. The main focus was the Haynes 282 to Udimet 720Li material combination since the extent of gamma prime strengthening and age hardening had the highest probability for postweld heat treatment cracking.

For comparison purposes, the industry-recommended heat treatments for each alloy are shown below.

- $\quad$ IN 617 Plate

Bright Anneal $2150{ }^{\circ} \mathrm{F}\left(1176{ }^{\circ} \mathrm{C}\right)$

- Haynes 282 Plate

Bright Anneal $2100^{\circ} \mathrm{F}\left(1150^{\circ} \mathrm{C}\right)+1850^{\circ} \mathrm{F}\left(1010{ }^{\circ} \mathrm{C}\right) / 2 \mathrm{hr} / \mathrm{air}+1450^{\circ} \mathrm{F}\left(788^{\circ} \mathrm{C}\right) / 8 \mathrm{hr} / \mathrm{air}$

- U720LI Forged Disk

Sub-solvus solution anneal $2020^{\circ} \mathrm{F}\left(1104^{\circ} \mathrm{C}\right) / 2 \mathrm{hrs} /$ oil quench + Age $1202^{\circ} \mathrm{F}\left(650{ }^{\circ} \mathrm{C}\right) / 24 \mathrm{hrs} /$ air + $1400^{\circ} \mathrm{F}\left(760^{\circ} \mathrm{C}\right) / 16 \mathrm{hrs} /$ air

For the Inconel 617, the material is typically used in the solution annealed condition. The Haynes 282 has a solution anneal followed by a dual age for gamma prime optimization and age hardening. The Udimet 720Li has a subsolvus solution anneal also followed by a dual age for gamma prime optimization and age hardening. As with most dissimilar weld joints, a compromise post-weld heat treatment must be established. For similar alloys, as with the Haynes 282 to itself, the dual age or solution heat treatment plus dual age of Haynes 282 would be its post weld heat treatment. The investigation was, however, only pursued on the Haynes 282 to Udimet 720Li. Since an optimized heat treatment had not yet been established for generating the best possible mechanical properties, three different heat treatments on three pieces cut from welded Trial 3 were completed. Those heat treatments were completed in a vacuum of 10-4 torr or better. The heat treatments are detailed below. 
- Sample 1: The Udimet 720Li subsolvus heat treat plus dual age was completed on one piece of the welded sample

2020F $\left(1104^{\circ} \mathrm{C}\right) / 2$ hours / Oil or water quench to room temperature

$1202 \mathrm{~F}\left(650^{\circ} \mathrm{C}\right) / 24$ hours / Air Cool

$1400 \mathrm{~F}\left(760^{\circ} \mathrm{C}\right) / 16$ hours / Air Cool

- $\quad$ Sample 2: The Haynes 282 solution heat treat plus dual age was completed on one piece of the welded sample

$2075 \mathrm{~F}\left(1135^{\circ} \mathrm{C}\right) / 2$ hours / Oil or water quench to room temperature

$1850 \mathrm{~F}\left(1010^{\circ} \mathrm{C}\right) / 2$ hours / Air cool

$1450 \mathrm{~F}\left(788^{\circ} \mathrm{C}\right) / 8$ hours / Air cool

- Sample 3: The Udimet 720Li subsolvus heat treatment plus secondary age (no primary age) was completed on one piece of the welded sample.

\section{F $\left(1104^{\circ} \mathrm{C}\right) / 2$ hours / Oil or water quench to room temperature \\ 1400F $\left(760^{\circ} \mathrm{C}\right) / 16$ hours / Air Cool}

After heat treatment, the samples passed visual inspection as well as metallurgical evaluations as shown in Figure 13. The weld penetration is consistent with that seen in Trial 2 of the Haynes 282 to Udimet 720Li weld; the penetration is $18 \mathrm{~mm}$. It is recommended to increase the weld penetration by increasing the heat input as well as implementing the slope out parameters developed for the other material combinations. Further analysis was completed on these samples per Vickers hardness evaluations. Using a 500g load, Vickers readings were taken in the Haynes 282, the weld and the U720Li for each heat treatment condition. Those results are compiled in Table 1. Additional analysis is required to draw conclusions of these hardness readings.

\section{$\underline{\text { Summary }}$}

In summary, a preliminary study on the use of electron beam welding for joining A-USC alloy combinations was completed with favorable results. Defect free weldments were made between Haynes 282 and itself, Haynes 282 and 617, and Haynes 282 and Udimet 720Li. The most challenging joint was Udimet 720Li to Haynes 282 which required careful control of pre-weld heat-treatment and welding parameters. Post-weld heat-treatments were successfully completed but a much more thorough investigation is needed including mechanical property testing of the weld joint and scale-up of the technology before the results can be used to develop procedures for an A-USC turbine. 

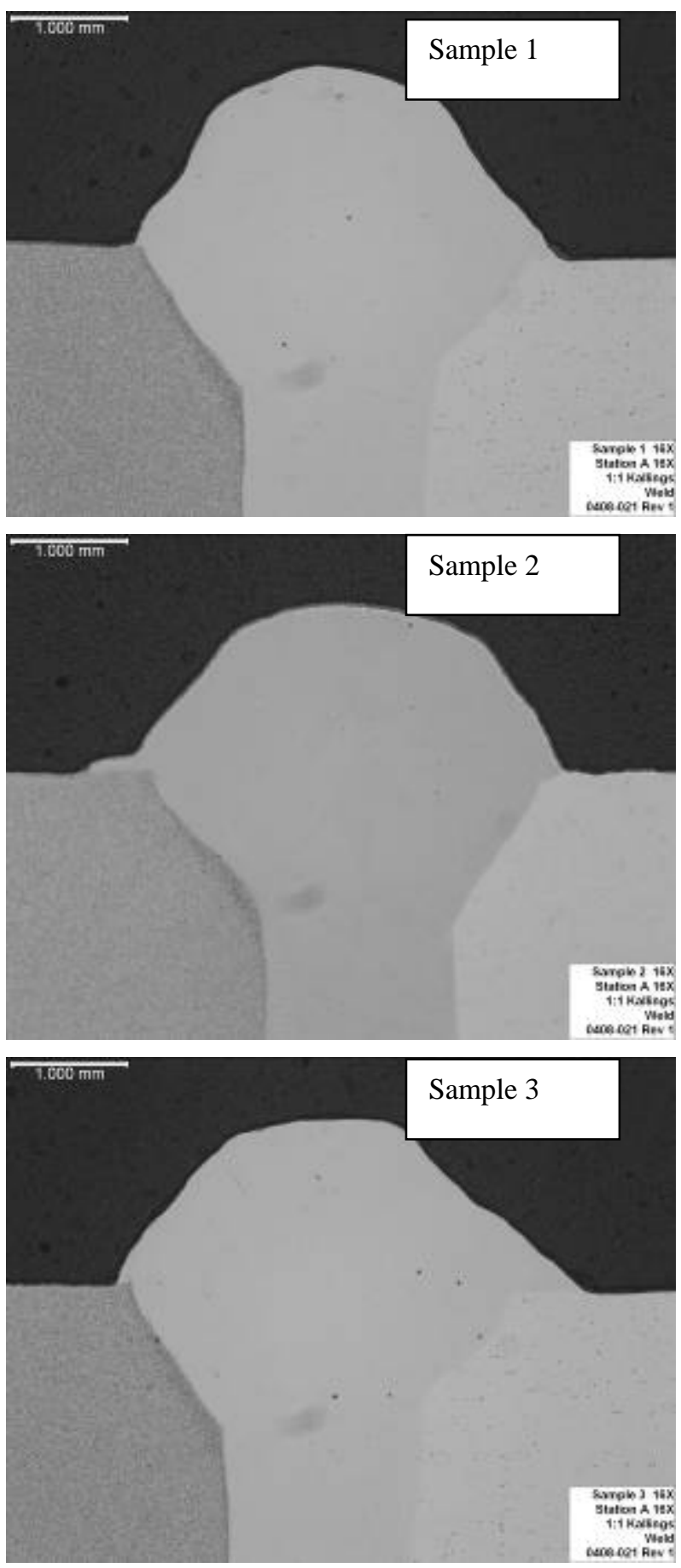

Figure 13. Metallographic results of post-weld heat treatments 1-3 on U720Li to Haynes 282 for Trial 3. 
Table 1. Hardness results from Haynes 282 to Udimet 720Li Joint Following 3 Different Post-Weld HeatTreatments

\begin{tabular}{|l|lll|}
\hline \multirow{2}{*}{ Location } & \multicolumn{3}{|l|}{ Vickers Hardness readings } \\
\cline { 2 - 4 } & Sample & Sample 2 & Sample 3 \\
\hline Haynes 282 & 351 & 348 & 348 \\
Weld & 463 & 401 & 459 \\
Udimet 720Li & 450 & 439 & 470 \\
\hline
\end{tabular}




\section{TASK 12.3 MATERIALS FOR NON-WELDED ROTORS, BUCKETS, AND BOLTING (GENERAL ELECTRIC)}





\section{LIST OF ACRONYMS}

AP

A-USC

CTQ

DOE

ESR

FCC

HCF

HP

HT

HTC

IP

LCF

LMP

$\mathrm{OA}$

OEM

PA

RA

RT

SA

SEM

SM

SW

TCP

TEM

UTS

VAR

VIM

WQ

YS
As-processed

Advanced Ultra Supercritical

Critical to Quality

Department of Energy

Electro-slag Remelting

Face Centered Cubic

High Cycle Fatigue

High Pressure

Heat Treat

Heat Transfer Coefficient

Intermediate Pressure

Low Cycle Fatigue

Larson-Miller Parameter

Over Aged

Original Equipment Manufacturer

Peak Aged

Reduction in Area

Room Temperature

Solution Annealed

Scanning Electron Micrographs

Special Metals

Siemens-Westinghouse

Topologically Close Packed

Transmission Electron Micrographs

Ultimate Tensile Strength

Vacuum Arc Remelting

Vacuum Induction Melting

Water Quench

Yield Strength 



\section{TABLE OF CONTENTS}

Task 12.3 Materials for non-Welded Rotors, Buckets, and Bolting (General

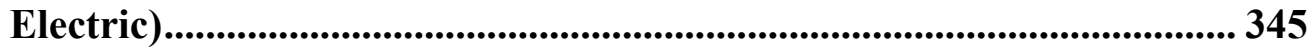

$1 \quad$ Task 12.3 - Materials for Non-Welded Rotors, Buckets, and Bolting ........ 357

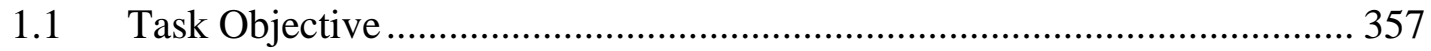

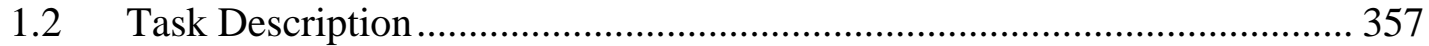

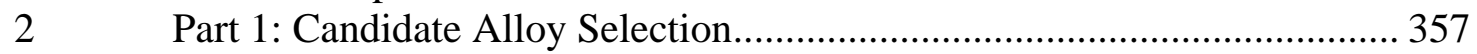

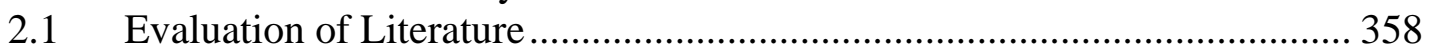

2.2 Preliminary Critical Rotor Mechanical Properties ...................................... 360

2.3 Available Information on Nickel-Base Alloys ........................................... 360

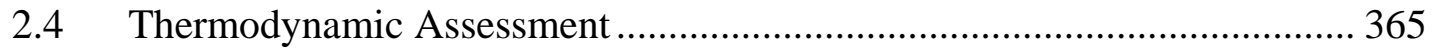

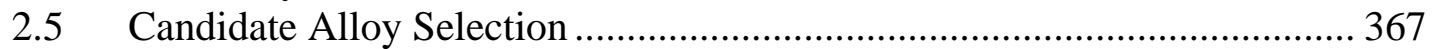

3 Part 2: Material Procurement, Heat Treatment, and Screening Tests.......... 369

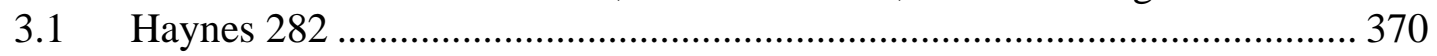

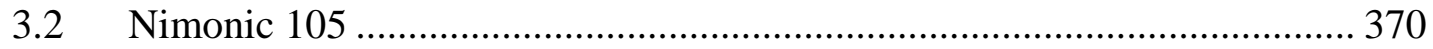

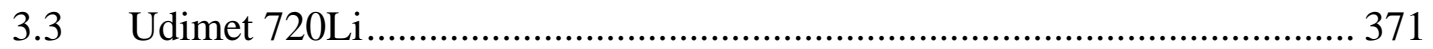

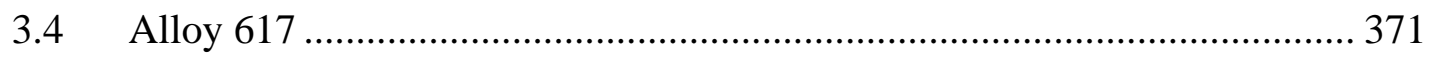

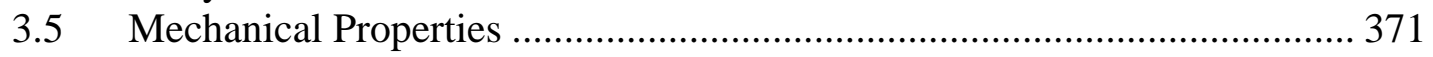

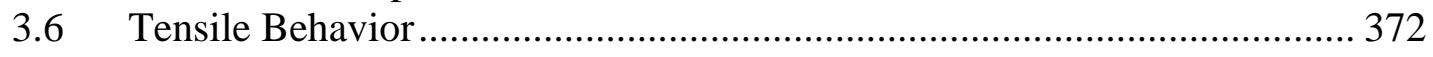

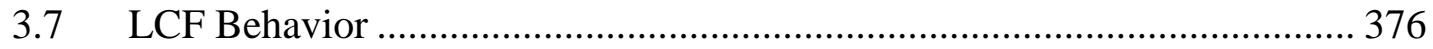

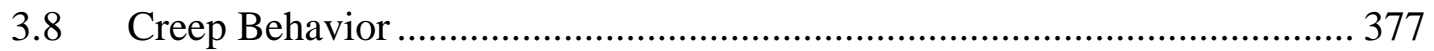

3.9 Summary of Candidate Alloy Screening Tests.......................................... 379

$4 \quad$ Part 3: Simulated Rotor Cooling Analysis................................................. 379

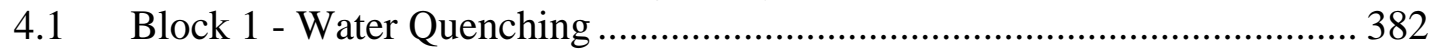

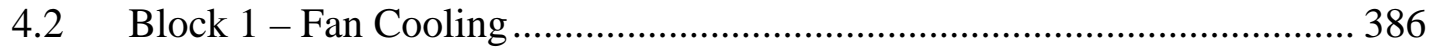

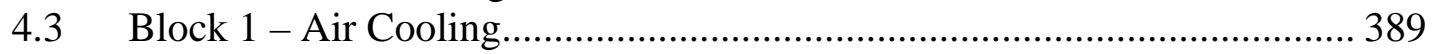

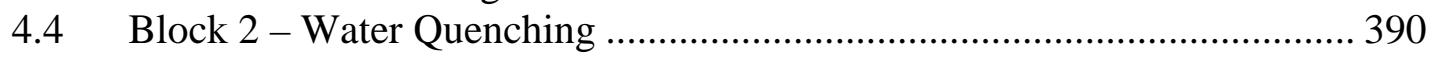

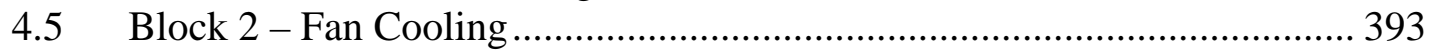

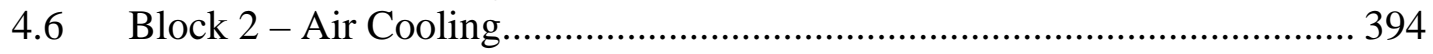

4.7 Summary Cooling Rate Computations .................................................. 397

5 Part 4: Microstructural Evaluation of Haynes 282, Nimonic 105, and Udimet

$720 \mathrm{Li} \quad 400$

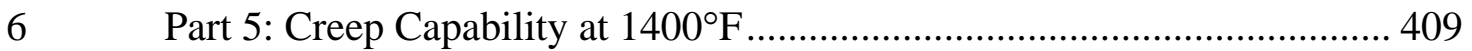

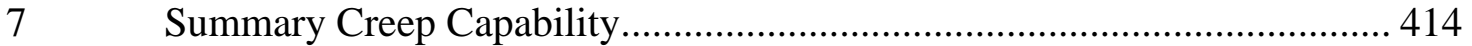

8 Part 6: Summary and Recommendations.................................................. 415

8.1 Phase II Rotor Test Program....................................................................... 416

8.2 Phase II Blade, Bolt, and Valve Test Program ......................................... 417

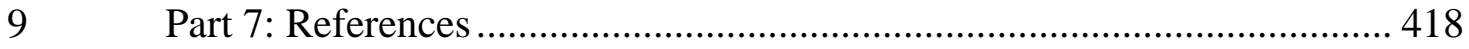

Appendix 1 Physical, mechanical, and processing data for Candidate Nickel

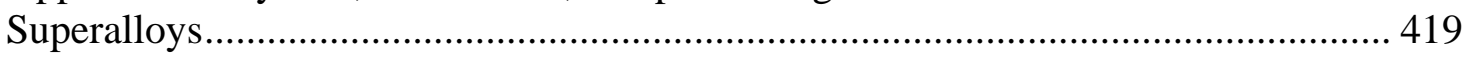

Appendix 2 Chemical Composition for Candidate Nickel Superalloys .................... 429

Appendix 3 Tensile Mechanical Properties for Candidate Nickel Superalloys.......... 431

Appendix 4 Low Cycle Fatigue for Candidate nickel superalloy ............................. 443

Appendix 5 Creep and Creep Rupture for Candidate Nickel Superalloy .................. 455 
Appendix 6A Microstructural Charaterization of Candidate Nickel Superalloy: Haynes

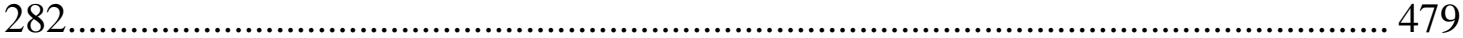

Appendix 6B Microstructural Characterization of candidate nickel superalloys:

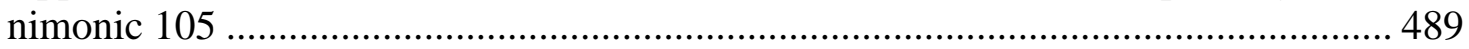
Appendix 6C Microstructural Characterization of Candidate Nickel Superalloys: Udimet 720Li 497

Appendix 7 Microstructural Stability for Candidate Nickel Superalloys..................... 501 Appendix 8 Phase II Statement of Work Preliminary Description of Tasks 503 


\section{LIST OF FIGURES}

Figure 1: Heat transfer coefficient (HTC) for water quenching of a generic nickelbase alloy with physical properties similar to Haynes 282 .

Figure 2: Temperature distribution and (b) cooling curves within a full-size rotor ingot, using physical properties of a generic nickel-base alloy, 10 hours after water quenching.

Figure 3: Temperature distribution and (b) cooling curves within a full-size rotor ingot, using physical properties of a generic nickel-base alloy, after 50 hours of air-cooling.

Figure 4: ThermoCalc phase diagram for Haynes 282 showing ideal mole fractions of $\gamma, \gamma^{\prime}, \mu$ and $\sigma$.

Figure 5: ThermoCalc phase diagram for Nimonic 105 showing ideal mole fractions of $\gamma$ and $\gamma^{\prime}$.....

Figure 6: ThermoCalc phase diagram for Udimet $720 \mathrm{Li}$ showing ideal mole fractions of $\gamma, \gamma^{\prime}, \mu$ and $\sigma$.

Figure 7: ThermoCalc phase diagram for Inconel 740 showing ideal mole fractions of $\gamma, \gamma^{\prime}, \mu$ and $\sigma$.

Figure 8: ThermoCalc phase diagram for Waspaloy showing ideal mole fractions of $\gamma, \gamma^{\prime}, \mu$ and $\sigma$.

Figure 9: UTS as a function of temperature for Haynes 282 in the solution annealed (SA) heat-treated for peak strength (PA) and overaged (OA) conditions.

Figure 10: $0.2 \%$ YS as a function of temperature for Haynes 282 SA, Udimet 720Li HT, Nimonic 105 AP, and Nimonic 105 HT.

Figure 11: Mechanical behavior as a function of temperature for Nimonic 105, all processing and heat treatment conditions.

Figure 12: Mechanical behavior as a function of temperature for Haynes 282 for all processing and heat treatment conditions.

Figure 13: Combined LCF behavior for Nimonic 105, Haynes 282, Udimet 720 , and Inconel 617 at $1400^{\circ} \mathrm{F}(\mathrm{R}=0$ and -1$)$.

Figure 14: Heat transfer coefficient (HTC) for water quenching of Haynes 282.

Figure 15: Graph of the change in thermal conductivity (btu in/in2 $\mathrm{s}^{\circ} \mathrm{F}$ ) with temperature $\left({ }^{\circ} \mathrm{F}\right)$ for Haynes 282 from room temperature to $1800^{\circ} \mathrm{F}$.

Figure 16: Graph of the change in specific heat $\left(\mathrm{Btu} / \mathrm{lb}{ }^{\circ} \mathrm{F}\right)$ with temperature $\left({ }^{\circ} \mathrm{F}\right)$ for Haynes 282 from room temperature to $1800^{\circ} \mathrm{F}$.....

Figure 17: Graph of the change in density $\left(\mathrm{Ib} / \mathrm{in}^{3}\right.$ with temperature $\left({ }^{\circ} \mathrm{F}\right)$ for Haynes 282 from room temperature to $1800^{\circ} \mathrm{F}$.

Figure 18:(a-d): show stages in the cooling sequence for Block 1 - Water Quenching Time is seconds, starting at $30 \mathrm{sec}$, and then showing the block at 300,600 , and $3600 \mathrm{sec}$. Note that the color scales change with each time increment block. 
Figure 19: This figure shows the locations on Block 1 where cooling rates were calculated for the cooling rate curves for water and air quench simulations.

Figure 20: Cooling rate curves for Block 1, water quenched, at the specific location designated in Figure X6. Elapsed time was approximately 3600 seconds $(1 \mathrm{~h})$

Figure 21: (a-d): show stages in the cooling sequence for Block 1 - Fan Cooling.

Time is in seconds, starting at $150 \mathrm{sec}$, and then showing the block at 600 , 1800 , and $7200 \mathrm{sec}$. Note that the color scales change with each time increment block.

Figure 22: Cooling rate curves for Block 1, fan cooled, at the specific location designated in Figure X6. Elapsed time was approximately 7200 seconds (2 h).

Figure 23 (a-d): show stages in the cooling sequence for Block 1 - Air Cooling.

Time is in seconds, starting at $3600 \mathrm{sec}$, and then showing the block at $7200,36,000$, and $108,000 \mathrm{sec}$. Note that the color scales change with each time increment block.

Figure 24: Cooling rate curves for Block 1, fan cooled at the specific location designated in Figure X6. Elapsed time was approximately 108,000 seconds $(30 \mathrm{~h})$.

Figure 25: (a-d): show stages in the cooling sequence for Block 2, water quenched. Time is in seconds, starting at $30 \mathrm{sec}$, and then showing the block at $600,1,800$, and $3,600 \mathrm{sec}$. Note that the color scales change with each time increment block.

Figure 26: Cooling rate curves for Block 2, water quenched, at the specific location designated in Figure X6. Elapsed time was approximately 3,600 seconds $(1 \mathrm{~h})$

Figure 27(a-d): show stages in the cooling sequence for Block 2 - Fan Cooling.

Time is in seconds, starting at $150 \mathrm{sec}$, and then showing the block at 600 , 1,800 , and $7,200 \mathrm{sec}$. Note that the color scales change with each time increment block.

Figure 28: Cooling rate curves for Block 2, fan cooled, at the specified location designated in Figure X6. Elapsed time was approximately 7,200 seconds (2 h).

Figure 29: (a-d): show stages in the cooling sequence for Block 1 - Air Cooling.

Time is in seconds, starting at 3,600 sec, and then showing the block at $7,200,36,000$, and $108,000 \mathrm{sec}$. Note that the color scales change with each time increment block.

Figure 30: Cooling rate curves for Block 2, air cooled, at the specified location designated in Figure X6. Elapsed time was approximately 108,000 seconds $(30 \mathrm{~h})$

Figure 31: Cooling Rate Computation ( ${ }^{\circ} \mathrm{F} / \mathrm{h}$ ) from $1900^{\circ} \mathrm{F}$ to $1600^{\circ} \mathrm{F}$ for Block 1 (37" diameter $\times 14 "$ thick)

Figure 32: Cooling Rate Computation ( ${ }^{\circ} \mathrm{F} / \mathrm{h}$ ) from $1900^{\circ} \mathrm{F}$ to $1600^{\circ} \mathrm{F}$ for Block 2 (46" diameter x 42" thick)

Figure 33: Starting microstructure for Haynes 282 alloy (a) solution annealed showing small $\gamma^{\prime}$ precipitates $(10-20 \mathrm{~nm})$, (b) peak aged Haynes 282 
showing $\gamma^{\prime}$ precipitates approximately $50 \mathrm{~nm}$ in diameter and (c) overaged

Haynes 282 with $\gamma^{\prime}$ precipitates slightly larger than $50 \mathrm{~nm}$.

Figure 34: Yield strength (ksi) versus temperature for Haynes 282 alloy in

solution annealed, peak aged and overaged conditions.

Figure 35: Potential deformation mechanisms that operate in nickel-base alloys.

From the top there is dislocation climb, particle shearing and micro-twinning.

Figure 36: Composite representation that shows the dislocation interaction within the $\gamma$ matrix for various temperature-stress conditions.

Figure 37: Various view of the $\gamma$ matrix showing Orowan loops, particledislocation interactions and cross-slip. Sample tested at $1450^{\circ} \mathrm{F}$ and 32.5 ksi. Crept to $0.2 \%$ strain.

Figure 38: High magnification of image of Orowan left behind after dislocation moved through the matrix. High magnification view of dislocation line and Orowan loops from Figure $37(\mathrm{a})$. Sample tested at $1450^{\circ} \mathrm{F}$ and $32.5 \mathrm{ksi}$.

Crept to $0.2 \%$ strain.

Figure 39: Various views of the $\gamma$ matrix showing Orowan loops, particledislocation interactions and cross-slip. Sample tested at $1450^{\circ} \mathrm{F}$ and 32.5 ksi. Crept to $4.0 \%$ strain.

Figure 40: Various views of the $\gamma$ matrix showing Orowan loops, particledislocation interactions and cross-slip. Sample tested at $1450^{\circ} \mathrm{F}$ and 27.5 ksi. Crept to $0.2 \%$ strain.

Figure 41: LMP plot for Haynes 282 showing up-to-date analysis for tests done by Siemens and GE combined with Haynes literature data.

Figure 42: LMP plot for Nimonic 105 showing up-to-date analysis for test done by GE combined with Special Metals literature data.

Figure 43: Short-term creep rupture tests showing particle shearing as a possible deformation mechanism. As temperature increases, shearing action transitions to one of Orowan looping and climb.

Figure 44: Long-term creep rupture tests (stopped before failure) showing particle bypass as a possible deformation mechanism. In these instances, Orowan looping and climb are clearly seen. Little shearing of the $\gamma^{\prime}$ particles has taken place.

Figure 45: LMP versus stress for $1400^{\circ} \mathrm{F}$ candidate alloys for steam turbine rotor 414 



\section{LIST OF TABLES}

Table 1: Representative Material Screening Criteria for $1400^{\circ} \mathrm{F}$ Steam Turbine Rotor.

Table 2: Materials Capability at $1400^{\circ} \mathrm{F}$ 367

Table 3: Predicted Phase Formation in Heat Treatment Window ( $\left.\leq 1500^{\circ} \mathrm{F}\right)$ 368

Table 4: LMP Coefficients for $3^{\text {rd }}$ Order Polynomial 



\section{$1 \quad$ Task 12.3 - Materials for Non-Welded Rotors, Buckets, and Bolting}

\section{$1.1 \quad$ Task Objective}

To identify suitable materials that can be made into a single piece rotor or the highest temperature portion of a mechanically coupled rotor, buckets and bolting operating in a steam turbine with an inlet temperature of $760^{\circ} \mathrm{C}\left(1400^{\circ} \mathrm{F}\right)$.

\subsection{Task Description}

Candidate alloys for this task will likely include current aerospace materials. Conventional and non-conventional processing will be considered during an initial evaluation phase to identify the best candidate alloys and processing for longer-term evaluation. In the case of rotors, computer models will be used to identify material processing that simulates large rotor forgings. For all components, short-term tests will be used for screening. The best candidate alloys and processes will then be subjected to longer-term evaluations that will include measurement of tensile, creep, fracture toughness, crack growth and fatigue properties. Fatigue testing will include tests with extended hold time at the peak stress. In the case of rotors, ultrasonic inspection penetrability will also be evaluated.

\section{Part 1: Candidate Alloy Selection}

In order to select the candidate alloys for the $1400^{\circ} \mathrm{F}$ steam turbine, five tasks were undertaken:

i. Evaluate available literature for nickel-base alloys.

ii. Determine preliminary critical rotor mechanical properties.

iii. Collect information related to chemistry, microstructure, mechanical properties, physical properties, processing and manufacturing capability for nickel-base alloys.

iv. Perform thermodynamic assessment on nickel-base alloys to determine relevant information, such as, precipitate type and volume fraction, TCP phases, solvus temperatures, etc.

v. Assess information and select candidate nickel-base alloys. 


\subsection{Evaluation of Literature}

From a materials perspective the AD700 program offered a good starting point in assessing current state-of-the-art material availability for Advanced Ultra Supercritical (A-USC) steam turbine technology. In this European program, austenitic materials and nickel-based superalloys were identified and investigated for the hottest sections of the boiler, steam lines and steam turbine. With regard to materials for A-USC plants, four major areas of development have been explored within the AD700 program with extensive testing completed [1-5]:

1. Alloy identification and development

2. Alloy processing and fabrication

3. Component design for COMTES demonstration

4. Construction of AD700 power plant

Of these four issues, materials identification and development, and processing and fabrication, pose the major hurdles to implementation. At $700^{\circ} \mathrm{C}\left(1292^{\circ} \mathrm{F}\right)$ ferritic and martensitic steels are not suitable and austenitic alloys must be employed.

On the one hand, austenitic alloys, both steel and nickel-base, generally possess sufficient creep strength to work at $700^{\circ} \mathrm{C}\left(1292^{\circ} \mathrm{F}\right)$. However, austenitic alloys present other difficulties such as low thermal conductivity and high thermal expansion coefficients. Additionally, nickel-base alloys are quite complex with chemistry, processing and heat treatment critically important in achieving long-term microstructural stability and strength. The chemistry and crystal structure (FCC) plus the strengthening precipitate (either $\gamma^{\prime}$ or $\gamma^{\prime \prime}$ or both) make processing nickel-base alloys in the large sizes needed for rotor shafts or disk segments difficult. In addition, if composite rotors are envisioned, thermal expansion mismatch, dissimilar alloy welding (e.g., nickel-base alloys to other nickel-base alloys and/or ferritic or martensitic steels) and subsequent heat treatment make the problem especially difficult. Also, many of the nickel-based alloys identified for use as steam turbine components were initially developed for aero-engine applications where high strength and creep resistance for only several thousand hours were needed. In steam turbine rotating components, creep lifetimes greater than $100 \mathrm{khr}$ are required. In addition, the alloys must have adequate uniaxial strength, that is, high yield strength to withstand the stresses within the rotor upon start-up. Also important is the fatigue characteristics of the alloy, specifically, low cycle fatigue capability for the rotor segments and high cycle fatigue capability for the blades. Identifying alloys that possess the requisite creep strength, yield strength and fatigue behavior is difficult, especially in steam. One benefit of utilizing nickel-base alloys is their overall general hot corrosion and oxidation resistance. However, some nickel-base alloys are more resistant than others to steam, so evaluation of the oxidation behavior of the steam turbine materials is required.

For completeness, evaluation of current materials for A-USC steam turbine casings shows only currently available age-hardenable nickel-base alloys have the requisite strength required for the desired application temperature using current steam turbine design. These alloys, by necessity, have significant amounts of aluminum, which forms the major strengthening precipitate, $\gamma^{\prime}$. The production of these alloys involves 
combinations of highly controlled casting processes such as electro-slag remelting (ESR), vacuum induction melting (VIM) or vacuum arc remelting (VAR). Production of large steam turbine casings requires the use of air casting processes. When cast in air, the aluminum in these alloys oxidizes, which removes aluminum from the melt, causing porosity, with subsequent reduction in the amount of $\gamma^{\prime}$, and possibly resulting in significant decreases in mechanical strength. Improved air-based casting processes or new alloy formulations without (or minimizing) aluminum additions are needed to realize large castings with requisite strength for A-USC steam turbine casings.

From preliminary investigations leading up to the AD700 program, the following nickelbased alloys were selected for in-depth study, both from a materials testing and component evaluation point of view. Broadly speaking, the alloys were classed as follows [5]:

1. Alloys 617 and 625 for turbine castings and rotor forgings

2. Alloys 718 and 263 for rotor forgings

3. Alloys 105 and Waspaloy for blades and bolting

Alloys 617, 625, 263, and 718 have been produced as full-size rotor forgings. Alloys 617 and 625 have also been cast into shaped forms approaching several thousand kilograms by weight and with sufficient features to simulate final component forms. Mechanical behavior for these manufactured items has been assessed with acceptable properties at $700^{\circ} \mathrm{C}\left(1292^{\circ} \mathrm{F}\right)$.

Achieving additional efficiency gains by going to $760^{\circ} \mathrm{C}$ reduces still further the number of current nickel-base alloys with minimum mechanical properties suitable for steam turbine service. The DOE $1400^{\circ} \mathrm{F}\left(760^{\circ} \mathrm{C}\right.$ main inlet steam temperature) program for steam turbine development was initiated to identify and evaluate potential alloys that could operate at this temperature for at least $100 \mathrm{khr}$.

An additional search of the available literature, including manufacturer product literature, revealed how little information was available on high-temperature $\left(\geq 760^{\circ} \mathrm{C}\right)$ and longterm ( $>1000$ hours) creep behavior of nickel-base alloys. Most mechanical property information was originally developed for aerospace applications or oil and gas use. In either case, long-term, high-temperature information, suitable for steam turbine design, was generally unavailable, or at best useful only for screening with further verification of creep and creep rupture properties required. Consequently, the following approach was adopted.

As a first pass on obtaining information, the databases of nickel-base alloy manufacturers was investigated with follow-up contacts made with those companies to discuss potential alloy selection. The second task was to collect available information from the Thermie AD700 program as it pertained to material selection and property evaluation. Discussions with the participants of the DOE $1400^{\circ} \mathrm{F}$ Boiler program were held at the steam turbine kick-off meeting in Charlotte, NC, in January 2006. Follow-up discussions were held between the steam turbine participants as well as with GE engineers within GE Infrastructure. From data collection activities and follow-up discussions approximately 25 nickel-base alloys were identified for in-depth analysis, leading to candidate alloy selection. 


\subsection{Preliminary Critical Rotor Mechanical Properties}

In order to make a rational selection of candidate alloys for evaluation and testing, creep rupture life at $1400^{\circ} \mathrm{F}$ for $100 \mathrm{khr}, 0.2 \%$ yield strength at $1400^{\circ} \mathrm{F}$ and room temperature fracture toughness were selected as critical rotor mechanical properties, and minimum values were selected to aid screening of potential candidate alloys.

For most rotor applications, rupture strength of at least $15 \mathrm{ksi}$ ( 100 MPa) at $100 \mathrm{khr}$ is necessary at the operational temperature. Ideally, rupture strength of $15 \mathrm{ksi}$ ( $\sim 100 \mathrm{MPa})$ at $250 \mathrm{khr}$ is desirable. As such, the literature was searched for creep and creep rupture information at $1400^{\circ} \mathrm{F}$, and where available this information was collated.

$100 \mathrm{khr}$ Rupture Life at $1400^{\circ} \mathrm{F}$ : In order to differentiate the creep potential of the nickel-base alloys, $15 \mathrm{ksi}(\sim 100 \mathrm{MPa})$ rupture strength at $1400^{\circ} \mathrm{F}$ and $100 \mathrm{khr}$ was selected as the cut-off property. Examination of the literature showed that insufficient data exist for nickel-base alloys at these conditions to make a rational decision.

$1400^{\circ} \mathrm{F}$ Yield Stress: A minimum $0.2 \%$ yield strength of $60 \mathrm{ksi}(\sim 400 \mathrm{MPa})$ in the radial direction at $1400^{\circ} \mathrm{F}$ was used as the cut-off stress for the nickel superalloys, although higher strength would be desirable. Mechanical property data were readily available for the candidate alloys with regard to yield strength, tensile strength, elongation and reduction in area.

Room Temperature Fracture Toughness: A minimum of $50 \mathrm{ksi} \cdot \sqrt{ }$ in $(\sim 55 \mathrm{MPa} \cdot \sqrt{\mathrm{m}})$ was used as the cut-off room temperature fracture toughness for these alloys. Mechanical property data were not readily available with respect to fracture toughness for the candidate alloys.

Table 1: Representative Material Screening Criteria for $1400^{\circ} \mathrm{F}$ Steam Turbine Rotor

\begin{tabular}{|l|c|c|c|}
\hline Material Property CTQ & Metric & Units & $\begin{array}{c}\text { Target } \\
\text { Minimum }\end{array}$ \\
\hline $\begin{array}{l}\text { 100,000 h Rupture Strength at } \\
\text { Steam Inlet Temperature }\end{array}$ & $\begin{array}{c}\text { Rupture Stress at LMP }=46.50 \\
(\mathrm{C}=20)\end{array}$ & $\mathrm{ksi}$ & 15 \\
\hline $\begin{array}{l}0.2 \% \text { Yield Strength } \\
\text { (Body Radial) }\end{array}$ & Steam Inlet Temperature & $\mathrm{ksi}$ & 60 \\
\hline $\begin{array}{l}\text { Room Temperature } \\
\text { Fracture Toughness }\end{array}$ & Body Radial $\mathrm{K}_{\mathrm{ic}}$ & $\mathrm{ksi} \cdot \sqrt{\mathrm{in}}_{\mathrm{in}}$ & 50 \\
\hline
\end{tabular}

\subsection{Available Information on Nickel-Base Alloys}

Information collected during steps 1 and 2 were used to set up a master spreadsheet that included chemistry, microstructure information, critical precipitation and heat treatment process ranges, mechanical and physical property information, critical processing parameters and any other relevant information. This information is provided in Appendix 1 in tabular form. Tables $1 \mathrm{~A}, 1 \mathrm{~B}$ and $1 \mathrm{C}$ contain this information. Also included in the tabular information are the results of ThermoCalc (see Section D for details) simulations based on the nominal chemical composition of the alloys in Appendix 1. 
As part of the data collection effort to understand processing of large size ingots, a study was undertaken to assess the forging capability of a representative nickel-base alloy used for a full-size rotor (58" diameter with a length much greater than the diameter) in terms of temperature distribution within the forging and the resultant change in temperature in the forging with time for two different quenching routes: (a) water quenched (fast cooling) and (b) air quenched (slow cooling). This preliminary assessment of internal temperature distribution was used to provide an estimate of how long a generic nickelbase alloy might be at temperatures and how this would affect the microstructure in terms of $\gamma^{\prime}$ nucleation and $\gamma^{\prime}$ coarsening potential, and the potential affect that this time at temperature might affect the mechanical properties.

In developing this generic model simulation, nickel-base alloy properties similar to Haynes 282 were used to develop thermal conductivity, specific heat and density versus temperature graphs. This information was then used to determine the heat transfer coefficients for water quenching. In addition the heat transfer coefficients for air quenching the ingot were also determined. From this information finite element simulations for the temperature distribution after 10 hours for water quenching and after 50 hours for air quenching were developed. Water quenching and air quenching were charted from $2012^{\circ} \mathrm{F}$ to $100^{\circ} \mathrm{F}$.

Figure 1 shows the change in heat transfer coefficient with temperature for water quenching for a generic nickel-base alloy with physical properties similar to Haynes 282. Figure 2 depicts the temperature distribution within a full-size rotor ingot, using physical properties of a generic nickel-base alloy that is similar to Haynes 282, after 10 hours of water quenching. Finally, Figure 3 shows the temperature distribution within a full-size rotor ingot, using physical properties of a generic nickel-base alloy similar to Haynes 282, after 50 hours of air-cooling. 


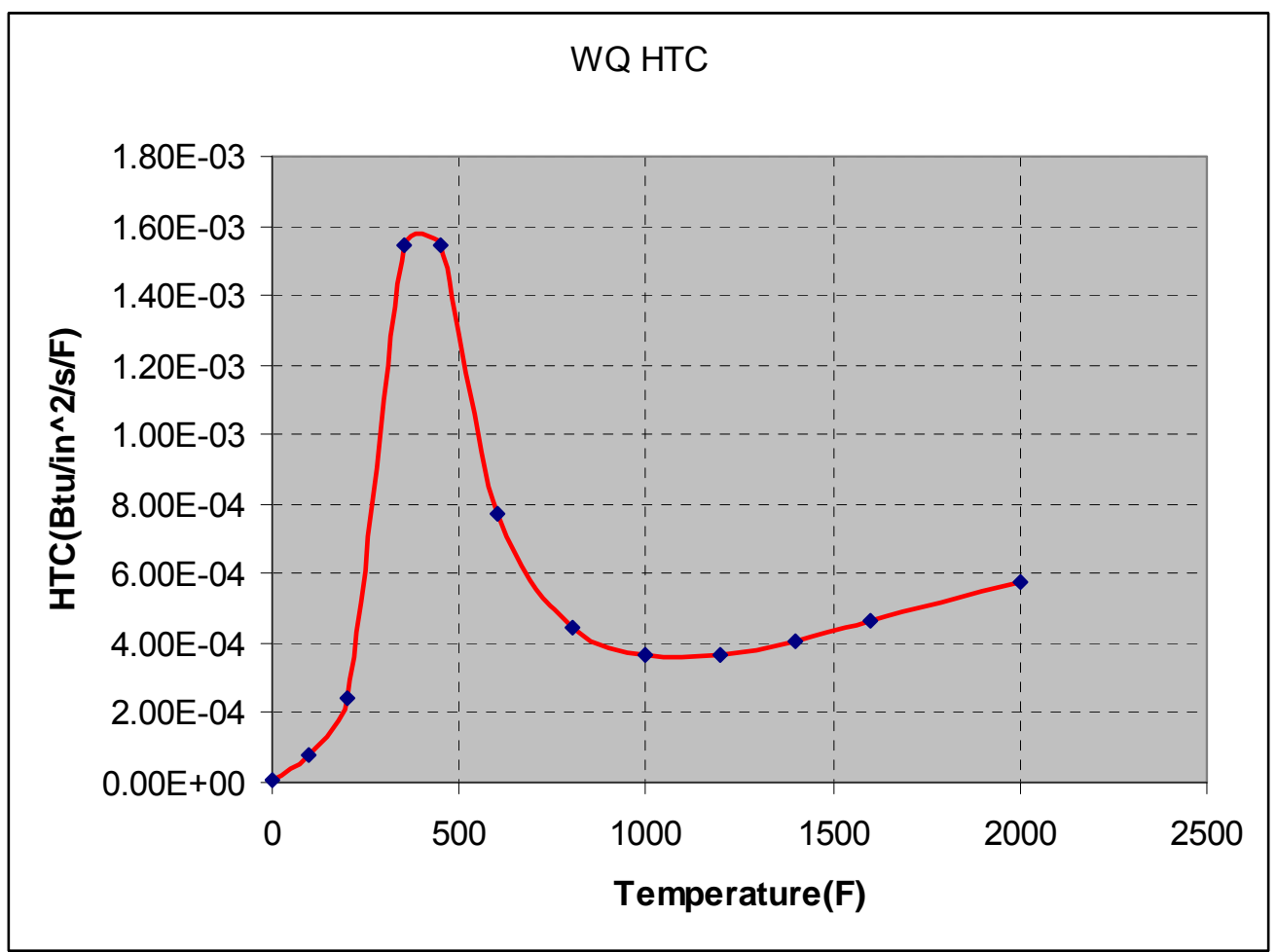

Figure 1: Heat transfer coefficient (HTC) for water quenching of a generic nickel-base alloy with physical properties similar to Haynes 282. 

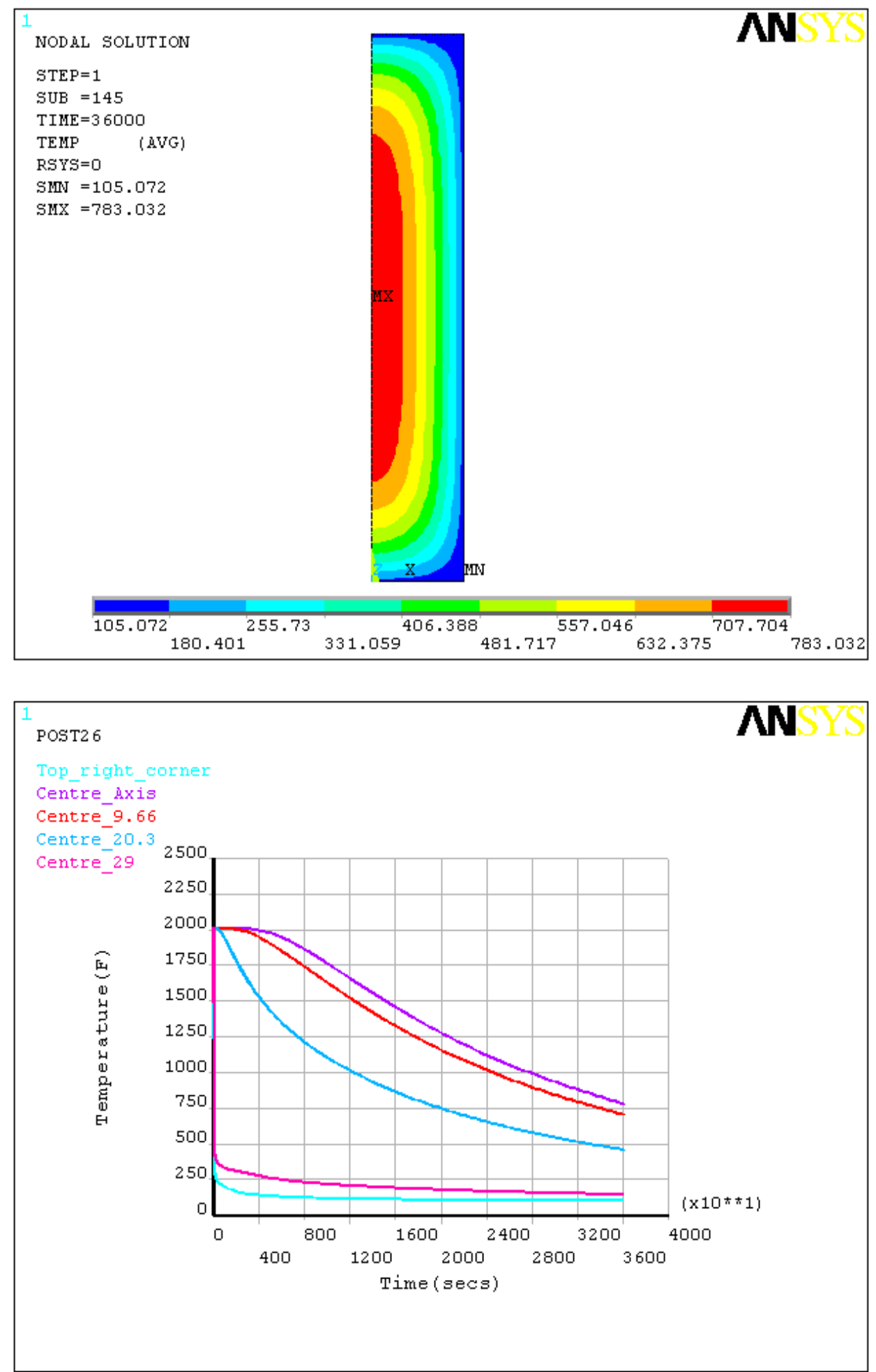

Figure 2: Temperature distribution and (b) cooling curves within a full-size rotor ingot, using physical properties of a generic nickel-base alloy, 10 hours after water quenching. 

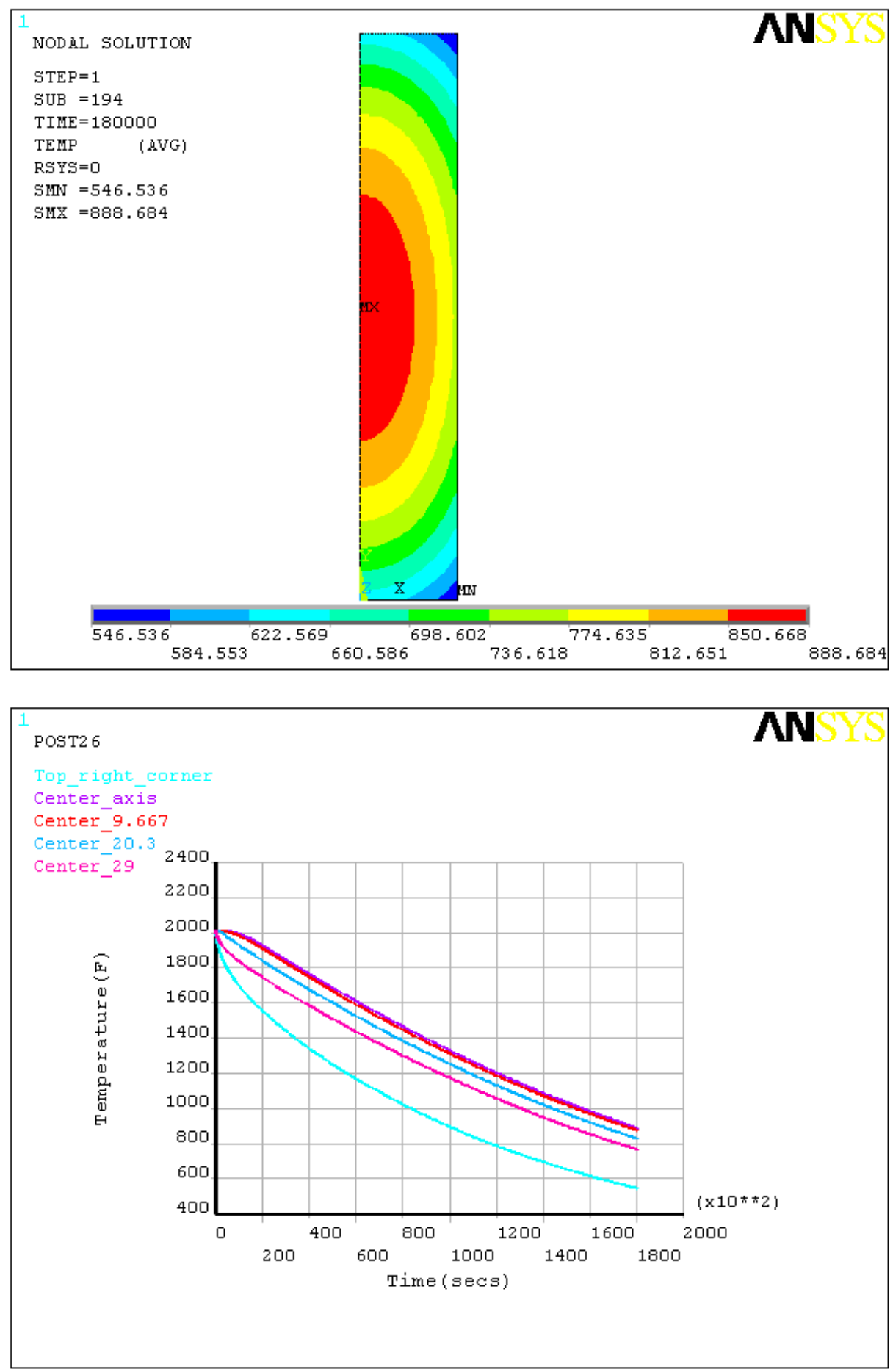

Figure 3: Temperature distribution and (b) cooling curves within a full-size rotor ingot, using physical properties of a generic nickel-base alloy, after 50 hours of air-cooling. 
During quenching it was observed that the center portion of the rotor forging cooled from $2012^{\circ} \mathrm{F}$ to $783^{\circ} \mathrm{F}$ after 10 hours when water quenched. In the example of air-cooling, the simulation shows that the center portion of the rotor ingot cooled from $2012^{\circ} \mathrm{F}$ to $888^{\circ} \mathrm{F}$ after 50 hours. It was also observed during the water quenching simulation that the cooling rate at the corners of the rotor ingot (i.e., the top right corner in the 2-D axisymmetric model in Figure 2), and at a location a distance of 29" from the central axis (Figure 2), underwent extremely severe cooling, which depending upon the alloy might make the rotor prone to cracking during the initial quench period. During air-cooling, on the other hand, the temperature gradients were less severe during this initial period (see Figure 3). For example, even after 50 hours of air-cooling, the temperature at the top right corner of the rotor ingot and 29" from the center of the ingot at the midpoint were still greater than those points in the water quenched rotor ingot. Consequently, cracking is unlikely.

In summary, the temperature gradient at the end of quenching was observed to be more severe for water quenching with temperatures ranging from 105 to $783^{\circ} \mathrm{F}$ and less severe for air-quenching with gradients ranging from 546 to $888^{\circ} \mathrm{F}$.

\subsection{Thermodynamic Assessment}

ThermoCalc simulations were performed on all candidate alloys and microstructural stability was assessed based on precipitate, carbide and TCP phase formation, solvus temperatures, processing windows, etc. This information is found in tabular form in Appendix 1, Tables 1B and 1C. Figures 4-8 show the phase space for the matrix and major precipitates for each of the candidate alloys.

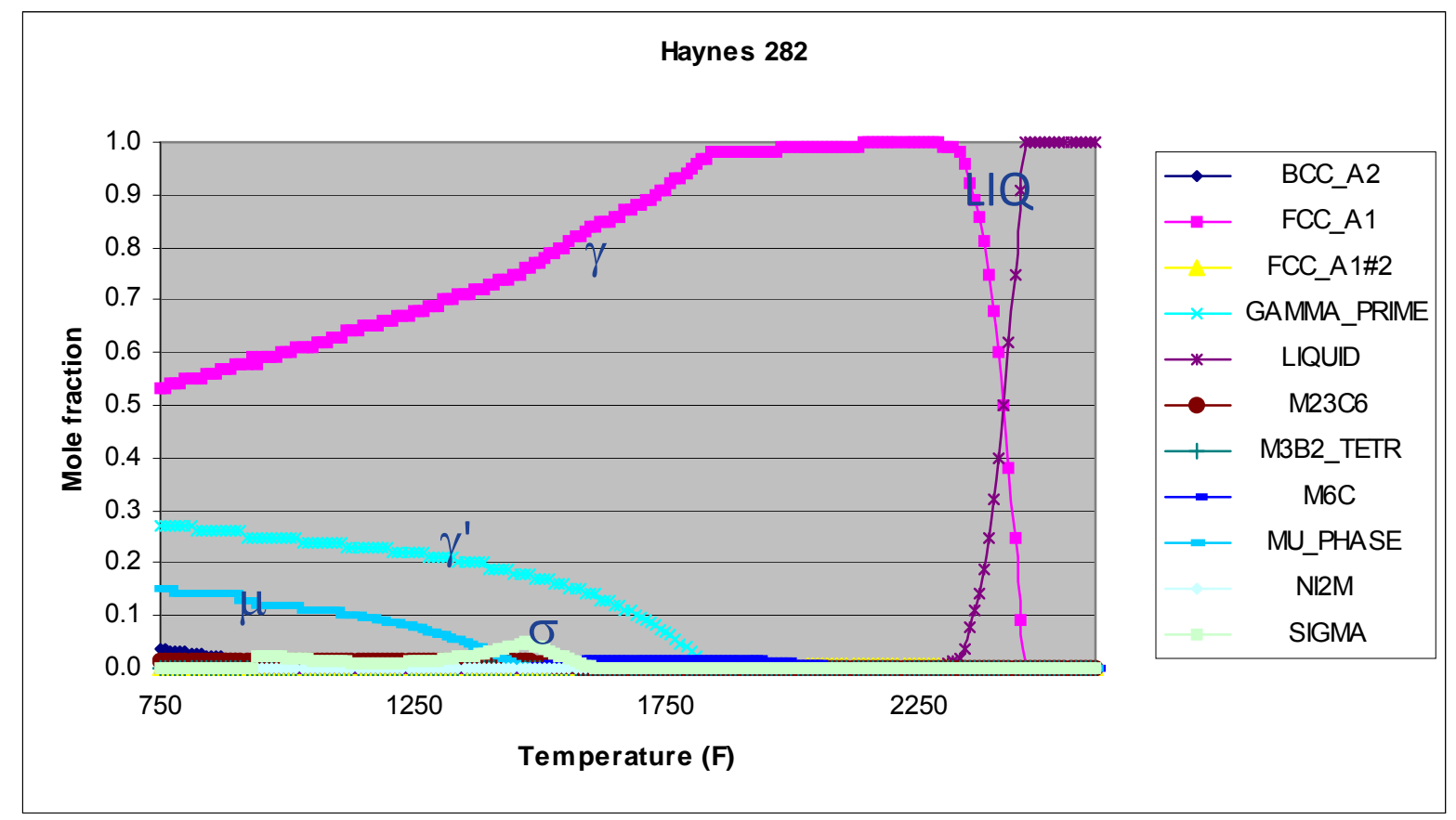

Figure 4: ThermoCalc phase diagram for Haynes 282 showing ideal mole fractions of $\gamma, \gamma^{\prime}, \mu$ and $\sigma$. 


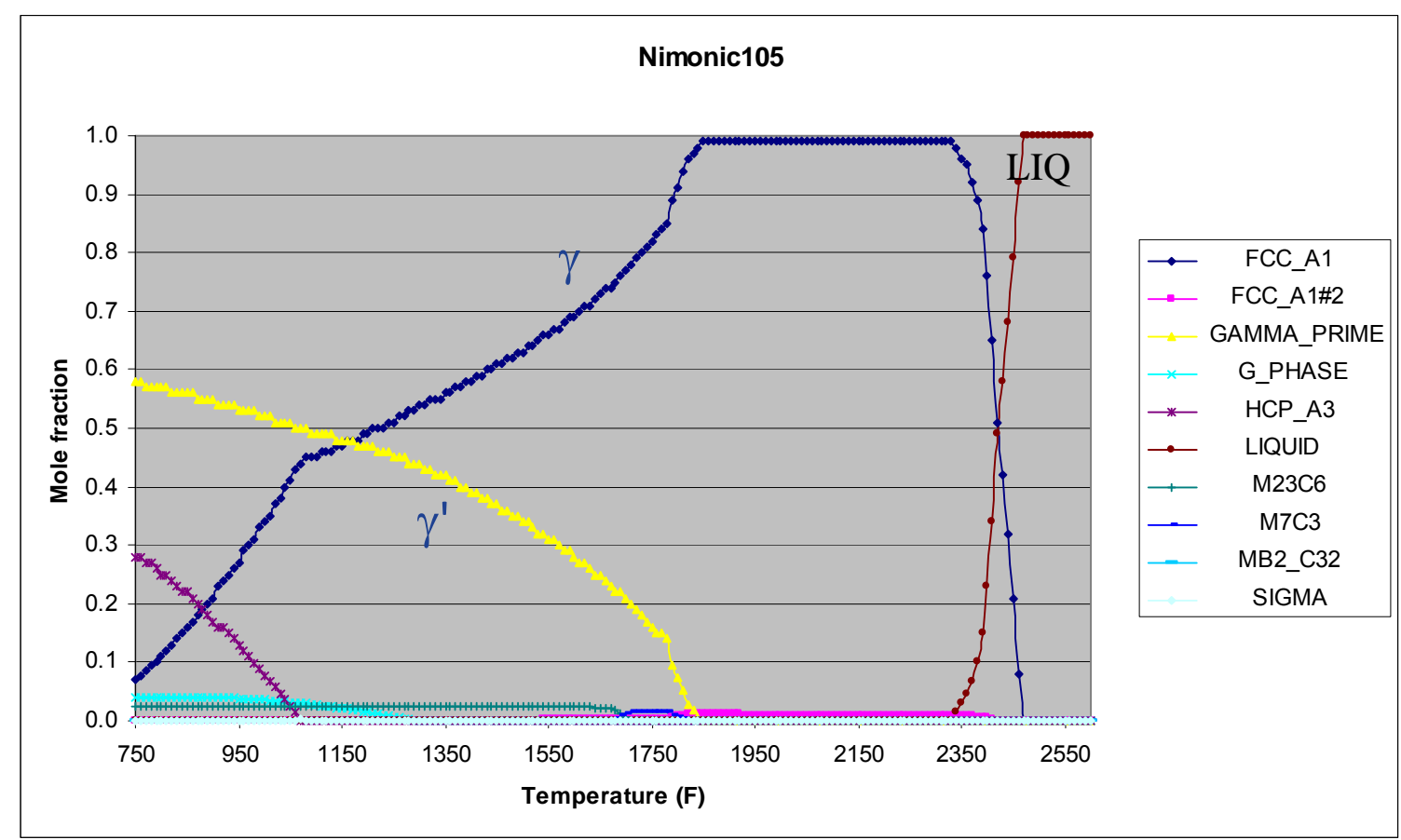

Figure 5: ThermoCalc phase diagram for Nimonic 105 showing ideal mole fractions of $\gamma$ and $\gamma^{\prime}$.

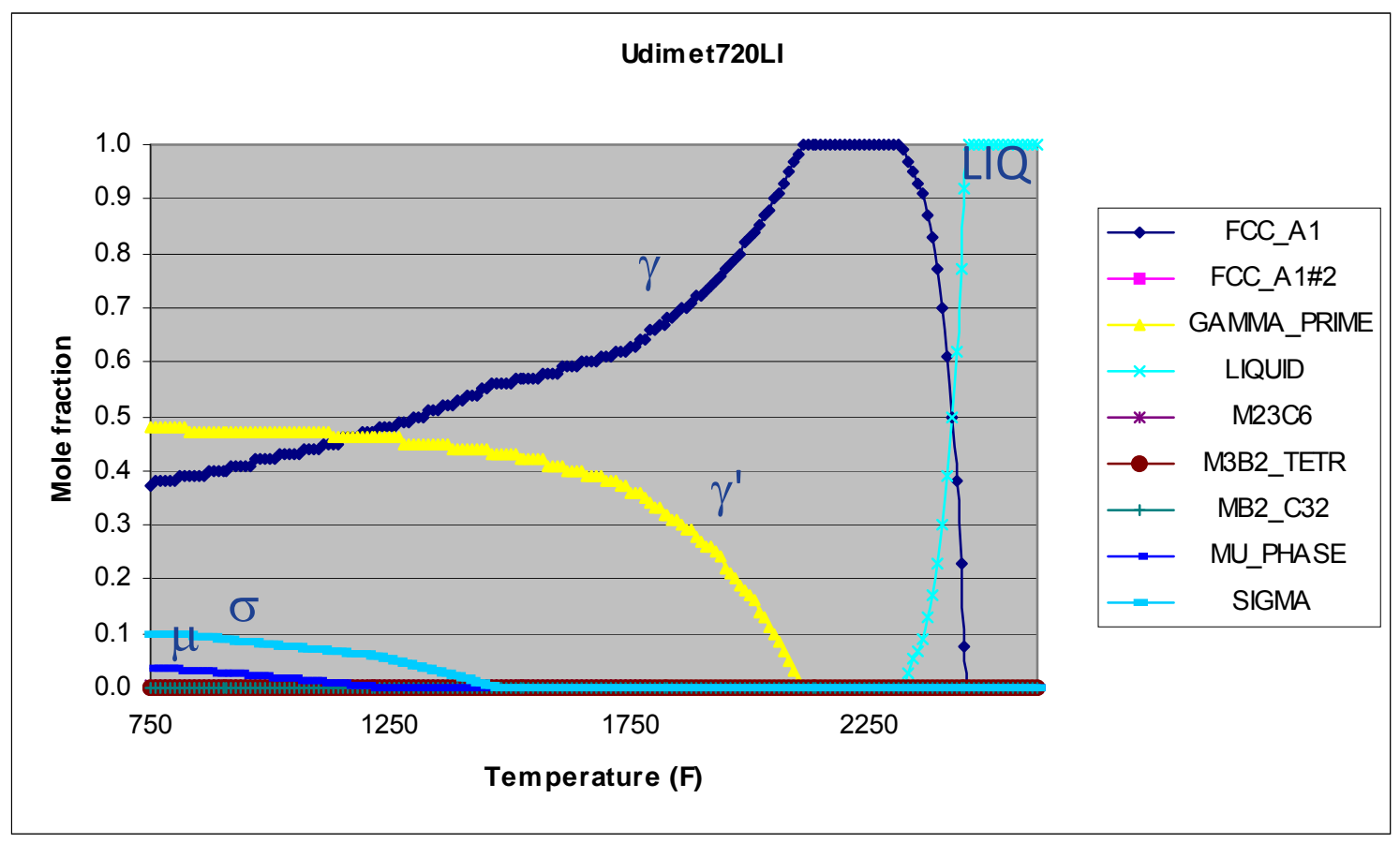

Figure 6: ThermoCalc phase diagram for Udimet 720Li showing ideal mole fractions of $\gamma, \gamma^{\prime}, \mu$ and $\sigma$. 


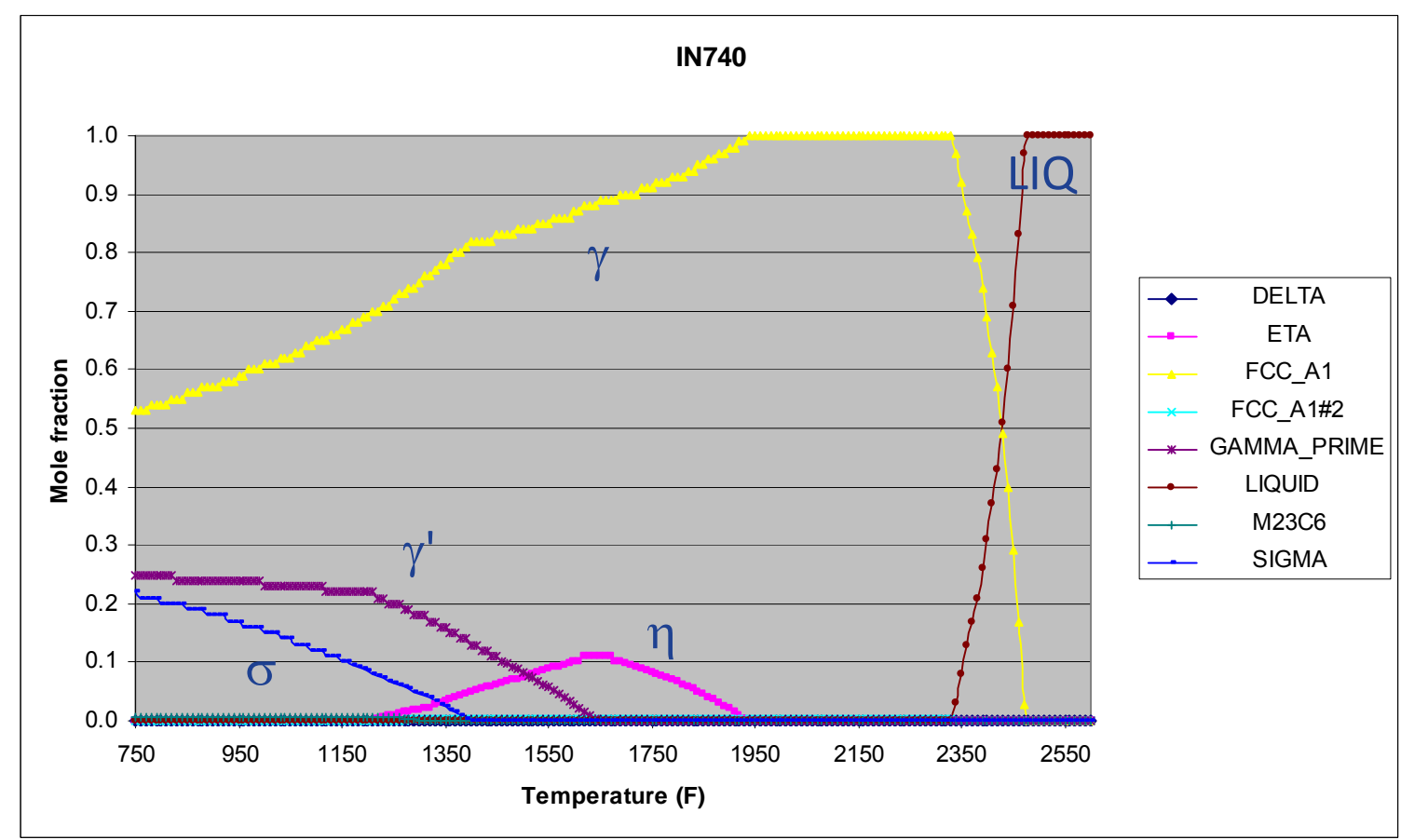

Figure 7: ThermoCalc phase diagram for Inconel 740 showing ideal mole fractions of $\gamma, \gamma^{\prime}, \mu$ and $\sigma$.

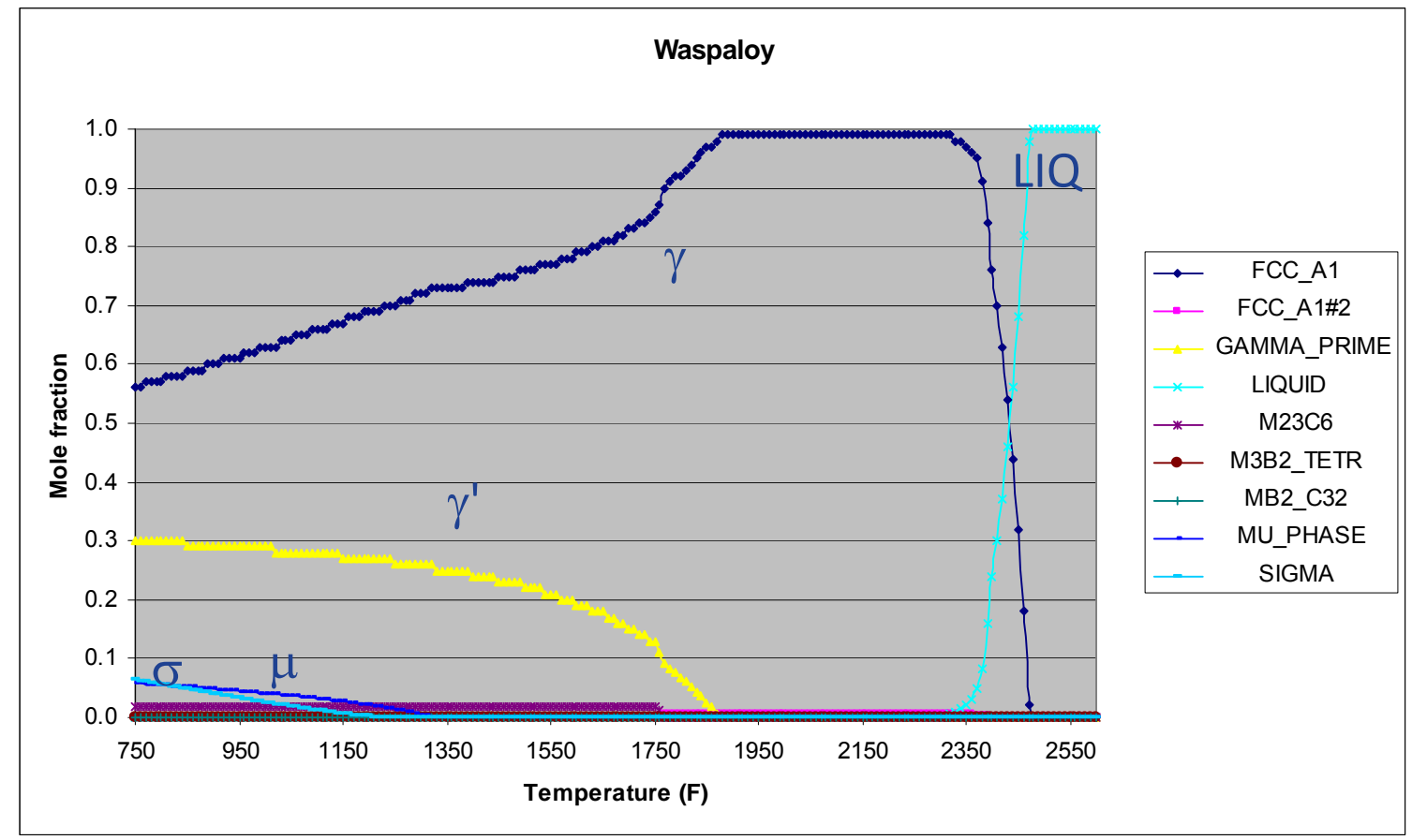

Figure 8: ThermoCalc phase diagram for Waspaloy showing ideal mole fractions of $\gamma, \gamma^{\prime}, \mu$ and $\sigma$.

\subsection{Candidate Alloy Selection}

From the initial evaluation of available information (Appendix 1) and from the ThermoCalc simulations of phase formation and stability, the following alloys were considered as possible candidates.

Table 2: Materials Capability at $1400^{\circ} \mathrm{F}$ 


\begin{tabular}{|c|c|c|c|}
\hline Alloy & $\begin{array}{c}\text { Creep Rupture Capability } \\
\left(100,000 \mathrm{~h} / 1400^{\circ} \mathrm{F}\right)\end{array}$ & $\begin{array}{c}1400^{\circ} \mathrm{F} \mathrm{0.2} \% \mathrm{YS} \\
(\mathrm{ksi})\end{array}$ & $\begin{array}{c}\text { RT Fracture Toughness } \\
(\mathrm{ksi} \cdot \sqrt{ } \mathrm{in})\end{array}$ \\
\hline IN740 & $16-21$ & 88 & Unknown \\
\hline Udimet 700 & 33 & $120-125$ & Unknown \\
\hline Udimet 720 & Unknown & $105-140$ & Unknown \\
\hline Udimet 720Li & Unknown & 125 & Unknown \\
\hline Rene 41 & 22 & $130-135$ & Unknown \\
\hline Haynes 282 & Unknown & 87 & Unknown \\
\hline Astroloy & 32 & $85-130$ & Unknown \\
\hline Waspaloy & $15-19$ & $85-135$ & Unknown \\
\hline Nimonic 105 & 25 & $105-110$ & \\
\hline
\end{tabular}

In order to appreciate the microstructural stability of these alloys, phase formation in the typical heat treatment temperature range was investigated. The alloys in Table 2 were evaluated for eta $(\eta)$, sigma $(\sigma)$ and $\mathrm{mu}(\mu)$ as well as various typical carbides. The results are contained in Table 3.

Table 3: Predicted Phase Formation in Heat Treatment Window $\left(\leq 1500^{\circ} \mathrm{F}\right)$

\begin{tabular}{|c|c|c|c|c|c|c|}
\hline Alloy & $\eta$ & $\sigma$ & $\mu$ & MC & M23C6 & M6C \\
\hline IN740 & 12.9 & 11.4 & --- & 0.3 & 0.7 & --- \\
\hline Udimet 700 & --- & --- & 2.3 & --- & --- & --- \\
\hline Udimet 720 & --- & --- & 1.1 & --- & --- & --- \\
\hline Udimet 720Li & --- & --- & 1.1 & --- & --- & --- \\
\hline Rene 41 & --- & --- & 9.8 & --- & --- & 3.0 \\
\hline Haynes 282 & --- & --- & 10.4 & --- & --- & 2.0 \\
\hline Astroloy & --- & --- & --- & --- & --- & --- \\
\hline Waspaloy & --- & 0.6 & 3.2 & --- & --- & --- \\
\hline Nimonic 105 & --- & --- & --- & --- & --- & --- \\
\hline
\end{tabular}

Further evaluation in the turbine rotor operating temperature range (i.e., $\leq 1400^{\circ} \mathrm{F}$ ) showed that carbide formation disappeared while eta $(\eta)$, sigma $(\sigma)$ and $m u(\mu)$ formation persisted at the levels noted in Table 3. (Note: Carbides form in these alloys but the temperature at which the carbides form is higher than $1500^{\circ} \mathrm{F}$ and as such were not noted in Table 3. Only those carbide phases and phase fraction that formed at, or below, $1500^{\circ} \mathrm{F}$ were included.)

Based on available mechanical property data, processing guidance from the manufacturers and microstructural stability information, the following nickel-base alloys were selected for further study for a monoblock configuration for a steam turbine rotor: 
Haynes 282, Nimonic 105, Udimet 720Li and IN740. As a backup candidate alloy, Waspaloy was also considered.

Of this group of potential rotor alloys, the DOE 1400F Boiler Consortium had previously evaluated IN740 for a variety of components and extensive creep testing had been performed. Therefore, Haynes 282, Nimonic 105 and Udimet 720Li were selected for further study and material was obtained to verify properties relative to the literature and to explore possible rotor microstructures based on typical alloy heat treatments and extended temperature excursions between $1400-1500^{\circ} \mathrm{F}$ to simulate very slow cooling from the rotor ingot forging temperature.

\section{$3 \quad$ Part 2: Material Procurement, Heat Treatment, and Screening Tests}

Material for the screening tests was procured from Haynes International (alloys 617 and 282), Special Metals Corp. (alloys 105 and 720Li), and Ladish Co. (alloy 720). The material was received either as plate ( $>1$ " thickness), forged disk or small diameter rod. Although the product form and size is not equivalent to a rotor forging, the material was sufficient to determine baseline mechanical properties, which was used to assess candidate alloy capability at $1400^{\circ} \mathrm{F}$ and to verify manufacturer product literature where available.

In determining the way to assess mechanical behavior of the alloys for use as a rotor, one concern was of primary importance, the effect that cooling such a large chunk of material would have on mechanical properties. Because these alloys have not been used for power generation activities, the robustness of the alloy in terms of heat treatment and long-term strength at temperature up to, and greater than, $1400^{\circ} \mathrm{F}$ were unknown. As such, the alloys were investigated in several conditions: the as-processed condition whether it be solution annealed or cold-drawn rod, aged to peak hardness as per manufacturer recommendation and overaged in a manner that might simulate the cooling of a large rotor segment. In this way, a range of properties would be available that would define the robustness of the alloy. The heat treatments used for each alloy are described separately in the discussion of that alloy.Screening tests were designed to determine baseline mechanical properties for the four alloys, i.e., Haynes 282, Nimonic 105, Udimet 720Li and alloy 617, and limited to tensile, low cycle fatigue and creep and creep rupture. The Haynes 282, Nimonic 105, and Udimet 720Li alloys were under consideration as monoblock rotor alloys while alloy 617 was of interest as a lower temperature alloy in a welded rotor configuration. Alloys 740 and Waspaloy were not tested in Phase I because alloy 740 was intensively investigated in the boiler portion of the $1400^{\circ} \mathrm{F}$ project as a piping and tubing material. Waspaloy was not tested because data is available to assess the alloy for $1400^{\circ} \mathrm{F}$ use.

Screening tests consisted of quasi-static tensile tests from room temperature through $1500^{\circ} \mathrm{F}$ to establish the shapes of the strength versus temperature curve and ductility versus temperature curve. Low cycle fatigue testing was performed to determine if there were any premature signs of alloy cracking leading to cyclic failure. Finally, creep and creep rupture testing was performed on the alloys for times up to 10,000 hours. 


\subsection{Haynes 282}

The first batch of Haynes 282 (\# 2082-5-8354) was received as 2.175" rolled plate (11" x 14 " width and length, respectively) in the solution-annealed condition. Tensile, LCF and creep tests were performed in this condition to establish base-line mechanical behavior against which the effects of peak age-hardened and overaged (i.e., a condition that could simulate the worst condition of a large rotor ingot cooled in manner previously described) microstructures could be compared. A second batch of Haynes 282 (\# 2082-6-8356) in the solution-annealed condition was subsequently received as $1.365^{\prime \prime}$ rolled plate $\left(10^{\prime \prime} \mathrm{x}\right.$ 40 " width and length, respectively). The $40^{\prime \prime}$ length of plate was cut into thirds, approximately 13.25" in length, with two pieces heat treated to peak age-hardened condition for mechanical testing as per the first heat of Haynes 282. A third batch of Haynes 282 (\# 2082-6-8356) was procured by Siemens Westinghouse, also in the form of solution-annealed rolled plate: $1^{\prime \prime}$ x $36^{\prime \prime}$ x $120^{\prime \prime}$, thickness by width by length, respectively. The chemical compositions of three heats of Haynes 282 are found in Appendix 2, Table 2A.

\section{Haynes 282: Peak Age-Hardened Condition}

1. Heat to $1850^{\circ} \mathrm{F}$ and hold at this temperature for 2 hours.

2. Air cool between 1400 and $1450^{\circ} \mathrm{F}$, or any convenient temperature below $1450^{\circ} \mathrm{F}$.

3. Reheat/heat to $1450^{\circ} \mathrm{F}$ and hold at this temperature for 8 hours.

4. Air cool to room temperature.

Haynes 282: Overaged Condition

Heat-treat the peak age-hardened Haynes 282 for an additional 250 hours at $1425^{\circ} \mathrm{F}$ : furnace cool to room temperature when done.

\subsection{Nimonic 105}

The first batch of Nimonic 105 (SM \# FEY-5183; primary cast \#: FPE-3361) was received as cold drawn bar, $0.866 "$ in diameter by 288" in length. The cold drawn bar was sectioned into thirds. One section of the bar in the cold drawn condition was used to determine base-line tensile, LCF and creep properties. Subsequently, the other two sections of the bar were heat treated to peak age-hardened condition and the overaged condition according to the following schedules (see below). Mechanical testing as per the cold drawn bar was conducted on the heat-treated material. A second batch of Nimonic 105 (SM \# JEY-5793; primary cast \#: JPE-5637) was received as bar, approximately 2" in diameter by 12 " in length. The bar was heat treated to the age-hardended condition and tested as per the first heat of material. Both heats of Nimonic 105 were induction airmelted and then vacuum arc remelted prior to forming into bar. The chemical compositions of both heats of Nimonic 105 are found in Appendix 2, Table 2B.

Nimonic 105: Age-Hardened Condition

Two-Step Super-Sub Solvus Heat Treatment

1. Preheat to $1925^{\circ} \mathrm{F}$ in vacuum and hold for $1 / 2$ hour. 
2. Heat to $2125^{\circ} \mathrm{F}$ in vacuum and hold for 4 hours.

3. Heat to $2125^{\circ} \mathrm{F}$ in vacuum and hold at temperature for 4 hours followed by fan cooling RT.

4. Heat to $1475^{\circ} \mathrm{F}$ and hold for 24 hours followed by air-cooling.

Nimonic 105 HT-Overage Schedule

Heat-treat the two-step solvus solution heat-treated material at $1450^{\circ} \mathrm{F}$ for 250 -hours, furnace cool when done.

\subsection{Udimet $720 \mathrm{Li}$}

The Udimet 720Li was received as two forged disks (SM heat \# 9-23592-x), each disk approximately $6.5^{\prime \prime}$ in diameter by 1 " thick. The disks were heat-treated according to the following schedule:

1. Preheat to $1925^{\circ} \mathrm{F}$ in vacuum and hold for $1 / 2$ hour.

2. Heat to $2025^{\circ} \mathrm{F}$ in vacuum and hold for 4 hours.

3. Nitrogen quench in vacuum, then reheat to $1200^{\circ} \mathrm{F}$ in air. Hold for 24 hours then quench in oil.

4. Reheat to $1425^{\circ} \mathrm{F}$ in air and hold for 16 hours. Air cool to room temperature.

A laboratory heat of alloy 720 was produced by Ladish Co., Inc. for Siemens Westinghouse in the form of a forged disk as part of the DOE 1400F Steam Turbine program. The billet was produced from -140 mesh powder, which was subsequently subsolvus HIP'd before being cogged into a 9" diameter billet. The final forged billet was 17.9" in diameter with a variable machined thickness ranging from 4.5" (maximum) to 1.6" at the rim. Grain size was ASTM 11 average, with ALA ASTM 9. Post forge heat treatment $2020^{\circ} \mathrm{F}$ for $2 \mathrm{~h}$ followed with oil quenching to RT before the first aging heat treatment at $1202^{\circ} \mathrm{F}$ for $24 \mathrm{~h}$ with air cool to RT. This was followed by a second aging step at $1400^{\circ} \mathrm{F}$ for an additional $16 \mathrm{~h}$ with air cool to RT. The heat treatment given to this heat of alloy 720 was similar to the heat treatment performed on the GE material.

The chemical compositions of these two heats of alloy 720 are found in Appendix 2, in Table 2C. Tensile, LCF and creep tests were performed in this condition to establish base-line mechanical behavior. No additional heat treatments were done to this alloy due to insufficient material and less than desired creep rupture performance.

\subsection{Alloy 617}

Alloy 617, procured by Siemens Westinghouse for welding studies, was obtained in plate form (heat \# 8617-6-8838) in the solution annealed condition from Haynes International: $1 " \mathrm{x} 36^{\prime \prime} \mathrm{x} 36^{\prime \prime}$, thickness by width by length, respectively. The chemical compositions of this alloy is found in Appendix 2, Table 2D. Tensile, LCF and creep tests were performed in this condition to establish base-line mechanical behavior.

\subsection{Mechanical Properties}

The tensile mechanical properties for Haynes 282, Nimonic 105, Udimet 720Li and alloy 617 for use in $1400^{\circ} \mathrm{F}$ steam are collated into tabular form in Appendix 3 as Tables 3A

thru $3 \mathrm{H}$. The tensile data consists of two complementary tabular sets: one set of tables has 
been constructed on the material tensile tested as part of the $1400^{\circ} \mathrm{F}$ steam turbine program while the second set of tables is collated manufacturer and literature (where available and documented) data published for that alloy. Comparing testing results with manufacturer data verifies and validates the testing performed during the course of Phase I.

Appendix 4 contains the raw data for low cycle fatigue screening tests for the aforementioned alloys at $1400^{\circ} \mathrm{F}$ (Tables $4 \mathrm{~A}$ thru $4 \mathrm{E}$ ). Where fatigue data exist in the literature (Haynes 282 alloy specifically where limited additional tests have been performed at $1200^{\circ} \mathrm{F}, 1500^{\circ} \mathrm{F}$ and $1600^{\circ} \mathrm{F}$ ), this information has been included in complementary tables.

The creep rupture data for Haynes 282, Nimonic 105, Udimet 720 and Inconel 617 are found in Appendix 5 in Tables 5A thru 5L. Creep rupture data is presented as LMP vs. stress and stress vs. LMP for each alloy. Also, graphs of stress vs. LMP have been included for Haynes 282, Nimonic 105 and Udimet 720 as the time to reach a specified percent strain level (i.e., 0.1, 0.2, 0.5, 1.0, 2.0 and 5.0). Insufficient testing was done on Inconel 617 to construct graphs of this type.

As for tensile and fatigue data, information in the tables comes from tests conducted during the course of this project and from literature data where available and from information provided by the manufacturer.

\subsection{Tensile Behavior}

The tensile behavior for Haynes 282, Nimonic 105, Udimet 720 and Inconel 617 are tabulated in Appendix 3. In addition, graphs of UTS, $0.2 \% \mathrm{YS}$ and elongation are provide for Haynes 282 in the solution annealed (SA) condition (Figure 3.1), peak aged (HT) condition (Figure 3.2) and overaged, or heat conditioned, state (Figure 3.3). Figures 3.4 thru 3.6 show the same information for Nimonic 105, but for this alloy instead of the solution annealed condition the material was in the as-processed (AP) state. Udimet 720 was only tested in the heat-treated condition for best general tensile strength. At this juncture the information on Inconel 617 is only presented in tabular form since a minimum of screening tests were performed by the team.

Figure 9 shows some selected information on tensile strength (UTS) for Haynes 282 (SA), Udimet 720 (HT to peak age) and Nimonic 105 (AP condition and HT to peak age). Even though selected data is presented, the graphs show the general stratification of tensile strength for these alloys. Udimet 720 was by far the strongest alloy of the three candidate materials, only approaching the strength of Nimonic 105 at temperatures $>1400^{\circ} \mathrm{F}$. Nimonic 105 in the as-processed, heat treated and overaged conditions were roughly equivalent in strength at all temperatures. For Nimonic 105 the overaged condition yielded, on average, the highest values of tensile strength of the alloy. Haynes 282 was roughly equivalent to, or slightly stronger, than the Nimonic 105 in the heat treated and overaged conditions. However, Haynes 282 in the SA condition possessed the lowest strength. Although this should seem obvious, subsequent microstructural analysis showed that even in the SA state the Haynes 282 had 5-20 nm diameter $\gamma^{\prime}$ precipitates.

From Figure 9 the tensile strength of the candidate alloys is bound by Udimet 720 in the HT for peak age condition at the upper end. The Haynes 282 forms the lower bound in 
the quasi-SA condition. The tensile strength of the Haynes 282 in the HT for peak strength (and overaged condition) is very similar to the Nimonic 105. The tensile strength of the three alloys converges to roughly the same strength level at $1500^{\circ} \mathrm{F}$. There is one common trend for these three alloys: there is a gradual decrease in strength from room temperature to about $1200^{\circ} \mathrm{F}$, and then the alloys begin to loose strength at a slightly more rapid rate. One interesting behavior was noted for Haynes 282. At $1300^{\circ} \mathrm{F}$, there was a slight increase in strength before it decreased again. This behavior was consistent with published data by Haynes International and was not an artifact of the testing.

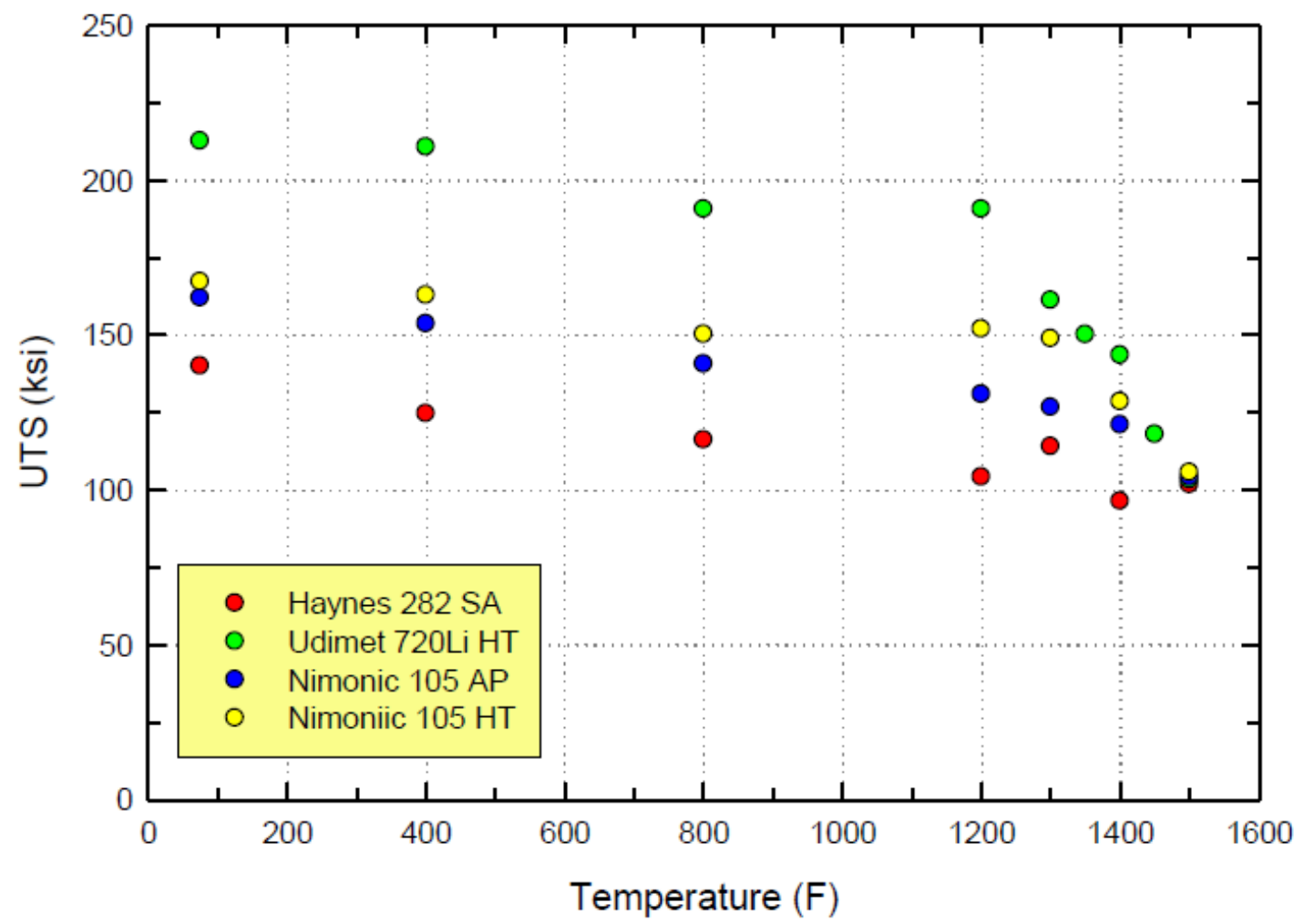

Figure 9: UTS as a function of temperature for Haynes 282 in the solution annealed (SA) heattreated for peak strength (PA) and overaged (OA) conditions.

Figure 10 presents the same alloy conditions as Figure 9. Again, the same general trend is observed in $0.2 \%$ YS as was exhibited for tensile strength. The Udimet 720 had by far the highest $0.2 \%$ YS, while the SA Haynes 282 had the lowest. The Nimonic 105 fell in between these two alloys. The $0.2 \%$ YS for the HT to peak age Haynes 282 was slightly less than the Nimonic 105 at all temperatures. The $0.2 \%$ YS for the HT Haynes 282 was about 105 ksi at room temperature. This was about 5-8 ksi lower than the Nimonic 105. 


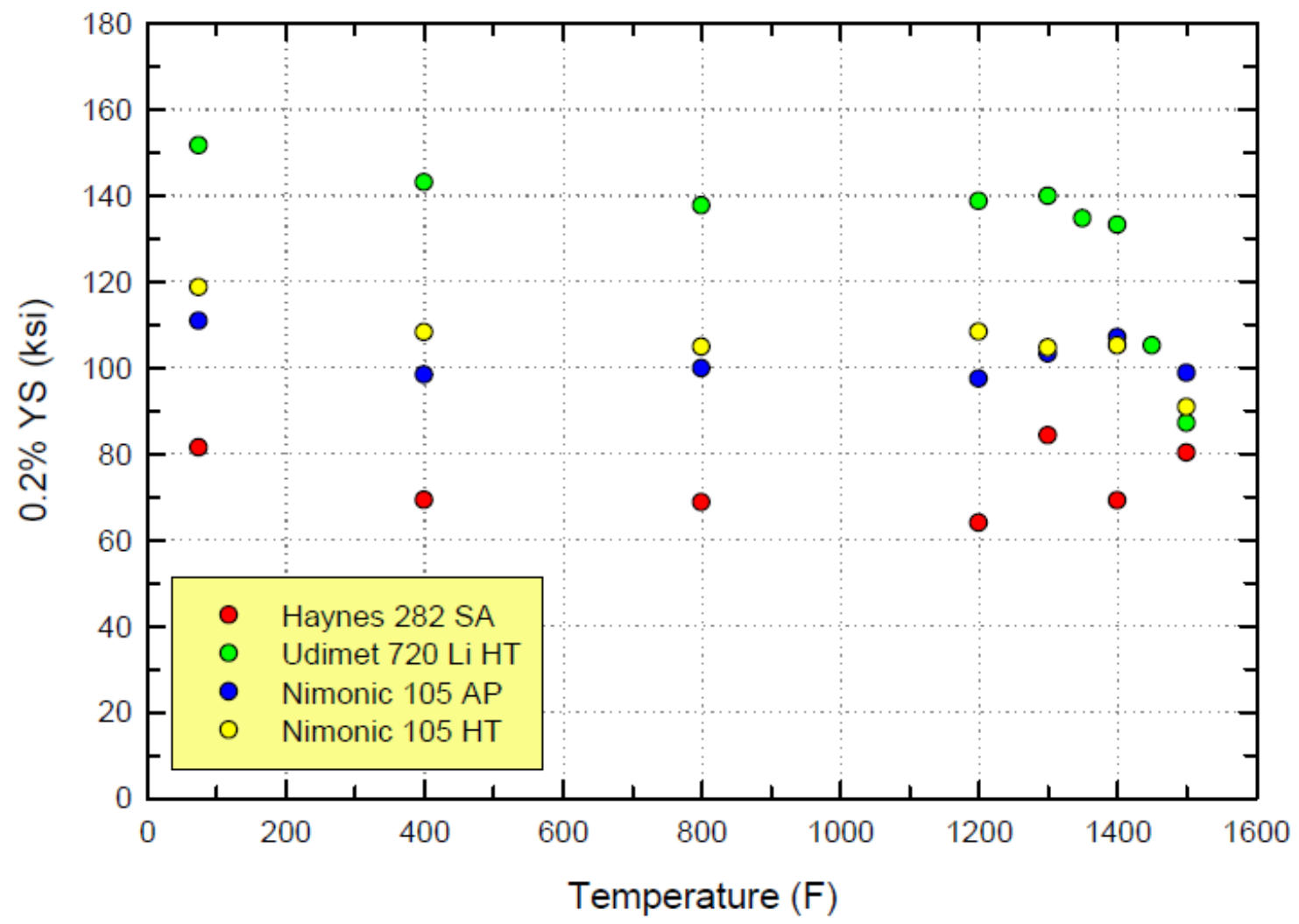

Figure 10: 0.2\% YS as a function of temperature for Haynes $282 \mathrm{SA}$, Udimet $720 \mathrm{Li}$ HT, Nimonic 105 AP, and Nimonic 105 HT.

The other interesting behavior of these alloys with respect to $0.2 \%$ YS was the relatively flat behavior from room temperature to about $1400^{\circ} \mathrm{F}$. Each alloy exhibited about a $10 \%$ decrease in $0.2 \%$ YS from room temperature to $400^{\circ} \mathrm{F}$, at which point the strength remained relatively constant until $1400^{\circ} \mathrm{F}$. Once again, the Haynes 282 showed an increase in $0.2 \% \mathrm{YS}$ from $1200^{\circ} \mathrm{F}$ to $1300^{\circ} \mathrm{F}$. In this instance it decreased a little at $1400^{\circ} \mathrm{F}$ to a value roughly the same as that observed at $800^{\circ} \mathrm{F}$ before increasing slightly again at $1500^{\circ} \mathrm{F}$. As was noted for tensile strength, the values of the three alloys converged at $1500^{\circ} \mathrm{F}$ with the Nimonic 105 in the as-processed condition being slightly stronger than the others. The Haynes 282 was again the weakest but it had a $0.2 \%$ YS equal to that of its room temperature value.

From a general behavior point of view, the nickel-base superalloys are relatively stable, yield strength wise, up through $1400^{\circ} \mathrm{F}$. The Udimet 720 shows the most dramatic decrease in yield strength (i.e., it loses about $50 \%$ of its room temperature $0.2 \% \mathrm{YS}$ at $1500^{\circ} \mathrm{F}$ ). The AP Nimonic 105 is only about $10 \%$ less than its room temperature value while as mentioned previously the Haynes 282 has approximately the same $0.2 \%$ YS at $1500^{\circ} \mathrm{F}$ as it had at room temperature.

The results of this study provide a good indication of the relative tensile behavior of these alloys for different processing conditions, allowing a rational choice of processing options for large-scale ingots subject to slow cooling rates. Of special note are the results 
of those alloys with an overaged, or heat conditioned, precipitate structure. For both the Haynes 282 and Nimonic 105 overaging benefited strength.

For example, Figure 11 shows a compilation of all test data for Nimonic 105. For the peak aged material two heats were tested, so there is duplicate data. There is some stratification of data for tensile strength, especially at $1200-1400^{\circ} \mathrm{F}$. The data again converge at $1500^{\circ} \mathrm{F}$. Alternatively, the data are very consistent and very uniform for $0.2 \%$ YS. In this case there is no more than a $10 \%$ difference at any test temperature.

Elongation was little affected as well by initial heat treatment/processing condition. Percent elongation was very consistent from room temperature to about $1400^{\circ} \mathrm{F}$. There was some separation in data between PA heats with the second heat having more ductility up through $1200^{\circ} \mathrm{F}$ at which point the ductility decreased, reaching a low value $(\sim 6 \%)$ at $1500^{\circ} \mathrm{F}$. Alternatively, the overaged material exhibited an increase in ductility with temperature up to and including $1500^{\circ} \mathrm{F}$. Up through $1400^{\circ} \mathrm{F}$, ductility in terms of elongation is $10 \%$ or better. Reduction in area values are also good, typically better than $15 \%$ at all temperatures up to and including $1400^{\circ} \mathrm{F}$.

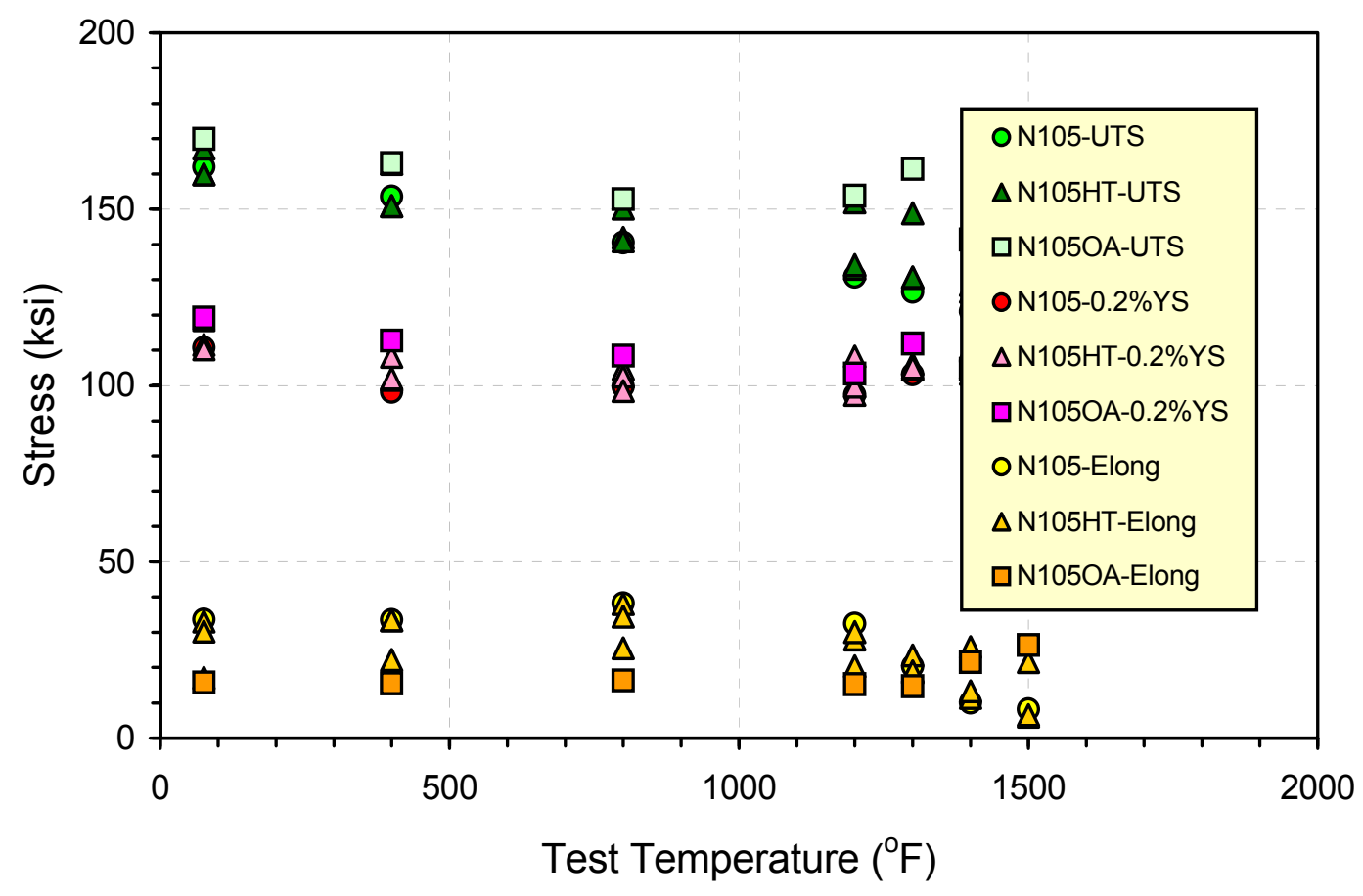

Figure 11: Mechanical behavior as a function of temperature for Nimonic 105, all processing and heat treatment conditions.

Figure 12 shows the same type of graph for Haynes 282. If one ignores the SA data curves, strength data for UTS and YS is quite consistent for the peak aged and overaged conditions. There are also two heats of data. Tensile strength begins to drop off at $1300^{\circ} \mathrm{F}$. Yield strength is, however, very constant up through $1400^{\circ} \mathrm{F}$ and the test data are tight. There is a bit more scatter is ductility but in general elongation is better than $18 \%$ and reduction in area is uniformly better than $19 \%$. 


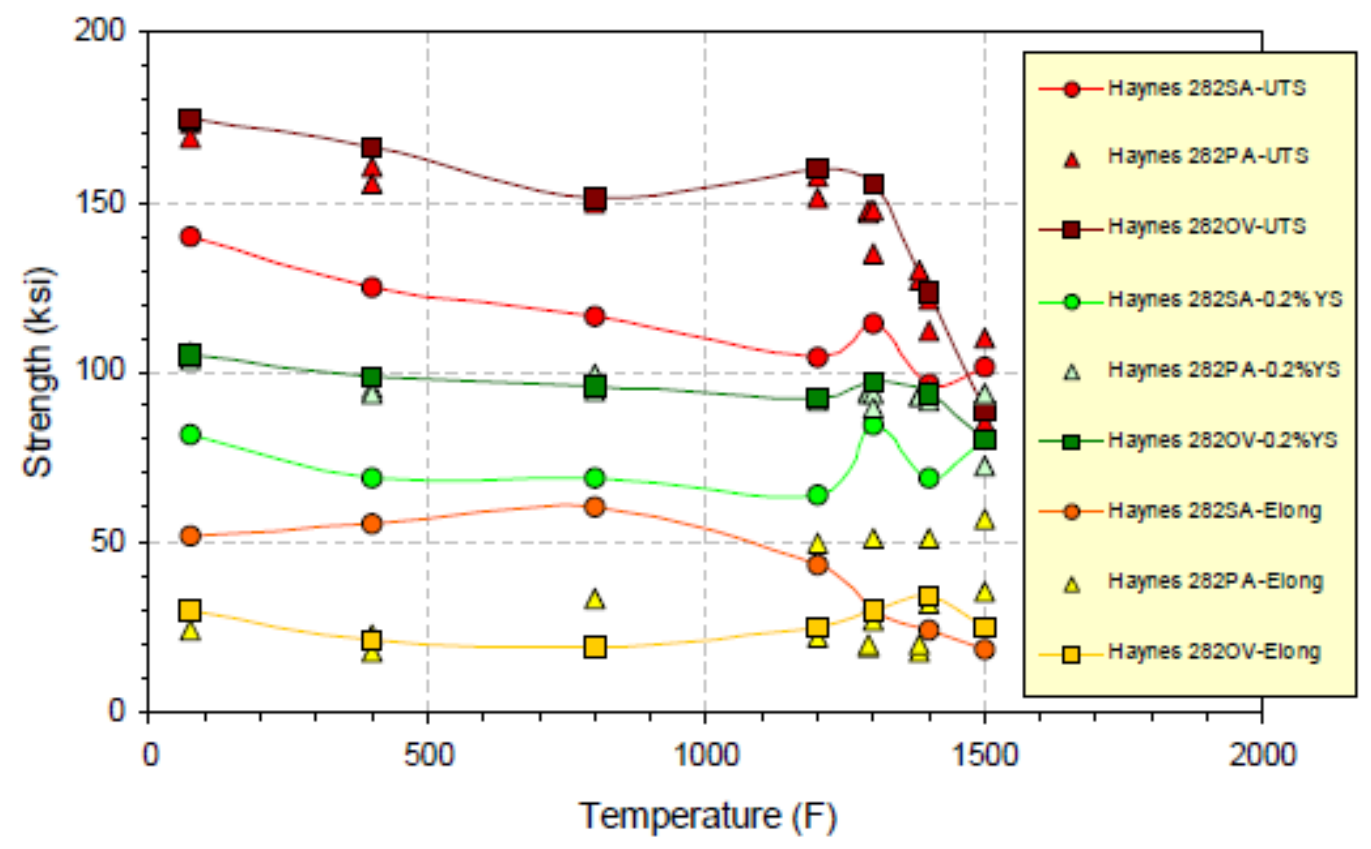

Figure 12: Mechanical behavior as a function of temperature for Haynes 282 for all processing and heat treatment conditions.

Mention has not been made on the strength of Inconel 617. Alloy 617 is a solid solution strengthened alloy, and as such, has a low yield strength, approximately $50 \mathrm{ksi}$ at room temperature. This alloy readily work hardens, reaching a tensile strength of about $110 \mathrm{ksi}$. Ductility is excellent. At $1400 \mathrm{~F}$ the $0.2 \%$ YS is typically between $30-40 \mathrm{ksi}$. Tensile strengths can reach $80 \mathrm{ksi}$. Again ductility is excellent with elongation to failure of between $50-60 \%$ and reduction in area of around 55\%. Even so, at room temperature the $0.2 \%$ YS of Inconel 617 is only a little greater than 60\% of SA Haynes 282. When compared against peak aged Haynes 282 or Nimonic 105, the 617 alloy has about 50\% of the strength of these two alloys. As such, for applications requiring high yield strength, Inconel 617 may not be acceptable even though it has excellent microstructural stability.

\subsection{LCF Behavior}

Low cycle fatigue data are found in Appendix 4. Comprehensive tests were run at $1400^{\circ} \mathrm{F}$ for Haynes 282 and Nimonic 105. GE tests were run at R = 0, while Haynes and SW data are at $\mathrm{R}=-1$. Even so data are very consistent in terms of the cycles to initiation (or failure) at a particular strain level. Figure 13 shows the combined data for Haynes 282 ( $R$ $=0$ and -1$)$, Nimonic $105(\mathrm{R}=0)$, Inconel $617(\mathrm{R}=-1$ : 2 data points) and Udimet $720(\mathrm{R}$ $=-1: 2$ data points).

The data points for Nimonic 105 and Haynes 282 overlap pretty much at all strain levels, although it appears the Nimonic 105 might trend towards a lower number of cycles to initiation at high $(>1.0 \%)$ strain levels. Examining the data for Udimet 720 would seem to indicate a shallower slope (based on just two data points) with better LCF capability. On the other hand, Inconel 617 had a slightly lower LCF capability than either Haynes 282 or Nimonic 105 . In general, LCF capability at $0.5 \%$ strain is greater than 10,000 cycles to crack initiation and at $0.4 \%$ strain 100,000 cycles are reached. 


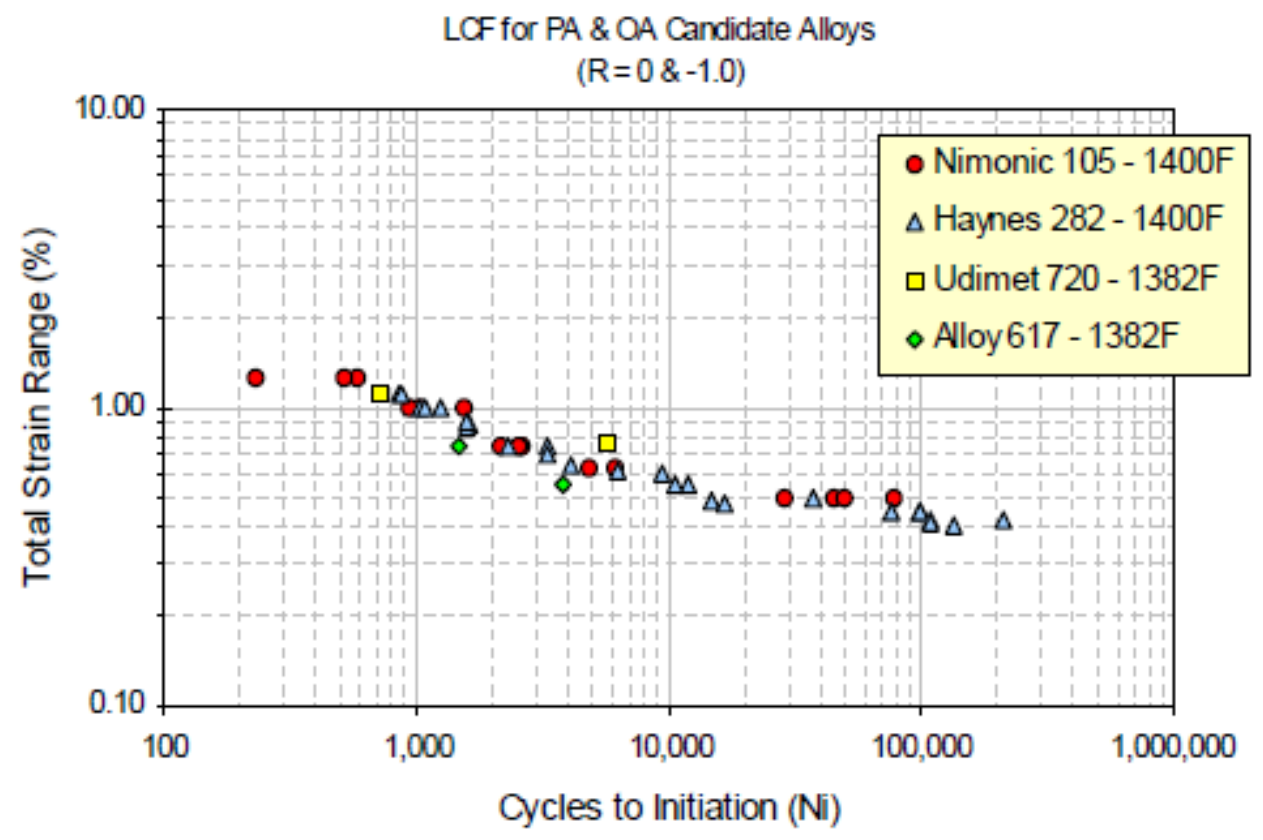

Figure 13: Combined LCF behavior for Nimonic 105, Haynes 282, Udimet 720, and Inconel 617 at $1400^{\circ} \mathrm{F}(\mathrm{R}=\mathbf{0}$ and -1$)$

\subsection{Creep Behavior}

The Phase I screening creep tests have been completed except for two Nimonic 105 samples. Creep rupture results in tabular and graphical form are found in Appendix 5. The discussion of creep capability for various alloys is found in Part 5. This section will briefly review test parameters and general results.

Based on $0.2 \% \mathrm{YS}$ and tensile strength levels for each alloy initial stress and temperature parameter values were determined to give failure at approximately 7,000 hours, or less. Two events occurred. The Udimet 720 alloy failed at times much less than expected based on its strength level relative to the other alloys and the Haynes 282 samples lasted very much longer than expected. It was as a consequence of these results that Udimet 720 was dismissed as a potential $1400^{\circ} \mathrm{F}$ candidate alloy. On the other hand the Haynes material exhibited far better creep strength than expected for the solution annealed condition. In fact, the creep behavior in the solution annealed condition was for all intents and purposes the same as that for the peak aged and overaged material. It was much later that the reason was deduced and it relates to the fact that very small $\gamma^{\prime}(5-20 \mathrm{~nm})$ precipitates exist in the SA alloy and they coarsen at $1400^{\circ} \mathrm{F}$ at low creep strains, thereby strengthening the alloy in the first several hundred hours of testing. The $\gamma^{\prime}$ in the SA material coarsens more rapidly initially until solute is depleted in the general vicinity of each $\gamma^{\prime}$ precipitate at which point the driving force decreases to that of the peak aged and overaged material. Only at high stresses would this effect become important.

A number of tests at low stress levels were terminated as a result. These samples were withdrawn from testing at $0.2 \%$ strain of less for times up to about 14,000 hours for the SA samples and $>10,000$ hours for the peak aged material. These samples were subsequently examined in the TEM to better understand the operative deformation 
mechanisms and creep exposed microstructure relative to the starting microstructure. This discussion is found in Part 4.

Nimonic 105 performed as expected. Tests were initiated at higher stresses and failures occurred during the first round of testing at 10,000 hours or less. Subsequent testing of a second heat of material confirmed the initial results.

An interesting observation was noted. For the Nimonic 105 overaging the alloy actually seemed to have the effect of increasing the creep strength of the alloy relative to the peak aged samples. It should be noted that only three overaged samples were tested and one is still in test at over 20,000 hours. However, the LMP curve is shifted to the right, or to a higher creep potential and the slope of the curve is shallower, another indication of better creep potential. However, there is also more scatter in the Nimonic 105 data, especially from the second heat of material, which was peak aged prior to testing. These data fall between the as-processed data from the first heat and the overaged material. Until samples of the Nimonic 105 creep microstructures can be analyzed a definitive cause of this behavior cannot be determined. It would be my recommendation to examine corresponding samples of the peak aged and overaged material to document similarities and differences. It may be that conditioning the Nimonic 105 alloy may enhance its creep capability.

Mention should be made of the creep results for Inconel 617. SW performed five shortterm screening tests on current production 617. This information is found in Table 5J in Appendix 5. Also in this table are four historical data points from GE tests from 1974. Although this is hardly a sufficient number of tests to determine the creep behavior of an alloy, ECCC has some published a sheet of information. Even though access to the actual tests was not possible, it was possible to extract temperatures, stress levels and time to failure for the published curves. This information is found in Table 5L. In addition Special Metals provided historical data for creep and creep rupture testing they have performed over the years in support of Inconel 617 alloy development. This information is not provided in tabular form. However, Figures 5.25 and 5.26 show this data. Layered on top of the SM data points are the GE historical data and the SW test results. It is clear that both data sets fall within the scatter of the SM testing. Further testing of 617 is probably not required.

Finally, with any nickel-base superalloy embrittlement is a potential concern. In this regard creep ductility, or lack thereof, is an indication that embrittlement might be a problem. In the case of Haynes 282 elongation to failure was typically better than 20\%, with most creep samples exhibiting ductility of between 20\% and 34\% (15 of 17 peak aged samples). One sample failed at $14 \%$. This was a high stress test (73 ksi) and one sample failed at $19 \%$. Conversely, the Haynes overaged creep samples exhibited ductility of approximately $17-18 \%$. Reduction in area was typically greater than $40 \%$. Only one sample had a value less than $20 \%$ and this sample was the high stress creep condition that had led to the low elongation value. So in general it appears that the Haynes 282 is not susceptible to embrittlement but this must be investigated in more detail in Phase II.

Nimonic 105, in general, had lower creep ductility than the Haynes alloy. Three samples failed with elongation less than $10 \%$, and while most samples exhibited elongation to failure of between $10 \%$ and $29 \%$, the majority of samples failed in the range of 10 to 
$20 \%$. Reduction in area values ranged between 20 and 50\%. Five samples had values less than $15 \%$, with some of these low values associated with high stress creep tests. There was no indication of embrittlement (i.e., low elongation and low reduction in area). However, as noted for Haynes alloy, additional testing is required to verify this preliminary observation.

As an aside Inconel 617 is an environmentally stable alloy. Inspecting the limited elongation data from SW testing shows that low elongation to failure occurs when the applied creep stress is high relative to the $0.2 \%$ YS of the alloy. When the elongation is low so also is the reduction in area. When the stress levels are low, i.e., more equivalent to the stress in a rotor, the reduction in area is typically high. The ductility behavior of Haynes 282 and Nimonic 105 are similar to that of Inconel 617.

\subsection{Summary of Candidate Alloy Screening Tests}

Preliminary mechanical testing of $1400^{\circ} \mathrm{F}$ candidate alloys has been completed. Udimet 720 has been eliminated from consideration due to less than expected, and totally unacceptable, creep rupture behavior. Although the alloy has good tensile properties, creep capability at $1400^{\circ} \mathrm{F}$ was the deciding factor in eliminating this alloy from further consideration.

Nimonic 105 has a good combination of tensile strength, LCF capability and creep strength to serve as a $1400^{\circ} \mathrm{F}$ alloy. Although the Haynes alloy is not quite as strong in creep as the Nimonic 105 material, its physical metallurgy is perhaps more tolerant of heat treatment, and given the small size of the $\gamma^{\prime}$ precipitate in the SA condition the alloy may be more amenable to forging operations and welding processes. In the peak aged condition Haynes 282 has the tensile strength and LCF capability to also make it a viable $1400^{\circ} \mathrm{F}$ alloy.

Inconel 617 performed as expected with respect to tensile strength and creep behavior. Additional testing may only be necessary in so far as to support dissimilar alloy welding with post weld heat treatment. As such, if 617 were to be selected as a low temperature rotor segment, then additional heat testing to add density to mid-temperature portion of the strength versus temperature curves would allow more accurate parameter models to be developed for conceptual steam turbine design evaluation.

\section{$4 \quad$ Part 3: Simulated Rotor Cooling Analysis}

Following the format established for the preliminary study on processing capability, i.e., forging followed by heat treatment with emphasis on various cooling methodologies, Haynes 282 was investigated in more detail using physical property information for Haynes 282 alloy. In the previous example, the general trend for large ingot processing was examined to better understand the cooling potential for a generic superalloy similar to Haynes 282 as a result of the cooling route. The same approach was taken with Haynes 282 except in this case in addition to two quenching routes, (a) water quenched (fast cooling) and (b) air quenched (slow cooling), the air cooling route was further differentiated into still air cooling (very slow) and fan cooling (slow compared to water quenching). 
Specific physical properties for Haynes 282 were used in this simulation to determine the heat transfer coefficients for water quenching (same as the earlier example) and the convective heat transfer coefficients for fan cooled and air cooled items. Two different rotor block geometries were also analyzed. Block 1 is a rotor segment 37" in diameter by 14 " in thickness. This block geometry would be similar to a gas turbine disk, which could subsequently be attached to other similar or dissimilar disk segments of equal size. Block 2 is a rotor segment with a diameter of $46^{\prime \prime}$ but with a longer thickness segment, equal to in this case 42". In this example a less than full-size rotor segment is envisioned, which could then be connected to one or more dissimilar rotor segments. In calculating the cooling rates and temperatures at various locations within the rotor segment a 2-D axisymmetric model was used.

Figure 14 shows the heat transfer coefficients used for simulating the water quench route. The convective heat transfer coefficient (HTC) used for fan cooling in the simulation was $2.77 \times 10^{-4} \mathrm{Btu} / \mathrm{in} \cdot \mathrm{s} \cdot \mathrm{F}$, while in the case of air cooling the HTC used was $2.73 \times 10^{-6}$ Btu/in.s.F. From this information finite element simulations were performed to determine the temperature distribution after 1 hour for water quenching, after 2 hours for fan cooling and after approximately 30 hours for air quenching. Water quenching and air quenching were charted from $2100^{\circ} \mathrm{F}$ to $100^{\circ} \mathrm{F}$ to define the general shape and relative magnitudes of the cooling curves at five critical locations: (1) at 1 inch below the surface along the centerline, (2) at the center surface, (3) at the center point at the center surface, (4) at1 inch below the surface at the mid-perimeter, and (5) at the mid-perimeter.

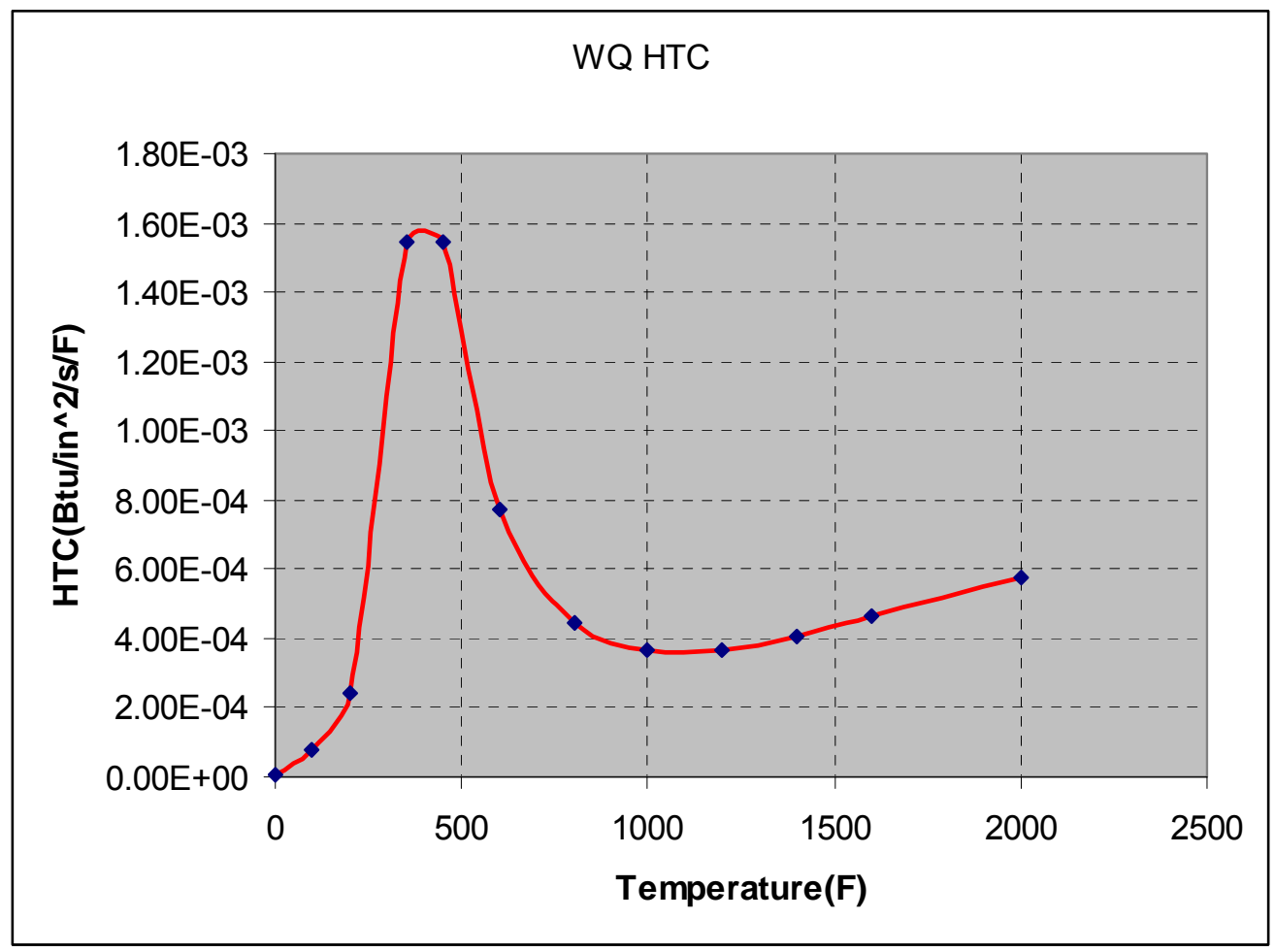

Figure 14: Heat transfer coefficient (HTC) for water quenching of Haynes 282.

Figure 15 shows the change in thermal conductivity $\left(\mathrm{Btu} \cdot \mathrm{in} / \mathrm{in}^{2} \cdot \mathrm{s} \cdot{ }^{\circ} \mathrm{F}\right)$ with temperature $\left({ }^{\circ} \mathrm{F}\right)$ for Haynes 282, values which were used in subsequent finite element simulations. 
Figure 16 shows the change in specific heat $\left(\mathrm{Btu} / \mathrm{lb} \cdot{ }^{\circ} \mathrm{F}\right)$ with temperature $\left({ }^{\circ} \mathrm{F}\right)$ for Haynes 282, while Figure 17 shows the change in density (lb/in $\left.{ }^{3}\right)$ with temperature $\left({ }^{\circ} \mathrm{F}\right)$.

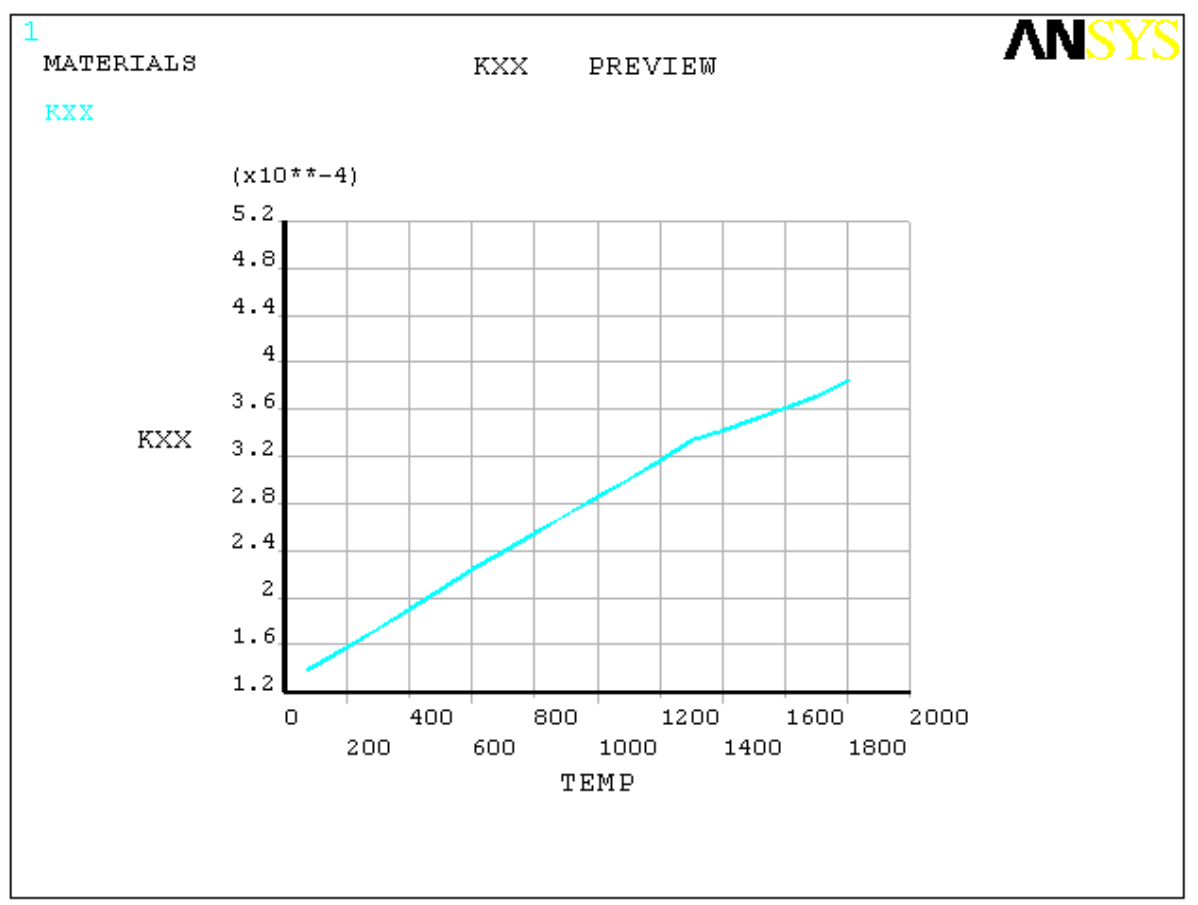

Figure 15: Graph of the change in thermal conductivity (btu in/in $\left.2 \mathrm{~s}^{\circ} \mathrm{F}\right)$ with temperature $\left({ }^{\circ} \mathrm{F}\right)$ for Haynes 282 from room temperature to $1800^{\circ} \mathrm{F}$.

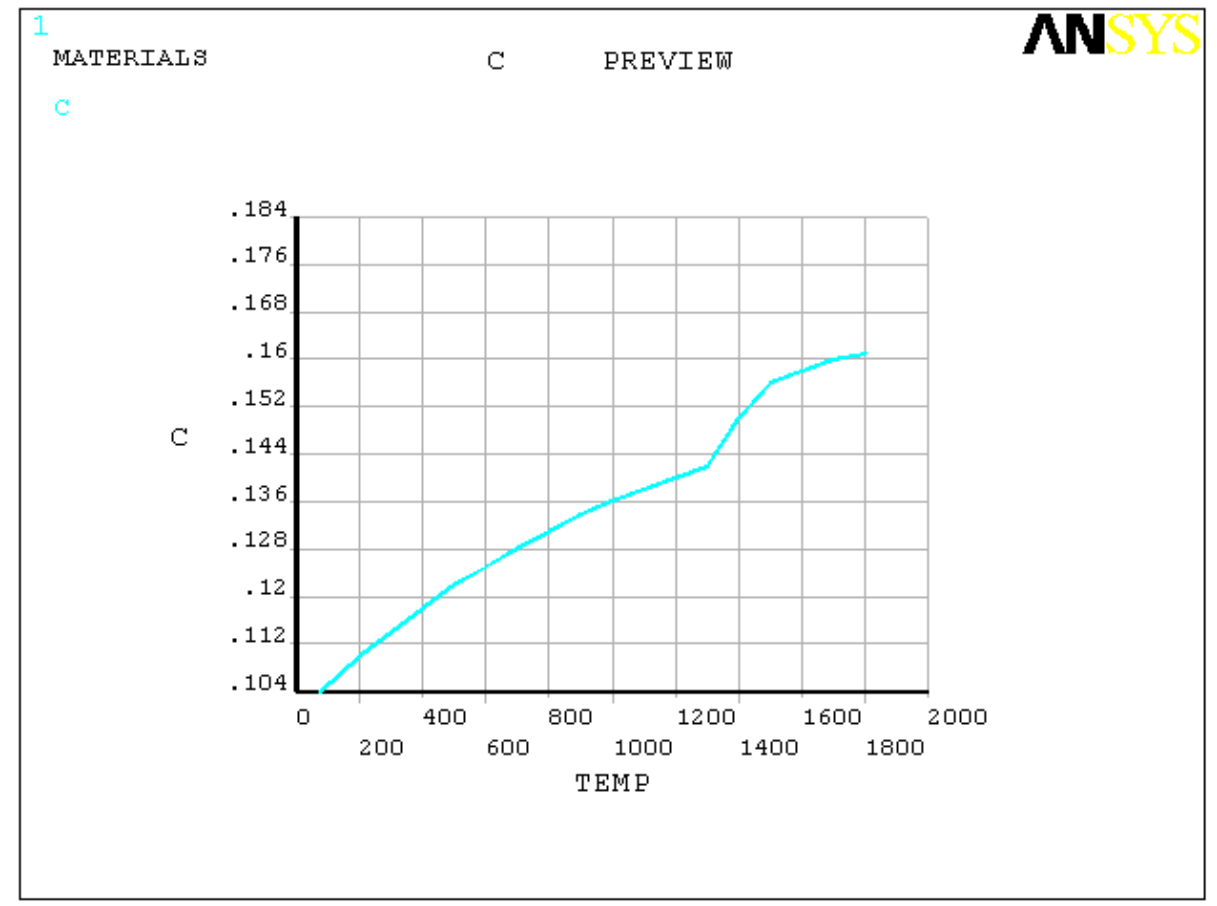

Figure 16: Graph of the change in specific heat $\left(B+u / l b{ }^{\circ} \mathrm{F}\right)$ with temperature $\left({ }^{\circ} \mathrm{F}\right)$ for Haynes 282 from room temperature to $1800^{\circ} \mathrm{F}$. 


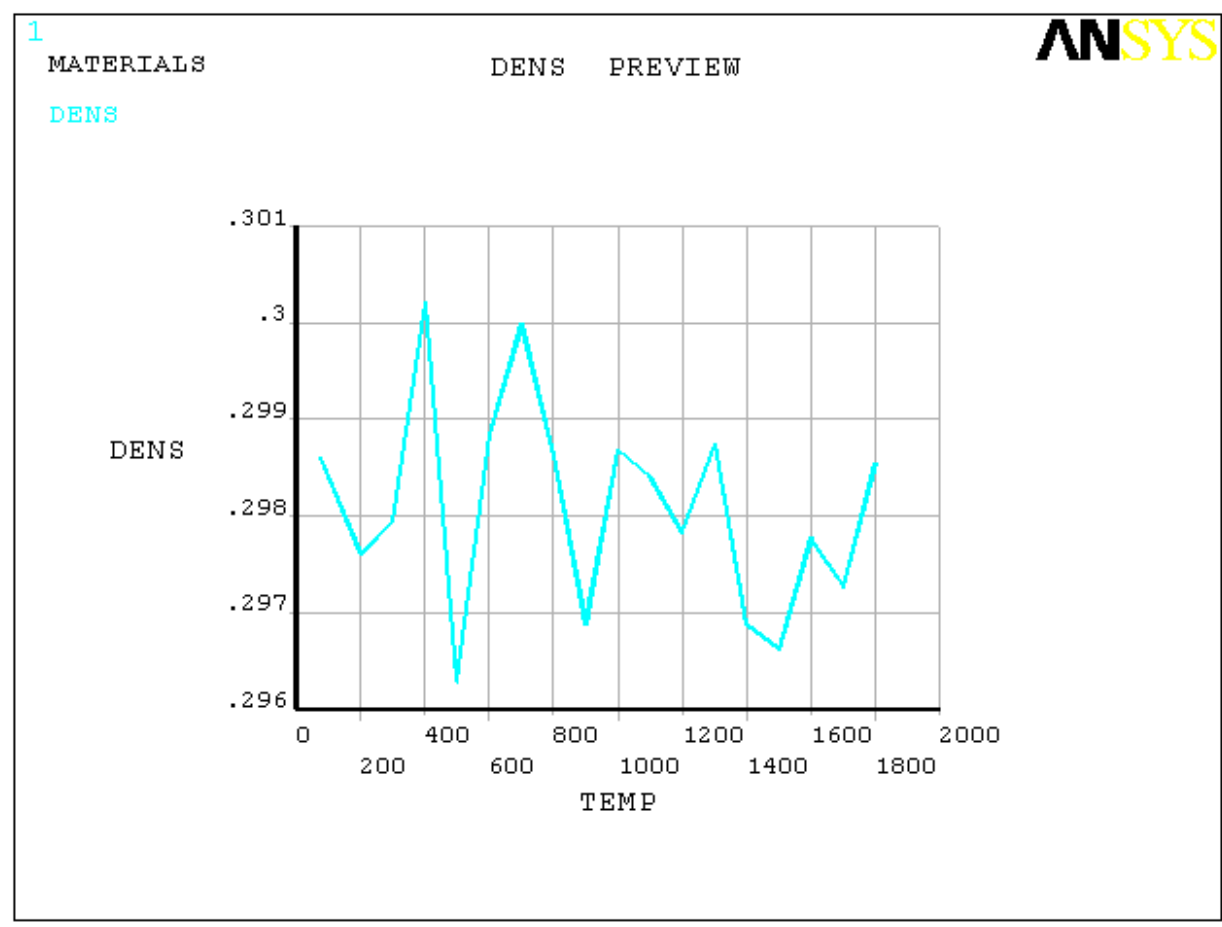

Figure 17: Graph of the change in density $\left(\mathrm{lb} / \mathrm{in}^{3}\right.$ with temperature $\left({ }^{\circ} \mathrm{F}\right)$ for Haynes 282 from room temperature to $1800^{\circ} \mathrm{F}$.

\subsection{Block 1 - Water Quenching}

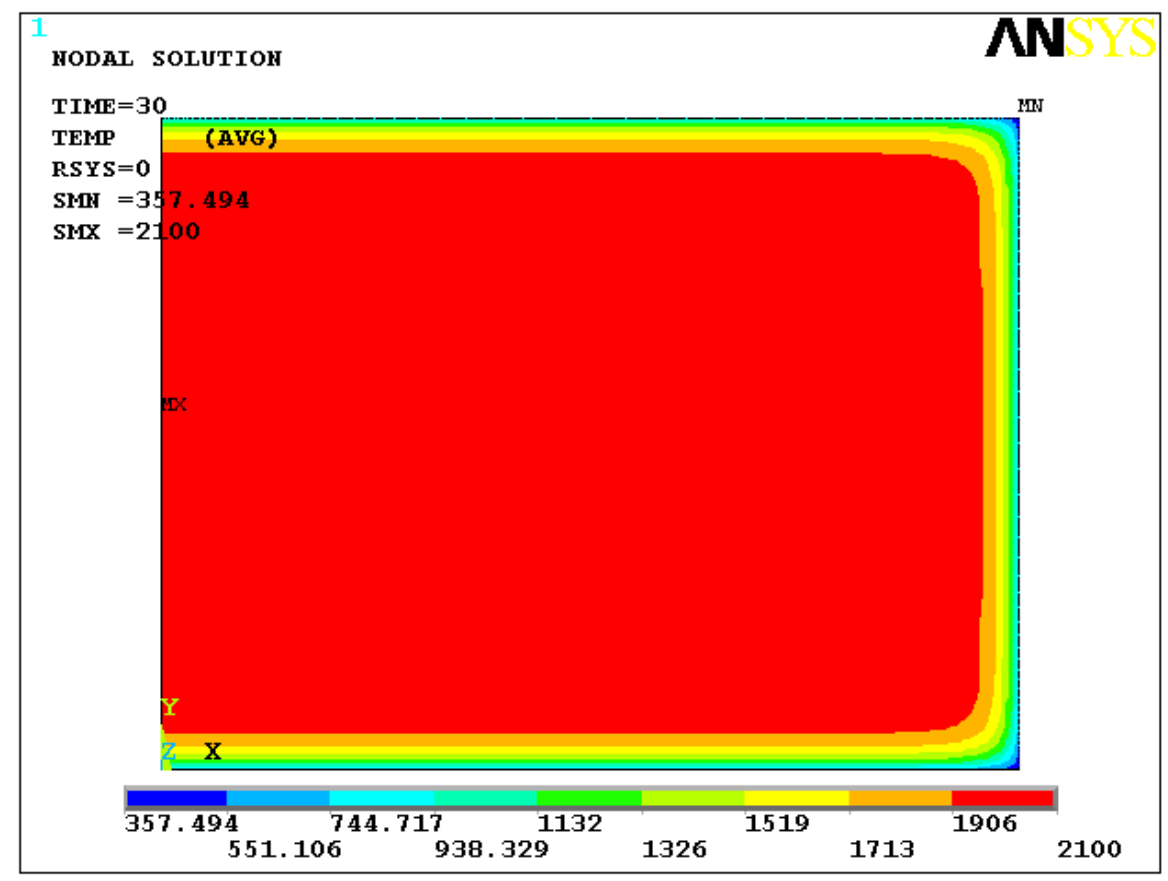

(a) 


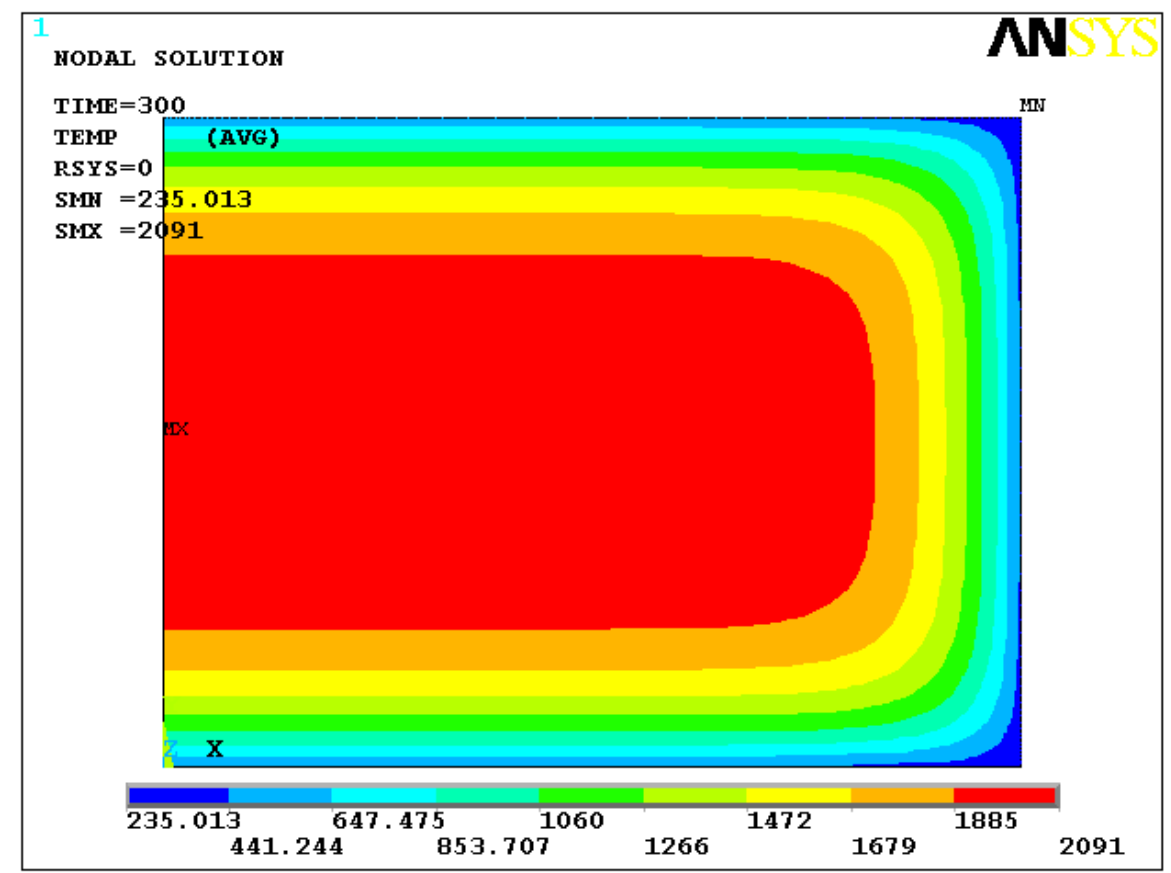

(b)

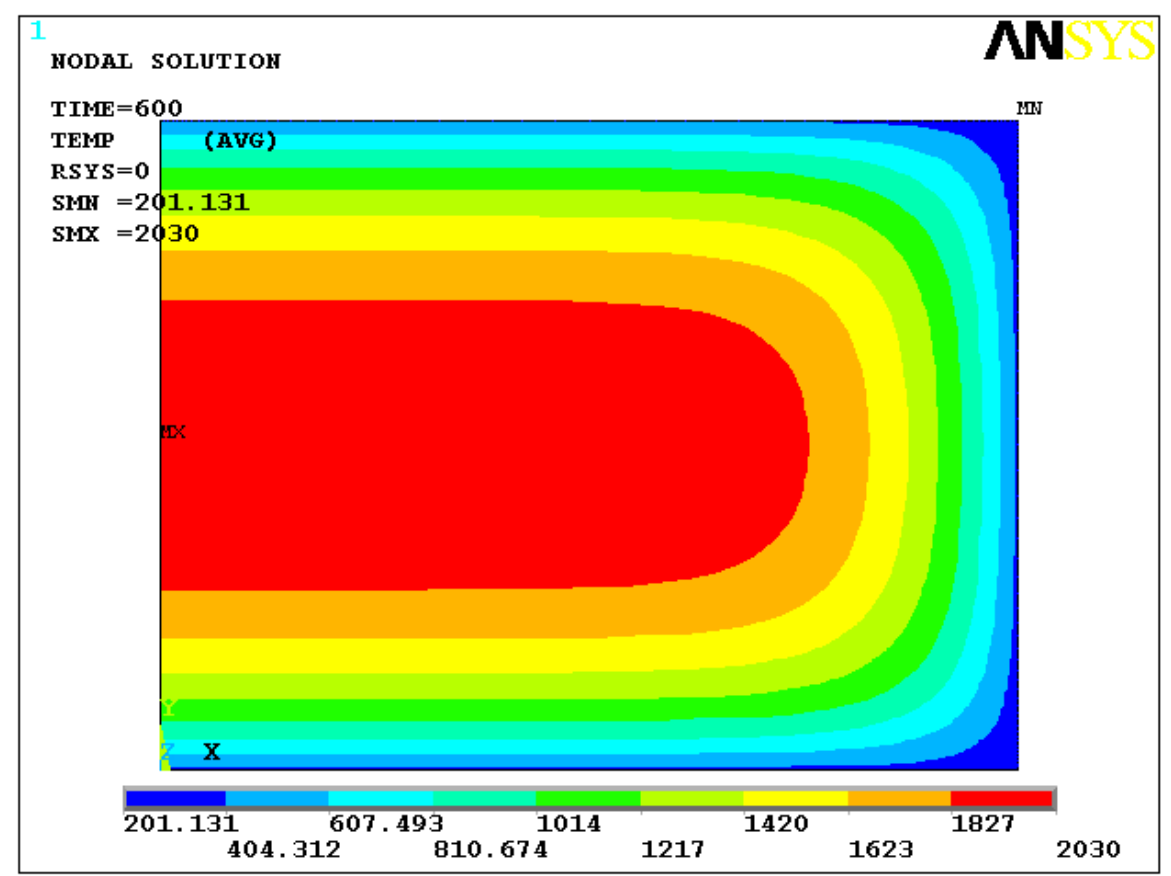

(c) 


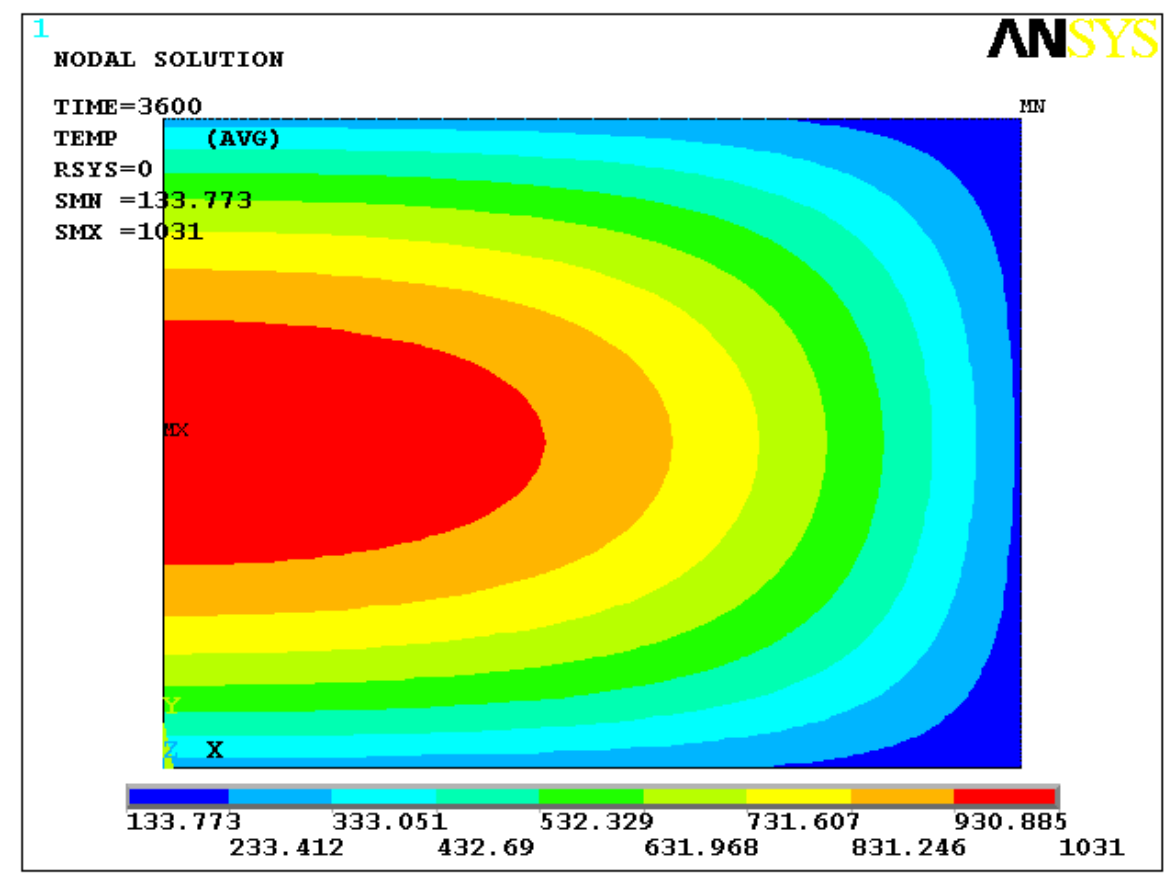

(d)

Figure 18:(a-d): show stages in the cooling sequence for Block 1 - Water Quenching Time is seconds, starting at 30 sec, and then showing the block at 300, 600, and 3600 sec. Note that the color scales change with each time increment block. 


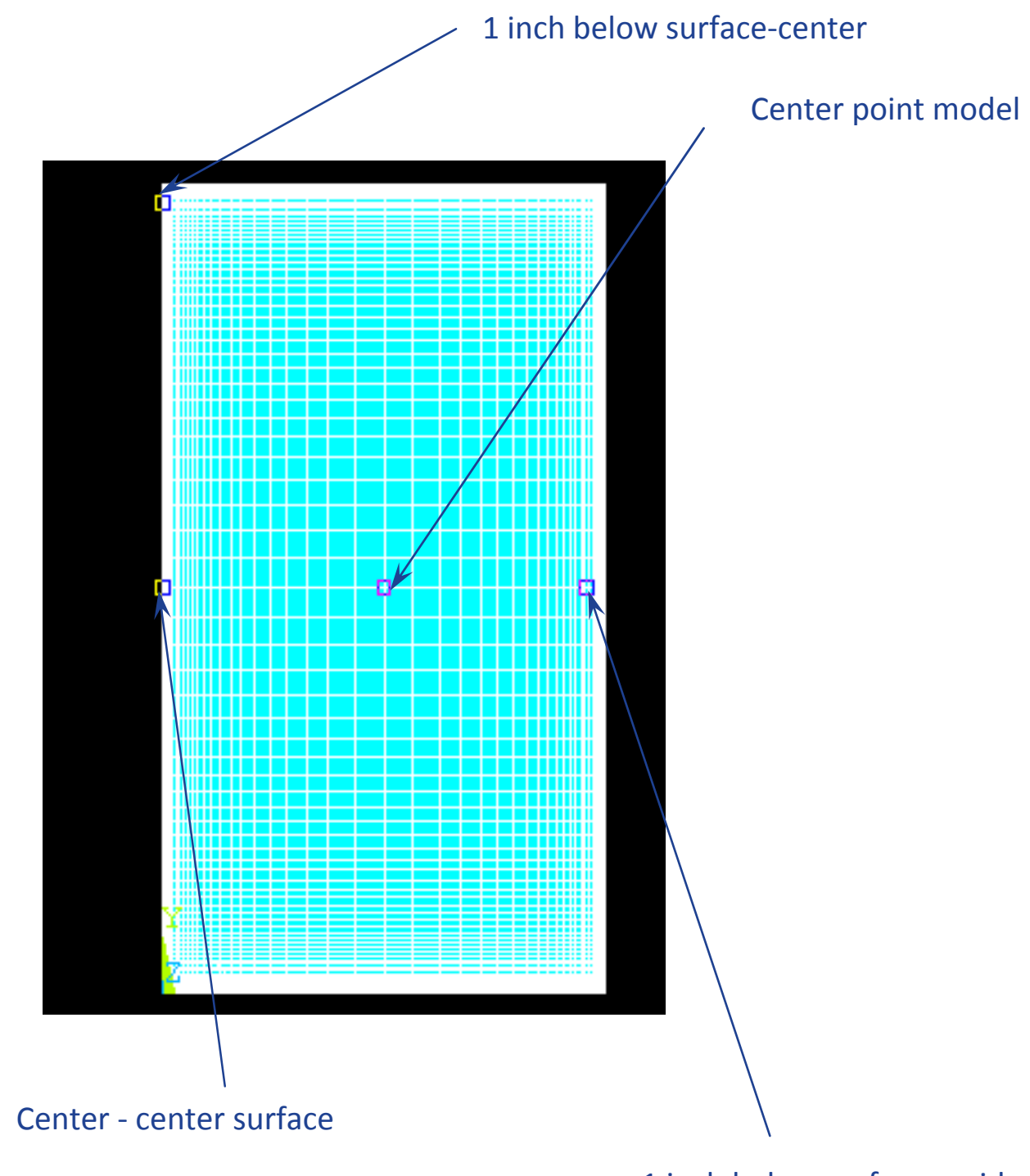

1 inch below surface - mid-perimeter

Figure 19: This figure shows the locations on Block 1 where cooling rates were calculated for the cooling rate curves for water and air quench simulations. 


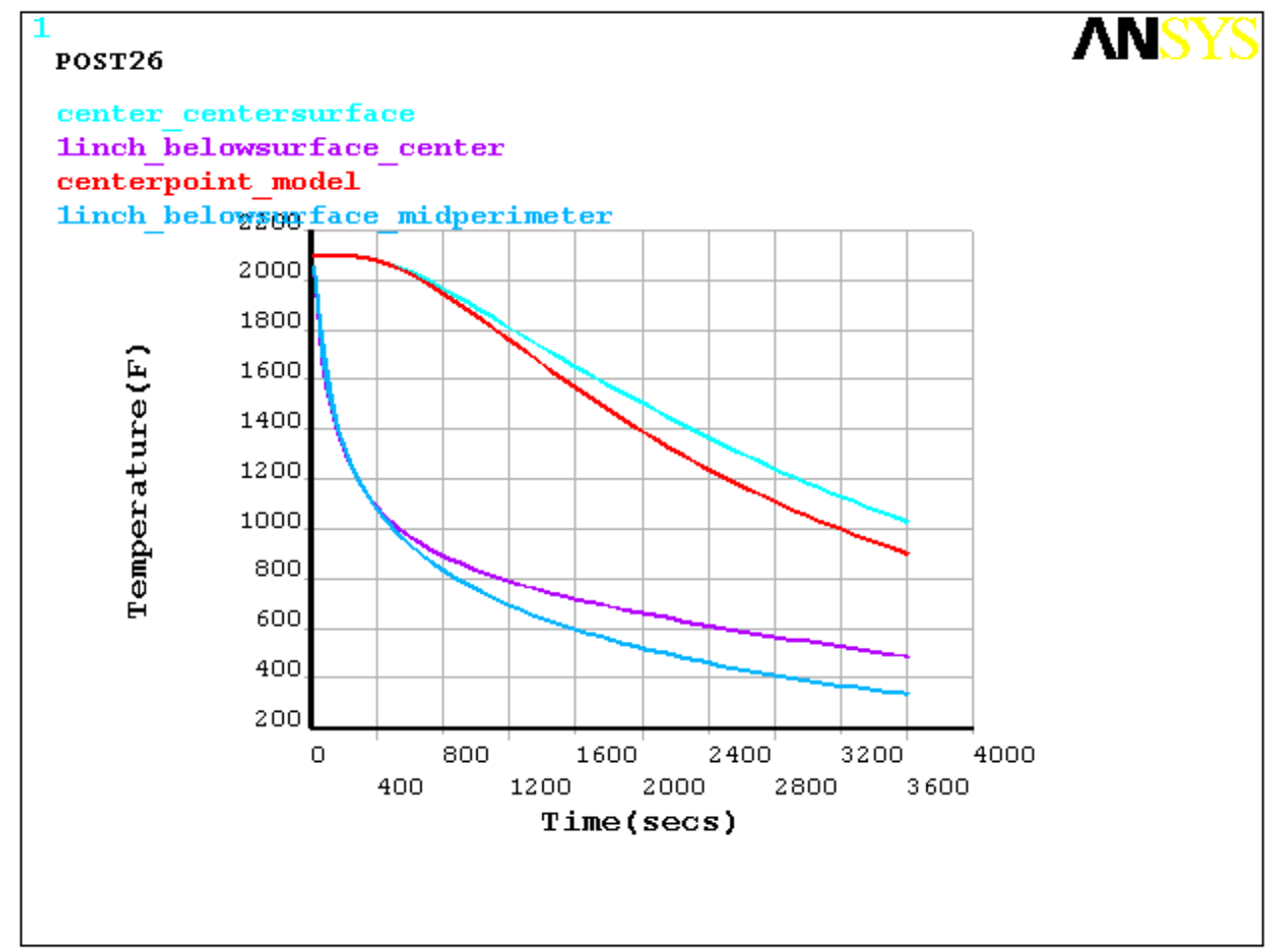

Figure 20: Cooling rate curves for Block 1, water quenched, at the specific location designated in Figure X6. Elapsed time was approximately 3600 seconds $(1 \mathrm{~h})$.

\subsection{Block 1 - Fan Cooling}

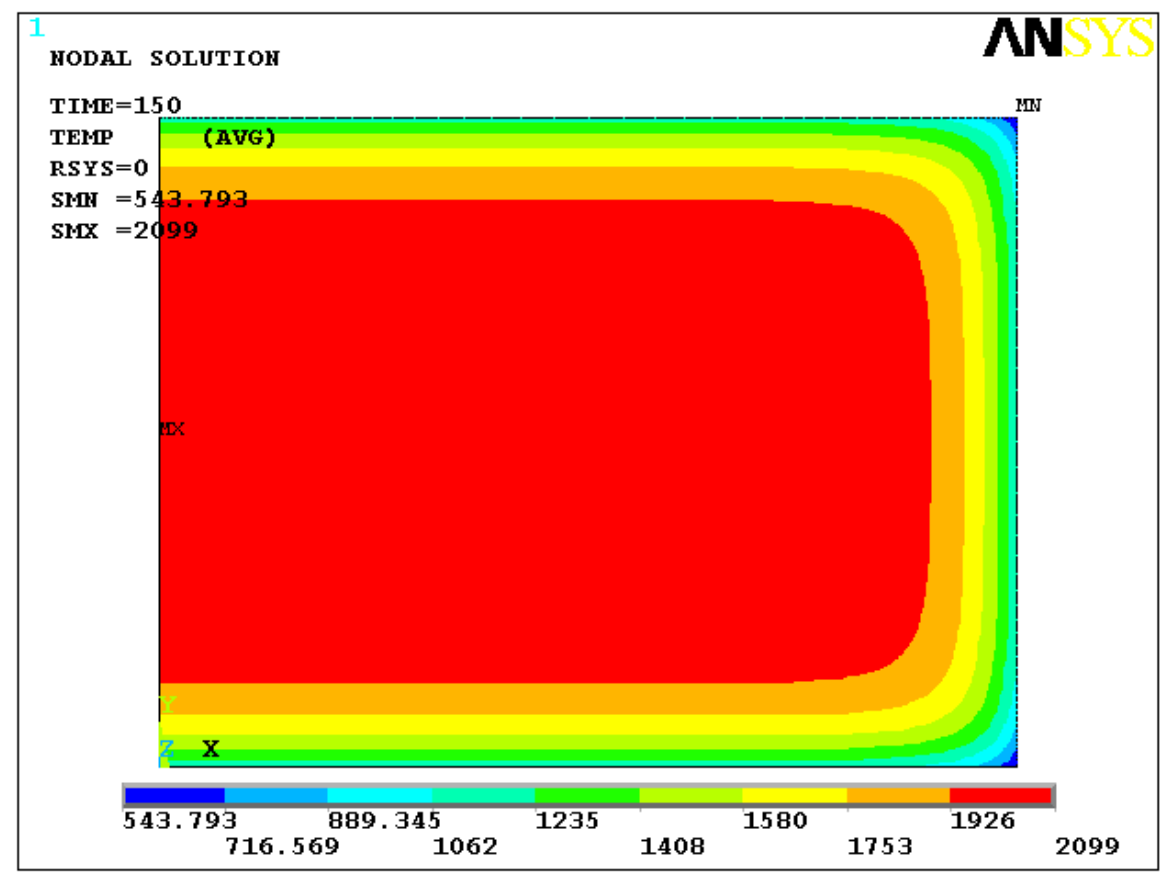

(a) 


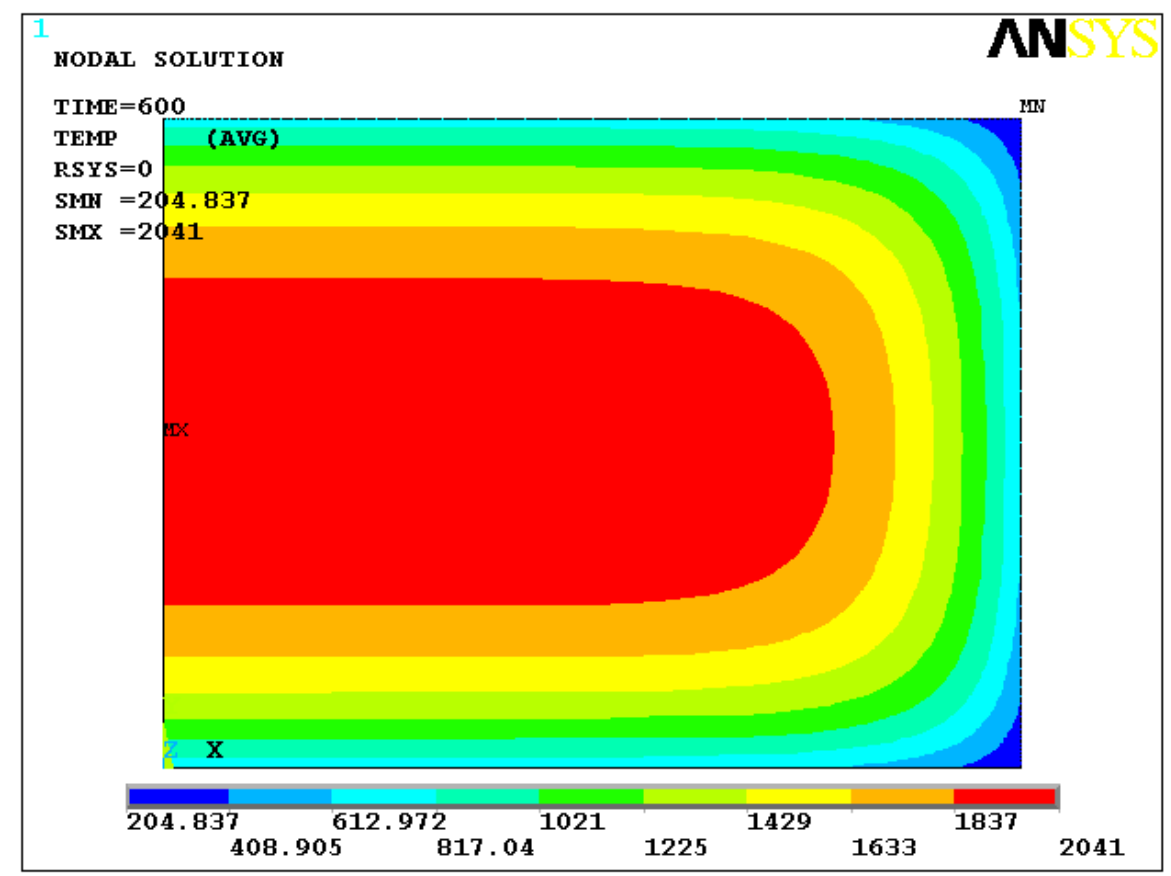

(b)

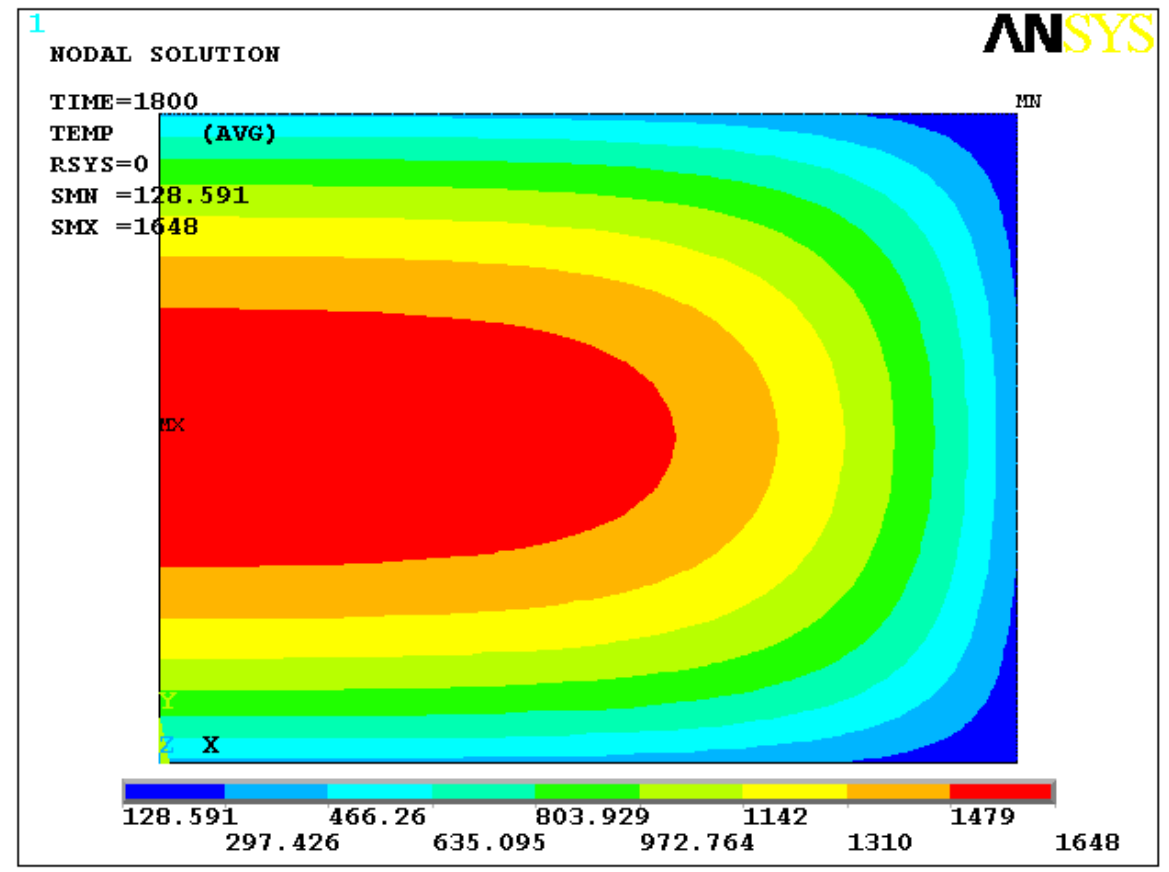

(c) 


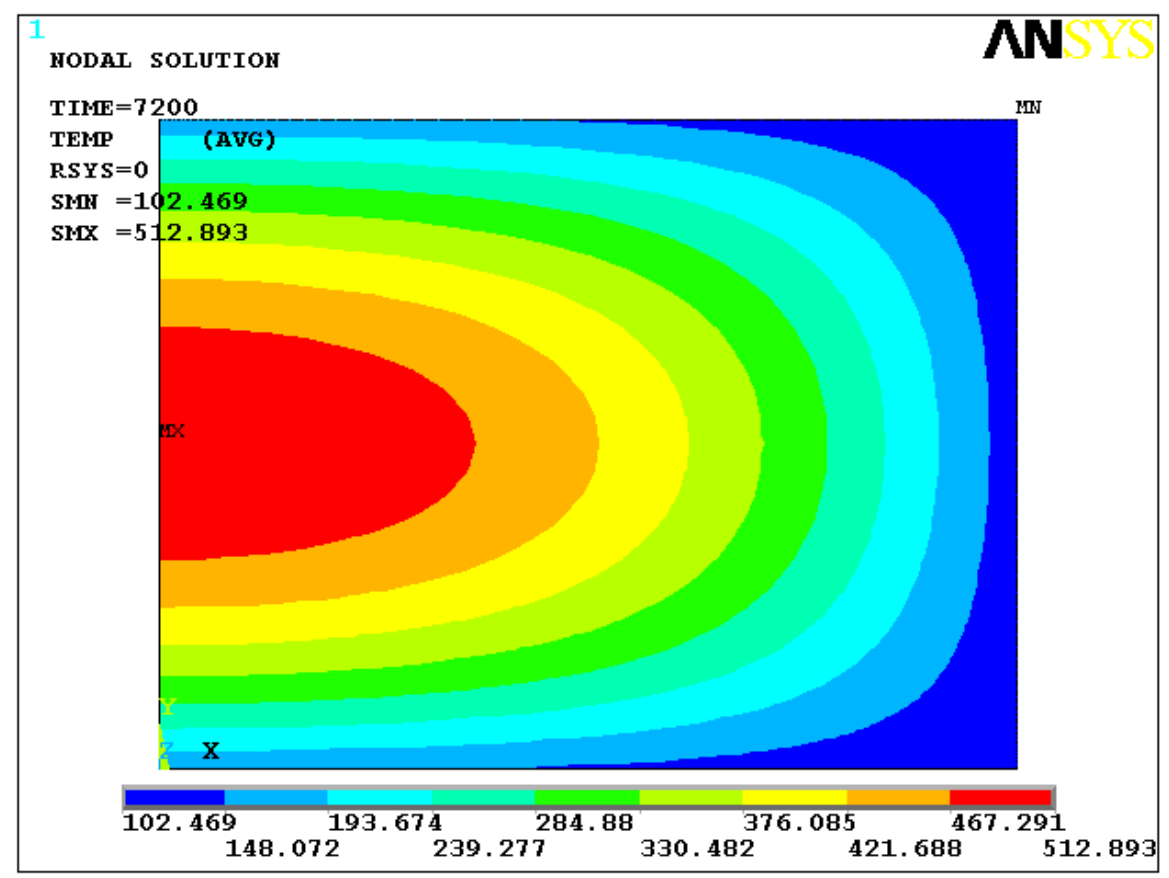

(d)

Figure 21: (a-d): show stages in the cooling sequence for Block 1 - Fan Cooling. Time is in seconds, starting at $150 \mathrm{sec}$, and then showing the block at 600, 1800, and $7200 \mathrm{sec}$. Note that the color scales change with each time increment block.

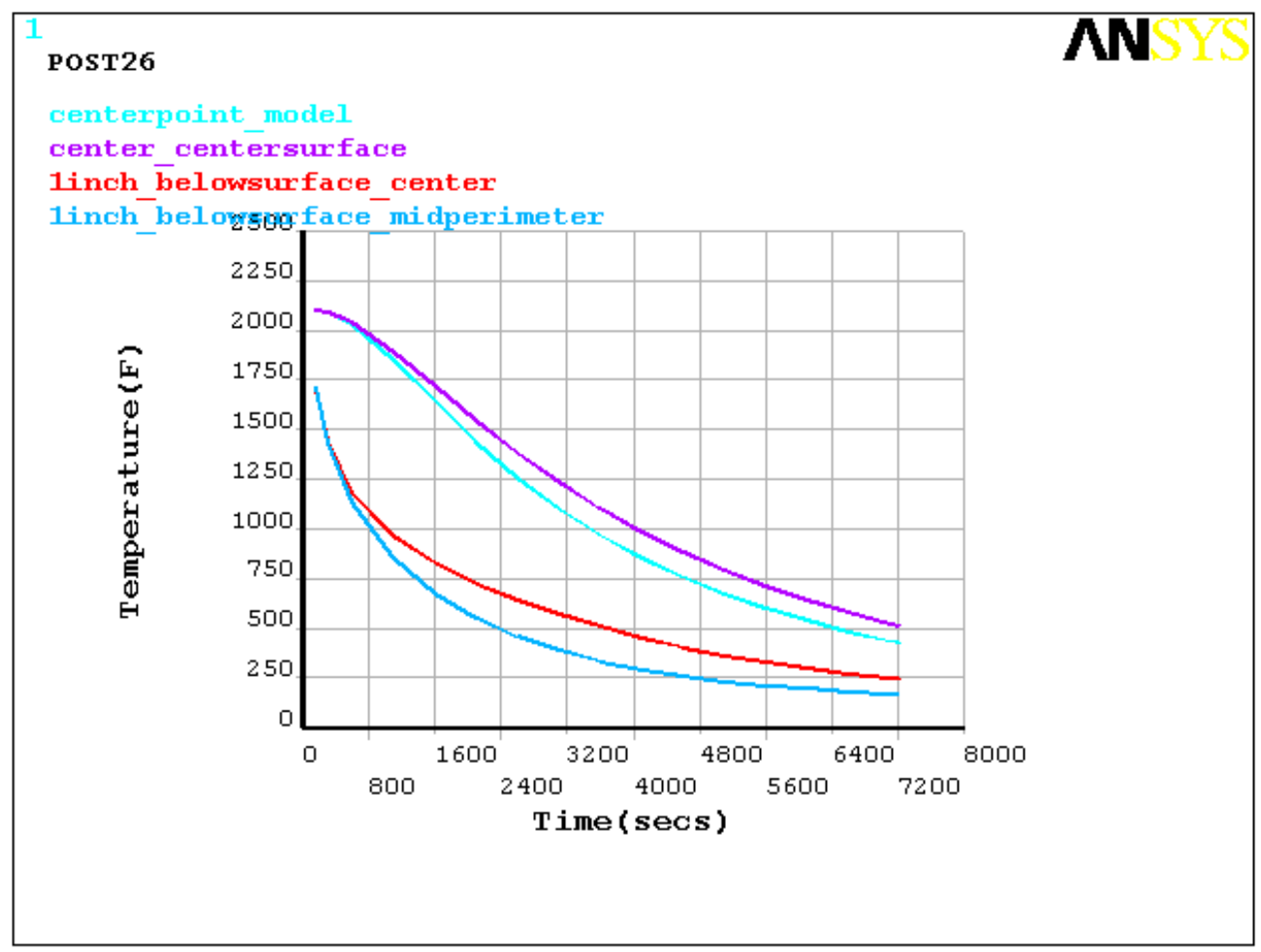

Figure 22: Cooling rate curves for Block 1, fan cooled, at the specific location designated in Figure X6. Elapsed time was approximately 7200 seconds $(2 \mathrm{~h})$. 


\subsection{Block 1 - Air Cooling}

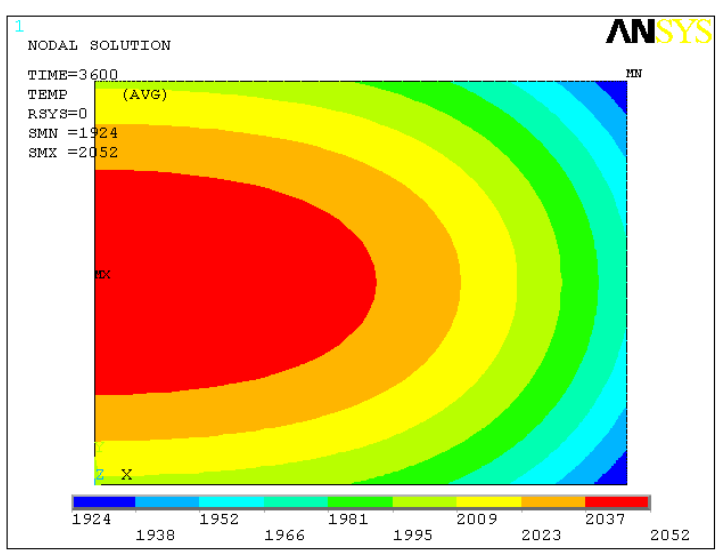

(a)

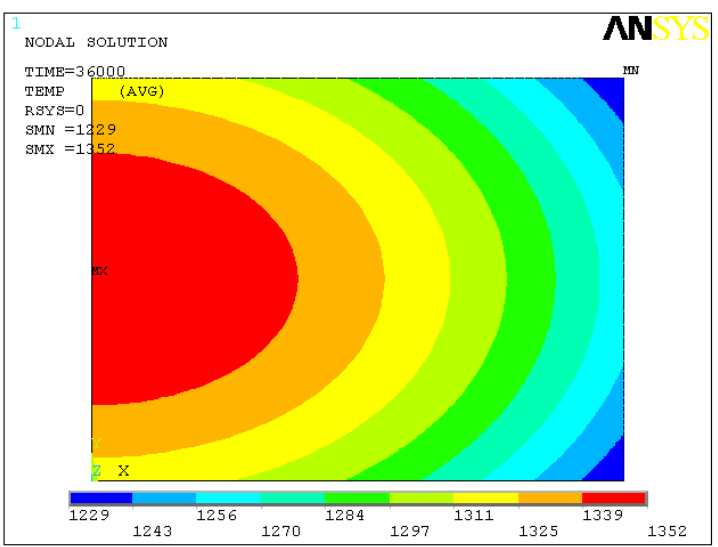

(c)

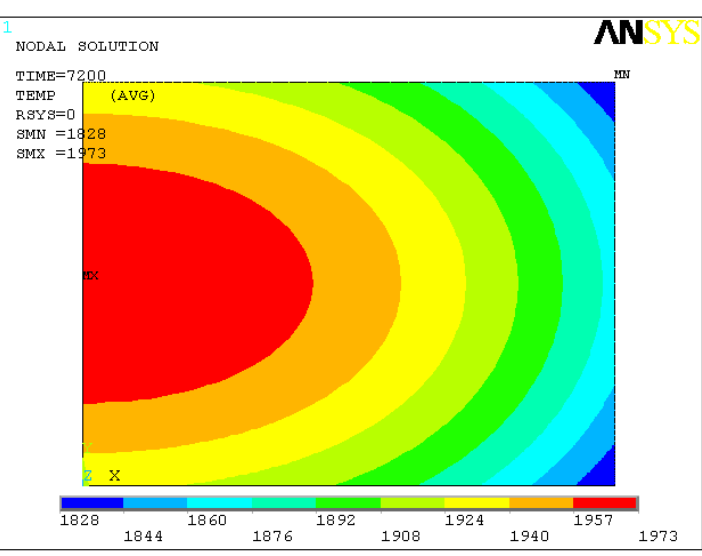

(b)

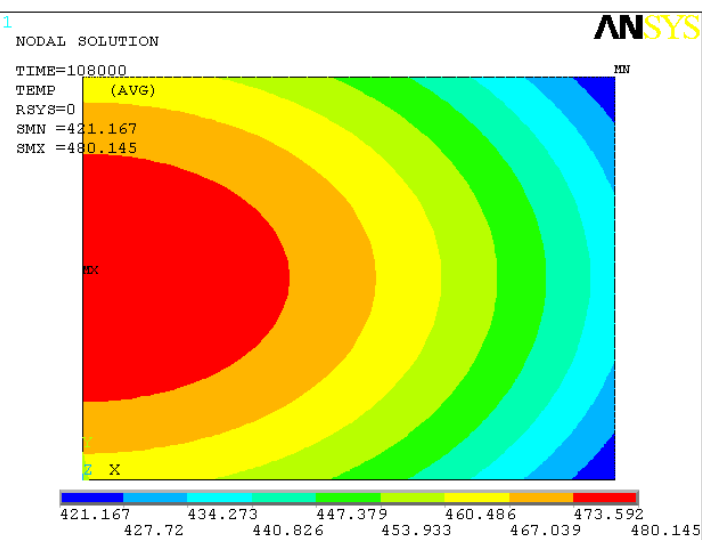

(d)

Figure 23 (a-d): show stages in the cooling sequence for Block 1 - Air Cooling. Time is in seconds, starting at $3600 \mathrm{sec}$, and then showing the block at $7200,36,000$, and 108,000 sec. Note that the color scales change with each time increment block. 


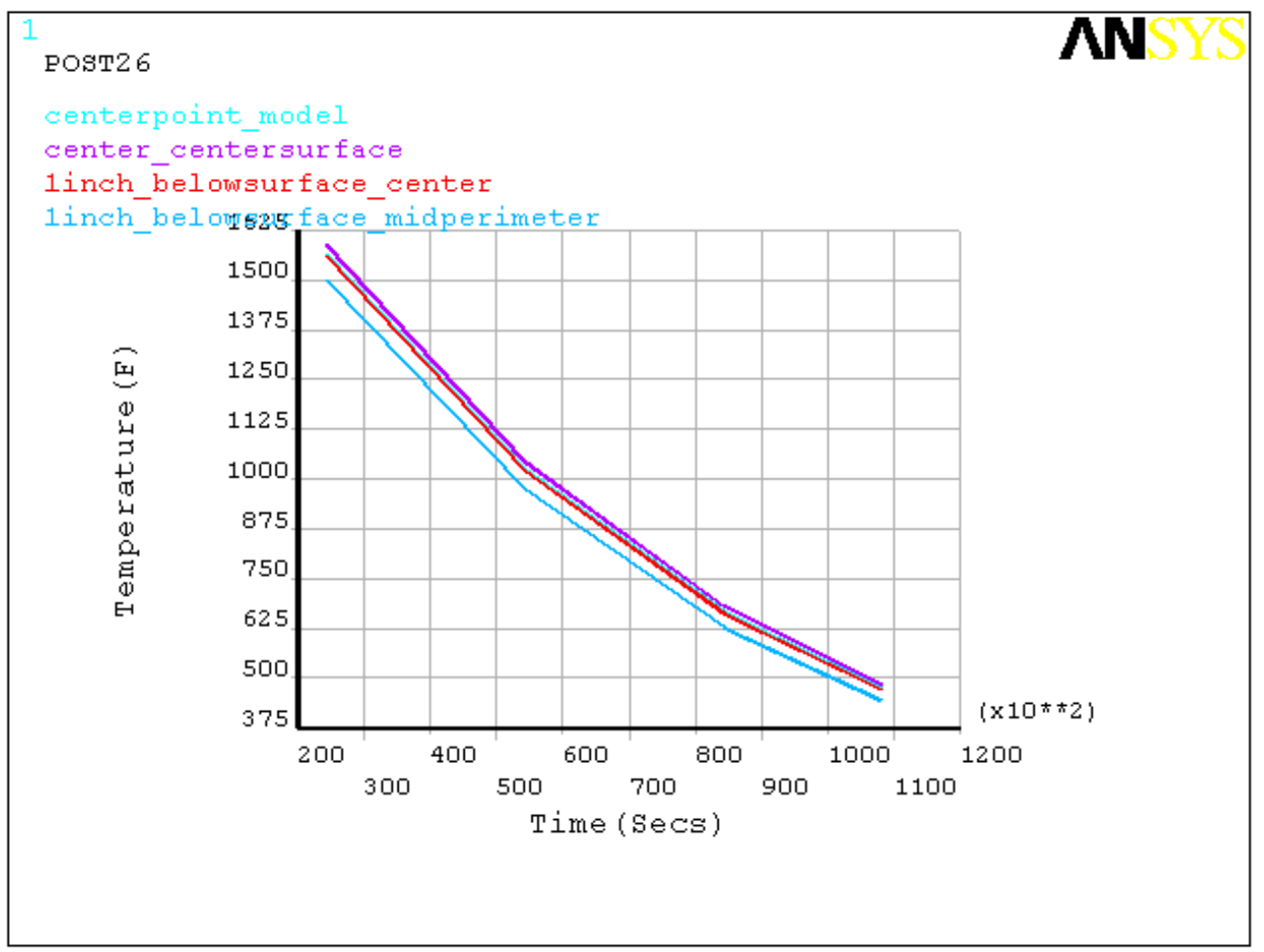

Figure 24: Cooling rate curves for Block 1, fan cooled at the specific location designated in Figure X6. Elapsed time was approximately 108,000 seconds $(30 \mathrm{~h})$.

\subsection{Block 2 - Water Quenching}

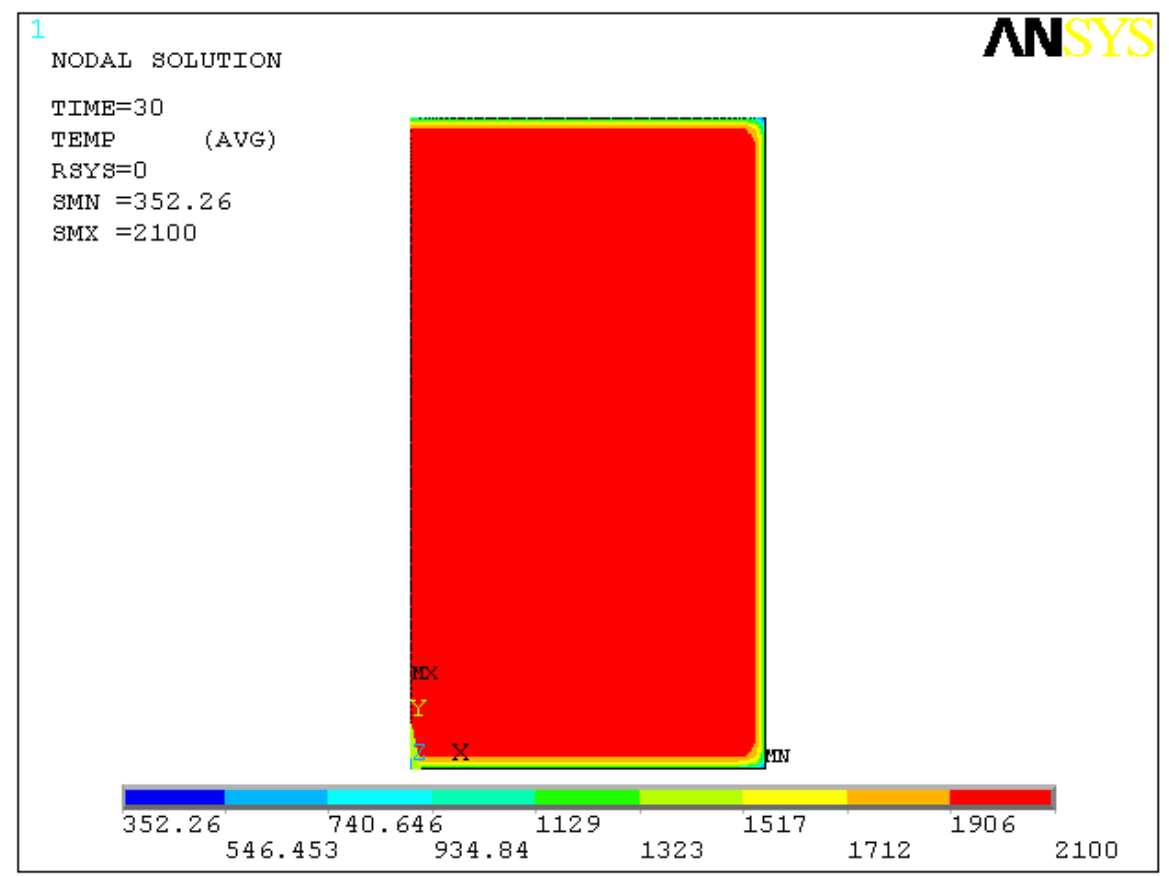

(a) 


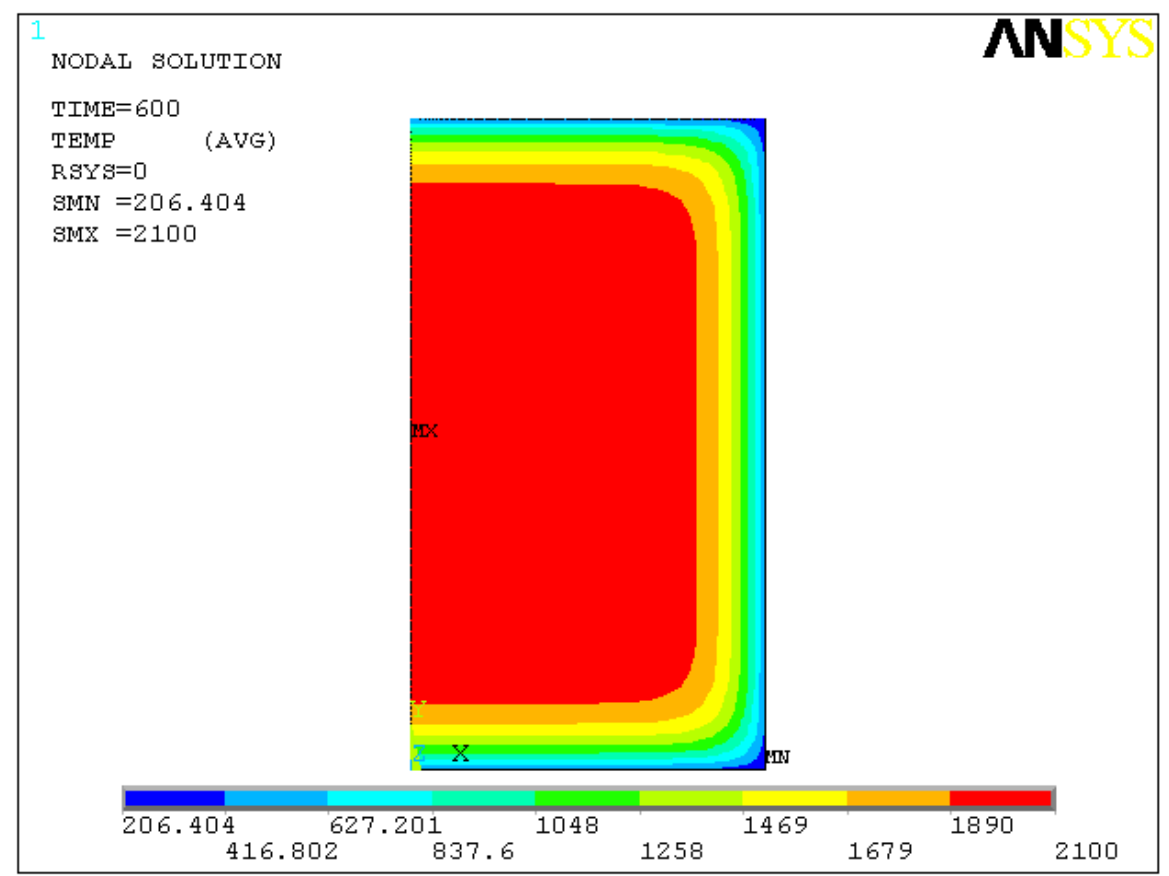

(b)

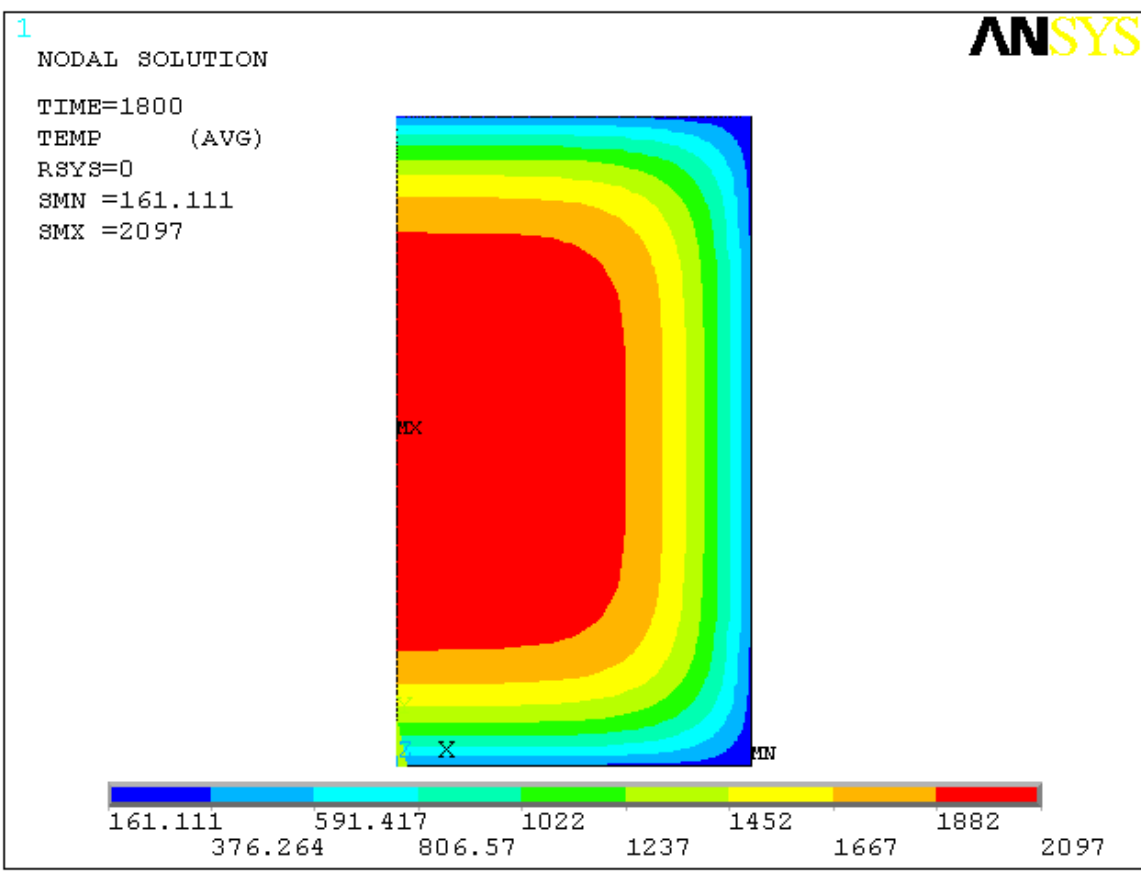

(c) 


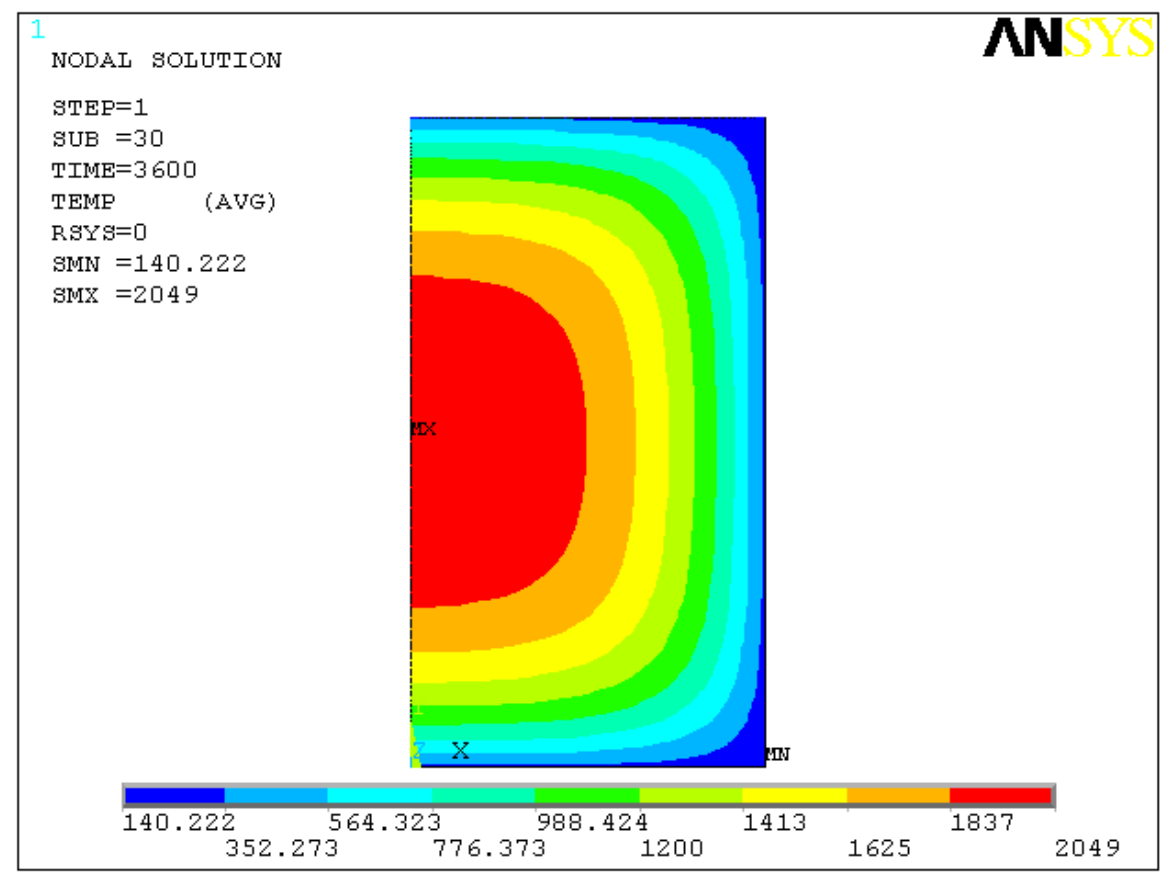

(d)

Figure 25: (a-d): show stages in the cooling sequence for Block 2, water quenched. Time is in seconds, starting at $30 \mathrm{sec}$, and then showing the block at $600,1,800$, and 3,600 sec. Note that the color scales change with each time increment block.

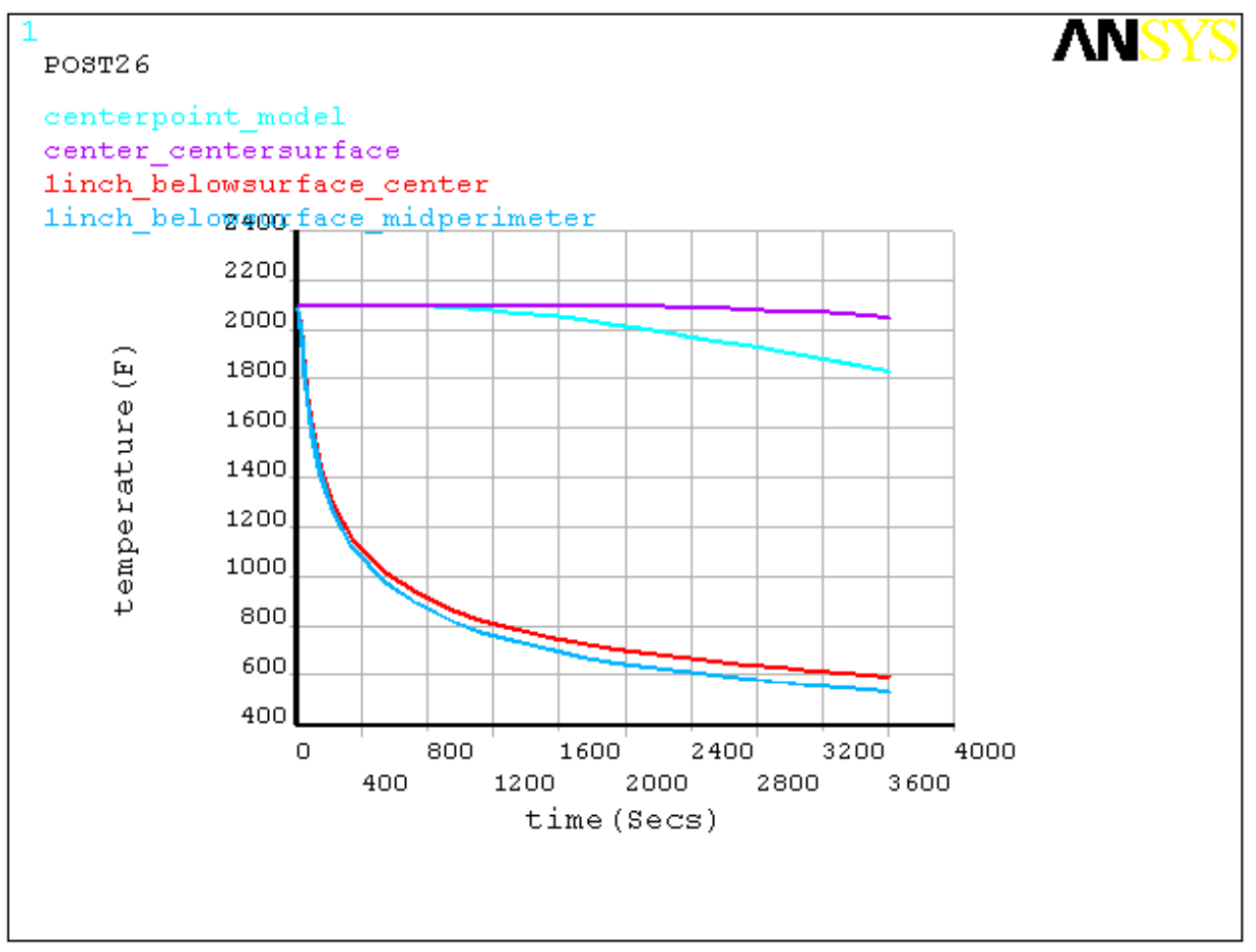

Figure 26: Cooling rate curves for Block 2, water quenched, at the specific location designated in Figure X6. Elapsed time was approximately 3,600 seconds $(1 \mathrm{~h})$. 


\subsection{Block 2 - Fan Cooling}

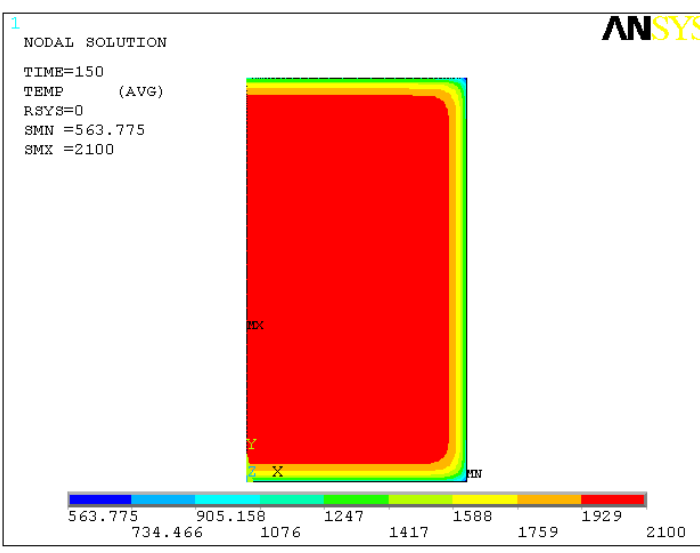

(a)

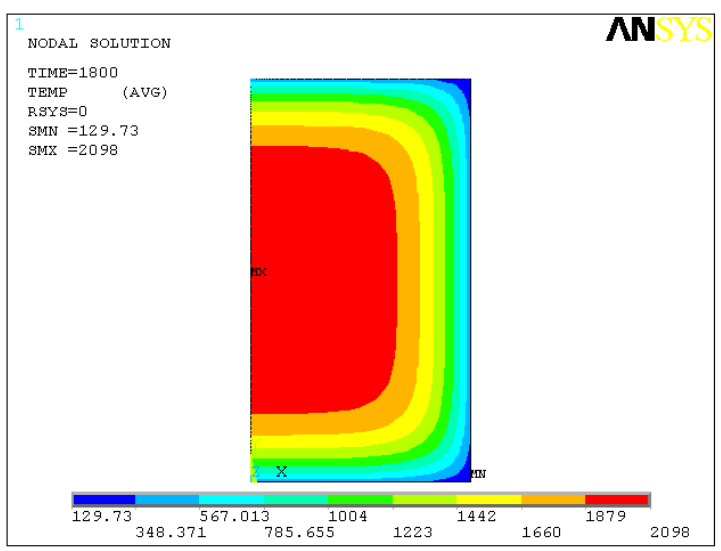

(c)

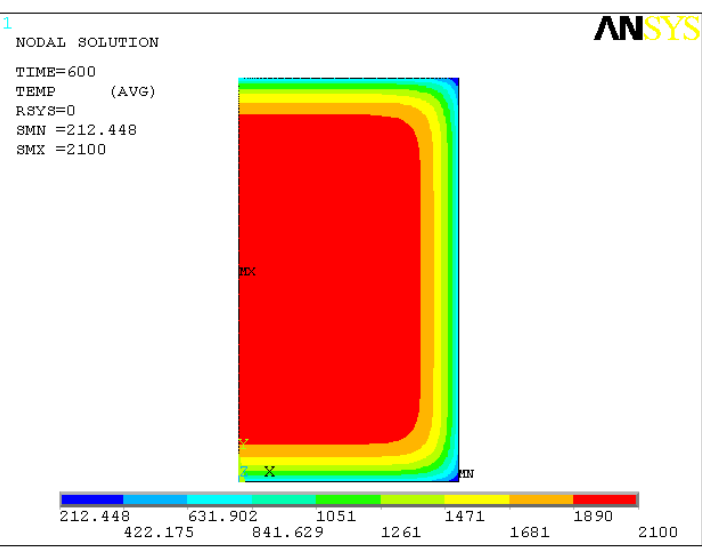

(b)

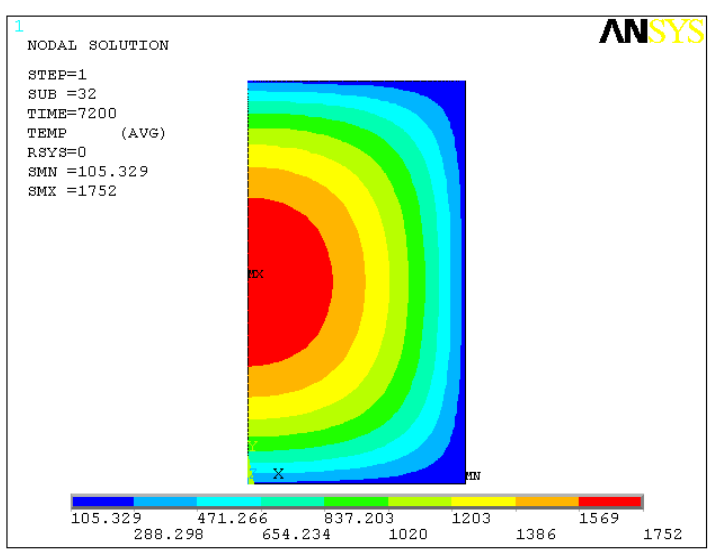

(d)

Figure 27(a-d): show stages in the cooling sequence for Block 2 - Fan Cooling. Time is in seconds, starting at $150 \mathrm{sec}$, and then showing the block at $600,1,800$, and 7,200 sec. Note that the color scales change with each time increment block. 


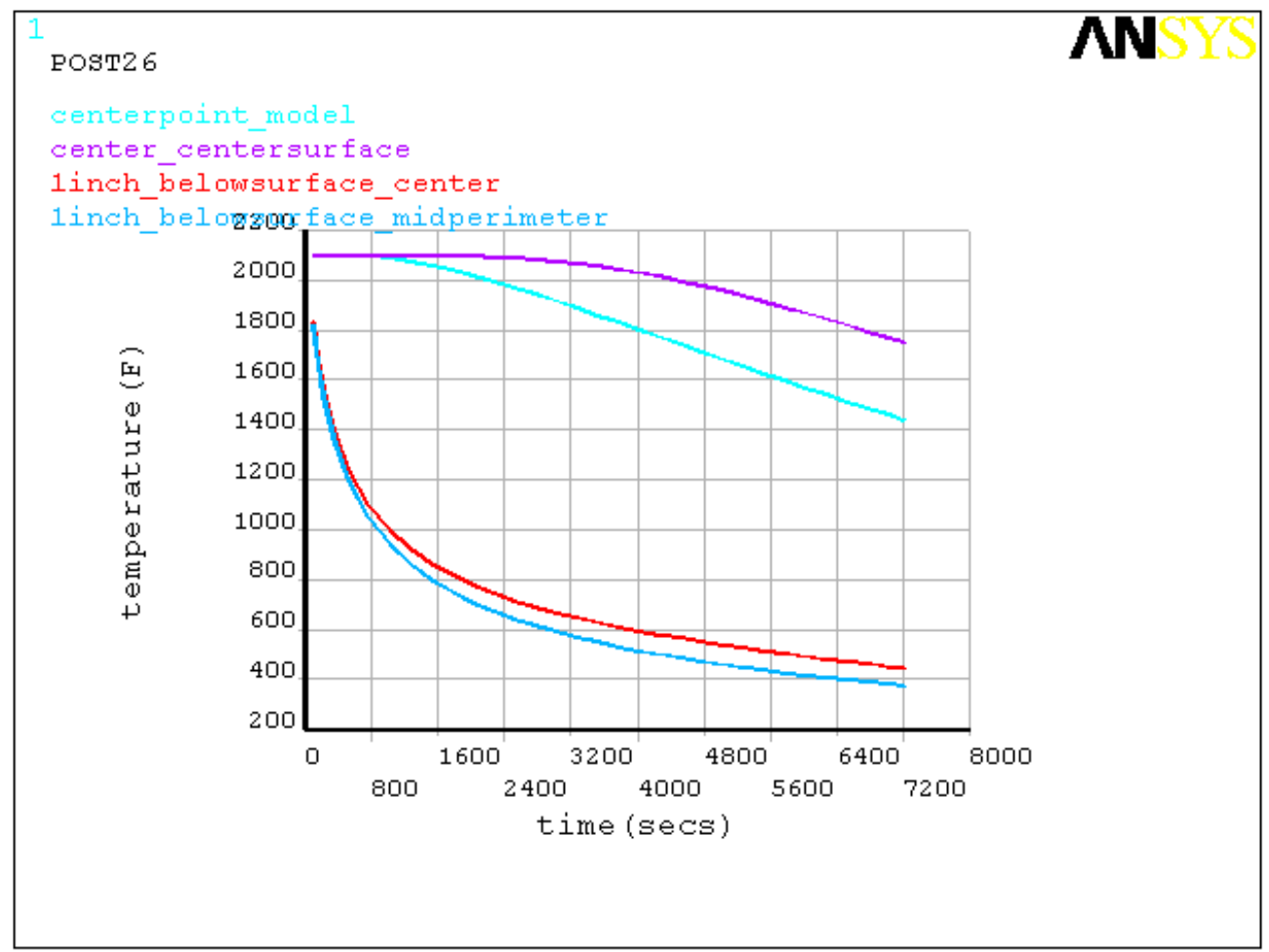

Figure 28: Cooling rate curves for Block 2, fan cooled, at the specified location designated in Figure X6. Elapsed time was approximately 7,200 seconds $(2 \mathrm{~h})$.

\subsection{Block 2 - Air Cooling}

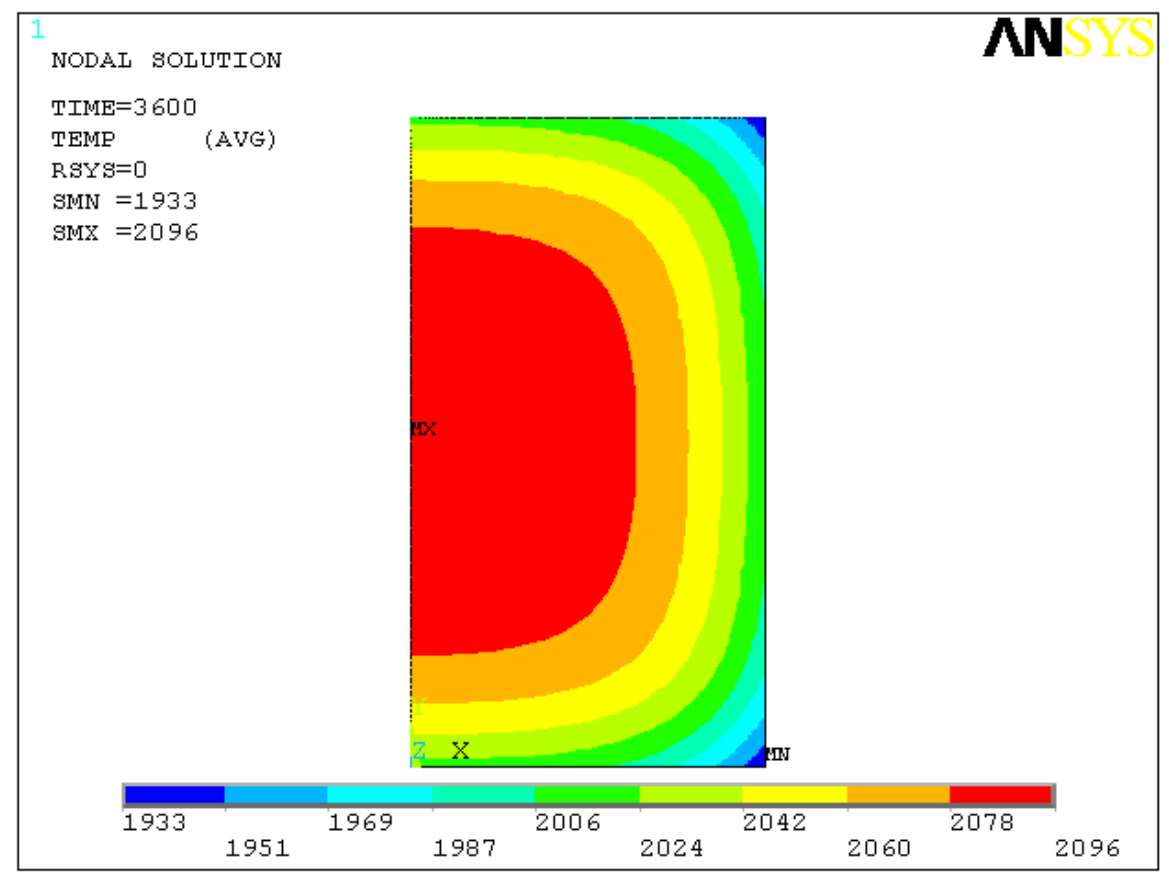

(a) 


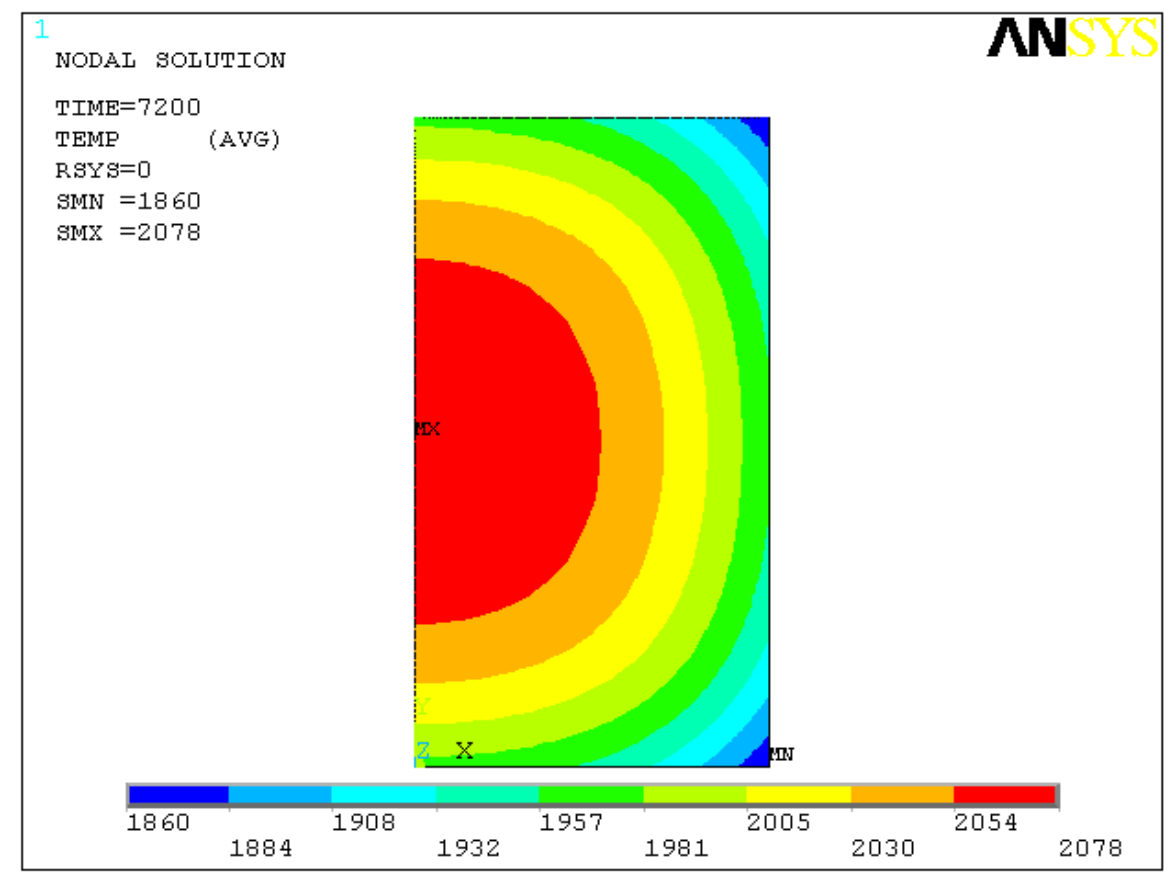

(b)

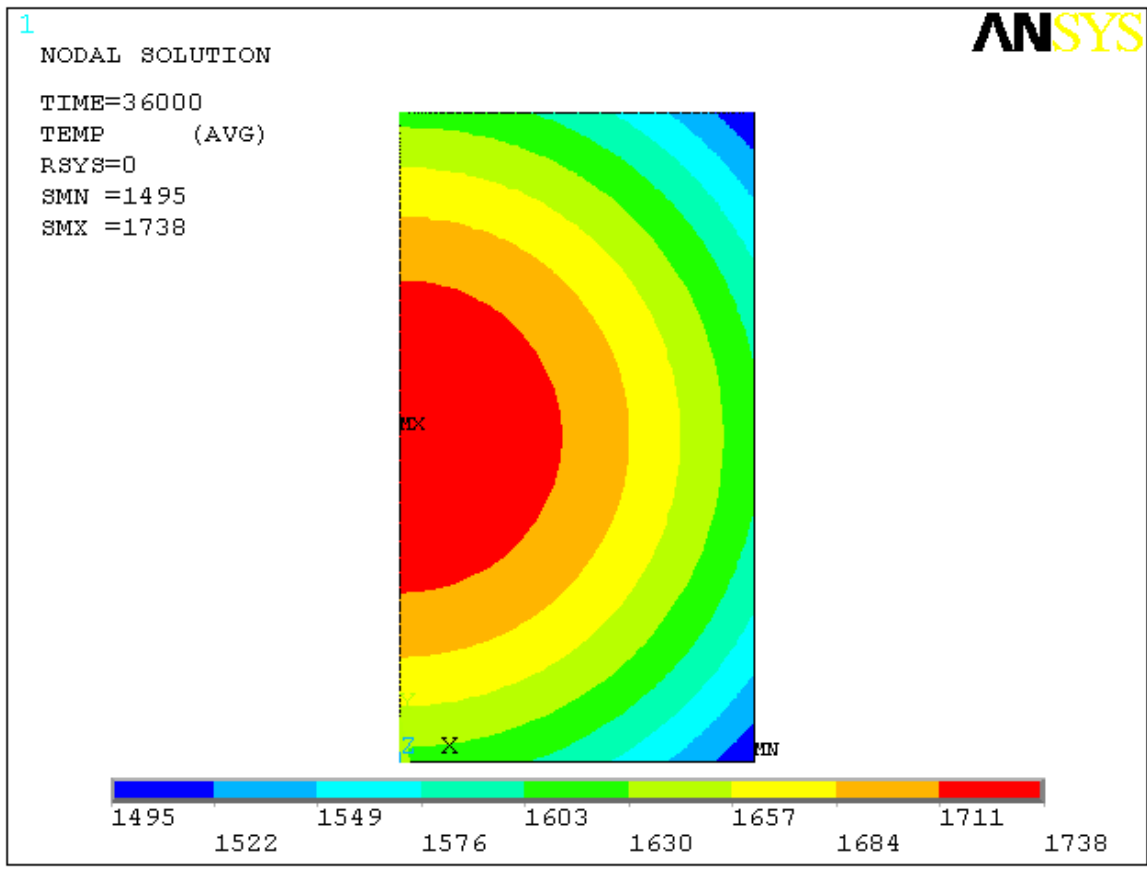

(c) 


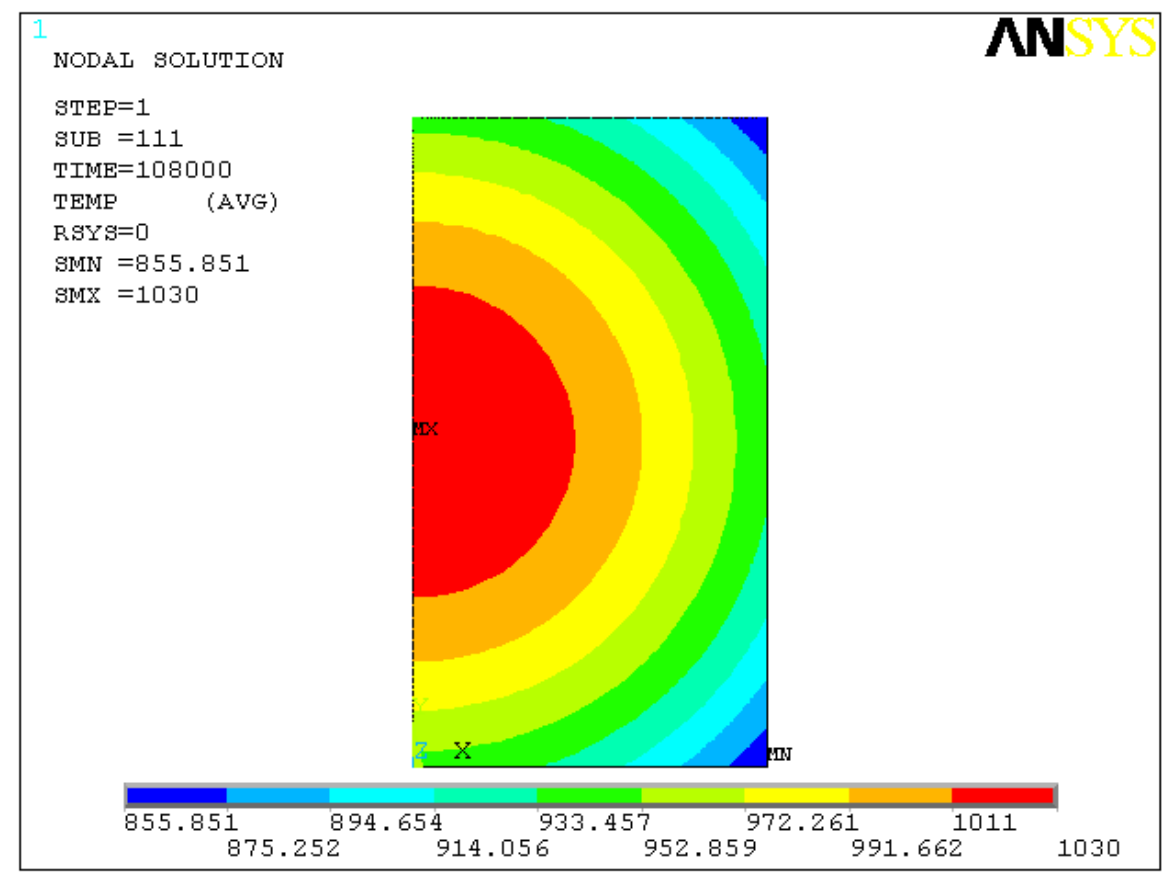

(d)

Figure 29: (a-d): show stages in the cooling sequence for Block 1 - Air Cooling. Time is in seconds, starting at 3,600 sec, and then showing the block at 7,200,36,000, and 108,000 sec. Note that the color scales change with each time increment block.

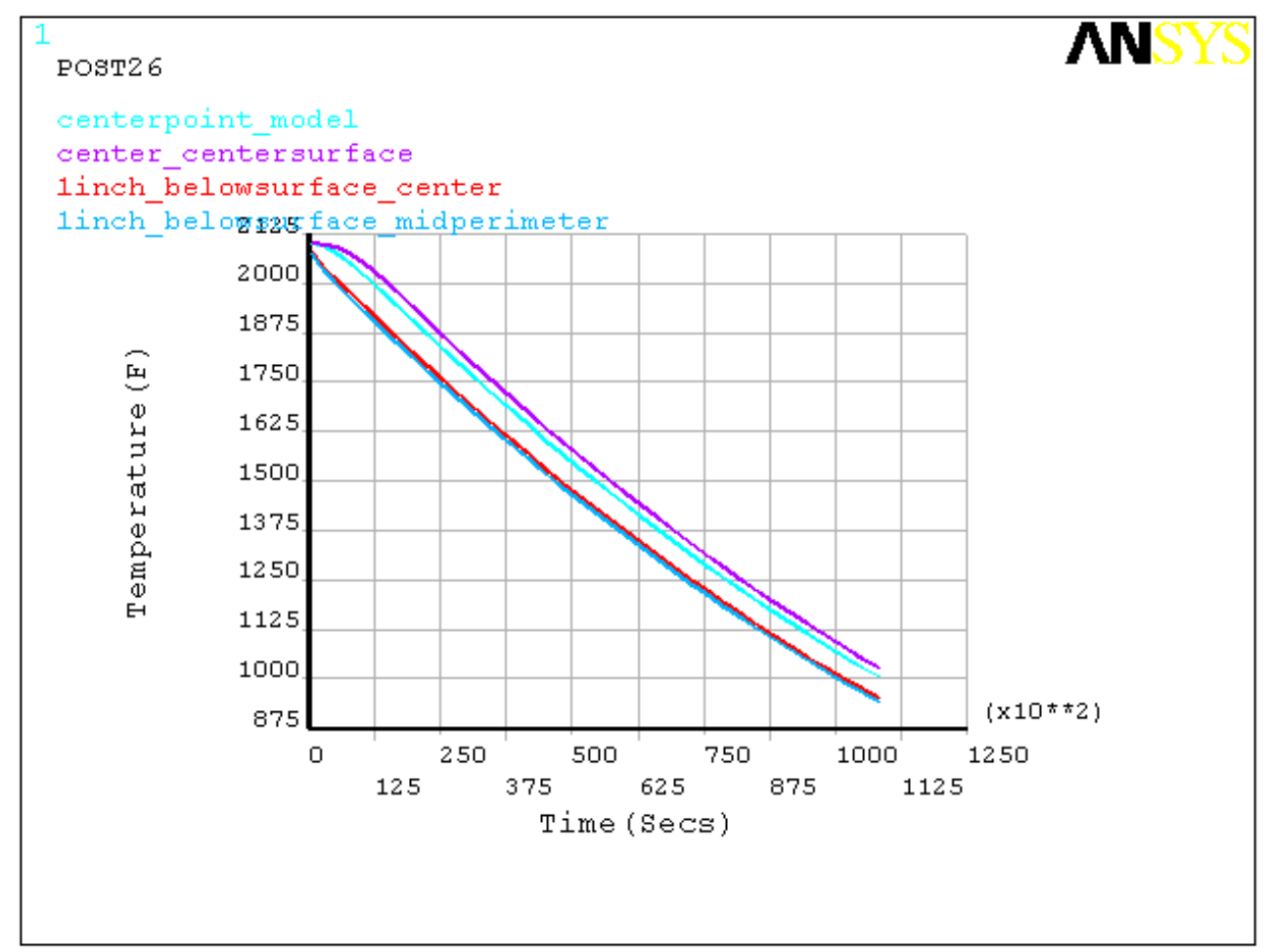

Figure 30: Cooling rate curves for Block 2, air cooled, at the specified location designated in Figure X6. Elapsed time was approximately 108,000 seconds $(30 \mathrm{~h})$. 


\subsection{Summary Cooling Rate Computations}

Blocks 1 and 2 are reproduced in Figures 31 and 32 along with tables that present data for cooling rates for each of the three cooling methods at five different equivalent locations on each block.

For Block 1 water quenching results in the most rapid cooling rates at all locations. Fan cooling results is cooling rates approximately $8 \%$ less than water quenching at center surface, center point - center surface and mid-perimeter. Nearer the surface, fan cooling the rotor segment results in a cooling rate about $20 \%$ less than water quenching. On the other hand, air cooling the rotor segment results in substantially slower cooling rates at all positions for the Block 1 geometry. This difference is readily evident from looking at the time to reach $1600^{\circ} \mathrm{F}$ at a location $1^{\prime \prime}$ below the surface at mid-perimeter or $1^{\prime \prime}$ below the surface at the centerline, where it takes about $4 \mathrm{sec}$ when water quenched, $30 \mathrm{sec}$ when fan cooled but $>17,000$ sec $(>4.7$ h) when air cooled.

For Block 2 water quenching results in the most rapid cooling rates at all locations. Near the surface, fan cooling the rotor segment results in a cooling rate about $22.5 \%$ less than water quenching. On the other hand, air cooling the rotor segment results in substantially slower cooling rates at all positions for the Block 2 geometry, which is approximately half that of Block 1. This difference is even more striking when looking at the time to reach $1600^{\circ} \mathrm{F}$ at a location $1^{\prime \prime}$ below the surface at mid-perimeter or 1 " below the surface at the centerline. In this case, the time to reach $1600^{\circ} \mathrm{F}$ when water quenched is about twice that for Block 2 compared to Block 1 and roughly the same for fan cooling. However, when air cooled the time to reach $1600^{\circ} \mathrm{F}$ increased to $>26,000 \mathrm{sec}(>7.4 \mathrm{~h})$.

The results of the cooling rate computations allow a better understanding of the internal temperature distribution for this specific alloy. With that a Continuous Cooling Transformation (CCT) diagram may be constructed (planned for Phase II) to better determine the affect of cooling method and rate on microstructure and, ultimately, the mechanical properties of the component. 
Figure 31: Cooling Rate Computation $\left({ }^{\circ} \mathrm{F} / \mathrm{h}\right)$ from $1900^{\circ} \mathrm{F}$ to $1600^{\circ} \mathrm{F}$ for Block 1 (37" diameter x14" thick)

\begin{tabular}{|c|c|c|c|c|c|c|c|c|}
\hline \multirow[b]{2}{*}{ S. No } & \multirow[b]{2}{*}{$\begin{array}{l}\text { Cooling } \\
\text { Method }\end{array}$} & \multicolumn{5}{|c|}{ Cooling Rate $\left({ }^{\circ} \mathrm{F} / \mathrm{h}\right)$ at Specified Location - Block 1} & \multirow[b]{2}{*}{$\begin{array}{l}\text { Time to Reach } \\
1900^{\circ} \mathrm{F} \\
(\mathrm{sec})\end{array}$} & \multirow[b]{2}{*}{$\begin{array}{c}\text { Time to Reach } \\
1600^{\circ} \mathrm{F} \\
(\mathrm{sec})\end{array}$} \\
\hline & & Center Surface & $\begin{array}{c}\text { Center Point } \\
\text { Center Surface }\end{array}$ & Mid-perimeter & $\begin{array}{c}1 \text { " below } \\
\text { Surface along } \\
\text { Centerline }\end{array}$ & $\begin{array}{c}1^{\prime \prime} \text { below } \\
\text { Surface - Mid- } \\
\text { perimeter }\end{array}$ & & \\
\hline 1 & Water Quench & $1,343.5$ & $1,343.5$ & $1,343.5$ & $15,795.1$ & $16,920.4$ & 0.257 & 3.764 \\
\hline 2 & Fan Cool & $1,239.0$ & $1,239.0$ & $1,239.0$ & $12,814.8$ & $12,996.1$ & 2.022 & 29.598 \\
\hline 3 & Air Cool & 80.9 & 81.1 & 81.1 & 81.0 & 84.2 & $4,542.4$ & $17,052.5$ \\
\hline
\end{tabular}

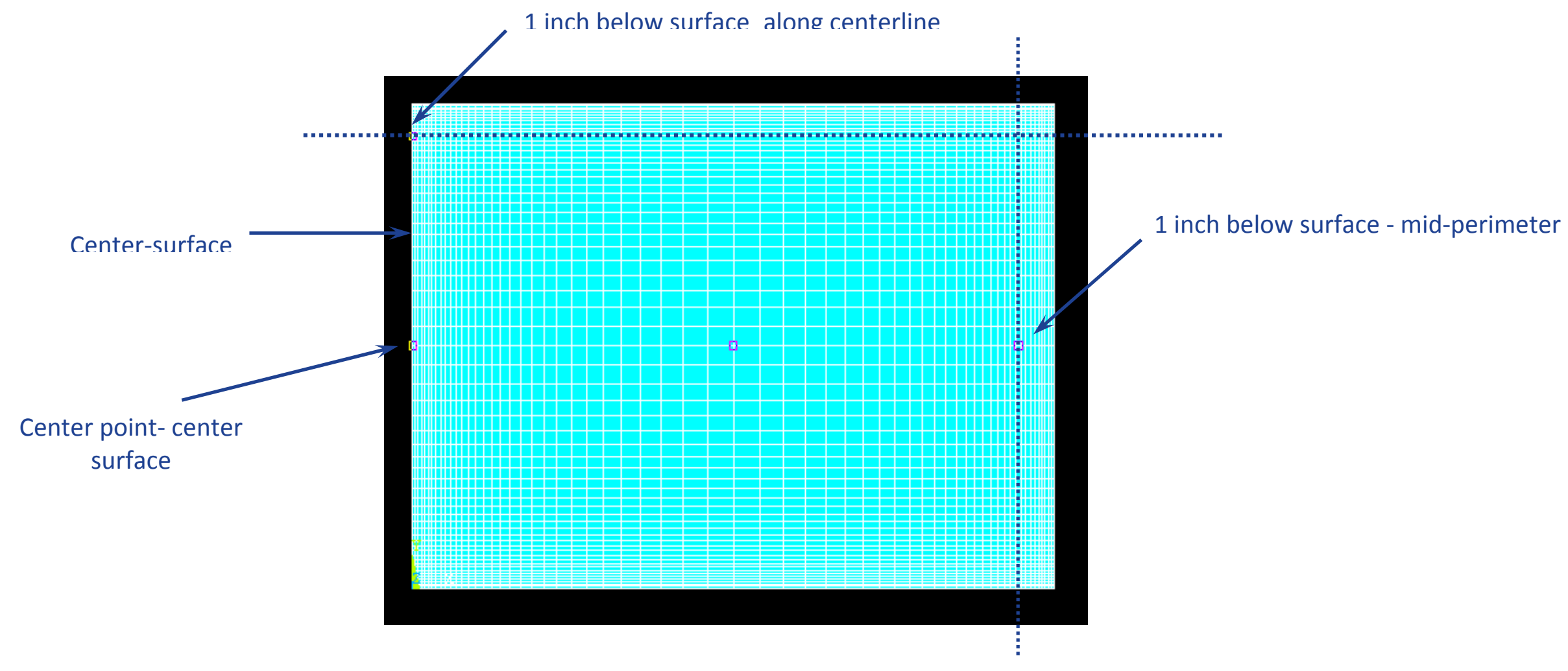


Figure 32: Cooling Rate Computation $\left({ }^{\circ} \mathrm{F} / \mathrm{h}\right)$ from $1900^{\circ} \mathrm{F}$ to $1600^{\circ} \mathrm{F}$ for Block 2 (46" diameter $\mathrm{x} 42^{\prime \prime}$ thick)

\begin{tabular}{|c|c|c|c|c|c|c|c|c|}
\hline \multirow[b]{2}{*}{ S. No } & \multirow[b]{2}{*}{$\begin{array}{l}\text { Cooling } \\
\text { Method }\end{array}$} & \multicolumn{5}{|c|}{ Cooling Rate $\left({ }^{\circ} \mathrm{F} / \mathrm{h}\right)$ at Specified Location - Block 2} & \multirow[b]{2}{*}{$\begin{array}{c}\text { Time to Reach } \\
1900^{\circ} \mathrm{F} \\
(\mathrm{sec})\end{array}$} & \multirow[b]{2}{*}{$\begin{array}{c}\text { Time to Reach } \\
1600^{\circ} \mathrm{F} \\
(\mathrm{sec})\end{array}$} \\
\hline & & Center Surface & $\begin{array}{l}\text { Center Point } \\
\text { Center Surface }\end{array}$ & Mid-perimeter & $\begin{array}{c}1 \text { 1" below } \\
\text { Surface along } \\
\text { Centerline }\end{array}$ & $\begin{array}{c}\text { 1" below } \\
\text { Surface - Mid- } \\
\text { perimeter }\end{array}$ & & \\
\hline 1 & Water Quench & --- & --- & --- & $18,218.7$ & $19,250.7$ & 0.988 & 6.219 \\
\hline 2 & Fan Cool & 371.3 & 762.4 & 380.6 & $14,020.2$ & $14,935.7$ & 2.042 & 29.887 \\
\hline 3 & Air Cool & 42.8 & 42.7 & 42.7 & 43.5 & 43.3 & $5,201.4$ & $26,724.3$ \\
\hline
\end{tabular}

1 inch below surface along centerline

Center point- center surface

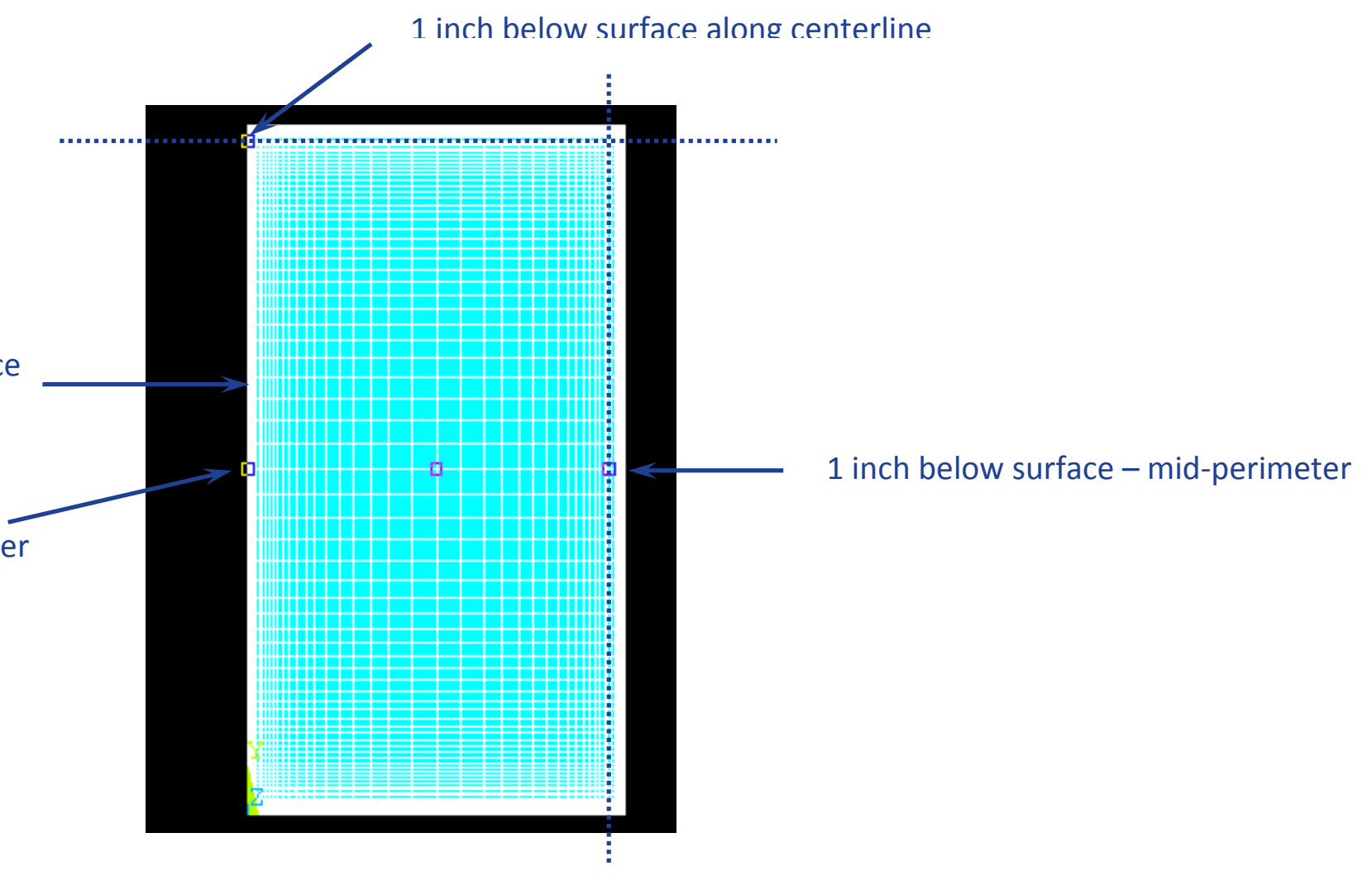




\section{$5 \quad$ Part 4: Microstructural Evaluation of Haynes 282, Nimonic 105, and Udimet $720 \mathrm{Li}$}

The alloys investigated in Phase I were $\gamma^{\prime}$ strengthened nickel-base superalloys. In general the wrought microstructure in nickel superalloys is fairly straightforward: $\gamma^{\prime}$ particles in a $\gamma$ matrix at a volume fraction directly related to the chemical composition, and with carbide and intermetallic phases dispersed throughout the matrix with the majority of the carbide along the grain boundaries. Appendix 6 contains optical, SEM and TEM micrographs of the characteristic features found in these alloys: Appendix 6A (Haynes 282), Appendix 6B (Nimonic 105) and Appendix 6C (Udimet 720). Since there is nothing outstanding with respect to the as-processed or heat treated microstructures no further discussion is necessary regarding the pre-crept samples. Pertinent information on grain size and $\gamma^{\prime}$ size and volume fraction are provided in the respective appendices for each of the alloys. Suffice to say that grain size in these alloys is typically a couple hundred microns or less with $\gamma^{\prime}$ particles sizes ranging from 5-20 nm in the SA Haynes 282 to about $0.1 \mu \mathrm{m}$ in Udimet 720 . Carbide was found in each alloy most prominently at the grain boundaries.

Because the alloys were similar in terms of microstructural characteristics except for the volume fraction of $\gamma^{\prime}$, and because Haynes 282 was the least studied of the alloys, this alloy was selected for more in-depth investigation. In the end, Haynes 282 exhibited classic deformation behavior during creep with specific features related to shear, looping of particles and climb past particles clearly seen.

Most of the TEM investigations were performed on Haynes 282 for different conditions of stress and temperature at different levels of evolved creep strain. The remainder of the narrative will focus on Haynes 282 microstructure and the deformation mechanisms that operate under creep loading. Figure 33 shows $\gamma^{\prime}$ in each of the three starting alloy conditions. Figure 34 is the associated yield strength versus temperature graphs for these starting microstructure conditions.

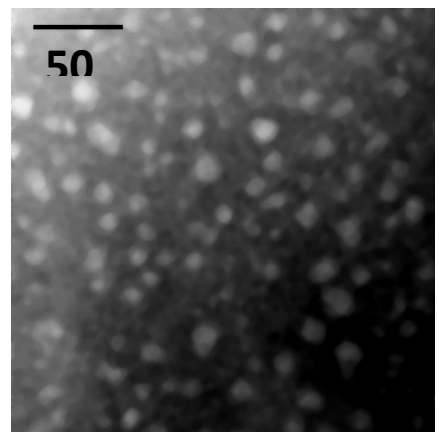

Solution Annealed

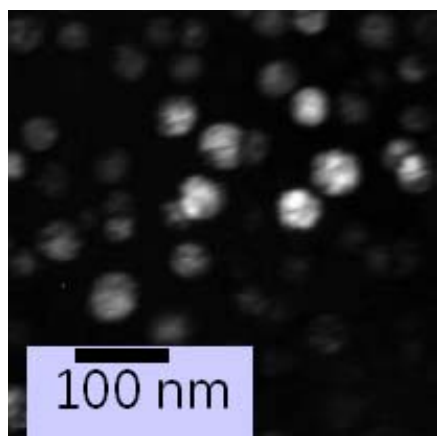

$\mathrm{PA}=\mathrm{SA}+8 \mathrm{~h} @ 1450^{\circ} \mathrm{F}$

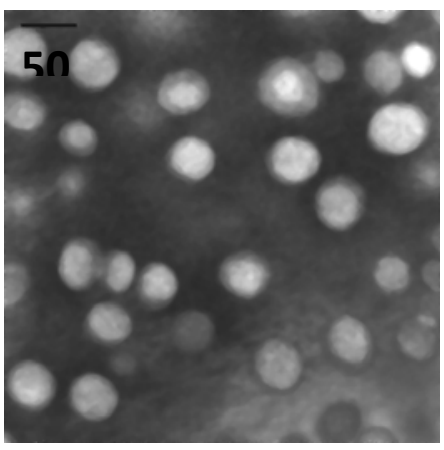

$\mathrm{OV}=\mathrm{PA}+250 \mathrm{~h} @ 1425^{\circ} \mathrm{F}$

(c)

(a)

(b)

Figure 33: Starting microstructure for Haynes 282 alloy (a) solution annealed showing small $\gamma^{\prime}$ precipitates $(10-20 \mathrm{~nm})$, (b) peak aged Haynes 282 showing $\gamma^{\prime}$ precipitates approximately $50 \mathrm{~nm}$ in diameter and (c) overaged Haynes 282 with $\gamma^{\prime}$ precipitates slightly larger than $50 \mathrm{~nm}$. 
The peak aged and overaged material have roughly the same starting microstructures in terms of grain size and $\gamma^{\prime}$ particle size although the $\gamma^{\prime}$ in the overaged $(50-60 \mathrm{~nm})$ material marginally larger than in the peak aged material $(25-40 \mathrm{~nm})$. Consequently, the strength is very similar between the peak aged and overaged materials. The solution aged condition in reality does not exist in the strictest sense. As seem from the TEM micrograph (Figure 33 (a)), $\gamma^{\prime}$ particles are indeed present although quite small (5-20 $\mathrm{nm}$ ). It is interesting that at temperatures up to $1200^{\circ} \mathrm{F}$, yield strength is significantly lower than for either peak aged or overaged material. The small $\gamma^{\prime}$ particle size obviously does not enhance tensile strength until $1300^{\circ} \mathrm{F}$ and above. It is unclear at this point why this is so.

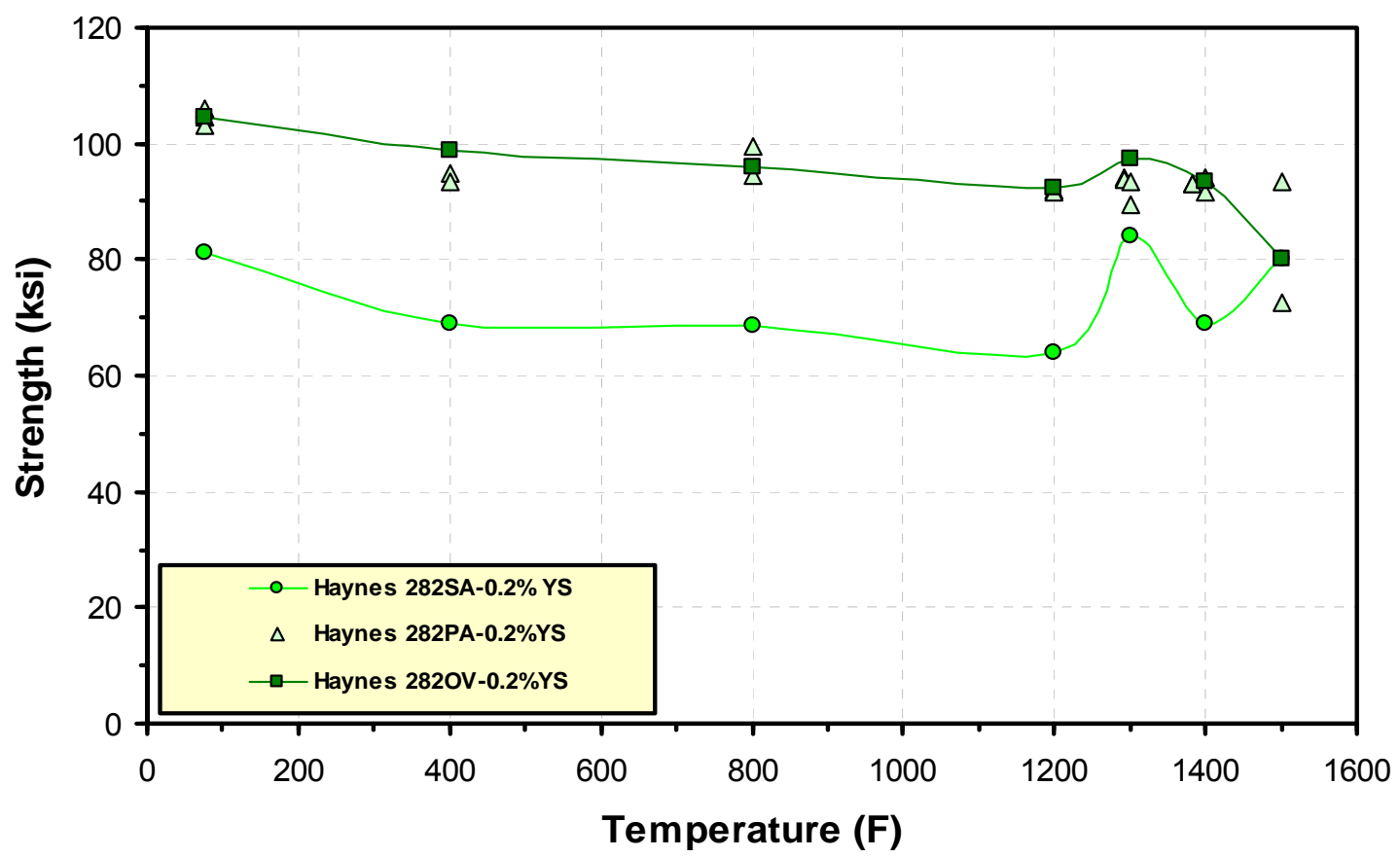

Figure 34: Yield strength (ksi) versus temperature for Haynes 282 alloy in solution annealed, peak aged and overaged conditions.

Figure 35 is a composite figure showing the many possible deformation mechanisms that can occur in an FCC material like Haynes 282. The first column states the potential mechanism, e.g., climb by a dislocation over an obstacle. In (1), a dislocation line approaches a matrix particle. In the left most representation the dislocation is stopped by the particle. In order to move past a particular particle the dislocation must cut through it (shear) or pass by the particle on the operative slip plane (loop) or move out of the slip plane to pass by the particle on another one (climb). 


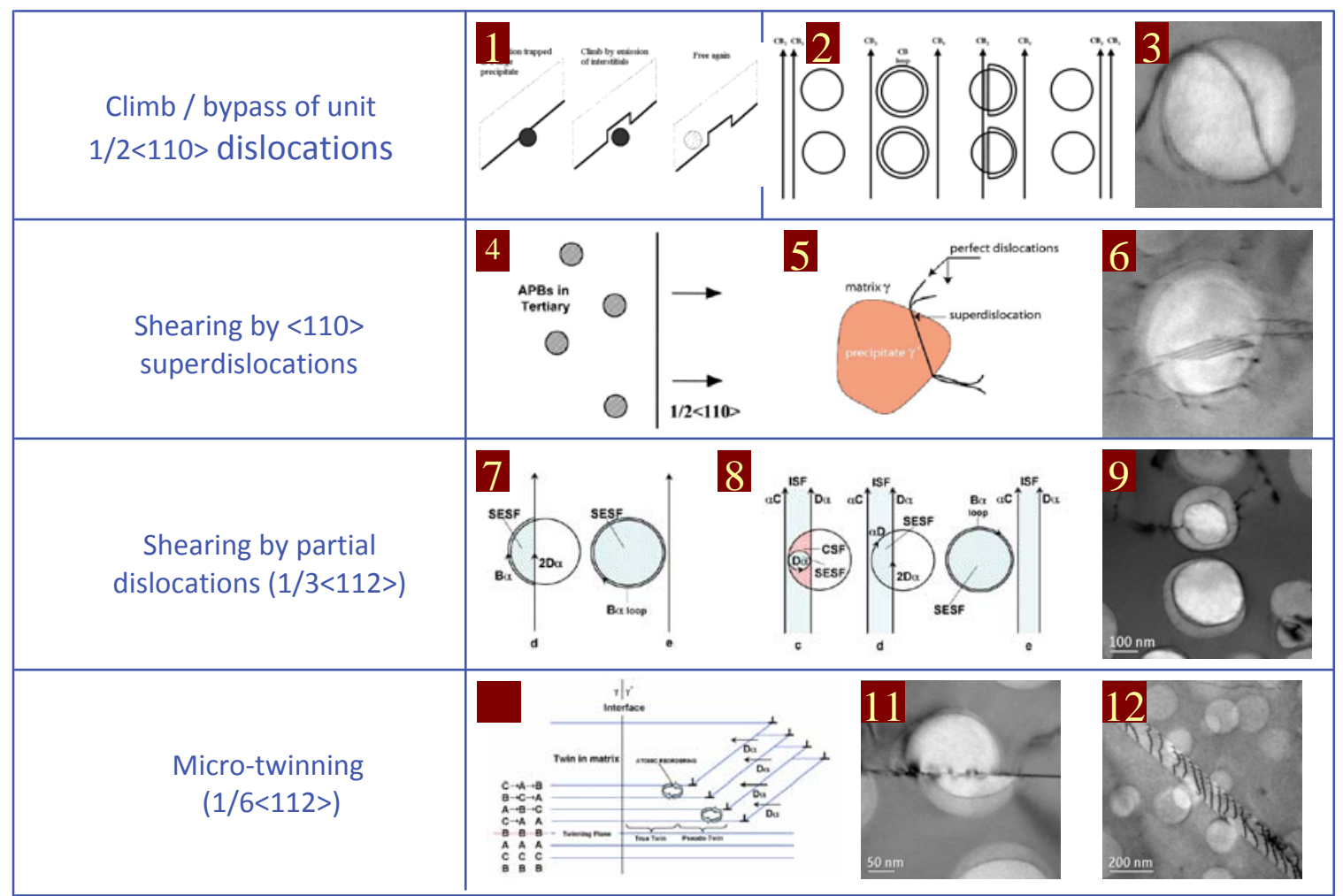

Figure 35: Potential deformation mechanisms that operate in nickel-base alloys. From the top there is dislocation climb, particle shearing and micro-twinning.

In (3) in Figure 35, a dislocation is interacting with the particle in such a way as to suggest a looping mechanism. This is usually associated with Orowan who calculated the theoretical stress needed for a dislocation to push past a particle and leave a loop around that particle. Also associated with the Orowan process is the possibility of climb past the particle. Where Orowan looping can occur at low temperatures when the stress is sufficiently high, climb is a diffusion related process that occurs at elevated temperatures. Consequently, when a dislocation encounters an obstacle as in (1), there are two routes for the dislocation to move past the particle. If the stress on the dislocation is equal to or greater than the Orowan stress, then the dislocation can push past the obstacle on either side (assuming the particle is sufficiently hard, i.e., has reached a certain size, to keep the dislocation from shearing through it) and pinch off a loop on the far side. Alternatively, if the stress on the dislocation is not sufficient to do this, then it is possible for the dislocation to climb to a more favorable slip plane so that the dislocation can once more continue to move in response to the applied stress.

A dislocation moving through an array of obstacles by the Orowan mechanism leaves a ring of dislocation around each one. These Orowan loops may affect the stress for subsequent dislocations moving along the same slip plane by reducing the effective spacing between obstacles and raising the stress needed to push past the obstacles for each subsequent dislocation on the slip plane.

A second way for the dislocation to bypass an obstacle that it cannot cut through is to climb past it. Movement of a dislocation in its slip plane is defined as glide, or conservative motion. It is characterized such that the dislocation moves in the surface that 
contains its line and Burgers vector. Climb on the other hand is non-conservative motion in that the dislocation moves out of its glide surface (slip plane) and thus normal to the Burgers vector. In doing so, the dislocation leaves behind two segments that are sessile, i.e., these fragments of the dislocation line are constrained such that they cannot glide with the rest of the dislocation. These fragments subsequently become obstacles in their own right to any subsequent dislocation moving in either the original slip plane or the new one. The processes of Orowan looping (i.e., leaving behind a shear loop), climb of a dislocation from one slip plane to another while leaving behind jogs (out of plane dislocation fragment bridging the slip planes), and other looping processes contribute to strengthen the alloy by providing additional obstacles to subsequent dislocation motion.

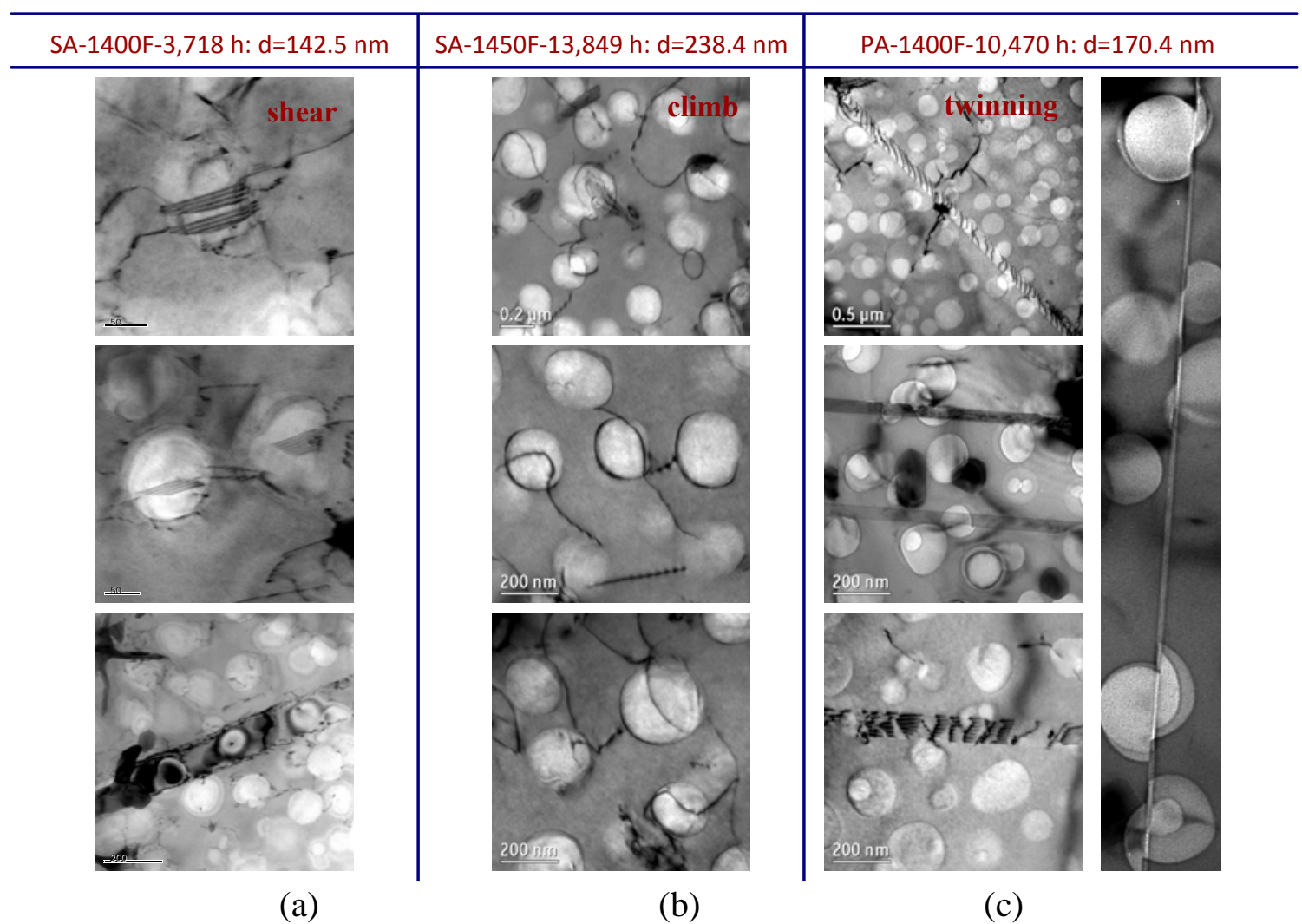

Figure 35: Observed deformation mechanisms in Haynes 282. From the left ther is (a) shear of $\gamma^{\prime}$ precipitates as a consequence of high stress creep conditions, (b) particle climb (and Orowan looping) as a consequence of higher temperature conditions $\left(1450^{\circ} \mathrm{F}\right.$ compared to $\left.1400^{\circ} \mathrm{F}\right)$ and (c) microtwinning at low temperature and low stress.

With this in mind examination of Figure 35 summarizes the deformation mechanisms observed in Haynes 282. In the left most column (a), for small $\gamma^{\prime}$ precipitates and high stresses, dislocations can pass through the particles, leaving behind disordered material along the plane cut by the dislocation (i.e., antiphase boundary-fringed region in the $\gamma^{\prime}$ precipitate). In the middle column (b), dislocation segments have moved out of the slip plane and are bypassing the $\gamma^{\prime}$ precipitate in this non-conservative manner. Also seen in the middle column are Orowan loops and other prismatic loops that resulted from crossslip. In the right most columns (c) twinning has occurred, displacing one surface relative to the other. This twin plane is just another region of disordered crystal that provides an additional obstacle to subsequent dislocations passing along slip planes that intersect the 
twinned region. These various deformation mechanisms damage the crystal structure and thus make it harder to move subsequent dislocations through the crystal. Consequently, as the number of obstacles increases the strength of crystal increases, or to put it another way, the strength does not decrease as quickly as might be expected if the debris from previous dislocations were not there.

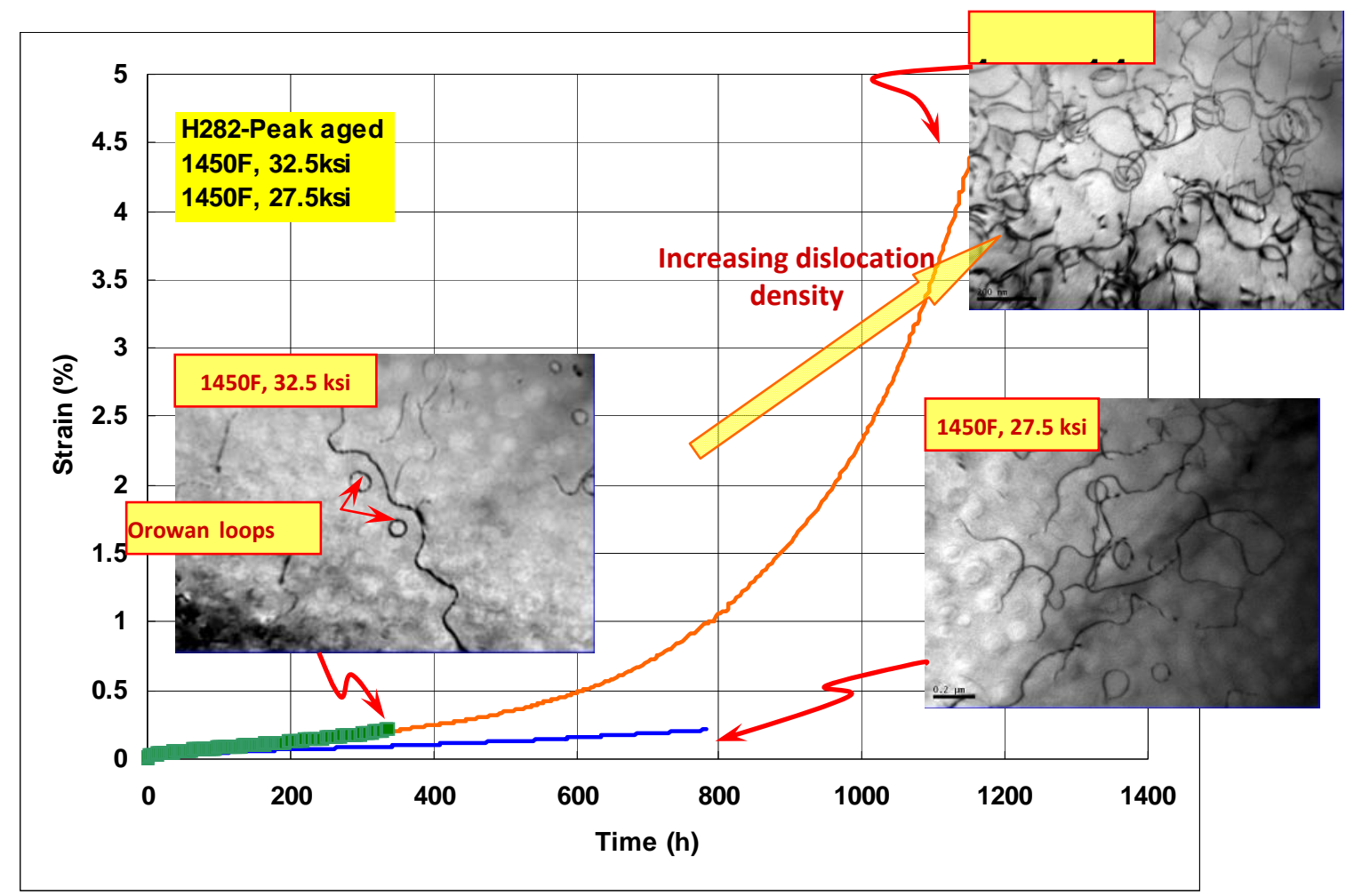

Figure 36: Composite representation that shows the dislocation interaction within the $\gamma$ matrix for various temperature-stress conditions.

Figure 36 shows this quite dramatically. In this figure there are three creep tests at $1450^{\circ} \mathrm{F}$ run to different times (or different percent strain levels). For the test at $1450^{\circ} \mathrm{F}$ and $32.5 \mathrm{ksi}$, which was stopped at $0.2 \%$ strain, dislocation density is low. Even so, Orowan looping is clearly evident as is distortion of the dislocation line as a result of Orowan loop formation and possible cross-slip.

For the example at $27.5 \mathrm{ksi}$ stress, also stopped at $0.2 \%$ strain, the density of dislocations in the matrix has increased. Orowan looping and climb are clearly evident with many Orowan and prismatic loops. For the example that was carried out to a much higher strain level (4.0\% strain or 20 times), the dislocation density is quite significant with a tremendous amount of debris in the form of Orowan and prismatic loops, dislocation tangles, dislocation fragments (most probably jogs from cross-slip and climb). 

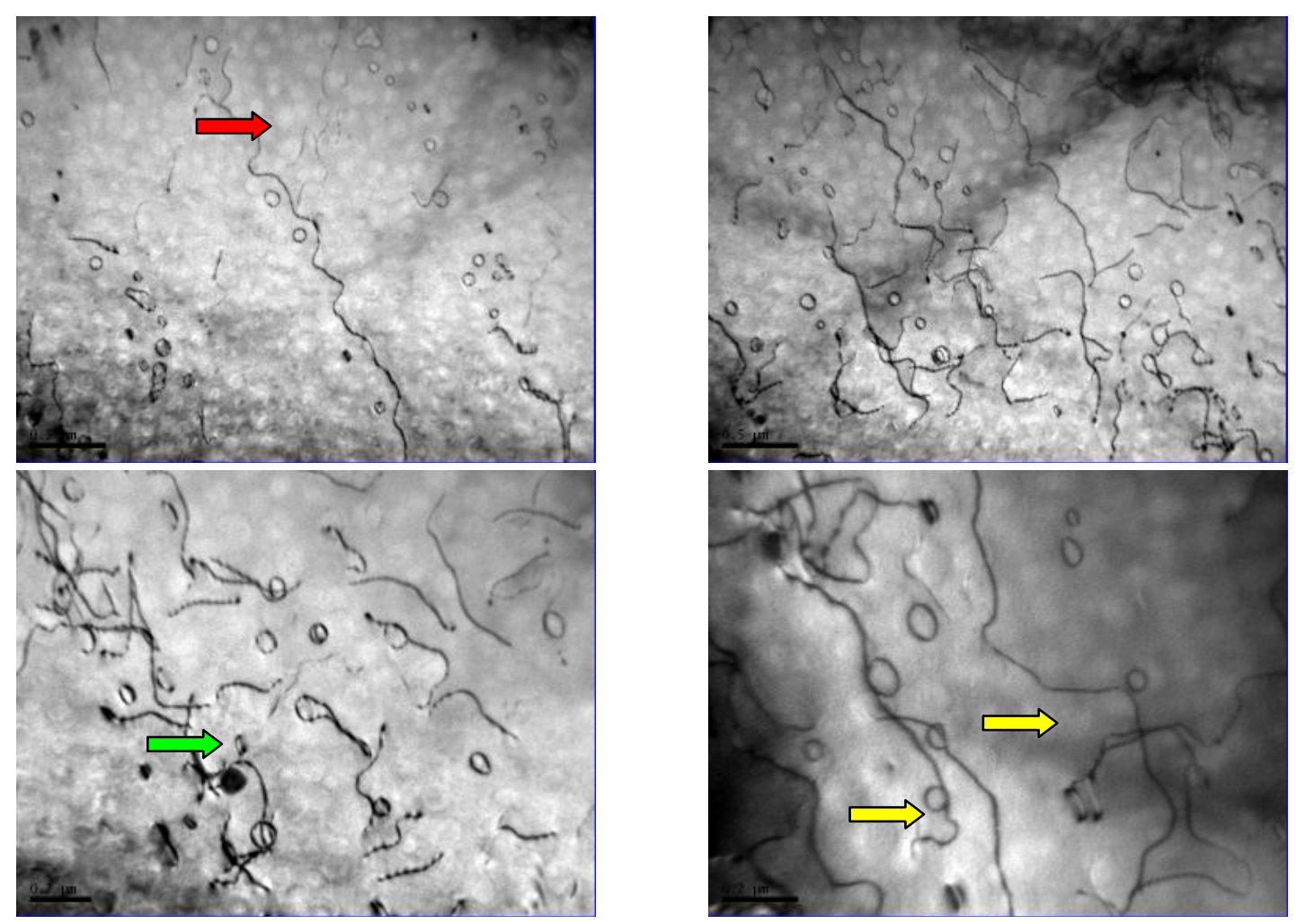

Figure 37: Various view of the $\gamma$ matrix showing Orowan loops, particle-dislocation interactions and cross-slip. Sample tested at $1450^{\circ} \mathrm{F}$ and $32.5 \mathrm{ksi}$. Crept to $0.2 \%$ strain.

Figure 37 shows additional micrographs from that first very short creep test ( $350 \mathrm{~h})$. Clearly evident in the micrographs are Orowan looping (numerous examples, but red arrow in upper left micrograph designates two such Orowan loops left in the wake of associated moving dislocation), prismatic dislocation loops (lower right micrograph with yellow arrows), climb around a $\gamma^{\prime}$ precipitate (lower left micrograph as indicated by green arrow), and other debris such as jogs. Figure 38 shows at high magnification the Orowan loops and associated dislocation. 


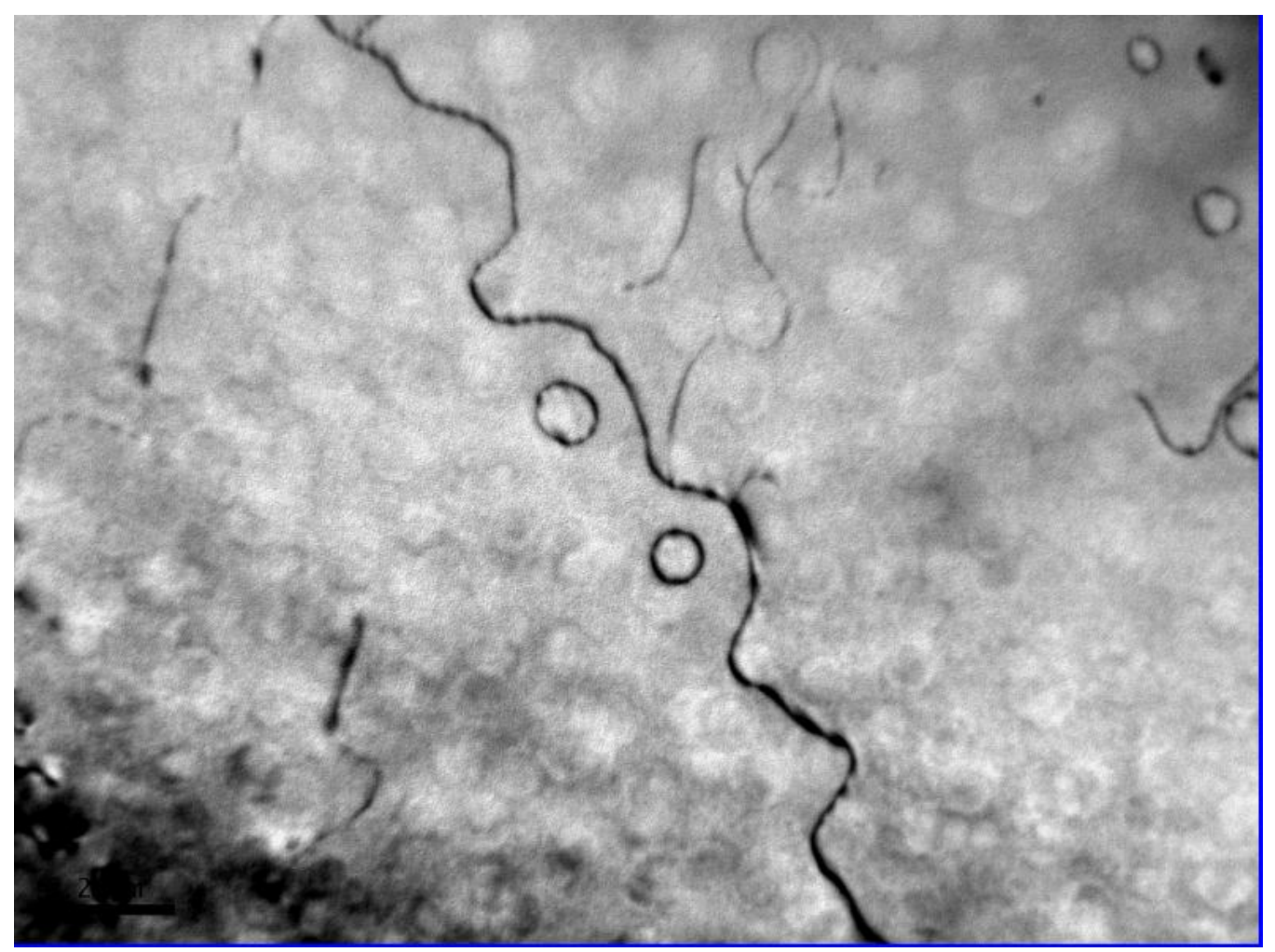

Figure 38: High magnification of image of Orowan left behind after dislocation moved through the matrix. High magnification view of dislocation line and Orowan loops from Figure 37(a). Sample tested at $1450^{\circ} \mathrm{F}$ and $32.5 \mathrm{ksi}$. Crept to $0.2 \%$ strain.

In Figure 38 other dislocation-particle interactions can be seen. The $\gamma^{\prime}$ precipitates are seen as faint outlines against the dark strain field of the dislocation. Each interaction point will cause the dislocation to either loop the particle by the Orowan mechanism or by climb and/or cross-slip. The process of doing so increases the line length of the dislocation as well as leaving behind sessile fragments, which also slows down the movement of the dislocation because for these sessile segments to move requires diffusion of vacancies to the dislocation. As creep strain increases dislocations become more entangled thereby raising the stress needed to move them an equivalent distance in the matrix compared to the initial state. 

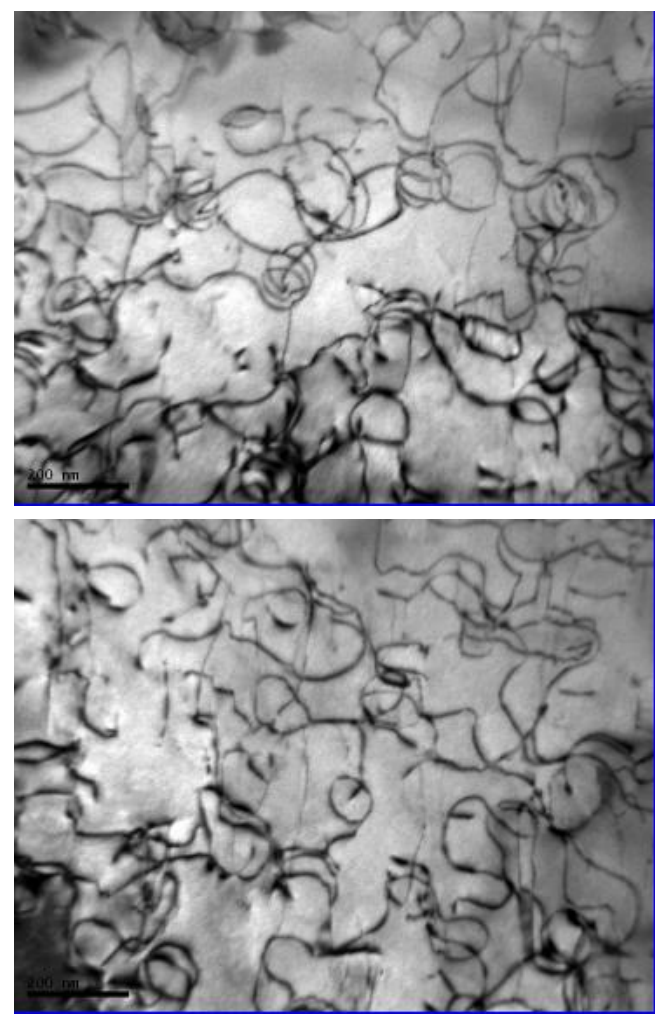
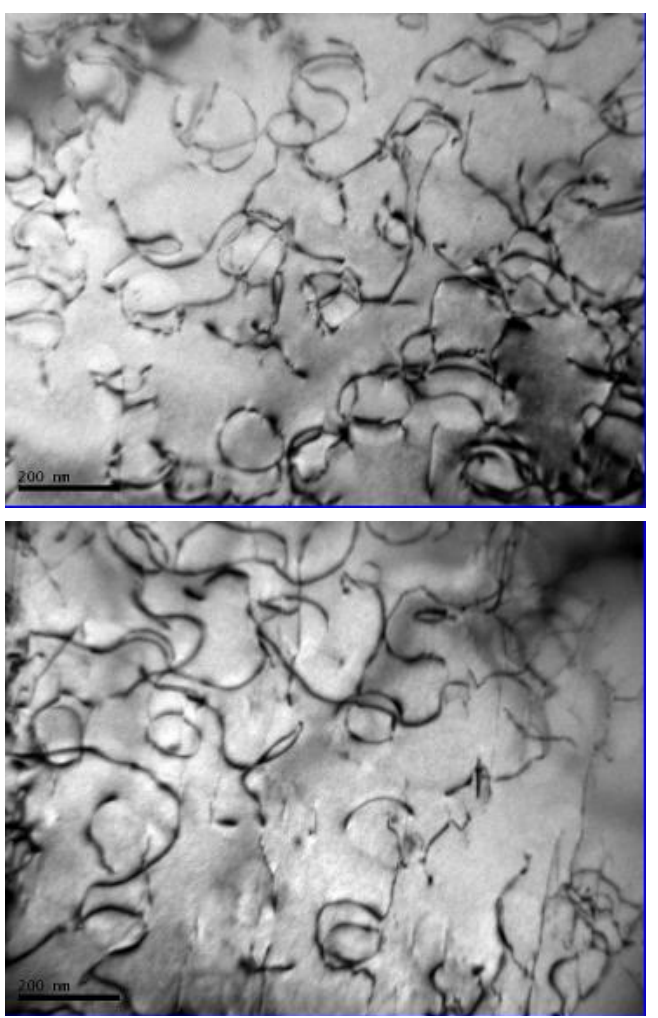

Figure 39: Various views of the $\gamma$ matrix showing Orowan loops, particle-dislocation interactions and cross-slip. Sample tested at $1450^{\circ} \mathrm{F}$ and $32.5 \mathrm{ksi}$. Crept to $4.0 \%$ strain.

Figure 39 shows the example at 4.0\% creep strain. Everything observed in Figure 38 also occurs in the material depicted in Figure 39, but there is so much more of everything. At this point it is clear that $\gamma^{\prime}$ precipitate strengthening is Haynes 282 is very effective. Precipitate bypass processes have caused a significant increase in the dislocation density and the resulting debris has complicated dislocation movement to the extent that it is almost impossible to discern individual dislocations as was possible in Figure 38. 

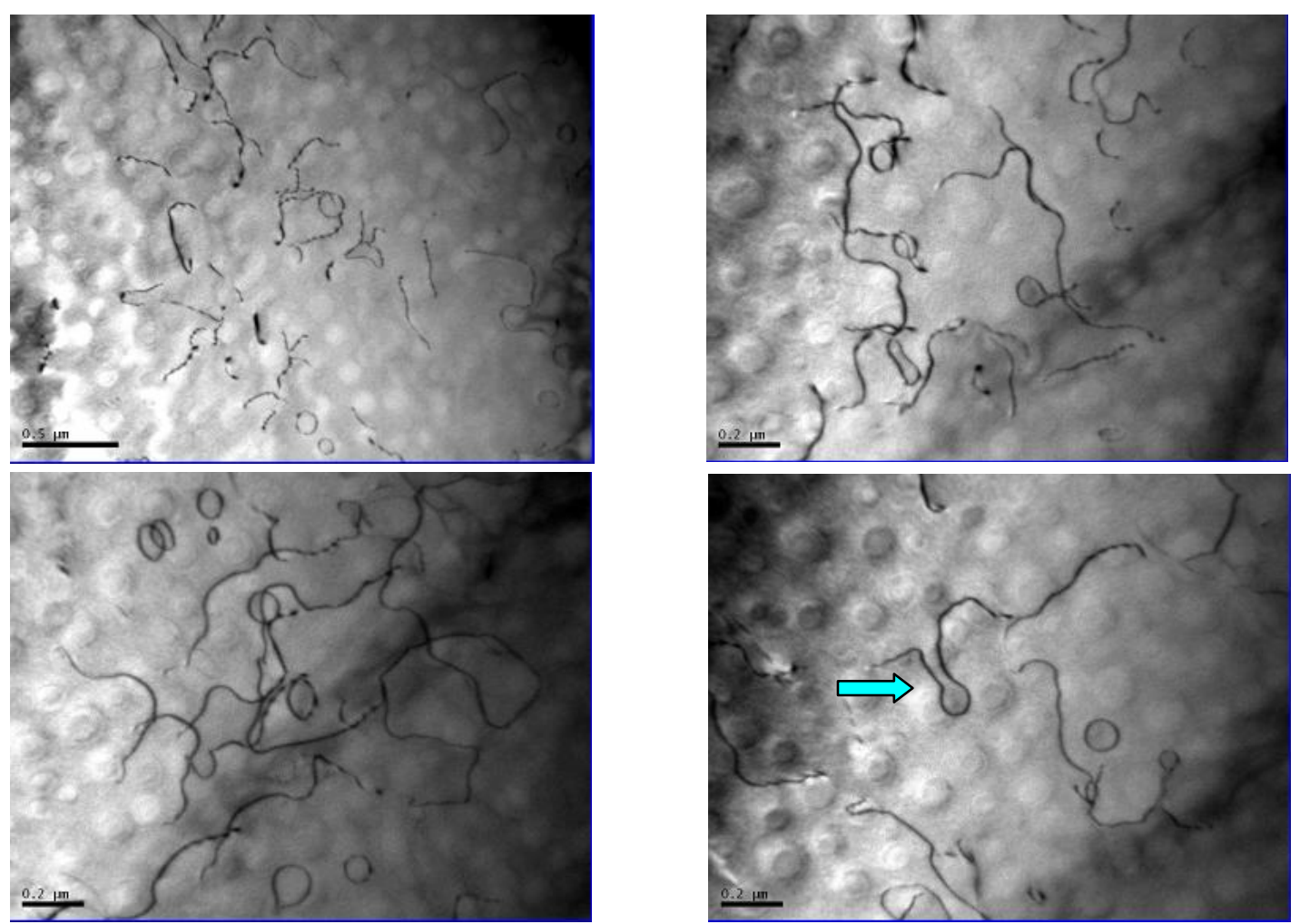

Figure 40: Various views of the $\gamma$ matrix showing Orowan loops, particle-dislocation interactions and cross-slip. Sample tested at $1450^{\circ} \mathrm{F}$ and $27.5 \mathrm{ksi}$. Crept to $0.2 \%$ strain.

Figure 40 completes the picture begun in Figure 36. In the previous figures the end result of the Orowan looping process was seen in loops surrounding discrete $\gamma^{\prime}$ precipitates but in Figure 40, highlighted by the blue arrow, the Orowan/cross-slip bypass operation is seen mid-point, or just before the loop is pinched off. This example clearly illustrates how the dislocation moves past the obstacle, although it is not completely clear if the dislocation is still in the slip plane or has climbed past/cross-slipped around the particle. In any event, if the creep specimen had been allowed to go longer, the dislocation would have pinched off this segment and continued along in response to the applied stress, leaving a shear or prismatic loop around the particle, whatever the case may be. As was observed for the other low creep strain sample, the dislocation density is still low and the debris left behind from moving dislocations is still minimal. This will change as more dislocation pass through the area.

The investigation of the Haynes 282 creep samples has proven quite informative. It conclusively shows that the various possible deformation mechanisms that operate in precipitate strengthened alloys at elevated temperature operate effectively in Haynes 282. When the particle size is small (weak-force condition), and/or the applied stress is high, shearing of the $\gamma^{\prime}$ precipitate occurs, leaving behind antiphase boundaries within the $\gamma^{\prime}$ precipitate.

As the size of the $\gamma^{\prime}$ precipitate increases from that found in the SA material, either by precipitate coarsening in the SA material from elevated temperature exposure during creep, or by aging the alloy to peak strength, or beyond, to produce a larger diameter particle (strong-force condition), which by the way leads to an incoherent precipitate 
interface, the particle becomes effectively stronger and resists dislocation penetration. This results in the Orowan stress ( $\tau$ Orowan $\cong 0.84 \mathrm{~Gb} / \Lambda$, where $\mathrm{G}$ is the shear modulus, $\mathrm{b}$ is the spacing between atoms in the direction of the shear stress, or Burgers vector, and $\Lambda$ is the mean obstacle spacing) being reached by the dislocation as it interacts with the obstacle, thereby facilitating either the traditional Orowan bypass operation or climb/cross-slip. By whatever mechanism the bypass of the obstacle is accomplished, dislocation debris, either in the form of Orowan loops, prismatic loops, jogs, etc., is left behind, and this along with the $\gamma^{\prime}$ precipitates, creates more obstacles to subsequent dislocations moving along the same or adjacent slip planes, leading to even more effective high temperature strengthening of the matrix. These observations support the experimental evidence from Phase I creep testing that indicated better than expected performance of the Haynes 282 alloy compared to other higher volume fraction nickel superalloys.

Microstructural examination in conjunction with strengthening theory and the physical metallurgy of Haynes 282 (sluggish precipitation kinetics) suggests that there exists a critical $\gamma^{\prime}$ precipitate size where deformation changes from shear to bypass mechanisms. If the stress is low, shearing of the obstacles is non-existent even though the $\gamma^{\prime}$ precipitate may still be below the critical size to promote the bypass mechanisms. And because the microstructure of the SA Haynes 282 really consists of very small $\gamma^{\prime}$ precipitates, exposure at $1400^{\circ} \mathrm{F}$, which is near the aging temperature of the alloy, facilitates rapid initial coarsening of the $\gamma^{\prime}$ precipitate until the solute in the immediate vicinity has been depleted, thus lowering the driving force for further coarsening.

This explains in part the observed creep rupture behavior where there is very little difference in the time to rupture for creep samples produced to give different starting precipitate sizes. At $1400^{\circ} \mathrm{F}$ and low stress levels, the $\gamma^{\prime}$ precipitate has time to coarsen from the SA condition to the size of those precipitates in the peak aged or overaged alloy. Even though the initial coarsening from 5-20 nm to about $60 \mathrm{~nm}$ may occur in the first several hundred hours of exposure, subsequent coarsening will slow as solute is depleted locally from the matrix. Then the rate of coarsening will converge to that of the peak aged and overaged material and creep will proceed in a similar manner for all alloy conditions.

\section{Part 5: Creep Capability at $1400^{\circ} \mathrm{F}$}

Screening tests on candidate materials for the non-welded rotor have been completed. Included in this report are preliminary LMP correlations using short-term creep data and vendor literature data. From the analyses, LMP equations have been developed that verify that Nimonic 105 and Haynes 282 meet the minimum requirements of mean creep strength at $10^{5} \mathrm{~h}$ and $2.5 \times 10^{5} \mathrm{~h}$ for a $15 \mathrm{ksi}$ applied stress. Figure 41 shows the LMP plot and accompanying equation for Haynes 282. Figure 42 shows the LMP plot and accompanying equation for Nimonic 105. 


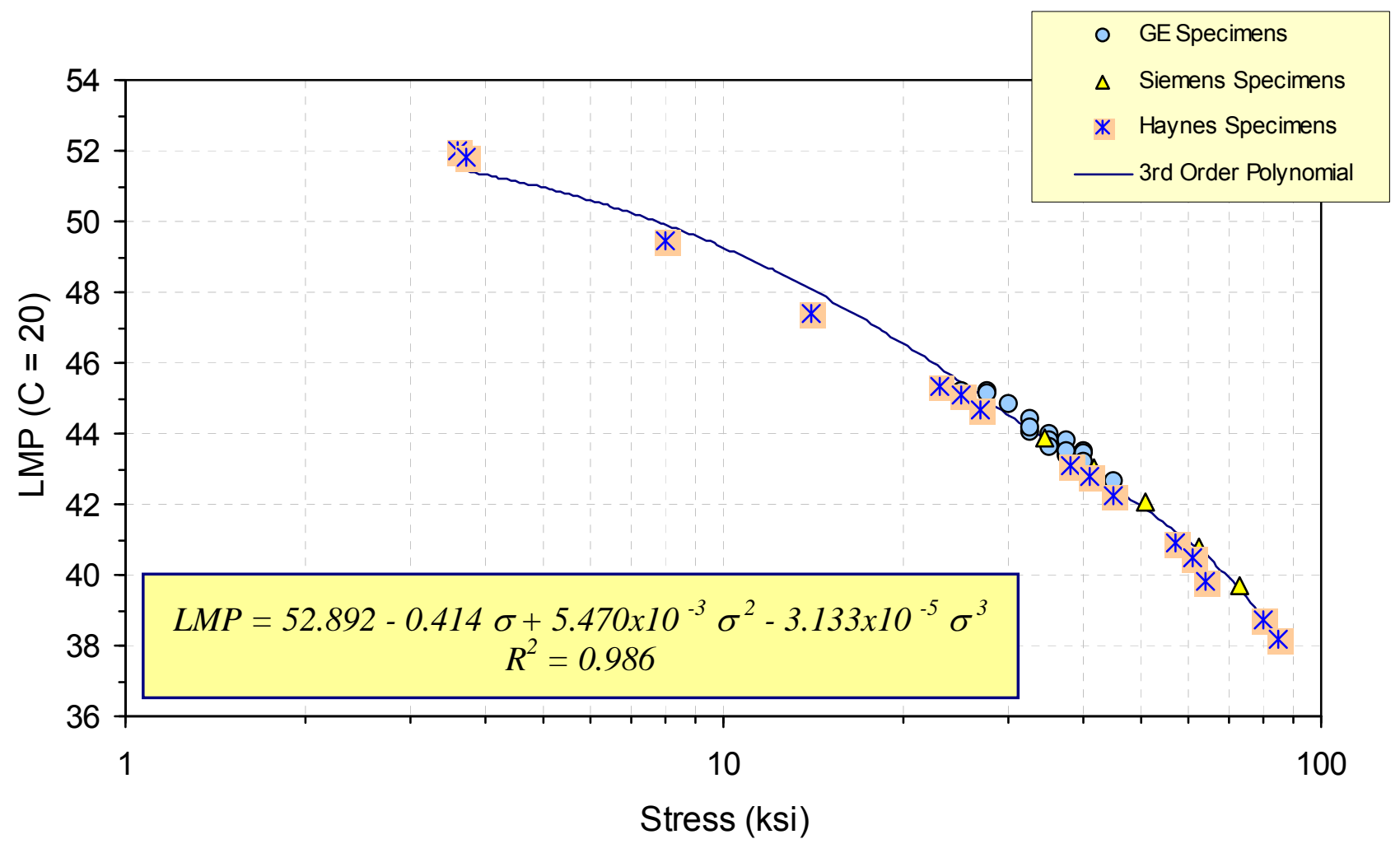

Figure 41: LMP plot for Haynes 282 showing up-to-date analysis for tests done by Siemens and GE combined with Haynes literature data. 


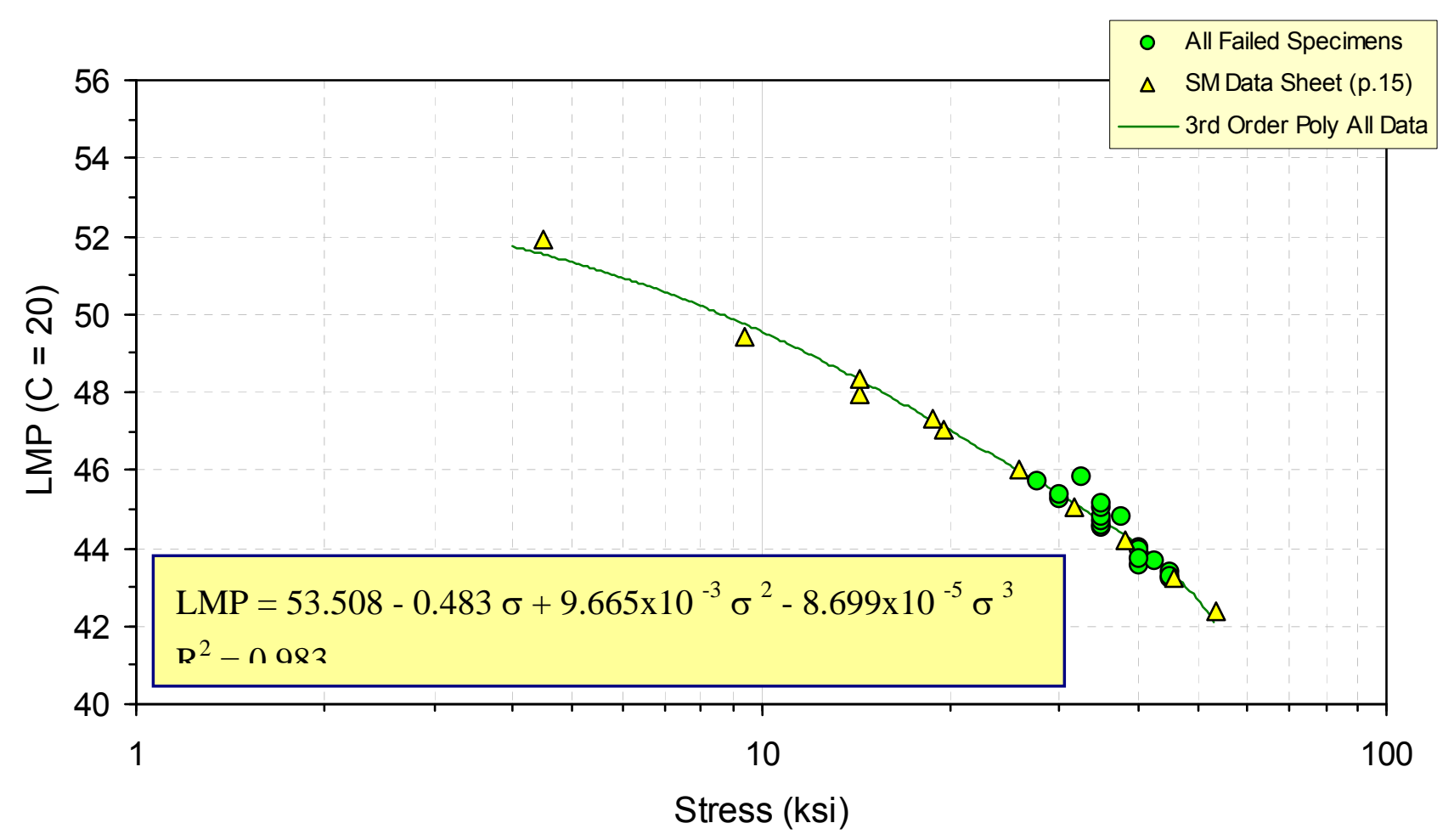

Figure 42: LMP plot for Nimonic 105 showing up-to-date analysis for test done by GE combined with Special Metals literature data.

Additional analysis has confirmed that Waspaloy is also capable as a rotor alloy at $1400^{\circ} \mathrm{F}$ and $15 \mathrm{ksi}$, with mean creep strength intermediate between Nimonic 105 (best) and Haynes 282.

IN 740, while having excellent mean creep strength up to $1400^{\circ} \mathrm{F}$ for $10^{5} \mathrm{~h}$, does not meet the minimum strength requirements for a rotor alloy at $2.5 \times 10^{5} \mathrm{~h}$. This alloy could possibly be suitable for operating temperatures greater than $1300^{\circ} \mathrm{F}$ but less than $1400^{\circ} \mathrm{F}$.

Udimet 720Li in the high strength heat-treated condition does not meet mean creep capability at $1400^{\circ} \mathrm{F}$, and in fact exhibits mean creep strength barely suitable for rotor applications at $1300^{\circ} \mathrm{F}$. No further work should be devoted to Udimet $720 \mathrm{Li}$ as a nonwelded rotor, although as a welded segment in the rotor in the cooler sections $\left(\sim 1300^{\circ} \mathrm{F} \pm\right.$ $25^{\circ} \mathrm{F}$ ) of the HP and IP it might work when a combination of tensile and creep strength are needed (although IN740 could perform well here too).

Preliminary microstructural (TEM) studies have been performed on samples of Haynes 282 in order to determine the operative creep deformation mechanism. Figure 43 shows the TEM microstructures of three samples tested at $1400^{\circ} \mathrm{F}, 1425^{\circ} \mathrm{F}$ and $1450^{\circ} \mathrm{F}$ for times shorter than 6,000 h. This grouping of microstructures is termed short-term. Figure 44 shows the TEM microstructures of three samples tested at $1400^{\circ} \mathrm{F}, 1425^{\circ} \mathrm{F}$ and $1450^{\circ} \mathrm{F}$ for times just greater than $13,6000 \mathrm{~h}$. This grouping of microstructures is termed longterm. 


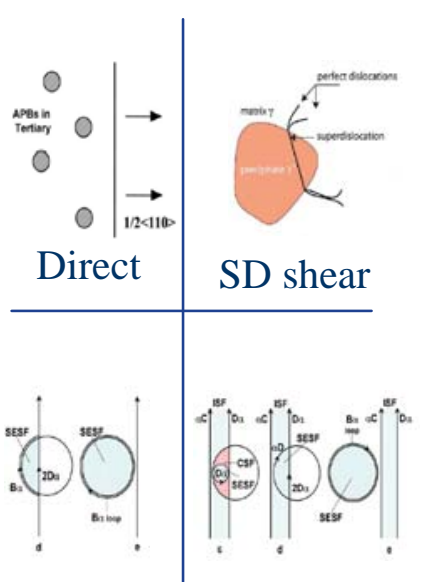

PD shear

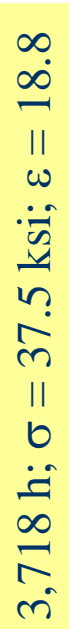

Mechanism

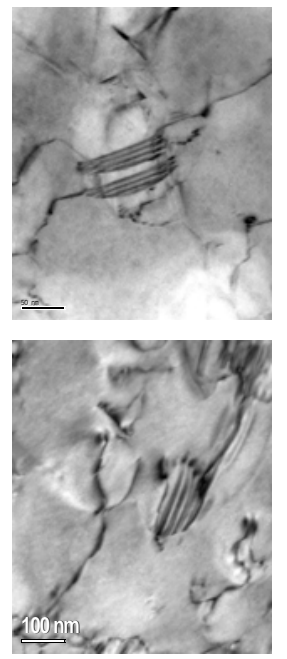

$1400^{\circ} \mathrm{F}-\mathrm{SA}$

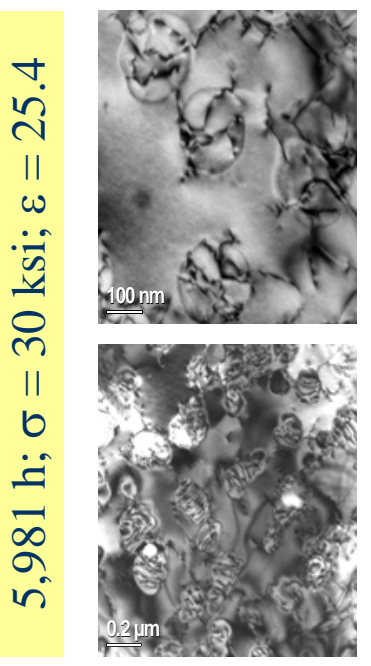

$1425^{\circ} \mathrm{F}-\mathrm{SA}$
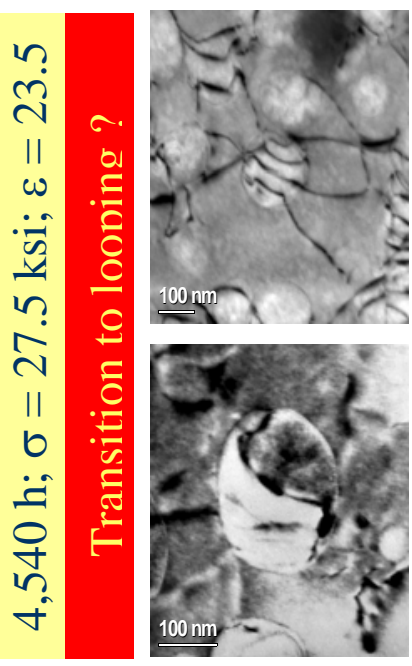

$1450^{\circ} \mathrm{F}-$

SA

Figure 43: Short-term creep rupture tests showing particle shearing as a possible deformation mechanism. As temperature increases, shearing action transitions to one of Orowan looping and climb.

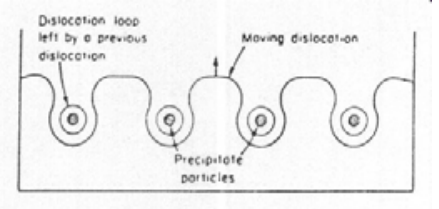

Orowan bypass
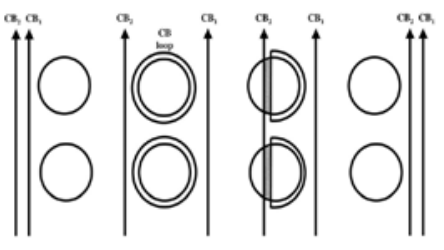
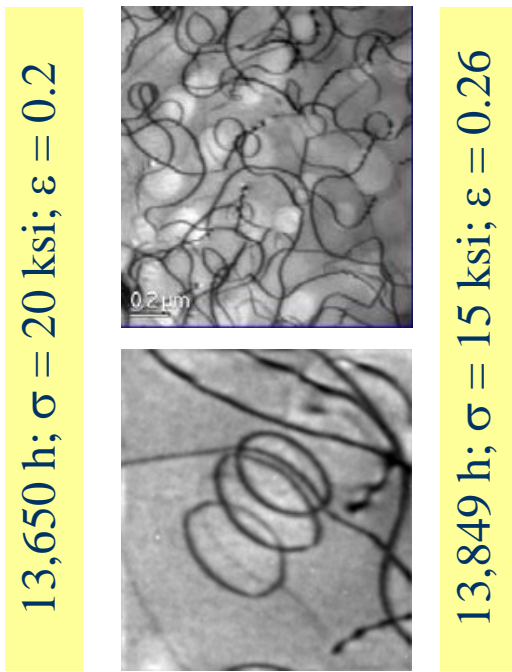

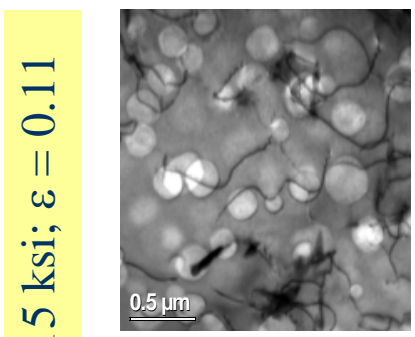

Figure 44: Long-term creep rupture tests (stopped before failure) showing particle bypass as a possible deformation mechanism. In these instances, Orowan looping and climb are clearly seen. Little shearing of the $\gamma^{\prime}$ particles has taken place.

The short-term specimens were tested to rupture and exhibit clearly a cutting/shearing mechanism. The elongations-to-failure for these three samples was between about $19 \%$ and $25 \%$. Clearly, this is a high-stress phenomenon and does not affect the overall creep ductility of the alloy.

At $1400^{\circ} \mathrm{F}$ the deformation mechanism is by cutting/shearing of the $\gamma^{\prime}$ strengthening particles. Antiphase boundaries can be seen in the particles as a consequence of multiple dislocations passing through the particle along the same slip plane. With each pass a bit of disordered crystal is left behind. Note the difference in contrast within the $\gamma^{\prime}$ particle as observed in the micrograph. At $1425^{\circ} \mathrm{F}$ and $1450^{\circ} \mathrm{F}$, particle cutting/shearing still occurs, 
but some dislocation looping and out of plane dislocation fragments, indicative of climb, are seen more frequently.

As mentioned, this mechanism seems to be primarily stress related because as the creep stress decreases for these short-term tests, so too does the relative fraction of cut particles. Concurrent with the decrease in cut particles is an increase in observed looping and dislocation climb around $\gamma^{\prime}$ particles. There is some critical stress where the dislocation can no longer punch through the strengthening particle, and for the dislocation to move past the $\gamma^{\prime}$ particle it must either loop it, thereby leaving a dislocation fragment behind, or it must climb out of its primary slip plane. Either mechanism increases the resistance to that dislocation moving in the $\gamma$ matrix as the overall dislocation line length increases as a result of these interactions with the $\gamma^{\prime}$ particles.

The long-term samples were discontinued at around 13,600 $\mathrm{h}$. The creep strain was less than $0.26 \%$ for all samples with the $1450^{\circ} \mathrm{F}$ sample exhibiting the lowest creep strain at $0.11 \%$. In these micrographs it is clear that Orowan looping of $\gamma^{\prime}$ particles and climb out the slip plane by the dislocations are the major mechanisms of creep deformation. Particle cutting/shearing is not observed to any great extent and its absence as a deformation mechanism is probably related to the lower stresses used for these creep tests (i.e., the maximum stress was $20 \mathrm{ksi}$ at $1400^{\circ} \mathrm{F}$ ). This is an encouraging development because the stresses in the steam turbine rotor and other rotating parts will be generally less than 20 ksi except at isolated high-stress locations in the dovetail notch, for example, and very much so throughout most of the bulk of the rotor.

Orowan looping and climb past $\gamma^{\prime}$ particles lead to improved creep resistance of the alloy because the moving dislocations leave behind loops and out of plane fragments as they bypass the strengthening $\gamma^{\prime}$ particles or a portion of the dislocation line moves out of the primary slip plane. As the dislocations climb out of plane, the overall dislocation line length increases and it becomes increasing more difficult to move the entire dislocation through the array of $\gamma^{\prime}$ particles in the microstructure as the out of plane dislocation fragment is not on a primary slip plane and is usually pinned at the point it leaves the slip plane. When Orowan looping occurs, the effective volume of the strengthening precipitate increases and the mean particle spacing decreases. Thus, the strain field around the particle increases due to single or multiple loops around the enveloped $\gamma^{\prime}$ particles. This may be one indication of the perceived creep strength enhancement of the Haynes alloy, which was better than expected given the low volume fraction of strengthening particles compared to other $\gamma^{\prime}$ strengthened superalloys such as Nimonic 105.

At this time there is nothing in the creep results to suggest a detrimental interaction with the environment that would reduce expected creep lifetime based on the testing to date. For example, in the Haynes series of creep tests, creep strain was between 15 and 30\% for all tested temperature and stress conditions, whether short-term or long-term. If embrittlement had occurred a precipitous decrease in ductility (either manifested in creep strain, elongation-to-failure or reduction-in-area) would be expected, and this was not observed.

In the Nimonic 105 alloy, there was a wider disparity in creep strain and the other forms of ductility measurement but at this time, given the random nature of the anomalous 
results, it would be premature to associate these lower values of ductility with embrittlement as opposed to some other fracture initiation event. In general, creep strains ranged between 10 and 25\%, with most of the creep strains for the failed specimens ranging from 15 to $20 \%$.

At this time, preliminary screening and collation of available mechanical property data have identified three alloys that could serve as a rotor, be it welded, bolted or monolithic in nature: Nimonic 105, Waspaloy and Haynes 282. However, it must be kept in mind that this analysis is based on mean creep strength at the $1400^{\circ} \mathrm{F}$ operating temperature, and when specific steam turbine design rules are applied this may change.

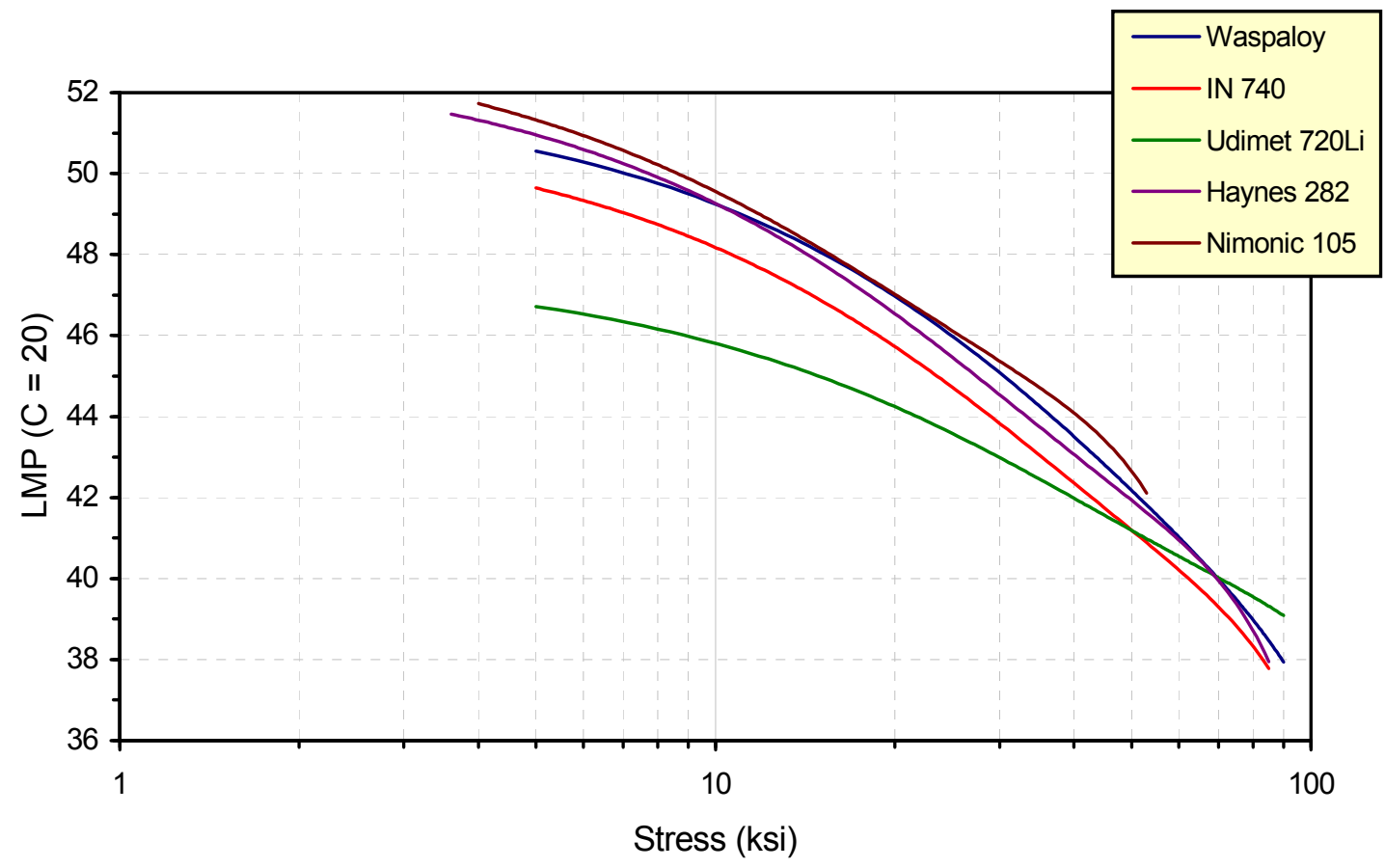

Figure 45: LMP versus stress for $1400^{\circ} \mathrm{F}$ candidate alloys for steam turbine rotor.

\section{$7 \quad$ Summary Creep Capability}

As mentioned in Part 2, creep data from the Phase I test program as well as vendor and literature data are found in Appendix 5. In Figure 45 a LMP vs. stress curve is shown for Inconel 740. Analysis of creep data was performed on information provided by Special Metals and the 1400F Boiler Consortium. The creep data for Waspaloy, Inconel 740, Udimet 720, Haynes 282 and Nimonic 105 was analyzed using a third order polynomial, with a general relationship of the form given by Equation 1. Table 4 shows the coefficients for the variables in Equation 1. This approach was taken in order to compare the candidate alloys on a relative basis. A more accurate analysis of the creep data whereby the value of $\mathrm{C}$ is determined for each alloy data group will yield the most accurate estimation for component life. However, until the long-term creep testing from Phase II is complete, there is no good reason to pursue this course of analysis.

$$
L M P=a+b \sigma+c \sigma^{2}+d \sigma^{3}
$$


Table 4: LMP Coefficients for $3^{\text {rd }}$ Order Polynomial

\begin{tabular}{|c|c|c|c|c|}
\hline Alloy & $\underline{\mathbf{a}}$ & $\underline{\mathbf{b}}$ & $\underline{\mathbf{c}}$ & $\underline{\mathbf{d}}$ \\
\hline Waspaloy & 51.98 & -0.2983 & 0.002623 & $-1.159 \times 10^{-5}$ \\
\hline IN740 & 51.29 & -0.3491 & 0.003951 & $-2.018 \times 10^{-5}$ \\
\hline $\mathrm{U} 720 \mathrm{Li}$ & 47.73 & -0.2111 & 0.002019 & $-8.222 \times 10^{-6}$ \\
\hline $\mathrm{H} 282$ & 52.89 & -0.4144 & 0.005470 & $-3.133 \times 10^{-5}$ \\
\hline $\mathrm{N} 105$ & 53.51 & -0.4829 & 0.009665 & $-8.699 \times 10^{-5}$ \\
\hline
\end{tabular}

The use of a 3rd order polynomial was justified by examining the r2 values for each alloy data set and subsequent analysis. In addition inspection of the curves using the 3rd order polynomial showed good correspondence with the data for the entire range of LMP and stress. The values of r2 ranged from a low of 0.9813 for Inconel 740 to a high of 0.9927 for Udimet 720Li.

\section{Part 6: Summary and Recommendations}

At the beginning of the project, the major goal of the monolithic rotor development program was to determine if there were any commercial nickel-base superalloys suitable for long-term use at $1400^{\circ} \mathrm{F}$. Most well known nickel-base superalloys have been used in aero-engine applications or other niche applications (e.g., chemical industry and down hole oil and gas drilling operations). In these applications lifetime is measured in thousands or tens of thousands of hours. For steam turbine rotors, for example, a lifetime of at least 100,000 hours, if not longer, is desirable. In analyzing the creep capability of the nickel-base superalloys in Phase I of this project, a projected lifetime of 250,000 hours was assumed.

From preliminary creep and creep rupture testing, and in combination with literature and vendor data, creep capability for Nimonic 105, Waspaloy and Haynes 282 met the 250,000 hours lifetime goal at $1400^{\circ} \mathrm{F}$. However, this lifetime is based on relatively short-term creep testing and longer-term information is needed to verify extrapolated creep capability. This capability also does not assume other rotor strategies such as cooling to extend temperature capability and lifetime.

From a practical point of view, Nimonic 105 is the best alloy from a tensile strength and creep perspective, based in large part on the strength derived from $\gamma^{\prime}$ and matrix $\gamma$. However, Nimonic 105 would be difficult to process as a large ingot for a rotor segment. Also, Nimonic 105 is not easily weldable. These practical issues in no way detract from using this alloy at $1400^{\circ} \mathrm{F}$. Nimonic 105 has, in the past, been forged into gas turbine blades, and its use in a $1400^{\circ} \mathrm{F}$ steam turbine can be envisioned for blades, bolts, valve stems, and other parts of this nature. 
Waspaloy and Haynes 282 have similar creep capability but of the two, Haynes 282 is unique in that its creep capability as evaluated from the creep program is relatively insensitive to the starting microstructural condition. That is, the creep behavior in the solution annealed, peak aged and overaged, or heat conditioned, state is very similar. This unique behavior arises from the sluggish nucleation kinetics of the $\gamma^{\prime}$ precipitate in this alloy, such that there is only a minor difference in the starting precipitate size between these three processed states, and the $\gamma^{\prime}$ precipitates quickly reach the same size after exposure at $1400^{\circ} \mathrm{F}$ compared to the projected life of the part. Another factor that makes Haynes 282 a good rotor alloy is that it can be easily welded (i.e., for a $\gamma^{\prime}$ strengthened alloy). One drawback of Haynes 282 is that it has the lowest yield strength of the three alloys, especially in the solution annealed condition. If yield strength is a primary design limiting concern, then the starting condition of Haynes 282 must be considered carefully in order to obtain the necessary level of yield stress.

Phase I has conclusively shown that there are several commercial nickel-base superalloys that can be used for rotor segments at $1400^{\circ} \mathrm{F}$. Of the three leading candidate alloys, the Haynes 282 possesses the greatest flexibility in terms of processing, heat treatment and welding capability, in addition to creep capability. Nimonic 105 and Waspaloy are also $1400^{\circ} \mathrm{F}$ capable alloys and can be used for components that need higher strength, in addition to the requisite $1400^{\circ} \mathrm{F}$ creep capability.

It is clear from the two DOE $1400 \mathrm{~F}$ sponsored vendor meetings, that a monolithic rotor manufactured from any of the $1400^{\circ} \mathrm{F}$ capable nickel-base superalloys, is impractical in terms of cost and not possible from a manufacturing perspective at the current time. This would necessitate a composite rotor design of some sort, be it a welded design or one that is bolted together. With that in mind the direction for the rotor test program in Phase II should take a different approach from that followed in Phase I.

\subsection{Phase II Rotor Test Program}

In short, Phase II testing (see Appendix 8 for details regarding statement of work, deliverables and preliminary task description) will add density to the current mechanical property data set in terms of quality of data viz. additional testing of heats, evaluating rotor specific properties (such as creep-fatigue through hold-time LCF testing, impacttoughness and crack growth), extending the duration of Phase I creep tests to 30,000 hours and beyond, and thereby verifying the results of the short-term program, and evaluating long-term microstructural stability through long-term isothermal exposure with the goal of establishing $\gamma^{\prime}$ and carbide stability (i.e., coarsening rates for each major phase).

Testing would focus on Haynes 282 as the primary, high temperature rotor alloy, i.e., at $1400^{\circ} \mathrm{F}$, with additional testing on another alloy that could see service at temperatures in the HP and IP at temperatures less than $1400^{\circ} \mathrm{F}$. During Phase I alloy 617 was one such lower temperature alloy investigated for this purpose. One of the first tasks in Phase II should be identification of a potential lower temperature rotor alloy. Specific mechanical tests similar to those specified for Haynes 282 would be performed in conjunction with the Haynes 282 test matrix. 


\subsection{Phase II Blade, Bolt, and Valve Test Program}

A number of alloys could be investigated for blades, bolts and valve internals during Phase II (see Appendix 8 for details regarding statement of work, deliverables and preliminary task description). Of primary importance is establishing mechanical property extremes at $1400^{\circ} \mathrm{F}$, especially for component specific properties (e.g., creep-fatigue through hold-time LCF testing, impact-toughness, HCF and stress relaxation for blades and bolts since little vendor data exist here, and extension of creep data to 30,000 hours and beyond for all alloys). The physical properties of blade, bolt and valve candidate materials will also have to be determined to aid in the conceptual steam turbine design process. In addition to Nimonic 105 and Waspaloy, Haynes 282 could also be investigated as an alloy for these components, but some consensus should be reached as to the best candidate alloys for Phase II testing based on availability and cost.

Although not specifically called out in the Phase II test plan, in the lower temperature areas of the steam turbine more traditional alloys like 718 and 625 could be used, depending on strength-temperature requirements. Property data exist for these alloys but may need to be augmented by the OEM at slightly higher temperatures than currently utilized, depending on specific steam turbine design considerations. 


\section{$9 \quad$ Part 7: References}

1. R. Blum and R.W. Vanstone, "Materials development for boilers and steam turbines operating at $700^{\circ} \mathrm{C}$," in Materials for Advanced Power Engineering 2006, Proceedings of the $8^{\text {th }}$ Liege Conference, 18-20 September 2006, Liege, Belgium.

2. H. Edelmann, M. Effert, K. Wieghardt and H. Kirchner, “The $700^{\circ} \mathrm{C}$ steam turbine power plant-status of development and outlook,” Int. J. Technology and Policy, Vol. 5, No. 3, 2007, pp. 366-382.

3. J. Bugge, S. Kjaer and R. Blum, "High-efficiency coal-fired power plants development and perspectives,” Energy, Vol. 31, 2006, pp. 1437-1445.

4. R. Blum, S. Kjaer and J. Bugge, "Development of a PF fired high efficiency power plant (AD700),” Riso-R-1608 (EN), pp. 69-80.

5. C.G. Stolzenberger, “The European road map for $700^{\circ} \mathrm{C}$ USC power plant,” in Parsons 2007, Proceedings of the $7^{\text {th }}$ International Charles Parsons Turbine Conference, Power Generation in an Era of Climate Change, 11-13 September 2007, University of Strathclyde, Glasgow, UK. 


\section{APPENDIX 1 \\ PHYSICAL, MECHANICAL, AND PROCESSING DATA FOR CANDIDATE NICKEL SUPERALLOYS}


Table 1A: Nominal Chemical Composition of Potential Alloys for $1400^{\circ} \mathrm{F}$ Rotor and Other Forged Components as per Manufacturer Published Literature

\begin{tabular}{|c|c|c|c|c|c|c|c|c|c|c|c|c|c|c|c|c|c|c|c|c|}
\hline & $\mathrm{C}$ & $\mathrm{Ni}$ & $\mathrm{Cr}$ & Mo & Co & $\mathrm{Al}$ & $\mathrm{Ti}$ & $\mathrm{Cb}$ & $\mathrm{Ta}$ & Mn & $\mathrm{Fe}$ & $\mathrm{Si}$ & $\mathrm{B}$ & $\mathrm{Cu}$ & $\mathrm{Zr}$ & W & $\mathrm{S}$ & $\mathrm{P}$ & $\mathrm{N}$ & $\mathrm{RE}$ \\
\hline 155 & 0.120 & 20.00 & 21.00 & 3.00 & 20.00 & & & 1.00 & & 1.50 & 29.73 & 1.00 & & & & 2.50 & & & 0.15 & \\
\hline 617 & 0.070 & 53.93 & 22.00 & 9.00 & 12.50 & 1.20 & 0.30 & & & & 1.00 & & & & & & & & & \\
\hline CA617 & 0.060 & 56.66 & 21.50 & 8.60 & 11.30 & 1.24 & 0.39 & 0.02 & & 0.03 & 0.07 & 0.10 & 0.003 & 0.01 & & & 0.001 & 0.003 & 0.01 & \\
\hline 625 & 0.030 & 58.85 & 21.00 & 9.00 & 1.00 & 0.40 & 0.40 & 3.65 & & 0.50 & 5.00 & 0.15 & & & & & & & 0.02 & \\
\hline 718 & 0.050 & 53.04 & 18.50 & 3.00 & 0.30 & 0.50 & 1.00 & 5.10 & & 0.10 & 18.20 & 0.15 & 0.003 & 0.05 & & & 0.001 & 0.006 & & \\
\hline 718 Plus & 0.060 & 50.85 & 19.00 & 2.80 & 9.00 & 1.50 & 0.75 & 5.30 & & 0.35 & 9.00 & 0.35 & 0.008 & & & 1.00 & 0.010 & 0.020 & & \\
\hline 740 & 0.030 & 48.27 & 25.00 & 0.50 & 20.00 & 0.90 & 1.80 & 2.00 & & 0.30 & 0.70 & 0.50 & & & & & & & & \\
\hline Haynes 25 & 0.100 & 10.30 & 20.00 & & 50.70 & & & & & 1.50 & 2.30 & 0.15 & & & & 15.00 & 0.002 & 0.008 & & \\
\hline Haynes 188 & 0.100 & 22.00 & 22.00 & & 37.27 & & & & & 1.25 & 3.00 & 0.35 & & & & 14.00 & & & & 0.03 \\
\hline Haynes 214 & 0.050 & 75.63 & 16.00 & & & 4.50 & & & & 0.50 & 3.00 & 0.20 & 0.010 & & 0.100 & & & & & 0.01 \\
\hline Haynes 230 & 0.100 & 52.66 & 22.00 & 2.00 & 5.00 & 0.30 & & & & 0.50 & 3.00 & 0.40 & 0.015 & & & 14.00 & & & & 0.02 \\
\hline Haynes 263 & 0.060 & 49.24 & 20.00 & 6.00 & 20.00 & 0.60 & 2.40 & & & 0.60 & 0.70 & 0.40 & & & & & & & & \\
\hline Haynes 282 & 0.060 & 56.38 & 19.50 & 8.50 & 10.00 & 1.50 & 2.10 & & & 0.30 & 1.50 & 0.15 & 0.005 & & & & & & & \\
\hline 901 & 0.050 & 42.53 & 12.50 & 5.70 & & 0.20 & 2.80 & & & 0.10 & 36.00 & 0.10 & 0.015 & & & & & & & \\
\hline Udimet 700 & 0.150 & 50.83 & 15.00 & 5.00 & 17.00 & 4.25 & 3.25 & & & 0.15 & 4.00 & 0.20 & 0.050 & 0.10 & 0.006 & & 0.015 & & & \\
\hline Udimet 720 & 0.015 & 57.43 & 16.00 & 3.00 & 14.75 & 2.50 & 5.00 & & & & & & 0.015 & & 0.038 & 1.25 & & & & \\
\hline $\begin{array}{c}\text { Udimet } \\
\text { 720Li }\end{array}$ & 0.025 & 57.40 & 16.20 & 3.02 & 14.60 & 2.44 & 4.95 & & & & & & 0.016 & & 0.037 & 1.31 & & & & \\
\hline Pyromet 41 & 0.090 & 50.30 & 19.00 & 9.75 & 11.00 & 1.50 & 3.15 & & & 0.10 & 5.00 & 0.10 & 0.007 & & & & & & & \\
\hline René 88 & 0.045 & 56.39 & 16.00 & 4.00 & 13.00 & 2.10 & 3.70 & 0.70 & & & & & 0.016 & & 0.045 & 4.00 & & & & \\
\hline Astroloy & 0.060 & 54.39 & 15.00 & 5.00 & 17.00 & 4.00 & 3.50 & & & 0.15 & 0.50 & 0.20 & 0.025 & 0.10 & 0.060 & & 0.015 & & & \\
\hline Waspaloy & 0.080 & 56.21 & 19.00 & 4.30 & 13.50 & 1.50 & 3.00 & & & 0.10 & 2.00 & 0.15 & 0.006 & 0.10 & 0.050 & & & & & \\
\hline $\begin{array}{c}\text { Nimonic } \\
105\end{array}$ & 0.120 & 55.89 & 14.88 & & 20.00 & 4.70 & 1.20 & & & 1.00 & 1.00 & 1.00 & 0.007 & 0.20 & 0.150 & & 0.010 & & & \\
\hline GTD 222 & 0.100 & 50.69 & 22.50 & 0.09 & 19.00 & 1.20 & 2.35 & 1.00 & 1.00 & & 0.10 & & 0.009 & & 0.015 & 2.00 & 0.002 & & & \\
\hline
\end{tabular}


Table 1B: Physical, Mechanical, Microstructure and Processing Properties of Potential Alloys for $1400^{\circ} \mathrm{F}$ Rotor and Other Forged Components

\begin{tabular}{|c|c|c|c|c|c|c|c|c|c|c|}
\hline Alloys & Condition & $\begin{array}{c}\text { Overage } \\
\text { Potential @ } \\
1450^{\circ} \mathrm{F}\end{array}$ & $\begin{array}{c}\text { ASTM } \\
\text { Grain Size }\end{array}$ & $\begin{array}{c}\text { Critical GG } \\
\text { (ASTM) }\end{array}$ & $\begin{array}{l}\text { Precipitation } \\
\text { Kinetics }\end{array}$ & $\begin{array}{c}\text { Phase } \\
\text { Stability }\end{array}$ & $\begin{array}{l}\text { Strengthening } \\
\text { Strategy }\end{array}$ & $\begin{array}{c}\gamma^{\prime}-\gamma^{\prime \prime} \\
\text { Formation } \\
\text { Range }\left({ }^{\circ} \mathrm{F}\right)\end{array}$ & $\begin{array}{c}\gamma^{\prime} \text { Solvus } \\
\left({ }^{\circ} \mathrm{F}\right)\end{array}$ & $\begin{array}{c}\text { TC Pred Eq. } \\
\gamma^{\prime} \text { Solvus } \\
\left({ }^{\circ} \mathrm{F}\right)\end{array}$ \\
\hline 155 & Conventional & & & & & & & & & NP \\
\hline CA617 & Conventional & & & No & & $\mathrm{M}_{23} \mathrm{C}_{6}$ & SS & & & 1490 \\
\hline 625 & Conventional & & & No & Slow & & SS \& PPT & & & 1444 \\
\hline 718 & Conventional & & & No & & $\delta-\mathrm{Ni}_{3} \mathrm{Nb}$ & PPT & $1300-1650$ & & $\mathrm{NP}$ \\
\hline 718 Plus & Conventional & & & No & Slow & & PPT & & & 1828 \\
\hline 740 & Conventional & $\begin{array}{c}\gamma^{\prime} \text { coarsens } \\
\text { rapidly at } 1475\end{array}$ & & & & $\begin{array}{l}\text { १; G phase; } \\
\text { MC; } \mathrm{M}_{23} \mathrm{C}_{6}\end{array}$ & PPT & & & 1600 \\
\hline Haynes 25 & Conventional & & & & & $\mathrm{Co}_{2} \mathrm{~W} ; \mathrm{Co}_{3} \mathrm{~W}$ & SS \& Carbide & & & NP \\
\hline Haynes 188 & Conventional & & & $\begin{array}{c}1-3 \text { after } 24 \mathrm{~h} \text { at } \\
2200\end{array}$ & & $\mathrm{Co}_{2} \mathrm{~W}$ & & & & NP \\
\hline Haynes 214 & Conventional & & & & & & & & 1750 & 1748 \\
\hline Haynes 230 & Conventional & & & $\begin{array}{c}4 / 4.5 \text { after } 24 \mathrm{~h} \text { at } \\
2200\end{array}$ & & & SS & & & NP \\
\hline Haynes 263 & Conventional & & & & & & PPT & & & 1603 \\
\hline 901 & Conventional & & & & & & PPT & & & NP \\
\hline Udimet 700 & Conventional & & & & & $\sigma$ & PPT & & & 2026 \\
\hline Udimet 720 & Conventional & & $3 / 4$ to $9 / 10$ & & & $\sigma ; \mathrm{M}_{23}(\mathrm{C}, \mathrm{B})_{6}$ & PPT & & 2107 & 2115 \\
\hline Udimet 720Li & Conventional & & $8 / 9$ & Rapid $>$ solvus & & & PPT & & & 2106 \\
\hline Pyromet 41 & Conventional & & & Yes $>\gamma^{\prime}$ solvus & Fast & & PPT & & $1960-1980$ & 1924 \\
\hline René 88 & Conventional & & & & & $\begin{array}{c}\text { M3B2; } \mu ; \\
\text { M }_{23} \mathrm{C}_{6}\end{array}$ & PPT & & 2065 & 2028 \\
\hline Astroloy & Conventional & & & & & $\sigma$ & PPT & & 2100 & 2079 \\
\hline Waspaloy & Conventional & & $0 / 00$ to $8 / 9$ & $0 / 00>4 \mathrm{~h}$ at 2200 & Fast & & PPT & & & 1879 \\
\hline Nimonic 105 & Conventional & & & & & & SS \& PPT & & & 1845 \\
\hline GTD 222 & Conventional & & $\begin{array}{l}00 / 4 \text { low } C \\
6 / 7 \text { high } C\end{array}$ & & & & PPT & & $\begin{array}{l}1820-1845 \\
1855-1881\end{array}$ & 1826 \\
\hline
\end{tabular}


Table 1B: Physical, Mechanical, Microstructure and Processing Properties of Potential Alloys for $1400^{\circ} \mathrm{F}$ Rotor and Other Forged Components

\begin{tabular}{|c|c|c|c|c|c|c|c|c|c|c|}
\hline Alloys & $\begin{array}{c}\gamma^{\prime \prime} \text { Solvus } \\
\left({ }^{\circ} \mathrm{F}\right)\end{array}$ & $\begin{array}{c}\text { TC Pred Eq. } \\
\gamma^{\prime \prime} \text { Solvus }\left({ }^{\circ} \mathrm{F}\right)\end{array}$ & $\begin{array}{c}\text { Est } \gamma^{\prime} \\
\text { Volume } \\
\text { Fraction }\end{array}$ & $\begin{array}{c}\text { TC Pred Eq. } \\
\gamma^{\prime} \text { Volume } \\
\text { Fraction }\end{array}$ & $\begin{array}{c}\text { Est } \gamma^{\prime \prime} \\
\text { Volume } \\
\text { Fraction }\end{array}$ & $\begin{array}{c}\text { TC Pred Eq. } \\
\gamma^{\prime \prime} \text { Volume } \\
\text { Fraction }\end{array}$ & $\begin{array}{c}\text { Incipient } \\
\text { Melting Point } \\
\left({ }^{\circ} \mathrm{F}\right)\end{array}$ & $\begin{array}{l}\text { TC Pred Eq. } \\
\text { Incipient } \\
\text { Melting Point }\end{array}$ & $\begin{array}{l}\text { TCP } \\
\text { Phase }\end{array}$ & $\begin{array}{c}\text { TC Pred TCP } \\
\text { Solvus } \\
\left({ }^{\circ} \mathrm{F}\right) \\
\end{array}$ \\
\hline 155 & & NP & & NP & & NP & & 2312 & & 1633 \\
\hline CA617 & & NP & & 8.7 & & $\mathrm{NP}$ & 2430 & 2339 & & \\
\hline 625 & & 1539 & & 4.9 & & 6.9 & 2350 & 2251 & & 1706 \\
\hline 718 & 1675 & 1713 & & $\mathrm{NP}$ & & 10.9 & & 2156 & & 1858 \\
\hline 718 Plus & & 1663 & & 23.4 & & 4.0 & & 2182 & & 1884 \\
\hline 740 & & NP & 17 & 22.5 & & $\mathrm{NP}$ & & 2324 & & 2013 \\
\hline Haynes 25 & & NP & & NP & & NP & & & & \\
\hline Haynes 188 & & NP & & NP & & NP & 2375 & 2332 & & 1951 \\
\hline Haynes 214 & & NP & & 55.1 & & NP & & 2339 & & NP \\
\hline Haynes 230 & & NP & & $\mathrm{NP}$ & & NP & & 2319 & & 1785 \\
\hline Haynes 263 & & NP & & 17.0 & & NP & & 2345 & & 1803 \\
\hline Haynes 282 & & NP & & 23.7 & & NP & & 2296 & & 1607 \\
\hline 901 & & NP & & NP & & NP & & 2280 & & \\
\hline Udimet 720 & & NP & 38 & 47.3 & & NP & & 2317 & & 1483 \\
\hline Udimet 720Li & & NP & 20 & 46.6 & & NP & & 2318 & & \\
\hline Pyromet 41 & & NP & & 29.2 & & NP & 2250 & 2266 & & \\
\hline René 88 & & NP & 40 & 40.2 & & NP & & 2306 & & 1556 \\
\hline Astroloy & & NP & 45 & 54.5 & & NP & & 2309 & & 1693 \\
\hline Waspaloy & & NP & 22 & 27.9 & & NP & 2425 & 2309 & & 1319 \\
\hline Nimonic 105 & & NP & & 11.1 & & $\mathrm{NP}$ & 2354 & 2329 & & \\
\hline GTD 222 & & NP & & 24.6 & & NP & & 2334 & & 1947 \\
\hline
\end{tabular}


Table 1B: Physical, Mechanical, Microstructure and Processing Properties of Potential Alloys for $\mathbf{1 4 0 0}^{\circ} \mathrm{F}$ Rotor and Other Forged Components

\begin{tabular}{|c|c|c|c|c|c|c|c|c|c|c|}
\hline Alloys & $\begin{array}{c}\text { TC } \\
\text { Predicted } \\
\text { Max TCP } \\
\text { Mole \% } \\
\end{array}$ & $\begin{array}{c}1450^{\circ} \mathrm{F} \\
0.2 \% \mathrm{YS}\end{array}$ & $\begin{array}{c}1450^{\circ} \mathrm{F} \\
\text { UTS }\end{array}$ & $\begin{array}{c}\text { Stress For } \\
\text { Rupture in } \\
1000 \mathrm{~h} \text { at } \\
1400^{\circ} \mathrm{F}\end{array}$ & $\begin{array}{l}\text { Rupture Life at } \\
1400^{\circ} \mathrm{F} \& 15 \mathrm{ksi}\end{array}$ & $\begin{array}{c}100,000 \text { h } \\
\text { Rupture at } \\
1400^{\circ} \mathrm{F} \text { (ksi) }\end{array}$ & $\begin{array}{c}100,000 \text { h } \\
\text { Rupture at } \\
1350^{\circ} \mathrm{F} \text { (ksi) }\end{array}$ & $\begin{array}{l}20 \mathrm{cpm} \\
\left(10^{6}\right) \text { at } \\
1400^{\circ} \mathrm{F}\end{array}$ & $\begin{array}{c}\mathrm{HCF}\left(10^{7}\right) \\
\text { at } 1200^{\circ} \mathrm{F} \\
(\mathrm{a}=\mathrm{inf})\end{array}$ & $\begin{array}{l}\text { Hold } \\
\text { Time }\end{array}$ \\
\hline 617 & 10.5 & 40 & 78 & 22 & {$[\sim 10,000-$ ORNL $]$} & 13 [10.1-ORNL] & [13.5-ORNL] & & & \\
\hline CA617 & & & & [28-ORNL] & [ 12,000-ORNL] & [10.1-ORNL] & $\begin{array}{l}\text { [14.0-ORNL; } \\
\text { 14.5-AD700] }\end{array}$ & & & \\
\hline 625 & 18.3 & 50 & 87 & 23 & 19,000 & 12 & 16 & & 45 & Excellent \\
\hline 718 & 13.6 & $110-115$ & $125-150$ & $25-28$ & & & & & 88 & Very Good \\
\hline 718 Plus & 11.3 & 120 & 140 & & & & & & & \\
\hline 740 & 24.3 & 88 & 111 & [38.7-ORNL] & 124,000 & 21 [16.2-ORNL] & 22 [22.7-ORNL] & & & \\
\hline Haynes 25 & & 35 & 80 & [25.3-ORNL] & {$[30,000-\mathrm{ORNL}]$} & [12.1-ORNL] & [15.2-ORNL] & & & \\
\hline Haynes 188 & 11.3 & $36-39$ & $70-95$ & $24-26$ & 35,000 & & & & & \\
\hline Haynes 214 & NP & 74 & 97 & 24 & 6,000 & & & & & \\
\hline Haynes 230 & 8.7 & 37 & 77 & 20 & 8,200 & [10.2-ORNL] & [12.8-ORNL] & & & \\
\hline Haynes 263 & 14.8 & 75 & 105 & 28 & & & & & & \\
\hline 901 & & $90-92$ & 105 & 30 & & & & & & \\
\hline Udimet 700 & & $120-125$ & 150 & $58-62$ & & & & & $>50$ & \\
\hline Udimet 720 & 8.3 & $105-140$ & $150-170$ & $67-70$ & & & & & & \\
\hline \multicolumn{11}{|l|}{ Udimet 720Li } \\
\hline Pyromet 41 & & $130-135$ & 160 & $40-50$ & & & & & & \\
\hline René 88 & 7.1 & 140 & $145-170$ & & $>30,000$ & & & & & \\
\hline Astroloy & 14.2 & $85-130$ & $125-150$ & $40-60$ & & 32 & 40 & & & \\
\hline Waspaloy & 3.8 & $85-135$ & $120-170$ & $35-42$ & & 15 & 22 & 48 & & \\
\hline Nimonic 105 & & $105-110$ & $135-145$ & 48 & $>100,000$ & 25 & & & 40 & \\
\hline GTD 222 & 7.2 & 93 & 118 & & & & & & & \\
\hline
\end{tabular}


Table 1B: Physical, Mechanical, Microstructure and Processing Properties of Potential Alloys for $1400^{\circ} \mathrm{F}$ Rotor and Other Forged Components

\begin{tabular}{|c|c|c|c|c|c|c|c|c|}
\hline Alloys & $\begin{array}{c}\text { Process } \\
\text { Route }\end{array}$ & $\begin{array}{c}\text { Ingot } \\
\text { Diameter }\end{array}$ & $\begin{array}{c}\text { Forging } \\
\text { Temp }\end{array}$ & $\begin{array}{l}\text { Solution } \\
\text { Heat Treat }\end{array}$ & $\begin{array}{c}\text { Relative } \\
\text { Cost }\end{array}$ & $\begin{array}{l}\text { Thermal } \\
\text { Expansion } \\
\text { at } 1400^{\circ} \mathrm{F}\end{array}$ & $\begin{array}{l}\text { Oxidation } \\
\text { at } 1800^{\circ} \mathrm{F} \\
\text { (mils) }\end{array}$ & General Comments \\
\hline 155 & $C \& W$ & & 2200 & $2100-2280$ & Low & 9.8 & & $\begin{array}{l}\text { Haynes Multimet Alloy at a Glance; Haynes Multimet } \\
\text { Technical Information (1988). }\end{array}$ \\
\hline 617 & C \& W & $28-40$ & $1850-2200$ & 2150 & Medium-Low & 8.4 & 1.3 & ASMH; H617 at a Glance; SM IN617. \\
\hline CA617 & $\mathrm{C} \& \mathrm{~W}$ & & $1850-2200$ & & Medium-Low & 8.4 & & Open Literature. \\
\hline 625 & $\mathrm{C} \& \mathrm{~W}$ & $28-40$ & $1800-2150$ & $2000-2200$ & Medium-Low & 8.7 & 0.7 & $\begin{array}{l}\text { ASMN; AL 625HP; AL Altemp 625; CarTech P625; SM } \\
\text { IN625; SM IN625LCF; H625SQ at a Glance; H625 } \\
\text { Technical Information. }\end{array}$ \\
\hline 718 & C \& W & 36 & $1650-2050$ & $1700-1850$ & Medium-Low & 8.9 & & $\begin{array}{l}\text { ASMH; Allvac } 718 \text { \& 718-OP; CarTech P718; AL Altemp } \\
\text { 718; SM IN718 \& 718SPF; H718. }\end{array}$ \\
\hline 718 Plus & $\mathrm{C} \& \mathrm{~W}$ & & $1800-2025$ & $1750-1800$ & Medium-Low & 8.5 & & Allvac 718 Plus. \\
\hline 740 & $\mathrm{C} \& \mathrm{~W}$ & & & 2100 & High & 8.6 & & SM datasheet for IN740 \& ORNL Creep Data. \\
\hline Haynes 25 & $\mathrm{C} \& \mathrm{~W}$ & & & & Medium & & & ORNL Database. \\
\hline Haynes 188 & $\mathrm{C} \& \mathrm{~W}$ & & 2150 & 2150 & Medium & 9.0 & 0.6 & $\begin{array}{l}\text { SM U188; H188 Alloy at a Glance; and H188 Product } \\
\text { Brochure. }\end{array}$ \\
\hline Haynes 214 & $\mathrm{C} \& \mathrm{~W}$ & & $1800-2200$ & 2000 & Medium & 9.0 & 0.2 & H214 Hot Working; H214 Product Brochure. \\
\hline Haynes 230 & $C \& W$ & & $2150-2275$ & & Medium & 8.3 & 0.7 & $\begin{array}{l}\text { H230 Product Brochure; H230 Tech Brief; Alloy } 230 \text { for } \\
\text { Gas Turbine \& Aerospace Applications (1990). }\end{array}$ \\
\hline Haynes 263 & $\mathrm{C} \& \mathrm{~W}$ & & $1750-2100$ & 2100 & Medium & 8.3 & 1.1 & H263 Product Brochure; SM N263. \\
\hline Haynes 282 & C \& W & 20 & & 2125 & High & 8.1 & 0.2 & $\begin{array}{l}\text { H282 Alloys at a Glance and H282 Alloy 'Preliminary } \\
\text { Data' - Oct 5, } 2005 .\end{array}$ \\
\hline 901 & $\mathrm{C} \& \mathrm{~W}$ & & $1740-2100$ & $1975-2025$ & Low & 9.2 & & ASMH; SM datasheet for N901. \\
\hline Udimet 700 & $\mathrm{C}$ & & & & High & 8.4 & & ASMH. \\
\hline Udimet 720 & C \& W & & & $\begin{array}{l}\text { SubS:2020 } \\
\text { SuperS: } 2135\end{array}$ & High & & & SM datasheet for U720; superalloy literature. \\
\hline Udimet 720Li & $\mathrm{C} \& \mathrm{~W}$ & & $1900-2100$ & $2020-2075$ & High & & & Open Literature. \\
\hline Pyromet 41 & $\mathrm{C} \& \mathrm{~W}$ & & $1875-2100$ & $1900-2100$ & High & 8.2 & & CarTech P41; Haynes R41 Technical Literature; SM U41. \\
\hline René 88 & $\mathrm{PM}$ & & & & High & & & Superalloy literature. \\
\hline Astroloy & $\mathrm{PM}$ & & $1850-2150$ & & High & 8.6 & & Allvac technical data sheet. \\
\hline Waspaloy & C \& W & & $1800-2150$ & $1825-1900$ & Medium & 8.4 & 0.9 & $\begin{array}{l}\text { ASMH; Allvac Waspaloy; Haynes Waspaloy at a Glance; } \\
\text { CarTech Waspaloy. }\end{array}$ \\
\hline Nimonic 105 & $\mathrm{C} \& \mathrm{~W}$ & & $1825-2240$ & & High & 8.3 & & ASMH; SM datasheet for N105. \\
\hline GTD 222 & C \& W & & & $2000-2150$ & High & 8.8 & & Open Literature. \\
\hline
\end{tabular}


Table 1C: Phase Formation Potential for Candidate Alloys for $1400^{\circ}$ F Rotor and Other Forged Components

\begin{tabular}{|c|c|c|c|c|c|c|c|c|c|c|}
\hline Alloys & $\begin{array}{c}\eta \text { Upper } \\
\left({ }^{\circ} \mathrm{F}\right)\end{array}$ & $\begin{array}{c}\eta \text { Lower } \\
\left({ }^{\circ} \mathrm{F}\right)\end{array}$ & $\begin{array}{c}\eta \text { Span } \\
\left({ }^{\circ} \mathrm{F}\right)\end{array}$ & $\begin{array}{c}\eta \mathrm{Max} . \mathrm{NP} \\
(\%)\end{array}$ & $\begin{array}{c}\delta \text { Upper } \\
\left({ }^{\circ} \mathrm{F}\right)\end{array}$ & $\begin{array}{c}\delta \text { Max. NP } \\
(\%)\end{array}$ & $\begin{array}{c}\sigma \text { Upper } \\
\left({ }^{\circ} \mathrm{F}\right)\end{array}$ & $\begin{array}{c}\sigma \text { Lower } \\
\left({ }^{\circ} \mathrm{F}\right)\end{array}$ & $\begin{array}{c}\sigma \text { Span } \\
\left({ }^{\circ} \mathrm{F}\right)\end{array}$ & $\begin{array}{c}\sigma \text { Max. NP } \\
(\%)\end{array}$ \\
\hline 155 & & & & & & & 1464 & & & 10.2 \\
\hline \multicolumn{11}{|l|}{617} \\
\hline \multicolumn{11}{|l|}{ CA617 } \\
\hline 625 & & & & & 1721 & 8.5 & 1669 & 1387 & 314 & 6.1 \\
\hline 718 & 1641 & & & 6.2 & 1858 & 12.6 & 1498 & & & 7.4 \\
\hline \multicolumn{11}{|l|}{718 Plus } \\
\hline 740 & 2013 & 1127 & 918 & 12.9 & & & 1374 & & & 11.4 \\
\hline \multicolumn{11}{|l|}{ Haynes 25} \\
\hline \multicolumn{11}{|l|}{ Haynes 188} \\
\hline \multicolumn{11}{|l|}{ Haynes 214} \\
\hline \multicolumn{11}{|l|}{ Haynes 230} \\
\hline Haynes 263 & 1803 & & & 7.5 & & & & & & \\
\hline Haynes 282 & & & & & & & 1607 & & & 5.1 \\
\hline 901 & 1798 & & & 13.4 & & & 1664 & & & 3.0 \\
\hline Udimet 700 & & & & & & & 1669 & & & 11.1 \\
\hline Udimet 720 & & & & & & & 1483 & & & 7.2 \\
\hline Udimet 720Li & & & & & & & 1469 & & & 6.9 \\
\hline Pyromet 41 & & & & & & & 1953 & & & 16.1 \\
\hline René 88 & & & & & & & 1230 & & & 2.0 \\
\hline Astroloy & & & & & & & 1693 & & & 10.3 \\
\hline Waspaloy & & & & & & & 1172 & & & 0.6 \\
\hline \multicolumn{11}{|l|}{ Nimonic 105} \\
\hline GTD 222 & 1947 & & & 5.3 & & & 1163 & & & 1.9 \\
\hline
\end{tabular}


Table 1C: Phase Formation Potential for Candidate Alloys for $1400^{\circ} \mathrm{F}$ Rotor and Other Forged Components

\begin{tabular}{|c|c|c|c|c|c|c|c|c|c|c|}
\hline Alloys & $\begin{array}{c}\mu \text { Upper } \\
\left({ }^{\circ} \mathrm{F}\right)\end{array}$ & $\begin{array}{c}\mu \mathrm{Max} . \mathrm{NP} \\
(\%)\end{array}$ & $\begin{array}{l}\text { P Upper } \\
\left({ }^{\circ} \mathrm{F}\right)\end{array}$ & $\begin{array}{c}\text { P Lower } \\
\left({ }^{\circ} \mathrm{F}\right)\end{array}$ & $\begin{array}{c}\text { P Span } \\
\left({ }^{\circ} \mathrm{F}\right)\end{array}$ & $\begin{array}{c}\text { P Max. NP } \\
(\%)\end{array}$ & $\begin{array}{c}\text { MC Upper } \\
\left({ }^{\circ} \mathrm{F}\right)\end{array}$ & $\begin{array}{c}\text { MC Lower } \\
\left({ }^{\circ} \mathrm{F}\right)\end{array}$ & $\begin{array}{c}\text { MC Span } \\
\left({ }^{\circ} \mathrm{F}\right)\end{array}$ & $\begin{array}{c}\text { MC Max. NP } \\
(\%)\end{array}$ \\
\hline 155 & 1555 & 1.6 & & & & & 2433 & & & 1.5 \\
\hline 617 & 1488 & 10.5 & & & & & & & & \\
\hline CA617 & 1452 & 9.1 & & & & & 2732 & & & 0.1 \\
\hline 625 & 1457 & 11.7 & & & & & 2732 & & & 0.2 \\
\hline 718 & & & & & & & 2324 & 1336 & 1021 & 0.5 \\
\hline \multicolumn{11}{|l|}{718 Plus } \\
\hline \multicolumn{11}{|l|}{ Haynes 25} \\
\hline Haynes 188 & 1950 & 11.3 & & & & & & & & \\
\hline Haynes 214 & & & & & & & 2103 & 1561 & 574 & 0.04 \\
\hline Haynes 230 & 1142 & 0.6 & 1785 & & & 8.1 & & & & \\
\hline Haynes 263 & 1514 & 7.3 & & & & & 2357 & 1693 & 696 & 0.6 \\
\hline Haynes 282 & 1462 & 10.4 & & & & & 2350 & 1911 & 471 & 0.4 \\
\hline 901 & 1624 & 2.6 & & & & & 2367 & 1551 & 849 & 0.5 \\
\hline Udimet 700 & 1295 & 2.3 & & & & & 2415 & 1810 & 637 & 1.4 \\
\hline Udimet 720Li & 1227 & 1.1 & & & & & 2378 & 1784 & 626 & 0.2 \\
\hline Pyromet 41 & 1400 & 9.8 & & & & & 2344 & 1789 & 587 & 0.9 \\
\hline René 88 & 1535 & 4.8 & 1556 & 1527 & 61 & 0.2 & 2385 & 1761 & 656 & 0.4 \\
\hline Astroloy & 1424 & 3.9 & & & & & 2395 & 1755 & 672 & 0.6 \\
\hline Waspaloy & 1319 & 3.2 & & & & & 2395 & 1755 & 672 & 0.7 \\
\hline \multicolumn{11}{|l|}{ Nimonic 105} \\
\hline GTD 222 & & & & & & & 2419 & 1203 & 1247 & 1.0 \\
\hline
\end{tabular}


Table 1C; Phase Formation Potential for Candidate Alloys for $1400^{\circ} \mathrm{F}$ Rotor and Other Forged Components

\begin{tabular}{|c|c|c|c|c|c|c|c|c|c|c|}
\hline Alloys & $\begin{array}{c}\mathrm{M}_{23} \mathrm{C}_{6} \text { Upper } \\
\left({ }^{\circ} \mathrm{F}\right)\end{array}$ & $\begin{array}{c}\mathrm{M}_{23} \mathrm{C}_{6} \text { Max. NP } \\
(\%)\end{array}$ & $\begin{array}{c}\mathrm{M}_{6} \mathrm{C} \text { Lower } \\
\left({ }^{\circ} \mathrm{F}\right)\end{array}$ & $\begin{array}{c}\mathrm{M}_{6} \mathrm{C} \text { Lower } \\
\left({ }^{\circ} \mathrm{F}\right)\end{array}$ & $\begin{array}{c}\mathrm{M}_{6} \mathrm{C} \text { Span } \\
\left({ }^{\circ} \mathrm{F}\right)\end{array}$ & $\begin{array}{c}\mathrm{M}_{6} \mathrm{C} \text { Max. NP } \\
(\%)\end{array}$ & $\begin{array}{c}\mathrm{M}_{7} \mathrm{C}_{3} \text { Upper } \\
\left({ }^{\circ} \mathrm{F}\right)\end{array}$ & $\begin{array}{c}\mathrm{M}_{7} \mathrm{C}_{3} \text { Lower } \\
\left({ }^{\circ} \mathrm{F}\right) \\
\end{array}$ & $\begin{array}{c}\mathrm{M}_{7} \mathrm{C}_{3} \text { Span } \\
\left({ }^{\circ} \mathrm{F}\right)\end{array}$ & $\begin{array}{c}\mathrm{M}_{7} \mathrm{C}_{3} \text { Max. NP } \\
(\%) \\
\end{array}$ \\
\hline 155 & 2074 & 2.5 & 1790 & 1529 & 293 & 0.8 & & & & \\
\hline 617 & 1905 & 1.6 & 2371 & 1481 & 922 & 2.1 & & & & \\
\hline CA617 & 1892 & 1.4 & 2352 & 1450 & 933 & 1.7 & & & & \\
\hline 625 & 1473 & 0.7 & 2245 & 1456 & 821 & 1.0 & & & & \\
\hline 718 & 1345 & 1.2 & & & & & & & & \\
\hline \multicolumn{11}{|l|}{718 Plus } \\
\hline \multicolumn{11}{|l|}{ Haynes 25} \\
\hline Haynes 188 & 2202 & 2.5 & 2318 & 1921 & 430 & 1.6 & & & & \\
\hline Haynes 214 & 1606 & 1.3 & & & & & 2415 & 1583 & 864 & 0.9 \\
\hline Haynes 230 & 1598 & 2.5 & 2435 & 1467 & 1000 & 3.6 & & & & \\
\hline Haynes 263 & 1699 & 1.4 & & & & & & & & \\
\hline Haynes 282 & 1593 & 1.4 & 2146 & 1461 & 716 & 2.0 & & & & \\
\hline 901 & & & 1592 & & & 1.7 & & & & \\
\hline Udimet 700 & 1842 & 3.3 & & & & & & & & \\
\hline Udimet 720Li & 1788 & 0.6 & & & & & & & & \\
\hline Pyromet 41 & 1719 & 2.1 & 1863 & 1491 & 404 & 3.0 & & & & \\
\hline René 88 & 1774 & 1.1 & & & & & & & & \\
\hline Astroloy & 1871 & 1.3 & & & & & & & & \\
\hline Waspaloy & 1773 & 1.8 & & & & & 1822 & & & 1.3 \\
\hline \multicolumn{11}{|l|}{ Nimonic 105} \\
\hline GTD 222 & 1570 & 2.5 & & & & & & & & \\
\hline
\end{tabular}


Table 1C: Phase Formation Potential for Candidate Alloys for $1400^{\circ} \mathrm{F}$ Rotor and Other Forged Components

\begin{tabular}{|c|c|c|c|c|c|c|}
\hline Alloys & $\begin{array}{c}\mathrm{M}_{3} \mathrm{~B}_{2} \text { Upper } \\
\left({ }^{\circ} \mathrm{F}\right)\end{array}$ & $\begin{array}{c}\mathrm{M}_{3} \mathrm{~B}_{2} \text { Max. NP } \\
(\%)\end{array}$ & $\begin{array}{c}\mathrm{MB}_{2}-\mathrm{C} 32 \text { Lower } \\
\left({ }^{\circ} \mathrm{F}\right)\end{array}$ & $\begin{array}{c}\mathrm{MB}_{2}-\mathrm{C} 32 \text { Lower } \\
\left({ }^{\circ} \mathrm{F}\right)\end{array}$ & $\begin{array}{c}\mathrm{MB}_{2}-\mathrm{C} 32 \text { Span } \\
\left({ }^{\circ} \mathrm{F}\right)\end{array}$ & $\begin{array}{c}\mathrm{MB}_{2}-\mathrm{C} 32 \mathrm{Max} . \mathrm{NP} \\
(\%)\end{array}$ \\
\hline \multicolumn{7}{|l|}{155} \\
\hline \multicolumn{7}{|l|}{617} \\
\hline CA617 & 2225 & 0.04 & & & & \\
\hline \multicolumn{7}{|l|}{625} \\
\hline 718 & 2157 & 0.04 & 2186 & 2172 & 46 & 0.04 \\
\hline \multicolumn{7}{|l|}{718 Plus } \\
\hline \multicolumn{7}{|l|}{740} \\
\hline \multicolumn{7}{|l|}{ Haynes 25} \\
\hline \multicolumn{7}{|l|}{ Haynes 188} \\
\hline \multicolumn{7}{|l|}{ Haynes 214} \\
\hline Haynes 230 & 2320 & 0.22 & & & & \\
\hline \multicolumn{7}{|l|}{ Haynes 263} \\
\hline Haynes 282 & 2296 & 0.07 & & & & \\
\hline 901 & 2069 & 0.20 & 2286 & 2056 & 262 & 0.12 \\
\hline Udimet 700 & 2150 & 0.64 & 2350 & 2105 & 277 & 0.37 \\
\hline Udimet 720 & 1948 & 0.20 & 2333 & 1939 & 426 & 0.11 \\
\hline Udimet 720Li & 1946 & 0.21 & 2333 & 1937 & 429 & 0.12 \\
\hline Pyromet 41 & 2267 & 0.09 & & & & \\
\hline René 88 & 2012 & 0.22 & 2320 & 2006 & 347 & 0.12 \\
\hline Astroloy & 2121 & 0.32 & 2339 & 2101 & 269 & 0.19 \\
\hline Waspaloy & 2043 & 0.08 & 2312 & 2039 & 305 & 0.04 \\
\hline \multicolumn{7}{|l|}{ Nimonic 105} \\
\hline GTD 222 & & & 2337 & 1545 & 823 & 0.07 \\
\hline
\end{tabular}




\section{APPENDIX 2 \\ CHEMICAL COMPOSITION FOR CANDIDATE NICKEL SUPERALLOYS}


Table 2A: Chemical Composition for Haynes 282 Heats

\begin{tabular}{|c|c|c|c|c|c|c|c|c|c|c|c|c|c|c|c|c|c|c|c|c|c|c|c|c|c|c|c|c|c|c|c|c|c|c|}
\hline Heat & $\mathrm{Al}$ & $\mathrm{B}$ & $\mathrm{C}$ & $\mathrm{Co}$ & $\mathrm{Cr}$ & $\mathrm{Cu}$ & $\mathrm{Fe}$ & $\mathrm{Mn}$ & $\mathrm{Mo}$ & $\mathrm{Ni}$ & $\mathrm{P}$ & $\mathrm{S}$ & $\mathrm{Si}$ & $\mathrm{Ti}$ & $\mathrm{V}$ & $\mathrm{W}$ & $\mathrm{Nb}$ & $\mathrm{Ta}$ \\
\hline 8354 & 1.45 & 0.004 & 0.067 & 10.36 & 19.62 & $<0.01$ & 0.4 & 0.08 & 8.56 & $\mathrm{BAL}$ & 0.002 & 0.003 & 0.05 & 2.19 & & $<0.01$ & $<0.1$ & $<0.01$ \\
\hline 8356 & 1.41 & 0.004 & 0.054 & 10.17 & 19.17 & $<0.01$ & 1.18 & 0.05 & 8.47 & BAL & 0.003 & $<0.002$ & 0.05 & 2.11 & & $<0.01$ & $<0.1$ & $<0.01$ \\
\hline
\end{tabular}

Table 2B: Chemical Composition for Nimonic 105 Heats

\begin{tabular}{|c|c|c|c|c|c|c|c|c|c|c|c|c|c|c|c|c|c|c|c|c|c|c|c|c|c|}
\hline Heat & $\mathrm{Al}$ & $\mathrm{B}$ & $\mathrm{C}$ & $\mathrm{Co}$ & $\mathrm{Cr}$ & $\mathrm{Cu}$ & $\mathrm{Fe}$ & $\mathrm{Mn}$ & $\mathrm{Mo}$ & $\mathrm{Ni}$ & $\mathrm{P}$ & $\mathrm{S}$ & $\mathrm{Si}$ & $\mathrm{Ti}$ & $\mathrm{V}$ & $\mathrm{W}$ & $\mathrm{Nb}$ & $\mathrm{Zr}$ \\
\hline 5183 & 4.7 & 0.0053 & 0.13 & 19.4 & 15.49 & 0.02 & 0.55 & 0.08 & 5.09 & $\mathrm{BAL}$ & $<0.005$ & $<0.001$ & 0.16 & 1.29 & $<0.01$ & $<0.05$ & 0.02 & 0.108 \\
\hline 8356 & 4.73 & 0.0056 & 0.14 & 19.4 & 15.38 & 0.02 & 0.49 & 0.18 & 5.00 & $\mathrm{BAL}$ & $<0.005$ & $<0.001$ & 0.14 & 1.32 & $<0.01$ & $<0.05$ & 0.02 & 0.117 \\
\hline
\end{tabular}

Table 2C: Chemical Composition for Udimet 720Li Heat

\begin{tabular}{|c|c|c|c|c|c|c|c|c|c|c|c|c|c|c|c|c|c|c|c|c|c|c|c|c|c|}
\hline Heat & $\mathrm{Al}$ & $\mathrm{B}$ & $\mathrm{C}$ & $\mathrm{Co}$ & $\mathrm{Cr}$ & $\mathrm{Cu}$ & $\mathrm{Fe}$ & $\mathrm{Mn}$ & $\mathrm{Mo}$ & $\mathrm{Ni}$ & $\mathrm{P}$ & $\mathrm{S}$ & $\mathrm{Si}$ & $\mathrm{Ti}$ & $\mathrm{V}$ & $\mathrm{W}$ & $\mathrm{Nb}$ & $\mathrm{Zr}$ \\
\hline 23592 & 2.54 & 0.0153 & 0.012 & 14.82 & 15.62 & 0.01 & 0.14 & 0.01 & 3.01 & $\mathrm{BAL}$ & 0.001 & 0.0001 & 0.02 & 5.230 & 0.02 & 1.21 & 0.01 & 0.031 \\
\hline
\end{tabular}

Table 2D: Chemical Composition for Alloy 617 Heat

\begin{tabular}{|c|c|c|c|c|c|c|c|c|c|c|c|c|c|c|c|c|c|c|c|c|c|c|c|c|c|}
\hline Heat & $\mathrm{Al}$ & $\mathrm{B}$ & $\mathrm{C}$ & $\mathrm{Co}$ & $\mathrm{Cr}$ & $\mathrm{Cu}$ & $\mathrm{Fe}$ & $\mathrm{Mn}$ & $\mathrm{Mo}$ & $\mathrm{Ni}$ & $\mathrm{P}$ & $\mathrm{S}$ & $\mathrm{Si}$ & $\mathrm{Ti}$ & $\mathrm{V}$ & $\mathrm{W}$ & $\mathrm{Nb}$ & $\mathrm{Zr}$ \\
\hline 8838 & 1.07 & $<0.002$ & 0.080 & 12.30 & 22.10 & 0.02 & 1.13 & 0.07 & 9.49 & $\mathrm{BAL}$ & 0.002 & $<0.002$ & 0.06 & 0.38 & & & & & \\
\hline
\end{tabular}




\section{APPENDIX 3 \\ TENSILE MECHANICAL PROPERTIES FOR CANDIDATE NICKEL SUPERALLOYS}


Table 3A: Tensile Properties for Haynes 282: GE \& SW Testing

\begin{tabular}{|c|c|c|c|c|c|c|}
\hline $\begin{array}{c}\text { Heat } \\
\text { No. }\end{array}$ & $\begin{array}{c}\text { Processing } \\
\text { Condition }\end{array}$ & $\begin{array}{c}\text { Test Temp } \\
\left({ }^{\circ} \mathrm{F}\right)\end{array}$ & $\begin{array}{c}\text { UTS } \\
(\mathrm{ksi})\end{array}$ & $\begin{array}{c}0.2 \% \text { YS } \\
(\mathrm{ksi})\end{array}$ & $\begin{array}{c}\text { Elongation } \\
(\%)\end{array}$ & $\begin{array}{c}\text { RA } \\
(\%)\end{array}$ \\
\hline 8354GE & SA & 75 & 140.0 & 81.3 & 51.6 & 49.1 \\
\hline 8354GE & PA & 75 & 172.8 & 104.7 & 29.5 & 26.4 \\
\hline 8356GE & PA & 75 & 174.0 & 106.0 & 30.0 & 26.0 \\
\hline 8354SW & PA & 75 & 168.8 & 103.2 & 24.0 & 24.0 \\
\hline 8354GE & OA & 75 & 174.6 & 104.7 & 29.5 & 27.2 \\
\hline 8354GE & SA & 400 & 124.6 & 69.1 & 55.6 & 47.4 \\
\hline 8354GE & PA & 400 & 160.5 & 94.7 & 22.5 & 22.9 \\
\hline 8356GE & PA & 400 & 155.0 & 93.5 & 18.0 & 21.0 \\
\hline 8354GE & OA & 400 & 166.1 & 98.7 & 21.2 & 24.6 \\
\hline 8354GE & SA & 800 & 116.1 & 68.6 & 60.5 & 48.3 \\
\hline 8354GE & PA & 800 & 151.3 & 94.6 & 33.1 & 31.8 \\
\hline 8356GE & PA & 800 & 150.0 & 99.5 & 19.0 & 19.0 \\
\hline 8354GE & OA & 800 & 151.4 & 95.9 & 19.4 & 23.3 \\
\hline 8354GE & SA & 1200 & 104.1 & 63.8 & 43.4 & 47.7 \\
\hline 8354GE & PA & 1200 & 157.7 & 92.0 & 21.7 & 25.6 \\
\hline 8356GE & PA & 1200 & 151.0 & 91.5 & 50.0 & 43.0 \\
\hline 8354GE & OA & 1200 & 159.7 & 92.5 & 25.1 & 21.0 \\
\hline 8354SW & PA & 1292 & 147.1 & 94.1 & 19.5 & 21.0 \\
\hline 8354SW & PA & 1292 & 147.6 & 93.8 & 20.0 & 22.5 \\
\hline 8354GE & SA & 1300 & 114.0 & 84.1 & 29.5 & 25.2 \\
\hline 8354GE & PA & 1300 & 147.3 & 93.4 & 26.9 & 29.0 \\
\hline 8356GE & PA & 1300 & 135.0 & 89.5 & 51.0 & 49.0 \\
\hline 8354GE & OA & 1300 & 155.6 & 97.4 & 30.1 & 30.1 \\
\hline 8354SW & PA & 1382 & 127.3 & 92.9 & 18.0 & 24.0 \\
\hline 8354SW & PA & 1382 & 129.9 & 93.2 & 20.0 & 23.0 \\
\hline 8354GE & SA & 1400 & 96.3 & 69.0 & 24.0 & 26.3 \\
\hline 8354GE & PA & 1400 & 121.0 & 94.0 & 31.7 & 35.8 \\
\hline 8356GE & PA & 1400 & 112.0 & 91.5 & 51.0 & 51.0 \\
\hline 8354GE & OA & 1400 & 123.7 & 93.3 & 34.3 & 42.2 \\
\hline 8354GE & SA & 1500 & 101.7 & 80.1 & 18.5 & 20.7 \\
\hline 8354GE & PA & 1500 & 110.0 & 93.4 & 35.2 & 40.8 \\
\hline 8356GE & PA & 1500 & 85.0 & 72.5 & 57.0 & 60.0 \\
\hline 8354GE & OA & 1500 & 88.6 & 80.2 & 25.1 & 51.6 \\
\hline
\end{tabular}




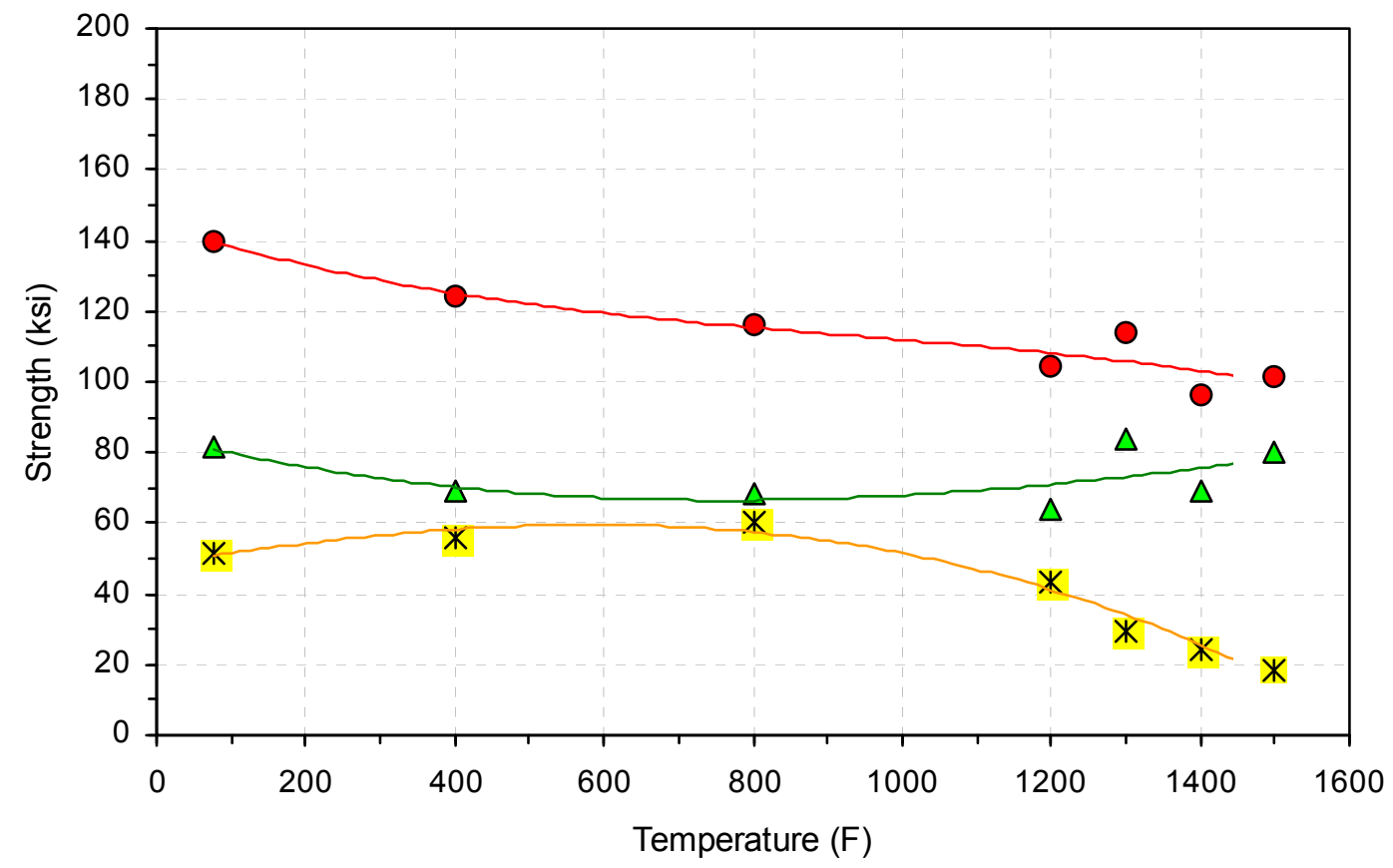

Figure 3.1: Graph showing the $0.25 \%$ YS, UTS and elongation for Haynes 282 from room temperature to $1500^{\circ} \mathrm{F}$ in the solution annealed condition.

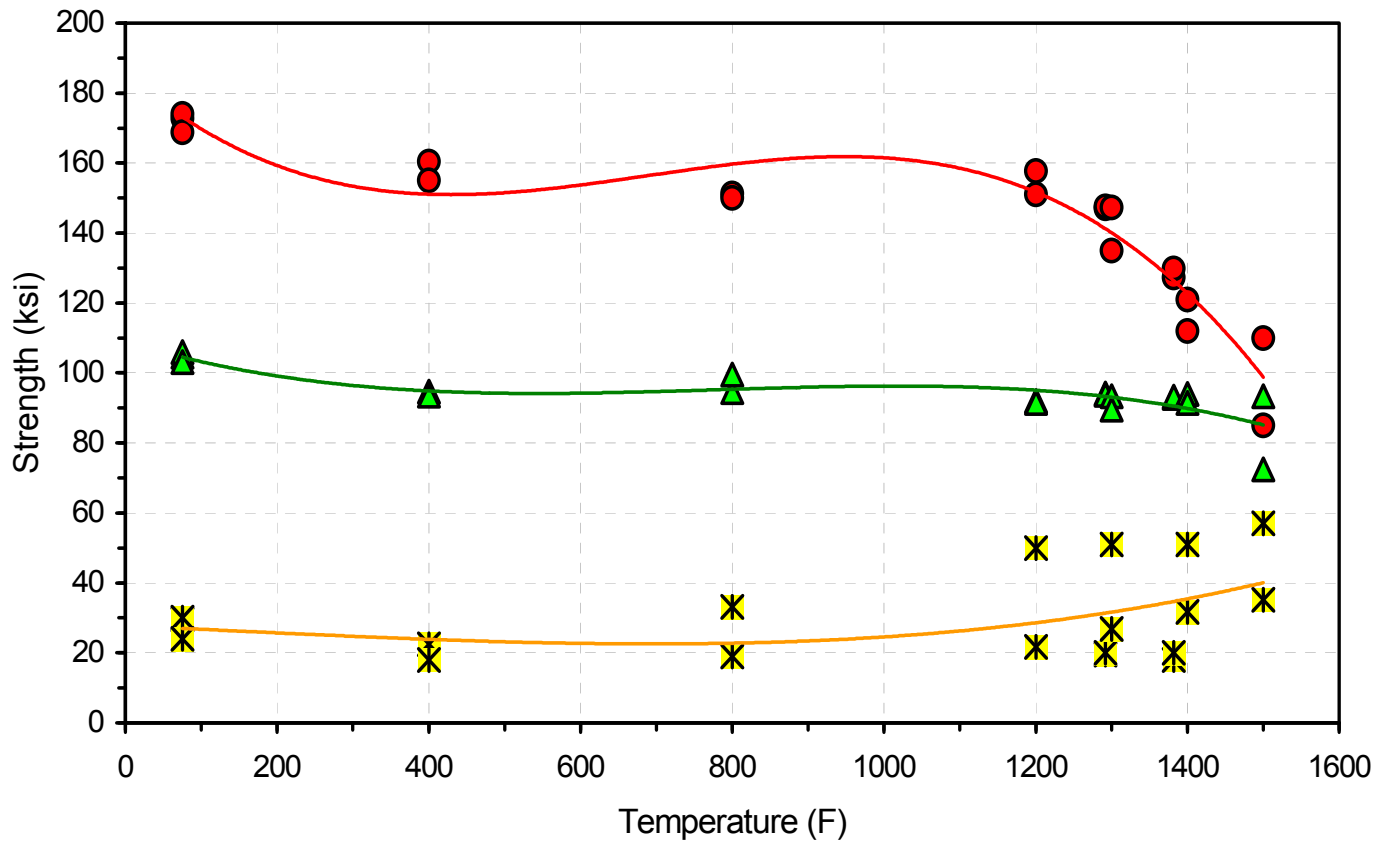

Figure 3.2: Graph showing the $0.25 \%$ YS, UTS and elongation for Haynes 282 from room temperature to $1500^{\circ} \mathrm{F}$ in the solution annealed condition. 


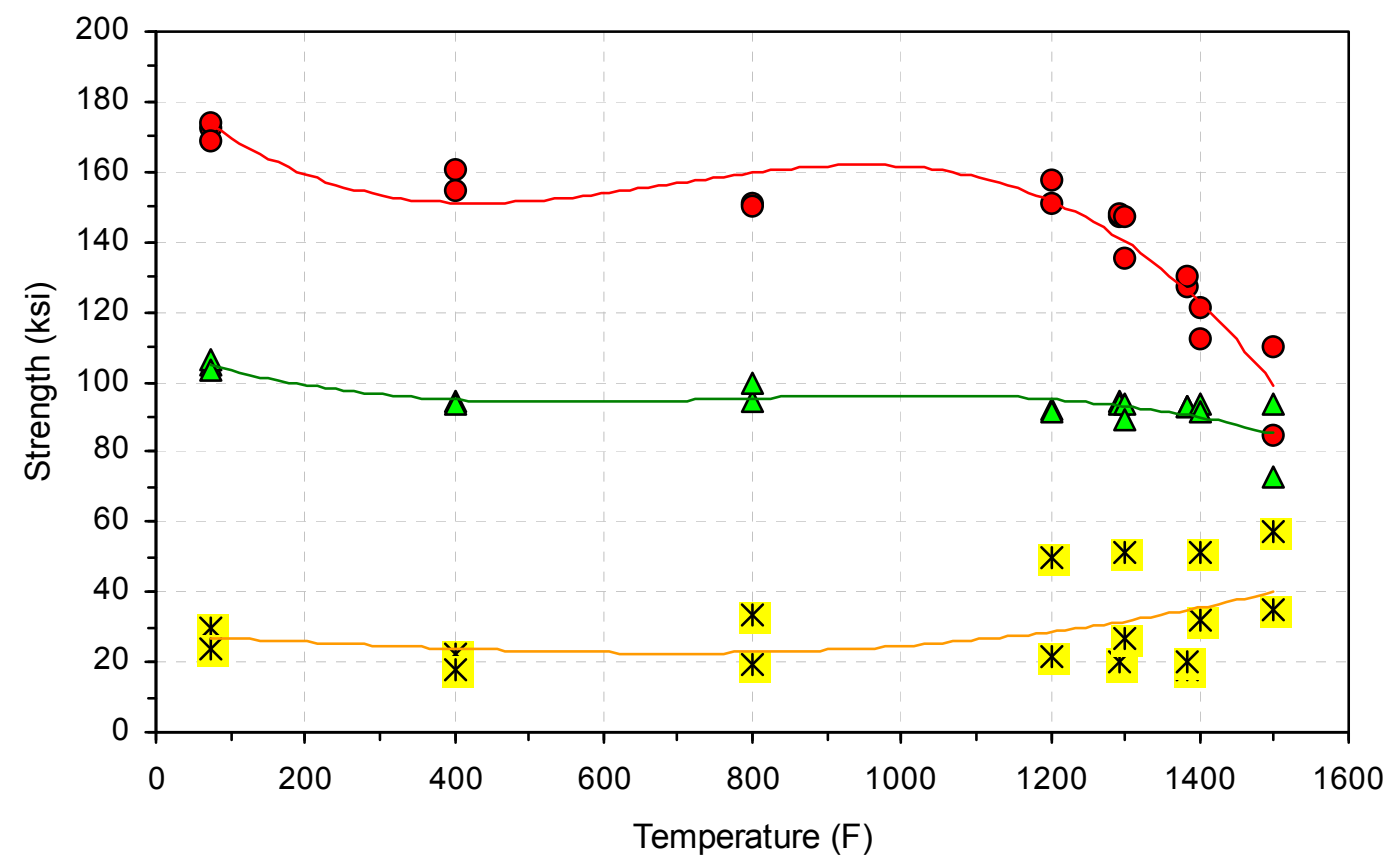

Figure 3.2: Graph showing the $0.25 \%$ YS, UTS and elongation for Haynes 282 from room temperature to $1500^{\circ} \mathrm{F}$ in the peak aged condition.

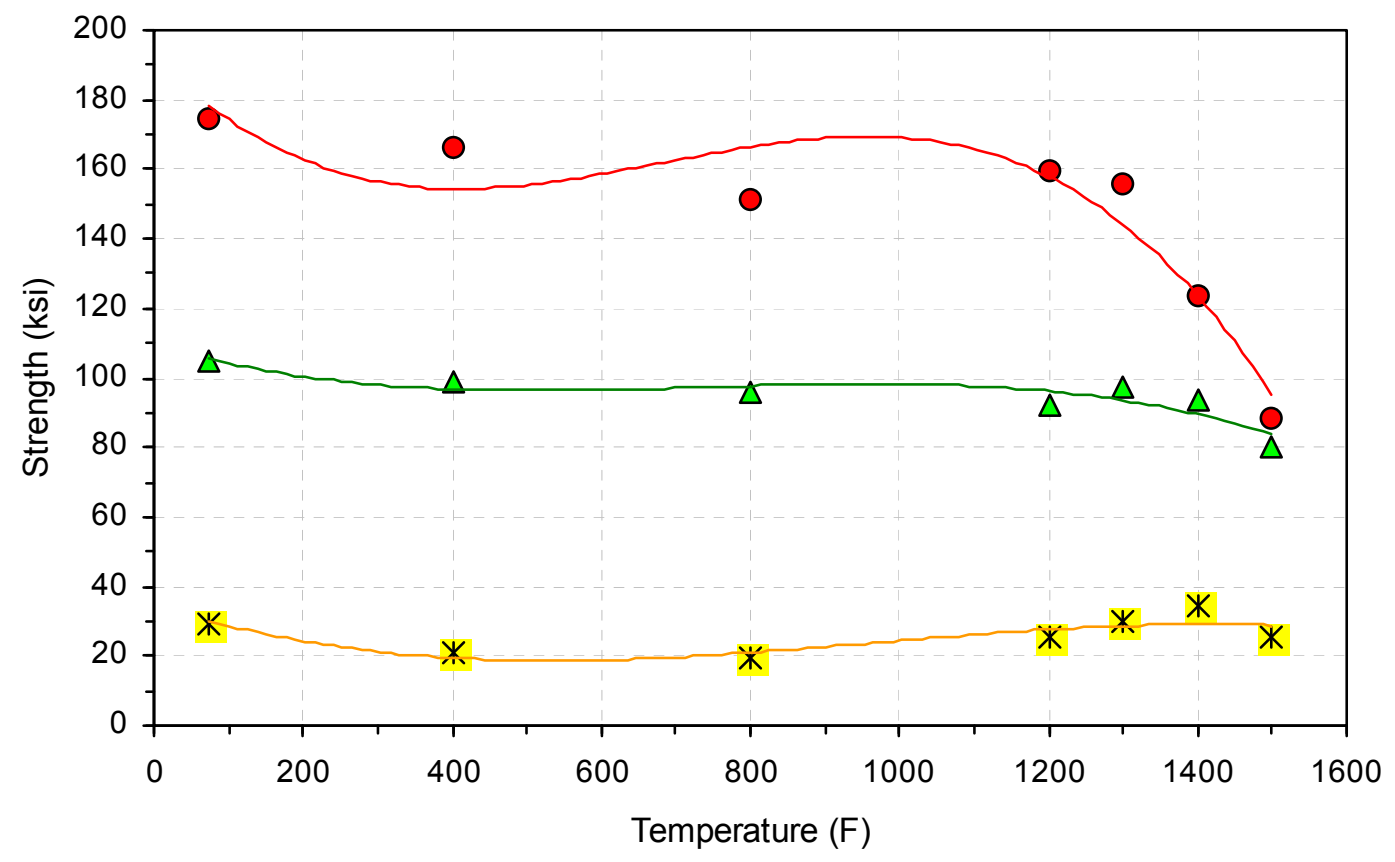

Figure 3.3: Graph showing the $0.25 \%$ YS, UTS and elongation for Haynes 282 from room temperature to $1500 \mathrm{~F}$ in the overaged, or heat conditioned, state. 
Table 3B: Tensile Properties for Haynes 282 Publication H-3173, p. 8, Solution Annealed and AgeHardened Plate

\begin{tabular}{|c|c|c|c|c|c|c|}
\hline $\begin{array}{c}\text { Heat } \\
\text { No. }\end{array}$ & $\begin{array}{c}\text { Processing } \\
\text { Condition }\end{array}$ & $\begin{array}{c}\text { Test Temp } \\
\left({ }^{\circ} \mathrm{F}\right)\end{array}$ & $\begin{array}{c}\text { UTS } \\
(\mathrm{ksi})\end{array}$ & $\begin{array}{c}0.2 \% \text { YS } \\
(\mathrm{ksi})\end{array}$ & $\begin{array}{c}\text { Elongation } \\
(\%)\end{array}$ & $\begin{array}{c}\text { RA } \\
(\%)\end{array}$ \\
\hline H-3173 & PA & 75 & 166.4 & 103.7 & 30.0 & 31.0 \\
\hline H-3173 & PA & 1000 & 143.8 & 94.1 & 34.0 & 36.0 \\
\hline H-3173 & PA & 1200 & 152.0 & 93.2 & 31.0 & 31.0 \\
\hline H-3173 & PA & 1300 & 141.8 & 94.2 & 29.0 & 28.0 \\
\hline H-3173 & PA & 1400 & 124.2 & 91.1 & 22.0 & 24.0 \\
\hline H-3173 & PA & 1500 & 102.8 & 83.4 & 28.0 & 31.0 \\
\hline H-3173 & PA & 1600 & 82.1 & 73.6 & 31.0 & 42.0 \\
\hline H-3173 & PA & 1700 & 52.1 & 44.9 & 50.0 & 69.0 \\
\hline H-3173 & PA & 1800 & 25.3 & 19.1 & 71.0 & 91.0 \\
\hline
\end{tabular}

Solution Aging: $2075^{\circ} \mathrm{F}$

Age-Hardening: $1850^{\circ} \mathrm{F}$ for $2 \mathrm{~h} \& \mathrm{AC}+1450^{\circ} \mathrm{F}$ for $8 \mathrm{~h} \& \mathrm{AC}$ 
Table 3C: Tensile Properties for Nimonic 105: GE Testing

\begin{tabular}{|c|c|c|c|c|c|c|}
\hline $\begin{array}{c}\text { Heat } \\
\text { No. }\end{array}$ & $\begin{array}{c}\text { Processing } \\
\text { Condition }\end{array}$ & $\begin{array}{c}\text { Test Temp } \\
\left({ }^{\circ} \mathrm{F}\right)\end{array}$ & $\begin{array}{l}\text { UTS } \\
\text { (ksi) }\end{array}$ & $\begin{array}{c}0.2 \% Y S \\
(\mathrm{ksi})\end{array}$ & $\begin{array}{c}\text { Elongation } \\
(\%)\end{array}$ & $\begin{array}{l}\text { RA } \\
(\%)\end{array}$ \\
\hline FEY-5183 & SA & 75 & 162.0 & 110.7 & 33.6 & 49.0 \\
\hline FEY-5183 & $\mathrm{PA}$ & 75 & 167.2 & 118.5 & 17.1 & 15.2 \\
\hline JEY-5793 & PA & 75 & 159.8 & 111.5 & 33.0 & 46.8 \\
\hline JEY-5793 & $\mathrm{PA}$ & 75 & 159.9 & 110.3 & 30.2 & 40.1 \\
\hline FEY-5183 & OA & 75 & 169.9 & 119.2 & 15.7 & 14.6 \\
\hline FEY-5183 & SA & 400 & 153.6 & 98.2 & 33.5 & 48.5 \\
\hline FEY-5183 & $\mathrm{PA}$ & 400 & 162.8 & 108.1 & 22.1 & 20.4 \\
\hline JEY-5793 & PA & 400 & 150.8 & 101.6 & 33.4 & 40.9 \\
\hline JEY-5793 & PA & 400 & 150.8 & 102.0 & 33.4 & 40.9 \\
\hline FEY-5183 & $\mathrm{OA}$ & 400 & 163.1 & 112.7 & 15.5 & 19.7 \\
\hline FEY-5183 & SA & 800 & 140.6 & 99.7 & 38.2 & 50.8 \\
\hline FEY-5183 & $\mathrm{PA}$ & 800 & 150.2 & 104.7 & 25.5 & 25.7 \\
\hline JEY-5793 & PA & 800 & 141.9 & 102.6 & 38.0 & 41.0 \\
\hline JEY-5793 & $\mathrm{PA}$ & 800 & 140.9 & 98.4 & 34.4 & 29.9 \\
\hline FEY-5183 & $\mathrm{OA}$ & 800 & 152.9 & 108.5 & 16.3 & 21.3 \\
\hline FEY-5183 & SA & 1200 & 130.8 & 97.3 & 32.5 & 39.4 \\
\hline FEY-5183 & PA & 1200 & 151.9 & 108.2 & 20.4 & 20.6 \\
\hline JEY-5793 & $\mathrm{PA}$ & 1200 & 133.1 & 97.3 & 27.9 & 24.6 \\
\hline JEY-5793 & $\mathrm{PA}$ & 1200 & 134.2 & 99.7 & 30.1 & 28.7 \\
\hline FEY-5183 & $\mathrm{OA}$ & 1200 & 153.8 & 103.4 & 15.3 & 22.7 \\
\hline FEY-5183 & SA & 1300 & 126.6 & 103.1 & 20.4 & 23.7 \\
\hline FEY-5183 & PA & 1300 & 148.8 & 104.5 & 23.4 & 25.0 \\
\hline JEY-5793 & PA & 1300 & 130.5 & 106.1 & 18.6 & 22.4 \\
\hline JEY-5793 & $\mathrm{PA}$ & 1300 & 130.7 & 105.0 & 18.9 & 22.3 \\
\hline FEY-5183 & $\mathrm{OA}$ & 1300 & 161.4 & 111.9 & 14.7 & 17.0 \\
\hline FEY-5183 & SA & 1400 & 121.0 & 106.9 & 10.1 & 16.6 \\
\hline FEY-5183 & $\mathrm{PA}$ & 1400 & 128.5 & 105.0 & 25.8 & 27.4 \\
\hline JEY-5793 & $\mathrm{PA}$ & 1400 & 123.6 & 105.2 & 11.4 & 15.4 \\
\hline JEY-5793 & PA & 1400 & 126.6 & 103.3 & 13.3 & 17.2 \\
\hline FEY-5183 & $\mathrm{OA}$ & 1400 & 141.4 & 104.7 & 21.6 & 23.4 \\
\hline FEY-5183 & SA & 1500 & 104.1 & 98.6 & 8.2 & 10.6 \\
\hline FEY-5183 & $\mathrm{PA}$ & 1500 & 105.6 & 90.7 & 21.5 & 24.1 \\
\hline JEY-5793 & PA & 1500 & 102.6 & 96.1 & 6.0 & 9.9 \\
\hline JEY-5793 & PA & 1500 & 109.0 & 98.8 & 6.5 & 5.8 \\
\hline FEY-5183 & $\mathrm{OA}$ & 1500 & 104.4 & 87.7 & 26.4 & 32.9 \\
\hline
\end{tabular}




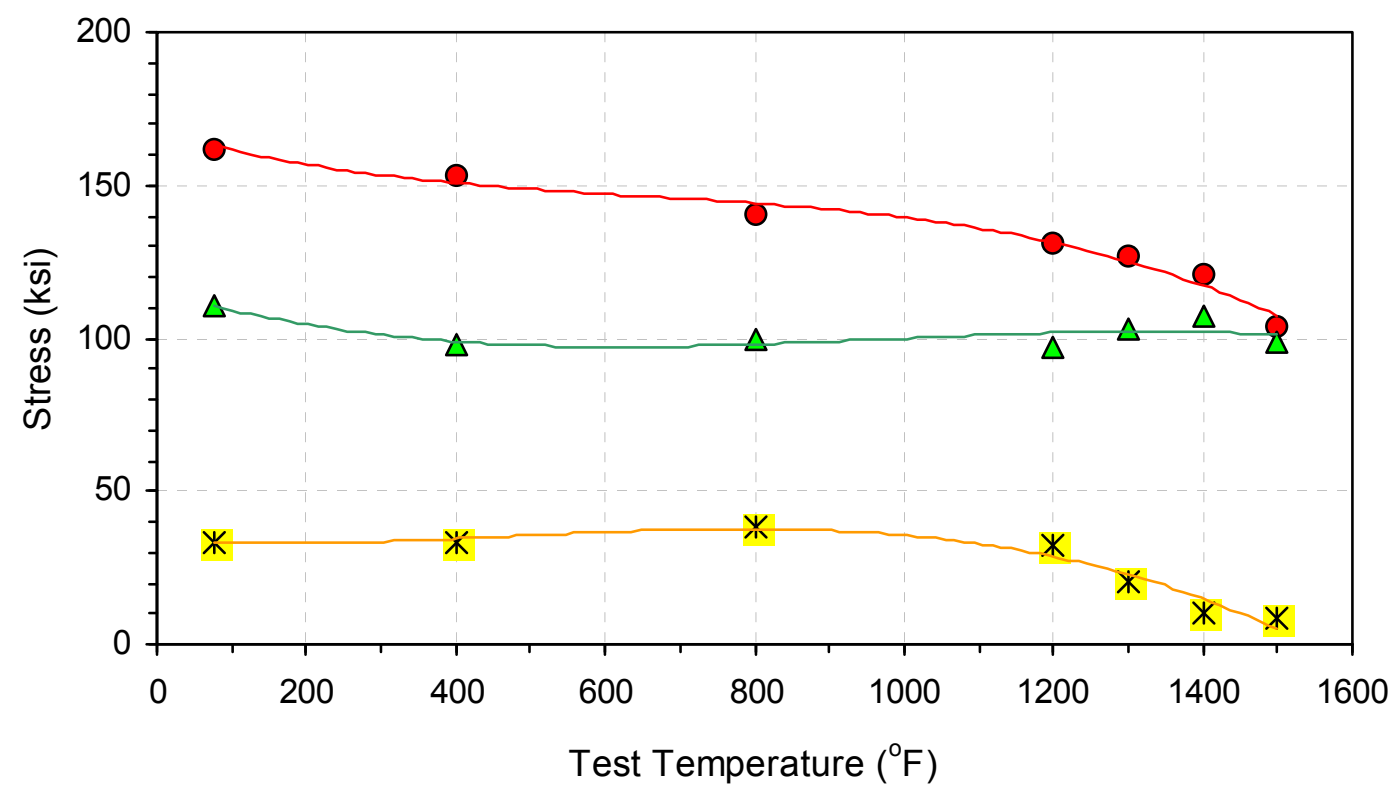

Figure 3.4: Graph showing the $0.25 \%$ YS, UTS and elongation for Nimonic 105 from room temperature to $1500^{\circ} \mathrm{F}$ in the as-processed condition.

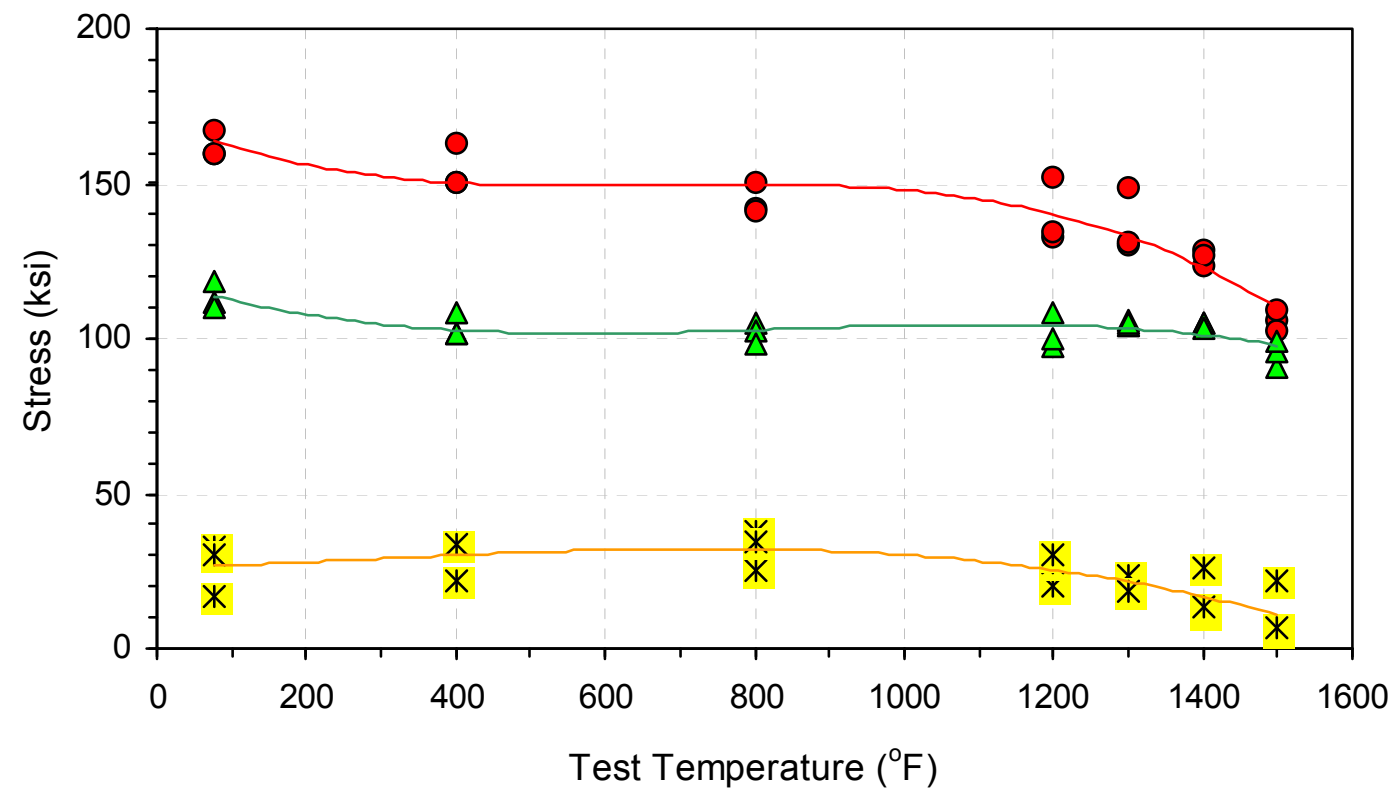

Figure 3.5: Graph showing the $0.25 \%$ YS, UTS and elongation for Nimonic 105 from room temperature to $1500^{\circ} \mathrm{F}$ in the peak aged condition. 


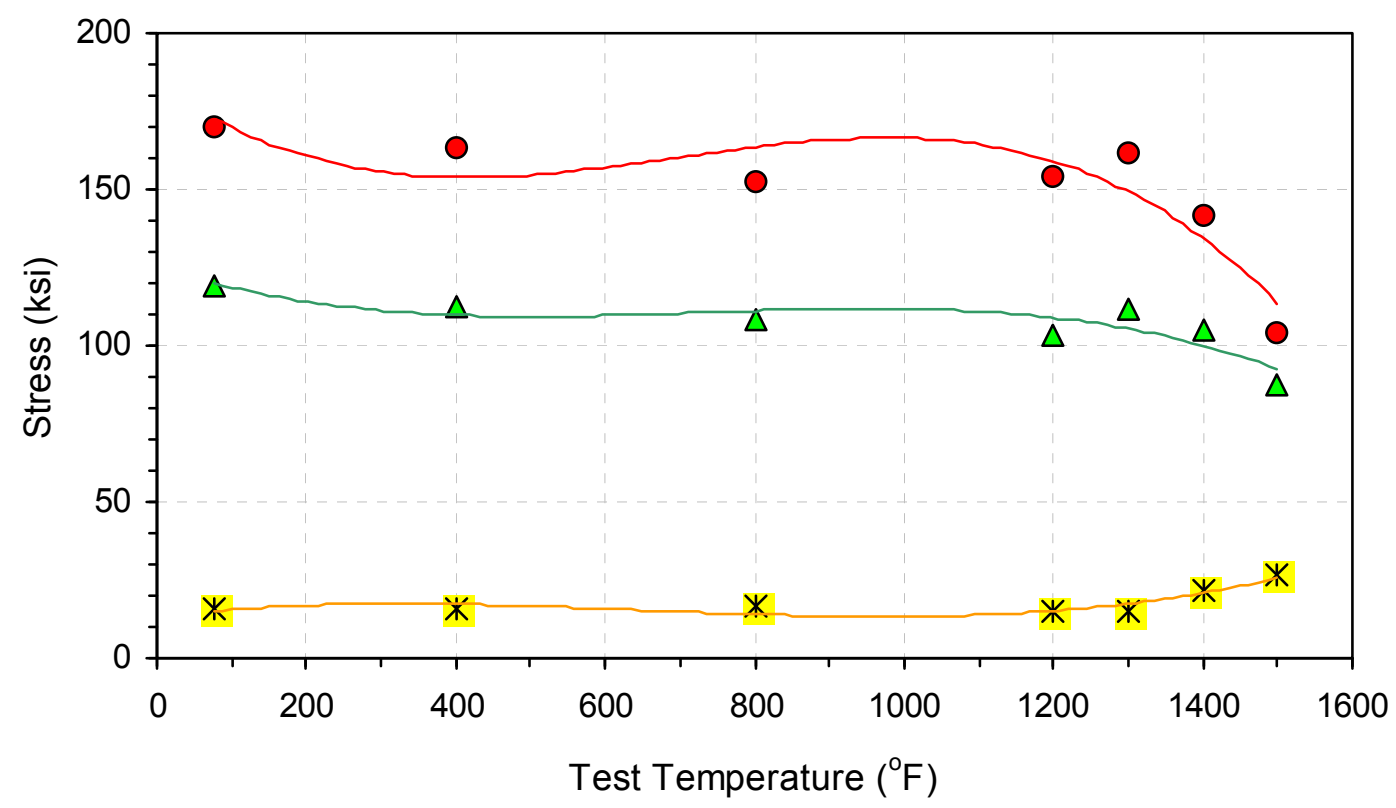

Figure 3.6: Graph showing the 0.25\% YS, UTS and elongation for Nimonic 105 from room temperature to $1500^{\circ} \mathrm{F}$ in the overaged, or heat conditioned, state.

Table 3D: Tensile Properties for Nimonic 105: SM Publication SMC-081, p.5, Extruded Bar, Subsequently Forged and Age-Hardened

\begin{tabular}{|c|c|c|c|c|c|c|}
\hline $\begin{array}{c}\text { Heat } \\
\text { No. }\end{array}$ & $\begin{array}{c}\text { Processing } \\
\text { Condition }\end{array}$ & $\begin{array}{c}\text { Test Temp } \\
\left({ }^{\circ} \mathrm{F}\right)\end{array}$ & $\begin{array}{c}\text { UTS } \\
(\mathrm{ksi})\end{array}$ & $\begin{array}{c}0.2 \% \text { YS } \\
(\mathrm{ksi})\end{array}$ & $\begin{array}{c}\text { Elongation } \\
(\%)\end{array}$ & $\begin{array}{c}\text { RA } \\
(\%)\end{array}$ \\
\hline SMC-081 & E-F-PA & 75 & 171.1 & 119.9 & 16.0 & 16.0 \\
\hline SMC-081 & E-F-PA & 212 & 171.9 & 115.0 & 21.0 & 24.0 \\
\hline SMC-081 & E-F-PA & 392 & 172.3 & 112.3 & 24.0 & 34.0 \\
\hline SMC-081 & E-F-PA & 572 & 168.5 & 111.1 & 20.0 & 24.0 \\
\hline SMC-081 & E-F-PA & 752 & 163.3 & 110.7 & 23.0 & 33.0 \\
\hline SMC-081 & E-F-PA & 932 & 166.5 & 113.4 & 23.0 & 31.0 \\
\hline SMC-081 & E-F-PA & 1112 & 161.1 & 111.5 & 22.0 & 32.0 \\
\hline SMC-081 & E-F-PA & 1292 & 155.9 & 111.4 & 26.0 & 33.0 \\
\hline SMC-081 & E-F-PA & 1472 & 121.3 & 103.6 & 24.0 & 34.0 \\
\hline SMC-081 & E-F-PA & 1652 & 71.2 & 59.6 & 28.0 & 38.0 \\
\hline SMC-081 & E-F-PA & 1832 & 27.4 & 22.6 & 43.0 & 60.0 \\
\hline SMC-081 & E-F-PA & 2012 & 8.1 & 4.5 & 132.0 & 99.0 \\
\hline
\end{tabular}

Solution Aging: $2102^{\circ} \mathrm{F}$ for $4 \mathrm{~h} \& \mathrm{AC}$

Age-Hardening: $1922^{\circ} \mathrm{F}$ for $16 \mathrm{~h} \& \mathrm{AC}+1562^{\circ} \mathrm{F}$ for $16 \mathrm{~h} \& \mathrm{AC}$ 
Table 3E: Tensile Properties for Udimet 720Li: GE \& SW Testing and data from Figure 3 (a \& b), p. 2342, in the paper by K. Gopinath et al.*

\begin{tabular}{|c|c|c|c|c|c|c|}
\hline $\begin{array}{c}\text { Heat } \\
\text { No. }\end{array}$ & $\begin{array}{c}\text { Processing } \\
\text { Condition }\end{array}$ & $\begin{array}{c}\text { Test Temp } \\
\left({ }^{\circ} \mathrm{F}\right)\end{array}$ & $\begin{array}{c}\text { UTS } \\
(\mathrm{ksi})\end{array}$ & $\begin{array}{c}0.2 \% \text { YS } \\
(\mathrm{ksi})\end{array}$ & $\begin{array}{c}\text { Elongation } \\
(\%)\end{array}$ & $\begin{array}{c}\text { RA } \\
(\%)\end{array}$ \\
\hline SM 9-23592-x & PA & 75 & 212.6 & 151.5 & 13.0 & 15.4 \\
\hline SW LC Lab Ht & PA & 75 & 235.4 & 169.9 & 18.0 & 19.0 \\
\hline Gopinath et al. & PA & 75 & 232.4 & 164.0 & 19.4 & 18.3 \\
\hline Gopinath et al. & PA & 392 & 226.4 & 165.2 & 16.3 & 16.8 \\
\hline SM 9-23592-x & PA & 400 & 210.7 & 142.9 & 15.1 & 16.1 \\
\hline Gopinath et al. & PA & 536 & 225.1 & 166.5 & 21.7 & 24.9 \\
\hline Gopinath et al. & PA & 572 & 233.5 & 168.8 & 24.1 & 25.4 \\
\hline Gopinath et al. & PA & 662 & 232.4 & 167.7 & 22.0 & 24.3 \\
\hline Gopinath et al. & PA & 752 & 225.1 & 162.9 & 24.9 & 28.6 \\
\hline SM 9-23592-x & PA & 800 & 190.6 & 137.5 & 27.4 & 24.2 \\
\hline Gopinath et al. & PA & 842 & 220.3 & 158.1 & 23.0 & 27.9 \\
\hline Gopinath et al. & PA & 887 & 223.9 & 156.9 & 23.5 & 33.2 \\
\hline Gopinath et al. & PA & 1022 & 209.6 & 155.6 & 28.8 & 35.9 \\
\hline SM 9-23592-x & PA & 1200 & 190.6 & 138.5 & 27.4 & 24.2 \\
\hline Gopinath et al. & PA & 1202 & 173.6 & 147.4 & 28.8 & 30.9 \\
\hline SW LC Lab Ht & PA & 1292 & 176.3 & 152.1 & 28.0 & 47.5 \\
\hline SW LC Lab Ht & PA & 1292 & 171.2 & 148.7 & 30.5 & 43.5 \\
\hline SM 9-23592-x & PA & 1300 & 161.2 & 139.7 & 23.6 & 24.3 \\
\hline SM 9-23592-x & PA & 1350 & 150.1 & 134.5 & 18.5 & 19.0 \\
\hline SW LC Lab Ht & PA & 1382 & 147.2 & 129.9 & 23.5 & 37.0 \\
\hline SW LC Lab Ht & PA & 1382 & 146.7 & 132.0 & 28.0 & 45.0 \\
\hline SM 9-23592-x & PA & 1400 & 143.5 & 133.0 & 24.1 & 29.4 \\
\hline SM 9-23592-x & PA & 1450 & 117.9 & 89.4 & 32.1 & 21.9 \\
\hline SM 9-23592-x & PA & 1500 & 103.2 & 76.5 & 32.2 & 19.1 \\
\hline
\end{tabular}

* K. Gopinath, A.K. Gogia, S.V. Kamat, R. Balamuralikrishnan, and U. Ramamurty, "Tensile Properties of Ni-Based Superalloy 720Li: Temperature and Strain Rate Effects,” Metall. Mater. Trans. A, Vol. 39, 2008, pp. 2340-2350.

Solution Aging: $1994^{\circ} \mathrm{F}$ for $4 \mathrm{~h} \& \mathrm{OQ}$

Age-Hardening: $1202^{\circ} \mathrm{F}$ for $24 \mathrm{~h} \& \mathrm{AC}+1400^{\circ} \mathrm{F}$ for $16 \mathrm{~h} \& \mathrm{AC}$ 


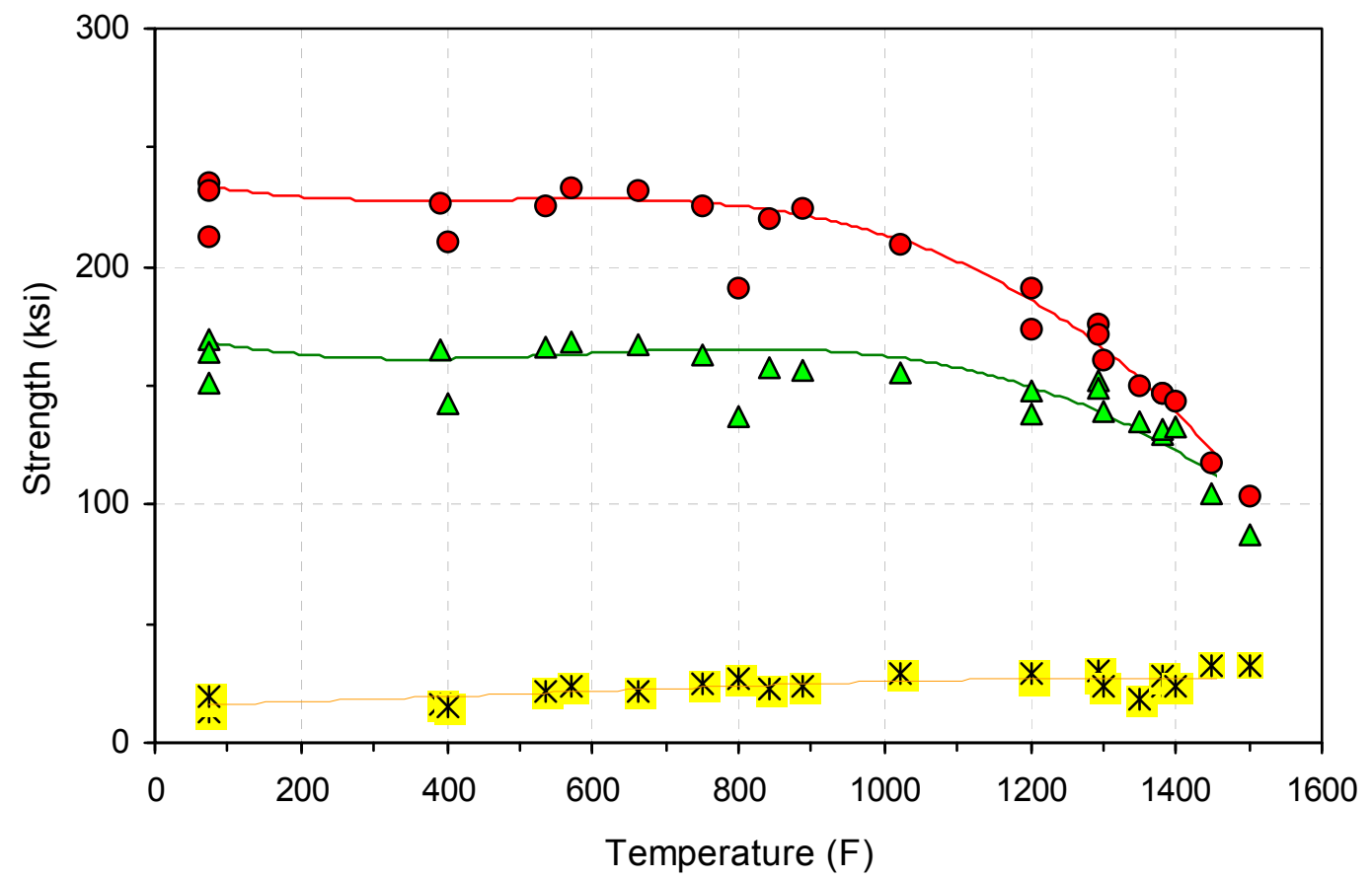

Figure 3.5: Graph showing the $0.25 \%$ YS, UTS and elongated for Udimet 720 from room temperature to $1500^{\circ} \mathrm{F}$ in the peak aged condition.

Table 3F: Tensile Properties for Udimet 720: SM Publication SMC-106, p. 1, Figure 1 (data extracted from graph for precipitation hardened UDIMET 720)

\begin{tabular}{|c|c|c|c|c|c|c|}
\hline $\begin{array}{c}\text { Heat } \\
\text { No. }\end{array}$ & $\begin{array}{c}\text { Processing } \\
\text { Condition }\end{array}$ & $\begin{array}{c}\text { Test Temp } \\
\left({ }^{\circ} \mathrm{F}\right)\end{array}$ & $\begin{array}{c}\text { UTS } \\
(\mathrm{ksi})\end{array}$ & $\begin{array}{c}0.2 \% \text { Y } \\
(\mathrm{ksi})\end{array}$ & $\begin{array}{c}\text { Elongation } \\
(\%)\end{array}$ & $\begin{array}{c}\text { RA } \\
(\%)\end{array}$ \\
\hline SMC-106 & PA & 75 & 160.0 & 129.0 & 5.0 & ND \\
\hline SMC-106 & PA & 400 & 163.0 & 120.0 & 7.5 & ND \\
\hline SMC-106 & PA & 600 & 165.0 & 116.0 & 10.0 & ND \\
\hline SMC-106 & PA & 800 & 170.0 & 112.0 & 10.0 & ND \\
\hline SMC-106 & PA & 1000 & 180.0 & 109.0 & 10.0 & ND \\
\hline SMC-106 & PA & 1200 & 181.0 & 110.0 & 10.0 & ND \\
\hline SMC-106 & PA & 1400 & 150.0 & 108.0 & 18.5 & ND \\
\hline SMC-106 & PA & 1600 & 100.0 & 80.0 & 20.0 & ND \\
\hline
\end{tabular}

UTS \& $0.2 \%$ YS rounded to nearest ksi

Elongation rounded to nearest $0.5 \%$

$$
\text { ND - no data }
$$


Table 3G: Tensile Properties for Inconel 617, solution annealed condition: SW Testing \& GE Historical Data

\begin{tabular}{|c|c|c|c|c|c|c|}
\hline $\begin{array}{c}\text { Heat } \\
\text { No. }\end{array}$ & $\begin{array}{c}\text { Processing } \\
\text { Condition }\end{array}$ & $\begin{array}{c}\text { Test Temp } \\
\left({ }^{\circ} \mathrm{F}\right)\end{array}$ & $\begin{array}{c}\text { UTS } \\
(\mathrm{ksi})\end{array}$ & $\begin{array}{c}0.2 \% Y S \\
(\mathrm{ksi})\end{array}$ & $\begin{array}{c}\text { Elongation } \\
(\%)\end{array}$ & $\begin{array}{c}\text { RA } \\
(\%)\end{array}$ \\
\hline 8838 & SA & 75 & 115.3 & 49.9 & 56.0 & 53.0 \\
\hline XX00A5US & SA & 75 & 111.9 & 46.9 & 59.0 & 50.0 \\
\hline XX00A5US & SA & 600 & 96.1 & 32.2 & 63.2 & 47.8 \\
\hline XX00A5US & SA & 1000 & 88.6 & 32.0 & 64.9 & 45.4 \\
\hline XX00A5US & SA & 1200 & 83.3 & 28.7 & 60.0 & 42.1 \\
\hline 8838 & SA & 1292 & 90.1 & 39.5 & 61.5 & 47.0 \\
\hline 8838 & SA & 1292 & 89.3 & 36.3 & 63.0 & 45.5 \\
\hline XX00A5US & SA & 1300 & 85.2 & 31.8 & 48.1 & 38.2 \\
\hline XX00A5US & SA & 1300 & 85.0 & 40.8 & 37.8 & 31.5 \\
\hline 8838 & SA & 1382 & 77.5 & 38.8 & 56.5 & 59.5 \\
\hline 8838 & SA & 1382 & 80.1 & 50.9 & 50.5 & 57.0 \\
\hline XX00A5US & SA & 1400 & 76.2 & 29.8 & 61.7 & 53.0 \\
\hline XX00A5US & SA & 1600 & 52.1 & 28.0 & 100.8 & 77.6 \\
\hline
\end{tabular}

* GE historical data for alloy 617 (1974).

Table 3H: Tensile Properties for Alloy 617: Haynes Publication H-3171, p. 2, Typical Tensile Properties, Plate and Special Metals Publication SMC-029, p. 3, Figure 1 (data extracted from graph for solution annealed, hot-rolled-rod) and Table 5

\begin{tabular}{|c|c|c|c|c|c|c|}
\hline $\begin{array}{c}\text { Heat } \\
\text { No. }\end{array}$ & $\begin{array}{c}\text { Processing } \\
\text { Condition }\end{array}$ & $\begin{array}{c}\text { Test Temp } \\
\left({ }^{\circ} \mathrm{F}\right)\end{array}$ & $\begin{array}{c}\text { UTS } \\
(\mathrm{ksi})\end{array}$ & $\begin{array}{c}0.2 \% \text { Y } \\
(\mathrm{ksi})\end{array}$ & $\begin{array}{c}\text { Elongation } \\
(\%)\end{array}$ & $\begin{array}{c}\text { RA } \\
(\%)\end{array}$ \\
\hline H-3171 & SA-plate & 75 & 113.0 & 53.0 & 52.0 & ND \\
\hline SMC-029 & SA-plate & 75 & 106.5 & 46.7 & 62.0 & 56.0 \\
\hline SMC-029 & SA-bar & 75 & 111.5 & 46.1 & 56.0 & 50.0 \\
\hline SMC-029 & SA-HR rod & 75 & 109.0 & 52.0 & 60.0 & ND \\
\hline SMC-029 & SA-HR rod & 400 & 95.0 & 37.0 & 60.0 & ND \\
\hline SMC-029 & SA-HR rod & 600 & 92.0 & 35.0 & 61.5 & ND \\
\hline SMC-029 & SA-HR rod & 800 & 90.0 & 35.0 & 63.0 & ND \\
\hline H-3171 & SA-plate & 1000 & 90.0 & 37.0 & 67.0 & ND \\
\hline SMC-029 & SA-HR rod & 1000 & 87.0 & 35.0 & 63.5 & ND \\
\hline H-3171 & SA-plate & 1200 & 91.0 & 35.0 & 67.0 & ND \\
\hline SMC-029 & SA-HR rod & 1200 & 84.0 & 37.0 & 60.0 & ND \\
\hline H-3171 & SA-plate & 1400 & 70.0 & 36.0 & 92.0 & ND \\
\hline SMC-029 & SA-HR rod & 1400 & 77.0 & 40.0 & 53.5 & ND \\
\hline H-3171 & SA-plate & 1600 & 41.0 & 30.0 & 99.0 & ND \\
\hline SMC-029 & SA-HR rod & 1600 & 51.0 & 38.0 & 43.5 & ND \\
\hline
\end{tabular}

Solution anneal, plate: $2150^{\circ} \mathrm{F}$ 



\section{APPENDIX 4 \\ LOW CYCLE FATIGUE FOR \\ CANDIDATE NICKEL SUPERALLOY}


Table 4A: Low Cycle Fatigue Data for Haynes 282 (plate): GE \& SW Testing GE-plate, solution-annealed (SA)

\begin{tabular}{|c|c|c|c|c|c|c|c|c|c|c|c|c|c|c|c|c|c|c|}
\hline \multirow[b]{2}{*}{$\begin{array}{c}\text { Heat } \\
\text { No. }\end{array}$} & \multirow{2}{*}{$\begin{array}{c}\text { Test } \\
\text { Temp } \\
\text { (F) }\end{array}$} & \multirow[b]{2}{*}{$\begin{array}{l}\text { Freq. } \\
(\mathrm{Hz})\end{array}$} & \multirow{2}{*}{$\begin{array}{c}\text { RT } \\
\text { Mod } \\
\text { Ex10 }\end{array}$} & \multicolumn{4}{|c|}{ First Cycle } & \multirow{2}{*}{$\begin{array}{l}\text { Cycle } \\
\text { Data } \\
\text { Calc. }\end{array}$} & \multicolumn{7}{|c|}{ Midlife } & \multirow[b]{2}{*}{$\begin{array}{c}\text { Cycles } \\
\mathrm{N}_{\mathrm{i}}\end{array}$} & \multirow[b]{2}{*}{$\begin{array}{c}\text { Cycles } \\
\mathrm{N}_{\mathrm{f}}\end{array}$} & \multirow[b]{2}{*}{ Notes } \\
\hline & & & & $\begin{array}{c}\text { Mod } \\
\text { Ex10 }\end{array}$ & $\begin{array}{l}\Delta \varepsilon_{\mathrm{t}} \\
(\%)\end{array}$ & $\begin{array}{c}\sigma_{\max } \\
(\mathrm{ksi})\end{array}$ & $\begin{array}{r}\sigma_{\min } \\
(\mathrm{ksi})\end{array}$ & & $\begin{array}{l}\text { Mod } \\
\text { Ex10 }\end{array}$ & $\begin{array}{c}\Delta \sigma \\
(\mathrm{ksi})\end{array}$ & $\begin{array}{l}\sigma_{\max } \\
(\mathrm{ksi})\end{array}$ & $\begin{array}{c}\sigma_{\min } \\
(\mathrm{ksi})\end{array}$ & $\begin{array}{l}\Delta \varepsilon_{\mathrm{t}} \\
(\%)\end{array}$ & $\begin{array}{l}\Delta \varepsilon_{\mathrm{e}} \\
(\%)\end{array}$ & $\begin{array}{l}\Delta \varepsilon_{\mathrm{p}} \\
(\%)\end{array}$ & & & \\
\hline 8354 & 1400 & 0.33 & 31.1 & 25.7 & 1.25 & 77.0 & -78.3 & 200 & 24.9 & 148.6 & 73.5 & -75.1 & 1.25 & 0.60 & 0.65 & 536 & 620 & $F$ \\
\hline 8354 & 1400 & 0.33 & 31.1 & 24.3 & 1.25 & 75.7 & -79.0 & 200 & 24.3 & 148.0 & 72.6 & -75.4 & 1.25 & 0.61 & 0.64 & 426 & 630 & $\mathrm{~F}$ \\
\hline 8354 & 1400 & 0.33 & 31.8 & 24.0 & 1.00 & 72.4 & -71.5 & 500 & 24.7 & 141.8 & 70.3 & -71.5 & 1.00 & 0.57 & 0.43 & 887 & 1,221 & $\mathrm{~F}$ \\
\hline 8354 & 1400 & 0.33 & 31.1 & 24.1 & 1.00 & 69.6 & -68.0 & 500 & 24.5 & 131.1 & 65.2 & -65.9 & 1.00 & 0.54 & 0.46 & 1,115 & 1,135 & $\mathrm{~F}$ \\
\hline 8354 & 1400 & 0.33 & 31.2 & 24.9 & 0.75 & 65.7 & -60.5 & 1000 & 24.9 & 120.4 & 60.9 & -59.5 & 0.75 & 0.48 & 0.27 & 1,766 & 2,335 & $\mathrm{~F}$ \\
\hline 8354 & 1400 & 0.33 & 31.6 & 24.8 & 0.75 & 71.6 & -68.7 & 1000 & 24.8 & 131.3 & 66.6 & -64.7 & 0.75 & 0.53 & 0.22 & 1,499 & 1,910 & $\mathrm{~F}$ \\
\hline 8354 & 1400 & 0.33 & 31.2 & 24.3 & 0.63 & 78.9 & -59.5 & 2000 & 24.0 & 126.1 & 68.8 & -57.3 & 0.64 & 0.53 & 0.11 & 3,124 & 3,590 & $\mathrm{TL}$ \\
\hline 8354 & 1400 & 0.33 & 31.3 & 24.1 & 0.50 & 64.5 & -50.4 & 2000 & 24.1 & 112.5 & 62.2 & -50.3 & 0.50 & 0.47 & 0.03 & 6,864 & 7,097 & TL \\
\hline 8354 & 1400 & 0.33 & 31.5 & 24.1 & 0.50 & 66.3 & -47.4 & 5000 & 24.7 & 109.9 & 60.4 & -49.5 & 0.50 & 0.44 & 0.06 & 7,936 & 8,180 & $\mathrm{~F}$ \\
\hline 8354 & 1400 & 0.33 & 30.6 & 23.9 & 0.50 & 70.5 & -46.3 & 2375 & 24.0 & 112.1 & 64.9 & -47.2 & 0.50 & 0.47 & 0.03 & 5,376 & 6,061 & TL \\
\hline 8354 & 1400 & 0.33 & 30.6 & 23.3 & 0.40 & 67.7 & -25.5 & 106195 & 23.8 & 94.9 & 67.7 & -27.2 & 0.40 & 0.40 & 0.00 & 106,200 & 106,200 & $\mathrm{R}$ \\
\hline 8354 & 1400 & 0.33 & 30.7 & 23.6 & 0.40 & 68.0 & -24.3 & 100200 & 23.6 & 93.0 & 70.6 & -22.4 & 0.40 & 0.39 & 0.01 & 100,200 & 100,200 & $\mathrm{R}$ \\
\hline
\end{tabular}

$\mathrm{R}=0$; triangular waveform

GE-plate, peak-aged (PA)

\begin{tabular}{|c|c|c|c|c|c|c|c|c|c|c|c|c|c|c|c|c|c|c|}
\hline \multirow[b]{2}{*}{$\begin{array}{l}\text { Heat } \\
\text { No. }\end{array}$} & \multirow{2}{*}{$\begin{array}{c}\text { Test } \\
\text { Temp } \\
(\mathrm{F})\end{array}$} & \multirow[b]{2}{*}{$\begin{array}{l}\text { Freq. } \\
(\mathrm{Hz})\end{array}$} & \multirow{2}{*}{$\begin{array}{c}\text { RT } \\
\text { Mod } \\
\text { Ex10 }\end{array}$} & \multicolumn{4}{|c|}{ First Cycle } & \multirow{2}{*}{$\begin{array}{l}\text { Cycle } \\
\text { Data } \\
\text { Calc. }\end{array}$} & \multicolumn{7}{|c|}{ Midlife } & \multirow[b]{2}{*}{$\begin{array}{c}\text { Cycles } \\
\mathrm{N}_{\mathrm{i}}\end{array}$} & \multirow[b]{2}{*}{$\begin{array}{c}\text { Cycles } \\
\mathrm{N}_{\mathrm{f}}\end{array}$} & \multirow[b]{2}{*}{ Notes } \\
\hline & & & & $\begin{array}{c}\text { Mod } \\
\text { Ex10 }\end{array}$ & $\begin{array}{l}\Delta \varepsilon_{\mathrm{t}} \\
(\%)\end{array}$ & $\begin{array}{l}\sigma_{\max } \\
(\mathrm{ksi})\end{array}$ & $\begin{array}{c}\sigma_{\min } \\
(\mathrm{ksi})\end{array}$ & & $\begin{array}{c}\text { Mod } \\
\text { Ex10 }\end{array}$ & $\begin{array}{c}\Delta \sigma \\
(\mathrm{ksi})\end{array}$ & $\begin{array}{l}\sigma_{\max } \\
(\mathrm{ksi})\end{array}$ & $\begin{array}{c}\sigma_{\min } \\
(\mathrm{ksi})\end{array}$ & $\begin{array}{l}\Delta \varepsilon_{\mathrm{t}} \\
(\%)\end{array}$ & $\begin{array}{l}\Delta \varepsilon_{\mathrm{e}} \\
(\%)\end{array}$ & $\begin{array}{l}\Delta \varepsilon_{\mathrm{p}} \\
(\%)\end{array}$ & & & \\
\hline 8354 & 1400 & 0.33 & 31.6 & 23.8 & 1.11 & 101.4 & -101.3 & 500 & 23.7 & 187.6 & 94.1 & -93.5 & 1.11 & 0.79 & 0.32 & 854 & 1,011 & $\mathrm{~F}$ \\
\hline 8354 & 1400 & 0.33 & 31.5 & 23.8 & 0.88 & 95.2 & -84.9 & 1000 & 23.6 & 163.9 & 84.8 & -79.1 & 0.88 & 0.69 & 0.19 & 1,607 & 2,009 & F \\
\hline 8354 & 1400 & 0.33 & 31.7 & 24.2 & 0.64 & 92.2 & -59.2 & 2000 & 24.4 & 142.3 & 86.6 & -55.7 & 0.64 & 0.58 & 0.05 & 4,051 & 4,876 & $\mathrm{~F}$ \\
\hline 8354 & 1400 & 0.33 & 31.2 & 23.6 & 0.49 & 88.5 & -26.8 & 5000 & 23.7 & 115.9 & 87.6 & -28.3 & 0.49 & 0.49 & 0.00 & 14,718 & 15,544 & $\mathrm{~F}$ \\
\hline 8354 & 1400 & 0.33 & 31.2 & 23.9 & 0.42 & 87.2 & -13.8 & 109775 & 22.9 & 94.0 & 67.6 & -26.4 & 0.42 & 0.42 & 0.01 & 109,780 & 109,780 & $\mathrm{R}$ \\
\hline
\end{tabular}

$\mathrm{R}=0$; triangular waveform 
GE-plate, overaged (OA)

\begin{tabular}{|c|c|c|c|c|c|c|c|c|c|c|c|c|c|c|c|c|c|c|}
\hline \multirow[b]{2}{*}{$\begin{array}{l}\text { Heat } \\
\text { No. }\end{array}$} & \multirow{2}{*}{$\begin{array}{c}\text { Test } \\
\text { Temp } \\
(\mathrm{F})\end{array}$} & \multirow[b]{2}{*}{$\begin{array}{l}\text { Freq. } \\
(\mathrm{Hz})\end{array}$} & \multirow{2}{*}{$\begin{array}{c}\text { RT } \\
\text { Mod } \\
\text { Ex10 }\end{array}$} & \multicolumn{4}{|c|}{ First Cycle } & \multirow{2}{*}{$\begin{array}{l}\text { Cycle } \\
\text { Data } \\
\text { Calc. }\end{array}$} & \multicolumn{7}{|c|}{ Midlife } & \multirow[b]{2}{*}{$\begin{array}{c}\text { Cycles } \\
\mathrm{N}_{\mathrm{i}}\end{array}$} & \multirow[b]{2}{*}{$\begin{array}{c}\text { Cycles } \\
\mathrm{N}_{\mathrm{f}}\end{array}$} & \multirow[b]{2}{*}{ Notes } \\
\hline & & & & $\begin{array}{c}\text { Mod } \\
\text { Ex10 }\end{array}$ & $\begin{array}{l}\Delta \varepsilon_{\mathrm{t}} \\
(\%)\end{array}$ & $\begin{array}{l}\sigma_{\max } \\
(\mathrm{ksi})\end{array}$ & $\begin{array}{r}\sigma_{\min } \\
(\mathrm{ksi})\end{array}$ & & $\begin{array}{c}\text { Mod } \\
\text { Ex10 }\end{array}$ & $\begin{array}{c}\Delta \sigma \\
(\mathrm{ksi})\end{array}$ & $\begin{array}{l}\sigma_{\max } \\
(\mathrm{ksi})\end{array}$ & $\begin{array}{l}\sigma_{\min } \\
(\mathrm{ksi})\end{array}$ & $\begin{array}{l}\Delta \varepsilon_{\mathrm{t}} \\
(\%)\end{array}$ & $\begin{array}{l}\Delta \varepsilon_{\mathrm{e}} \\
(\%)\end{array}$ & $\begin{array}{l}\Delta \varepsilon_{\mathrm{p}} \\
(\%)\end{array}$ & & & \\
\hline 8354 & 1400 & 0.33 & 31.2 & 23.3 & 1.12 & 100.2 & -95.5 & 500 & 23.2 & 197.4 & 100.3 & -97.1 & 1.12 & 0.85 & 0.27 & 867 & 995 & $\mathrm{~F}$ \\
\hline 8354 & 1400 & 0.33 & 31.4 & 22.5 & 0.87 & 94.2 & -83.4 & 1000 & 23.0 & 172.1 & 90.2 & -81.9 & 0.87 & 0.75 & 0.12 & 1,582 & 2,380 & $\mathrm{~F}$ \\
\hline 8354 & 1400 & 0.33 & 31.2 & 23.5 & 0.62 & 91.5 & -54.0 & 2000 & 23.5 & 143.9 & 89.6 & -54.3 & 0.62 & 0.61 & 0.01 & 6,257 & 6,329 & F \\
\hline 8354 & 1400 & 0.33 & 31.1 & 23.6 & 0.48 & 89.8 & -23.9 & 7313 & 23.9 & 113.6 & 86.4 & -27.2 & 0.48 & 0.48 & 0.00 & 16,587 & 20.011 & $\bar{F}$ \\
\hline 8354 & 1400 & 0.33 & 31.5 & 23.9 & 0.41 & 86.1 & -13.2 & 108047 & 24.5 & 99.8 & 78.6 & -21.2 & 0.41 & 0.42 & 0.01 & 108,051 & 108,051 & $\mathrm{R}$ \\
\hline
\end{tabular}

$\mathrm{R}=0$; triangular waveform

GE-plate, peak-aged (PA)

\begin{tabular}{|c|c|c|c|c|c|c|c|c|c|c|c|c|c|c|c|c|c|c|}
\hline \multirow[b]{2}{*}{$\begin{array}{c}\text { Heat } \\
\text { No. }\end{array}$} & \multirow{2}{*}{$\begin{array}{c}\text { Test } \\
\text { Temp } \\
(\mathrm{F})\end{array}$} & \multirow[b]{2}{*}{$\begin{array}{l}\text { Freq. } \\
(\mathrm{Hz})\end{array}$} & \multirow{2}{*}{$\begin{array}{c}\text { RT } \\
\text { Mod } \\
\text { Ex10 }\end{array}$} & \multicolumn{4}{|c|}{ First Cycle } & \multirow{2}{*}{$\begin{array}{l}\text { Cycle } \\
\text { Data } \\
\text { Calc. }\end{array}$} & \multicolumn{7}{|c|}{ Midlife } & \multirow[b]{2}{*}{$\begin{array}{c}\text { Cycles } \\
\mathrm{N}_{\mathrm{i}}\end{array}$} & \multirow[b]{2}{*}{$\begin{array}{c}\text { Cycles } \\
\mathrm{N}_{\mathrm{f}}\end{array}$} & \multirow[b]{2}{*}{ Notes } \\
\hline & & & & $\begin{array}{c}\text { Mod } \\
\text { Ex10 }\end{array}$ & $\begin{array}{l}\Delta \varepsilon_{\mathrm{t}} \\
(\%)\end{array}$ & $\begin{array}{l}\sigma_{\max } \\
(\mathrm{ksi})\end{array}$ & $\begin{array}{c}\sigma_{\min } \\
(\mathrm{ksi})\end{array}$ & & $\begin{array}{c}\text { Mod } \\
\text { Ex10 }\end{array}$ & $\begin{array}{c}\Delta \sigma \\
(\mathrm{ksi})\end{array}$ & $\begin{array}{l}\sigma_{\max } \\
(\mathrm{ksi})\end{array}$ & $\begin{array}{c}\sigma_{\min } \\
(\mathrm{ksi})\end{array}$ & $\begin{array}{l}\Delta \varepsilon_{\mathrm{t}} \\
(\%)\end{array}$ & $\begin{array}{l}\Delta \varepsilon_{\mathrm{e}} \\
(\%)\end{array}$ & $\begin{array}{l}\Delta \varepsilon_{\mathrm{p}} \\
(\%)\end{array}$ & & & \\
\hline 8356 & 1400 & 0.33 & 32.0 & 23.9 & 1.00 & 92.6 & -88.5 & 500 & 23.9 & 189.6 & 94.4 & -95.2 & 1.00 & 0.79 & 0.21 & 1,029 & 1,437 & TL \\
\hline 8356 & 1400 & 0.33 & 31.5 & 23.7 & 1.00 & 93.3 & -87.6 & 500 & 23.7 & 192.0 & 95.9 & -96.1 & 1.01 & 0.81 & 0.20 & 1,076 & 1,450 & TL \\
\hline 8356 & 1400 & 0.33 & 31.7 & 23.8 & 0.75 & 90.7 & -73.0 & 2000 & 23.9 & 166.6 & 90.1 & -76.5 & 0.75 & 0.70 & 0.05 & 3,298 & 4,495 & TL \\
\hline 8356 & 1400 & 0.33 & 31.4 & 23.8 & 0.75 & 89.1 & -73.3 & 2000 & 23.8 & 165.0 & 87.7 & -77.3 & 0.75 & 0.69 & 0.06 & 2,328 & 3,115 & TL \\
\hline 8356 & 1400 & 0.33 & 32.0 & 23.9 & 0.55 & 84.9 & -43.8 & 5000 & 24.0 & 128.8 & 82.7 & -46.1 & 0.55 & 0.54 & 0.01 & 11,858 & 13,006 & TL \\
\hline 8356 & 1400 & 0.33 & 31.9 & 23.9 & 0.55 & 83.4 & -46.3 & 6368 & 24.0 & 128.1 & 82.0 & -46.1 & 0.55 & 0.53 & 0.02 & 10.568 & 11,345 & TL \\
\hline 8356 & 1400 & 0.33 & 32.1 & 24.3 & 0.45 & 85.2 & -21.9 & 50000 & 24.1 & 107.5 & 79.9 & -27.6 & 0.45 & 0.45 & 0.00 & 100,190 & 100,190 & $\mathrm{R}$ \\
\hline 8356 & 1400 & 0.33 & 31.7 & 24.2 & 0.45 & 86.0 & -20.4 & 50000 & 24.1 & 107.8 & 81.3 & -26.5 & 0.45 & 0.45 & 0.00 & 100,100 & 100,100 & $\mathrm{R}$ \\
\hline
\end{tabular}

$\mathrm{R}=0$; triangular waveform 
SW-plate

\begin{tabular}{|c|c|c|c|c|c|c|c|c|c|c|c|c|c|c|c|c|c|c|}
\hline \multirow[b]{2}{*}{$\begin{array}{l}\text { Heat } \\
\text { No. }\end{array}$} & \multirow{2}{*}{$\begin{array}{c}\text { Test } \\
\text { Temp } \\
(\mathrm{F})\end{array}$} & \multirow[b]{2}{*}{$\begin{array}{c}\text { Freq. } \\
\text { (6\%/min) }\end{array}$} & \multirow{2}{*}{$\begin{array}{c}\text { RT } \\
\text { Mod } \\
\text { Ex10 }\end{array}$} & \multicolumn{4}{|c|}{ First Cycle } & \multirow{2}{*}{$\begin{array}{l}\text { Cycle } \\
\text { Data } \\
\text { Calc. }\end{array}$} & \multicolumn{7}{|c|}{ Midlife } & \multirow[b]{2}{*}{$\begin{array}{c}\text { Cycles } \\
\mathrm{N}_{\mathrm{i}}\end{array}$} & \multirow{2}{*}{$\begin{array}{c}\text { Cycles } \\
N_{f}\end{array}$} & \multirow[b]{2}{*}{ Notes } \\
\hline & & & & $\begin{array}{c}\text { Mod } \\
\text { Ex10 }\end{array}$ & $\begin{array}{l}\Delta \varepsilon_{\mathrm{t}} \\
(\%)\end{array}$ & $\begin{array}{l}\sigma_{\max } \\
(\mathrm{ksi})\end{array}$ & $\begin{array}{c}\sigma_{\min } \\
(\mathrm{ksi})\end{array}$ & & $\begin{array}{c}\text { Mod } \\
\text { Ex10 }\end{array}$ & $\begin{array}{c}\Delta \sigma \\
(\mathrm{ksi})\end{array}$ & $\begin{array}{l}\sigma_{\max } \\
(\mathrm{ksi})\end{array}$ & $\begin{array}{c}\sigma_{\min } \\
(\mathrm{ksi})\end{array}$ & $\begin{array}{l}\Delta \varepsilon_{\mathrm{t}} \\
(\%)\end{array}$ & $\begin{array}{l}\Delta \varepsilon_{\mathrm{e}} \\
(\%)\end{array}$ & $\begin{array}{l}\Delta \varepsilon_{\mathrm{p}} \\
(\%)\end{array}$ & & & \\
\hline 8356 & 1292 & 0.04 & & 23.6 & 1.20 & 99.8 & -100.4 & 400 & 23.8 & 185.8 & 92.8 & -93.0 & 1.200 & 0.763 & 0.437 & 792 & $\begin{array}{l}888 \\
\end{array}$ & $F$ \\
\hline 8356 & 1382 & 0.05 & & 24.1 & 1.10 & 90.8 & -93.3 & 500 & 23.9 & 151.1 & 76.4 & -74.7 & 1.102 & 0.639 & 0.463 & 745 & 1,175 & $\mathrm{~F}$ \\
\hline 8356 & 1292 & 0.06 & & 23.9 & 0.85 & 88.0 & -90.5 & 1000 & 23.3 & 160.9 & 78.5 & -82.4 & 0.850 & 0.669 & 0.181 & 2,779 & 3,213 & $\mathrm{~F}$ \\
\hline 8356 & 1382 & 0.06 & & 23.0 & 0.82 & 94.3 & -79.1 & 1000 & 23.2 & 139.8 & 75.4 & -64.4 & 0.817 & 0.626 & 0.191 & 1,900 & 2,249 & $\mathrm{~F}$ \\
\hline 8356 & 1382 & 0.08 & & 24.0 & 0.65 & 77.2 & -76.9 & 2000 & 23.9 & 135.9 & 70.5 & -65.4 & 0.647 & 0.563 & 0.084 & 4,371 & 5,130 & $\mathrm{~F}$ \\
\hline
\end{tabular}

$\mathrm{R}=-1$; triangular waveform

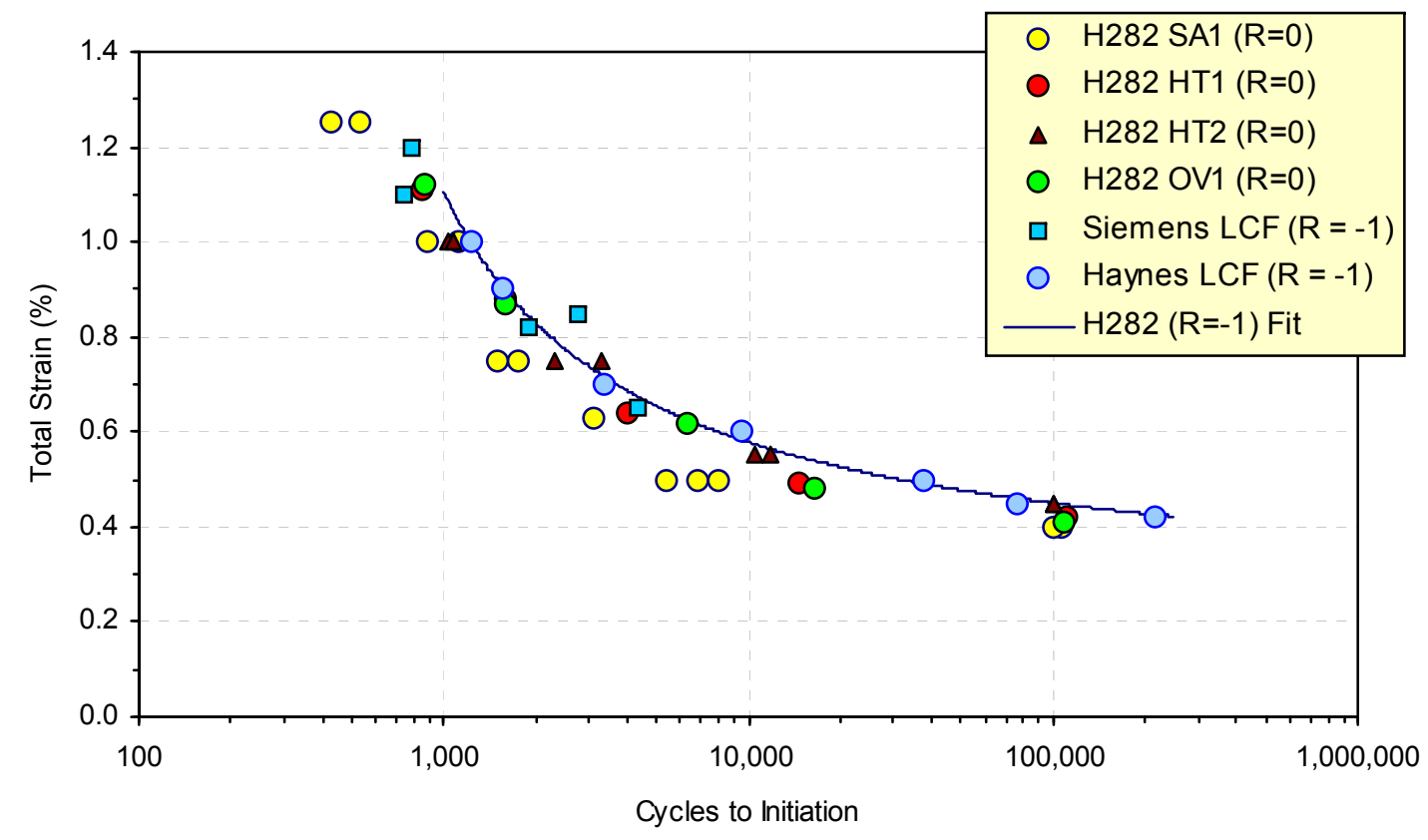

Figure 4.1: Combined low cycle fatigue data for Haynes 282 at $1400^{\circ} \mathrm{F}$ for $\mathrm{R}=$ ) and $\mathrm{R}=-1$ from $1.25 \%$ strain to $0.40 \%$ strain. 
Table 4B: Low Cycle Fatigue Data for Haynes 282 (sheet): Courtesy of Haynes International, Inc.

Haynes-sheet

\begin{tabular}{|c|c|c|c|c|c|c|c|c|c|c|c|c|c|c|c|c|c|c|}
\hline \multirow[b]{2}{*}{$\begin{array}{l}\text { Heat } \\
\text { No. }\end{array}$} & \multirow{2}{*}{$\begin{array}{c}\text { Test } \\
\text { Temp } \\
(\mathrm{F})\end{array}$} & \multirow[b]{2}{*}{$\begin{array}{l}\text { Freq. } \\
(\mathrm{Hz})\end{array}$} & \multirow{2}{*}{$\begin{array}{c}\text { RT } \\
\text { Mod } \\
\text { Ex10 }\end{array}$} & \multicolumn{4}{|c|}{ First Cycle } & \multirow{2}{*}{$\begin{array}{c}\text { Cycle } \\
\text { Data } \\
\text { Calc. }\end{array}$} & \multicolumn{7}{|c|}{ Midlife } & \multirow[b]{2}{*}{$\begin{array}{c}\text { Cycles } \\
\mathrm{N}_{\mathrm{i}}\end{array}$} & \multirow[b]{2}{*}{$\begin{array}{c}\text { Cycles } \\
\mathrm{N}_{\mathrm{f}}\end{array}$} & \multirow[b]{2}{*}{ Notes } \\
\hline & & & & $\begin{array}{c}\text { Mod } \\
\text { Ex10 }\end{array}$ & $\begin{array}{l}\Delta \varepsilon_{\mathrm{t}} \\
(\%)\end{array}$ & $\begin{array}{r}\sigma_{\max } \\
(\mathrm{ksi})\end{array}$ & $\begin{array}{l}\sigma_{\min } \\
(\mathrm{ksi})\end{array}$ & & $\begin{array}{c}\text { Mod } \\
\text { Ex10 }\end{array}$ & $\begin{array}{c}\Delta \sigma \\
(\mathrm{ksi})\end{array}$ & $\begin{array}{l}\sigma_{\max } \\
(\mathrm{ksi})\end{array}$ & $\begin{array}{c}\sigma_{\min } \\
(\mathrm{ksi})\end{array}$ & $\begin{array}{l}\Delta \varepsilon_{\mathrm{t}} \\
(\%)\end{array}$ & $\begin{array}{l}\Delta \varepsilon_{\mathrm{e}} \\
(\%)\end{array}$ & $\begin{array}{l}\Delta \varepsilon_{\mathrm{p}} \\
(\%)\end{array}$ & & & \\
\hline Haynes & 1200 & 0.33 & 29.3 & 25.0 & 1.00 & 84.8 & -91.5 & 1200 & 24.6 & 175.4 & 96.7 & -78.7 & 1.01 & 0.71 & 0.41 & 1,853 & 1,990 & $F$ \\
\hline Haynes & 1200 & 0.33 & 30.2 & 24.2 & 0.70 & 79.6 & -82.5 & 1430 & 23.8 & 131.8 & 64.0 & -67.8 & 0.70 & 0.55 & 0.15 & 4,840 & 5,714 & $\mathrm{~F}$ \\
\hline Haynes & 1200 & 0.33 & 29.6 & 24.5 & 0.60 & 72.5 & -72.5 & 2705 & 24.7 & 128.0 & 64.0 & -64.0 & 0.60 & 0.52 & 0.08 & 10,713 & 11,807 & $\mathrm{~F}$ \\
\hline Haynes & 1200 & 0.33 & 31.0 & 25.9 & 0.60 & 74.3 & -77.1 & 2000 & 25.9 & 131.0 & 63.6 & -67.4 & 0.60 & 0.51 & 0.09 & 4,746 & 5,621 & $\mathrm{~F}$ \\
\hline Haynes & 1200 & 0.33 & 29.6 & 24.3 & 0.50 & 59.7 & -59.2 & 47220 & 23.3 & 112.8 & 59.7 & -53.1 & 0.50 & 0.48 & 0.02 & 91,800 & 92,306 & $\mathrm{~F}$ \\
\hline
\end{tabular}

$\mathrm{R}=-1$; triangular waveform

Haynes-sheet

\begin{tabular}{|c|c|c|c|c|c|c|c|c|c|c|c|c|c|c|c|c|c|c|}
\hline \multirow[b]{2}{*}{$\begin{array}{l}\text { Heat } \\
\text { No. }\end{array}$} & \multirow{2}{*}{$\begin{array}{c}\text { Test } \\
\text { Temp } \\
\text { (F) }\end{array}$} & \multirow[b]{2}{*}{$\begin{array}{l}\text { Freq. } \\
(\mathrm{Hz})\end{array}$} & \multirow{2}{*}{$\begin{array}{c}\text { RT } \\
\text { Mod } \\
\text { Ex10 }\end{array}$} & \multicolumn{4}{|c|}{ First Cycle } & \multirow{2}{*}{$\begin{array}{l}\text { Cycle } \\
\text { Data } \\
\text { Calc. }\end{array}$} & \multicolumn{7}{|c|}{ Midlife } & \multirow[b]{2}{*}{$\begin{array}{c}\text { Cycles } \\
\mathrm{N}_{\mathrm{i}}\end{array}$} & \multirow[b]{2}{*}{$\begin{array}{c}\text { Cycles } \\
\mathrm{N}_{\mathrm{f}}\end{array}$} & \multirow[b]{2}{*}{ Notes } \\
\hline & & & & $\begin{array}{c}\text { Mod } \\
\text { Ex10 }\end{array}$ & $\begin{array}{l}\Delta \varepsilon_{\mathrm{t}} \\
(\%)\end{array}$ & $\begin{array}{l}\sigma_{\max } \\
(\mathrm{ksi})\end{array}$ & $\begin{array}{l}\sigma_{\min } \\
(\mathrm{ksi})\end{array}$ & & $\begin{array}{c}\text { Mod } \\
\text { Ex10 }\end{array}$ & $\begin{array}{c}\Delta \sigma \\
(\mathrm{ksi})\end{array}$ & $\begin{array}{l}\sigma_{\max } \\
(\mathrm{ksi})\end{array}$ & $\begin{array}{l}\sigma_{\min } \\
(\mathrm{ksi})\end{array}$ & $\begin{array}{l}\Delta \varepsilon_{\mathrm{t}} \\
(\%)\end{array}$ & $\begin{array}{l}\Delta \varepsilon_{\mathrm{e}} \\
(\%)\end{array}$ & $\begin{array}{l}\Delta \varepsilon_{\mathrm{p}} \\
(\%)\end{array}$ & & & \\
\hline Haynes & 1400 & 0.33 & 30.3 & 22.6 & 1.00 & 78.2 & -82.9 & 400 & 21.8 & 134.1 & 64.9 & -69.2 & 1.00 & 0.62 & 0.41 & 1,238 & 1,523 & $\mathrm{~F}$ \\
\hline Haynes & 1400 & 0.33 & 29.9 & 22.8 & 0.90 & 77.3 & -82.5 & 500 & 22.8 & 135.6 & 65.9 & -69.7 & 0.90 & 0.59 & 0.31 & 1,576 & 1,857 & $\mathrm{~F}$ \\
\hline Haynes & 1400 & 0.33 & 29.6 & 22.1 & 0.70 & 72.3 & -74.6 & 2500 & 22.7 & 112.7 & 55.4 & -57.3 & 0.70 & 0.50 & 0.20 & 3,337 & 3,979 & $\mathrm{~F}$ \\
\hline Haynes & 1400 & 0.33 & 30.3 & 22.9 & 0.60 & 67.6 & -67.4 & 4140 & 22.9 & 111.9 & 56.4 & -55.5 & 0.60 & 0.49 & 0.11 & 9,535 & 10,281 & $\mathrm{~F}$ \\
\hline Haynes & 1400 & 0.33 & 30.2 & 22.6 & 0.50 & 58.0 & -55.2 & 12571 & 22.2 & 102.8 & 55.2 & -47.6 & 0.50 & 0.46 & 0.04 & 37,877 & 39,484 & $\mathrm{~F}$ \\
\hline Haynes & 1400 & 0.33 & 30.0 & 22.9 & 0.45 & 49.5 & -50.5 & 27100 & 22.2 & 94.7 & 49.0 & -45.7 & 0.45 & 0.43 & 0.02 & 76,027 & 77,179 & $\mathrm{~F}$ \\
\hline Haynes & 1400 & 0.33 & 29.4 & 22.4 & 0.42 & 47.9 & -47.9 & 106510 & 22.4 & 90.5 & 47.9 & -42.6 & 0.42 & 0.40 & 0.02 & 214,727 & 216,151 & $\mathrm{~F}$ \\
\hline Haynes & 1400 & 0.33 & 30.3 & 23.0 & 0.40 & 44.8 & -45.7 & 85730 & 23.4 & 91.2 & 48.8 & -42.4 & 0.40 & 0.39 & 0.01 & 135,076 & 135,076 & $\mathrm{R}$ \\
\hline
\end{tabular}

$\mathrm{R}=-1$; triangular waveform 
Haynes-sheet

\begin{tabular}{|c|c|c|c|c|c|c|c|c|c|c|c|c|c|c|c|c|c|c|}
\hline \multirow[b]{2}{*}{$\begin{array}{l}\text { Heat } \\
\text { No. }\end{array}$} & \multirow{2}{*}{$\begin{array}{c}\text { Test } \\
\text { Temp } \\
(\mathrm{F})\end{array}$} & \multirow[b]{2}{*}{$\begin{array}{l}\text { Freq. } \\
(\mathrm{Hz})\end{array}$} & \multirow{2}{*}{$\begin{array}{c}\text { RT } \\
\text { Mod } \\
\text { Ex10 }\end{array}$} & \multicolumn{4}{|c|}{ First Cycle } & \multirow{2}{*}{$\begin{array}{c}\text { Cycle } \\
\text { Data } \\
\text { Calc. }\end{array}$} & \multicolumn{7}{|c|}{ Midlife } & \multirow[b]{2}{*}{$\begin{array}{c}\text { Cycles } \\
\mathrm{N}_{\mathrm{i}}\end{array}$} & \multirow[b]{2}{*}{$\begin{array}{c}\text { Cycles } \\
\mathrm{N}_{\mathrm{f}}\end{array}$} & \multirow[b]{2}{*}{ Notes } \\
\hline & & & & $\begin{array}{c}\text { Mod } \\
\text { Ex10 }\end{array}$ & $\begin{array}{l}\Delta \varepsilon_{\mathrm{t}} \\
(\%)\end{array}$ & $\begin{array}{l}\sigma_{\max } \\
(\mathrm{ksi})\end{array}$ & $\begin{array}{r}\sigma_{\min } \\
(\mathrm{ksi})\end{array}$ & & $\begin{array}{c}\text { Mod } \\
\text { Ex10 }\end{array}$ & $\begin{array}{c}\Delta \sigma \\
(\mathrm{ksi})\end{array}$ & $\begin{array}{c}\sigma_{\max } \\
(\mathrm{ksi})\end{array}$ & $\begin{array}{c}\sigma_{\min } \\
(\mathrm{ksi})\end{array}$ & $\begin{array}{l}\Delta \varepsilon_{\mathrm{t}} \\
(\%)\end{array}$ & $\begin{array}{l}\Delta \varepsilon_{\mathrm{e}} \\
(\%)\end{array}$ & $\begin{array}{l}\Delta \varepsilon_{\mathrm{p}} \\
(\%)\end{array}$ & & & \\
\hline Haynes & 1500 & 0.33 & 29.4 & 20.6 & 1.00 & 73.1 & -79.7 & 460 & 21.2 & 127.8 & 61.8 & -66.0 & 0.99 & 0.60 & 0.39 & 908 & 1,123 & $\mathrm{~F}$ \\
\hline Haynes & 1500 & 0.33 & 29.6 & 21.6 & 0.70 & 69.3 & -72.2 & 1225 & 21.7 & 116.0 & 56.6 & -59.4 & 0.70 & 0.53 & 0.17 & 1,639 & 2,444 & $\mathrm{~F}$ \\
\hline Haynes & 1500 & 0.33 & 29.4 & 21.5 & 0.60 & 62.3 & -62.7 & 2830 & 21.3 & 106.6 & 52.4 & -54.2 & 0.60 & 0.50 & 0.10 & 5,570 & 6,446 & $\mathrm{~F}$ \\
\hline Haynes & 1500 & 0.33 & 29.6 & 21.5 & 0.50 & 54.0 & -54.0 & 4930 & 21.9 & 101.6 & 50.2 & -51.4 & 0.50 & 0.46 & 0.04 & 8,601 & 9,135 & $\mathrm{~F}$ \\
\hline Haynes & 1500 & 0.33 & 29.9 & 21.9 & 0.50 & 54.0 & -54.9 & 6450 & 22.6 & 100.5 & 50.5 & -50.0 & 0.50 & 0.44 & 0.06 & 12,346 & 13,130 & $\mathrm{~F}$ \\
\hline Haynes & 1500 & 0.33 & 30.0 & 21.9 & 0.40 & 44.3 & -43.4 & 56534 & 21.9 & 88.2 & 47.2 & -41.0 & 0.41 & 0.40 & 0.01 & 116,379 & 118,360 & $\mathrm{~F}$ \\
\hline
\end{tabular}

$\mathrm{R}=-1$; triangular waveform

Haynes-sheet

\begin{tabular}{|c|c|c|c|c|c|c|c|c|c|c|c|c|c|c|c|c|c|c|}
\hline \multirow[b]{2}{*}{$\begin{array}{l}\text { Heat } \\
\text { No. }\end{array}$} & \multirow{2}{*}{$\begin{array}{c}\text { Test } \\
\text { Temp } \\
\text { (F) }\end{array}$} & \multirow[b]{2}{*}{$\begin{array}{l}\text { Freq. } \\
(\mathrm{Hz})\end{array}$} & \multirow{2}{*}{$\begin{array}{c}\text { RT } \\
\text { Mod } \\
\text { Ex10 }\end{array}$} & \multicolumn{4}{|c|}{ First Cycle } & \multirow{2}{*}{$\begin{array}{c}\text { Cycle } \\
\text { Data } \\
\text { Calc. }\end{array}$} & \multicolumn{7}{|c|}{ Midlife } & \multirow[b]{2}{*}{$\begin{array}{c}\text { Cycles } \\
\mathrm{N}_{\mathrm{i}}\end{array}$} & \multirow[b]{2}{*}{$\begin{array}{c}\text { Cycles } \\
\mathrm{N}_{\mathrm{f}}\end{array}$} & \multirow[b]{2}{*}{ Notes } \\
\hline & & & & $\begin{array}{c}\text { Mod } \\
\text { Ex10 }\end{array}$ & $\begin{array}{l}\Delta \varepsilon_{\mathrm{t}} \\
(\%)\end{array}$ & $\begin{array}{l}\sigma_{\max } \\
(\mathrm{ksi})\end{array}$ & $\begin{array}{r}\sigma_{\min } \\
(\mathrm{ksi})\end{array}$ & & $\begin{array}{c}\text { Mod } \\
\text { Ex10 }\end{array}$ & $\begin{array}{c}\Delta \sigma \\
(\mathrm{ksi})\end{array}$ & $\begin{array}{l}\sigma_{\max } \\
(\mathrm{ksi})\end{array}$ & $\begin{array}{c}\sigma_{\min } \\
(\mathrm{ksi})\end{array}$ & $\begin{array}{l}\Delta \varepsilon_{\mathrm{t}} \\
(\%)\end{array}$ & $\begin{array}{l}\Delta \varepsilon_{\mathrm{e}} \\
(\%)\end{array}$ & $\begin{array}{l}\Delta \varepsilon_{\mathrm{p}} \\
(\%)\end{array}$ & & & \\
\hline Haynes & 1600 & 0.33 & 30.3 & 20.1 & 0.70 & 64.2 & -67.0 & 460 & 20.1 & 123.1 & 59.9 & -63.2 & 0.70 & 0.61 & 0.09 & 869 & 930 & $\mathrm{~F}$ \\
\hline Haynes & 1600 & 0.33 & 30.0 & 20.0 & 0.60 & 56.8 & -57.3 & 800 & 19.7 & 108.9 & 53.5 & -55.4 & 0.60 & 0.55 & 0.05 & 1,345 & 1,744 & $\mathrm{~F}$ \\
\hline Haynes & 1600 & 0.33 & 30.0 & 20.3 & 0.50 & 50.7 & -50.9 & 1200 & 20.1 & 100.2 & 50.0 & -50.2 & 0.50 & 0.50 & 0.00 & 3,274 & 3,857 & $F$ \\
\hline Haynes & 1600 & 0.33 & 30.0 & 220.8 & 0.40 & 41.3 & -41.7 & 2000 & 20.4 & 82.8 & 41.5 & -41.3 & 0.40 & 0.41 & -0.01 & 14,959 & 15,795 & $\mathrm{~F}$ \\
\hline Haynes & 1600 & 0.33 & 29.6 & 21.1 & 0.30 & 31.9 & -31.0 & 82750 & 21.0 & 63.1 & 32.6 & -30.5 & 0.30 & 0.30 & 0.00 & 131,019 & 132,491 & $\mathrm{~F}$ \\
\hline
\end{tabular}

$\mathrm{R}=-1$; triangular waveform 


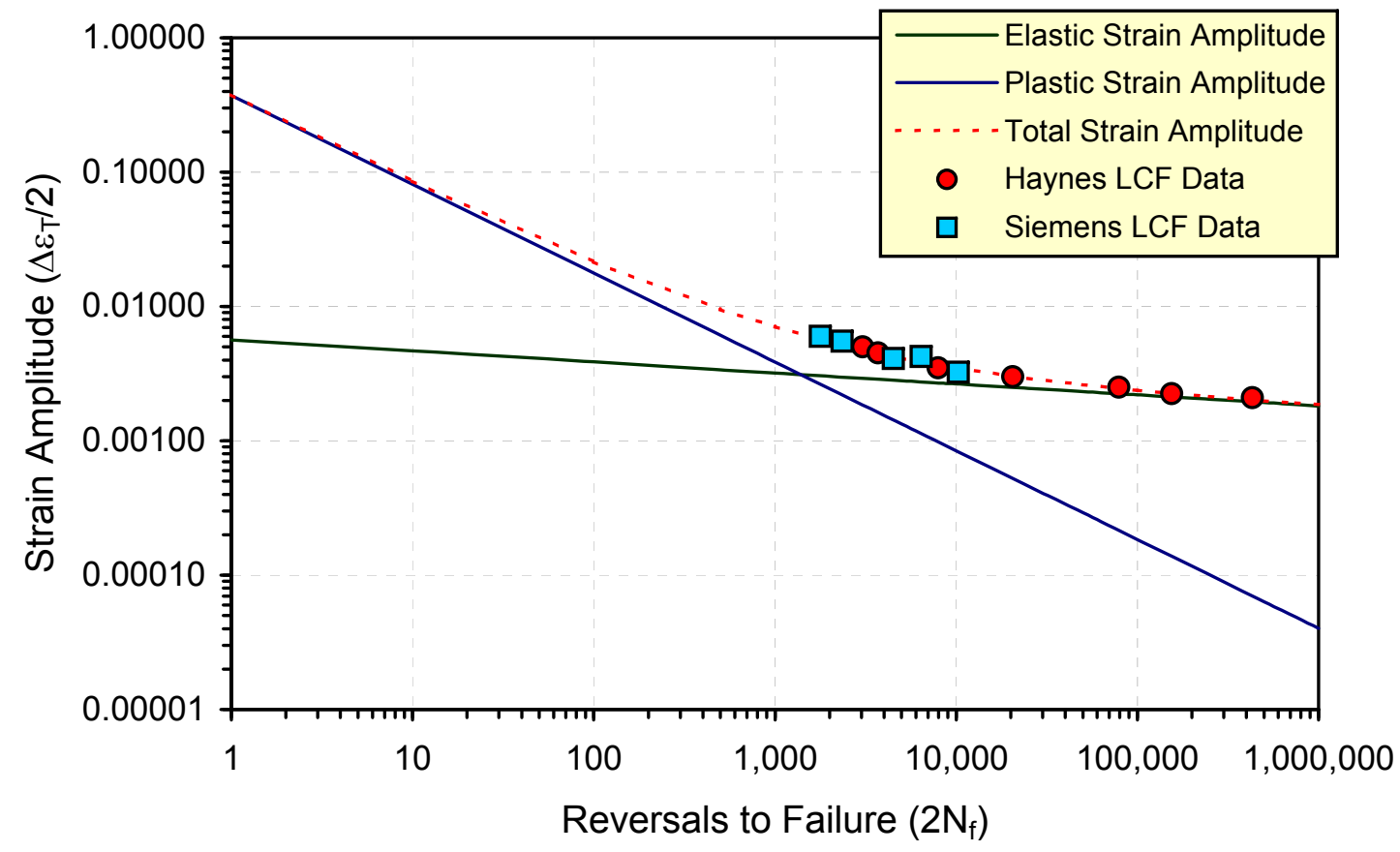

Figure 4.2: Strain amplitude versus reversals to failure for Haynes 282 at $1400^{\circ} F$ and $R=-1$ 
Table 4C: Low Cycle Fatigue Data for Nimonic 105 (rod): GE Testing

GE-cold drawn rod, as-processed (AP)

\begin{tabular}{|c|c|c|c|c|c|c|c|c|c|c|c|c|c|c|c|c|c|c|}
\hline \multirow[b]{2}{*}{$\begin{array}{l}\text { Heat } \\
\text { No. }\end{array}$} & \multirow{2}{*}{$\begin{array}{c}\text { Test } \\
\text { Temp } \\
(\mathrm{F})\end{array}$} & \multirow[b]{2}{*}{$\begin{array}{l}\text { Freq. } \\
(\mathrm{Hz})\end{array}$} & \multirow{2}{*}{$\begin{array}{c}\text { RT } \\
\text { Mod } \\
\text { Ex10 }\end{array}$} & \multicolumn{4}{|c|}{ First Cycle } & \multirow{2}{*}{$\begin{array}{l}\text { Cycle } \\
\text { Data } \\
\text { Calc. }\end{array}$} & \multicolumn{7}{|c|}{ Midlife } & \multirow[b]{2}{*}{$\begin{array}{c}\text { Cycles } \\
\mathrm{N}_{\mathrm{i}}\end{array}$} & \multirow[b]{2}{*}{$\begin{array}{c}\text { Cycles } \\
\mathrm{N}_{\mathrm{f}}\end{array}$} & \multirow[b]{2}{*}{ Notes } \\
\hline & & & & $\begin{array}{c}\text { Mod } \\
\text { Ex10 }\end{array}$ & $\begin{array}{l}\Delta \varepsilon_{\mathrm{t}} \\
(\%)\end{array}$ & $\begin{array}{l}\sigma_{\max } \\
(\mathrm{ksi})\end{array}$ & $\begin{array}{c}\sigma_{\min } \\
(\mathrm{ksi})\end{array}$ & & $\begin{array}{c}\text { Mod } \\
\text { Ex10 }\end{array}$ & $\begin{array}{c}\Delta \sigma \\
(\mathrm{ksi})\end{array}$ & $\begin{array}{l}\sigma_{\max } \\
(\mathrm{ksi})\end{array}$ & $\begin{array}{c}\sigma_{\min } \\
(\mathrm{ksi})\end{array}$ & $\begin{array}{l}\Delta \varepsilon_{\mathrm{t}} \\
(\%)\end{array}$ & $\begin{array}{l}\Delta \varepsilon_{\mathrm{e}} \\
(\%)\end{array}$ & $\begin{array}{l}\Delta \varepsilon_{\mathrm{p}} \\
(\%)\end{array}$ & & & \\
\hline 5183 & 1400 & 0.17 & 26.6 & 20.1 & 1.25 & 111.2 & -97.7 & 200 & 20.1 & 211.3 & 108.8 & -102.5 & 1.25 & 1.05 & 0.20 & 537 & 722 & $\mathrm{~F}$ \\
\hline 5183 & 1400 & 0.17 & 26.2 & 19.7 & 1.25 & 110.9 & -96.5 & 200 & 19.7 & 210.6 & 108.6 & -102.0 & 1.25 & 1.07 & 0.18 & 574 & 642 & F \\
\hline 5183 & 1400 & 0.33 & 27.0 & 20.4 & 1.00 & 109.2 & -81.1 & 1000 & 20.4 & 180.7 & 97.8 & -82.9 & 1.00 & 0.89 & 0.11 & 1,650 & 2,036 & $\mathrm{~F}$ \\
\hline 5183 & 1400 & 0.33 & 26.8 & 19.8 & 1.00 & 107.3 & -79.4 & 1000 & 20.2 & 178.2 & 96.4 & -81.8 & 1.00 & 0.88 & 0.12 & 1,625 & 2,040 & $\mathrm{~F}$ \\
\hline 5183 & 1400 & 0.33 & 26.5 & 20.5 & 0.75 & 105.7 & -46.8 & 200 & 20.3 & 152.5 & 104.2 & -48.3 & 0.75 & 0.75 & 0.00 & & 307 & $S$ \\
\hline 5183 & 1400 & 0.33 & 26.5 & 20.5 & 0.75 & 105.7 & -46.8 & 2000 & 20.5 & 152.5 & 97.8 & -54.7 & 0.75 & 0.74 & 0.01 & 6,146 & 6,456 & $\mathrm{~F}$ \\
\hline 5183 & 1400 & 0.33 & 26.4 & 20.1 & 0.75 & 106.2 & -43.2 & 2000 & 20.0 & 149.5 & 105.1 & -44.4 & 0.75 & 0.75 & 0.00 & 5,628 & 5,778 & $\mathrm{~F}$ \\
\hline 5183 & 1400 & 0.33 & 26.0 & 20.0 & 0.63 & 103.0 & -21.9 & 20000 & 20.3 & 128.1 & 88.9 & -39.2 & 0.63 & 0.63 & 0.00 & 45,328 & 48,827 & TL \\
\hline 5183 & 1400 & 0.33 & 26.3 & 20.0 & 0.50 & 94.9 & -5.5 & 111579 & 20.4 & 101.4 & 80.5 & -20.9 & 0.51 & 0.50 & 0.01 & 111,580 & 111,580 & $\mathrm{R}$ \\
\hline 5183 & 1400 & 0.33 & 26.5 & 20.1 & 0.50 & 96.3 & -4.4 & 109923 & 20.0 & 100.4 & 79.7 & -20.7 & 0.51 & 0.50 & 0.01 & 109,924 & 109,924 & $\mathrm{R}$ \\
\hline
\end{tabular}

$\mathrm{R}=0$; triangular waveform

GE-cold drawn rod, peak aged (PA)

\begin{tabular}{|c|c|c|c|c|c|c|c|c|c|c|c|c|c|c|c|c|c|c|}
\hline \multirow[b]{2}{*}{$\begin{array}{l}\text { Heat } \\
\text { No. }\end{array}$} & \multirow{2}{*}{$\begin{array}{c}\text { Test } \\
\text { Temp } \\
\text { (F) }\end{array}$} & \multirow[b]{2}{*}{$\begin{array}{l}\text { Freq. } \\
(\mathrm{Hz})\end{array}$} & \multirow{2}{*}{$\begin{array}{c}\text { RT } \\
\text { Mod } \\
\text { Ex10 }\end{array}$} & \multicolumn{4}{|c|}{ First Cycle } & \multirow{2}{*}{$\begin{array}{c}\text { Cycle } \\
\text { Data } \\
\text { Calc. }\end{array}$} & \multicolumn{7}{|c|}{ Midlife } & \multirow[b]{2}{*}{$\begin{array}{c}\text { Cycles } \\
\mathrm{N}_{\mathrm{i}}\end{array}$} & \multirow[b]{2}{*}{$\begin{array}{c}\text { Cycles } \\
\mathrm{N}_{\mathrm{f}}\end{array}$} & \multirow[b]{2}{*}{ Notes } \\
\hline & & & & $\begin{array}{c}\text { Mod } \\
\text { Ex10 }\end{array}$ & $\begin{array}{l}\Delta \varepsilon_{\mathrm{t}} \\
(\%)\end{array}$ & $\begin{array}{l}\sigma_{\max } \\
(\mathrm{ksi})\end{array}$ & $\begin{array}{l}\sigma_{\min } \\
(\mathrm{ksi})\end{array}$ & & $\begin{array}{c}\text { Mod } \\
\text { Ex10 }\end{array}$ & $\begin{array}{c}\Delta \sigma \\
(\mathrm{ksi})\end{array}$ & $\begin{array}{l}\sigma_{\max } \\
(\mathrm{ksi})\end{array}$ & $\begin{array}{r}\sigma_{\min } \\
(\mathrm{ksi})\end{array}$ & $\begin{array}{l}\Delta \varepsilon_{\mathrm{t}} \\
(\%)\end{array}$ & $\begin{array}{l}\Delta \varepsilon_{\mathrm{e}} \\
(\%)\end{array}$ & $\begin{array}{l}\Delta \varepsilon_{\mathrm{p}} \\
(\%)\end{array}$ & & & \\
\hline 5183 & 1400 & 0.17 & 27.1 & 20.2 & 1.25 & 108.9 & -96.6 & 351 & 19.5 & 192.8 & 98.4 & -94.4 & 1.25 & 0.99 & 0.26 & 580 & 588 & TL \\
\hline 5183 & 1400 & 0.17 & 26.2 & 19.3 & 1.25 & 107.8 & -94.5 & 200 & 19.5 & 208.3 & 106.7 & -101.6 & 1.24 & 1.07 & 0.17 & 520 & 529 & $\mathrm{~F}$ \\
\hline 5183 & 1400 & 0.33 & 27.1 & 19.9 & 1.00 & 106.2 & -80.2 & 500 & 19.8 & 170.6 & 93.6 & -77.0 & 1.00 & 0.86 & 0.14 & 1,561 & 1,578 & $\mathrm{~F}$ \\
\hline 5183 & 1400 & 0.33 & 26.3 & 19.6 & 1.00 & 105.3 & -80.6 & 500 & 19.7 & 170.2 & 94.7 & -75.5 & 1.00 & 0.86 & 0.14 & & 1,305 & $\mathrm{~F}$ \\
\hline 5183 & 1400 & 0.33 & 27.1 & 20.2 & 1.00 & 105.1 & -82.6 & 500 & 19.9 & 173.7 & 95.2 & -78.5 & 1.00 & 0.87 & 0.13 & 1,022 & 1,053 & TL \\
\hline 5183 & 1400 & 0.33 & 28.4 & 20.9 & 0.75 & 102.5 & -54.2 & 1000 & 20.8 & 149.6 & 94.5 & -55.1 & 0.76 & 0.72 & 0.04 & 2,140 & 2,694 & $\mathrm{~F}$ \\
\hline 5183 & 1400 & 0.33 & 26.4 & 19.9 & 0.75 & 101.7 & -46.4 & 1000 & 19.9 & 144.4 & 94.6 & -49.8 & 0.75 & 0.73 & 0.02 & 2,613 & 2,812 & $\mathrm{~F}$ \\
\hline 5183 & 1400 & 0.33 & 27.0 & 20.0 & 0.75 & 99.6 & -50.2 & 2000 & 20.3 & 142.5 & 88.6 & -53.9 & 0.75 & 0.70 & 0.05 & 2,579 & 2,668 & TL \\
\hline 5183 & 1400 & 0.33 & 27.3 & 20.6 & 0.50 & 90.9 & -10.4 & 28724 & 20.6 & 101.9 & 79.3 & -22.6 & 0.50 & 0.49 & 0.01 & 45,030 & 47,230 & TL \\
\hline 5183 & 1400 & 0.33 & 27.2 & 20.2 & 0.50 & 91.4 & -8.5 & 24510 & 20.1 & 99.6 & 84.2 & -15.4 & 0.50 & 0.50 & 0.00 & 28,800 & 30,459 & TL \\
\hline
\end{tabular}

$\mathrm{R}=0$; triangular waveform 
GE-rod, peak aged (PA)

\begin{tabular}{|c|c|c|c|c|c|c|c|c|c|c|c|c|c|c|c|c|c|c|}
\hline \multirow[b]{2}{*}{$\begin{array}{l}\text { Heat } \\
\text { No. }\end{array}$} & \multirow{2}{*}{$\begin{array}{l}\text { Test } \\
\text { Temp } \\
(\mathrm{F})\end{array}$} & \multirow[b]{2}{*}{$\begin{array}{l}\text { Freq. } \\
(\mathrm{Hz})\end{array}$} & \multirow{2}{*}{$\begin{array}{c}\text { RT } \\
\text { Mod } \\
\text { Ex10 }\end{array}$} & \multicolumn{4}{|c|}{ First Cycle } & \multirow{2}{*}{$\begin{array}{l}\text { Cycle } \\
\text { Data } \\
\text { Calc. }\end{array}$} & \multicolumn{7}{|c|}{ Midlife } & \multirow[b]{2}{*}{$\begin{array}{c}\text { Cycles } \\
\mathrm{N}_{\mathrm{i}}\end{array}$} & \multirow[b]{2}{*}{$\begin{array}{c}\text { Cycles } \\
\mathrm{N}_{\mathrm{f}}\end{array}$} & \multirow[b]{2}{*}{ Notes } \\
\hline & & & & $\begin{array}{c}\text { Mod } \\
\text { Ex10 }\end{array}$ & $\begin{array}{l}\Delta \varepsilon_{\mathrm{t}} \\
(\%)\end{array}$ & $\begin{array}{l}\sigma_{\max } \\
(\mathrm{ksi})\end{array}$ & $\begin{array}{c}\sigma_{\min } \\
(\mathrm{ksi})\end{array}$ & & $\begin{array}{c}\text { Mod } \\
\text { Ex10 }\end{array}$ & $\begin{array}{c}\Delta \sigma \\
(\mathrm{ksi})\end{array}$ & $\begin{array}{l}\sigma_{\max } \\
(\mathrm{ksi})\end{array}$ & $\begin{array}{c}\sigma_{\min } \\
(\mathrm{ksi})\end{array}$ & $\begin{array}{l}\Delta \varepsilon_{\mathrm{t}} \\
(\%)\end{array}$ & $\begin{array}{l}\Delta \varepsilon_{\mathrm{e}} \\
(\%)\end{array}$ & $\begin{array}{l}\Delta \varepsilon_{\mathrm{p}} \\
(\%)\end{array}$ & & & \\
\hline 5793 & 1400 & 0.17 & 28.6 & 21.8 & 1.25 & 107.5 & -102.7 & 100 & 21.6 & 206.6 & 104.0 & -102.6 & 1.25 & 0.96 & 0.29 & 229 & 291 & $\mathrm{~F}$ \\
\hline 5793 & 1400 & 0.33 & 28.6 & 22.0 & 1.00 & 99.0 & -87.0 & 500 & 21.7 & 167.1 & 87.9 & -79.2 & 1.00 & 0.77 & 0.23 & 940 & 1,088 & $F$ \\
\hline 5793 & 1400 & 0.33 & 29.2 & 22.3 & 0.75 & 103.5 & -61.9 & 1868 & 22.3 & 150.0 & 87.7 & -62.3 & 0.75 & 0.67 & 0.08 & 2,568 & 3,213 & $\mathrm{~F}$ \\
\hline 5793 & 1400 & 0.33 & 29.0 & 22.2 & 0.63 & 99.6 & -39.0 & 2000 & 22.3 & 136.3 & 94.6 & -41.7 & 0.63 & 0.61 & 0.02 & 4,855 & 4,913 & $\mathrm{~F}$ \\
\hline 5793 & 1400 & 0.33 & 29.0 & 22.4 & 0.63 & 101.3 & -38.7 & 2000 & 22.3 & 137.1 & 95.4 & -41.7 & 0.63 & 0.61 & 0.02 & 6,103 & 6,225 & $\mathrm{~F}$ \\
\hline 5793 & 1400 & 0.33 & 30.3 & 23.5 & 0.50 & 97.8 & -19.3 & 50000 & 23.6 & 117.7 & 94.0 & -23.7 & 0.50 & 0.50 & 0.00 & 78,225 & 78,536 & $\mathrm{~F}$ \\
\hline 5793 & 1400 & 0.33 & 28.6 & 21.9 & 0.50 & 95.3 & -13.2 & 26272 & 22.0 & 109.5 & 92.5 & -17.0 & 0.50 & 0.50 & 0.00 & 49,461 & 49,893 & $\mathrm{~F}$ \\
\hline
\end{tabular}

$\mathrm{R}=0$; triangular waveform 


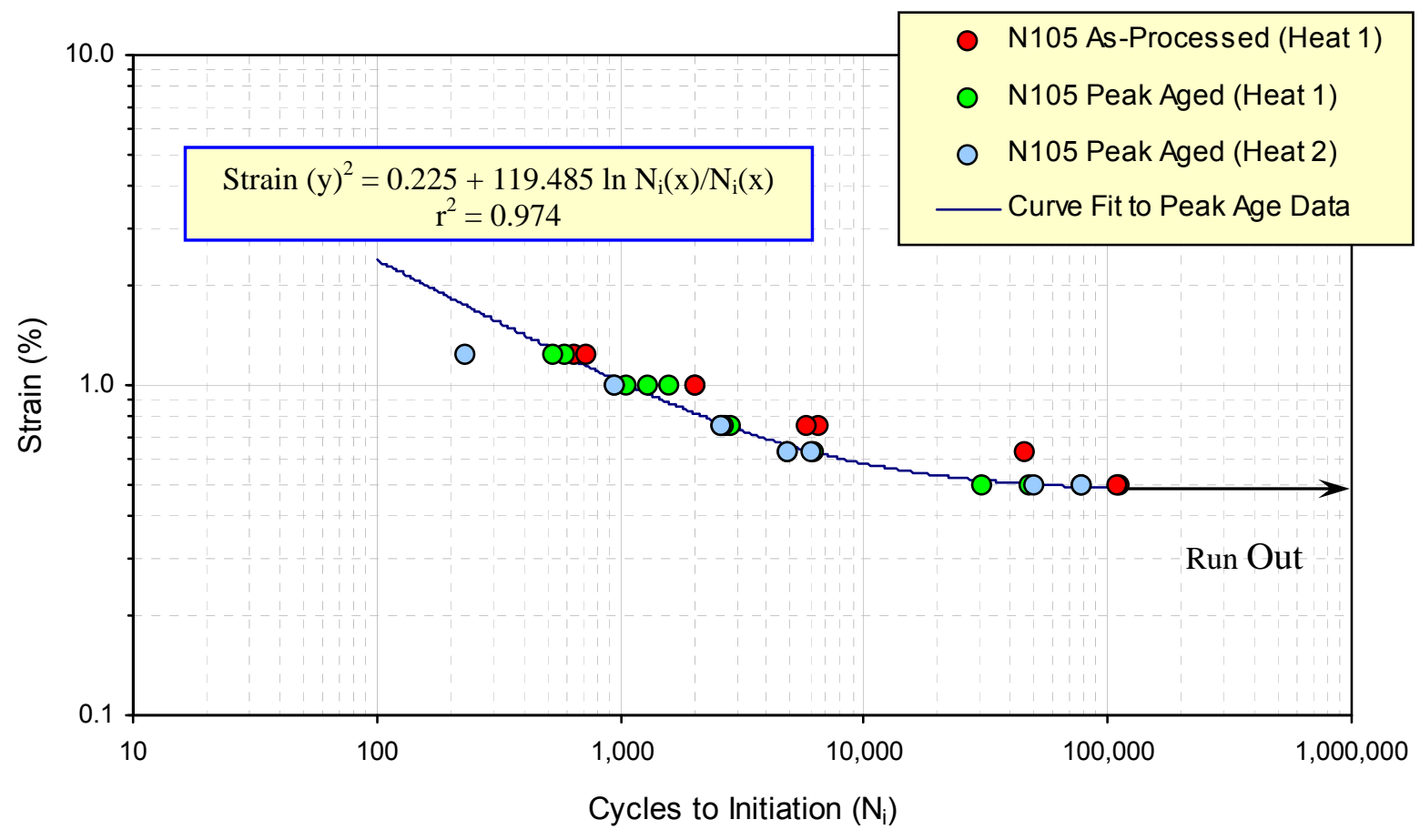

Figure 4.1: Combined low cycle fatigue data for Nimonic 105 at $1400^{\circ} \mathrm{F}$ for $\mathrm{R}=0$ from $1.25 \%$ strain to $0.50 \%$ strain. 
Table 4D: Low Cycle Fatigue Data for Udimet 720Li (forged disk): SW Testing SW-forged disk

\begin{tabular}{|c|c|c|c|c|c|c|c|c|c|c|c|c|c|c|c|c|c|c|}
\hline \multirow[b]{2}{*}{$\begin{array}{c}\text { Heat } \\
\text { No. }\end{array}$} & \multirow{2}{*}{$\begin{array}{c}\text { Test } \\
\text { Temp } \\
(\mathrm{F})\end{array}$} & \multirow[b]{2}{*}{$\begin{array}{c}\text { Freq. } \\
(6 \% / \mathrm{min})\end{array}$} & \multirow{2}{*}{$\begin{array}{c}\text { RT } \\
\text { Mod } \\
\text { Ex10 }\end{array}$} & \multicolumn{4}{|c|}{ First Cycle } & \multirow{2}{*}{$\begin{array}{c}\text { Cycle } \\
\text { Data } \\
\text { Calc. }\end{array}$} & \multicolumn{7}{|c|}{ Midlife } & \multirow[b]{2}{*}{$\begin{array}{c}\text { Cycles } \\
\mathrm{N}_{\mathrm{i}}\end{array}$} & \multirow{2}{*}{$\begin{array}{c}\text { Cycles } \\
\mathrm{N}_{\mathrm{f}}\end{array}$} & \multirow[b]{2}{*}{ Notes } \\
\hline & & & & $\begin{array}{c}\text { Mod } \\
\text { Ex10 }\end{array}$ & $\begin{array}{l}\Delta \varepsilon_{\mathrm{t}} \\
(\%)\end{array}$ & $\begin{array}{l}\sigma_{\max } \\
(\mathrm{ksi})\end{array}$ & $\begin{array}{c}\sigma_{\min } \\
(\mathrm{ksi})\end{array}$ & & $\begin{array}{c}\text { Mod } \\
\text { Ex10 }^{6}\end{array}$ & $\begin{array}{c}\Delta \sigma \\
(\mathrm{ksi})\end{array}$ & $\begin{array}{l}\sigma_{\max } \\
(\mathrm{ksi})\end{array}$ & $\begin{array}{l}\sigma_{\min } \\
(\mathrm{ksi})\end{array}$ & $\begin{array}{l}\Delta \varepsilon_{\mathrm{t}} \\
(\%)\end{array}$ & $\begin{array}{l}\Delta \varepsilon_{\mathrm{e}} \\
(\%)\end{array}$ & $\begin{array}{l}\Delta \varepsilon_{\mathrm{p}} \\
(\%)\end{array}$ & & & \\
\hline $\mathrm{LH}$ & 1292 & 0.04 & & 25.6 & 1.20 & 142.9 & -142.8 & 400 & 25.5 & 278.0 & 140.1 & -137.9 & 1.200 & 1.083 & 0.117 & 772 & 865 & $\mathrm{~F}$ \\
\hline $\mathrm{LH}$ & 1382 & 0.05 & & 25.0 & 1.10 & 123.9 & -109.3 & 300 & 25.1 & 236.2 & 126.7 & -109.5 & 1.100 & 0.958 & 0.142 & 718 & 789 & $\mathrm{~F}$ \\
\hline $\mathrm{LH}$ & 1292 & 0.01 & & 24.5 & 0.83 & 101.8 & -97.1 & 2000 & 25.0 & 203.4 & 117.4 & -85.9 & 0.833 & 0.810 & 0.023 & & 5,000 & $\mathrm{R}$ \\
\hline $\mathrm{LH}$ & 1382 & 0.07 & & 25.5 & 0.76 & 93.8 & -94.7 & 3000 & 25.0 & 182.4 & 94.7 & -87.7 & 0.759 & 0.712 & 0.047 & 5,730 & 6,314 & $\mathrm{~F}$ \\
\hline LH & 1382 & 0.13 & & 24.4 & 0.40 & 48.1 & -48.2 & 5000 & 23.8 & 95.6 & 50.7 & -44.8 & 0.401 & 0.391 & 0.010 & & 10,000 & $\mathrm{R}$ \\
\hline
\end{tabular}

$\mathrm{R}=-1$, triangular waveform

Table 4E: Low Cycle Fatigue Data for Alloy 617 (plate): SW Testing SW-plate

\begin{tabular}{|c|c|c|c|c|c|c|c|c|c|c|c|c|c|c|c|c|c|c|}
\hline \multirow[b]{2}{*}{$\begin{array}{l}\text { Heat } \\
\text { No. }\end{array}$} & \multirow{2}{*}{$\begin{array}{c}\text { Test } \\
\text { Temp } \\
(\mathrm{F})\end{array}$} & \multirow[b]{2}{*}{$\begin{array}{c}\text { Freq. } \\
(6 \% / \mathrm{min})\end{array}$} & \multirow{2}{*}{$\begin{array}{c}\text { RT } \\
\text { Mod } \\
\text { Ex10 }\end{array}$} & \multicolumn{4}{|c|}{ First Cycle } & \multirow{2}{*}{$\begin{array}{l}\text { Cycle } \\
\text { Data } \\
\text { Calc. }\end{array}$} & \multicolumn{7}{|c|}{ Midlife } & \multirow[b]{2}{*}{$\begin{array}{c}\text { Cycles } \\
\mathrm{N}_{\mathrm{i}}\end{array}$} & \multirow[b]{2}{*}{$\begin{array}{c}\text { Cycles } \\
\mathrm{N}_{\mathrm{f}}\end{array}$} & \multirow[b]{2}{*}{ Notes } \\
\hline & & & & $\begin{array}{l}\text { Mod } \\
\text { Ex10 }\end{array}$ & $\begin{array}{l}\Delta \varepsilon_{\mathrm{t}} \\
(\%)\end{array}$ & $\begin{array}{l}\sigma_{\max } \\
(\mathrm{ksi})\end{array}$ & $\begin{array}{l}\sigma_{\min } \\
(\mathrm{ksi})\end{array}$ & & $\begin{array}{c}\text { Mod } \\
\text { Ex10 }\end{array}$ & $\begin{array}{c}\Delta \sigma \\
(\mathrm{ksi})\end{array}$ & $\begin{array}{l}\sigma_{\max } \\
(\mathrm{ksi})\end{array}$ & $\begin{array}{r}\sigma_{\min } \\
(\mathrm{ksi})\end{array}$ & $\begin{array}{l}\Delta \varepsilon_{\mathrm{t}} \\
(\%)\end{array}$ & $\begin{array}{l}\Delta \varepsilon_{\mathrm{e}} \\
(\%)\end{array}$ & $\begin{array}{l}\Delta \varepsilon_{\mathrm{p}} \\
(\%)\end{array}$ & & & \\
\hline 8356 & 1292 & 0.06 & & 23.5 & 0.80 & 55.3 & -55.8 & 1000 & 23.9 & 136.3 & 67.6 & -68.7 & 0.805 & 0.579 & 0.226 & 1,756 & 2,317 & $F$ \\
\hline 8356 & 1382 & 0.07 & & 23.6 & 0.75 & 52.5 & -54.9 & 700 & 23.9 & 127.9 & 62.5 & -65.3 & 0.749 & 0.470 & 0.279 & 1,471 & 1,559 & $\mathrm{~F}$ \\
\hline 8356 & 1292 & 0.08 & & 25.8 & 0.60 & 48.5 & -50.1 & 2000 & 25.4 & 121.1 & 60.2 & -60.9 & 0.600 & 0.490 & 0.110 & & 5,000 & $\mathrm{R}$ \\
\hline 8356 & 1382 & 0.09 & & 23.0 & 0.55 & 51.9 & -47.5 & 1000 & 23.0 & 107.4 & 55.1 & -52.4 & 0.551 & 0.468 & 0.083 & 3,787 & 3,913 & $\mathrm{~F}$ \\
\hline 8356 & 1382 & 0.12 & & 24.0 & 0.43 & 45.3 & -45.9 & 5000 & 24.7 & 99.1 & 50.2 & -48.9 & 0.433 & 0.399 & 0.034 & & 10,000 & $\mathrm{R}$ \\
\hline
\end{tabular}

$\mathrm{R}=-1$; triangular waveform 



\begin{abstract}
APPENDIX 5
CREEP AND CREEP RUPTURE FOR CANDIDATE NICKEL SUPERALLOY
\end{abstract}


Table 5A: Creep and Creep Rupture for Haynes 282 (plate): GE \& SW Testing

\begin{tabular}{|c|c|c|c|c|c|c|c|c|c|}
\hline $\begin{array}{l}\text { Heat } \\
\text { No. }\end{array}$ & Cond. & $\begin{array}{l}\text { Temp. } \\
\text { (F) }\end{array}$ & $\begin{array}{c}\text { Stress } \\
\text { (ksi) }\end{array}$ & $\begin{array}{l}\text { Time } \\
\text { (h) }\end{array}$ & $\begin{array}{c}\text { Strain } \\
(\%)\end{array}$ & $\begin{array}{c}\text { Elong. } \\
\text { (\%) }\end{array}$ & $\begin{array}{l}\text { RA } \\
(\%)\end{array}$ & $\mathrm{LMP}_{\mathrm{f}}$ & Status \\
\hline 8354 & SA & 1375 & 40.0 & $5,092.0$ & 23.266 & 24.8 & 40.0 & 43.5021 & Failed \\
\hline 8354 & SA & 1375 & 20.0 & $13,988.0$ & 0.083 & & & & Removed \\
\hline 8354 & SA & 1375 & 17.5 & $13,998.2$ & 0.049 & & & & Removed \\
\hline 8354 & SA & 1400 & 37.5 & $3,718.4$ & 18.786 & 20.3 & 37.7 & 43.8409 & Failed \\
\hline 8354 & SA & 1400 & 32.5 & 7,921.7 & 18.293 & 19.2 & 44.2 & 44.4518 & Failed \\
\hline 8354 & SA & 1400 & 20.0 & $13,650.4$ & 0.204 & & & & Removed \\
\hline 8354 & SA & 1400 & 17.5 & $13,881.1$ & 0.113 & & & & Removed \\
\hline 8354 & SA & 1400 & 15.0 & $13,852.4$ & 0.062 & & & & Removed \\
\hline 8354 & SA & 1425 & 30.0 & 5,980.9 & 25.394 & 26.9 & 45.9 & 44.8192 & Failed \\
\hline 8354 & SA & 1425 & 20.0 & $13,841.1$ & 0.329 & & & & Removed \\
\hline 8354 & SA & 1425 & 17.5 & $13,703.9$ & 0.229 & & & & Removed \\
\hline 8354 & SA & 1425 & 15.0 & $13,877.2$ & 0.109 & & & & Removed \\
\hline 8354 & SA & 1450 & 27.5 & $4,540.3$ & 23.466 & 24.9 & 51.9 & 45.1850 & Failed \\
\hline 8354 & SA & 1450 & 22.5 & $12,555.5$ & 23.486 & 24.8 & 40.3 & 46.0288 & Failed \\
\hline 8354 & SA & 1450 & 15.0 & $13,849.8$ & 0.260 & & & & Removed \\
\hline 8356SW & PA & 1292 & 73.1 & 452.6 & 14.682 & 14.0 & 17.2 & 39.6928 & Failed \\
\hline 8356SW & PA & 1292 & 62.5 & $1,960.4$ & 18.003 & 20.7 & 27.8 & 40.8082 & Failed \\
\hline 8356 & PA & 1375 & 37.5 & $4,487.7$ & 20.989 & 22.4 & 47.9 & 43.4015 & Failed \\
\hline 8356SW & PA & 1382 & 50.9 & 689.3 & 30.617 & 33.4 & 43.6 & 42.0683 & Failed \\
\hline 8356SW & PA & 1382 & 41.8 & $2,357.0$ & 26.141 & 28.2 & 41.5 & 43.0519 & Failed \\
\hline 8356SW & PA & 1382 & 34.5 & $6,459.8$ & 29.378 & 31.3 & 37.1 & 43.8584 & Failed \\
\hline 8356 & PA & 1400 & 35.0 & $3,412.3$ & 21.500 & 23.4 & 49.8 & 43.7715 & Failed \\
\hline 8354 & PA & 1400 & 20.0 & $10,370.2$ & 0.109 & & & & Removed \\
\hline 8354 & PA & 1400 & 17.5 & $10,469.7$ & 0.054 & & & & Removed \\
\hline 8354 & PA & 1400 & 15.0 & $10,470.6$ & 0.042 & & & & Removed \\
\hline 8356 & PA & 1425 & 32.5 & 2,409.8 & 24.427 & 27.5 & 55.8 & 44.0750 & Failed \\
\hline 8356 & PA & 1425 & 27.5 & $5,794.8$ & 30.769 & 32.6 & 56.3 & 44.7933 & Failed \\
\hline 8356 & PA & 1450 & 25.0 & $4,750.2$ & 30.815 & 32.0 & 55.8 & 45.2225 & Failed \\
\hline 8356 & PA & 1450 & 22.5 & $8,650.4$ & 28.825 & 29.8 & 48.7 & 45.7197 & Failed \\
\hline 8354 & OA & 1375 & 40.0 & $4,772.7$ & 17.316 & 18.2 & 41.8 & 43.4505 & Failed \\
\hline 8354 & OA & 1400 & 35.0 & $4,503.7$ & 15.909 & 16.6 & 44.0 & 43.9956 & Failed \\
\hline 8354 & OA & 1425 & 27.5 & $9,080.6$ & 16.818 & 18.2 & 28.2 & 45.1610 & Failed \\
\hline
\end{tabular}




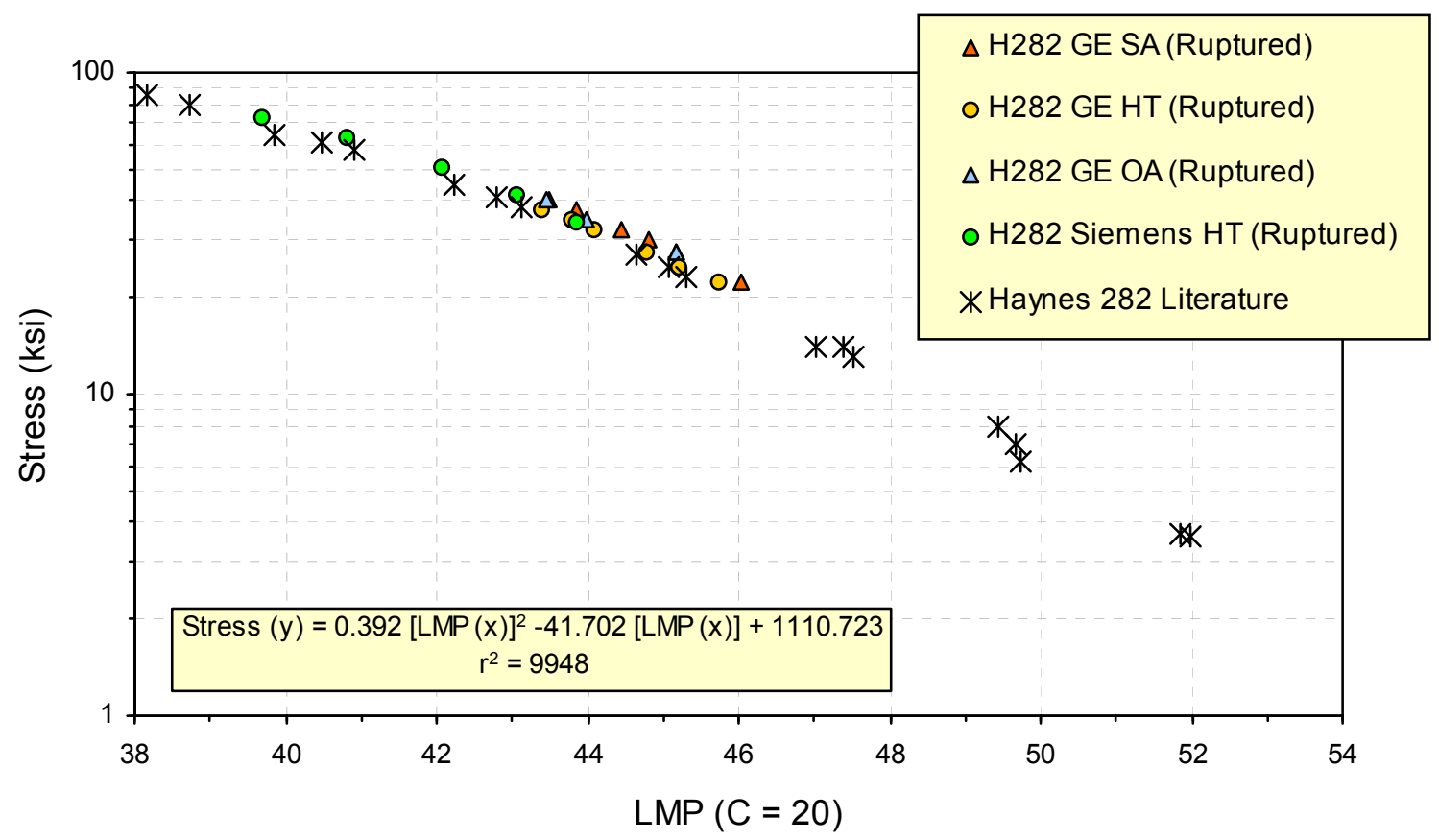

Figure 5.1: Stress $(\mathrm{ksi})$ versus LMP $(\mathrm{C}=\mathbf{2 0})$ for Haynes 282 in three alloy conditions: solution annealed (SA), heat treated to peak age (HT), and overaged (OA).

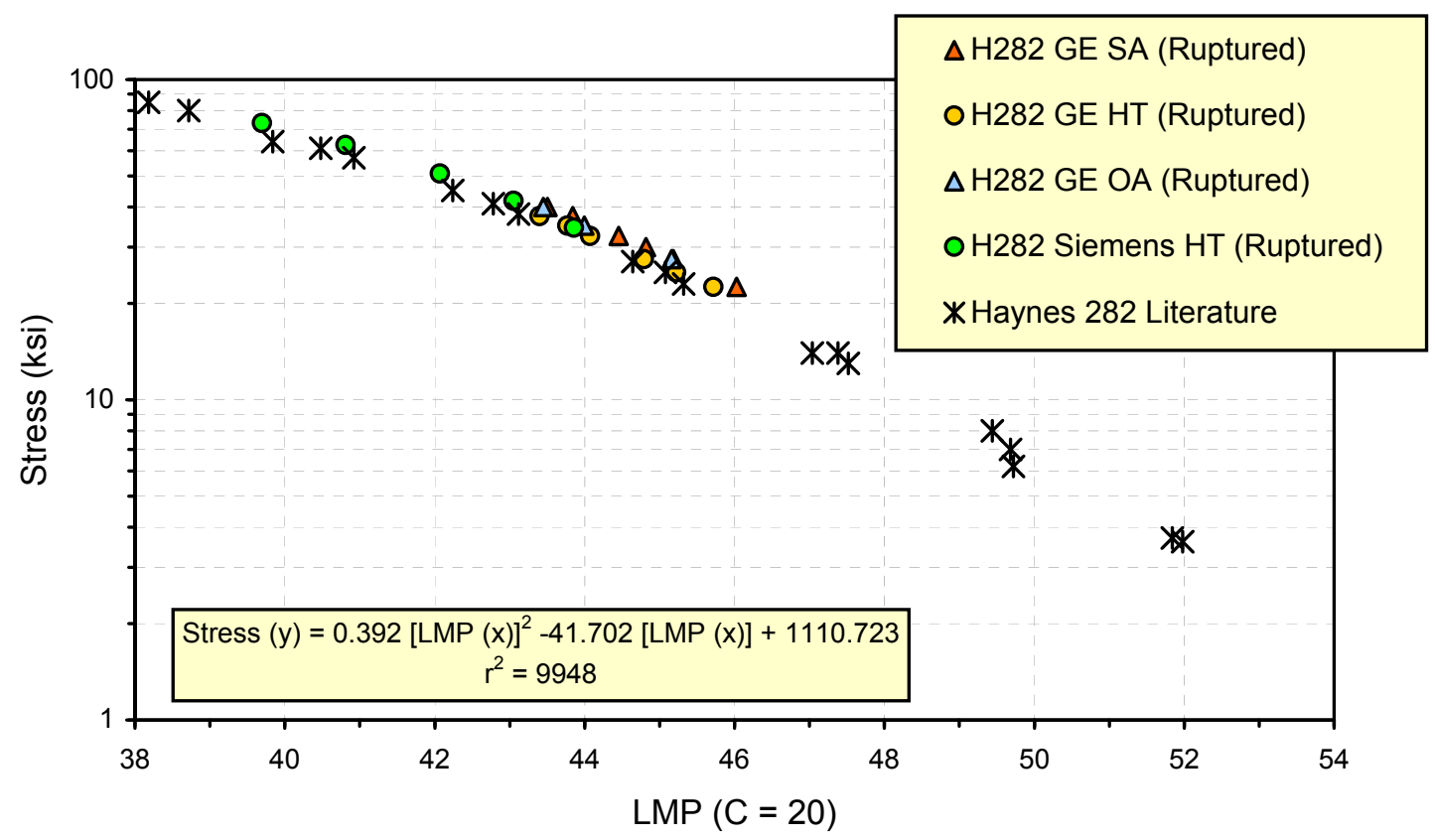

Figure 5.2: LMP $(C=20)$ versus stress $(\mathrm{ksi})$ for combined Haynes 282 rupture data. 
Table 5B: Time to Reach \% Creep Strain for Haynes 282 (plate): GE \& SW Testing

\begin{tabular}{|c|c|c|c|c|c|c|c|c|c|}
\hline \multirow{2}{*}{$\begin{array}{l}\text { Heat } \\
\text { No. }\end{array}$} & \multirow{2}{*}{ Cond. } & \multirow{2}{*}{$\begin{array}{c}\text { Temp. } \\
\text { (F) }\end{array}$} & \multirow{2}{*}{$\begin{array}{c}\text { Stress } \\
\text { (ksi) }\end{array}$} & \multicolumn{6}{|c|}{ Time to Reach Creep Strain } \\
\hline & & & & $0.1 \%$ & $0.2 \%$ & $0.5 \%$ & $1.0 \%$ & $2.0 \%$ & $5.0 \%$ \\
\hline 8354 & SA & 1375 & 40.0 & 305.1 & 844.5 & $1,760.4$ & $2,491.5$ & $3,188.4$ & $4,078.5$ \\
\hline 8354 & SA & 1375 & 20.0 & & & & & & \\
\hline 8354 & SA & 1375 & 17.5 & & & & & & \\
\hline 8354 & SA & 1400 & 37.5 & 318.9 & 731.0 & $1,392.2$ & $1,952.9$ & $2,457.4$ & $3,072.7$ \\
\hline 8354 & SA & 1400 & 32.5 & 964.4 & $1,880.0$ & $3,315.0$ & $4,396.4$ & $5,436.2$ & $6,661.9$ \\
\hline 8354 & SA & 1400 & 20.0 & $4,110.0$ & $13,478.7$ & & & & \\
\hline 8354 & SA & 1400 & 17.5 & $10,520.8$ & & & & & \\
\hline 8354 & SA & 1400 & 15.0 & & & & & & \\
\hline 8354 & SA & 1425 & 30.0 & 688.9 & $1,394.8$ & $2,405.1$ & $3,120.9$ & $3,880.6$ & $4,818.8$ \\
\hline 8354 & SA & 1425 & 20.0 & $5,107.8$ & $9,587.9$ & & & & \\
\hline 8354 & SA & 1425 & 17.5 & $5,658.9$ & $11,651.1$ & & & & \\
\hline 8354 & SA & 1425 & 15.0 & $11,808.2$ & & & & & \\
\hline 8354 & SA & 1450 & 27.5 & $1,327.9$ & $1,665.3$ & $2,213.7$ & $2,603.5$ & $3,038.2$ & $3,650.5$ \\
\hline 8354 & SA & 1450 & 22.5 & $1,143.5$ & $2,549.3$ & $4,599.7$ & $6,180.4$ & $7,634.8$ & $9,563.0$ \\
\hline 8354 & SA & 1450 & 15.0 & $2,004.7$ & $9,202.3$ & & & & \\
\hline 8356SW & PA & 1292 & 73.1 & 76.7 & 124.9 & 188.8 & 231.3 & 277.1 & 350.7 \\
\hline 8356SW & PA & 1292 & 62.5 & 249.5 & 465.7 & 806.9 & $1,033.3$ & $1,253.5$ & $1,555.2$ \\
\hline 8356 & PA & 1375 & 37.5 & 118.8 & 530.6 & $1,450.9$ & $2,174.2$ & $2,900.9$ & $3,729.7$ \\
\hline 8356SW & PA & 1382 & 50.9 & 27.9 & 63.7 & 193.0 & 292.8 & 376.4 & 487.4 \\
\hline 8356SW & PA & 1382 & 41.8 & 105.7 & 303.5 & 834.0 & $1,179.0$ & $1,489.5$ & $1,866.4$ \\
\hline 8356SW & PA & 1382 & 34.5 & 625.1 & $1,413.3$ & $2,636.2$ & $3,431.9$ & $4,168.4$ & $5,145.1$ \\
\hline 8356 & PA & 1400 & 35.0 & 294.7 & 746.8 & $1,404.4$ & $1,870.0$ & $2,299.6$ & $2,846.3$ \\
\hline 8354 & PA & 1400 & 20.0 & $8,528.6$ & & & & & \\
\hline 8354 & PA & 1400 & 17.5 & & & & & & \\
\hline 8354 & PA & 1400 & 15.0 & & & & & & \\
\hline 8356 & PA & 1425 & 32.5 & 185.8 & 429.0 & 849.5 & $1,198.7$ & $1,515.8$ & $1,908.6$ \\
\hline 8356 & PA & 1425 & 27.5 & 718.4 & $1,363.1$ & $2,296.9$ & $2,973.2$ & $3,621.7$ & $4,518.8$ \\
\hline 8356 & PA & 1450 & 25.0 & 511.8 & $1,007.9$ & $1,773.1$ & $2,398.4$ & $3,002.6$ & $3,769.3$ \\
\hline 8356 & PA & 1450 & 22.5 & 850.1 & $1,720.1$ & $3,120.4$ & $4,144.5$ & $5,205.1$ & $6,614.7$ \\
\hline 8354 & OA & 1375 & 40.0 & 542.3 & $1,121.7$ & $1,958.4$ & $2,543.9$ & $3,140.6$ & $3,945.0$ \\
\hline 8354 & OA & 1400 & 35.0 & 392.0 & $1,191.5$ & $1,959.7$ & $2,495.0$ & $3,007.0$ & $3,716.1$ \\
\hline 8354 & $\mathrm{OA}$ & 1425 & 27.5 & $1,602.6$ & $2,555.9$ & $3,894.3$ & $5,064.1$ & $6,179.1$ & $7,630.2$ \\
\hline
\end{tabular}




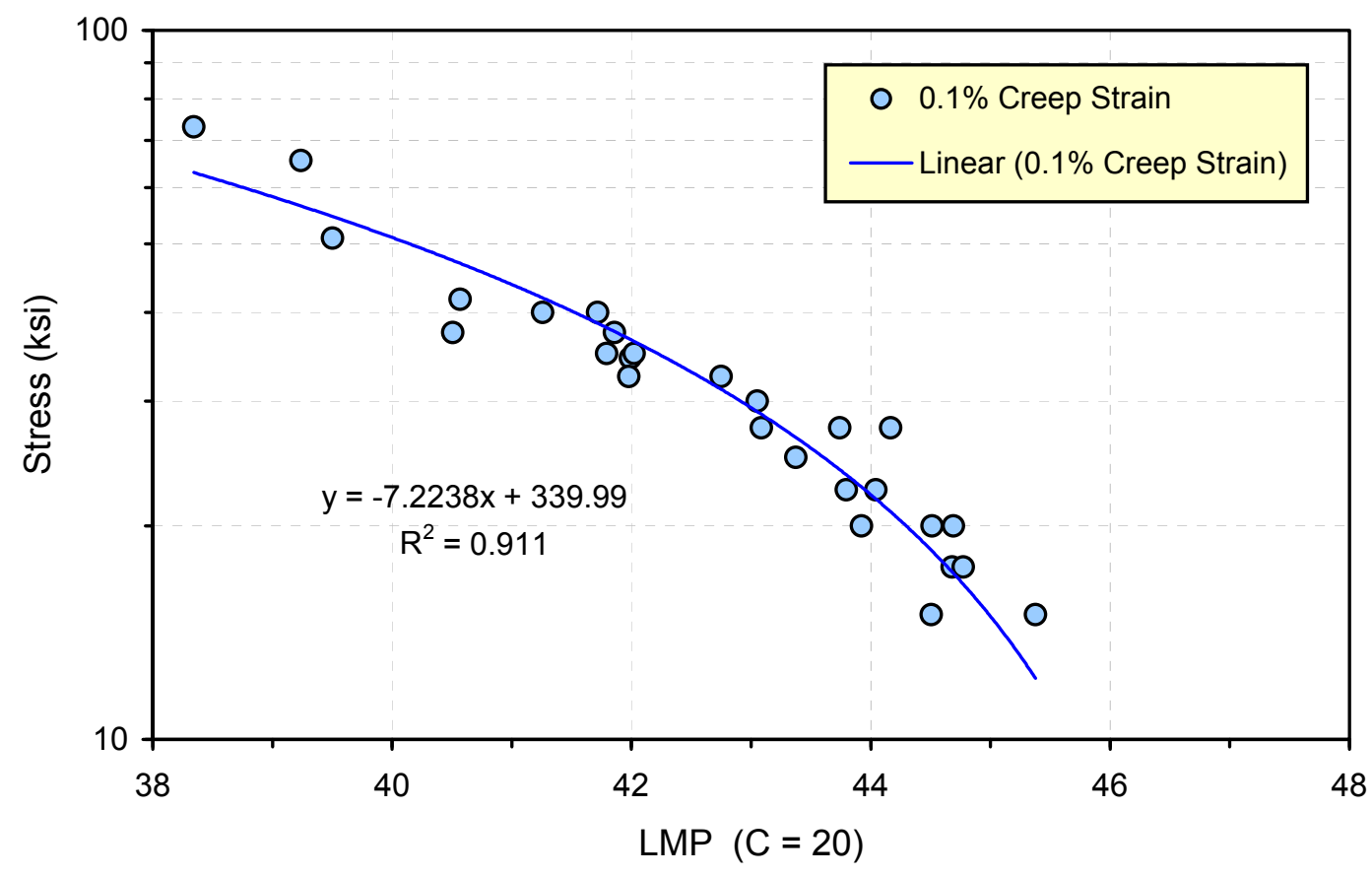

Figure 5.3: Stress $(\mathrm{ksi})$ versus LMP $(\mathrm{C}=\mathbf{2 0})$ at 0.1 creep strain for Haynes 282 .

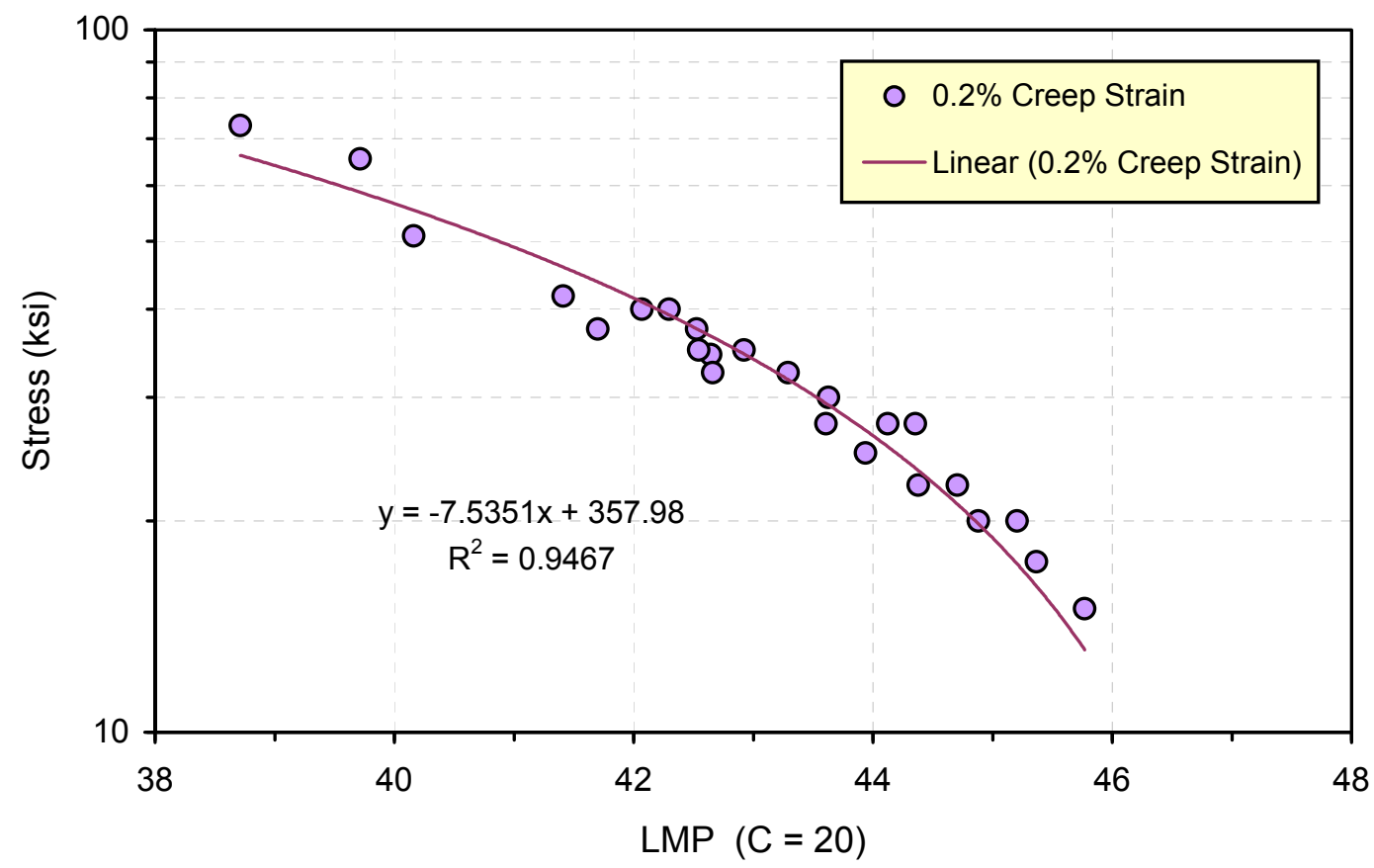

Figure 5.4: Stress $(\mathrm{ksi})$ versus LMP $(\mathrm{C}=20)$ at 0.2 creep strain for Haynes 282. 


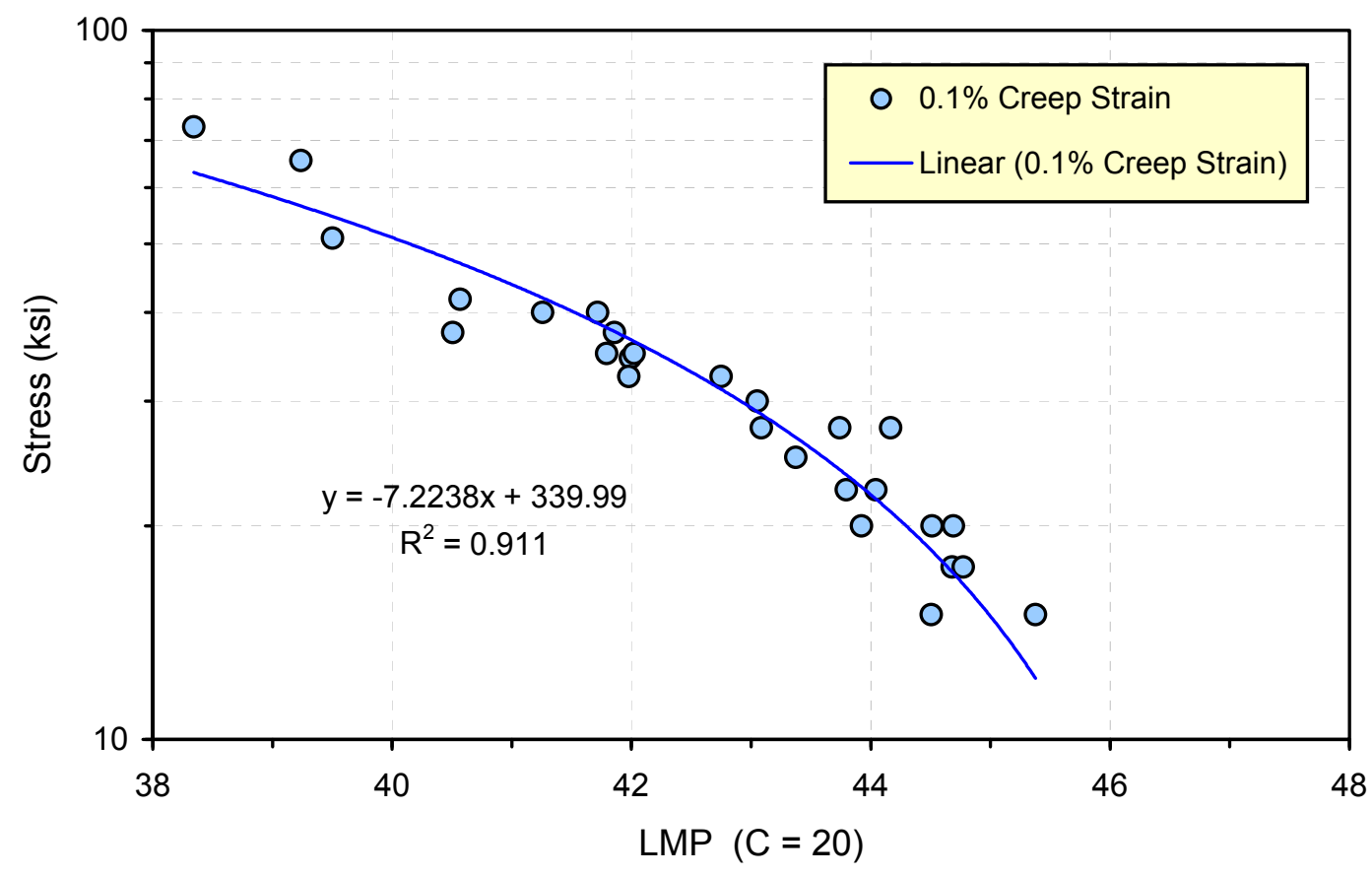

Figure 5.5: Stress $(\mathrm{ksi})$ versus LMP $(\mathrm{C}=\mathbf{2 0})$ at 0.5 creep strain for Haynes 282 .

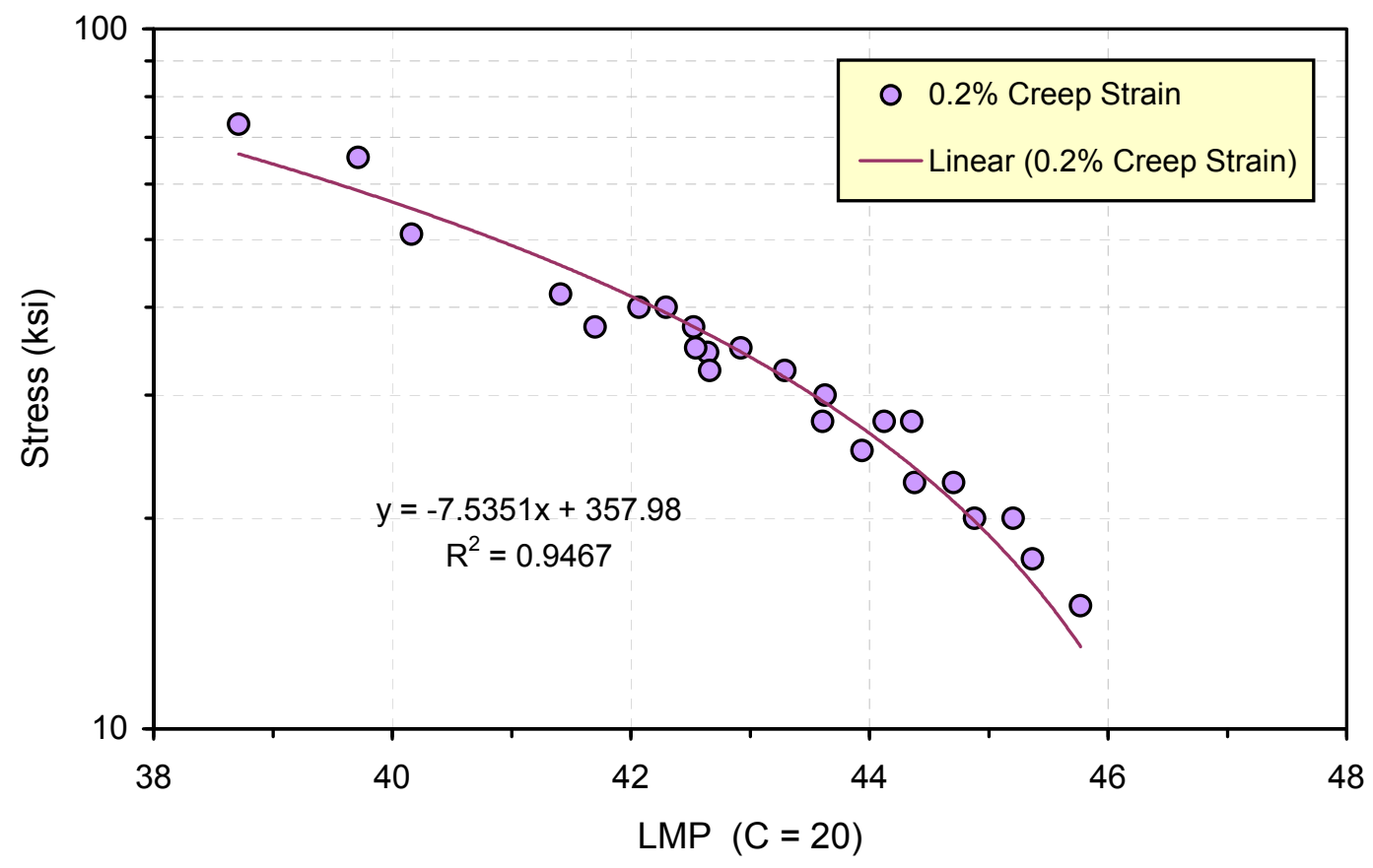

Figure 5.6: Stress $(\mathrm{ksi})$ versus LMP $(\mathrm{C}=\mathbf{2 0})$ at $\mathbf{1 . 0}$ creep strain for Haynes 282 . 


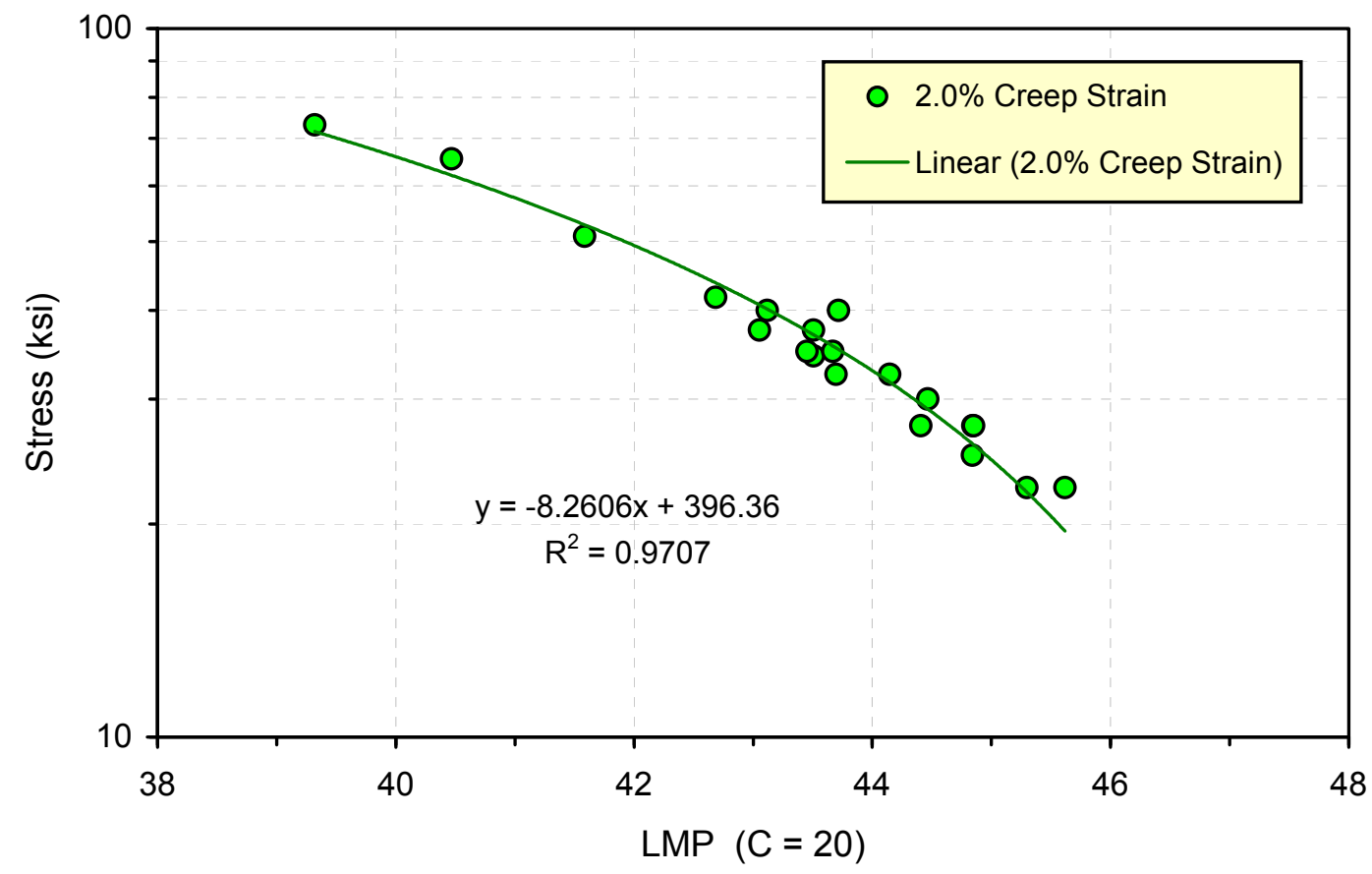

Figure 5.7: Stress (ksi) versus LMP $(C=20)$ at 2.0 creep strain for Haynes 282 .

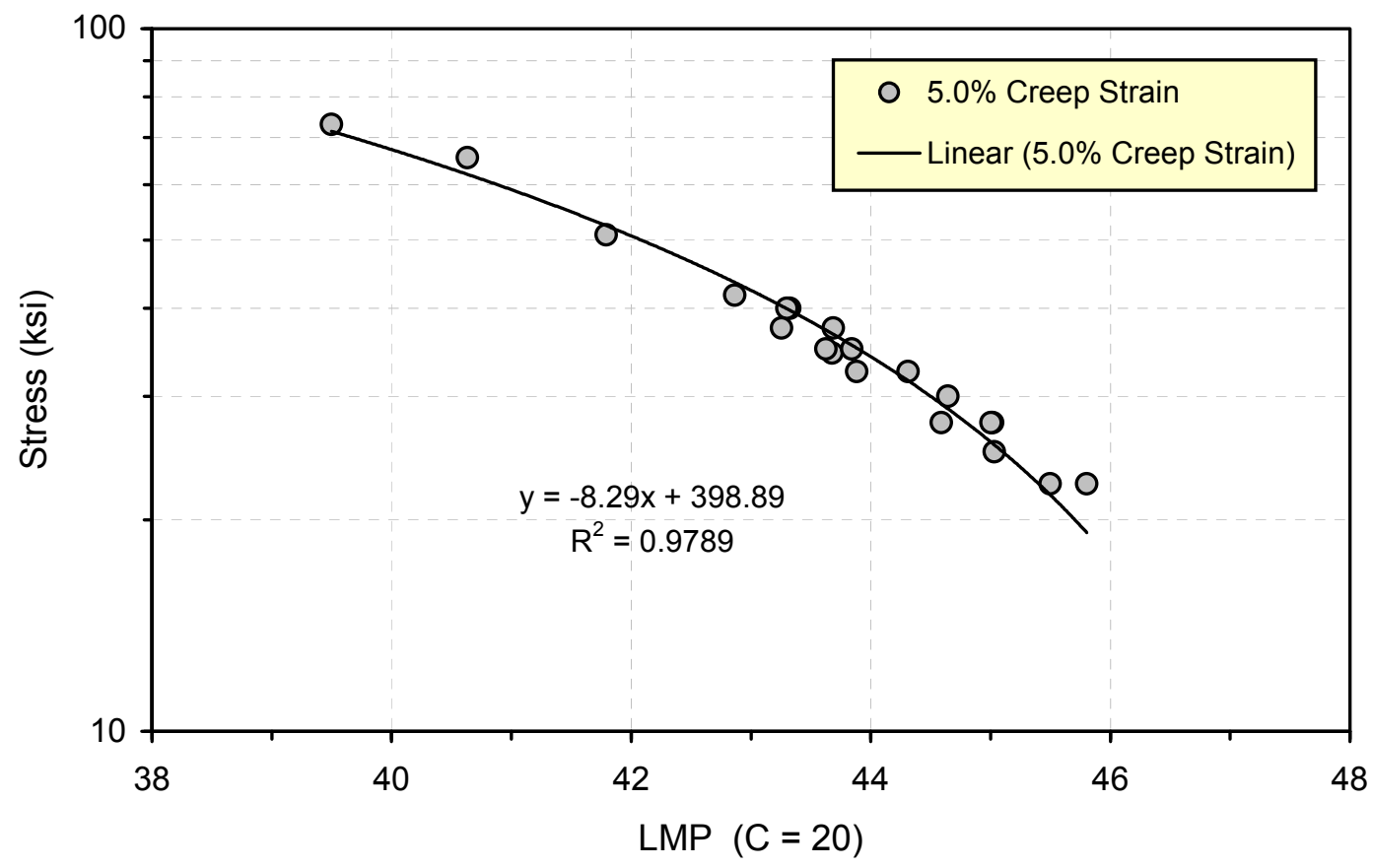

Figure 5.8: Stress $(\mathrm{ksi})$ versus LMP $(\mathrm{C}=\mathbf{2 0})$ at 5.0 creep strain for Haynes 282 . 
Table 5C: Creep and Creep Rupture for Haynes 282 (plate): Haynes Testing

\begin{tabular}{|c|c|c|c|c|c|c|c|c|c|}
\hline $\begin{array}{c}\text { Heat } \\
\text { No. }\end{array}$ & Cond. & $\begin{array}{c}\text { Temp. } \\
(\mathrm{F})\end{array}$ & $\begin{array}{c}\text { Stress } \\
(\mathrm{ksi})\end{array}$ & $\begin{array}{l}\text { Time } \\
\text { (h) }\end{array}$ & $\begin{array}{c}\text { Strain } \\
(\%)\end{array}$ & $\begin{array}{c}\text { Elong. } \\
(\%)\end{array}$ & $\begin{array}{l}\text { RA } \\
(\%) \\
\end{array}$ & $\mathrm{LMP}_{\mathrm{f}}$ & Status \\
\hline Haynes & PA & 1300 & 80.0 & 100.0 & & & & 38.7200 & \\
\hline Haynes & PA & 1400 & 57.0 & 100.0 & & & & 40.9200 & \\
\hline Haynes & PA & 1500 & 38.0 & 100.0 & & & & 43.1200 & \\
\hline Haynes & PA & 1600 & 23.0 & 100.0 & & & & 45.3200 & \\
\hline Haynes & PA & 1700 & 13.0 & 100.0 & & & & 47.5200 & \\
\hline Haynes & PA & 1800 & 6.2 & 100.0 & & & & 49.7200 & \\
\hline Haynes & PA & 1200 & 85.0 & $1,000.0$ & & & & 38.1800 & \\
\hline Haynes & PA & 1300 & 61.0 & $1,000.0$ & & & & 40.4800 & \\
\hline Haynes & PA & 1400 & 41.0 & $1,000.0$ & & & & 42.7800 & \\
\hline Haynes & PA & 1500 & 25.0 & $1,000.0$ & & & & 45.0800 & \\
\hline Haynes & PA & 1600 & 14.0 & $1,000.0$ & & & & 47.3800 & \\
\hline Haynes & PA & 1700 & 7.0 & $1,000.0$ & & & & 49.6800 & \\
\hline Haynes & PA & 1800 & 3.6 & $1,000.0$ & & & & 51.9800 & \\
\hline Haynes & PA & 1200 & 64.0 & $10,000.0$ & & & & 39.8400 & \\
\hline Haynes & PA & 1300 & 45.0 & $10,000.0$ & & & & 42.2400 & \\
\hline Haynes & PA & 1400 & 27.0 & $10,000.0$ & & & & 44.6400 & \\
\hline Haynes & PA & 1500 & 14.0 & $10,000.0$ & & & & 47.0400 & \\
\hline Haynes & PA & 1600 & 8.0 & $10,000.0$ & & & & 49.4400 & \\
\hline Haynes & PA & 1700 & 3.7 & $10,000.0$ & & & & 51.8400 & \\
\hline
\end{tabular}

Includes extrapolated data. 
Table 5D: Creep and Creep Rupture for Nimonic 105 (rod): GE Testing

\begin{tabular}{|c|c|c|c|c|c|c|c|c|c|}
\hline $\begin{array}{l}\text { Heat } \\
\text { No. }\end{array}$ & Cond. & $\begin{array}{c}\text { Temp. } \\
\text { (F) }\end{array}$ & $\begin{array}{c}\text { Stress } \\
(\mathrm{ksi})\end{array}$ & $\begin{array}{l}\text { Time } \\
(\mathrm{h})\end{array}$ & $\begin{array}{c}\text { Strain } \\
(\%)\end{array}$ & $\begin{array}{c}\text { Elong. } \\
\text { (\%) }\end{array}$ & $\begin{array}{l}\text { RA } \\
(\%)\end{array}$ & $\mathrm{LMP}_{\mathrm{f}}$ & Status \\
\hline 5183 & AP & 1375 & 45.0 & $3,728.1$ & 7.624 & 8.1 & 11.2 & 43.2537 & Failed \\
\hline 5183 & AP & 1400 & 45.0 & $2,092.2$ & 10.125 & 11.6 & 14.8 & 43.3763 & Failed \\
\hline 5183 & AP & 1400 & 40.0 & $2,713.4$ & 11.759 & 12.6 & 15.3 & 43.5863 & Failed \\
\hline 5183 & AP & 1400 & 35.0 & $8,914.0$ & 16.485 & 18.8 & 28.9 & 44.5471 & Failed \\
\hline 5183 & AP & 1425 & 40.0 & $2,268.2$ & 17.487 & 17.8 & 23.4 & 44.0255 & Failed \\
\hline 5183 & AP & 1425 & 35.0 & $4,560.8$ & 19.494 & 21.0 & 25.4 & 44.5973 & Failed \\
\hline 5183 & AP & 1425 & 30.0 & $10,546.0$ & 17.780 & 18.2 & 33.6 & 45.2835 & Failed \\
\hline 5183 & AP & 1450 & 35.0 & $2,537.4$ & 23.246 & 25.1 & 34.8 & 44.7024 & Failed \\
\hline 5183 & AP & 1450 & 30.0 & $5,946.2$ & 17.620 & 18.8 & 35.1 & 45.4088 & Failed \\
\hline 5183 & AP & 1450 & 27.5 & $8,969.1$ & 22.474 & 23.2 & 38.7 & 45.7498 & Failed \\
\hline 5183 & PA & 1400 & 45.0 & $1,849.5$ & 13.016 & 14.2 & 26.8 & 43.2767 & Failed \\
\hline 5793 & PA & 1400 & 42.5 & $3,114.0$ & 19.077 & 20.3 & 48.0 & 43.6976 & Failed \\
\hline 5793 & PA & 1400 & 40.0 & $4,382.4$ & 12.400 & 14.0 & 45.2 & 43.9736 & Failed \\
\hline 5183 & $\mathrm{PA}$ & 1400 & 35.0 & $12,170.4$ & 10.736 & 11.7 & 26.7 & 44.7987 & Failed \\
\hline 5793 & $\mathrm{PA}$ & 1400 & 32.5 & 21173.4 & 1.187 & 13.7 & 17.8 & 45.2460 & Failed \\
\hline 5183 & $\mathrm{PA}$ & 1425 & 40.0 & $1,655.2$ & 3.848 & 4.4 & 11.1 & 43.7675 & Failed \\
\hline 5793 & PA & 1425 & 37.5 & $4,519.8$ & 23.035 & 24.4 & 40.4 & 44.5899 & Failed \\
\hline 5183 & $\mathrm{PA}$ & 1425 & 35.0 & $8,045.7$ & 16.855 & 17.5 & 22.5 & 45.0620 & Failed \\
\hline 5793 & PA & 1425 & 32.5 & 11746.4 & 28.241 & 28.7 & 43.3 & 45.3718 & Failed \\
\hline 5793 & PA & 1425 & 30.0 & $11,123.5$ & 6.051 & 6.6 & 39.7 & 45.3272 & Failed \\
\hline 5793 & $\mathrm{PA}$ & 1450 & 37.5 & $2,844.9$ & 25.270 & 26.8 & 40.8 & 44.7973 & Failed \\
\hline 5183 & $\mathrm{PA}$ & 1450 & 35.0 & $4,273.8$ & 17.732 & 18.3 & 23.2 & 45.1349 & Failed \\
\hline 5793 & PA & 1450 & 30.0 & $10,277.3$ & 22.412 & 24.0 & 39.5 & 45.8627 & Failed \\
\hline 5183 & $\mathrm{OA}$ & 1400 & 37.5 & $15,514.6$ & 7.424 & 11.2 & 13.3 & 44.9948 & Failed \\
\hline 5183 & $\mathrm{OA}$ & 1425 & 32.5 & $20,048.2$ & 8.209 & & & & Running \\
\hline 5183 & OA & 1450 & 32.5 & $10,316.6$ & 10.770 & 11.8 & 19.8 & 45.8659 & Failed \\
\hline
\end{tabular}




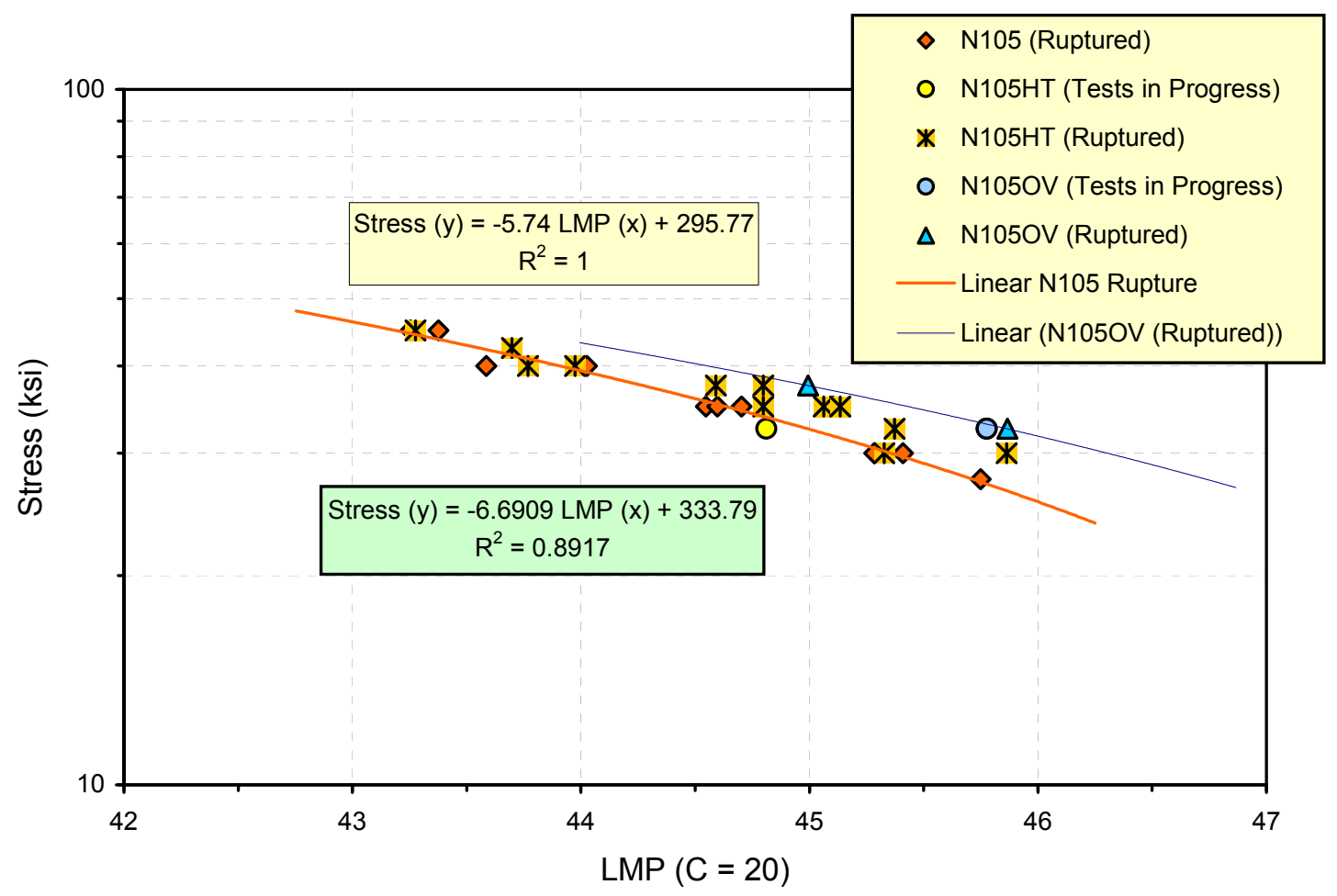

Figure 5.9: Stress $(\mathrm{ksi})$ versus LMP $(\mathrm{C}=\mathbf{2 0})$ for Nimonic 105 in three alloy conditions as-processed (AP), heat treated to peak age (HT), and overaged (AG), or heat conditions, state (OV).

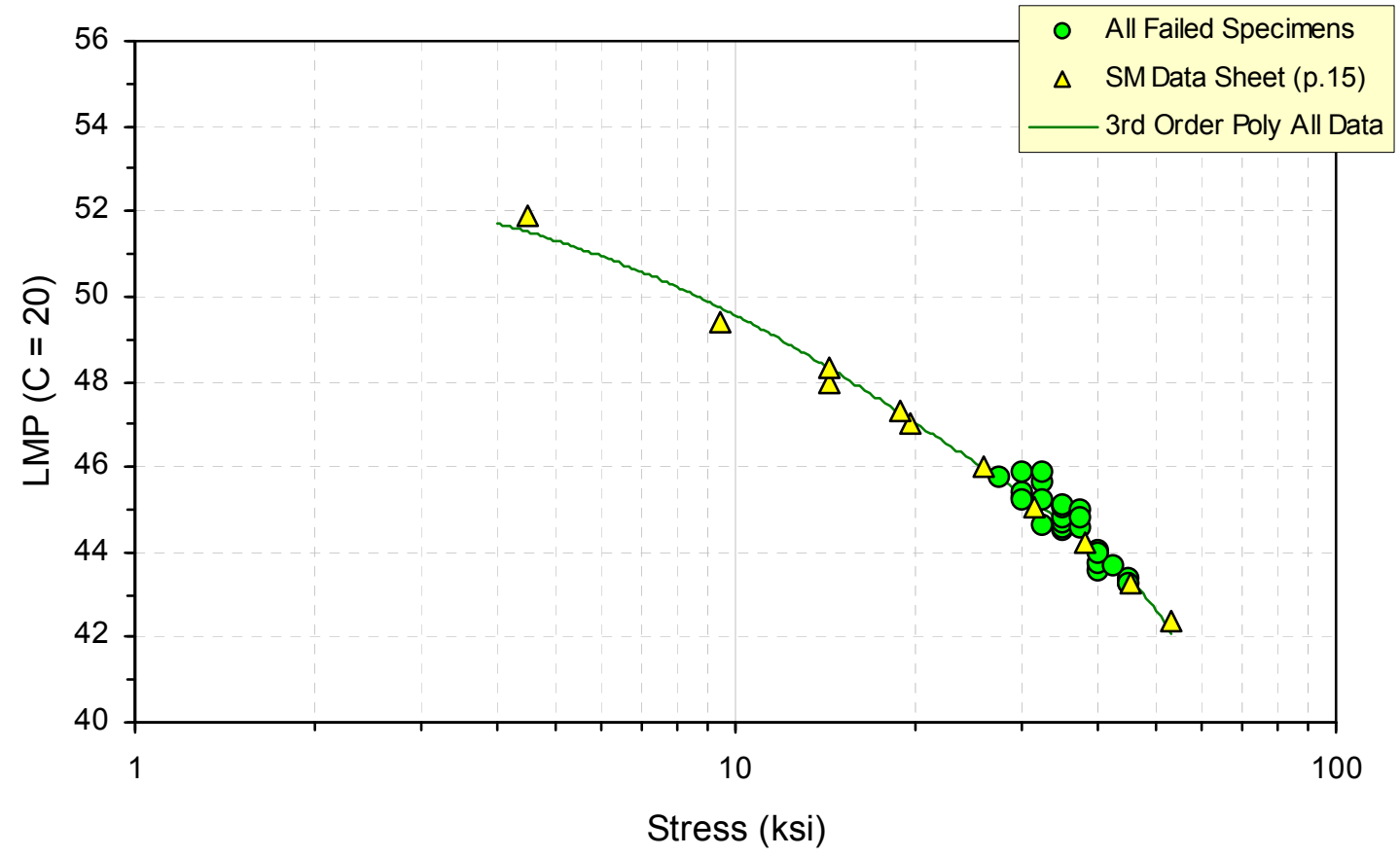

Figure 5.10: Stress (ski) versus LMP $(C=20)$ for combined Nimonic 105 rupture data. 
Table 5E: Time to Reach \% Creep Strain for Nimonic 105 (rod): GE Testing

\begin{tabular}{|c|c|c|c|c|c|c|c|c|c|}
\hline \multirow{2}{*}{$\begin{array}{l}\text { Heat } \\
\text { No. }\end{array}$} & \multirow{2}{*}{ Cond. } & \multirow{2}{*}{$\begin{array}{c}\text { Temp. } \\
\text { (F) }\end{array}$} & \multirow{2}{*}{$\begin{array}{c}\text { Stress } \\
\text { (ksi) }\end{array}$} & \multicolumn{6}{|c|}{ Time to Reach Creep Strain } \\
\hline & & & & $0.1 \%$ & $0.2 \%$ & $0.5 \%$ & $1.0 \%$ & $2.0 \%$ & $5.0 \%$ \\
\hline 5183 & AP & 1375 & 45.0 & 253.2 & 626.0 & $1,488.4$ & $2,227.9$ & $2,848.4$ & $3,479.4$ \\
\hline 5183 & AP & 1400 & 45.0 & 199.9 & 398.9 & 857.3 & $1,209.9$ & $1,511.4$ & $1,860.7$ \\
\hline 5183 & AP & 1400 & 40.0 & 144.2 & 459.3 & $1,067.1$ & $1,560.4$ & $1,927.4$ & $2,386.5$ \\
\hline 5183 & AP & 1400 & 35.0 & 295.2 & $1,100.3$ & $2,858.9$ & $4,324.1$ & $5,621.6$ & $7,154.7$ \\
\hline 5183 & AP & 1425 & 40.0 & 190.7 & 382.8 & 850.9 & $1,218.8$ & $1,518.8$ & $1,858.6$ \\
\hline 5183 & AP & 1425 & 35.0 & 243.6 & 599.4 & $1,486.9$ & $2,175.0$ & $2,808.5$ & $3,569.3$ \\
\hline 5183 & AP & 1425 & 30.0 & 287.5 & 920.1 & $2,682.5$ & $4,993.6$ & $6,222.3$ & $8,289.4$ \\
\hline 5183 & $\mathrm{AP}$ & 1450 & 35.0 & 136.8 & 350.3 & 862.2 & $1,254.4$ & $1,580.9$ & $1,987.0$ \\
\hline 5183 & AP & 1450 & 30.0 & 201.5 & 645.0 & $1,705.2$ & $2,725.4$ & $3,664.1$ & $4,795.4$ \\
\hline 5183 & AP & 1450 & 27.5 & 47.8 & 383.4 & $1,830.8$ & $3,472.3$ & $5,021.7$ & $6,841.3$ \\
\hline 5183 & PA & 1400 & 45.0 & 129.3 & 327.6 & 756.4 & $1,051.1$ & $1,310.2$ & $1,597.8$ \\
\hline 5793 & PA & 1400 & 42.5 & 152.0 & 509.2 & $1,246.3$ & $1,761.4$ & $2,174.4$ & $2,606.2$ \\
\hline 5793 & PA & 1400 & 40.0 & 326.6 & 936.3 & $2,051.8$ & $2,782.5$ & $3,324.1$ & $3,945.9$ \\
\hline 5183 & PA & 1400 & 35.0 & 930.2 & $2,598.5$ & $5,677.0$ & $7,498.6$ & $8,933.2$ & $10,759.7$ \\
\hline 5793 & PA & 1400 & 32.5 & 2205 & 5817 & 10607 & 12952 & 15233 & 18336 \\
\hline 5183 & PA & 1425 & 40.0 & 142.7 & 370.4 & 859.8 & $1,191.9$ & $1,460.9$ & \\
\hline 5793 & PA & 1425 & 37.5 & 186.8 & 757.7 & $1,950.2$ & $2,590.7$ & $3,101.2$ & $3,708.9$ \\
\hline 5183 & PA & 1425 & 35.0 & 648.0 & $1,840.0$ & $3,545.2$ & $4,565.9$ & $5,393.7$ & $6,484.6$ \\
\hline 5793 & PA & 1425 & 32.5 & 873.7 & $2,061.7$ & $4,749.6$ & $6,290.4$ & $7,476.7$ & $9,080.1$ \\
\hline 5793 & PA & 1425 & 30.0 & $1,999.4$ & $4,453.9$ & $7,385.6$ & $8,945.0$ & $10,022.9$ & $11,046.6$ \\
\hline 5793 & PA & 1450 & 37.5 & 194.8 & 624.0 & $1,276.0$ & $1,645.4$ & $1,939.5$ & $2,299.6$ \\
\hline 5183 & PA & 1450 & 35.0 & 320.0 & 969.6 & $1,935.8$ & $2,462.8$ & $2,909.1$ & $3,462.8$ \\
\hline 5793 & PA & 1450 & 30.0 & 428.1 & $1,792.4$ & $4,155.9$ & $5,398.7$ & $6,569.5$ & $8,019.6$ \\
\hline 5183 & $\mathrm{OA}$ & 1400 & 37.5 & $1,444.0$ & $4,366.0$ & $8,600.3$ & $10,714.8$ & $12,441.6$ & $14,607.9$ \\
\hline 5183 & $\mathrm{OA}$ & 1425 & 32.5 & & & & & & \\
\hline 5183 & OA & 1450 & 32.5 & $1,214.8$ & $3,112.5$ & $5,381.1$ & $6,622.1$ & $7,689.2$ & $9,188.3$ \\
\hline
\end{tabular}




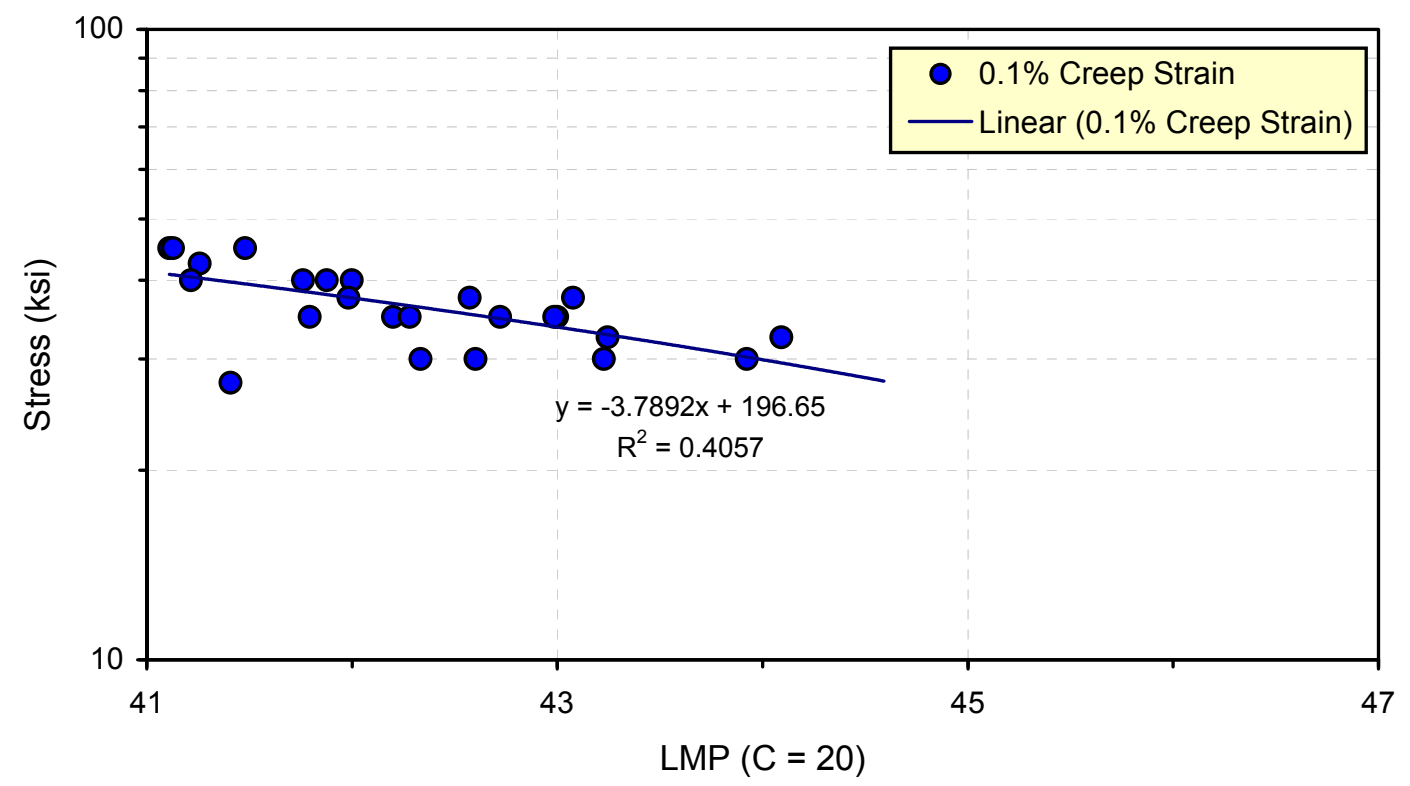

Figure 5.11: Stress $(\mathrm{ksi})$ versus LMP $(C=20)$ at 0.1 creep strain for Nimonic 105 .

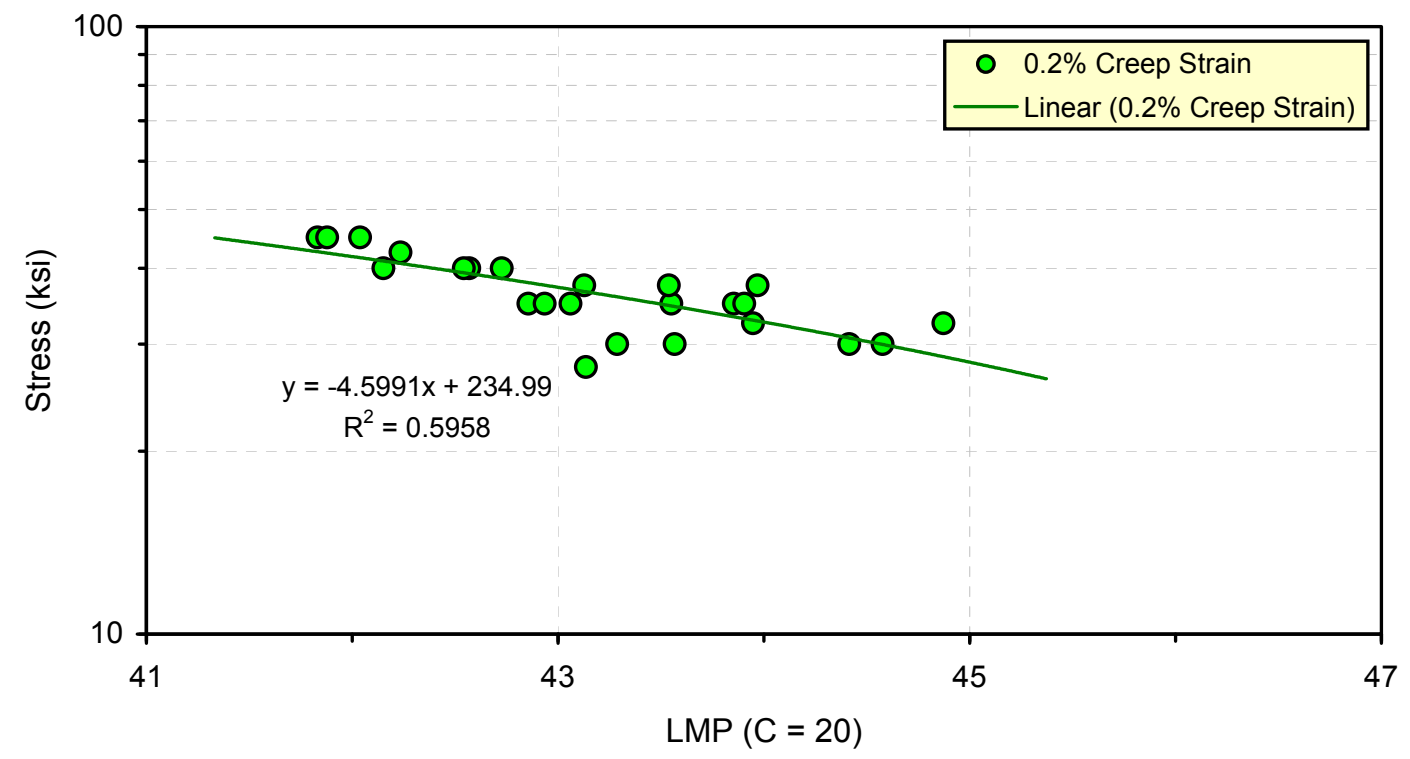

Figure 5.12: Stress $(\mathrm{ksi})$ versus LMP $(C=20)$ at 0.2 creep strain for Nimonic 105 . 


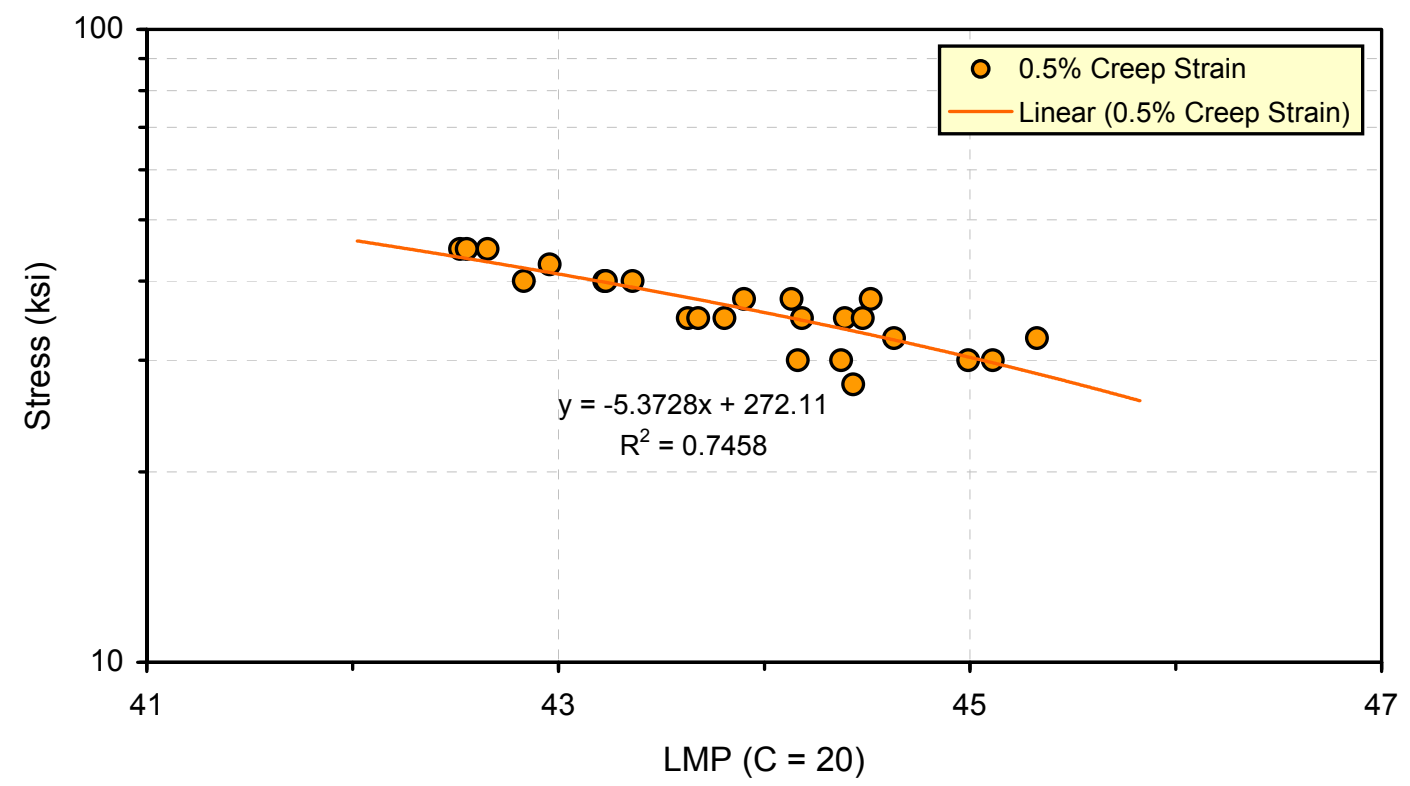

Figure 5.13: Stress $(\mathrm{ksi})$ versus LMP $(C=20)$ at 0.5 creep strain for Nimonic 105 .

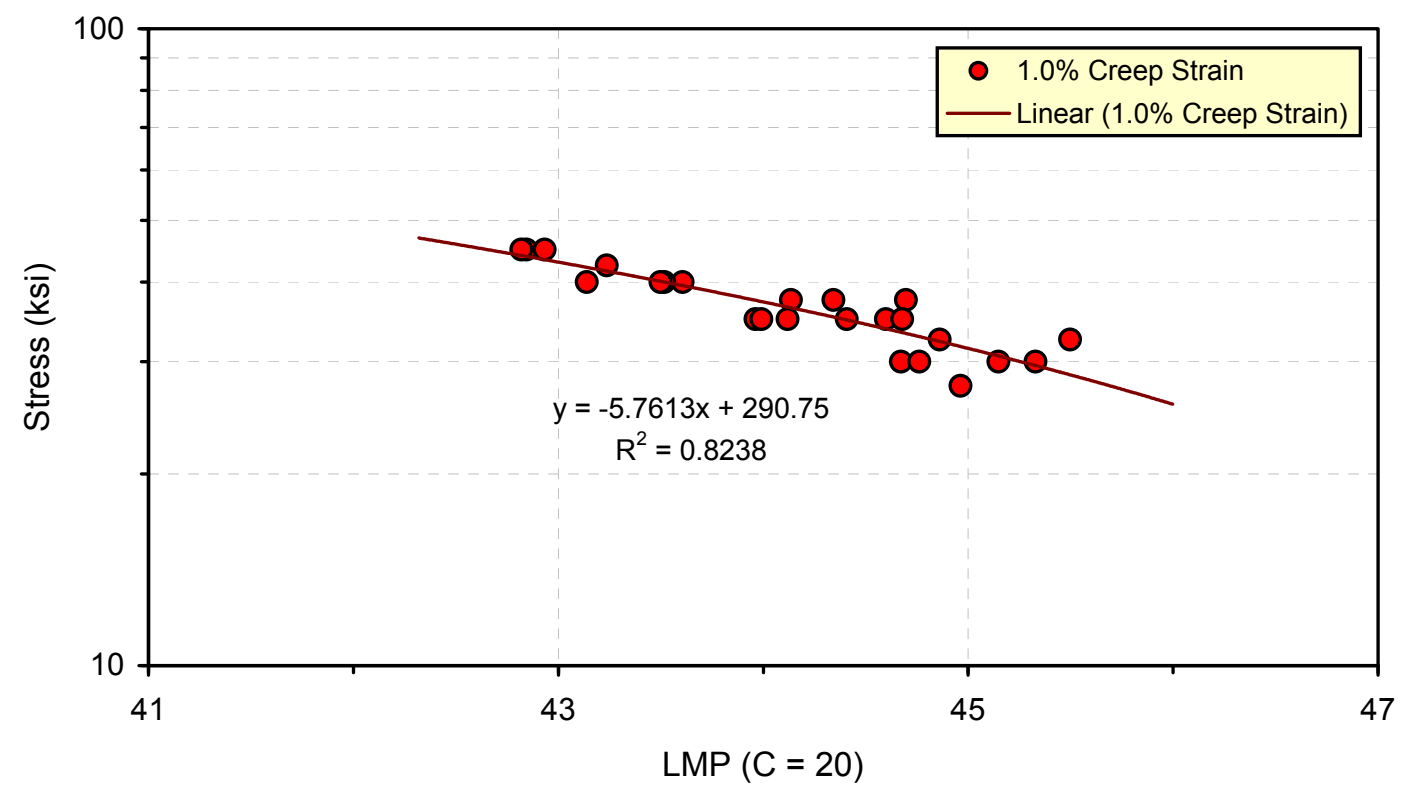

Figure 5.14: Stress $(\mathrm{ksi})$ versus LMP $(\mathrm{C}=\mathbf{2 0})$ at 1.0 creep strain for Nimonic 105 . 


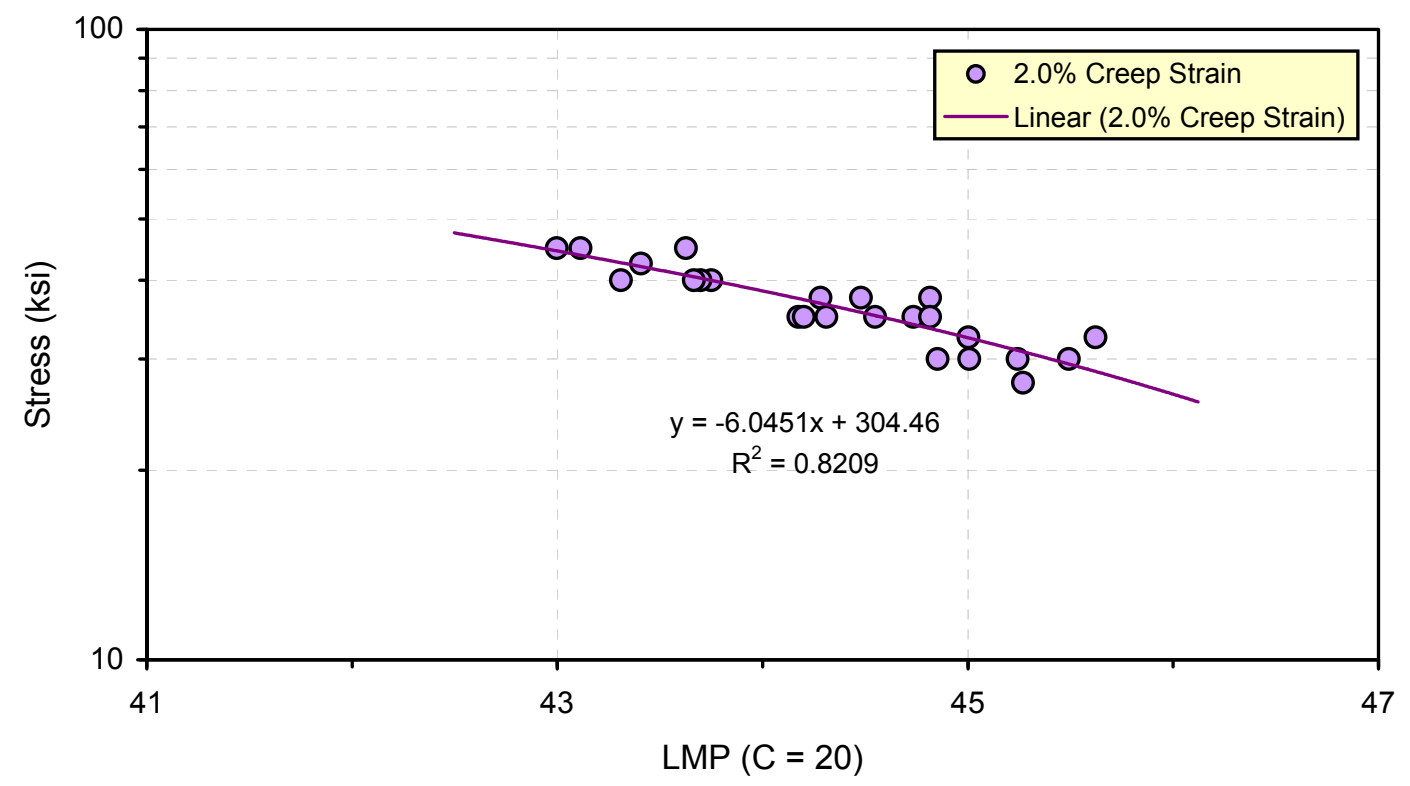

Figure 5.15: Stress $(\mathrm{ksi})$ versus LMP $(C=20)$ at 2.0 creep strain for Nimonic 105 .

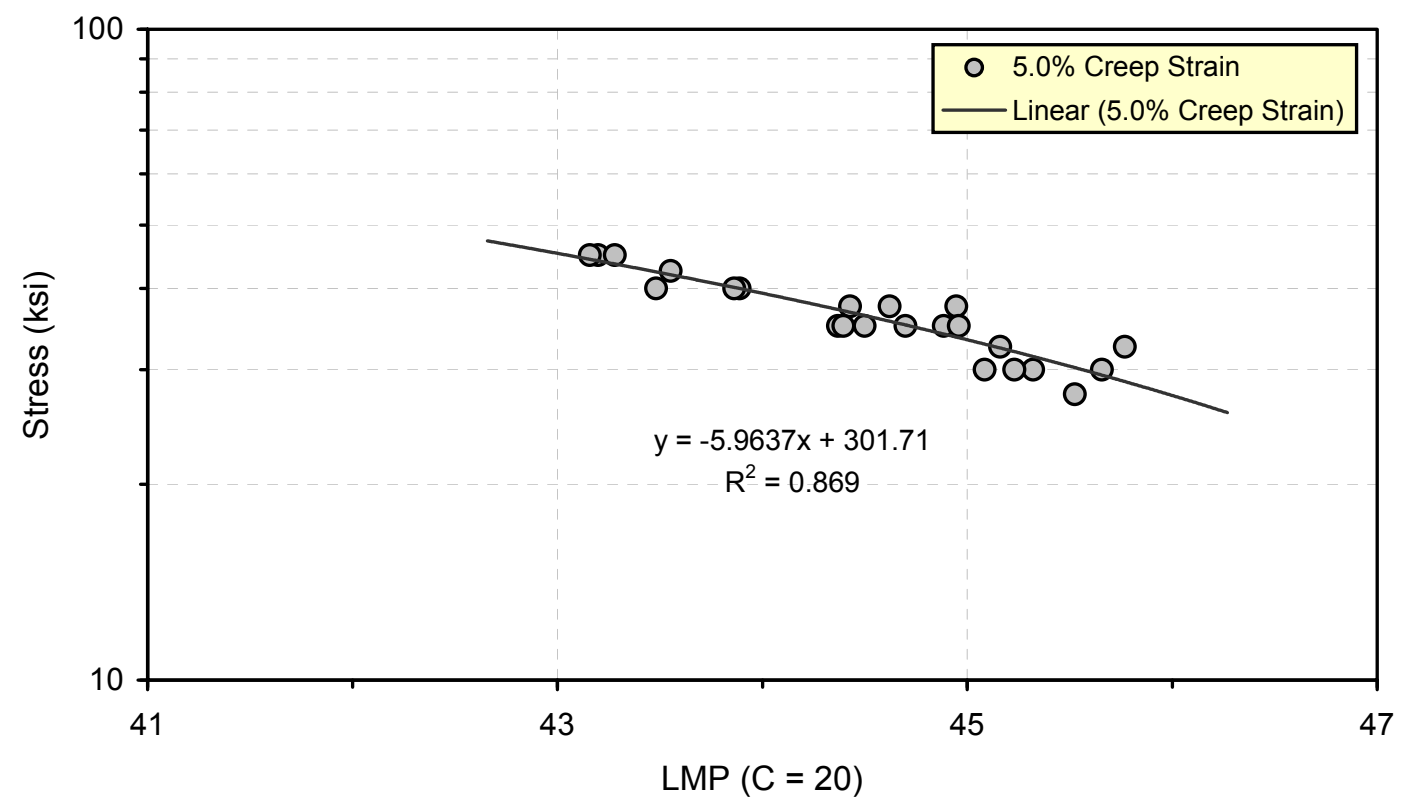

Figure 5.16: Stress $(\mathrm{ksi})$ versus LMP $(C=20)$ at 5.0 creep strain for Nimonic 105 . 
Table 5F: Creep and Creep Rupture for Nimonic 105 (bar: extruded \& subsequently forged and extruded \& subsequently cold worked): Special Metals Testing

\begin{tabular}{|c|c|c|c|c|c|c|c|c|c|}
\hline $\begin{array}{l}\text { Heat } \\
\text { No. }\end{array}$ & Cond. & $\begin{array}{l}\text { Temp. } \\
\text { (F) }\end{array}$ & $\begin{array}{c}\text { Stress } \\
\text { (ksi) }\end{array}$ & $\begin{array}{l}\text { Time } \\
\text { (h) }\end{array}$ & $\begin{array}{c}\text { Strain } \\
(\%)\end{array}$ & $\begin{array}{c}\text { Elong. } \\
\text { (\%) }\end{array}$ & $\begin{array}{l}\text { RA } \\
\text { (\%) }\end{array}$ & $\mathrm{LMP}_{\mathrm{f}}$ & Status \\
\hline SM-p. 11 & PA & 1382 & 64.977 & 100.0 & & & & 40.5240 & \\
\hline SM-p. 11 & PA & 1499 & 46.992 & 100.0 & & & & 43.0980 & \\
\hline SM-p. 11 & PA & 1598 & 30.168 & 100.0 & & & & 45.2760 & \\
\hline SM-p. 11 & PA & 1724 & 15.664 & 100.0 & & & & 48.0480 & \\
\hline SM-p. 11 & PA & 1796 & 9.863 & 100.0 & & & & 49.6320 & \\
\hline SM-p. 11 & PA & 1382 & 60.481 & 300.0 & & & & 41.4029 & \\
\hline SM-p. 11 & PA & 1499 & 39.160 & 300.0 & & & & 44.0327 & \\
\hline SM-p. 11 & PA & 1598 & 25.092 & 300.0 & & & & 46.2579 & \\
\hline SM-p. 11 & PA & 1724 & 12.328 & 300.0 & & & & 49.0900 & \\
\hline SM-p. 11 & PA & 1796 & 7.397 & 300.0 & & & & 50.7084 & \\
\hline SM-p. 11 & PA & 1382 & 52.649 & $1,000.0$ & & & & 42.3660 & \\
\hline SM-p. 11 & PA & 1499 & 32.488 & $1,000.0$ & & & & 45.0570 & \\
\hline SM-p. 11 & PA & 1598 & 19.435 & $1,000.0$ & & & & 47.3340 & \\
\hline SM-p. 11 & PA & 1796 & 4.641 & $1,000.0$ & & & & 51.8880 & \\
\hline SM-p. 11 & PA & 1382 & 45.977 & $3,000.0$ & & & & 43.2449 & \\
\hline SM-p. 11 & PA & 1499 & 26.832 & $3,000.0$ & & & & 45.9917 & \\
\hline SM-p. 11 & PA & 1598 & 14.794 & $3,000.0$ & & & & 48.3159 & \\
\hline SM-p.15 & PA & 1202 & 111.969 & 100.0 & & & & 36.5640 & \\
\hline SM-p.15 & PA & 1382 & 69.473 & 100.0 & & & & 40.5240 & \\
\hline SM-p.15 & PA & 1499 & 44.817 & 100.0 & & & & 43.0980 & \\
\hline SM-p.15 & PA & 1598 & 27.992 & 100.0 & & & & 45.2760 & \\
\hline SM-p.15 & PA & 1796 & 8.702 & 100.0 & & & & 49.6320 & \\
\hline SM-p.15 & PA & 1202 & 101.961 & 300.0 & & & & 37.3570 & \\
\hline SM-p.15 & PA & 1382 & 61.931 & 300.0 & & & & 41.4029 & \\
\hline SM-p.15 & PA & 1499 & 38.145 & 300.0 & & & & 44.0327 & \\
\hline SM-p.15 & PA & 1598 & 23.786 & 300.0 & & & & 46.2579 & \\
\hline SM-p.15 & PA & 1796 & 6.237 & 300.0 & & & & 50.7084 & \\
\hline SM-p.15 & PA & 1202 & 89.633 & $1,000.0$ & & & & 38.2260 & \\
\hline SM-p.15 & PA & 1382 & 53.374 & $1,000.0$ & & & & 42.3660 & \\
\hline SM-p.15 & PA & 1499 & 31.618 & $1,000.0$ & & & & 45.0570 & \\
\hline SM-p.15 & PA & 1598 & 18.855 & $1,000.0$ & & & & 47.3340 & \\
\hline SM-p.15 & PA & 1796 & 4.496 & $1,000.0$ & & & & 51.8880 & \\
\hline SM-p.15 & PA & 1202 & 79.626 & $3,000.0$ & & & & 39.0190 & \\
\hline SM-p.15 & PA & 1382 & 45.542 & $3,000.0$ & & & & 43.2449 & \\
\hline SM-p.15 & PA & 1499 & 25.817 & $3,000.0$ & & & & 45.9917 & \\
\hline SM-p.15 & PA & 1598 & 14.358 & $3,000.0$ & & & & 48.3159 & \\
\hline SM-p.15 & PA & 1796 & 3.191 & $3,000.0$ & & & & 52.9644 & \\
\hline SM-p.15 & PA & 1202 & 68.313 & $10,000.0$ & & & & 39.8880 & \\
\hline SM-p.15 & PA & 1382 & 38.145 & $10,000.0$ & & & & 44.2080 & \\
\hline SM-p.15 & PA & 1499 & 19.580 & $10,000.0$ & & & & 47.0160 & \\
\hline SM-p.15 & PA & 1598 & 9.427 & $10,000.0$ & & & & 49.3920 & \\
\hline SM-p.15 & PA & 1796 & 1.740 & $10,000.0$ & & & & 54.1440 & \\
\hline SM-p.15 & PA & 1202 & 59.465 & $30,000.0$ & & & & 40.6810 & \\
\hline SM-p.15 & PA & 1499 & 14.359 & $30,000.0$ & & & & 47.9507 & \\
\hline SM-p.15 & PA & 1598 & 5.802 & $30,000.0$ & & & & 50.3739 & \\
\hline
\end{tabular}

\# Special Metals Publication SMC-081, January 2007, 23 p. Includes extrapolated data. 
Table 5G. Creep and Creep Rupture for Udimet 720Li (forged disk): GE \& SW Testing

\begin{tabular}{|c|c|c|r|r|r|r|r|r|c|}
\hline $\begin{array}{c}\text { Heat } \\
\text { No. }\end{array}$ & Cond. & $\begin{array}{c}\text { Temp. } \\
\text { (F) }\end{array}$ & $\begin{array}{c}\text { Stress } \\
(\mathrm{ksi})\end{array}$ & \multicolumn{1}{c|}{$\begin{array}{c}\text { Time } \\
\text { (h) }\end{array}$} & $\begin{array}{c}\text { Strain } \\
(\%)\end{array}$ & $\begin{array}{c}\text { Elong. } \\
(\%)\end{array}$ & $\begin{array}{c}\text { RA } \\
(\%)\end{array}$ & LMP $_{\mathrm{f}}$ & Status \\
\hline LH-SW & PA & 1292 & 98.3 & 136.1 & 7.733 & 10.6 & 11.0 & 38.7785 & Failed \\
\hline LH-SW & PA & 1292 & 89.2 & 249.8 & 15.723 & 16.7 & 22.6 & 39.2406 & Failed \\
\hline 23592 & PA & 1375 & 60.0 & 144.8 & 23.804 & 30.0 & 65.3 & 40.6650 & Failed \\
\hline 23592 & PA & 1375 & 55.0 & 207.1 & 19.248 & 23.7 & 69.6 & 40.9502 & Failed \\
\hline LH-SW & PA & 1382 & 78.3 & 23.9 & 9.905 & 11.1 & 12.9 & 39.3790 & Failed \\
\hline LH-SW & PA & 1382 & 69.2 & 44.5 & 15.334 & 26.6 & 22.9 & 39.8763 & Failed \\
\hline LH-SW & PA & 1382 & 61.2 & 93.0 & 23.656 & 25.0 & 30.2 & 40.4659 & Failed \\
\hline 23592 & PA & 1400 & 55.0 & 109.3 & 26.071 & 25.0 & 67.7 & 40.9918 & Failed \\
\hline 23592 & PA & 1400 & 50.0 & 179.8 & 27.517 & 29.8 & 71.8 & 41.3939 & Failed \\
\hline 23592 & PA & 1400 & 45.0 & 261.2 & 21.149 & 28.7 & 78.0 & 41.6956 & Failed \\
\hline 23592 & PA & 1425 & 55.0 & 47.9 & 16.772 & 21.6 & 66.3 & 40.8674 & Failed \\
\hline 23592 & PA & 1425 & 50.0 & 86.2 & 24.118 & 27.7 & 71.6 & 41.3484 & Failed \\
\hline 23592 & PA & 1425 & 45.0 & 119.9 & 20.418 & 31.0 & 75.1 & 41.6186 & Failed \\
\hline 23592 & PA & 1450 & 50.0 & 40.9 & 20.381 & 34.2 & 70.5 & 41.2784 & Failed \\
\hline 23592 & PA & 1450 & 45.0 & 64.7 & 28.292 & 36.2 & 74.9 & 41.6588 & Failed \\
\hline 23592 & PA & 1450 & 40.0 & 95.2 & 24.087 & 29.7 & 77.3 & 41.9792 & Failed \\
\hline 23592 & PA & 1475 & 45.0 & 30.8 & 18.836 & 30.1 & 72.6 & 41.5803 & Failed \\
\hline 23592 & PA & 1475 & 40.0 & 57.0 & 26.014 & 36.0 & 77.7 & 42.0976 & Failed \\
\hline 23592 & PA & 1500 & 40.0 & 24.6 & 22.662 & 73.9 & 79.3 & 41.9262 & Failed \\
\hline
\end{tabular}




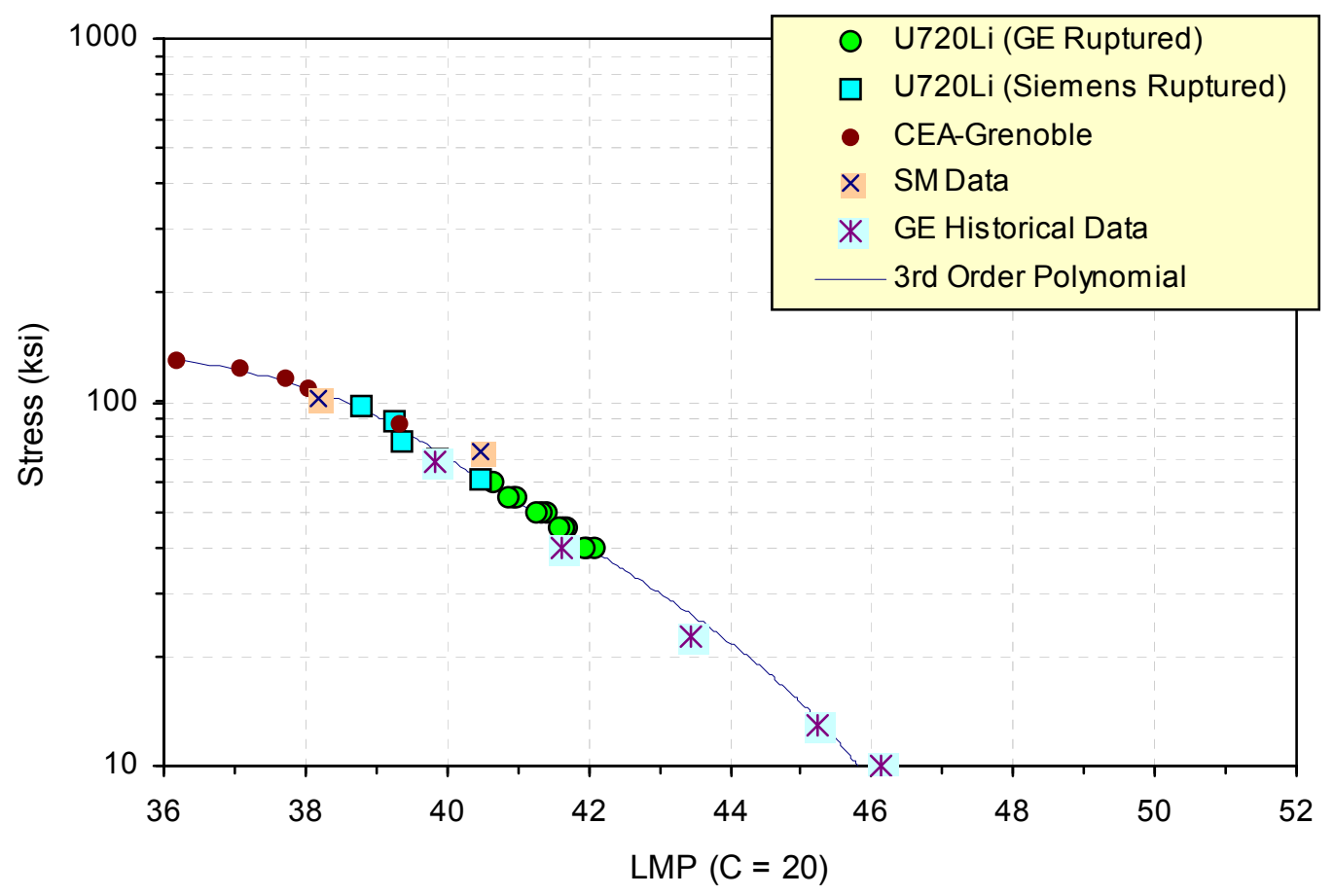

Figure 5.16: Stress $(\mathrm{ksi})$ versus LMP $(\mathrm{C}=\mathbf{2 0})$ for combined Udimet 720 rupture data (peak aged condition).

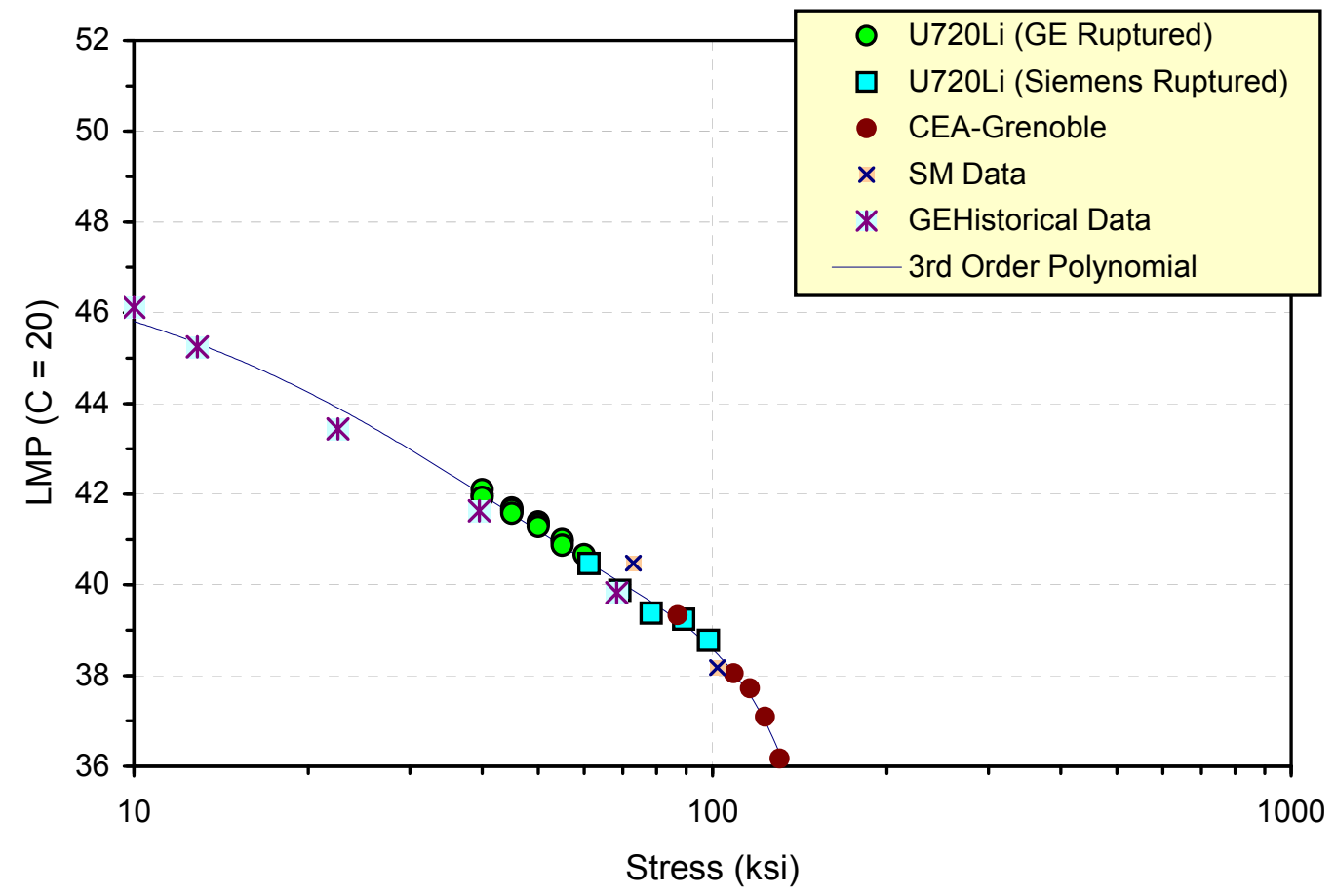

Figure 5.18: LMP $(C=20)$ versus Stress (ksi) for combined Udimet 720 rupture data (peak aged condition). 
Table 5H: Time to Reach \% Creep Strain for Udimet 720Li (forged disk): GE \& SW Testing

\begin{tabular}{|c|c|c|c|c|c|c|c|c|c|}
\hline \multirow{2}{*}{$\begin{array}{c}\text { Heat } \\
\text { No. }\end{array}$} & \multirow{2}{*}{ Cond. } & \multirow{2}{*}{$\begin{array}{c}\text { Temp. } \\
\text { (F) }\end{array}$} & \multirow{2}{*}{$\begin{array}{c}\text { Stress } \\
\text { (ksi) }\end{array}$} & \multicolumn{6}{|c|}{ Time to Reach Creep Strain } \\
\hline & & & & $0.1 \%$ & $0.2 \%$ & $0.5 \%$ & $1.0 \%$ & $2.0 \%$ & $5.0 \%$ \\
\hline LH-SW & PA & 1292 & 98.3 & 2.1 & $\begin{aligned} & 8.1 \\
&\end{aligned}$ & 28.1 & 51.7 & 80.5 & 119.5 \\
\hline LH-SW & PA & 1292 & 89.2 & 4.0 & 11.8 & 38.0 & 74.4 & 122.3 & 192.1 \\
\hline 23592 & PA & 1375 & 60.0 & 2.7 & 6.6 & 18.0 & 29.3 & 48.3 & 87.4 \\
\hline 23592 & PA & 1375 & 55.0 & 4.2 & 11.0 & 27.8 & 48.7 & 81.8 & 141.3 \\
\hline LH-SW & PA & 1382 & 78.3 & 0.3 & 0.9 & 2.9 & 5.8 & 10.4 & 18.3 \\
\hline LH-SW & PA & 1382 & 69.2 & 0.5 & 0.9 & 3.9 & 8.1 & 15.3 & 26.9 \\
\hline LH-SW & PA & 1382 & 61.2 & 1.0 & 3.6 & 10.2 & 19.9 & 36.3 & 62.1 \\
\hline 23592 & PA & 1400 & 55.0 & 0.7 & 4.1 & 11.7 & 21.7 & 36.7 & 65.2 \\
\hline 23592 & PA & 1400 & 50.0 & 3.0 & 7.3 & 19.7 & 35.0 & 59.8 & 106.8 \\
\hline 23592 & PA & 1400 & 45.0 & 3.6 & 9.7 & 28.5 & 55.2 & 94.8 & 163.7 \\
\hline 23592 & PA & 1425 & 55.0 & 0.6 & 1.6 & 4.6 & 8.8 & 15.4 & 28.7 \\
\hline 23592 & PA & 1425 & 50.0 & 1.3 & 3.3 & 9.2 & 17.8 & 29.8 & 52.9 \\
\hline 23592 & PA & 1425 & 45.0 & 1.6 & 4.0 & 12.1 & 22.8 & 40.4 & 73.4 \\
\hline 23592 & PA & 1450 & 50.0 & 0.6 & 1.4 & 3.8 & 7.3 & 12.8 & 23.7 \\
\hline 23592 & PA & 1450 & 45.0 & 1.0 & 2.2 & 6.2 & 11.7 & 21.0 & 38.3 \\
\hline 23592 & PA & 1450 & 40.0 & 1.0 & 2.8 & 8.9 & 17.6 & 28.6 & 54.8 \\
\hline 23592 & PA & 1475 & 45.0 & 0.4 & 0.9 & 2.9 & 5.5 & 9.6 & 17.8 \\
\hline 23592 & PA & 1475 & 40.0 & 0.7 & 2.0 & 5.4 & 10.0 & 17.1 & 31.1 \\
\hline 23592 & PA & 1500 & 40.0 & 0.3 & 0.9 & 1.9 & 4.0 & 6.6 & 13.0 \\
\hline
\end{tabular}




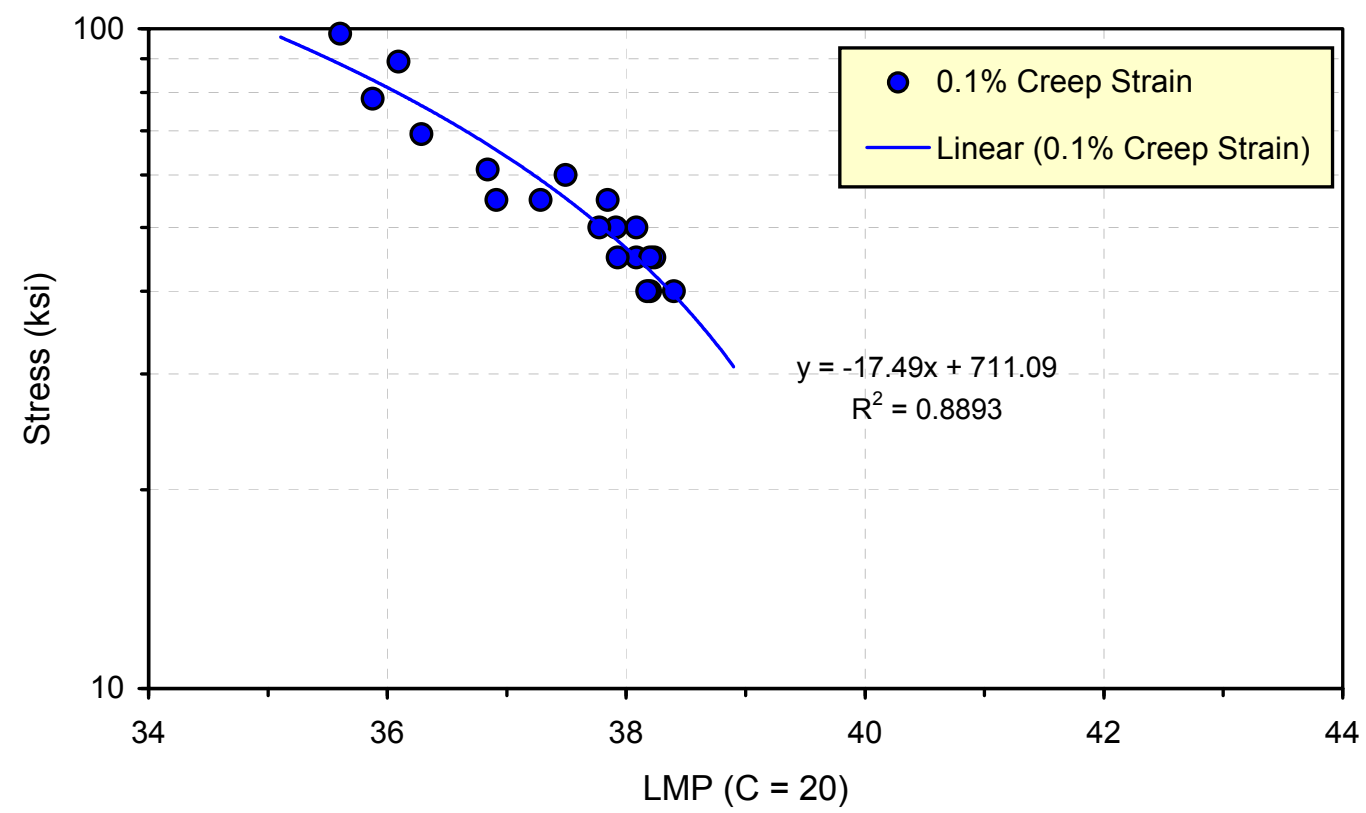

Figure 5.19: Stress $(\mathrm{ksi})$ versus LMP $(\mathrm{C}=\mathbf{2 0})$ at 0.1 creep strain for Udimet 720 .

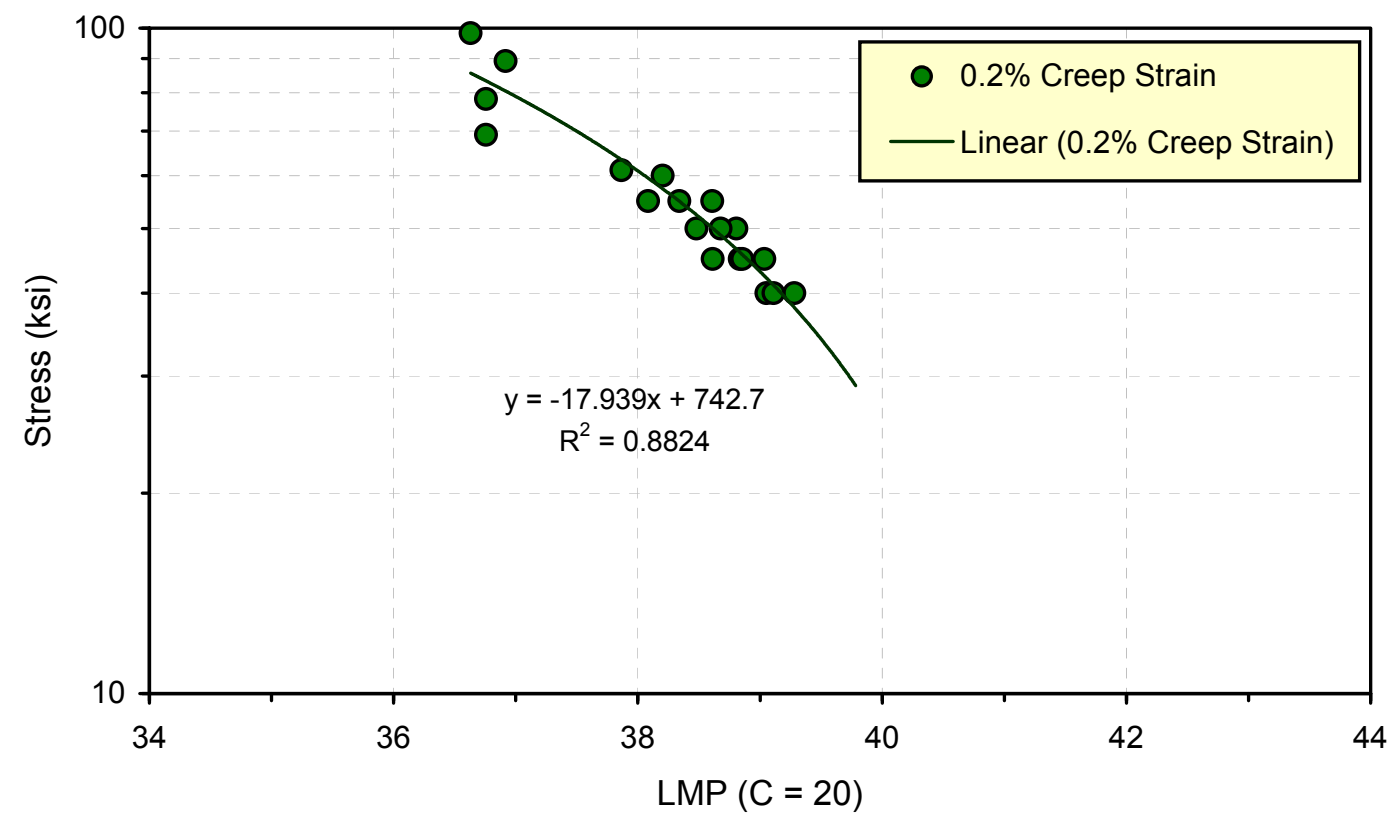

Figure 5.20: Stress $(\mathrm{ksi})$ versus LMP $(C=20)$ at 0.2 creep strain for Udimet 720 . 


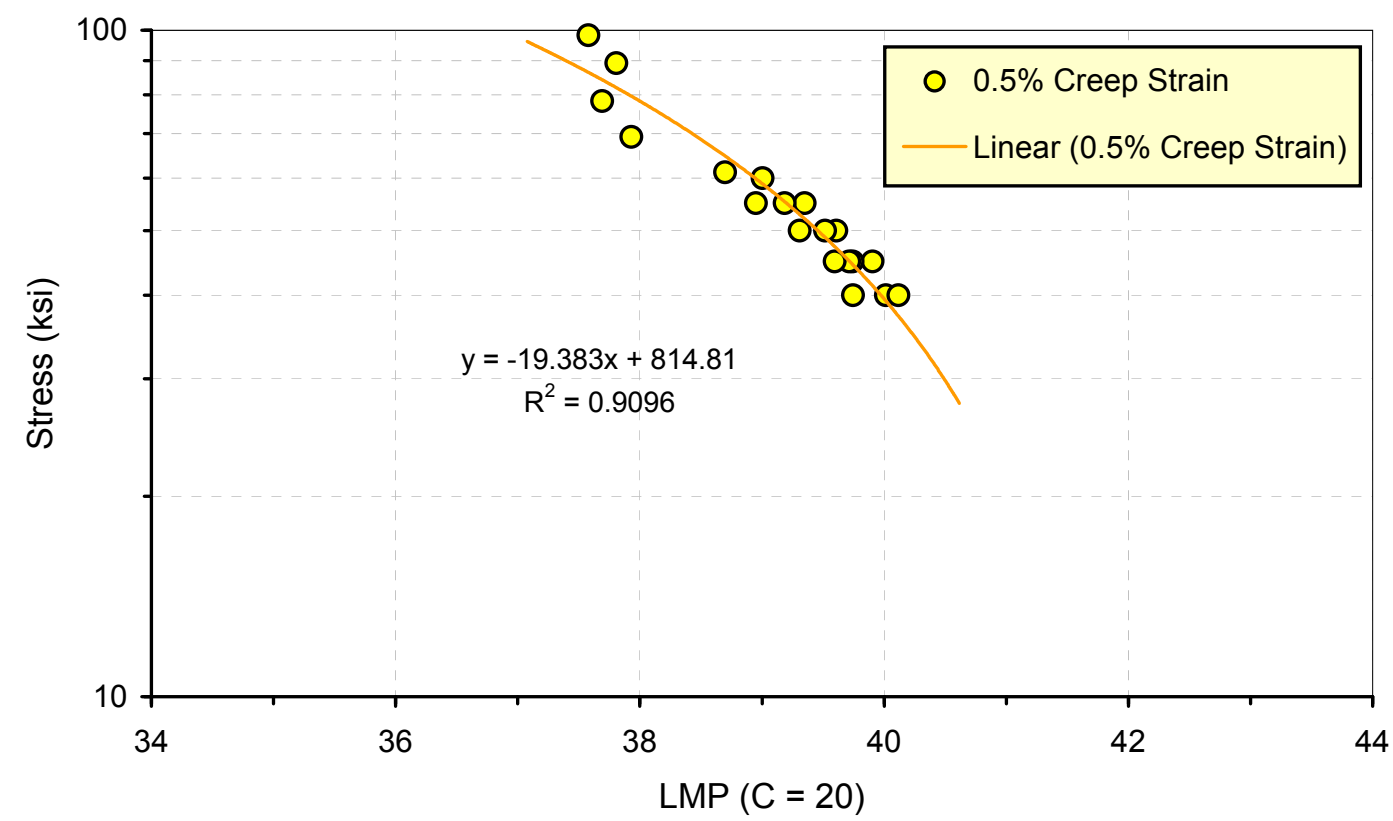

Figure 5.21: Stress $(\mathrm{ksi})$ versus LMP $(\mathrm{C}=\mathbf{2 0})$ at 0.5 creep strain for Udimet 720 .

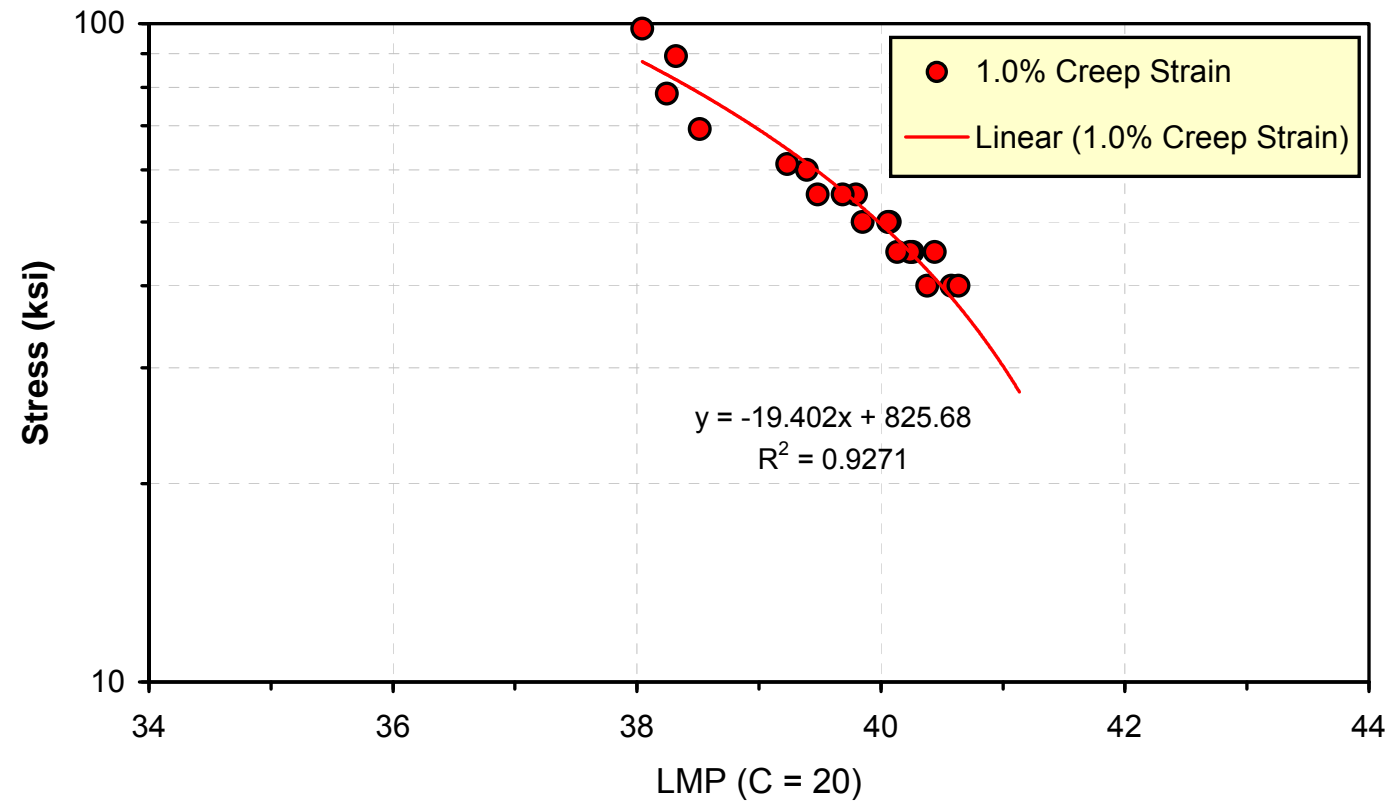

Figure 5.22: Stress $(\mathrm{ksi})$ versus LMP $(C=\mathbf{2 0})$ at 1.0 creep strain for Udimet 720 . 


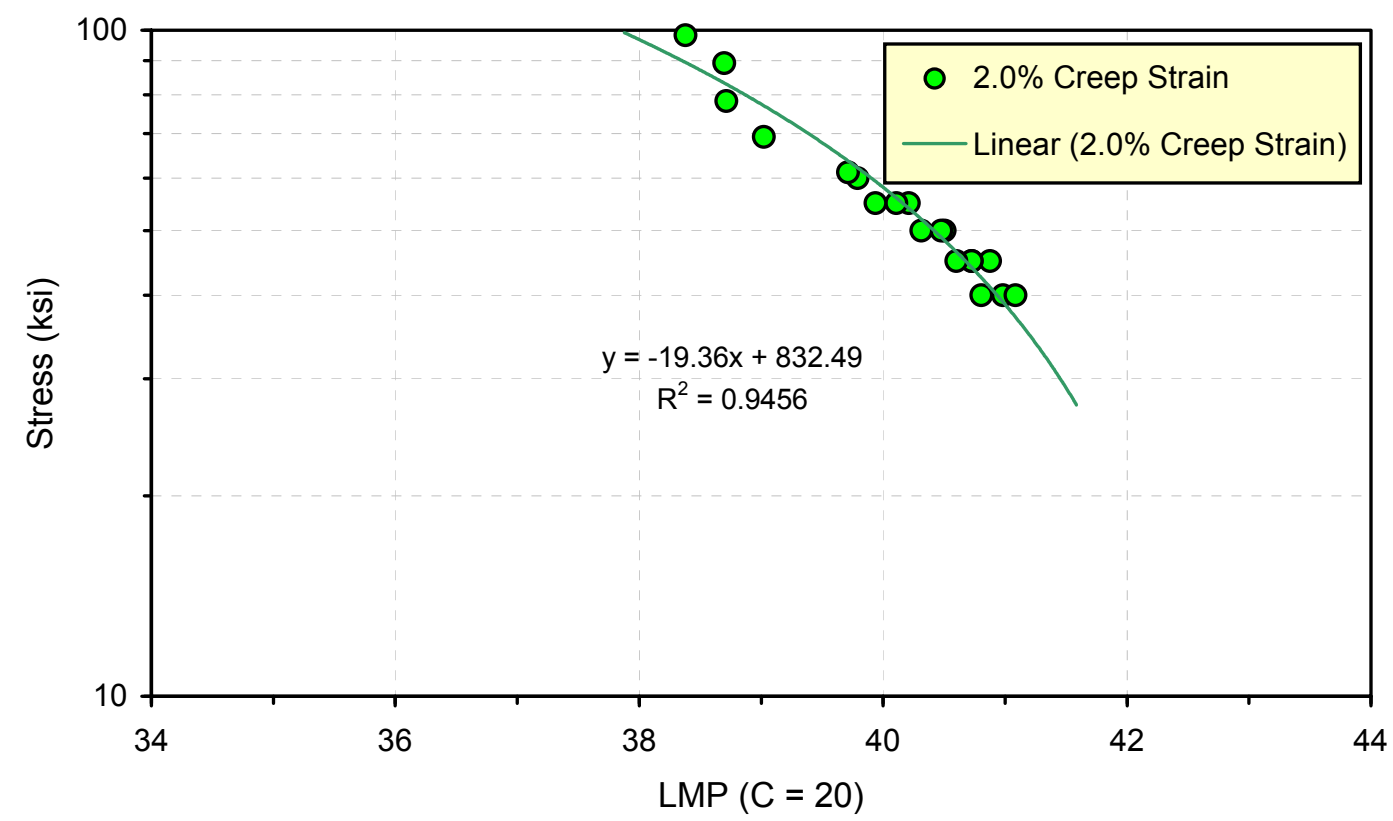

Figure 5.23: Stress $(\mathrm{ksi})$ versus LMP $(\mathrm{C}=\mathbf{2 0})$ at 2.0 creep strain for Udimet 720 .

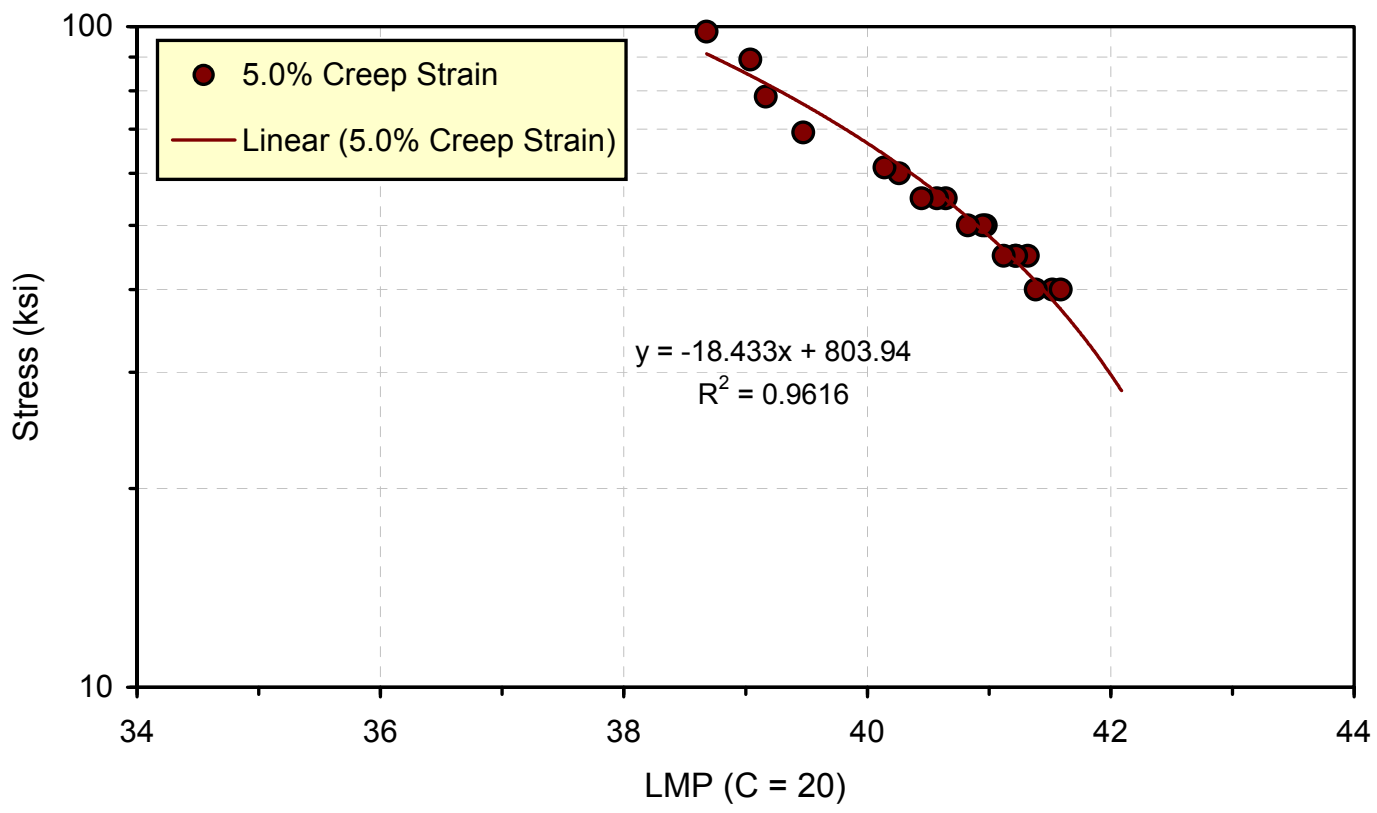

Figure 5.24: Stress $(\mathrm{ksi})$ versus LMP $(\mathrm{C}=\mathbf{2 0})$ at 5.0 creep strain for Udimet 720 . 
Table 5I: Creep and Creep Rupture for Udimet 720 (bar): Miscellaneous Testing at SM (Table 3) GE historical data ${ }^{+}$, and Fig. 2, p. 600, in paper by S. Dubiez-Le Goff et al.*

\begin{tabular}{|c|c|c|c|r|r|r|r|r|c|}
\hline $\begin{array}{c}\text { Heat } \\
\text { No. }\end{array}$ & Cond. & $\begin{array}{c}\text { Temp. } \\
(\mathrm{F})\end{array}$ & $\begin{array}{c}\text { Stress } \\
(\mathrm{ksi})\end{array}$ & $\begin{array}{c}\text { Time } \\
(\mathrm{h})\end{array}$ & $\begin{array}{c}\text { Strain } \\
(\%)\end{array}$ & $\begin{array}{c}\text { Elong. } \\
(\%)\end{array}$ & $\begin{array}{c}\text { RA } \\
(\%)\end{array}$ & LMP $_{\mathrm{f}}$ & Status \\
\hline SM & PA & 1200 & 102.0 & $1,000.0$ & ND & ND & ND & 38.1800 & \\
\hline CEA & PA & 1202 & 130.5 & 57.7 & 7.3 & ND & ND & 36.1670 & Failed \\
\hline CEA & PA & 1202 & 123.3 & 207.7 & 6.9 & ND & ND & 37.0920 & Failed \\
\hline CEA & PA & 1202 & 116.0 & 496.2 & 8.0 & ND & ND & 37.7200 & Failed \\
\hline CEA & PA & 1202 & 108.8 & 784.6 & 5.8 & ND & ND & 38.0510 & Failed \\
\hline CEA & PA & 1202 & 87.0 & $4,600.0$ & 7.4 & ND & ND & 39.3280 & Failed \\
\hline SM & PA & 1300 & 73.0 & $1,000.0$ & ND & ND & ND & 40.4800 & \\
\hline GE & PA & 1350 & 68.2 & 100.0 & ND & ND & ND & 39.8200 & \\
\hline GE & PA & 1350 & 39.5 & $1,000.0$ & ND & ND & ND & 41.6300 & \\
\hline GE & PA & 1350 & 22.5 & $10,000.0$ & ND & ND & ND & 43.4400 & \\
\hline GE & PA & 1350 & 12.9 & $100,000.0$ & ND & ND & ND & 45.2500 & \\
\hline GE & PA & 1350 & 10.0 & $300,000.0$ & ND & ND & ND & 46.1136 & \\
\hline
\end{tabular}

\# Special Metals Publication SMC-106, Sept 2004. Includes extrapolated data.

${ }^{+}$GE historical data. Includes extrapolated data.

* S. Dubiez-Le Goff, R. Couturier, L. Guetaz and H. Burlet, Mater. Sci. Eng., Vol. A 387-389, 2004, pp. 599-603.

Table 5J: Creep and Creep Rupture for Alloy 617 (plate): SW Testing \& GE Historical Data*

\begin{tabular}{|c|c|c|c|r|r|c|c|c|c|}
\hline $\begin{array}{c}\text { Heat } \\
\text { No. }\end{array}$ & Cond. & $\begin{array}{c}\text { Temp. } \\
(\mathrm{F})\end{array}$ & $\begin{array}{c}\text { Stress } \\
(\mathrm{ksi})\end{array}$ & $\begin{array}{c}\text { Time } \\
(\mathrm{h})\end{array}$ & $\begin{array}{c}\text { Strain } \\
(\%)\end{array}$ & $\begin{array}{c}\text { Elong. } \\
(\%)\end{array}$ & $\begin{array}{c}\text { RA } \\
(\%)\end{array}$ & LMP $_{\mathrm{f}}$ & Status \\
\hline 8838SW & SA & 1292 & 37.9 & $2,298.4$ & 6.822 & 7.8 & 13.2 & 40.9292 & Failed \\
\hline $8838 S W$ & SA & 1292 & 32.6 & $6,098.2$ & 9.214 & 10.2 & 12.9 & 41.6717 & Failed \\
\hline $8838 S W$ & SA & 1382 & 27.1 & 935.6 & 22.433 & 23.7 & 35.7 & 42.3127 & Failed \\
\hline $8838 S W$ & SA & 1382 & 23.1 & $2,590.0$ & 23.864 & 27.1 & 31.9 & 43.1273 & Failed \\
\hline 8838SW & SA & 1382 & 19.7 & $5,890.0$ & 24.374 & 27.0 & 34.2 & 43.7846 & Failed \\
\hline XX00A5US & SA & 1400 & 30.0 & 61.7 & ND & ND & 88.8 & 40.5299 & Failed \\
\hline XX00A5US & SA & 1500 & 13.0 & 1037.2 & ND & ND & 72.8 & 45.1111 & Failed \\
\hline XX00A5US & SA & 1600 & 16.0 & 23.9 & ND & ND & 44.0 & 44.0395 & Failed \\
\hline XX00A5US & SA & 1600 & 12.0 & 158.3 & ND & ND & 45.7 & 45.7309 & Failed \\
\hline
\end{tabular}

* GE historical data for alloy 617 (1974). ND - no data

Table 5K: Time to Reach Creep Strain for Alloy 617 (plate): SW Testing

\begin{tabular}{|c|c|c|c|r|r|r|r|r|r|}
\hline Heat & \multirow{2}{*}{$\begin{array}{c}\text { No. } \\
\text { Cond. }\end{array}$} & Temp. & Stress & \multicolumn{6}{|c|}{ Time to Reach Creep Strain } \\
\cline { 5 - 10 }$(\mathrm{ksi})$ & & $0.1 \%$ & \multicolumn{1}{c|}{$0.2 \%$} & \multicolumn{1}{c|}{$0.5 \%$} & \multicolumn{1}{c|}{$1.0 \%$} & \multicolumn{1}{c|}{$2.0 \%$} & \multicolumn{1}{c|}{$5.0 \%$} \\
\hline 8838SW & SA & 1292 & 37.9 & 113.4 & 234.1 & 625.5 & $1,056.6$ & $1,510.1$ & $2,107.5$ \\
\hline 8838SW & SA & 1292 & 32.6 & 167.9 & 546.5 & $1,717.9$ & $2,843.6$ & $3,860.4$ & $5,286.2$ \\
\hline $8838 S W$ & SA & 1382 & 27.1 & 30.0 & 64.2 & 159.9 & 276.0 & 415.8 & 617.1 \\
\hline 8838SW & SA & 1382 & 23.1 & 82.6 & 188.0 & 594.4 & 949.0 & $1,305.1$ & $1,783.1$ \\
\hline 8838SW & SA & 1382 & 19.7 & 324.9 & 809.5 & $1,600.2$ & $2,223.8$ & $2,924.8$ & $4,004.6$ \\
\hline XX00A5US & SA & 1400 & 30.0 & & 36.9 & 37.4 & 37.6 & 38.0 & \\
\hline XX00A5US & SA & 1500 & 13.0 & & 40.2 & 41.0 & 41.6 & 42.3 & \\
\hline XX00A5US & SA & 1600 & 16.0 & & & 39.5 & 40.3 & 41.1 & \\
\hline XX00A5US & SA & 1600 & 12.0 & & 40.4 & 41.4 & 42.2 & 43.0 & \\
\hline
\end{tabular}


Table 5L.: Creep and Creep Rupture for Alloy 617 (strip, plate, tube, bar \& forging): ECCC Data Sheet, Alloy 617, 2005, 3 p.*

\begin{tabular}{|c|c|c|r|c|c|c|c|c|c|}
\hline $\begin{array}{c}\text { Heat } \\
\text { No. }\end{array}$ & Cond. & $\begin{array}{c}\text { Temp. } \\
(\mathrm{F})\end{array}$ & $\begin{array}{c}\text { Stress } \\
(\mathrm{ksi})\end{array}$ & $\begin{array}{c}\text { Time } \\
(\mathrm{h})\end{array}$ & $\begin{array}{c}\text { Strain } \\
(\%)\end{array}$ & $\begin{array}{c}\text { Elong. } \\
(\%)\end{array}$ & $\begin{array}{c}\text { RA } \\
(\%)\end{array}$ & LMP $_{\mathrm{f}}$ & Status \\
\hline ECCC & SA & 1112 & 50.7632 & $10,000.0$ & & & & 37.7280 & \\
\hline ECCC & SA & 1202 & 35.2442 & $10,000.0$ & & & & 39.8880 & \\
\hline ECCC & SA & 1292 & 23.6411 & $10,000.0$ & & & & 42.0480 & \\
\hline ECCC & SA & 1382 & 15.3740 & $10,000.0$ & & & & 44.2080 & \\
\hline ECCC & SA & 1472 & 9.7175 & $10,000.0$ & & & & 46.3680 & \\
\hline ECCC & SA & 1562 & 6.0916 & $10,000.0$ & & & & 48.5280 & \\
\hline ECCC & SA & 1652 & 3.7710 & $10,000.0$ & & & & 50.6880 & \\
\hline ECCC & SA & 1742 & 2.4221 & $10,000.0$ & & & & 52.8480 & \\
\hline ECCC & SA & 1112 & 45.2518 & $30,000.0$ & & & & 38.4780 & \\
\hline ECCC & SA & 1202 & 30.7480 & $30,000.0$ & & & & 40.6810 & \\
\hline ECCC & SA & 1292 & 20.0152 & $30,000.0$ & & & & 42.8839 & \\
\hline ECCC & SA & 1382 & 12.4732 & $30,000.0$ & & & & 45.0869 & \\
\hline ECCC & SA & 1472 & 7.6870 & $30,000.0$ & & & & 47.2898 & \\
\hline ECCC & SA & 1562 & 4.7862 & $30,000.0$ & & & & 49.4927 & \\
\hline ECCC & SA & 1652 & 2.9008 & $30,000.0$ & & & & 51.6957 & \\
\hline ECCC & SA & 1742 & 1.8275 & $30,000.0$ & & & & 53.8986 & \\
\hline ECCC & SA & 1112 & 39.5953 & $100,000.0$ & & & & 39.3000 & \\
\hline ECCC & SA & 1202 & 25.9617 & $100,000.0$ & & & & 41.5500 & \\
\hline ECCC & SA & 1292 & 16.2442 & $100,000.0$ & & & & 43.8000 & \\
\hline ECCC & SA & 1382 & 9.8626 & $100,000.0$ & & & & 46.0500 & \\
\hline ECCC & SA & 1472 & 5.9465 & $100,000.0$ & & & & 48.3000 & \\
\hline ECCC & SA & 1562 & 3.4809 & $100,000.0$ & & & & 50.5500 & \\
\hline ECCC & SA & 1652 & 2.1611 & $100,000.0$ & & & & 52.8000 & \\
\hline
\end{tabular}

Data extracted from table for average rupture strength for strip, plate, tube, bar and forgings used to develop isothermal rupture curves at $10 \mathrm{kh}, 30 \mathrm{kh}$ and $100 \mathrm{kh}$ using PD-6605 procedure to extrapolate from creep data. Information should be used for guidance and comparison purposes only. 


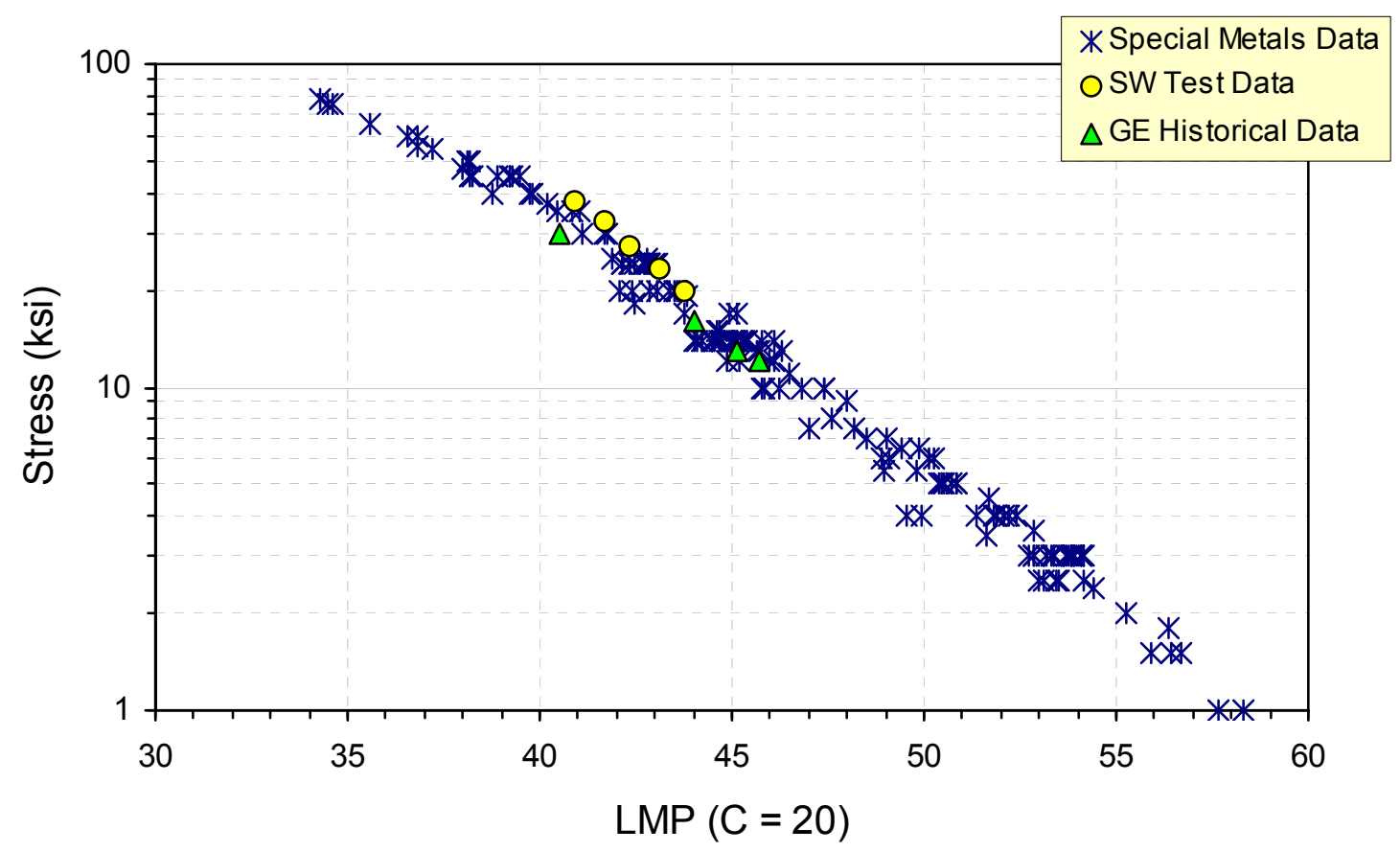

Figure 5.25: Stress $(\mathrm{ksi})$ versus LMP $(C=20)$ for Inconel 617 in the solution annealed condition. Note: SM data not included in Appendix tables.

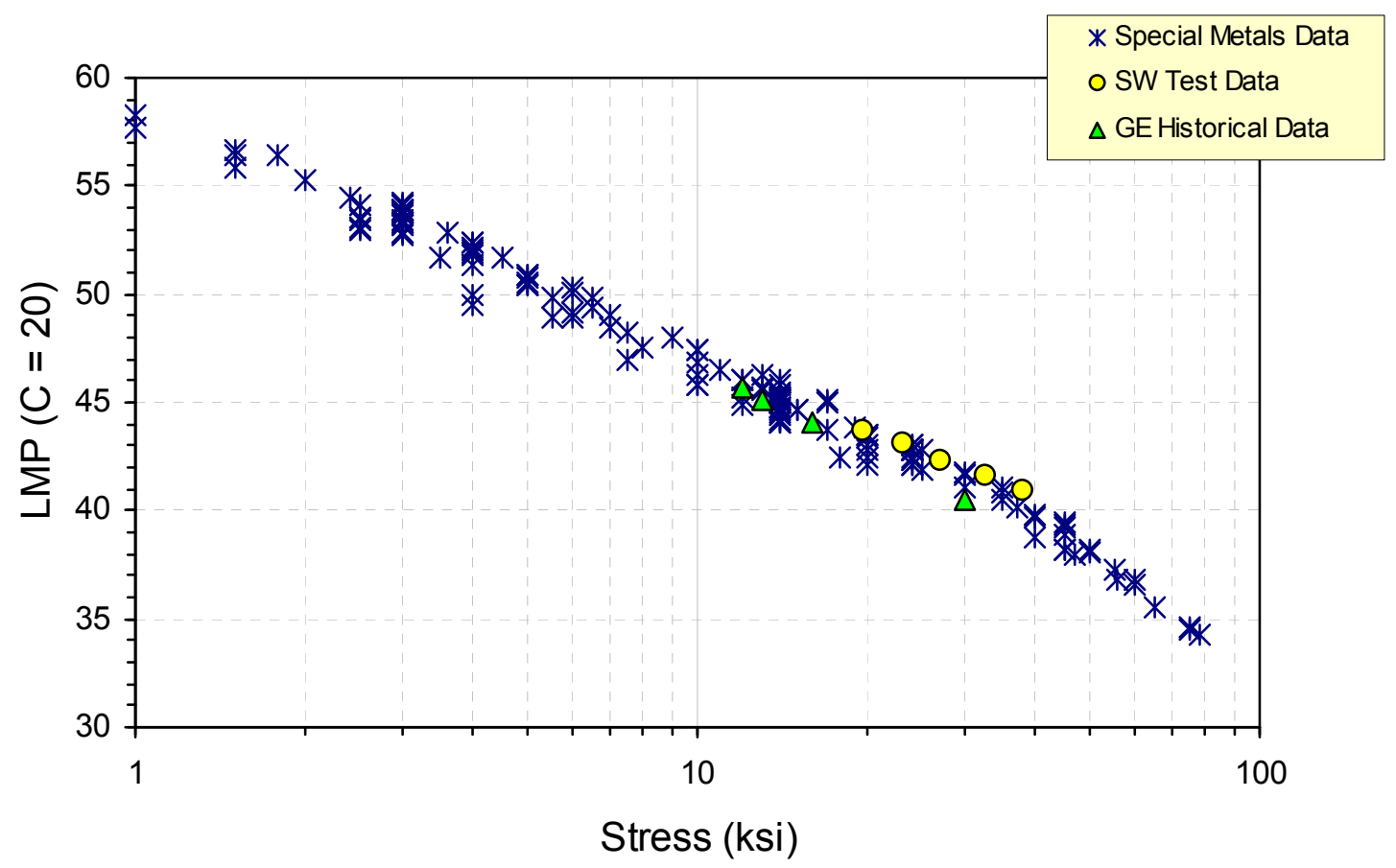

Figure 5.26: LMP $(C=20)$ versus Stress $(\mathrm{ksi})$ for Inconel 617 in the solution annealed condition. Note: SM data not included in Appendix Tables. 


\section{APPENDIX 6A \\ MICROSTRUCTURAL CHARATERIZATION OF \\ CANDIDATE NICKEL SUPERALLOY: HAYNES 282}




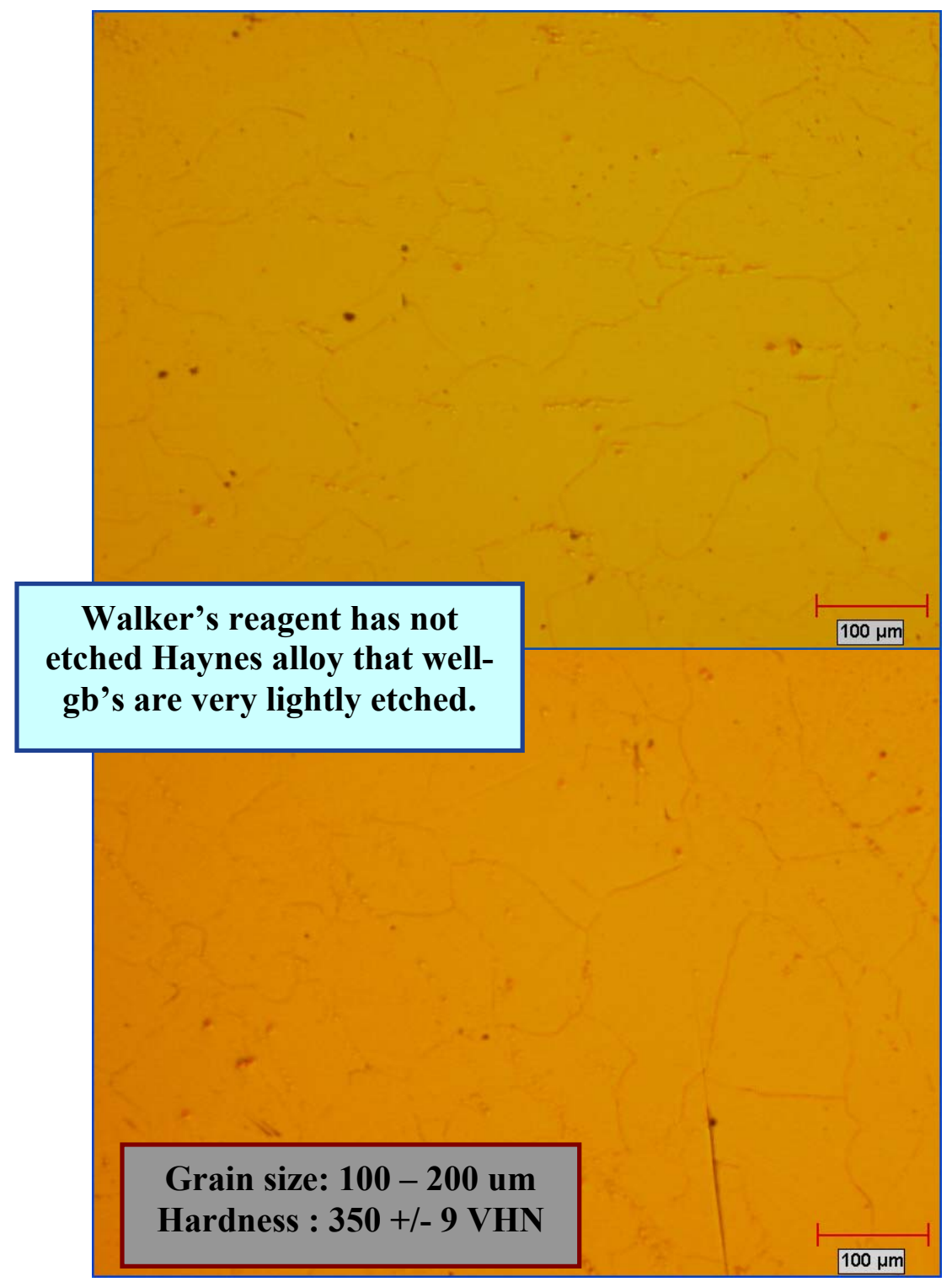

Figure 6.1: Optical micrograph of etched Haynes 282 in the solution annealed condition. 


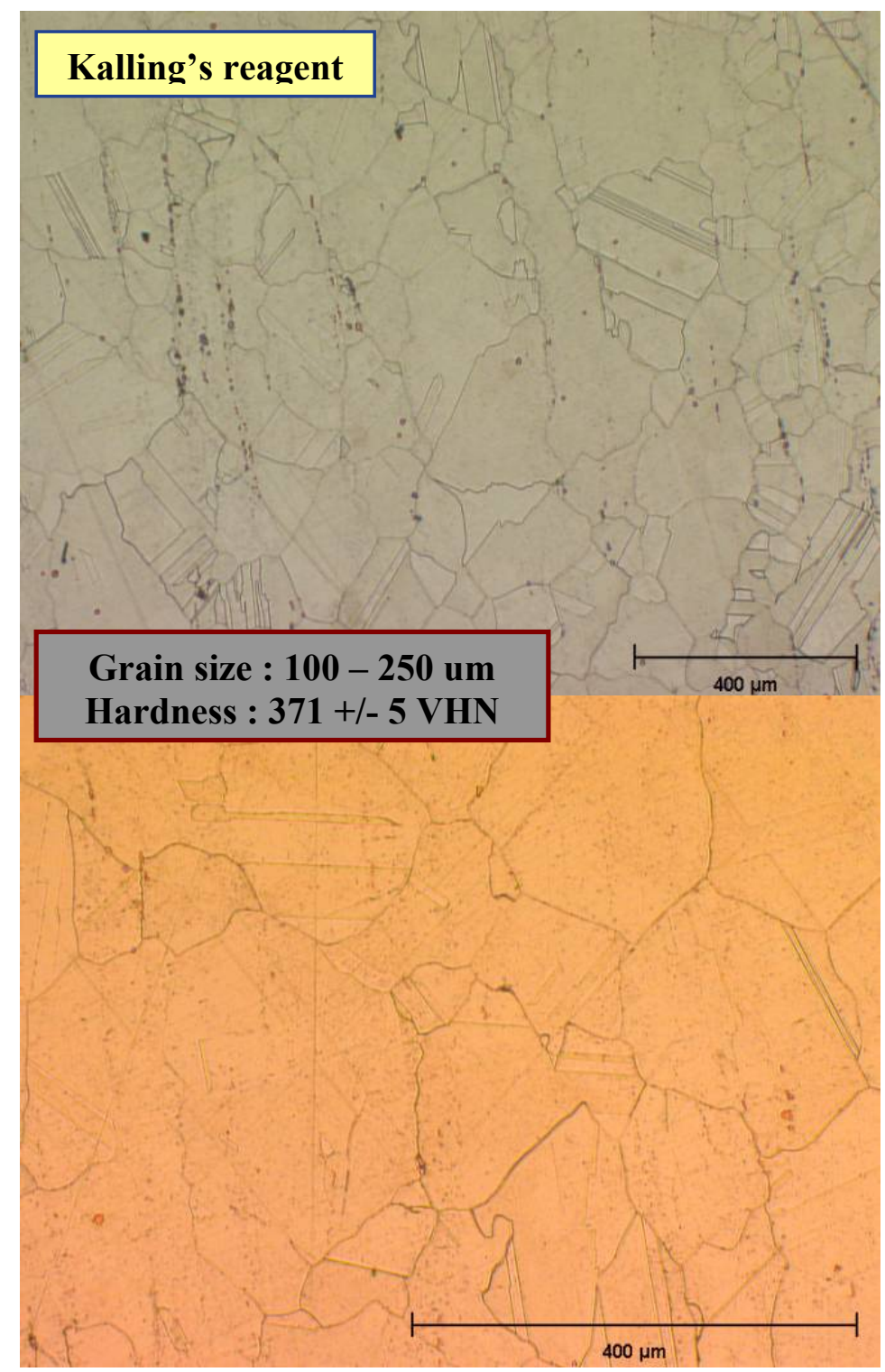

Figure 6.2: Optical micrograph of etched Haynes 282 in the peak aged condition. 


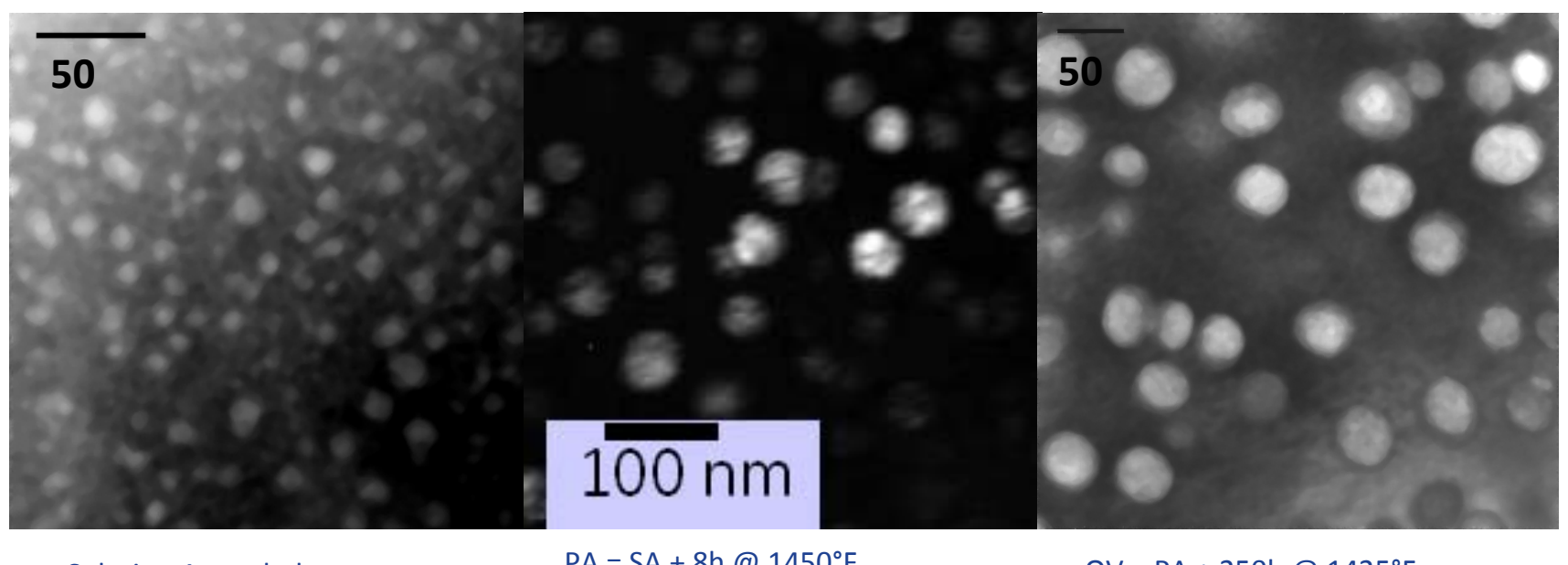

Solution Annealed

$\mathrm{PA}=\mathrm{SA}+8 \mathrm{~h} @ 1450^{\circ} \mathrm{F}$

$\mathrm{OV}=\mathrm{PA}+250 \mathrm{~h} @ 1425^{\circ} \mathrm{F}$

Figure 6.3: TEM micrographs of Haynes 282 in the solution annealed (left), peak aged (center), and overaged (right) conditions. 


\section{Solution Annealed H282}

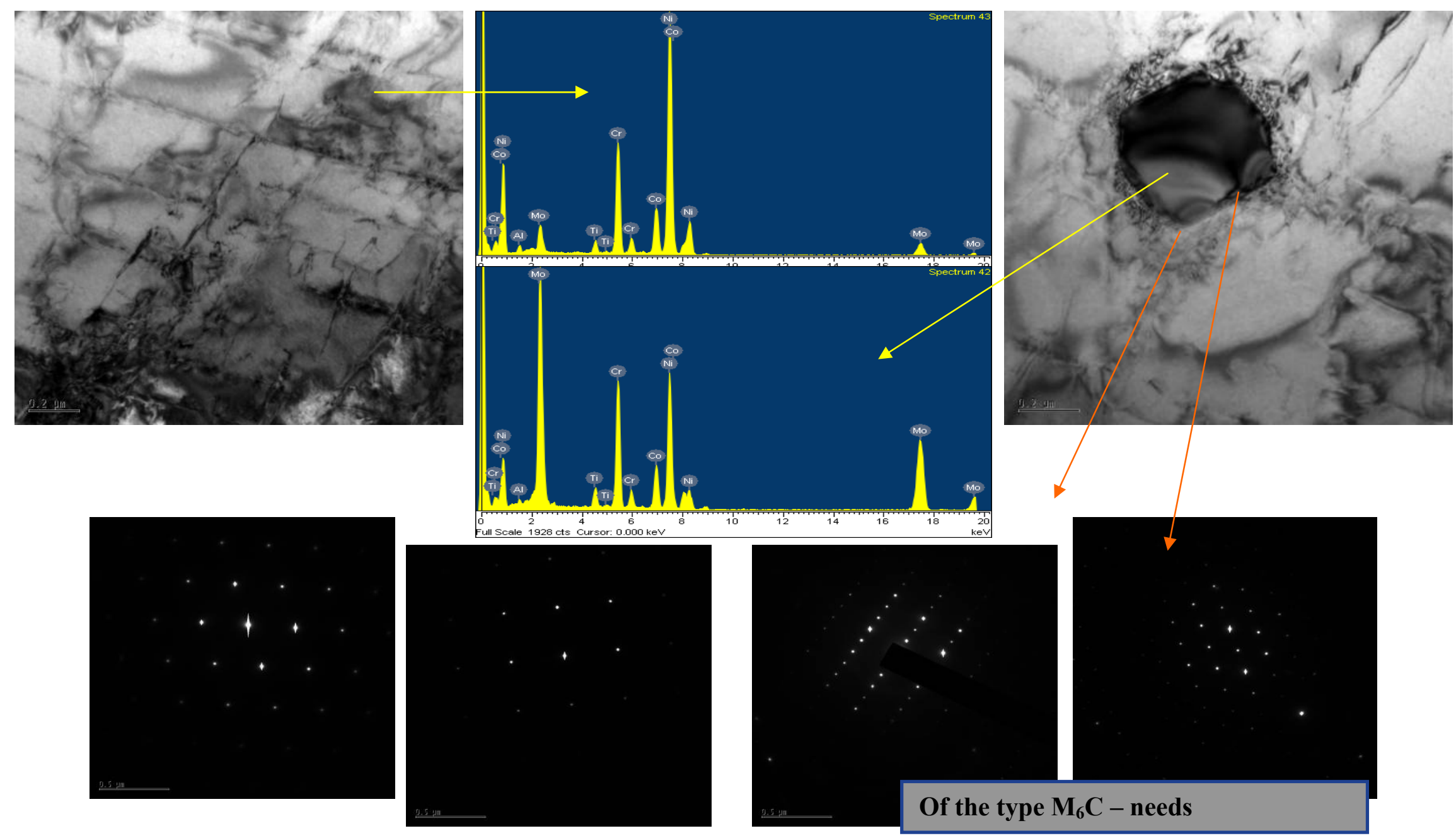

Figure 6.4: TEM micrographs and SAD patterns of Haynes 2828 microstructure in SA condition showing general matrix area (left upper micrograph), $M_{6} C$ carbide (upper right) and SAD patterns (lower figures) with EDS (center). 


\section{Peak Aged H282}

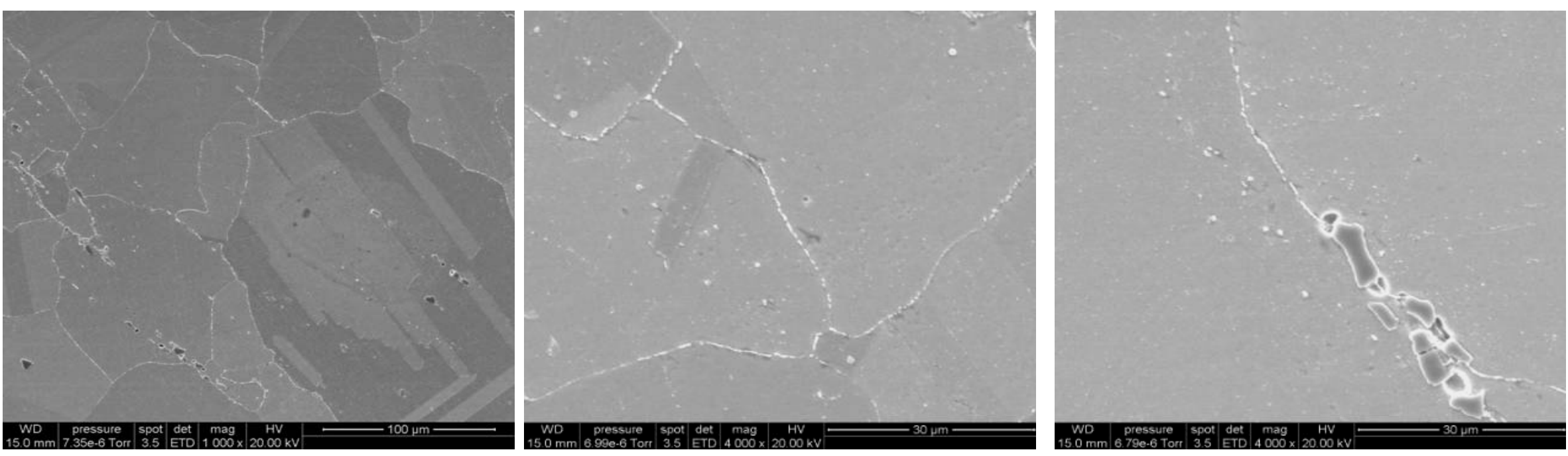

Grain boundaries decorated by fine carbides.

Figure 6.5: SEM micrographs of Haynes 282 microstructure in the peak aged condition showing general matrix carbide and grain boundary precipitation morphology. 


\section{Peak Aged H282}

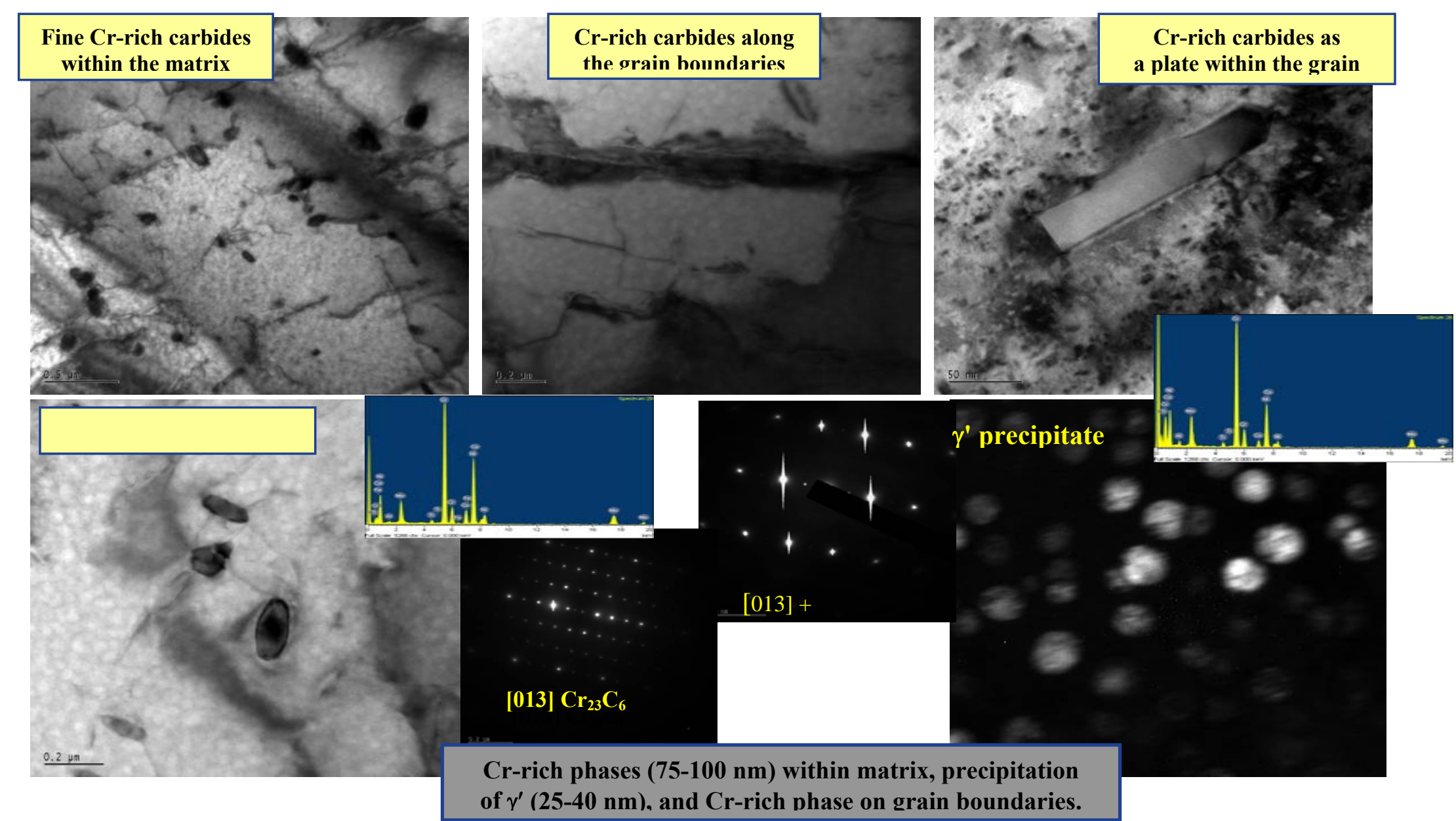

Figure 6.6: TEM micrographs and SAD patterns of Haynes 282 microstructure in PA condition showing general matrix area with various carbides (upper row and lower left), SAD patterns with EDS (lower center left) and $\gamma^{\prime}$ precipitates in the matrix (lower right) with associated SAD pattern with EDS of the matrix (upper center right and right center edge) 


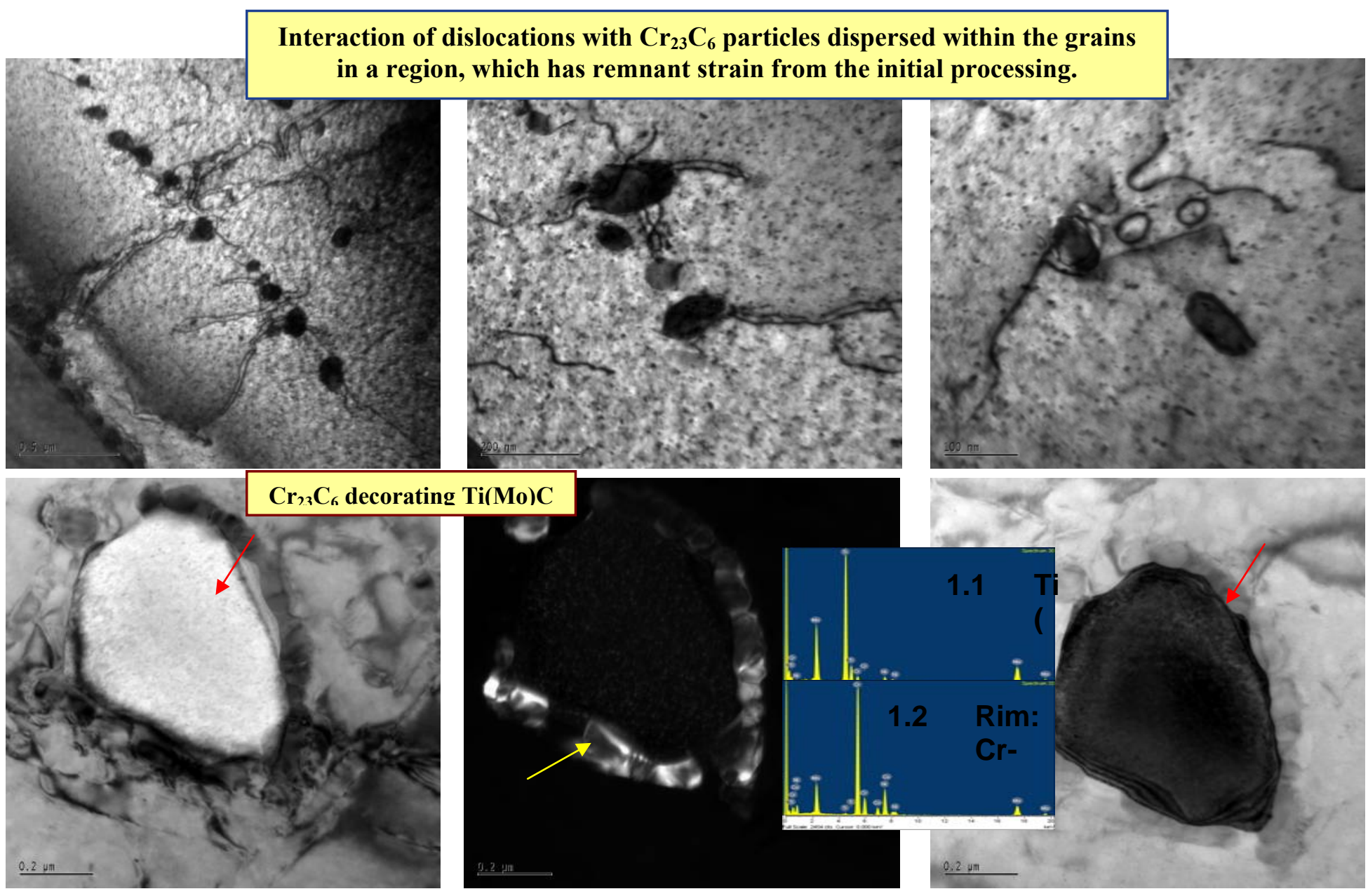

Figure 6.7: TEM micrographs of Haynes 282 microstructure in PA condition showing carbide arrangement that pin dislocations in a low energy boundary structure (upper row). In the bottom row of micrographs, note the ring of $\mathrm{Cr}_{23} \mathrm{C}_{6}$ carbides decorating a larger Ti(Mo)C-type carbide (EDS shows differences in carbide chemistry). 


\section{Comparison H282 - SA versus PA}

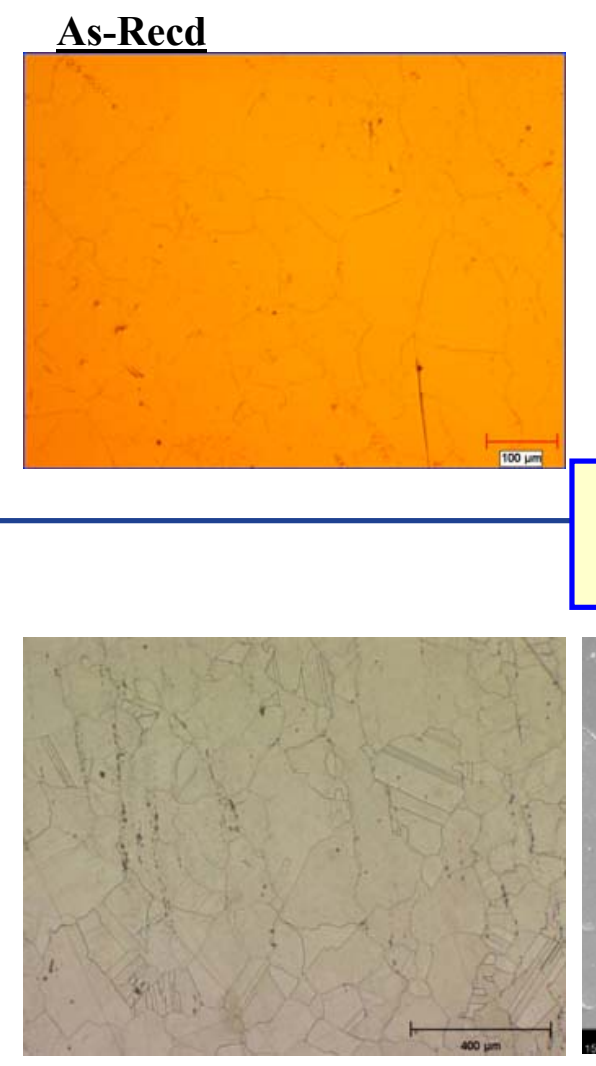

Figure 6.8: Comparison of Haynes 282 microstructure in SA and PA conditions showing matrix grain boundaries, $\gamma$ 'precipitates and typical carbides. Even though Haynes 282 after solution heat treatment is considered not to have $\gamma^{\prime}$, very small $\gamma^{\prime}$ precipitates $(\sim 10-20$ $\mathrm{nm}$ ) are found in the matrix.

\section{SEM not done}

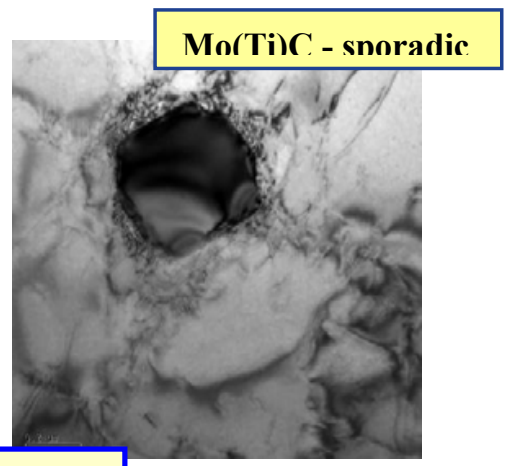

Grain size almost invariant between SA and PA conditions. However, precipitation of $\mathrm{g}^{\prime}(25-40 \mathrm{~nm})$ and precipitation of carbides within and along the grain boundaries makes $\mathrm{H} 282$ more

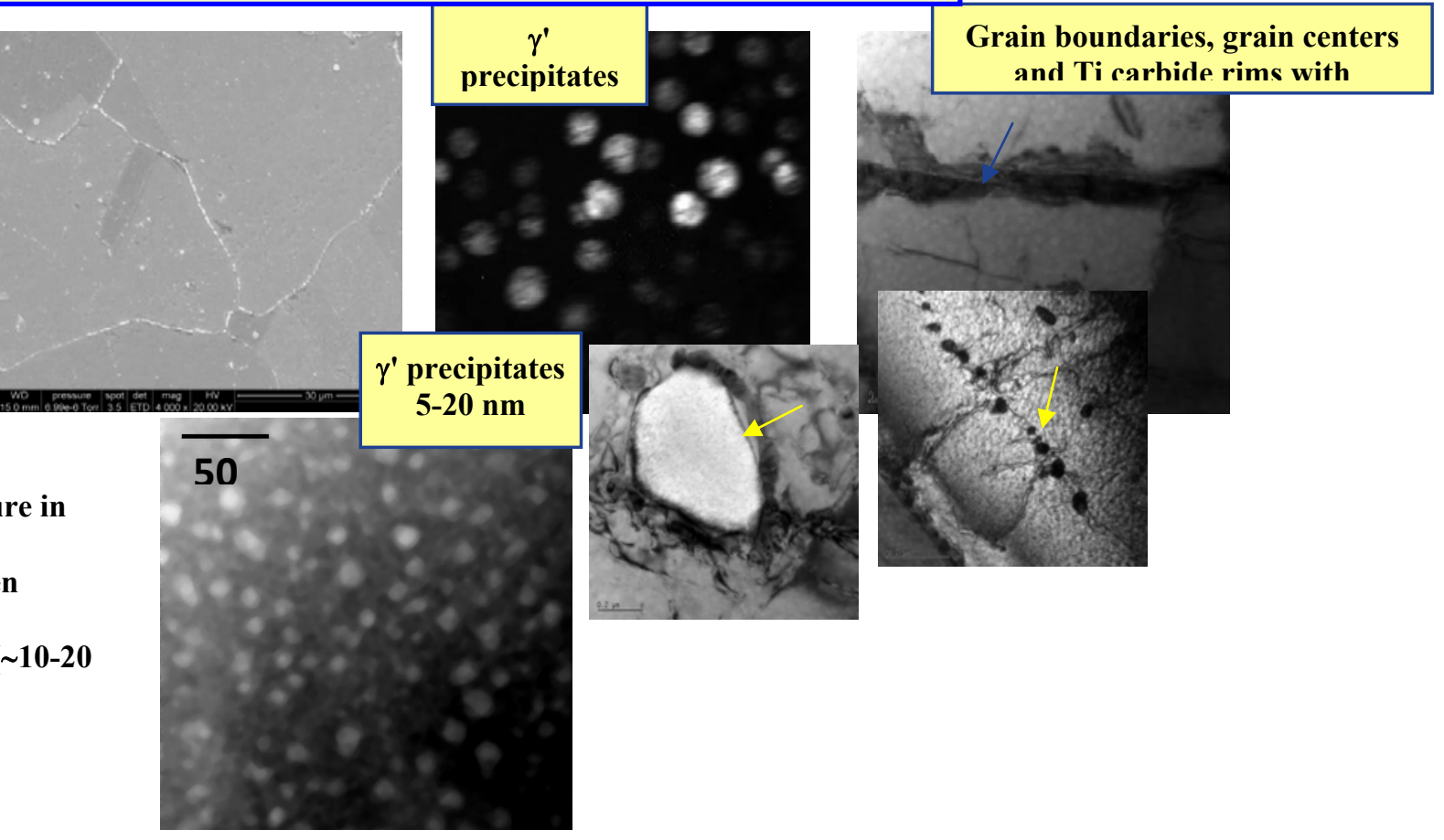





\begin{abstract}
APPENDIX 6B
MICROSTRUCTURAL CHARACTERIZATION OF CANDIDATE NICKEL SUPERALLOYS: NIMONIC 105
\end{abstract}




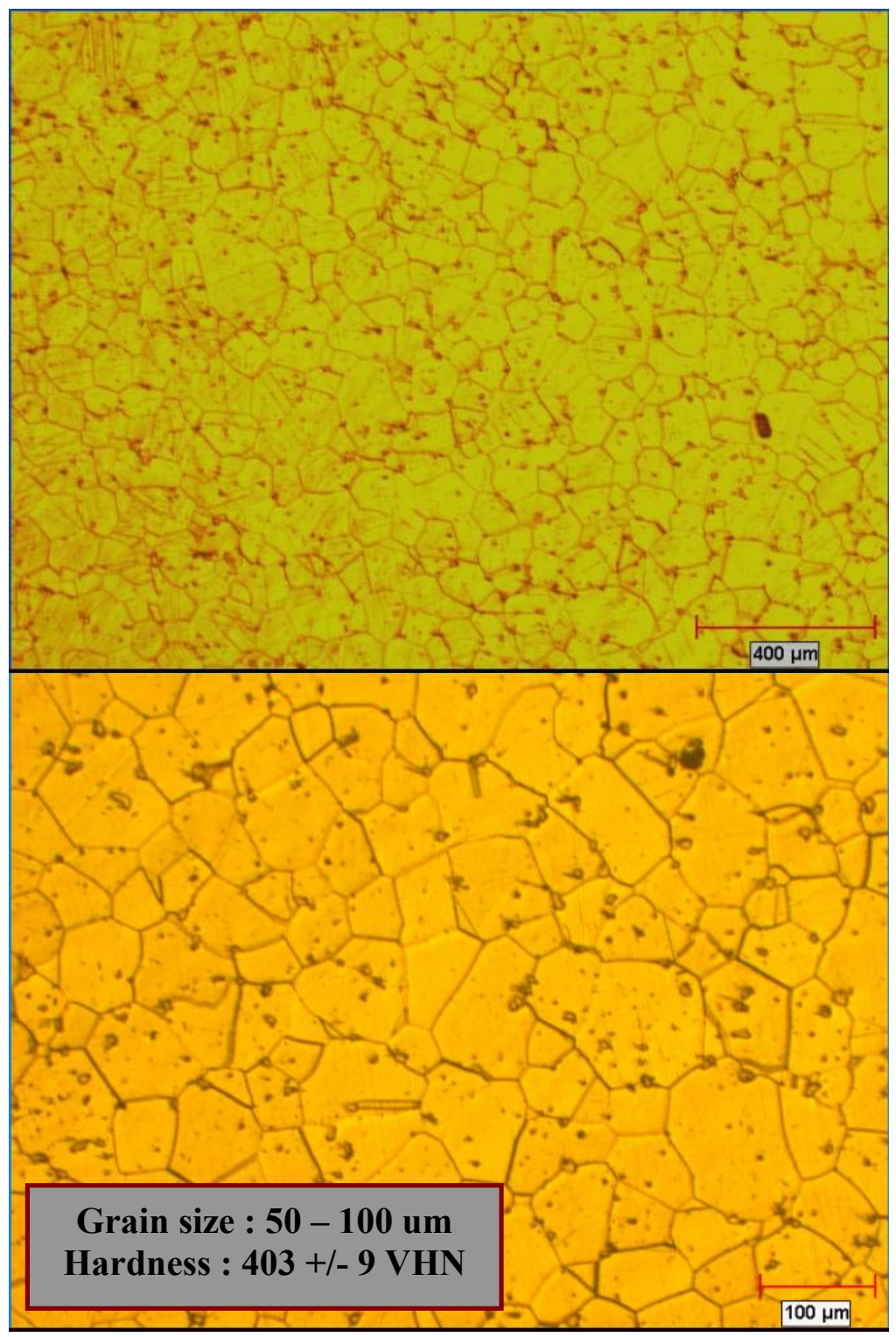

Figure 6.9: Optical micrograph of etched Nimonic 105 in the as-processed condition. 


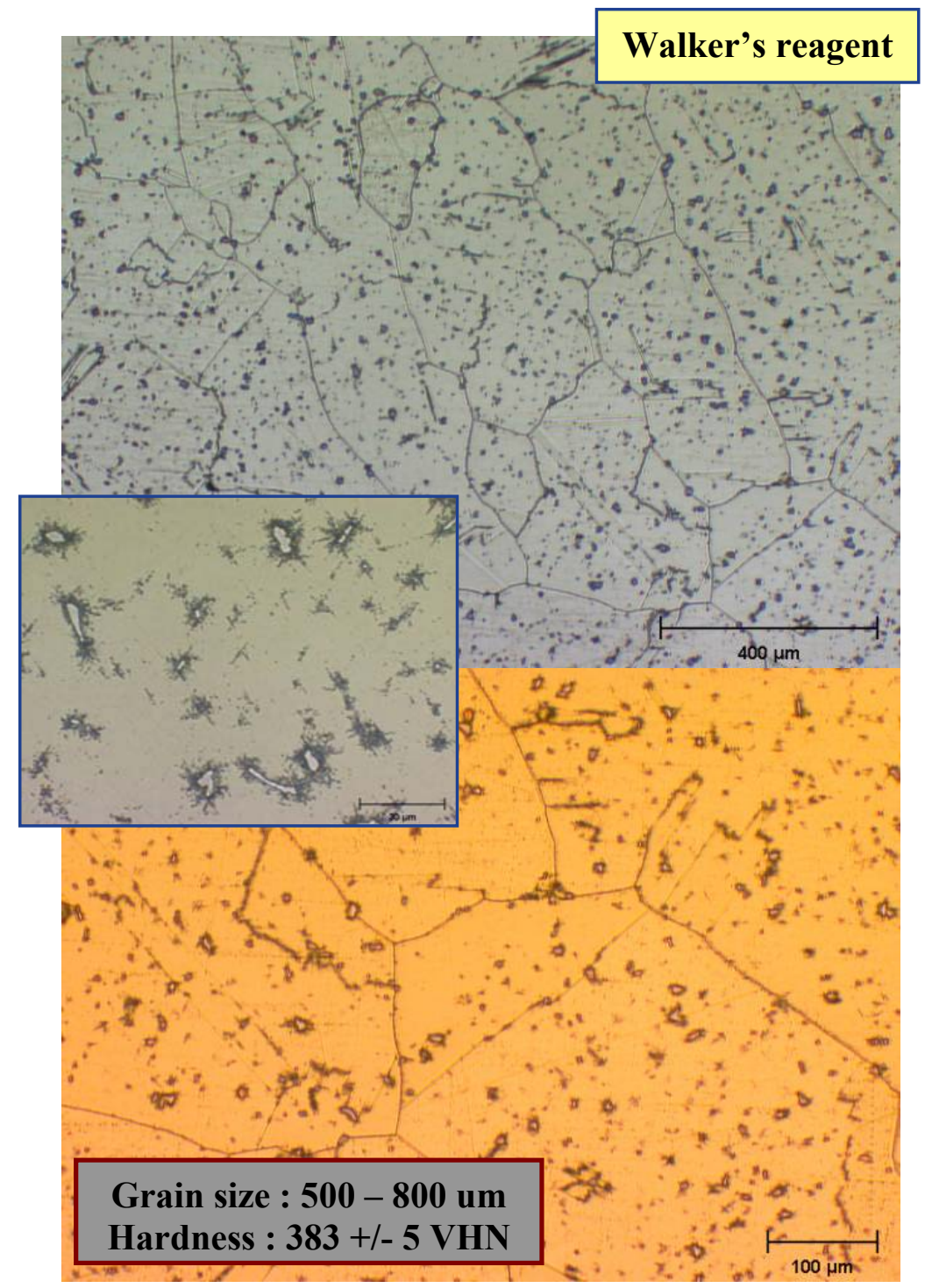

Figure 6.10: Optical micrograph of etched Nimonic 105 in the peak aged condition. 

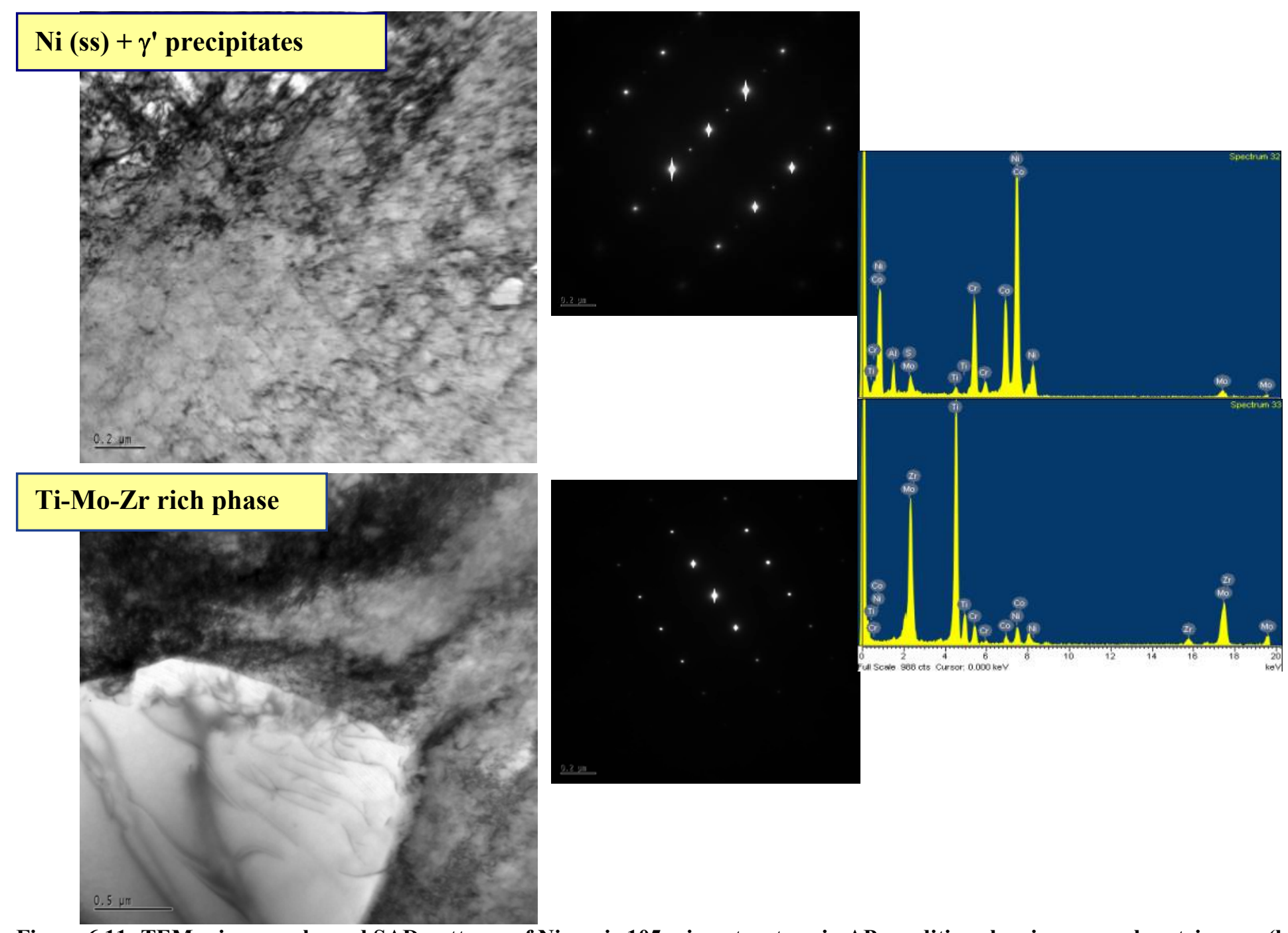

Figure 6.11: TEM micrographs and SAD patterns of Nimonic 105 microstructure in AP condition showing general matrix area (left upper micrograph), TI-MO-Zr phase (lower left) with associated SAD patterns (center) and EDS (right). 

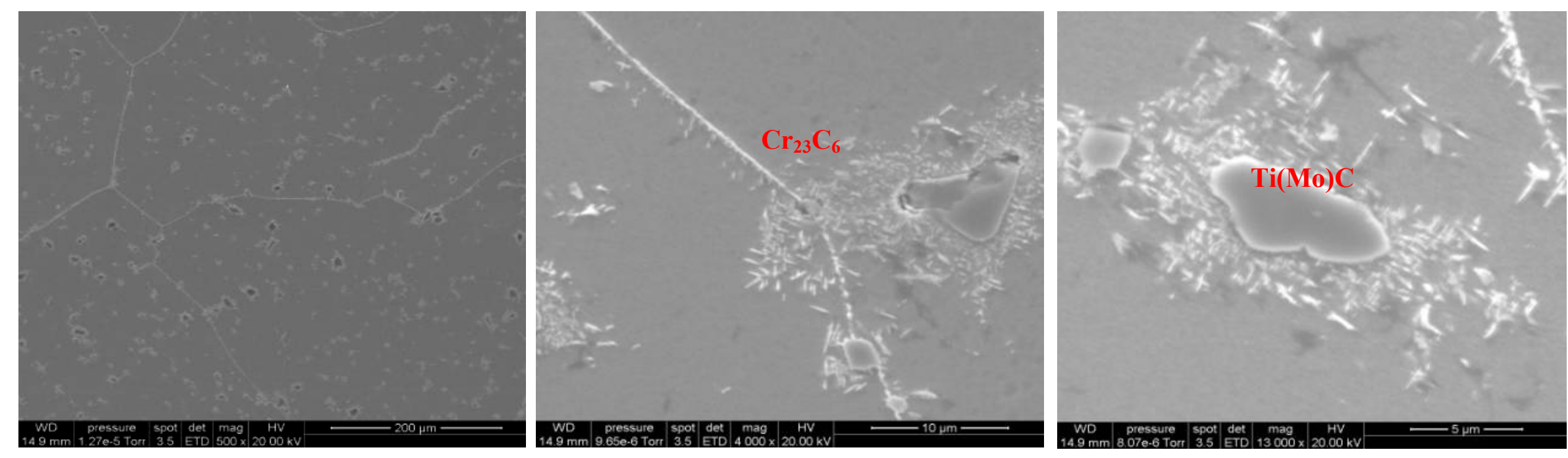

Large fraction of carbides after HT, especially Cr-rich ones decorating the grain boundaries.

Figure 6.12: SEM micrographs of Nimonic 105 microstructure in the peak aged condition showing general matrix features, including $\mathrm{Cr}_{23} \mathrm{C}_{6} \mathrm{phase}$ along grain boundary and $\mathrm{Ti}(\mathrm{MO}) \mathrm{C}$ phase. 


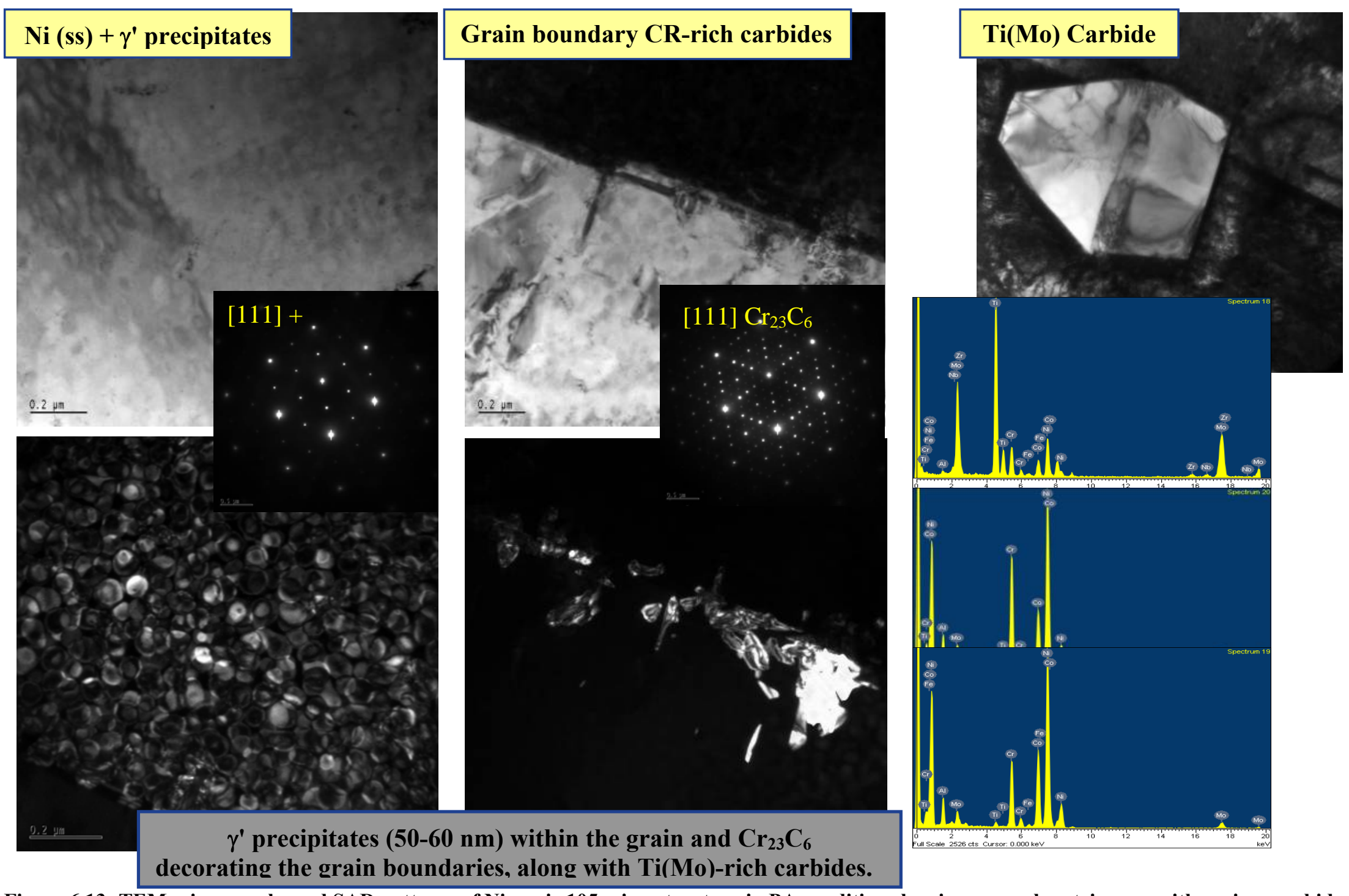

Figure 6.13: TEM micrographs and SAD patterns of Nimonic 105 microstructure in PA condition showing general matrix area with various carbides (upper row, center and right), SAD patterns with EDS (center and right) and $\gamma^{\prime}$ precipitates in the matrix (lower left) with associated SAD pattern with EDS of the matrix (center left and right). 


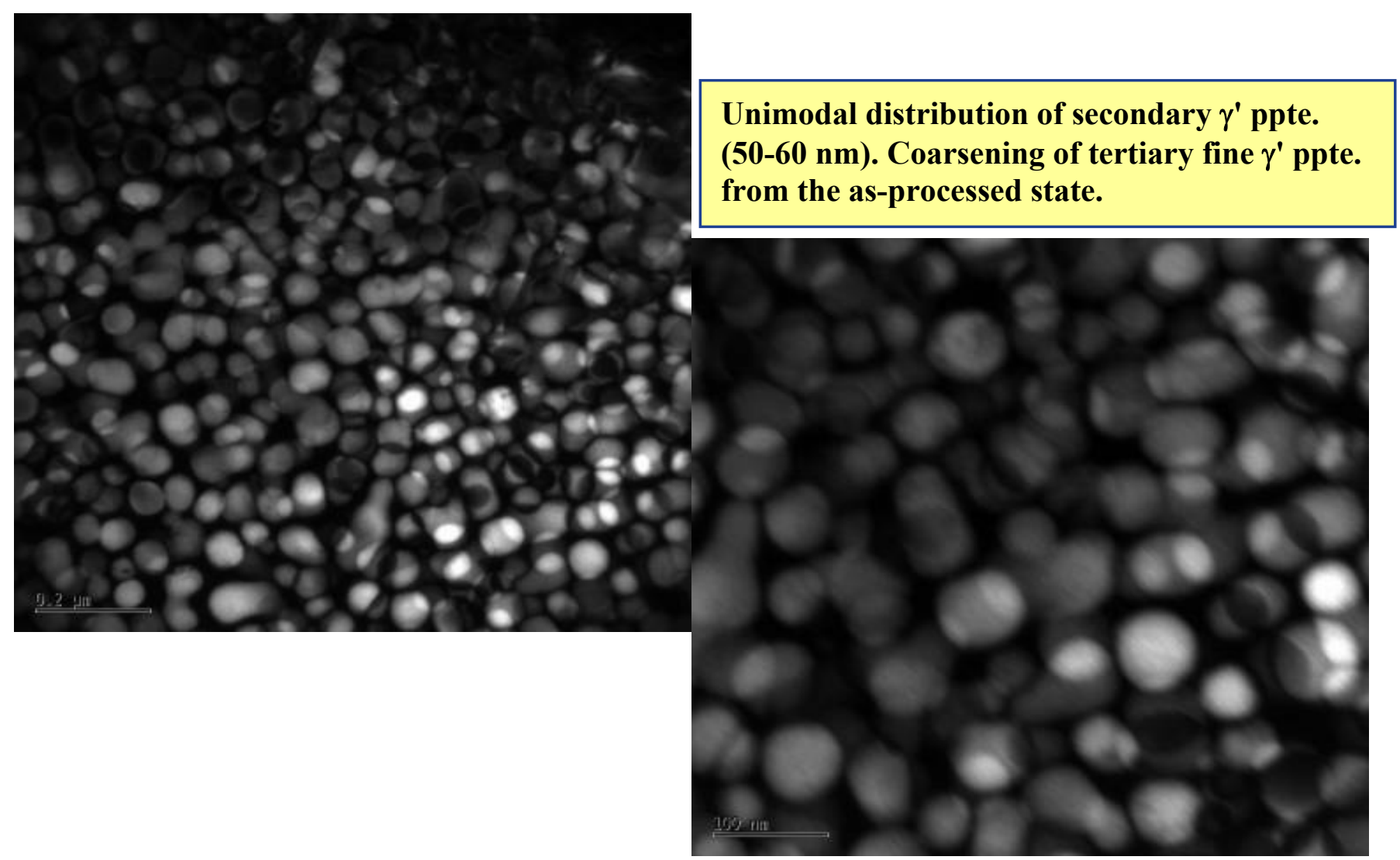

Figure 6-14: : TEM micrographs of Nimonic 105 that show the unimodal distribution of $\gamma^{\prime}$ in the peak aged condition, where coarsening of the tertiary fine $\gamma^{\prime}$ precipitates has proceeded from the as-processed state. 


\section{$\underline{\text { As-Processed }}$}

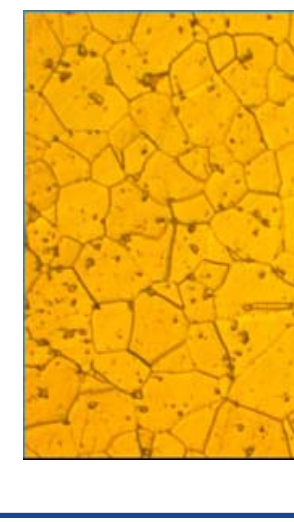

\section{Peak-Aged}

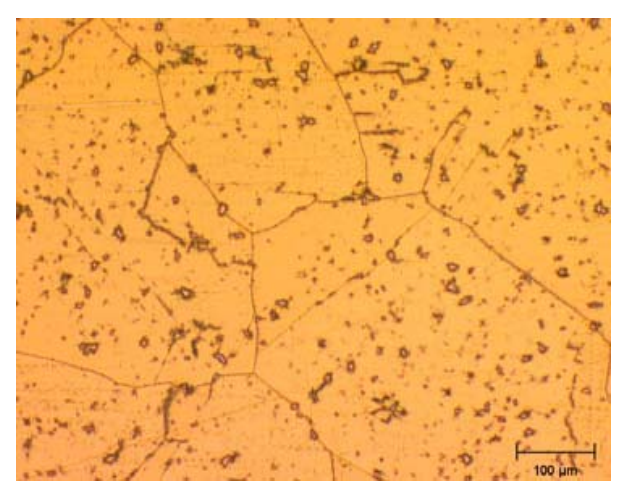

Not done

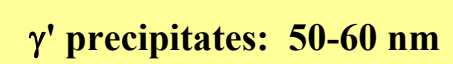

$5 x$ increase in grain size between the as-processed and peak-aged conditions. Coarsening of tertiary $\gamma^{\prime}$, leading to $25-40 \mathrm{~nm}$ particle size, $40-45 \%$ by volume, showing discontinuous precipitation of carbides along the grain boundaries. There is a decrease in hardness between the two conditions.

Figure 6.15: Comparison of Nimonic 105 microstructure in AP and PA conditions showing matrix, grain boundaries, $\gamma^{\prime}$ precipitates and typical carbides.
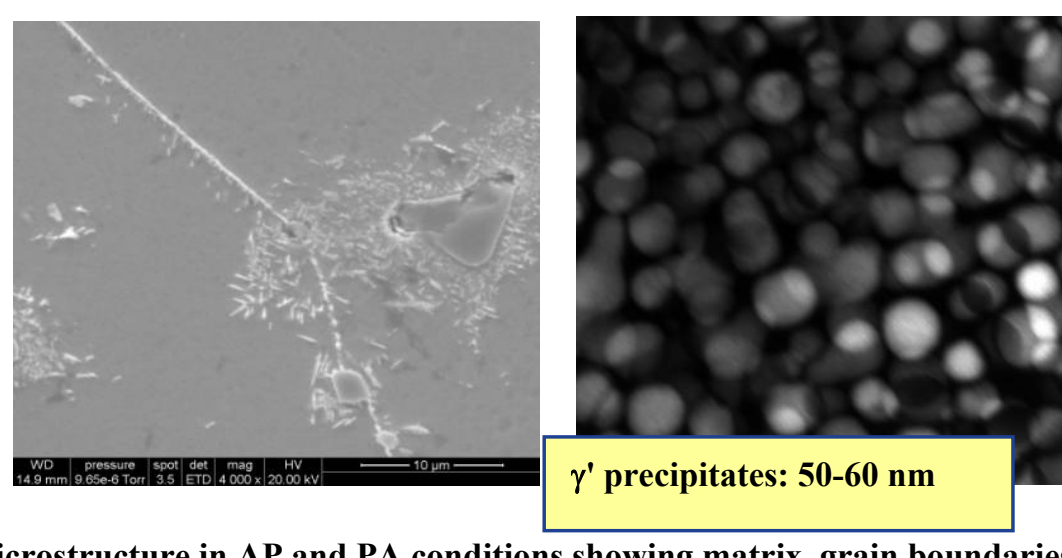

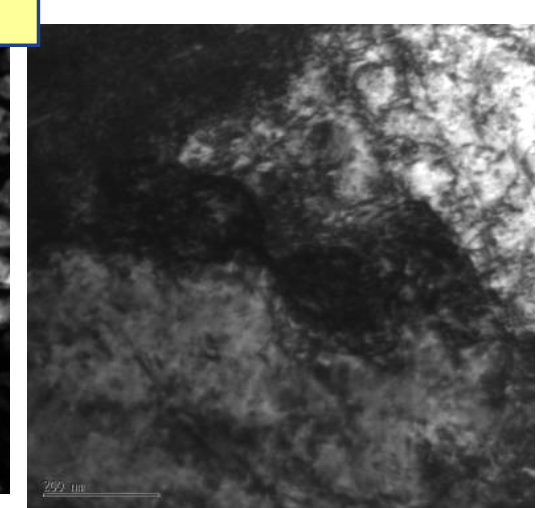

Grain boundaries, grain centers and Ti carbide rims with carbides

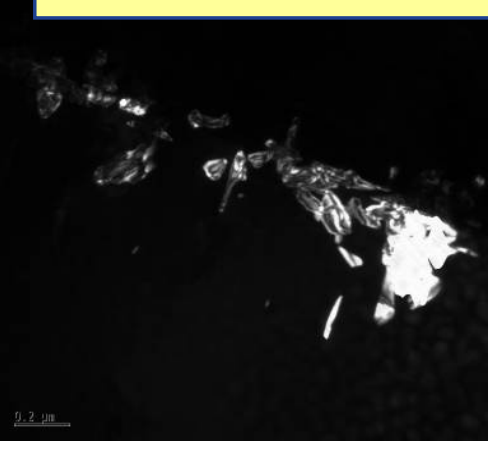




\section{APPENDIX 6C MICROSTRUCTURAL CHARACTERIZATION OF CANDIDATE NICKEL SUPERALLOYS: UDIMET 720LI}




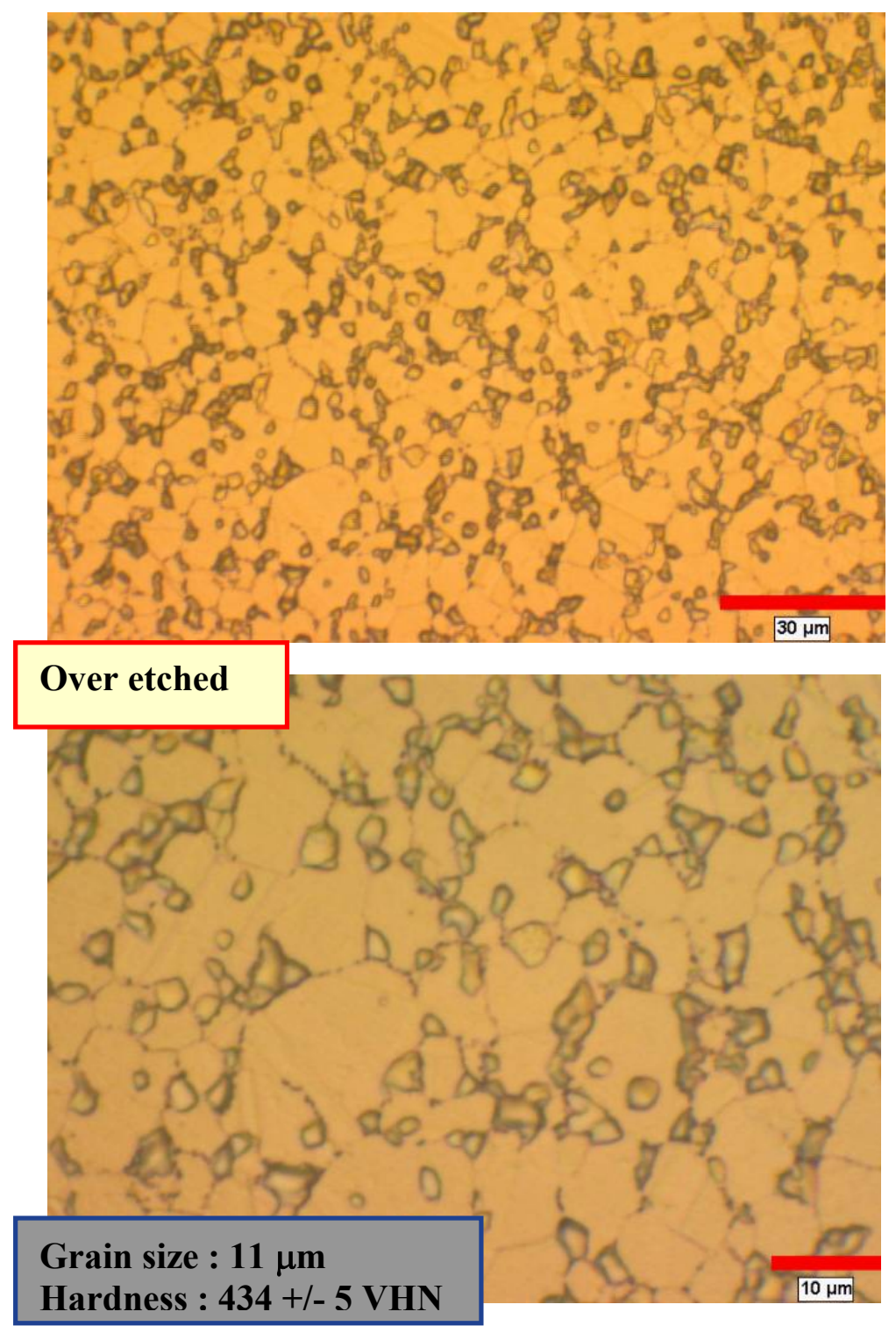

Figure 6.16: Optical micrograph of etched Udimet $720 \mathrm{Li}$ in the peak aged condition. 

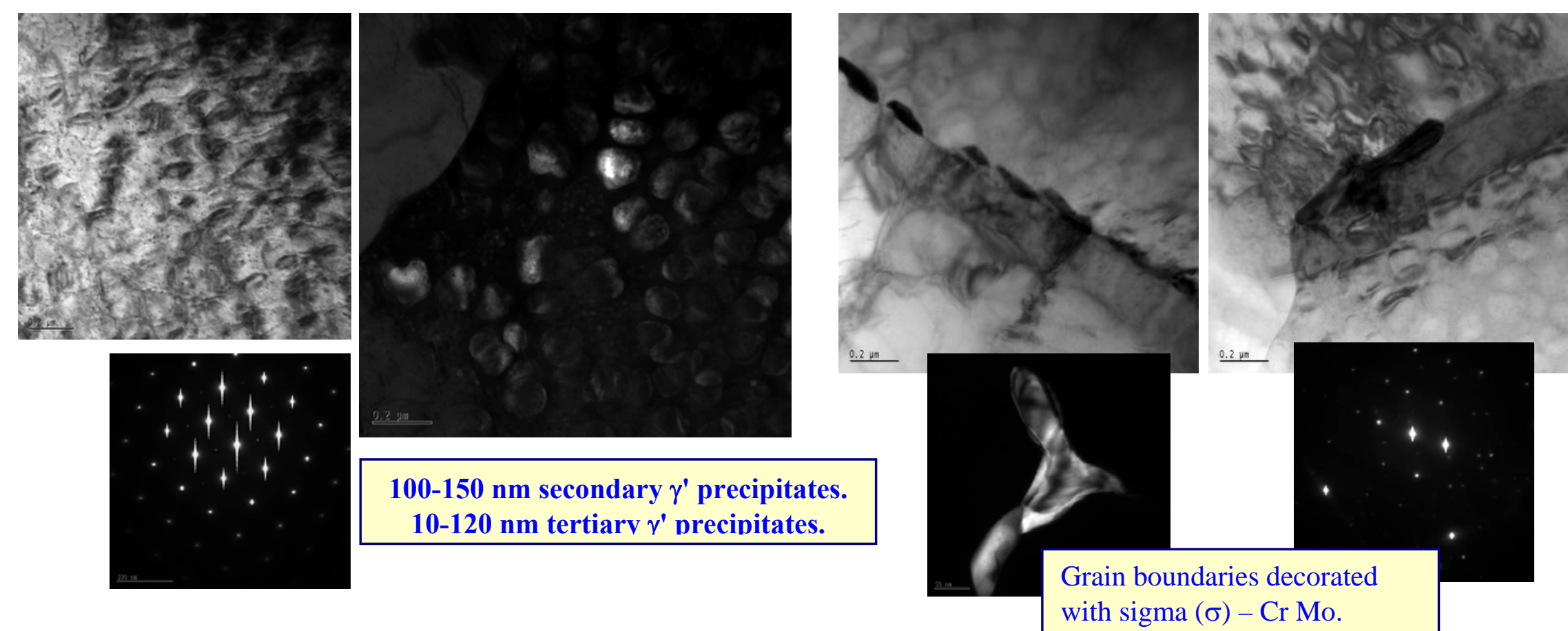

Figure 6.17: TEM micrographs showing the general features of the matrix including $\gamma^{\prime}$ precipitation (left figures) with associated SAD pattern and Cr-o (sigma) precipitates along the grain boundaries (right) with associated SAD pattern. 



\section{APPENDIX 7 \\ MICROSTRUCTURAL STABILITY FOR CANDIDATE NICKEL SUPERALLOYS}


Table 7A: Room Temperature Tensile Properties for Haynes 282 After Thermal Exposure (Haynes Puvlication H-3173, p. 14) *

\begin{tabular}{|c|c|c|c|c|c|}
\hline $\begin{array}{c}\text { Exposure } \\
\text { Temperature }\end{array}$ & $\begin{array}{c}\text { Duration } \\
\text { (hours) }\end{array}$ & $\begin{array}{c}0.2 \% Y S \\
(\mathrm{ksi})\end{array}$ & $\begin{array}{l}\text { UTS } \\
\text { (ksi) }\end{array}$ & $\begin{array}{c}\text { Elongation } \\
(\%)\end{array}$ & $\begin{array}{l}\text { RA } \\
(\%)\end{array}$ \\
\hline \multirow{6}{*}{1200} & 0 & 102 & 167 & 30 & 33 \\
\hline & 100 & 116 & 181 & 27 & 31 \\
\hline & 1,000 & 118 & 181 & 26 & 29 \\
\hline & 4,000 & 120 & 182 & 26 & 29 \\
\hline & 8,000 & 119 & 183 & 24 & 27 \\
\hline & 16,000 & 118 & 183 & 23 & 25 \\
\hline \multirow{6}{*}{1400} & 0 & 102 & 167 & 30 & 33 \\
\hline & 100 & 110 & 177 & 27 & 30 \\
\hline & 1,000 & 108 & 178 & 26 & 29 \\
\hline & 4,000 & 103 & 175 & 21 & 22 \\
\hline & 8,000 & 100 & 173 & 20 & 21 \\
\hline & 16,000 & 96 & 168 & 20 & 19 \\
\hline \multirow{6}{*}{1600} & 0 & 102 & 167 & 30 & 33 \\
\hline & 100 & 90 & 162 & 31 & 36 \\
\hline & 1,000 & 77 & 155 & 30 & 30 \\
\hline & 4,000 & 71 & 148 & 31 & 31 \\
\hline & 8,000 & 69 & 146 & 31 & 31 \\
\hline & 16,000 & 66 & 142 & 32 & 32 \\
\hline
\end{tabular}

Solution Aging: $2075^{\circ} \mathrm{F}$

Age-Hardening: $1850^{\circ} \mathrm{F}$ for $2 \mathrm{~h} \& \mathrm{AC}+1450^{\circ} \mathrm{F}$ for $8 \mathrm{~h} \& \mathrm{AC}$ 


\section{APPENDIX 8 \\ PHASE II STATEMENT OF WORK \\ PRELIMINARY DESCRIPTION OF TASKS}




\section{Task I: Materials for Non-welded Rotor/Disk, Blades, Bolts, and Valve Internals}

\section{Sub-Task 3B:}

Mechanical property and microstructural characterization of rotor/disk alloys selected for use in the $1400^{\circ} \mathrm{F}$ steam turbine.

\section{Objective:}

Develop sufficient mechanical property information on nickel-base rotor/disk candidate alloys so preliminary steam turbine design calculations can be initiated. Establish the long-term microstructural and environmental stability of the candidate alloys to predict 100,000 and 250,000 hour creep rupture life at $1400^{\circ} \mathrm{F}$ and $15 \mathrm{ksi}$.

\section{How the objective will be achieved:}

1. Short-term mechanical and physical property characterization. Mechanical properties to be developed include: $0.2 \%$ yield strength, ultimate tensile strength, elongation to failure, reduction in area, fracture energy (as a function of exposure time at $1400^{\circ} \mathrm{F}$ ), elastic modulus, room temperature fracture toughness and fracture toughness up to approximately $1000^{\circ} \mathrm{F}$. Physical properties to be developed include: thermal expansion, thermal conductivity, dynamic elastic modulus, Poisson's ratio, density, and specific heat (all as a function of temperature).

2. Long-term (>30,000 hours) creep, creep rupture and load-control creep-fatigue tests will be run to develop robust life prediction methods for creep and creep with an imposed fatigue cycle. Creep information will include the time to rupture, elongation at rupture, reduction in area at rupture, and a full creep curve (strain versus time). The load-based creep-fatigue information (as a function of dwell time at maximum load) will include stress, number of cycles to failure, and total time to failure sufficient to assess cracking susceptibility.

3. Continuation of fatigue testing program will look at a $3^{\text {rd }}$ heat of Haynes 282 and Nimonic 105. Selected LCF tests will be performed as needed and fatigue crack growth rate behavior will be studied at $1400^{\circ} \mathrm{F}$. Low-cycle fatigue tests on the $3^{\text {rd }}$ heat of material will be performed at $1400^{\circ} \mathrm{F}$ at $\mathrm{R}=0$, consistent with previous screening tests. The information will be analyzed to determine the variability in LCF behavior as a function of strain level. Selected strain-control hold-time tests will be conducted on the two candidate alloys to establish the approximate effect of a tensile hold at maximum strain on the low-cycle fatigue life. Fatigue crack growth rate tests will be used to develop ( $d a / d N)$ behavior and the threshold K value for crack growth.

4. Microstructural characterization activities related to understanding the interaction of environment $\left(1400^{\circ} \mathrm{F}\right.$ air and steam) on crack growth and microstructure stability ( $\gamma^{\prime}$ coarsening and grain growth). Examination of creep and creep-fatigue samples will be done in the TEM expressly to determine $\gamma^{\prime}$ coarsening behavior and the development of any TCP phases or carbides as a result of long-term exposure. The fracture surfaces of creep, creep-fatigue, and fatigue crack growth rate samples will be examined in the SEM to determine mode of failure and possible change in failure mechanism. 


\section{Deliverables:}

- Short-term mechanical and physical properties as a function of test temperature will be developed for Haynes 282 and Nimonic 105 suitable for $1400^{\circ} \mathrm{F}$ steam turbine rotor design activities.

- Creep and creep rupture data will be collected sufficient to develop parametric equations (LarsonMiller, Manson-Haferd, etc.) to predict 100,000 and 250,000 hour creep rupture life.

- Preliminary screening experiments for hold-time effects will be performed on Haynes 282 and Nimonic 105. Based on LCF, fatigue crack growth rate, creep and load-control creep-fatigue tests, an assessment of creep-fatigue behavior will be developed.

- Determination of the long-term microstructural stability of Haynes 282 and Nimonic 105 with respect to $\gamma^{\prime}$ coarsening, TCP phase formation, grain growth and crack growth will be established at $1400^{\circ} \mathrm{F}$.

- Compiled data book of all mechanical and physical properties of the rotor/disk alloys, including copies of original vendor test data, material certification reports, etc., will be provided to the consortium as a final report.

\section{Schedule:}

TBD

\section{Costs (to be finalized):}

Task A: \$1,077,000 (including material purchase) 


\section{Sub-Task 3C:}

Mechanical property and microstructural characterization of candidate blade/bolting alloys selected for use in the $1400^{\circ} \mathrm{F}$ steam turbine.

\section{Objective:}

Develop sufficient mechanical property information on nickel-base blade/bolting candidate alloys so preliminary steam turbine design calculations can be initiated. Establish the long-term microstructural and environmental stability of the candidate alloys to predict 100,000 and 250,000 hour creep rupture life at $1400^{\circ} \mathrm{F}$ and $15 \mathrm{ksi}$.

\section{How the objective will be achieved:}

1. Short-term mechanical and physical property characterization. Mechanical properties to be developed include: $0.2 \%$ yield strength, ultimate tensile strength, elongation to failure, reduction in area, fracture energy (as a function of exposure time at $1400^{\circ} \mathrm{F}$ ), elastic modulus, room temperature fracture toughness and fracture toughness up to approximately $1000^{\circ} \mathrm{F}$. Physical properties to be developed include: thermal expansion, thermal conductivity, dynamic elastic modulus, Poisson's ratio, density, and specific heat (all as a function of temperature).

2. Long-term (>30,000 hours) creep, creep rupture and load-control creep-fatigue tests (based on screening tests on the rotor alloys) will be run to develop robust life prediction methods for creep and creep with an imposed fatigue cycle. Creep information will include the time to rupture, elongation at rupture, reduction in area at rupture, and a full creep curve (strain versus time). The load-based creep-fatigue information (as a function of dwell time at maximum load) will include stress, number of cycles to failure, and total time to failure sufficient to assess cracking susceptibility.

3. High cycle fatigue (HCF) tests will be run at $1400^{\circ} \mathrm{F}$ and three R-ratios (e.g., $\mathrm{R}=-1, \mathrm{R}=0.05$ and $\mathrm{R}=0.5$ ) for the candidate blade alloys. The HCF data will allow calculation of Goodman-type diagram for a preliminary estimate of fatigue life at $1400^{\circ} \mathrm{F}$.

4. Stress relaxation tests will be performed for up to 10,000 hours at $1350,1400 \& 1450^{\circ} \mathrm{F}$ and three strain levels (e.g., $0.25 \%, 0.20 \%$ and $0.15 \%$ strain) for two candidate blade/bolting alloys. The relaxation response of the blade/bolting alloys will be explored and the results compared to the creep results.

5. Microstructural characterization activities related to understanding the interaction of environment $\left(1400^{\circ} \mathrm{F}\right.$ air and steam) on microstructure stability ( $\gamma^{\prime}$ coarsening and grain growth). Examination of creep samples will be done in the TEM expressly to determine $\gamma^{\prime}$ coarsening behavior and the development of any TCP phases or carbides as a result of long-term exposure. The fracture surfaces of creep and high cycle fatigue samples will be examined in the SEM to determine mode of failure and possible change in failure mechanism as a function of exposure time.

\section{Deliverables:}

- Short-term mechanical and physical properties as a function of test temperature will be developed for two blade/bolting alloys (i.e., Haynes 282, Nimonic 105, Waspaloy or another alloy of the consortium's choice), suitable for $1400^{\circ} \mathrm{F}$ steam turbine rotor design activities. 
- Creep and creep rupture data will be collected sufficient to develop parametric equations (LarsonMiller, Manson-Haferd, etc.) on two blade/bolting alloys (i.e., Haynes 282 or Nimonic 105 or Waspaloy or another alloy of the consortium's choice) for 100,000 and 250,000 hour creep rupture life prediction.

- Preliminary screening experiments for hold-time effects will be performed on two blade/bolting alloys (i.e., Haynes 282 or Nimonic 105 or Waspaloy or another alloy of the consortium's choice). Based on creep and load-control creep-fatigue tests, an assessment of creep-fatigue behavior will be developed.

- Preliminary Goodman-type diagrams will be constructed for the blade alloys (i.e., Haynes 282, Nimonic 105, Waspaloy or another alloy of the consortium's choice) at $1400^{\circ} \mathrm{F}$.

- Stress relaxation response will be determined at $1400 \mathrm{~F}$ for two blade/bolting alloys (i.e., Haynes 282, Nimonic 105, Waspaloy or another alloy of the consortium's choice). In addition, a compilation on stress relaxation response of nickel-base alloys will be developed for other bolting alloys at temperatures less than $1400^{\circ} \mathrm{F}$ (e.g., Inconel 718, Nimonic 80A, etc.).

- Determination of the long-term microstructural stability of two blade/bolting alloys (i.e., Haynes 282, Nimonic 105, Waspaloy or another alloy of the consortium's choice) with respect to $\gamma^{\prime}$ coarsening, TCP phase formation, and grain growth will be established at $1400^{\circ} \mathrm{F}$.

- Compiled data book of all mechanical and physical properties of the blade/bolting alloys, including copies of original vendor test data, material certification reports, etc., will be provided to the consortium as a final report.

\section{Schedule:}

TBD

Costs (to be finalized):

Task B: \$910,000 (including material purchase) 


\section{Sub-Task 3D:}

Mechanical property and microstructural characterization of candidate valve internal alloy, e.g., Haynes 282 or Nimonic 105 or Waspaloy or another alloy of the consortium's choice, selected for use in the $1400^{\circ} \mathrm{F}$ steam turbine.

\section{Objective:}

Develop sufficient mechanical property information on nickel-base valve candidate alloy so preliminary steam turbine design calculations can be initiated. Establish the long-term microstructural and environmental stability of the candidate alloy to predict 100,000 and 250,000 hour creep rupture life at $1400^{\circ} \mathrm{F}$ and $15 \mathrm{ksi}$.

How the objective will be achieved:

There are two possible approaches to this objective. First, if the alloy for valve internals is the same as either the rotor/disk alloy, blade alloy or bolting alloy, then only those tests necessary to provide the minimum mechanical and physical properties will be performed. Second, if the candidate valve alloy is different from the other alloys in these tasks, then the following approach will be used.

1. Short-term mechanical and physical property characterization. Mechanical properties to be developed include: $0.2 \%$ yield strength, ultimate tensile strength, elongation to failure, reduction in area, fracture energy (as a function of exposure time at $1400^{\circ} \mathrm{F}$ ), elastic modulus, room temperature fracture toughness and fracture toughness up to approximately $1000^{\circ} \mathrm{F}$. Physical properties to be developed include: thermal expansion, thermal conductivity, dynamic elastic modulus, Poisson's ratio, density, and specific heat (all as a function of temperature).

2. Long-term (>30,000 hours) creep and creep rupture will be run to develop robust life prediction methods. Creep information will include the time to rupture, elongation at rupture, reduction in area at rupture, and a full creep curve (strain versus time).

3. Fatigue testing will consist of LCF and HCF. The LCF portion will characterize one alloy at $1400^{\circ} \mathrm{F}$ and four strain levels. The HCF portion will look at one alloy at $1400^{\circ} \mathrm{F}$ and three Rratios (e.g., $\mathrm{R}=-1, \mathrm{R}=0.05$ and $\mathrm{R}=0.5$ ), sufficient to allow calculation of a preliminary Goodmantype diagram.

4. Microstructural characterization activities related to understanding the interaction of environment $\left(1400^{\circ} \mathrm{F}\right.$ air and steam) on microstructure stability ( $\gamma^{\prime}$ coarsening and grain growth). Examination of creep samples will be done in the TEM expressly to determine $\gamma^{\prime}$ coarsening behavior and the development of any TCP phases or carbides as a result of long-term exposure. The fracture surfaces of creep and fatigue samples will be examined in the SEM to determine mode of failure and possible change in failure mechanism.

\section{Deliverables:}

- Short-term mechanical and physical properties as a function of test temperature will be developed for one valve alloy (i.e., Haynes 282, Nimonic 105, Waspaloy or another alloy of the consortium's choice), suitable for $1400^{\circ} \mathrm{F}$ steam turbine rotor design activities.

- Creep and creep rupture data will be collected for one valve alloy (i.e., Haynes 282, Nimonic 105, Waspaloy or another alloy of the consortium's choice), sufficient to develop parametric equations (Larson-Miller, Manson-Haferd, etc.) for 100,000 and 250,000 hour creep rupture life prediction.

- Preliminary Goodman-type diagrams will be constructed for one valve alloy (i.e., Haynes 282, Nimonic 105 , Waspaloy or another alloy of the consortium's choice) at $1400^{\circ} \mathrm{F}$. The LCF response 
(i.e., cycles to failure) for one valve alloy (i.e., Haynes 282, Nimonic 105, Waspaloy or another alloy of the consortium's choice) at $1400^{\circ} \mathrm{F}$ will be established as a function of total strain range.

- Determination of the long-term microstructural stability of the one valve alloy (i.e., Haynes 282, Nimonic 105, Waspaloy or another alloy of the consortium's choice) with respect to $\gamma^{\prime}$ coarsening, TCP phase formation, and grain growth will be established at $1400^{\circ} \mathrm{F}$.

- Compiled data book of all mechanical and physical properties of the valve alloy, including copies of original vendor test data, material certification reports, etc., will be provided to the consortium as a final report.

Schedule:

TBD

Costs (to be finalized):

Task C: \$343,000 (including material purchase) 


\section{Task II: Superalloy Casting Development and Materials for Casing/Valve Bodies}

Sub-Task 4B:

Casting alloy selection and chemistry optimization for superalloys used as cast articles in the $1400 \mathrm{~F}$ steam turbine.

\section{Objective:}

Work with NETL-Albany and ORNL to evaluate superalloys chemistries with sufficient high temperature strength and long-term environmental stability to be used as cast articles for turbine shell casings and valve bodies. Develop cast articles of sufficient size for material characterization, property evaluation and welding potential. Establish a standard of practice for producing large superalloy castings suitable for use in steam turbines.

How the objective will be achieved:

1. Evaluate candidate alloys for thick section castings in terms of casting potential and microstructural stability (ThermCalc and JMatPro activities at ORNL and NETL-Albany).

2. Produce small-scale castings ( $20 \mathrm{lb})$ using candidate alloy chemistries from Task 1 and assess integrity of casting from metallographic examination of casting (NETL-Albany).

3. Select the most promising chemistries from Task 2 and produce large-scale castings ( 200 lb). Assess integrity of casting from metallographic examination of casting (NETL-Albany). Provide cast material to consortium suitable for mechanical testing and microstructural evaluation.

4. Develop manufacturing practice for producing large castings.

\section{Deliverables:}

- Establish superalloy chemistry/chemistries that can be used to make large castings for shell and valve applications.

- Develop manufacturing practice to produce large castings.

- Deliver cast articles of sufficient size and complexity to evaluate casting process and determine mechanical properties.

Schedule:

TBD

Costs (to be finalized):

Task A: $\$ 250,000$

(Funding proposed to produce castings for program: NETL-Albany for material and shipping. Internal program direction from DOE-NETL to provide manpower to project.) 


\section{Sub-Task 4C:}

Initiate discussions with potential cast houses for making a very large cast article suitable for evaluation of scale-up potential from Task II, Sub-Task A. Determine costs of making such article and delivery schedule.

\section{Objective:}

Develop a feature article casting drawing that has various section thicknesses and features that will allow welding pipe sections and repair activities.

\section{How the objective will be achieved:}

Contact casting manufacturers to assess potential for making a large, multi-feature superalloy casting with section sizes large enough to simulate cooling in a full-size shell or valve box.

\section{Deliverables:}

- Prototype feature casting drawing.

- Estimate of cost to produce feature casting.

- Estimate of production schedule to produce feature casting.

\section{Schedule:}

TBD

\section{Costs (to be finalized):}

Task C:\$35,000

DOE USC Steam Turbine - Task 3B: Materials for Non-welded Rotor/Disk

\begin{tabular}{|c|c|c|c|c|c|c|}
\hline $\begin{array}{r}\text { Sub } \\
\text { Task }\end{array}$ & Name & Details & Performer & $\begin{array}{r}\text { Preliminary } \\
\text { Material Cost }\end{array}$ & $\begin{array}{r}\text { Preliminary } \\
\text { Labor Cost }\end{array}$ & $\begin{array}{r}\text { Preliminary } \\
\text { Duration }\end{array}$ \\
\hline & & & Total Cost & $\$ \$ 50,000$ & (\$1,027,000 & \\
\hline 1.1 & Acquire Materials & $\begin{array}{r}\text { 4-6" diameter by 20" cylindrical ingots of two } \\
\text { materials: H282 \& N105 }\end{array}$ & GE & $\$ 45,000$ & $\$ 5,000$ & $3 \mathrm{mo}$ \\
\hline 1.2 & Physical Properties & $\begin{array}{l}\text { Thermal expansion, thermal conductivity, specific } \\
\text { heat, dynamic modulus, Poisson's ratio, density } \\
\text { (two alloys; one heat) }\end{array}$ & MetCut & & $\$ 10,000$ & \\
\hline 1.3 & Tensile Tests & $\begin{array}{r}\text { Tensile tests at RT, 400, 800, } 1200,1300,1400 \& \\
1500^{\circ} \mathrm{F} . \\
\text { Two alloys; one heat treatment condition. }\end{array}$ & Dirats & & $\$ 3,500$ & \\
\hline 1.4 & Tensile Tests & $\begin{array}{r}\text { Tensile tests at RT \& } 1400^{\circ} \mathrm{F} \text { after isothermal } \\
\text { exposure at } 1400^{\circ} \mathrm{F} \text { for } 1000,4000,8000 \& 16000\end{array}$ & Dirats & & $\$ 3,500$ & \\
\hline 1.5 & Impact Tests & $\begin{array}{l}\text { Tours. } \\
\text { Two alloys; one heat treatment condition. } \\
\text { Charpy V-notch tests at RT for as-heat treated alloy } \\
\text { plus RT tests after isothermal exposure at } 1400^{\circ} \mathrm{F} \\
\text { for } 1000,4000,8000 \& 16000 \text { hours. }\end{array}$ & Dirats & & $\$ 2,500$ & \\
\hline 1.6 & $\begin{array}{r}\text { Creep \& Creep } \\
\text { Rupture Tests }\end{array}$ & $\begin{array}{l}\text { Two alloys; one heat treatment condition; duplicate } \\
\text { samples. } \\
\qquad \begin{array}{r}4 \text { tests: } 20,000 \text { hours } \\
4 \text { tests: } 30,000 \text { hours } \\
4 \text { tests: } 40,000 \text { hours }\end{array}\end{array}$ & Joliet & & $\$ 360,000$ & \\
\hline
\end{tabular}


Two alloys; one heat treatment condition.

1.7 Load-Control CreepFatigue Tests

1.8 Strain-Control HoldTime Fatigue Tests

1.9 Fracture Toughness Tests
Load-control tests at $1400^{\circ} \mathrm{F}$ and four stress levels Metcut/Mar-test with 8 h hold-time.

Two alloys; two samples at each condition.

Strain-control tests at $1400^{\circ} \mathrm{F} \&$ two strain levels with $1 \mathrm{~h}$ hold-time.

Two alloys; one sample at each condition

Compact tension-type $\mathrm{K} 1 \mathrm{c} / \mathrm{J} 1 \mathrm{c}$ tests at $\mathrm{RT}, 400^{\circ} \mathrm{F}$, $750^{\circ} \mathrm{F} \& 1000^{\circ} \mathrm{F}$.

Two alloys; two samples at each condition.

1.10 Fatigue Crack Growth Compact tension FCG tests at $1400^{\circ} \mathrm{F}$ : stress in axial Rate (FCGR) Tests orientation, crack growth in radial; R-ratios of 0.05 , $0.25 \& 0.50$.

Two alloys; one sample at each condition
1.11 Low-Cycle Fatigue Tests

1.12 Post-Test Examination Microstructural TEN Examination

1.14 Program Management
Smooth bar, $20 \mathrm{cpm}$ LCF tests at $1400^{\circ} \mathrm{F}$; total strain of $1.25,1.00,0.75 \& 0.50 \% ; \mathrm{R}=0$. Two alloys; two tests per strain value.

Fractographic analysis \& metallographic (SEM) examination of isothermally exposed \& tested specimens.

TEM examination of long-term exposed samples \& tested samples to chart microstructural evolution.

Program management and reporting.
$\$ 190,000$

Metcut/Mar-test

$\$ 105,000$

$\$ 9,000$

Metcut

Metcut

Metcut

$\$ 8,500$

GE

$\$ 100,000$

GE

$\$ 75,000$

GE 
DOE USC Steam Turbine - Task 3C: Materials for Blade \& Bolting

\begin{tabular}{|c|c|c|c|c|c|c|}
\hline $\begin{array}{l}\text { Sub } \\
\text { Task }\end{array}$ & Name & Details & Performer & $\begin{array}{l}\text { Preliminary } \\
\text { Material Cost }\end{array}$ & $\begin{array}{l}\text { Preliminary } \\
\text { Labor Cost }\end{array}$ & $\begin{array}{l}\text { Preliminary } \\
\text { Duration }\end{array}$ \\
\hline & & & Total Cost & $\$ 70,000$ & $\$ 840,000$ & \\
\hline 2.1 & Acquire Materials & $\begin{array}{l}\text { 4-6" diameter by } 20 " \text { cylindrical ingots of three } \\
\text { materials: H282, N105, Waspaloy or other } \\
\text { candidate alloy }\end{array}$ & GE & $\$ 65,000$ & $\$ 5,000$ & $3 \mathrm{mo}$ \\
\hline 2.2 & Physical Properties & $\begin{array}{l}\text { Thermal expansion, thermal conductivity, specific } \\
\text { heat, dynamic modulus, Poisson's ratio, density } \\
\text { (three alloys; one heat). }\end{array}$ & MetCut & & $\$ 15,000$ & \\
\hline 2.3 & Tensile Tests & $\begin{array}{l}\text { Tensile tests at RT, } 400,800,1200,1300,1400 \& \\
1500^{\circ} \mathrm{F} \text {. } \\
\text { Three alloys; one heat treatment condition. }\end{array}$ & Dirats & & $\$ 5,250$ & \\
\hline 2.4 & Tensile Tests & $\begin{array}{l}\text { Tensile tests at RT \& } 1400^{\circ} \mathrm{F} \text { after isothermal } \\
\text { exposure at } 1400 \mathrm{~F} \text { for } 1000,4000,8000 \& 16000 \\
\text { hours. }\end{array}$ & Dirats & & $\$ 5,250$ & \\
\hline 2.5 & Impact Tests & $\begin{array}{l}\text { Three alloys; one heat treatment condition. } \\
\text { Charpy V-notch tests at RT for as-heat } \\
\text { treated alloy plus RT tests after } \\
\text { isothermal exposure at } 1400^{\circ} \mathrm{F} \text { for } \\
1000,4000,8000 \& 16000 \text { hours. }\end{array}$ & Dirats & & $\$ 3,750$ & \\
\hline 2.6 & $\begin{array}{l}\text { Creep \& Creep } \\
\text { Rupture Tests }\end{array}$ & $\begin{array}{l}\text { Three alloys; one heat treatment condition; duplicate } \\
\text { samples. } \\
9 \text { tests: }<10,000 \text { hours (all) } \\
6 \text { tests: } 15,000 \text { hours (all) } \\
4 \text { tests: } 20,000 \text { hours (blade only) } \\
4 \text { tests: } 30,000 \text { hours (blade only) } \\
\text { Three alloys: one heat treatment condition. }\end{array}$ & Joliet & & $\$ 380,000$ & \\
\hline 2.7 & $\begin{array}{l}\text { Load-Control Creep- } \\
\text { Fatigue Tests }\end{array}$ & $\begin{array}{l}\text { Load-control tests at } 1400^{\circ} \mathrm{F} \text { and two stress levels } \\
\text { with } 8 \text { h hold-time. } \\
\text { Three alloys; two samples at each condition. }\end{array}$ & Metcut/Mar-test & & $\$ 147,500$ & \\
\hline 2.8 & $\begin{array}{l}\text { High-Cycle Fatigue } \\
\text { Tests }\end{array}$ & $\begin{array}{l}\text { Smooth bar, axial HCF tests at } 1400^{\circ} \mathrm{F} ; 6 \text { stress } \\
\text { levels at } \mathrm{R}=-1,0.05 \& 0.50 \text { out to } 10^{7} \text { cycles at } 50 \\
\text { Hz with selected duplicates. }\end{array}$ & Metcut & & $\$ 40,000$ & \\
\hline 2.9 & Stress Relaxation & $\begin{array}{l}\text { Two alloys; one heat treatment condition. } \\
\text { Tests at } 1350,1400 \& 1450^{\circ} \mathrm{F} \& \text { three strain levels } \\
(0.25,0.20 \& 0.15 \%) \text { for } 10,000 \mathrm{~h} \text {. } \\
\text { Two alloys; one sample at each test condition. }\end{array}$ & M \& P Lab & & $\$ 93,250$ & \\
\hline 2.10 & Post-Test Examination & $\begin{array}{l}\text { Fractographic analysis \& metallographic (SEM) } \\
\text { examination of isothermally exposed \& tested } \\
\text { specimens. }\end{array}$ & GE & & $\$ 50,000$ & \\
\hline 2.11 & $\begin{array}{l}\text { Microstructural } \\
\text { Examination }\end{array}$ & $\begin{array}{l}\text { TEM examination of long-term exposed samples \& } \\
\text { tested samples to chart microstructural evolution. }\end{array}$ & GE & & $\$ 50,000$ & \\
\hline 2.12 & Program Management & Program management and reporting. & GE & & $\$ 50,000$ & \\
\hline
\end{tabular}


DOE USC Steam Turbine - Task 3D: Materials for Valve Internals

\begin{tabular}{|c|c|c|c|c|c|c|}
\hline $\begin{array}{l}\text { Sub } \\
\text { Task }\end{array}$ & Name & Details & Performer & $\begin{array}{l}\text { Preliminary } \\
\text { Material Cost }\end{array}$ & $\begin{array}{l}\text { Preliminary } \\
\text { Labor Cost }\end{array}$ & $\begin{array}{l}\text { Preliminary } \\
\text { Duration }\end{array}$ \\
\hline & & & Total Cost & $\$ 20,000$ & $\$ 323,000$ & \\
\hline 3.1 & Acquire Materials & $\begin{array}{l}\text { 4-6" diameter by } 20 " \text { cylindrical ingots of one } \\
\text { material: H282, N105, Waspaloy or other candidate } \\
\text { alloy }\end{array}$ & GE & $\$ 15,000$ & $\$ 5,000$ & $3 \mathrm{mo}$ \\
\hline 3.2 & Physical Properties & $\begin{array}{l}\text { Thermal expansion, thermal conductivity, specific } \\
\text { heat, dynamic modulus, Poisson's ratio, density } \\
\text { (three alloys; one heat). }\end{array}$ & MetCut & & $\$ 5,000$ & \\
\hline 3.3 & Tensile Tests & $\begin{array}{l}\text { Tensile tests at RT, } 400,800,1200,1300,1400 \& \\
1500^{\circ} \mathrm{F} \text {. } \\
\text { One alloy; one heat treatment condition. }\end{array}$ & Dirats & & $\$ 2,000$ & \\
\hline 3.4 & $\begin{array}{l}\text { Creep \& Creep } \\
\text { Rupture Tests }\end{array}$ & $\begin{array}{l}6 \text { tests: } 10,000 \text { hours or less } \\
2 \text { tests: } 15,000 \text { hours }\end{array}$ & Joliet & & $\$ 190,000$ & \\
\hline & & $\begin{array}{l}2 \text { tests: } 20,000 \text { hours } \\
2 \text { tests: } 30,000 \text { hours } \\
\text { One alloy; one heat treatment condition. }\end{array}$ & & & & \\
\hline 3.5 & $\begin{array}{l}\text { High-Cycle Fatigue } \\
\text { Tests }\end{array}$ & $\begin{array}{l}\text { Smooth bar, axial HCF tests at } 1400^{\circ} \mathrm{F} ; 6 \text { stress } \\
\text { levels at } \mathrm{R}=-1,0.05 \& 0.50 \text { out to } 10^{7} \text { cycles at } 50 \\
\text { Hz with selected duplicates. } \\
\text { One alloy; one heat treatment condition. }\end{array}$ & Metcut & & $\$ 18,000$ & \\
\hline 3.6 & $\begin{array}{l}\text { Low-Cycle Fatigue } \\
\text { Tests }\end{array}$ & $\begin{array}{l}\text { Smooth bar, } 20 \mathrm{cpm} \text { LCF tests at } 1400^{\circ} \mathrm{F} \text {; total } \\
\text { strain of } 1.25,1.00,0.75 \& 0.50 \% \text {; }=0 \text {. } \\
\text { One alloy; two tests per strain value. }\end{array}$ & Metcut & & $\$ 8,000$ & \\
\hline 3.7 & Post-Test Examination & $\begin{array}{l}\text { Fractographic analysis \& metallographic (SEM) } \\
\text { examination of isothermally exposed \& tested } \\
\text { specimens. }\end{array}$ & GE & & $\$ 50,000$ & \\
\hline 3.8 & Program Management & Program management and reporting. & GE & & $\$ 50,000$ & \\
\hline
\end{tabular}


TASK12.4 CAST NI-BASED SUPERALLOYS FOR TURBINE CASING APPLICATION 



\section{SUMMARY}

This task was performed jointly by NETL Albany and ORNL under direct funding from DOE/NETL since Siemens withdrew participation from the consortium. The purpose of the task was to develop cast versions of the wrought superalloys currently being considered for USC turbine components, including Inconel 740 and HR282. The approach consisted of developing laboratory size castings of several modified versions of these alloys. A first series of conference calls with the various turbine OEMs evolved and defined this collaborative effort which was presented to the Consortium Steering Committee Meeting in June, 2008, and endorsed. A second series of conference calls then defined the final group of 7 cast alloys (4 precipitation-hardenable alloys, including Nimonic 105, Haynes 282, Inconel740, and alloy 263, and 3 solid-solution alloys, including alloys 617, 625 and Haynes 230) and the aim chemistries in August, 2008.

NETL/Albany made $15 \mathrm{lb}$ cylindrical geometry castings of all 7 alloys (in September, 2008) in a protective atmosphere. Albany/NETL developed an innovative two-step homogenization treatment on the basis of computational diffusional analyses, and demonstrated that treatment on a piece of the Nimonic 105 alloy casting in October, 2008. Input from Consortium indicated that effective homogenization eliminated the need to solution-anneal prior to heat-treatments for gamma-prime hardening. The consortium agreed on the details of the final heat-treatments, and NETL/Albany completed the homogenization treatments for all alloys, and the heat-treatments for the gamma-prime strengthened alloys. Phase 1 of this collaborative effort is now complete with ORNL and NETL/Albany having half of each ingot for initial testing. Phase 2 of this effort has begun and the testing and analysis includes microstructure, mechanical properties and steam oxidation testing of these various cast Ni-based superalloys at both ORNL and NETL/Albany. 



\section{TABLE OF CONTENTS}

TASK12.4 CAST NI-BASED SUPERALLOYS FOR TURBINE CASING

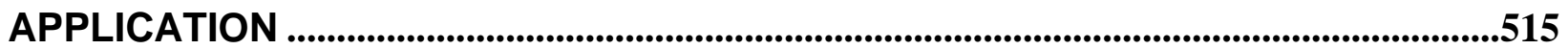

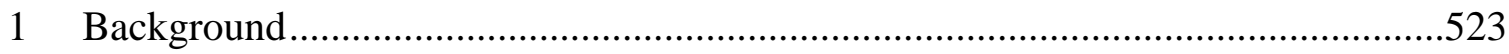

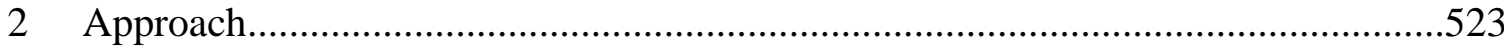

3 Technical Progress and Results .........................................................................524

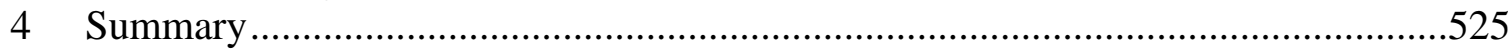

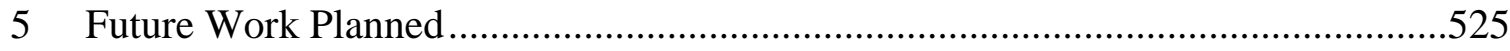




\section{LIST OF FIGURES}

Figure 1 - Schematic of cast ingot geometry and combination of graphite mold insulated by loose sand, used to obtain lower cooling rates typical of larger section castings. 529

Figure 2 - Photo of the ingots of the various alloys after they were cut in half. Alloys were homogenized and heat-treated. NETL/Albany and ORNL each received one-half of each alloy for characterization and testing.

Figure 3 - Macro-etched grain structures (NETL/Albany) of as-cast ingot cross-sections, showing a fine columnar grain structure on outer portion of the ingot, and coarser equiaxed grain structure in the center part of the ingot. Structures of two different as-cast ingots, for Nimonic 105 and HR 282 alloys, are shown.

Figure 4 - ThermoCalc analysis (NETL/Albany) of cast HR 282 alloy showing the effects of compositional segregation due to dendrite formation and "coring", and suppressed melting point of such regions relative to a "uniform" alloy.

Figure 5 - DICTRA analysis (NETL/Albany) of diffusional profiles of Mo interdendritic segregation of Mo in cast Nimonic 105 alloy, showing the beneficial effects of the two-step homogenization heat-treatment.

Figure 6 - Metallography of as-cast and then homogenized Nimonic 105 alloy, demonstrating the effectiveness of the NETL/Albany two-step homogenization treatment to eliminate as-cast segregation of $\mathrm{Mo}, \mathrm{Nb}$ and various other alloying elements.

Figure 7 - Metallographic analysis (ORNL) of typical wrought structures of Nimonic 105 and HR 282, obtained from alloy characterization and properties determinations being conducted on other Tasks of the A-USC Consortium Turbine Project. 532

Figure 8 - Back-scattered scanning electron microscope (SEM/BS) analysis (ORNL) of the microstructures of typical wrought and cast structures of Nimonic 105 alloy. The dendritic grain structure in the castings is much coarser than the fine, uniform grain structure in the wrought material.

Figure 9 - High magnification SEM/BS analysis (ORNL) of polished and lightly etched specimens of wrought and cast Nimonic 105, showing similar (magnifications are different) dense, uniform dispersions of (Ni,Ti)3Al gamma prime particles produced by the final heat-treatment. 534

Figure 10 - Estimated creep-rupture lives of various wrought Ni-based superalloys, using data being generated on other Tasks within the A-USC Consortium Boiler and Turbine Projects. Data on wrought alloys will provide the baseline data for comparison with the cast versions of each of these alloys, which will be evaluated in Phase 2 of this project effort. 535 


\section{LIST OF TABLES}

Table 1 - Ni-based Casing Alloy Compositions Cast at NETL/Albany (wt.\%) 527

Table 2- Homogenization and Aging Heat-Treatments for Cast Ni-based Superalloy Casing Ingots (NETL/Albany)

Table 3 - Summary of the Overall Plan for NETL/Albany and ORNL to Cast and Test Ni-based Superalloys for the Turbine Casing Application (Phase 1 is Steps $1-10)$ 528 



\section{Background}

At the beginning of 2008, ORNL had an opportunity to assist the A-USC Steam Consortium - Turbine Project. After the USC Project Steering Committee Meeting (2/20-2/21/2008, Chicago, IL), ORNL began work on the technical challenge of obtaining cast Ni-based superalloys for the turbine casing application. The A-USC Consortium (Siemens) had been unsuccessful up to that point trying to obtain large commercial castings of new alloys like Inconel (IN) 740 or Haynes (HR) 282 from the alloy producers (Special Metals/PCC and Haynes International, respectively). This was documented in the $1^{\text {st }}$ FY2008 quarterly report by Siemens. Ideally, one Ni-based alloy foundry would be able to cast several of the desired alloys in the same condition so that fair properties comparisons could be made. Data on cast nickel-based superalloys are needed to evaluate such materials for the steam turbine casing application, and to interact with designers.

\section{Approach}

In February, 2008, ORNL (Phil Maziasz) initiated a joint collaborative effort with NETL/Albany (Paul Jablonski) to utilize their casting equipment and expertise, and combine that with the ORNL expertise and capabilities for high-temperature mechanical testing and steam-corrosion equipment, to address the need for cast superalloy testing by the consortium. ORNL and NETL/Albany held a series of conference calls with GE and Siemens to define the collaborative ORNL and NETL/Albany effort to obtain cast versions of the various wrought Ni-based superalloys being characterized for other Tasks on the Boiler and Turbine Projects. The initial strategy and approach were presented at the A-USC Consortium Steering Committee Meeting held in June, 2008 (Palo Alto, CA). After that meeting, Alstom was added to the Turbine OEM Group supporting this collaborative national laboratory effort. Another series of conference calls then defined the group of cast Ni-based superalloys to be considered, addressed the need for homogenization treatments, and defined the heat-treatments needed for the agehardenable alloys.

The initial ingots were cast in September, 2008, preliminary microstructures were analyzed, and data was presented to the A-USC Consortium Steering Committee Meeting in November, 2008. Details about homogenization and heat-treatments were discussed and resolved by the group after the Steering Committee Meeting, and NETL/Albany homogenized and heat-treated the new cast alloy ingots at the end of November, 2008. One-half of each ingot was received by ORNL in early December, 2008, and that concluded Phase 1 of this effort. Phase 2 effort of this project will involve mechanical properties and steam oxidation testing at both ORNL and NETL/Albany, and begin in January, 2009. This report covers Phase 1 of this effort. Ongoing research on Phase 2 activities were preliminary at the time of writing this report and are not included in this final report. These activities will be reported on in the quarterly reports and steering committee meetings as directed by DOE. 


\section{$3 \quad$ Technical Progress and Results}

On the A-USC Consortium Turbine Project, GE had identified Nimonic 105 (N105) and the HR 282 alloy as having the best creep-rupture strength of the alloys considered for steam turbine blading and bolting applications. Siemens also had high-temperature creep data on HR 282 and some data on the new IN 740 alloy for turbine component applications. Extensive data on IN 740 was also available from the A-USC Consortium Boiler Project, which identified that alloy as the strongest available for the boiler piping and superheater tubing applications. Therefore, for the new effort on cast Ni-based superalloys for steam turbine casing applications, the group of Nimonic 105, Haynes 282, and IN 740 alloys was identified as the preferred alloys of choice. Compositions of the various Ni-based superalloys to be made as castings are given in Table 1. Concerns about the high gamma-prime contents and $\mathrm{Al}+\mathrm{Ti}$ contents of 4-6 wt.\% (oxidation during air-casting and internal oxidation during service in steam) then prompted consideration of a second group of alloys, including alloy 263 (pre-cursor for development of IN 740), and the solid-solution alloys 617, 625 and Haynes 230, which should all be easier to cast, and be less prone to internal oxidation. The aim chemistry for the cast IN 740 alloy took into consideration all prior work on the A-USC Consortium Boiler Project on compositional variations and modifications. The cast IN740 heat chemistry specified in Table 1 has the lower $\mathrm{Nb}$ (1.5 wt\%) and $\mathrm{Ti} / \mathrm{Al}$ ratio closer to 1 (1.5/1.3 \%, respectively), deemed best for improved weldability and resistance to cracking.

Figure 1 shows the ingot geometry, mold design and insulating sand that NETL/Albany used to cast each superalloy ingot to simulate the slow cooling rates expected in a large steam turbine casing. Figure 2 show those ingots cut in half to expose the center crosssection for verification of sound castings and further characterization of the as-cast structure. Figure 3 shows macro-etching of the grain structure of Nimonic 105 and HR 282 alloys. A fine columnar grain outer region and coarser equiaxed grain central region was characteristic of each alloy ingot.

ORNL and NETL/Albany performed and exchanged ideas on computational thermodynamics calculations to identify phases expected in the as-cast structure for each of the alloys. NETL/Albany calculations showed that interdentritic segregation of alloying elements, such as Mo and Nb, was of concern and that these alloys would require homogenization treatments to remove these compositional gradients. An example of one of these calculations is shown in Figure 4 for the HR 282 alloy. To prevent melting of the compositional regions with lower melting points, NETL/Albany used the computational diffusion tool (DICTRA) to start homogenization at a lower temperature $\left(1100^{\circ} \mathrm{C}\right)$ followed by homogenization at a higher temperature $\left(1200^{\circ} \mathrm{C}\right)$ as indicated in Figure. 5. Table 2 defines the two step homogenization treatments designed for all the various as-cast alloys based on their unique chemistry. NETL/Albany then tested this homogenization treatment on a piece of Nimonic 105 alloy, and the results, Figure 6, showed that the 2-step heat treatment succeeded at eliminating the segregation present in the as-cast structure.

ORNL also began preparing the baseline information of microstructure and phases in the various wrought forms of these alloys, for evaluating the new cast alloys. Metallographic 
analysis of wrought Nimonic 105 shows a relatively finer and more uniform grain structure than found in HR 282, which has coarser grains and sparce bands of precipitation and finer grains as shown in Figure 7. SEM analysis the grain structures in wrought and cast Nimonic 105 alloy shows the orders of magnitude coarser grains in the cast structure (Figure 8), but higher magnification SEM shows that both wrought and cast alloys contain the dense and fine dispersions of gamma-prime phase that is expected to strengthen this material at higher temperatures. ORNL collected wrought creep-rupture data available on all of these alloys from the A-USC Boiler Consortium project tasks to compare the relative behavior of the precipitation-hardened alloy group. One of these comparsions is shown in Figure 10 and is the recommended creep-screening test conditions to be used for the castings. Both HR282 and Nimonic 105 are much stronger than IN 740 at $800^{\circ} \mathrm{C}$. Phase 2 data generation will not only test and rank the behavior of the various cast Ni-based superalloys, but comparison of cast to wrought conditions for each alloy should give much more insight into mechanistic understand of the creepresistance of these various alloys. This will enhance the technical position of the A-USC Consortium project that is pursuing the most aggressive advanced steam conditions in the world.

\section{$4 \quad$ Summary}

A collaborative project between ORNL and NETL/Albany has been defined, endorsed and guided by the turbine OEMs to produce 7 new cast versions of wrought Ni-based superalloys. These 7 alloys include those deemed strongest and best in wrought form for various components being investigated on both the A-USC Consortium Boiler and Turbine Projects. Therefore one accomplishment of this collaborative effort is integrating the results of both Boiler and Turbine Projects. The group of 7 cast alloys include the precipitation-strengthened Nimonic 105, HR 282, IN 740 and 263 alloys, as well as the solid-solution 625, 617 and HR 230 alloys. Another technical accomplishment of this collaborative effort was comparing all the alloys after the same casting process. After casting, NETL/Albany showed significant interdendritic segregation in the as-cast structures, and used computational thermodynamics and diffusion calculations to define a unique two-step homogenization heat-treatment that eliminated that segregation. This technical accomplishment was understanding the nature and purpose of the heattreatments, and adapting the final heat-treatments typical for wrought alloys (Solution anneal + heat-treatment) to those needed for cast alloys (homogenize + heat-treatment).

All 7 cast alloys were homogenized and heat-treated (as appropriate) by the end of November, 2008, which concluded Phase 1 activity. One half of each ingot is at NETL/Albany and the other half at ORNL for Phase 2 characterization of microstructure, high-temperature mechanical properties and steam oxidation behavior in 2009.

\section{$5 \quad$ Future Work Planned}

ORNL and NETL/Albany will develop and finalize test matrices for screening tests and other testing conditions, with input and guidance from the steam turbine OEMs. ORNL will also include complete comparisons between wrought and cast versions of each of the alloys. Reporting of this work will be included as part of the U.S. DOE/OCDO quarterly steering committee meeting and updates will be provided for inclusion in the quarterly 
reports. 
Table 1 - Ni-based Casing Alloy Compositions Cast at NETL/Albany (wt.\%)

\begin{tabular}{|l|l|l|l|l|l|l|l|l|l|l|l|}
\hline & $\mathrm{C}$ & $\mathrm{Cr}$ & $\mathrm{Mo}$ & $\mathrm{Co}$ & $\mathrm{Al}$ & $\mathrm{Ti}$ & $\mathrm{Cb}$ & $\mathrm{Mn}$ & $\mathrm{Si}$ & $\mathrm{B}$ & $\mathrm{W}$ \\
\hline $\begin{array}{l}\text { Nimonic } \\
105\end{array}$ & 0.15 & 14.85 & 5.00 & 20.00 & 4.70 & 1.10 & & 0.50 & 0.50 & 0.05 & \\
\hline \hline & 0.16 & 14.61 & 5.02 & 20.04 & 4.43 & 1.10 & & 0.51 & 0.51 & 0.05 & \\
\hline $\begin{array}{l}\text { Haynes } \\
230\end{array}$ & 0.120 & 22.00 & 2.00 & & 0.35 & & & 0.70 & 0.50 & & 14.00 \\
\hline \hline & 0.12 & 21.59 & 2.01 & & 0.37 & & & 0.69 & 0.50 & & 13.91 \\
\hline \hline Haynes \\
263
\end{tabular}

$1^{\text {st }}$ row - nominal or aim composition,

$2^{\text {nd }}$ row - actual measured composition

Table 2- Homogenization and Aging Heat-Treatments for Cast Ni-based Superalloy Casing Ingots (NETL/Albany)

Alloy Homogenization Treatment

Nimonic $1053 \mathrm{~h} / 1100^{\circ} \mathrm{C}+9 \mathrm{~h} / 1200^{\circ} \mathrm{C} / \mathrm{GFC}$

HR 282

IN 740

HR 263

Alloy 625

Alloy 617

HR 230
$3 \mathrm{~h} / 1100^{\circ} \mathrm{C}+9 \mathrm{~h} / 1200^{\circ} \mathrm{C} / \mathrm{GFC}$

$3 \mathrm{~h} / 1100^{\circ} \mathrm{C}+9 \mathrm{~h} / 1200^{\circ} \mathrm{C} / \mathrm{GFC}$

$3 \mathrm{~h} / 1100^{\circ} \mathrm{C}+9 \mathrm{~h} / 1200^{\circ} \mathrm{C} / \mathrm{GFC}$

$3 \mathrm{~h} / 1100^{\circ} \mathrm{C}+9 \mathrm{~h} / 1200^{\circ} \mathrm{C} / \mathrm{GFC}$

$3 \mathrm{~h} / 1100^{\circ} \mathrm{C}+9 \mathrm{~h} / 1200^{\circ} \mathrm{C} / \mathrm{GFC}$

$3 \mathrm{~h} / 1200^{\circ} \mathrm{C}+9 \mathrm{~h} / 1250^{\circ} \mathrm{C} / \mathrm{GFC}$
Aging Heat-Treatment

$4 \mathrm{~h} / 1100^{\circ} \mathrm{C} / \mathrm{AC}+24 \mathrm{~h} / 800^{\circ} \mathrm{C} / \mathrm{AC}$

$2 \mathrm{~h} / 1010^{\circ} \mathrm{C} / \mathrm{AC}+8 \mathrm{~h} / 788^{\circ} \mathrm{C} / \mathrm{AC}$

$16 \mathrm{~h} / 800^{\circ} \mathrm{C}$

$8 \mathrm{~h} / 800^{\circ} \mathrm{C} / \mathrm{AC}$

none

none

none

GFC - gas fan cooled in vacuum furnace

AC - Air cooled 
Table 3 - Summary of the Overall Plan for NETL/Albany and ORNL to Cast and Test Ni-based Superalloys for the Turbine Casing Application (Phase 1 is Steps 1-10)

1. Cast each alloy (6.8kg; 50C superheat).

2. Slice off top of ingot.

3. Sample top for chemistry: xrf for majors, pins for gasses, turnings for $\mathrm{C} / \mathrm{S}$ and ICP (if need be).

4. Cut the ingot in half through the diameter.

5. Take photos of the ingot halves.

6. Prepare metallographic samples of the crucible skull material and photo document.

7. Grain etch one ingot half and photo document.

8. Measure secondary dendrite arm spacing on one alloy (H282).

9. Use these measurements and the Dictra predictions to design a homogenization heat treatment for all the alloys.

10. Homogenize and age the castings.

11. Prepare and test mechanical test specimens.

12. Review of microstructure and fracture surfaces.

13. Oxidation coupons if mechanical performance warrants.

14. Modify chemistry/heat treatment if required.

15. Cast additional small ingots of modified chemistry or larger ingots if acceptable. 


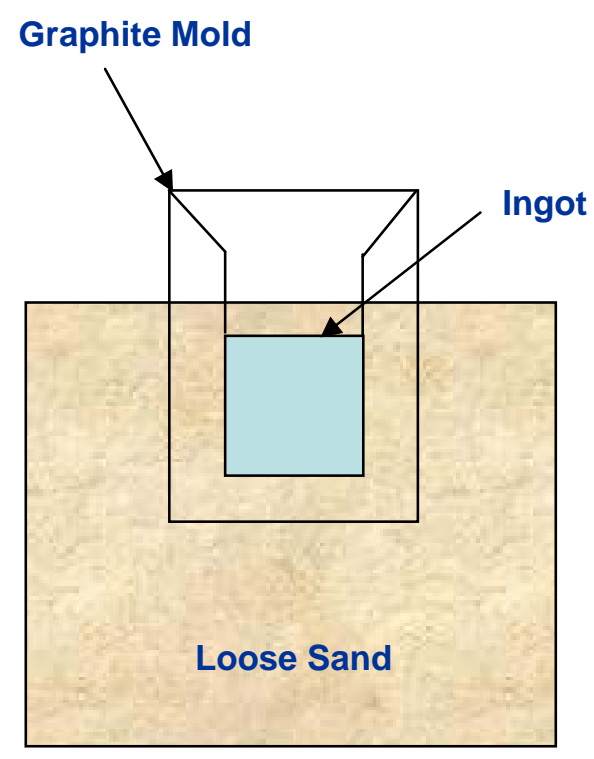

NETL/Albany casting layout
is shown schematically
on the left. A
permanent graphite
mold was used. This
mold was surrounded
by loose sand such
that the top of the
casting was below the
sand line. This is our
attempt to emulate the
"semi-infinite" plate
model of the turbine
casing.

Figure 1 - Schematic of cast ingot geometry and combination of graphite mold insulated by loose sand, used to obtain lower cooling rates typical of larger section castings.

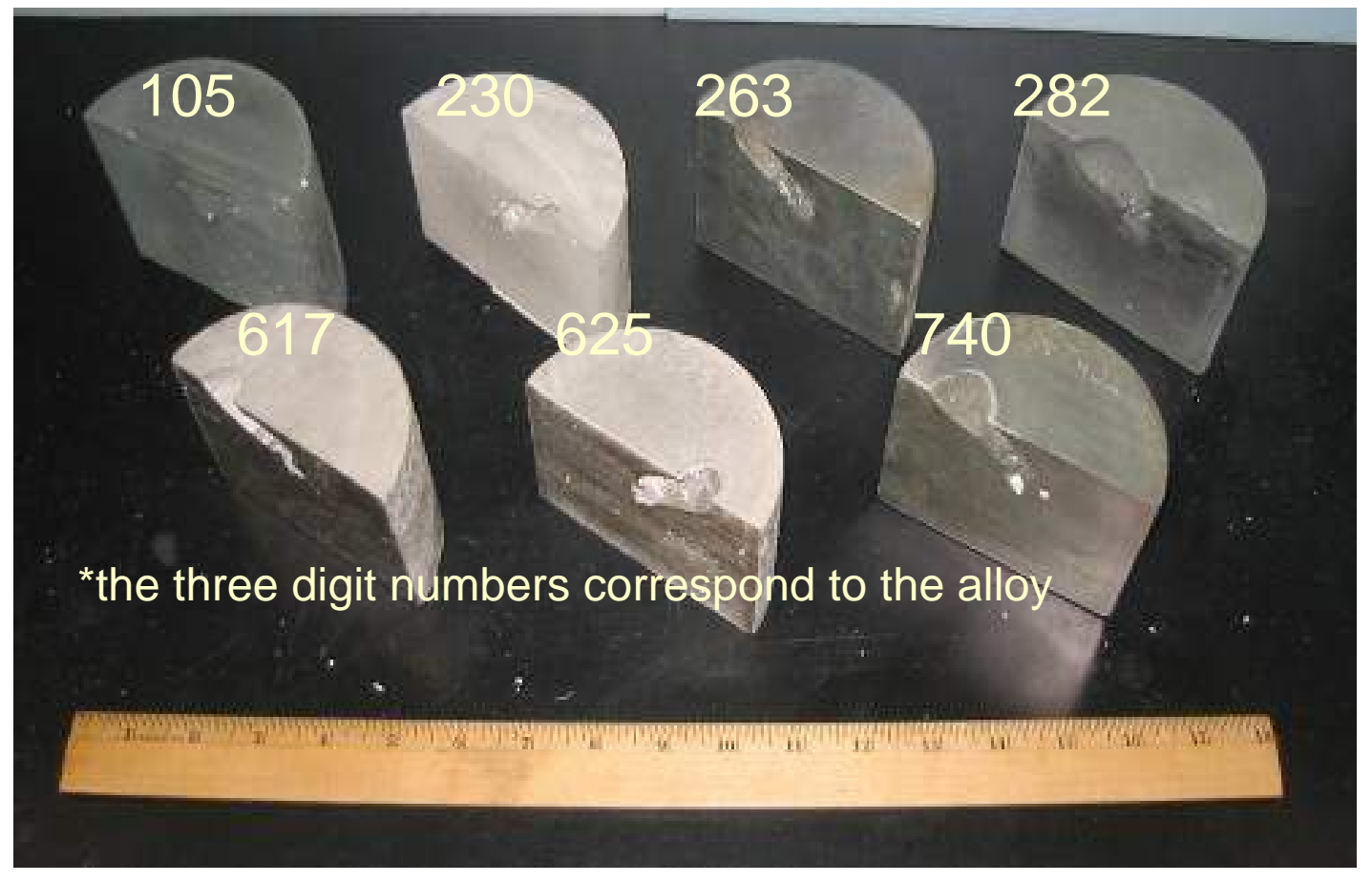

Figure 2 - Photo of the ingots of the various alloys after they were cut in half. Alloys were homogenized and heat-treated. NETL/Albany and ORNL each received one-half of each alloy for characterization and testing. 

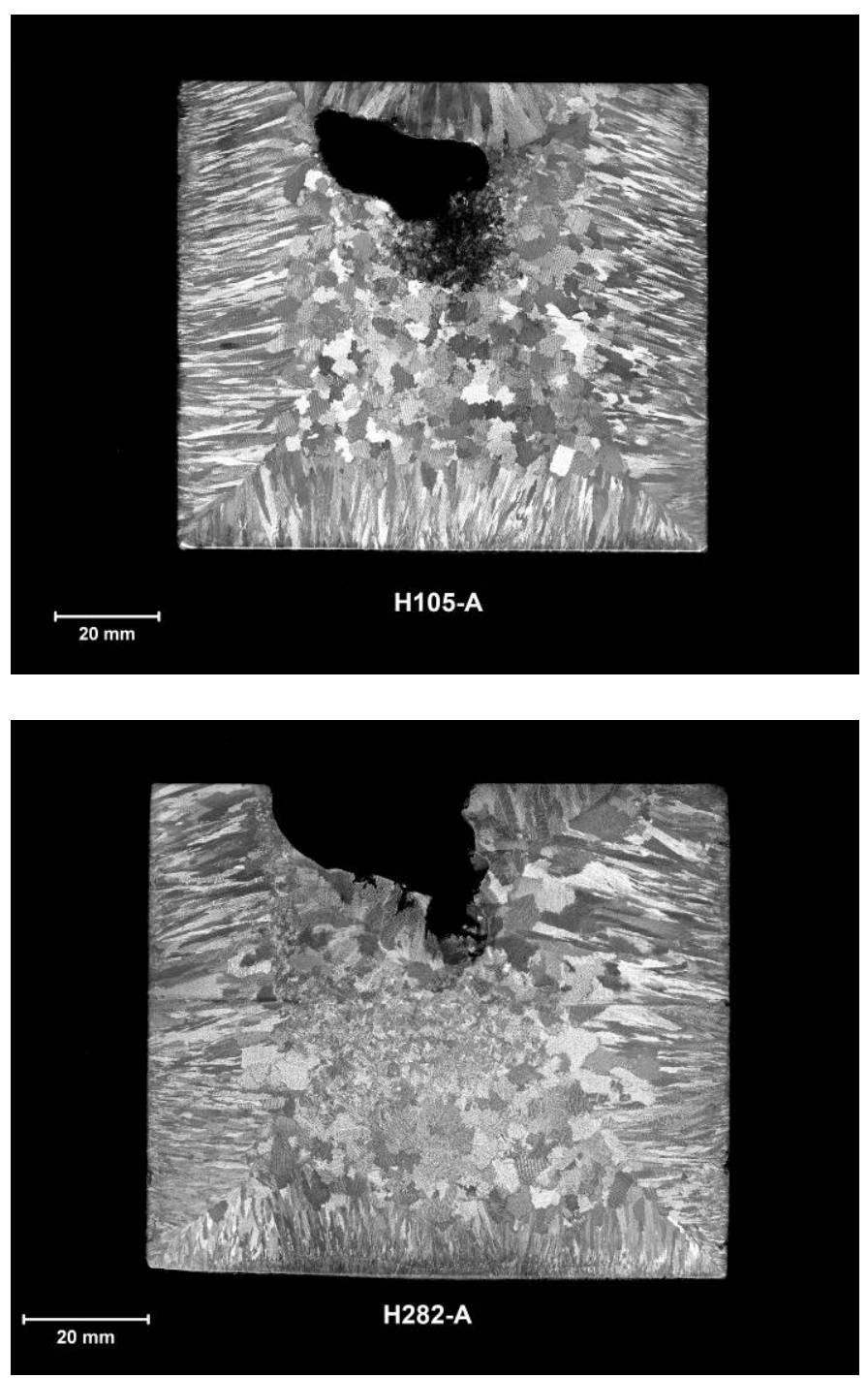

Figure 3 - Macro-etched grain structures (NETL/Albany) of as-cast ingot cross-sections, showing a fine columnar grain structure on outer portion of the ingot, and coarser equiaxed grain structure in the center part of the ingot. Structures of two different as-cast ingots, for Nimonic 105 and HR 282 alloys, are shown. 
THERMO-CALC (2008.05.22:10.04) :

DATABASE:NI

$W(C)=W C, W(C R)=W C R, W(C O)=W C O, W(A L)=W A L, W(T I)=W T I, W(M O)=W M O, W(M N)=W M N$,

$W(\mathrm{FE})=W F E, W(\mathrm{Sl})=W S \mathrm{I}, W(\mathrm{~B})=W B, P=1 E 5, N=1$;

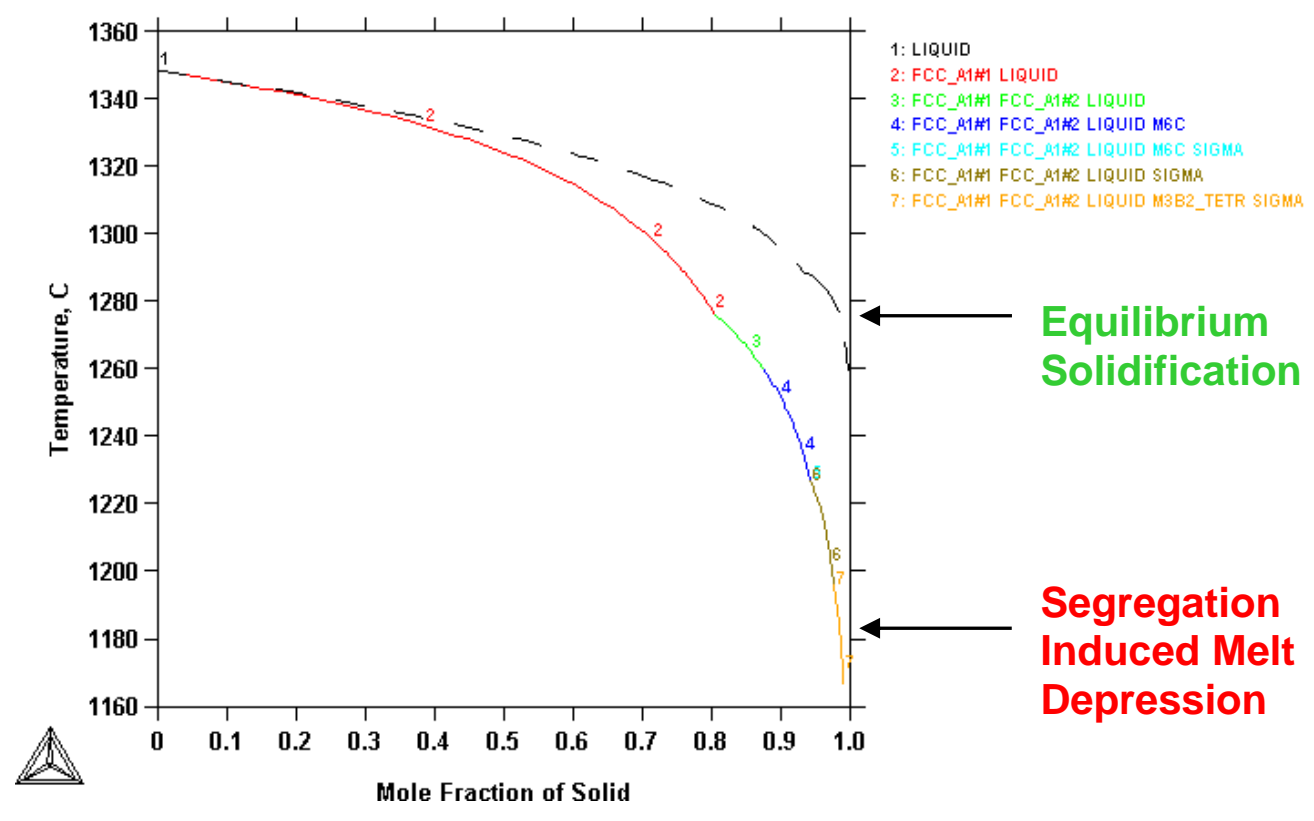

Figure 4 - ThermoCalc analysis (NETL/Albany) of cast HR 282 alloy showing the effects of compositional segregation due to dendrite formation and "coring", and suppressed melting point of such regions relative to a "uniform" alloy.
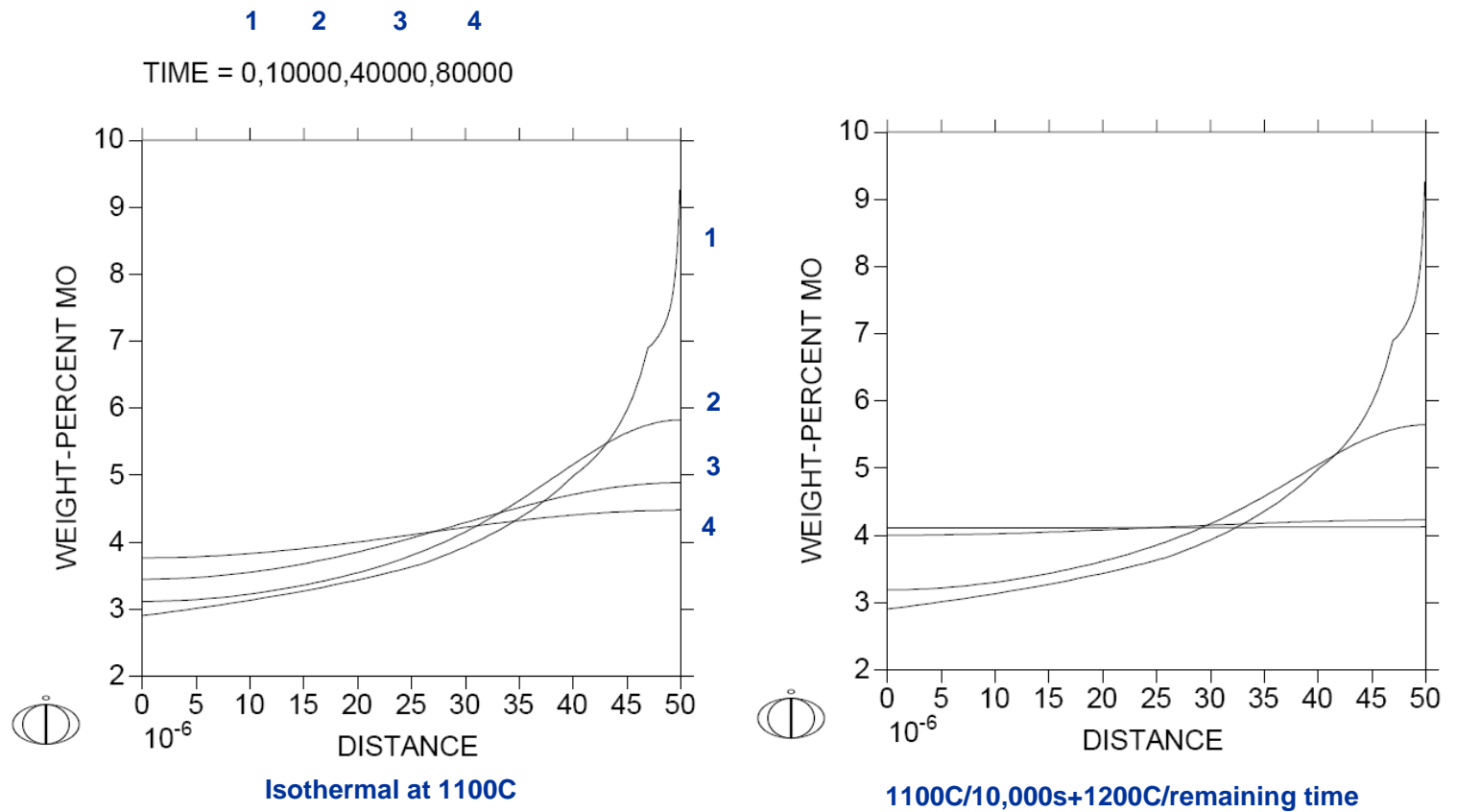

Figure 5 - DICTRA analysis (NETL/Albany) of diffusional profiles of Mo interdendritic segregation of Mo in cast Nimonic 105 alloy, showing the beneficial effects of the two-step homogenization heattreatment. 


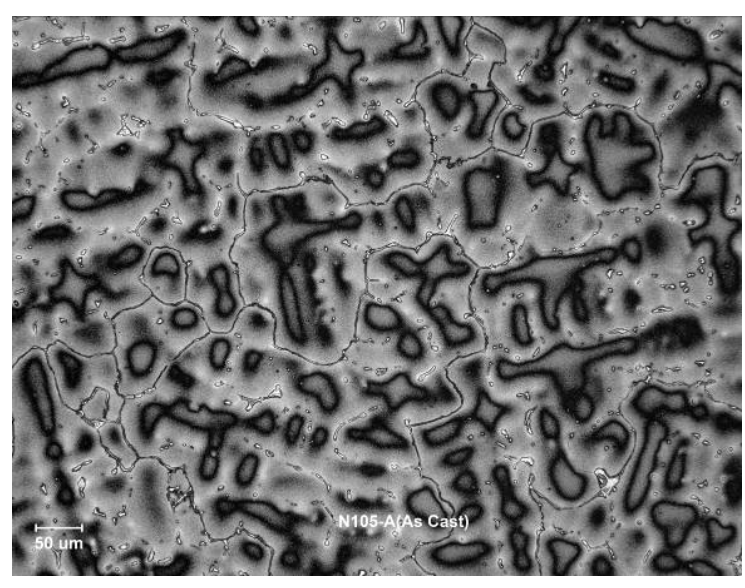

As-Cast

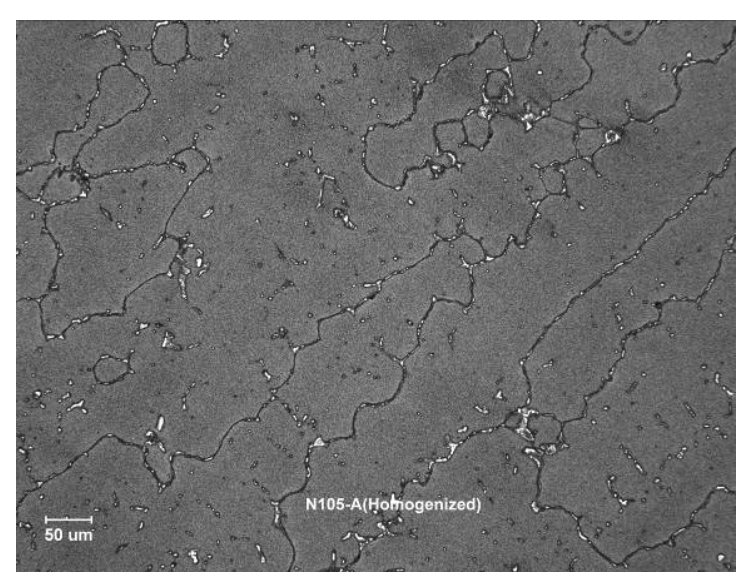

Homogenized

Figure 6 - Metallography of as-cast and then homogenized Nimonic 105 alloy, demonstrating the effectiveness of the NETL/Albany two-step homogenization treatment to eliminate as-cast segregation of $\mathrm{Mo}, \mathrm{Nb}$ and various other alloying elements.

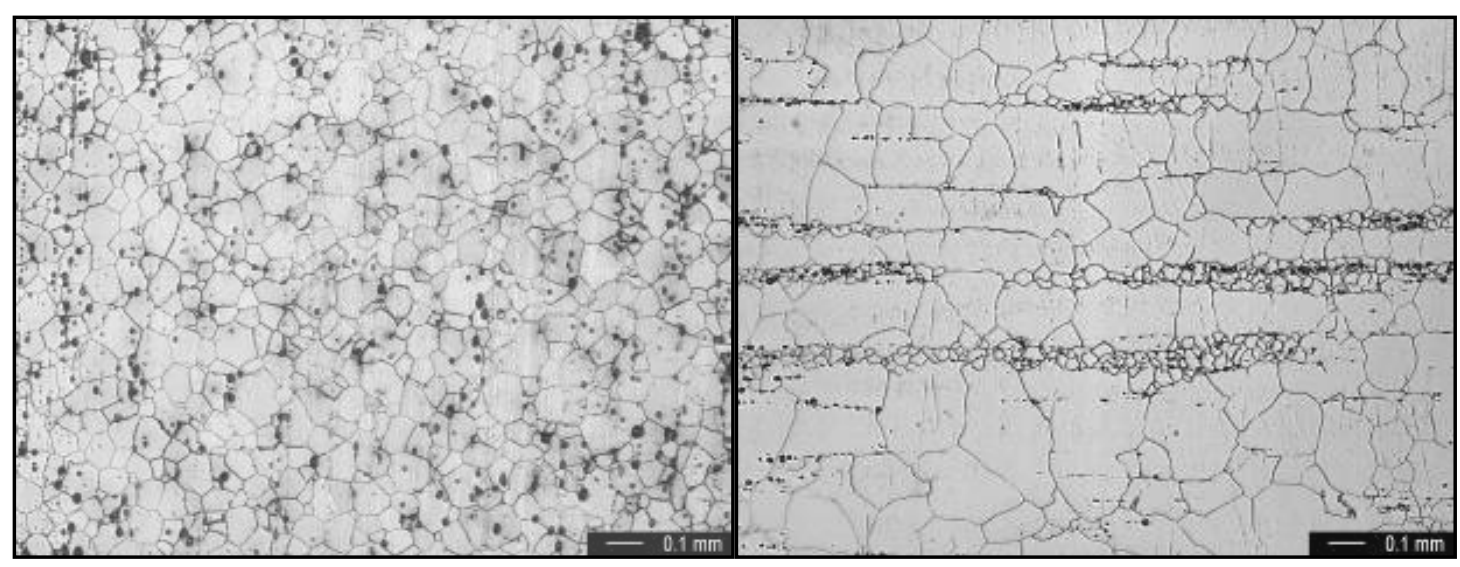

Nimonic 105

HR 282

Figure 7 - Metallographic analysis (ORNL) of typical wrought structures of Nimonic 105 and HR 282, obtained from alloy characterization and properties determinations being conducted on other Tasks of the A-USC Consortium Turbine Project. 


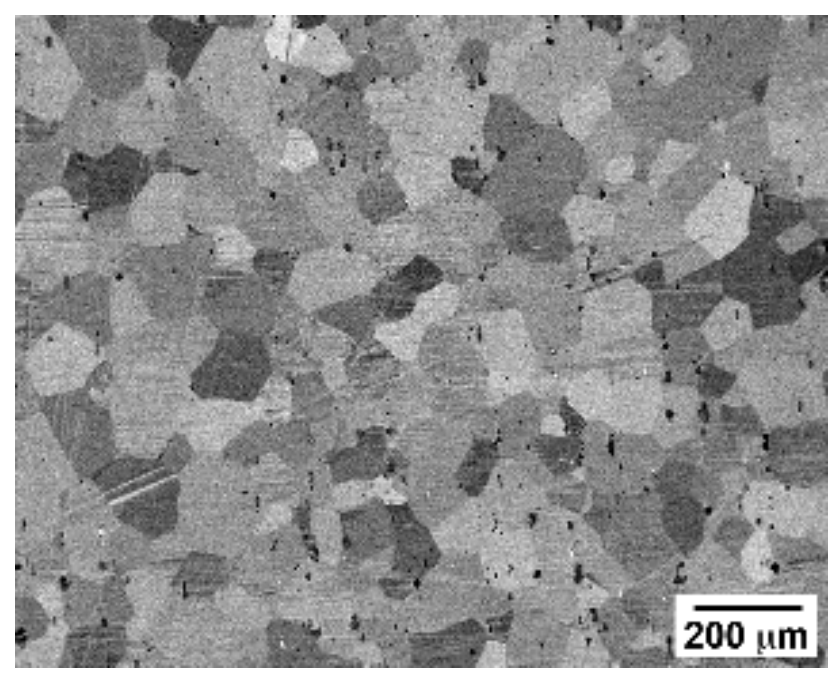

Wrought Nimonic 105

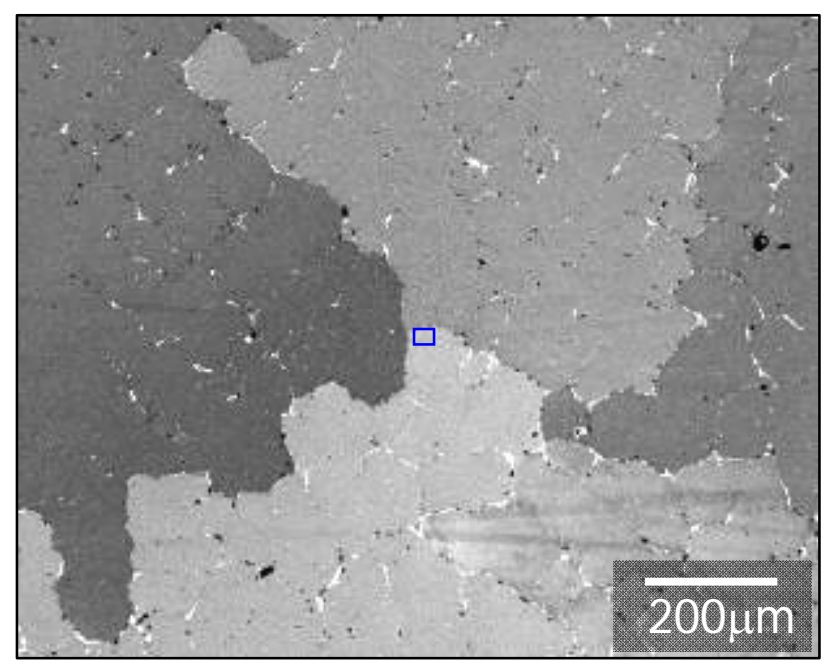

Cast Nimonic 105

Figure 8 - Back-scattered scanning electron microscope (SEM/BS) analysis (ORNL) of the microstructures of typical wrought and cast structures of Nimonic 105 alloy. The dendritic grain structure in the castings is much coarser than the fine, uniform grain structure in the wrought material. 


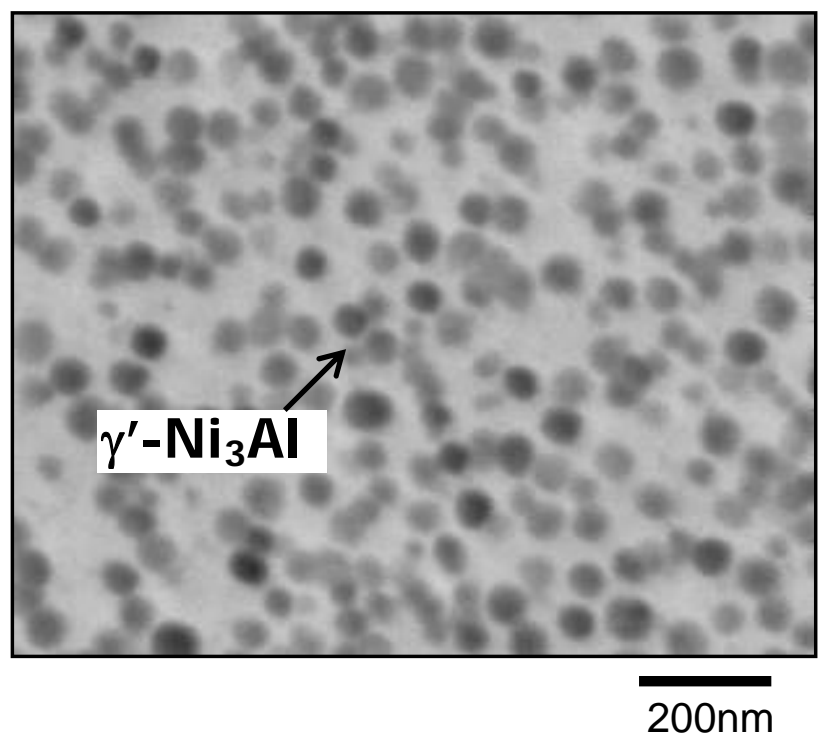

Gamma-prime in wrought Nimonic 105

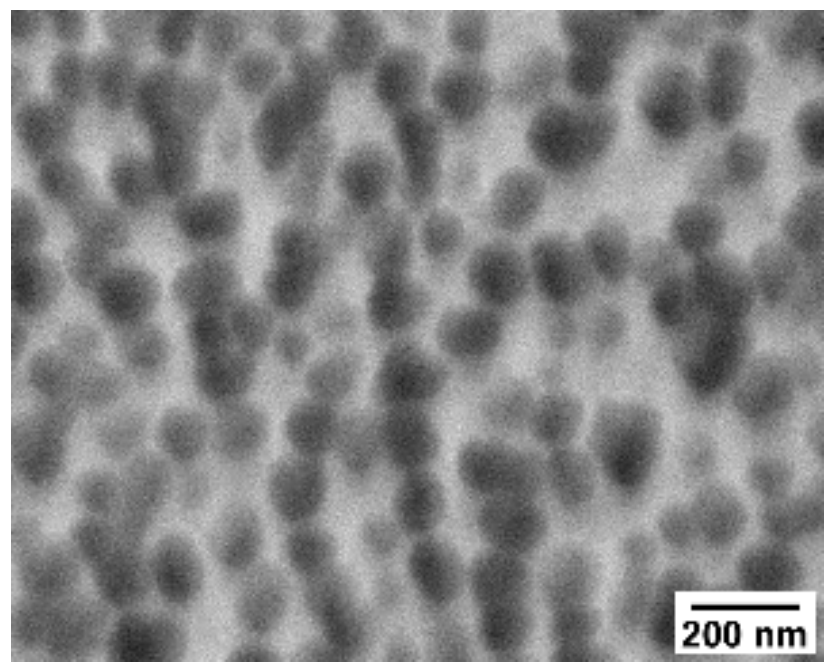

Gamma-prime in cast Nimonic 105

Figure 9 - High magnification SEM/BS analysis (ORNL) of polished and lightly etched specimens of wrought and cast Nimonic 105, showing similar (magnifications are different) dense, uniform dispersions of ( $\mathrm{Ni}, \mathrm{Ti}) 3 \mathrm{Al}$ - gamma prime particles produced by the final heat-treatment. 


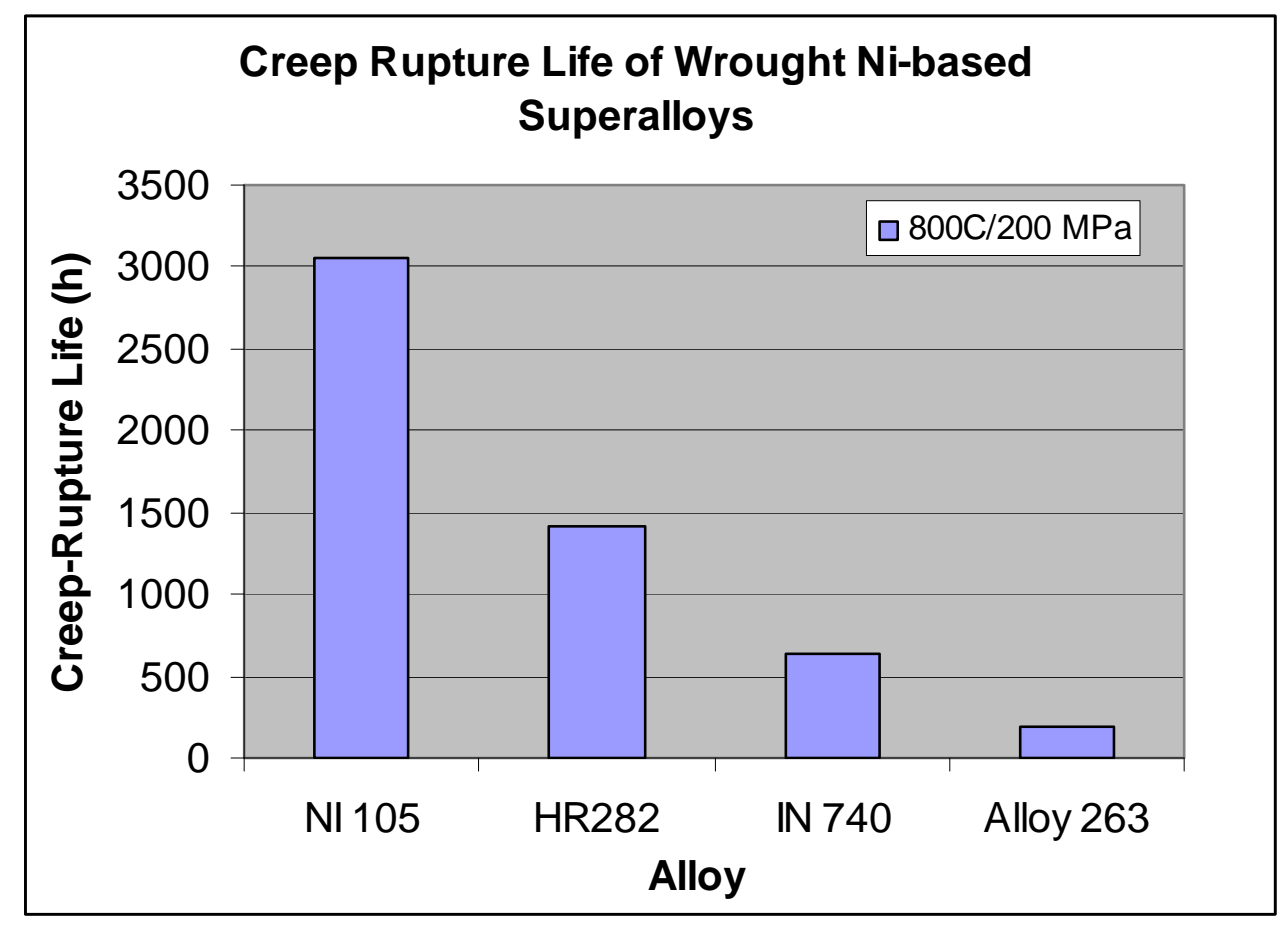

Figure 10 - Estimated creep-rupture lives of various wrought Ni-based superalloys, using data being generated on other Tasks within the A-USC Consortium Boiler and Turbine Projects. Data on wrought alloys will provide the baseline data for comparison with the cast versions of each of these alloys, which will be evaluated in Phase 2 of this project effort. 
TASK12.5 DESIGN AND ECONOMIC STUDIES

(ALSTOM POWER) 


\section{REPORT SUMMARY}

A project has been established by the U.S. Department of Energy (DOE) through the National Energy Technology Laboratory (NETL), and the Ohio Coal Development Office (OCDO) as a government/industry consortium to undertake an effort to evaluate materials that allow the use of advanced steam cycles in coal-based power plants. These advanced cycles, with steam temperatures up to $760^{\circ} \mathrm{C}\left(1,400^{\circ} \mathrm{F}\right)$, will increase the efficiency of coal-fired steam plants from an average of 36-39\% efficiency (current domestic fleet) to nearly 44\% (HHV basis) in single reheat and $45 \%$ (HHV basis) in a double reheat configuration. This efficiency increase will enable coal-fired power plants to generate electricity at competitive rates while reducing $\mathrm{CO}_{2}$ and other fuel-related emissions by as much as $22 \%$.

The fundamental step in market introduction of ultra-supercritical steam conditions requires that a variety of materials related concerns associated with high temperature application are assessed. For this purpose, the conceptual design of a nominal 1,000 MW power plant for steam turbine throttle conditions of $350 \mathrm{bar} / 730^{\circ} \mathrm{C} / 760^{\circ} \mathrm{C}\left(5,076 \mathrm{psi} / 1,346^{\circ} \mathrm{F} / 1,400^{\circ} \mathrm{F}\right)$ was developed and materials required for high temperature components were defined. This report discusses and compares plant performance, investment costs, and economic parameters of merit for this ultrasupercritical plant with that of a state-of-the-art supercritical plant $258 \mathrm{bar} / 593^{\circ} \mathrm{C} / 593^{\circ} \mathrm{C}$ $\left(3,748 \mathrm{psi} / 1,100^{\circ} \mathrm{F} / 1,100^{\circ} \mathrm{F}\right)$. The information developed herein provides necessary input into the research and development program for new plant alloys that are considered for high temperature application. 



\section{LIST OF ACRONYMS}

$\begin{array}{ll}\text { BOP } & \text { Balance of Plant } \\ \text { Btu } & \text { British Thermal Unit } \\ \text { COE } & \text { Cost of Electricity } \\ \text { dBA } & \text { Decibel } \\ \text { DOE/NETL } & \text { Department of Energy/National Energy Technology Laboratory } \\ \text { EPA } & \text { Environmental Protection Agency } \\ \text { EPC } & \text { Engineered, Procured and Constructed } \\ \text { EPRI } & \text { Electric Power Research Institute } \\ \text { ESP } & \text { Electrostatic Precipitator } \\ \text { FD } & \text { Forced Draft } \\ \text { FGD } & \text { Flue Gas Desulfurization } \\ \text { FOM } & \text { Fixed Operation \& Maintenance } \\ \text { GSC } & \text { Gland Steam Condenser } \\ \text { HHV } & \text { Higher Heating Value } \\ \text { HP } & \text { High Pressure } \\ \text { hr } & \text { Hour } \\ \text { HT } & \text { High Temperature } \\ \text { HVAC } & \text { Heating, Ventilating and Air Conditioning } \\ \text { Hz } & \text { Hertz } \\ \text { ID } & \text { Induced Draft } \\ \text { in. } H_{2} \mathrm{O} & \text { Inches of Water } \\ \text { in. Hga } & \text { Inches of Mercury, Absolute } \\ \text { IP } & \text { Intermediate Pressure } \\ \text { kWe } & \text { Kilowatts electric } \\ \text { kWh } & \text { Kilowatt-hour } \\ \text { Ibm } & \text { Pound mass } \\ \text { LHV } & \text { Lower Heating Value } \\ \text { LNB } & \text { Low Nox Burners } \\ \text { LP } & \text { Low Pressure } \\ \text { LPFWH } & \text { Low Pressure Feedwater Heater } \\ \text { LT } & \text { Low Temperature } \\ \text { MCR } & \text { Maximum Continuous Rating } \\ \text { MWe } & \text { Megawatt electric } \\ \text { Ni } & \text { Nickel } \\ \text { NPHR } & \text { Net Plant Heat Rate } \\ \text { OFA } & \text { Over Fire Air } \\ \text { O\&M } & \text { Operation \& Maintenance } \\ \text { PA } & \text { Primary Air } \\ \text { PC } & \text { Pulverized Coal } \\ \text { PRB } & \text { Powder River Basin } \\ \text { psia } & \text { Pound per square inch, absolute } \\ \text { psig } & \text { Pound per square inch, gauge } \\ \text { SA } & \text { Secondary Air } \\ \text { USC } & \text { Vltra-Supercritical } \\ \text { VOC } & \\ \text { VOM } & \text { Variable Operation \& Maintenance } \\ & \end{array}$





\section{TABLE OF CONTENTS}

TASK12.5 DESIGN AND ECONOMIC STUDIES (ALSTOM POWER).................536

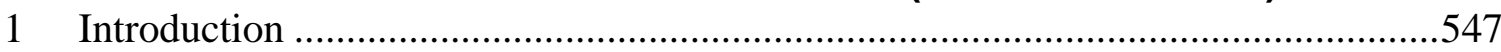

2 Plant Design Basis and Scope ……………........................................................549

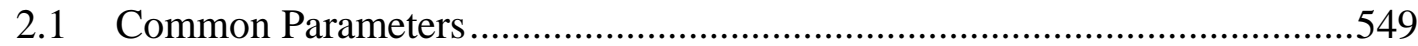

2.2 Major Plant Design Data.............................................................................551

$3 \quad$ Plant Performance..........................................................................................552

3.1 Steam Cycle Parameters ............................................................................552

3.2 Turbine Heat Balances and Steam Cycle Description ......................................552

3.3 Auxiliary Power and Plant Performance Parameter Comparison...................556

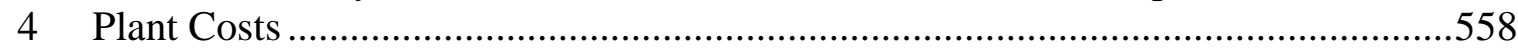

4.1 Investment Cost Basis..............................................................................558

4.2 Investment Cost Results..........................................................................562

4.3 Operating and Maintenance Costs ................................................................565

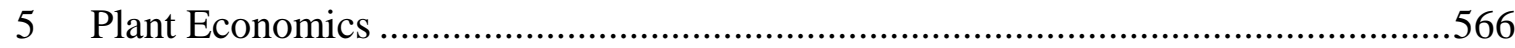

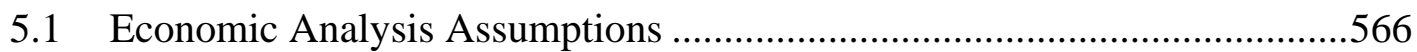

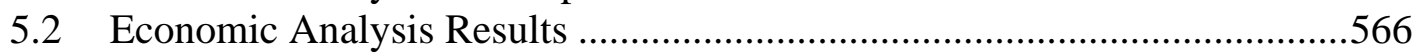

$5.3 \quad$ Economic Sensitivity Studies …………………….......................................568

6 Conclusions \& Recommendations.....................................................................575

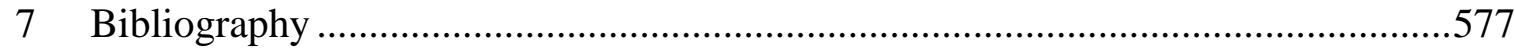





\section{LIST OF FIGURES}

Figure 3-1: Turbine Heat Balance for $600^{\circ} \mathrm{C}$ State-of-the-Art Supercritical Case.................... 554

Figure 3-2: Turbine Heat Balance for $730^{\circ} \mathrm{C}$ Ultra-Supercritical Case.................................... 555

Figure 3-3: Plant Thermal Efficiency Comparison........................................................... 557

Figure 3-4: Plant Thermal Efficiency Increase (Relative to $600^{\circ} \mathrm{C} 258$ bar Supercritical Case) 557

Figure 4-1: Plant Investment Cost Breakdown................................................................. 563

Figure 4-2: Plant Investment Cost Increase Breakdown for the Ultra-supercritical Case (Relative to $600^{\circ} \mathrm{C} 258$ bar Supercritical Case) ............................................................. 564

Figure 4-3: Total Plant Investment Costs ........................................................................... 565

Figure 5-1: Cost of Electricity Breakdown Comparison ....................................................... 567

Figure 5-2: Economic Sensitivity Study (Ni Alloy Cost).................................................. 569

Figure 5-3: Economic Sensitivity Study with "High” Ni Alloy Cost..................................... 571

Figure 5-4: Sensitivity with "Low” Ni Cost, Coal Cost $=4.5$ \$MM-Btu, Capacity Factor $=90 \%$

Figure 5-5: Economic Sensitivity Study with “Low” Ni Alloy Cost ..................................... 574 



\section{LIST OF TABLES}

Table 2-1: Design Coal Analysis (Powder River Basin Sub-bituminous)............................... 550

Table 3-1: Steam Cycle Parameters ............................................................................... 552

Table 3-2: Plant Auxiliary Power Comparison.................................................................. 556

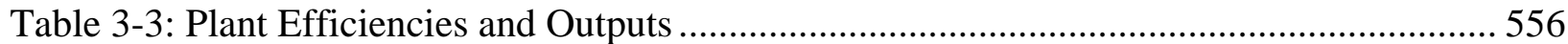

Table 4-1: Steam Piping \& Tubing Material Costs ......................................................... 561

Table 4-2: Plant Investment Cost Breakdown .................................................................... 562

Table 5-1: Primary Economic Assumptions ......................................................................... 566

Table 5-2: Basic Economic Results ............................................................................... 567 



\section{Introduction}

During the 1950's, advances made in power plant component designs, manufacturing processes, and the introduction of new materials for pressure part components enabled designers to increase steam turbine inlet conditions and to offer significant improvements in plant efficiency. Since the early 1960's, for a variety of reasons, deployment of advanced steam conditions have not been pursued by utilities in the United States. There was little motivation to continue improving thermal efficiency of fossil-fired plants because of the expected increase in nuclear power generation for base load application and the availability of relatively inexpensive fossil fuels. In recent years, however, due to high fuel cost and global warming concerns, plant efficiency is again beginning to play a major role. In a planning stage, there are supercritical designs with main steam temperatures as high as $600^{\circ} \mathrm{C}\left(1,112^{\circ} \mathrm{F}\right)$ approaching the operating limits of traditional ferritic materials.

The corollary of higher efficiency is lower fuel consumption and lower release rates of criteria pollutants and greenhouse gases for the same rate of electrical output. As a direct function of efficiency, $\mathrm{CO}_{2}$ emissions are reduced directly in proportion to improved efficiency, as are $\mathrm{NO}_{\mathrm{x}}$ and $\mathrm{SO}_{\mathrm{x}}$ emissions, which are contributors to acid rain. Particulate emissions, volatile organic compounds (VOC), carbon monoxide (CO) and trace metal emissions are similarly reduced. It also means that for every pound of coal, which doesn't have to be burned, there is a pound of coal that doesn't need to be mined, purchased, transported, stored and pulverized. If that coal is not burned it is not necessary to collect and dispose of the residues of combustion.

This project has been established as a government/industry consortium to undertake an effort to evaluate and develop advanced materials that allow the use of advanced steam cycles in coalbased power plants. The project is based on an R\&D plan developed by the Electric Power Research Institute (EPRI) that supplements the recommendations of several DOE workshops on the subject of advanced materials. In view of the variety of skills and expertise required for the successful completion of the proposed work, a consortium that includes EIO, EPRI, and the major domestic boiler manufacturers (Alstom Power, Babcock and Wilcox, Foster Wheeler and Babcock Power Co.) and the Oak Ridge Research National Labs was developed. This project will be referred to as the steam boiler consortium. Additionally, a steam turbine consortium, made up of EIO, EPRI, and the major steam turbine suppliers (Alstom Power, GE, and Siemens) has been formed to address steam turbine materials reseach.

To quantify the benefits of the high steam conditions, this program (steam turbine consortium) includes a conceptual design effort for an ultra-supercritical power plant (Task 12.5 - Design \& Economic Analysis). Specific objectives of this task are:

1. Develop a conceptual plant design for ultra-supercritical steam conditions including main steam conditions of $730^{\circ} \mathrm{C} / 350$ bar $\left(1,346^{\circ} \mathrm{F} / 5,076 \mathrm{psi}\right)$.

2. Identify plant performance improvements relative to a comparable state-of-the-art supercritical plant with main steam conditions of $593^{\circ} \mathrm{C} / 258$ bar $\left(1,100^{\circ} \mathrm{F} / 3,748 \mathrm{psi}\right)$.

3. Compare ultra-supercritical plant thermal efficiency, investment cost and economic parameters of merit relative to a state-of-the-art supercritical plant.

There are many definitions of ultra-supercritical steam conditions in the power generation industry. They continue to evolve depending on the maximum steam conditions achievable with currently acceptable materials used. For the purpose of this study, however, ultra-supercritical 
steam conditions will be defined as any design at temperatures $650^{\circ} \mathrm{C}\left(1,202^{\circ} \mathrm{F}\right)$ or higher. 


\section{Plant Design Basis and Scope}

The two power plants designed for this conceptual level study are assumed to be located on a common Greenfield site, and are assumed to be operated under common conditions of fuel, limestone, utility and environmental standards. This section is intended to describe the design basis and identify the common parameters for each case, the scope of the cost estimate, and other items, which will be used as a common design basis for all these plants.

Because much of the plant design and cost data were simply prorated or adapted from previous EPRI work (Wheeldon, 2008), much of what follows in this section to describe the plant site and the common design basis was taken directly or summarized from that work.

\subsection{Common Parameters}

The two Greenfield plants were designed for the identical coal and limestone analyses, ambient conditions, site conditions, etc. such that each case study provides results which are directly comparable, on a common basis, to the other case analyzed within this work. Additionally, each case was designed for a near constant heat input to the steam cycles (i.e. boiler heat output). Many other items were common between cases also such as the site, plant services, etc. as described below.

\subsubsection{Plant Site and Scope}

The generic plant site is common to each study case. The plants, of indoor construction type, are located in Kenosha, Wisconsin at an elevation 600 feet above mean sea level. The site is clear and level in a Seismic Zero Zone and 30-m (100-feet) deep pile foundations are required. Available at the site boundary are rail and transmission access, raw water supplied from Lake Michigan, and natural gas.

\subsubsection{Ambient Conditions}

Annual average ambient air conditions are required to calculate plant material balances, thermal efficiencies, to develop system designs, and to size plant equipment. These conditions are listed below:

- Atmospheric pressure

- Dry bulb temperature

- Maximum dry bulb temperature

- Wet bulb temperature

- Maximum wet bulb temperature

1.0 bar (14.4 psia)
$16^{\circ} \mathrm{C}\left(60^{\circ} \mathrm{F}\right)$
$35^{\circ} \mathrm{C}\left(95^{\circ} \mathrm{F}\right)$
$13^{\circ} \mathrm{C}\left(55^{\circ} \mathrm{F}\right)$
$24^{\circ} \mathrm{C}\left(75^{\circ} \mathrm{F}\right)$

\subsubsection{Environmental Requirements}

The stack gas emission limits and the flue gas cleanup technology used are as follows:

- $\mathrm{SO}_{2} ; 30 \mathrm{mg} / \mathrm{Nm}^{3}$ (0.03 lb/MMBtu), wet flue gas desulfurization system (wet FGD)

- $\mathrm{NO}$; $30 \mathrm{mg} / \mathrm{Nm}^{3}$ (0.03 lb/MMBtu), low-NO burners (LNB) with over-fired air (OFA), and selective catalytic reduction (SCR)

- $\mathrm{PM}_{2.5} ; 13 \mathrm{mg} / \mathrm{Nm}^{3}(0.013 \mathrm{lb} / \mathrm{MMBtu})$, wet FGD

- $\mathrm{PM}_{10} ; 10 \mathrm{mg} / \mathrm{Nm}^{3}$ (0.01 lb/MMBtu), electrostatic precipitator (ESP)

- Mercury; 90 percent reduction, $\mathrm{CaBr}_{2}$ injection into furnace to promote oxidation across the SCR followed by co-capture in the wet FGD. 


\subsubsection{Fuel Characteristics}

Fuel, delivered by rail, is Wyoming Powder River Basin (PRB) sub-bituminous coal, with characteristics as detailed in Table 2-1.

Table 2-1: Design Coal Analysis (Powder River Basin Sub-bituminous)

$\begin{array}{cc}\text { Coal Ultimate Analysis (\% by Weight) } \\ \text { Carbon } & 51.00 \\ \text { Hydrogen } & 3.50 \\ \text { Sulfur } & 0.32 \\ \text { Oxygen } & 11.88 \\ \text { Nitrogen } & 0.70 \\ \text { Moisture } & 27.30 \\ \text { Ash } & 5.30 \\ & \\ \text { High Heating Value 8,800 Btu/lb (20,469kJ/kg) } \\ \text { Coal Proximate Analysis (\% by Weight) } \\ \text { Moisture } & 27.30 \\ \text { Volatile Matter } & 32.90 \\ \text { Fixed Carbon } & 34.50 \\ \text { Ash } & 5.30\end{array}$

\subsubsection{Waste Water Streams}

The various wastewater streams from the process will be treated as shown below.

\section{Process Wastewater}

Water associated with combustion activity and storm water that contacts equipment surfaces will be collected and treated for disposal through a permitted discharge.

Sanitary Waste Disposal

Design will include a packaged domestic sewage treatment plant with effluent discharged to the industrial wastewater treatment system. Sludge will be hauled off site. The packaged plant will be sized for 1,500 gallons per day.

Water Discharge

Blow-down will be treated for $\mathrm{pH}$, chloride and metals. Evaluation of other constituents is needed to determine if added treatment is needed before discharge.

Wastewater discharged following treatment must comply with the U.S. Environmental Protection Agency (U.S. EPA) Effluent Guidelines and Standards.

\subsubsection{Additional Plant Requirements}

Additional plant design requirements are as follows: 
- The plant equipment and facilities shall be designed so that all ash from the combustion process and sludge from water treatment are disposed off site in accordance with the nonhazardous waste disposal guidelines of the Resource Conservation and Recovery Act. Appropriate temporary onsite storage facilities shall be specified in accordance with the guidelines.

- In-plant noise levels must not exceed $90 \mathrm{dBA}$ for an 8-hour exposure. Plant perimeter noise levels must not exceed $65 \mathrm{dBA}$ during the day and $55 \mathrm{dBA}$ during the night.

- Inactive coal storage pile is sized for 90-days storage, and the active storage pile is sized for 7-days operation at full load.

- Limestone is delivered by road with an active storage pile sized for 30-days operation at full load.

- Limestone composition is 94.1 percent $\mathrm{CaCO}_{3}, 3.3$ percent $\mathrm{MgCO}_{3}, 0.6$ percent $\mathrm{SiO}_{2}$, and 2.0 percent $\mathrm{H}_{2} \mathrm{O}$.

- Gypsum is disposed of off-site (no requirement for commercial grade).

- Onsite emergency ash storage is sized for 90 days. Final disposal is off site.

- Plant design will include a high-voltage switchyard but transmission is excluded.

- Natural gas supply is available at the site boundary for start-up fuel.

- Raw water is from Lake Michigan.

- Potable water, de-ionized water, and process makeup water for the process is drawn from municipal sources.

- Plant is designed for base-load duty with a book life of 30 years

\subsection{Major Plant Design Data}

Major design data for the power cycle includes:

- Steam conditions for the supercritical case are $258 \mathrm{bar} / 593^{\circ} \mathrm{C} / 593^{\circ} \mathrm{C}\left(3,748 \mathrm{psi} / 1,100^{\circ} \mathrm{F}\right.$ / $\left.1,100^{\circ} \mathrm{F}\right)$

- Steam conditions for the ultra-supercritical case are $350 \mathrm{bar} / 730^{\circ} \mathrm{C} / 760^{\circ} \mathrm{C}(5,076 \mathrm{psi} /$ $1,346^{\circ} \mathrm{F} / 1,400^{\circ} \mathrm{F}$ ) as discussed in Section 3.1. 


\section{Plant Performance}

This section of the report discusses the plant performance results for the two coal-fired steam power plants, each with differing steam conditions. The performance part of the study compares a state-of-the-art supercritical plant with steam conditions that are currently available to a future plant that utilizes ultra-supercritical steam conditions. This part of the study therefore quantifies the performance benefits of the ultra-supercritical steam conditions for a future generation of coal-fired steam power plants. Conceptual designs were developed for these two power plants for approximately constant fuel consumption rates ( 8.0 x $10^{9} \mathrm{Btu} / \mathrm{hr}$ : HHV Basis). In this manner, furnace sizes, fans, flue gas cleanup systems, and other gas and solid flow (coal, limestone, ash) related equipment were common among the cases, which helps to simplify the cost estimation task.

\subsection{Steam Cycle Parameters}

Two steam cycles were selected for the cases in this study. These steam cycles ( 990 and $\sim 1,080$ MWe generator output) have discretely different steam conditions, thermodynamic performance, and power cycle equipment designs. Steam turbine design conditions for these two steam cycles are shown in Table 3-1 and range from state-of-the-art supercritical conditions being designed for today $\left(\sim 600^{\circ} \mathrm{C}, 258 \mathrm{bar} / 1,100^{\circ} \mathrm{F}, 3,748 \mathrm{psi}\right)$ to ultra-supercritical conditions expected for the power plants of the future $\left(730^{\circ} \mathrm{C}, 350 \mathrm{bar} / 1,346^{\circ} \mathrm{F}, 5,076 \mathrm{psi}\right)$.

\section{Table 3-1: Steam Cycle Parameters}

Main Steam Pressure
Main Steam Temperature
Reheat Steam Temperature
Feedwater Temperature
Number of Feedwater Heaters

\begin{tabular}{crr} 
& 600C 258Bar & 730C 350Bar \\
\cline { 2 - 3 } (psia) & 3,748 & 5,076 \\
(bar) & 258 & 350 \\
(Deg F) & 1,100 & 1,346 \\
(Deg C) & 593 & 730 \\
(Deg F) & 1,100 & 1,400 \\
(Deg C) & 593 & 760 \\
(Deg F) & 579 & 624 \\
(Deg C) & 304 & 329 \\
(no.) & 8 & $9+$ T-dsh
\end{tabular}

The goal of the U.S. DOE program is to develop the materials technology to build and operate a $760^{\circ} \mathrm{C}\left(1400^{\circ} \mathrm{F}\right)$ steam powerplant. Basic design studies by multiple boiler OEMs were conducted in the preliminary stages of the boiler consortium to develop strength and temperature requirements for materials in such a plant. The consortium determined that for main steam components, the stresses at $760^{\circ} \mathrm{C}\left(1400^{\circ} \mathrm{F}\right)$ and approximately 350bar (5,000 psi) would result in boiler header and piping thicknesses beyond traditional boiler design and fabrication. However, the lower pressure of the reheat cycle meant that $760^{\circ} \mathrm{C}\left(1400^{\circ} \mathrm{F}\right)$ steam temperatures were possible. Therefore, the consortium determined that a maximum practically achievable steam temperatures based on the current state-of-knowledge for boiler manufacture were a $\sim 730^{\circ} \mathrm{C}\left(1350^{\circ} \mathrm{F}\right)$ main steam and $760^{\circ} \mathrm{C}\left(1400^{\circ} \mathrm{F}\right)$ hot reheat. Thus, the conditions in Table 3-1 follow this guidance.

\subsection{Turbine Heat Balances and Steam Cycle Description}

Figure shows the turbine heat balance for the state-of-the-art supercritical design, which is used as a basis of comparison for the ultra-supercritical case. The ultra-supercritical case turbine heat balance is shown in Figure 3-2. 
Each steam cycle starts at the condenser hot well, which is a receptacle for the condensed steam from the exhaust of the low-pressure (LP) steam turbines. The condensate flows to the suction side of the condensate pumps, which increase the pressure of the fluid and transport it through the condensate piping system, and low-pressure feedwater heaters (LPFWH's) and enable it to enter the open contact heater, or deaerator. The condensate pumps are electric motor driven. The condensate passes first through a gland steam condenser (GSC), followed in series by four or five (depending on the steam cycle) low-pressure feedwater heaters. The supercritical steam cycle uses four LPFWH's whereas the ultra-supercritical steam cycle utilizes five. The heaters successively increase the condensate temperature by condensing and partially sub-cooling steam extracted from the LP steam turbine sections. Each heater receives a separate extraction steam stream at successively higher pressure and temperature. For the supercritical cycle, the condensed steam (now referred to as heater drains) is progressively passed to the next lower pressure heater, with the drains from the lowest heater draining to the condenser hot well. For the ultra-supercritical cycle, the drains on heaters \#2 and \#4 are pumped ahead and mixed with the condensate leaving the heater, which thermodynamically is slightly more efficient.

The condensate stream entering the deaerator is heated and stripped of non-condensable gases, which are vented, by contact with the extracted steam entering the unit. The extracted steam condenses and, along with the heated condensate, flows by gravity to a deaerator storage tank.

The boiler feedwater pumps (BFP) take suction from the deaerator storage tank and increase the fluid pressure to that pressure required by the boiler. The boiler feed pumps are steam turbine driven. While, in general, the practice is to select at least one of the boiler feedwater pumps to be electric motor driven, for simplicity, only steam driven boiler feedwater pumps were deployed in this study.

The high-pressure feedwater leaving the BFP flows through three more high-pressure feedwater heaters, in the supercritical case, increasing in temperature and then enters the boiler economizer section. For the ultra-supercritical case the boosted feedwater also flows through three more high-pressure feedwater heaters and then through a fourth heater referred to as a topping desuperheater, increasing in temperature and then enters the boiler economizer section. Each heater receives a separate extraction steam stream at successively higher pressure and temperature. The condensed steam (drains) is progressively passed to the next lower pressure heater, with the drains from the lowest high-pressure feedwater heater draining to the deaerator in both the supercritical case and the ultra-supercritical case.

Within the boiler the feedwater is progressively heated to higher temperatures and exits the finishing superheater in the superheated state. The high temperature and pressure superheated steam leaving the finishing superheater is piped to and expanded through the high-pressure (HP) steam turbine. The exhaust from the HP turbine is piped to the boiler, reheated, and is piped back to the intermediate-pressure (IP) turbine. The reheated steam expands through the IP and LP turbines before exhausting to the condenser to complete the cycle.

For both the supercritical ultra-supercritical steam turbines a single HP turbine is used with a double flow IP turbine and three double flow LP turbines on the same shaft as the electric generator. 


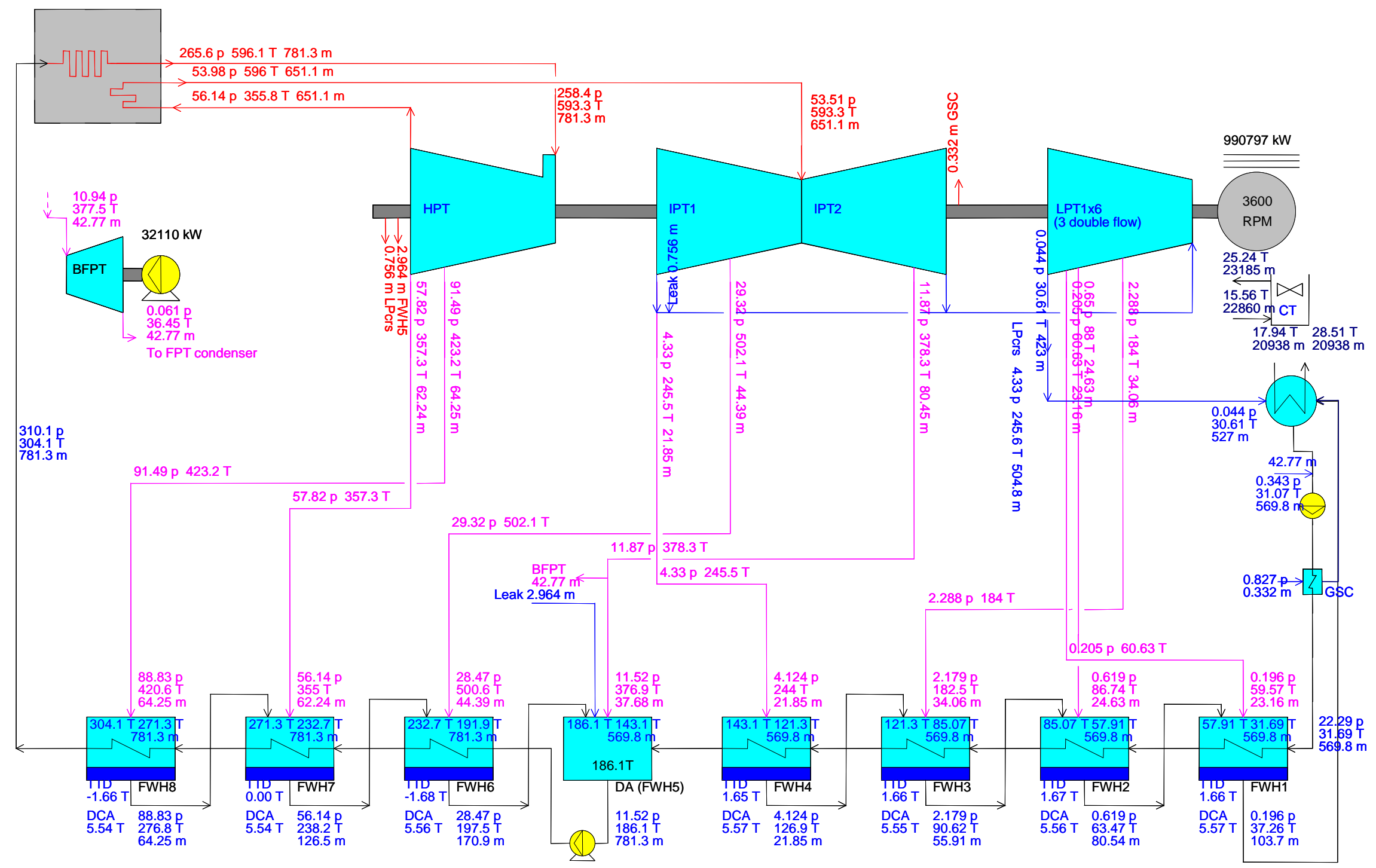

Figure 3-1: Turbine Heat Balance for $600^{\circ} \mathrm{C}$ State-of-the-Art Supercritical Case 


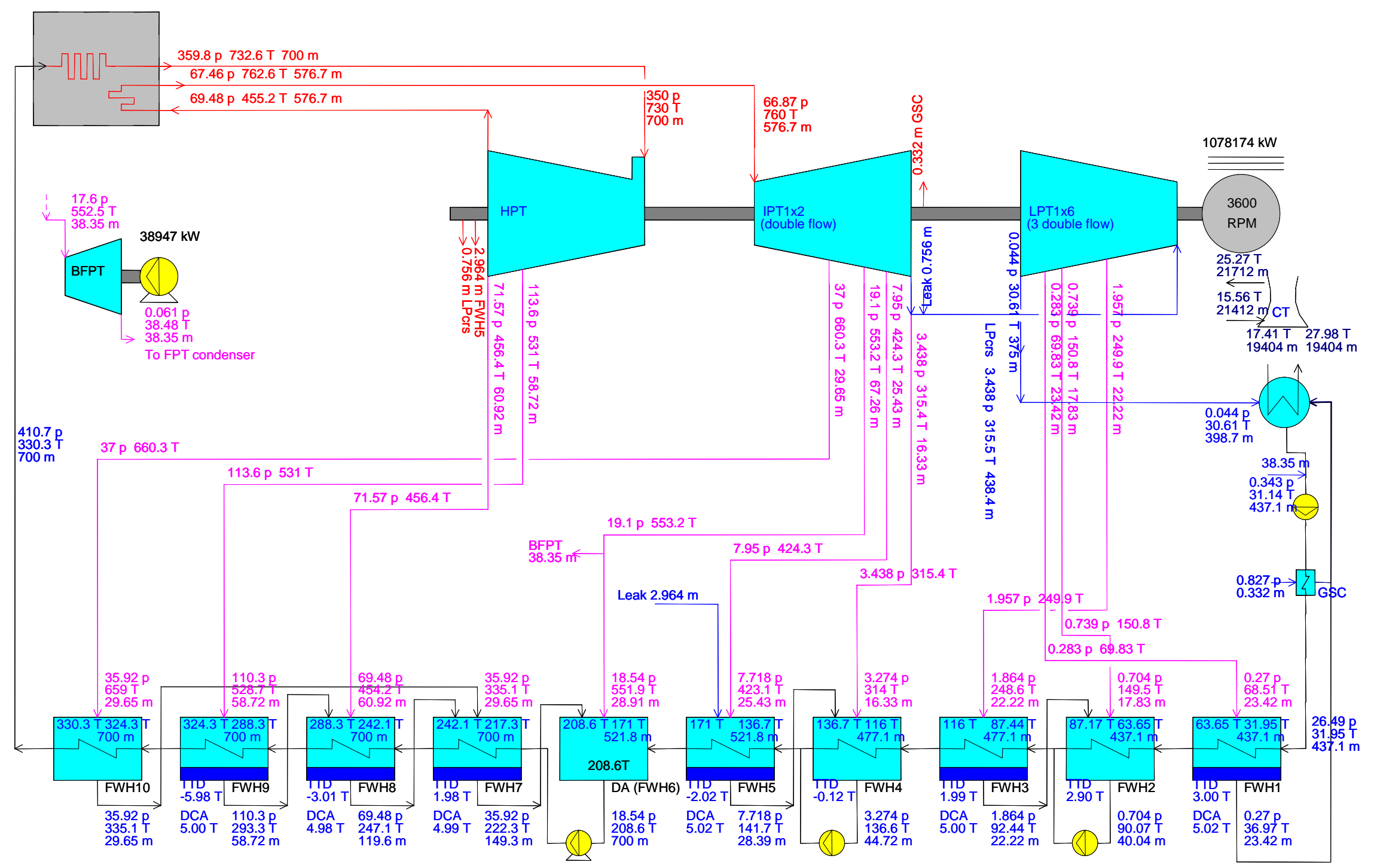

Figure 3-2: Turbine Heat Balance for $730^{\circ} \mathrm{C}$ Ultra-Supercritical Case 


\subsection{Auxiliary Power and Plant Performance Parameter Comparison}

Table 3-2 shows a comparison of plant auxiliary power and Table 3-3 compares various plant performance parameters for the two cases including boiler efficiency, steam cycle efficiency, steam turbine generator output, net plant output, fuel heat input, net plant heat rate, and plant thermal efficiency.

\section{Table 3-2: Plant Auxiliary Power Comparison}

\begin{tabular}{|c|c|c|c|}
\hline & (units) & 600C 258Bar & 730C 350Bar \\
\hline Feedwater Pumps (electrical) & $(\mathrm{kw})$ & $\mathrm{n} / \mathrm{a}$ & $\mathrm{n} / \mathrm{a}$ \\
\hline Main Condensate Extraction Pumps & $(\mathrm{kw})$ & 1,894 & 1,931 \\
\hline Main Cooling Water Pumps & $(\mathrm{kw})$ & 5,967 & 4,992 \\
\hline Secondary Cooling Water Pumps & $(\mathrm{kw})$ & 251 & 210 \\
\hline Closed Circuit Cooling Water Pumps & $(\mathrm{kw})$ & 460 & 385 \\
\hline Cooling Tower Fans & $(\mathrm{kw})$ & 4,103 & 3,433 \\
\hline Forced Draft Fans & $(\mathrm{kw})$ & 2,905 & 2,930 \\
\hline Primary Air Fans & $(\mathrm{kw})$ & 2,340 & 2,360 \\
\hline Induced Draft Fans & $(\mathrm{kw})$ & 12,133 & 12,235 \\
\hline Coal Handling & $(\mathrm{kw})$ & 905 & 912 \\
\hline Pulverizers & $(\mathrm{kw})$ & 3,495 & 3,515 \\
\hline Ash Handling & $(\mathrm{kw})$ & 945 & 953 \\
\hline Limestone Handling & $(\mathrm{kw})$ & 175 & 177 \\
\hline Electrostatic Precipitator & $(\mathrm{kw})$ & 2,087 & 2,105 \\
\hline FGD System & $(\mathrm{kw})$ & 9,964 & 10,049 \\
\hline SCR Auxiliary Power & $(\mathrm{kw})$ & 275 & 277 \\
\hline Boiler Circulation Pumps & $(\mathrm{kw})$ & $\mathrm{n} / \mathrm{a}$ & $\mathrm{n} / \mathrm{a}$ \\
\hline Steam Turbine Auxiliaries & $(\mathrm{kw})$ & 683 & 743 \\
\hline Misc. Aux. Power (Controls, Lighting, HVAC, etc.) & $(\mathrm{kw})$ & 4,121 & 4,121 \\
\hline Transformer Loss & $(\mathrm{kw})$ & 3,963 & 4,313 \\
\hline Total Auxiliary Power Consumption & $(\mathrm{kw})$ & 56,666 & 55,640 \\
\hline Fraction of Gener & (fraction) & 0.057 & 0.052 \\
\hline
\end{tabular}

Table 3-3: Plant Efficiencies and Outputs

Boiler Efficiency (HHV basis)

Steam Cycle Efficiency

Generator Output

Net Plant Output

Fuel Heat Input (HHV basis)

Net Plant Heat Rate (HHV basis)

Thermal Efficiency (HHV basis)

Efficiency improvement (vs 600C 258 Bar)

\begin{tabular}{|c|c|c|}
\hline $\begin{array}{l}\text { (units) } \\
\text { (fraction) }\end{array}$ & $\frac{600 \mathrm{C} 258 \mathrm{Bar}}{0.8707}$ & $\frac{730 \mathrm{C} 350 \mathrm{Bar}}{0.8707}$ \\
\hline (fraction) & 0.4864 & 0.5248 \\
\hline (Btu/kwhr) & 7,017 & 6,503 \\
\hline$(\mathrm{kw})$ & 990,796 & $1,078,173$ \\
\hline$(k w)$ & 934,130 & $1,022,533$ \\
\hline (MM-Btu/hr) & 7,985 & 8,053 \\
\hline (Btu/kwhr) & 8,548 & 7,876 \\
\hline (fraction) & 0.3993 & 0.4334 \\
\hline (\% Points) & 0.00 & 3.41 \\
\hline
\end{tabular}


Figure 3-3 shows a comparison of plant thermal efficiency fractions for both cases and Figure 3-4 shows the thermal efficiency increase (3.41 percentage points) for the ultra-supercritical case $\left(730^{\circ} \mathrm{C} / 350 \mathrm{bar} ; 1,346^{\circ} \mathrm{F} / 5,076 \mathrm{psi}\right)$ relative to the supercritical case $\left(600^{\circ} \mathrm{C} / 258 \mathrm{bar} ; 1,112^{\circ} \mathrm{F}\right.$ / 3,748 psi).

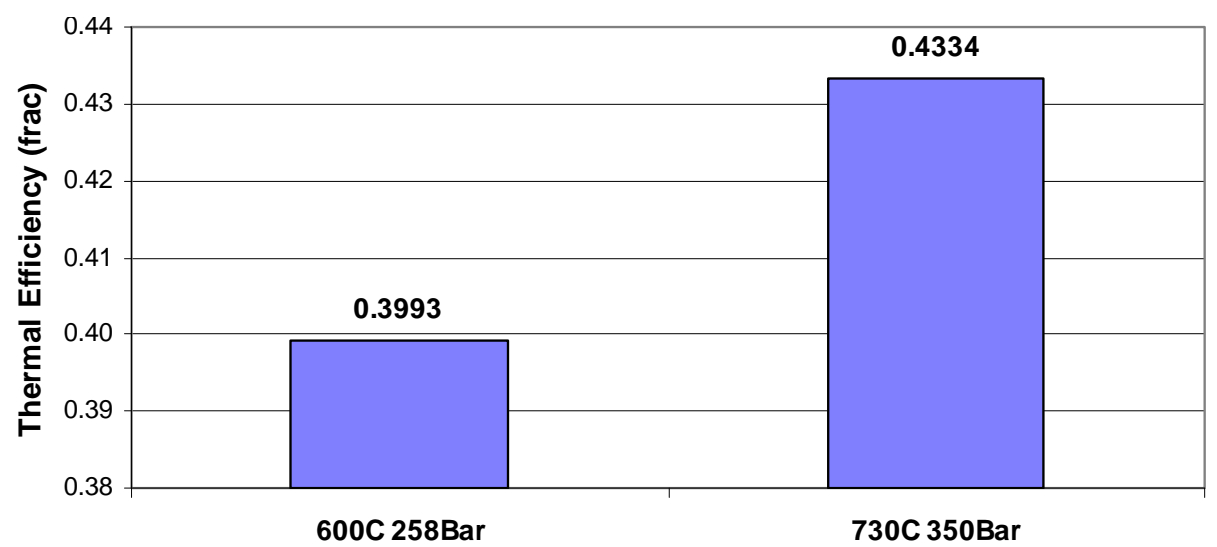

Steam Cycle Parameters

Figure 3-3: Plant Thermal Efficiency Comparison

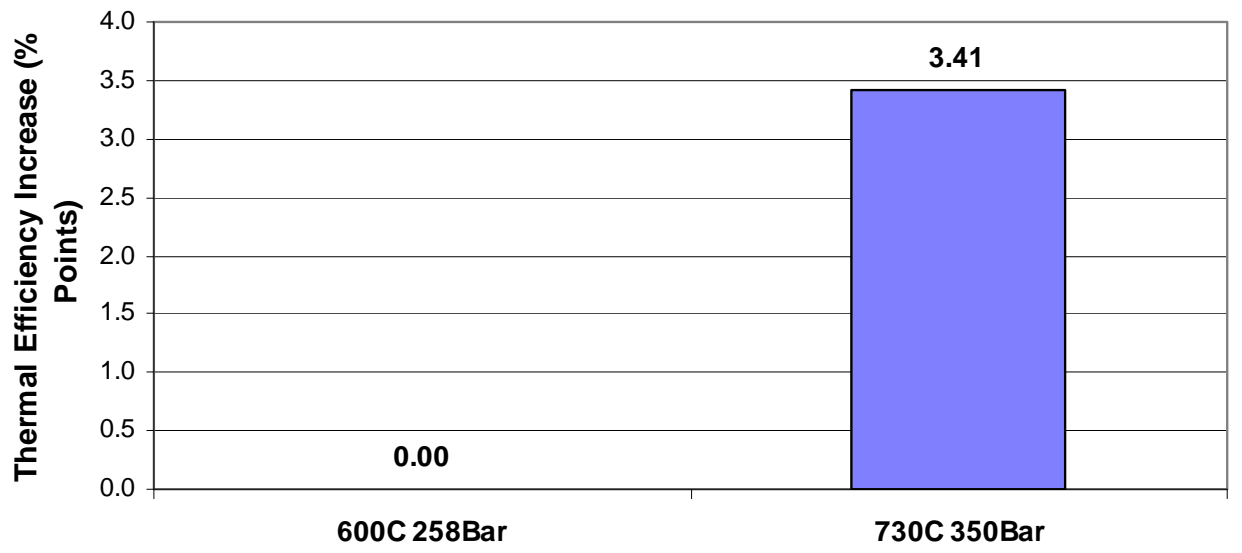

Steam Cycle Parameters

Figure 3-4: Plant Thermal Efficiency Increase (Relative to $600^{\circ} \mathrm{C} 258$ bar Supercritical Case)

In general, as the steam conditions (temperature and pressure) are increased from supercritical to these ultra-supercritical conditions, with constant fuel heat input, an increase in steam turbine output, net plant output, and plant thermal efficiency, of approximately 8 percent is obtained. The plant thermal efficiency increase represents, on an absolute basis, about 3.41 percentage points. The ultra-supercritical steam conditions case offers more than an 8 percent thermal efficiency improvement over a state-of-the-art supercritical design, which also represents more than an 8 percent reduction in $\mathrm{CO}_{2}$ emissions and other criteria pollutants. 


\section{$4 \quad$ Plant Costs}

The plant investment cost estimate summaries, including engineering, procurement, and construction (EPC basis), are shown in this section for the two power plants (a state-of-the-art supercritical plant and an ultra-supercritical plant) included in this study. Two cost estimates are shown for the ultra-supercritical case, one with "high" and one with "low" Ni alloy material costs. A sensitivity study was also done for this variable with one higher Ni alloy cost and intermediate costs. The "low" Ni alloy cost case is included to be representative of the future when costs for these materials, relative to traditional materials will be reduced (see Section 4.1.1).

The EPC basis does not include owner's costs. Owner's costs are however included in the economic analysis (Section 5). Operating and Maintenance costs are also shown in this section. All costs are expressed in mid-2009 dollars.

\subsection{Investment Cost Basis}

Much of the cost data included in this document were estimated based on two very similar cases (Supercritical Case, and Advanced USC Case) included in a previous EPRI study (Wheeldon, 2008). In particular, all the plant costs for the two cases in the current document $\left(600^{\circ} \mathrm{C} / 258\right.$ bar $-1,112^{\circ} \mathrm{F}, 3,748 \mathrm{psi}$; and $730^{\circ} \mathrm{C} / 350$ bar $-1,346^{\circ} \mathrm{F}, 5,076 \mathrm{psi}$ ) were prorated from this previous study except for the Alstom estimated costs for the PC Boiler System, and for the Steam Piping.

It should be pointed out, however, that Wheeldon's Advanced USC Case was designed for a lower main steam temperature $\left(680^{\circ} \mathrm{C} / 350 \mathrm{bar}-1,256^{\circ} \mathrm{F}, 5,076 \mathrm{psi}\right)$ and would require a smaller quantity of high Ni alloys in the construction of the steam turbine. Since the high temperature steam impacts relatively small sections of the steam turbine, for the purpose of this study it was decided to neglect the potential increase in steam turbine cost resulting from the difference in steam temperatures. It was judged that the cost of electricity (COE) due to this increment in cost would not vary significantly to affect the report conclusions.

As such, much of the plant investment cost basis is also the same as was used in this previous EPRI study and the basis is summarized below. These plants are assumed to be constructed on a common Greenfield site in Kenosha, Wisconsin. The boundary limit for these plants includes the complete plant facility within the "fence line". It includes the coal and limestone receiving and water supply systems and terminates at the high-voltage side of the main power transformers.

The EPC costs include all required equipment, including the traditional Boiler Island equipment (PC boiler, draft system, and gas clean-up system), and Balance of Plant equipment (steam turbine generator, condensate and feedwater system, material feed and waste material handling systems, cooling system, electrical system, instrumentation and control, and misc.).

The cost estimates include equipment, materials, labor, indirect construction costs, and engineering.

The PC Boiler costs were estimated based on calculated material weights for all components, conceptual equipment arrangement drawings, and equipment lists that were developed as a part of the conceptual design of the required equipment (Palkes, et al., 2009).

The following assumptions were made in developing the EPC cost estimates for each concept evaluated: 
- Investment costs are expressed in mid-2009 US dollars.

- The plant is constructed on a Greenfield site in Kenosha, Wisconsin.

- Owner's costs (including interest during construction, start-up fuel, land, land rights, plant licensing, permits, etc.) are not included in the investment costs but are included in the economic analysis.

- Ash is to be shipped off site with provisions for short-term storage only.

- Investment in new utility systems is outside the scope.

- No special limitations for transportation of large equipment.

- No protection against unusual airborne contaminants (dust, salt, etc.).

- No unusual windstorms.

- No earthquakes.

- No piling required.

- Annual operating time is 7,008 h/yr (80 percent capacity factor).

- The investment cost estimate was developed as a factored estimate based on a combination of vendor quotes and in-house data for the major equipment.

- No purchases of utilities or charges for shutdown time have been charged against the project.

Other exclusions from the EPC investment cost estimate are as follows:

- Fuels required for startup

- Relocation or removal of buildings, utilities, and highways

- Permits

- Land and land rights

- Soil investigation

- Environmental Permits

- Disposal of hazardous or toxic waste

- Disposal of existing materials

- Custom's and Import duties

- Sales/Use tax

- Forward Escalation

- Capital spare parts

- Chemical loading facilities

- Financing cost

- Owners costs

- Guards during construction

- Site Medical and Ambulance service

- Cost \& Fees of Authorities

- Overhead High voltage feed lines

- Cost to run a natural gas pipeline to the plant

- Excessive piling

Overall plant investment costs and the associated specific plant investment costs ( $\$ / \mathrm{kWe}-\mathrm{net})$ can vary quite significantly for any given plant design depending on several factors. Some of the more important factors are listed below.

- Plant Location and Site Conditions 
- Construction Labor Basis

- Coal Analysis

- Cost of Materials

- Ambient Conditions

For the cases in this study, the design coal analysis, design ambient conditions, plant location and site conditions are described previously in Section 2 under Plant Design Basis.

Each plant was designed for approximately the same coal-firing rate $\left(\sim 8.0 \times 10^{9} \mathrm{Btu} / \mathrm{hr}-\mathrm{HHV}\right.$ Basis). The estimated investment cost for each case includes all major Alstom and vendor supplied components for the complete power plant from coal pile to buss bar. The investment cost was first estimated for the supercritical case $\left(600^{\circ} \mathrm{C} / 258\right.$ bar: $\left.\left.1,112^{\circ} \mathrm{F} / 3,748 \mathrm{psi}\right)\right)$. The plant cost for the two ultra-supercritical cases $\left(730^{\circ} \mathrm{C} / 350 \mathrm{bar} ; 1,346^{\circ} \mathrm{F} / 5,076 \mathrm{psi}\right.$ - "high" and "low" Ni alloy cost) was determined by estimating new absolute costs or cost differences as compared to the supercritical case for the components that required modifications because of changes in system design parameters. These costs were developed consistent with the approach and basis identified in the Plant Design Basis (Section 2).

In estimating the costs for the plants, the following assumptions were made:

- The configuration of components was similar for each plant design and the structure of all buildings remained unchanged.

- The locations of the terminal points for pipe connections to the steam generator were the same for all cases.

- Location of the terminal points for the steam turbines was the same for all cases.

- Electrical components (except for the generator, transformer and large motors) and the instrumentation and controls package remained unchanged for each case.

\subsubsection{Ni Alloy Costs}

Significant quantities of Ni alloys are deployed in the design of the ultra-supercritical boiler and piping. These materials are used for high temperature steam piping, for tubing, headers, and connecting links associated with various heat exchanger sections in the boiler, and in the high temperature areas of the steam turbine. Obtaining reliable and consistent costs of high temperature $\mathrm{Ni}$ alloy tubing and piping became a major challenge. In the past some investigators used costs for IN-617 as high as 100\$/lb. In discussions with suppliers of IN-617 tubing and piping, Alstom has received prices of about \$31/lb and \$41/lb for tubing and piping materials respectively. These prices are very high when compared to traditional alloys deployed in the construction of the state-of-the art plants but were used in the cost estimates. However, it is not clear whether the high costs are the reflection of true costs of future commercial designs or whether the high costs are due to the current limited fabrication capacity. Wheeldon in his EPRI study (Wheeldon, 2008) uses \$28/lb for IN-617 piping.

As would be the case with any emerging new technology, a reduction in $\mathrm{Ni}$ alloy cost, relative to traditional materials, is anticipated as we learn more about large-scale utilization of these materials in the future. This anticipated relative cost reduction is the result of a "learning curve" that commonly occurs because of "learning by doing", process improvements, scale up effects, (increased fabrication capacity) as well as the benefits derived from investments in research and development in this area. 
A good example of this "learning curve" in the power industry is the reduction in the cost of $\mathrm{SO}_{2}$ scrubbers as more and more capacity was installed. The literature (Rubin, et. al, 2004) shows a decrease in $\mathrm{SO}_{2}$ scrubber system capital cost (using a common basis comparison) of about 11 percent for each doubling in installed capacity. Another example, also cited in the same work, is for selective catalytic reduction systems (SCR). In these systems, the decrease in SCR system capital cost is about 12 percent for each doubling in installed capacity. Learning rates of this magnitude (11-12 percent) are fairly typical for a broad array of energy technologies (McDonald, et. al., 2002) and this is anticipated to also happen with the future deployment of high temperature Ni alloys.

Because of this, two cost estimates were developed for the ultra-supercritical case, one using "high" and one using "low" Ni alloy costs as defined in Table 4-1. This table shows the material costs used for steam piping and tubing in the current study. The left side of the table shows the "high" values and the right side shows the "low" values. The upper part of the table shows the material costs for traditional materials and the last row shows the material costs used for IN-617. The costs of other high Ni alloys not shown in Table 4-1 were prorated on the basis of costs of the individual elements contained within the alloys. Costs for the traditional materials are not changed for these two scenarios.

Table 4-1: Steam Piping \& Tubing Material Costs

"High" Ni Alloy Costs

\begin{tabular}{|c|c|c|c|}
\hline \multicolumn{2}{|c|}{ Piping Material Costs } & \multicolumn{2}{c|}{ Tubing Material Costs } \\
\hline Mat'I & $\mathbf{( \$ / l b m )}$ & Mat'I & $\$ / \mathbf{l b m}$ \\
\hline $106 \mathrm{C}$ & $\$ 2.68$ & $210 \mathrm{C}$ & $\$ 0.76$ \\
\hline P12 & $\$ 2.81$ & $\mathrm{~T} 12$ & $\$ 1.21$ \\
\hline P23 & $\$ 3.80$ & $\mathrm{~T} 23$ & $\$ 2.08$ \\
\hline P91 & $\$ 6.43$ & $\mathrm{~T} 91$ & $\$ 2.70$ \\
\hline P92 & $\$ 7.76$ & T92 & $\$ 3.26$ \\
\hline & & $304 S \mathrm{~S}$ & $\$ 4.10$ \\
\hline & & $347 \mathrm{SS}$ & $\$ 5.00$ \\
\hline & & $\mathrm{S} 304 \mathrm{SS}$ & $\$ 9.09$ \\
\hline & & & \\
\hline 617 & $\$ 41$ & 617 & $\$ 31$ \\
\hline
\end{tabular}

\section{“Low” Ni Alloy Cost}

\begin{tabular}{|c|c|c|c|}
\hline \multicolumn{2}{|c|}{ Piping Material Costs } & \multicolumn{2}{c|}{ Tubing Material Costs } \\
\hline Mat'I & $\mathbf{( \$ / l b m )}$ & Mat'I & $\$ / \mathbf{l b m}$ \\
\hline $106 \mathrm{C}$ & $\$ 2.68$ & $210 \mathrm{C}$ & $\$ 0.76$ \\
\hline P12 & $\$ 2.81$ & $\mathrm{~T} 12$ & $\$ 1.21$ \\
\hline P23 & $\$ 3.80$ & $\mathrm{~T} 23$ & $\$ 2.08$ \\
\hline P91 & $\$ 6.43$ & $\mathrm{~T} 91$ & $\$ 2.70$ \\
\hline P92 & $\$ 7.76$ & T92 & $\$ 3.26$ \\
\hline & & $304 S \mathrm{~S}$ & $\$ 4.10$ \\
\hline & & $347 \mathrm{SS}$ & $\$ 5.00$ \\
\hline & & $\mathrm{S} 304 \mathrm{SS}$ & $\$ 9.09$ \\
\hline & & & \\
\hline 617 & $\$ 16$ & 617 & $\$ 12$ \\
\hline
\end{tabular}

Material costs for tubing and piping are different with piping costs being significantly higher than for tubing due to a higher cost of piping fabrication and lower capacity for the mills. The ratio between the costs of tubing to piping for other high $\mathrm{Ni}$ alloys was assumed to be the same as for IN-617.

\subsubsection{Steam Piping Costs}

Steam piping is used to transport the high temperature, high-pressure superheated steam leaving the boiler superheater section to the HP steam turbine. Steam piping is also used to return the exhaust steam leaving the HP turbine to the boiler for reheating. The reheated steam is then transported from the boiler reheater section to the IP turbine with additional high temperature steam pipes.

Steam piping is also used within the boiler for connecting links between various heat exchanger sections and for steam headers where the heat exchanger tubes are connected. The costs of these 
link and header components are included within the PC Boiler cost account.

Steam piping costs were calculated based on "high" and "low" Ni alloy material costs shown in Table 4-1. Procedures obtained from similar previous EPRI work (Wheeldon, 2008) were applied to obtain EPC based costs for steam piping. The procedures were used to add additional costs to the Steam Piping account to include fabrication, installation, construction management, and contingency such that an EPC cost basis was used. Piping lengths were calculated using a typical arrangement for plants of this size.

\subsection{Investment Cost Results}

The total plant investment cost breakdown for the plants is summarized in Table 4-2. Two cases are shown for the ultra-supercritical case, one with "high" and one with "low" Ni alloy costs (see Table 4-1). The reason for showing two costs for the ultra-supercritical case is explained previously in Section 4.1.1.

Table 4-2: Plant Investment Cost Breakdown

\begin{tabular}{|c|c|c|c|c|c|c|c|}
\hline \multirow[b]{4}{*}{ Acct No. } & \multirow[b]{4}{*}{ Account Description } & & & \multicolumn{4}{|c|}{ Ni Alloy Material Cost } \\
\hline & & & & \multirow{2}{*}{\multicolumn{2}{|c|}{$\begin{array}{c}\text { "High" } \\
\text { 730C 350Bar }\end{array}$}} & \multirow{2}{*}{\multicolumn{2}{|c|}{$\begin{array}{c}\text { "Low" } \\
\text { 730C 350Bar }\end{array}$}} \\
\hline & & \multicolumn{2}{|c|}{ 600C 258Bar } & & & & \\
\hline & & $\mathrm{K} \$$ & $\$ / \mathrm{kWe}$ & $\mathrm{K} \$$ & $\$ / \mathrm{kWe}$ & $\mathrm{K} \$$ & $\$ / \mathrm{kWe}$ \\
\hline 1 & Coal \& Sorbent Handling & 79,455 & 85 & 80,127 & 78 & 80,127 & 78 \\
\hline 2 & Coal \& Sorbent Preparation \& Feed & 34,820 & 37 & 35,114 & 34 & 35,114 & 34 \\
\hline 3 & Feedwater \& Miscelaneuos BOP Systems & 128,785 & 138 & 138,079 & 135 & 138,079 & 135 \\
\hline 4 & PC Boiler & 537,864 & 576 & 780,083 & 763 & 688,476 & 673 \\
\hline 5 & Flue Gas Cleanup & 214,308 & 229 & 216,119 & 211 & 216,119 & 211 \\
\hline 7 & Ducting \& Stack & 85,617 & 92 & 86,340 & 84 & 86,340 & 84 \\
\hline $8-8.4-8.3 a$ & Steam Turbine Generator & 139,345 & 149 & 183,851 & 180 & 183,851 & 180 \\
\hline 8.4 & Steam Piping & 51,457 & 55 & 211,418 & 207 & 173,534 & 170 \\
\hline $8.3 a$ & Condenser & 16,072 & 17 & 13,446 & 13 & 13,446 & 13 \\
\hline 9 & Cooling Water System & 52,289 & 56 & 43,747 & 43 & 43,747 & 43 \\
\hline 10 & Ash \& Spent Sorbent Handling System & 19,711 & 21 & 19,877 & 19 & 19,877 & 19 \\
\hline 11 & Accessory Electrical Plant & 107,437 & 115 & 117,605 & 115 & 117,605 & 115 \\
\hline 12 & Instrumentation \& Control & 39,968 & 43 & 40,305 & 39 & 40,305 & 39 \\
\hline 13 & Improvements to Site & 27,552 & 29 & 27,785 & 27 & 27,785 & 27 \\
\hline 14 & Buildings \& Structures & 107,261 & 115 & 108,167 & 106 & 108,167 & 106 \\
\hline & Total Plant Cost @ Constant Fuel Ir & $1,641,940$ & 1,758 & $2,102,063$ & 2,056 & $1,972,572$ & 1,929 \\
\hline & Total Plant Cost @ 1,000 MWe Net Output & $1,733,930$ & 1,734 & $2,064,923$ & 2,065 & $1,937,719$ & 1,938 \\
\hline
\end{tabular}

In Figure 4-1, the specific costs have been grouped into five categories for each plant. The five categories are as listed below:

1. PC Boiler System

2. Turbine Island

3. Steam Piping

4. Flue Gas Cleanup System

5. Balance of Plant

The PC Boiler System category includes only Account 4 from Table 4-2. The Turbine Island category includes Account 3 (Feedwater System), Account 9 (Cooling Water System), and most 
of Account 8 (Steam Turbine Generator) including Account 8.3a (Condenser), and excludes Account 8.4 (Steam Piping). The Steam Piping category includes only Account 8.4 (part of Account 8). The Flue Gas Cleanup System category includes Account 5 (Flue Gas Cleanup) and Account 7 (Ducting And Stack). The Balance of Plant category comprises all remaining Accounts (1, 2, 10,11, 12, 13, and 14), which comprises the Fuel, Sorbent, and Ash Systems, as well as Electrical, Instrument \& Control, Site Improvements, and Buildings \& Structures. While the plants were designed with the same firing rate, many of the Balance of Plant (category 5) accounts actually had lower specific and actual costs because they encompass parts of the flue gas clean-up and because the higher efficiency plant had a greater net output.

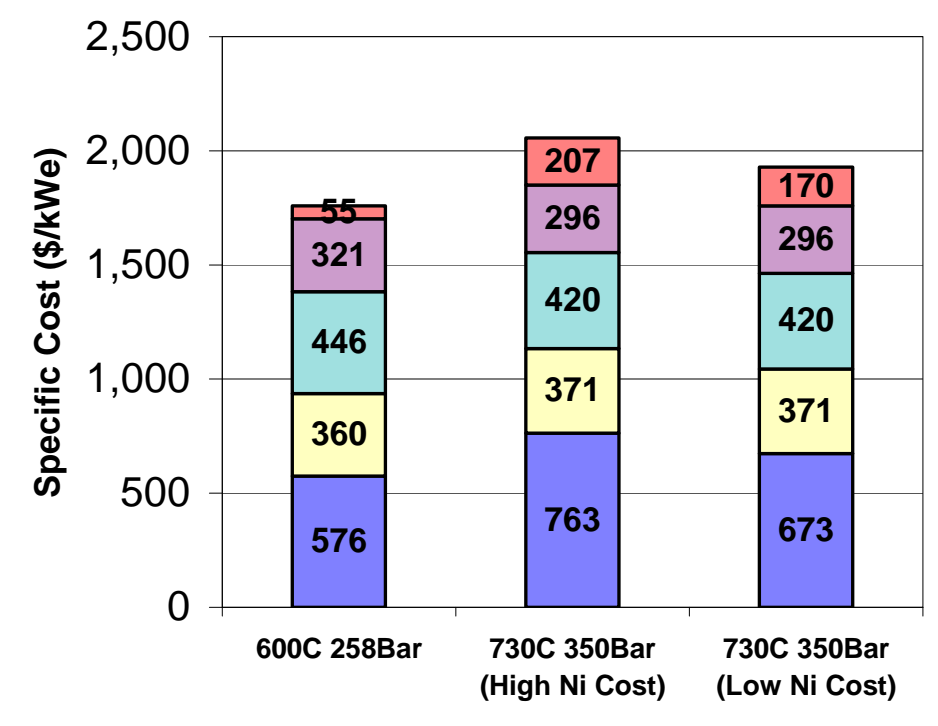

Steam Piping (Superheater Oultet Leads, Reheater Outlet \& Inlet Leads, Other piping)

$\square$ Flue Gas Cleanup System, Ducting \& Stack

Balance of Plant (Coal \& Sorbent Handling, Prep \& Feed, Ash Sys, Acc Elec Sys, I\&C, Site Impr, Bldg \& Strc).

$\square$ Turbine Island (Turbine/Generator, Feedwater System, Condenser, Cooling Water System) $\square$ PC Boiler System

Figure 4-1: Plant Investment Cost Breakdown

Figure 4-2 and Table 4-2 show how the high temperature Ni alloy usage for the ultrasupercritical case significantly increases the cost for the PC Boiler System, Steam Piping, and to a lesser extent, Turbine Island. They also show how the specific costs are decreased for the Flue Gas Cleanup System and Balance of Plant groups.

The PC Boiler System (Account 4), which represents the single largest account in all cases, increases in specific cost $(\$ / \mathrm{kWe})$ by about 17-32 percent for the ultra-supercritical case, depending on $\mathrm{Ni}$ alloy cost. The conceptual boiler design for the ultra-supercritical case is described in detail in an associated document (Palkes, et al., 2009).

The Steam Piping (Account 8.4) increases in specific cost ( $\$ / \mathrm{kWe}$ ) by more than triple to almost quadruple (310-376 percent) for the ultra-supercritical cases, depending on Ni alloy cost. This represented the largest percentage increase by far for the five categories selected.

The Steam Turbine Island also increases in cost but not as significantly (about 3 percent). The cost of the Steam Turbine Generator component itself increased by about 32 percent but this was 
partially offset by a reduction in costs in the other accounts included within the Steam Turbine Island grouping. In particular, the Cooling Water System (condenser, cooling tower, circulation system, etc.), which rejects about 17 percent less heat, is proportionally lower in cost for the ultra-supercritical plant.

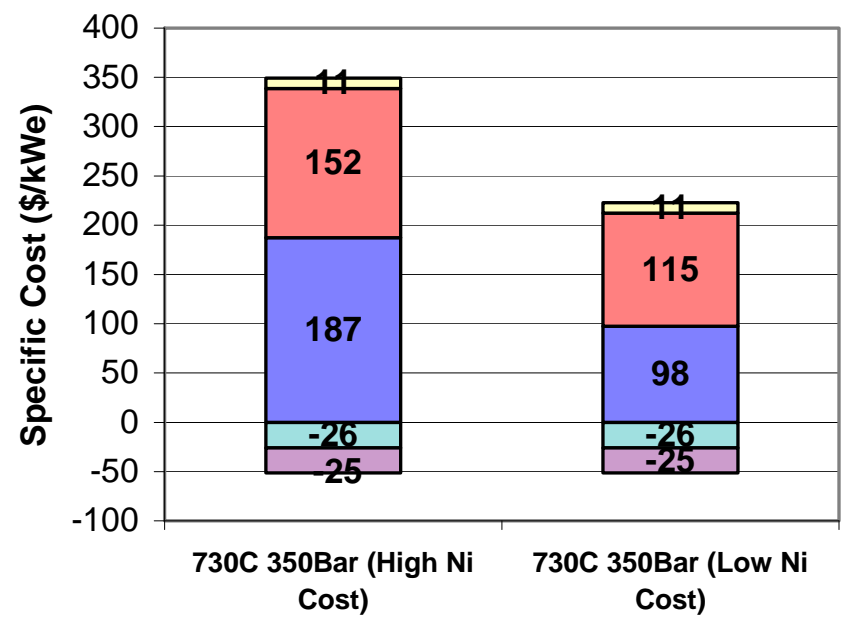

Figure 4-2: Plant Investment Cost Increase Breakdown for the Ultra-supercritical Case (Relative to $600^{\circ} \mathrm{C} 258$ bar Supercritical Case)

The specific costs (\$/kWe-net) for the Flue Gas Cleanup System and other Balance of Plant cost groups both decreased by about 8 and 6 percent respectively due to the higher net plant output for the ultra-supercritical case.

Figure 4-3 shows the total plant investment costs for both the constant fuel input basis ( $\sim 8 \mathrm{x}$ $10^{9} \mathrm{Btu} / \mathrm{hr}-\mathrm{HHV}$ Basis) and for the constant net plant output basis (1,000 MWe-net). The ultrasupercritical plant specific cost is shown to be about 12-19 percent higher than the state-of-theart supercritical case, depending on Ni alloy cost, using the constant net plant output basis. 


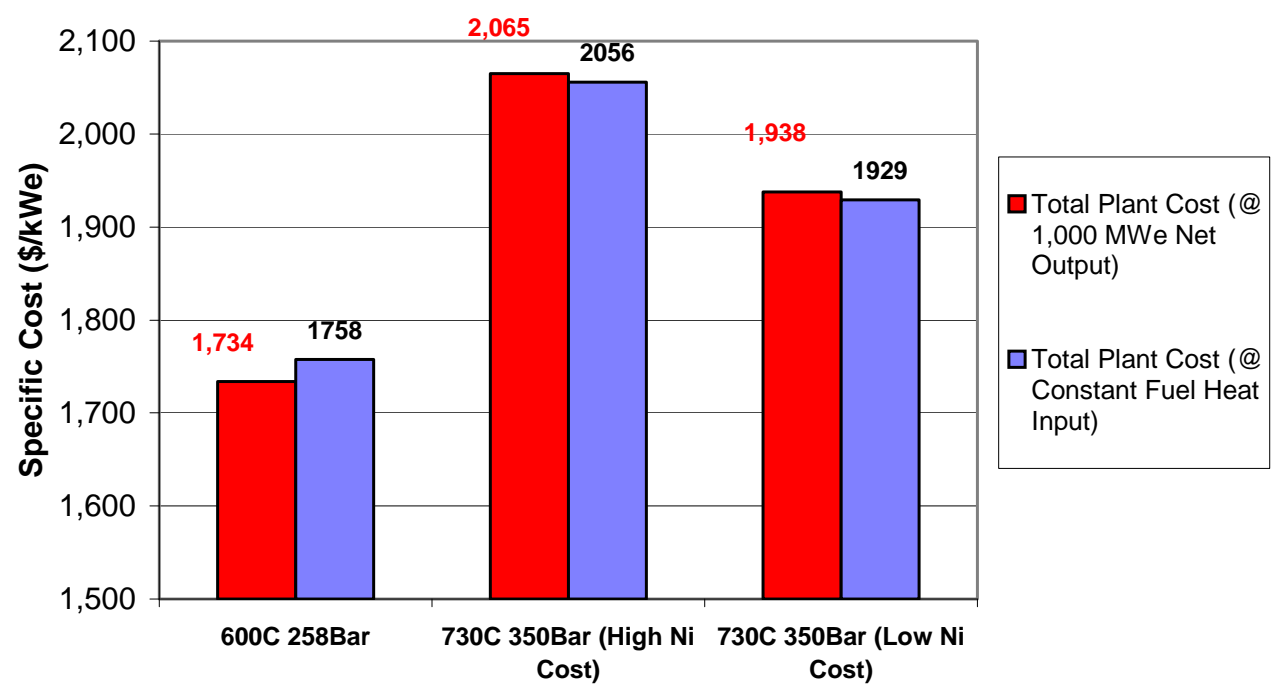

Figure 4-3: Total Plant Investment Costs

\subsection{Operating and Maintenance Costs}

The operating costs and related maintenance expenses (O\&M) pertain to those charges that are associated with operating and maintaining the power plants over their expected life. These costs include the following components:

- Operating labor

- Maintenance - material and labor

- Administrative and support labor

- Consumables

- Fuel

- Waste disposal

In this study fuel costs were accounted for separately and therefore they were not included in the O\&M cost account.

The O\&M costs are typically broken into two components: fixed O\&M, which is independent of the amount of power generation, and variable O\&M, which is directly proportional to the amount of power generation.

A very simplified procedure was used in this study for calculating the operating and maintenance (O\&M) costs. The total annual O\&M costs (fixed + variable) for each case were assumed to be 4 percent of the total plant EPC investment costs. This percentage accounts for both the fixed and the variable components of the total O\&M costs. The 4 percent factor has traditionally been a reasonable approximation of the value a more rigorous O\&M calculation would yield and keeping it the same percentage for the ultra-supercritical case represents a conservative assumption. 


\section{$5 \quad$ Plant Economics}

An economic evaluation comparing these Rankine cycle power plants was performed as part of this study. The purpose of the evaluation was to quantify the impact of ultra-supercritical steam cycle conditions on the Cost of Electricity (COE) as compared to a state-of-the-art supercritical plant. Previously specified costs of high Ni alloys were used in the ultra-supercritical case.

The economic evaluation results are presented in terms of Cost of Electricity (levelized basis). Dispatch costs are also discussed. Additionally, various economic sensitivity analyses were also completed for these cases.

\subsection{Economic Analysis Assumptions}

Numerous financial assumptions were required in performing the economic evaluations. Some of the more important parameters are plant capacity factor, fuel cost, and capital charge rate. Table 5-1 summarizes the primary financial assumptions used in the simplified economic model.

Table 5-1: Primary Economic Assumptions

\begin{tabular}{|r|r|l||}
\hline Fuel Cost & $\mathbf{1 . 8}$ & (\$/MM-Btu) \\
Capital Charge Rate & $\mathbf{0 . 1 4}$ & (fraction) \\
Annual Operating Time & $\mathbf{7 0 0 8}$ & (Hrs/yr) \\
O\&M Cost & $\mathbf{0 . 0 4}$ & (frac of inv/yr) \\
\hline
\end{tabular}

Levelized cost of electricity (COE) was used as one criterion to compare the systems in this study. The cost of electricity consists of the following four components: financial, fuel, fixed $\mathrm{O} \& \mathrm{M}$, and variable O\&M . The financial component of the COE represents the costs which are associated with payment of the original engineered, procured and constructed (EPC) price of the power plant, all associated owner's costs, custom's and financing fees, and interests accrued both during construction and during operation. A 30-year plant life was used in this study. The fuel cost component of the COE represents the cost of the fuel, which is consumed by a given plant. The fixed O\&M component represents the costs that occur regardless of whether the unit is in operation or not. The variable O\&M component of the COE represents the incremental costs, which occur when the unit is in operation.

\subsection{Economic Analysis Results}

The economic analysis results for these PC-fired steam power plants are discussed in this section. The case studies are compared using levelized cost of electricity (COE) evaluation criterion. Table 5-2 shows the economic results for the plants using the base economic assumptions defined above. The first row of the table shows the supercritical case results. Two cases are shown for the ultra-supercritical case, one with "high" Ni alloy costs $\left(2^{\text {nd }}\right.$ row) and one with "low" Ni alloy costs ( $3^{\text {rd }}$ row). The Ni alloy cost was also used as one of the variables for the sensitivity studies as discussed later in Section 5.3.1. 
Table 5-2: Basic Economic Results

\begin{tabular}{|c|c|c|c|c|c|c|c|c|c|c|}
\hline \multirow[b]{2}{*}{ Case } & \multicolumn{3}{|c|}{ Efficiency } & \multirow{2}{*}{$\begin{array}{c}\text { EPC Cost } \\
\text { Investment Costs, } \\
\$ / k W\end{array}$} & \multicolumn{6}{|c|}{ Cost of Electricity (COE) } \\
\hline & $\begin{array}{l}\text { Plant Thermal } \\
\text { Efficiency }\end{array}$ & $\begin{array}{c}\text { NPHR } \\
\text { (Btu/kwhr) }\end{array}$ & $\begin{array}{l}\text { CO2 Emitted } \\
\text { (lbm/kwhr) }\end{array}$ & & $\begin{array}{c}\text { Fuel } \\
\text { (Cents/kwhr) }\end{array}$ & $\begin{array}{c}\text { Capital } \\
\text { (Cents/kwhr) }\end{array}$ & $\begin{array}{c}\text { O\& M } \\
\text { (Cents/kwhr) }\end{array}$ & $\begin{array}{c}\mathrm{CO} 2 \\
\text { (Cents/kwhr) }\end{array}$ & $\begin{array}{c}\text { Total } \\
\text { (Cents/kwhr) }\end{array}$ & Relative COE \\
\hline 600C 258Bar & 39.93 & 8548 & 1.82 & 1734 & 1.54 & 3.39 & 0.99 & 0.00 & 5.91 & 1.00 \\
\hline 730C 350Bar (High Ni Cost) & 43.34 & 7876 & 1.67 & 2065 & 1.42 & 4.03 & 1.18 & 0.00 & 6.63 & 1.12 \\
\hline 730C 350Bar (Low Ni Cost) & 43.34 & 7876 & 1.67 & 1938 & 1.42 & 3.78 & 1.11 & 0.00 & 6.31 & 1.07 \\
\hline
\end{tabular}

Figure 5-1 shows the COE results for the supercritical case on the left and on the right the ultrasupercritical cases. As mentioned, the ultra-supercritical case is shown for two Ni alloy costs. These results show that the $\mathrm{COE}$ increase for the $730^{\circ} \mathrm{C}\left(1,346^{\circ} \mathrm{F}\right)$ ultra-supercritical case could range from about 7-12 percent higher than for the supercritical case using the primary economic assumptions shown in Table 5-1.

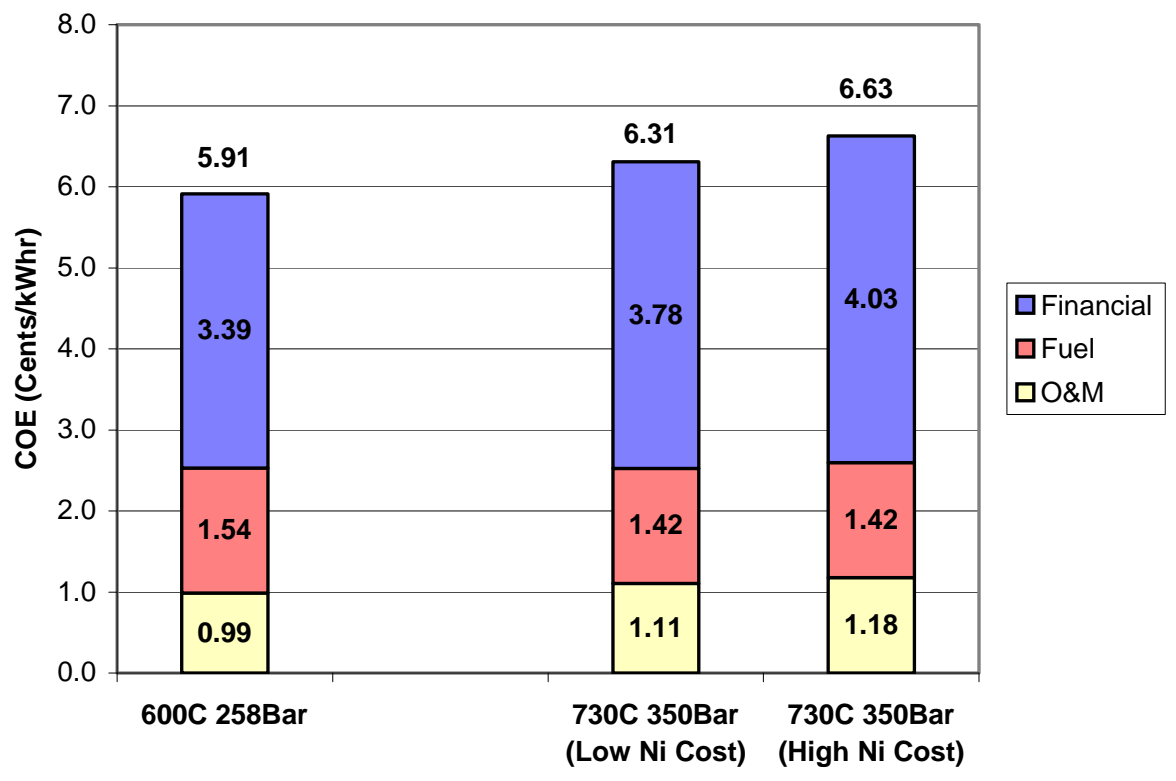

Figure 5-1: Cost of Electricity Breakdown Comparison

The ultra-supercritical case realizes about an 8 percent advantage in the fuel cost component of $\mathrm{COE}$ as compared to the supercritical case, which will provide a lower dispatch cost. However, the fuel cost advantage is overcome by about a 12-19 percent increase in both the financial and O\&M components of COE for the ultra-supercritical case. The total COE for the ultrasupercritical case is about 7-12 percent higher than the supercritical case. 


\subsection{Economic Sensitivity Studies}

This section reports the results for several sensitivity studies done for these cases. Economic sensitivity studies were done to investigate the effects of variations in several important parameters as listed below:

- Ni Alloy Material Cost

- Coal Cost

- Capacity Factor

- $\mathrm{CO}_{2}$ Allowance Price

\subsubsection{Economic Sensitivity Study (High Temperature Nickel Alloy Material Cost)}

$\mathrm{Ni}$ alloys are used in the ultra-supercritical power plant for high temperature steam piping, headers, tubing for heat exchangers within the boiler, and in the steam turbine. As mentioned previously, currently, it is difficult to obtain reliable, consistent cost data for high temperature $\mathrm{Ni}$ alloys. Because of anticipated reductions in Ni alloy costs relative to traditional materials (see Section 4.1.1) a sensitivity study was conducted with respect to high temperature Ni alloy material cost variations. Results of changes in high temperature Ni alloy material cost for several plant cost items (listed below) are reported.

- Boiler Cost

- Steam Piping Cost

- Total Plant Cost

- Cost of Electricity

The tubing material costs used in this sensitivity study for Ni alloy IN-617 were about 12, 19, 24, 31 , and $43 \$ / \mathrm{lb}$. The material costs for the other Ni alloys were also changed by the same percentages as for alloy IN-617. The $43 \$ / 1 b$ value is about 40 percent higher than the material cost shown previously for alloy IN-617 in Table 4-1 shown in Section 4.2. Ni alloy piping material costs were also adjusted proportionally.

Figure 5-2 shows the basic results of this Ni alloy material cost sensitivity study. The $\mathrm{x}$-axis of all the plots shown in Figure 5-2 shows the material costs for alloy IN-617 tubing. The material costs for all other $\mathrm{Ni}$ alloys used were also changed by the same percentages in this sensitivity study.

Also shown on these plots is the supercritical case $\left(600^{\circ} \mathrm{C} / 258\right.$ bar; $\left.1,112^{\circ} \mathrm{F} / 3,748 \mathrm{psi}\right)$ for reference only. The cost of the supercritical case does not change as a function of the cost of $\mathrm{Ni}$ alloy since this plant does not utilize these materials.

For the ultra-supercritical case, all the cost categories investigated in these graphs (Boiler Cost, Steam Piping Cost, Total plant Cost, and Cost of Electricity) are shown to be quite sensitive to high temperature Nickel alloy material cost. With $\mathrm{Ni}$ alloy material costs at the low end of the range, Boiler Cost is reduced by about 12 percent, Steam Piping cost is reduced about 18 percent, Total Plant cost about 6 percent and COE by about 5 percent. If, in combination with the reduced Ni alloy cost, a $\mathrm{CO}_{2}$ allowance price of about 55\$/ton is used, the COE for the ultrasupercritical case is equivalent to the supercritical case. 
Boiler Costs

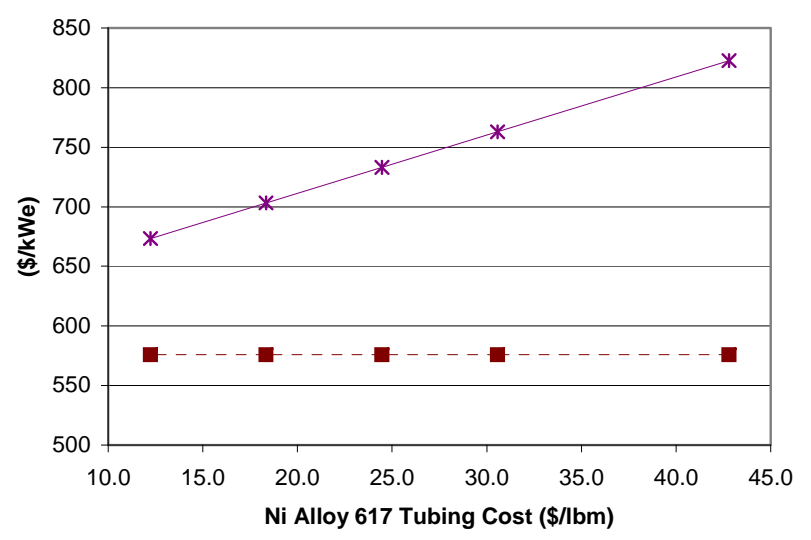

Steam Piping Costs

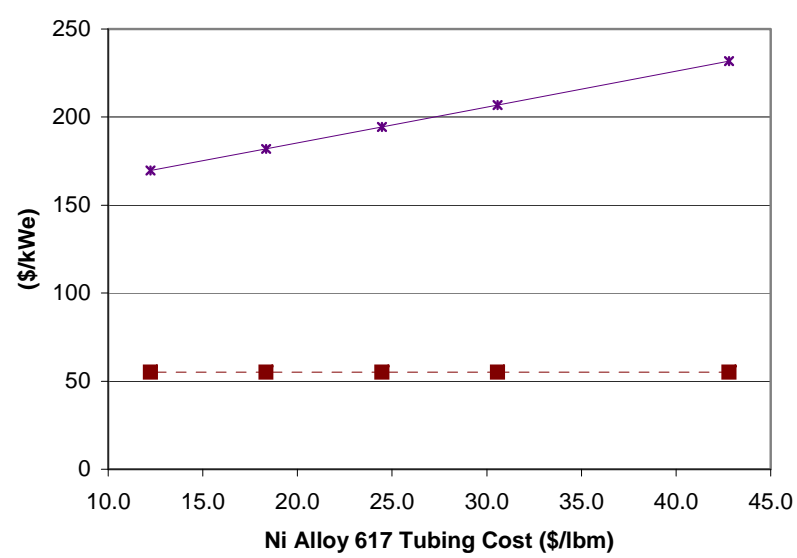

Total Plant Costs

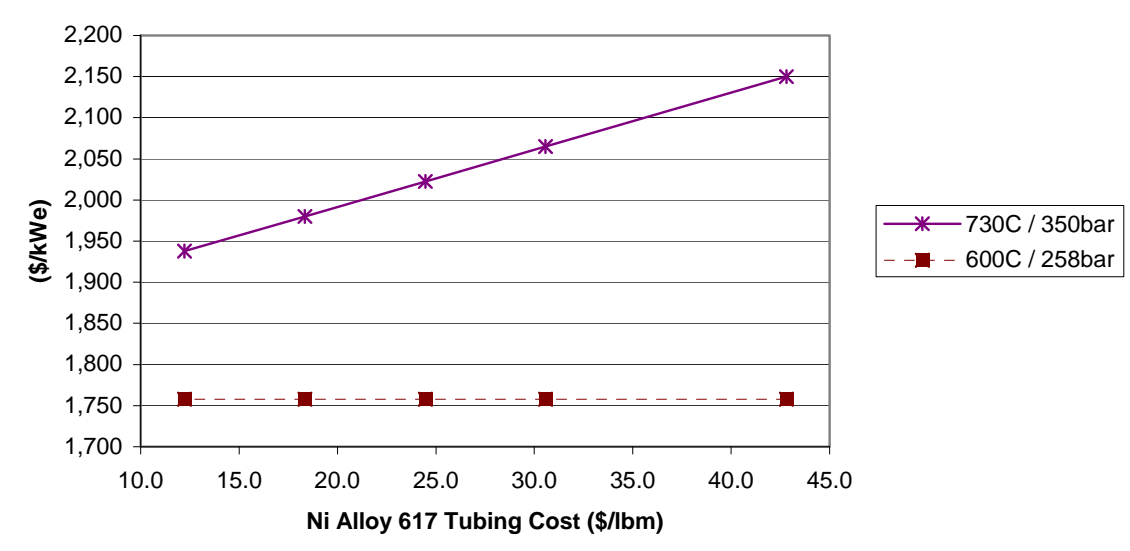

Cost of Electricity

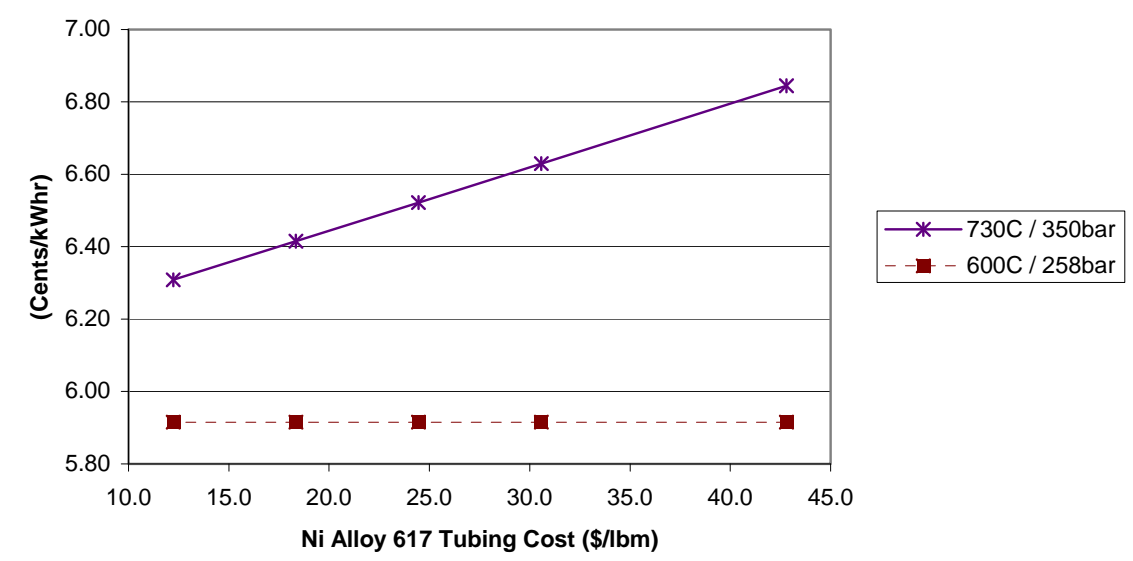

Figure 5-2: Economic Sensitivity Study (Ni Alloy Cost) 


\subsubsection{Economic Sensitivity Study with "High" Ni Alloy Cost (Coal Cost, Capacity Factor, $\mathrm{CO}_{2}$ Allowance Price)}

This sensitivity study shows results with Ni alloy costs at the "high" end of the range (see Table 4-1). Various sensitivity analyses were conducted for these cases to determine the effect on COE of variation of selected base parameter values. The varied parameter ranges are Coal Cost ( +150 , - 50 percent), Capacity Factor (90, 80, and 70 percent), and $\mathrm{CO}_{2}$ Allowance Price (0-100 $\$ /$ ton $\mathrm{CO}_{2}$ emitted). Figure 5-3 shows the results of these variations with $\mathrm{Ni}$ alloy material costs at the "high" end of the range (i.e. IN-617 tubing 31 \$/lb). As shown, the ultra-supercritical $\left(730^{\circ} \mathrm{C} ; 1,346^{\circ} \mathrm{F}\right)$ plant $\mathrm{COE}$ ranges from equivalent $\left(\mathrm{CO}_{2}\right.$ allowance price $=100 \$$ /ton $)$ to 15 percent higher $\left(\right.$ Coal Cost $=0.90 \$ / \mathrm{MM}$-Btu) than the supercritical plant $\left(600^{\circ} \mathrm{C} ; 1,112^{\circ} \mathrm{F}\right)$ for the scenarios investigated. The following list indicates various scenarios where the COE's are equivalent or better than the supercritical case.

- $\mathrm{COE}_{730^{\circ} \mathrm{C}}=1.0 \times \mathrm{COE} 600^{\circ} \mathrm{C}$ with Coal Cost $=1.8 \$ / \mathrm{MM}-\mathrm{Btu}$, Capacity Factor $=80 \%, \mathrm{CO}_{2}$ allowance price $=100 \$ /$ ton

- $\operatorname{COE} 730^{\circ} \mathrm{C}=0.98 \times \mathrm{COE}_{600^{\circ} \mathrm{C}}$ with Coal Cost $=4.5 \$ / \mathrm{MM}-\mathrm{Btu}$, Capacity Factor $=90 \%, \mathrm{CO}_{2}$ Allowance Price $=100 \$ /$ ton

- $\operatorname{COE} 730^{\circ} \mathrm{C}=1.0 \times$ COE $600^{\circ} \mathrm{C}$ with Coal Cost $=4.5 \$ / \mathrm{MM}-\mathrm{Btu}$, Capacity Factor $=90 \%, \mathrm{CO}_{2}$ Allowance Price $=62 \$ /$ ton 

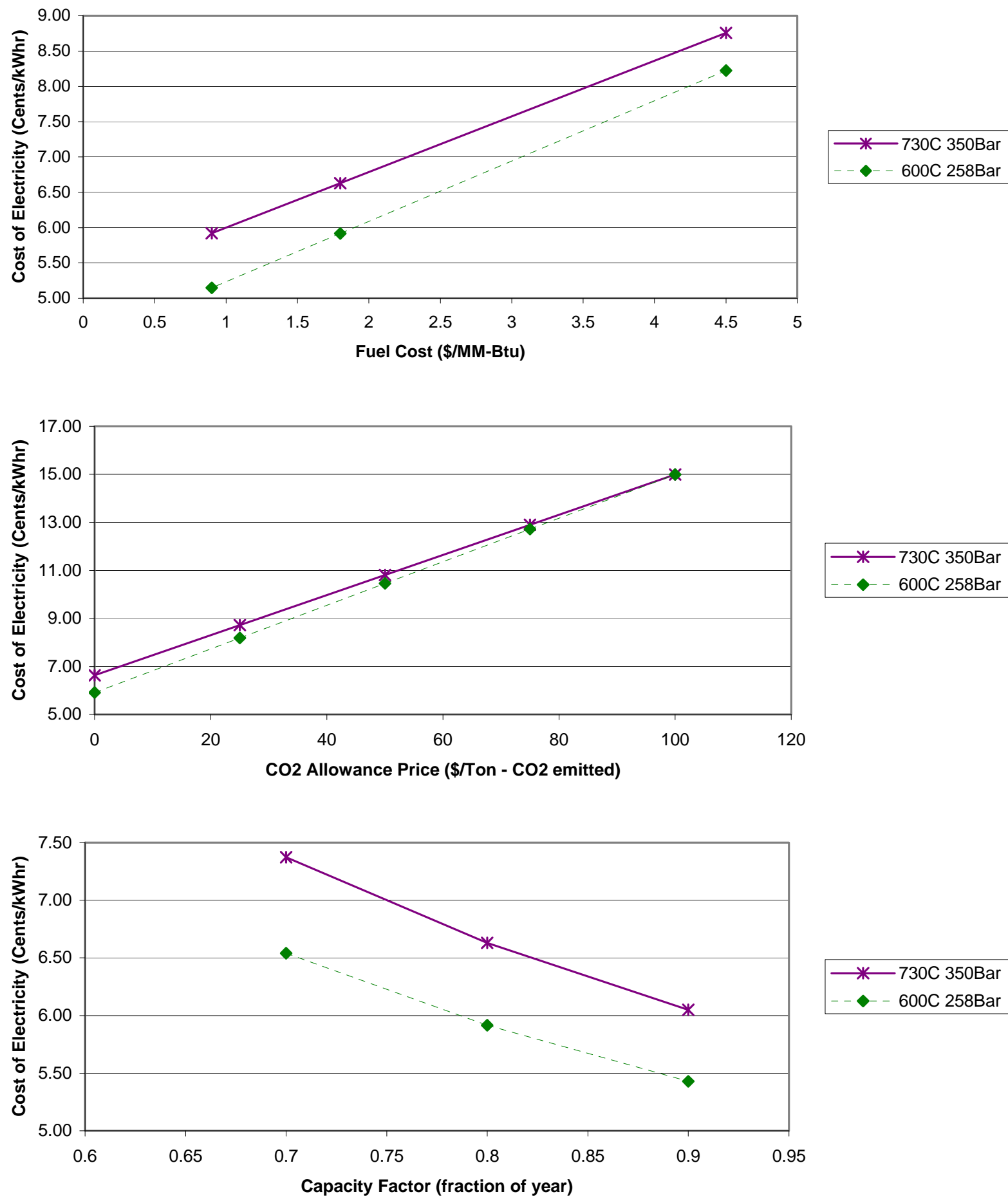

Figure 5-3: Economic Sensitivity Study with "High" Ni Alloy Cost (Coal Cost, $\mathrm{CO}_{2}$ Allowance Price, Capacity Factor) 


\subsubsection{Economic Sensitivity Study with "Low" Ni Alloy Cost (Coal Cost, Capacity Factor, $\mathrm{CO}_{2}$ Allowance Price)}

This sensitivity study was completed with Ni alloy cost at the "low" end of the cost range with IN-617 tubing at $\sim 12 \$ / l b$ (see Table $4-1$ ). The sensitivity variables are Coal Cost, Capacity Factor and $\mathrm{CO}_{2}$ Allowance Price. Figure 5-5 shows these results. The varied parameters ranges are Coal Cost (+150, - 50 percent), Capacity Factor (90, 80, and 70 percent), and $\mathrm{CO}_{2}$ Allowance Price (0-100 \$/ton $\mathrm{CO}_{2}$ emitted). As shown, the ultra-supercritical $\left(730^{\circ} \mathrm{C} ; 1,346^{\circ} \mathrm{F}\right)$ plant $\mathrm{COE}$ ranges from about 2 percent lower $\left(\mathrm{CO}_{2}\right.$ Allowance Price $=100 \$ /$ ton $)$ to 9 percent higher (Coal Cost $=0.90 \$ / \mathrm{MM}-\mathrm{Btu})$ than the supercritical plant $\left(600^{\circ} \mathrm{C} ; 1,112^{\circ} \mathrm{F}\right)$ for the scenarios investigated. The following list indicates various scenarios where the COE's are equivalent or better than the supercritical case.

- $\operatorname{COE} 730^{\circ} \mathrm{C}=0.98 \times$ COE $600^{\circ} \mathrm{C}$ with Coal Cost $=1.8 \$ / \mathrm{MM}-\mathrm{Btu}$, Capacity Factor $=80 \%, \mathrm{CO}_{2}$ allowance price $=100 \$ /$ ton

- $\mathrm{COE}_{730^{\circ} \mathrm{C}}=1.0 \times \mathrm{COE}_{600^{\circ} \mathrm{C}}$ with Coal Cost $=4.5 \$ \mathrm{MM}-\mathrm{Btu}$, Capacity Factor $=90 \%, \mathrm{CO}_{2}$ Allowance Price $=22 \$ /$ ton

- $\operatorname{COE} 730^{\circ} \mathrm{C}=0.97 \times \mathrm{COE} 600^{\circ} \mathrm{C}$ with Coal Cost $=4.5 \$ / \mathrm{MM}-\mathrm{Btu}$, Capacity Factor $=90 \%, \mathrm{CO}_{2}$ Allowance Price $=100 \$ /$ ton

For the scenario with Coal Cost $=4.5 \$ / M M-B t u$, and Capacity Factor $=90 \%$, Figure 5-4 shows that the ultra-supercritical case is more economical than the supercritical case for $\mathrm{CO}_{2}$ allowance prices higher than about $\$ 21.6 /$ ton emitted.

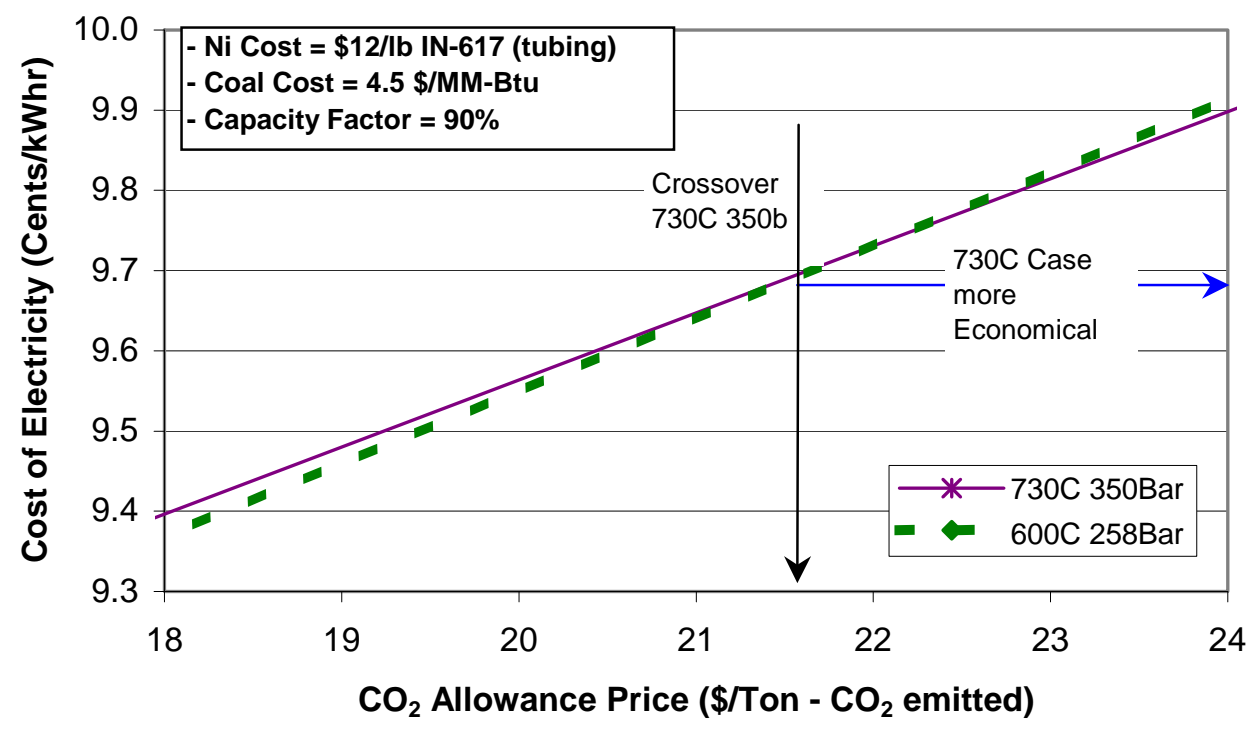

Figure 5-4: Sensitivity with "Low" Ni Cost, Coal Cost $=4.5 \$ / M M-B t u$, Capacity Factor $=90 \%$ 

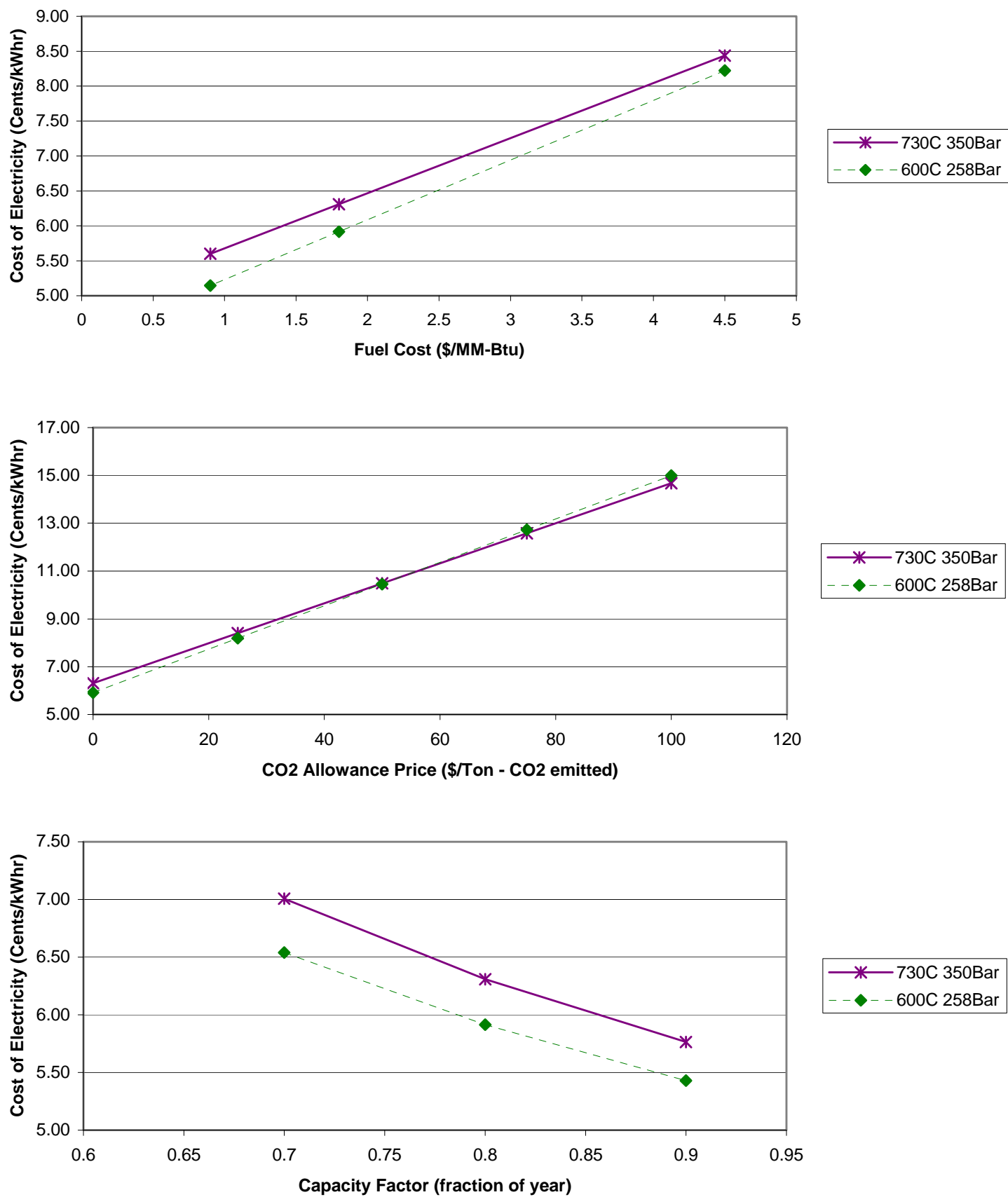

$\longrightarrow *$ 730C 350Bar
--- 600C 258Bar 

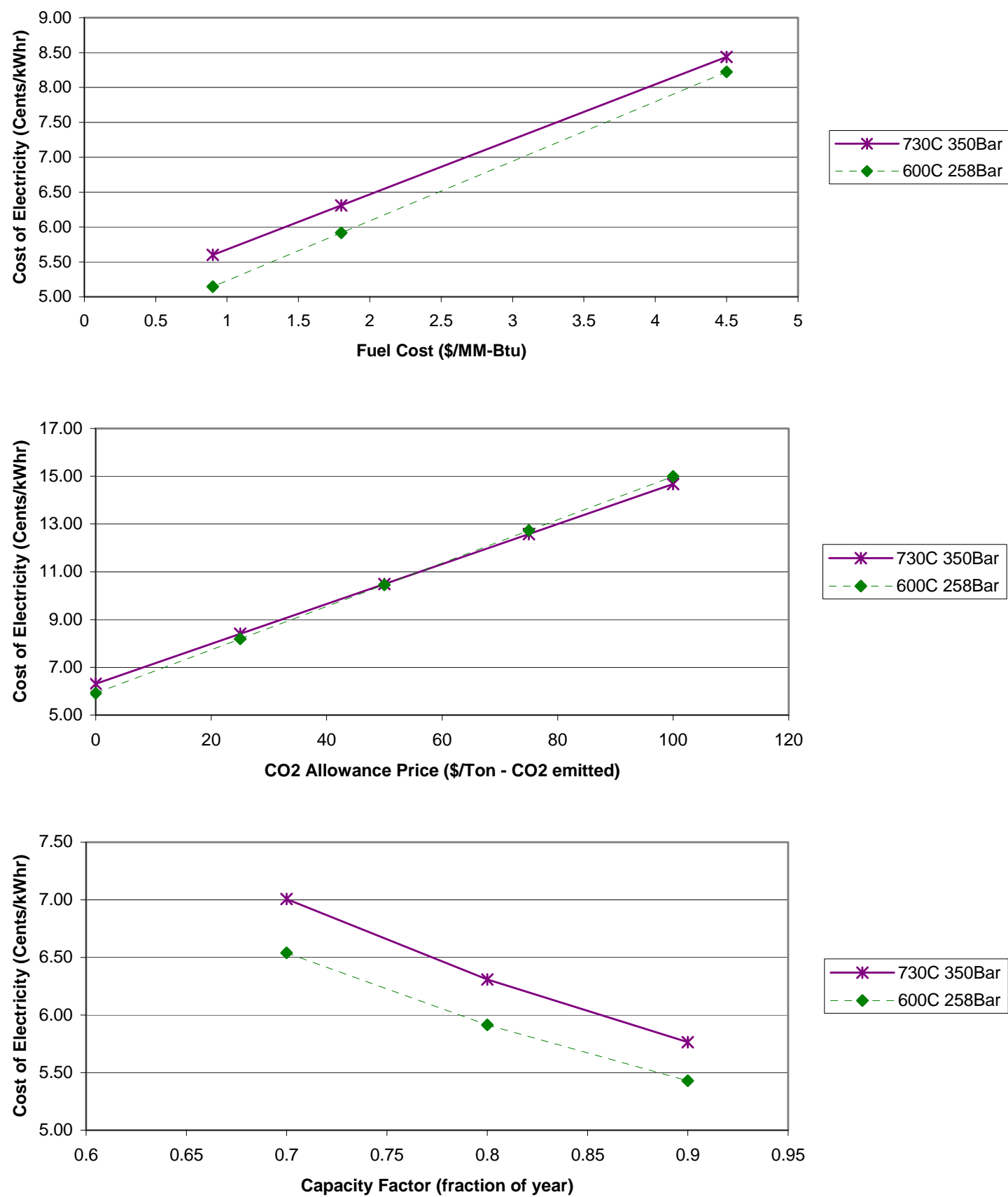

$\longrightarrow *$ 730C 350Bar
$---600 \mathrm{C} 258 \mathrm{Bar}$

Figure 5-5: Economic Sensitivity Study with "Low" Ni Alloy Cost (Coal Cost, $\mathrm{CO}_{2}$ Allowance Price, Capacity Factor) 


\section{Conclusions \& Recommendations}

In this study, an advanced ultra-supercritical plant was compared with a state-of-the-art supercritical plant. The primary comparisons included for this plant included thermal efficiency, investment costs, and economic performance.

Of primary interest is the increase in plant thermal efficiency from about 39.9 percent to 43.3 percent (HHV basis) due to the improved thermodynamic cycle of the future generation USC plant. This increase in thermal efficiency leads to a decrease of approximately 8 percent in several parameters, as listed below, as compared to a state-of-the-art supercritical plant with an equivalent net electrical output value.

- Criteria emissions $\left(\mathrm{SO}_{\mathrm{x}}, \mathrm{NO}_{\mathrm{x}}\right.$, Particulate)

- $\mathrm{CO}_{2}$ emissions

- Coal feed rate

- Limestone feed rate

- Ash disposal

- FGD waste disposal

- Water usage

The reduction in most of these items all contribute to a reduction in the variable operating and maintenance (VOM) costs for the ultra-supercritical plant. The reduced coal feed also means that for every pound of coal, which doesn't have to be burned, there is also a pound of coal that doesn't need to be mined, purchased, transported, stored and pulverized.

Additionally, for the same net plant electrical output, the flue gas flow rate would also be about 8 percent lower, which reduces back end investment costs for such items as the ESP, ID Fans, FGD system, and the interconnecting ductwork and stack. The reduced flue gas flow would also reduce the cost for a post-combustion $\mathrm{CO}_{2}$ capture plant (or other type of $\mathrm{CO}_{2}$ capture systems) if this were included. As indicated above, the flows of air, coal, sorbent, ash, process water and waste are also reduced by about 8 percent, and therefore, the costs for the Balance of Plant equipment associated with these items would also decrease for the ultra-supercritical case.

Similarly, the Cooling Water System (condenser, pumps \& piping, cooling tower, etc.), which rejects about 17 percent less heat for the ultra-supercritical plant, is also proportionally smaller. However, the reduced costs for the cooling water system, balance of plant equipment, and backend items mentioned above were out weighed by the cost increases for the PC Boiler, Steam Piping, and to a lesser extent, the Steam Turbine. The increased costs in these areas were primarily due to the required use of high temperature Ni alloys, which are costly. It should be emphasized however, that it is difficult to obtain reliable, consistent cost data for these high temperature $\mathrm{Ni}$ alloys at this time and for this reason, as well as an anticipated cost reduction relative to traditional materials (see Section 4.1.1), a range of $\mathrm{Ni}$ alloy costs were used in this study. Overall, the ultra-supercritical plant specific cost $(\$ / \mathrm{kWe})$ was increased by about $12-19$ percent, depending on the cost of high Ni alloy, as compared to the supercritical plant.

The economic analysis involves the calculation of the cost of electricity (COE). This calculation combines the impacts of the reduced fuel costs (about 8 percent lower) associated with improved thermal efficiency and the increased investment costs for the ultra-supercritical plant, as compared to the state-of-the-art supercritical plant. Results show that with the base parameter 
values $\left(\right.$ Coal Cost $=1.8 \$ / \mathrm{MM}-\mathrm{Btu}$, Capacity Factor $=80 \%, \mathrm{CO}_{2}$ allowance price $=0 \$ /$ ton $)$ the increase in investment costs out weighs the reduction in fuel usage for the ultra-supercritical plant and that the COE is about 7-12 percent higher, depending on Ni alloy cost, as compared to the supercritical plant. The dispatch cost, which is primarily fuel cost related, would always be lower for the ultra-supercritical plant. This advantage would become even greater if a $\mathrm{CO}_{2}$ emissions tax were implemented in the future.

With a Coal Cost of 1.8 \$MM-Btu, and a Capacity Factor of $80 \%$, if $\mathrm{CO}_{2}$ is valued at $55-100$ \$/ton, depending on Ni alloy cost, the COE's are equivalent to the state-of-the-art supercritical plant. With a Coal Cost of 4.5 \$/MM-Btu, and a Capacity Factor of $90 \%$, if $\mathrm{CO}_{2}$ is valued at 2262 \$/ton, depending on Ni alloy cost, the COE's are equivalent to the state-of-the-art supercritical plant.

The variable Ni alloy cost scenario was investigated because, as with any newly deployed technology, a reduction in $\mathrm{Ni}$ alloy cost relative to traditional materials is anticipated as we learn more about large-scale utilization of these materials in the future. This "learning curve" is a result of process improvements, learning by doing, scale-up, and the benefits derived from investments in research and development in this area. 


\section{Bibliography}

McDonald A., Schrattenholzer L., “Learning Curves and Technology Assessment”, International Journal of Technology Management, 2002; 23(7/8): 718-45

Palkes M., Zhang, W. D., Liljedahl G. N., ”Conceptual Design of Steam Generator for 350 bar / $730^{\circ} \mathrm{C} / 760^{\circ} \mathrm{C}\left(1,346^{\circ} \mathrm{F} / 1,400^{\circ} \mathrm{F} / 5,076 \mathrm{psi}\right)$ Ultra-Supercritical Coal Power Plant” Report submitted to DOE National Energy Technology Laboratory, December 2009 - in-press

Palkes M., Waryasz R. E., Liljedahl G. N., “Economics and Feasibility of Rankine Cycle Improvements for Coal Fired Power Plants”, Report submitted to DOE National Energy Technology Laboratory (Contract No DE-FCP-01NT41222), February 2004

Rubin E. S., Taylor M. R., Yeh S., Hounshell D. A., "Learning Curves for Environmental Technology and their Importance for Climate Policy Analysis”, 2004, Energy 29 1551-1559

Wheeldon, J.M., “Engineering and Economic Evaluation of $1,300^{\circ} \mathrm{F}$ Series Ultra-Supercritical Pulverized Coal Power Plants: Phase 1”, EPRI, Palo Alto, CA: 2008, 1015699 